\title{
Solar Design Workbook
}

June 1981

Gregory Franta, SERI

Barbara Glenn, SERI

Steven Hogg SER

Bruce Hunn, LASL.

William Kolor, SERI

Steven Ternoey, SERI

John I. Yellotr, Consultant

\section{SF्सा:}

Solar Energy Research Institute A Division of Midwest Research Institute Operated for the

U.S. Department of Energy

Under Contract No EG-77-C-01-4043
University of Calitornia

\section{Los Alarnos}

Los Alamos National Laboratory 


\section{DISCLAIMER}

This report was prepared as an account of work sponsored by an agency of the United States Government. Neither the United States Government nor any agency Thereof, nor any of their employees, makes any warranty, express or implied, or assumes any legal liability or responsibility for the accuracy, completeness, or usefulness of any information, apparatus, product, or process disclosed, or represents that its use would not infringe privately owned rights. Reference herein to any specific commercial product, process, or service by trade name, trademark, manufacturer, or otherwise does not necessarily constitute or imply its endorsement, recommendation, or favoring by the United States Government or any agency thereof. The views and opinions of authors expressed herein do not necessarily state or reflect those of the United States Government or any agency thereof. 


\section{DISCLAIMER}

Portions of this document may be illegible in electronic image products. Images are produced from the best available original document. 


\section{THE AMERICAN INSTITUTE OF ARCHITECTS}

R. Randall Vosbeck, FAIA

President

Dear Reader:

As President of the AIA in 1981, my most important goal is

to give every Institute member an opportunity to develop the expertise necessary to meet the challenges of energyconscious design. That means not only emphasizing energy, but integrating it with excellent architectural design. To assist in meeting this goal, AIA has 1aunched a threeyear energy professional development program and has used the theme of "A Line on Design and Energy" for the AIA in 1981 .

AIA intends to best utilize the resources of other institutions and organizations that are producing useful information related to energy in architecture. In this regard, AIA is working closely with the Solar Energy Research Institute to integrate its appropriate products with AIA programs.

This Solar Design Workbook contains a tremendous resource of information for architects, engineers, and other members of the design profession. Several AIA members have in fact been an integral part in preparing material for this technical reference on solar applications for buildings. AIA is considering ways of enhancing and updating this material for incorporation into AIA programs. Upon reading this book, I'm sure you will appreciate the usefulness of this valuable resource.

Sincerely yours,

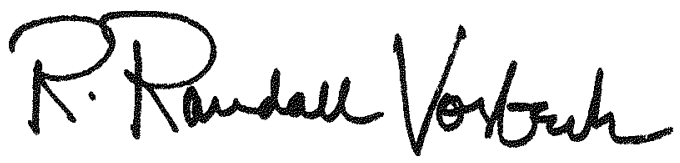

R. Randall Vosbeck, FAIA

President

The American Institute of Architects 


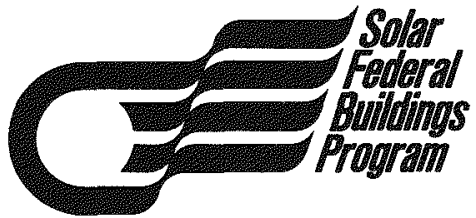

SOLAR DESIGN WORKBOOK

\section{EDITORS :}

GREGORY FRANTA, SERI

BARBARA GLENIN, SERI

STEVEN HOGG, SERI

BRUCE HUNN, LANL

WILLIAM KOLAR, SERI

STEVEN TERNOEY, SERI

JOHN I. YELLOTT, CONSULTANT

JUNE 1981

FINAL DRAFT

\section{Solar Energy Research Institute}

A Division of Midwest Research Institute

1617 Cole Boulevard

Golden, Colorado 80401

Prepared for the

U.S. Department of Energy

Contract No. EG-77-C-01-4042

AND

LOS ALAMOS NATIONAL LABORATORY

UNIVERSITY OF CALIFORNIA 


\section{NOTICE}

This report was prepared as an account of work sponsored by the United States Government. Neither the United States nor the United States Department of Energy, nor any of their employees, nor any of their contractors, subcontractors, or their employees, makes any warranty, express or implied, or assumes any legal liability or responsibility for the accuracy, completeness or usefulness of any information, apparatus, product or process disclosed, or represents that its use would not infringe privately owned rights. 


\section{FOREWORD}

This Solar Design Workbook presents solar building design applications for commercial buildings. The book is divided into four sections. The first section describes the variety of solar applications in buildings including conservation aspects, solar fundamentals, passive systems, active systems, daylighting, and other solar options. Solar system design evaluation techniques including considerations for building energy requirements, passive systems, active systems, and economics are presented in Section II. The third section attempts to assist the designer in the building design process for energy conservation and solar applications including options and considerations for pre-design, design, and post-design phases. The information required for the solar design process has not been fully developed at this time. Therefore, Section III is incomplete, but an overview of the considerations with some of the design process elements is presented. Section IV illustrates case studies that utilize solar applications in the building design.

The Solar Design Workbook was developed to accompany presentations at a series of short courses conducted in support of the Solar Federal Buildings Program by the Buildings Division of the Solar Energy Research Institute (SERI). The workbook is intended to aid architects, engineers, project managers, and others who want to increase their knowledge on the practical applications of solar energy and conservation for buildings in the federal and private sector.

The Solar Federal Buildings Program (SFBP) was authorized under Part 2, Title V, National Energy Conservation Policy Act (1978). The program was developed to establish a federal leadership role in supporting the use of feasible solar applications for buildings as well as in obtaining maintenance and operating experience for solar systems. The SFBP is managed by William Lemeshewsky, U.S. Department of Energy, Washington, D.C.

This draft edition of the Solar Design Workbook was prepared with the assistance of many authors and editors acknowledged within the book. Their expert work and dedication to fulfilling this task is greatfully appreciated. A final edition is currently being prepared by SERI with the assistance of LOS Alamos National Laboratory (LANL). It will include the information that is needed to complete the pre-design, design, and postdesign phases of energy-conscious commercial buildings. The final edition will be ready in late 1981 and is considered to be a very complete technical reference for the design, operation and maintenance of solar applications in commercial buildings.

The Solar Design Workbook was prepared by SERI under the Solar Federal Buildings Program, FY 198 1, Task 1121.30; William Kolar, Task Leader.

Gregory Franta, AIA, Manager

Commercial Buildings Group 


\section{CONTRIBUTORS}

Frank Baylin

Nancy Carlisle

John B. Carlock

John Crane

Richard Crowther

Elaine Davis

Fred Dubin

James Easterly

David Feasby

Gregory Franta

Barbara Glenn

Amanda Grace

J. W. Griffith

Steven Hogg

John Holton

Michael Holtz

Bruce Hunn

Ronald Judkoff

Thomas A. King

William Kolar
Chuck Kutscher

William Lemeshewsky

Bob Lorand

Jim Marx

Douglas Nordham

Jeanne Powell

Rosalie Ruegg

Paul A. Sabatiuk

Thomas Sav

Stephen Selkowitz

Jefferson G. Shingleton

Theodore D. Swanson

Steve Ternoey

John Veigel

Marguerite Villecco

David R. Wedekind

Stephen Weinstein

Byron Winn

John 1. Yellott 
SECTION I. SOLAR APPLICATIONS IN BUILDINGS AND INDUSTRIAL PROCESSES

1 Overview of Solar Design.......................... 1-1

2 Energy Conservation in Buildings ..................... 2-1

$3 \quad$ Solar Fundamentals................................. 3-1

4 Passive Systems and Components ...................... 4-1

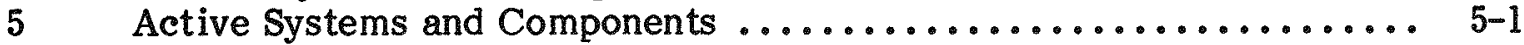

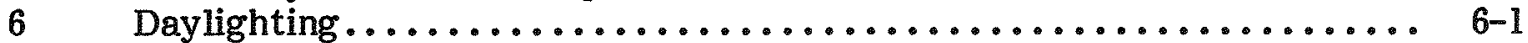

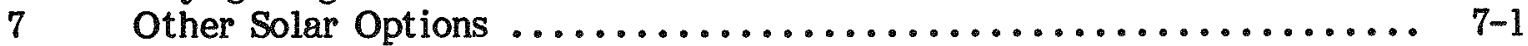

\section{SECTION II. SOLAR SYSTEM EVALUATION}

8 Building Loads, Energy Requirements, and Characteristics ........ 8-1

9 Passive System Design and Sizing Methods .................... 9-1

10 Active System Design and Sizing Methods ................. 10-1

11 Life-Cycle Costing of Solar Energy Investments .............. 11-1

SECTION III. THE SOLAR DESIGN PROCESS*

12 Solar Design Process Overview $\ldots \ldots \ldots \ldots \ldots \ldots \ldots \ldots \ldots \ldots \ldots \ldots \ldots$

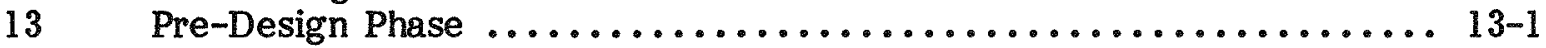

14 Design Phase ...................................... 14-1

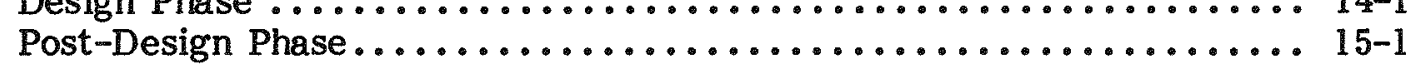

\section{SECTION IV. CASE STUDIES}

16 Solarizing a Historic Building: A Case Study of the White House .................................. 16-1

17 The Commercial Demonstration Program for Solar Heating and Cooling of Commercial Buildings .................. 17-1

*Incomplete at this time. 
viii 
Section 1.

Solar Applicarions in Buildings and Industrial Processes 


\title{
Communtes
}

\author{
chapter

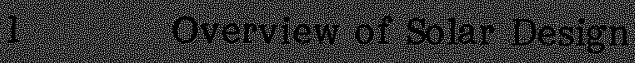 \\ 2 2. \\ 3.

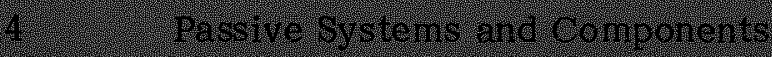

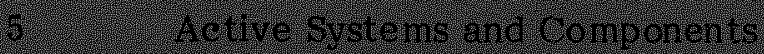 \\ 6. \\ 7. - mether solat Options: \\ Solar industriat pacess Hell \\ wind Ineigy \\ Photovoltates \\ Biomass
}

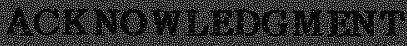

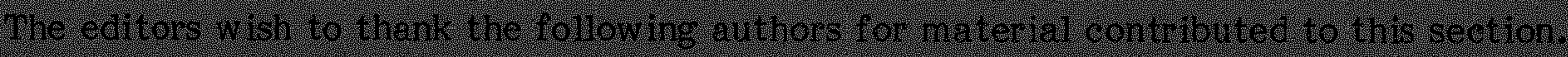

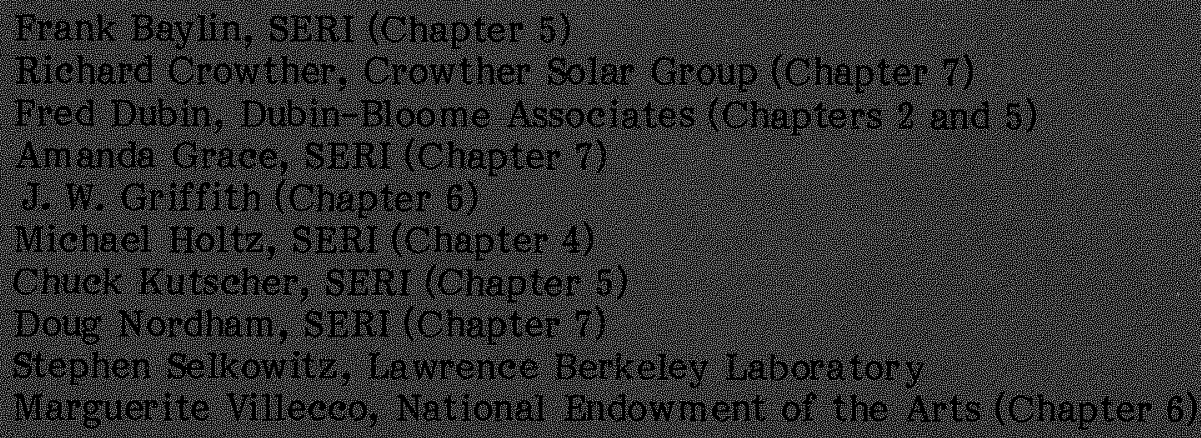


1

Overview of Solar Design 
1. Over view of Solar Design

The energy problem

Overview of the solar technologies 
The integration of solar design into standard architectural-engineering practice is of utmost importance in order to reduce reliance on fossil fuels. Our nonrenewable resources, including fassil fuels, are being consumed at an ever-increasing and exhausting rate to meet our immense energy appetite. Appropriate energy sources and careful and wise use of energy are the keys to meeting these immense energy demands and to providing a sound interrelationship of people, nature, and technology. Appropriate and successful solar design will demonstrate to the American public the applicability of solar energy for use in solving our energy problem.

\section{THE ENERGY PROBLEM}

Society is faced with the problem of rapid depletion of fossil fuels to meet our energy demands and the accompanying problems that high energy use will place on our natural environment. Fossil fuels are being used worldwide at such a rate that reliance on them as our primary source is no longer justified (Fig. 1-1). The fossil fuels currently consumed in one day's energy production took millenia to form. In particular, there has been an astounding increase in the rate of energy use in the United States, and it is expected that this will reach $100 \times 10^{15} \mathrm{Btu}$ by the year 2000* (Fig. 1-2) unless conservation is practiced diligently. At the present consumption rates severe shortages are inevitable in the future.

*National Energy Plan III.

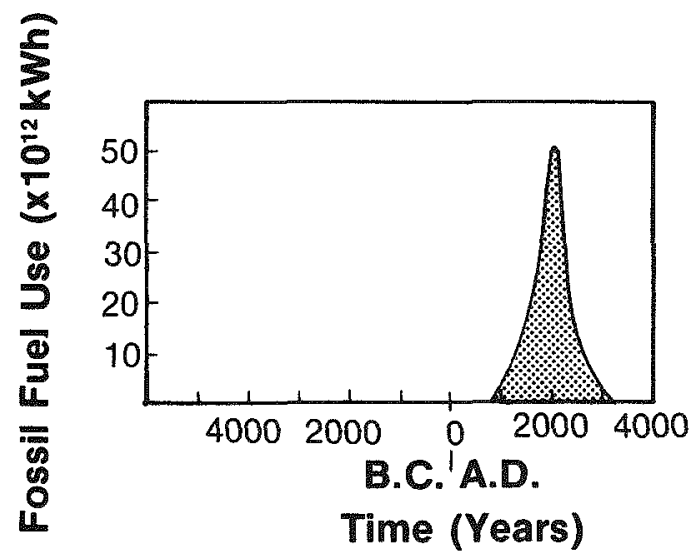

Fig 1-1. Worldwide fossil fuel use

\section{Quadrillion Btu}

150

125

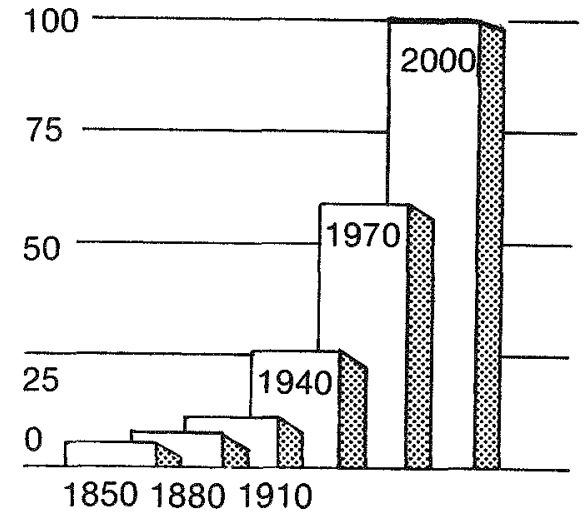

Fig. 1-2. Total U.S. energy use [1]

The complexity of contemporary life, complete with all its amenities and liabilities, belies the extreme intricacy of the present energy problem. Sophisticated technology is often applied to problems regardless of the circumstances. Although technology itself is neither good nor evil, its success lies in its ability to aid people in maintaining control over their lives and in resolving those problems impinging upon them. Appropriate development and use of technology are essential to the resolution of the energy problem while maintaining a comfortable human existence and assuring the long-term survival of our natural environment.

Although the United States has only $20 \%$ of the world's supply of fossil fuels and only $6 \%$ of the world's population, the United States uses more than $32 \%$ of the world's fossil fuel resources. The total U.S. energy use, classified into economic sectors, is illustrated in Fig. 1-3 [2]. Note that the energy used directly in residential and commercial buildings is approximately $33 \%$ of the total U.S. energy use. This is in addition to the approximately $15 \%$ of the energy used in the industry classification for 
the construction of buildings and the unknown amount used for the transportation of construction materials and equipment.

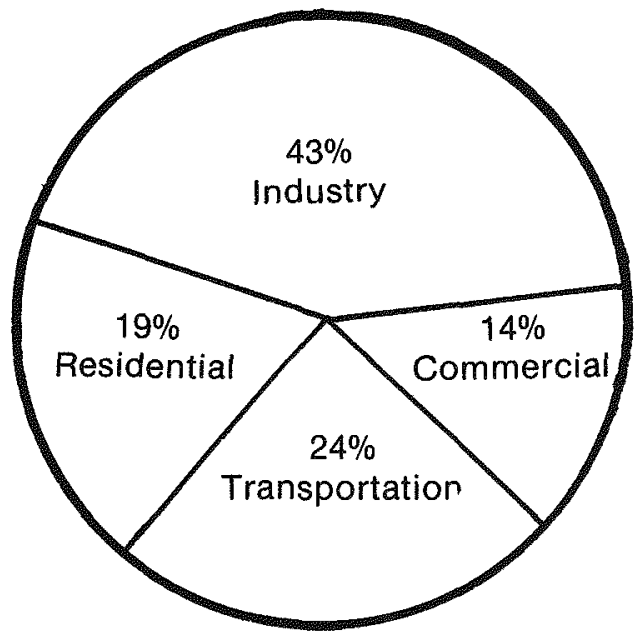

Fig. 1-3. Division of U.S. total energy use by economic sector

To establish a basis for determining where to conserve energy and when to use alternate sources of energy, Table 1-1 illustrates a breakdown of energy end use.

Table 1-1. ENERGY END USE IN THE UNITED STATES [3].

\begin{tabular}{lr}
\hline \multicolumn{1}{c}{ Energy End Use } & $\begin{array}{r}\text { Percent } \\
\text { of Total }\end{array}$ \\
\hline $\begin{array}{l}\text { Transportation (Fuel; excludes lubes, } \\
\text { grease) }\end{array}$ & 24.9 \\
$\begin{array}{l}\text { Space Heating (Resi dential, Commercial) } \\
\text { Process Steam (Industrial) }\end{array}$ & 17.9 \\
Direct Heat (Industrial) & 16.7 \\
Electric Drive (Industrial) & 11.5 \\
Feedstocks, Raw Materials (Commercial, & 7.9 \\
$\quad$ Industrial, Transportation) & 5.5 \\
Water Heating (Resi dential, Commercial) & 4.0 \\
Air-Conditioning (Residential, Commercial) & 2.5 \\
Refrigeration (Residential, Commercial) & 2.2 \\
Lighting (Resi dential, Comm ercial) & 1.5 \\
Cooking (Residential, Commercial) & 1.3 \\
Electrolytic Processes (Industrial) & 1.2 \\
$\quad$ Total & $\frac{97.1}{}$ \\
\hline
\end{tabular}

Note that space heating for residential and commercial buildings is the second highest end use. Air conditioning, water heating, and lighting are also important factors in building energy use but are less significant in the total energy end use. Because solar energy can readily be collected and delivered at temperatures well-matched to building space and water heating loads, solar energy can meet a significant portion of our energy needs.

Table 1-1 also indicates that space heating is a substantially higher energy end use than air conditioning or lighting for combined residential and commercial applications. Furthermore, space heating represents a substantial portion of energy end use in many types of commercial buildings (warehouses, schools, churches, small stores). However, because the major load for office buildings is often determined by uses of and activities within the building, and not by the building envelope, space heating is less significant in office buildings than in residences. On the average in commercial buildings, $67 \%$ of the energy used is in the form of electricity and only $33 \%$ is by purchased fuels. Cooling and lighting are the dominant electrical uses in office buildings (Fig. 1-4) [4]. Solar energy, with various applications, can meet heating, cooling, and lighting dem ands.

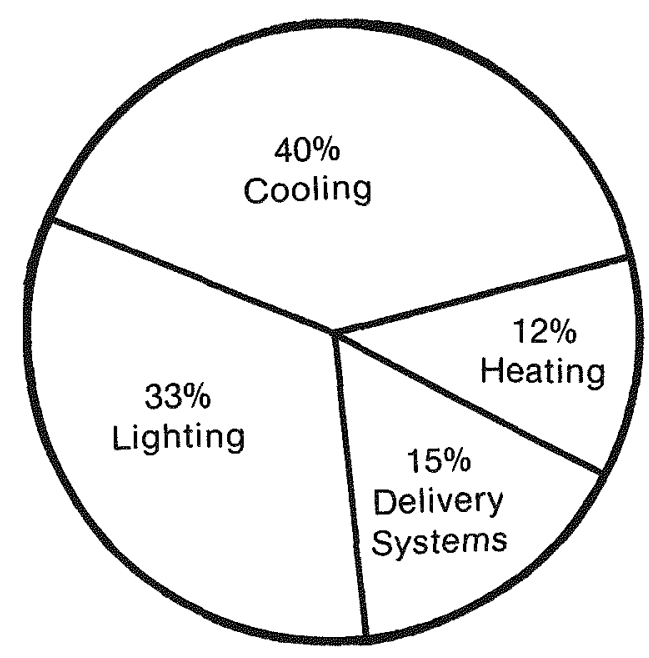

Fig. 1-4. Electrical energy use in office
buildings

Table 1-2 illustrates the total energy used by typical office buildings. This table shows that considerable potential exists for reduction of energy use in buildings. The American Institute of Architects (AIA) estimates that by 1990 with proper conservation in buildings, more energy can be saved than can be produced from the U.S. domestic oil, nuclear power, or natural gas (domestic and import). Conservation in buildings could come close to the coal production by 1990 and could be about two-thirds of foreign oil imports (Fig. 1-5). Conservation is the first step in reducing fossil fuel energy usage in buildings, 
Table 1-2. OFHCE BUILDING ENERGY USE [4]

\begin{tabular}{|c|c|c|}
\hline & $\begin{array}{l}50 \\
(B t u / s q f t)\end{array}$ & $\begin{array}{l}100 \quad 150 \\
\text { (in thousands) }\end{array}$ \\
\hline \multicolumn{3}{|l|}{ GSA Federal "Actual" } \\
\hline \multicolumn{3}{|l|}{ Private large } \\
\hline \multicolumn{3}{|l|}{ GSA Federal "Poor" } \\
\hline \multicolumn{3}{|l|}{$\begin{array}{l}\text { Designer's } \\
\text { "Realistic Ideal" }\end{array}$} \\
\hline \multicolumn{3}{|l|}{ GSA Federal "Good" } \\
\hline \multicolumn{3}{|l|}{ GSA Federal "Ideal" } \\
\hline $\begin{array}{l}\text { New Energy-Conserving } \\
\text { Buildings }\end{array}$ & & \\
\hline
\end{tabular}

whether the building will use conventional or alternate energy sources. Solar technologies should then be applied as appropriate to further reduce the demand on fossil fuels. The smaller the energy demand, the less solar equipment is required and the lower are the capital costs.

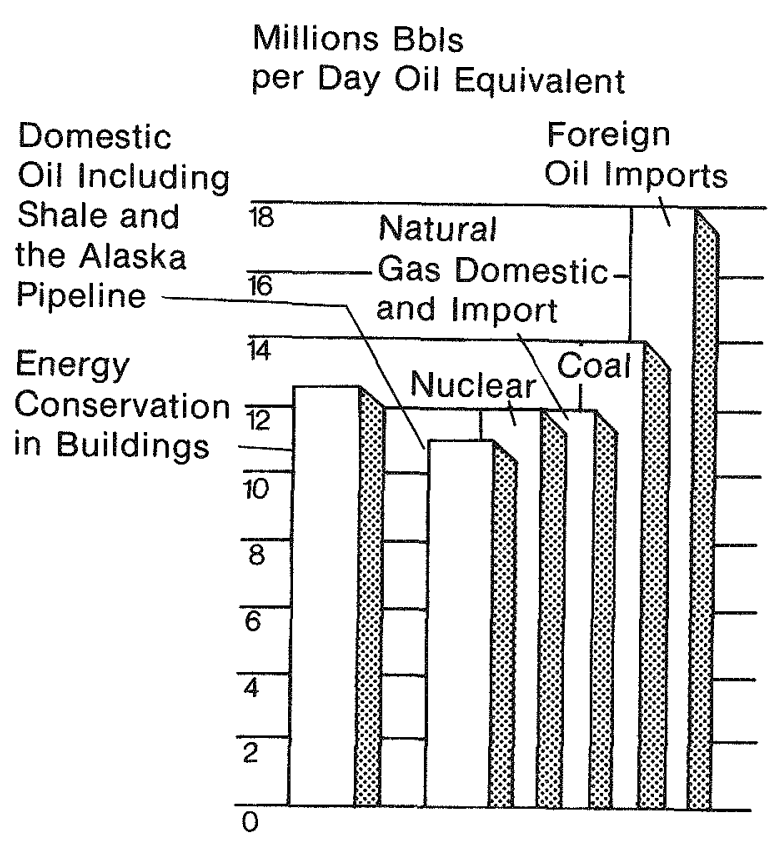

Fig. 1-5. Energy conservation in buildings as a substitute for supply-1990 [5]
Several options must be thoroughly investigated with each building to arrive at the most appropriate solution of careful and wise use of energy and proper energy sources. The balance among energy conservation, solar energy, and other energy sources must be adequately evaluated to best meet the energy needs of the building.

\section{OVPRVIEW OF SOLAR TECHNOLOGIES}

In order to properly apply solar technologies to various buildings, one must first understand the fundamental applications of solar energy technologies. Solar energy technologies can be divided into two broad classifications: Natural Collection Systems and Technical Conversion Systems. (See Fig. 1-6.)

The total biosphere-the Earth, the wind, and the waterparticipates in the natural collection processes and provides free collector surfaces. Since no collectors need to be built, the energy costs for natural systems are determined by the converter; example-the wind turbine.

For technological conversion systems, the amount of collectable energy is determined by the amount of solar energy reaching a unit area of collector at a given geographic location during a specified time period.

\section{Solar Heating and Cooling}

Solar energy is presently making its biggest impact on the space heating and cooling, domestic hot water, and natural lighting of buildings. As noted in Table 1-1, these end use applications constitute a major portion of the energy used in the United States and more specifically, make up the largest energy loads in buildings. Two distinet but complementary approaches are used to convert solar radiation to thermal energy-passive and active systems. (See Figs. 1-7 and 1-8.)

The most widely accepted definition of a passive system is one in which the thermal energy flow is by the natural processes of conduction, convection, radiation, and evaporation. An active system is one in which the thermal energy flow is by forced means such as fans or pumps. A hybrid system is one incorporating a major passive aspect, where at least one of the significant thermal energy flows is by natural means and at least one is by forced means.

This workbook presents an in-depth discussion of solar designs related to solar heating and cooling applications. Included are the fundamentals, description of systems, components and subcomponents, economics, design and sizing, design process, instrumentation and monitoring, standards, and project examples.

\section{Biomass}

Biomass is any material derived from growing organisms-wood, corncobs, or seaweed-that can be used as a fuel. Biomass is a direct and natural form of solar energy and can be produced as long as the Sun shines on land and aceans. Direct combustion of wood has been 


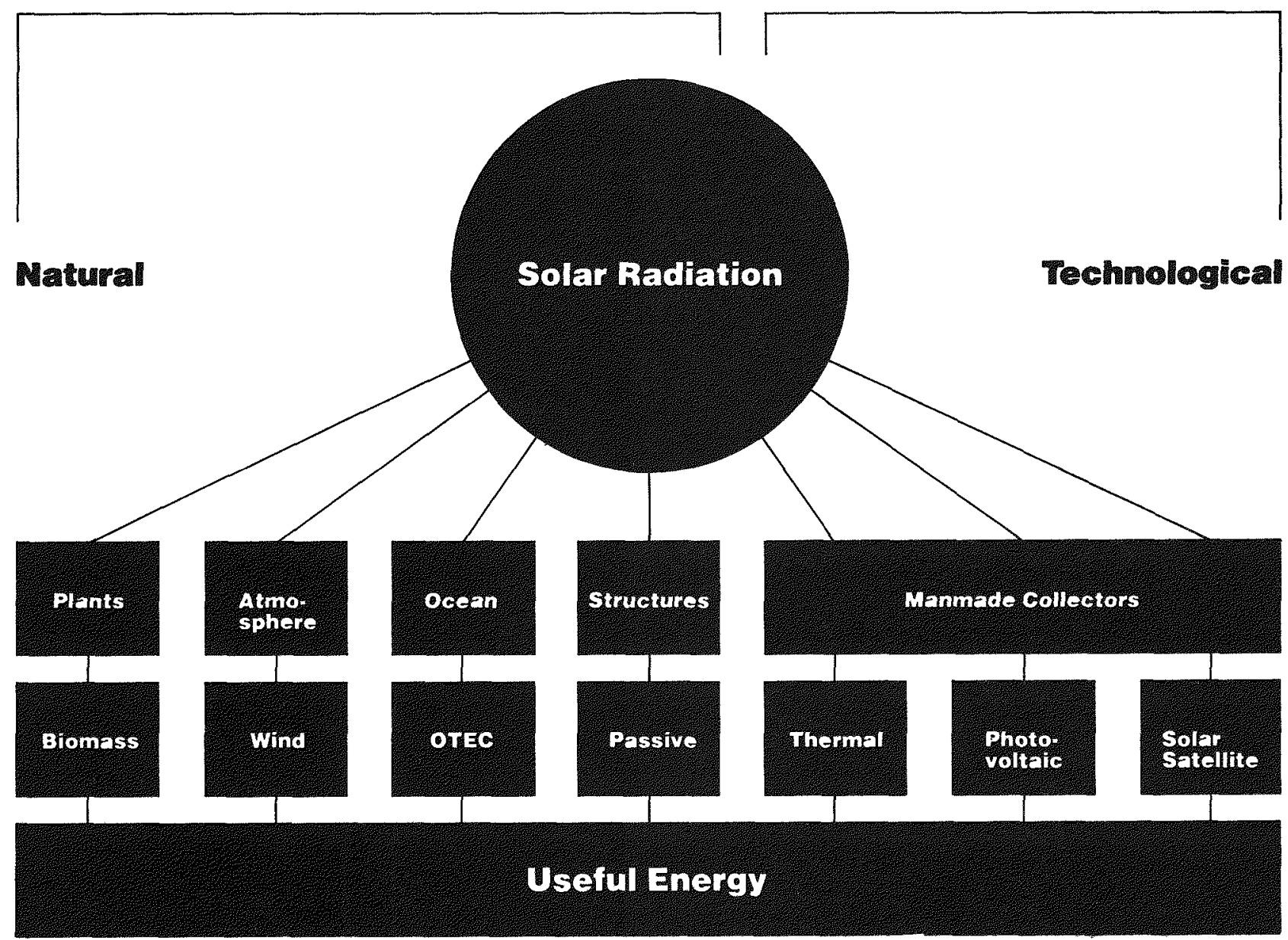

Fig. 1-6. Solar energy technologies

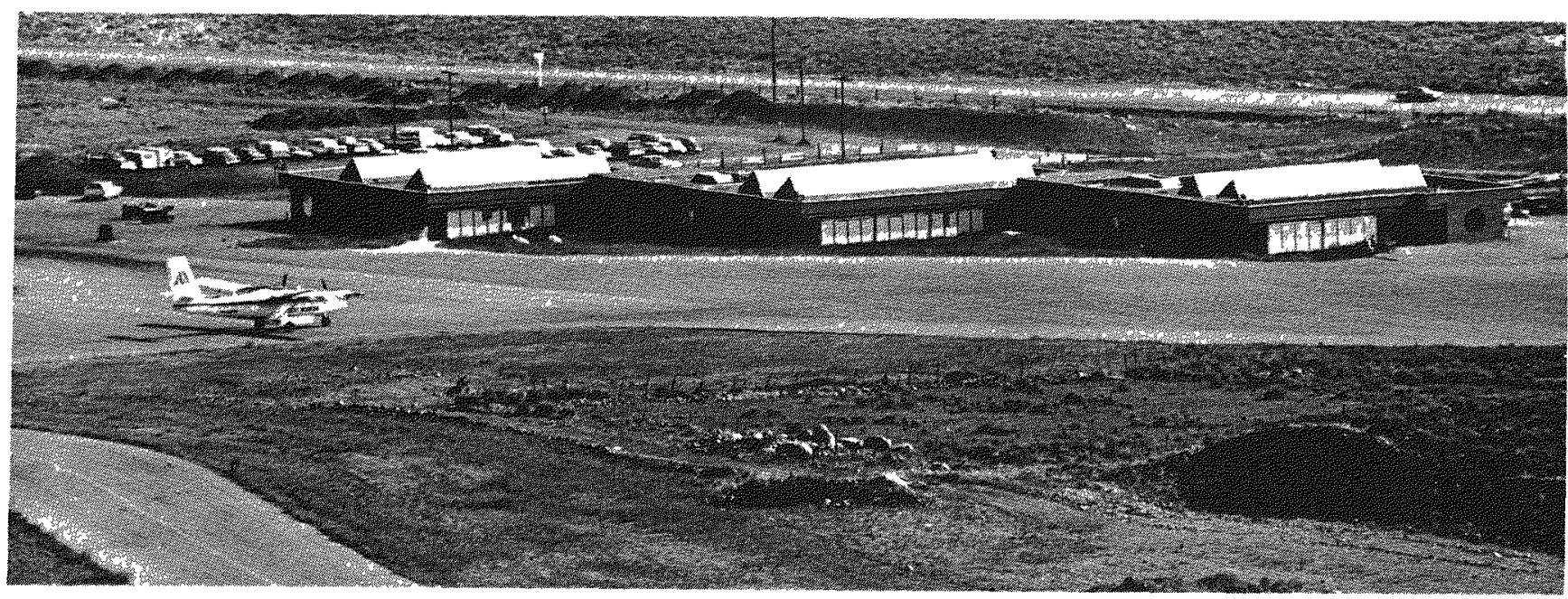

Fig. 1-7. Pitkin County Air Terminal. This passive system provides the majority of the heating and cooling for this air terminal building in the cold climate at Aspen, Colorado. 


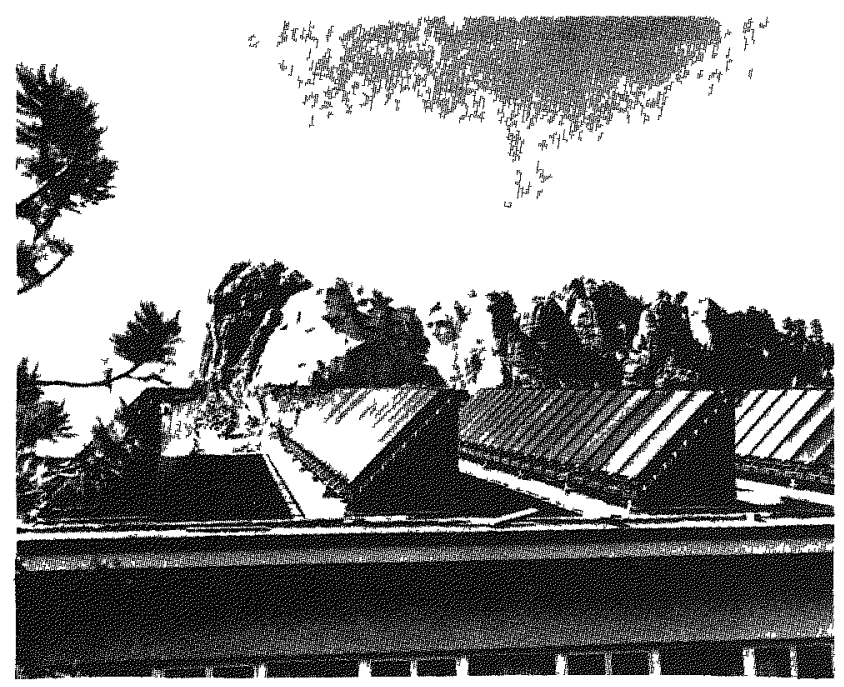

Fig. 1-8. Mount Rushmore Visitor's Center. This active system provides partial heating and cooling for this building in South Dakota.

humanity's principal form of energy for most of its existence. In the United States, wood provided $75 \%$ of our energy a hundred years ago, a quantity equivalent to approximately $3 \%$ of our present enormous appetite. Sweden currently obtains $8 \%$ of its total national energy supply from wood, and Finland relies on wood for a full $17 \%$ of total energy. The United States, too, may well turn to using the biomass that provided virtually all our energy only a century ago (Fig. 1-9).

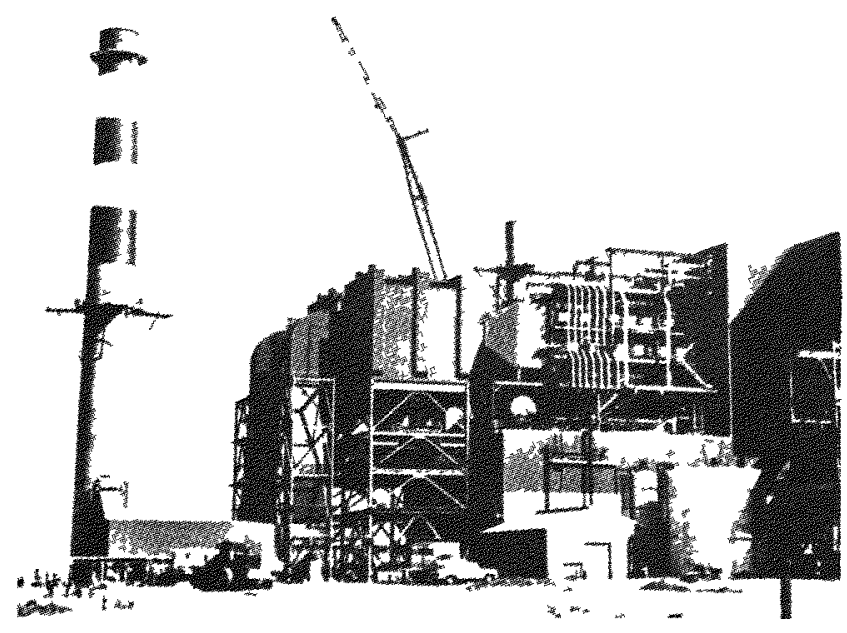

Fig. 1-9. This biomass plant will charge a fee to burn garbage of at least 10 surrounding towns. The heat from the burning trash will produce steam to provide energy to generate electricity for a manufacturing plant.
Gasifiers are being developed to generate from organic residues a low-Btu gas which can substitute for natural gas and oil in existing equipment. Digesters that convert cattle manure from large feedlots into pipeline quality gas are being initiated on a commercial scale, and the byproducts from these digesters can be used for fertilizer and cattle feed.

Al though gas is a useful form of energy, we also require liquid fuels. Pyrolysis (high-temperature heating in the absence of oxygen) of biomass can produce a dark oil which may replace petroleum in industrial applications. Biomass is also an attractive source of alcohol. Possible fuels from this process are: (1) methanol-wood alcohol derived from wood or municipal wastes and (2) ethanolgrain alcohol produced by fermentation from agricultural products.

Alcohols are in many ways superior to gasoline as a fuel because they have higher octane and burn cleaner than gasoline. One promising use of alcohol is as a mixture with gasoline. This composite fuel, "gasohol," has been satisfactorily tested in fleets of cars in Nebraska, Germany, and Sweden and is currently being marketed in several states.

\section{Wind Fnergy}

A fraction of the solar radiation incident on the Earth is converted by the atmosphere into the kinetic energy of winds. A windmill or wind turbine converts the kinetic energy of moving air into mechanical motion. This mechanical energy has long served humanity, providing power for transportation at sea from the beginning of civilization and for agricultural purposes in Western Europe as early as the 11 th century.

Wind power was used extensively in the United States until recent times. More than 6 million small windmills (each less than $1 \mathrm{~kW}$ ) were used in this country before 1950 to pump water and to generate electricity.

Modern designs to use wind power cover a wide range of sizes and technologies. Deployment plans range from units for a single home to plants with the capacity of some fossil fuel generating facilities. The federal wind program has grown significantly in funding since 1973. This vigorous program is demonstrating both small and large wind generators (Fig. 1-10).

\section{Ocean Thermal Energy Conversion (OTLC)}

Ocean Thermal Energy Conversion (OTEC) is an indrect form of solar energy use. OTEC systems tap the thermal gradients between various ocean depths: surface water, heated by the Sun, vaporizes a fluid such as ammonia. The pressurized vapor drives a turbine to produce electricity, which is then transmitted to land via cable. The vapor is then pumped back to the deep regions of colder water, where it cooled and is again converted to a liquid. It is then ready to be sent back to the warm surface for the cycle to begin again (Fig. I-11). Another process that uses water vapor directly in the turbine is under development at the Solar Energy Research Institute (SERI). 


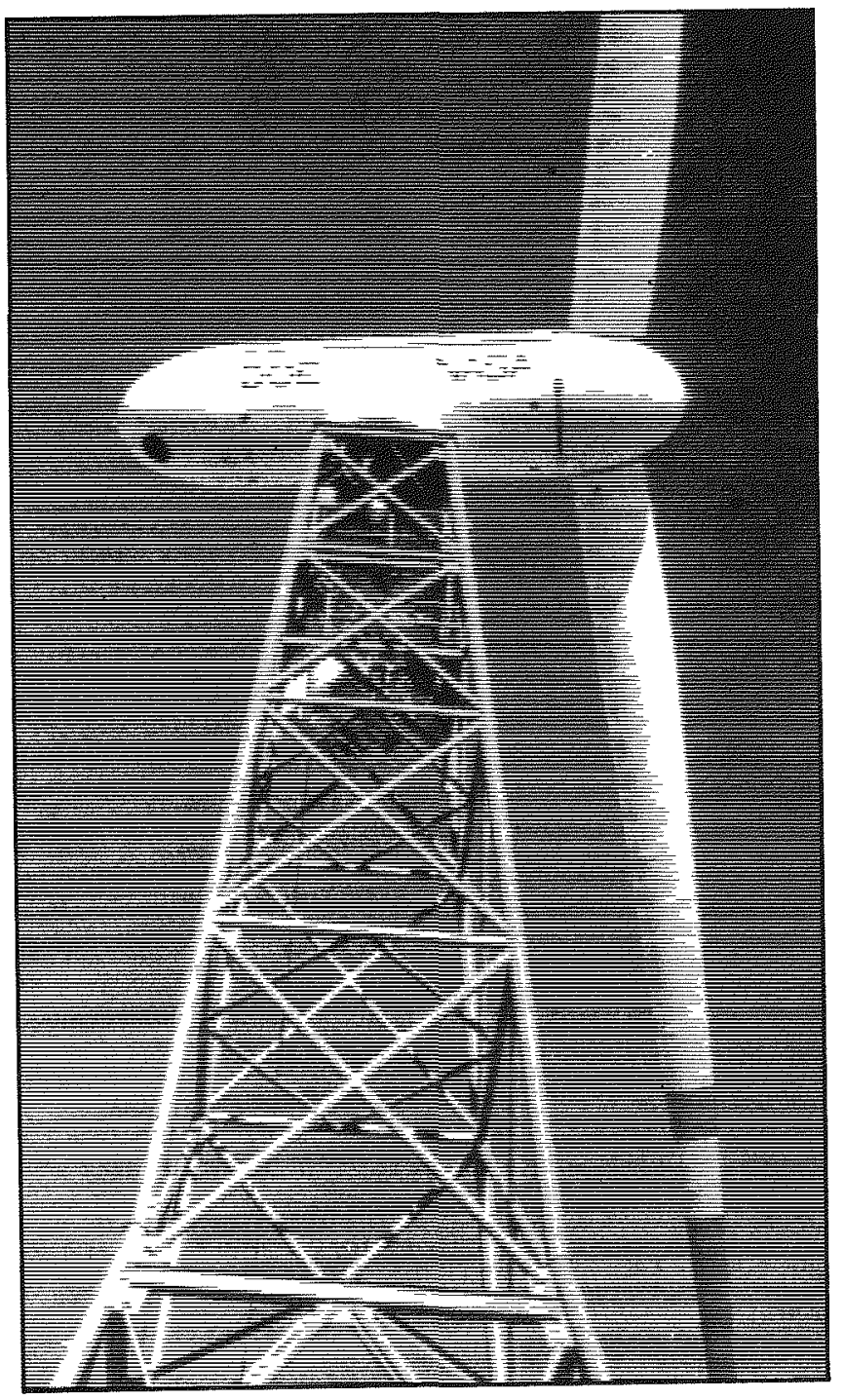

Fig. 1-10. This large wind turbine generates $200 \mathrm{~kW}$, providing electricity for about 60 homes in Clayton, New Mexico. The Department of Energy is planning larger wind turbines and is considering clustering them on windmill "farms."

The available thermal energy within the ocean is large, but converting this energy requires development of efficient, durable, and cheap heat exchange equipment that can withstand rough and corrosive conditions. The first demonstration plant is expected to begin operation in 1985 and the first commercial plant by 1992 .

The second method of using the capacity of the oceans for energy generation is through harnessing ocean waves and tidal currents. Systems to accomplish this are being developed in Japan and the United Kingdom, where prototype installations are being built. Cost estimates and projections in areas of the world favorable for this type of solar energy use look promising.

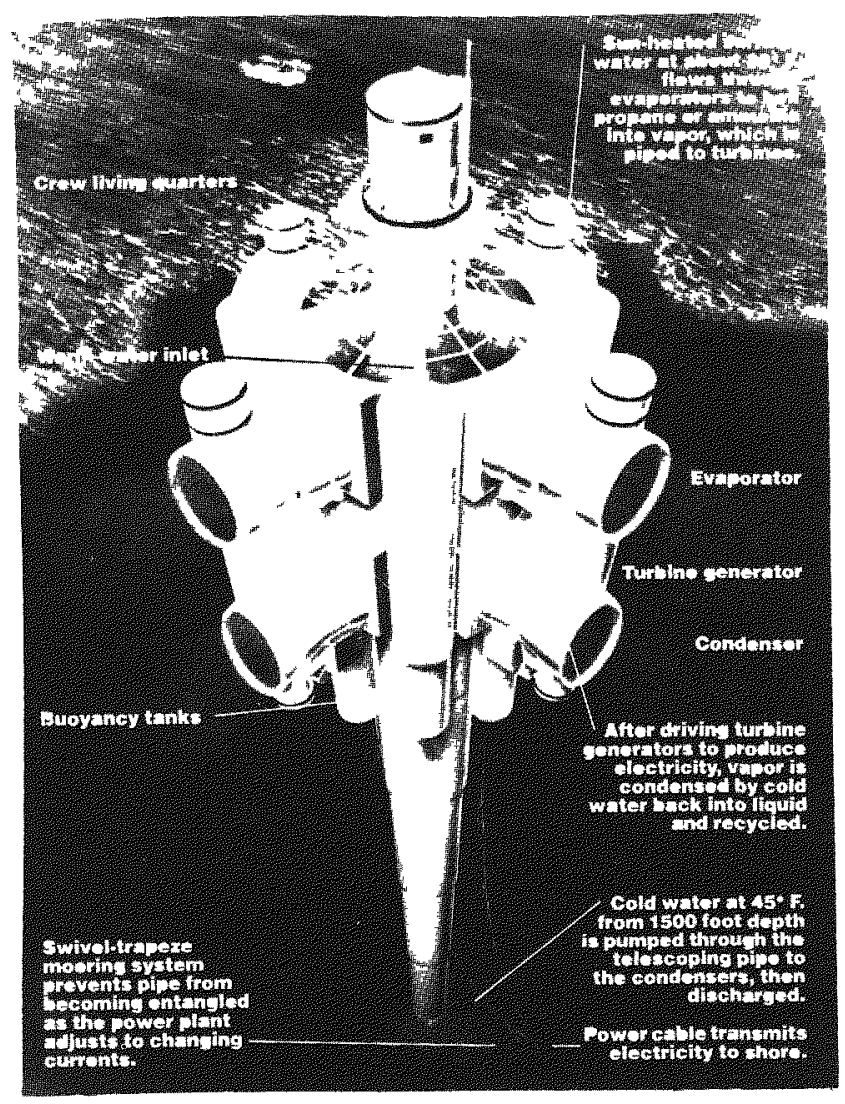

Fig. 1-11. This is an artist's concept of a structure proposed by Lockheed's Ocean Systems Division for an Ocean Thermal Energy Conversion (OTEC) system. The structure is a platform with crew quarters and maintenance facilities. Attached around the outside are turbine generators and pumps. The structure, $250 \mathrm{ft}$ in diameter, $1,600 \mathrm{ft}$ long, and weighing about 300,000 tons, is designed to send 160 million watts of power ashore to distribution networks. This is enough power to meet the needs of a city with 100,000 people. 


\section{Agricul tural and Industrial Process Heat}

As the technology of solar heating for residences was developed, it became apparent that this same technology could well be applied to other sectors of our economy. The possibility of using a solar system year-round, much as is done with a solar water heater, makes the solar industrial process heat market attractive. Approximately $40 \%$ of all the energy required in the United States each year goes to industry. At least $60 \%$ of this amount, or about $25 \%$ of our energy requirement, goes into processes such as heating clean-up water, cooking, curing, steamhea ting, and air-drying.

Farmers hard hit by the increasing cost of propane and natural gas can look to inexpensive solar collectors for grain and crop drying, water heating, and shelter heating. Perhaps as much as $50 \%$ of agricultural needs could be supplied by solar by the turn of the century.

Numerous demonstration projects throughout the United States have been funded by the Department of Energy for industrial and agricultural process heat. Everything from drying lumber in Mississippi, drying raisins in California, providing steam for bleaching surgical gauze and producing concentrated orange juice, to heating water for can washing are end uses for existing solar technologies (Fig. 1-12).

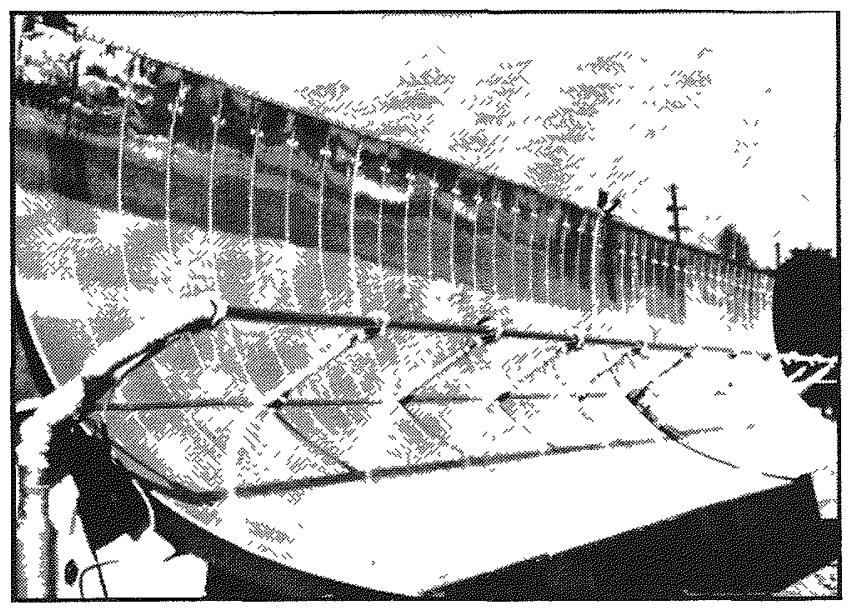

Fig. 1-12. This parabolic trough collector has important applications in the areas of agricultural and industrial process heat.

\section{Conversion of Solar Thermal Energy to Electricity}

The conversion of solar energy into electricity is a problem with a variety of possible solutions. One solution is solar thermal conversion. Solar thermal conversion uses various types of solar collectors to generate steam which drives a turbine and generator to produce electricity. Only the solar heating of the boiler distinguishes this cycle from that of a coal- or gas-fired power plant.

This use of existing power generating technologies is a major reason that solar thermal power systems are being studied for future commercial applications.
Two major types of solar collection systems are used in solar thermal power systems. The first is the power tower, or central receiver, concept. This collector system consists of a large tower surrounded by a field of tracking mirrors (heliostats) which concentrate the Sun's rays onto a boiler located in the top of the tower (Fig. 1-13).

The other type of collector system consists of distributed collector systems which feed thermal energy into central power generating equipment.

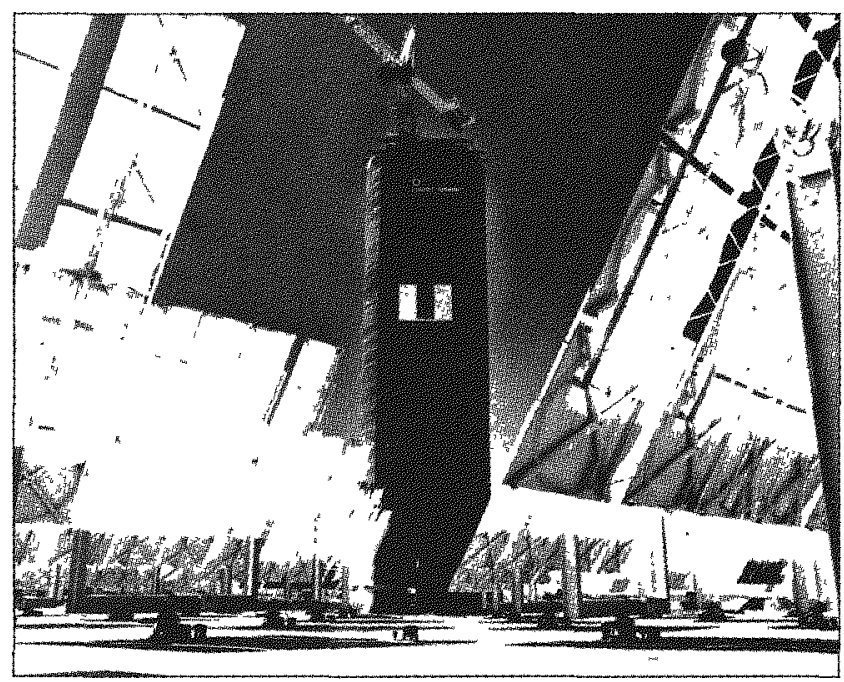

Fig. 1-13. Rear view of some of the heliostat arrays in "ready" position for the first major focusing test at DOE's Solar Thermal Test Facility at Sandia Laboratories, Albuquerque, New Mexico. A $2 \times 3$ th hole was burned in the 1/4-in. thick steel target (a black rectangle mounted in front of a white insulating material) in less than 2 minutes.

\section{Photovol taics}

The conversion of solar radiation into electrical energy by solar cells is a direct spinoff of the satellite and space program. Photovoltaic cells, unlike conventional collectors which convert solar radiation into heat, produce electricity directly. This simple, solid-state device holds the promise of long operating life with little need for servicing. Since it is expected that by 1985 a full one-third of all our energy requirements will be electrical, solar cells could contribute greatly to the wide range of applications that consume electricity.

Solar cells are connected and placed into a sealed glass or plastic unit called a module. Any number of these modules, each of which might deliver 12 watts, are then positioned into a rigid frame to provide a specific power rating (Fig. 1-14). 


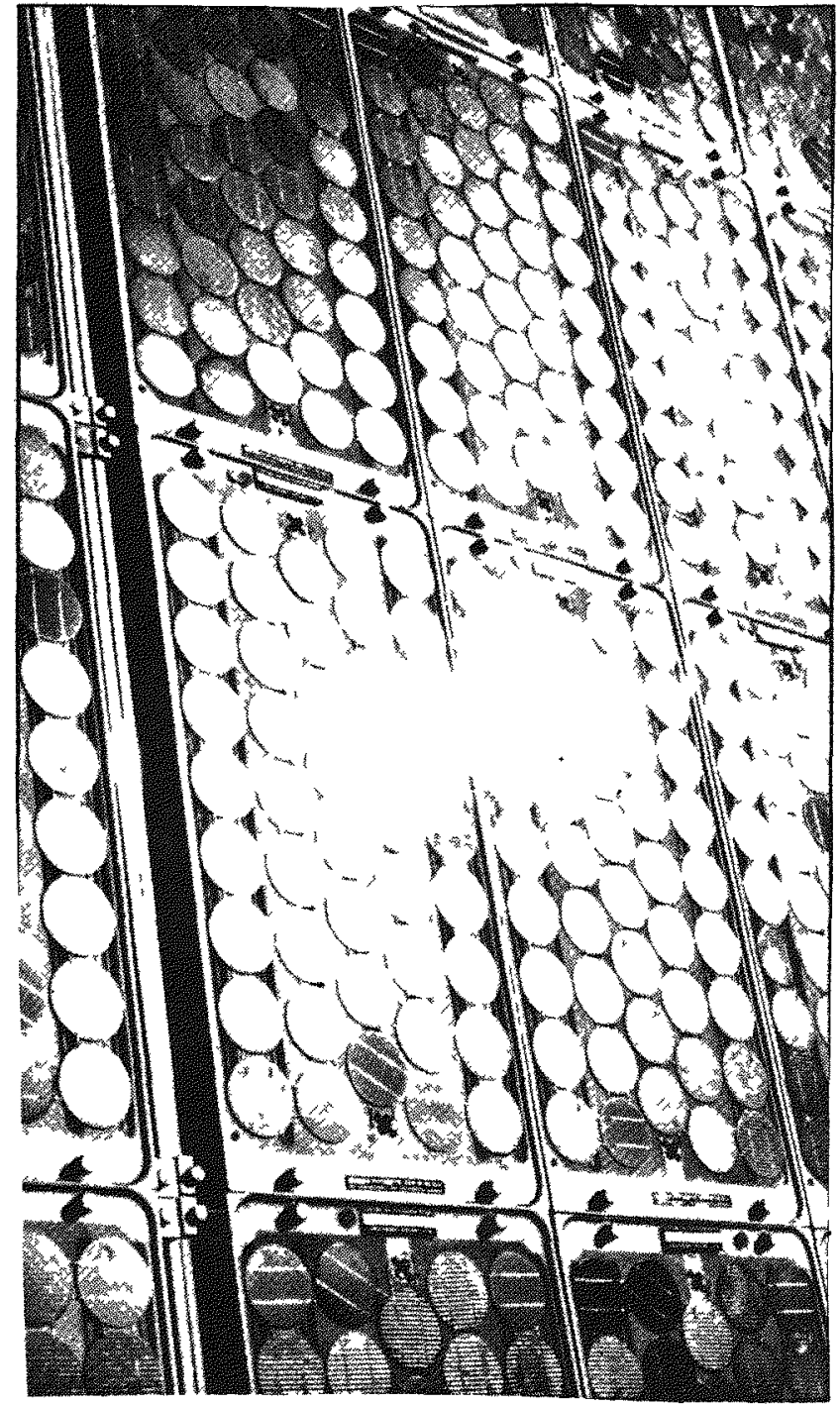

Fig. 1-14. This solar cell array is used to run a $100 \mathrm{hp}$ irrigation pump.

Since solar cells only deliver power during daylight hours, a photovoltaic system requires storage (usually a battery system) if power is to be supplied at night or during cloudy weather. Also, the cells require power conditioning by an inverter to change the d.c. current to a.c. current and to keep the voltage output constant.

Perhaps one of the most immediate applications for this particular technology is to provide power to remote areas where there is no existing power grid or where other electric sources can only be operated at high cost.

\section{SUMMARY}

The question is not whether we will be able to make the inevitable transition to renewable energy resources. The question is whether this generation can plan now to help make it a smooth transition. Energy policy decisions are dictated less by technological factors than by social, environmental, and political ones. Solar energy can deliver a substantial and growing part of our energy needs but at a price, in varying amounts, ways, and time frames.

Solar systems will become economic as a consequence of societal choices that are now being made. These choices are being pressured today by the realization that our conventional fossil fuels are running out. Time is not on our side, and a commitment must be made now.

The national solar energy program is designed to implement a strategy for removing the technical and economic barriers to widespread use of solar energy. It is the prime responsibility of the Department of Energy and the Solar Energy Research Institute to act as facilitators and catalysts for the research and development of new technologies and to assume the initial risks in development until private industry can take over.

This workbook will focus on energy conservation in buildings, building energy loads, and solar applications for commercial buildings (meaning nonresidential buildings used for commercial, institutional, industrial, and agricultural applications). Section I provides descriptions of solar applications in buildings and industrial processes. Design and sizing procedures used for evaluating solar systems are addressed in Section II. Section III specifically addresses the design process to assist the designer in investigating the available options. This type of design process is not limited to solar applications and should be applied to the design of all new buildings and, if appropriate, to the retrofit of existing buildings. Section IV presents case studies of commercial buildings using solar applications.

\section{REFERENCES}

1. American Institute of Architects, Energy and the Built Environment: A Gap in Current Strategies. Washington, D.C.: American Institute of Architects, p. 6 .

2. "A Study of the Impact of Reduced Store Operating Hours on Sales, Employment, Economic Concentration and Energy Consumption." Washington, D.C.: Federal Energy Administration, 1974.

3. Gregory Franta (ed.), Solar Architecture, ASC/AIA Forum 75. Washington, D.C.: U.S. Energy Research and Development Administration, 1975. p. 1.5 .

4. Caudill, Rowlett and Scott, Compilation of Energy Data. Houston, Texas: 1979.

5. American Institute of Architects, op. cit., p. 14. 
2

Energy Conservation in Buildings 
2. Energy Conservation in Buildings

Building design

Building use and operation

Building systems 


\section{INTRODUCTION}

By first reducing the heating, cooling, lighting, and hot water loads of a building, a given solar application will provide a substantially larger percentage of the building's annual energy requirements. The magnitude of loads in a commercial building depends on many factors: how a building is used, the type of equipment used, location and climate, building design and the performance of the building structure, the degree and type of environmental control, the number of occupants, and the period of occupancy.

Design teams shape buildings in accordance to the particular site, budget, building function, aesthetics, technology, the design team, and many other factors. This chapter will focus on the effects of building planning and configuration on the building's energy requirements, and then on conservation measures which may be taken to reduce building loads and increase the efficiency of the building's mechanical equipment.

\section{BUILDNG DESIGN}

\section{Orientation}

The orientation of each building facade and roof has a unique effect on energy use and the potential for energy savings. Orientation will influence indoor lighting requirements, the quality of daylight available for natural lighting, and the design approach taken to make use of it. Building orientation can greatly influence the rate of infiltration, depending upon whether a "large" or a "small" amount of area is exposed to severe winds. Similarly, the orientation of building surfaces will determine the amount of solar radiation reaching each of those surfaces annually. Common sense tells us that for heating, a northern exposure will exhibit the greatest load; and the southern exposure, the smallest. On the other hand, the cooling load of the northern orientation of a building will be significantly less than the southern orientation if the surfaces are not protected from the sun. The relative benefits or disadvantages of each environmental factor must be studied with respect to orientation and building loads throughout the year.

\section{Configuration}

Building configuration will determine in large part the amount of energy the building will use, if a significant portion of the heating and cooling loads is due to heat flow through the envelope because variations in building configuration greatly affect the amount of exterior surface area it has for a given volume enclosed. A tall, narrow building has a relatively high surface to volume ratio. It has a small roof area and is affected less by solar gain on this surface during the summer months. On the other hand, tall buildings are generally subjected to higher wind velocities, and thus have greater infil tration rates and heat loss. Conversely, low buildings have a greater roof area in proportion to wall area, so special attention must be given to the roof's thermal characteristics. A cube-shaped building will have the smallest amount of exterior surface area for a given volume. These variations in building surface areas with differing building forms are illustrated in Fig. 2-1.

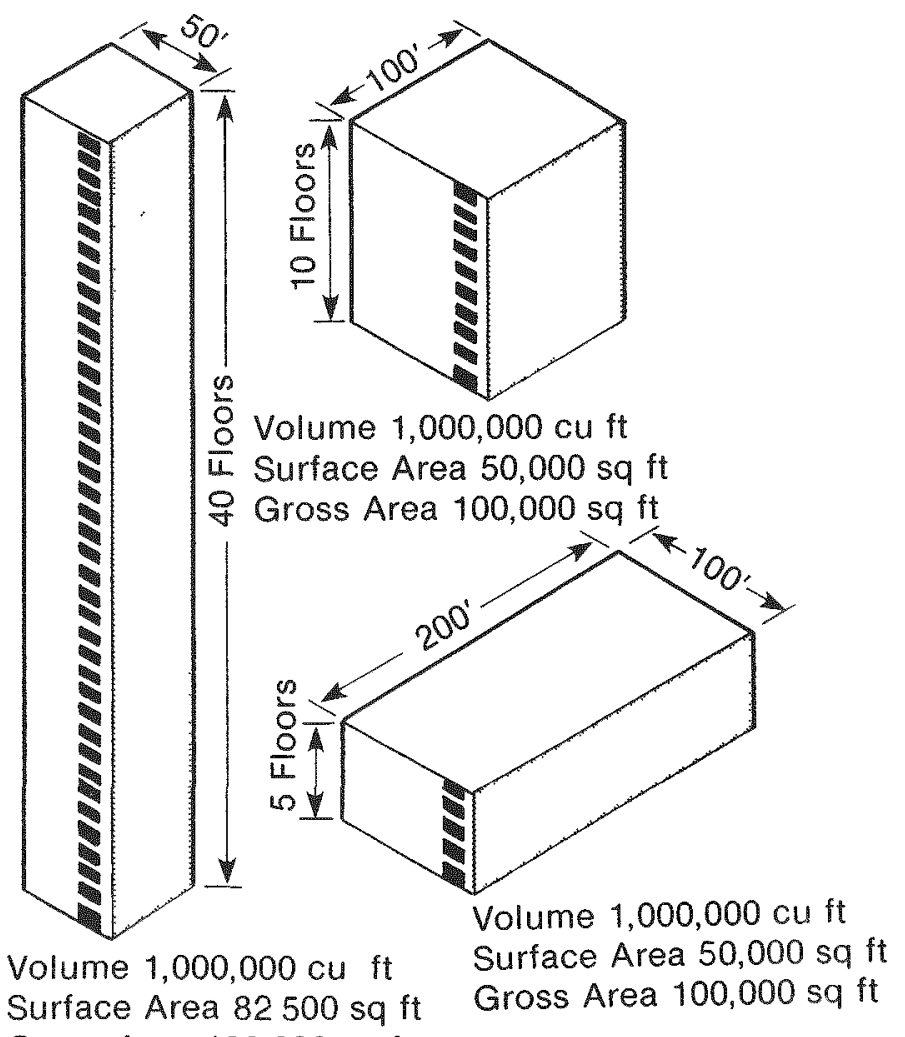

Gross Area $100,000 \mathrm{sq} f t$

Fig. 2-1. Variations in building surface areas
with differing building forms [1] 


\section{Building Plan}

The building plan can have a major effect on the energy required to maintain comfort conditions year-round. A plan must respond to the functional program; however, a critical review of a functional program that includes energy considerations of ten reveals opportunities to change the plan for energy conservation. Grouping spaces having similar environmental control needs can reduce the extent and complexity of the mechanical systems. Particular attention should be paid when some spaces are used 24 hours per day (e.g., computer rooms) and others for just a few hours per day (e.g., conference rooms or auditoriums). Spaces that do not demand a tightly controlled environment (e.g., corridors, storage rooms, service areas, bathrooms, and equipment spaces) should be used as buffer zones against outdoor conditions in skin-dominated buildings.

\section{Building Envelope}

The building envelope, which consists of walls, windows, doors, roofs, and floor surfaces, is subjected to varying influences of climate in each of its orientations. The characteristics of the building envelope can influence the heating and cooling requirements of portions of the building. Again, the extent of this influence depends upon the percentage of the thermal load that is due to heat transfer through the building envelope versus loads resulting from internal generation. In many commercial buildings, only perimeter zones may be subject to envelope losses or gains.

The thermal properties of the envelope are primarily determined by the combination of wall mass; thermal resistance; location of insulation; exterior surface color and texture; and the type, amount, and location of glazing. Windows have a significant effect on energy use because of their high transmission of heat and solar radiation, and air infiltration if it is an operating window. Excessive amounts of glass area may also cause discomfort in building perimeter zones because of the effect of a cold radiant surface, overheating by direct sunlight, and glare. The amount and placement of glazed areas need careful consideration. Some of these problems can be minimized through the use of various types of glass, shading devices, and interior controls such as drapes or blinds.

Walls of large thermal mass have high thermal inertia, which modifies the effect of heat transmission by delay and damping. A wall of high thermal mass which is subjected to solar radiation will absorb heat at its outer surface and transfer it to the interior over a period of perhaps 12 hours. Conversely, a wall having the same U-value but little thermal mass will transfer heat much more quickly, in perhaps 30 minutes. The damping effect of thermal mass will often reduce the short cycling of heating and cooling equipment.

In residential buildings, the amount of heating and cooling required will depend largely upon the U-value of the building walls and roof. The smaller the U-value, the lower is the thermal demand. However, this is not the ease in most commercial buildings. Heat generated by occupants, lighting, and equipment outweighs the effects of envelope heat gains or losses. Building envelopes with low U-values are not necessarily better for commercial buildings. Heat generated internally will not escape as rapidly through an extremely well-insulated building envelope, and this will result in a higher cooling load. Since building and system types, operating conditions, and climatic conditions vary so much, there are no rules of thumb to use as guides in determining U-values that will result in minimum energy consumption.

\section{BUILDING USE AND OPERATION}

According to Lawrence Spielvogel, "The one factor that, more than any other, determines energy consumption of a building is how it is used" [2]. He further states that the number of hours per day which equipment and systems are operated will determine how much energy is consumed. Studies on energy usage by Princeton University demonstrate the significance of the "occupant" factor. When energy usage was monitored in identical dwellings, variation of a factor of two was found between the lowest and highest users. So, by analyzing a building's use patterns, one can identify times of day when certain systems and equipment are left operating unnecessarily and should be shut off to conserve energy.

\section{Controls}

The type of control of the heating and cooling systems can influence energy use to a great extent [1]. Spielvogel classifies control systems as either direct or indirect, depending upon how the need for climate control determines energy consumption.

It is implied that with direct control, energy is supplied as the need exists and in proportion to the amount needed. An example of this approach would be a building that is thermostatically controlled space by space, as is the case in many residences.

Indirect controls are described as including such things as fixed cooling coil supply-air temperature or outdoortemperature reset schedules, where the amount of heat or cooling delivered is determined by outdoor ambient conditions. This approach is not the most efficient because more energy than necessary is supplied in many cases. Much more energy is wasted with indirect controls than with direct controls.

Allowance should always be made for manual control of lighting and HVAC systems. The building owner or operator should have the flexibility of turning lights on and off in relatively small zones, or reducing or shutting of heating or cooling in unoccupied areas.

\section{BUILDING SYSTEMS}

\section{Heating}

Heating is, in many large buildings, a major element of the building load. Following are some recommendations for reducing heat loss from a building. These will also apply to reducing heat gain, which will be of concern in the section on cooling that follows. Included are measures to improve the thermal resistance of the building envelope and means to reduce air infiltration. The greatest savings are achieved by simply reducing 
indoor air temperatures and the rates of ventilation. Outlined below are some of the ways to conserve energy during heating.

- Set back indoor temperatures in heating season during unoccupied periods.

Much of the energy expended to heat unoccupied buildings to comfort conditions may be wasted, and most buildings are indeed unoccupied most of the time. In areas where it is not necessary to maintain high temperatures during occupied periods as in corridors and lobbies, temperatures can be lowered further. However, be sure that more energy is saved than is used to recover original building conditions.

- Reduce indoor temperatures during occupied periods. Maintaining lówer indoor temperatures during occupied periods conserves energy, although savings are not as great as those for unoccupied hours.

- Avoid radiation effects to cold surfaces.

People located in a room at a temperature of 70 or $75 \mathrm{~F}\left(21-24^{\circ} \mathrm{C}\right)$ can still feel cold because of the effect of a cold radiant surface such as a large window. Close curtains or Venetian blinds to reduce radiation of heat from occupants to cold surfaces.

- Reduce levels of relative humidity.

Humidification systems are of ten installed to maintain the comfort and health of occupants and to prevent crying and cracking of wood, furniture, and building contents. Where preservation of materials is not a problem, humidification should be minimized when the building is unoccupied.

- Shut down the ventilation system during unoccupied hours.

Cold outdoor air, introduced for ventilation, must be heated to indoor temperatures. Many buildings are ventilated at a rate far in excess of that necessary to maintain comfort, dilute odors, or meet code requirements. Ventilation systems are not infrequently operated 24 hours per day; they should be shut down when they are not needed.

- Reduce ventilation rates during occupied periods.

Ventilation is required for replacement of expended oxygen, but this requirement is a very small proportion of the outdoor air typically introduced into most buildings. No more cold outdoor air than is actually necessary for health and safety, odor and smoke control, or other code requirements should be brought into the building.

- Reduce rate of infil tration.

Particularly effective measures include caulking around windows and door frames and weatherstripping windows and doors.

- Increase solar heat gain into the building.

If heating is required during daylight hours in the winter months, direct solar gain through south glazing can be very helpful in reducing the load. (This is discussed in more detail in the chapters on passive solar systems.)
- Use separate makeup air supply for exhaust hoods to reduce outdoor air ventilation.

If the exhaust air up the hood is drawn from room air, the HVAC system must heat or cool outdoor air to make up this exhaust. This can be a considerable heating or cooling load.

- Reduce heat loss through windows and skylights.

Conversion of windows from single to double or triple glazing will drastically reduce the conduction heat loss and reduce infiltration rates. In most states, double glazing is required in new buildings. Storm windows may also be applied to either the outside or inside of an existing window to reduce heat loss by conduction and infil tration. New glazing materials and techniques that reduce heat loss even more are rapidly being developed and should be considered when evaluating glazing options. Movable devices that insulate the glazing at night should also be investigated.

- Reduce heat loss through walls, roofs, and floors.

Properly insulate all exterior exposures to arrive at the optimal thermal resistance for the particular climate and building.

\section{- Reduce infil tration with building al terations.}

Infiltration can be reduced through the use of airlock entries, revolving doors, and windscreens.

\section{Cooling}

Windows were originally conceived to provide light and a view. Perimeter spaces can be well lit with daylight, even while protecting indoor spaces from direct sunlight with exterior shading devices. However, with the advent and common utilization of artificial light sources, windows are now simply used for the view. Artificial light, together with people and equipment, add heat to interior spaces that must be removed during the summer (and frequently winter) by the cooling system.

As with heating, dramatic savings in cooling energy are available immediately by simply altering the levels of air temperature, humidity, and ventilation maintained. The following guidelines begin with these measures.

- Increase levels of indoor temperature and relative humidity.

Substantial energy can be saved by increasing the levels of indoor temperature and relative humidity. For example, by increasing the indoor temperature and humidity levels from $74 \mathrm{~F} \mathrm{DB}\left(23^{\circ} \mathrm{C}\right)$ and $50 \%$ relative humidity $(\mathrm{RH})$ to $78 \mathrm{~F} \mathrm{DB}\left(25^{\circ} \mathrm{C}\right)$ and $55 \% \mathrm{RH}$, the energy required for cooling will be reduced by approximately $13 \%$.

- Reduce ventilation.

When outdoor conditions are too warm for comfort, all ventilation air must be cooled as it is brought into the building. By reducing the quantity, less energy is consumed in cooling it. 
- Reduce solar heat gain through windows.

Shading glass from direct sunlight during cooling months is extremely important. Direct solar radiation through windows will significantly add to the cooling load.

- Reduce heat gains through walls, floors, and roofs.

Low absorptivity surfaces will reduce solar gains, and adequate insulation will inhibit absorbed solar energy from entering the building's interior.

- Reduce internal heat gains from lights and equipment. Heat gain from lights is of ten the major part of the cooling load in an office building. Lighting levels are of ten far in excess of those required for visual acuity, so steps may be taken to reduce lighting levels and accompanying heat gain. Electrically operated machines and equipment generate heat and should be shut off when not in use.

\section{- Use outdoor air for cooling.}

Economizer cooling brings outdoor air into conditioned areas to remove internal heat gain without operating the refrigeration compressor when outside air is cool enough. During the night, outdoor air which is $5 \mathrm{~F}$ $\left(3^{\circ} \mathrm{C}\right)$ or more below indoor temperature can be used effectively for cooling. During occupied periods, the opportunities to use outdoor air for cooling depend on the outdoor wet bulb temperature as well as dry bulb temperature. Install an economizer cycle to open outside air dampers when outdoor wet bulb temperature is below $65 \mathrm{~F}\left(18^{\circ} \mathrm{C}\right)$ and dry bulb temperature is below $85 \mathrm{~F}\left(29^{\circ} \mathrm{C}\right)$.

\section{Domestic Water Heating}

Significant energy savings can be achieved through proper design of domestic or service hot water systems. Selecting the type of system which is best designed to meet the particular requirements of the building will conserve energy from the outset. However, measures can be taken to increase the efficiency of an existing system. Energy in hot water systems is generally lost through distribution, storage, and heater fuel conversion. The following section on conservation follows the order of reduction of hot water quantity and temperature requirements, then reduction of piping losses, then reduction of conversion losses for hot water generation.

- Reduce domestic hot water quantity.

Water consumption can be lowered to $1-1 / 2 \mathrm{gpd}$ $(5.67 \% / d)$ per person in office buildings. Install spraytype faucets that use only $1 / 4 \mathrm{gpm}(1 \mathrm{l} / \mathrm{m})$ instead of 2 or $3 \mathrm{gpm}(7.5-11 \mathrm{l} / \mathrm{m})$ and use other types of water conserving fixtures.

- Reduce domestic hot water system losses.

The entire piping system and storage tank should be insulated properly. Calculate energy savings by determining the amount of heat lost before and after insulating.
- Improve domestic hot water system performance with equipment modifications.

Patterns of hot water use within the building should be analyzed to determine whether installation of local units or a central water heater would be more efficient. When the majority of hot water use is at a lower temperature, and higher temperatures are required only at a few specific locations, booster heaters should be installed where needed rather than maintaining all the water at a higher temperature. Continuously circulating systems should be shut down when the building is unoccupied.

\section{POW:日e}

Of interest is an assortment of electrical equipment that includes elevators, coffeepots, soft-drink machines, and typewriters, and operations that control their consumptive use. of additional concern are measures that limit peak electrical demands for the whole building (to drastically reduce electricity bills where utility rates include demand charges), measures that improve the efficiency of motors, and measures that reduce transformer losses.

- Reduce energy requirements for elevators and escalators.

Reduce the number of elevators in service during hours when a majority of persons are not leaving or entering the building. Operate demand escalators only during peak hours.

- Reduce energy consumption for equipment and machines.

Equipment not in use should be turned off. Automatic timers with remote control switching are valuable to deenergize equipment which is not required at night and during weekends.

- Reduce energy requirements for commercial refrigeration.

Internal lights in refrigerated cabinets heat the cold air and increase the load on the refrigerating machine. Each kilowatt of "lighting heat" eliminated will reduce the refrigeration load by 0.28 ton. Insulated night covers can be installed on open deep-freeze chests.

\section{- Reduce peak loads.}

Where manual load shedding cannot be instituted because of cost and demand on personnel, consider automatic load shedding. Available automatic loadlimiting devices range in complexity from a simple thermal sensor which works much like a circuit breaker thermal element and switches off a low-priority load when the building load reaches a preset point, to a unit that reads current and provides for shedding and restoring loads.

\section{- Reduce transformer losses.}

Even when equipment served by a transformer is inoperative, some energy is lost unless primary power to the transformer is switched off. When the transformer serves loads which are not required for relatively long periods of time, complete disconnection 
from the primary power may be feasible. When adding or replacing transformers, select efficient dry-type transformers.

- Improve the efficiency of motors.

Motors that are not loaded to at least $60 \%$ of their potential are relatively inefficient. Underloaded motors can be exchanged. Proper maintenance is also important to their efficient operation.

\section{- Correct the power factor.}

Low power factors (PF) increase losses in electrical distribution and utilization equipment such as wiring, motors, and transformers, and reduces the loadhandling capability and voltage regulation of the building's electrical system. At a PF of $80 \%$, spare capacity is decreased by an additional $25 \%$ of the load; and transmission losses are increased by $56 \%$ when compared with unity PF. Where the load is primarily inductive, capacitors can be installed at any point in the electrical system and will improve the power factor between the point of application and the power source, but the power factor between the equipment and the capacitor will remain unchanged. Capacitors are usually added at each piece of offending equipment, ahead of groups of small motors (ahead of motor control centers or distribution panels).

Heating, Ventilating, and Air-Conditioning (HVAC)
Systems

HVAC systems must often be designed to serve the varying needs of large multizone buildings. As a result, the control, operation, and detailing of such a system are crucial to efficient operation. The total number of hours of operation will also significantly influence energy use. When certain zones or spaces in a building are not being used and do not need conditioning, it is pointless to do so since no matter how efficient a system may be, its energy consumption will increase according to the hours of operation. The efficiency of system components is important. However, another aspect deserving careful attention is the amount of energy consumed in the distribution system. The reason for the emphasis on distribution energy is that even though it may be small in magnitude, it is typically large in duration, in that fans and pumps run (with the exception of a cooling tower or a variable volume system) at full load for every occupied hour [1].

- Reduce resistance to flow in air distribution systems.

Careful attention should be given to filters, heating and cooling coils, duct fittings, and unnecessary dampers.

- Reduce the volume of flow in air distribution systems.

If it is possible to reduce the volume of air in a system by $10 \%$ through reduced loads and reduced resistance to airflow, the savings in fan power will be about $27 \%$.

- Reduce thermal losses in air distribution systems.

Insulate bare ductwork passing through unheated spaces. Insulation applied to ducts supplying only warm air need not be vapor sealed. Insulation applied to ducts supplying warm air in winter and cold air in summer must be vapor sealed to prevent condensation from forming within the insulation.

- Reduce thermal losses in water and steam distribution systems.

Insulation for piping is very important. Heat losses from piping should not exceed $0.25 \mathrm{Btu} / \mathrm{sq} \mathrm{ft}-\mathrm{F}$ $\left(2,851 \mathrm{~J} / \mathrm{sq} \mathrm{m}-{ }^{\circ} \mathrm{C}\right)$.

- Reduce resistance to flow in piping systems.

Strainers should be cleaned or replaced on a regular maintenance schedule. Heat exchangers are prone to fouling and must also be cleaned.

- Reduce volume of flow in water distribution systems.

Reducing the water flow rate through a piping system also reduces the resistance to flow, and a smaller pump may be used.

- Direct hot water and steam heating systems.

Keep radiators free from blockage. Clean the air side of all direct radiators, fin tube convectors, and coils to enhance heat transfer. Vent all hot water radiators and convectors to ensure that water will completely fill the interior passages. Check radiator steam traps to ensure that they are passing only condensate, not steam.

- Single duct, single zone systems.

Any measure which prevents simultaneous heating and cooling and delivers warm or cool air to spaces in accordance with thermal needs, rather than in bursts of overheated and overcooled air, is more efficient and provides more comfort to occupants. Maintain filters to reduce resistance to airflows. To reduce heat loss and heat gain, repair torn insulation.

- Terminal reheat systems.

As with single duct systems, energy can be saved by reducing the supply air volume. Where dehumidification can be eliminated and a zone control can be satisfactorily maintained, operate the terminal reheat system on a temperature demand cycle only. Install an interlock between the two valves to prevent simul taneous heating and cooling.

\section{- Mul tizone systems.}

Analyze multizone systems carefully; treat each zone as a singlezone system, and adjust air volumes and temperatures accordingly. Check hot-deck and colddeck dampers for leakage. Adjust controls to give the minimum hot-deck temperature and maximum colddeck temperature consistent with the loads of critical zones. Install controls to shut off fans and heating control anc cooling control valves during unoccupied periods.

\section{- Dual duet systems.}

Reduce system pressure by replacing high-pressure mixing boxes with lower pressure mixing boxes. Install controls which will shut off the heating or cooling portions of the system when they are not required. Provide volume control for the supply air fan and 
reduce air volumes by lowering fan speed when both hot-deck and cold-deck air quantities can be diminished to meet peak loads.

- Variable air volume (VAV) systems.

To conserve energy, the fan volume can be regulated by a variable speed motor according to the demands of the system. Provide controls to modify fan speeds up or down to maintain constant pressures in the supply duct. Install controls to reduce the hot water temperature and raise the chilled water temperature in accordance with shifting thermal demands. With single duct variable volume systems with reheat, set controls to delay reheat until the volume is reduced to a minimum. Where possible, eliminate reheat coils.

\section{- Induction systems.}

Reschedule the temperature of the heating water and the cooling water according to the load. If the building has a light cooling load, the chilled water temperature should be raised; if the building has a light heating load, the hot water temperature should be lowered. Avoid simultaneous heating and cooling in any one zone. Schedule the temperature of the primary supply air at the air handling unit according to the load. Remove lint screens in induction units and clean colls regularly. For night operation during the heating season, shut down primary air fans, raise the hot water temperature, and operate the induction units as gravity convectors.

\section{- Fan colls and unit ventilators.}

Heating and cooling colls should be cleaned, and air and water flow reduced to the minimum required to meet space conditions. For fan coil systems that have separate coils for heating and cooling, install a control to prevent simultaneous heating and cooling. Install a 7 -day timer to shut off fans, valves, chilled water pumps, compressors and cooling towers, or air-cooled condensers during unoccupied periods. Close outside air dampers any time infiltration equals ventilation requirements, or block them off permanently. When fan coll units are not located in conditioned areas, insulate casings to reduce heat loss or gain.

\section{- Heat pumps and air conditioners.}

Replace air-to-air heat pumps with water-to-water heat pumps where there is a source of heat such as solar-heated water or ground water with temperatures above average ambient winter air temperatures. Install a 7-day timer to program operation of compressors in accordance with occupied-unoccupied periods. Replacement compressors should have an EER (energy efficiency ratio) of $9 \mathrm{Btu} / \mathrm{Wh}$ or better during the cooling cycle. Rewire the power supply to heat pumps in such a manner that one-third, two-thirds, or all units in any zone can be turned on and off, depending on whether the bulding is occupied or not and what conditions are expected. When retrofiting, install one larger unit pather than multiple smaller units for greater efficiency.

\section{Exhaust systems.}

All recommendations which have been made to reduce fan power requirements by flow rate and resistance reduction apply equally to exhaust systems and to supply systems. Exhaust systems should be balanced so that exhaust airflow rates do not exceed supply airflow rates of associated systems. Exhaust fan volumes should be modulated in step with associated VAV supply fans by installing inlet guide vanes or variable speed controls. Recirculate toilet room exhaust air through charcoll fil ters to reduce makeup air requirements.

\section{Ligghting}

Lighting systems, as they are customarily designed and operated, can be directly related to a large percentage (perhaps $50 \%$ of the total energy consumption for large commercial buildings. Significant energy reductions are possible through taskmoriented lighting and the use of daylighting. This subject is discussed in Chapter $b$ of this workbook.

\section{CONCHUSION}

The application of conservation techniques such as those mentioned in this chapter are just as important to reduced energy consumption in buildings as the application of solar energy; they should always go hand in hand. It is only through such an approach that building designers will be able to meet the stringent energy goals being envisioned today.

\section{REFTRENCRS}

1. Fred S. Dubin and Chalmers G. Long, JP. Energy Conservation Standards: For Building Design, Construction and Operation, 1978.

2. Lawrence G. Spielvogel, "How and Why Buildings Use Energy," in Energy Conservation Through Building Design, Donald Watson, ed., McGraw-Hill 1979.

3. Fred S. Dubin, "Energy Management for Commercial Buildings: A Primer," in Energy Conservation Through Building Design, Donald Watson, ed., 1979.

4. Lawrence G. Spielvogel, Energy Management in Buildings. New York University, School of Continuing Education, Division of Business and Management, 1978.

\section{ACRMOWLEDGMENT}

Much of the material in the sections on "Building Design" and "Building Systems" has been taken directly from Energy Conservation Standards for Building Design, Construction and Operation by Dubin and Long. Thanks are extended to the authors for permission to use the material. 
3

Solar Fundamentals 
3. Solar Fundam entals

Solar Radiation at the Earth's surface

Solar geom etry

Solar angles

Magnetic declination

Radiation incident on tilted surfaces

Climatology

Shading

nlumination data for daylighting studies 
SOLAR FUNDAMENTALS

This chapter presents the fundamentals of solar energy. It is designed to introduce the designer to the basic principles of solar geometry and intensity, and to climatological factors that should be considered in the solar design process. The intent is also to define the terms and concepts that must be understood to effectively use the design information that follows. The final purpose is to direct the designer to the basic resource materials needed in the solar design process.

For an in-depth discussion of the topies introduced here, the reader should see Refs. 1-3.

\section{SOLAR RADIATION AT THE EARTHS SURFACE}

\section{The Solar Constant}

The solar constant is defined as the intensity of solar radiation, essentially in the 0.3 to $5 \mu \mathrm{m}$ wavelength range, on a surface normal to the Sun's rays beyond the Earth's atmosphere at the average Earth-Sun distance. The presently accepted value is $429.2 \mathrm{Btu} / \mathrm{hr}-\mathrm{sq} \mathrm{ft}$ of irradiated area or $1,353 \mathrm{~W} / \mathrm{sq} \mathrm{m}$. The data on which the $429.2 \mathrm{Btu} / \mathrm{hr}-\mathrm{sq} \mathrm{ft}(1353 \mathrm{~W} / \mathrm{sq} \mathrm{m})$ value was based has been reexamined. The resulting new value for the solar constant is on the order of $1.5 \%$ higher or 435.2 Btu/hr-sq ft ( $1373 \mathrm{~W} / \mathrm{sq} \mathrm{m})$.

Although atmospheric transmittance is a major uncertainty, emission of energy by the Sun can be considered constant. However, because the Earth's orbit is slightly elliptical, the normal incidence intensity on an extraterrestrial surface varies from 0.97 to 1.03 times the solar constant.

Because of atmospheric absorption and scattering, two types of solar radiation reach the Earth's surface. Direct, or beam, radiation is that received from the Sun without change of direction. Diffuse radiation is received from all parts of the sky due to scattering by the molecules of oxygen and nitrogen and by dust. (See Fig. 3-1.) Solar radiation also reaches collecting surfaces by reflection from the adjacent ground or structures.

\section{Attenuation of Direct (Beam) Radiation}

Normal incidence solar radiation at the Earth's surface is subject to changes because of variations in Earth-Sun distance; atmospheric scattering by air molecules, water vapor, and dust; and atmospheric absorption by $\mathrm{O}_{2}$, ozone, $\mathrm{H}_{2} \mathrm{O}$, and $\mathrm{CO}_{2}$. The atmospheric path length is generally expressed in terms of the air mass, $\mathbf{m}$, which is

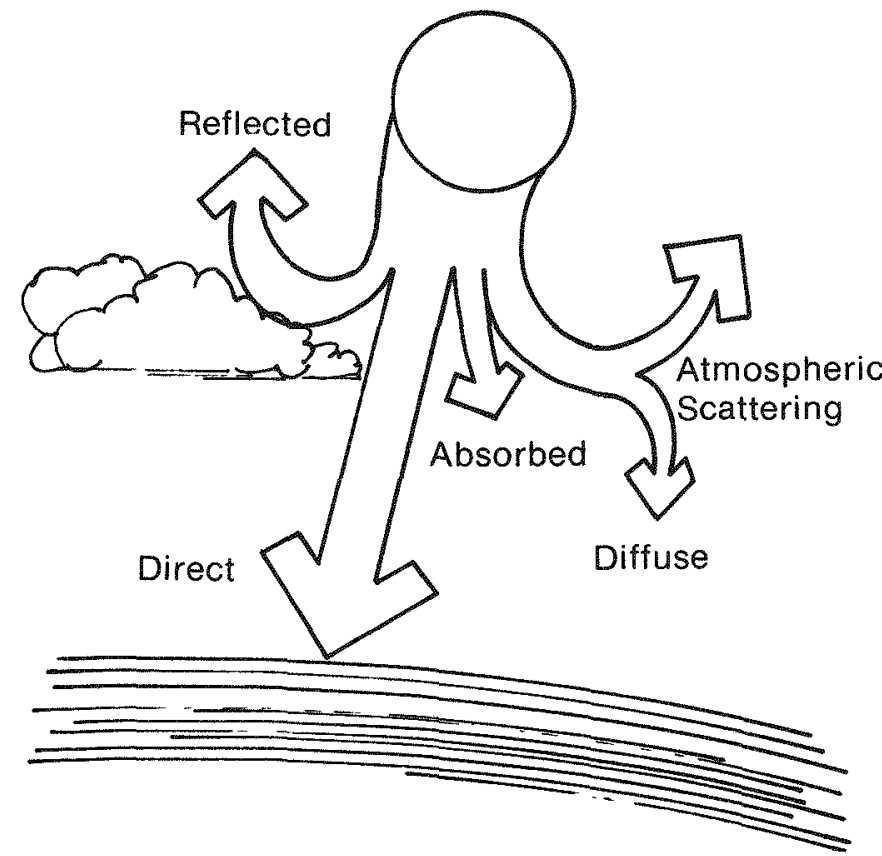

Fig. 3-1. Atmospheric scattering of solar radiation (Source: Edward Mazria, The Passive Solar Energy Book, 1979)

the ratio of the mass of atmosphere in the actual EarthSun path to the mass that would exist if the Sun were directly overhead at sea level $(m=1.0)$. (See Fig. $3-2$. ) For all practical purposes, at sea level, $m=1.0 / \sin \beta$. Beyond the Earth's atmosphere, $m=0$. Chapter 58 of Ref. 4 gives the annual variation of direct normal irradiation with solar altitude.

Because local atmospheric water content and elevation vary markedly from the sea level average, the concept of Clearness Number was introduced to express the ratio between the actual clear-day direct radiation intensity at a specific location and the intensity calculated given the standard atmosphere at the same location and date. 


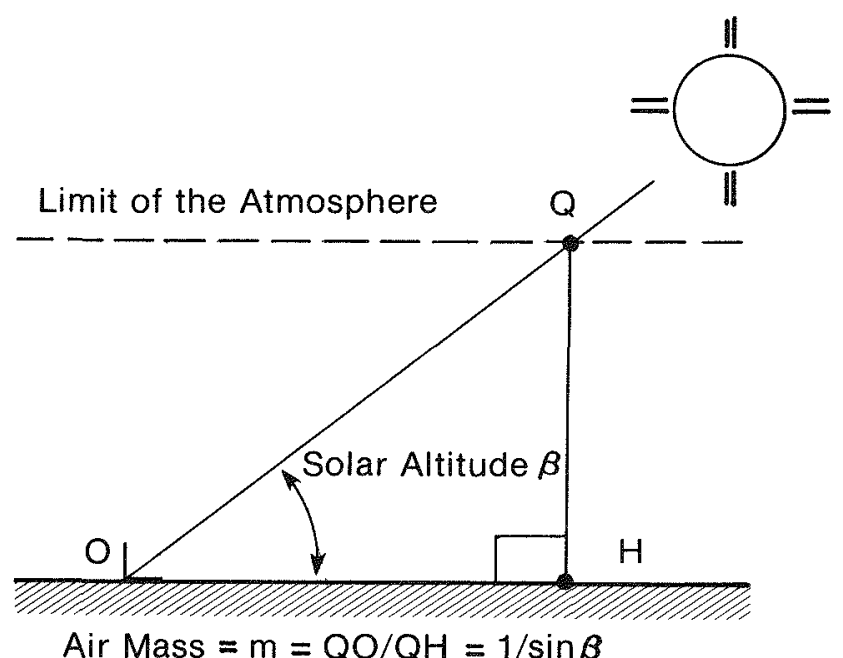

Fig. 3-2. Atmospheric path in terms of air mass
Fig. 3-3 is a map of winter and summer Clearness Numbers for the continental United States. Total irradiation values given in Tables 2 and 3 , Chapter 58, Ref. 4 should be adjusted by the Clearness Numbers applicable to each particular location to obtain correct clear-day values.

\section{Diffuse Radiation at the Ground}

Because atmospheric components scatter part of the solar radiation toward the Earth, there is always some diffuse radiation, even when the sky is very clear. All radiation reaching the ground is diffuse during heavy cloudiness. The distribution of diffuse radiation is highly variable, depending upon atmospheric conditions. As a first approximation, one can assume that diffuse radiation is isotropic over the sky dome.

There are no adequate data on which to base a detailed computation of the intensity of diffuse radiation at the ground. However, estimates given in Fig. 5, Chapter 58, Ref. 4, or in Chapter IV, Ref. 5 are adequate for most design calculations. The methods in Chapter V, Ref. 5 should be used to determine more detailed hourly, daily, or monthly values of diffuse radiation.

Hourly, daily, and monthly values of total solar irradiation ineident on til ted surfaces will be discussed later in this chapter.

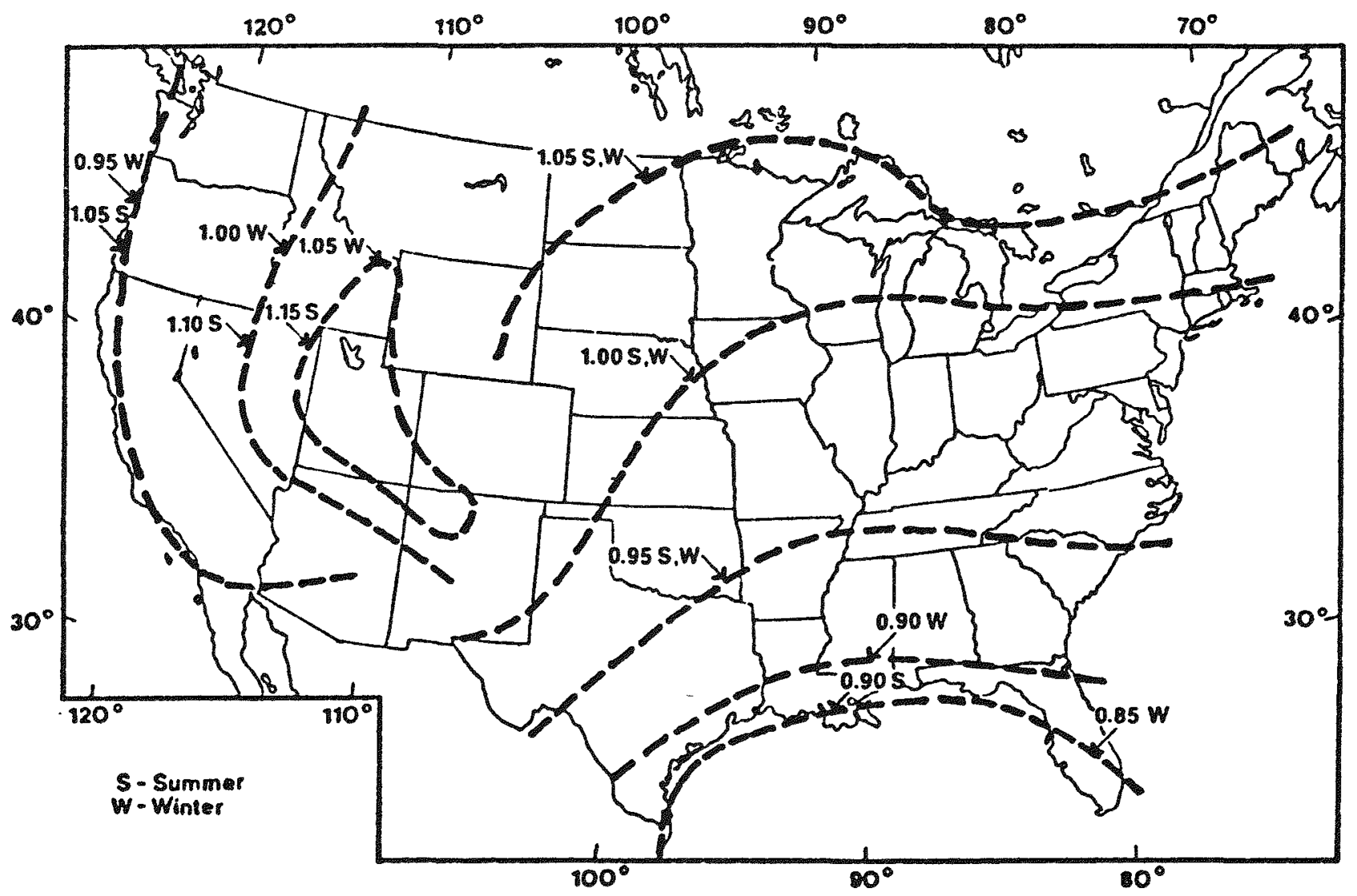

Fig. 3-3. Summer and winter Cleamess Numbers [3] 


\section{SOLAR GEOMETRY}

The angle at which a beam of direct solar radiation strikes the Earth's surface is influenced by several factors-principally the declination ( $\delta)$, latitude (L), and the hour angle $(\mathrm{H})$.

Declination is defined as the Sun's angular position at solar noon relative to the plane of the equator, (see Fig. 3-4) and is caused by the Earth's axis being tilted at $231 / 2^{\circ}$ from the vertical to the Earth's orbital plane. Because of the Earth's annual orbit around the Sun, the declination varies from $231 / 2^{\circ}$ north of the equator on June 21 to $231 / 2^{\circ}$ south of the equator on December 21 , and is zero at the spring and fall equinoxes.

The influence of latitude on solar position, more specifically, solar altitude $(\beta)$, is illustrated in Fig. 3-5 at either the spring or fall equinox. Assume that the date is March 21, and the time is 12:00 noon. To someone standing on the equator, the Sun appears directly overhead $\left(\beta_{\text {on }}=90^{\circ}\right)$, and to someone standing at $60^{\circ} \mathrm{N}$. latitude, the sun is only $30^{\circ}$ above the horizon $\left(\beta_{\text {noon }}=30^{\circ}\right)$.

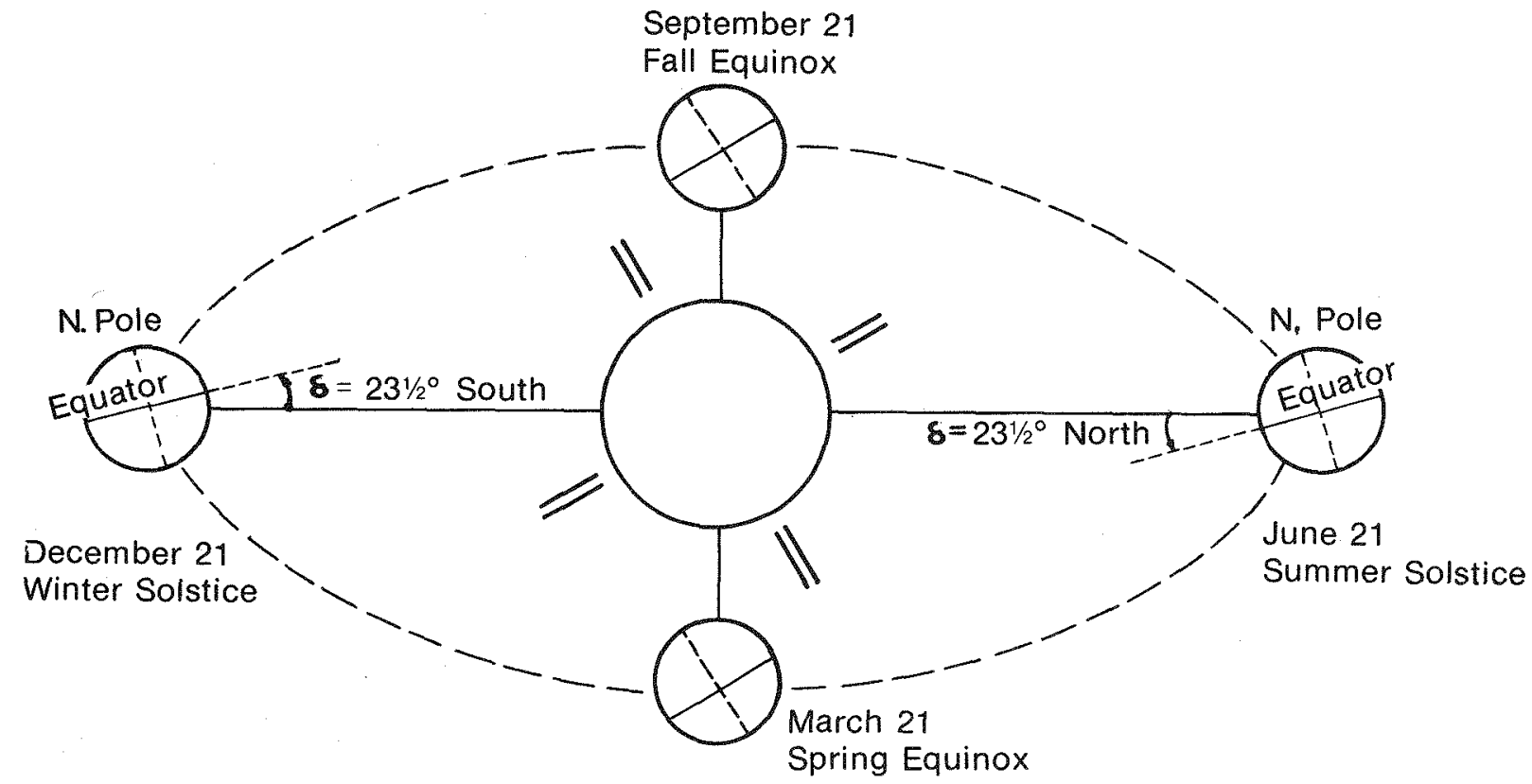

Fig. 3-4. solar declination

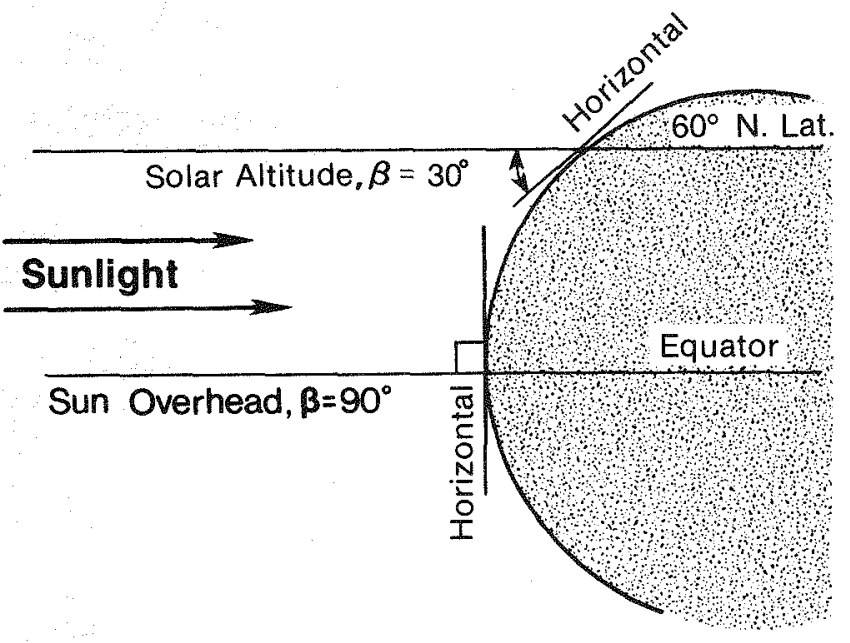

Fig. 3-5. Influence of latitude on solar altitude shown at noon, on the equinoxes
The hour angle $(H)$ is the product of the Sun's apparent angular rate of movement, $15^{\circ}$ per hour, and the number of hours from solar noon. As an example, $\mathrm{H}=15^{\circ}$ at $11: 00$ a.m. (AST) and $37.5^{\circ}$ at $2: 30$ p.m. (AST).

Apparent solar time usually varies from local standard time; the difference can be significant, particularly when Daylight Savings Time is in effect. The procedure for finding AST is:

$$
\begin{aligned}
\text { AST }= & \text { Local Standard Time }+ \text { equation of time } \\
& +4 \text { minutes } \mathrm{x} \text { (Local Standard Time Meridian - } \\
& \text { Local Longitude) }
\end{aligned}
$$

As an example, find AST for Madison, Wisconsin, given:

10:30 a.m. Central Standard Time

Date: February 2

Longitude: $89.38^{\circ}$

from Table $3-1$

Equation of time $=-13.7 \mathrm{~min}$. 
Table 3-1. SOLAR POSITION DATA FOR 1977

(Values of declination and Equation of Time will vary slightly for specific dates in other years.)

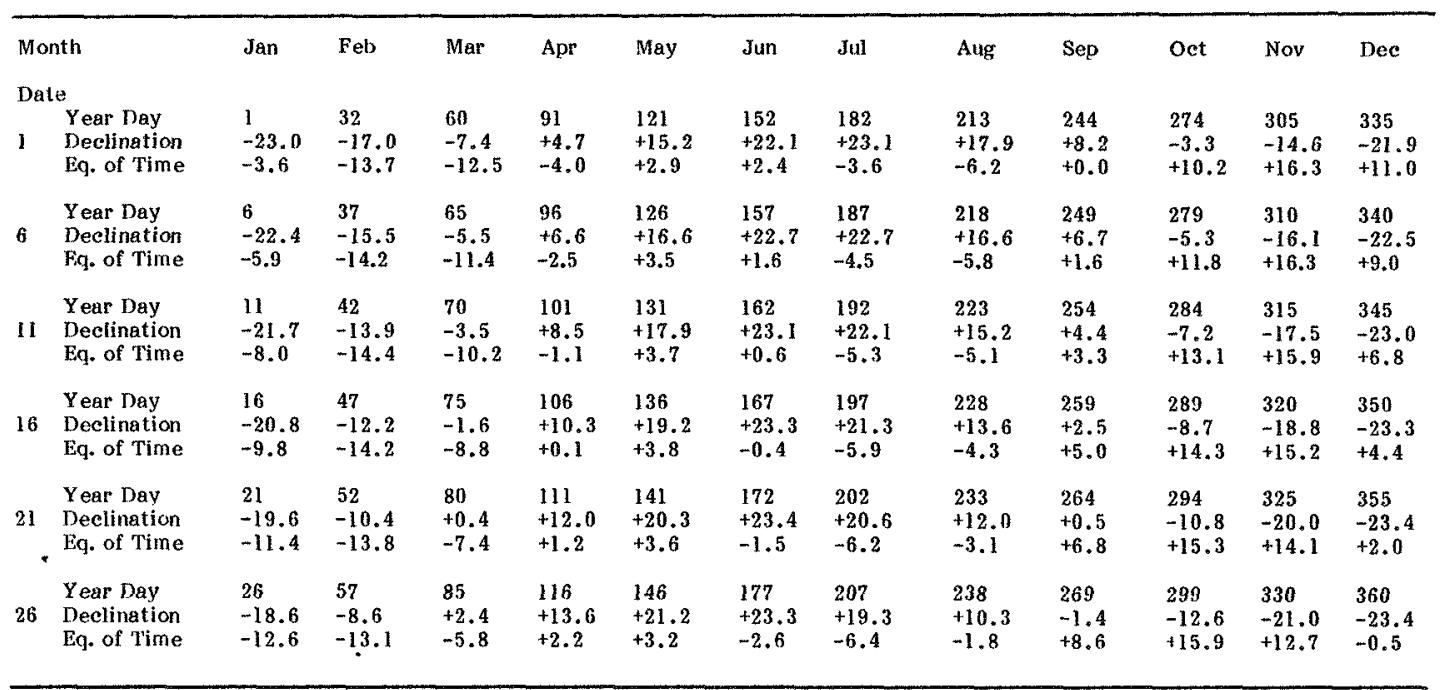

(Units for declination are angular degrees; units for Equation of Time are minutes of time.)

Standard Time Meridians: so using Equation 3-1:

AST $=10: 30-13.7+4(90-89.38)$

$\operatorname{AST}=10: 19$ a.m.

A detailed discussion of solar geometry is given in Ref. 1.

\section{SOLAR ANGLES}

Solar angles must be calculated to determine the intensity of direct solar radiation incident on a collector at a oiven instant or to determine the shading of an object surface, or collector. The geometric relationships between a plane oriented arbitrarily relative to the Earth, such as a solar collector, and the incoming beam of solar radiation, that is, the position of the Sun relative to the plane, can be described in terms of several angles. These angles and their interrelationships are as follows (Figs. $3-6$ and $3-7$ ):

solar

altitude $(\beta)$

surface tilt angle $(\Sigma)$

solar

azimuth $(\phi)$
$=$ the angle between the horizontal and the direct solar beam. At noon, $\beta=90^{\circ}$ - Latitude (L) + Declination $(\delta)$. At other times of the day, $\sin \beta=\cos L \cos \delta$ $\cos H+\sin \mathrm{L} \sin \delta$.

$=$ the angle between the horizontal and the surface in question.

$=$ the Sun's position measured east or west of true (solar) south. At solar noon, $\phi=0$. At other times of the day, $\operatorname{SIN} \phi=$ $\cos \delta \operatorname{SIN} H$ $\cos \beta$ incident angle $(\theta)$ azimuth $(\psi)$

wall - solar azimuth $(\gamma)$ wall or surface

Sun path diagrams, showing solar altitude and azimuth angles for several latitudes, are found in Refs. 6 and 7. Tables of solar altitude, azimuth, and incident angle are given in App. C of Ref. 3. A detailed treatment of solar angles is presented in Ref. 1.

\section{MAGNETIC DECLINATION}

Solar and wall azimuth angles are measured with respect to true south. The most common method of locating south is by the use of a magnetic compass. However, in most parts of the world, magnetic south and true south differ by several degrees. This difference is called magnetic declination and can be read from the isogonic 


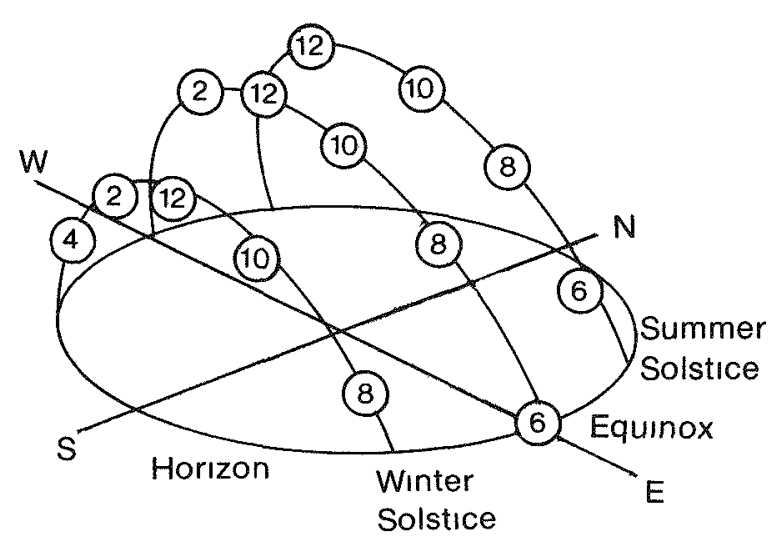

Fig. 3-6. Solar position at different times of
day and year

chart (Fig. 3-8). The letters $\mathrm{E}$, for east, and W, tor west, indicate the direction that the compass reads off true north. The numbers indicate the angle distance in degrees that the compass reads off true north. For example, Los Angeles has a declination of about $15^{\circ} \mathrm{E}$, indicating that a compass reads $15^{\circ} \mathrm{E}$ of true north.

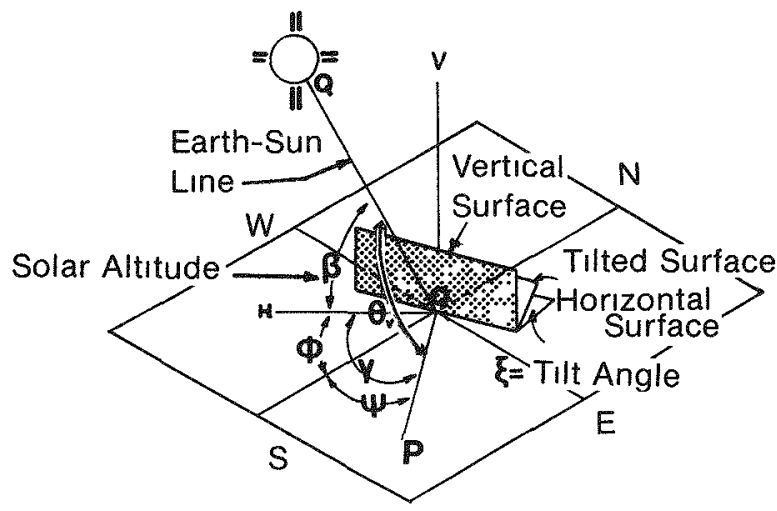

Solar Altitude $\beta=<\mathrm{HOQ}$ Solar Azımuth $\phi=<$ HOS Wall Azımuth $\boldsymbol{\psi}=<\mathrm{SOP}$ Wall-Solar Azımuth $V=<$ HOP Incident Angle on Vertical Surface $\theta_{V}=<$ QOP

Fig. 3-7. Solar angles

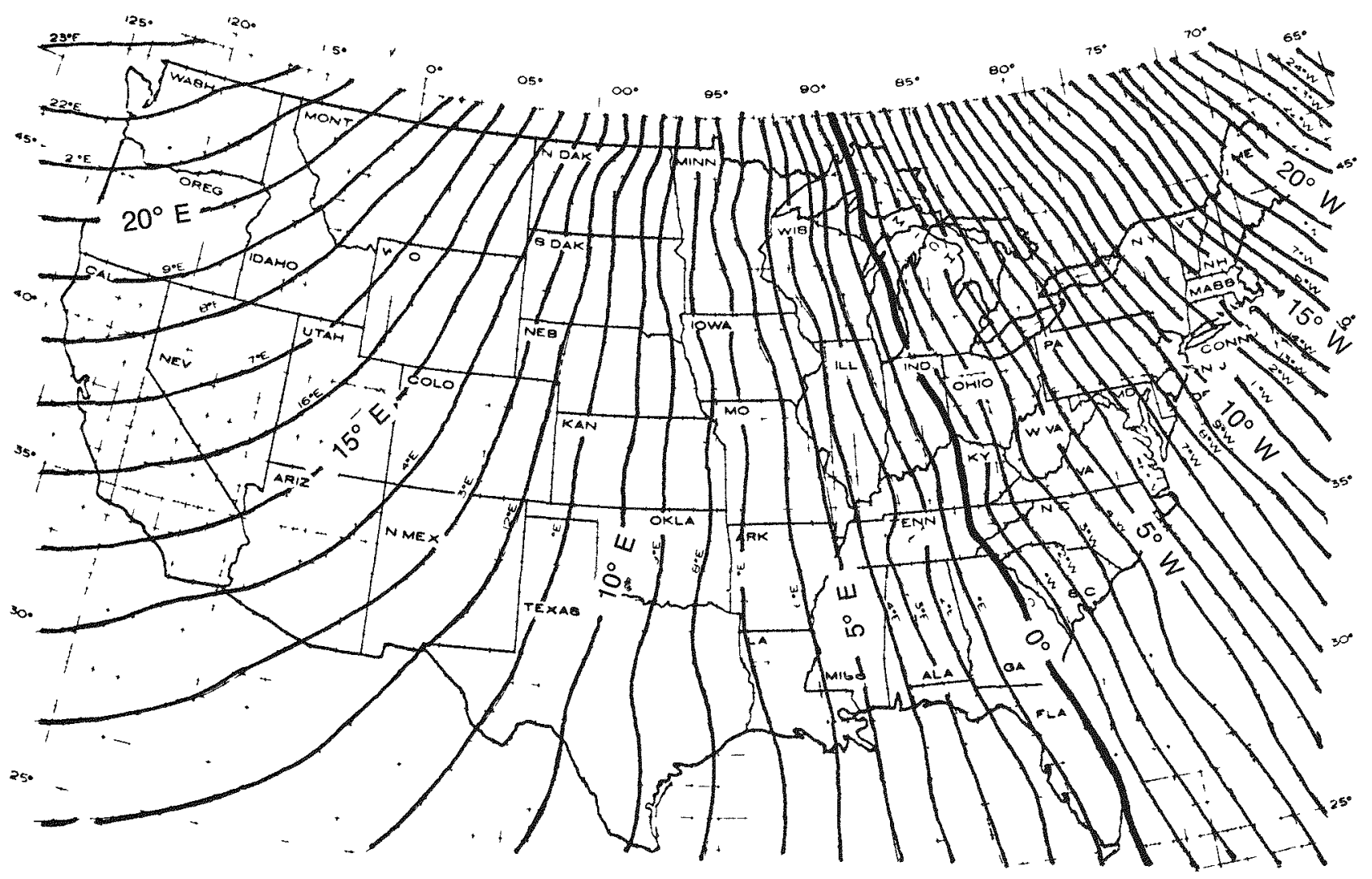

Fig. 3-8. The isogonic chart of the United States showing magnetic declination. For example, Los Angeles has a declination of about $15^{\circ} \mathrm{E}$, indicating that a compass reads $15^{\circ} \mathrm{E}$ of true north or $15^{\circ} \mathrm{W}$ of true south (U.S. Department of Commerce, Coast and Geodetic Survey, 1965). 


\section{RADIATION INCIDENT ON TLTED SURFACES}

\section{Hourly Values of Total Solar Irradiation}

Hourly insolation values are required for collector efficiency calculations. In such cases, the total radiation on a tilted surface is given by

$$
I_{t \theta}=I_{D N} \cos \theta+I_{d H} \frac{(1+\cos \Sigma)}{2}+I_{r} \frac{(1-\cos \Sigma)}{2}
$$

$=$ Direct + Diffuse + Reflected,

\section{where}

$\mathrm{I}_{\mathrm{DN}}$ is the direct normal insolation,

$I_{\mathrm{dH}}$ is the diffuse radiation on a horizontal surface, and $I_{r}$ is the reflected radiation.

The intensity of reflected radiation depends on the nature of the reflecting surface and the incident angle. Year round, a reasonable, conservative ground reflectance value is 0.20 . Values for various characteristic landscapes are given in Ref. 8 and Chap. 26 of Ref. 17. The reflected radiation, $I_{r}$, is obtained by multiplying the total horizontal insolation by the ground reflectance.

Hourly insolation can also be computed by using the tables in App. C of Ref. 3 which show total hourly and daily clear-day insolation on the 21 st of each month at selected latitudes and tilt angles. These values do not include any reflected component. The insolation values listed, when corrected by the Clearness Number, may be used as conservative estimates of clear-day insolation.

To account for cloud cover, the hourly clear-day values in App. C of Ref. 3 must be reduced by the hourly "Cloud Cover Factor." The cloud indexes to be used with the Cloud Cover Factor are the "Total Sky Cover" (or Mean Sky Cover) and the amount of cover by three different types of clouds [9]. However, the monthly "Percent Possible Sunshine" from the Climatic Atlas of the United States [12 (also in Ref. 15) almost always correlates measured daily, monthly, or annual radiation better than "Mean Sky Cover" does.

Hourly values of direct normal and total horizontal radiation are available for selected cities in SOLMET magnetic tape format from the National Oceanic and Atmospheric Administration (NOAA), National Climatic Center, Asheville, North Carolina. In addition, measured total hourly radiation data for $30 \mathrm{U}$.S. locations are given in Ref. 10.

\section{Mean Daily and Monthly Average Insolation}

Most simplified solar heating/cooling system design methods require monthly or annual total radiation incident on the collector. Measured solar irradiation data are preferred. However, other meteorological measurements and solar data can be used to estimate insolation. These produce calculated values of radiation incident on surfaces oriented at various tilt angles. Most often, monthly average values are obtained from mean daily values for a characteristic day of the month.
The most recent, reliable, and widely used mean daily insolation data are those developed by NOAA from the SOLMET data [11]. Measured and derived data for total insolation on a horizontal surface for 248 U.S. stations are included. They are average values based on 25-year records. In addition, measured long-term average total horizontal radiation data and attenuation factors, $\overline{\mathrm{K}}_{\mathrm{T}}$, are given for these same 248 stations in Ref. 10 .

Where data for the stations mentioned above do not represent the location in question, monthly (mean daily) and annual radiation incident on a horizontal surface can be estimated from the Climatic Atlas maps [12].

To find monthly horizontal insolation, one can also use the same set of maps, based on mean daily data, in App. A of Ref. 3. For a given month, the site in question is located on the map; and the radiation in langleys per day is determined by interpolation. Multiplying this number by $3.69 \mathrm{Btu} / \mathrm{sq} \mathrm{ft}$-langley $(42.04 \mathrm{~kJ} / \mathrm{sq} \mathrm{m})$ gives the horizontal surface total insolation, $\mathrm{H}_{\mathrm{H}}$, in $\mathrm{Btu} / \mathrm{sq} \mathrm{ft}-$ day $\left(\mathrm{J} / \mathrm{sq} \mathrm{m}\right.$-day). If $\mathrm{H}_{\mathrm{H}}$ is multiplied by $\mathrm{N}$, the number of days in the month, the monthly insolation is found in Btu/sq ft-month (kJ/sq m-month).

Mean daily, monthly, or annual values can be adjusted for the tilt of the collector by use of any of several procedures. The Los Alamos National Laboratory has developed an appropriate correlation for horizontal insolation data available on a monthly basis [6]. The total monthly radiation on a surface tilted at $\Sigma=1$ lat $+10^{\circ}$ is given by:

$\mathbf{H}_{\mathrm{M \Sigma}}=1.025 \mathrm{~d}-8200$

where

$$
\mathrm{d}=\frac{\mathrm{H}_{\mathrm{MH}}, \mathrm{Btu} / \mathrm{ft}^{2}-\text { month }}{\cos (\mathrm{L}-\text { declination at mid-month) }}
$$

Declination at mid-month $\simeq 23.45^{\circ} \cos (30 \mathrm{M}-187)$ where $\mathrm{M}=$ month number (January $=1$, December $=12$ ). Table 3-2 gives expressions for $\mathbf{H}_{M}$ s as a function of latitude for each month. Note that this correlation loses accuracy at more northern latitudes and for tilt angles other than lat $+10^{\circ}$. For latitudes below $34^{\circ}$ and above $46^{\circ}$, use equations $3-3 \mathrm{a}$ and $3-3 \mathrm{~b}$.

A more approximate method of adjusting for the tilt angle is to start with the calculated clear-day mean daily values given in Ref. 4, Chapter 58 (or App. C of Ref. 3) for several tilt angles plus horizontal. These tilted surface values should be multiplied by the ratio of measured horizontal insolation (from Ref. 11 or 12) to calculated clear-day horizontal insolation (from Ref. 4 or App. C of Ref. 3) to obtain a tilted-surface estimate. This estimate should then be further adjusted by applying the Clearness Number for the site.

The U.S. Army Construction Engineering Research Laboratory (CERL) has developed a simple empirical correlation for converting from horizontal surface to tilted surface insolation on an annual basis [13]. The 
Table 3-2. THLTED SURFACE INSOLATION CORRECTION FACTORS

\begin{tabular}{|c|c|c|c|c|c|c|c|c|}
\hline & & $\mathbf{H}_{\mathrm{V}}$ & $\begin{array}{l}\mathrm{H}_{\mathrm{M \Sigma}}= \\
\mathrm{C}=\mathrm{va} \\
\text { izontal }\end{array}$ & $\begin{array}{l}\text { (C) }\left(\mathrm{H}_{\mathrm{MH}}\right) \\
\text { where } \\
\text { lues showr } \\
\text { insolation }\end{array}$ & $\begin{array}{l}-8,200 \\
n \text { below } \\
\text { in Btu }\end{array}$ & onth & & \\
\hline Month & 34 & 36 & 38 & Latitude & 40 & 42 & 44 & 46 \\
\hline 1 & 1.8135 & 1.9122 & 2.0247 & & 2.1541 & 2.3041 & 2.4799 & 2.6882 \\
\hline 2 & 1.5349 & 1.5984 & 1.6691 & & 1.7486 & 1.8384 & 1.9404 & 2.0570 \\
\hline 3 & 1.2811 & 1.3163 & 1.3552 & & 1.3983 & 1.4460 & 1.4990 & 1.5580 \\
\hline 4 & 1.1295 & 1.1487 & 1.1701 & & 1.1938 & 1.2199 & 1.2488 & 1.7945 \\
\hline 5 & 1.0625 & 1.0734 & 1.0858 & & 1.0999 & 1.1158 & 1.1335 & 1.1532 \\
\hline 6 & 1.0433 & 1.0508 & 1.0598 & & 1.0703 & 1.0823 & 1.0959 & 1.1112 \\
\hline 7 & 1.0496 & 1.0583 & 1.0685 & & 1.0803 & 1.0937 & 1.1088 & 1.1256 \\
\hline 8 & 1.0900 & 1.1046 & 1.1210 & & 1.1393 & 1.1597 & 1.1822 & 1.2072 \\
\hline 9 & 1.1976 & 1.2241 & 1.2535 & & 1.2858 & 1.3216 & 1.3611 & 1.4047 \\
\hline 10 & 1.4053 & 1.4537 & 1.5075 & & 1.5675 & 1.6345 & 1.7096 & 1.7945 \\
\hline 11 & 1.6925 & 1.7750 & 1.8683 & & 1.9746 & 2.0963 & 2.2369 & 2.4010 \\
\hline 12 & 1.8960 & 2.0062 & 2.1327 & & 2.2793 & 2.4506 & 2.6533 & 2.8963 \\
\hline
\end{tabular}

radiation incident on a south-facing surface tilted at an angle of approximately lat $-10^{\circ}$ from the horizontal (optimal for year-round combined heating and cooling performance) is given by:

$$
\mathrm{H}_{\mathrm{A} \Sigma}=\frac{\mathrm{H}_{\mathrm{AH}}, \mathrm{Btu} / \mathrm{ft}^{2}-\mathrm{yr}}{\cos (\mathrm{L}-\delta)} \text {, }
$$

where $L$ is the site latitude in degrees. Eq. (3-4) gives good results over a wide range of tilt angles.

A limited set of data is available that can be used without adjustment for insolation on a surface tilted at lat $+10^{\circ}$. Using several years of measured insolation data for 21 U.S. cities, the Los Alamos National Laboratory has simulated the performance of solar heating systems in each city. The simulations determine the radiation on a south-facing tilted surface. Table 3-3 lists monthly and annual total radiation incident on a tilted (lat $+10^{\circ}$ ) surface for these locations. No correction is needed for collecting surfaces that face up to $10^{\circ}$ east or west.

Another method for computino insolation on tilted surfaces is that of Liu and Jordan, as presented by Klein Beckman, and Duffie [14]. It uses an empirical correlation of the ratio of diffuse to total radiation, as a function of the attenuation factor, $\overline{\mathrm{K}}_{\mathrm{T}}$, which, in turn, accounts for latitude and collector tilt angle. Typical values of monthly average daily radiation on $\&$ tilted surface produced by this method are presented in Table $3-4$. Note that these daily values must be multiplied by the number of days in a given month to obtain monthly values.

Finally, if mean daily, calculated clear-day insolation values from ASHRAE sources are adjusted for cloud cover, the monthly "Percent Possible Sunshine" from the
Climatic Atlas [12] (also in Ref. 15) should be used. This index almost always correlates measured daily, monthly, or annual radiation better than "Mean Sky Cover" does [16].

\section{CLIMATOLOGY}

\section{Design Considerations}

The various climates in which we build are characterized by four major elements: temperature, wind, humidity, and solar irradiation. Human comfort is directly influenced by these elements; therefore, they should be considered throughout the design process and eventually reflected in the built environment.

The overall objective of identifying a climatological data base is to provide the designer with both general and specific weather data to promote climate-responsive design. Data should be presented in a form that gives the designer a feeling for the specific climate. Diurnal and seasonal characteristics are the basis of this data base. The influence of climatic variables on the built environment, and sources of climatic data will now be presented.

\section{Dry-Bulb Temperature}

Data on dry-bulb temperature, a primary determinant of building heat loss, are summarized by month in terms of degree-days, average ambient temperature, or maximum and minimum design temperature. These data for selected cities are available in Chapter 38 of Ref. 17 .

Extensive data on winter design dry-bulb temperatures, summer design dry- and wet-bulb temperatures, dry-bulb temperature (with coincident wet-bulb temperature) data in $5 \mathrm{~F}\left(2.8^{\circ} \mathrm{C}\right)$ bins, as well as heating and cooling degreedays, are available for many stations in Air Force Manual 88-29 [18]. 
Table 3-3. MONTHLY AND ANNUAL INSOLATION ON TULTED SURFACE $\left(L A T+10^{\circ}\right)^{a}$

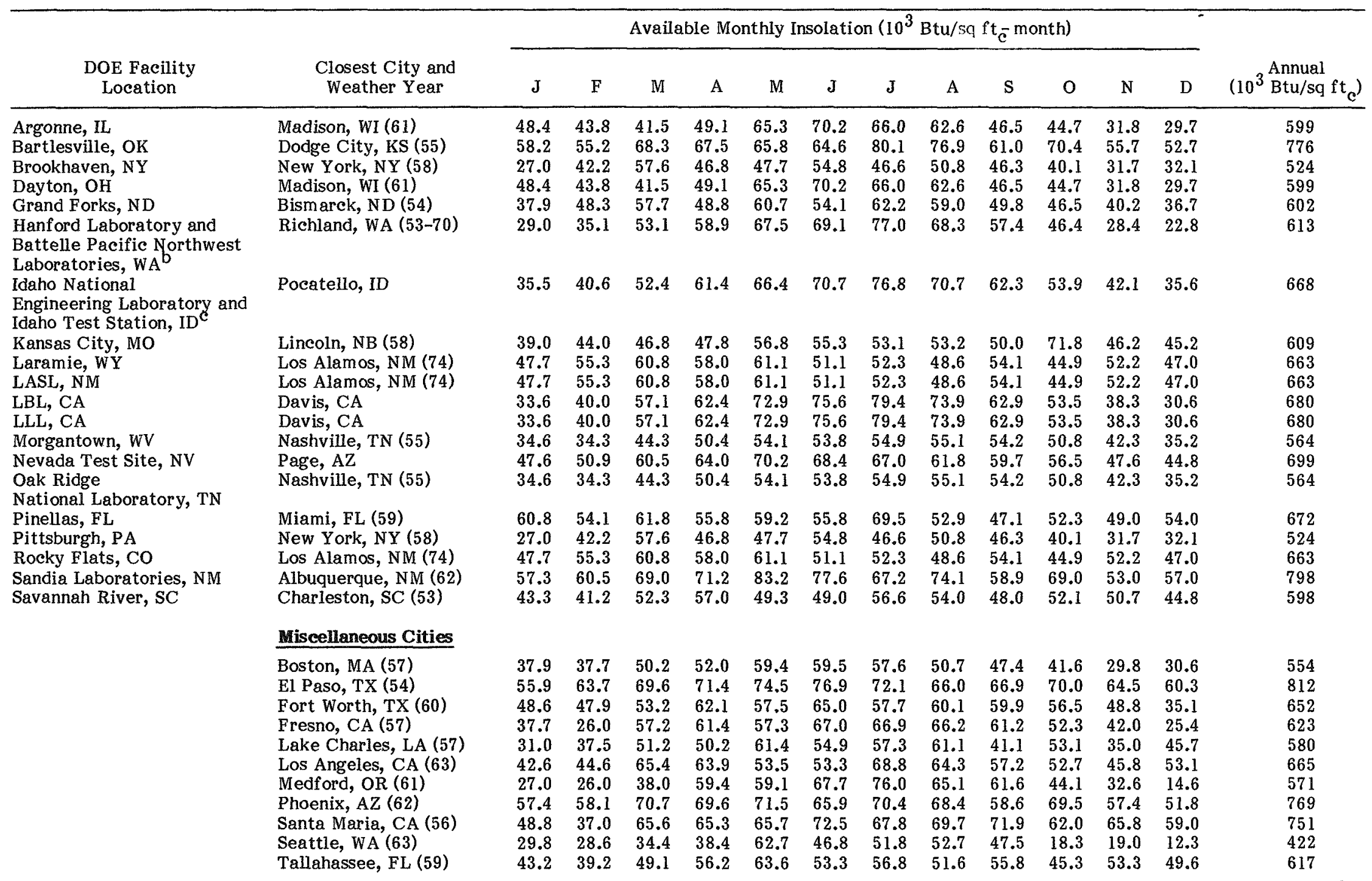

${ }^{a}$ Los Alamos National Laboratory supplied solar data incident on a solar collector tilted at lat $+10^{\circ}$ for the indicated cities. Year chosen is most representative of typical conditions for which complete data are available. For individual sites, either interpolate from the above data or use actual site data.

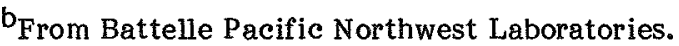

$\mathbf{c}_{\text {From Idaho National Engineering Laboratory. }}$ 
Table 3-4. MONTHLY AVERAGE DAILY RADIATION ON A TLTED SURFACE [14]

$\overrightarrow{\mathrm{H}}_{\Sigma}(\mathrm{Btu} / \mathrm{sq} \mathrm{ft}-$ day $)$ for $\mathrm{K}_{\mathrm{T}}=\mathbf{0 . 4}, \quad=$ Latitude $+15^{\circ}$

\begin{tabular}{|c|c|c|c|c|c|c|c|c|c|c|c|c|}
\hline Lat & Jan & Feb & Mar & Apr & May & Jun & Jul & Aug & Sep & Oct & Nov & Dec \\
\hline 20 & 1173 & 1219 & 1245 & 1215 & 1178 & 1144 & 1151 & 1200 & 1219 & 1217 & 1182 & 1160 \\
\hline 25 & 1136 & 1178 & 1215 & 1215 & 1178 & 1143 & 1158 & 1186 & 1206 & 1181 & 1141 & 1038 \\
\hline 30 & 1008 & 1130 & 1173 & 1193 & 1171 & 1147 & 1157 & 1177 & 1171 & 1141 & 1015 & 979 \\
\hline 35 & 948 & 1089 & 1142 & 1175 & 1156 & 1144 & 1149 & 1159 & 1137 & 1093 & 965 & 923 \\
\hline 40 & 890 & 1059 & 1095 & 1148 & 1147 & 1135 & 1135 & 1134 & 1103 & 1050 & 909 & 863 \\
\hline 45 & 837 & 928 & 1060 & 1111 & 1132 & 1121 & 1129 & 1113 & 1066 & 1012 & 855 & 846 \\
\hline 50 & 709 & 878 & 1013 & 1088 & 1117 & 1102 & 1103 & 1085 & 1033 & 900 & 816 & 686 \\
\hline 55 & 666 & 821 & 971 & 1044 & 1086 & 1094 & 1088 & 1061 & 990 & 854 & 680 & 661 \\
\hline 60 & 516 & 780 & 928 & 1009 & 1058 & 1072 & 1058 & 1030 & 950 & 802 & 652 & 515 \\
\hline
\end{tabular}

\section{Prevailing Wind Conditions}

Topography affects wind patterns by constricting the wind, increasing its velocity in certain areas while sheltering others [19]. Of all climatic variables, wind is the most affected by local conditions. General climatic data are probably insufficient for building design; sitespecific conditions must be observed. Wind velocities appearing in climatic data are normally recorded at a height of 20 or $30 \mathrm{ft}(6$ or $9 \mathrm{~m})$ off the ground. Because of the boundary layer near the ground, and the effect of surface objects, these wind velocities may not be representative of actual site conditions. Thus, local wind data must be modified by site conditions. Geiger [20] details the relationship among climate variables as they interact with site characteristics to produce the microclimate.

Location of buildings should take prevailing winds into account to avoid excessive heat losses because of wind and local low temperatures. Calculations indicate that the heating load of an unprotected house with a $20-\mathrm{mph}$ $(32 \mathrm{kmh})$ wind is approximately 2.4 times as great as that for a $5-\mathrm{mph}(8 \mathrm{kmh})$ wind under the same temperature

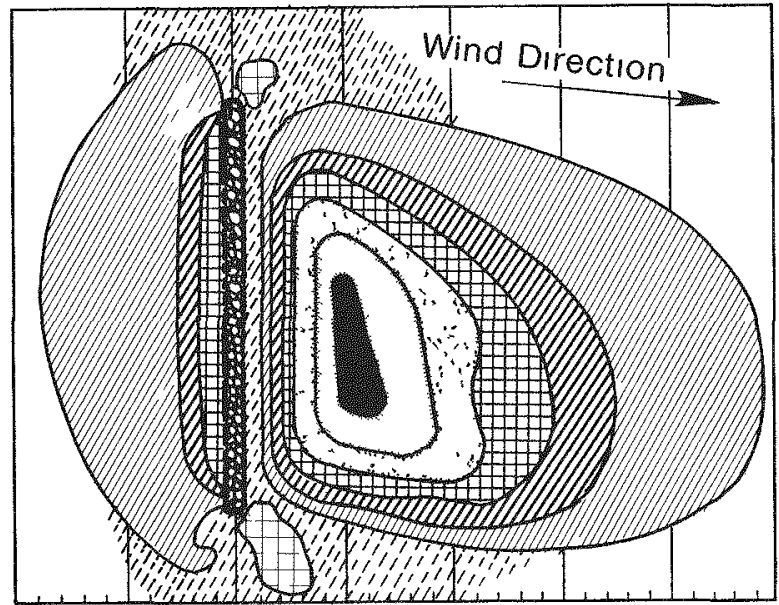

Percent of free-stream velocity

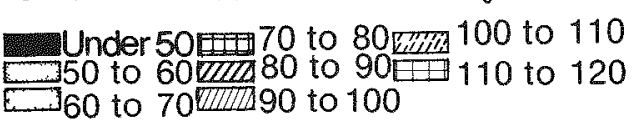

Fig. 3-9. Field of protection of windbreak [21]

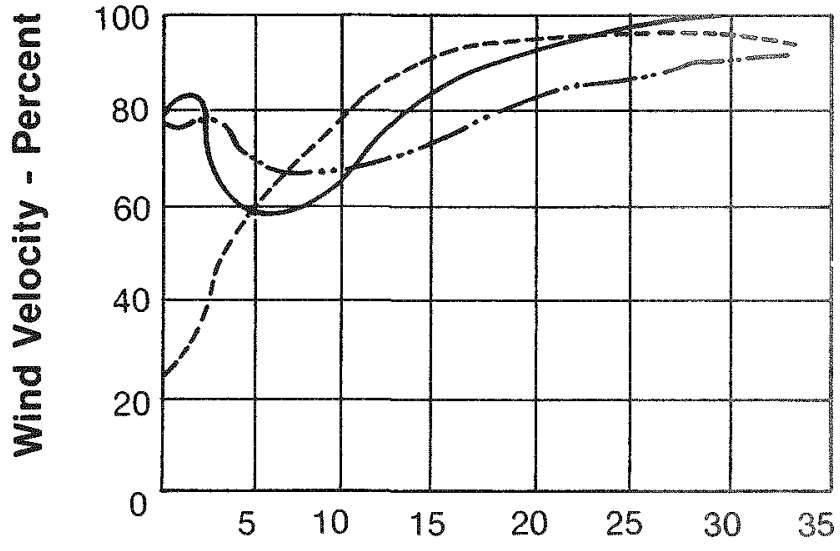

Distance Leeward in Tree-Height Units

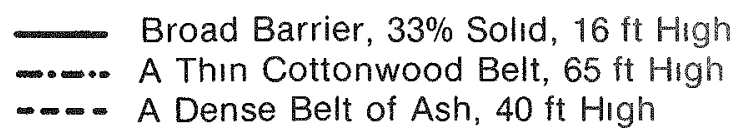

Fig. 3-10. Wind velocity at three Iypes of windbreaks [21]

conditions [21]. The extent to which a buildingis heating load is influenced by exposure to winds will depend greatly upon what type of building is in question. If loads are envelope-dominated, then wind protection should be an important consideration.

Figs. 3-9 and 3-10 illustrate the effectiveness of windbreaks.

If the site is hilly, the mid-slopes are best, away from high winds at the crests and cold air that settles into low spots. Protection from prevailing winter winds can be provided by the shielding effects of the other bullings, walls, or windbreaks of evergreen trees. The building itself may be placed partly underground to reduce heat losses because of prevailing winds in extremely cold climates [22].

In climates where cooling is a problem, buildings should be oriented and shaped to achieve cross ventilation [23]. 
Cooling can also be achieved by facilitating the escape of rising hot air by properly locating vents relative to wind direction [19]. The proper use of landscaping will also enhance the effectiveness of natural ventilation.

Data on wind velocity and direction are presented in monthly average form in Ref. 12. Maximum velocities, as well as daily and yearly variations, are important.

\section{Fumidity}

Relative humidity is an important index of human comfort. Vapor pressure is exerted by the moisture contained in the atmosphere. People usually notice a "close" or depressed feeling if vapor pressure surpasses the $15 \mathrm{~mm}$ mercury mark. This fact should be kept in mind if evaporative cooling is being considered. ASHRAE has published the most widely used comfort criteria [4]

Humidity can also be a factor in the deterioration of solar collectors, piping, and insulation.

Design values for outdoor relative humidity for selected cities can be determined from the design dry-bulb and wet-bulb temperatures listed in Refs. 4 and 18.

A series of bioclimatic charts, which relate human comfort to humidity and dry bulb temperature conditions on a psychrometric chart, are presented by Milne and Givoni in Ref. 35. These charts, which define climate design strategies for heating and cooling as functions of outdoor air conditions, allow the designer to determine to what extent natural energy systems can be used to provide for human comfort.

\section{SHADING}

\section{Solar Access}

A careful study of solar access at the building site is critical for two reasons: solar radiation must not be obstructed from collecting surfaces during the winter

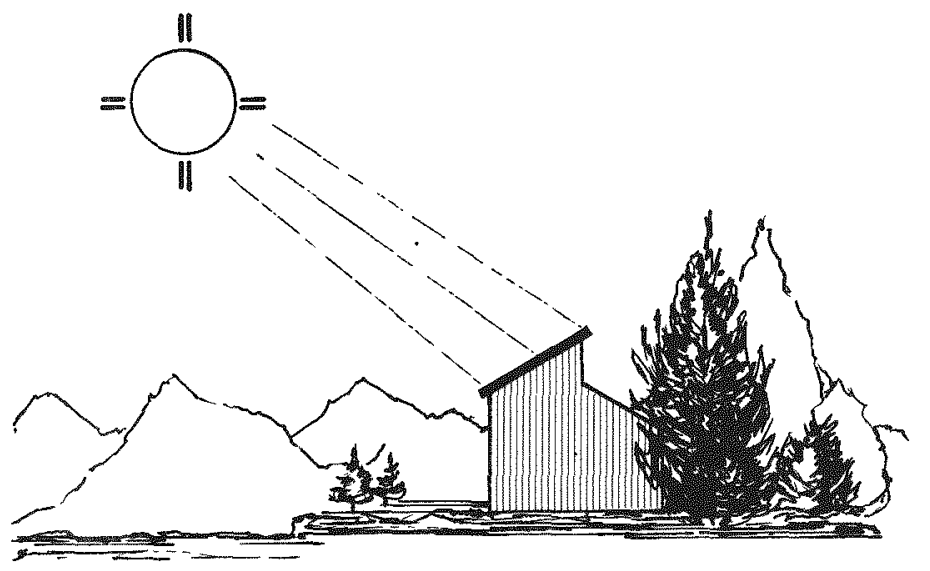

Fig. 3-11. Solar access months, and proper sun control is essential to minimizing overheating during summer months. Building sites should be chosen to avoid winter time shading of collecting surfaces by nearby structures and/or vegetation. Partial shading of solar collectors may significantly reduce the daylong efficiency of the system, and its energy output will be less than that calculated under no-shade conditions. Locating collecting surfaces in the northern part of a site will decrease the probability of shading by future offsite development. If solar access is at all in question, a study of winter time shadow patterns should be made. (See Fig. 3-11.)

\section{Shadow Mapoing}

As a rule of thumb, collecting surfaces should be exposed to direct sunlight between the hours of $9 \mathrm{a.m}$. and 3 p.m. Using this time span, the designer should trace the shadow patterns cast on-site and determine where the optimal location for solar collection might be. The following example illustrates the very simple process of shadow mapping.

\section{Problem}

Assume the following conditions:

Date: December 21

Latitude: $40^{\circ} \mathrm{N}$

Trace the shadows cast by an object on this date.

\section{Solution}

1. See appropriate tables in Ref. 17 for solar altitude and azimuth values for this date and latitude.

\begin{tabular}{lcc} 
Time & Altitude, & Azimuth, \\
\hline & & \\
$8: 00$ & 5.5 & $53.0 \mathrm{E}$ \\
$9: 00$ & 14.0 & $41.9 \mathrm{E}$ \\
$10: 00$ & 20.7 & $29.4 \mathrm{E}$ \\
$11: 00$ & 25.0 & $15.2 \mathrm{E}$ \\
$12: 00$ & 26.6 & 0 \\
$1: 00$ & 25.0 & $15.2 \mathrm{~W}$ \\
$2: 00$ & 20.7 & $29.4 \mathrm{~W}$ \\
$3: 00$ & 14.0 & $41.9 \mathrm{~W}$ \\
$4: 00$ & 5.5 & $53.0 \mathrm{~W}$ \\
\hline
\end{tabular}

2. Project the solar altitude angles on the elevation to determine the shadow length.

3. Draw the shadow length in the direction indicated by the azimuth angles on the plan drawing. (Note: Shadows will be symmetrical about solar noon.) 
Shadow lengths can be determined in two ways: (a) if the shadow mapping has been drawn accurately to scale they may be measured directly from the drawing, or (b) the following formula can be used:
To aid in shadow mapping, various solar site survey devices are available on the market. These devices are designed to be used at the site to determine the effect of potential solar obstructions [36].

$$
\mathbf{S}=\frac{H}{\tan \beta} \quad \text { where: } \begin{aligned}
& \mathrm{S}=\text { shadow length. } \\
& \mathrm{H}=\text { height of object. }
\end{aligned}
$$
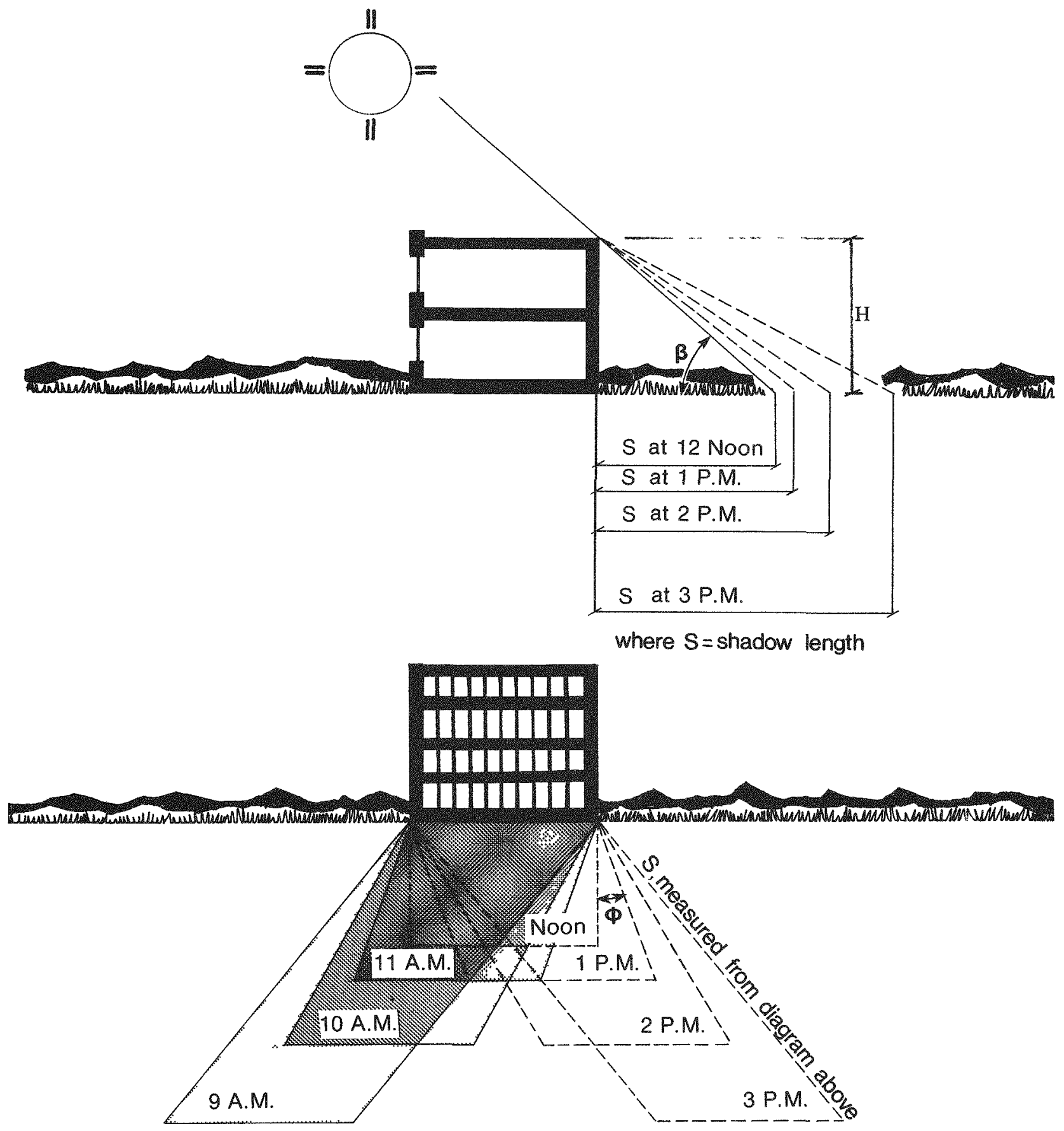

Fig. 3-12. Plotting shadows in plan \& elevation 


\section{Vegetation}

Vegetation can be used effectively as a means to control microclimatic conditions-the climate in the immediate vicinity of a building. It may obstruct or control the Sun's rays; deflect or funnel winds; control precipitation, humidity, and temperature. The designer must keep site planning in mind throughout the design process because it is essential to the concept of energy conservation. If climatic conditions surrounding a building can be moderated or manipulated, the net result is a significant reduction in the heating and cooling loads of the building.

\section{Glazing}

Windows have the potential for being a tremendous source of heat gain-both in winter and summer. For this reason, glazed areas must be properly analyzed and designed. In climates that require substantial heating during the winter months, the largest percentage of glass should face south in envelope dominated buildings. This will allow direct space heating by the low winter Sun and also make it easier to shade the.glass with an overhang during the summer. Large areas of north-facing glass, a source of great heat loss, should be avoided in all but the mildest climates; and large areas of west-facing glass should be avoided in regions with hot summers, since it is very difficult to adequately shade these areas.

"Heliothermic" site planning, which accounts for natural solar heating and cooling processes and their relationship to building shape and orientation, is examined in detail by Olgyay [21]. A more recent study of the effect of building shape and orientation on solar collection through windows and walls is the National Bureau of Standards (NBS) analysis of the GSA Manehester Building [24] .

\section{HLUMNATION DATA FOR DAYLIGHTING STUDIFS}

As passive solar design focuses on commercial buildings, which are often lighting rather than heating-load dominated, a logical design approach is to regard windows and other solar apertures as a source of natural illumination (daylighting). The careful use of daylighting can result in considerable savings in cost and energy [25].

To use daylight to advantage, the following general factors should be taken into account by the building designer:

- Variations in the amount and direction of the incident daylight;

- Luminance (photometric brightness) and luminance distribution of clear, partly cloudy, and overcast skies; and

- Effect of local terrain, landscaping, and nearby buildings on the availability and quality of light.

The literature on daylighting calculative techniques is extensive [26]. Two main classes of techniques exist: those using the lumen method [27] and those using the daylight factor method [28]. The lumen method, used primarily in the United States, can consider both cloudy and clear sky conditions. However, it is applicable for a limited range of window configurations and calculation points within a room [29]. The daylight factor method used in Europe does not have these limitations but applies only to overcast skies. A recent simplified methodology has extended the daylight factor method to include clear skies [29]. Another simplified design method, intended for use by architects, gives predictions that show the patterns of daylight distribution as well as illumination levels [30].

These limitations in the calculative techniques lead most designers to use scale models and light meters to test their daylighting designs. Unlike thermal models, daylighting scale models are accurate without complicated size and scale factors. At present, scale models are the only way to simulate advanced daylighting apertures such as light shelves and to judge lighting quality.

Several computer programs are also available for computing daylighting. The LUMEN II program, which is available on a computer service network, calculates both natural and artificial lighting [31]. The University of Washington has developed a computer program, UWLIGHT, that calculates and displays illumination levels resulting from both natural and artificial lighting sources [32]. UWLIGHT can be coupled with a thermal simulation program to evaluate the overall effects of integrated window and lighting system design [33]. Another detailed model for calculating the natural light in a perimeter zone has recently been developed [34].

Various well-developed graphical design aids are also available. A set of 10 daylight protractors and an accompanying test to allow building designers to predict the influence of window size and placement on natural illumination have been developed by The British Research Establishment. These are available from Pendragon House, Inc., 2595 East Bayshore Road, Palo Alto, CA 94303. A sun angle calculator is available from the Libbey Owens Ford Company, Merchandising Department $\mathrm{P}-1,811$ Madison Avenue, Toledo, OH 43695. Overlays allow determination of angle of incidence and profile angle for a vertical surface of arbitrary orientation. A booklet, "How to Predict Interior Daylight Illumination," is also qvailable from Libbey Owens Ford, and a similar booklet is available from PPG Industries.

Finally, the Energy Efficient Windows Program at the Lawrence Berkeley Laboratory is preparing a daylighting resource information package that is expected to be available in 1981.

Chapter 6 discusses daylighting design in some detail.

\section{REFERENCES}

1. J. Duffie and Beckman, Solar Engineering of Thermal Processes, Wiley-Interscience, New York, 1980.

2. F. Kreith and J. F. Kreider, Principles of Solar Engineering, McGraw-Hill, New York, 1978.

3. DOE Facilities Solar Design Handbook, U.S. Department of Energy, DOE/AD-0006/1, January 1978. 
4. ASHRAE, Handbook and Product Directory, Applications, ASHRAE 1978.

5. B. Y. H. Liu and R. C. Jordan, Eds., "Applications of Solar Energy for Heating and Cooling of Buildings," ASHRAE GRP 170, 1977.

6. "ERDA's Pacific Regional Solar Heating Handbook," 2nd Ed., ERDA San Francisco Operations Office, November 1976, Superintendent of Documents, Washington, D.C., Stock No. 060-000-00024-7.

7. B. Anderson, Solar Energy: Fundamentals in Building Design, McGraw-Hill, New York, 1977.

8. B. D. Hunn and D. O. Calafell, "Determination of Average Ground Reflectivity for Solar Collectors," Solar Energy, Vol. 19, No. 1, 1977.

9. K. Kimura and D. G. Stephenson, "Solar Radiation on Cloudy Days," ASHRAE Transactions, Part 1, 1969.

10. Insolation Data Manual, Solar Energy Research Institute, report SERI/SP-755-789, October 1980.

11. V. Cinquemani, J. R. Owenby, Jr., and R. G. Baldwin, Input Data for Solar Systems, report prepared for the U.S. Department of Energy, November 1978.

12. U.S. Department of Commerce, Environmental Sciences Services Administration, Environmental Data Services, Climatic Atlas of the United States, 1968.

13. D. Hittle, D. Holshouser, and G. Walton, "Interim Feasibility Assessment Method for Solar Heating and Cooling of Army Buildings," U.S. Army Construction Engineering Research Laboratory Technical Report E-91, May 1976.

14. Solar Energy Applications Laboratory, Colorado State University, "Solar Heating and Cooling of Residential Buildings-Design of Systems," U.S. Department of Commerce, October 1977.

15. "Solar Heating Systems Design Manual," ITT Training and Education Department, Fluid Handling Division, Bulletin TESE-576, 1976.

16. I. Bennett, "Correlation of Daily Insolation with Daily Total Sky Cover, Opaque Sky Cover, and Percentage of Possible Sunshine," Solar Energy, Vol. 12, 1969.

17. ASHRAE, Handbook of Fundamentals, ASHRAE 1977.

18. Air Force Manual AFM 88-29, "Engineering Weather Data," Departments of the Air Force, Army, and Navy, July 1978.

19. J. Leckie, G. Masters, H. Whitehouse, and L. Young, Other Homes and Garbage, Sierra Club Books, San Francisco, California 1975.

20. R. Geiger, The Climate Near the Ground, Harvard University Press, Cambridge, Massachusetts, 1957.
21. V. G. Olgyay, Design with Climate: Bioclimatic Approach to Architectural Regionalism, Princeton University Press, 1963.

22. P. Steadman, Energy, Environment, and Building, Cambridge University Press, New York, 1975.

23. "Energy Conscious Design," U.S. Army Corps of Engineers, Norfolk District, Norfolk, Virginia.

24. J. E. Hill and T. Kusuda, "Manchester's New Federal Building: An Energy Conservation Project," ASHRAE Journal, August 1975.

25. J. W. Griffith, "Benefits of Daylighting-Cost and Energy Savings," ASHRAE Journal, January 1978.

26. Illuminating Engineering Society, "Recommended Practice of Daylighting," Illuminating Engineering, Vol. 57, August 1962.

27. J. W. Griffith, W. J. Arner, and E. W. Gonover, "A Modified Lumen Method of Daylighting Design," Illuminating Engineering, Vol. 50, March 1955.

28. R. G. Hopkinson, P. Petherbridge, and J. Longmore, Daylighting, Heineman, London, 1966.

29. H. J. Bryan, "A Simplified Daylighting Design Methodology for Clear Skies," Proceedings of the 3rd National Passive Solar Conference, American Section of the International Solar Energy Society, San Jose, California, January 1979.

30. M. S. Millet, J. R. Bedrick, G. S. Spencer, and G. B. Varey, "Designing for Daylight: A New Prediction Technique," Proceedings of the 3rd National Passive Solar Conference, American Section of the International Solar Energy Society, San Jose, California, January 1979.

31. D. L. DiLaura and G. A. Hauser, "On Calculating the Effects of Daylighting in Interior Spaces," Journal of the Illuminating Engineering Society, October 1978.

32. J. R. Bedrick, M. S. Millet, G. S. Spencer, D. R. Heerwagen, and G. B. Varey, "The Development and Use of the Computer Program UWLIGHT for the Simulation of Natural and Artificial Illumination in Buildings," Proceedings of the 2nd National Passive Solar Conference, Vol. 2, American Section of the International Solar Energy Society, Philadelphia, Pennsylvania, March 1978.

33. J. R. Bedrick, A. F. Emery, D. R. Heerwagen, C. J. Kippenhan, M. S. Millet, and G. B. Varey, "The Coupling of Thermal and Lighting Simulation Programs for Evaluating the Effectiveness of Daylighting Design," Proceedings of the 4th National Passive Solar Conference, Vol. 4, American Section of the International Solar Energy Society, Kansas City, Missouri, October 1979.

34. S. A. Jurovics, "Solar Radiation Data, Natural Daylighting, and Building Energy Minimization," paper presented at the ASHRAE 1979 Annual Meeting, Detroit, Michigan, June 1979. 
35. "Architectural Design Based on Climate," Chapter 6 in Energy Conservation Through Building Design, Edited by Donald Watson, MeGraw-Hill Book Co., New York, NY, 1979.

36. Robert S. Clarke, "Shadows at the Site: Solar Access Measurement," Solar Age, Vol. 5, No. 10, October 1980. 
4

Passive Systems and Components 
4. Passive Systems and Components

General definitions

Heating

Cooling

Character istics of several common passive systems

Shading 


\section{INTRODUCTION}

A passive solar building design attempts, within economic constraints, to maximize the benefits of environmental resources and to minimize dependence on fossil fuels and mechanical equipment. This is accomplished by selectively coupling parts of the building to the environment most appropriate to the energy transfer desired at any given time. In contrast to traditional conservation, which stresses isolation from the environment, passive heating, cooling and lighting represent an assertive attempt to use the environment through judicious interaction.

Passive solar heating systems use elements of the building to collect, store, and distribute energy. Passive cooling also uses elements of the building to store and distribute energy and, when prevailing conditions are favorable, to discharge heat to the cooler parts of the environment (sky, atmosphere, ground). Natural lighting systems use elements of the building to collect and distribute energy of suitable quantity and quality for interior illumination needs. In all cases, energy transfers to, from, and within the building rely primarily on natural processes (i.e., conduction, convection, and radiation) with minimal dependence on mechanical equipment such as fans, pumps, and compressors. Mechanical equipment can be used effectively to augment natural energy flows when the capital cost and operating energy are justified by the improved system performance.

Since the collection, discharge, storage, and distribution of energy are generally accomplished by the architectural elements and features of the building, the passive system components are not easily distinguishable from the remainder of the structure. Because of the integral nature of passive systems and myriad of possible configurations, considerable confusion has existed concerning how to define and classify them. This chapter presents a general framework for thinking about passive systems and a systematic method for defining and classifying the more common configurations.

\section{GENERAL DEFINTIIONS}

A solar space heating system contains the following elements (Fig. 4-1):

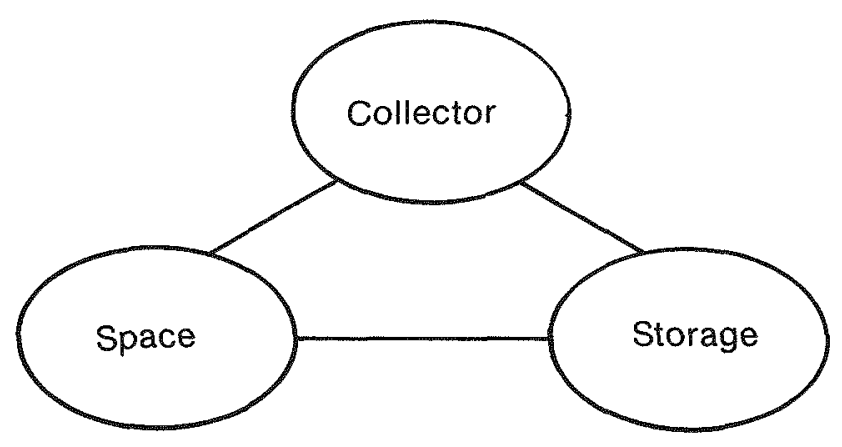

Fig. 4-1. Elements in a passive solar space heating system

- space (or, more specifically, contents) to be heated;

- collector where solar radiation is admitted into the system and converted to heat by an absorber (this may be nothing more than a surface of the normal building envelope); and

- thermal storage (this may be nothing more than the normal thermal capacity of the building mass).

Possible energy exchanges exist between:

- collector and storage,

- collector and space, and

- storage and space.

A space cooling system contains the following elements (Fig. 4-2):

- space (or, more specifically, contents) to be cooled;

- an environmental sink (sky, atmosphere, or ground) to which heat is discharged; and

- thermal storage (this may be nothing more than the normal thermal capacity of the building mass).

Possible energy exchanges exist between:

- sink and storage,

- sink and space, and

- storage and space. 


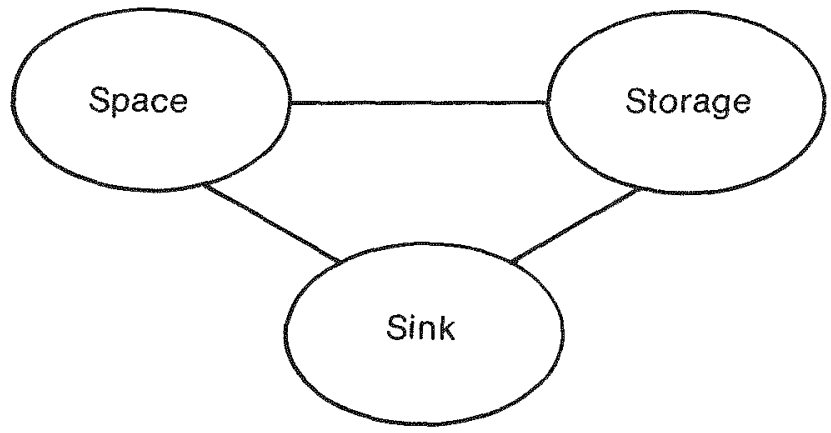

Fig. 4-2. Elements in a passive solar space cooling system

Daylighting is an instantaneous energy exchange between collector, reflector (or distribution technique) and task to be illuminated. In a given heating or cooling system, some exchanges may not exist, or at least they may be insignificant.

The energy exchanges fall into two categories:

- forced (using fans, pumps, and compressors) and

- natural (involving conduction, convection, evaporation and radiation).

The distinction made is based on the driving influence causing the energy flow, and not on the degree of regulation. The term "natural energy flow" is not synonymous with "unregulated energy flow." Natural energy flow can, in fact, be highly regulated by mechanically actuated controls, such as dampers or moving insulation. The point is that the flow motivation derives from nonmechancial sources.

If all significant exchanges linking the three elements of a heating, cooling, or lighting system involve forced flow, the system is classified as active.

If all significant exchanges linking the three elements of a heating or cooling system involve purely natural flow, the system is classified as passive.

If some of the significant exchanges linking the three elements of a heating or cooling system involve predominantly natural flow, but the system also incorporates mechanical devices to move energy, the system is classified as hybrid.

\section{HEATING}

Two particularly important factors must be accounted for in any scheme for characterizing passive solar heating systems:

- The characteristics of the collection aperture:

- orientation with respect to south and vertical and

- location relative to the rest of the building.
The method of delivering energy to the conditioned space:

- the energy mechanism(s) and

- inherent degree of thermal control.

\section{Collection Aperture Characteristics}

In the temperate zones of the Earth's northern hemisphere, the winter sun rises south of east and remains generally low in the southern sky until it sets south of west. In contrast, the summer Sun rises north of east and soars to high al titude angles before setting north of west.* (See Figs. 4-3 and 4-4.) Consequently, southfacing vertical glazing accepts direct-beam winter Sun at favorable angles of incidence throughout the day.

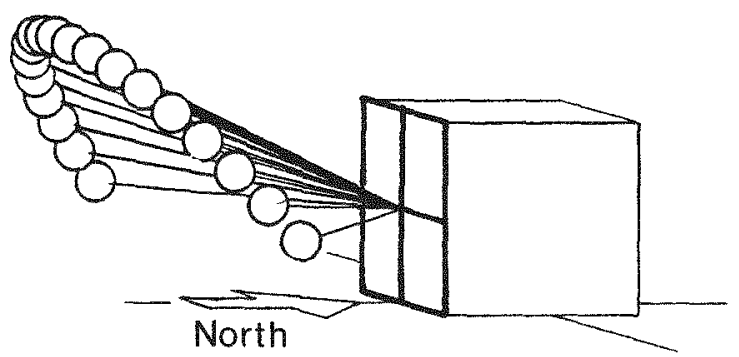

Fig. 4-3. Winter sun angles on a southfacing vertical surface

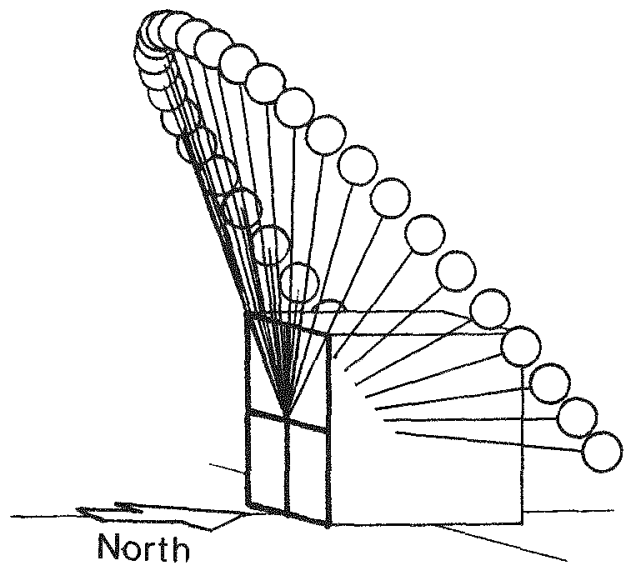

Fig. 4-4. Summer sun angles on a southfacing vertical surface

* For a more detailed discussion of Sun angles see Wayne Place, "The Solar Resource: Motion and Amplitude," p. 769 of the Proceedings of the Second National Passive Solar Conference. 
On the other hand, south-facing vertical glazing is not exposed to direct-beam summer Sun during a substantial portion of the day; and during those hours when exposure does occur, the angle of incidence is unfavorable to penetration.

Futhermore, modest overhangs can completely eliminate all exposure to direct-beam summer Sun. In this sense, south-facing vertical glazing may represent the "ultimate passive technique." Within the building's environment, the Sun's motion is used to "counteract the seasons" which that motion has generated. The Sun's apparent motion is the major control of the building's thermal environment.

At the opposite extreme, horizontal glazing receives modest amounts of direct-beam winter Sun, generally at unfavorable angles of incidence, and is subjected to severe direct-beam summer Sun, generally at angles corresponding to high glazing transmittance.

By itself, horizontal glazing responds to the Sun's motion in a manner that amplifies the seasonal temperature variation. The greatest transmittance of solar radiation will be during the summer months because of the smaller angle of incidence on horizontal surfaces. Figs, 4-5 and 4-6 show the impact the Sun has on a horizontal surface during winter and summer.

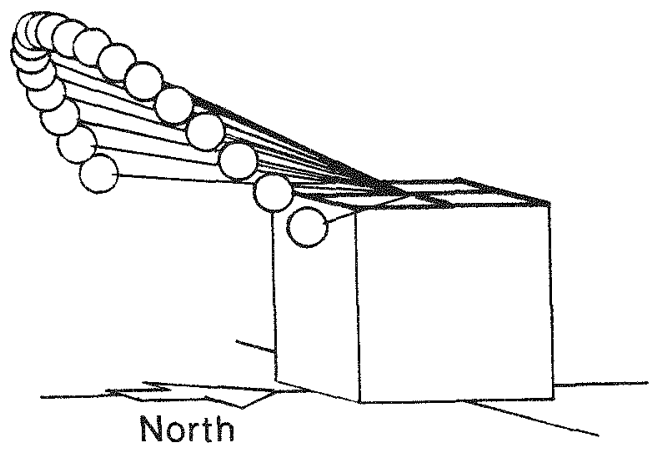

Fig. 4-5. Winter sun angles on a horizontal surface

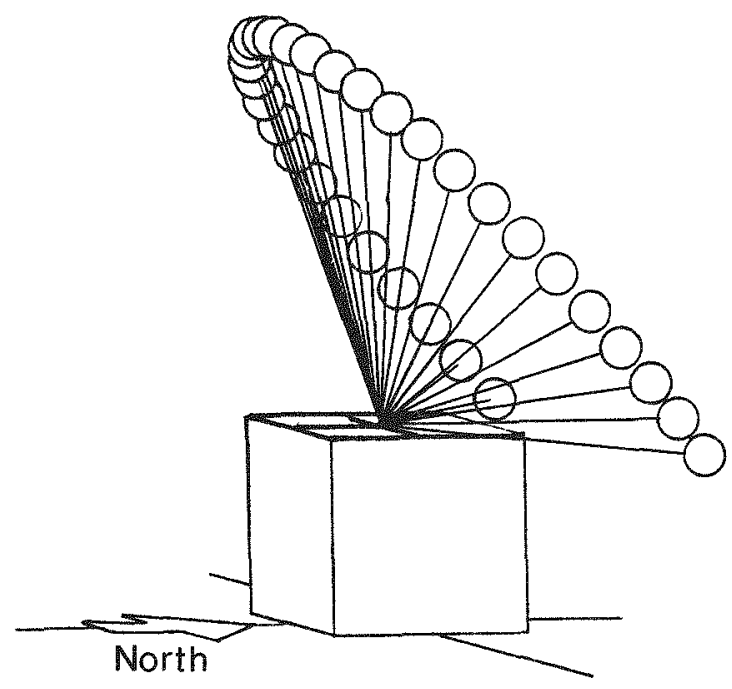

Fig. 4-6. Summer sun angles on a horizontal surface
Also important is the location of the aperture relative to the rest of the building. In the common passive solar heating systems, the three possible locations are the south wall, the roof, and somewhere remote from the building envelope proper. South wall heating systems have the advantages of simplicity and economy. Roof heating systems work well in situations where land constraints limit south wall exposure or restrict proper orientation of the building. They also have the advantage of treating all zones equally. Remote heating systems can be designed to have simple controls that limit unwanted gains or losses from the building. They also have the advantage of providing additional collection area to supplement energy collected through the building envelope proper.

There are a limited number of energy-advanțageous combinations of aperture orientation and location:

- A south aperture in the building consists of vertical glazing elements in the south wall. Such an aperture accepts sunlight predominantly from the southern part of the sky (winter Sun).

- A shaded roof aperture in the building consists of vertical glazing elements and sloping opaque elements on the roof. Such an aperture accepts sunlight predominantly from the southern part of the sky (winter Sun).

- A roof aperture in the building consists of horizontal glazing elements on the roof. Unless controlled by special methods (e.g., moving insulation), such an aperture accepts sunlight predominantly from the upward part of the sky (summer Sun).

- A remote aperture (i.e., one that is not part of the building envelope proper), can be set at any angle to accept sunlight from any part of the sky.

\section{Energy Delivery Method}

The manner in which energy is delivered to the conditioned space has a profound impact on the degree of thermal unif ormity that can be imposed. Selection of the most cost-effective system for any application is strongly influenced by the severity of the thermal requirements. There exist three broad eategories of passive solar heating systems based on the energy delivery to the space:

- For direct heating, sunlight is admitted directly to the space, where it is converted to heat by absorption on the interior surfaces and contents of the space (walls, floors, furnishings, plants, etc.). The contents or surfaces of the space must be exposed to sunlight in order for the system to collect energy. The air temperature in the space "floats" with the temperature of the absorbing surfaces and/or the storage.

- For indirect heating, sunlight is converted to heat by absorption on an external surface of the space. Contents of the space are not exposed to direct sunlight. The air temperature in the space "floats" with the temperature of the absorber and/or the storage.

- For isolated heating, sunlight is converted to heat by absorption on a surface independent of the space. 
Contents of the space are not exposed to direct sunlight. The air temperature in the space can be regulated independently of the absorber and storage temperature.

The following matrix (Fig. 4-7) indicates for each type of system (direct, indirect, or isolated) whether the heated space is exposed to sunlight and how air temperature is affected by storage mass.

The choice of a direct, indirect, or isolated system is strongly influenced by the desired degree of thermal uniformity or control. Where very fine thermal regulation is stipulated, isolated systems will generally be preferred. Isolated heating systems can be completely passive, but in terms of control over the thermal environment, they resemble active systems; that is, the system interaction with the space can be fully regulated and turned "on" and "off." If sizable thermal fluctuation can be tolerated and minimum auxiliary energy use is desired, direct gain or indirect gain systems will generally be preferred.

\begin{tabular}{|l|c|c|c|}
\cline { 2 - 4 } \multicolumn{1}{c|}{} & Direct & Indirect & Isolated \\
\hline $\begin{array}{l}\text { Sunlight Enters } \\
\text { Space }\end{array}$ & Yes & No & No \\
$\begin{array}{l}\text { Air Temperature } \\
\text { Floats with } \\
\text { Absorber and/or } \\
\text { Storage }\end{array}$ & Yes & Yes & No \\
\hline
\end{tabular}

Fig. 4-7. Characteristics of direct, indirect, and isolated passive systems

Given these basic definitions, Fig. 4-8 classifies the common passive heating systems in relation to aperture location.

\section{Direct Indirect Isolated}

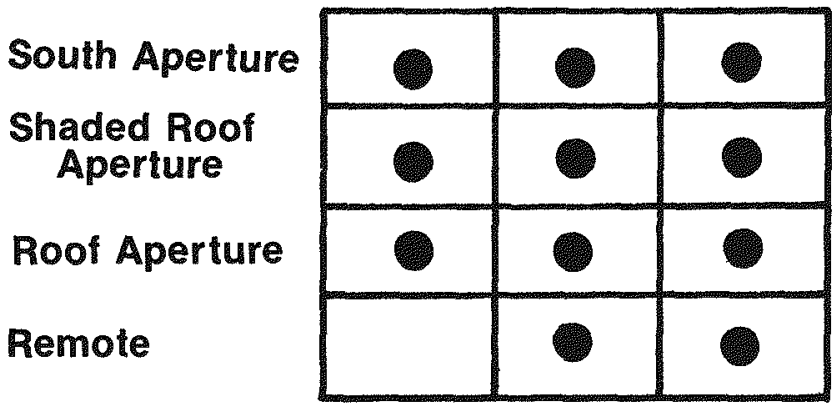

Fig. 4-8. Aperture locations for common passive heating systems
Combinations of the three systems are of considerable importance. For example, direct gain openings can be placed in a storage wall or in an isolated storage wall. The openings can be sized to account for daytime winter heating requirements and for year-round illumination. Another example of combined direct and indirect heating is the use of clear or translucent water storage containers placed in the aperture. Some energy is absorbed and stored in the water, and some energy is transmitted into the space to heat and illuminate.

There exists an assortment of multizone, single-story schemes with solar heating applied to each zone. Some of the more interesting two-zone examples are illustrated in Fig. 4-9. In these systems each zone can be individually designed to meet the particular thermal and illumination requirements dictated by the intended function of the space. The extension of these schemes to single-story buildings of three or more zones is obvious.

A more difficult classification problem is posed by large, mul tistory buildings. Asymmetric solar excitations, such as occur in south aperture systems, naturally drive a north-south zone separation. Multistory commercial structures will clearly be north-south zoned in most cases, and the functional use of the space must be planned accordingly. However, to fully implement passive design concepts and maintain flexibility in space utilization, methods of enhancing or suppressing the natural zone structure of the space must be developed. In some cases this can be accomplished by purely passive means; in other cases, hybrid schemes involving mechanically assisted heat transfer will be more appropriate. The problem of energy transport becomes very critical in large-scale buildings, particularly for high-occupancy commercial applications or situations where industrial processes require high ventilation rates.

The most appropriate roles for passive solar within more general energy management schemes are not presently identified, and the identification of those roles will require a substantial level of effort in innovative concept generation as well as rigorous technical evaluation. Until these roles are identified and the resulting systems are thoroughly investigated, any attempt to develop a comprehensive classification scheme for large-scale buildings would be premature.

\section{COOLING}

Passive cooling involves the discharge of energy by selective coupling of the system to the cooler parts of the environment. If the environmental conditions are correct, this energy flow will occur by natural means. Possible environmental sinks for heat from the system are the sky, atmosphere, and ground.

In sky cooling, radiation from the system passes to and through the atmosphere and dissipates into outer space. Environmentally, it is the purest mode of cooling, since none of the energy discharged from the system appears in the local microclimate. Radiative sky cooling works well in environments with clear skies and has the potential to cool the system below the ambient air temperature. The primary limit to this cooling mechanism is convective and radiative heat gain from the surrounding atmosphere and little heat loss because of low-temperature emission of the emitting surface. 

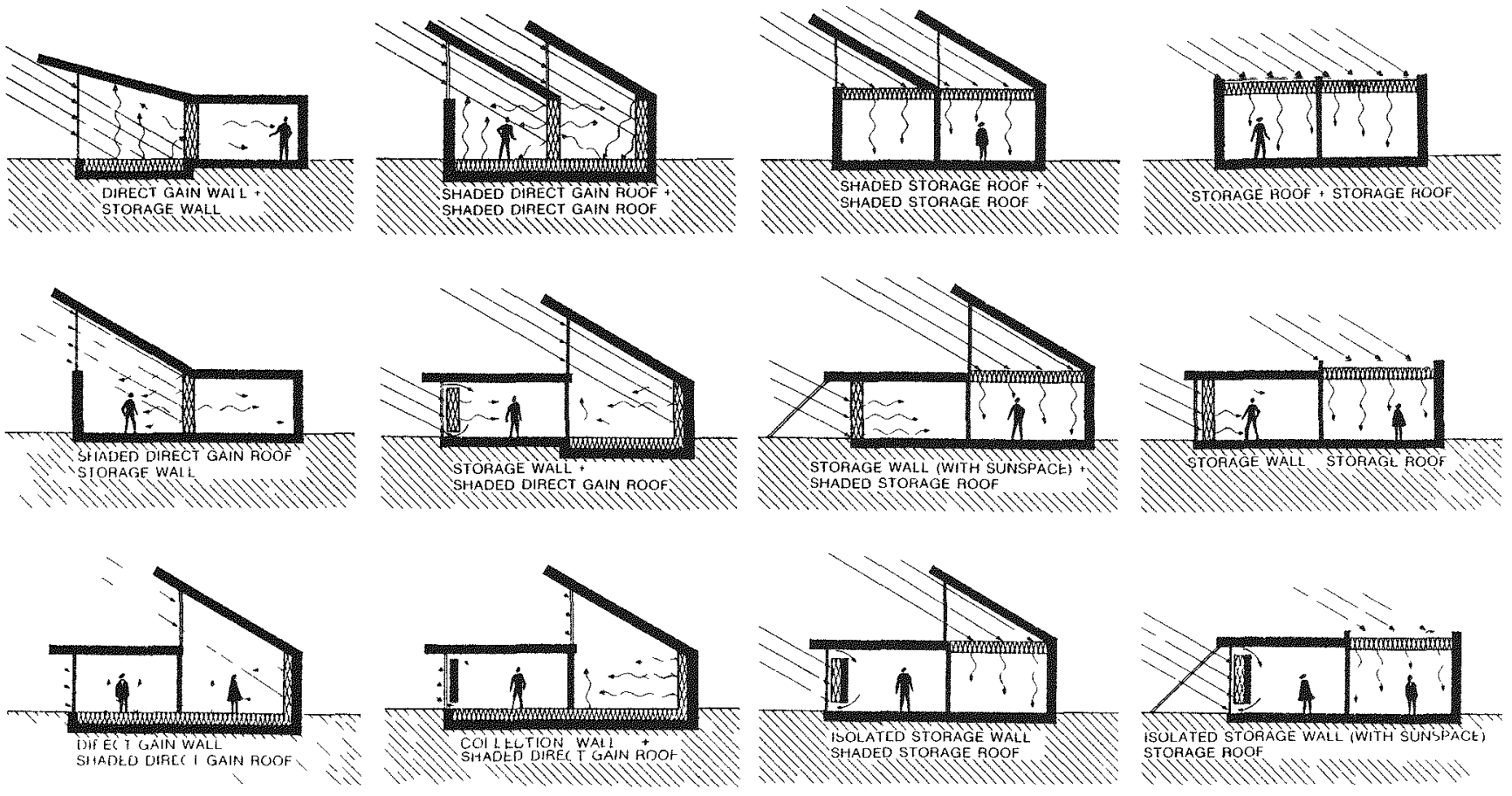

Fig.4-9. Examples of single-story, multizone passive solar systems

Energy from the system can also be discharged directly to the atmosphere during those times when the ambient air conditions are favorable to such an exchange. Heat can be dissipated by raising the sensible heat energy of the surrounding air (e.g., night air cooling) or by raising its latent heat energy (e.g., evaporative cooling). In either case, the energy transfer can be greatly enhanced by increased air movement. The driving force for this movement can come from wind, fans, or special convective drive mechanisms. In dry environments, evaporative cooling has the potential, like radiative sky cooling, to reduce the system temperature below the ambient air dry bulb temperature. Rock beds can be used in conjunction with evaporative coolers. Temperatures in the rock bed will usually be 6 to $8 \mathrm{~F}\left(3-4^{\circ} \mathrm{C}\right)$ above the wet bulb temperature.

In climates where outdoor air can be used for cooling at certain times of the year, advantage should be taken of the opportunity. Natural ventilation may be utilized through proper building orientation and design and use of surrounding landscape to direct breezes (Fig. 4-10).

Locate air inlets in high pressure areas (windward side) and outlets in low pressure areas (leeward side). For good ventilation, outlets should be larger than inlets, and the building plan must be open enough to allow good air flow. A larger outlet than inlet will cause breezes to accelerate through indoor spaces (Fig, 4-11a). If the inlet were larger, the greatest wind velocity would occur beyond the building. The placement of the inlet governs the air flow pattern within the building, so it must be located in a way that the greatest cooling effect is achieved.
Daytime outdoor air ventilation can also be induced through a building with the use of a solar chimney. A solar chimney works the same way as a thermosyphon air collector (an updraft of hot air is created within the collector) except that air is drawn through the building and exhausted to the outdoors through the solar chimney. Fig. 4-11b illustrates the application of a solar chimney.

When outdoor ambient conditions permit, a building's interior mass can be cooled off using nighttime ventilation. However, one must not be overly optimistic in the amount of cooling that can be expected through this technique. The greatest limiting factor is the relatively small amount of heat exchange area between building mass and circulating air (when compared to a rock bed for instance). As a result, the rate at which heat can be removed from the building mass through night air ventilation is reduced significantly.

Unlike evaporative or radiative sky cooling, which requires special climatic conditions such as dry air or clear skies, ground cooling can be used to displace a substantial fraction of the normal cooling load, even in humid, overcast environments. However, dehumidification by mechanical means may still be required. Because of the great thermal mass of the Earth, ground temperatures during the summer will normally be several degrees below the average ambient air temperature.

Ground temperatures are influenced by several factors: climatic conditions, depth below the surface, and thermal conductivity of the soil. A few inches below the surface, ground temperature fluctuates with daily temperature swings. At a depth of $10 \mathrm{ft}(3 \mathrm{~m})$ it varies on a seasonal basis and after a considerable timelag-perhaps three months out of phase with the season. As a result, soil 

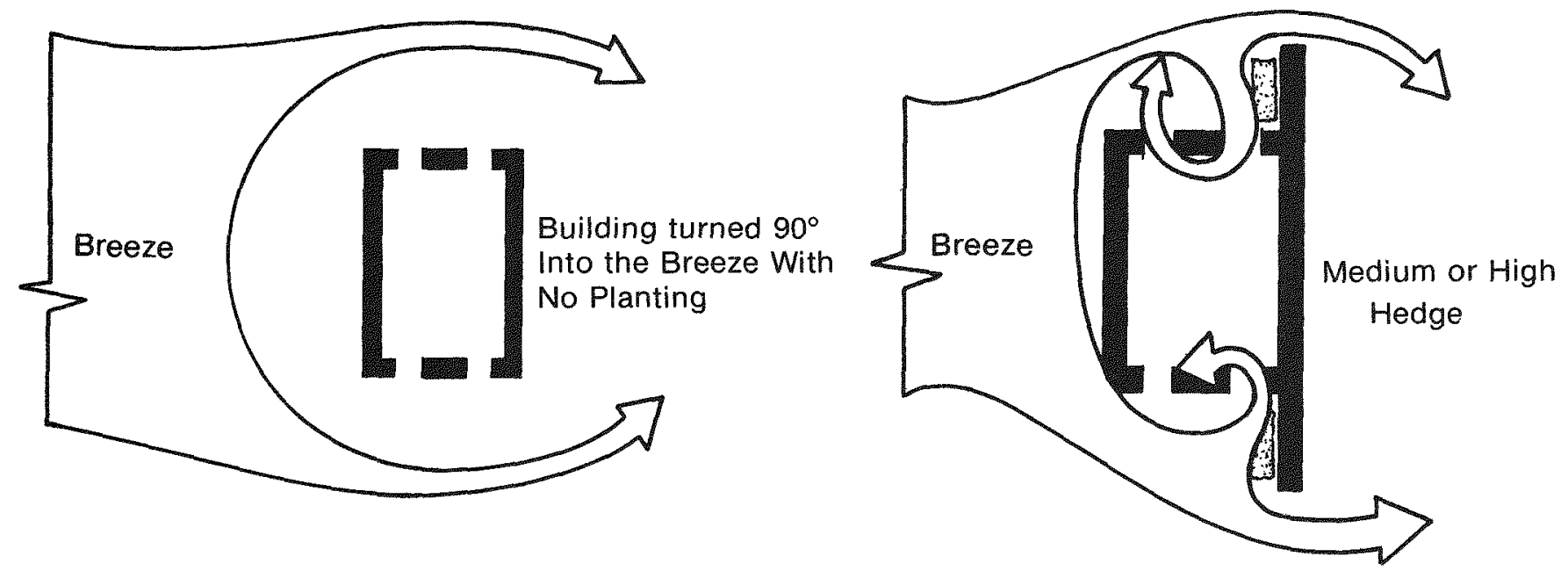

Fig.4-10. Plan view of air flow pattern modification, with landscaping Source: Olgyay, V., Design with Climate, 1963.

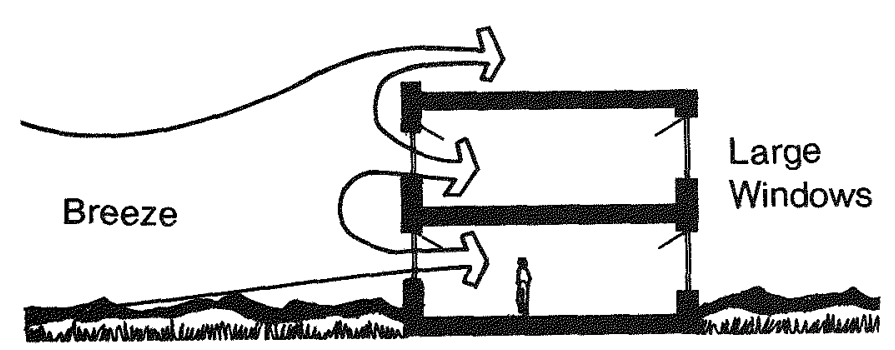

Fig.4-11a. Location of windows with respect to prevalling wind direction

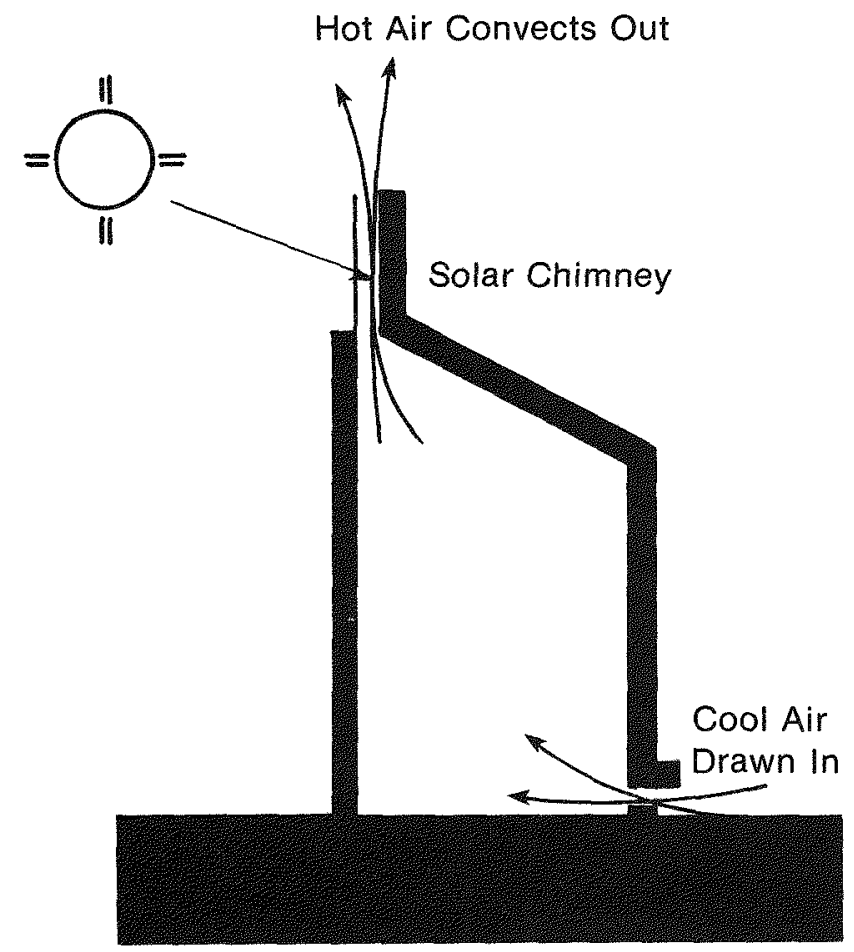

Fig. 4-11b. Solar chimney temperatures at 5 to $10 \mathrm{ft}(1.5-3 \mathrm{~m})$ below the surface will be close to their minimum as the cooling season begins, providing an excellent source for cooling. Outside air which is drawn through pipes buried underground will be cooled by the earth. The length of pipe required is substantial because of the relatively small amount of heat exchange area between the air and pipe and the low heat transfer coefficient. As a very rough rule of thumb, a $1 \mathrm{ft}(30 \mathrm{~cm})$ square pipe measuring $100 \mathrm{ft}(30 \mathrm{~m})$ in length will cool $1,000 \mathrm{sq} \mathrm{ft}(93 \mathrm{sq} \mathrm{m})$ of occupied space. Air velocities through the pipe should be slow, less than 5 $\mathrm{ft} / \mathrm{sec}(152 \mathrm{~cm} / \mathrm{sec})$ to maximize the amount of heat transfer. (See Fig. 4-11c.)

Fig. 4-12 summarizes the environmental sinks, along with the primary mechanisms involved in the energy transfer.

In analogy to heating systems, there are direct, indirect, and isolated cooling processes:

- Direct cooling occurs when the interior surfaces and contents of the space are exposed directly to the environmental energy sink(s).

- Indirect cooling occurs when the space is cooled by uncontrolled radiation to storage (or some exchange surface) that is in tum cooled by exposure to the environmental energy sink(s).

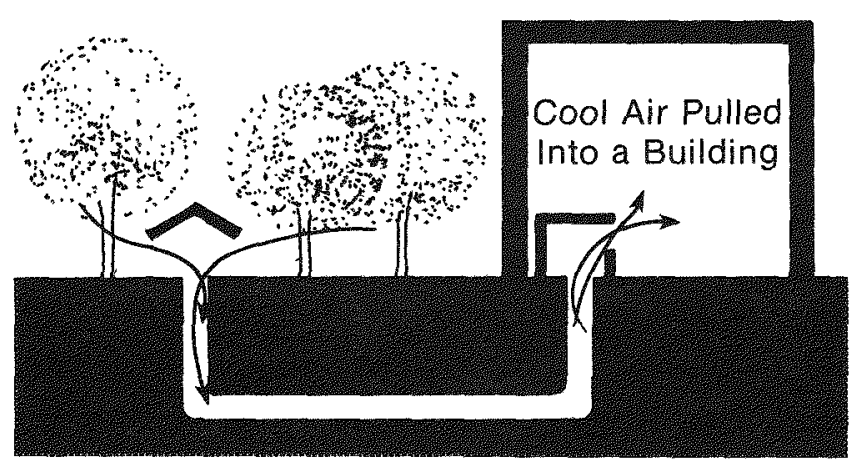

Fig.4-11c. Earth Cooling Pipe 


\begin{tabular}{|c|c|}
\hline Sink & $\begin{array}{c}\text { Primary Energy } \\
\text { Transfer Mechanism }\end{array}$ \\
\hline Sky & Radiatıon \\
\hline Atmosphere & $\begin{array}{l}\text { Convection } \\
\text { Evaporation }\end{array}$ \\
\hline Ground & Conduction \\
\hline
\end{tabular}

Fig.4-12. Environmental sinks and energy transfer mechanisms in passive cooling

- Isolated cooling occurs when the space is cooled by controlled fluid or radiative transfer to storage (or some exchange surface) that is in turn cooled by exposure to the environmental energy sink(s).

As in the case of heating, we can classify passive cooling systems in terms of a matrix (Fig. 4-13).

\section{Direct Indirect Isolated}

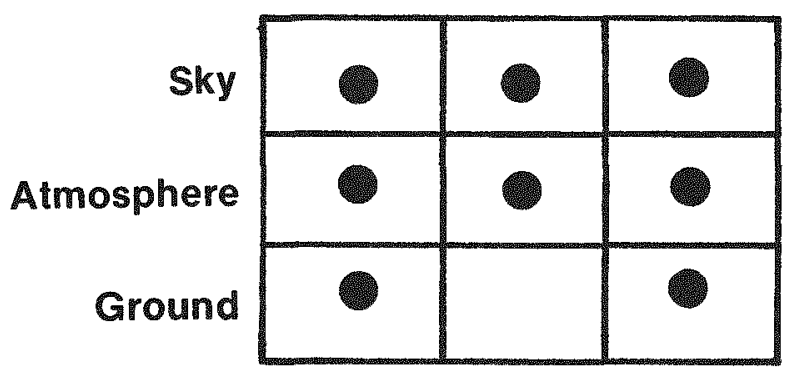

Fig.4-13. Environmental sinks associated with various passive cooling systems

Various combinations of the environmental thermal energy sinks and mechanisms for transferring energy to the occupied space are shown in Fig. 4-14. The configurations shown include the currently most common passive cooling systems in current use and a representative sampling of less common systems that may have equal potential. These combinations by no means exhaust the list of possibilities. The figure introduces a general nomenclature for passive cooling system description.

Emphasis has been placed on systems whose elements can serve both a heating and cooling function, and whenever possible the heating system nomenclature is retained. For example, a storage roof cooling system uses all the same elements as a storage roof heating system, except that the air space, which may be necessary to reduce winter losses, must be eliminated for summer cooling. Also listed in the figure are several promising cooling schemes whose elements do not serve a heating function. In general, passive heating is considerably more advanced than passive cooling.

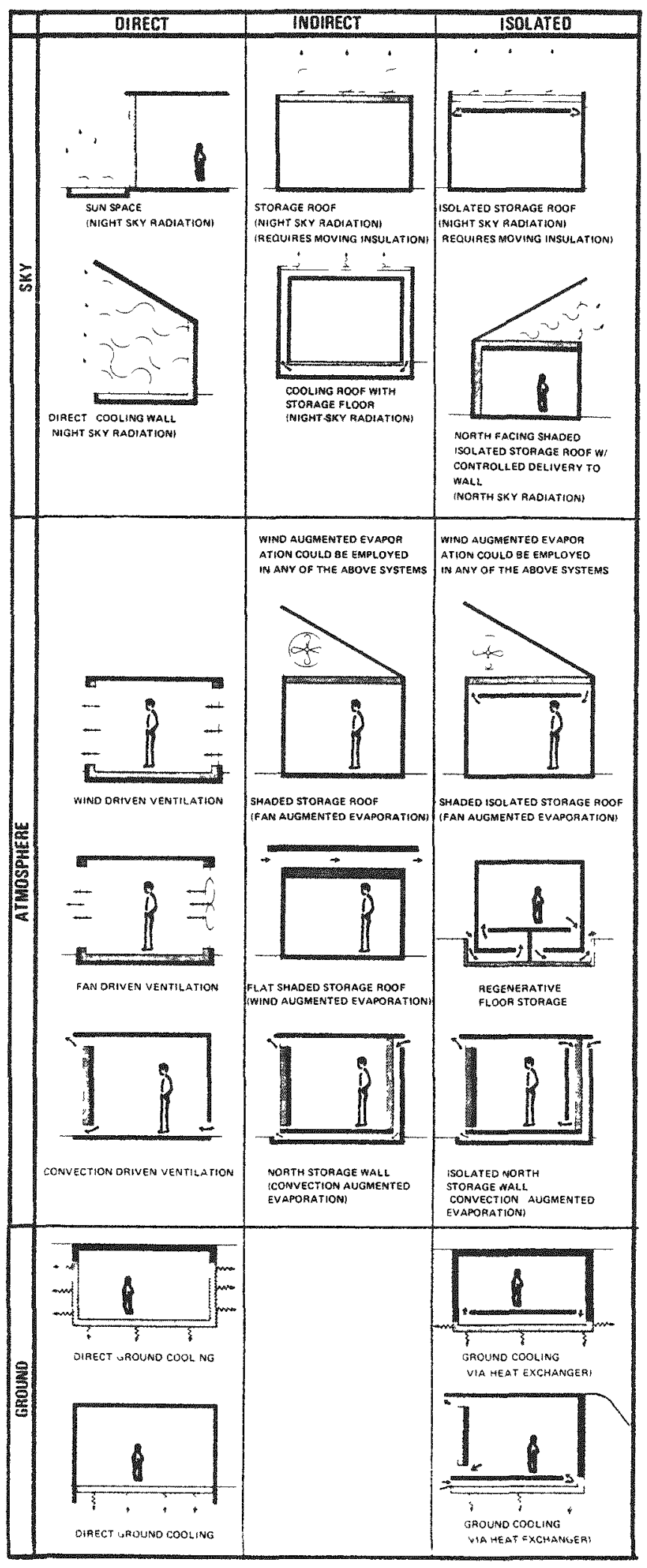

Fig.4-14. Examples of passive solar cooling systems 
For many advanced heating systems there does not exist a well-defined cooling system employing some or all of the same elements. For example, there are several wellunderstood storage wall heating systems, but no welldefined schemes for using that mass with comparable effectiveness in the cooling mode. Despite the lack of well-defined concepts, the idea of using storage walls in the cooling mode appears to merit further consideration.

As in the case of passive space heating, roles for passive cooling in more general energy management schemes for large-scale commercial and industrial buildings remain to be identified and evaluated.

\section{CHARACTERISTICS OF SEVERAL COMMON PASSIVE SYSTEMS}

Each passive heating and cooling system has specific design limitations and opportunities. Rather than selecting the system and attempting to integrate it with the architectural design, one should let the design requirements of the building or each space in the building determine the most appropriate passive system(s). Factors entering into identifying the most appropriate passive system or combination of systems include the location of the space in the building (access to environmental resource), thermal requirements of the space, daylighting requirements of the space, desirable views from the space, material characteristics of the space, degree of thermal control required, privacy considerations, and aesthetic considerations. The characteristics of some common passive systems are described, highlighting some of the factors mentioned above.

\section{Direet-Gain}

The direct-gain heating system is using the occupied space as a solar collector. Heat can be stored in the building structure (floors, walls, ceilings). Concrete, brick, stone, and containers of water are effective for thermal storage. Phase change materials (i.e., eutectic salts) using heat of fusion are also becoming effective thermal storage. To avoid overheating in the summer, an overhang that shades the glazing should be used; and to reduce winter heat losses, movable insulation is recommended. (See Fig, 4-15.)

The direct-gain heating system has the following charac teristics:

- Glazing is an inexpensive form of solar collector. It is widely available in large sizes and $i$ ts thermal and physical properties are well understood.

- By proper orientation and organization of building spaces (e.g., relocation of north, east, and west windows on the south side of the building), the overall system costs can be very similar to those for a conventional building.

- Because the space is directly coupled to the incoming solar radiation, the glazing serves multiple functions: solar collection, natural daylighting, and visual connection to the outside.

- For low (up to $25 \%$ ) solar heating fractions, generally no additional thermal storage is required.
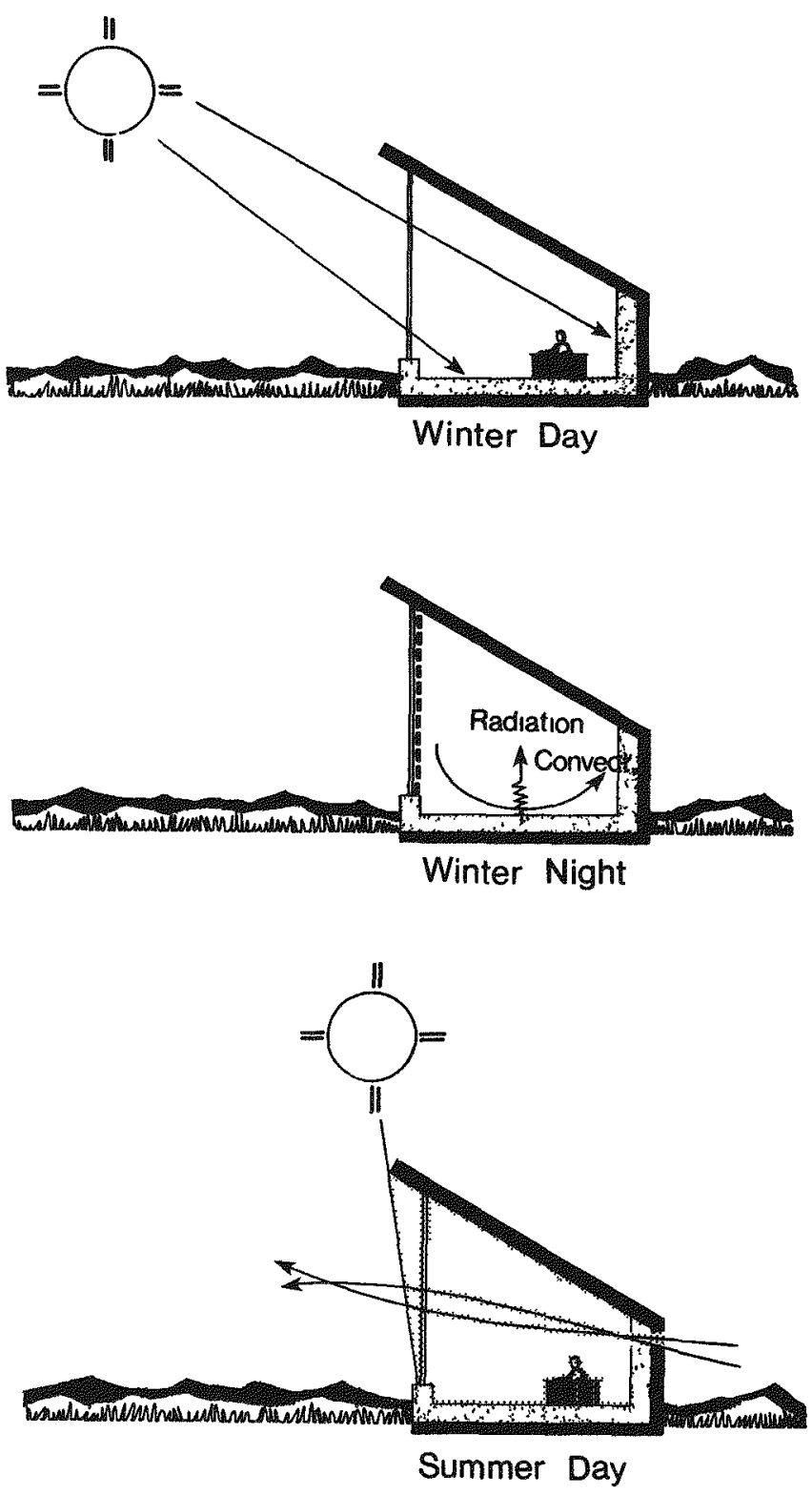

Fig-4-15. Direct gain heating system

- To achieve large (more than 50\%) solar heating fractions, additional thermal mass is required to decrease temperature fluctuations. This additional thermal storage can be a significant expense.

- Daytime glare and loss of privacy at night can result from large areas of glass.

- Ultraviolet radiation can degrade fabries, furniture, and art work exposed to direct sunlight.

- Interior space temperature swings of from 15 to $20 \mathrm{~F}$ $\left(8-11^{\circ} \mathrm{C}\right)$ are common, even in well-designed buildings. However, the "effective" temperature swing which an occupant senses is reduced by the effect of the mean radiant temperature of surrounding surfaces. 
- Thermal storage mass must be insulated on the exterior wall surface to use the mass effectively to temper the interior temperature fluctuations.

- Movable insulation systems over the glazing are generally required to reduce night heat losses but such systems can be expensive and awkward for large areas.

- Glazing is a familiar design element that building designers understand and therefore should minimize reluctance or uncertainty in using direct gain systems.

\section{Storage Wall}

Rather than distributing the thermal storage evenly on the space surfaces as in a direct-gain system, a storage wall heating system places the thermal mass directly behind the glazing. The mass intercepts the sunlight on its outer surface and transmits this heat through the wall by conduction. By adding vents high and low in the wall, heat can also be supplied immediately to the space by convection. (See Figs. 4-16 and 4-17.)

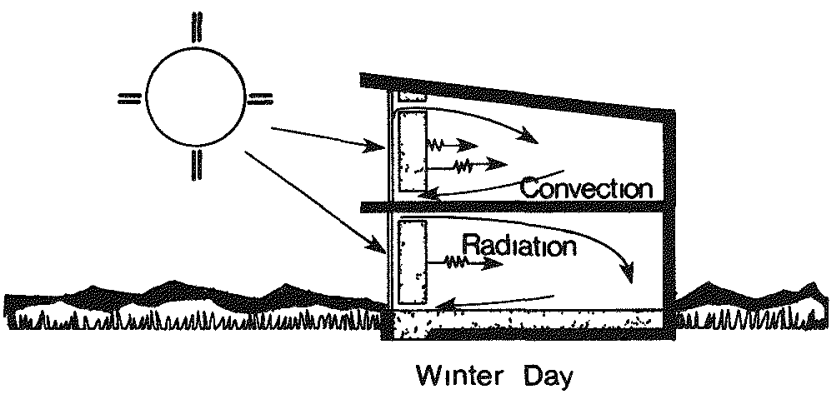

Fig. 4-16. Storage wall in heating mode

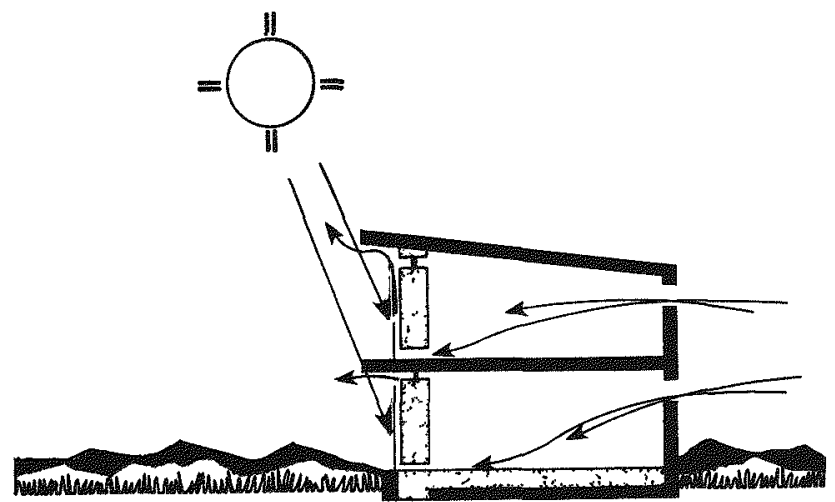

Summer Day

\section{Fig.4-17. Storage wall in cooling mode}

The storage wall heating system has the following characteristics:

- Thermal storage is consolidated in one building element, thereby reducing its impact on the overall building design.

- The exterior surface of a storage wall must be highly absorptive to maximize energy collected. The application of a selective surface to storage walls is being studied as a means to improve their performance.

- Energy delivery to the space is more controllable than for a direct-gain system. It can be immediate through convection to satisfy daytime loads or delayed through conduction and reradiation from the wall's inside surface to meet evening and nighttime loads.

- Glare, ul traviolet degradation, and reduction of night privacy are not problems with this system; but visual access to the outside is lost unless a window is placed in the mass wall.

- The performance of storage walls is well characterized for a variety of design and climate parameters.

- Indoor temperature swings are less than in direct gain systems, on the order of 10 to $15 \mathrm{~F}\left(5-8^{\circ} \mathrm{C}\right)$.

- At times, mass walls will reverse syphon at night, taking heated air from indoor spaces. To prevent this from happening it may be necessary to use backoraft dampers (Fig. 4-18).

- Heat losses are increased because of the proximity of the thermal storage mass to the glazing.

- To minimize overheating during summer months, a mass wall must be shaded and vented to the outdoors.

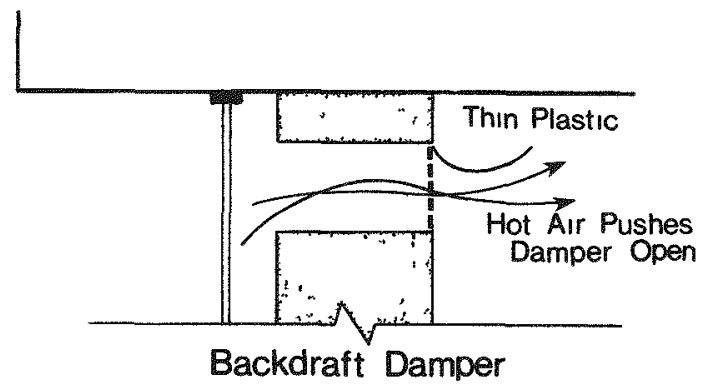

Fig.4-18. Back draft damper for storage
wall vents

\section{Storage Roof}

The storage roof system is similar to a storage wall except the intercepting thermal mass is located in the roof of the building. The thermal mass is usually water enclosed within transparent plastic bags. Also, movable insulation is required to control thermal gains and losses. The system is equally suited to provide both heating and cooling. (See Fig. 4-19.)

The storage roof system has the following charac ter is tics:

- Because the thermal mass is uniformly distributed over the entire building floor area, the heat or cooling is more evenly distributed to the building spaces.

- Interior space temperature swings are typically very small, on the order of 2 to $4 \mathrm{~F}\left(1-2^{\circ} \mathrm{C}\right)$.

- Glare and ultraviolet degradation of interior materials or furniture are not problems with this system.

- Wall openings can be placed to take advantage of additional thermal gains and views. 

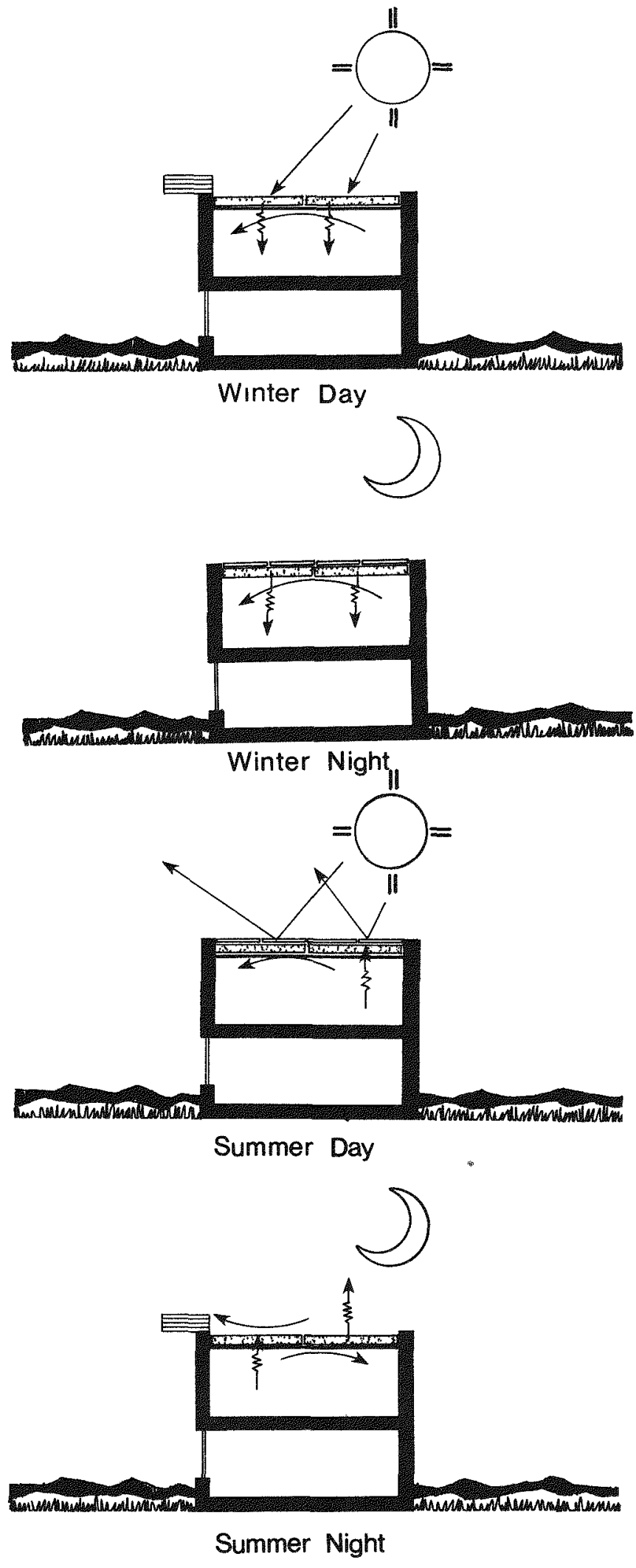

Fig.4-19. Storage roof heating and cooling system
- The building structure must be strengthened to carry the large structural load of the thermal storage. This includes the horizontal roof structural members as well as the vertical support walls or columns.

- Because this system works best when the space is in direct thermal contact with the thermal storage, mul tistory buildings are not practical.

\section{Attached Sunspace}

Technically, a "sunspace" is a direct gain heating space with a south-sloping aperture. It is generally added on to temper the south wall of a primary living space. In this mode, the temperature in the sunspace floats over a fairly wide range in winter; and overheating is partially controlled by venting in summer. If plants and vegetables are to be grown, thermal storage must be included in the sunspace to keep temperatures from dropping below freezing. (See Fig. 4-20.)

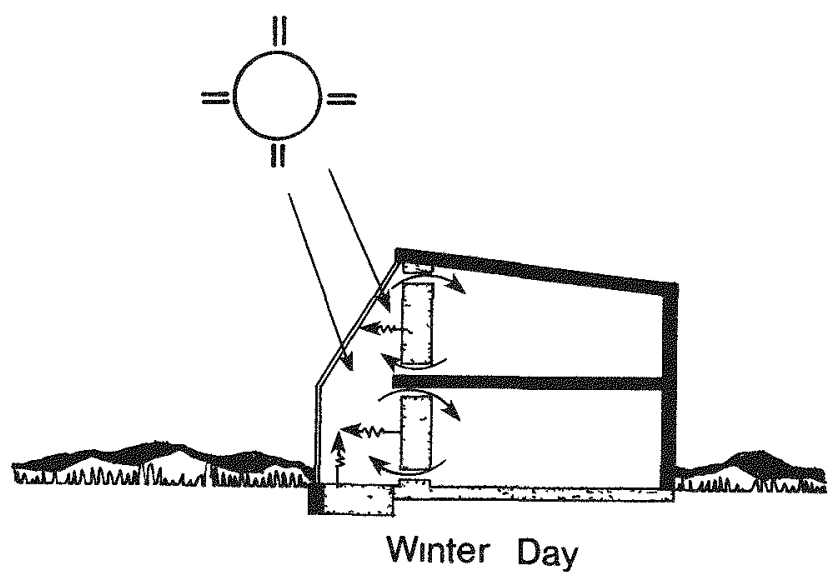

\section{Fig.4-20. Attached sunspace heating system}

An attached sunspace has the following characteristics:

- Because the primary living space is buffered by the sunspace, temperature swings in the living space are small [3 to $\left.8 \mathrm{~F}\left(2-5^{\circ} \mathrm{C}\right)\right]$.

- An attached sunspace provides relatively inexpensive additional living space that is usable most of the year.

- The sunspace provides an area for growing food and plants year-round.

- The sunspace acts as a thermal buffer zone between the outside and the primary living space.

- Attached sunspaces are amenable to existing buildings.

- An attached sunspace represents a major design element and therefore must be carefully integrated to achieve optimum thermal and architectural effect.

- Thermal control (primarily through shading and natural ventilation) is critical to reduce overheating in the summer.

- Often, the hot air from the top of the sunspace will be drawn through ducts by a fan to a rock bed storage and back to the sunspace. This will improve the system efficiency and reduce overheating in the sunspace. 


\section{Remote Collection}

Natural convection and thermosyphoning can be used with conventional flat plate solar collectors to passively heat a building or service water. Air or liquids are used as the heat transfer medium. To collect and store energy, the basic configuration of the system can vary only slightly (Fig. 4-21). To "allow the heated fluid to rise up into storage, the storage container must be located at the same height or above the top of the collector. The driving force within the system is the difference in density between the fluid in the collector (hot and light) and the fluid in storage (warm and slightly heavier). The rate of flow is a function of this difference in density.

A thermosyphon flat plate collector system has the following characteristics:

- Flow rates are dependent upon the difference in temperature between the hot and cold sides of the loop.

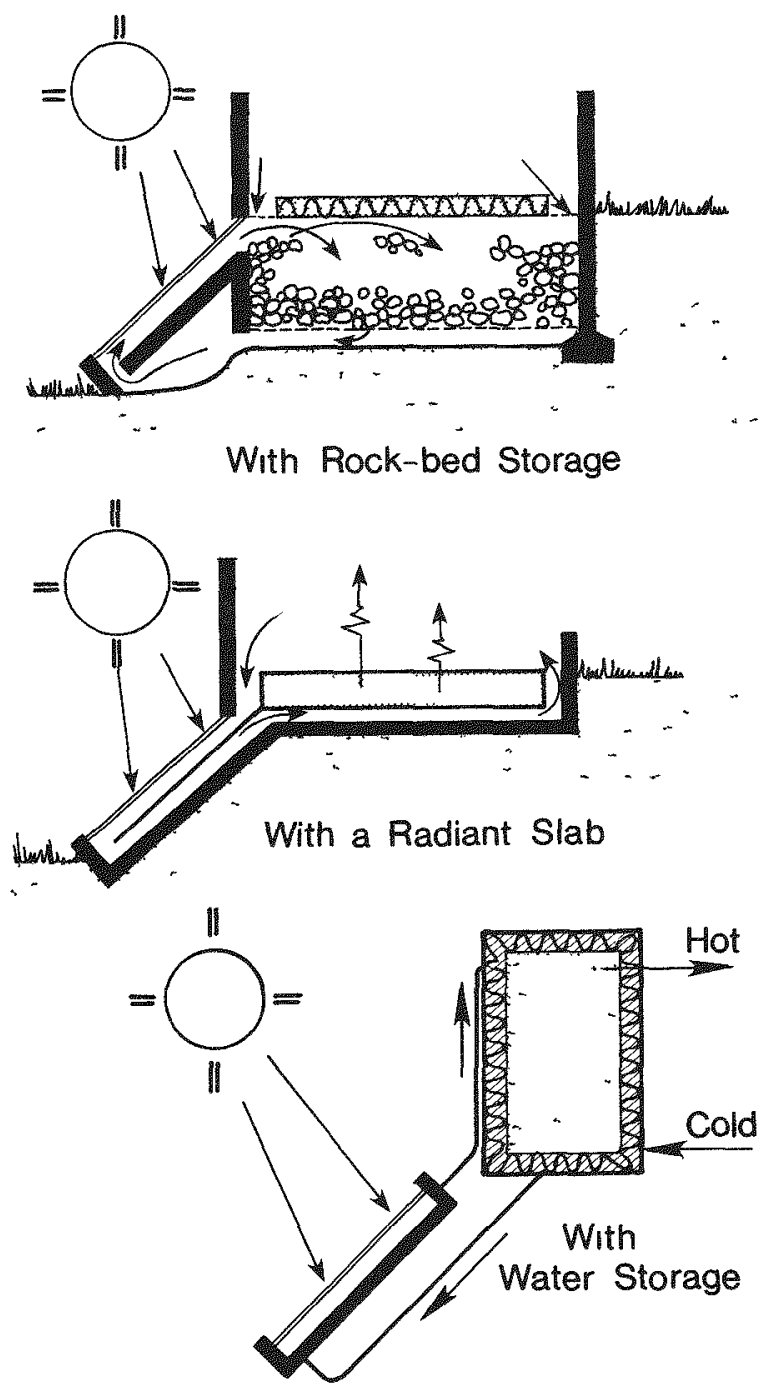

Fig.4-21. Flat plate collector thermo. syphoning systems
- Storage can be thermally isolated or connected to living spaces.

- Reverse convective flow can occur in improperly designed air or liquid systems.

- Dampers or valves can be used to control reverse convec tive flow.

- In an air system, heat may be supplied drectly to the load or to storage.

- In a water system, freezing must be positively prevented.

Thermosyphoning water heaters are appealing because of their simplicity and relatively low cost. Water circulation is maintained by natural convective currents that are produced when water in the collector is heated above the temperature of the storage tank. This results in a density difference between the fluid in the collector (hot and buoyant) and the storage tank (cooler and heavier). Convective water circulation will continue until collector and storage tank temperatures stabilize at the end of the day. In order to induce good flow rates, the bottom of the storage tank should be at least as high as the height of the collector outlet. When freezing can occur, an antif reeze loop must be used, or the collectors must be drained. In mild climates, domestic water may be heated directly through the collector.

\section{SHADING}

\section{Introduction}

The proper use and control of sunlight are essential to energy-conscious design. Fortunately, daily and seasonal changes in the Sun's motion are predictable and can, therefore, be used to our advantage. Several tools are presently available to determine solar positions yearround, and for the analysis and design of shading devices. One method will be described here. Others, such as those mentioned below, may be just as effective and are also available. Shading analysis techniques are discussed in Architectural Graphic Standards, sixth edition; Solar Control and Shading Devices by Aladar and Victor Olgyay; and Sun Angles for Design by Robert Bennett. The 1977 ASHRAE Fundamentals Handbook lists profile (shadow line) angles for surfaces facing various directions at different latitudes. Solar altitude and azimuth angles are also listed in ASHRAE, beginning on p. 26.4, for varying latitudes and dates throughout the year.

The shading analysis procedure which follows is taken from The Passive Solar Energy Book by Edward Mazria. The sun chart enables the user to locate the position of the Sun at any time of day, during any month, for any location within the United States (excluding Alaska) and southern Canada. The curved lines going from east to west, marked by two dates of the year, represent the Sun's path at various times of year. The time of day is indicated by dashed lines intersecting the sun path lines (see Fig. 4-22). One can find the exact position of the Sun at any time of year by reading the altitude angle along the vertical axis and the azimuth or bearing angle from south along the horizontal axis. Sun charts vary with latitude; therefore, the appropriate chart must be used for the location in question. 
$40^{\circ} \mathrm{NL}$

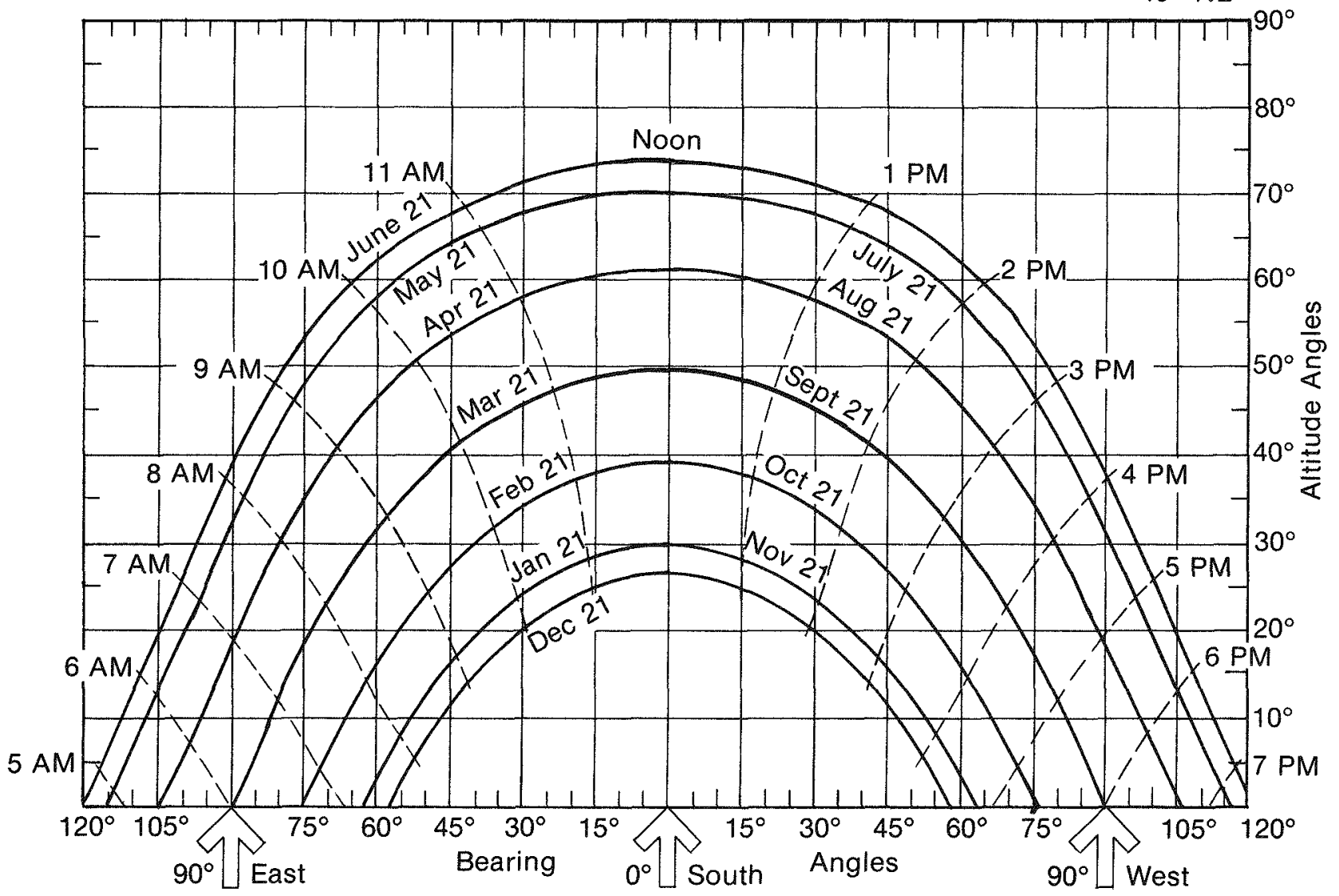

Fig. 4-22. Sun Chart.

Source: Edward Mazria, The Passive Solar Energy Book, 1979

To accurately determine the times that direct sunlight is blocked from reaching any point on a site, it is necessary to plot the obstructions as seen from that point. This is done by plotting the skyline directly on the sun chart. Tools needed for this procedure include either a transit or a compass to find the azimuth angles of the objects on the skyline and $a$ hand level to find the altitude angle of these objects. These measurements can be plotted on a sun chart, as illustrated in Fig. 4-23, and the year-long shading effect of surrounding objects can be seen in terms of dates and time.

Shading devices can be graphically plotted on a shading calculator to construct a shading mask. When this mask is superimposed on a sun chart, the times during which direct sunlight is blocked from reaching that surface can be determined (Fig. 4-24).

Shading devices can be grouped into three categories: the horizontal overhang, vertical fin, and an overhang/fin combination or eggerate. The horizontal overhang is characterized by $a$ shading mask with a curved shadow line running from one edge of the mask to the other. The vertical fin is characterized by a shading mask with a vertical shading line; and the eggerate, by a combination of both.
To construct a shading mask for a window with a horizontal overhang, first determine the angle from a line perpendicular to the bottom of the window to the edge of the overhand (angle $a$ ), and the angle from the middle of the window to the edge of the overhang (angle b). These angles represent $100 \%$ and $50 \%$ shading of the window. Then, using the shading calculator, draw in the shade lines that represent angle $a$ and angle b (Fig. 4-25).

This completes the shading mask. The mask has a pointer and a base line for alignment with the sun chart. Select the sun chart for your latitude, then keeping the base line of the mask directly over the base line of the sun chart, shift the pointer of the mask to line up with the number of degrees (azimuth angle) your window faces to the east or west of true south. The window will be completely shaded during the times that the Sun is above the $100 \%$ shading line, and partially shaded $(50 \%)$ at the $50 \%$ shading line.

There are two basic types of vertical fin shading devices: those that project perpendicularly from the face of the window and those that project at an angle. To construct a mask for either device, determine angles a and $b$ as shown in Fig. 4-26. These angles represent the $100 \%$ shading lines. Then determine angles $c$ and $d$ which represent the $50 \%$ shading lines. From the base line of the shading calculator draw vertical lines that correspond to angles $a, b, c$, and $d$. This completes the shading mask. 


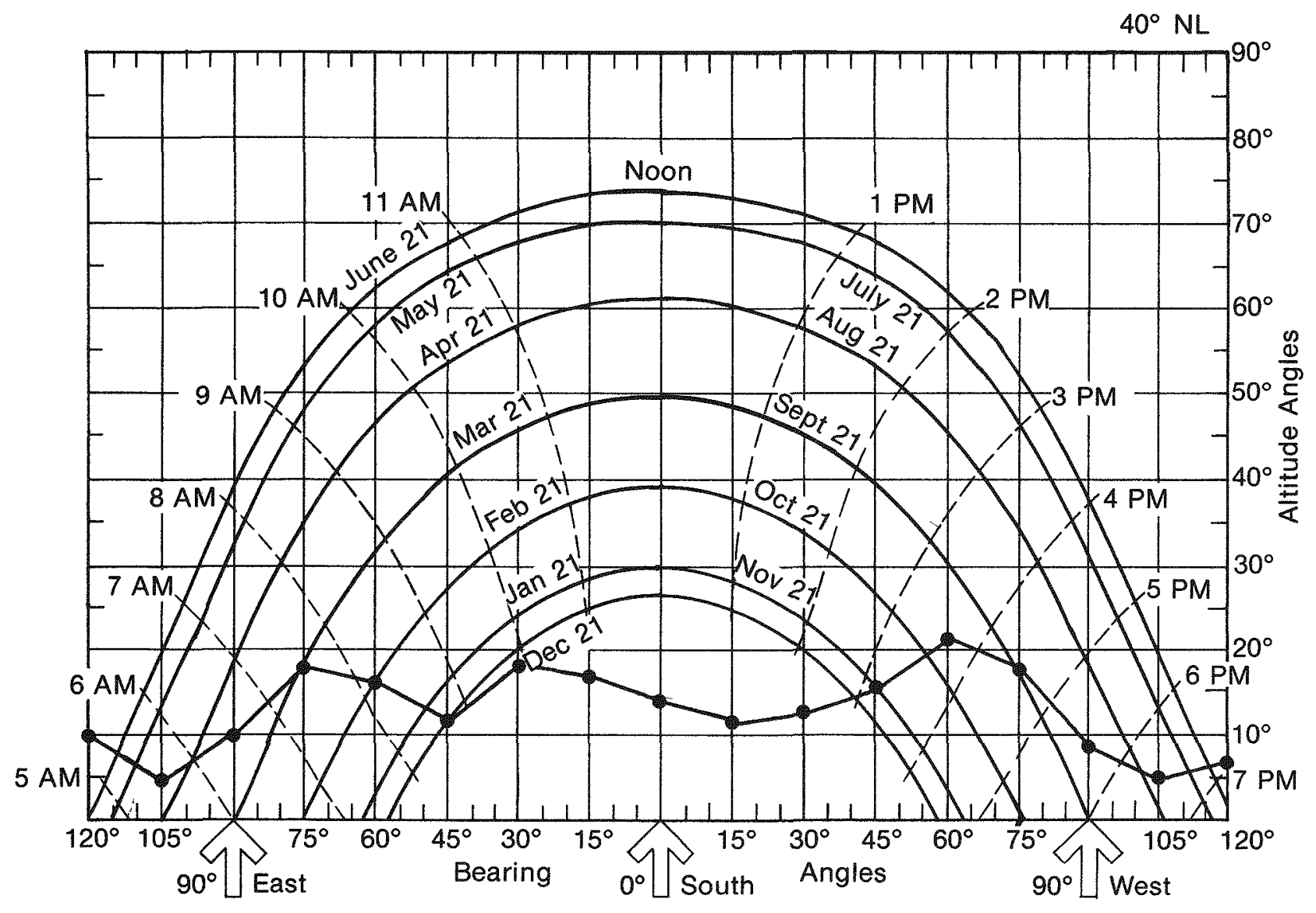

Fig. 4-23. Plotting the Skyline on a Sun Chart.

Source: Edward Mazria, The Passive Solar Energy Book, 1979

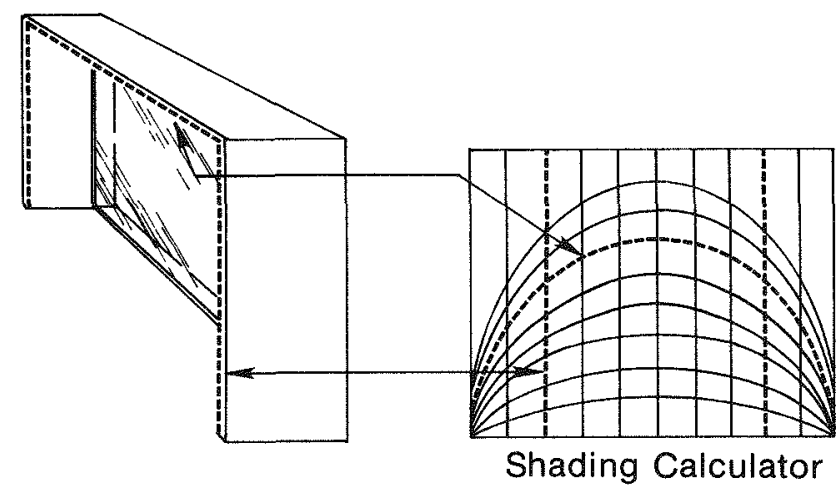

Fig.4-24. Drawing a shading mask on the shading calculator.

Source: Mazria, E., The Passive Solar Energy Book, 1979.

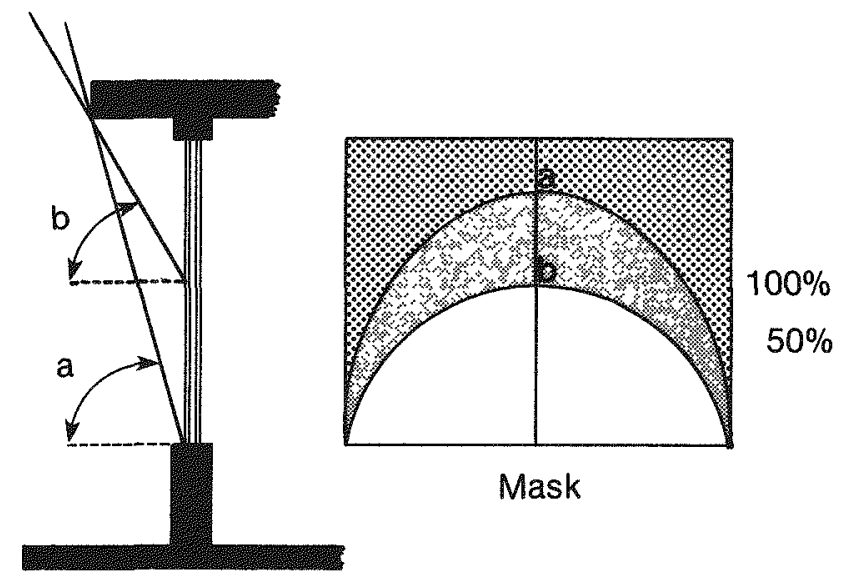

Fig.4-25. Shading mask for a horizontal overhang. Source: Mazria, E., The Passive Solar Energy Book, 1979. 


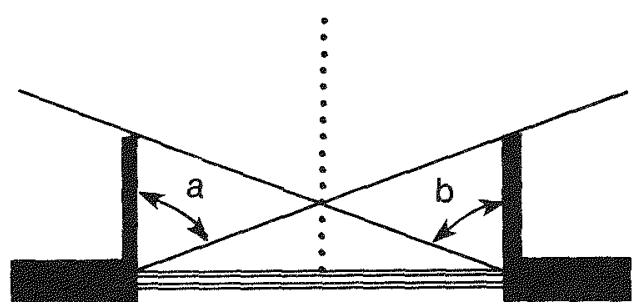

$100 \%$ Shading

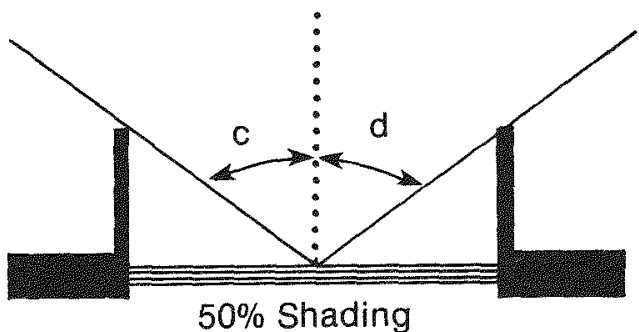

$50 \%$ Shading

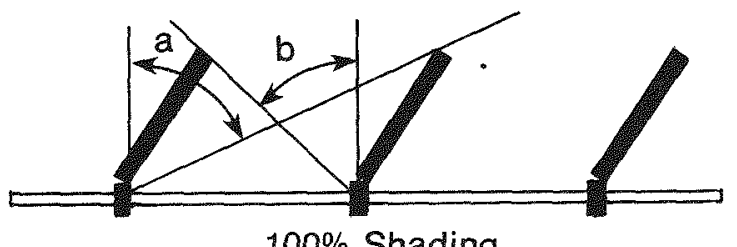

$100 \%$ Shading

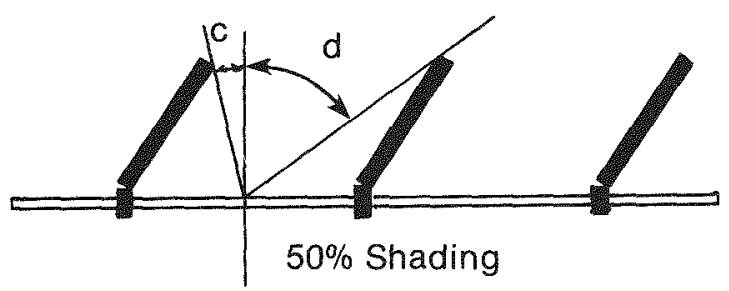

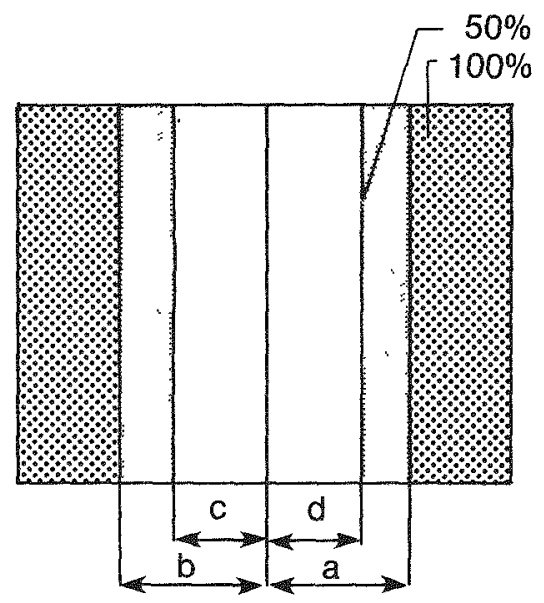

Mask

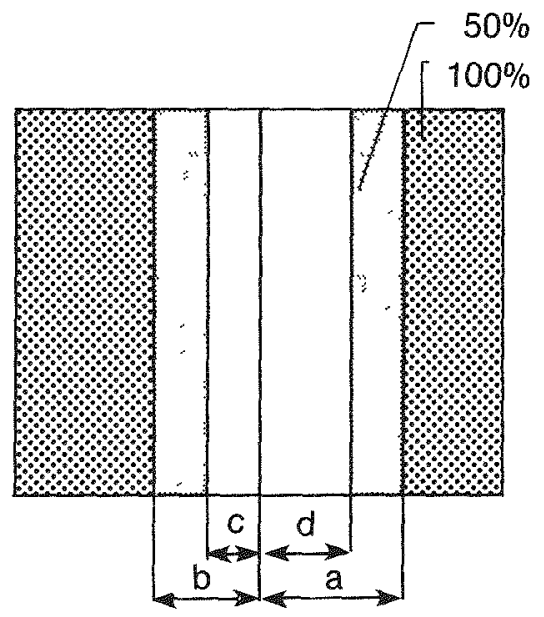

Mask

Fig.4-26. Shading mask for vertical fins. Source: Mazria, E., The Passive Solar Energy Book, 1979.

Align the shading mask over the sun chart to the angle the window faces to the east or west of true south. The window will be completely shaded during the times the Sun is outside of the $100 \%$ shading lines and partially shaded (50\%) at the $50 \%$ shading lines.

To construct the shading mask for a combination horizontal overhang/vertical fin, simply combine the shading masks for each device (Fig. 4-27).

The procedure just outlined is one which is used to analyze an existing shading device. If one is trying to design a shading device for a particular window, the same tools are used, but the technique is essentially reversed. First, the times of year when complete or partial shading is desirable must be determined from climatic conditions of the particular location. Then, a corresponding shading mask can be drawn on the appropriate sun chart. By superimposing a shading calculator on the masked sun chart, the angles between the window and shading surfaces necessary for the desired sun control can be read on the shading calculator. Finally, by knowing the dimensions of the window in question, vertical and horizontal shading devices can be sized through simple trigonom etry.

Generally, fixed shading devices are the simplest solution but not necessarily the best. The climatic seasons don't correspond exactly to the Sun's seasons, so there is a significant time period between the longest days of the year and the hottest days of the year or the shortest and coldest days. This time lag may cause fixed shading devices to perform inadeguately, particularly during the fall or spring. The best solution to this problem is to provide a means for some seasonal adjustment of the shading devices. 

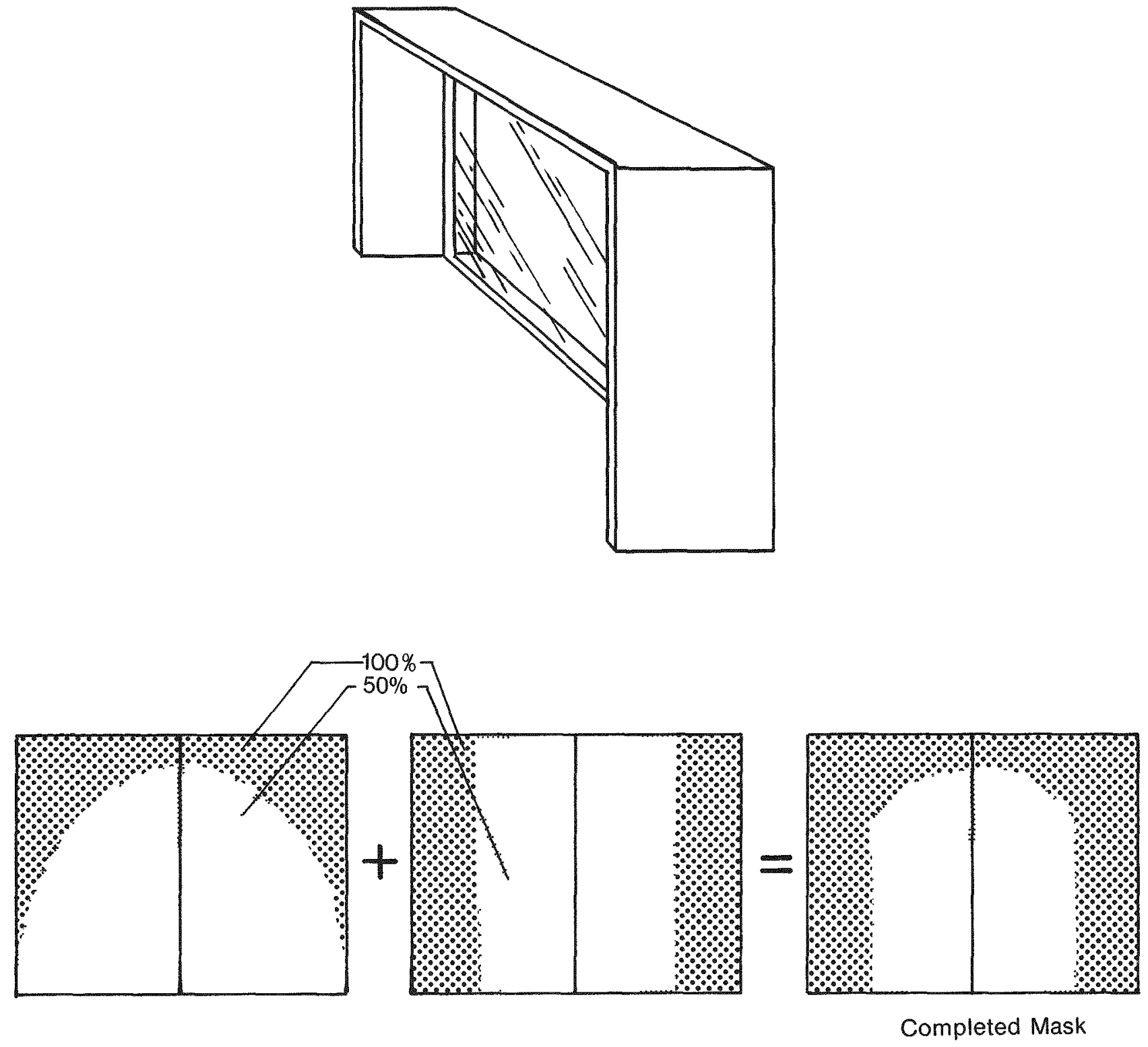

Fig.4-27. Shading mask for combination horizontal overhang and vertical fins. Source: Mazria, E., The Passive Solar Energy Book, 1979. 


\section{S=PI糙}

4-16 
5

Active Systems and Components 
5. Active Systems and Components

A. Active Solar Heating/Cooling Systems

Systems and components

BSHW heating systems

Active space heating systems

Solar-heat pump combinations

Solar cooling

B. Active System Components

Solar collectors

Collector coolants

Thermal energy storage for building heating and cooling applications

C. Active Subsystem Components

Heat exchangers

Pumps

Pipe, fittings, insulation

Expansion tanks

Controls 


\section{ACTVE SYSTEMS AND COMPONENTS}

\section{A. ACTIVE SOLAR HEATING/COOLING SYSTEMS}

\section{SYSTEMS AND COMPONENTS}

In active systems, either air or a liquid may be used for collection of solar heat. Heat exchange with another fluid may be provided, in which case, the manner of supplying heat to the load is not dependent on the nature of the heat collection medium. For example, a solar collector of the liquid-heating type may be used in a system in which heat storage is accomplished by use of a hot water tank. The stored hot water may then be used as the heat source for a hydronic space heating system, a Building Service Hot Water (BSHW) system, or a cooling system. Alternatively, in space heating systems, by means of a central heat exchanger (a water-to-air coil), warm air may be used as the medium of heat transfer to the heated space. If air is the original solar collection medium, its direct delivery to the spaces in a warm air heating system is practical; storage may be provided by a rock bed with subsequent delivery of heat to air circulated through the heated rocks to the occupied space.

A solar collector of the liquid- or air-heating type, in combination with an insulated storage reservoir with associated pumps (or blowers), piping (or ducting), auxiliary heater, and a control system are the components necessary for solar heating or cooling of a space or solar heating of BSHW.

The collectors may be of the flat plate, evacuated tube, or concentrating type, depending on the temperatures required by the load. Storage may be by a hot water tank, a rock bed (for air systems), or phase change materials.

A control system, consisting of thermostats, differential thermostats, and associated relays, controls the operation of the solar collection system, the heat distribution system, and their interaction with the auxiliary heating or cooling system. A differential thermostat turns the collector on and off, activates the freeze protection system (if required), and may vary the speed of the solar collector pump or blower. Control systems for the auxiliary supply may be designed to operate the auxiliary in either a series or parallel mode (see Fig. 5-8).

Several additional subsystem components, common to most conventional heating, ventilating, and airconditioning systems, but designed specifically for solar systems, are heat exchangers, pumps and blowers, valves, dampers, air vents, and expansion tanks. The design of these components and their arrangement in solar heating and/or cooling systems are discussed in the sections below and in Chapter 14.

\section{BSHW HEATTI SYSTEMS}

Details of solar BSHW (domestic and process) heating systems are discussed in Refs. 1 and 2 . Only the highlights will be presented here. Note that many features of BSHW systems particularly in the collectorto-storage loop, are also common to active solar space heating systems. Details of the collector-to-storage configuration, particularly regarding freeze protection, are discussed in the Liquid Heating Systems Section under Active Space Heating Systems below.

\section{Separate Systems}

Simple thermosyphon solar water heaters are common in many parts of the world where freezing is not a problem. There is no separate heat transfer fluid in these roof top units, and hot water from them is used directly in the building. These systems produce a reasonably constant temperature rise of about $32 \mathrm{~F}\left(18^{\circ} \mathrm{C}\right)$ and $a$ peak water flow rate of about $15 \mathrm{lb} / \mathrm{hr}-\mathrm{sq} \mathrm{ft}$ $(73 \mathrm{~kg} / \mathrm{hr}-\mathrm{sq} \mathrm{m})$, about the same as pump circulation systems [2]. In fact, a recent NBS experimental study reported that a thermosiphon system outperformed several active BSHW systems (Ref. 3). Thermosyphon solar water heaters with a heat exchanger placed in the storage tank have been the subject of recent research.

A flat plate collector can heat water to be used directly (with a storage tank). However, in colder climates, unless the system can be drained, it must use a nonfreezing heat transfer fluid with a liquid-to-water heat exchanger between the collector and storage.

A flat plate BSHW (domestic and/or process hot water) system can be classified as a single- or double-tank type. Within each of these types, the system can be either an indirect or a direet system, depending on whether a heat exchanger is placed between the collector and the load. An indirect system employs a heat exchanger. 


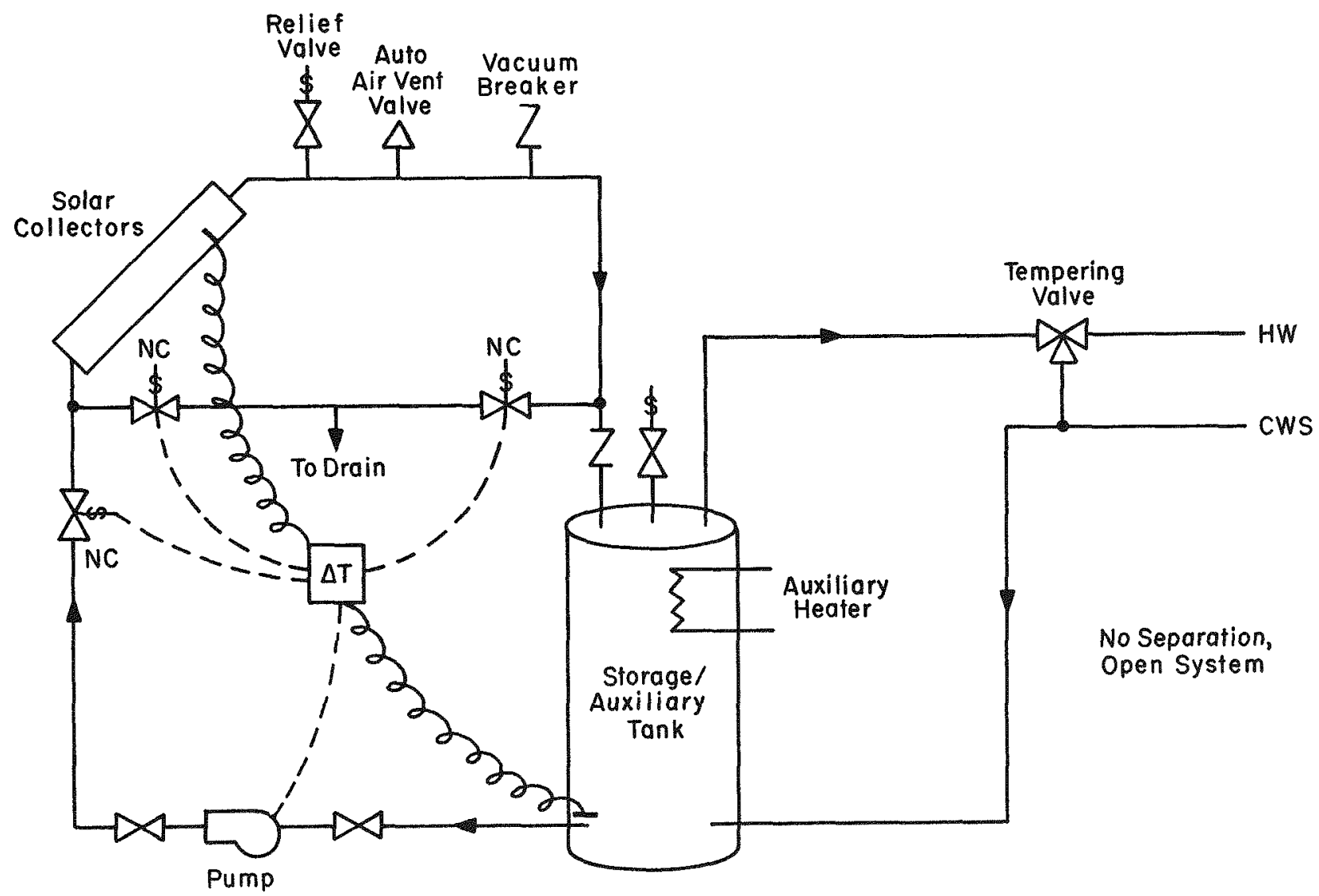

Fig. 5-1. Single-tank, direct, drain-down
BSHW system

In the single-tank system the solar storage and auxiliary heating occur in the same tank that is maintained by the auxiliary heater at a minimum setpoint temperature. One of three possible freeze protection strategies, the drain-down option, is shown in Fig. 5-1 for a direct, single-tank system. The collector and storage fluid in this case would be ordinary tap water because it mixes intimately with the DHW in the load loop. Freeze protection is accomplished by a series of solenoid valves that are opened when near-freezing conditions are detected by the controller, allowing the collector fluid to drain onto the ground or to a sump. The collector and storage tank are maintained at line pressure. A vacuum breaker allows air into the line whenever the drain-down valves are opened and line pressure is lost. A check valve and a solenoid valve prevent the loss of storage tank fluid under these circumstances; just the collector fluid is lost. The collector loop must be recharged before restarting the system. An automatic air vent valve at the high point of the system allows air to escape. Also, the piping must be pitched to assure proper drainage. Shut-off, relief, and other valves are also shown on Fig. 5-1. A commonly used variation on this system to prevent freezing is to pulse the collector pump during periods of marginally freezing ambient temperatures. The system is then drained during intervals of severely cold weather.
The second freeze protection strategy is used in the single-tank, indirect BSHW system shown in Fig. 5-2. In this case a glycol/water antifreeze coolant is used in the collector loop with heat exchange to the load loop through a double-walled, jacketed solar preheat tank. Many manufacturers employ coils in tanks and external heat exchangers to accomplish the necessary isolation. The toxic glycol/water mixture is thus double separated from the potable water supply. Other non-freezing fluids of the non-aqueous type could be used instead of a glycol/ water mixture. (See the discussion of collector coolants later in this chapter.) An expansion tank and relief valve are provided to prevent overpressurization of the colleetors as the coolant expands with heating. Performance is degraded over the direct system because the heat exchanger forces the collectors to operate at a higher temperature.

In a double-tank system the functions of solar storage and auxiliary heat addition can be separated so that the solar tank acts as a preheater for the conventional gas or electric unit. Because the auxiliary heat is supplied to the second tank, not to the solar-heated tank, the solarheated part of the system can operate at lower storage (and hence collector) temperatures and higher (but not significant) overall collection efficiency. This can be done in either a direct or indirect configuration. Fig. 5-3 


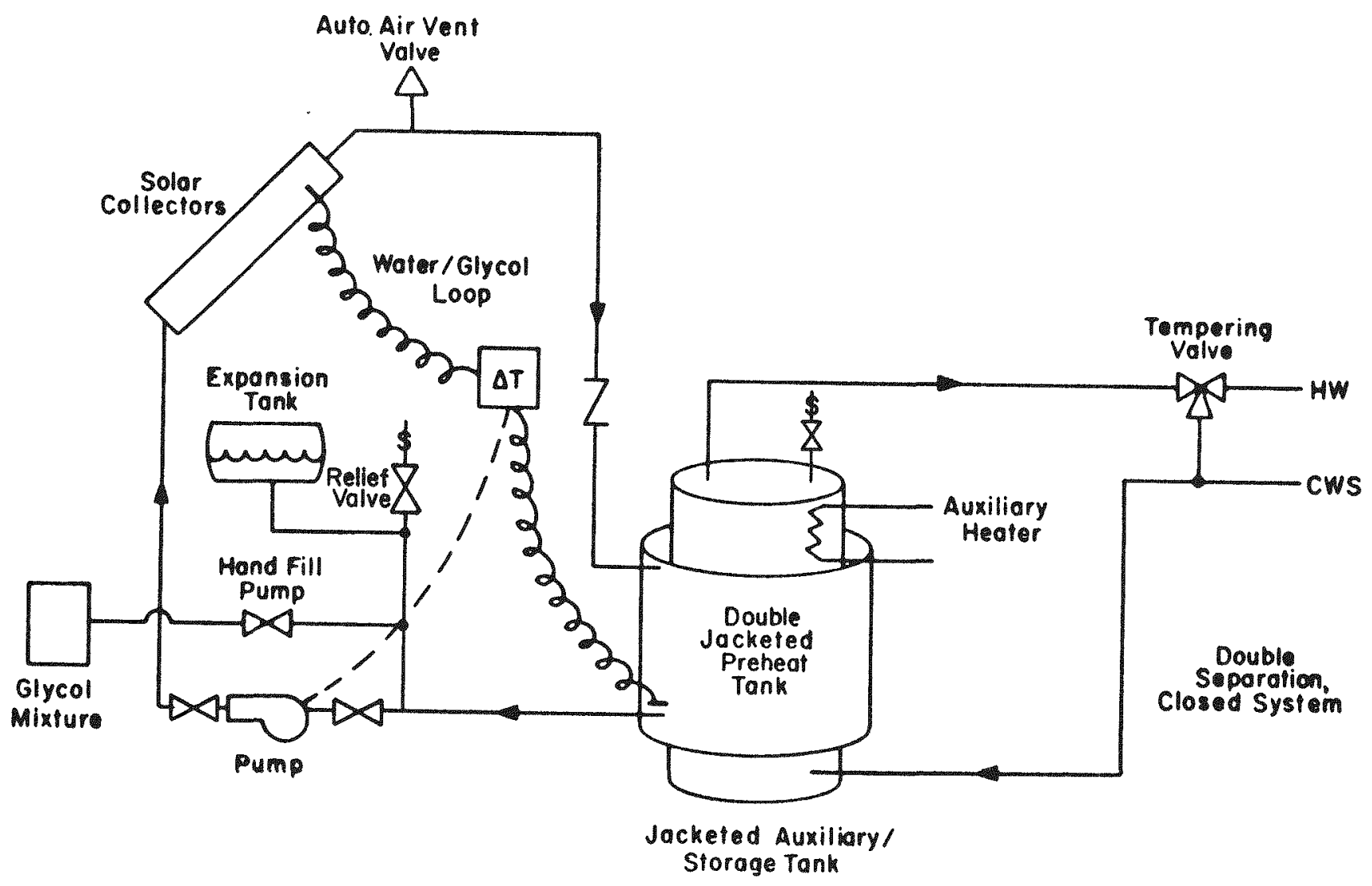

Fig. 5-2. Single-tank, indirect, glycol BSHW system

shows a double-tank, direct, drain-down BSHW system. Like in the single-tank, direct system there is no separation between the collector fluid and the potable water supply, thus ordinary tap water flows through the collector. The system is identical to the single-tank, direct system except for the interposition of the solar preheat tank. A variation is possible in which warm, solar-heated fluid can be circulated by means of a circulating pump actuated by a differential temperature controller between the tanks, from the solar tank to the auxiliary tank. Otherwise, this system applies solar-heated water to the load only when hot water is drawn off at the top.

Finally, a double-tank system can be configured in an indirect fashion where the cold water supply passes through a heat exchanger in the solar preheat tank on its way to the auxiliary tank. Such a system is the doubletank, indirect, drain-back system shown in Fig. 5-4. Freeze protection is accomplished by draining the collector fluid, usually tap water, back into the solar preheat tank whenever the circulating pump shuts off. Thus air is introduced into the collector every time the system drains; that air is purged through the vent in the preheat tank whenever the circulation pump starts again. As in the double-tank direct system, an optional circulating pump may be placed between the tanks to transfer stored solar energy from the preheat tank to the auxiliary tank even if no hot tap water is drawn off.
The third type of freeze protection, to be used in climates where it seldom freezes, is recirculation of the storage fluid. In such a system, if the controller senses imminent freezing conditions at the collector or in exposed piping, warm storage fluid is recirculated to the collector to prevent freezing. Although this loses some of the solar energy collected earlier, these losses are quite small.

A recent NBS study [3] compared the measured and simulated performance of several solar domestic hot water systems. Aside from the thermosiphon system, the single-tank systems performed better than the doubletank systems by roughly $15 \%$. This was probably the result of the fact that the double-tank systems had a considerably larger surface area for losses from storage. The direct systems performed about $5 \%$ better than the indirect systems in both cases.

A BSHW system may also employ an air collector and an air-to-water heat exchange coil.

\section{Combined Space and BSHW Systems}

The economic advantage of solar space heating can be improved if this function is combined with a solar BSHW system. A dual-purpose system is usually the more cost 


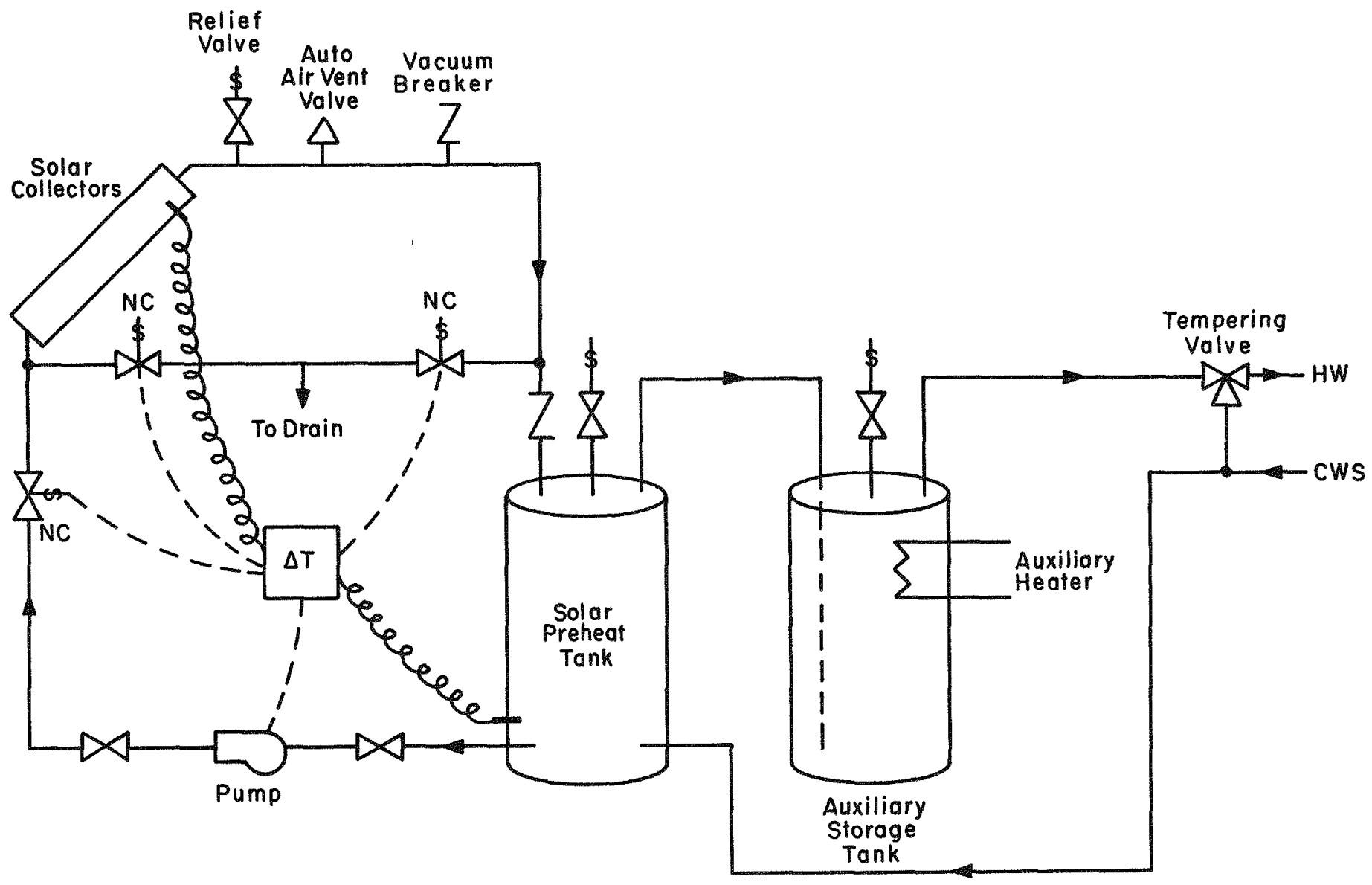

Fig. 5-3. Double-tank, direct, drain-down BSHW system

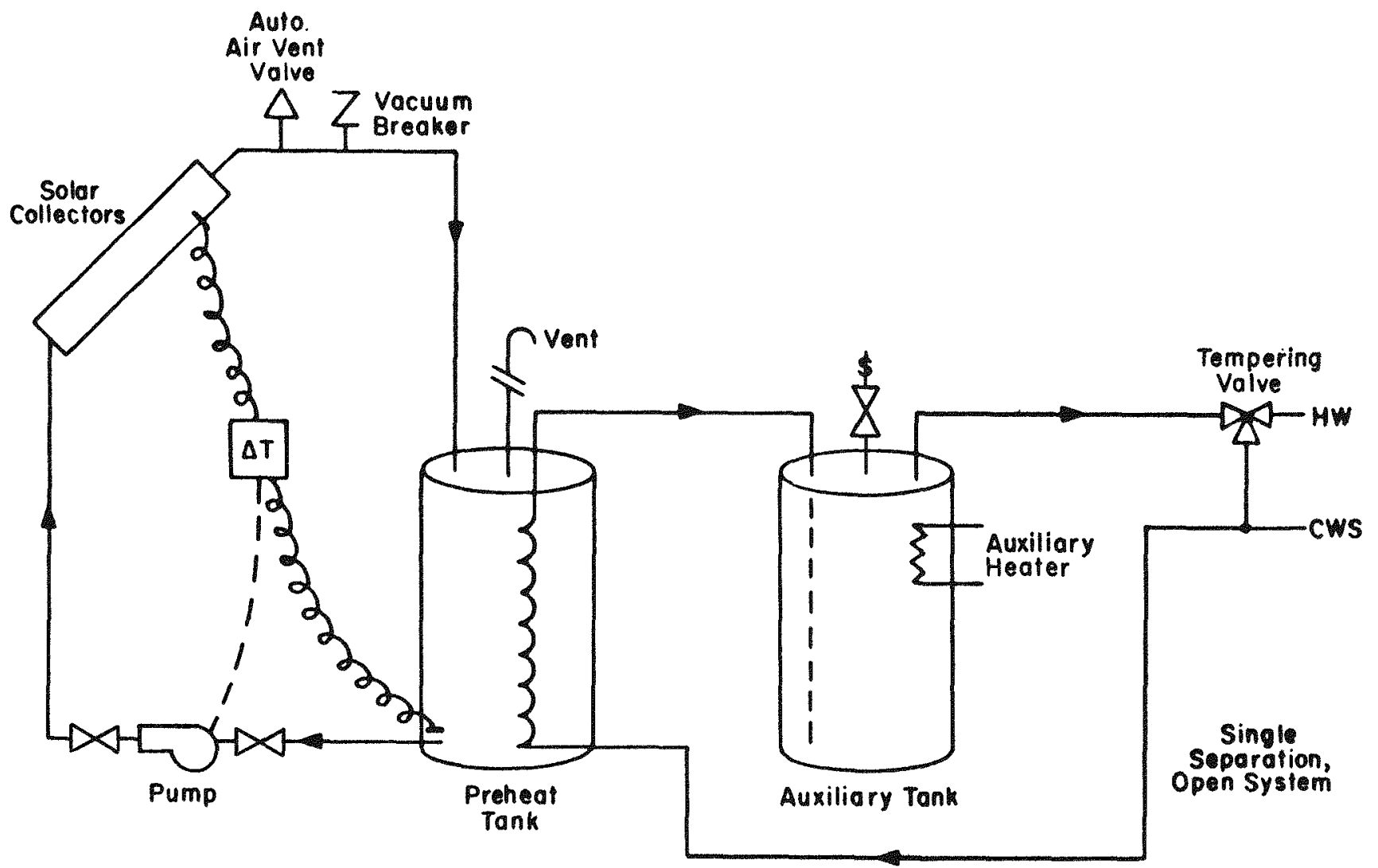

Fig. 5-4. Double-tank, indirect, drain-back BSHW system 
effective because an otherwise idle collector can be used in the summer for BSHW heating.

In the combined system, an example of which is shown in Fig. 5-5, solar heat can be transferred from the main storage tank to a much smaller domestic hot water tank through a liquid-to-liquid heat exchanger. Pumped circulation of both liquids, as in Fig. 5-5, or thermosyphon circulation* can be used. Whenever a positive temperature difference exists between main solar storage and this solar preheater tank (with a temperature limit control to avoid overheating), circulation and heat transfer occur. Cold water from the mains is supplied to the preheat tank when a hot water tap is opened, and warm water from this tank flows to the thermostatted auxiliary heater. The auxiliary unit is a standard hot water heater (gas-fired or electric).

Another type of auxiliary heater arrangement is an inline, high-input (flash) heater that has very little storage and simply boosts the temperature of water passing through it. A disadvantage of this booster unit is the variable temperature of the solar-heated water supplied to it and the resulting variable delivery temperature from it. The use of a thermostatted hot water heater avoids this difficulty.

Because of building code restrictions, conventional shelland-tube exchangers for transfer of heat from solar storage to potable water may not be usable. The possibility of leakage and contamination of the potable supply can impose a design requirement that eliminates all back-flow possibility. Such an exchanger should be of the double-walled type designed so that neither fluid can mix with the other if one of the tube walls develops a leak.

The systems described above involve the use of conventional shell-and-tube, liquid-to-liquid heat exchangers external to the solar storage tank. An alternate arrangement is the use of coils inside the storage tank; one for circulation of the collector fluid and another for transfer from solar storage to the BSHW supply. Natural convection in the storage tank results in a low heat transfer coefficient outside the tube surfaces. The total surface area of these coil-type exchangers must therefore be considerably larger than the area of external exchangers, but the cost may be lower. Only one pump is required for each heat exchanger, rather than two, but the power requirements

*Thermosyphon arrangements depend on natural convection currents in the heat transfer fluid to transport thermal energy. In general the storage tank is placed well above the collector so that the captured heat rises into the tank.

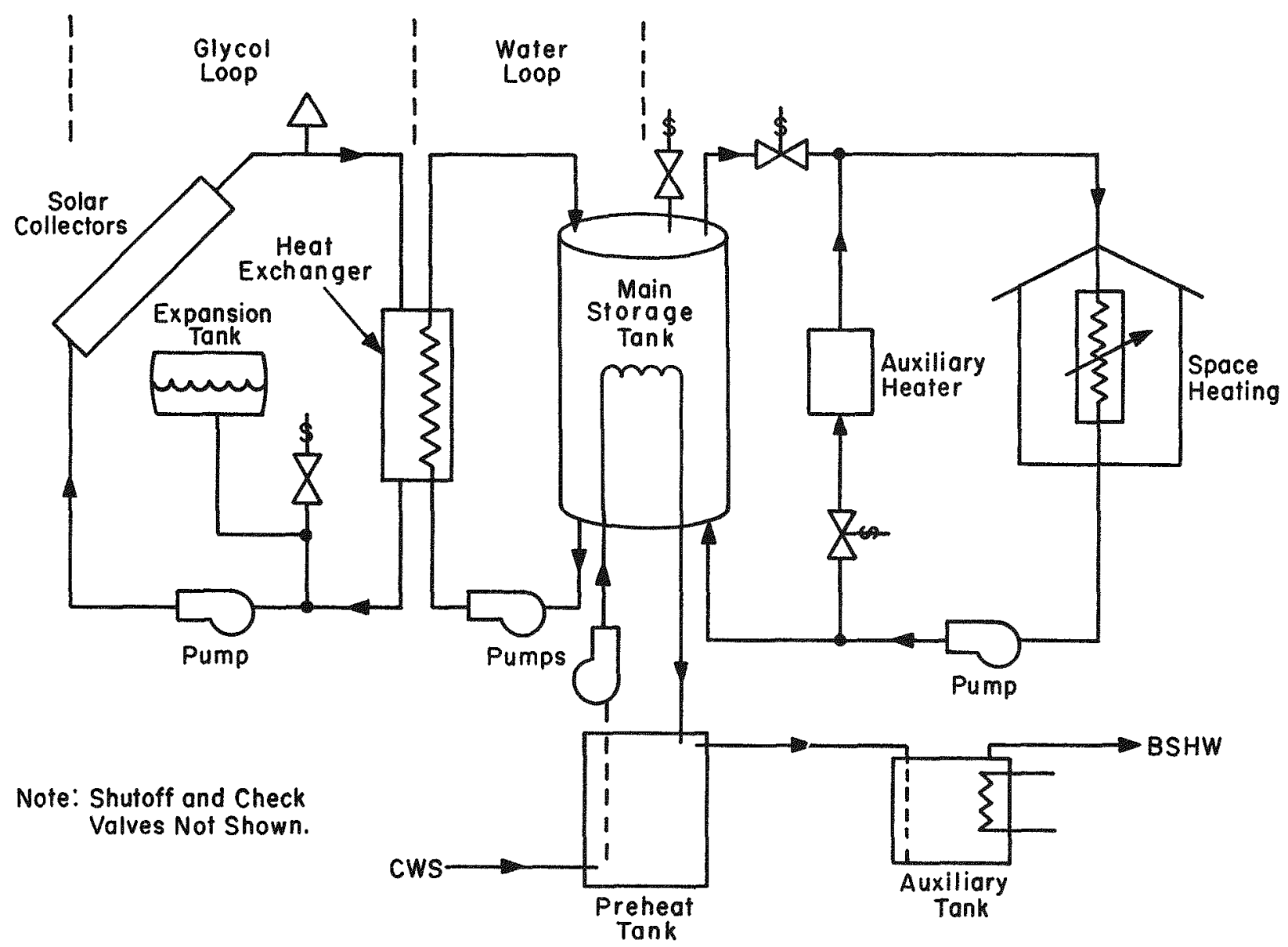

Fig. 5-5. Typical combined space and BSHW configuration 
may be greater because of larger pressure drop through the long tubing. Comparison of alternatives should also include such considerations as accessibility and maintenance, assurance of leakage detection, compliance with codes, overall thermal performance and economic feasibility.

Another option is the immersion of the solar service water preheat tank in the larger main solar storage tank. With no pumps or heat exchangers, heat can be conducted from the main storage through the tank wall into the BSHW supply. Again, questions of accessibility and leak detection must be appraised. Many building codes would not permit this design because of the possibility for contamination of the potable supply by leakage from the main storage tank. Another problem is the near equality of temperature between the two tanks. There appears to be no way to prevent overheating of the service hot water other than by its withdrawal. However, end delivery of over-heated water can be prevented by use of a tempering valve.

One has less flexibility in connecting a BSHW system to an air heating solar system. It involves an air-to-liquid heat exchanger at the collector outlet and a one-tank hot water system. This arrangement will provide BSHW less efficiently than the all-liquid system because of the resistance on the air side of the heat exchangers, but it prevents the possibility of BSHW system contamination.

In winter, heat supplied to service water by the solar unit is not available for space heating, so it is immaterial (if the same auxiliary energy is used for water heating and space heating) to which use the solar heat is applied. In summer, however, nearly all of the service hot water requirements can be supplied by the solar air system. Hot air from the collector, after passing through the service water coil and blower, can be vented outside the building. Air to the collector ean be supplied from the building space itself or from outdoors through an inlet duct and damper. A simple arrangement requires adjustment of a manual damper twice a year to provide hot water in the summer by drawing building air through the collector, through the coil and blower to the discharge vent. Another alternative is a closed loop providing air from collector through the coil and blower, then back to the collector through a bypass duct rather than through the rock bed. Several system configurations and control schemes for BSHW heating are discussed in Ref. 4.

\section{ACTTVE SPACE HEATING SYSTEMS}

A detailed discussion of space heating methods and solar space heating systems is given in Chapter XII of Ref. 2. Additional information is presented in Ref. 1 .

In active systems, either air or a liquid may be used for collection of solar heat, and the same medium may be employed in the supply of heat to the occupied space. However, heat exchange with another fluid may be provided; in this case, the manner of heating the building is not dependent on the nature of the heat collection medium. For example, a solar collector of the liquidheating type may be used in a system in which heat storage is accomplished by use of a hot water tank. The stored hot water may then be used as the heat source for one of the hydronic heating systems (under-the-window radiators, baseboard heating strips, radiant floor or ceiling panels, etc.) Alternatively, by means of a central heat exchanger (a water-to-air coil), warm air may be used as the medium of heat transfer to the rooms. If air is the original solar collection medium, its direct delivery to the rooms in a warm air heating system is practical; storage may be provided by heat transfer to a rock bed and subsequent delivery to air circulated through the heated rocks to the occupied space. Warm air is normally supplied to rooms at temperatures of 120 to $150 \mathrm{~F}$ $\left(49-66^{\circ} \mathrm{C}\right)$, a comparatively moderate requirement for air collectors. For commercial buildings, liquid systems are usually preferred because such buildings are nearly always heated by terminal boxes, fan coil units, heating coils in air ducts, or radiant hot water units, all requiring hot water. Air systems, on the other hand, may be appropriate for small buildings.

The temperature at which heater fluid must be supplied to the rooms in a building is dictated primarily by the amount of heat transfer surface available. With liquid systems, the smaller the heat exchange surface, the higher the temperature must be. Because solar space heating systems using flat plate collectors are seldom operated at delivery temperatures above $150 \mathrm{~F}\left(66^{\circ} \mathrm{C}\right)$, use of solar-heated water is usually impractical in baseboard heating installations, whereas it is suitable for radiant floor or ceiling systems and in finned coil warm air systems. The performance of a solar-heated facility employing flat plate collectors will be considerably better in those systems that do not require the higher temperatures. Assuming availability at acceptable cost, concentrating or evacuated tube collectors can be used when higher temperatures are required.

Fluid temperature requirements are thus seen to be dependent on the characteristics of the specific heating system in the building. These requirements affect, in turn, the operating conditions in the solar heat supply and storage system.

\section{Liquid Heating Systems}

\section{Collector and Storage}

In regions where freezing does not occur, water may be used both as the collection medium and as storage. In a region where freezing seldom occurs, a recirculation system (see BSHW Heating Systems section above) for freeze protection may be used. Fig. 5-6 is a typical flow diagram of a system suitable for use in a nonf reezing or seldom freezing climate, or in a freezing climate. In a freezing climate the drain-down or drain-back systems discussed in the BSHW Heating Systems section above can be used. Provisions for collector drainage include an automatic liquid discharge valve and an air venting valve. Alternatively, an unpressurized, vented collector may be designed to drain into storage whenever the pump (centrifugal) stops. Air then enters the collector through the open vent. On starting, the pump forces air out through the vent. Pumping head and power use may be substantially higher in this design than in a permanently filled system because of unrecovered static head loss.

If a self-draining collector is not used and if the climate is characterized by subfreezing temperatures, a non- 


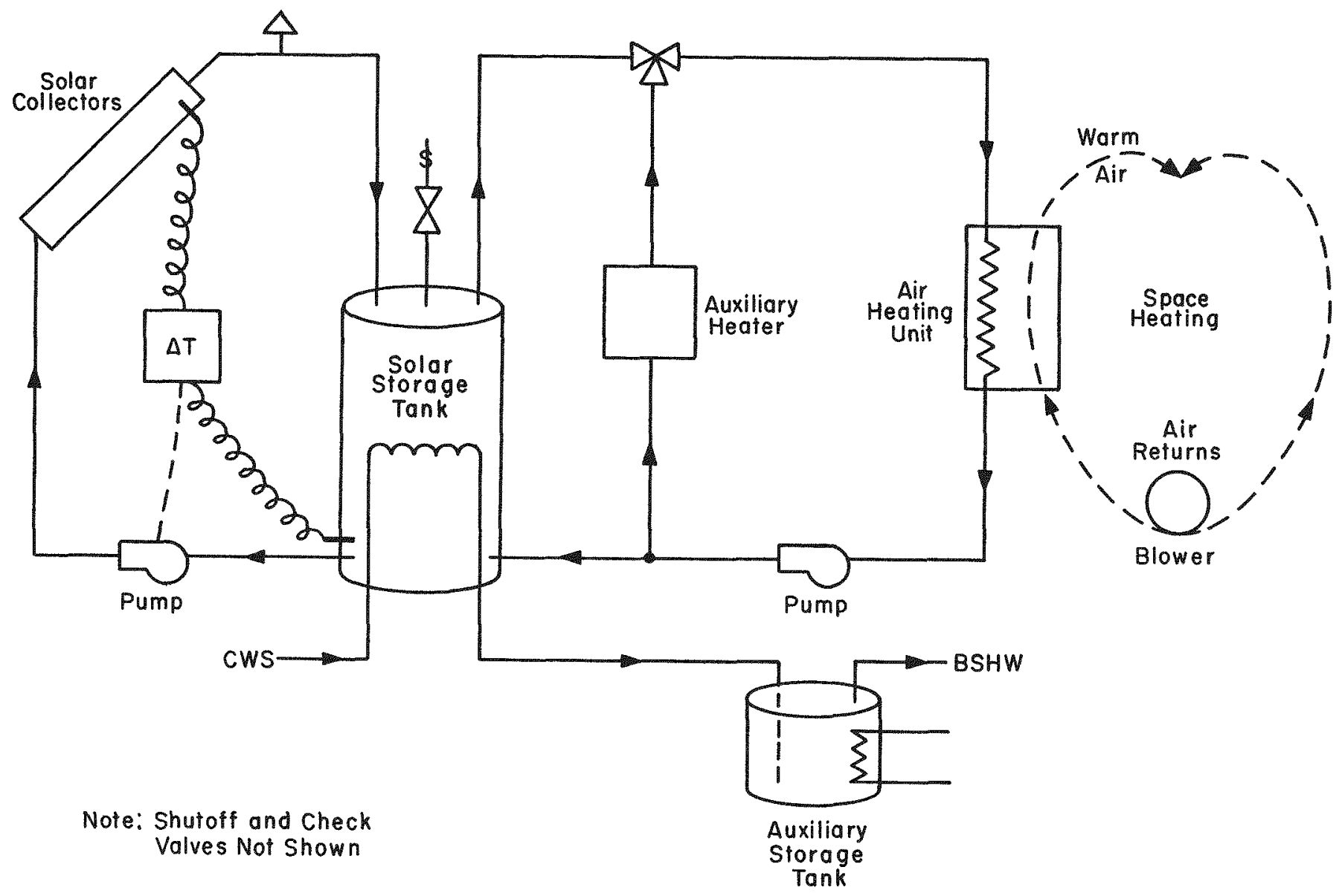

Fig. 5-6. Combined space and BSHW system for nonfreezing climates

freezing liquid should be used in the collector and a heat exchanger provided for transfer of heat from the collector loop to the water storage tank. A design employing such a system is shown in Fig. 5-7. Fluids suitable for use in the collector are common antifreeze solutions of ethylene or propylene glycol in water and certain organic heat transfer liquids, such as silicone oil. When glycol-water solutions are used, corrosion and toxicity must be dealt with.

Protection against boiling can be provided by draining the collectors, by pressurizing the piping system, or by "dumping" excess collected heat through an air-cooled fan coil unit. Nevertheless, under low or no load conditions in a non-pressurized system, the collector or storage fluid may be allowed to boil off through a relief valve. If so, the evaporated fluid must be replaced. In glycol/water systems, the water will boil off first because of its lower boiling point. The water must be replaced to maintain a proper glycol concentration. Repeated boiling can cause deposit build-up on the inner tube surfaces.

The penalties in the use of a heat exchanger are the temperature loss between the two liquids, the cost of the exchanger and the pump circulating water between the exchanger and the storage tank, and the cost of pump operation. These disadvantages can be weighed against questions as to the reliability of a self-draining system and the cost of using a nonfreezing liquid throughout the collector-storage system.

Collector-to-storage heat exchangers are generally of the shell-and-tube type, either single or multiple pass, although in some cases finned-tube exchangers are used. The high flow rates required for efficient heat exchange in single-pass exchangers cause pumping power expense and reduced storage tank stratification because of mixing. However, efficient heat exchange is more important to overall system performance than is establishment of storage tank stratification.

The heat exchanger between the collector and storage is usually sized so that its effectiveness is not less than 0.70 . This design provides an approach temperature difference (the difference between the incoming heating fluid and the outgoing heated fluid) of 5 to $15 \mathrm{~F}\left(3-8^{\circ} \mathrm{C}\right)$ [4]. Exchangers sized to less than a $5 \mathrm{~F}\left(3^{\circ} \mathrm{C}\right)$ approach will improve collector performance only very slightly for a comparatively large increase in exchanger size and cost. Heat exchangers sized for greater than $15 \mathrm{~F}\left(8^{\circ} \mathrm{C}\right)$ approach will reduce collector performance excessively 


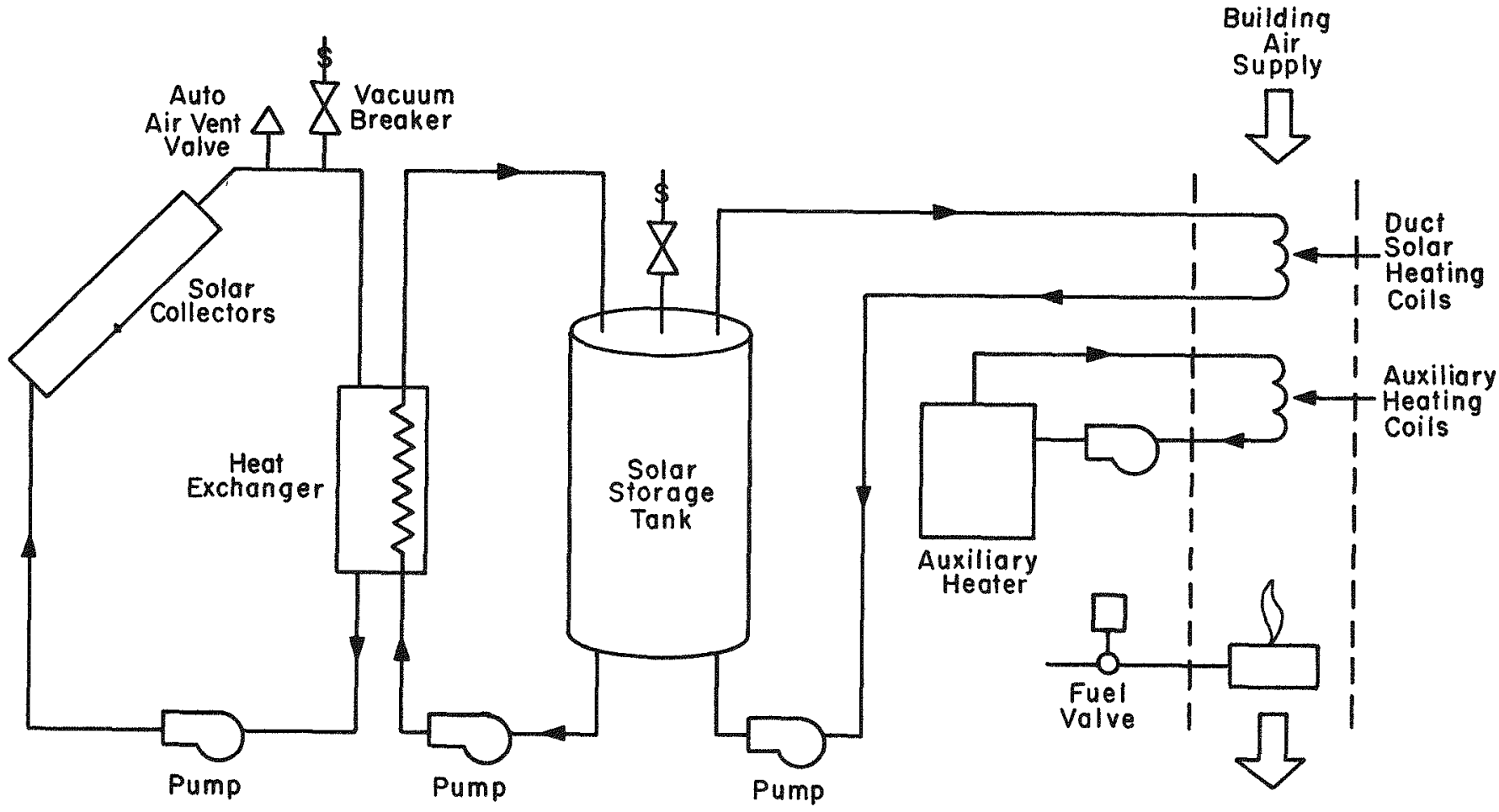

Note: Either Auxiliary Heater or Burner is Used as Auxiliary

Tank, and Shutoff and Check

Valves Not Shown

Fig. 5-7. Indirect space heating system with antifreeze loop and external heat exchanger

relative to the decreased exchanger cost. Approach methods are not commonly used to size collector to storage heat exchangers. Since the collector and storage temperatures are constantly changing during normal operation, a constant approach temperature cannot be achieved. For detailed information on heat exchanger design see Chapter 14, Section D.

If the heat exchanger is immersed in the storage tank, a much greater heat transfer surface area is required because of the lower heat transfer coefficient resulting from the natural convection heat transfer on the storage tank side. Continuous pipe coils or finned tube exchangers may be used; but scaling can result, and pressure loss may be excessive.

Pumps used in the collector-storage loop should be of the centrifugal type. Centrifugal pumps offer advantages over positive displacement types. (See Section $C$ on Active Subsystem Components.)

Valves and air vents must be included in a liquid system. A purpose of the valves is to provide the proper rate and uniformity of flow through the collectors, as well as proper drainage. If valves are used for flow balancing, they should be adjusted after the system is installed to insure that the flow rates are close to those required by the design. Because it is virtually impossible to exclude air from an unpressurized system, air vents are necessary. The air vents and valves should be of the same material as the piping so that corrosion is minimized.

Additional components that are usually included are filters, check valves, expansion tank, isolation valves, and ion getters and/or dielectric couplers, if necessary for corrosion prevention. Methods for selection and placement of these components are discussed in Refs. 1 and 4.

A few solar heating systems have used two or more heat storage tanks, arranged so that different temperatures may be obtained in each. The controller selects the tank to be heated and the tank to be used for heating the building in such a way that it maximizes solar energy collection while maintaining the highest practical heat delivery temperatures. The highest temperature tank is heated when solar energy collectability is high, a cooler tank being heated when solar intensity is low. Water may be supplied to the collector from a cool tank and returned to a warmer tank, with series flow between them. The load is carried by the tank that is at the temperature nearest that required to meet the demand. The added 
cost of a considerably more complex control system and of multiple insulated tanks must be weighed against the performance improvement. It is unlikely that the benefit outweighs the costs in residential-size installations, but there may be economic advantages in large commercial systems.

\section{Space Heating and Auxiliary Use}

It is possible to design a solar space heating system to supply $100 \%$ of the annual energy requirements of a building without an auxiliary system, given sufficient solar collector area and thermal storage capacity. However, it is generally not cost effective to do so; a direct solar system is normally designed to meet from 30 to $70 \%$ of the annual energy requirements for heating. The backup system should be designed to meet $100 \%$ of the building's heating or cooling requirements. It need not be as durable as a conventional system without solar since it operates for fewer hours. Backup systems can include oil or gas-fired furnaces or boilers, electric resistance heat, wood furnaces or stoves, central steam or hot water generated offsite, or a heat pump. The nature of the backup system will affect the system's configuration and controls.

The auxiliary heater employs conventional energy and means for transferring heat from storage to the occupied space. In most solar heating systems involving liquid collection and storage, heat is supplied to the building by warm air circulated through a central blower and a water-to-air exchanger. Alternatively, warm water from the storage tank can be circulated through heat exchange surfaces in the occupied space. Practical design temperatures are about $140 \mathrm{~F}\left(60^{\circ} \mathrm{C}\right)$ for the air exchange system and about $120 \mathrm{~F}\left(49^{\circ} \mathrm{C}\right)$ in panel ("radiant") heating systems. Unlike that in conventional systems, the temperature of the solar-heated water available to the heating system may vary considerably, so the components must be able to provide good heat exchange at the lower supply water temperatures.

For maximum efficiency, the collector should be supplied with the coolest available liquid, whereas the warmest should be supplied to the load. Water from the bottom of the storage tank is therefore supplied to the collector (or to the collector heat exchanger), and heated water from the collector or exchanger is delivered to the top of the tank. Similarly, the load loop is supplied with hot water from the top of the tank, and the return from the load is admitted to the bottom. Under normal conditions of operation, temperature gained through the collector loop is 10 to $20 \mathrm{~F}\left(6-11^{\circ} \mathrm{C}\right)$ near noon on a sunny day, and the load exchange system is designed for approximately the same water temperature decrease. Although storage temperatures could be 10 to $20 \mathrm{~F}\left(6-11^{\circ} \mathrm{C}\right)$ higher at the top than at the bottom if effective baffles are used, stratification is difficult to achieve because of comparatively high pumping rates, turbulence at tank entrance and exit openings, and the variation in temperature rise through the collector during the day. Practical design therefore should normally be based on assumptions of uniform storage tank temperature. Mechanisms to enhance stratification are typically not used in ordinary design practice because increased performance does not pay for the cost of implementation.
Of several locations for the addition of auxiliary heat, maximum advantage is gained by its supply to the load loop rather than to the collector loop or storage unit. Such a design minimizes the use of auxiliary energy by employing it only when necessary and only to augment or replace solar heat being supplied to use. Any other design forces the collector to operate at a higher temperature (and corresponding lower efficiency) than necessary, and also results in some of the heat storage capacity being used for auxiliary heat rather than the solar heat for which it is designed.

Auxiliary heat may be supplied by a conventional hot water boiler in one of two modes. Although not usual, solar-heated water can be pumped through the auxiliary heater on its way to the load (auxiliary in series), as shown in Fig. 5-8a, with a temperature increase provided by auxiliary energy if needed. Water is then returned to the storage tank. In this mode, auxiliary heat is used as a "booster" so that solar-heated water is further heated in the boiler, and the temperature of the water returning to storage from the load may be higher than the storage temperature, thereby adding part of the auxiliary energy to storage. Continued operation would gradually drive the solar storage temperature up, thereby using storage capacity for auxiliary rather than solar and reducing collector efficiency. To avoid this problem, however, a storage bypass loop can be provided.

A preferable arrangement, minimizing auxiliary fuel use, in which the auxiliary is in parallel with the load, uses solar-heated water exclusively whenever the storage temperature exceeds the required heating coil, convector, or radiant panel temperature (Fig. 5-8b). When the storage temperature is too low, circulation of solar-heated water is discontinued and auxiliary heat is used exclusively. Piping and valving must be arranged so that the water bypasses the storage tank when auxiliary heat is in use; an automatic valve and single pump provide heat from the appropriate source. Under severe conditions, comparatively warm water in storage may go unused for a time while the auxiliary supply is meeting a high demand in the building. However, stored solar heat may be called upon later, when the load is less severe or when storage temperature has been increased by addition of solar heat. Solar heat is therefore not wasted.

Where distribution is by air heated by exchange, a better strategy is to use a two-coil arrangement. In this mode, solar-heated water supplies heat to the air in a preheater coil whenever the storage temperature is above a minimum, usually about $80 \mathrm{~F}\left(27^{\circ} \mathrm{C}\right)$. A second coil, immediately downstream of the solar preheater coil, is heated by auxiliary energy, increasing the air temperature to the required level. This method ensures maximum use of solar heat and minimum use of fuel, because even low-temperature solar heat is applied usefully whenever it is available. The cost of a second heating coil and increased blower power is incurred, typically a small expense for improved performance. This method is used in the system shown in Fig. 5-7.

An alternative design of the warm air system in which an auxiliary hot water boiler is used involves only one waterto-air heat exchanger. Solar-heated water is circulated to the coil when it is at a temperature sufficient to meet the heating demand. If not adequate, the solar supply is discontinued, and hot water from the auxiliary boiler is circulated through the coil. 


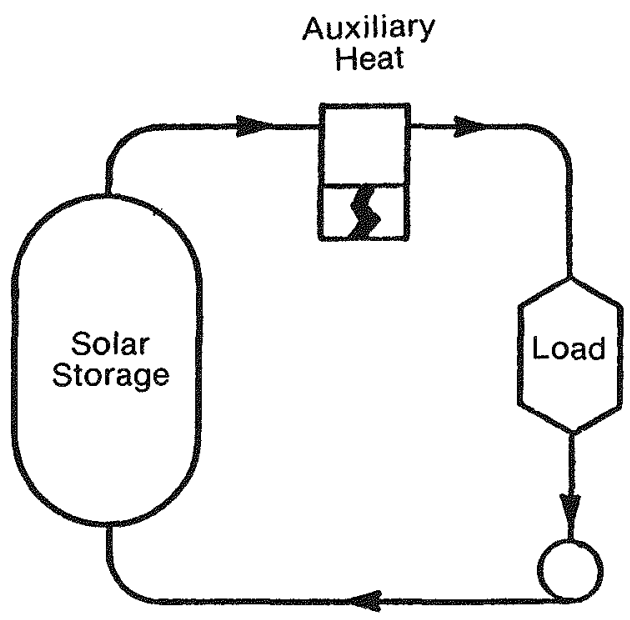

(a)

Auxiliary Heat in Series with Storage to Load

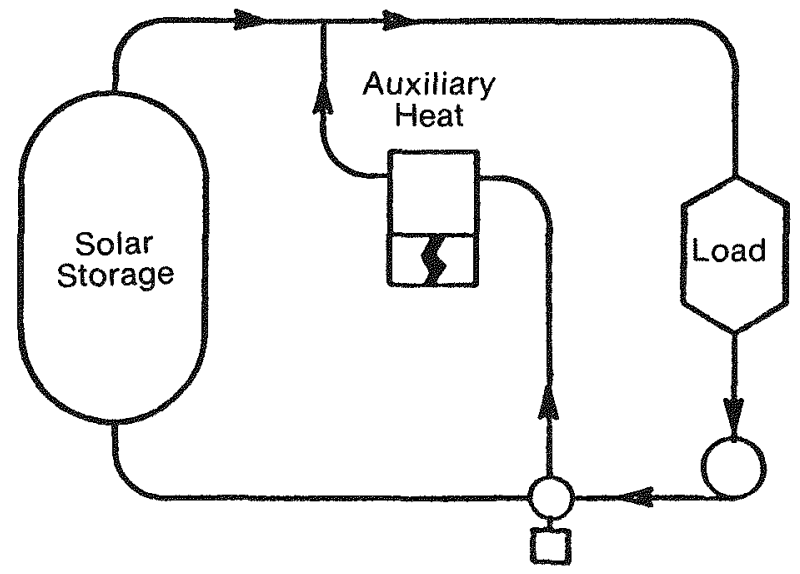

Automatic Valve

(b)

Auxiliary Heat in Parallel with Storage to Load

Fig. 5-8. Auxiliary interfacing with solar storage

A variation on this last strategy uses a conventional warm-air furnace just downstream of the solar preheater coil (Fig. 5-9). The furnace, designed to meet peak heating requirements, boosts the air temperature when necessary or can furnish all the heat if none is available in solar storage. In warm-air systems, this is the most economical means of auxiliary supply.

Another location for the furnace is in a bypass air circuit designed for use exclusively with auxiliary energy. In this arrangement either solar or auxiliary is used, but not both together. The temperature "boosting" advantage is sacrificed for better furnace efficiency, but an additional controlled damper is needed.

\section{System Operation and Control}

The controls for a solar heating system using a liquid collection medium must have functions commensurate with the operating requirements previously outlined. Although numerous operating and control procedures are possible, most solar heating control systems involve sensors, switches, and motors for (a) transferring solarheated liquid from collector to storage, directly or indirectly, whenever storage temperature can be increased by this operation; (b) transferring heated water from storage to the loads whenever heat is required for those uses and when solar-heated water is at a useful temperature; and (c) providing auxiliary energy to the loads whenever solar storage cannot meet the requirements. Other control elements may be required for safety and other purposes, such as prevention of undesirably high temperature and protection from freezing.

A practical method for controlling the solar collection process involves use of a sensor that actuates the collector pump (and associated storage pump if a heat exchanger is used) whenever the temperature of the fluid leaving the collector exceeds the lowest temperature in the storage by a preset amount, say $10 \mathrm{~F}\left(6^{\circ} \mathrm{C}\right)$. Setting of only the collector temperature is not advisable because, under many conditions, the fluid would be cooled rather than heated. The collector sensor should be located on the absorber plate near the fluid exit or close enough to the absorber plate to be influenced by the collector temperature even though the pump is not running.

Several differential thermostats are now commercially available for this service. The on-off control described above is common in residential applications; but in some commercial installations, improved performance is obtained by use of modulating controls. With added control costs, electric energy can be saved by operating the collector pump at reduced flow (by variable speed motors or by modulating valves) when solar input is below normal 


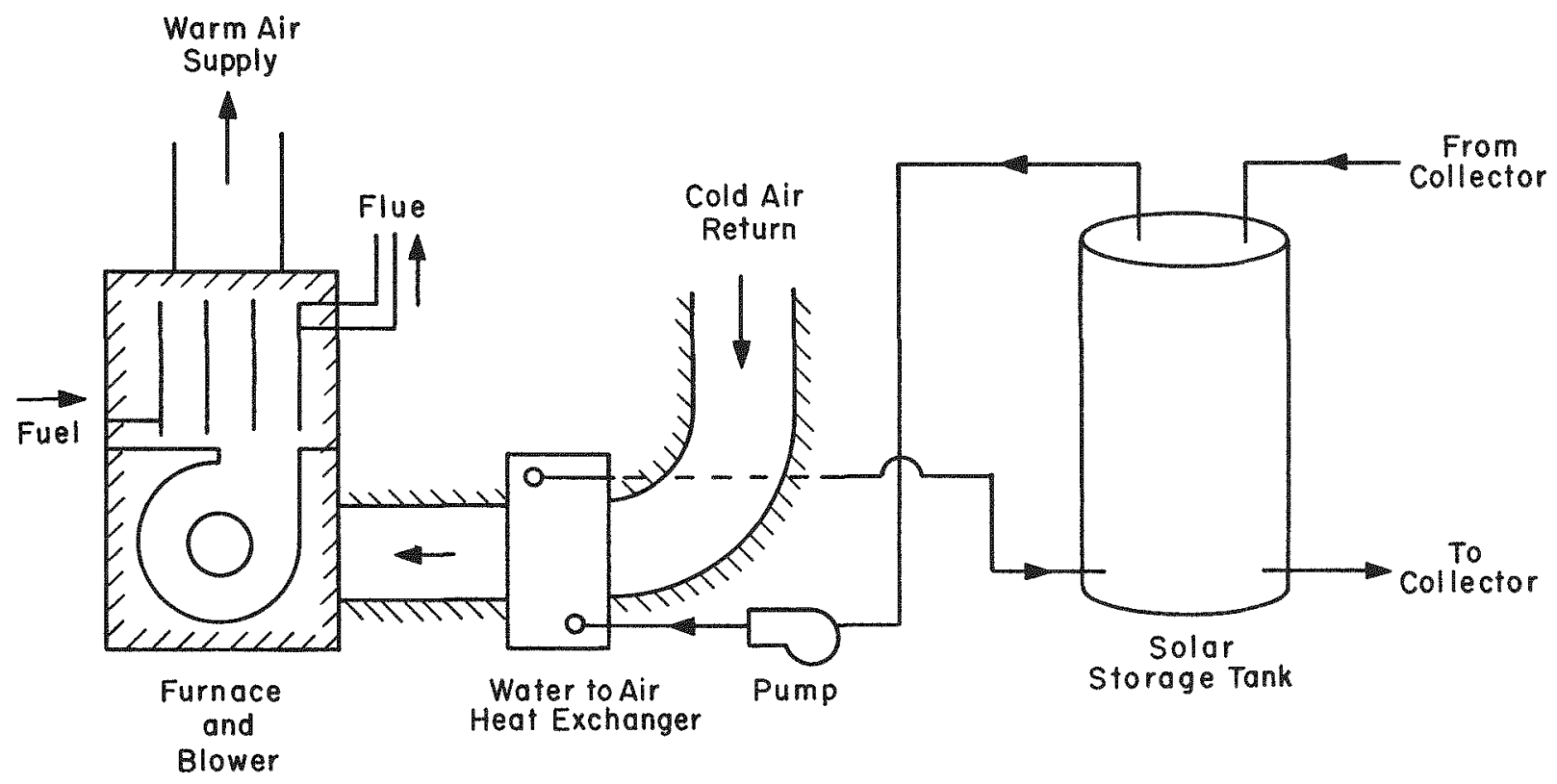

Fig. 5-9. Solar-heated forced air system

levels. Blower power requirements in air solar systems can be substantial; therefore, variable air flow rates can pay off more substantially than in liquid systems. With constant flow rate, the collector-storage thermostat should be set at the lowest temperature difference, typically 5 to $10 \mathrm{~F}\left(3-6^{\circ} \mathrm{C}\right)$, at which the cost of energy required for pumping does not exceed the value of the heat collected. Variable flow can provide a nearly constant temperature rise in the collector fluid and a decrease in pumping energy use. The added cost should be balanced against the value of these benefits.

Probably the simplest method (but not the best for minimizing auxiliary energy use) for controlling heat supply from storage to the load uses a temperature sensorcontroller in the storage tank. When storage temperature is above a fixed set point such as $120 \mathrm{~F}\left(49^{\circ} \mathrm{C}\right)$, solarheated water is supplied to the load by the pump (and automatic valves, if any) on command from the room thermostat. If the storage temperature is below this value, another circuit actuates another pump (or the same pump with repositioning of automatic valves) and auxiliary heat is supplied to the load.

This simple controller fails to provide any solar heat when the storage temperature is somewhat lower than the set point, even though a moderate heating demand could be met by storage. But if the set point is lowered, stored solar heat will fail to meet the demand when ambient temperatures are lowest. An improvement on this control strategy is the resetting of the control point in the storage tank. This could be done manually every few weeks, or an automatic load sensor could be used to improve the solar utilization. If, for example, the ambient temperature sensor measures $40 \mathrm{~F}\left(4^{\circ} \mathrm{C}\right)$ the storage controller set point could be say $110 \mathrm{~F}\left(43^{\circ} \mathrm{C}\right)$, whereas with an ambient temperature of $0 \mathrm{~F}\left(-18^{\circ} \mathrm{C}\right)$, the controller set point would have to be $140 \mathrm{~F}\left(60^{\circ} \mathrm{C}\right)$. Although this control system is an improvement over those above, it fails to use any solar heat unless solar can meet the entire load.

The most practical control strategy for residential heating involves a room thermostat with double set point, thereby eliminating the need for sensing the storage temperature. Whenever the rooms require heat, water from the solar storage tank is pumped to the load, regardless of storage tank temperature. (A low limit near $80 \mathrm{~F}\left(27^{\circ} \mathrm{C}\right)$ may, however, be useful in reducing temporary decreases in room temperature.) If storage is warm enough, room temperature $r$ ises, and heat supply is subsequently discontinued. If, however, the stored water is not hot enough to meet the load, the room temperature will continue to decrease until another contact in the thermostat, set to operate at 1 to $2 \mathrm{~F}\left(0.6-1.1^{\circ} \mathrm{C}\right)$ below the initial or higher temperature contact, turns on the auxiliary system and discontinues operation of the solar circuit. This control system prevents use of auxiliary heat when solar heat can carry the entire load and provides intermittent deliveries of solar heat when the source is not hot enough to meet the full demand.

If the building is heated by air from a solar water-to-air coil and auxiliary heat is supplied to the air either by a hot water boiler and separate water-to-air coil or by a warm air furnace, the most practical control system involves the double-contact thermostat described above. This thermostat first actuates the air blower and hot water pump for solar heat supply. If that source is not adequate, the second thermostat contact actuates the auxiliary heat to supplement (boost) the solar. Solar heat, even when at low temperature, is thus fully utilized.

A typical control system for a liquid space and BSHW system is shown in Fig. 2-9 of Ref. 1 . 


\section{Air Heating Systems}

Although development activity in solar air heating has been much more limited than in liquid systems, the continuity of effort has been sufficient to place solar air heating at a fully comparable development stage.

In addition to the obvious differences between heat collection in liquids and in air, the following technical and operational factors may be noted:

- Solar air systems involve the same medium for solar collection and space heating; solar-heated air can be delivered directly to the building without heat exchange or storage.

- Heat storage can be accomplished in a bed of loose solids, typically $1 / 2$ to $2 \mathrm{in} .(12-51 \mathrm{~mm})$ rocks, which also serves as the heat exchanger.

- Temperature stratification in a rock bed and the return of air to the collector directly from the living space both provide low-temperature $70 \mathrm{~F}\left(21^{\circ} \mathrm{C}\right)$ air to the collector with resulting favorable efficiency.

- The combination of air density, specific heat, and practical flow rates provides a considerably higher temperature rise through the collector, typically 70 to $90 \mathrm{~F}\left(33-50^{\circ} \mathrm{C}\right)$, than in a liquid type.

\section{Typical System Design}

As with liquid heating systems, there are numerous options for integrating the solar collector and rock-bed storage into the complete building heating assembly. A schematic of one of the practical designs is shown in Fig. 5-10. This system employs a solar air collector, rock-bed storage, air-to-water heat exchanger for BSHW supply, a single blower, and a conventional gas-fired furnace and distribution duct system. There are three primary modes of operation, use of which depends on the availability of solar energy and the heating requirement. There are also two modes of auxiliary use for space heating and one for BSHW supply.

Collector to Storage Mode: Storing Solar Heat. Solar collection and delivery of heat to storage are achieved in the collector. The blower is actuated by a differential thermostat, with the hot sensor in the air passage at the collector exit and the cold sensor near the cold end of the storage bed. A temperature difference setting of 10 to $20 \mathrm{~F}\left(6-11^{\circ} \mathrm{C}\right)$ permits operation whenever the value of collected heat exceeds the cost of blower operation. The signal from the controller that actuates the blower also positions dampers so that collector discharge air passes to the hot end of the storage bed, through the rocks, and

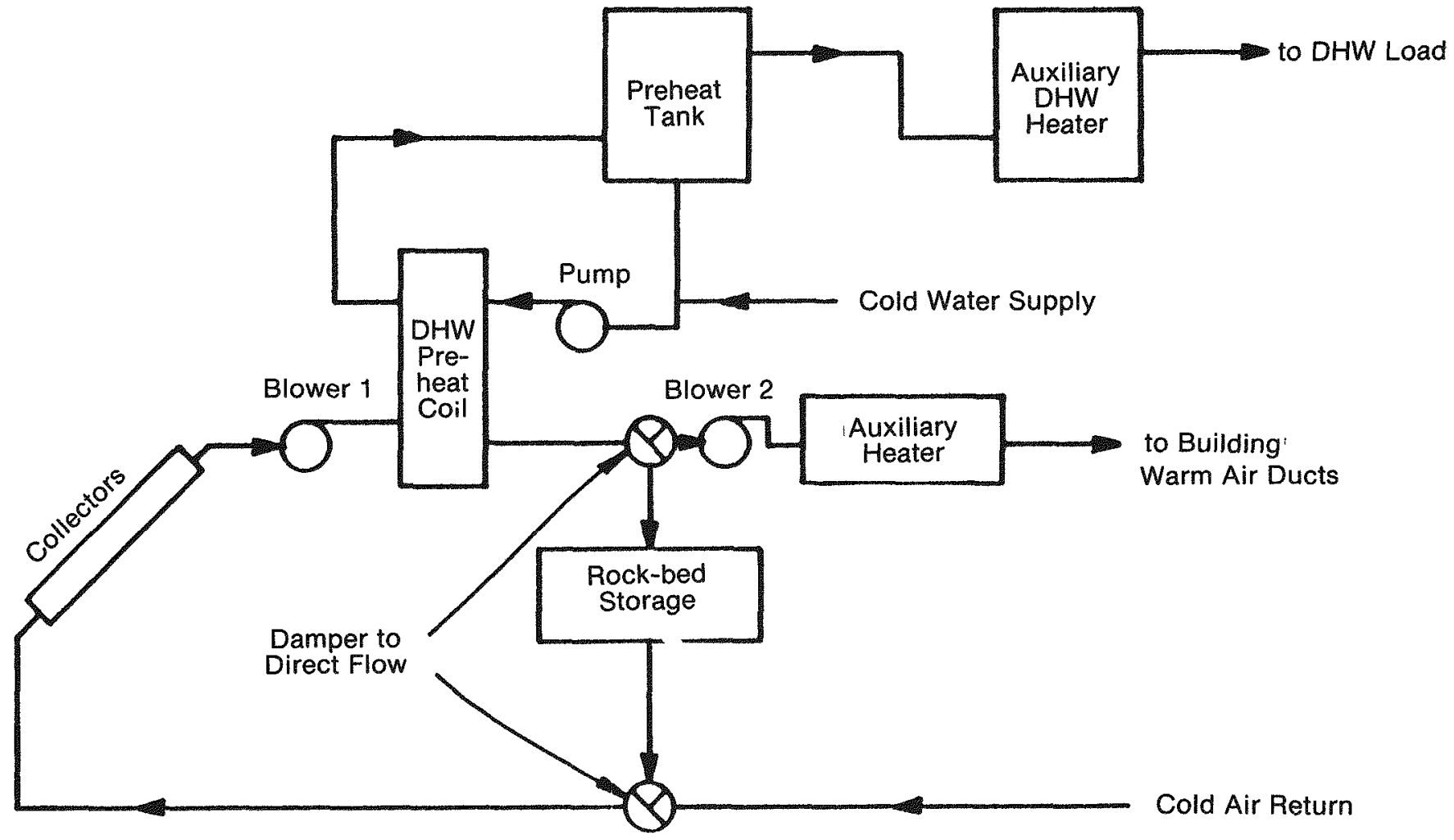

Fig. 5-10. Flow diagram for air type collectors 


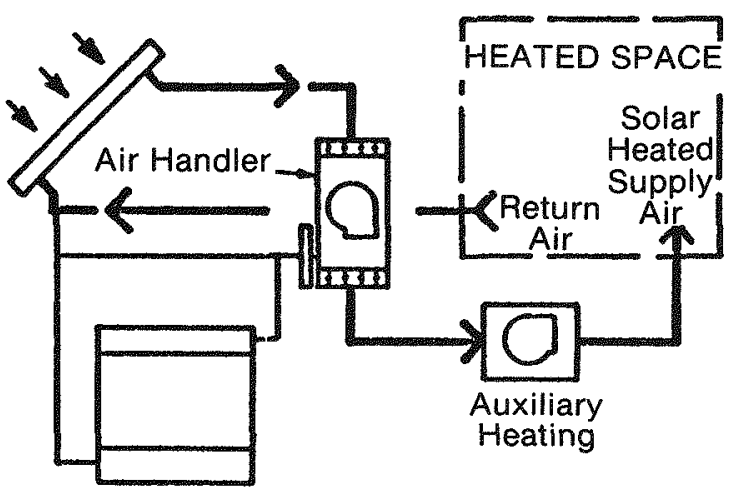

A HEATING from Collectors

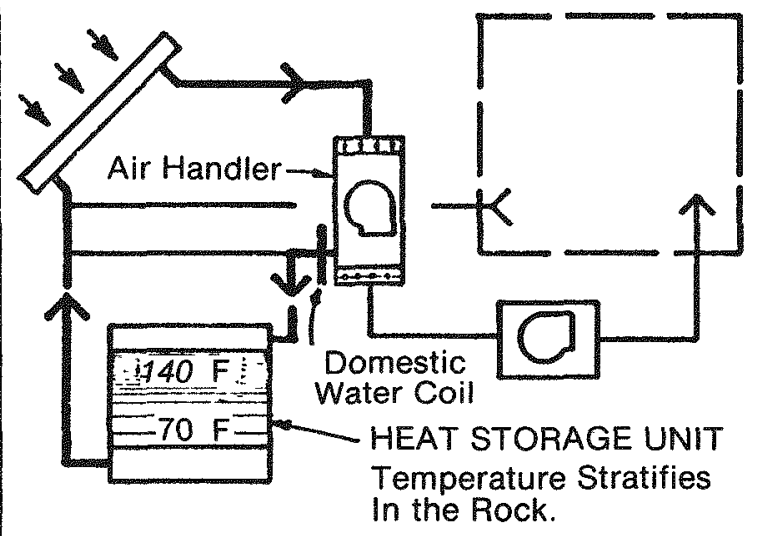

B STORING Heat

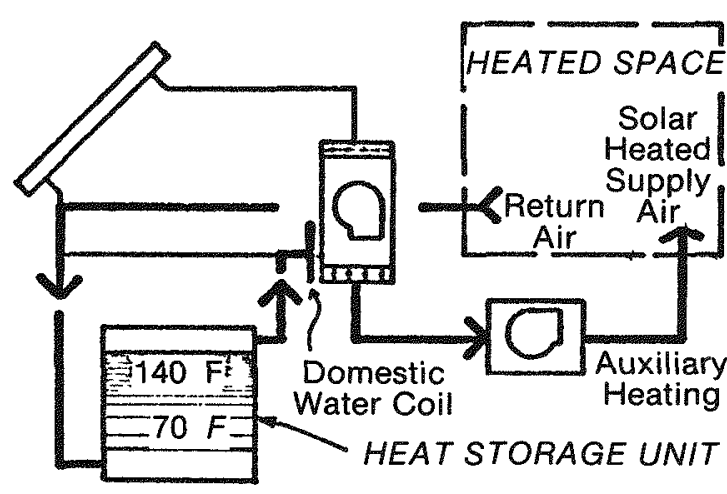

C HEATING from Storage

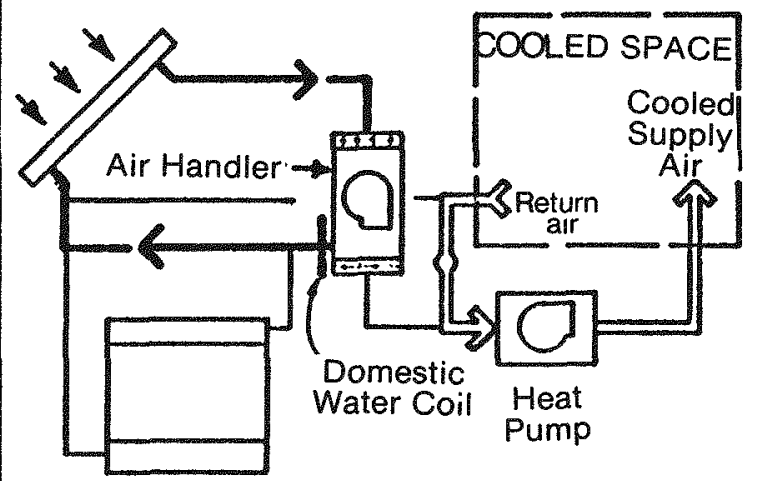

D SUmmer WATER HEATING
Optional AIR CONDITIONING

Fig. 5-11. Operating modes of air type collectors with rock-bed storage

from the cold end back to the collector. Fig. 5-11b illustrates this mode of operation.

At a flow rate of about $2 \mathrm{cfm} / \mathrm{sq} \mathrm{ft}(10 \mathrm{~L} / \mathrm{s}-\mathrm{sq} \mathrm{m})$ of collector, midday air temperature from the collector usually range from 130 to $170 \mathrm{~F}\left(54-77^{\circ} \mathrm{C}\right)$ when air is being, admitted to the collector at $70 \mathrm{~F}\left(21^{\circ} \mathrm{C}\right)$. As sundown approaches, the temperature declines, and when the preset turn-off difference is reached, usually 3 to $4 \mathrm{~F}$ $\left(2^{\circ} \mathrm{C}\right)$, the controller turns off the blower and repositions directional dampers.

The rock bed operates both as heat-exchanger and heatstorage medium. The large heat exchange surface provided by the rocks and the very low thermal conductivity from one rock to another result in rapid transfer of heat from air to rock and a steep temperature-distance profile through the bed in the direction of air flow. Under normal conditions, as the temperature of the air supplied to the rock bed varies throughout the day, nearly all of the actual heat transfer occurs in a zone occupying about $3 \mathrm{ft}(1 \mathrm{~m})$ of bed depth [5]. The useful heat is completely extracted from the air delivered to the bed from the collector when the cold end of storage is essentially at room temperature, 68 to $77 \mathrm{~F}$ $\left(20-25^{\circ} \mathrm{C}\right)$.

During mild weather and on most days in the spring and fall, sufficient heat may be supplied to storage during a single day (or during several days when there has been little use of stored heat) for rock temperatures at the cold end of the bed to be driven upward. The entire rock bed can then be at temperatures substantially above room temperature. Under this condition, air returning to the collector is at a temperature considerably higher than $70 \mathrm{~F}\left(21^{\circ} \mathrm{C}\right)$. Heating in the collector can then drive the outlet air temperature to 200 to $250 \mathrm{~F}\left(93-121^{\circ} \mathrm{C}\right)$ in mild sunny weather. Collector efficiencies are significantly lower at those conditions, and total energy collection is reduced as the bed becomes fully heated. 
Collector to Space Mode: Daytime Space Heating. When heat is needed in the building at the same time the collectors are on, a room thermostat signals the control unit to move dampers and direct the flow of hot air from the collector directly to the zones requiring heat, bypassing storage, as shown in Fig. 5-11a. In this mode, hot air passes from the collector through the blower, through the furnace, and into the warm-air distribution system. Air from the rooms, circulates back to the collector through the conventional cold-air return ducts. Either a motorized damper or a check damper (operated by a slight pressure difference) is in this return duct. When room temperature requirements are satisfied, the thermostat breaks contact, and the storing mode is resumed.

When there is a high heat demand and when the temperature of the air being delivered from the collector is insufficient to meet the demand, room temperature will continue to decline. A lower thermostat set point then turns on the auxiliary heater that increases the temperature of the air in the distribution system. The full design capacity of the furnace will always provide sufficient heat to meet any demand, so the building temperature will be restored to the preset value.

Storage to Space Mode: Space Heating from Storage. The third mode of operation, illustrated in Fig. 5-11c, is called for when heat is required in the building and solar collection is not taking place. Under these conditions, a room thermostat signals the blower to operate and dampers to move so that room air will flow to the cold end of the storage bed, from the hot end of the bed through the blower and the furnace, and to the rooms by the air distribution system. Heat is then supplied to the room air by transfer from the heated rocks. The air leaving the hot end of the bed is only a few degrees below the rock temperature at that point.

If the rock-bed discharge temperature is sufficient, air entering the rooms will provide enough heat to satisfy the thermostat, and the blower will cease operation. If, however, room temperature continues to drop, the auxiliary heat supply will be actuated by the lower thermostat set point, and auxiliary heat will also be supplied. Operation then alternates between stored heat and stored heat plus auxiliary, until stored heat is again sufficient to maintain the load by itself or until direct solar heat is available. Alternatively, the system may run until the upper set point is regained and shutoff occurs.

It can be seen from the above description that the use of solar heat is maximized by (1) collecting solar heat whenever moderate temperature delivery of 80 to $90 \mathrm{~F}$ $\left(27-32^{\circ} \mathrm{C}\right)$ is possible; (2) utilizing even such lowtemperature heat, supplemented if necessary with auxiliary; (3) providing, by means of temperature stratification, high-temperature storage even when the storage unit is only partially heated; (4) bypassing storage when heat is needed during sunny hours; and (5) using auxiliary energy only as a supplement, not as a replacement for solar.

\section{Air Circulation Rates}

The designer of a solar air system determines the air flow rate through the collector. Delivery temperature and, hence, the absorber plate temperature are strongly dependent on air circulation rate; in a specific design, the coefficient of heat transfer between plate and fluid depends on air velocity. But fan power requirement is also a function of air flow, and there are practical limits to air circulation rates in the occupied space of a building. As discussed in Chapter XII of Ref. 2, the efficiency of a solar air heater is dependent not only on volumetric air rate, but also on air velocity. Velocity, in turn, is affected by manifolding and length of travel of air in the collector, as well as on the width of the air passages.

A practical air flow rate is $2 \mathrm{cfm} / \mathrm{sq} \mathrm{ft}(10 \mathrm{~L} / \mathrm{s}-\mathrm{sq} \mathrm{m})$ of collector, and a practical velocity is about $10 \mathrm{ft} / \mathrm{s}$ $(3 \mathrm{~m} / \mathrm{s})$. Efficiency rises and exit temperature falls as air velocity is increased (see Ref. 2, Chap. XII). At velocities lower than $2 \mathrm{cfm} / \mathrm{sq} \mathrm{ft}(10 \mathrm{~L} / \mathrm{s}-\mathrm{sq} \mathrm{m})$, considerably higher temperatures can be realized, but efficiency declines. At an air flow rate of $2 \mathrm{cfm}$ with a $13-\mathrm{ft}(4-\mathrm{m})$ air path through a solar collector having a $1 / 2$-in. (13-mm) air passage, a pressure drop of approximately 0.25 in. of water $(62 \mathrm{~Pa})$ is typical. Power requirements at this point of operation are moderate, less than $1 \mathrm{hp}(746 \mathrm{~W})$ for circulation $1,000 \mathrm{cfm}(472 \mathrm{~L} / \mathrm{s})$ of air through the collector and rock bed.

\section{System Efficieney}

There is an important difference in the factors affecting efficiency in air collection and water collection systems. If an air collector, in combination with a temperature-stratified rock-bed storage, were not normally supplied with $70 \mathrm{~F}\left(21^{\circ} \mathrm{C}\right)$ fluid (rather than a warm fluid from an isothermal storage), air collector efficiency would be substantially lower. Efficiencies in air collector systems, therefore, are strongly dependent on the type of storage used, whereas in liquid systems, storage is not an important factor because collector inlet and outlet temperatures are usually near each other. The higher temperature difference between the absorber plate and the fluid in an air collector is thus compensated for by the lower temperature of fluid supply to the collector. The net result of these effects is an average difference between plate temperature and ambient temperature approximately equal in the two systems, so collection efficiencies are comparable.

\section{Storage Options}

In addition to rock-bed storage for use in a solar air system, storage in water with a heat exchanger, and in phase-change materials has been suggested. System efficiency is reduced, however, with either of .these storage media, because of the lack of temperature stratification. For a detailed discussion on storage systems see Section $B$ below on thermal energy storage for building heating and cooling. 


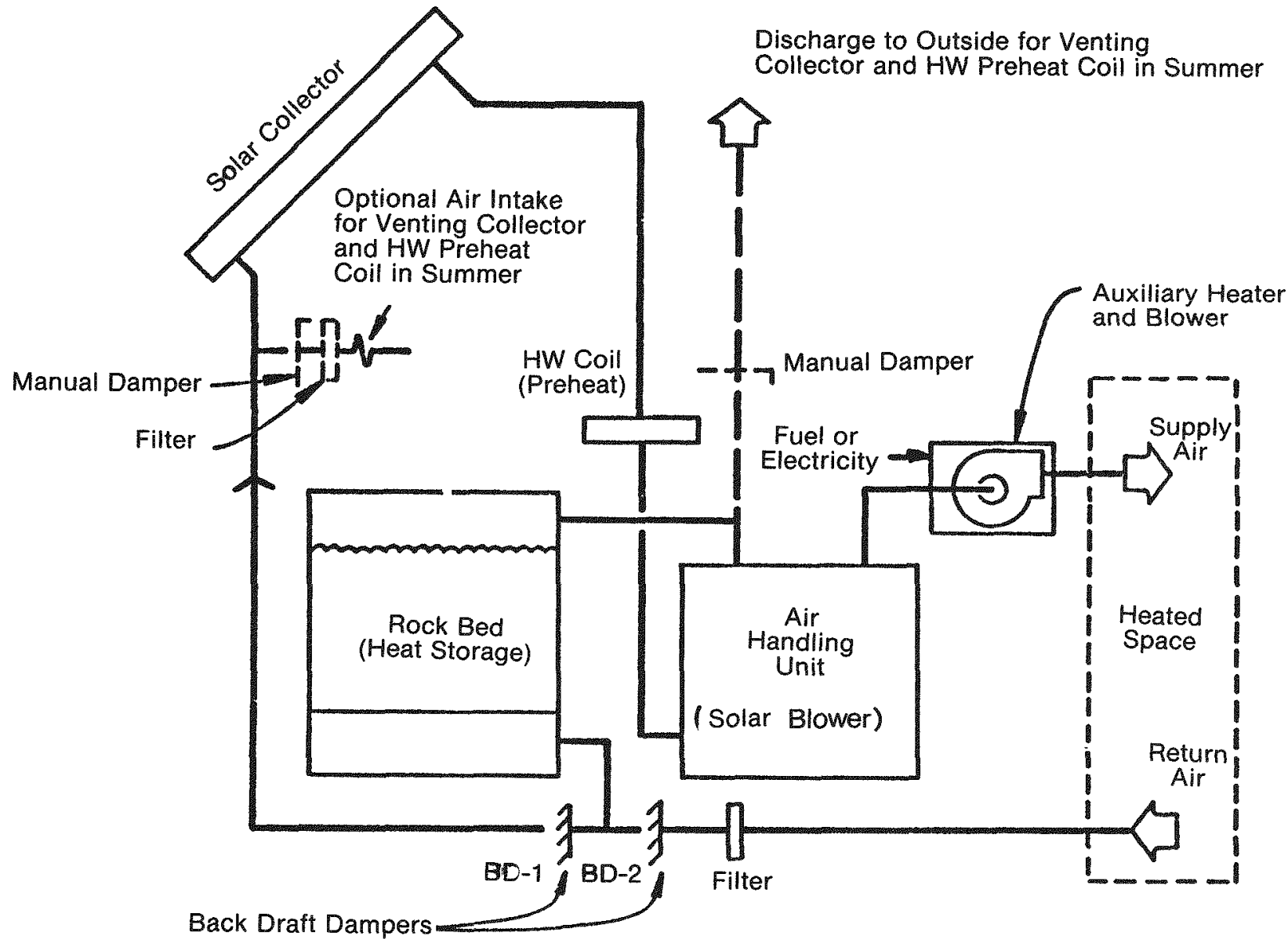

Fig. 5-12. Alternative design for air type collectors

One other type of storage may be comparable to a rock bed in its capability to store heat and produce low recirculation temperature. A bin filled with stacked or dumped plastic spheres, small metal cans, or other small containers of water or other high heat capacity liquid can be employed [6]. Small jars of water have been successfully used in a full-scale experiment at the Los Alamos Scientific Laboratory [7]. Temperature stratification can be achieved within a substantially smaller volume than in a rock bed. Whether the cost of the containers can be competitive with the very low price of rock, even including the larger space rock requires, has yet to be demonstrated. Also, whether water is a reliable material for this use is not certain because of the possibility of temperatures reaching levels at which pressures might rupture the containers.

\section{Air-Handling System Options}

Another system design involves the use of two blowers rather than one. In this system, shown in Fig. 5-12, the solar blower is used only when solar heat is being collected, whereas the load blower supplies hot air to the rooms either from collector or storage. Both blowers operate when the building is being heated from the collector or storage.

The following are advantages of the two-blower design: (1) the control system is somewhat simpler than in the one-blower design; (2) only two control dampers, instead of four, are required; (3) automatic damper operation is simplified; (4) most conventional heating units employed as auxiliary already contain a blower that is used in this two-blower system; and (5) air flow rate through the rooms need not be limited to that desired in the collector. Although the additional motor and blower involve extra cost, the economies achieved by simpler dampers and controls usually result in overall savings.

Substantial savings in installation costs can be made by use of an air-handling module, a factory-made unit that combines a blower, water-heating coil, solar collector damper, solar storage damper, and summer vent damper in a cabinet that can be used along with the conventional furnace. Figs. 5-13 and 5-14 show commercially manufactured air handlers for use in the single-blower and two-blower systems, respectively. 


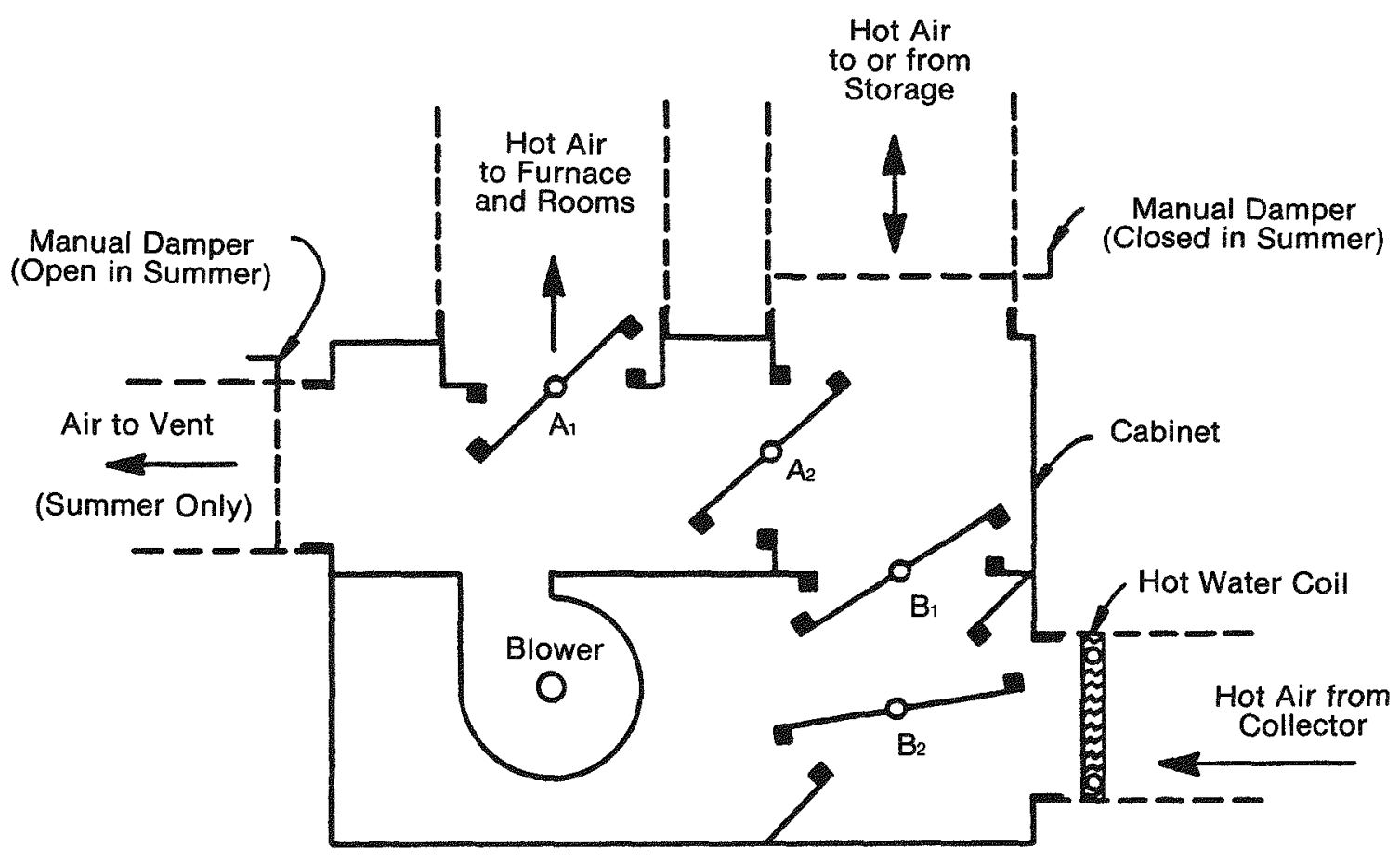

Automatic Dampers $A_{1}$ and $A_{2}$ Actuated by Operator $A$ Automatic Dampers $B_{1}$ and $B_{2}$ Actuated by Operator $B$

\begin{tabular}{lllll} 
& \multicolumn{1}{c}{$\mathrm{A}_{1}$} & $\mathrm{~A}_{2}$ & $\mathrm{~B}_{1}$ & $\mathrm{~B}_{2}$ \\
Heating Rooms from Collector & Open & Closed & Closed & Open \\
Storing Heat from Collector & Closed & Open & Closed & Open \\
Heating Rooms from Storage & Open & Closed & Open & Closed \\
Summer Hot Water Heating & Closed & Open & Closed & Open
\end{tabular}

Fig. 5-13. Air handler control strategy for air type collectors and forced air heating system 


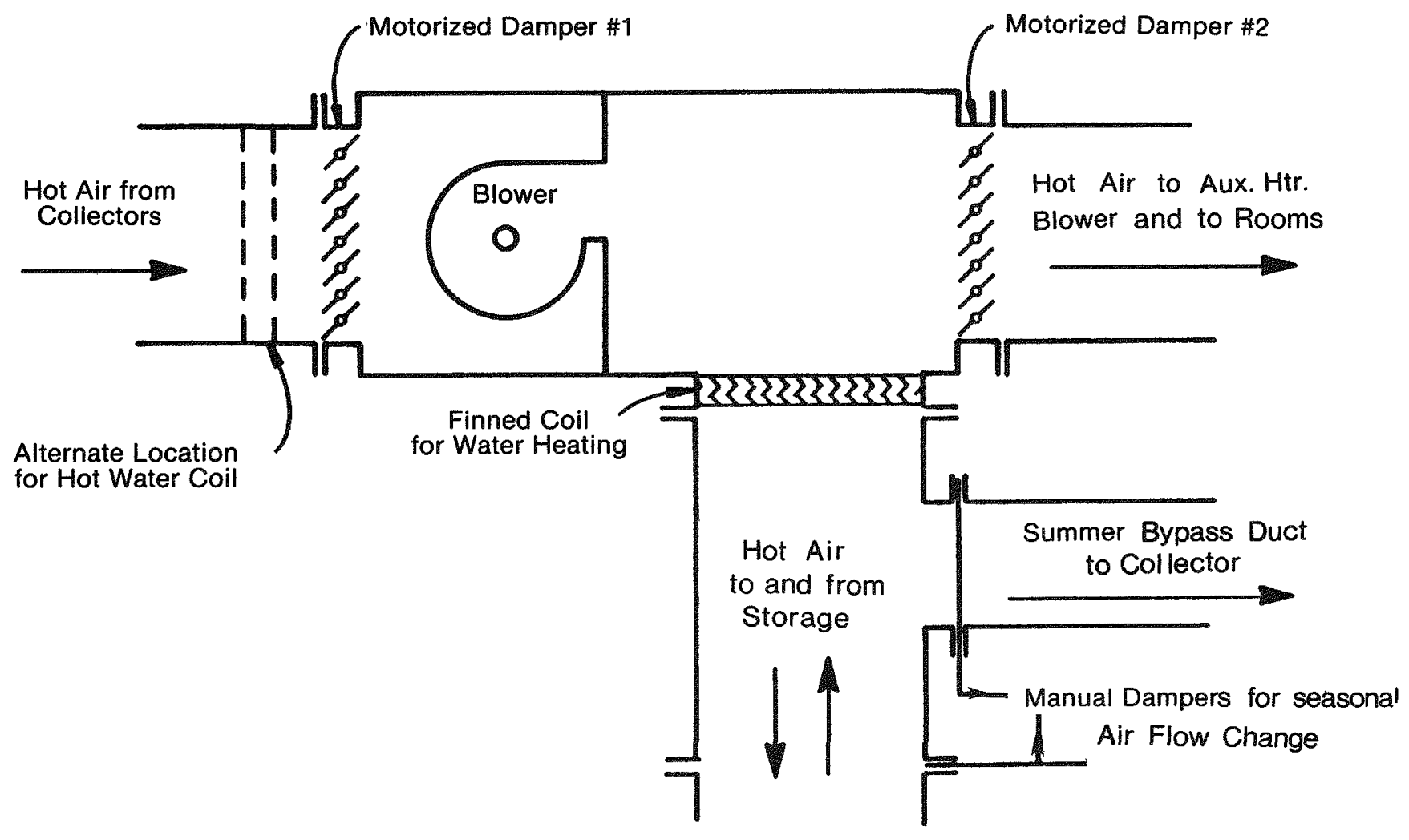

Fig. 5-14. Air space heating system with domestic hot water coil

\section{Commentary on Air and Liguid Systems}

The relative virtues of solar air collection and liquid collection systems have been a subject of considerable attention. There are advantages and disadvantages to each that bear on the types of use, the most suitable geographic locations, and the future potential for widespread application.

Historically, liquid systems have had more attention and use. The conduits for transfer of heated fluid between collector and storage are conveniently small, and the high specific heat of water makes it a compact storage medium. Solar-driven absorption air-conditioning systems require hot water for their energy supply. The disadvantages of the liquid system are the possible freezing of collector water, the corrosive effects of water in the presence of air on many metals of common availability and moderate cost, the damage that can result from accidental leakage from a solar system, and the problems associated with boiling under occasional conditions. These problems and hazards can all be satisfactorily handled, but at the cost disadvantages imposed by heat exchanger, self-draining and-venting collector arrangement, pumping energy increases, corrosion-resistant metals, leakproof fittings, and control requirements.
Air systems have advantages and disadvantages essentially the reverse of those associated with liquid systems. Their drawbacks are the bulkier conduits involved in moving heated fluid between collector and storage, a storage volume about three times that of the water storage required, and the lack of a commercial air conditioner that can be operated with solar-heated air. Advantages of the air system are freedom from hazards associated with corrosion, freezing, boiling, and liquid leakage. Additional advantages are the direct association with warm-air heating systems, and the supply of heat at temperatures usable in those systems.

Although performance data for operating systems are limited, the seasonal output of solar heating systems employing air collectors approximates that of systems in which liquid collectors of comparable transmittance, absorptance, and heat loss coefficient are used. Comparisons of typical performance by use of the f-Chart design method show a slight air system advantage in certain climates [8]. Real world solar air systems consume much more electrical power than similarly sized liquid systems.

If solar cooling equipment is employed, and/or if outdoor freezing temperatures are not encountered, a liquid system using water in the collector and storage is 
probably less costly than a comparable air system. In commercial and industrial applications, system sizes are large so the compactness and the probable future solar air-conditioning capability of water systems are important advantages. Also, the availability of routine maintenance service in most commercial buildings reduces operating problems and costs associated with liquid systems. In freezing climates, however, and particularly in new residential applications, solar air systems avoid the use of expensive measures that liquid systems require. In those circumstances, air collector/ rock-bed installations appear to be more cost effective than the liquid type. An air system also has more appeal for residential space heating where maintenance must be minimized. Commercial and industrial buildings in nearly all climates require air conditioning, so the use of airtype solar heating systems would require, under present conditions, conventional cooling facilities. The potential of solar cooling is not yet clear, so commercial and industrial buildings in freezing climates are candidates for either system type. Buildings heated by warm air are well adapted to the solar air system, whereas those employing hot water heat at temperatures below $140 \mathrm{~F}$ $\left(60^{\circ} \mathrm{C}\right)$ are well suited to solar hot water systems.

In summary, air and liquid systems offer the following advantages and disadvantages:

\section{LIQUID}

Collectors generally more more efficient.

Can be combined with domestic hot water and air cooling systems.

Freeze protection may require antifreeze and heat exchangers. Costlier and reduces efficiency.

Precautions must be taken against corrosion, leakage, and boiling.

Insulated pipes take up nominal space. More convenient to install in existing buildings.

Usually higher installation costs for collectors and storage components.

Has receiver greater attention from solar industry.

\section{SOLAR-HEAT PUMP COMBINATIONS}

A heat pump can reduce auxiliary electricity use in either a liquid or an air system, but it adds complexity and expense. Its advantage over electric resistance heating as a solar supplement is the reduced electricity consumption; a coefficient of performance (COP)* of about 2 to 4 is usually obtained. However, the COP depends strongly on the heat supply temperature, usually the outdoor temperature. The heat pump capacity or the amount of heat that can be delivered versus time is also influenced by the source temperature. A heat pump in combination with an air or liquid solar heating system can efficiently use heat supplied by solar at low temperatures, of ten proving more cost effective in colder climates than direct solar heating [9]. Solar-assisted heat pumps permit the solar contribution to provide 15 to $50 \%$ more of the annual energy requirements than direct solar systems.

Low-temperature heat (from either outside air or water) applied to one side of the heat pump system evaporates the low-pressure refrigerant liquid. The compressor then raises the pressure and temperature of the vapor, which, when next condensed, gives off heat at a higher temperature than at which heat was provided. When this temperature difference is less than 30 to $40 \mathrm{~F}\left(17-22^{\circ} \mathrm{C}\right)$, a good heat pump can provide heat at 160 to $180 \mathrm{~F}$ $\left(71-82^{\circ} \mathrm{C}\right)$ with a COP of 3.5 . The heat pump is also available for power-operated summer cooling by reversing the functions of evaporator coil and condenser coil.

operate at slightly lower temperatures.

Simpler. Space heat can be supplied directly. Can preheat domestic hot water.

Does not adapt easily to air cooling.

No freeze protection required.

Low maintenance requirements. Leaks easily repaired with duct tape; however they may be difficult to find.

Ductwork and rock storage bed bulky.

Lower equipment costs.

More energy required to drive fans than pumps. Noisier in operation.
Because solar collector efficiency improves as collection temperature requirements are reduced, and conventional air-to-air heat pump system performance rises as heat source temperature increases, a combination of these two systems appears to have advantages. During winter, the energy collected at temperatures too low for direct solar heating may be used as a source for the heat pump. Because this energy usually would be at a temperature above that of the ambient outdoor air, the capacity and COP of the heat pump would increase over that for the heat pump alone. At these low temperatures, collector heat losses would decrease and higher collection efficiency would result. Alternatively, less expensive collectors might be used without efficiency sacrifice. However, use of an air-to-air heat pump in parallel with the solar system, shown in Fig. 5-15, with outdoor air rather than solar heat as the heat pump source, may require less electric energy than does the series system.

\section{System Descriptions}

Combined solar-heat pump systems can be designed with:

- Liquid in the solar collector loop, water storage, and a water-to-water heat pump;

- An air-to-air heat pump in conjunction with liquid-toair heat exchangers, and a liquid solar collector loop; or

- Air in the solar collector loop with rock-bed storage and an air-to-air heat pump. 


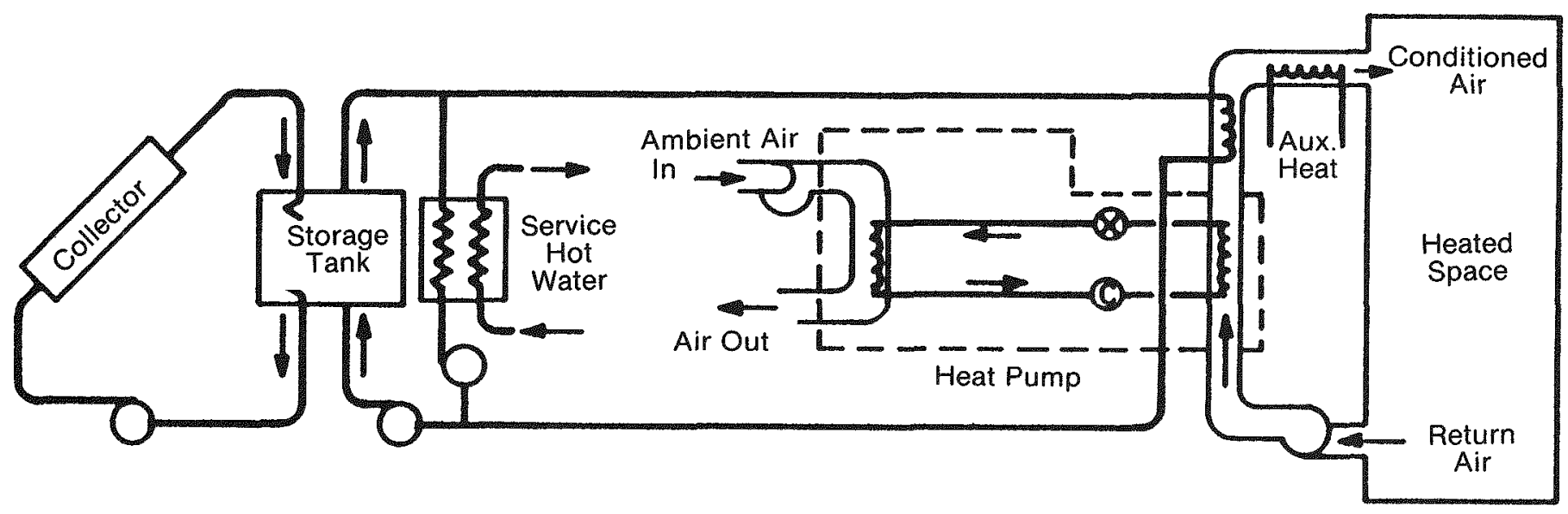

Fig. 5-15. Parallel solar-heat pump system

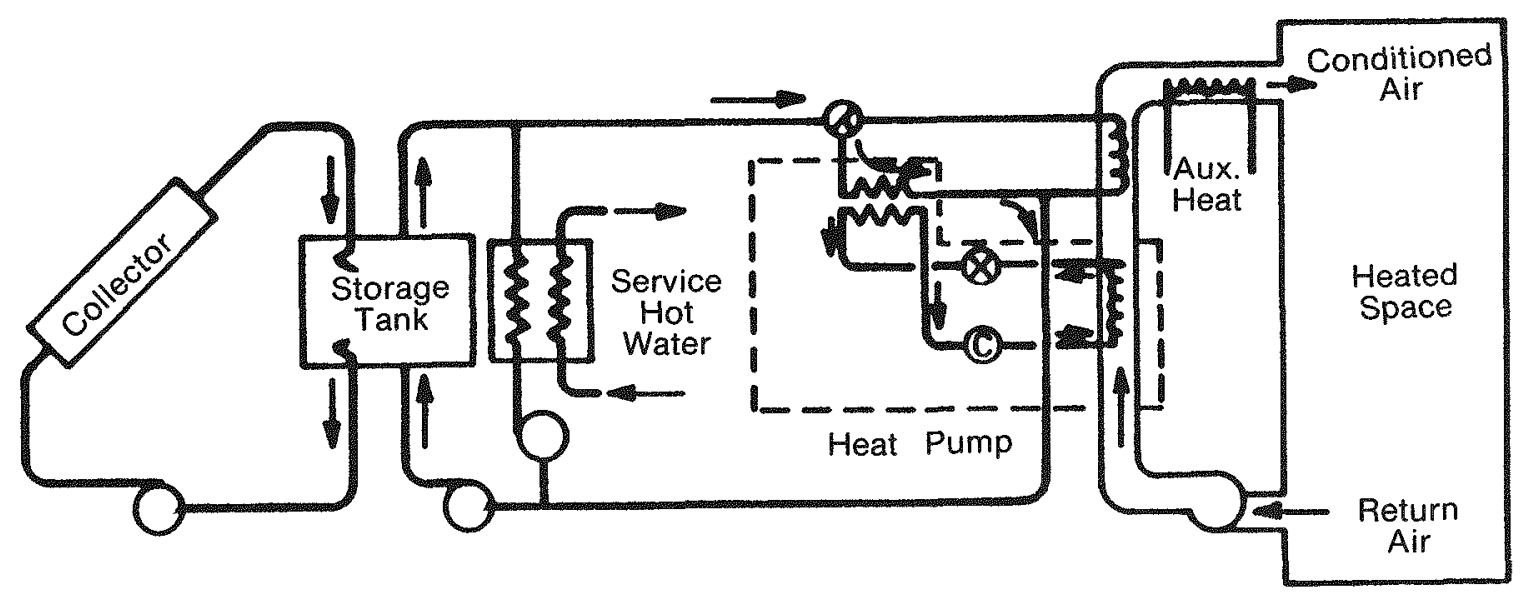

Fig. 5-16. Series solar-heat pump system

There are three basic combined heat pump system types: parallel, series, and dual source [10,11]. The simplest combined system is a conventional solar system with an air-to-air heat pump as an auxiliary energy source. This arrangement is called a parallel system (Fig. 5-15). Direct solar heating is used whenever possible, and the heat pump operates whenever there is insufficient solar energy. Electric resistance heat may be used when neither source can meet the load. This arrangement does not benefit from the use of solar energy as a source for the heat pump.

In the series solar-heat pump system, the heat pump is placed between the solar system and the load so that the heat pump "boosts" the temperature of the solar energy by using solar as the source for the heat pump (Fig. 5-16). The condenser supplies heat to the fluid being circulated to the building. The heat pump uses stored solar energy whenever storage is above a set minimum temperature. Provision is also made for direct solar heating by bypassing the heat pump when the storage temperature is high enough to deliver heat directly to the load. The series system has the advantage of raising both the heat pump COP and the collector efficiency, but it has the disadvantage of depleting storage in mid-winter so that direct solar heating is seldom possible.

In the dual source system, the heat pump has two evaporators, one placed in the storage tank and the other outdoors. This arrangement allows the heat pump to use either the collected solar energy or ambient air as the source depending on which results in a higher COP. Direct heating is possible when the tank is at a high temperature. When the tank temperature drops below the control point, the heating mode is the same as in the series system. When the tank temperature is either below the minimum (usually just above the freezing point of the liquid in the tank) or less than the outdoor air temperature, operation is like that of the parallel 


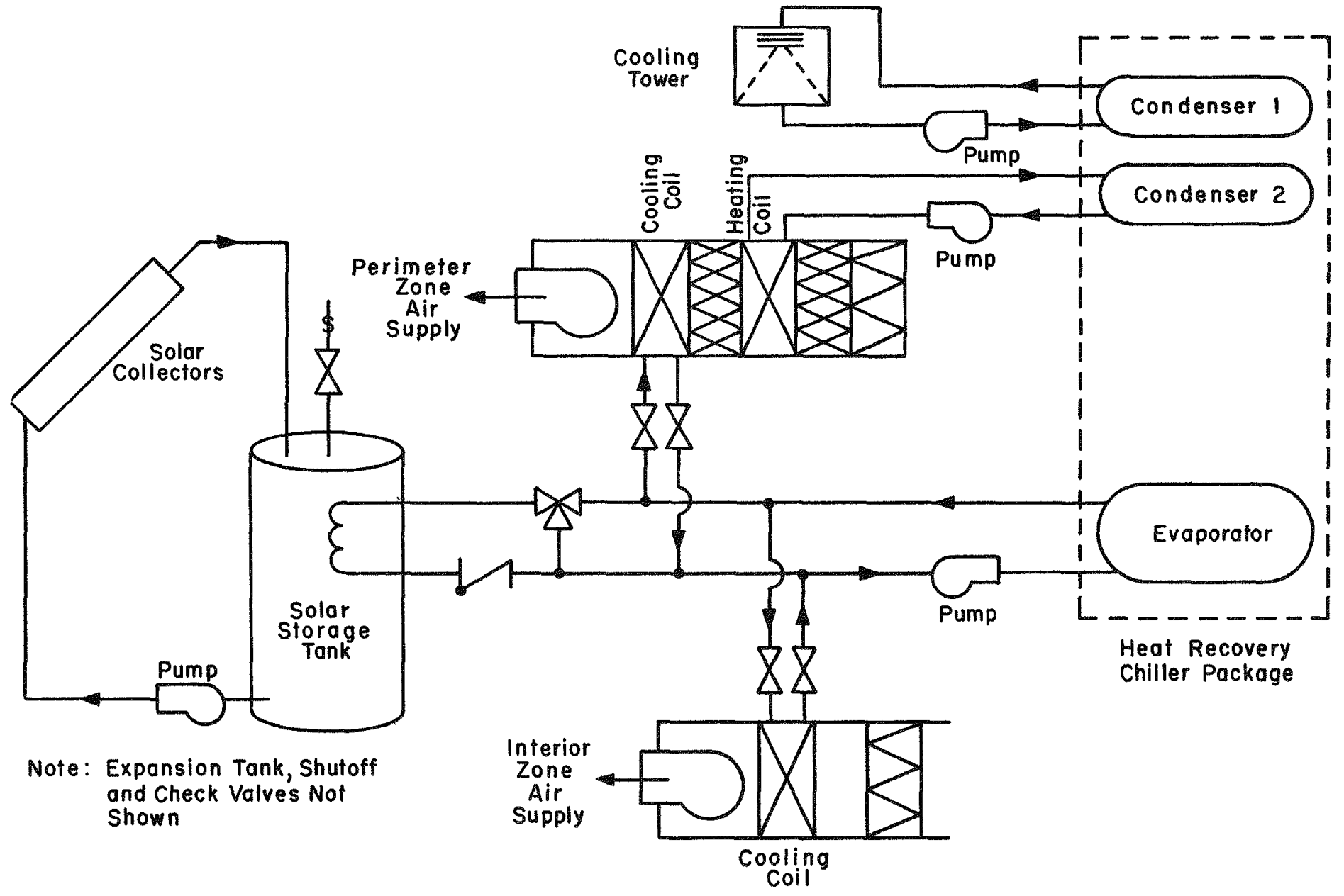

Fig. 5-17. Solar-assisted, double-bundle condenser chiller

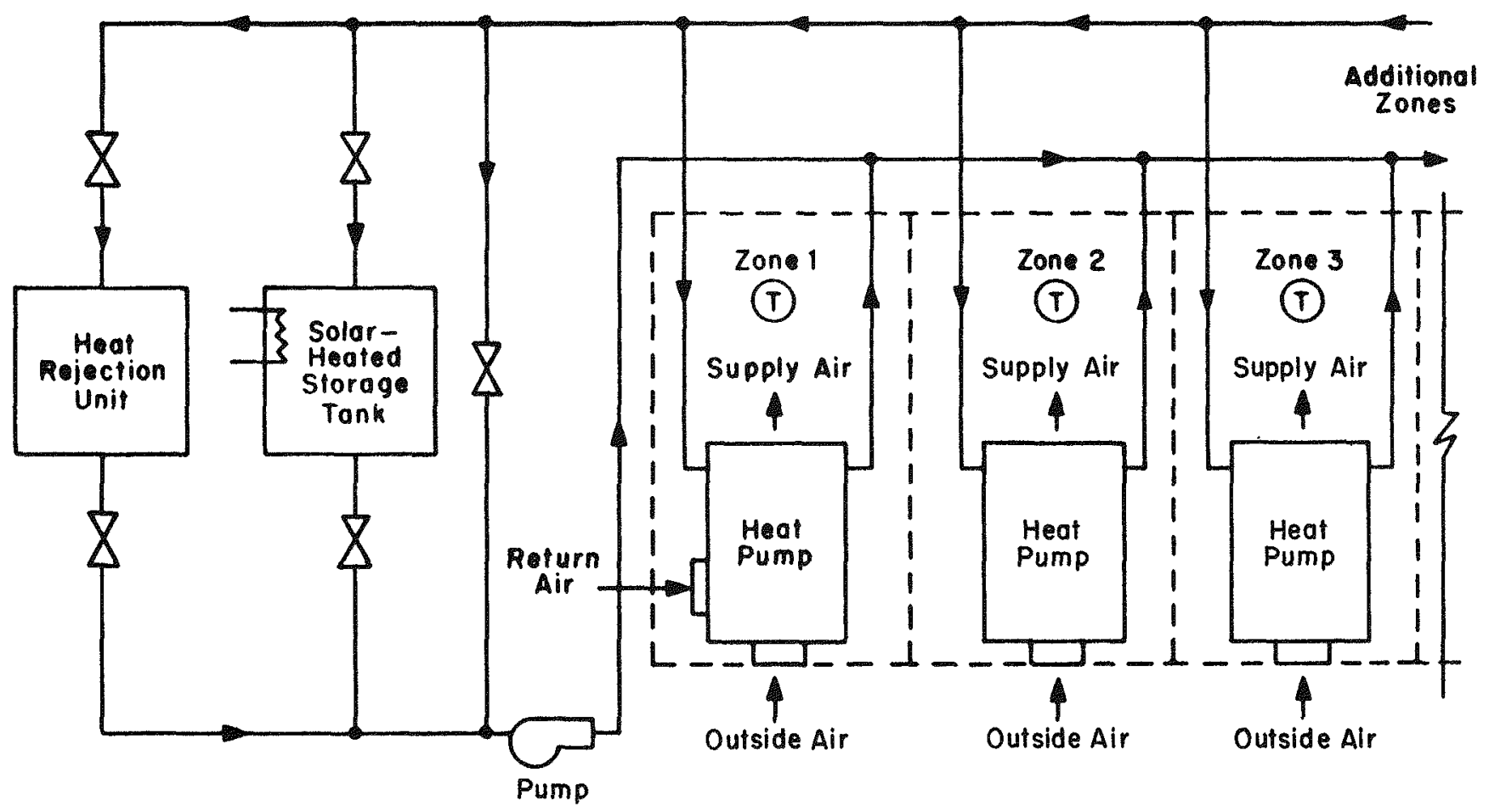

Fig 5-18. Solar unitary hydronic heat pump system 


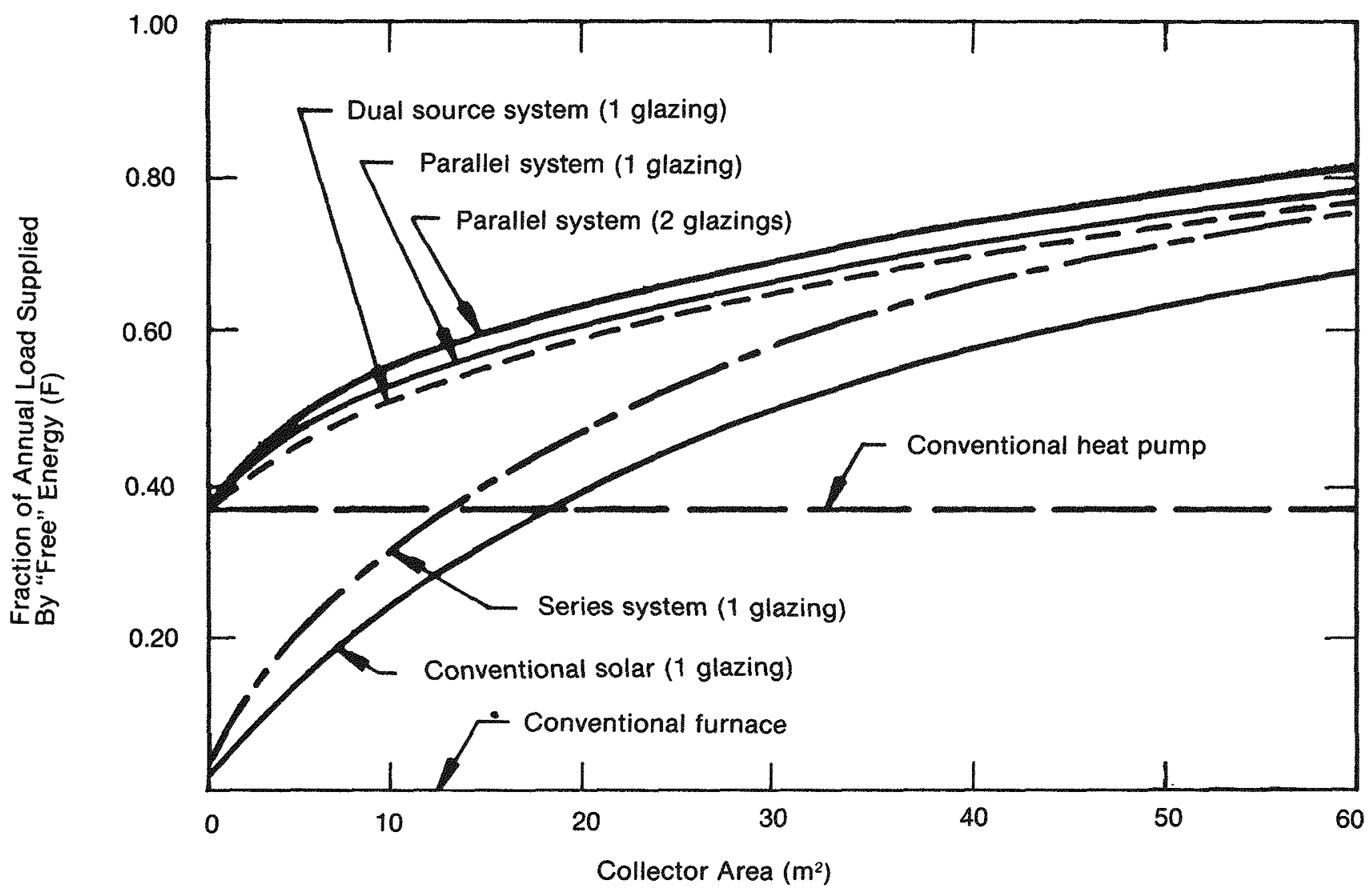

Fig. 5-19. Performance comparisons for solar-heat pump options [9]

system. Thus the dual-source system appears to take advantage of the best features of the parallel and series systems, but the equipment is more expensive and control is more complex.

For summer cooling a solar-assisted double-bundle condenser heat recovery chiller can (Fig. 5-17) can operate as a conventional central station chilled-water air-conditioning system by day, while taking advantage of favorable ambient temperatures and offpeak power rates at night to produce chilled water or ice in the storage system. In the winter, the chiller acts as a heat pump utilizing solar and recovered building heat. This system, suitable for large buildings, has the advantage of a heat pump without the complications associated with the reversing cycle features, and can simultaneously heat and cool different zones in the building.

Air-to-air unitary heat pumps can be used with liquidbased solar systems, in three possible arrangements, as follows:

- When insufficient solar-heated water is available for direct heating, only the air-to-air heat pump operates.

- The solar-heated water [when above $\left.100\left(38^{\circ} \mathrm{C}\right)\right]$ supplies heat directly to the heat pump by a separate coil in the air-source air system.
- A combination of the above. The solar-heated water can be used for heat indirectly or can be used in a separate heating coil in the air-source air stream that supplements the heat pump. This is energy conserving, but not generally cost effective for small installations.

Water-to-air unitary hydronic heat pumps, Fig. 5-18, operating in a closed loop are available from a number of manufacturers. The solar-heated water is used as the heat source in combination with rejected heat from the cooling units. The loop temperature operates between 55 and $75 \mathrm{~F}\left(13-24^{\circ} \mathrm{C}\right)$. Auxiliary heat from boilers or alternative sources are employed as boosters when solar energy is inadequate.

Commercial building applications offer opportunities for the use of combined solar-heat pump combinations. Several of these are described in Ref. 12. A study of an office building in Ottawa, Ontario, Canada, concluded that a solar-assisted heat pump system was the most attractive energy-conserving system [13]. Solar heat may be used as a source in closed-loop (unitary) water-to-air heat pump systems $[12,14]$. In such cases, waste heat from building equipment and occupants can be effectively "boosted" and recovered by a solar-heat pump system. Heat pumps can also be used in conjunction with passive solar systems in commercial buildings [15]. 


\section{System Performance}

Numerous studies have been conducted on the performance of combined solar-heat pump systems [9-18]. At this time, however, no substantial advantage has been proven for one arrangement over another throughout the range of possible variables. In general, a properly designed combination of solar-heat pump systems can be built that require less auxiliary heating energy than either a strict solar or heat pump system. However, the energy saved by each of the separate systems is relatively large, and combining the two does not always produce a synergistic effect on energy savings. An illustration of the potential performance, for one specific set of parameters, is shown in Fig. 5-19. Although under particular design criteria one system approach may appear to be superior to another, many factors involving relative storage capacity, heating degree days, winter design temperatures, and collector efficiency characteristics all play important roles in system performance. For example, series layouts perform better when relatively large amounts of storage are available, 5 to $200 \mathrm{gal} . / \mathrm{sq} \mathrm{ft}(202-8,068 / \mathrm{sq} \mathrm{m})$, since a comparatively low $\left[40\right.$ to $\left.105 \mathrm{~F}\left(5-40^{\circ} \mathrm{C}\right)\right]$ stable source temperature is more desirable than in a direct or parallel configuration where temperatures over $160 \mathrm{~F}\left(70^{\circ} \mathrm{C}\right)$ are sought. This allows a longer storage period and smaller storage temperature fluctuations which, to a limited degree, improve collector performance. The solar designer should always consult the heat pump manufacturer during the design phase so as to allow for the characteristics of the specific heat pump and compensate for its performance traits.

Another consideration involves ambient temperature extremes. Although two distinct regions of the United States may have identical Heating Degree Days, the profile of minimum daily temperature occurrence will considerably alter the values for system benefits in these two regions. As an example, San Francisco, California, and Florence, Alabama, both have 3,000 Heating DD $\left(1667^{\circ} \mathrm{C}\right.$-days) per year [base $65 \mathrm{~F}\left(18^{\circ} \mathrm{C}\right)$ ]. However, San Franeisco has an ASHRAE design temperature of $35 \mathrm{~F}$ $\left(2^{\circ} \mathrm{C}\right)$ whereas Florence has a value of $13 \mathrm{~F}\left(-11^{\circ} \mathrm{C}\right)$. These numbers taken together will usually dictate that San Francisco has a large number of fairly cool days [45 to $55 \mathrm{~F}\left(7-13^{\circ} \mathrm{C}\right)$ and that Florence, Alabama, would experience a generally warmer climate with a few very cold days. Thus, a stand-alone heat pump or parallel arrangement would appear to be better suited to San Francisco since balance point temperatures (the condition under which the heat pump is only as efficient as an electric resistance unit, i.e., $\mathrm{COP}=1$ ) would rarely be encountered, Conversely, a solar-heat pump series system would deserve investigation in Alabama since much of the time a conventional heat pump (stand-alone) or parallel system would need to activate its energy consuming defrosting cycle and/or electric backup unit in order to match demand.

\section{Heat Pump Types}

\section{Variable-Capacity Heat Pumps}

At present, the heat pump most widely available has the disadvantage of a COP curve that rises with the evaporator temperature, peaks, then falls off, thus restricting the temperature range over which solar heat can be efficiently utilized. Small variable-capacity heat pumps with variable-speed compressors are presently being developed in which the capacity varies with the load; these have the advantage of higher COPs over a wider load range. Variable-capacity heat pumps for larger systems using screw machines or centrifugal compressors are also commereially available.

\section{Fuel-Driven Heat Pumps}

A heat pump's compressor can be powered electrically or by a fuel-powered engine. The gas- and oil-fired heat pumps tend to require greater maintenance than electric units.

\section{Thermoelectric Heat Pumps}

Heat pumps can be based on thermodynamic cycles other than the vapor compression cycle. One such cycle uses an electric current flowing through a junction of two different materials. (Semiconductor alloys are currently the most promising materials.) Heating or cooling occurs at the junction, depending on the direction of the electric current. Advantages of thermoelectric heat pumps include no moving parts, no refrigerants, ease of operation control, a wider temperature range, and compactness. At present, however, the high cost of thermoelectric heat pumps limits production to only small units.

The selection of proper equipment to accomplish an appropriate task is also an imperative process in system design. Medium- or high-temperature, concentrating collectors should be restricted to direct space or parallel applications where the efficiencies at the higher temperatures are better and the higher quality heat can be optimally utilized.

A final consideration on the subject of solar-heat pump interfacing applies to specific building load character istics. Large commercial buildings possess very different thermal demands than does a residential application. An appreciation of the daily load profiles can result in proper system choices which account for large daytime loads in a properly managed commercial building, for example. In this case, short-term storage (1 day) may not be as important as in a situation where nighttime loads are a prime consideration. In conclusion, as with any proper design the Architect-Engineer must optimize his design for the specific application.

\section{SOLAR COOLNG}

Solar energy may be used to operate cooling (space conditioning) equipment by supplying collected solar thermal energy to energize any of several types of heatactivated cycles. The three cycles that have received the greatest study are the absorption, the Rankine, and the adsorption (desiccant) cycles (Chap. XIII of Ref, 2). Each of these will be discussed in this section.

Solar cooling is particularly applicable to commercial buildings that have significant cooling loads during much of the year. In combination with a solar heating system, a solar cooling system can make efficient use of solar collectors that would otherwise be idle during the cooling 
season. Although attractive from this standpoint, solar cooling is in an earlier stage of development than is solar heating, and we have less experience with solar cooling. Although the predicted thermodynamic efficiency of solar absorption cooling is very nearly equivalent to that of an electrically driven, vapor-compression system, economically solar absorption cooling is marginal [19]. If a solar absorption cooling system alone does not replace a large part of the cooling annual energy requirements, it may not be cost effective. If the cooling system is designed with limited solar absorption cooling and with limited electric backup cooling, however, the system may be cost effective especially if it also supplies space heating and BSHW. Nevertheless, solar cooling technology is advancing, and this type of application should be considered for some buildings. Detailed information on solar cooling systems may be found in Refs. $2,20,21$, and 22. An extensive solar cooling bibliography is given in Ref. 22.

\section{Absorption Cooling Systems}

Lithium bromide-water vapor absorption cooling units, originally designed for gas, steam, or hot water firing, have been developed to operate at generator temperatures as low as $170 \mathrm{~F}\left(77^{\circ} \mathrm{C}\right)$ with a typical COP (heat removed from cooled space/energy supplied from external sources) of 0.5 to 0.6 [23] for single-effect machines and 1.1 to 1.2 for double-effect machines. Water cooling is essential because of the crystallization problem of lithium bromide. Flat plate collectors and cooling towers are usually employed. These units are commercially available in limited sizes and have been used successfully in both residential and commercial installations. Three-ton residential units, optimized for solar applications, are in use in several demonstration projects [23]. Manufacturers of large-capacity absorption chillers are beginning to examine their potential use in solar-powered systems. These units can be used without any hardware modification or only slight modification in generator heat transfer surface. Absorption cooling is recommended for cooling with solar energy because it has been demonstrated successfully and is currently the least expensive method when used in conjunction with solar energy applications.

The ammonia-water absorption cycle also has been demonstrated successfully [20] using concentrating solar collectors. Generator input temperature of 250 to $350 \mathrm{~F}$ $\left(121-177^{\circ} \mathrm{C}\right)$ is required and air cooling is possible. A comparative analytical study of absorption airconditioning systems concluded that lithium bromidewater systems yield significantly better performance than do ammonia-water systems [24]. Typical COP values are 0.4 to 0.5 [23] but such units are not yet commercially available.

Fig. 5-20 shows a combined solar heating and cooling system that includes an absorption chiller. In such combined systems, multiple storage tank capability can be provided. Two or three tanks can be used; one or two for hot water, and one for chilled water.

Performance degradation of ten results when the cooling load is low and on-off cycling of the absorption unit occurs. The use of cold-side storage can significantly reduce unit cycling and improve the system COP by allowing the coolness produced by continuous running to be stored and used later [25]. Also, cold-side storage allows the cooling eapacity to be reduced by sizing it to meet the daily, rather than hourly, peak cooling load.

Absorption chillers can be operated at above half of nominal capacity with little sacrifice in COP. Absorption units from 3 to 1,000 tons are available and can operate satisfactorily at generator temperatures down to $165 \mathrm{~F}$ $\left(74^{\circ} \mathrm{C}\right)$, if cooling water at less than $85 \mathrm{~F}\left(29^{\circ} \mathrm{C}\right)$ is supplied by a cooling tower and the unit is operated at chiller water temperatures of 40 to $50 \mathrm{~F}\left(4-10^{\circ} \mathrm{C}\right)$. However, at or near this low generator temperature, the unit is greatly derated. The steady-state COP, as a function of the solar thermal source temperature, for both single- and double-effect lithium bromide-water -machines, is shown in Fig. 5-21 for typical cooling water temperatures and a $44 \mathrm{~F}\left(7^{\circ} \mathrm{C}\right)$ chilled water temperature.

Research is underway to increase the COP of absorption machines [23]. This research is aimed at double-effect and ammonia-water units, advanced and hybrid cycles, new working fluids, and absorption heat pumps. System studies are focusing on system configuration, subsystem options, control and storage strategies, and parasitic power requirements.

\section{Rankine Cooling Systems}

Solar-powered Rankine cycle turbine engines have been used to drive conventional vapor compression cooling systems. These engines use a fluorocarbon refrigerant, such as Freorl, as the working fluid because of its ease of evaporation at the temperatures available in advanced flat plate $200 \mathrm{~F}\left(93^{\circ} \mathrm{C}\right)$ or medium concentration $320 \mathrm{~F}$ $\left(160^{\circ} \mathrm{C}\right)$ collectors. For a condensing temperature of $90 \mathrm{~F}$ $\left(32^{\circ} \mathrm{C}\right)$, cycle efficiencies of about $10 \%$ are attainable at a COP of $0.3-0.7$. A schematic of a solar Rankine cooling cycle is shown in Fig. 5-22 [26]. The conversion of thermal energy into mechanical work is accomplished by first pumping the liquid working fluid into a boiler where it is evaporated by the addition of heat from solar-heated water. This vapor is expanded through an expander, usually of the turbine or rotary vane type, which lowers the temperature and pressure of the vapor and drives a shaft. The vapor then flows to a condenser where it returns to the liquid phase in rejecting heat to the cooling tower or ambient air. This liquid is pumped to the boiler and the cycle is repeated [26].

The other component of the Rankine unit shown in Fig. 5-22 is a standard vapor compression refrigeration machine. Its energy efficiency ratio (thermal energy removed from the building/shaft energy supplied to machine) averages about 5 for water-cooled machines and 3 for air-cooled machines [26]. Thus the cycle COP is as shown in Fig. 5-21.

Although these systems have been demonstrated successfully $[20,22,26]$, they are experimental and prohibitively expensive, so they are not yet considered practical. Several solar Rankine cooling field tests are in progress; system capacities range from 3 to 77 tons [22, $26]$. 


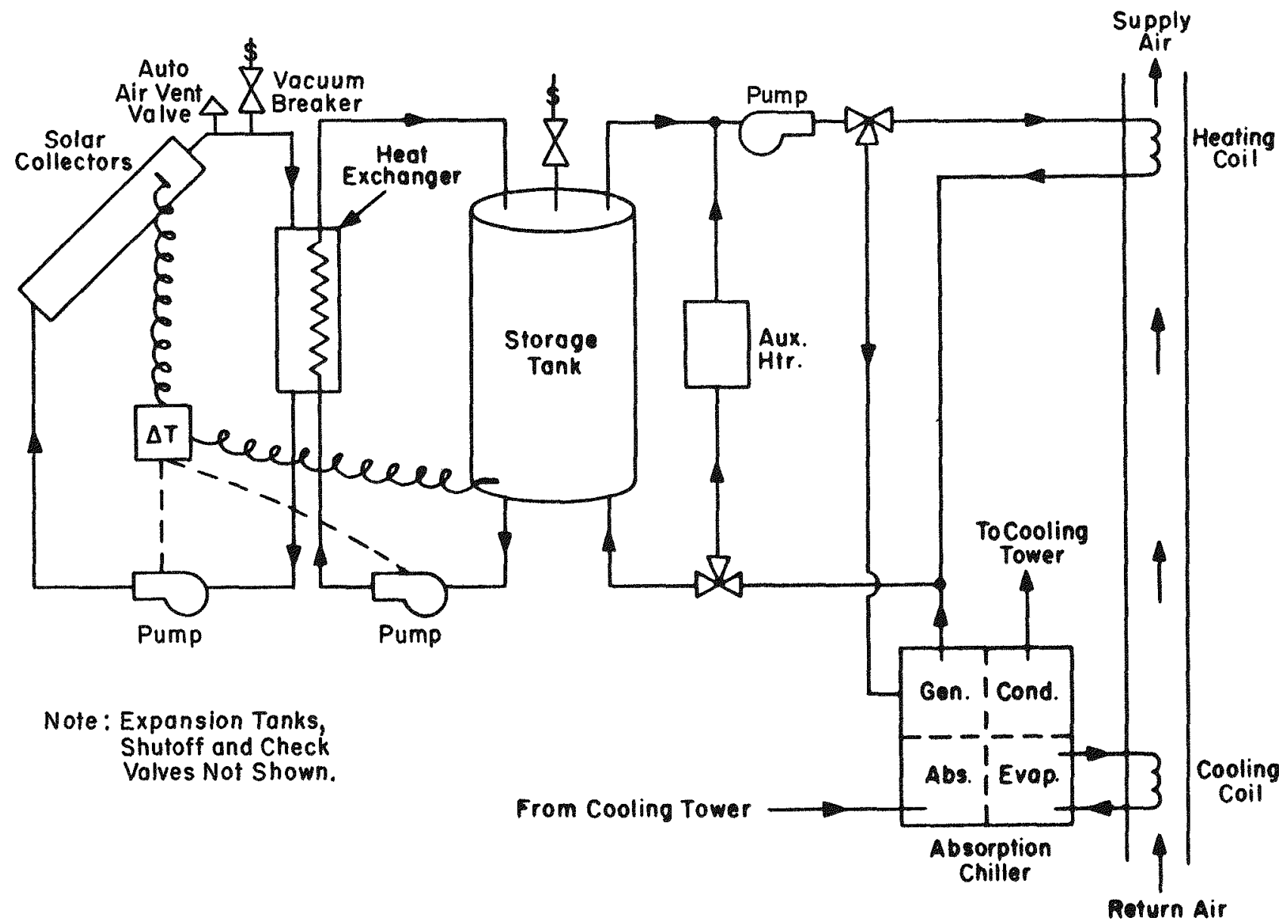

Fig. 5-20. Typical solar absorption cooling system

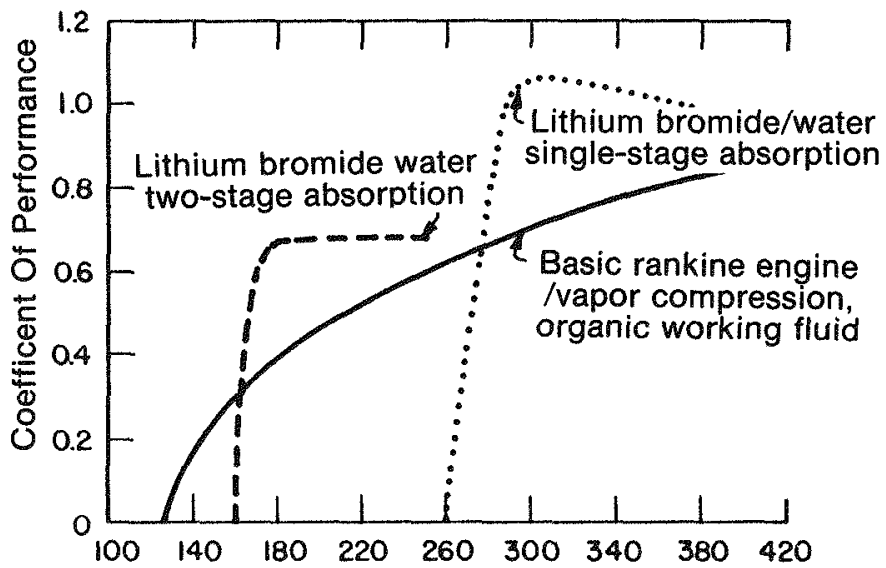

Temperature Of Solar Derived Thermal Energy Input To Cooling Unit (F)

Fig. 5-21. Source temperature dependency for solar cooling systems 


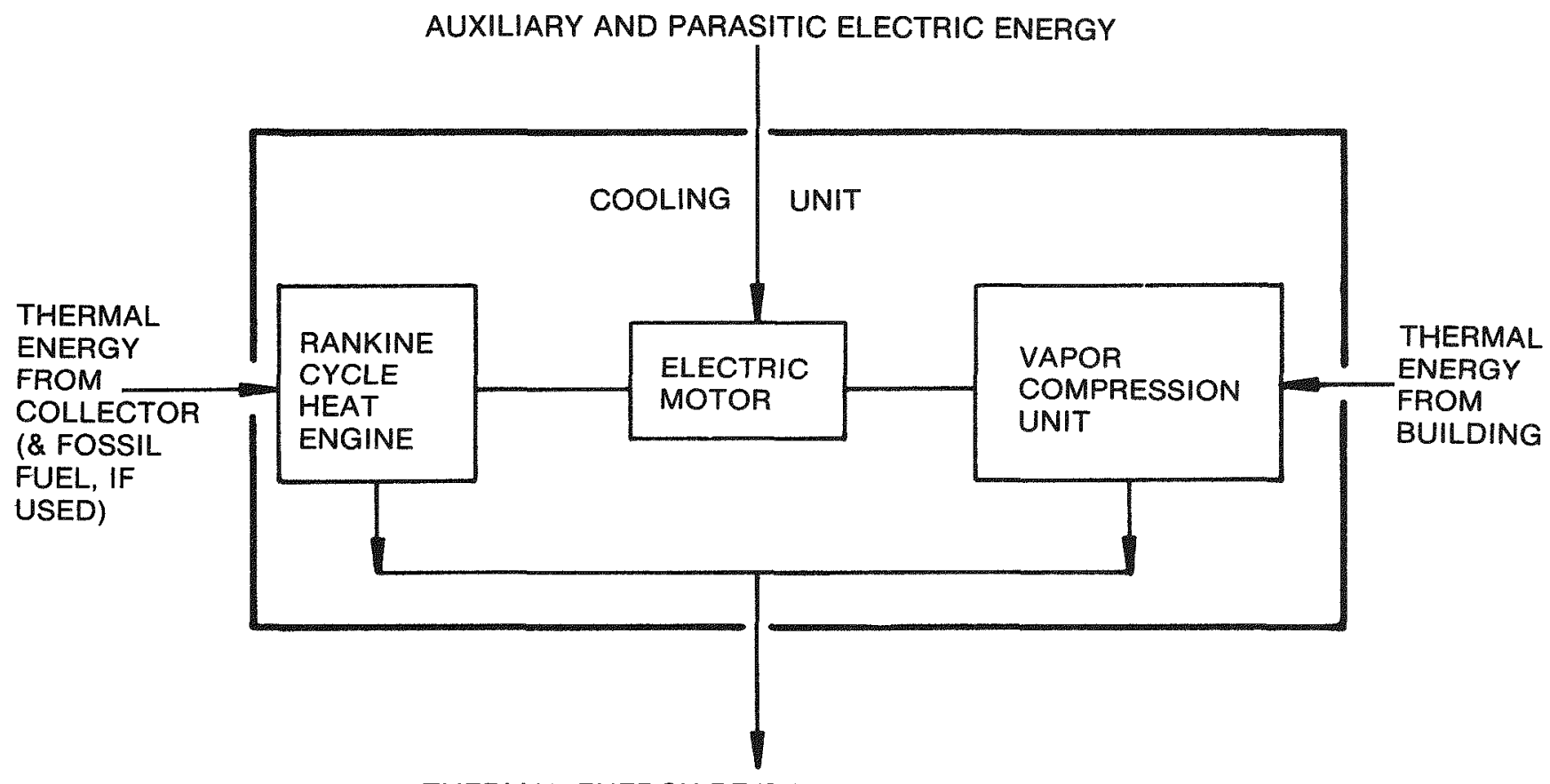

THERMAL ENERGY REJECTED TO ENVIRONMENT

Fig. 5-22. Typical Rankine cycle cooling system

\section{Desiccant (Adsorption) Cooling Systems}

A recently introduced prototype desiccant cooling system, to be powered by solar energy and natural gas, performs particularly well in dry climates, but its COP in humid regions may be lower than that of absorption chillers. This system uses solar-heated water in a heating coil to regenerate a molecular sieve desiccant impregnated on a rotating asbestos heat exchanger [20]. (Other systems use a silica gel desiccant [26].) The rotating heat exchanger is preconditioned with solarwarmed air and is topped by the gas-fired burner only when necessary. The unit requires no cooling towers or external heat exchangers.

Major advantages of solar desiccant cooling systems are [27]:

- They use inexpensive materials and have the potential to be manufactured at low cost.

- They can tolerate air leakage and would be easily serviced.

- They can tolerate a wide range in solar input and still generate usable output.
An advanced desiccant system with a COP in the range of 0.6 to 0.8 can be achieved at solar collector temperatures of about $160 \mathrm{~F}\left(71^{\circ} \mathrm{C}\right)$. To realize this potential, a lower pressure loss desiccant bed and reduction of parasitic power requirements must be accomplished. Other problems to be surmounted include the reduction in cost or amount of adsorbent material used, development of cost-effective heat exchangers, and development of optimized system control strategy and hardware.

Although several prototype desiccant systems are under development $[22,27]$, none is yet commercially available.

\section{ACKNOWLEDGMENTS}

The material on active solar heating systems in this chapter is adapted from a chapter entitled "Building Space Heating: Active Systems," by B. D. Hunn and G. O. G. Löf, in The Solar Energy Technology Handbook, Part $B$, to be published by Marcel Dekker, Inc., New York, New York. 


\section{B. ACTIVE SYSTEM COMPONENTS}

\section{SOLAR COLLECTORS}

Solar collectors are basically heat exchangers which transfer the radiant energy of incident solar radiation to the sensible heat of a working fluid-liquid or air. In space heating/hot water systems, the working fluid transports heat to the building interior where it is used to supply building service hot water (BSHW) and space heat and/or stored for later use. In most solar cooling applications, the working fluid heats the generator section of an absorption chiller.

The major types of collectors used in building heating and cooling applications are flat plates, evacuated tubes, and various linear concentrator types. Flat plates are by far the most common type used for heating and hot water; the others are of ten used to supply the higher temperatures needed for solar cooling.

\section{Flat Plate Collectors}

The flat plate collector is the most commonly used design for space heating and BSHW applications. It consists of the following basic components:

- Absorber plate - usually copper, steel, aluminum, or plastic; surface covered with flat black paint or a special selective coating to maximize absorption and minimize reradiation.

- Flow passages - in the case of liquids, flow is usually through tubes attached to, or an integral part of, the absorber plate. In the case of air, flow occurs above and/or below the plate; and heat transfer surface area is maximized by means of fins, slots, or metal screening.

- Cover plate(s) - one, two, or three transparent covers are used to reduce convective and radiative heat losses to the outside air. Tempered glass and various plastic materials are commonly used.

- Insulation - used to reduce heat losses out the back and sides of the collector, e.g. low binder isocyanurate fiberglass or polyurethane.

- Enclosure - a box to hold collector components together and protect them from the weather.

\section{Absorber Plate/Flow Passages}

In a liquid collector, tubes are spaced several inches apart with the absorber surface between acting as "fins" which absorb the heat and conduct it to the tubes. Tube spacing is determined by fin efficiency versus cost tradeoff. For the case of $1 / 2$ in. $(12.7 \mathrm{~mm})$ tubes spaced $6 \mathrm{in}$. $(152 \mathrm{~mm})$ apart in good thermal contact with a black copper plate 0.02 in. $(.5 \mathrm{~mm})$ thick, heat collection is $97 \%$ of that for the case of a completely water-cooled black sheet [28].
Copper tubes are of ten welded, soldered, or clamped to copper plates or clamped to aluminum plates. The thermal conductance of the bond is critical and can vary from $1,000 \mathrm{Btu} / \mathrm{hr}-\mathrm{ft} F(3,155 \mathrm{~W} / \mathrm{sq} \mathrm{m})$ for a well-soldered tube to less than $5 \mathrm{Btu} / \mathrm{hr}-\mathrm{ftF}(15.77 \mathrm{~W} / \mathrm{sq} \mathrm{m})$ for a poorly clamped one [29]. A better technique is to extrude or otherwise form a tube pattern into the plate during manufacture.

Tubes can be routed through the collector in parallel paths from inlet to outlet header, or a single tube can be routed in a serpentine fashion. The latter technique eliminates the possibility of header leaks and assures uniform flow but also increases pressure drop. If a draindown freeze protection system is used, the flow passages must be easy to drain.

Air collector absorber plates need not have high thermal conductivity because the air comes in contact with the entire surface. Flow can be above or below the plate, but the latter leads to less thermal loss through the glazing. The heat transfer from absorber to air can be enhanced by creating turbulent flow and by increasing the surface area with fins, corrugations, etc. However, this involves a tradeoff between heat transfer and fan power consumption. An air system eliminates freezing and boiling problems, and leaks are not as troublesome as in a liquid system; but fan power is significant, large ducts are required, and a greater storage volume is needed.

The type of coating on the collector absorber plate will determine the fraction of incident solar energy absorbed. Flat black paint is the most commonly used coating. It has an absorptivity, $\alpha$, between 0.92 and 0.96 , that is, it absorbs between $92 \%$ and $96 \%$ of the incident short-wave solar radiation. It is also quite durable. However, a hot absorber plate will radiate longwave energy to the cooler environment to an extent that depends on its emissivity, $\epsilon$. While flat black paint has a high $\alpha$, its $\epsilon$ is also high-on the order of 0.88 . So-called selective surfaces have a high short-wave absorptivity, yet a low long-wave emissivity, or to put it another way, have a high $\alpha / \epsilon$ ratio, and thus retain the heat better.

Unfortunately, a selective surface cannot simply be painted on. However, spray painted selective surfaces are expected in the market place in the near future. Ordinarily, a metal absorber plate is coated with a metal having a low $\epsilon$, and a thin layer [on the order of $10^{-5}$ in. $\left.\left(2.5 \times 10^{-4} \mathrm{~mm}\right)\right]$ of a high a material is laid on top [30]. Black chrome, one of the more popular selective surfaces, has an $\alpha$ of about 0.9 and an $\epsilon$ of 0.1 . Selective surfaces .improve collector performance; but they increase the cost, and their long-term durability is still questionable. An important characteristic of any absorptive coating is that it has good adhesion and does not peel or otherwise deteriorate during high-temperature stagnation (i.e., no flow) conditions. A list of absorptive coatings is given in Table $5-1$. 
Table 5-1. CHARACTERISTICS OF ABSORPTIVE COATINGS (from Ref. 36)

\begin{tabular}{|c|c|c|c|c|c|}
\hline $\begin{array}{l}\text { Property } \\
\text { or } \\
\text { Material }\end{array}$ & Absorptance $_{\alpha}^{1}$ & $\begin{array}{c}\text { Emittance } \\
\varepsilon\end{array}$ & $\frac{\alpha}{\varepsilon}$ & $\begin{array}{c}\text { Breakdown } \\
\text { Temperature } \\
\text { F }(\mathrm{C})\end{array}$ & Comments \\
\hline Black Chrome & $.87-.93$ & .1 & $\sim 9$ & & \\
\hline Alkyd Enamel & .9 & .9 & 1 & & $\begin{array}{l}\text { Durability limited at } \\
\text { high temperatures }\end{array}$ \\
\hline $\begin{array}{l}\text { Black Acrylic } \\
\text { Paint }\end{array}$ & $.92-.97$ & $.84-.90$ & $\sim 1$ & & \\
\hline $\begin{array}{l}\text { Black Inorganic } \\
\text { Paint }\end{array}$ & $.89-.96$ & $.86-.93$ & $\sim 1$ & & \\
\hline $\begin{array}{l}\text { Black Silicone } \\
\text { Paint }\end{array}$ & $.86-.94$ & $.83-.89$ & 1 & & Silicone binder \\
\hline $\begin{array}{l}\text { PbS/Silicone } \\
\text { Paint }\end{array}$ & .94 & .4 & 2.5 & $662(350)$ & $\begin{array}{l}\text { Has a high emittance for } \\
\text { thicknesses }>10 \mu \mathrm{m}\end{array}$ \\
\hline $\begin{array}{l}\text { Flat Black } \\
\text { Paint }\end{array}$ & $.95-.98$ & $.89-.97$ & $\sim 1$ & & \\
\hline Ceramic Enamel & .9 & .5 & 1.8 & & $\begin{array}{l}\text { Stable at high } \\
\text { temperatures }\end{array}$ \\
\hline Black Zine & .9 & .1 & 9 & & \\
\hline $\begin{array}{l}\text { Copper Oxide over } \\
\text { Aluminum }\end{array}$ & .93 & .11 & 8.5 & $392(200)$ & \\
\hline $\begin{array}{l}\text { Black Copper } \\
\text { over Copper }\end{array}$ & $.85-.90$ & $.08-.12$ & $7-11$ & $842(450)$ & Patinates with moisture \\
\hline Black Chrome & $.92-.94$ & $.07-.12$ & $8-13$ & $842(450)$ & $\begin{array}{l}\text { Stable at high } \\
\text { temperatures }\end{array}$ \\
\hline over Nickel & & & & & \\
\hline $\begin{array}{l}\text { Black Nickel } \\
\text { over Nickel }\end{array}$ & .93 & .06 & 15 & $842(450)$ & $\begin{array}{l}\text { May be influenced by } \\
\text { moisture at elevated } \\
\text { temperatures }\end{array}$ \\
\hline $\begin{array}{l}\text { Ni-Zn-S over } \\
\text { Nickel }\end{array}$ & .96 & .97 & 14 & $536(280)$ & \\
\hline $\begin{array}{l}\text { Black Iron } \\
\text { over Steel }\end{array}$ & .90 & .10 & 9 & & \\
\hline
\end{tabular}

1 Dependent on thickness and vehicle to binder ratio. 


\section{Cover Plates}

The most commonly used cover material is glass. A $1 / 8$ in $(3.2 \mathrm{~mm})$ sheet of window glass $(0.12 \%$ iron content) has a transmittance for solar radiation (at normal incidence) of $85 \%(\tau=.85)$. Water white glass $(0.01 \%$ iron) has a of 0.92 . Glass has the added advantage that it is practically opaque to any long-wave radiation given off by the absorber plate. If tempered, it has high durability as well. Deterioration is negligible, even over very long periods of exposure to intense ultraviolet radiation.

Various plastic materials used for collector glazings are cheaper and lighter than glass. Because they are used in thin sheets, they of ten have a higher transmittance as well. However, they of ten do not trap thermal radiation as well as glass and are generally not as durable. Degradation due to ultra-violet radiation or high temperature can be severe. Tedlar, for example, should not be used as an inner glazing in a two-cover collector because of its susceptibility to heat degradation.

The number of glazings used depends on the application and on a cost vs. performance tradeoff. Generally speaking, the higher the temperature difference between the collector plate and ambient temperature, the more covers that are needed. A single cover is suitable for domestic hot water applications in most climates. Two covers may be needed to supply space heat. However, a single glazed collector with a selective coating will of ten outperform a double glazed one with a nonselective coating. A list of cover plate materials and properties is given in Table 5-2.

\section{Insulation}

Various types of insulation are used in collectors to prevent heat losses out the back and sides. An important consideration is that the insulation does not outgas under stagnation conditions. Such gases could coat the inside of the glazing and greatly reduce transmittance. A list of insulation materials is given in Table 5-3.

\section{Enelosure}

The collector is ordinarily made of steel, aluminum, or fiberglass and supports the absorber plate and covers. Ideally, it will expand and contract with temperature changes along with the components, though adequate clearance (around a glass cover, for example) and proper use of gaskets must be provided for any differential expansion. The frame should cause little shading of the absorber plate, and aperture area should be at least $85 \%$ of gross area [1]. The box should be well sealed to keep water out. Use of a desiccant can prevent condensation on the inner surface of the cover. External pipe connections should receive particular attention. Sealing compounds and gaskets used should be capable of withstanding stagnation temperatures without outgassing and must be capable of withstanding thermal cycling. Various types of flat-plate collector designs are shown in Fig. 5-23a.

\section{Improving Flat-Plate Collectors}

A number of techniques have been used to improve the performance of the basic flat plate collector discussed above. Treatment of a glass cover to reduce reflection can increase performance by as much as $4 \%$ [28]. Coatings on the inner glass surface to reflect the longwave radiation (which would otherwise heat the glass) have been used, though these also reduce the transmittance. A honeycomb located between the inner cover and absorber plate can reduce both convective and radiative heat losses [31]. Planar reflectors used in front of a row of flat plate collectors can increase energy collection by as much as $40 \%$ over a heating season [32]. Most of these techniques, while offering varying advantages, have not yet been widely applied.

\section{Hybrid Colleetors}

Widely available hybrid collectors combine the better features of flat plate and concentrating collectors. The Falbel System shown in Fig. 5-23b illustrates this principle.

\section{Advaneed Colleetor Designs}

As the temperature requirement increases, the efficiency of a flat plate collector rapidly falls off. Other collector alternatives are of ten chosen particularly for supplying $195 \mathrm{~F}\left(91^{\circ} \mathrm{C}\right)$ water to operate an absorption chiller. Examples of some of the more commonly used advanced collector designs are discussed below.

\section{Evacuated Tube}

One way to reduce convective heat losses is to use a vacuum between the glazing and absorber surface. Since such a vacuum would cause a typical flat plate collector to collapse, this technique is used in conjunction with a tubular design. There are various types of evacuated tube collectors on the market.

One design, shown in Fig.5-23c, uses three concentric glass tubes. Fluid flows into the annular space between the inner and second tubes and back out the inner tube. The annulus between the second and third (outer) tube is evacuated, and the outside of the second tube contains a selective coating. 
Table 5-2. CHARACTERISTICS OF COVER PLATE MATERIALS (from Ref. 1)

\begin{tabular}{|c|c|c|c|c|c|c|c|c|c|}
\hline Test & $\begin{array}{l}\text { Polyvinyl } \\
\text { Fluoride }^{a}\end{array}$ & $\begin{array}{l}\text { Polyethyl- } \\
\text { ene Tereph- } \\
\text { thalate of } \\
\text { Polyester }\end{array}$ & $\begin{array}{l}\text { Polycar- } \\
\text { bonate }\end{array}$ & $\begin{array}{l}\text { Fiberglass } \\
\text { Reinforceed } \\
\text { Plastics }\end{array}$ & $\begin{array}{l}\text { Methyl } \\
\text { Methacry- } \\
\text { late }\end{array}$ & $\begin{array}{l}\text { Fluorinated } \\
\text { Ethylene- } \\
\text { Propylene }^{f}\end{array}$ & $\begin{array}{c}\text { Ordinary Clear } \\
\text { Lime Glass } \\
\text { (Float) (0.10- } \\
0.13 \% \text { iron) }\end{array}$ & $\begin{array}{l}\text { Sheet Lime } \\
\text { Glass (0.05- } \\
0.06 \% \text { iron) }\end{array}$ & $\begin{array}{l}\text { Water White } \\
\text { Glass }(0.01 \% \\
\text { iron) }\end{array}$ \\
\hline $\begin{array}{l}\text { Solar } \\
\text { Transmission (\%) }\end{array}$ & $92-94$ & 85 & $82-89$ & $77-90$ & 89 & 97 & 85 & 87 & $85-91$ \\
\hline $\begin{array}{l}\text { Maximum } \\
\text { Operating } \\
\text { Temp. (F) }\end{array}$ & 227 & 220 & $250-270$ & $\begin{array}{l}200^{\circ} \text { produces } \\
10 \% \text { transmis- } \\
\text { sion loss }\end{array}$ & $180-190$ & 248 & 400 & 400 & 400 \\
\hline $\begin{array}{l}\text { Tensile } \\
\text { Strength (psi) }\end{array}$ & 13000 & 24000 & 9500 & $15000-17000$ & 10500 & $2700-3100$ & $\begin{array}{l}1600 \text { annealed } \\
6400 \text { tempered }\end{array}$ & $\begin{array}{l}1600 \text { annealed } \\
6400 \text { tempered }\end{array}$ & $\begin{array}{l}1600 \text { annealed } \\
6400 \text { tempered }\end{array}$ \\
\hline $\begin{array}{l}\text { Thermal } \\
\text { Expansion } \\
\text { Coefficient } \\
\text { (in/in/F } \times 10^{6} \text { ) }\end{array}$ & 24 & 15 & 37.5 & $18-22$ & 41.0 & $8.3-10.5$ & 4.8 & 5.0 & $4.7-8.6$ \\
\hline $\begin{array}{l}\text { Elastic } \\
\text { Modulus } \\
\text { (psi } \times 10^{6} \text { ) }\end{array}$ & 0.26 & 0.55 & 0.345 & 1.1 & 0.45 & 0.5 & 10.5 & 10.5 & 10.5 \\
\hline Thickness (in) & 0.004 & 0.001 & 0.125 & 0.040 & 0.125 & 0.002 & 0.125 & 0.125 & 0.125 \\
\hline $\begin{array}{l}\text { Weight (lb/sg ft) } \\
\text { for above } \\
\text { thickness }\end{array}$ & 0.028 & 0.007 & 0.77 & 0.30 & 0.75 & 0.002 & 1.63 & 1.63 & 1.63 \\
\hline $\begin{array}{l}\text { Greatest Load } \\
\text { Area (psf:sq ft) }\end{array}$ & - & - & - & - & - & - & - & - & $\begin{array}{c}30: 30 \text { annealed } \\
100: 28 \text { tempered }\end{array}$ \\
\hline $\begin{array}{l}\text { Length of } \\
\text { Life }(y r)\end{array}$ & $\begin{array}{l}\text { In } 5 \text { years } \\
\text { retains 95\% } \\
\text { of total } \\
\text { transmission }\end{array}$ & 4 & - & $7-20$ & - & - & - & - & - \\
\hline$a_{\text {e.g., Tedlar }}$ & & $u_{e}$ & Iwall & lite & & & & & \\
\hline be.g., Mylar & & $e_{e .8}$ & Lucite, $P$ & kigles, Acryli te & & & & & \\
\hline
\end{tabular}

Values were obtained from the following sources:

D. P. Grimmer and S. W. Moore, "Practical Aspects of Solar Heating: A Review of Materials Use in Solar Heating Applications," Paper presented at Society for Advancement in Materials Process Engineering Meeting, October 14-16, 1975, Albuquerque, New Mexico.

T. Kobayashi and L. Sargent, "A Survey of Breakage-Resistant Materials for Flat-Plate Solar Collector Covers," Paper presented at U.S. Section of ISES Meeting, Ft. Collins, Colorado, August 20-23, 1974.

A. E. Scoville, "An Alternate Cover Materials for Solar Collectors," Paper presented at ISES Congress and Exposition, Los Angeles, California, July 1975.

C. W. Clarkson and J. S. Herbert, "Transparent Glazing Media for Solar Energy Collectors," Paper presented at U.S. Section of ISES Meeting, Ft. Collins, Coloredo, August 20-23, 1974 .

Modern Plastics Encyclopedia (McGraw-Hill 1975-1976).

R. B. Toenjes, "Integrated Solar Energy Collector Final Summary Report," Los Alamos Scientific Laboratory Report LA-6143-MS (November 1975). 
Table 5-3. CHARACTERISTCS OF INSULATION MATERIALS (from Ref. 36)

\begin{tabular}{lccc}
\hline \multicolumn{1}{c}{ Material } & $\begin{array}{c}\text { Density } \\
(\mathrm{lb} / \mathrm{cu} \mathrm{ft})\end{array}$ & $\begin{array}{c}\text { Thermal } \\
\text { Conductivity } \\
\text { at 200 F } \\
\text { (Btu/hr-sq ft F/in.) }\end{array}$ & $\begin{array}{c}\text { Temperature } \\
\text { Limits (F) }\end{array}$ \\
\hline Fiberglass with Organic Binder & 0.6 & 0.41 & 350 \\
& 1.0 & 0.35 & 350 \\
Fiberglass with Low Binder & 1.5 & 0.30 & 350 \\
Ceramic Fiber Blanket & 3.0 & 0.31 & 350 \\
Mineral Fiber Blanket & 1.5 & 0.4 at $400 \mathrm{~F}$ & $\mathbf{8 5 0}$ \\
Calcium Silicate & 3.0 & 0.31 & 1200 \\
Urea-Formaldehyde Foam & 10.0 & 0.38 & 1200 \\
Urethane Foam & 13.0 & 0.20 at $75 \mathrm{~F}$ & 210 \\
\hline
\end{tabular}

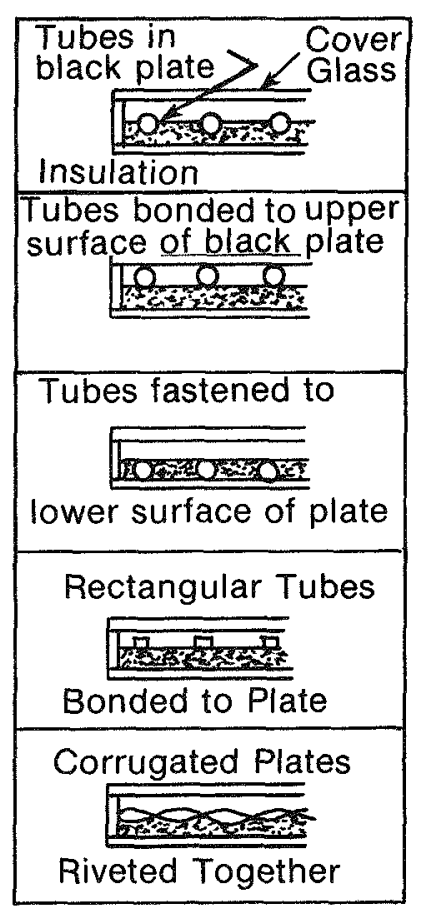

\begin{tabular}{l} 
Finned Plate \\
Air Heater \\
Air Flow Area \\
\hline Matrix-Type Air Heater \\
Air In \\
Using Black Gauze \\
\hline
\end{tabular}

LOF-Type Air Heater Using Overlapping
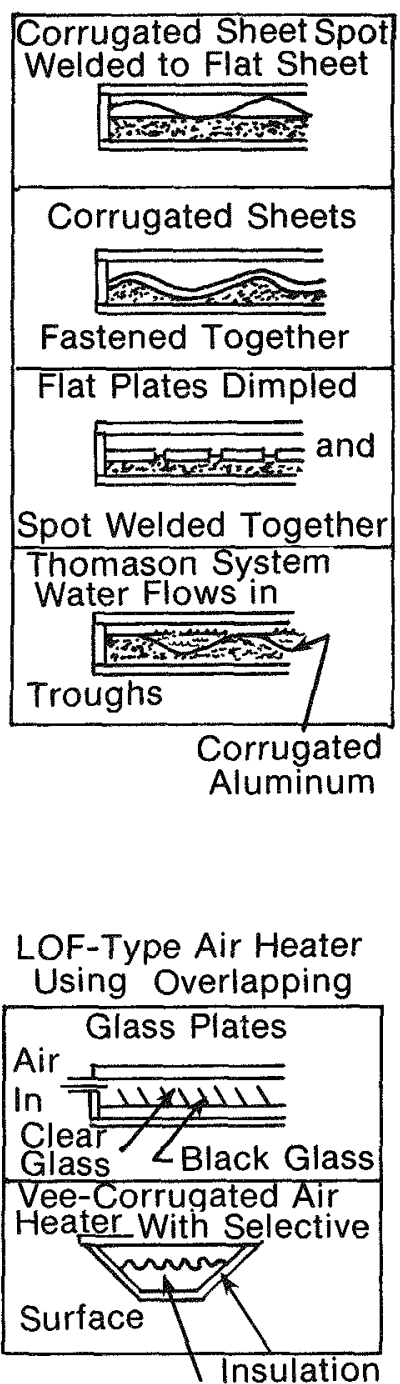

Air Flow Area

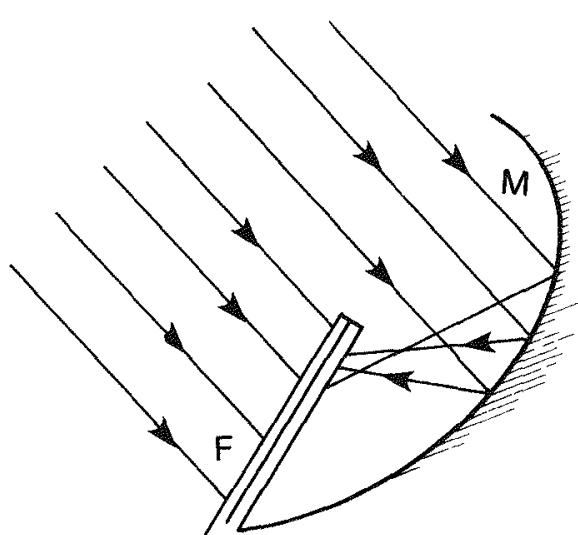

F = A Flat Plate Collector, Capable of Collecting Radiation Incident on the Front or Back.

$M=A$ Specially Shaped Curved Reflector Capable of Reflecting Light Incident Over a Large Range of Angles Onto the Rear of the Flat Plate Collector.

Fig. 5-23b. Hybrid collector example

Fig. 5-23a. Common collector configurations [1] 


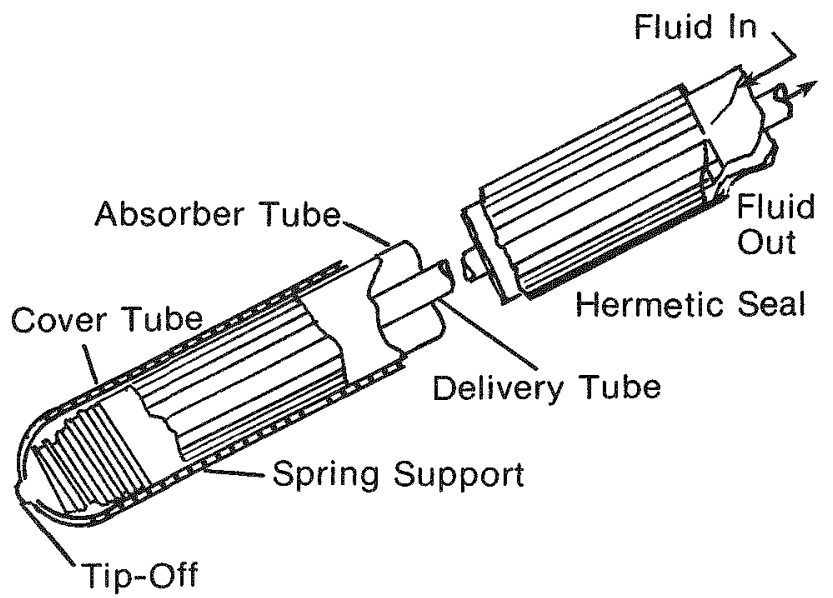

Fig. 5-23c. Concentric Glass evacuated tube collector

Another design (Fig.5-23d) employs only two concentric glass tubes with the space between evacuated and the outer surface of the inner tube containing the absorptive coating. A metal fin conforms to the inside surface of the inner tube, and to this attached a copper U-tube which carries the fluid. The U-tube readily accommodates thermal expansion, and glass breakage will not result in a leak.

Various shapes of reflectors are usually used behind evacuated tubes and provide a small amount of concentration. Evacuated tubes can collect both direct and diffuse solar radiation and do not require tracking. Because of the extremely high stagnation temperatures [over $600 \mathrm{~F}\left(316^{\circ} \mathrm{C}\right)$ ] that evacuated tube collectors can reach, thermal shocking with cold water and boiling during power failure have sometimes been a problem.

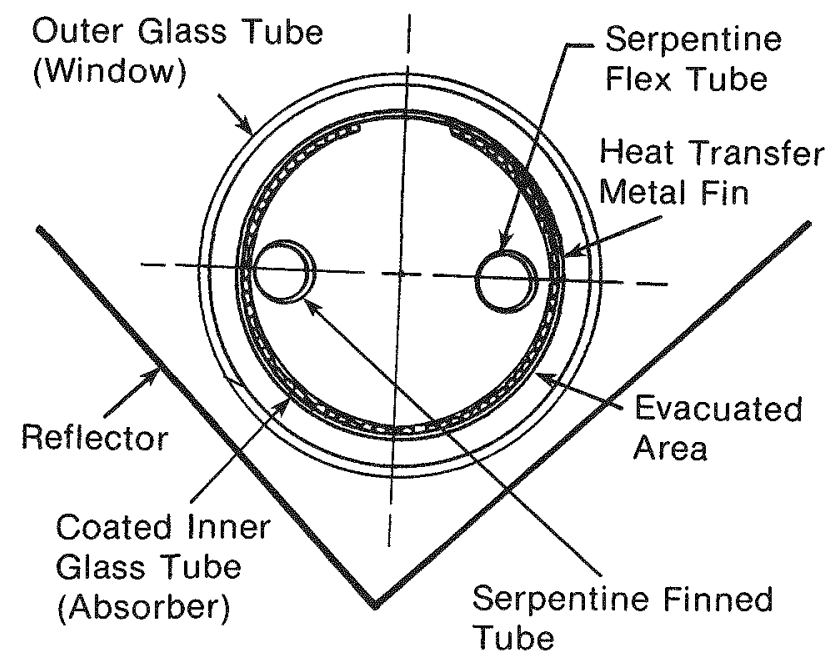

Fig. 5-23d. Evacuated tube collector with copper flow tube

\section{Parabolic Troughs}

Another way to cut down on heat losses that reduce efficiency is to concentrate the solar energy onto a smaller absorber surface. The most commonly used concentrator is a parabolic reflector trough with an absorber pipe located along the focal line as shown in Fig.5-23e. The collectors can be oriented east-west or north-south; in the latter case they are usually tilted from the horizontal. In most cases, concentration ratios (ratio of aperture to absorber area) are high enough that continuous tracking is required even in the case of eastwest troughs. Since most diffuse radiation is outside the concentrator's "acceptance angle," only direct radiation can be collected. As a result, a concentrating collector receives less available sunlight than a flat plate collector; and, in some cloudy climates, this can more than offset the gain in efficiency.

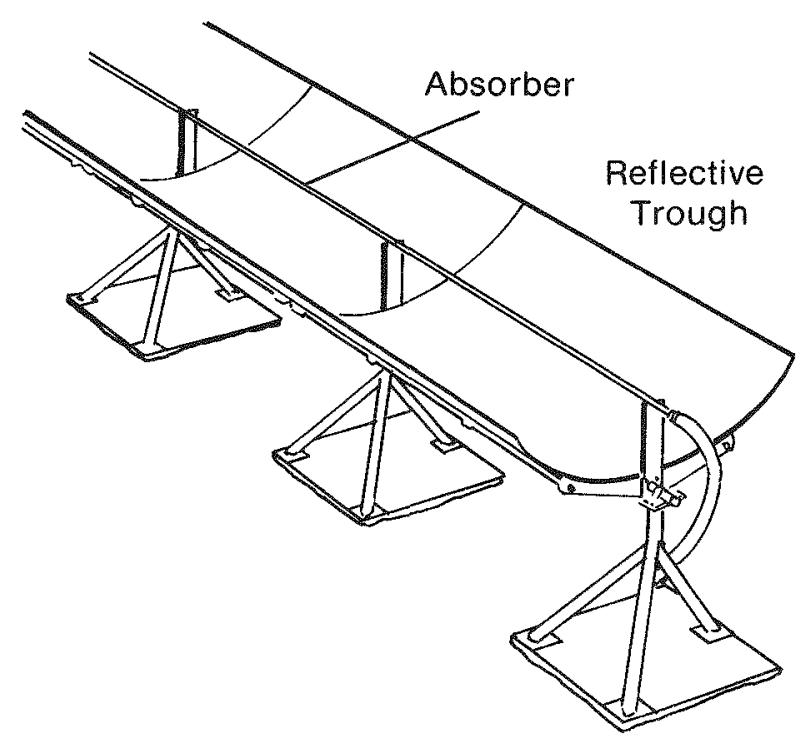

Fig. 5-23e. Parabolic trough collector

\section{Fresnel Lens}

Rather than sunlight being reflected onto an absorber pipe, it can instead be refracted as shown in Fig. 5-24. Although this can be done with a convex lens, a Fresnel lens (consisting of many small refractive surfaces) is ordinarily employed since it is cheaper, lighter, and absorbs less radiant energy. For the low-concentration applications, the Fresnel lens design has roughly the same advantages and drawbacks as the trough collectors but is generally more expensive. 


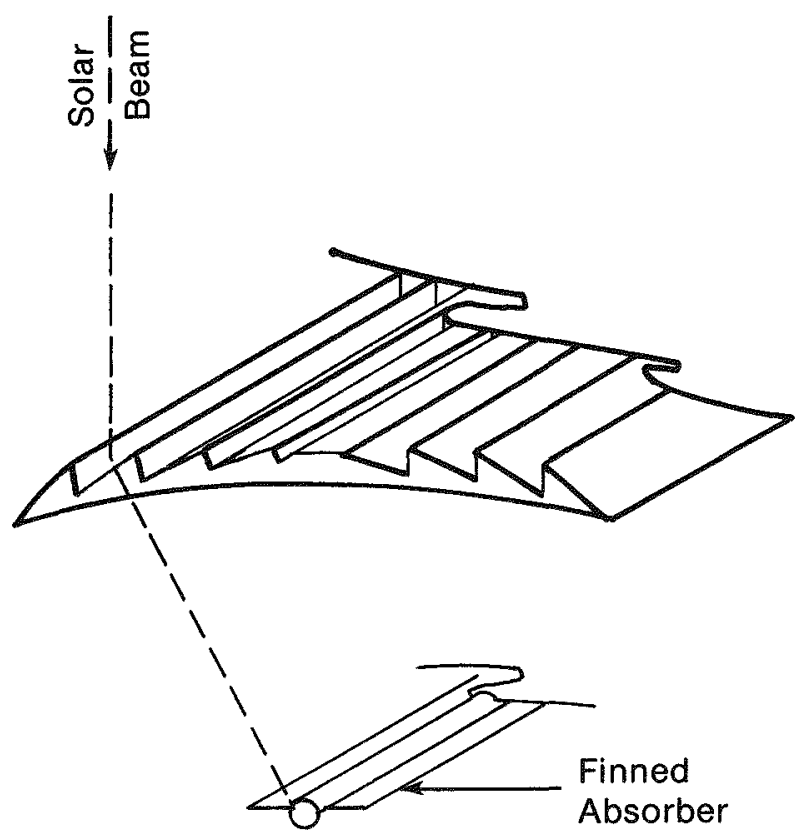

Fig. 5-24. Concentration with a Fresnel lens

\section{Compound Parabolic Concentrator (CPC)}

This design, as shown in Fig. 5-25, consists of a trough comprised of two half-parabolic reflectors with an absorber surface located at the bottom of the trough. Developed by Roland Winston of Argonne National Laboratory, this design has the advantage of providing a wide acceptance angle at low concentration ratios. The $\mathrm{CPC}$ is a nonimaging concentrator and essentially "funnels" the radiation rather than focuses it. If oriented east-west, troughs with a low concentration ratio would require only seasonal adjustment and would collect a considerable amount of diffuse as well as direct radiation. Unlike the other concentrators, its reflective surface need not be as highly specular and can thus better tolerate dust and degradation. A disadvantage is the relatively large amount of reflector area required. The $\mathrm{CPC}$ collector is still in the development phase.

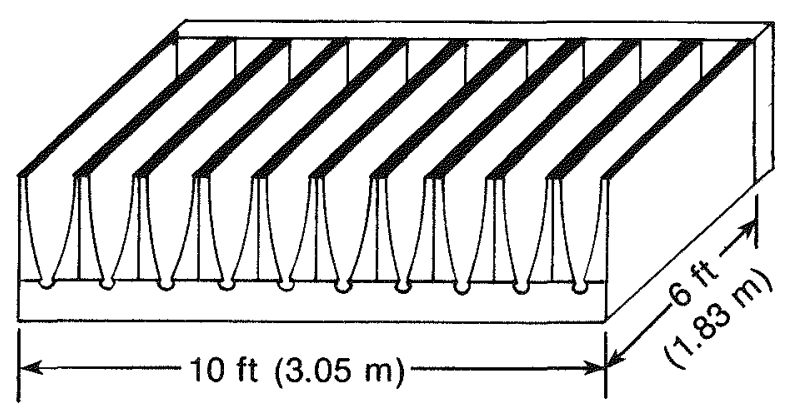

Fig. 5-25. A CPC collector module

\section{Colleetor Efficieney}

Consider an energy balance on a simple flat plate collector:

$$
\begin{aligned}
& \begin{array}{c}
\text { useful energy } \\
\text { collected }
\end{array}=\begin{array}{c}
\text { energy absorbed } \\
\text { by plate }
\end{array}-\begin{array}{c}
\text { energy lost } \\
\text { to surroundings }
\end{array} \\
& \frac{\mathrm{Q}}{\mathrm{A}}=\mathrm{I}_{\mathrm{t}}(\mathrm{t \alpha})-\mathrm{U}_{\mathrm{L}}\left(\mathrm{t}_{\mathrm{p}}-\mathrm{t}_{\mathrm{a}}\right)
\end{aligned}
$$

where

$\mathrm{Q}$ = rate of useful energy gain $[B t u / h r(W)]$

$\mathrm{A}=$ gross collector area [sq ft (sq $\mathrm{m})]$

$\mathrm{I}_{\mathrm{t}}=$ global insolation on collector plane $[\mathrm{Btu} / \mathrm{hr}-\mathrm{sq} \mathbf{f t}$ $(\mathrm{W} / \mathrm{sq} \mathrm{m})]$

$\tau \quad=$ net transmittance of glazings

$\alpha \quad=$ absorptance of collector plate

$\mathrm{U}_{\mathrm{L}}=$ overall energy loss coefficient $[\mathrm{Btu} / \mathrm{hr}-\mathrm{sq} \mathrm{ft}-\mathrm{F}$ $\left(\mathrm{W} / \mathrm{sq} \mathrm{m}^{\circ} \mathrm{C}\right)$

$t_{p}=$ average plate surface temperature $[\mathrm{F}(\mathrm{C})]$

$\mathrm{t}_{\mathrm{a}}^{\mathrm{p}}=$ ou tside ambient air temperature [F ( $\left.\left.{ }^{\circ} \mathrm{C}\right)\right]$

To eliminate the need to determine the plate temperature, the collector heat removal efficiency factor, $F_{R}$, is introduced:

$F_{R}=\frac{\text { Actual useful energy collected }}{\begin{array}{l}\text { Useful energy collected if entire } \\ \text { plate were at inlet fluid temperature }\end{array}}$

$$
=\frac{I_{t}(\tau \alpha)-U_{L}\left(t_{p}-t_{Q}\right)}{I_{t}(\tau \alpha)-U_{L}\left(t_{f, i}-t_{a}\right)}
$$

Then,

$\frac{Q}{A}=F_{R}\left[I_{t}(\tau \alpha)-U_{L}\left(t_{f, i}-t_{q}\right)\right]$

where:

$t_{f, i}=$ inlet fluid temperature $\left[F\left({ }^{\circ} \mathrm{C}\right)\right]$

The useful energy gained by the collector heats the collector fluid, so,

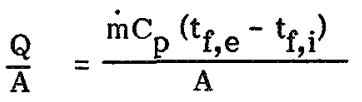

where

$\dot{\mathrm{m}}=$ mass flow rate of fluid [lb/hr $(\mathrm{kg} / \mathrm{s})]$

$\mathrm{C}_{\mathrm{p}}=$ heat capacity of fluid [Btu/lb F $\left.\left(\mathrm{J} / \mathrm{kg}^{\circ} \mathrm{C}\right)\right]$

$t_{f, e}^{p}=$ fluid exit temperature [F $\left.(\mathrm{C})\right]$ 
Thus,

$$
\begin{aligned}
\frac{Q}{A} & =F_{R}\left[I_{t}(t \alpha)-U_{L}\left(t_{f, i}-t_{Q}\right)\right] \\
& =\frac{\dot{m} C_{p}\left(t_{f, e}-t_{f, i}\right)}{A}
\end{aligned}
$$

The collector efficiency is defined as:

$\eta=\frac{\text { useful energy collected }}{\text { insolation on collector }}=\frac{\mathrm{Q} / \mathrm{A}}{\mathrm{I}_{\mathrm{t}}}$

So,

$$
\eta=F_{R}(\tau \alpha)-F_{R} U_{L} \frac{\left(t_{f, i}-t_{a}\right)}{I_{t}}=\frac{m_{p}\left(t_{f, e}-t_{f, i}\right)}{A I_{t}}
$$

The rightmost term in Eq. 5-7 is used in experimentally measuring a collector's efficiency. Although the $U_{L}$ term in the other part of the equation is a function of windspeed and temperature, it is approximately constant for a flat plate collector. Indeed, when test measurements are made and $n$ is plotted against $\left(t_{f, i}-t_{a}\right) / I_{t}$, a straight line is ordinarily fitted to the data points with:

$$
\text { slope }=-F_{R} U_{L}
$$

intercept $=F_{R}(\tau \alpha)$

Given a collector's efficiency curve and knowing $I_{t}(\tau \alpha)$, the $F_{R}$ and $U_{L}$ parameters can easily be calculated.

Fig. 5-26 shows efficiency curves for three flat plate collectors: two with flat black absorbers (one with a single cover and the other with two covers) and the other with a single cover and black chrome selective surface. Consider the two flat black collectors. Note that for large values of the parameter $\left(t_{f, i}-t_{a}\right) / \pi_{t}$ (corresponding to the collector supplying water at a much higher temperature than ambient), the two-cover collector has a higher efficiency. This is because the second cover reduces heat loss resulting in a smaller $U_{L}$ and a flatter slope of the curve. At small values of $\left(t_{f, i}-t_{a}\right) / I_{t}$, however, the single-cover collector actually outperforms the two-cover model. This is because the single cover collector has a higher transmittance, $\tau$, and thus a larger value of $\mathrm{F}_{\mathrm{R}}(\tau \alpha)$, the intercept. It is easy to take this one step further and see that for a swimming pool collector, which heats water oniy a few degrees above (or even below) ambient temperature, it is of ten best not to use any cover at all. Using a selective surface with a single cover has both advantages of high intercept and low heat loss.

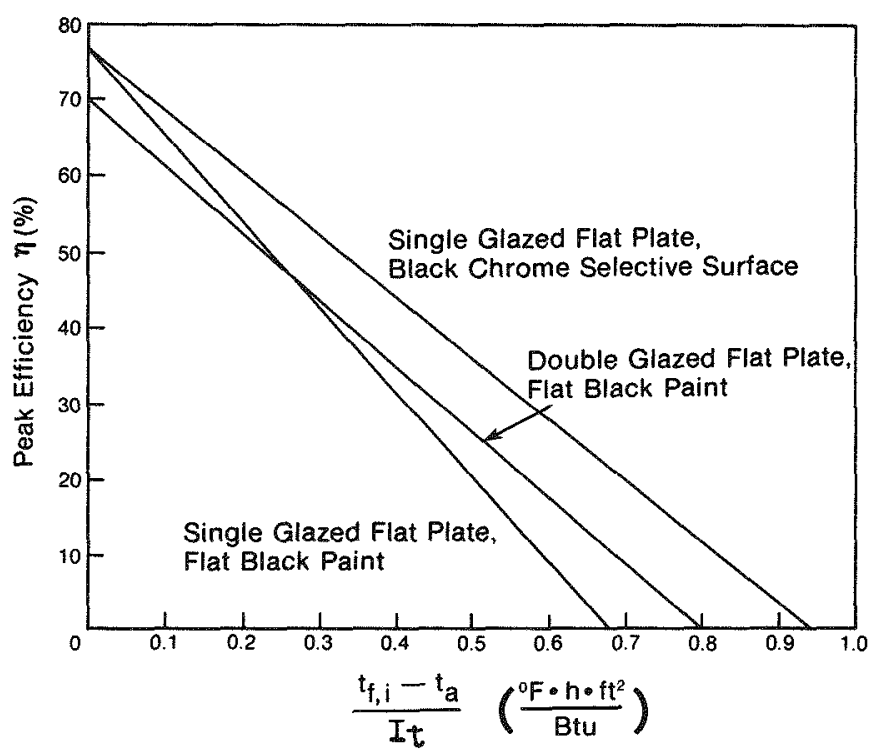

Fig. 5-26. Typical flat plate collector efficiency curves

Although the efficiency equation we have used was derived for flat plate collectors, a slightly modified form is of ten used for concentrating collectors [33]. For example, for a parabolic trough, we could write,

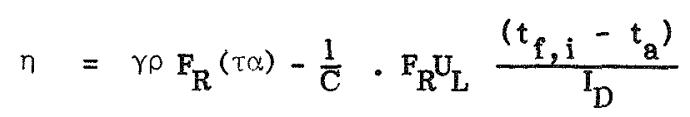

where:

$\rho=$ reflectance of the reflector surface

$\gamma=$ fraction of specularly reflected radiation intercepted by absorber surface

$\mathrm{C}=$ concentration ratio (ratio of aperture area to absorber area)

$\mathrm{I}_{\mathrm{D}}=$ direct insolation normal to aperture plane of collector [Btu/hr sq ft (W/sq m)]

Note that the intercept is reduced by the factors of $\gamma$ and $\rho$, although of ten no glozing will be used, and $\tau$ is 1. The concentration serves to reduce the slope of the efficiency curve, thus maintaining high efficiencies at high values of $\left(t_{f, i}-t_{a}\right) / I$. Of ten, higher order terms will be added to the equation for the case of concentrators, to account for the variation of $U_{L}$ with receiver temperature. Typical efficiency curves for various types of collectors are given in Fig. 5-27. 


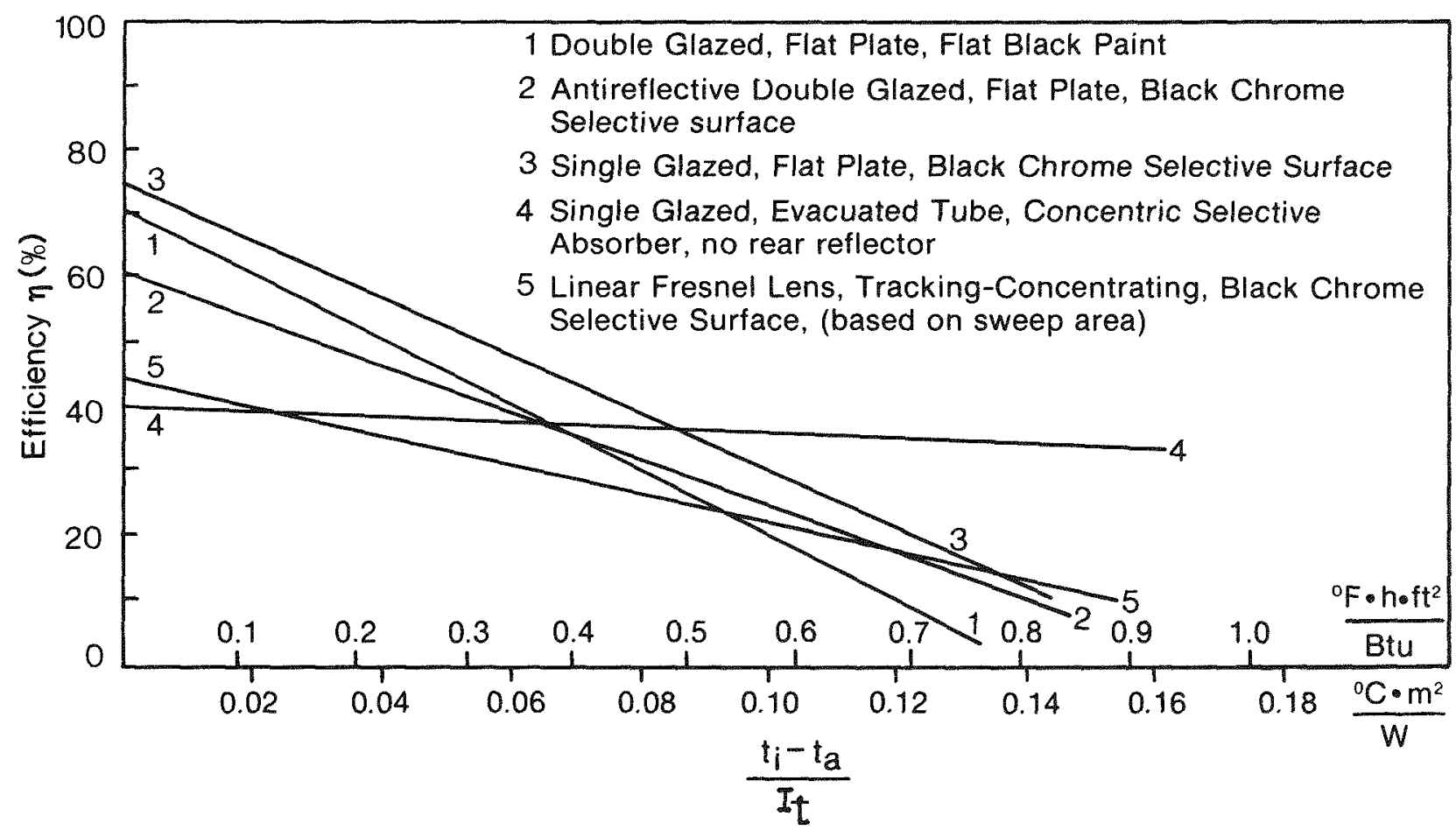

Fig. 5-27. Typical efficiency curves for liquid collectors [36]

\section{Collector Testing}

Two basic test methods have been used in the past to determine the efficiency of solar collectors [34]:

1. Calorimetric method - uses a closed system consisting of collector and small storage tank. The time rate of temperature change of the system is related to insolation and efficiency as:

$$
\eta=\frac{Q / A}{I_{t}}=\frac{m^{\prime} C_{p} d t / d T}{I_{t}}
$$

where:

$$
\begin{aligned}
\mathrm{m}^{\prime}= & \text { mass of the media in the calorimeter per unit area } \\
& \text { of collector [lb/sq } \mathrm{ft}(\mathrm{kg} / \mathrm{sq} \mathrm{m})] \\
C_{p}= & \text { specific heat of the medium in the calorimeter } \\
& {\left[\mathrm{Btu} / \mathrm{b} \mathrm{F}\left(\mathrm{J} / \mathrm{kg}^{\circ} \mathrm{C}\right)\right] } \\
t= & \text { average system temperature of the medium } \\
& {\left[\mathrm{F}\left({ }^{\circ} \mathrm{C}\right)\right] } \\
\mathrm{T}= & \text { time [sec] }
\end{aligned}
$$

This is a good method for determining the daylong efficiency of a collector; only $I_{t}$ and $\mathrm{d} t / \mathrm{d} T$ need to be measured during the day. However, it is difficult to extrapolate the results from one day to another day, and the procedure is sensitive to thermal losses. In addition, it is difficult to test an air collector by this method because of the low heat capacity of air.
2. Instantaneous method - uses an open system in which the collector alone is isolated. Fluid mass flow rate, inlet and outlet temperatures, and insolation are measured at solar noon under steady-state conditions. Efficiency is then determined as shown earlier.

$$
\eta=\frac{Q / A}{I_{t}}=\frac{\dot{m} C_{p}\left(t_{f, e}-t_{f, i}\right)}{I_{t}}
$$

This method requires accurate measurements of $\dot{m}, \Delta t$, and $I_{t}$ and is best suited for determining the instantaneous efficiency of a collector-liquid or air.

Based on a procedure developed by the National Bureau of Standards, the American Society of Heating, Refrigerating and Air Conditioning Engineers (ASHRAE) has adopted Standard 93-77, "Methods of Testing to Determine the Thermal Performance of Solar Collectors" [35]. This standard employs the instantaneous method for determining collector efficiency based on gross collector area. A test configuration for liquid collectors is shown in Fig. 5-28. Three basic tests are called for, and these determine the following:

- Collector time constant

- Instantaneous efficiency

- Incident angle modifier 


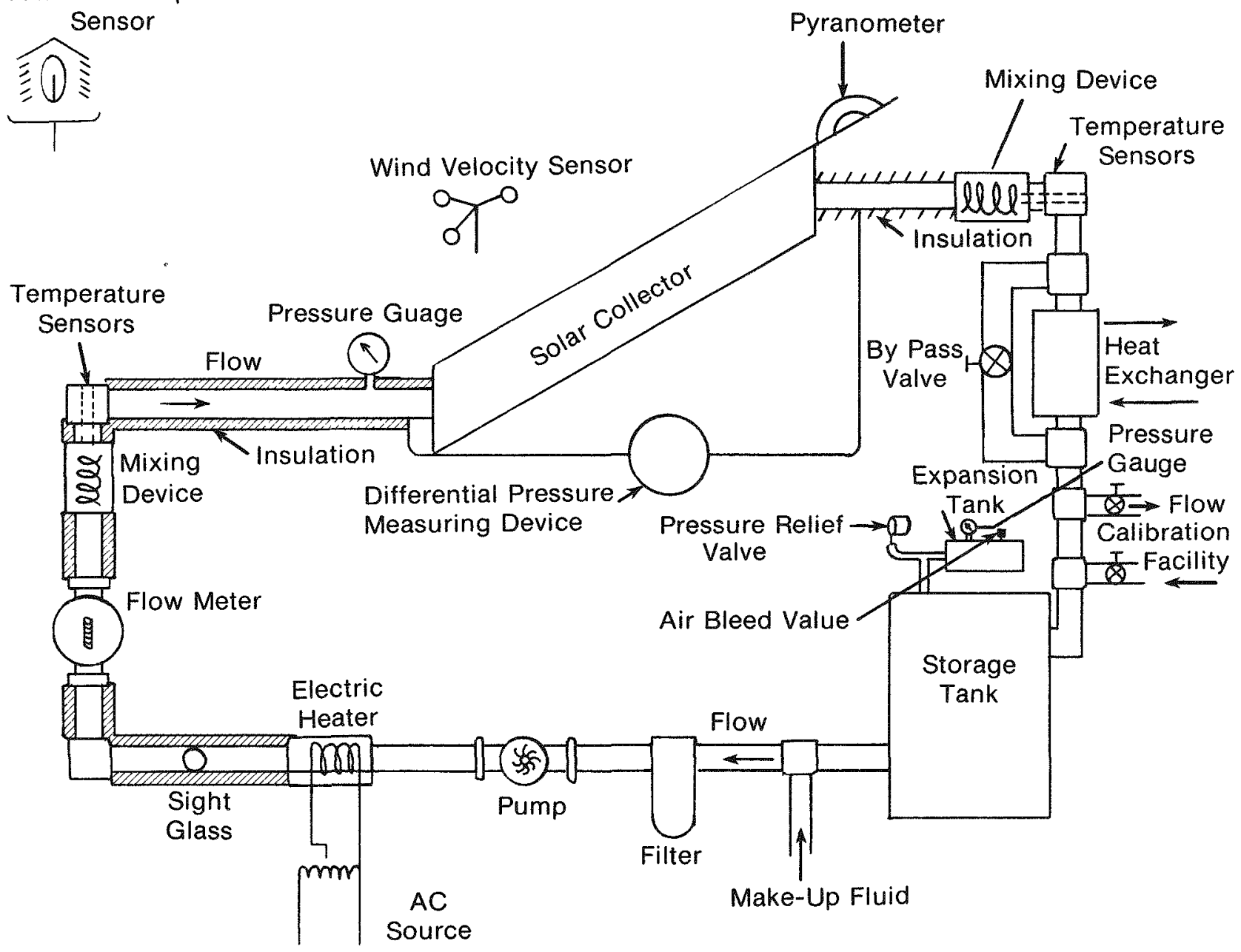

Fig. 5-28. Test configuration for liquid collectors [35]

\section{Collector Time Constant}

Collector time constant, $\tau_{c}$, is the time required for the difference between fluid inlet and outlet temperatures to drop to $36.8 \%$ of its initial value after a step decrease in insolation or inlet fluid temperature. In one such test the incident solar flux is abruptly reduced from a steadystate value of at least $250 \mathrm{Btu} / \mathrm{hr} \mathrm{sq} \mathrm{ft}(790 \mathrm{~W} / \mathrm{sq} \mathrm{m})$ to zero. At time $T=\tau_{c}$ after such a step change, with inlet collector temperature, $\mathrm{t}_{\mathrm{f}, \mathrm{i}}$, held constant,

$\frac{\left.t_{f_{,} e^{(\tau}}\right)-t_{f, i}}{t_{f, e}(0)-t_{f, i}}=\frac{1}{e}=0.368$

The smaller the time constant, the more rapidly a collector will respond to short periods of insolation.

\section{Efficiency Tests}

Over a time period, $\Delta \mathrm{d}_{2} \mathrm{~T}_{2}$, efficiency is determined as:

$$
\eta=\frac{\dot{m} C_{p}}{A} \frac{\int_{T_{1}}^{T_{2}}\left(t_{f, e}-t_{f, i}\right) d T}{\int_{T_{1}}^{T_{2} I_{t} d T}}
$$

For each data point, the efficiency is determined as the average over a period of 5 minutes or $\tau_{c}$ (whichever is larger) during which insolation is steady and flow is maintained at $14.7 \mathrm{lbm} / \mathrm{hr}-\mathrm{sq} \mathrm{ft}(0.02 \mathrm{~kg} / \mathrm{s}-\mathrm{sq} \mathrm{m})$ for a liquid collector and both 1.96 and $6.0 \mathrm{cfm} / \mathrm{sq} \mathrm{ft}(0.01$ and $0.03 \mathrm{cu} \mathrm{m} / \mathrm{s}-\mathrm{sq} \mathrm{m}$ ) for an air collector. (The efficiency of an air collector is more sensitive to flow rate than that of a liquid collector.) This is done for four different 
values of $\left(t_{f, i}-t_{a}\right): 10 \%, 30 \%, 50 \%$, and $70 \%$ of the stagnation temperature rise at the given conditions. For each case, four data points are taken symmetrically about solar noon. The resulting 16 points are plotted on a graph of $\eta$ vs. $\left(t_{f, j}-t_{a}\right) / I_{t}$ and, for flat plate collectors, a straight line is fitted using a least squares analysis.

\section{Ineident Angle Modifier}

The preceding efficiency tests should all be done very close to solar noon with the collector positioned normal to the Sun's direct rays. If the collector is left in this position, its efficiency will drop during morning and late afternoon hours because of the decreasing value of I and consequent increase in $\Delta t / \mathrm{I}_{\mathrm{t}}$. However, the efficiency curve determined above is valid only for near-normal incidence. At other angles, the to product will be less, thereby moving the whole efficiency curve downward. The incident angle modifier quantifies this change in $(\tau \alpha)$.

Two efficiency tests are performed on the collector for each of four different incident angles: $0^{\circ}$ (normal), $30^{\circ}$, $45^{\circ}$, and $60^{\circ}$. In each case the inlet temperature is controlled to within $\pm 1.8 \mathrm{~F}\left( \pm 1^{\circ} \mathrm{C}\right)$ of the ambient. In each case then,

$$
\begin{aligned}
\eta & =F_{R}(\tau \alpha)-F_{R} U_{L} \frac{t_{f_{,}, i}-t_{a}}{I_{t}} \\
& =\frac{\dot{m}_{p}\left(t_{f, e}-t_{f, i}\right)}{A I_{t}}
\end{aligned}
$$

Since $t_{f, i}=t_{a}, \quad \eta=F_{r}(\tau \alpha)$

The incident angle modifier, $K_{\alpha \tau}$ is defined as:

$$
\mathrm{K}_{\alpha \tau} \equiv \frac{(\tau \alpha)}{(\tau \alpha \ln }
$$

where

$(\tau \alpha)_{n}$ is $(\tau \alpha)$ for the normal incidence case.

Since $\eta=F_{R}(\tau \alpha)$ for these tests, $(\tau \alpha)=\frac{\eta}{F_{R}}$, and

$K_{\alpha \tau}=\frac{\eta}{F_{R}(\tau \alpha)_{n}}$

The $n$ values are determined for each angle, and $F_{R}$ $(\tau \alpha)_{n}$ is just the efficiency value for the $0^{\circ}$ case. The $K_{\alpha \tau}$ values allow one to take the normal incidence efficiency curve and determine the appropriate curve for other angles (i.e., morning and afternoon hours). For flat plate collectors using glass covers, a rule of thumb is that the average daylong value of $\mathrm{K}_{\alpha \tau}, \overline{\mathrm{K}}$ is as follows:

$$
\begin{aligned}
\overline{\mathrm{K}}= & 0.91-\text { double glass } \\
& 0.93-\text { single glass }
\end{aligned}
$$

The incident angle modifier as a function of incidence angle has been formulated as:

$K_{\tau \alpha}(\theta)=\frac{(\tau \alpha)_{\theta}}{(\tau \alpha)_{n}}=1+b_{0} \frac{1}{\cos \theta}-1$

where: $b_{0}$ is the incidence angle modifier coefficient, and $\theta$ is the angle of incidence.

This will give a representative daylong efficiency curve. Remember, however, that the actual efficiency will still vary during the day as $\left(t_{f, i}-t_{q}\right) / I_{t}$ changes.

Fig. 5-29 shows plots of incident angle modifier versus incident angle for several collectors. Note the rapid decrease in $K_{\alpha \tau}$ for a honeycomb collector, due to the absorption and reflection of light by the honeycomb. This deleterious effect must be weighed against the reduction in convective and radiative losses. An evacuated tube collector panel would actually show values of $K_{\alpha \tau}$ greater than one for off-normal incidence angles because of the effective shrinkage of the gaps between tubes.

\section{Stagnation Tests}

HUD has gone one step further and required that efficiency tests of collectors be performed both before and after a 30-day stagnation test. This test is described both in the HUD Intermediate Minimum Property Standards Supplement - Solar Heating and Domestic Hot Water Systems [36] (pp. 5-10) and the NBS Interim Performance Criteria for Solar Heating and Cooling Systems in Commercial Buildings [37] (p. 54).

Prior to the test, liquid collectors are filled with clean tap water, except those made exclusively for drain down systems which are gravity crained first. (If freezing temperatures are possible, an antifreeze solution is used in place of pure tap water). The collectors are sealed and capped with pressure relief set within $10 \%$ of the manufacturer's maximum recommended operating pressure. Flat plate collectors are set at a tilt angle which provides for insolation within $10^{\circ}$ of normal incidence at solar noon. The collector is then exposed to 30 days of cumulative exposure to a radiation flux of at least $1,500 \mathrm{Btu} / \mathrm{sq} \mathrm{ft-day}(17 \mathrm{MJ} / \mathrm{sq} \mathrm{m}$-day $)$ in the collector plane. This exposure must include at least 4 consecutive hours in a flux of $300 \mathrm{Btu} / \mathrm{hr}-\mathrm{sq} \mathrm{ft}$ $(946 \mathrm{~W} / \mathrm{sq} \mathrm{m})$ and with an outside ambient temperature of at least $80 \mathrm{~F}\left(27^{\circ} \mathrm{C}\right)$. This so-called 30 -day stagnation test will often require several months to complete according to the above criteria. 


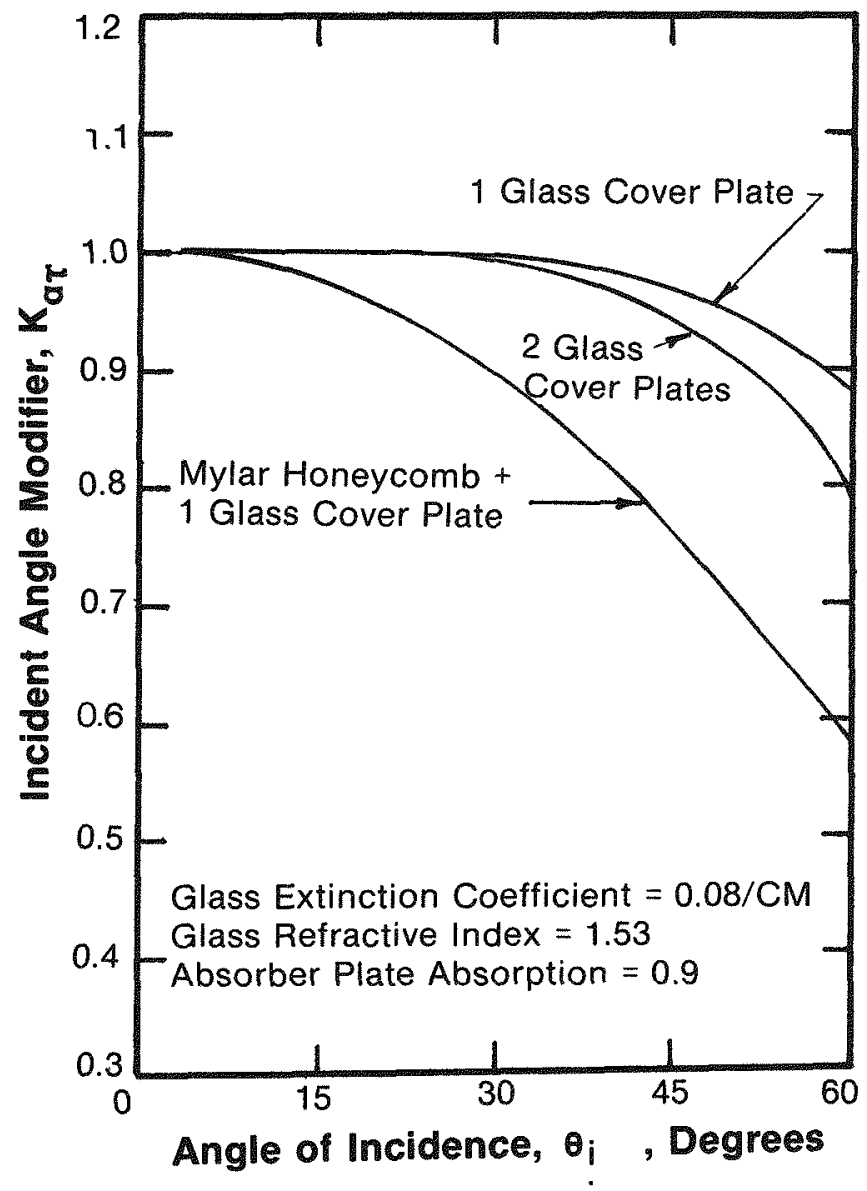

Fig. 5-29. Incident angle modifier for three flat plate collectors

There are several places in the United States that will perform collector testing for manufacturers. Florida has a collector certification program in operation, and California soon will. It is imperative that any collector used be properly tested. Although some people have considered the 30-day stagnation test excessive, it is not at all unusual to see a bank of newly installed collectors sit on the roof of a new building for several weeks prior to being connected to the piping.

\section{Collector Selection and Use}

Based on past government demonstration programs the following precautions are recommended [38-40]:

- Obtain and thoroughly review collector efficiency and stagnation test results.

- Consider maintenance costs, such as replacing plastic glazings every several years. Be sure the collector array installation provides access for maintenance.
- Ensure that collectors are not installed until flow can be provided, or make provisions to cover collectors to protect against stagnation.

- Protect collectors, especially the evacuated tube type, from thermal shock.

- If collectors are to be used at city water pressure, make sure that they are specified for such application. Collectors must be capable of withstanding design pressures without leaking.

- Make sure freeze protection is adequate, particularly in the event of power failure.

- Ensure that collectors are properly handled during delivery and installation. When collectors are delivered, open packages immediatelv in case a damage claim must be filed.

- Be sure header pipe sizes are adequate to ensure uniform flow in the collector array. Reverse return piping is recommended; and, in large arrays, flow balancing valves should be considered.

- When using a tracking collector, talk with others or review DOE project reports regarding problems encountered with trackers and pipe joints.

\section{COLLECTOR COOLANTS}

\section{$\underline{\text { Air }}$}

As a heat transfer fluid, air has the advantages of being readily available and free of cost. Also, leaks will not cause damage although they can definitely degrade system performance. Air cannot freeze or boil, but its low density and specific heat dictate high flow rates which consume fan power, require large duct sizes, and generate noise. Some care must be taken to avoid corrosion; for example, the use of aluminum should be avoided in an air system located near the ocean where the atmosphere is likely to be salty.

\section{Water}

If liquid collectors are to be used, the heat transfer fluid chosen must be compatible with the application. A liquid coolant should have good heat transport capabilities, require low pumping power, remain in a liquid state over the range of possible temperatures and pressures, not promote corrosion, be safe to use, and be inexpensive.

The first two parameters listed above are of ten lumped together to yield a heat transfer efficiency factor, HTEF, which is the ratio of heat transfer coefficient to pumping power [41]. Values of HTEF for a variety of coolants are given in Fig. 5-30. The superiority of water can be clearly seen. It is also inexpensive, safe, and (in most cases) readily available. If it is used in a warm climate or in conjunction with a drain-down freeze protection system and is kept below the boiling point, the only additives that might be needed are corrosion inhibitors. 
The likelihood of corrosion depends on the quality of the water used and the materials in the system. If copper pipe is employed throughout, plain tap water can ordinarily be used. Many solar hot water systems, in fact, circulate pressurized potable water directly through the collector loop. If aluminum or steel is used, corrosion ean be a more significant problem. Chromate or less toxic nitrite inhibitors can be added to tap water to reduce corrosion. More details on corrosion are given later in this section.

\section{Glycol Solutions}

A major problem with plain or corrosion-treated water is its susceptibility to freezing and boiling in many solar system applications. Since water is otherwise such an excellent coolant, it makes sense to solve this problem by mixing it with other fluids. Glycol solutions are the most commonly used antifreeze fluids and when mixed with

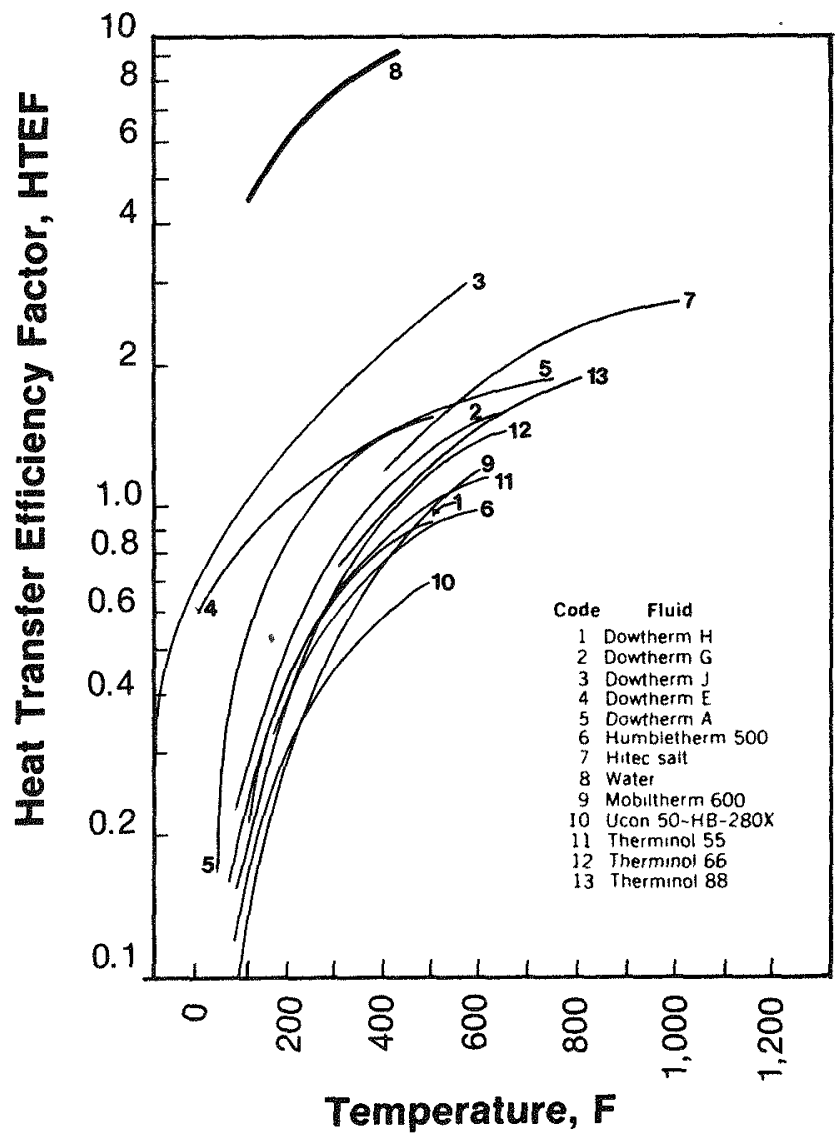

Fig. 5-30. Heat transfer efficiency factors for 13 fluids [41]
Table 5-4. INCREASED FLOW REQUIREMENT FOR SAME HEAT CONVEYANCE: 50\% GLYCOL AS COMPARED WTTH WATER

\begin{tabular}{cc}
\hline $\begin{array}{c}\text { Fluid Temperature } \\
(\mathrm{F})\end{array}$ & $\begin{array}{c}\text { Flow Increase Needed } \\
\text { for 50\% Glycol as Com- } \\
\text { pared with Water }\end{array}$ \\
\hline 40 & 1.22 \\
100 & 1.16 \\
140 & 1.15 \\
180 & 1.14 \\
220 & 1.14 \\
\hline
\end{tabular}

\section{Table 5-5. PRESSURE DROP CORRECTION FACTORS: $50 \%$ GLYCOL SOLUTION COMPARED WTTH WATER}

\begin{tabular}{ccc}
$\begin{array}{c}\text { Fluid } \\
\text { Temperature } \\
\text { (F) }\end{array}$ & $\begin{array}{c}\text { Pressure Drop } \\
\text { Correction } \\
\text { Flow Rates } \\
\text { Equal }\end{array}$ & $\begin{array}{c}\text { Combined Pressure Drop } \\
\text { Correction: 50\% Glycol } \\
\text { Flow Increased } \\
\text { Per Table 5-4 }\end{array}$ \\
\hline 40 & 1.45 & 2.14 \\
100 & 1.1 & 1.49 \\
140 & 1.0 & 1.32 \\
180 & 0.94 & 1.23 \\
220 & 0.9 & 1.18 \\
\hline
\end{tabular}

water will raise the boiling point as well. The two most commonly used glycols are ethylene glycol and propylene glycol.

Ethylene glycol is commonly used as an automobile antifreeze. Typically, the glycol will contain corrosion inhibitors and buffers. The buffers serve to maintain the proper pH level which would otherwise be lowered by organic acids which are formed when glycol is exposed to air at high temperatures. Some brands of ethylene glycol (such as Prestone II*) also contain silicates to inhibit aluminum corrosion.

Propylene glycol is quite similar to ethylene glycol but is less toxic and is somewhat inferior in terms of heat transport capability. Both types of glycol-water mixtures require periodic maintenance to prevent corrosion. They should be replaced at least once per year or, preferably, monitored regularly for pH. (It is also advisable to check the collector fluid after any stagnation condition.) It is generally not advisable to use an automatic water makeup system with a glycol-water loop, since the solution could become unexpectedly diluted and fail to provide adequate freeze protection.

*Prestone II is a trademark of Union Carbide
Corporation. 
A system employing glycols should be cleaned and flushed prior to filling. No galvanized pipe should be used because of the reaction of glycol inhibitors with zine to form sludge. Boiling should be avoided to prevent sludge formation. No chromate treatment should ever be added to glycol solutions.

When using a glycol-water solution, it is important to note that its physical characteristics are somewhat different from those of pure water. The typical $50 \%$ water-ethylene glycol mixture has a slightly higher density yet lower specific heat than water. This means that a higher volum etric flowrate is required, as shown in Table 5-4. The pumping power is also greater, both because of the increased flow rate and because of difference in viscosity. (See Table 5-5.) Finally, it is important to note that the glycol mixture has an expansion rate $20 \%$ greater than that of water. Thus, an expansion or compression tank must have a volume at least $20 \%$ greater than for a water system [3].

\section{Aqueous Salt Solutions}

The use of aqueous inorganic salt solutions has been suggested as an alternative to glycols. According to Kauffman [42], $23 \%$ sodium acetate and $38 \%$ sodium nitrite with phosphate and copper inhibitor additives are the preferred solutions. Their advantages are low toxicity, low pumping power, and long-term stability. (They will not oxidize at high temperatures like glycol.) Thus far, however, they have not been widely used.

\section{Nonaqueous Fluids}

A variety of other heat transfer fluids is available which offer such advantages as low vapor pressure at high temperatures, low corrosion, and long-term stability. Examples of some nonaqueous fluids are:

\section{Parafinic Oils}

Paraffinic oils are often used in high-temperature industrial applications and are generally low in toxicity. Example trade names are Exxon Caloria HT43 and Dowtherm HP. Exposure to air at high temperatures can result in corrosive byproducts, and pumping power is high, particularly at low temperature. Flash point of most paraffinic oils is fairly low $\left[374 \mathrm{~F}\left(190^{\circ} \mathrm{C}\right)\right]$. The flash point of most of the paraffinic oils will fail to meet the HUD and NBS requirement that flash points be at least $100 \mathrm{~F}\left(38^{\circ} \mathrm{C}\right)$ higher than the highest possible system (stagnation) temperature.

\section{Aromatic Oils}

Aromatic oils are similar to paraffinic oils, but have the disadvantages of higher toxicity, lower flash point, and higher cost. Examples are Dowtherm $J$ and Monsanto Therminol 55 and 60 . The flash point, of only $140 \mathrm{~F}$ $\left(60^{\circ} \mathrm{C}\right)$ is also low.

\section{Silicone Fluids}

Primarily manufactured by Dow Corning and GE, these have the advantages of low freezing and pour points, low vapor pressure, low toxicity, low corrosion, relatively high flash point, and excellent long-term stability. However, they are also high in viscosity (resulting in high pumping power), prone to leakage, and high in cost.

A variety of other heat transfer fluids is available. More details on the various heat transfer fluids can be found in Design and Installation Manual for Thermal Energy Storage (ANL-79-15) published by Argonne National Laboratory [43]. Table 5-6 lists the major characteristics of many of the heat transf er fluids discussed above.

\section{Toxicity}

The main hazard in the use of heat transfer fluid is the possibility that it will contaminate potable water. Table 5-7 lists the $L D_{50}$ values for various heat transfer fluids. $\mathrm{LD}_{50}$ refers to the quantity of substance which kills $50 \%$ of dosed test animals within 14 days.

For domestic hot water applications, HUD and NBS require a double-walled heat exchanger whenever a toxic collector fluid is used. Some fluids may qualify as nontoxic, but they can deteriorate with time. Also there is always the possibility that someone will inadvertently replace the fluid with a toxic substitute at some future date. It is thus safest to always use a double-walled heat exchanger, except when city water is supplied directly to the collectors. It is advisable in any case to place at the fluid fill location a tag which contains information regarding the proper coolant to be used.

\section{Corrosion}

The importance of corrosion prevention involving the use of water and water-glycol mixtures (by far the most commonly used fluids in solar heating and cooling applications) has already been mentioned in describing these fluids. Corrosion is a complex phenomenon in which many parameters are involved.

Popplewell [44] has cited four types of internal corrosion that can be affected by a heat transfer fluid: 
Table 5-6. COMMERCIALLY AVAILABLE HEAT TRANSFER FLUIDS ${ }^{(1)}$ (From Ref. 42)

\begin{tabular}{|c|c|c|c|c|c|c|c|c|}
\hline Medium & $\begin{array}{l}\text { Density } \\
\mathrm{kg} / \mathrm{cu} \mathrm{m}\end{array}$ & $\begin{array}{l}\text { Viscosity } \\
\text { centipoise }\end{array}$ & $\begin{array}{c}\text { Heat } \\
\text { Capacity } \\
\text { cal/gm }{ }^{\circ} \mathrm{C}\end{array}$ & $\begin{array}{l}\text { Freezing } \\
\text { Point } \\
{ }^{\circ} \mathrm{C}\end{array}$ & $\begin{array}{l}\text { Anti- } \\
\text { Corrosion } \\
\text { Protection } \\
\text { (2) }\end{array}$ & $\begin{array}{c}\text { High } \\
\text { Temperature } \\
\text { Reactions }\end{array}$ & $\begin{array}{c}\text { Toxicity } \\
\text { Requires } \\
\text { Double } \\
\text { Wall? (4) }\end{array}$ & $\begin{array}{l}\text { Price } \\
\text { \$/gallon }\end{array}$ \\
\hline \multicolumn{9}{|l|}{ AQUEOUS FLUIDS } \\
\hline Water & 1000 & $0.5-0.9$ & 1 & 0 & $\begin{array}{l}\text { None for copper, } \\
\text { nitrites or } \\
\text { chromates and a } \\
\text { pH buffer in a } \\
\text { closed loop for } \\
\text { steel or aluminum }\end{array}$ & Boils at $100^{\circ} \mathrm{C}$ & $\begin{array}{l}\text { No. (Yes if } \\
\text { chromate or } \\
\text { nitrite in- } \\
\text { hibitors are } \\
\text { added.) }\end{array}$ & \\
\hline $\begin{array}{l}50 \mathrm{wt} \text {. \% water- } \\
\text { ethylene glycol }\end{array}$ & 1050 & $1.2-4.4$ & 0.83 & -36 & $\begin{array}{l}\text { Silicates, } \\
\text { pH buffer (3) }\end{array}$ & $\begin{array}{l}\text { Boils at } 110^{\circ} \mathrm{C} \\
\text { degrades slowly } \\
\text { to formic acid } \\
\text { above } 150^{\circ} \mathrm{C}\end{array}$ & Yes & 1.50 \\
\hline $\begin{array}{l}50 \% \text { water- } \\
\text { propylene glycol }\end{array}$ & 1022 & $1.4-7.0$ & 0.87 & -31 & $\begin{array}{l}\text { Phosphates, } \\
\text { pH buffer ( } 3 \text { ) }\end{array}$ & $\begin{array}{l}\text { Boils at } 110^{\circ} \mathrm{C} \\
\text { not recommended } \\
\text { above } 150^{\circ} \mathrm{C}\end{array}$ & No & 2.00 \\
\hline ORGANIC FLUIDS & & & & (pour pt.) & & & & \\
\hline $\begin{array}{l}\text { Paraffinic Oils } \\
\text { (Exxon Caloria HT } 43 \\
\text { or Dowtherm HP) }\end{array}$ & 821 & 11 & 0.51 & -7 & Not needed & $\begin{array}{l}\text { Flash point } 190^{\circ} \mathrm{C} \\
\text { oxidizes slowly } \\
\text { if exposed to air } \\
\text { above } 110^{\circ} \mathrm{C}\end{array}$ & No & $1.65(5)$ \\
\hline $\begin{array}{l}\text { Aromatic Oils } \\
\text { (Dowtherm J or } \\
\text { Monsanto Therminol 55) }\end{array}$ & 830 & 0.6 & 0.46 & -70 & Not needed & $\begin{array}{l}\text { Flash point } 63^{\circ} \mathrm{C} \\
\text { oxidizes slowly on } \\
\text { exposure to air } \\
\text { above } 150^{\circ} \mathrm{C}\end{array}$ & Yes & 4.65 \\
\hline $\begin{array}{l}\text { Silicone Oils } \\
\text { (GE SF-96 or Dow }\end{array}$ & 970 & 50 & 0.36 & -85 & Not needed & $\begin{array}{l}\text { No known problems, } \\
\text { flash point is }\end{array}$ & No & $\begin{array}{l}14.90- \\
23.80\end{array}$ \\
\hline Corning Q2-1132) & 960 & 15 & 0.38 & -120 & & above $260^{\circ} \mathrm{C}$ & & \\
\hline
\end{tabular}

1. Properties are average values between $30^{\circ} \mathrm{C}$ and $65^{\circ} \mathrm{C}$. Thermal conductivities are not presented because of a lack of data.

2. Inhibitors are added primarily to protect aluminum and steel. Special copper anticorrosion agents such as MBT (2-mercaptobenzotriazole), BTZ (benzotriazole) or TTZ (tolyl triazole) may be added to prevent galvanic corrosion from copper ions.

3. Glyeol solutions should not be used with zine galvanized plumbing.

4. The double wall requirement applies only to potable water systems.

5. Prices are for 55 gallon drum orders except in the case of Dowtherm HP which is $\$ 0.25$ per pound for a 2,000 minimum order.

6. Prices quoted were in effect in 1977. 
Galvanic corrosion is caused by the junction of two dissimilar metals in an electrolytic solution. Insulating couplings used between dissimilar metals can sometimes eliminate this problem; however, in many cases metal can still enter the fluid and travel to the site of another metal.

Pitting corrosion involves rapid local metal loss. Aluminum and steel are susceptible to the presence of chloride ions. Aluminum is also susceptible to the presence of metal ions.

Crevice corrosion is similar to pitting corrosion but occurs at crevices in the system, such as those at spotwelded joints.

Erosion corrosion refers to the erosion that can be produced on any metal by high local fluid velocity.

The various parameters involved in corrosion are well described in the HUD Intermediate Minimum Property Standards Supplement - Solar Heating and Domestic Hot Water Systems.

These are:

- the composition of the metals

- the composition of the fluid

- the temperature

- the flow rate

- system design (such as use of multiple metals)

- presence of additives.

Corrosion is more of a problem with aqueous fluids than with the non-aqueous fluids discussed earlier. High oxygen or chloride content will accelerate corrosion, as will an improper $\mathrm{pH}$. Corrosion ordinarily increases with temperature. Table 5-8 shows the acceptable and unacceptable use conditions for various metals in contact with aqueous fluids in an open system (i.e., one in which the fluid is constantly exposed to air, such as drain-down systems). Table 5-9 shows similar conditions for a closed system. More details can be found in Refs. 36, 37, and 43. In addition to internal corrosion, the potential for damage to roofing material as a result of coolant leaks or discharge from a relief valve should also be considered. Relief valves should discharge to a drain to avoid this problem as well as to ensure the safety of any individuals near the collector array.

\section{THERMAL ENERGY STORAGE FOR BULDING HEATING AND COOLING}

Heating and cooling loads of buildings are of ten poorly matched to the time profile of the supply of available energy. The most obvious case of such a mismatch is
Table 5-7. TOXICITIES OF HEAT TRANSFER FLUIDS (g/kg) (Ref. 43)

\begin{tabular}{|c|c|}
\hline Fluid & $\mathrm{LD}_{50}$ \\
\hline Water & - \\
\hline $\begin{array}{l}100 \% \text { Ethylene Glycol } \\
\text { (No inhibitors) }\end{array}$ & 8.0 \\
\hline $\begin{array}{l}100 \% \text { Propylene Glycol } \\
\text { (No inhibitors) }\end{array}$ & 34.6 \\
\hline $\begin{array}{l}\text { 100\% Diethylene Glycol } \\
\text { (No inhibitors) }\end{array}$ & 30. \\
\hline $\begin{array}{l}\text { 100\% Triethylene Glycol } \\
\text { (No inhibitors) }\end{array}$ & 30. \\
\hline $100 \%$ Dowtherm SR-1 & 4. \\
\hline Mobiltherm Light & 20. \\
\hline SF-96(50) (Silicone) & 50 \\
\hline Q2-1132 (Silicone) & 50 \\
\hline Dowtherm J & 1.1 \\
\hline Therminol 44 & 13.5 \\
\hline Therminol 55 & 15.8 \\
\hline Therminol 60 & 13.0 \\
\hline Sun-Temp & $\begin{array}{l}\text { No test info } \\
\text { available }\end{array}$ \\
\hline
\end{tabular}

manifested in our inability to easily use summer warmth for winter heating demands. Solar energy, unlike energy from fossil fuels, is not available to heat buildings at night or on cloudy days. This is especially the case in northern latitudes. Cooling loads that are nearly coincident with maximum levels of solar radiation of ten are present after sunset. Energy storage can be an economical means of correcting this availability mismatch.

A building designer requires some basic information about energy storage before proceeding with any given project. What types of storage are available? How much storage is required? How will inclusion of storage affect system performance, reliability, and cost? What storage systems or designs are available? This section either provides answers to these questions or directs the reader to pertinent literature. Although energy can also be stored by a variety of chemical, electrochemical, or mechanical means, only low-temperature thermal energy storage (TES) is considered here. TES is presently the most economical storage technology for building heating and cooling applications. 
Table 5-8. GENERALLY ACCEPTABLE AND UNACCEPTABLE USE CONDITIONS FOR METALS IN DIRECT CONTACT WITH HEAT TRANSFER LIQUIDS IN OPEN SYSTEMS (from Ref. 36)

Generally Unacceptable

Use Conditions
Generally Acceptable

Use Conditions

\section{ALUMINUM}

1. When in direct contact with untreated tap water with $\mathrm{pH}<5$ or $>9$.

2. When in direct contact with aqueous liquid containing less electro positive metal ions such as copper or iron or halide ions.

3. When specific data regarding the behavior of a particular alloy are not available, the velocity of aqueous liquid shall not exceed $4 \mathrm{ft} / \mathrm{sec}$.

4. When in direct contact with a liquid which is in contact with corrosive fluxes.
1. When in direct contact with distilled or deionized water which contains appropriate inhibitors and does not contact copper or iron.

2. When in direct contact with distilled or deionized water which contains appropriate inhibitors and a means of removing heavy metal ions obtained from contact with copper or iron.

3. When in direct contact with stable anhydrous organic liquids.

\section{COPPER}

1. When in direct contact with aqueous liquid containing high concentrations of chlorides, sulfates, or liquid which contains hydroden sulfide.

2. When in direct contact with chemicals that can form copper complexes such as ammonium compounds.

3. When in direct contact with an aqueous liquid having a velocity greater than $4 \mathrm{ft} / \mathrm{sec}^{2}$

4. When in direct contact with a liquid which is in contact with corrosive fluxes.

5. When in contact with an aqueous liquid with a $\mathrm{pH}$ lower than 5 .

6. When the copper surface is initially locally covered with a copper oxide film or a carbonaceous film.

7. When operating under conditions conducive to water line corrosion.

\section{STEEL}

1. When in direct contact with untreated tap, distilled, or deionized water with $\mathrm{pH}<5$ or $>12$.

2. When in direct contact with a liquid which is in contact with corrosive fluxes.

3. When in direct contact with an aqueous liquid having a velocity greater than $6 \mathrm{ft} / \mathrm{sec}^{2}$

4. When operating under conditions conducive to water line corrosion.
1. When in direct contact with distilled, deionized or low chloride, low sulfate and low sulfide tap water.

2. When in direct contact with stable anhydrous organic liquids.

1. When in direct contact with distilled, deionized or low salt content water which contains appropriate corrosion inhibitors.

2. When in direct contact with stable anhydrous organic liquids.

3. When adequate cathodic protection of the steel is used (practical only for storage tanks). 
Table 5-8. GENERALLY ACCEPTABLE AND UNACCEPTABLE USE CONDITIONS CONTACT WITH HEAT TRANSFER LIQUIDS IN OPEN SYSTEMS (continued)

Generally Unacceptable

Use Conditions
Generally Acceptąble

Use Conditions

\section{STAINLESS STEEL}

1. When the grade of stainless steel selected is not corrosion resistant in the anticipated heat transfer liquid.

2. When in direct contact with a liquid which is in contact with corrosive fluxes.
1. When the grade of stainless steel selected is resistant to pitting, crevice corrosion, intergranular attack, and stress corrosion cracking in the anticipated use conditions.

2. When in direct contact with stable anhydrous organic liquids.

\section{GALVANIZED STEEL}

1. When in direct contact with aqueous liquid containing copper ions.

2. When in direct contact with aqueous liquid with $\mathrm{pH}$ $<7$ or $>12$.

3. When in direct contact with aqueous liquid with a temperature $>55 \mathrm{C}$.
1. When adequate cathodic protection of the galvanized parts is used (practical only for storage tanks.)

2. When in contact with stable anhydrous organic liquids.

\section{BRASS AND OTHER COPPER ALLOYS}

Brass copper-zine brass alloys (CDA 2XXX series) exhibit generally the same behavior as copper when exposed to the same conditions. However, the brass selected shall resist dezincification in the operating conditions anticipated. At the zinc contents of $15 \%$ and greater, these alloys become increasingly susceptible to stress corrosion. Selection of brass with a zinc content below $15 \%$ is advised. There is a variety of other copper alloys available, notably coppernickel alloys, which have been developed to provide improved corrosion performance in aqueous environments.

1 The use of suitable antifreeze agents and buffers is acceptable provided they do not promote corrosion of the metallic liquid containment system. The use of suitable corrosion inhibitors for specific metals is acceptable provided they do not promote corrosion of other metals present in the system. If thermal or chemical degradation of these compounds occurs, the degradation products shall not promote corrosion.

${ }^{2}$ The flow rates at which erosion/corrosion becomes significant will vary with the conditions of operation. Accordingly, the value listed is approximate. 
Table 5-9. GENERALLY ACCEPTABLE AND UNACCEPTABLE USE CONDITIONS FOR METALS IN DIRECT CONTACT WTH HEAT TRANSFER LIQUIDS IN CLOSED SYSTEMS (from Ref. 36)

Generally Unacceptable

Use Conditions
Generally Acceptable

Use Conditions

ALUMINUM

1. When in direct contact with untreated tap water with $\mathrm{pH}<5$ or $>9$.

2. When in direct contact with liquid containing copper, iron, or halide ions.

3. When specified data regarding the behavior of a particular alloy are not available, the velocity of aqueous liquids shall not exceed $4 \mathrm{ft} / \mathrm{sec}$.
1. When in direct contact with distilled or deionized water which contains appropriate corrosion inhibitors.

2. When in direct contact with stable anhydrous organic liquids.

\section{COPPER}

1. When in direct contact with an aqueous liquid having a velocity greater than $4 \mathrm{ft} / \mathrm{sec}^{2}$

2. When in contact with chemicals that can form copper complexes such as ammonium compounds.
1. When in direct contact with untreated tap, distilled, or deionized water.

2. When in direct contact with stable anhydrous organic liquids.

3. When in direct contact with aqueous liquids which do not form complexes with copper.

STEEL

1. When in direct contact with liquid having a velocity greater than $6 \mathrm{ft} / \mathrm{sec}^{2}$

1. When in direct contact with untreated tap, distilled, or deionized water.

2. When in direct contact with stable anhydrous organic liquids.

3. When in direct contact with aqueous liquids of $5<\mathrm{pH}>12$.

\section{STAINLESS STEEL}

1. When the grade of stainless steel selected is not corrosion resistant in the anticipated heat transfer liquid.

2. When in direct contact with a liquid which is in contact with corrosive fluxes.

1. When the grade of stainless steel selected is resistant to pitting, crevice corrosion, intergranular attack and stress corrosion cracking in the anticipated use conditions.

2. When in direct contact with stable anhydrous organic liquids.

\section{GALVANIZED STEEI}

1. When in direct contact with water with $\mathrm{pH}<7$ or $>12$. 1. When in contact with water of $\mathrm{pH}>7$ but $<12$.

2. When in direct contact with an aqueous liquid with a temperature $>\mathbf{5 5}{ }^{\circ} \mathrm{C}$. 
Table 5-9. GENERALIY ACCEPTABLE AND UNACCEPTABLE USE CONDMIONS FOR METALS IN DIRECT CONTACT WITH HEAT TRANSFER LIQUIDS IN CLOSED SYSTEMS (continued)

\section{BRASS AND OTHER COPPER ALLOYS}

Binary copper-zine brass alloys (CDA 2 XXX series) exhibit generally the same behavior as copper when exposed to the same conditions. However, the brass selected shall resist dezincification in the operating conditions anticipated. At zinc contents of $15 \%$ and greater, these alloys become increasingly susceptible to stress corrosion. Selection of brass with a zine content below $15 \%$ is advised. There is a variety of other copper alloys available, notably copper-nickel alloys, which have been developed to provide improved corrosion performanee in aqueous environments.

1 The use of suitable antifreeze agents and buffers is acceptable provided they do not promote corrosion of the metallic containment system. The use of suitable corrosion inhibitors for specific metals is acceptable provided they do not promote corrosion of other metals present in the system. If thermal or chemical degradation of these compounds occurs, the degradation products shall not promote corrosion.

${ }^{2}$ The flow rates at which erosion/corrosion becomes significant will vary with the conditions of operation. Accordingly, the value listed is approximate.

\section{SHACOB Path Schematics}

\section{DESCRIPTION/SOURCE}

THERMAL STORAGE

CONDITIONING

THERMAL STORAGE END USE
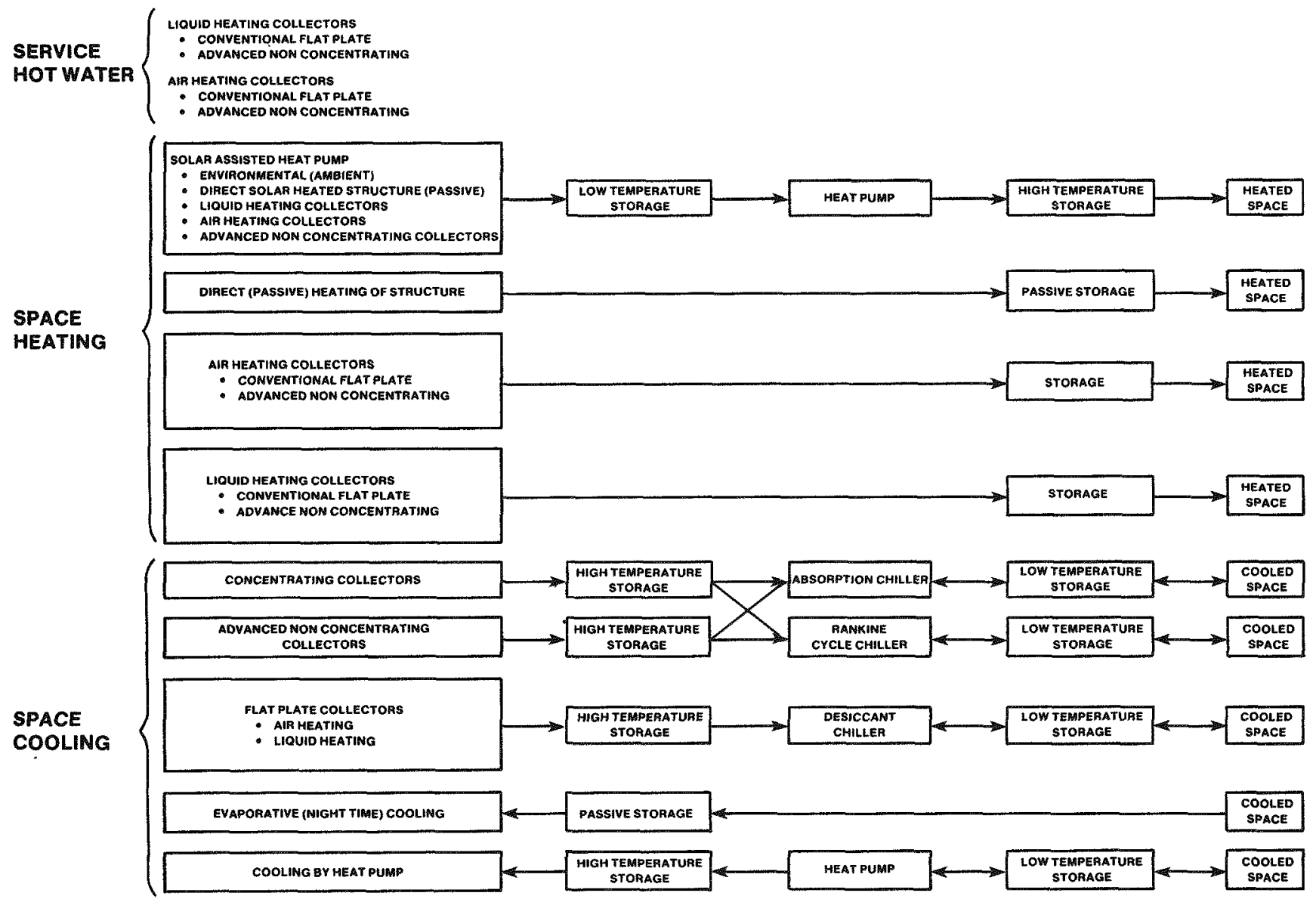

Fig. 5-31. Solar heating and cooling of buildings path schematics 
This section is organized as follows. First, various applications for TES are listed. Second, some unifying technical parameters of TES are explored. Third, technical options are categorized and briefly described. Fourth, design characteristics of water tank and rock-bed storages for building heating and cooling are detailed. Fifth, design characteristics of passive storage are briefly outlined. Information included in the fourth section also applies to passive storage. Finally, useful references are listed and discussed.

\section{TTS Applications}

TES can be critical components in many solar energy systems for delivering service hot water, space heating, or space cooling. Storage may allow solar energy to provide up to $100 \%$ of the requirement of a particular application. Fig. 5-31 from Ref. 45 demonstrates how both low- and high-temperature TES aids in matching energy loads and supplies. Aside from the possible use of nonsolar energy sources for powering energy conditioning equipment as indicated in Fig. 5-31, this schematic does not indicate how other renewable or nonsolar energy sources can be used either alone or in hybrid solar systems with TES. For example, research is underway to determine the feasibility of using industrial waste heat that would be stored in an underground aquifer for heating the homes of a nearby community [46]. Also, for example, TES used with off-peak electrical resistance heating for space heating is a proven technology in England, Wales, and Germany [47] and is being widely tested in the United States [48]. Applications for TES are numerous; and as suitable technologies having competitive economics are developed, such devices will be increasingly used.

\section{Technical Characteristics}

TES devices can be generically defined without detailing the underlying technical design. Such considerations allow the designer a more thorough perspective.

\section{Energy and Power Components}

The rate of input and withdrawal of energy from storage is determined by power-related components such as heat exchangers, piping, and ducting. The amount of energy stored is determined by container sizes; by the characteristics of the storage media; and, usually, by the temperature of the storage media.

\section{Storage Efficiency}

First law efficiency or round-trip storage efficiency is determined by energy losses. Except in cases where energy is lost directly to the load, required storage sizes are inversely proportional to storage efficiency. Second law efficiencies are also important design parameters. Even if round-trip efficiency were $100 \%$ (i.e., equal energy input and withdrawal), a lower output than input temperature allows less work to be done by this energy and also increases the requirement for heat exchanger surface area.

\section{Duration of Storage}

Solar applications require storage of thermal energy from very short durations (e.g., buffer storage of minutes for solar thermal power plants) to annual cycle time scales. Most solar systems presently use diurnal storages in which energy can be stored for a period of at most a day or two. Annual cycle storages have a number of advantages. Energy collected on long, hot summer days can be used on shorter and colder winter days. The need for backup systems can be eliminated because periods of adverse weather have little effect on thermal energy availability. Collector areas can be reduced, and problems with collector stagnation in summer are minimized. Also, annual cycle energy systems are a natural match for well-designed energy management systems in which excess heat or coolness from the environment or adjacent structures can be saved for later use. Diurnal systems have other advantages. Capital investments for storages and energy losses are usually lower. These devices are smaller and can be easily manufactured off-site. Sizing of daily storage for each application is not nearly as critical as it is for larger annual storage.

\section{Single Operation Colleetion/Storage Devices}

Some storages function both as energy collectors and storages (e.g., solar ponds, chemical heat pumps, mass walls). These allow for rather simple designs and may, in some cases, result in lower delivered energy costs.

\section{Scale}

Larger sensible heat or phase change material storages have lower unit heat losses (the surface area to volume ratio for a spherical tank decreases with increasing tank size). Community systems offer the potential for use of, at most, one backup system, statistical averaging of shared loads, and other economies of scale. However, annual storage may be economical only in multi-dwelling designs. In such cases, expensive energy distribution systems are required. Also, novel institutional arrangements relating to ownership and financing may have to be devised.

\section{Design Tradeoffs}

A number of design tradeoffs are listed below. This collection is not complete but illustrates the design 


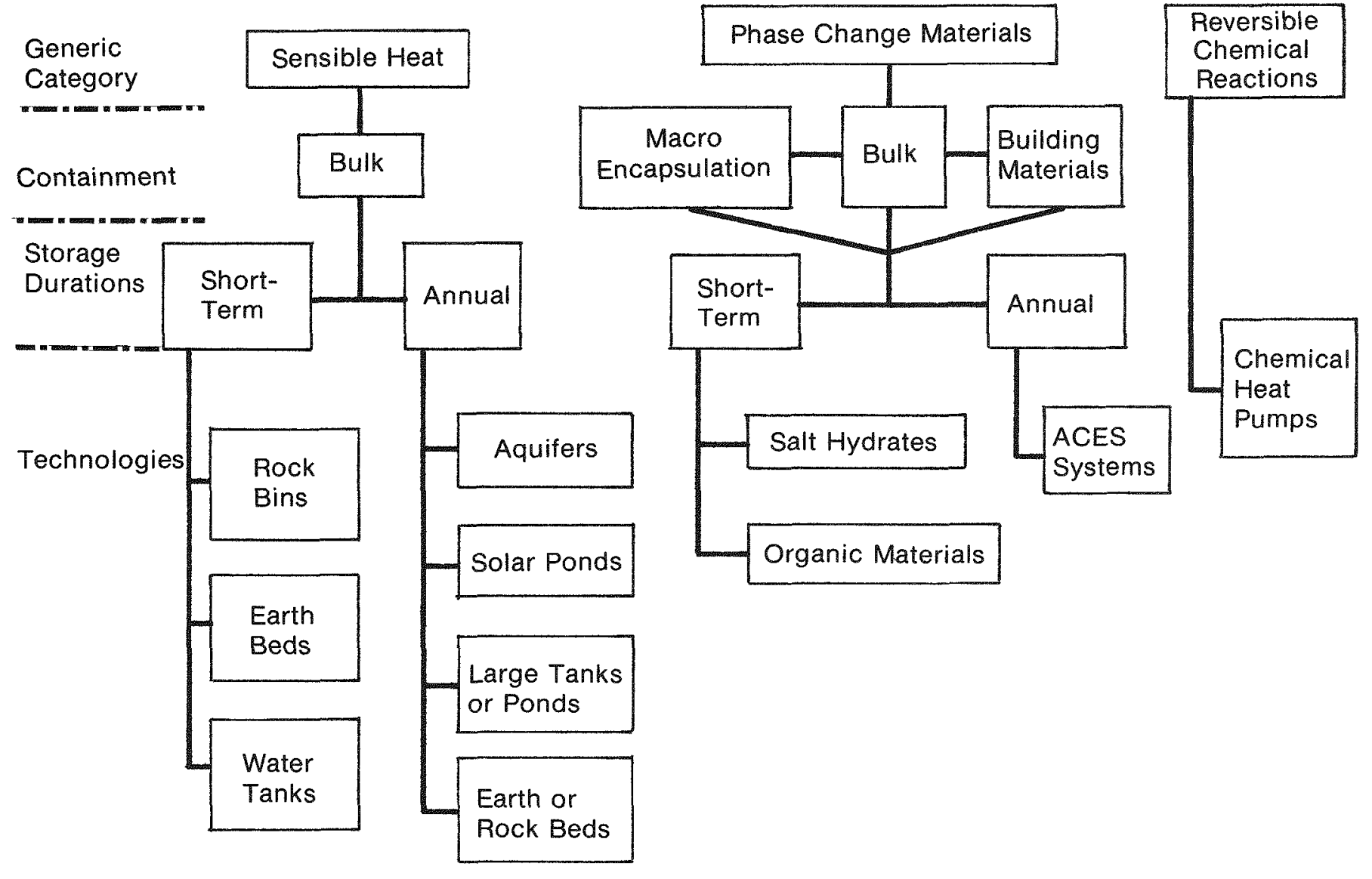

Fig. 5-32. Available devices for storing low-temperature thermal energy

complexity of incorporating storage into energy delivery systems.

- Storage temperature versus container size

- Storage temperature versus heat exchanger size

- Power requirements versus heat exchanger size

- Efficiency versus duration of storage

- Efficiency versus storage size

- Efficiency versus heat exchanger size

- Energy density versus materials corrosion

- Energy density versus container cost

\section{Storage Technologies}

Options for storing low temperature thermal energy are numerous. Fig. 5-32 lists a classification of the available devices. These are briefly described below. More complete descriptions can be found in the literature referred to at the end of the section.

\section{Sensible Heat Storage}

The amount of energy stored by sensible heat devices is proportional to the differences between storage input and output temperatures times the heat capacity of the particular medium used. Water has approximately twice the heat capacity $\left[1 \mathrm{Btu} / \mathrm{lb} \mathrm{F}\left(2,326 \mathrm{~J} / \mathrm{kg}^{\circ} \mathrm{C}\right)\right]$ of rock and earth. Sensible heat storages consist of a storage medium, a container, and input-output devices. Containers must both retain storage material and prevent the loss of thermal energy. Thermal stratification, a thermal gradient across storage, allows easier withdrawal of energy from storage because output temperatures are higher. In addition, solar collectors can operate in higher efficiency ranges for a given average storage temperature because the temperature of the fluid from storage to collectors is lower. Maintaining stratification is much simpler when using solid storage media such as rocks or earth than it is with water or other fluids.

A number of rather novel technologies are among the possible annual storages. Aquifers are large geological formations which can be tapped into by wells. Although some technical problems such as biofouling and clogging of pipes and wells remain to be solved, this technology 


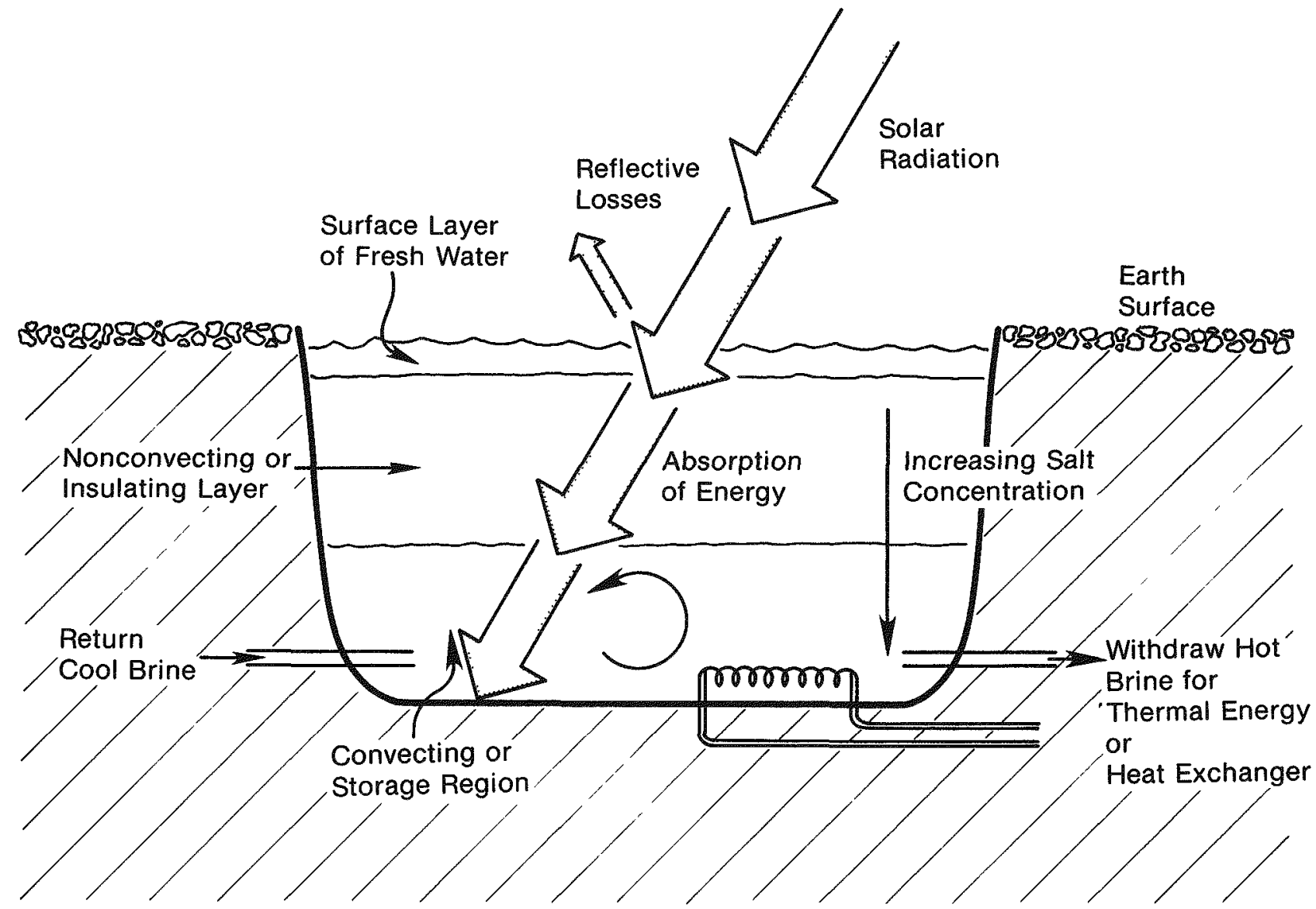

Fig. 5-33. Solar pond

offers potentially very low-cost storage for larger scale systems. Except for the cost of access wells, the aquifer container is essentially free. However, the rather low round-trip aquifer storage efficiencies ( 70\%) may mandate use of these technologies in conjunction with low-cost energy supplies such as industrial waste heat.

Solar ponds are both low-temperature solar collectors and long-term storage devices. Solar energy is trapped and stored (see Fig. 5-33) because the heavier salt water at the bottom counteracts the natural tendency to lose energy by convective currents. Salt gradient solar ponds may be economically attractive in climates having little snow and in areas where land is readily available.

\section{Latent Heat-of-Fusion Storage}

If they meet several criteria, materials that undergo a change of phase within a suitable temperature range can be useful for energy storage. The phase change must be accompanied by high latent heat and must be reversible over a very large number of cycles without serious degradation.

The most extensively tested phase change material is the "Glaubers' salt" $\left(\mathrm{Na}_{2} \mathrm{SO}_{4} 10 \mathrm{H}_{2} 0\right)$. A pound of Glaubers' salt absorbs $104 \mathrm{Btu}(109 \mathrm{~kJ})$ at melting at $90 \mathrm{~F}\left(32^{\circ} \mathrm{C}\right)$ and about $21 \mathrm{Btu}(22 \mathrm{~kJ})$ as its temperature rises another $30 \mathrm{~F}\left(17^{\circ} \mathrm{C}\right)$. To store the same $125 \mathrm{Btu}(132 \mathrm{~kJ})$ over the same rise would require about $4 \mathrm{lb}(1.8 \mathrm{~kg})$ of water or $20 \mathrm{lb}(9 \mathrm{~kg})$ of rock. Other combinations of sodium salts and nucleating agents, as well as paraffins, have melting points that cover a wide range of temperatures, making some suitable for cold storage on the low-temperature side of an air-conditioning system, while others are useful for storing heat gathered by solar collectors.

Heat-of-fusion storage systems show considerable promise for low-volume, low-cost storage, require less volume than water, and operate over a small temperature range. At present, the main disadvantage of phasechange storage is that after a number of phase-change cycles, as in the case of sodium sulfate decahydrate, the anhydrous salt tends to separate from the water, which slows down the reverse phase-change, and makes the storage much less effective. To prevent this separation, other substances are added to the phase-change salts. One common additive is Borax. Other thixotropic additives which prevent the anhydrous salt from settling down during the phase-change cycle have been attempted. 
To increase the efficiency of heat transfer to and from the phase-change salts, the salts should be enclosed in tubes or flat trays. At this writing, the salts are considerably more expensive than water storage tanks.

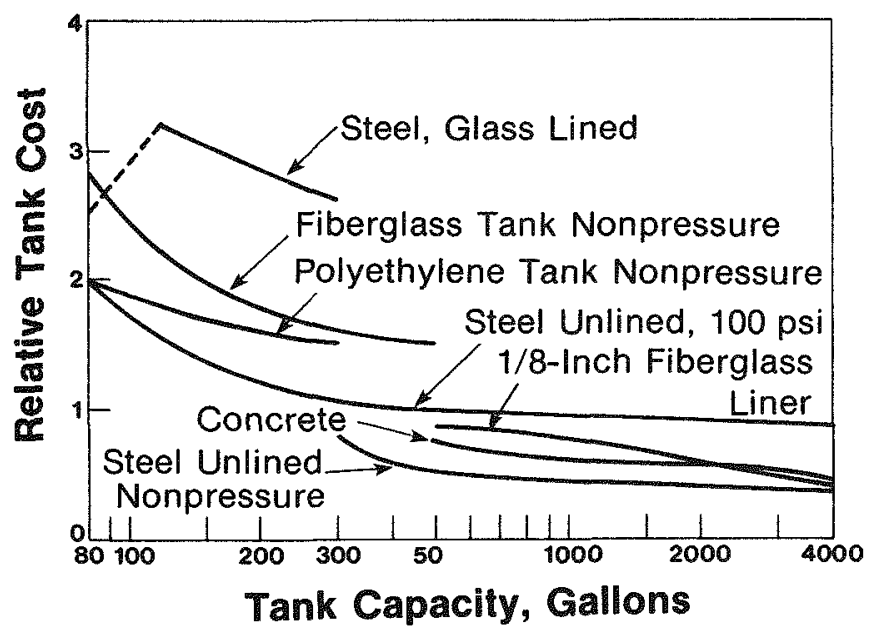

Fig. 5-34. Relative cost of various container
types

\section{Reversible Chemical Reaction Storage}

Thermal energy can be used to drive a chemical reaction, the products of which can be stored indefinitely at room temperature with no loss of capacity. When required, they are recombined in a chemical reaction which releases thermal energy.

The chemical heat pump (CHP) is the primary application for reversible chemical reactions in low-temperature TES. These devices can be used for both heating and cooling applications and, like standard electrical heat pumps, make use of environmental energy. COPs of 1.6 for heating and 0.7 for cooling applications have been predicted. Presently, six basic systems are in differing early stages of development. These are ammoniated salt, hydrated salt, methanolated salt, dilute/concentrated sulfuric acid, hydrated zeolite, and hydrogenated metal systems. All these devices are described in more detail in the publications listed in Table 5-12.

\section{Rock Beds and Water Tank Storages}

Commercially available storage devices consist of a wellinsulated container, a storage medium, and provisions for adding and withdrawing heat from storage. Design parameters of rock-bed and water storages are outlined below. It must be stressed that more detailed information can be found in the reports listed in the final section (especially the Design and Installation Manual for Thermal Energy Storage [53]).

\section{Type of Containers}

Water based storages require insulated leakproof tanks which are the major cost component of such systems. In December 1977, Solar Engineering Magazine [49] listed manufacturers of steel tanks and 17 manufacturers of plastic or fiberglass tanks of many different sizes and shapes. Tanks fall into four major categories: steel, fiberglass or reinforced plastics, concrete, and wooden. Characteristics, advantages, disadvantages, and costs of such tanks are listed in Table 5-10.

The cost ranges listed in Table 5-10 are very approximate. Such costs depend upon tank size (see Fig. 5-34), location, installation requirements, temperature ranges, and insulation needs. It must be stressed that the costs for much larger tanks for longer duration storages can be substantially lower, perhaps as low as $\$ 0.05 /$ gallon.

Rock beds are much simpler to construct than are water tanks. Common materials can be used, and excessive insulation is not required because rock has rather low thermal conductivity. In addition, corrosion problems are eliminated, and small leaks cause little problem. A detailed discussion of rock-bed design is given in Ref. 43 .

\section{Storage Size}

A given collector area will supply a given portion of the load of a building. Undersizing the thermal energy storage will result in heat supplied by the solar collectors being wasted. For short duration storages which are relatively much less expensive than collectors, this is an uneconomical behavior. Storage must be sized correctly.

A simple argument can be presented to explain the logic behind storage sizing. On a typical heating day, initial inerements to storage capacity are used during periods of cloud cover and during the night. As more storage is added a point is reached where all the capacity is not used every night. Solar systems designed to achieve total independence from backup energy sources using shortterm storage must be designed to have enough storage for periods of extended cloudy weather. The final marginal addition of storage to $100 \%$ solar system is found to be very expensive. This analysis is highly dependent on yearly demand and supply variations. The optimal amount of storage on mid-winter days is certainly different from the optimal amount of storage required on a fairly warm February night. Yearly data must be incorporated into a design simulation and optimization in order to provide the overall optimum. Such considerations demonstrate why systems that function year-round, such as combined heating and cooling or domestic hot water systems that are more highly utilized, have more economic promise. 
Table 5-10. STORAGE TANK CHARACTERISTICS

\begin{tabular}{|c|c|c|c|c|}
\hline Type & Advantages & Disadvantages & $\begin{array}{l}\text { Temperature } \\
\text { limitations }\end{array}$ & $\begin{array}{l}\text { Cost } \\
\text { range } \\
(\$ 1 \text { gal) }\end{array}$ \\
\hline Steel & $\begin{array}{l}\text { Can be pressurized } \\
\text { Much field experience } \\
\text { Easy plumbing } \\
\text { connections }\end{array}$ & $\begin{array}{l}\text { Complete tanks } \\
\text { difficult to install } \\
\text { indoors } \\
\text { Subject to rust } \\
\text { and corrosion }\end{array}$ & none & $0.70-0.96$ \\
\hline Fiberglass & $\begin{array}{l}\text { Factory insulated } \\
\text { tanks available } \\
\text { - Much field } \\
\text { experience } \\
\text { - No corrosion }\end{array}$ & $\begin{array}{l}\text { Maximum temperature } \\
\text { is limited } \\
\text { Cannot be } \\
\text { pressurized } \\
\text { Complete tanks } \\
\text { difficult to install } \\
\text { indoors }\end{array}$ & $<150-200^{\circ} \mathrm{F}$ & $1.29-2.42$ \\
\hline Concrete & $\begin{array}{l}\text { May be precast } \\
\text { or cast in place }\end{array}$ & $\begin{array}{l}\text { Possibility of } \\
\text { cracks and leaks } \\
\text { Cannot be } \\
\text { pressurized } \\
\text { Difficult to make } \\
\text { leak-tight plumbing } \\
\text { connections }\end{array}$ & $<210^{\circ} \mathrm{F}$ & $0.69-0.92$ \\
\hline Wooden & $\begin{array}{l}\text { Indoor instal- } \\
\text { lation easy }\end{array}$ & $\begin{array}{l}\text { Maximum temper- } \\
\text { ature limited } \\
\text { Cannot be } \\
\text { pressurized } \\
\text { Not suitable } \\
\text { for underground } \\
\text { installation }\end{array}$ & $<160^{\circ} \mathrm{F}$ & $0.62-1.78$ \\
\hline
\end{tabular}

a) These cost estimates are based upon 1975 costs inflated to 1979 prices. Costs are for smaller tanks for daily storages only. 
The quantity of storage media required is dependent upon the heat capacity or, for latent heat storages, the latent heat of fusion. The volumetric heat capacity, determined by multiplying a material's heat capacity by its density, defines how much volume of a material is required for a given amount of energy storage. Water has a volumetric heat capacity of $62.4 \mathrm{Btu} / \mathrm{cu} \mathrm{ft} \mathrm{F}$; rock (with allowances for $30 \%$ voids) has volumetric heat capacity of 20.6 Btu/cu ft F.

The quantity of heat stored is also dependent upon the daily temperature range which the storage material experiences. The larger this range the smaller the storage can be.

A number of design tools have been developed to aid in sizing all the components of a solar system. These are discussed in Chapter 10, as are rules of thumb for storage sizing. It is important to remember that use of a more sophisticated design tool such as TRNSYS may give substantially different results than rules of thumb for a particular application. For example, a well designed passive home with built-in storage in the form of thermal mass and a lower than normal heating load may require much less than $10 \mathrm{Btu}$ of storage capacity per degree $\mathrm{F}$ per $\mathrm{sq} \mathrm{ft}=1.2 \mathrm{gal} . / \mathrm{sq} \mathrm{ft}\left(200 \mathrm{~kJ} /{ }^{\circ} \mathrm{C}-\mathrm{sq} \mathrm{m}\right)$ of collector. The recently constructed $100 \%$ solar house in Saskatchewan [50] has $14.6 \mathrm{gal} . / \mathrm{sq} \mathrm{ft}\left(2,433 \mathrm{~kJ} /{ }^{\circ} \mathrm{C}-\mathrm{sq} \mathrm{m}\right)$ of collectors.

\section{Thermal Stratification}

Perfect thermal stratification will improve system performance by $5 \%$ to $10 \%$. In storage tanks, the hot liquid from the collector can transfer most of its heat to the upper layers in the tank, while the fluid returning to the collector (from the lower end of the tank) is at a lower temperature. A temperature difference of up to $10 \mathrm{~F}\left(6^{\circ} \mathrm{C}\right)$ can be maintained in a carefully designed storage tank. Ensuring stratification is much easier in rock beds than in water tanks because the storage medium is immobile in the former. Stratification can be facilitated somewhat by use of baffles or antiblending headers at the top and bottom in storage tanks, but a rapid input of heat can upset equilibrium conditions. A vertical storage tank is better for stratification but requires greater height for installation. Rock beds need an adequate plenum over the top to ensure that stratification is not upset by causing the hot injected air to move from the top of storage to the bottom before spreading over the entire top surface of all the rocks.

\section{Multiple Storage Tanks}

System performance can also be increased by using two storage tanks, one at a high temperature and the other at a relatively low temperature. Multiple tanks also allow the use of hot and cold storage. However, multiple-tank systems require more complicated piping, valving, and controls, and of ten do not justify their higher costs,

\section{Location}

Storage can be situated in a number of locations within or outside of a building. Advantages and disadvantages of the various options are listed in Table 5-11 (taken in large measure from Ref. 43). It should be noted that latent heat-of-fusion storages, which potentially have much smaller volumes for a given capacity, reduce storage weight and size problems.

\section{Insulation and Storage Efficiency}

Storage efficiency and thermal energy losses are opposite sides of the same coin. Heat losses can be reduced by insulation-at a cost. The SMACNA (Sheet Metal and Air Conditioning Contractors' National Association) recommends a standard of less than $2 \%$ losses in 12 hours. The HUD Intermediate Minimum property standard suggests at most $10 \%$ energy loss in 24 hours. When the thermal losses supplement the heating load and these losses can be easily vented in summer, lower storage efficiencies are acceptable.

Such considerations also apply for ducting and piping which can lose thermal energy coming from collectors to the load or to storage and from storage to the load.

\section{Laten Heat-of-Fusion Storage}

Most of the above considerations also apply to designing solar systems using latent heat-of-fusion storage. However, some major differences are apparent. First, these devices store heat over a narrow temperature range. As such, thermal stratification principles are not major design considerations. In addition, the isothermal nature of the storages make them attractive for passive designs. Second, the amount of energy stored per unit volume is potentially substantially higher than the amount in sensible heat storages. Therefore, use of such devices can facilitate retrofitting buildings with solar systems where system volume and/or weight is a consideration. Third, heat exchange into and out of storage is difficult because heat transfer is more difficuit from surfaces of solids than through fluids. This fact, however, allows use of less insulation when latent heat storages are used for coolness storage.

\section{Useful Publications}

The importance of TES to both the design and economics of solar systems has been underscored recently by publication of a number of useful documents. Table 5-12 lists references and provides a brief description of their content. 
Table 5-11. ADVANTAGES AND DISADVANTAGES OF STORAGE LOCATIONS (from Ref. 43)

\begin{tabular}{|c|c|c|}
\hline Locat i on & Advanteges & Disadvantages \\
\hline $\begin{array}{l}\text { Utility Room } \\
\text { or Basement }\end{array}$ & $\begin{array}{l}\text { Minimal insulation requirement } \\
\text { Insulation protected from weather } \\
\text { Thermal losses contribute to } \\
\text { building heat in winter } \\
\text { - Leaks easily detected } \\
\text { Easy access for repairs }\end{array}$ & $\begin{array}{l}\text { Reduced living space } \\
\text { Thermal losses increase } \\
\text { summer air conditioning load } \\
\text { Leaks possibly damaging } \\
\text { to building interior } \\
\text { - Difficult to install steel or } \\
\text { RFP tanks in an existing building }\end{array}$ \\
\hline Unheated Garage & $\begin{array}{l}\text { Insulation protected from weather } \\
\text { Leaks easily detected } \\
\text { Easy access for repair } \\
\text { Easy installation of steel or } \\
\text { FRP tanks in an existing garage }\end{array}$ & $\begin{array}{l}\text { Reduced garage space } \\
\text { Extra insulation required } \\
\text { Freeze protection most } \\
\text { often required } \\
\text { Possible damage to garage } \\
\text { from leaks } \\
\text { Thermal losses not recovered }\end{array}$ \\
\hline Crawl Space & $\begin{array}{l}\text { Insulation protected from weather } \\
\text { Thermal losses may contribute } \\
\text { to building heat in winter }\end{array}$ & $\begin{array}{l}\text { Thermal losses may add to summer } \\
\text { air conditioning load } \\
\text { Difficult access for retrofit } \\
\text { or repairs } \\
\text { Usual shaped tank may } \\
\text { require extra insulation }\end{array}$ \\
\hline $\begin{array}{l}\text { Outdoors, } \\
\text { above grade }\end{array}$ & $\begin{array}{l}\text { Easy access } \\
\text { No increased air conditioning } \\
\text { load from thermal losses } \\
\text { No reduction in living space }\end{array}$ & $\begin{array}{l}\text { Extra insulation required } \\
\text { Weather protection required } \\
\text { No recovery of thermal losses } \\
\text { Freeze protection usually required } \\
\text { Possibility of vermin attacking } \\
\text { insulation }\end{array}$ \\
\hline $\begin{array}{l}\text { Outdoors, } \\
\text { below grade }\end{array}$ & $\begin{array}{l}\text { No increased air conditioning } \\
\text { load from thermal losses } \\
\text { No living space reduction }\end{array}$ & $\begin{array}{l}\text { Access for repairs difficult } \\
\text { - Several problems can be caused } \\
\text { by contact with ground water } \\
\text { - Thermal losses not recovered } \\
\text { - Possibility of vermin attacking } \\
\text { insulation } \\
\text { Careful design required to ensure } \\
\text { sufficient net positive suction head } \\
\text { for the pump } \\
\text { cost for excavation }\end{array}$ \\
\hline
\end{tabular}


Table 5-12. PUBLICATIONS USEFUL IN STUDY OF TES

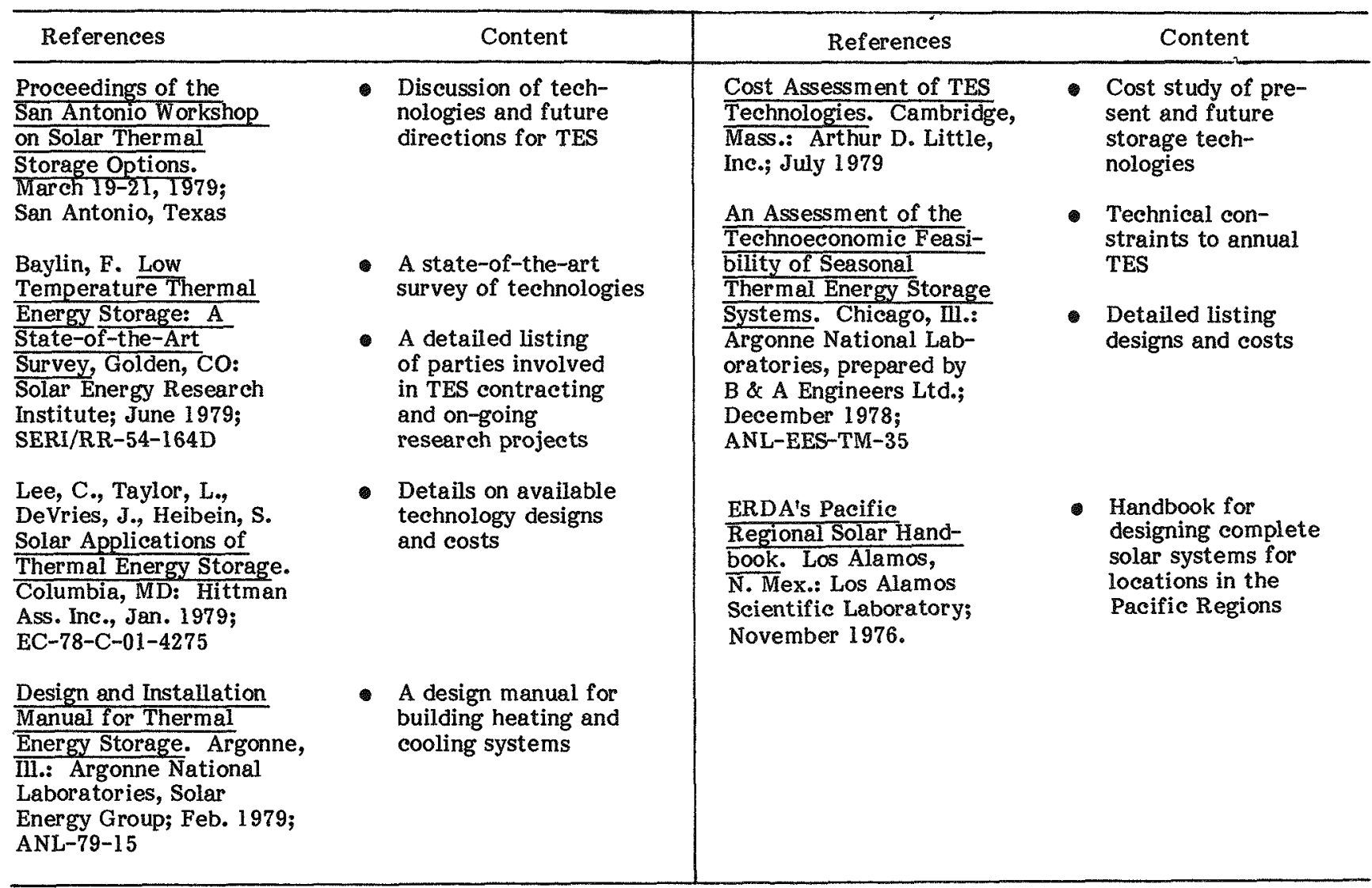




\section{ACTIVE SUBSYSTEM COMPONENTS}

This section describes the heat exchangers, pumps, piping, and insulation, expansion tanks, and controls that are all subcomponents of active and hybrid solar energy systems. They are interrelated in a functional way, each component influencing and being influenced by the size, type, and performance of the others. Each of these five subsystem components also requires a harmonious relationship with the four other major elements (i.e., solar collector, transport fluid, storage system, and terminal load devices) which make up the complete solar energy system. The selection and sizing of each subcomponent must not be made without studious regard to the other subcomponents. Subcomponent selection and sizing, including much quantitative design data, are discussed in Chapter 14.

\section{HEAT EXCHANGERS}

The heat exchanger is a device for transferring thermal energy from one fluid to another. In some solar energy systems, a heat exchanger may be required between the transf er medium circulated through the collector and the storage medium; in other systems, a heat exchanger will be required between the storage and the distribution medium. Heat exchangers are used to isolate collector piping loops containing antifreeze solution from storage and space heating or domestic hot water loops. Heat exchangers can be used to reduce hydrostatic head on storage tanks when collectors are mounted at a considerable height above the water storage tank; tanks for low pressure are considerably less expensive than pressure vessels.

The information presented here will serve as a general guide for selecting the heat exchange surface area during the early planning design phase. During final design, the heat exchanger selection is generally made in consultation with equipment suppliers who have access to computer program analysis techniques.

\section{Types Most Widely Used}

\section{Coil in Storage Tank}

This type of heat exchanger can be used to transfer heat either from the collector to the storage or from the storage to the end use. Finned coils providing a large surface area can be used to increase effectiveness. Fig. 5-35 illustrates the use of a coil in a storage tank where the storage is a preheat tank for hot water in a closed loop collector system. Even though building codes in some states allow such a design when antifreeze solution is circulated through the collector loop, the single separation between a possibly toxic liquid and the potable water supply is potentially dangerous and should not be specified. The coil should be located at the lower (cooler) section of the storage tank.

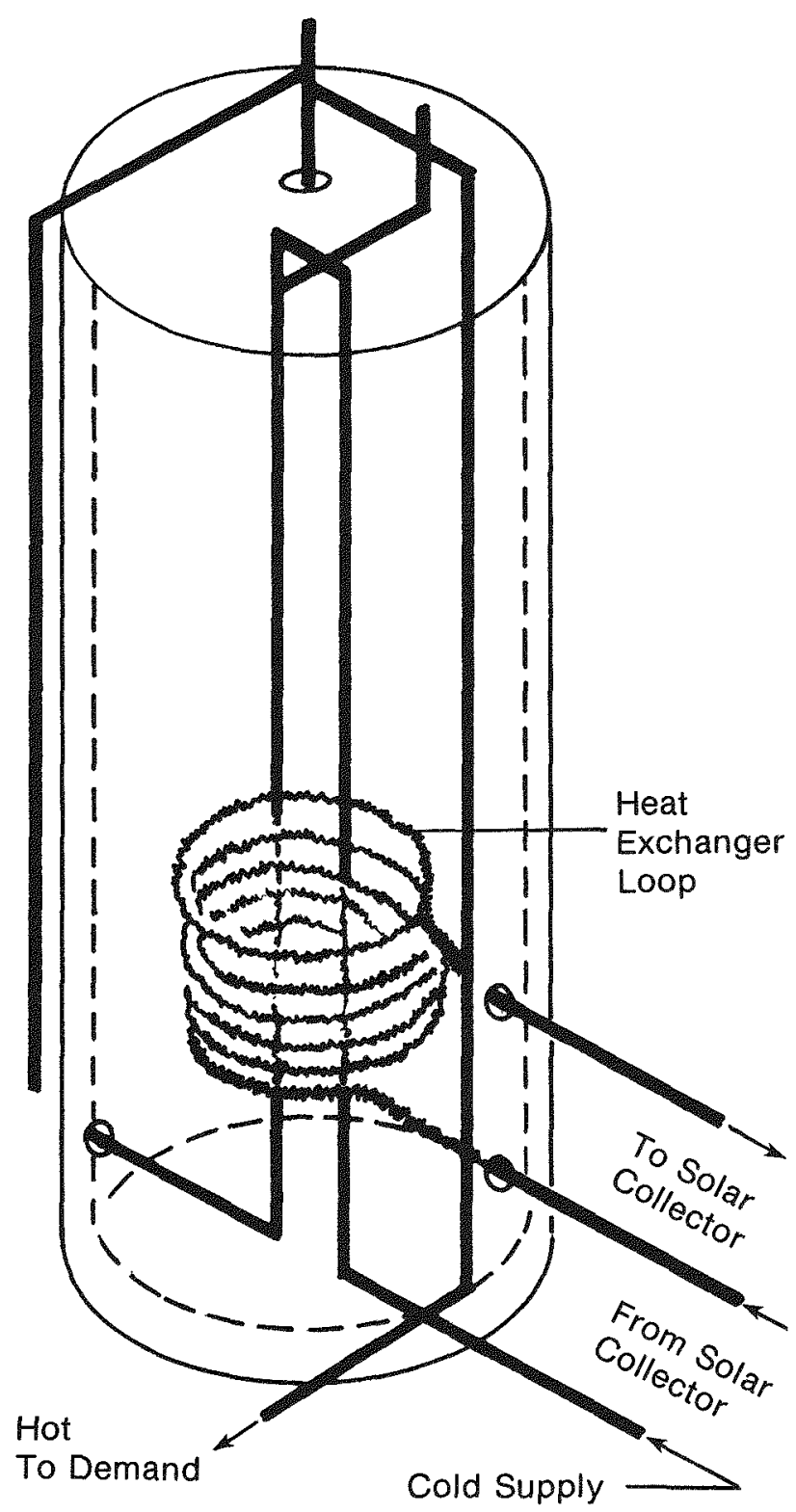

Fig. 5-35. Coil in tank heat exchanger

Coil or Plate-Coil Wrapped Around and Bonded to Storage Tank

This design provides a double separation between the transfer coolant and the potable water supply, which is heated as it circulates through the coil. Insulation enclosing the tank and heat exchanger should have an R-value of at least 7.5. The most effective heat exchange of the coil-around-storage tank is a counterflow design in which two tubes are wrapped in a serpentine pattern around the hot water tank; hot collector fluid is circulated through one tube pass while water to the hot water tank is circulated in the opposite direction through the other tube pass before it returns, preheated, to the hot water tank. 


\section{Double Walled (Tube-in-Tube) Coil in Storage Tank}

This type of heat exchanger provides double separation between the transfer coolant and the water supply; it is especially suitable for antifreeze systems.

\section{Tank in Tank}

In this type, an uninsulated domestic hot water tank constructed for the system pressure is placed in a larger storage tank sized for the space heating system.

\section{Shell and Tube}

In this type, there is only a single separation between the circulating transfer coolant and the hot water system; it should therefore not be used for heat transfer from a toxic liquid to potable water. Shell and tube heat exchangers consist of an outer casing or shell surrounding a bundle of tubes (Fig. 5-36). The water to be heated is normally circulated in the tubes, and the hot liquid from the collector is circulated in the shell. Tubes are usually constructed of copper or stainless steel.

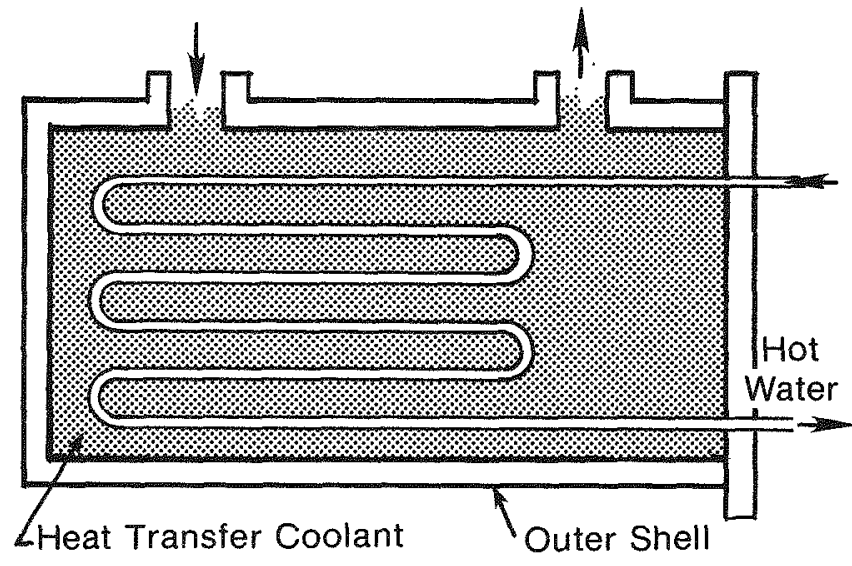

Fig. 5-36. Shell and tube heat exchanger

\section{Shell and Double Tube}

This type of heat exchanger is similar to the shell and tube except that a secondary chamber containing an intermediate fluid is located within the shell to surround the water tube in which potable water circulates (Fig. 5-37). The heated toxic liquid circulates in the outer shell, transferring heat to the intermediary fluid, which in turn transfers heat to the tube carrying potable water. The exchanger should be equipped with a sight glass to detect leaks by a change in color-toxic liquid can contain dye--or by a change in the liquid level in the intermediary chamber, which would indicate a failure in either the outer shell or intermediary tube lining.

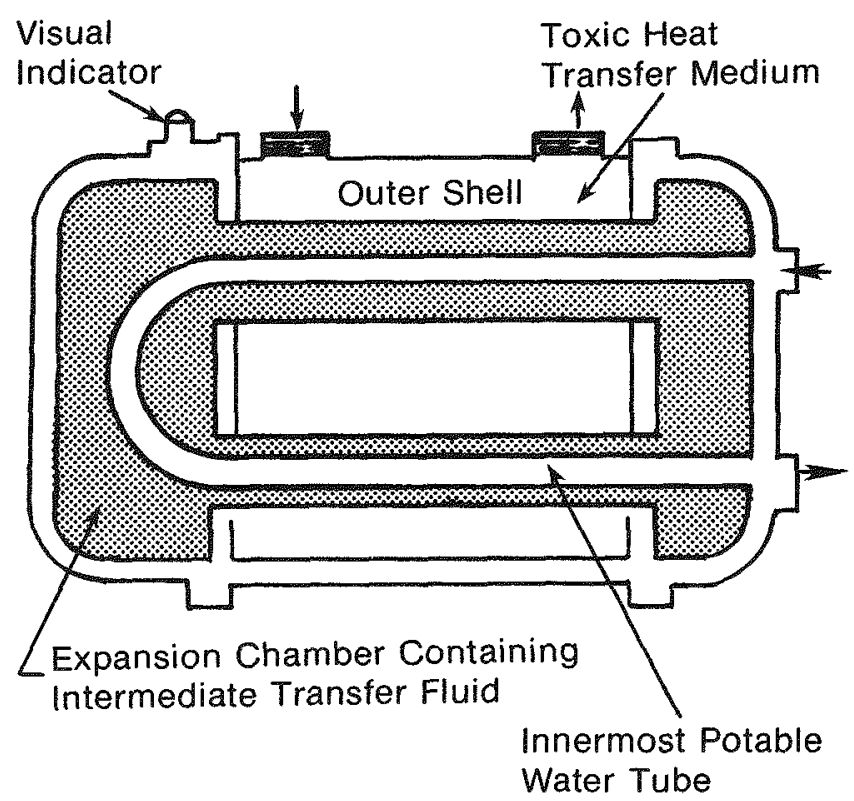

Fig. 5-37. Shell and double tube heat ex-
changer

\section{Two Separate Heat Exchangers}

Double separation can be provided by using two separate heat exchangers between the collector and storage. The two heat exchangers may be of the same or different types and are generally of the shell and tube type.

\section{Rock-Bed Storage}

This type of heat exchanger can be used in an air system. It should contain washed rocks $1 / 2$ to 3 in. $(15-80 \mathrm{~mm})$ in diameter, and air flow should be directed vertically rather than horizontally through the rock bed. A detailed discussion of rock-bed design is given in Ref. 43.

\section{Hot Water Coil in Air Handler}

This type of heat exchanger is used for preheating domestic hot water in a solar energy system with air collectors. The heat exchanger is located in the duct downstream of the solar collector.

\section{Heat Exchangers in Antifreeze Systems}

When an antifreeze or other potentially toxic solution is used in the collector, there must be a heat exchanger between the collector and the storage tank. When the system is used to heat potable water, the heat exchanger must provide double separation between the antifreeze liquid and the potable water. 
To avoid freezing of the potable water in the heat exchanger, precautions (specification of check valves, interlocks with pumps, and other) must be taken to prevent either thermosiphon or forced flow of the collector fluid through the heat exchanger, when the collector fluid is below $35 \mathrm{~F}\left(1.7^{\circ} \mathrm{C}\right)$.

Antifreeze solutions will have a generally higher density and a generally lower specific heat than water. The net effect is that an increased flow rate is required to obtain the same degree of heat transfer as water (e.g., with a $50 \%$ ethylene glycol solution between 100 and $140 \mathrm{~F}$ $\left(38-60^{\circ} \mathrm{C}\right)$, the flow rate should be approximately $15 \%$ greater than with water. See Table 5-4.

The pressure drop across the heat exchanger will be greater with an antifreeze solution than with water because (a) the flow rate is increased and (b) the viscosity of antifreeze is, on the average, higher than that of water. (Note that the viscosity depends on the temperature.) The net effect is that the heat exchanger should be designed for different values of flow rate and pressure drop when antifreeze solution rather than water is used. The pump too must be sized to accommodate the increased pump head.

\section{Sizing}

The heat exchanger for a given system must be chosen to satisfy the design criteria for that system and must satisfy the specifications as to thermal performance, materials, construction, requirements on pressure drop, and fluid velocity in the tubes; it must afford protection from high pressure and temperature and be reasonably priced. It is of utmost importance that the heat exchanger be adequately sized, for an undersized heat exchanger directly restricts the transfer of collected solar energy to the load; and consequently, because of the higher solar collector operating temperature that is required, a decrease in the solar collector efficiency results.

\section{PUMPS}

All liquid systems, other than thermosyphon configurations, require a pump in each separate circuit to circulate the heat transfer fluid.

Typically, pumps are required for each of the following circuits: (a) collector to heat exchanger or to storage direct, (b) heat exchanger to storage, (c) storage to space heating system, (d) storage to BSHW preheat tank or heat exchanger. The type of pump must be selected for the required specific task in the circulation system.

Pumps should be sized according to the required flow rate and system pressure head. This requirement will depend on whether the pump is to operate in an open or closed fluid circuit, on the nature of the liquid (either water or antifreeze solution), on the pipe lengths and diameter, heat exchangers and other resistances in the piping circuit. If the water in the system is open anywhere to the atmosphere, the system is open. A closed system, on the other hand, is not exposed to the atmosphere and may contain an antifreeze solution of water with ethylene or propylene glycol, mineral oil, or other. Closed loop systems usually have the collector fluid routed through a heat exchanger to transfer heat from the solar collector to a storage tank. Many systems are composed of both open and closed loops.

\section{Circulating System Flow and Pressure Loss Requirements}

Open and closed systems require different methods for calculating flow requirements and pressure loss resistance. Flow requirements are based on the energy to be delivered and the attainable temperature rise through the collectors, depending upon available insolation. Pressure losses are a result of pipe friction, flow resistance of the fittings and heat exchangers in the system, and the flow resistance of the collector. Similarly, pressure losses in open systems occur from these same sources and, additionally, from the net vertical rise of the fluid in the system. For instance, a drain down system for freeze protection is normally an open system; however, it can also be closed. The drain down system requires substantially more pressure from the pump to recharge the system and thus may require an additional pump.

Once the maximum flow and head requirements of the system have been established, the proper pump can be selected by examining the pump performance curve. Pump performance curves usually list flow on the horizontal axis and head (pressure) on the vertical axis. If the point at which head and flow requirements of the system meet is on or below the performance curve of the pump, the pump should be adequate.

Hypothetical system requirements of flow and head result in a point $\mathrm{A}$ below the performance curve of the pump (See Fig. 5-38). The system will operate on the curve itself; therefore, adjustments may become necessary by using speed selector switches available on some models. The installer may then more accurately adjust the pump performance to the system requirements (i.e., $B$ to $A^{\prime}$ ).

In a well-designed system, no more than the equivalent of 1 to $3.5 \%$ of the energy collected by the solar energy system should be consumed by the pump(s) used to circulate the fluids. Even though there are solar energy systems now in existence where an equivalent of as much as 7 to $8 \%$ of the energy collected is consumed by the pump in the system, the energy consumed by the pump and controllers in a system must always be taken into consideration when realistically evaluating the total system efficiency. 


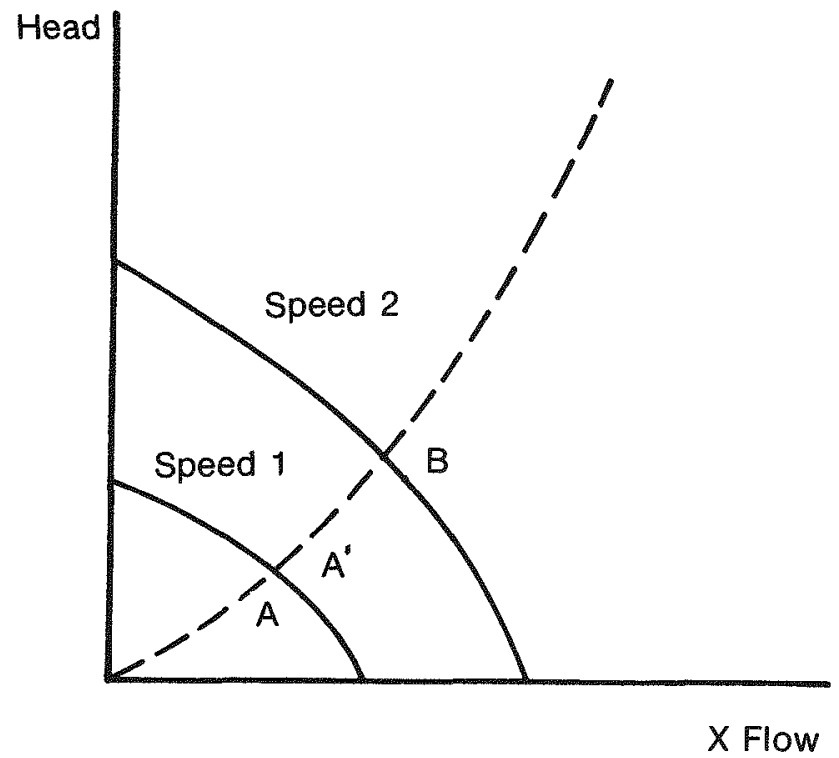

Fig. 5-38. Pump performance curve

Pump efficiency can be determined as follows:

$\eta($ efficiency $)=\frac{\text { Output }}{\text { Input }}$

where output is the work performed by the pump on the fluid and input is the electrical energy or work supplied. In a closed system with cold water at $8.33 \mathrm{lb} / \mathrm{gal}$. , the formula for pump horsepower reduces to: Pump HP = (gpm $x$ head in $\mathrm{ft}$ ) $/ 3960$. The efficiency $\eta$ of the pump (reflecting motor and drive line losses) can be determined by:

$$
\eta=\frac{\text { Pump hp }}{\text { Motor hp }}
$$

\section{Pumps for Higher Head Requirements}

Traditionally, single impeller hot water circulator pumps have been designed for relative low head and large flow. Typically, the point at which a circulating pump is most efficient is midway of maximum flow. A more energy efficient alternative is the staging of two or more smaller circulators in series. The result is twice the pressure and a more efficient pumping system. For example, one pump providing a maximum of $14 \mathrm{ft}$ $(4.27 \mathrm{~m})$ of head staged in series with another pump of the same capacity will result in a total of $28 \mathrm{ft}(8.54 \mathrm{~m})$ of head (Fig. 5-39).

Two circulators may be necessary in a system: one to boost the pressure and charge the system initially; the other to operate the system. In such a case, a time relay type of wiring schematic can be used ( $\mathrm{Fig}, 5-40$ ).
Submersible pumps offer another way to meet high head requirements in solar energy systems. The submersible pump can be installed directly in the storage tank and used either for only recharging the system or only circulating water, depending on the system design. The performances of submersible pumps range from 3 to $900 \mathrm{gpm}(11-3,407 / \mathrm{min})$ and from 50 to $2,000 \mathrm{ft}$ $(15-610 \mathrm{~m})$ head.

\section{Pump Selection}

Pumps should be selected so that there is no sustained rise in pressure when the water flow is throttled. In systems having considerable throttle, the pump should be selected on the flat portion of the "head-versus-flow" curve.

Brake Horsepower (BHP) should not exceed motor horsepower at any point on the pump curve, and the maximum shut-off head should not be greater than $125 \%$ of the design head. A typical pump efficiency is $70 \%$, BHP is:

$\mathrm{BHP}=\frac{\mathrm{Lb} / \mathrm{min} \times \text { feet head }}{33,000 \mathrm{ft}-\mathrm{bb} / \mathrm{min}-\mathrm{HP} \times \text { pump efficieney }}$

Centrifugal pumps offer advantages over positive displacement types. A safety feature is that they will pump only slightly above rated pressure if the fluid loop becomes blocked. Also, they provide increased flow rate as the fluid temperature increases. Centrifugal pumps with removal of built-in overload impedance protection are available for pumping fluids with temperatures as high as $290 \mathrm{~F}\left(150^{\circ} \mathrm{C}\right)$.

The centrifugal pump is always selected for the calculated pump head without the addition of safety factors for the following reason: newly installed pipe has less than design friction; consequently, the pump delivers greater flow than it was designed for and requires more power. If the pump is selected for the calculated head plus safety factors, the pump must handle a larger water quantity. When this occurs and provision is not made to throttle or bypass the excess water flow, the possibility of pump motor overload exists.

Multiple pumps may be interconnected to the same header, piping connections to be made as illustrated in Fig. 5-41. This method allows each pump to handle the same water quantity. Under partial load conditions and at reduced water flow or when one pump is out of the line, the pumps still handle equal water quantities. 

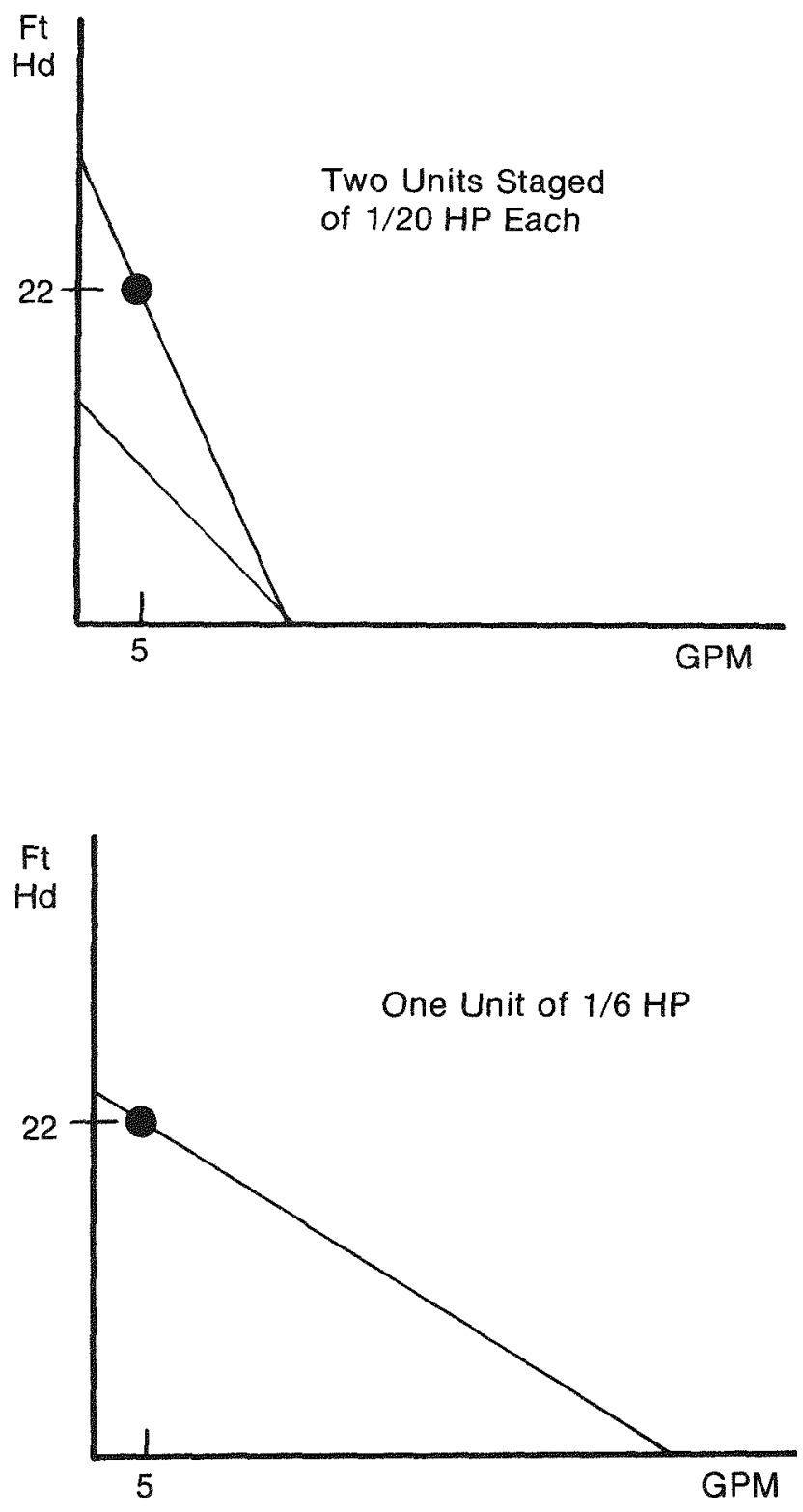

Fig. 5-39. Comparison of power requirements for circulators. Comparison is shown between using two circulators in series or one larger circulator pump for a requirement of 5 gpm at 22 it of head. The total horsepower of the staged pumps is $1 / 10 \mathrm{hp}$ in contrast to the $1 / 6 \mathrm{hp}$ required by the larger pump. The cost of the two smaller units is comparable to the one larger unit.

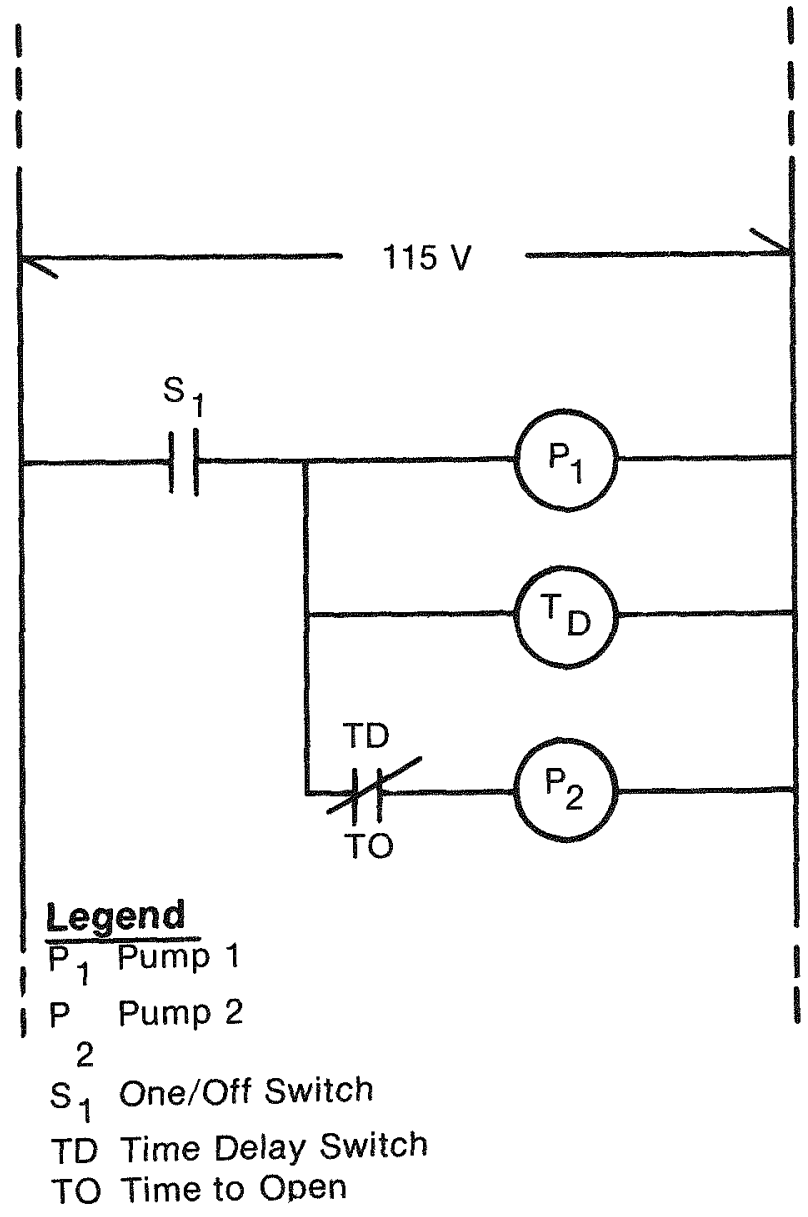

Fig. 5-40. Schematic wiring diagram for a two-pump system

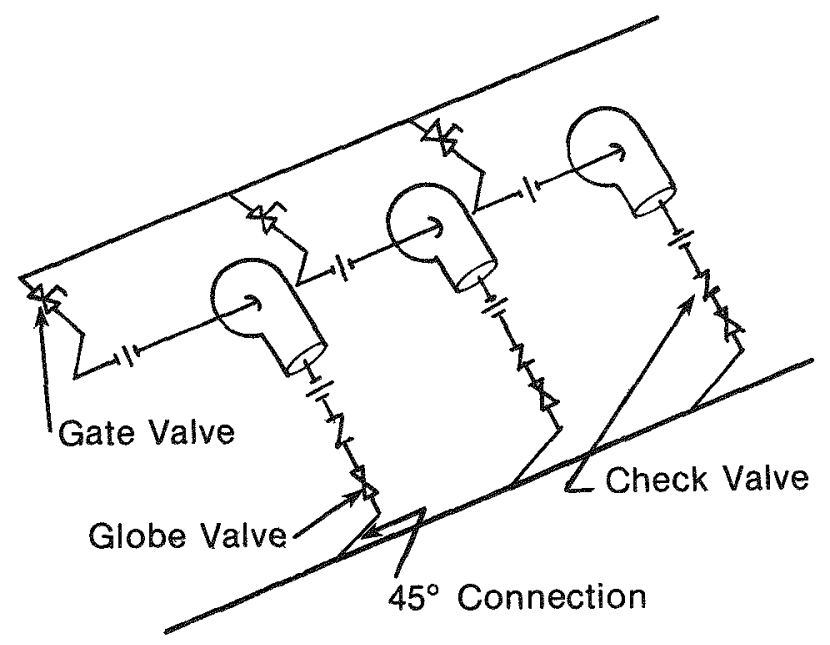

Fig. 5-41. Multiple pump piping 


\section{PIPE, FITTINGS, INSULATION}

A primary source of parasitic losses in the solar energy system is the energy transport system (i.e., piping, fittings, and pipe insulation). Therefore, great care must be taken to assure that thermal energy is not lost because the piping was incorrectly circuited or insufficiently insulated, that shutdowns do not occur because piping accessories were not carefully selected and properly installed; or that the system does not endure because durable materials were not selected. Especially, care must be taken to assure that pipe sizing and design conform to established standards. The purpose of this section is to discuss the physical characteristics of the piping system that are required to insure against thermal losses and pumping power losses and to assure durability and operating continuity of the system.

\section{Piping Layout}

\section{Collector Circuiting}

Collector piping and manifolding at solar collectors are important considerations in the design of solar energy systems. The design should minimize installed cost, leakage and maintenance problems, and heat losses and provide uniform flow to all collectors to maximize collector efficiency, minimize pump power requirements, and provide for air purging. There are two basic categories of collector manifolds: external and internal. External manifolds consist of insulated piping external to the collector that interconnects all collectors. Internal manifolds use piping internal to the collector as the major interconnecting manifold. Internal manifolds have great potential for reducing piping and insulation costs but require careful design to maintain proper flow to all collectors.

Collector piping is also classified as to circuiting arrangement. Some basic arrangements are shown in Fig. 5-42. These arrangements use series or parallel flow and external and internal headers. The type of arrangement should be carefully considered for the particular system being designed in terms of its size, type (e.g., drain down, filled, etc.), and application (heating, cooling, or hot water). Reverse return arrangements are generally preferred over other arrangements because they tend to provide equal flow to all collectors (provided low, uniform resistance is maintained in the manifolds). However, this arrangement generally requires more piping and, therefore, additional cost. Direct return is not generally recommended (especially for internal manif old collectors), except for small systems with large,

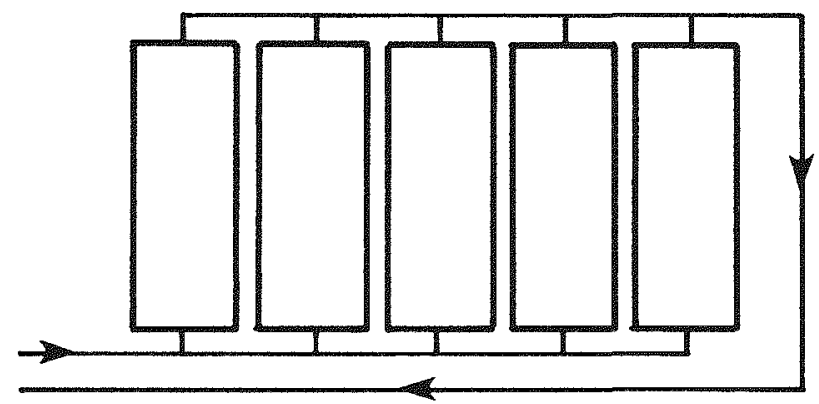

Reverse Return

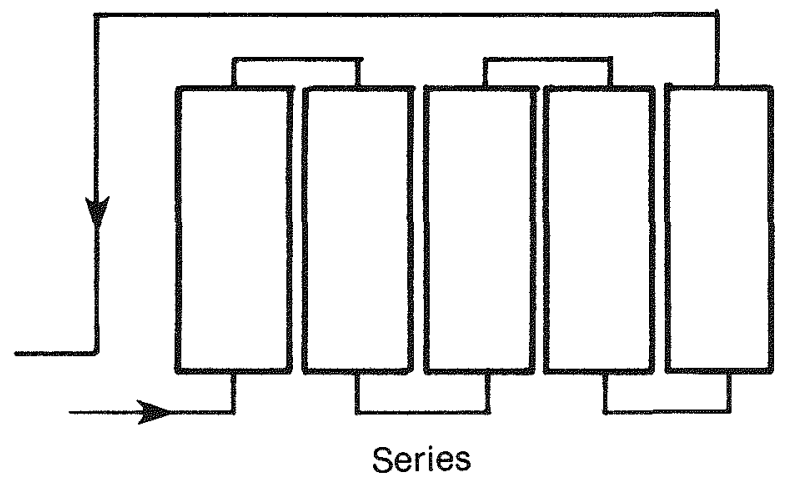

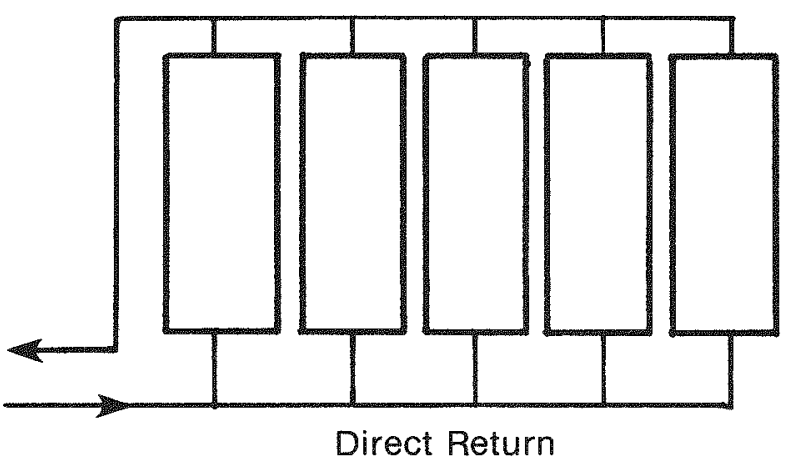

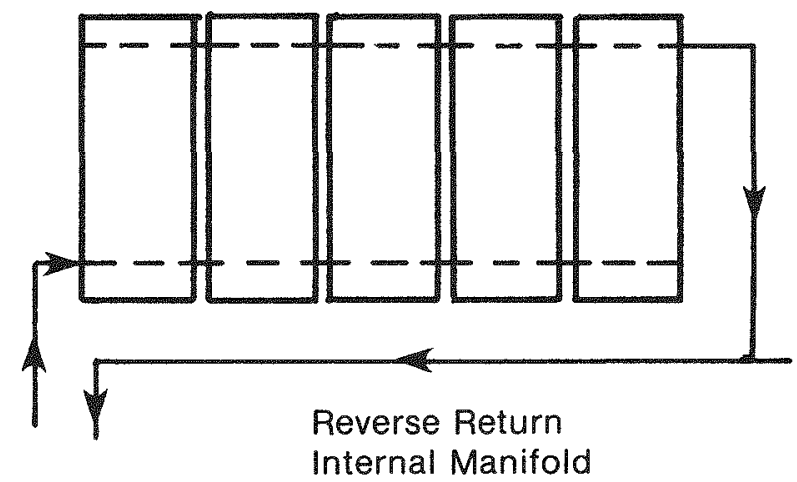

Fig. 5-42. Collector piping configuration 
low-resistance manifolds and balancing valves. Series flow can be used with only a limited number of collectors. Efficiencies for series-connected systems can be equivalent to parallel systems, provided flow rates are adequate to provide the same overall T. Series systems usually have greater resistance, however, and require larger pumps, thereby resulting in greater parasitic losses. However, for collectors with low relative flow resistance, series combinations can be advantageous.

\section{Flow Rates}

The flow rate through each system loop (collectorstorage, storage-distribution, and other subsystems) depends upon the thermal load, the temperature rise, and the fluid used. The piping system must be sized and designed to handle the flow rate determined by calculation. The tradeoff between smaller pipe sizes with corresponding cost savings in pipe, insulation, and fittings versus the higher frictional resistance, larger pumps, and greater energy consumption for pumping must be evaluated on a life-cycle cost basis.

\section{Pipe Friction Loss}

The pipe friction loss in a system depends on fluid velocity, pipe diameter, interior surface roughness, and pipe lengths. Varying any one of these factors influences the total friction loss in the pipe. The velocities recommended for water piping depend on three conditions: (l) the service for which the pipe is to be used, (2) the effects of erosion, and (3) noise resulting from excessive flow velocities.

If the pressure drop below the original static is great enough, the system pressure may drop to the boiling point, causing unstable water circulation and possible pump cavitation. If the system pressure drops below atmospheric, air sucked in at the air vents can collect in pockets and stop water circulation.

Quantitative recommendations on water velocities are given in Chapter 14 .

\section{EXPANSION TANKS}

Although expansion (or compression) tank sizing is considered a relatively straightforward procedure, the design of solar energy systems has brought a demand for minimized cost, reduced maintenance and energy use, and systems of greater complexity. Solar energy systems require extra consideration because they generally have larger storge volumes that can result in large, expensive expansion tanks. Also, the system operating temperatures vary widely including high stagnation temperatures requiring careful attention to system pressure control.
The purpose of an expansion tank is to limit system pressures at all system equipment to the allowable working pressure, and to maintain minimum pressure at all operating temperatures to provide positive air venting and to prevent flashing and pump cavitation.

\section{Open Expansion Tanks}

Open expansion tanks are vented to the atmosphere and merely provide a space for the expanded water in the system as the temperature rises.

\section{Closed Expansion Tanks}

Closed expansion tanks are watertight, airtight, and pressure rated, generally designed to $125 \mathrm{psi}(861 \mathrm{kPa})$. Three basic types are available: standard, diaphragm, and expansion volume in solar storage tank.

\section{Standard Tank}

This is a pressure rated tank in which the gas cushion is in contact with the expanded water volume.

\section{Diaphragm Tanks}

These are pressure rated tanks containing a diaphragm that separates the air cushion from the expanded water.

\section{Expansion Volume in Storage Tank}

This is a special case of the standard tank where the solar storage tank is only partially filled. Since the expansion gas volume is in direct contact with high-temperature water, the increase in gas volume at high temperatures must also be included in the sizing calculations. This usually results in an unnecessarily large tank volume and is generally not recommended.

\section{CONTROLS}

The heart of any system, whether solar or conventional, is the automatic temperature control system. All functions-"run-stop," "off-on," "open-close," "modulate"-are dependent on the type of controls used and the control sequence to be accomplished.

For large buildings, the central computerized energy management and control system (EMCS) can incorporate the solar control; and the solar system and the EMCS should be integrated.

It is essential to first determine the desired control and system operation logic. The objective may be any one or 
all of the following: (1) to collect and use as much energy as possible from the Sun; (2) to reduce operating time and wear and tear on active components and auxiliary energy supply equipment; (3) to reduce electric peak demand; (4) to minimize auxiliary energy use in heating and/or cooling of the space and/or the heating of BSHW; (5) to provide predictable and continuously satisfactory internal environmental conditions of temperature and humidity; (6) to assure continuity of operation, minimizing unscheduled shutdown; (7) to increase the life expectancy of the solar equipment; and (8) to minimize initial installation costs. All of these objectives may not be, and usually are not, mutually compatible.

\section{Control Strategies}

Select the desired modes of operation in a logical order of occurrence to include the following:

1. Heat from collector to storage;

2. Heat from collector directly to load (heating and cooling);

3. Heat from storage to load;

4. Heat from storage (or direct) to evaporator in heat pump operation;

5. Preheating BSHW with solar collectors directly, or from solar heated storage tank;

6. Heating from auxiliary for BSHW and/or space heating, and/or absorption or Rankine cycle cooling;

7. A combination of modes 1 to 6 inclusive.

In a solar energy system with different modes of operation, a control system is used to switch the system from one mode to another. The selection of the mode of operation is based on the temperature difference between collector and storage, and between storage and load. It is also based on whether solar heat can be used or auxiliary heat is necessary.

An automatic control system consists of some or all of the following devices:

Controller. A device that measures a controlled variable such as temperature or humidity by means of a sensing element and compares to the controlled variable with an input signal to produce a suitable action or impulse for transmission to the controlled devices. Thermostats, humidistats, and pressure controllers are examples.

Thermostats are designed to control introduction of heat to occupied spaces and are often of the two-stage variety. The first stage operates the system blower or pump to circulate from storage to the space, whereas the second stage operates the auxiliary energy source.
A Controlled Device. Has two components, its operator and its final control element.

Safety Device. In addition to a controller and a controlled device, every control system contains one or more safety devices that stop action, or initiate a new action, whenever a dangerous condition developes.

Controlled Agent. The medium manipulated by the controlled device is the control agent.

Controlled Variable. The condition such as temperature, humidity, or pressure being controlled is the controlled variable.

\section{Controls for Solar Space Heating}

A solar energized heating system consisting of collectors, storage system, and auxiliary heater can be controlled by the use of some or all of the following:

Space Thermostat. The space thermostat may have two or more stages with cooling if applicable. The two-stage action of the thermostat in the heating mode operates thus: Upon demand for heat by the first stage, the solar energy system is called upon to satisfy the space demand. If the heat loss of the building is greater than the solar energy system can provide and the space temperature continues to drop, the thermostat's second stage will activage the auxiliary heating system. The auxiliary system should meet the entire heating requirement of the space by itself or in conjunction with help from the solar energy system until the space temperature rises to the lower temperature limit of Stage 1, which stops the auxiliary energy supply.

Temperature Sensors are required to measure air or liquid temperatures at the discharge side of the collector, temperature of the thermal storage, and temperature of the BSHW storage tank. Sensing elements commonly used for this purpose include thermocouples, platinum resistance thermometers, thermistors, and diodes. Only sensors provided with the controller by the manufacturer should be used. The conditioned space sensor activates the room thermostat. The BSHW auxiliary sensor activates the BSHW auxiliary heater.

\section{Control Panel}

A central control panel should be provided to consolidate the circuits fuses and relays that provide the control functions. 
Pump Control. The minimum requirement of the pump control is to sense whether the temperature difference between the solar collector and solar storage tank is sufficient to justify pump operation. An adequate temperature dead band should be incorporated into the design to prevent harmful cycling of the pump in the morning and evening and intermittently during cloudy periods.

Input Cireuit. The most common input circuit, connecting the sensors to the comparator, is the balanced bridge. The common point of the temperature sensors is connected to the other input to provide a reference point. As the value of the sensor changes with temperature, a differential voltage is generated at ihe comparator, which responds by switching the driver circuit on and off.

Driver Circuit. The driver circuits may be relays or a solid-state device. When matching a control to a load, such as a pump motor, valve, or blower, the electrical ratings and isolation of the driver circuits must be considered to assure compatibility and safety.

\section{Fail-Safe Controls}

The control subsystem should be designed so that the temperatures and/or pressures developed in the solar energy system because of a power or system component failure will not damage any of the system components or the building, or endanger the occupants. For example, high-temperature limiting devices should be installed to protect the system from damage resulting from rupture, decompensation, etc.; and a low-temperature limiting device should be installed to protect the system against freeze-up damage.

If flammable or combustible fluids are involved, an alarm should be installed to indicate failure of the fluid transfer system or activation of relief valves.

A differential controller should be used to control operation of the heat transfer fluid pump or blower. The collector pump should operate only when the useful collected energy exceeds a minimum value. In practice, this is accomplished by comparing the temperature of the fluid in the collector exit header to the temperature of the fluid in the collector exit port of the storage tank. The pump or blower is operated only when this temperature difference exceeds a set value, usually $10 \mathrm{~F}$ $\left(5.5^{\circ} \mathrm{C}\right)$ in liquid systems and $15 \mathrm{~F}$ to $20 \mathrm{~F}\left(8-11^{\circ} \mathrm{C}\right)$ in air systems; a shutdown $\mathrm{T}$ of about 3 to $5 \mathrm{~F}\left(2-3^{\circ} \mathrm{C}\right)$ is commonly used. (See Fig. 5-43.)

If the collector is drained when not in use, the control should allow slight collector overheating before startup and some delay in the form of thermal response lag in the collector sensor to avoid premature shutdown when the first cool water from the piping enters the collector.

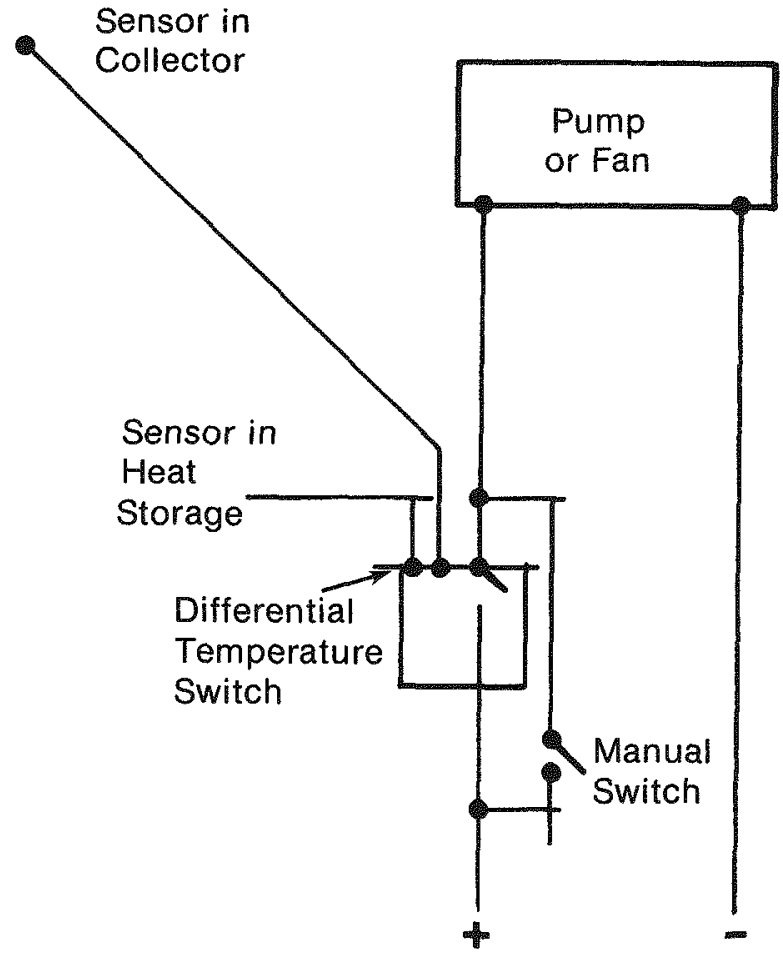

Fig. 5-43. Basic solar differential control system

An Example of a Control Sequence For Solar Space Heating

1. If the building temperature is satisfied, and the solar collector temperature is at least $10 \mathrm{~F}\left(5.5^{\circ} \mathrm{C}\right)$ above storage tank temperature, the loop pump is activated; and control valves are positioned to deliver heat from the solar collector to storage.

2. If the room temperature drops below $68 \mathrm{~F}\left(20^{\circ} \mathrm{C}\right)$ when $\propto$ cupied, $58 \mathrm{~F}\left(15^{\circ} \mathrm{C}\right)$ when unoccupied, and the storage temperature is above room temperature-the differential depending upon system configuration the valves are positioned; and the load circulator is activated to deliver heat from storage to the load.

3. If the space requires heat, but the solar tank temperature is below useful temperature, the valves are positioned to shut off the supply pipe from storage to load; and the auxiliary system delivers heat to the space. In some cases, the storage tank temperature may be too low to supply useful heat; but the collector can supply heat to the building by proper valving.

4. For cooling, heat is never delivered directly from the collector to the absorption generator or Rankine cycle engine because the surge resulting from collection temperature variations is undesirable. 
Where fluid does not contact the entire absorber surface, the absorber plate must have a high thermal conductivity such as copper, aluminum, or steel. Copper has the highest conductivity and is most corrosion resistant but is expensive.

\section{REFERENCES}

1. "DOE Facilities Solar Design Handbook," U.S. Department of Energy report DOE/AD-006/1, January 1978.

2. R. C. Jordan and B. Y. H. Liu, Eds., "Applications of Solar Energy for Heating and Coolino; of Buildings," ASHRAE GRP 170, 1977.

3. S. T. Liu and A. H. Fanney, "Comparison of Experimental and Computer-Predicted Performance for Six Solar Domestic Hot Water Systems, Paper LA-80-9, No. 2, ASHRAE 1980 Semi-Annual Meeting, Los Angeles, California (February 1980).

4. "Solar Heating Systems Design Manual," ITT Training and Education Dept., Fluid Handling Division, Bulletin TESE-576, 1976.

5. S. Karaki, P. R. Armstrong, and T. N. Bechtel, "Evaluation of a Residential Solar Air Heating and Cooling System," Report COO-2828-3, prepared for the U.S. Department of Energy by the Solar Energy Applications Laboratory, Colorado State University, December 1977.

6. H. Saha, "Heat Transfer Characteristics of Water Filled Cans as Solar Thermal Storage Medium: A Comparative Test Data Analysis," Proceedings of the 1978 Annual Meeting of the American Section of the International Solar Energy Society, V. 2.1, pp. 664670 , August 1978.

7. J. D. Balcomb and J. C. Hedstrom, "Thermal Performance of the LASL Solar Heated Mobile/ Modular Home," Proceedings of the 1977 Annual Meeting of the American Section of the International Solar Energy Society, V. 1, pp. 13-22, June 1977.

8. R. L. Oonk, L. E. Shaw, B. E. Cole-Appel, and G. O. G. Lof, "A Method of Comparing Flat-Plate Air and Liquid Solar Collectors for Use in Space Heating Applications," Proceedings of the Joint Conference of the American Section of the International Solar Energy Society and the Solar Energy Society of Canada, Inc., V. 2, pp. 83-93, Winnipeg, Manitoba, August 1976.

9. Solar and Heat Pump Systems Applications Handbook, prepared under contract to the U.S. Air Force, 1977.
10. T. L. Freeman, J. W. Mitchell, and T. E. Audit, "Performance of Combined Solar-Heat Pump Systems," Proceedings of the 1978 Annual Meeting of the American Section of the International Solar Energy Society, V. 2.1, pp. 293-298, August 1978.

11. J. W. Mitchell, T. L. Freeman, and W. A. Beckman, "Heat Pumps, Do They Make Economic and Performance Sense with Solar," Solar Age, pp. 24-28, July 1978.

12. "Solar Energy Heat Pump Systems for Heating and Cooling Buildings," S. F. Gilman, Ed., Proceedings of a workshop conducted by The Pennsylvania State University, College of Engineering, University Park, Pennsylvania, June 12-14, 1975. ERDA Document No. COO-2560-1.

13. J. B. Bisset and R. F. Monaghan, "Solar Systems for Commercial Buildings," ASHRAE Journal, May 1979.

14. M. Meckler, "Simulation of Solar Assisted Multiple Zone Water Source Heat Pump System With Diversity Cooling Loop," Proceedings of the 1978 Annual Meeting of the American Section of the International Solar Energy Society, V. 2.1, pp. 319327 , August 1978.

15. F. H. Bridgers, F. J. Stoltys, and D. R. Broughton, "Passive Solar Energy and the Heat Pump," ASHRAE Paper No. PH-79-2, January 1979.

16. Volume 3, Proceedings of the Joint Conference of the American Section, International Solar Energy Society and Solar Energy Society of Canada, Inc., Winnipeg, Manitoba, August 1976.

17. R. L. Oonk and H. H. Hopkinson, "Modelling of Combined Air Base Solar/Heat Pump Heating and Cooling Systems," Proceedings of the 1978 Annual Meeting of the American Section of the International Solar Energy Society, V. 2.1, pp. 308-312, August 1978.

18. J. W. Andrews, "Development of a Cost-Effective Solar Assisted Heat Pump System," Proceedings of the 1978 Annual Meeting of the American Section of the International Solar Energy Society, V. 2.1, pp. 281-287, August 1978.

19. D. S. Ward, "Solar Absorption Cooling Feasibility," Solar Energy, V. 22, pp. 259-268, 1979.

20. "The Use of Solar Energy for the Cooling of Buildings," F. de Winter, and J. W. de Winter, Eds., Proc. 2nd Workshop on Solar Cooling, University of California at Los Angeles, August 4-6, 1975, ERDA Division of Solar Energy Report SAN/1122-76-2, July 1976. 
21. H. M. Curran, "Assessment of Solar-Powered Cooling of Buildings," ERDA Report NSF-RA-N-75-012, April 1975.

22. Proceedings of the Third Workshop on the Use of Solar Energy for the Cooling of Buildings, E. F. Clark, and F. de Winter, Eds., American Section of the International Solar Energy Society, Inc., held in San Francisco, California, February 15-17, 1978.

23. P. C. Auh, "An Overview on Absorption Cooling Technology in Solar Applications," Proceedings of the Third Workshop on the Use of Solar Energy for the Cooling of Buildings, American Section of the International Solar Energy Society, Inc., held in San Francisco, Calif ornia, February 15-17, 1978.

24. P. J. Wilbur and T. R. Mancini, "A Comparison of Solar Absorption Air Conditioning Systems," Solar Energy, V. 18, pp. 569-576, 1976.

25. D. S. Ward, T. Uesaki, and G. O. G. Lof, "Cooling Subsystem Design in CSU Solar House III," Proceedings of the Joint Conference of the American Section, International Solar Energy Society and Solar Energy Society of Canada, Ine., Winnipeg, Manitoba, V. 3, August 1977.

26. H. M. Curran, "Overview of Solar Rankine Cooling," Proceedings of the Third Workshop on the Use of Solar Energy for the Cooling of Buildings, American Section of the International Solar Energy Society, Inc., held in San Francisco, California, February 1517,1978 .

27. B. Shelpuk, "Overview of Solar Cooling Systems Which Utilize Adsorption/Desorption Processes," Proceedings of the Third Workshop on the Use of Solar Energy for the Cooling of Buildings, American Section of the International Solar Energy Society, Inc., held in San Francisco, California, February 15-17, 1978.

28. B. Anderson, Solar Energy: Fundamentals in Building Design, McGraw-Hill Book Company, New York, 1977 .

29. J. I. Yellott, "Solar Energy Utilization for Heating and Cooling," Chapter 58 of the ASHRAE Handbook \& Product Directory - 1978 Applications, American Society of Heating, Refrigerating and AirConditioning Engineers, New York, N.Y., 1974.

30. A. B. Meinel and M. P. Meinel, Applied Solar Energy: An Introduction, Addison-Wesley Publishing Company, Reading, Mass., 1976.

31. K. G. T. Hollands, "Solar Collectors," presented at the Joint Meeting of the American Section of the International Solar Energy Society and the Solar Energy Society of Canada, Inc., Winnipeg, Canada, 1976.
32. H. D. Kaehn, et al., "Experimental Evaluation of the Reflector-Collector System." Proceedings of the 1978 Annual Meeting of the American Section of the International Solar Energy Society, Inc., Volume 2.1, Denver, Colo., 1978.

33. J. A. Duffie and W. A. Beckman, Solar Energy Thermal Processes, John Wiley \& Sons, Inc., New York, N.Y., 1974.

34. J. E. Hill and E. R. Streed, "Testing and Rating of Solar Collectors," Chapter X of Applications of Solar Energy for Heating and Cooling of Buildings, American Society of Heating, Refrigerating and Air Conditioning Engineers, GRP 170, 1977.

35. ASHRAE Standard 93-77, "Methods of Testing to Determine the Thermal Performance of Solar Collectors," New York, 1977.

36. HUD Intermediate Minimum Property Standards Supplement, Solar Heating and Domestic Hot Water Systems, 1977 Edition.

37. Interim Performance Criteria for Solar Heating and Cooling Systems in Commercial Buildings, National Bureau of Standards, 1976.

38. Preliminary Issue: Solar Heating and Cooling Project Experiences Handbook, Dept. of Energy, July 1978.

39. Proceedings of the Department of Energy's Solar Update, Appendix B, "Summary of the Problems Encountered in the Solar Heating and Cooling Commercial Demonstration Program," July 1978.

40. M. Cash, "Learning from Experience," Solar Age, November 1978.

41. J, R. Fried, "Heat Transfer Agents for High Temperature Systems," Chemical Engineering, May 28, 1973.

42. K. W. Kauffman, "Non-Corrosive, Non-Freezing and Non-Toxic Heat Transfer Fluids for Solar Heating and Cooling," Proceedings of the 1977 Annual Meeting of the American Section of the International Solar Energy Society, Orlando, Fla., 1977.

43. "Design and Installation Manual for Thermal Energy Storage," Solar Energy Group, Argonne National Laboratory, report ANL-79-15, 1979.

44. J. M. Popplewell, "Corrosion Considerations in the Use of Aluminum, Copper, and Steel Flat Plate Collectors," paper presented at the International Solar Energy Society Conference, UCLA, July 1975. 
45. National Plan for Solar Heating and Cooling of Buildings. Washington, D.C.: ERDA; 1976; ERDA 76-144.

46. Proceedings of 3rd Annual Energy Storage Contractor's Information Exchange Meeting. December 5-6, 1978; Springfield, Va.; Washington: U.S. Department of Energy.

47. J. Asbury, et al. Assessment of Energy Technologies and Systems, Phase 1: Electric Storage Heating, Storage Air Conditioning, and Storage Hot Water Heaters. Argonne, Ill.: Argonne National Laboratory; 1976; AN :/ES-54.

48. Survey of Utility Load Management and Energy Conservation Projects. Oak Ridge, Tenn.: prepared by EUS, Inc. for Oak Ridge National Laboratory; December 1978; ORNAL/Sub-77/13509/4.

49. "Product Classification." Solar Engineering Magazine; p. 68; Dec. 1977.

50. R. W. Besant, R. S. Dumont, and G. Schoenau, "Saskatchewan House: 100 Percent Solar in a Severe Climate." Solar Age, p. 18-24, May 1979. 
6

Daylighting 
6. Daylighting

A. Effective Daylighting in Buildings

Comm ercial sector focus

Daylight/sunlight

Skylights

Issues

Analysis and design

Sun/glare control

B. Strategies of Daylight Design

Controls

Integration

Analysis

Codes 


\section{DAYLIGHTING}

The following two articles are intended to aid in understanding the daylighting options available to the building designer. The first article, "Effective Daylighting in Buildings-Part I," by Stephen Selkowitz, is reproduced from Lighting Design and Application, February 1979. It is intended as an introduction. The second article is excerpted from the September 1979 issue of the AIA Joumal. The title is "Strategies of Daylighting Design $n^{\text {"nd }}$ was written by Marguerite Villeceo with Steve Selkowitz and J. W. Griffith. This article provides a more in-depth discussion of daylighting options and the benefits and problems involved. Further inf ormation on daylighting fundamentals and design tools is included in Section II of this workbook.

\section{EPPECTIVE DAYLIGHTING IN BUHLDINGS*}

Lighting accounts for about $20 \%$ of total electrical energy consumption in the United States or 420 billion kWh per year. This represents over $5 \%$ of total national energy consumption and is approximately equivalent, in terms of daily energy consumption, to the total output of the Alaskan oil pipeline. Growth in lighting power demand also places a strain on utility companies, which must site and build new electric power plants. Reductions in lighting energy consumption and associated peak power demand are thus essential elements of a national energy program to reduce our dependence on energy supplies which are associated with political or environm ental liabilities.

The winter of 1973-74 saw many lights extinguished in response to an energy shortage. Energy conservation in lighting became associated with delamping, which in turn was reviewed as "doing without," and a sacrifice in the quality of living or working environments. Energy conservation practices, however, can provide equivalent or improved visual performance and visual comfort while producing substantial energy and power savings. Four different elements in this process can be identified: 1) substitution of efficient lighting systems and components for less efficient products; 2) improved lighting design practice which eliminates wasteful energy use; 3) improved operation and maintenance of lighting systems; 4) and a return to a partial reliance on natural lighting techniques and practices.

*This article by Stephen Selkowitz, Lawrence Berkeley Laboratory, Berkeley, California, appeared in Lighting Design and Application, February 1979.
Prior to the introduction of the electric light, the best light available in buildings for visual tasks was daylight. Candles, kerosene lamps, and gas lamps must have run a distant second to daylight as a source for indoor illumination. Incandescent lamps represented a major improvement over open-flame sources, but were not capable of achieving illumination equivalent to daylight in commercial buildings because of their low luminous efficacy. At about the time that incandescents gave way to fluorescents in commercial buildings, other trends such as rising urban land costs, the advent of building air conditioning systems, and low-cost electricity combined to eliminate daylight as an essential element in building design. As a result, there has been little serious interest or activity in daylighting in the United States during the last 20 years.

International events and the resultant "energy crisis" in 1973 forced a modest reexamination of energy use patterns in the building sector. Early energy conservation checklists advocated "increased daylight utilization" without indicating how, or in what circumstances, one could expect to achieve significant savings. The same checklists, without concern for apparent contradictions, typically advocated reduction or elimination of window area as well. Five years later one finds an increased awareness and interest in daylighting but little that indicates daylighting design has yet found a comfortable niche in professional design practices.

As architects and engineers focus on thermal load reductions, lighting looms as the single largest energy consumer in the building. A renewed interest in daylighting has generated claims of very substantial energy savings in newly designed, energy conserving office buildings. Although the potential exists, it is not obvious that projected savings can be fully realized. Skills in daylighting design analysis have been rediscovered after 20 years of dormancy, but the experience which must temper knowledge to produce effective resul ts is frequently lacking. It is the intent of this article to continue the process of raising and exploring issues relating to daylight utilization with the ultimate goal of achieving substantial reductions in electrical energy use through good daylighting design.

\section{COMMERCIAL SECTOR FOCUS}

Natural lighting serves several important functions in buildings. Architects have long recognized the visual power of a shaft of sunlight penetrating a dark church sanctuary or the visual beauty of a stained glass 
window. Our concern here is for more pragmatic use of natural lighting to offset electrical lighting requirements in commercial and industrial buildings. The primary focus in the commercial and industrial sector is office buildings, schools, commercial low-rise, and warehouses. These building types are characterized by daytime use patterns, long hours of lighting use, relatively high lighting levels, and high installed watts per square foot. Lighting is thus a significant energy consumption factor in most of these building types and represents a large fraction of total building utility costs.

We pointedly ignore the potential daylighting savings in the residential sector for a number of reasons. Lighting energy consumption per house is typically quite small: on the order of $10 \%$ of household energy consumption. There is thus no strong financial incentive to conserve energy in the household lighting sector. Although $95 \%$ of typical household lighting is incandescent, with low lumens per watt, the hours per year of use are typically small. Light levels are quite low, and occupancy per unit area is very low. Thus, energy consumption per square foot is much smaller than for most commercial sector uses, Visual tasks in the home are frequently not fixed in one place. This gives the occupant the ability to move nearer a window if daylight levels are not sufficiently high in a given location. Although we downplay the significance of daylight savings in the residential sector, one must add a note of caution regarding current building code trends, which tend to restrict window size in new residences. Overly simplistic thermal codes may restrict window size to the point where occupants are forced to use lights during the day. Well-designed and managed windows in the home should be acceptable on a thermal balance alone if window management techniques are practiced, and useful solar gain is considered. Thus, although total lighting energy consumption in the residential sector is significant, a number of factors suggest that the commercial sector is a more appropriate focus for a renewed interest in potential daylighting savings.

\section{DAYLIGHT/SUNLIGHT}

Natural lighting techniques encompass both the use of diffuse light from the sky, or daylight, as well as beam radiation from the Sun, or sunlight. In addition, we consider both side lighting techniques or the use of natural light through windows, and top lighting or the use of skylights in buildings (Fig. 6-1).

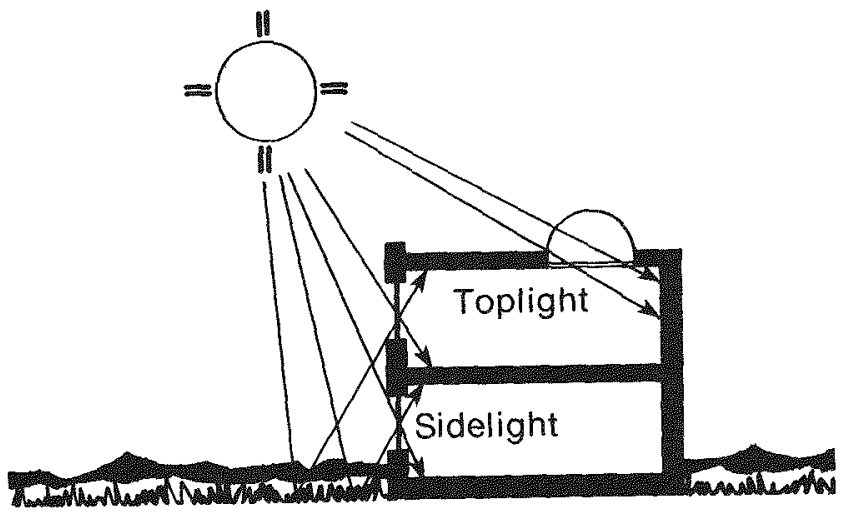

Fig. 6-1. Lighting from windows and skylights
Side lighting through windows typically utilizes diffuse radiation only. Direct solar gain, although occasionally pleasant, typically leads to overheating and thermal discomf ort. Daylighting levels from windows in one wall of a room fall off rapidly as we move deeper into the room, away from the window wall. A typical practical limit for daylight penetration into an office is 15 to $20 \mathrm{ft}$ $(4,575 \sim 6,100 \mathrm{~mm})$ from the window wall. Some techniques are available for extending the depth of this perimeter zone.

Glass blocks have been used extensively to direct sunlight deeper into rooms to complement diffuse light near windows (Fig, 6-2). Glass blocks of ten have ribs which provide some degree of light control for daily and seasonal variations in solar elevation and azimuth. Even deeper light penetration can be achieved by controlling sunlight directly. One concept which we call "beam sunlighting" involves reflecting direct rays from the Sun from silvered reflective venetian blinds mounted in the upper $2 \mathrm{ft}(610 \mathrm{~mm})$ of a typical window [1]. The

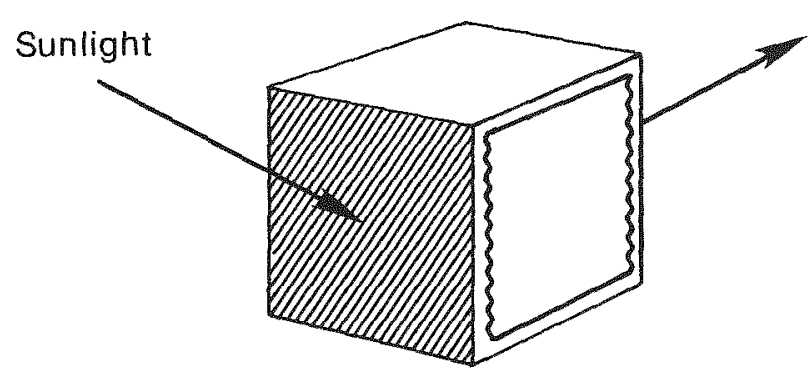

Fig. 6-2. Prismatic glass block

reflected rays are aimed toward the ceiling of the room to a maximum depth of approximately 30 to $40 \mathrm{ft}$ $(9,150-12,200 \mathrm{~mm}$ ) (Fig. 6-3). The ceiling then acts as a diffuse reflector, providing diffuse illumination deep inside the room. Although the lighting quality achieved by such a scheme is satisfactory, the control of reflected light as sun angles change is a significant problem. A variety of controllable reflecting or refractor-type devices has been examined, but the real issue is one of simplicity and low cost in these devices, without sacrificing the potential performance. In addition, more sophisticated lighting controls are required for partly cloudy sky conditions, in which case the Sun's intensity will change sharply over very short time intervals. This concept appears to have only limited applications in existing buildings because of window and ceiling design characteristics and problems with shading from adjacent buildings and other obstructions. However, new buildings specifically designed with this application in mind might realize substantial energy savings.

\section{SKYULGHTS}

Although skylights have been designed historically to exclude direct radiation (f or example, sawtooth designs or skylights with overhangs), most modern skylights lay flat in the roof plane and thus accept both direct and diffuse radiation. Light distribution within the space is 


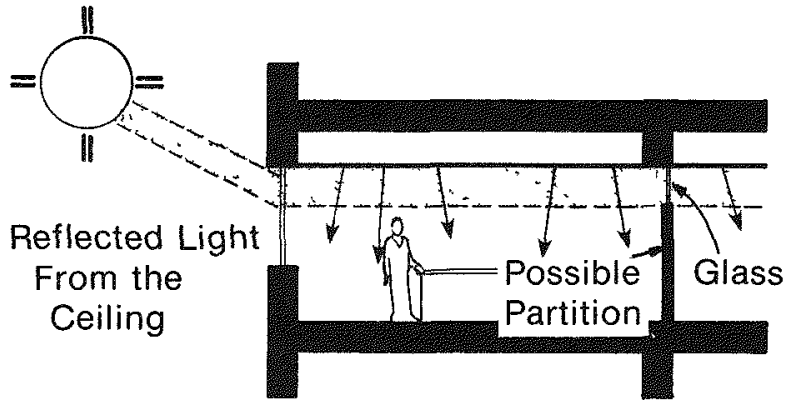

Fig. 6-3. Cross section of typical office space (south perimeter location) showing position and operation of beam daylighting apparatus

significantly more uniform than with side-lighting applications. Although conventional skylights are limited to providing daylighting in one-story spaces or multistory atrium spaces, several concepts have been published utilizing direct sunlight accepted through an aperture on the roof and then distributed throughout the building with a series of mirrors, lenses, and other optical controls [2]. Al though such schemes are technically feasible, their optical performance requirements and complexity make their use impractical.

We have thus argued for limiting the primary interest in daylighting applications to the commercial and industrial building sectors. In offices and schools with windows we are primarily interested in diffuse daylighting applications, and in single-story warehouses or low-rise retail buildings our interest is in conventional skylighting techniques.

\section{ISSUES}

Although the potential energy savings are significant, effective daylighting design requires that time and effort be expended to solve a series of problems and issues which currently act as obstacles to the widespread use of daylighting. There is a real danger in believing that good daylighting practice simply means the use of large windows and that use of large windows guarantees significant energy savings. Four major issues must be confronted before daylighting practice can be widely implemented in this country: 1) analysis and design techniques, 2) thermal/illumination tradeoffs, 3) sun and glare control, and 4) lighting controls. In addition, there are other issues relating to daylight design which we discuss at the close of this article.

\section{ANALYSIS AND DESIGN}

Ask a building designer today how to design a room to provide 50 footcandles on a desk throughout $80 \%$ of the working hours of the year using daylight, and you are likely to get puzzled looks and quick shuffling through textbooks and lighting handbooks. Simply stated, there is a lack of effective, widely used design methods in the United States today. The problem is not a lack of design methods; 58 are listed in a $1970 \mathrm{CIE}$ publication [3]. Most, however, were originated in European countries where cloudy skies are the typical minimum brightness conditions. In much of the United States, clear sky conditions prevail, and many of the techniques developed for analysis of overcast skies are not suitable for use with the variable luminance distributions one finds under clear sky conditions. Primary sources of information for daylighting design in the United States are the IES Recommended Practices [4] and a simplified design procedure based on the same "coefficient of utilization" approach [5]. A variety of different design methods has been and continues to be used. These include computational, graphical, tabular, nomographs, protractors, diagramatic, such as sky vault projections, and physical models. Very powerful computer models are available to compute footcandle levels and equivalent sphere illumination levels in rooms, but suffer from an inability to easily model detailed effects inside a room such as furniture placement. Al though current programs are relatively costly, it appears likely that computer run time can be substantially compressed with significant cost reductions. Physical modeling techniques which are already widely used by architects for other purposes can provide a very versatile simulation of detailed conditions to be expected in a typical building. A more fundamental problem than the lack of design methods is the lack of awareness and knowledge of these design methods by practicing professionals and in the schools now training the design professionals of the future. The lack of educational programs in the daylighting design field over the last 20 years has resulted in a generation of practicing architects and engineers who now have little academic or practical experience in daylighting design. This lack of professional design experience is compounded by the lack of well-documented examples of buildings incorporating effective daylighting. One can find many examples of architectural design with effective lighting, HVAC, and now solar heating systems in buildings, but few, if any, which focus on effective daylighting solutions to building design problems.

Having selected one of several daylighting design methods, the designer must confront the lack of information regarding daylighting availability in the United States. For a given location, are the skies characterized by clear, cloudy, or partly cloudy conditions? For what fraction of the working hours of the year can one expect certain minimum sky conditions to be exceeded? Data of this type exist for many European cities but for very few locations in the United States (Fig. 6-4). Measurements, which were made some time ago, in Washington, D.C., and other urban areas are now suspect due to atmospheric changes resulting from urban air pollution and changes in other climatic variables. Rather than wait several years before such new data can be collected, it may be feasible to generate daylighting availability data from the solar radiation data now being collected throughout the United States.

As part of a demonstration of efficient lighting systems in a building in San Francisco, we are now collecting, at 15-minute intervals, total horizontal radiation; diffuse horizontal radiation; illumination received on four vertical surfaces facing north, south, east, and west; and data from a sky luminance sensor which records sky brightness directly overhead (Fig. 6-5). These data will allow us to develop or select and then validate a computational procedure for converting the solar radiation data base into an illumination data base. 


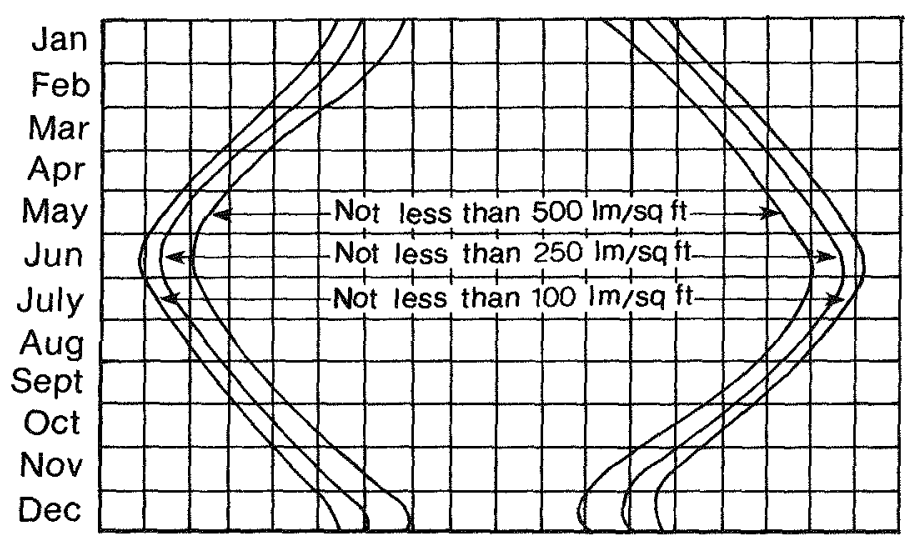

$\begin{array}{llllllllllllllll}3 & 4 & 5 & 6 & 7 & 8 & 9 & 1011 \text { Noon } 2 & 3 & 4 & 5 & 6 & 7 & 8 & 9\end{array}$
A.M.
Time of Day GMT
P.M.

Fig. 6-4. Average illumination on horizontal surface at Teddington, U.K., $51^{\circ} \mathrm{N}$, 1929-33

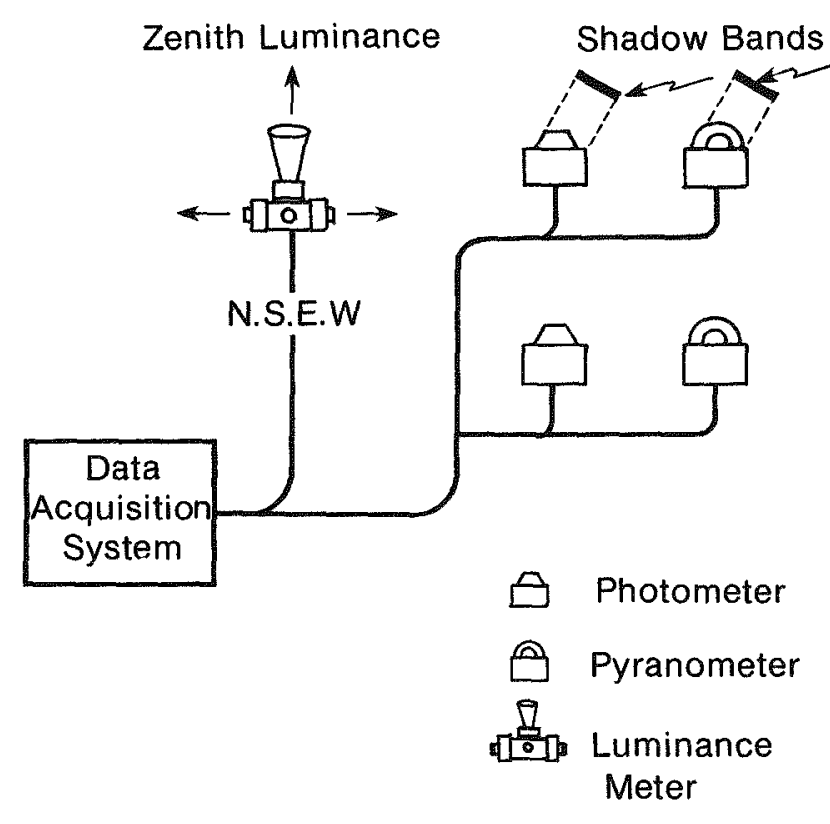
5 Instrumentation for Solar lllumination
Correlation Study

Fig. 6-5. Instrumentation for solar illumination correlation study
Building designs that have been optimized for daylighting use will have an impact on thermal gains and losses as well. Just as building design decisions that have been made to optimize thermal performance will inadvertently impact illumination issues, the sizing and placement of windows to maximize daylighting benefits will have thermal impacts which must be considered. A number of large computer programs are now available which will provide an annual energy analysis for large buildings. These are relatively complex programs which model building performance hour by hour throughout the year. Daylighting performance has been incorporated into several of these models in a limited way, but resul ts have yet to be validated and at this point must be considered preliminary $[6,7]$. A similar but simplified approach is available for predicting the annual performance of skylights in buildings [8]. In almost all cases, results indicate that consideration of daylighting benefits alters the determination of optimum window size toward larger windows or skylights than one would predict from a thermal analysis perspective alone. Although these general trends are predictable, there are problems and uncertainties associated with the use of the programs. The lack of validation is a major problem, and the effects of some of the simplifications introduced in order to keep the computational cost to a minimum are not entirely understood. Still, it is likely that simplified daylighting models can be developed and successfully incorporated into the existing energy analysis models. The availability of such a validated computer model will have important implications for building designers who must now make decisions regarding optimization, frequently without sufficient information.

What the output from these daylighting computer models actually represents is potential savings: the amount of daylight available at the task location is computed, but not necessarily the resultant energy saved. To address the question of actual energy savings, one must know whether the lights are controlled in an on-off mode or in a dimming mode, whether that control is automatic or manually operated, how the users will respond to solar gain and glare conditions of the room, and a variety of related information. At the moment, we do not have a comprehensive understanding of these issues nor do the programs have the computational ability to address all of them in any great detail. A decision regarding the degree of detail necessary for successful modeling and simulation awaits a comparison of simplified calculation techniques and actual resul ts in buildings.

\section{SUN/GLARE CONTROL}

The sleek all-glass buildings that dot most of our cities could not have been built without an array of sophisticated high performance solar control glazing systems. A whole array of sun control solutions is available to the building designer [9]. These include exterior architectural appendages; exterior sun control devices such as screens, shutters, blinds, and awnings; interior sun control devices such as shades, drapes and blinds; and heat-absorbing and solar-reflective glasses. Reflective coatings on plastic films are available for retrofits of older buildings to reduce solar gain. Many of these materials and devices reduce solar transmission to less than $10 \%$ of the incident energy. A simple solution is one which is permanent and fixed: a coating on glass or plastic. The danger of this approach, however, is that it 
may effectively wipe out daylighting potential in a building. It is the opinion of several experts in the field that daylighted offices may require highly transparent windows which incorporate operable window management devices such as shades and blinds to control excessive solar gain.

Various window management devices are commercially available in the form of internal and external venetian blinds and roll-up shades and shutters. Many of these come with motorized accessories which may be automatically or manually controlled. A more extensive list of manually operated devices is available, and these will typically be less complex and less costly. There is some uncertainty regarding how faithfully they will be employed. It seems likely that office occupants will close shades and blinds to reduce excessive heat gain or glare for thermal or visual comfort. It is not clear, however, that they can be effectively motivated to operate these devices to achieve energy savings. In particular, devices that have been closed in the af ternoon to reduce summer heat gain may not be opened the following morning to realize daylighting savings. Automatic controls and operators are, of course, more predictable but add complexity and cost. Recent work with venetian blinds indicates that office occupants will manage those blinds in a manner that distinguishes seasonal differences and differences in window orientation [10]. Additional studies of this type are required, but initial indications are that manual operation can be effective in some building types.

If interior and exterior shading devices are used to control excessive sun and glare, the question then becomes: What are the optimum glass properties for such a window design? Workers in a typical office have a view of the horizon or the sky in the immediate vicinity of the horizon. With standard overcast skies, the horizon is three times darker than the sky overhead. However, in the clear skies characteristic of much of the United States, the luminance distribution is inverted; and the horizon is brighter than the overhead sky. Furthermore, in urban areas, haze and air pollution produce additional light scattering and thus additional glare. Since sky luminance at the horizon may be 500 to 3,000 footlamberts and typical brightness in an office may be 25 to 75 footlamberts, severe discomf ort glare problems may exist. Some degree of light control in glazing is probably desirable, but it is unlikely that transmissions much lower than $50 \%$ will be desirable. Heat-absorbing and reflecting glass may also be desirable for special situations, such as sunlight reflected from water or from adjacent landscape or buildings.

The development of sophisticated glazing materials with heat absorbing and reflecting properties is a relatively recent innovation. We can reasonably expect to see additional improvements in the thermal and solar optical properties of glass to satisfy evolving performance demands on glazing systems. One research program being supported by the Department of Energy (DOE) is an effort to develop selective transmittance solar control costings for windows [11]. Approximately 50\% of the incident solar energy at a window is visible light, and the other $50 \%$ is invisible solar infrared heat. These selective transmitters will allow the visible to pass through the window into the room but reflect the solar infrared portion back to the outside environment (Fig. 6-6). Coatings of this type might have light

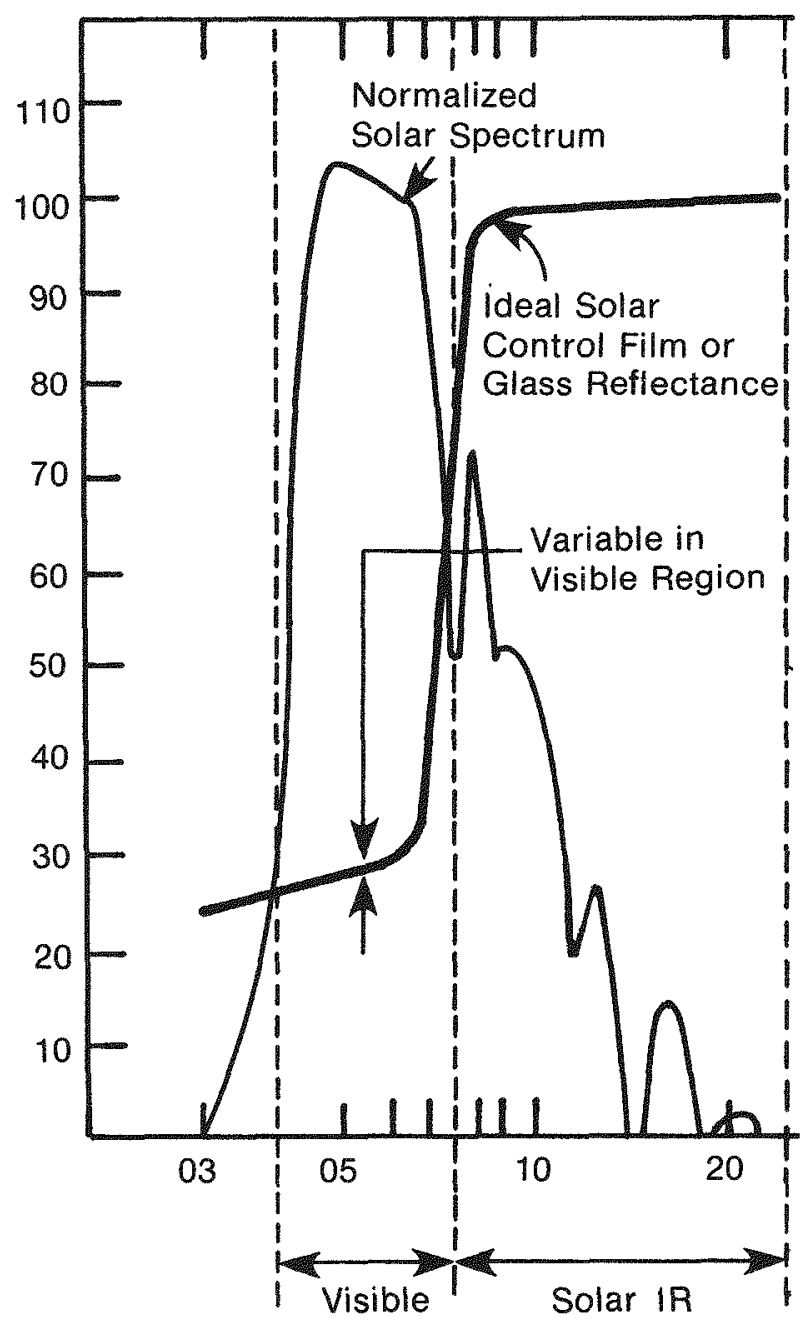

Fig. 6-6. Ideal selective reflective coatings

transmission values of 60 to $80 \%$ but shading coefficients as low as 0.3 or 0.4 . Although the concept is not new, products of this type are not available to designers today. The intent of the DOE program is to speed development and commercialization of such products and put them in the hands of building designers.

A more speculative approach to solar control in glass is the possibility of developing coatings that cause glass to act as an optical shutter, admitting light when it is desired and rejecting it when it is not wanted (Fig 6-7). The concept here is to take window management down to an atomic or molecular level. Similar types of coatings exist today, in the form of liquid crystal watch displays that switch from transparent to reflective, or the phototropic sunglasses which change optical density as a function of the ambient light environment. There are severe problems of product cost, lifetime, and durability: but if such a product can be developed, it would add greatly to the designer's bag of tricks in solving glare and sun control problems associated with daylighting design. 


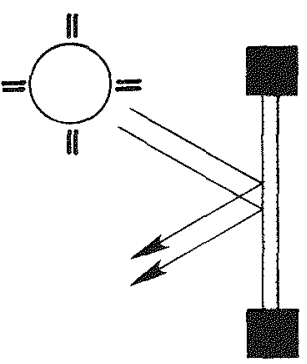

Reflective Mode

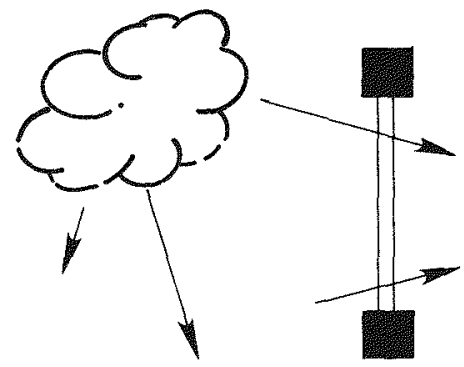

Transparent Mode
Fig. 6-7. Glazing with a selective solar transmittance coating

In summary, the building designer must balance requirem ents for sun control and glare control against the necessity for relatively high light transmission to achieve adequate daylighting in buildings. A variety of automatic devices is available to the designer although user response and actual product performance are not well defined. If undesired solar gain is not effectively excluded from a daylighted room, resultant cooling energy consumption may reduce or eliminate daylighting savings [12].

\section{REFERENCES}

1. Rosenfeld, A. H. and Selkowitz, S. E., "Beam Daylighting: Direct Use of Solar Energy for Interior Mlumination." Proceedings of the 1976 International Solar Energy Society Annual Conference, 1976.

2. Duguay, M. A. and Edgar, R. M., "Lighting with Sunlight using Sun Tracking Concentrators." Applied Opties, vol. 16, no. 5, pp. 1444-1446.

3. International Recommendations for the Calculation of Natural Daylight, Commission Internationale, De L'Eclairage, Publication No. 16 (E-3.2), 1970.

4. Daylighting Committee of the IES. "Recommended Practice of Daylighting." Illuminating Engineering, vol. 62, p. $517,1962$.

5. How to Predict Interior Daylight mlumination, Libbey-Owens-F ord Company, Toledo, Ohio, 1976.

6. Kusuda, T. and Collins, B., Simplified Analysis of Thermal and Lighting Characteristics of Windows: Two Case Studies, BSS 109, National Bureau of Standards, 1978.

7. Arumi, F., "Daylight as a Factor in Optimizing the Energy Performance of Buildings." Energy and Buildings, vol. 1, no. 2, pp. 175-182, 1977.

8. Voluntary Standard Procedure for Calculating Skylite Annual Energy Balance, Architectural Aluminum Manufacturers Association: Pub. No. AAMA 1602.1., Chicago, Ill., 1977.
9. Olgyay, A. and Olgyay, V., Solar Control and Shading Devices, Princeton University Press, Princeton, N.J.g 1976.

10. Rubin, A., Collins, B., and Tibbott, R., Window Blinds as a Potential Energy Saver-A Case Study. BSS 112, 1978.

11. King, W., High Performance Solar Control Office Windows, LBL report \#7825, Berkeley, California, 1977.

12. Hardy, A. C. and O'Sullivan, P.E., Insulation and Penetration. Oriel Press Ltd., Newcastle-upon-Tyne, 1967. 


\section{STRATRGIFS OF DAYULGHT DESIGN*}

Good daylight design does not simply mean large windows. It must be approached both quantitatively and qualitatively on broader and more sensitive design terms.

Daylighting seeks optimum amounts and areas of natural illumination for biological and task needs, which means good quantity and distribution of natural light. The impact of heating and cooling must be addressed and tradeoffs made appropriate to location and time.

Glare needs to be controlled to ensure that light will be comfortable and pleasant, as well as adequate in quantity. Appropriate surfaces need to be illuminated to dispel the perception of gloom.

Daylight is a dynamic phenomenon. The relationship to natural rhythms of the surroundings requires a dynamic design response, specific to time and place. Designers must learn to approach the design process with this dynamic in mind and understand that the building will be visually and functionally different according to day and season. Daylight is not something one adds to building design; it is implicit to every design decision.

Factors affecting daylight design include variations in the amount and source of daylight, caused by the position and intensity of sunlight. The luminance and luminance distribution of clear, partly cloudy, and overcast skies must also be considered. The effects of local terrain, landscaping, and nearby buildings and the glare and luminance patterns within view are important, as is the color of daylight as combined with other sources of light (Figs. 6-8 and 6-9).

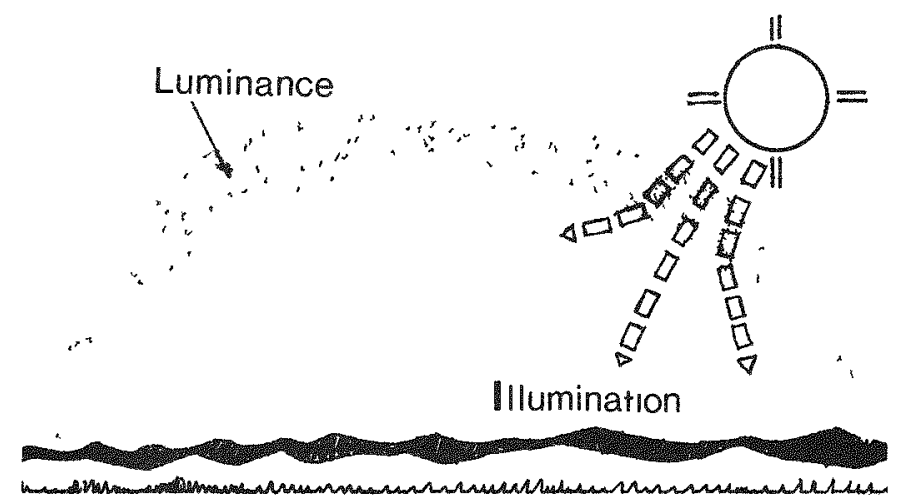

Fig. 6-8. Visible radiant energy (lumens)

*This article by Marguerite Villecco with Steve Selkowitz and J. W. Griffith appeared in AIA Journal, September 1979. Mr. Selkowitz is with Lawrence Berkeley Laboratories, and Mr. Griffith is former president and chairman of the daylight committee for the Illuminating Engineering Society. Material for this article also came from Harvey Bryan of LBL, lighting consultant William Lam, and the new IES handbook, Recommended Practice of Daylighting.

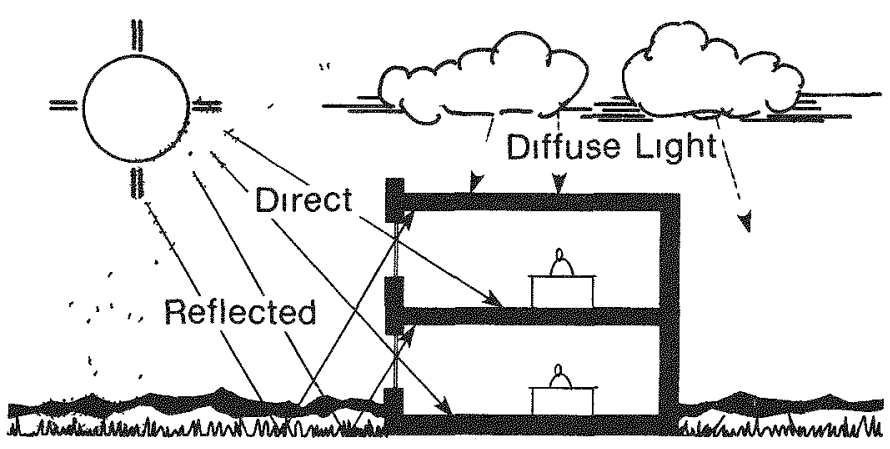

Fig. 6-9. Sources of solar radiation

The design strategies used for admitting natural light into the building must be responsive to all of these factors. Natural light is a diffuse form of sunlight; daylight design must deal not only with direct solar radiation but with sky light and reflected light.

Compared to the Sun, the sky has a large visual area and a relatively low luminance. The amount of daylight received from the sky depends on the position of the Sun and on atmospheric conditions. For design evaluation, one or more of three conditions of incident light on the exterior vertical surface of the building are usually considered. The first is light from an overcast sky only; the second is light from a clear sky only, and the third is light from a clear sky plus direct sunlight.

According to the new Mluminating Engineering Society handbook on daylight design, the amount of light received from an overcast sky and the direction from which this light reaches the windows of a building depend on the luminance pattern of the sky. The luminance distribution of an overcast sky varies with the location, time, density, and uniformity of the overcast. A uniformly overcast sky is normally 2.5 to 3 times as bright overhead as near the horizon. As a simplifying measure, a single luminance value representing the equivalent uniform sky luminance may be employed for design purposes.

The sky luminance on clear days varies with the position of the Sun and the amount of atmospheric dust or haze. Except in the immediate vicinity of the Sun, the clear sky is normally brighter near the horizon than overhead. The concept of equivalent sky luminance mentioned above may also be used for clear skies. In daylight calculations for clear days, sky light only is included on non-sun exposures, while light from both sun and sky is included in calculations for sun exposures.

The illumination received on a horizontal surface from the clear sky alone is correlated with solar altitude. In the case of vertical or tilted surfaces, this illumination also varies with the orientation of the particular surface.

Sunlight reflected from the ground commonly represents 10 to $15 \%$ of the total daylight reaching a window area. Snow, light sandy soils, or light vegetation may exceed these levels. On non-sun exposures, the light reflected from the ground may account for more than half of the total light reaching the windows. 
Daylight is constantly variable, which may cause difficulties for the designer, but is a psychological amenity to people relying on it. The variations are somewhat predictable, in accord with changing weather conditions and the daily and seasonal rhythms of the Sun. There is, however, a lack of information about daylight availability in the United States. It is difficult to obtain information on whether the sky for a particular area is predominantly clear or overcast, or data about the fraction of the working hours in a year that one can expect minimum sky conditions to be exceeded. Data of this type exist for many European cities, but for only a few cities here.

Measurements that were made some time ago in Washington, D.C., and other urban areas are now suspect due to atmospheric changes resulting from air pollution and other climatic variables. Rather than wait several years before such data can be collected, it may be feasible to generate daylighting availability data from the solar radiation data now being collected throughout the United States. Efforts to test the validity of such techniques are now in progress.

Daylight design requires sensitivity beyond that provided by simple rules of thumb. The thermal/illumination tradeoffs and the qualitative, as well as quantitative, issues cannot be grossly simplified. A starting point, nonetheless, is to note that for pure daylighting purposes, the bigger the window opening, the better. The higher in the wall and the higher the ceiling, the better the design. If glass must be limited for thermal or comfort reasons, take it off the bottom for visual task performance and off the top for ambient purposes, where ground reflections can be useful. Openings are better horizontal than vertical because vertical openings set up strong patterns of light and dark contrasts. A predominant north/south orientation is useful because it lends itself to seasonal, or fixed, controls. Separation of view glass from daylight sources may help in making thermal and illumination design tradeoffs.

The most familiar approach to daylight design is sidelighting. Typically, this uses diffuse radiation only. Direct solar gain, al though occasionally pleasant, typically leads to visual and thermal discomfort, aithough it may be integrated into a passive solar heating design approach.

Daylighting levels from windows in one wall of a room fall off rapidly as we move deeper into the room, from the window wall. A typical practical limit for daylight penetration into an office is 15 to $20 \mathrm{ft}(4,575-6,100 \mathrm{~mm})$ from the window wall. Design approaches based on sidelighting approaches were well developed in the 1940s and 1950s; and the basic strategies for unilateral, bilateral, and trilateral daylighting designs have remained unchanged.

Fig. 6-10 illustrates classic unilateral daylighting schemes. It shows sections that were tested under the artificial sky at Rice University during the mid-1960s. The rooms were typical unilateral designs, $30 \times 30 \mathrm{ft}$ $(9,150 \times 9,150 \mathrm{~mm})$ and with 8 -ft-high $(2,400 \mathrm{~mm})$ ceilings. Windows went from a sill height of $3 \mathrm{ft}$ $(910 \mathrm{~mm})$ up to the ceiling; reflectances were $85 \%$ for the ceiling; $60 \%$ for the walls; $40 \%$ for the floor; $40 \%$ for the terrain. Test stations were located $30 \mathrm{in} .(660 \mathrm{~mm})$ above the floor, or at about desk height.

\section{Illumination Levels - Unilateral Lighting}

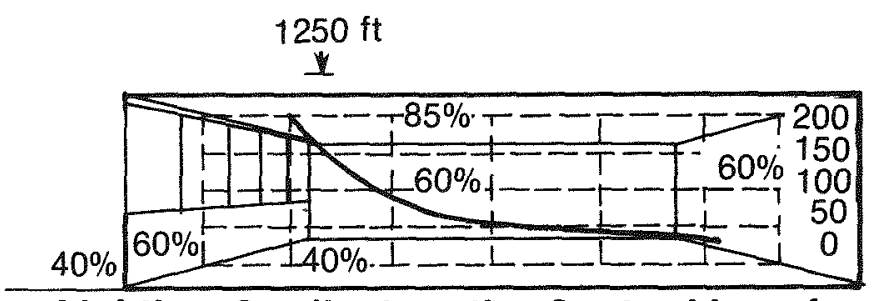

Lighting Gradient on the Center Line of Typical Room
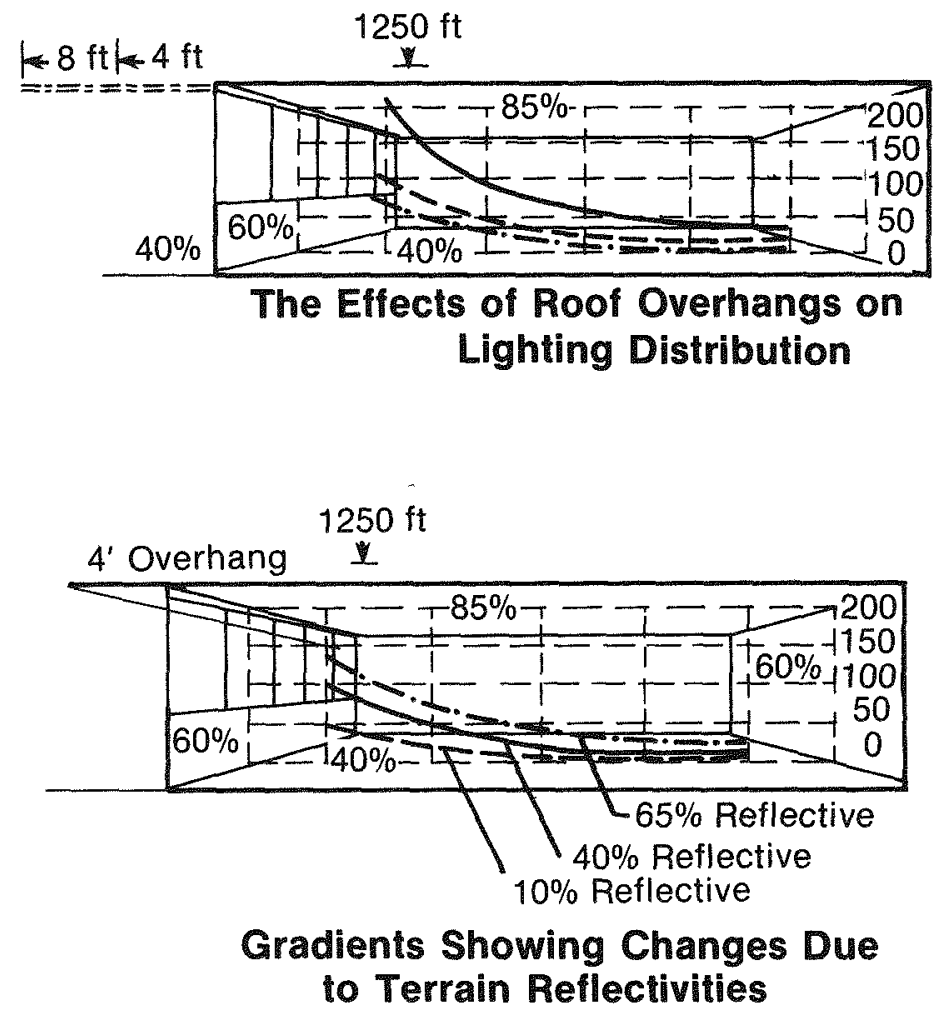

\section{Fig. 6-10. Tests under artificial sky by Rice University}

Lighting intensities decrease from a high at the center of the window space to approximately one-fourth intensity at the center of the room and one-sixth intensity at the center of the back wall. The researchers concluded that unilateral lighting must be balanced or reinforced by additional daylight or artificial light to achieve reasonable uniformity for tasks located away from the windows. 
The Rice researchers also tested a unilateral section with a succession of overhangs, from $4 \mathrm{ft}(1,200 \mathrm{~mm})$ to $8 \mathrm{ft}$ $(2,400 \mathrm{~mm})$. From a lighting standpoint, the rooms begin at the edge of the overhang; and the location of the window wall merely defines the usable portion of the space below the roof. The lighting at the windows decreased substantially as the overhangs increased; lighting at the center and rear of the space was less affected. The uniformity of distribution was improved.

The California schools designed in the 1940 s and 1950 s to use daylight are a good reference for classic bilateral daylight design. Effective sidelighting produces less veiling reflection, improved contrast, and thus greater visibility than equivalent foot-candles from most overhead systems. The schools are particularly useful because a survey of their performance was made in 1948 , which allows us to relate the design concept to information about their actual daylight performance. Fig. 6-11 shows generic diagrams of classic multilateral daylight building sections, examples of those sections as used in the schools, and reading of light levels on their interiors.

Some techniques for increasing daylight penetration, which either allow a wider building section or a greater percentage of daylight reliance, are being closely examined today. The most discussed strategy is beam daylighting, of which the Tennessee Valley Authority building is an example, using mirror reflectors and solar courts in its design.

One version of beam daylighting involves reflecting the direct rays of the Sun from silvered reflective Venetian blinds mounted in the upper $2 \mathrm{ft}(600 \mathrm{~mm})$ of a window. The reflected rays are aimed toward the ceiling of the room to a maximum depth of 30 to $40 \mathrm{ft}(9.14$ to $12.19 \mathrm{~m})$. The ceiling then acts as a diffuse reflector providing normal diffuse illumination deep inside the room. Although the light quality achieved by such a scheme is satisfactory, the control of reflected light as sun angles change is not a trivial problem.

A variety of controllable reflecting or refractor-type devices has been examined, but the real issue is achieving simplicity and low cost in these devices without sacrificing performance. In addition, more sophisticated lighting controls are required for partly cloudy sky conditions where the illumination levels will vary greatly and quickly. Beam sunlighting appears to have limited application to existing buildings because of window and ceiling design characteristics, but the concept offers promise for new buildings designed specifically for it.

Toplighting is another important daylight design strategy, promising more uniform light for general illumination, al though less appropriate light for tasks. Historically, skylights have been designed to exclude the direct sun. (Sawtooth and skylights with overhangs are examples.)

Large spaces, such as factories and warehouses, Iend themselves to variants of conventional sidelighting and toplighting designs, such as the roof monitors and sawtooth clerestory illustrated here. More recently, translucent roofs provide substantial access to daylight, al though control becomes difficult. An analysis of some industrial applications was published by Detroit Steel Products Co. in 1929.
Fig. 6-12 (John Van Range Co. of Cincinnati) illustrates a narrow sky monitor that produced nonunif orm daylighting levels that could be improved by widening the monitor.

Fig. 6-13 compares the daylight performance of vertical versus sloped clerestories at the Bethlehem Steel Co. An increase in monitor height increased performance, although the researchers concluded that 8-ft-high $(2,400 \mathrm{~mm})$ sloping windows admitted no more light than vertical windows $6 \mathrm{ft}, 10 \mathrm{in}$. high, $(2,100 \mathrm{~mm})$, as dirt accumulated over a 6 -month period.

The most successful example of natural lighting in this study was a General Electric plant, $340 \mathrm{ft}(113.63 \mathrm{~m})$ long with a sawtooth span of $25 \mathrm{ft}(7,500 \mathrm{~mm})$. This design gained high illumination and uniformity. (See Fig. 6-14.)

Most modern skylights lie flat in the roof plane and thus accept both direct and diffuse radiation. Domed or peaked skylights provide a larger window to the sky and thus more daylight. All skylights raise the issue of heat along with light, and various controls by orientation or insulation may be needed.

Conventional skylights are limited to providing daylight in one-story or multi-atrium spaces, but several concepts recently have been explored that use direct sunlight through a roof aperture and then distribute that light through the building by using mirrors, lenses, and other optical controls. Such schemes are feasible, but their optical performance requirements and complexity limit their practicality for most building applications.

Orientation is a significant factor in skylight design. Several recent strategies have sought dynamic adaptation to heating and cooling conditions by developing movable insulation systems within a skylight. A north-facing skylight accepts light but does not produce much solar heat gain; a south-facing skylight admits both heat and light. Movable insulation can allow the designer to take advantage of both at appropriate times.

\section{CONTROLS}

Control is a key element in daylight design, in terms of both direct solar radiation and sky brightness and to ensure a desired quality, as well as quantity, of light. The quantity of daylight illumination in a space is a function of the amount of daylight avallable, the site, the fenestration, and the room. The critical elements in daylight availability are the time of day, season, cloud cover, microclimate, and air pollution. The site must be considered in terms of orientation, latitude, landscape, and obstructions. Fenestration concerns include sun control, the framing and wall system, the sash, transmission characteristics, maintenance, wall location, and size. The geometry of the space plus its surface reflectance, maintenance, furniture, and task location, are also critical.

More light does not necessarily mean better light. The qualitative aspects of daylight and the tradeoffs between illumination and thermal design objectives must be considered. 

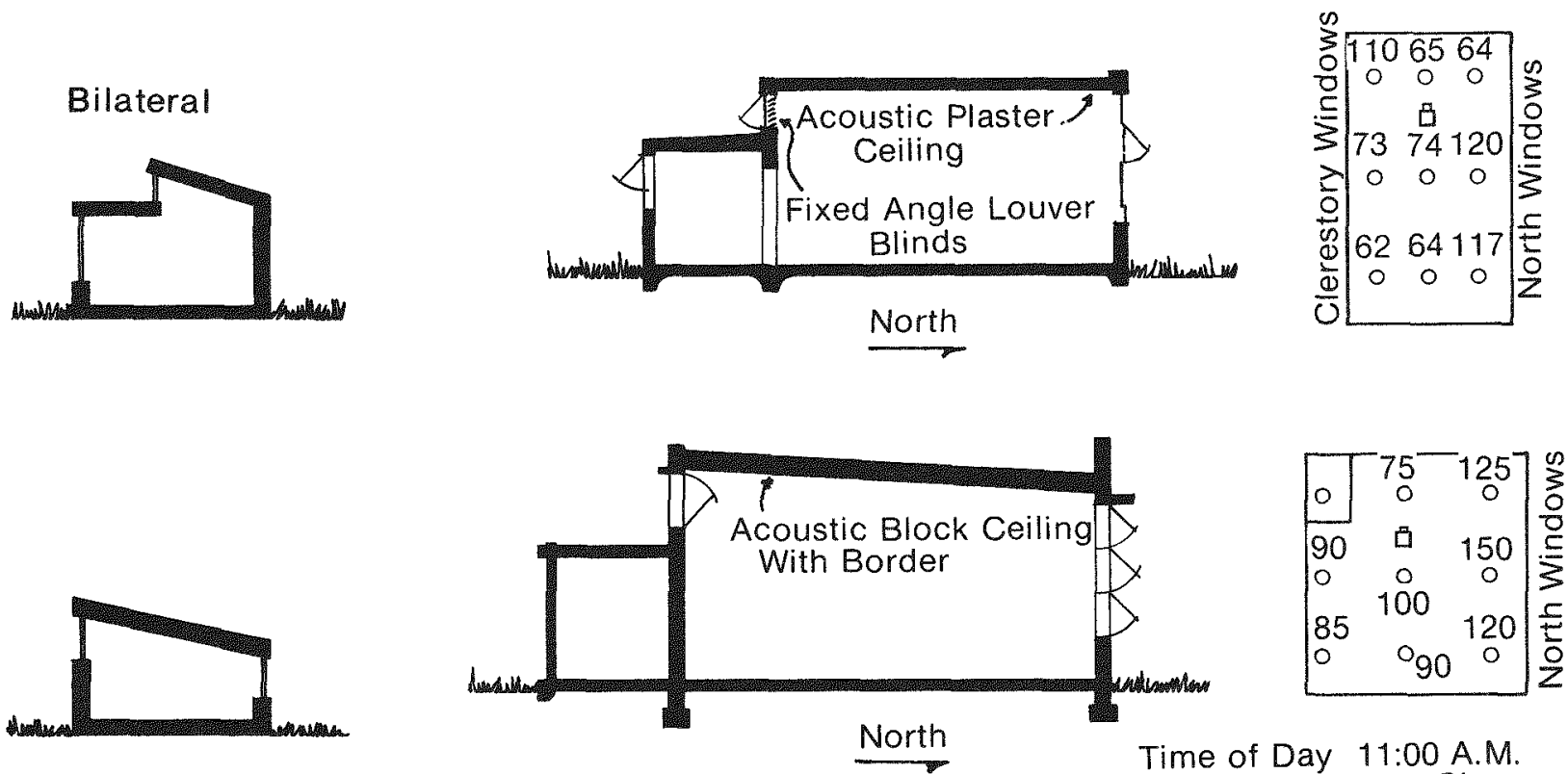

Time of Day 11:00 A.M General Weather Clear
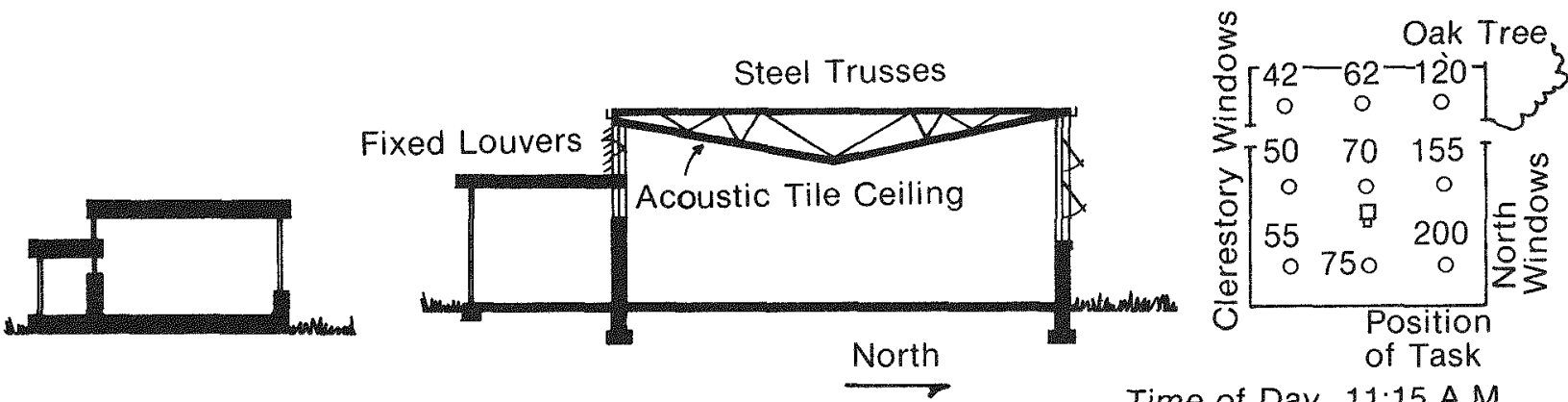

Time of Day 11:15 A.M.

General Weather Clear

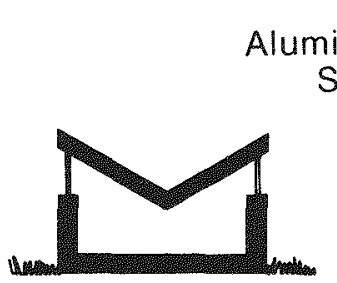

Aluminum Fin Corrugated Aluminum
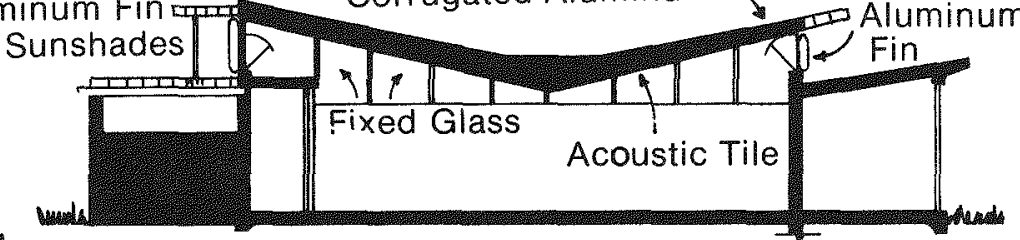

\begin{tabular}{|ccc|}
\hline 0 & 0 & 0 \\
62 & 50 & 56 \\
0 & 958 & 0 \\
85 & 0 & 61 \\
0 & 0 & 0 \\
74 & 55 &
\end{tabular}

Ceiling Ridge

North

Time of Day A.M.

General Weather Clear

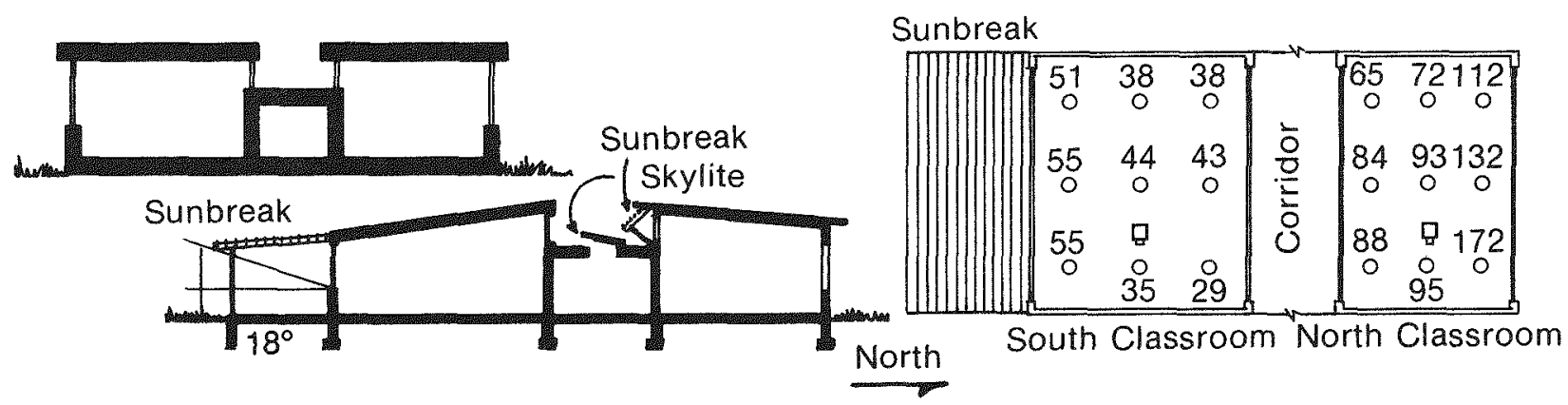

Fig.6-II Lighting levels for various building types 
Position of Task
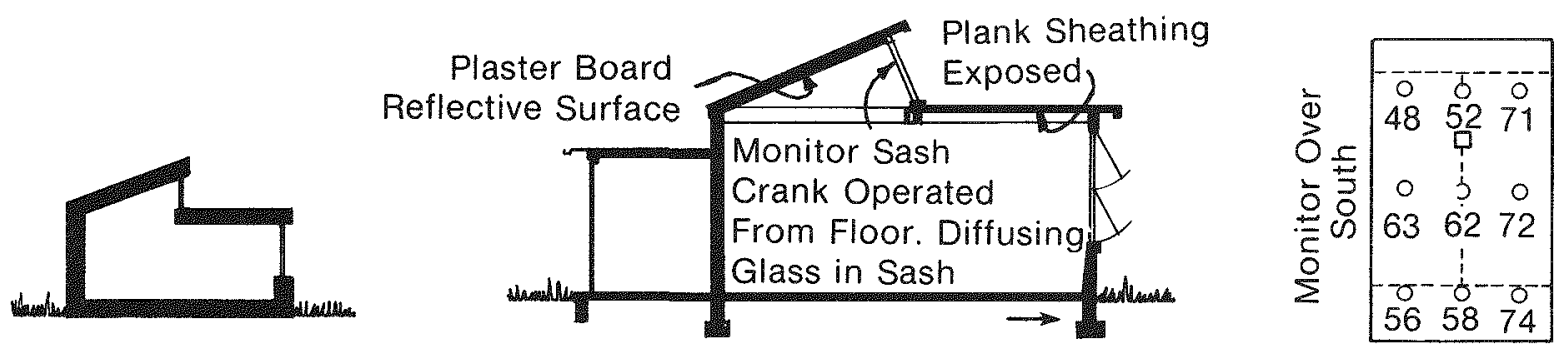

Time of Day 12:45 P.M.

General Weather Clear

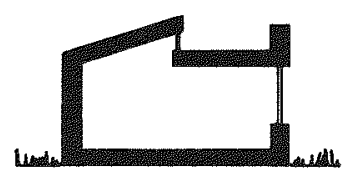

Trilateral

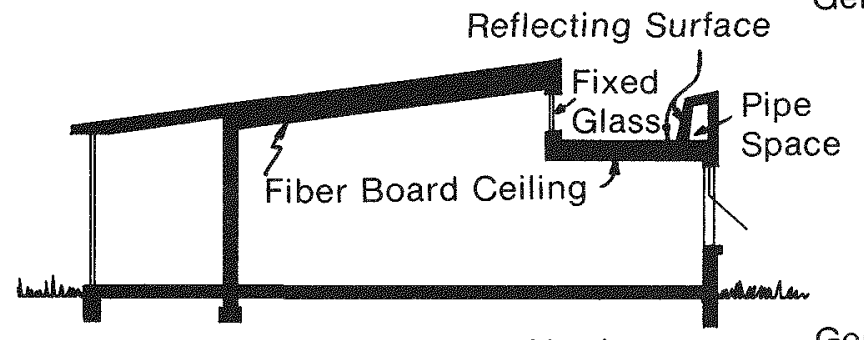

\begin{tabular}{|cc:c|}
\hline$\circ$ & 0 & $\circ$ \\
45 & 52 & 35 \\
$\circ$ & $\circ$ & 0 \\
76 & $\square_{\square}$ & 56 \\
$\circ$ & 52 & 36 \\
$\circ 60$ & 0 & 0 \\
\hline
\end{tabular}

North

General Weather Clear

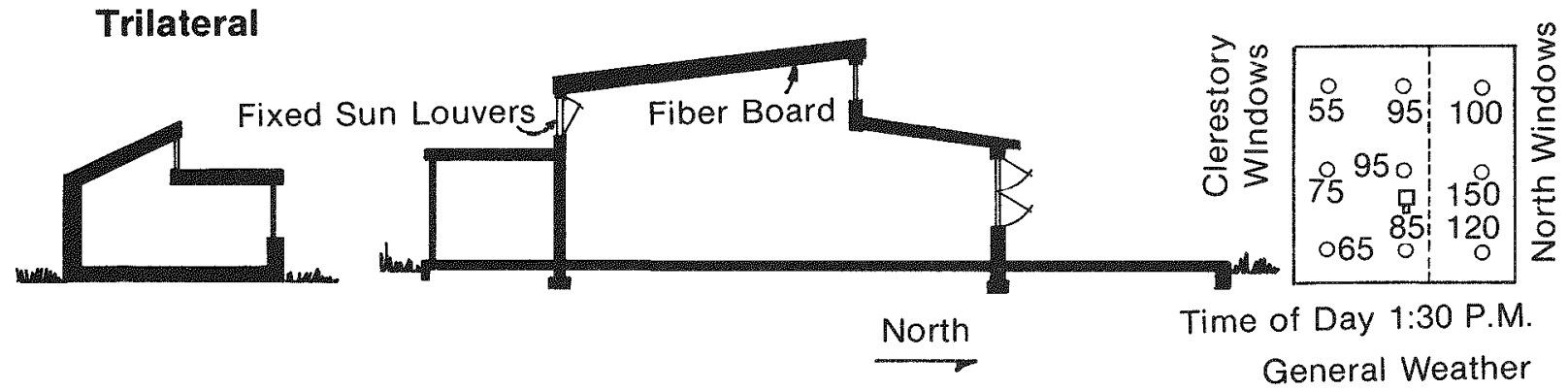

Light Haze

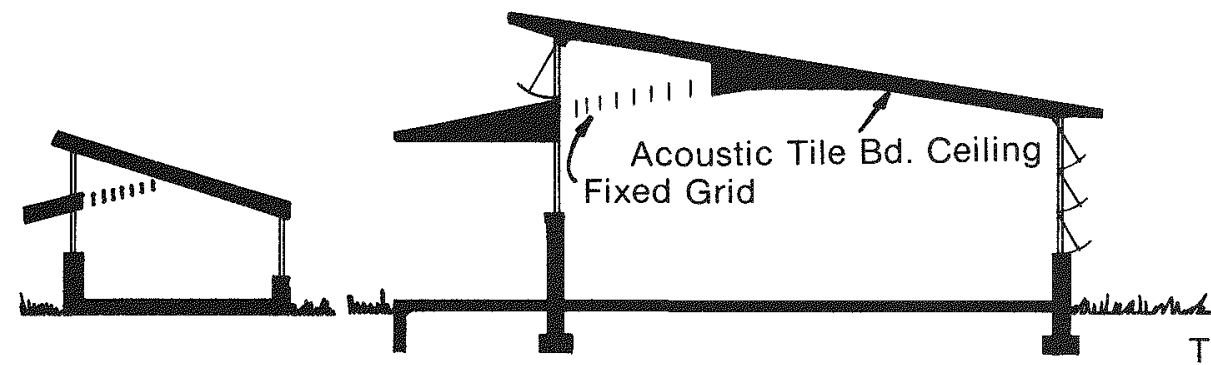

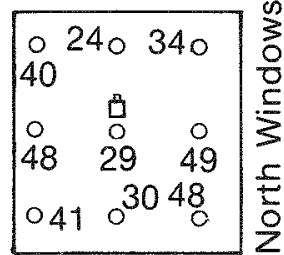

Time of Day 12:00 P.M.

General Weather Clear

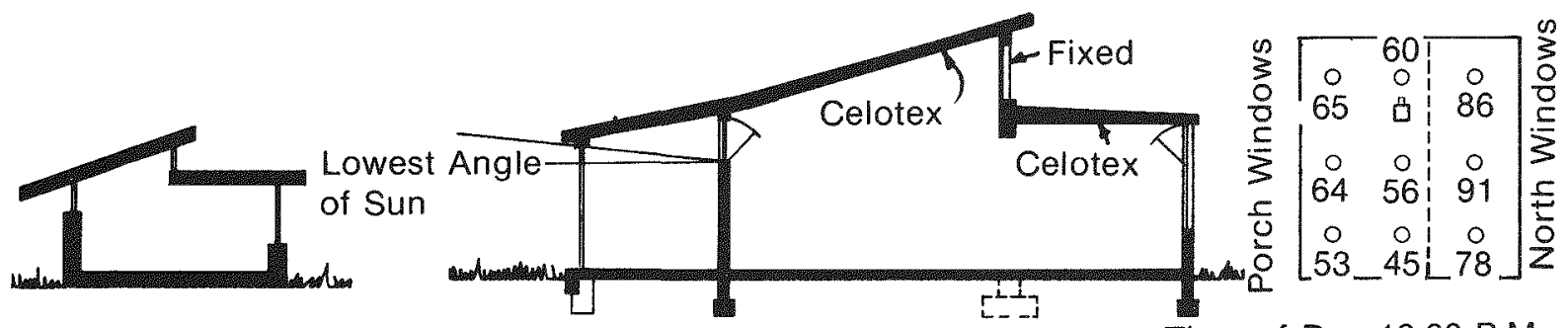

Time of Day 12:00 P.M.

General Weather Clear

Fig. 6-11. Lighting levels for various building types 


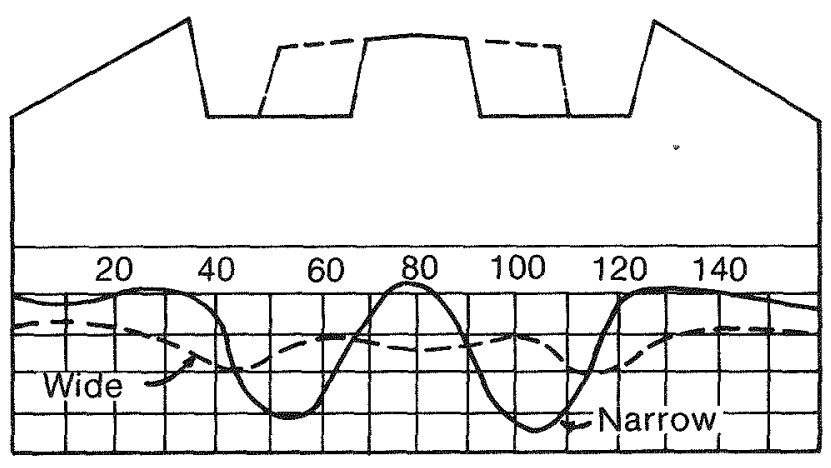

Fig. 6-12. John Van Range Co., Cincinnati, Ohio

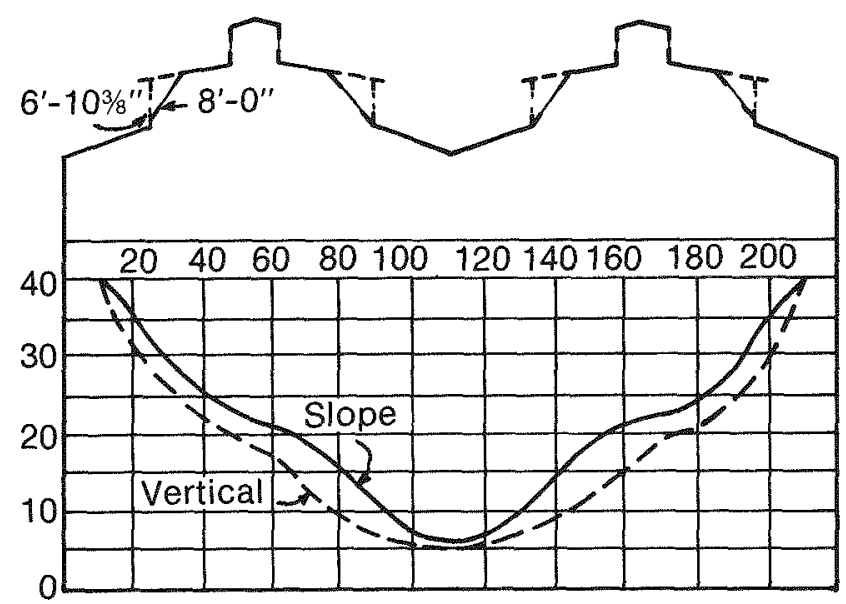

Fig. 6-13. Bethlehem Steel Co.

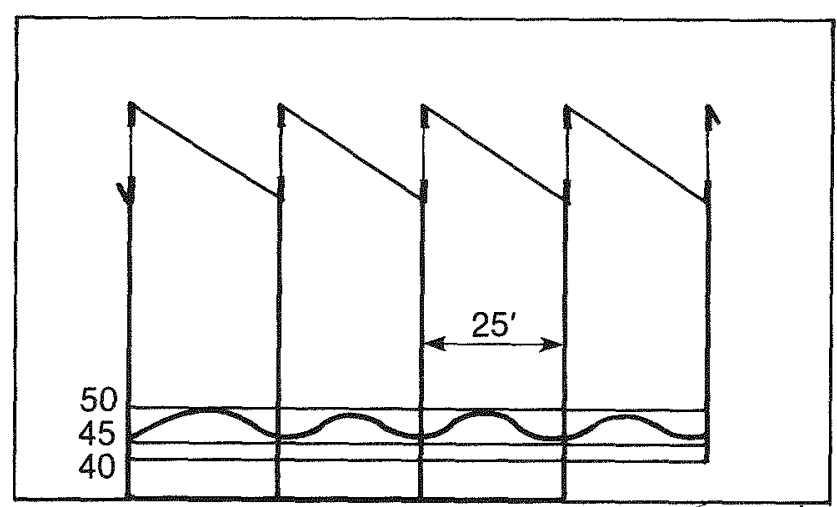

Fig. 6-14. General Electric Co. plant
There are three basic reasons to include daylight controls in any design strategy: to eliminate excessive illumination on interior surfaces, to eliminate high sky brightness or direct radiation, and to redistribute sunlight by diffusing it.

Orientation is critical. Even on the north facade, a clear glass window may see 5,000 footlamberts on a cloudy day; glare control is necessary. Controls on the south, east, and west are, of course, more critical because these elevations are exposed to direct radiation, which poses not only issues of illumination control but of thermal control. Ways must be found to respond to the rhythms of the Sun, rejecting heat when unwanted and admitting it when desired. In general, control is the essence of design. A discussion of typical control strategies follows.

Fixed exterior controls are used to limit excess sun or skylight. Overhangs eliminate the impact of direct sunlight and heat on glass during specified times of the year. Designs may be flat or sloping; sloping versions may be of shorter length but obstruct more of the sky view. They may be translucent or opaque. Translucent overhangs have the advantage of providing weather control and the transmission advantages of louvers.

Exterior louvered overhangs allow the reflected sunlight to illuminate the visible surface of the control to the room. If the louvers are not opaque, they allow better utilization of the sunlight and skylight in the room and also allow the dissipation of heat. Disadvantages are that louvers allow rain through them and cannot be used along narrow exterior corridors.

Exterior vertical or horizontal louvers are a variation that may be useful. The vertical louvers lend themselves to controlling sun on the east and west facades of a building; the horizontal louvers are most effective on the south side. Vertical louvers may also be used to control sky brightness on the north.

A diminutive louver can be applied to a window and not greatly obstruct the view; if the slats are fine enough, the eye will maintain clear vision by putting the image together as it does in pointillist paintings or with pictures screened for publication. Even a very small louver will shield the sun at critical times but allow a clear view if put across a vision strip. In Europe, rolling diminutive louvers are available.

Other exterior fixed controls include screens, trellises, and shrubbery. Trellises in particular have been used architec turally to control light, al though the design must be carefully considered.

Fixed exterior amplifying controls enhance the impact of the sun and skylight rather than diminish it. These include surfaces that either diffuse or reflect the light. For instance, white stones and concrete diffuse light; polished aluminum and mirror surfaces redirect it.

Overhangs with reflective surfaces underneath transmit maximum ground reflections. The surface may be painted white or may be of concrete. Light shelves are overhangs located below the window to reflect light up toward the ceiling inside. Parapet walls are another variation. These are effective in combination with a north-facing clerestory; they reflect the light from the 
southern sky and Sun through the clerestory and onto the ceiling. Louvered overhangs can be designed as a control to both limit solar radiation from direct penetration into a space and to amplify its effects by reflecting it into the interior of the building. (See Fig. 6-15.)

Variable exterior controls offer the greatest control potential by responding to changes in day and season. Such controls include window awnings or awnings attached to the edge of a fixed overhang. Louvers adjustable for tilt may also be used. On the east and west facades they may be drawn to the side; on the south side, they may be raised and lowered according to the time of day and season. Tracking mirrors, such as those on the new buildings for the Tennessee Valley Authority, are the most sophisticated systems. They require dynamic control to either track or adjust incrementally
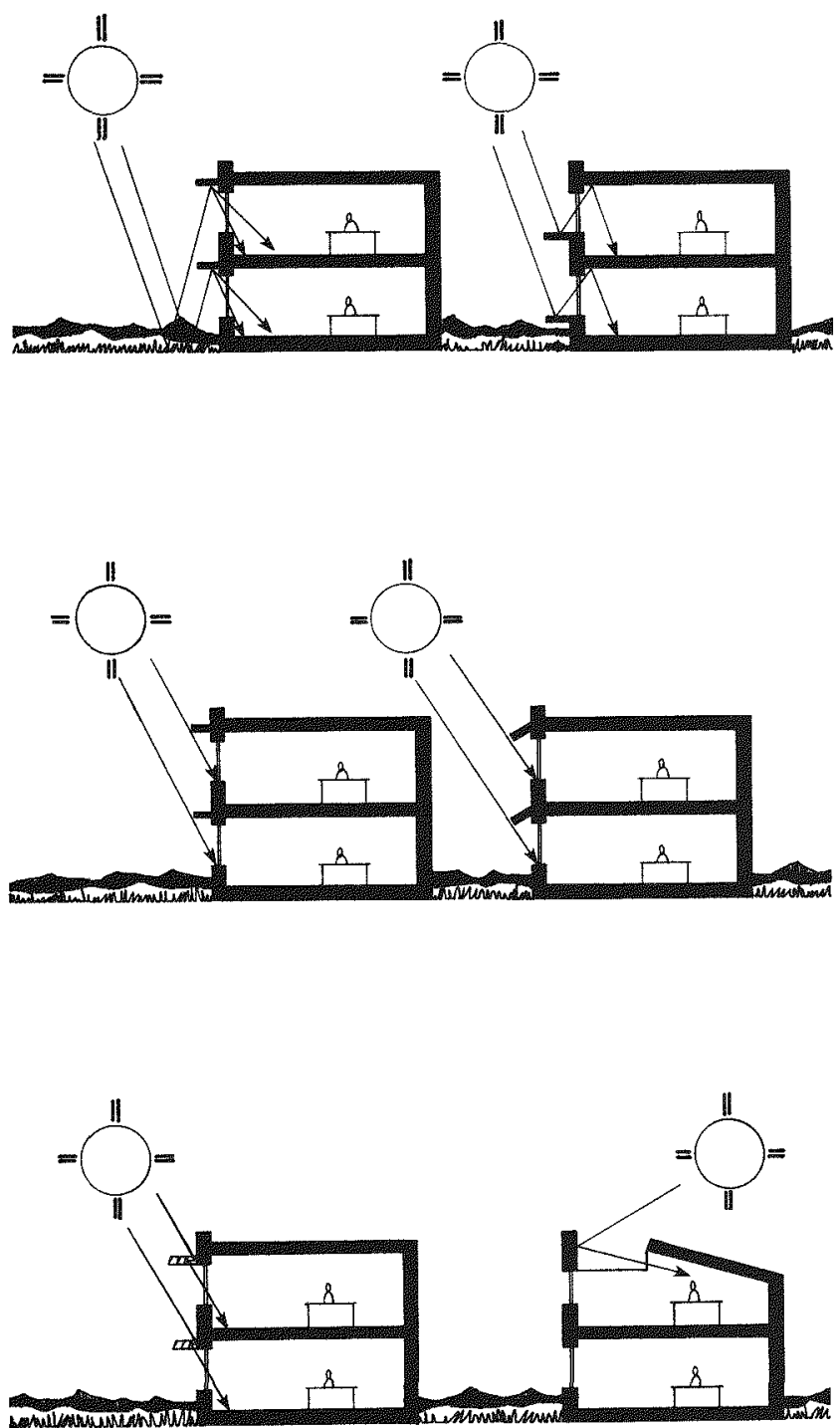

Fig. 6-15. Fixed exterior controls to the apparent movement of the Sun and to changing sky conditions. The cost of such systems must be considered in the context of the overall building performance and according to life cycle cost/benefit analysis.

Interior fixed controls include diffusers, such as translucent materials, to sof ten and diffuse sunlight. The material may be part of a shade device or may hang loosely between the natural light source and the space. Louvers, installed inside a window or between panes of glass, may be adjustable or fixed. They are generally less effective than exterior controls because they let more heat into the building. The louver concept may also be applied to an eggerate louver installed beneath a skylight.

Prisms are another daylight control strategy. Prismatic glass block was used in the 1940 s and 1950 s. The prisms on the inside of the glass block were designed to accept sunlight and to redirect it upward onto the ceiling of an interior space as diffuse light. The glass block has not been used recently because the interior surface gets very hot. A prismatic version of insulating glass has been experimentally developed but not commercially produced because it is too costly. Research may yield breakthroughs in this field.

Reflective glass and tinted glass control daylight but currently cannot respond dynamically. Diffusing glass, or milky patterned glass, has the same problem. These materials keep the sunlight out when the heat and glare are excessive, but they do the same when the heat or light may be desirable and result in generally lower daylight levels.

Variable interior controls include some of the simplest daylight devices, although they rarely are the most effective. Shades and draperies that diffuse the light or opaque versions that can be opened or closed to admit or reject heat and light are the most familiar. Variable horizontal or vertical louvers (Venetian blinds), can be adjusted for tilt and/or removed in response to natural light conditions. They may be installed inside a window or between its panes of glass. Reflective-coated shades or blinds can be used to reject unwanted heat and light. A variation has a black side to absorb heat in cold weather and a reflective side to redirect it in summer. Properly adjusted louvers can be used to amplify the effects of daylight by reflecting and redirecting it. Research in this area promises new developments soon. Multiple shades and draperies may also be installed and manipulated to diffuse light under one condition and to reject it under others. A familiar example is the sheer curtain as a light diffuser with a heavy fabric drapery to draw over it to keep heat and light in or out of the space.

Fixed interior amplifiers, or light shelves (Fig. 6-16), may be installed to take advantage of reflected light from below the horizontal or to reflect sunlight or sky brightness. The shelves operate similarly to exterior overhangs and may have either diffuse or specular reflective surfaces, although the specular surface can result in bright spots. Light-colored floors, ceilings, draperies, blinds, and fumiture also amplify interior light.

The issue of manual versus automatic solar and glare controls is part of the design tradeoff. It seems likely that office occupants will close shades and blinds to reduce excessive heat gain or glare for thermal or visual 


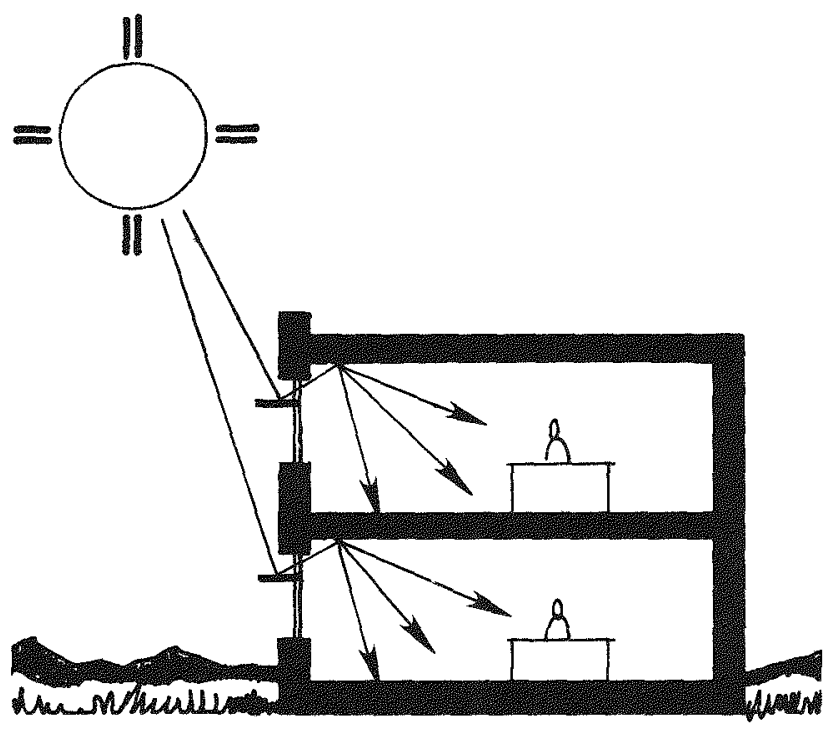

Fig. 6-16. Light shelves

comfort. It is not clear, however, that they will operate these devices to save energy. The blind that is closed in the afternoon to prevent glare may not be reopened to admit daylight the next morning, unless people are made aware of the daylight as a design strategy.

A side effect of the energy problems in this country is that people are becoming more aware of and concerned with the natural cycles of day and season. Recent work at the National Bureau of Standards with employees indicates that people will manage Venetian blinds in a way that distinguishes orientations and season. There is also evidence that an individual will exercise control of a private space, but that a large space with many people diffused a sense of individual responsibility and may not be as well managed. These are issues that need further attention as efforts to involve people in their own environment become more desirable.

If interior and exterior shading devices are used to control excessive sun and glare, the question of glazing properties becomes important. Workers in a typical office have a view of the horizon or the sky in the immediate vicinity of the horizon. With standard overcast skies, the horizon is three times darker than the sky overhead. In clear sky conditions, however, the luminance distribution is inverted; and the horizon is brighter than the overhead sky. In urban areas, haze and air pollution can produce additional scattering of the light and additional glare. Because sky luminance at the horizon may be 500 to 3,000 footlamberts versus 25 to 75 footlamberts for a typical office, severe discomfort glare problems may result.

Some degree of light control in glazing is probably desirable, but it is unlikely that transmissions of less than $50 \%$ would be desirable for daylighting. Heat absorbing and reflecting glass may also be desirable for such situations as sunlight reflected by water or from adjacent lands caping or buildings.
The development of sophisticated glazing materials, with heat absorbing and reflecting properties, is a relatively recent innovation.

We can reasonably expect additional improvements in the thermal and solar optical properties of glass to satisfy new performance criteria. One research program supported by the Department of Energy (DOE) is an effort to develop selective transmittance solar control coatings for windows. Approximately $50 \%$ of the incident solar energy at a window is visible light; the rest is invisible solar infrared and ultraviolet radiation.

A selective transmitting window will allow the visible light to pass through it into the room but reflect the solar infrared portion back to the outside environment. Coatings of this type might have light transmission values of 60 to $80 \%$, with shading coefficients as low as 0.3 or 0.4 .

Although the concept is not new, such products are not available to designers today; DOE is seeking to speed their delivery. Some of these materials are selective by absorption, such as blue/green glass; but the shading coefficients are not as low as reflective coatings, and some heat gets into the buildings. Selective reflective coatings are available in Europe but are still having cost and technical delays here.

A more speculative approach to solar glazing control involves coatings that cause glass to act as an optical shutter, admitting light when desired and rejecting it when not desired. The concept here is to take window management down to an atomic or molecular level. Similar types of coatings exist today in the form of liquid crystal watch displays, which switch from transparent to reflective. It also may be seen in the phototropic sunglasses that change optical density in response to changing ambient light levels. There are still severe problems in making such glass economical and durable, but the dynamic nature makes the concept very attractive.

\section{INTEGRATION}

Daylight can provide good visibility and amenity for indoor environments, but it will not reduce energy consumption unless people turn off the installed artificial lights. Daylight design may result in lower levels of installed lighting, but its greatest energy contribution is that it allows people to turn off the lights. This may sound obvious, but many of the buildings cited for good daylight design are operated as though daylight did not exist. This is partially the result of inappropriate control systems and lack of user awareness.

Efficient lighting controls can save energy even without daylight. Lighting systems can be controlled over both space and time to achieve these savings. DOE's "energy efficient lighting program" currently includes two demonstrations of the effectiveness of more sophisticated lighting control systems in typical office buildings. These systems are designed to provide more flexible user control and to prevent energy waste from overdesign required by lighting maintenance schedules and lamp lumen depreciation. One system also employs photosensors and will be capable of achieving energy savings in daylit of fices. 
Lighting control options include on/off switching, which has a low to moderate cost but may not realize the full daylight potential and implies uncertain user response. Dimmable and multilevel cut-off systems have a moderate cost, al though this is dropping. They add complexity in return for greater savings. Sensing and control devices are available as manual systems, which are fallible but flexible, and as automatic systems, which are reliable but limited.

On/off switching is available on an off-the-shelf basis and has predictable results on fluorescent lamp life. There are potential problems with user acceptance resulting from sharp changes in lighting levels as one or more fixtures are turned on or off. Experimental results on this issue are mixed. On/off switching can be handled on a circuit-by-circuit basis, fixture-by-fixture, on individual ballasts with a single fixture, or with multilevel ballasts. The latter options, al though they involve more expensive switching and control systems, provide effective multilevel responses that may be more acceptable to users.

Dimmable systems are typically more complex and more costly. Although dimmable fluorescent systems are available for specialty applications, there are no widely specified, cost-effective, dimmable fluorescent systems used in the United States.

Dimming need not be continuous. Multilevel step dimming can bridge the gap between on/off switching and conventional dimming systems. A new generation of fluorescent ballasts promises to provide dimming at little incremental cost. These solid state electronic ballasts are now under development by a number of U.S. firms and are receiving support from DOE. They should appear on the market within the next 3 years. The high-frequency electronic ballasts lend themselves easily to dimming. As sales increase and the ballasts incorporate integrated circuits, prices should fall to levels comparable to premium ballasts today.

The DOE ballast demonstration includes several floors in a typical office building that has been retrofitted with dimmable ballasts in both perimeter and interior offices. Various experiments are planned to determine the best use of these controls. For example, should photocell sensors be placed on the ceiling looking down or on a window looking out? On the work plane facing up and in single or multiple locations? Photosensors may require time delays to prevent them from being fooled by a transient reflective object in a room yet must be sensitive enough to respond to changing cloud conditions that can result in rapidly varying daylight illumination within a room. All of these issues are solvable, but we lack the experience to confidently answer them at this time. Controls in skylit rooms are simpler than in rooms that are sidelit becaus the light is more uniform.

Given either dimmable or on/off switching, controls can be actuated manually or automatically. Manual controls are flexible, combining sensitivity and judgment at their best. The main danger is that they will be forgotten or unused. Experiments suggest that people in a daylit room will sometimes select higher artificial lighting levels than they will in a windowless room in an apparent attempt to match indoor and outdoor brightness. People will turn lights on more readily than they will turn them off. But this is a matter of education. Most people prefer the idea of a daylit to an artificially lit space; that preference needs to be supplemented by active participation in the daylit scheme.

Automatic controls are more reliable but work without judgment. They must be kept simple to avoid complexity and high cost. Microprocessor controls provide virtually unlimited control but represent overkill in a simple office environment.

Selection of control systems depends on occupancy and function. Perhaps the simplest example is a warehouse with skylights distributed across the roof. Here we can provide simple daylighting over the entire space with a simple control system because the daylight is uniformly distributed. With sidelighting from a window, the daylight gradient into the room becomes significant.

In small offices, work stations should be oriented so that the occupant faces parallel to the window to reduce glare and to provide good contrast and high visibility. With one or two occupants in a small office, there should be little argument over lighting levels, and controls can be simple. Both ambient and task lighting levels can probably be achieved with daylight.

In larger offices, we find deep bays and open landscape furniture systems. It may be inconvenient to orient all tasks appropriately, and interior spaces may receive insufficient daylight for of fice tasks. However, daylight may provide adequate ambient light and some design strategies may increase interior daylight performance beyond conventional dimensional limits, which range from 24 to $40 \mathrm{ft}(7,310$ to $9,140 \mathrm{~mm})$. In the larger office, task light may be provided as a supplement to ambient daylight. A relatively simple system can then be used to control an artificial backup system for ambient light, while each occupant individually controls task lighting. Given hardware casts for various types of lighting control systems, analysis can reveal whether a specific control system is cost effective. Life-cycle cost/benefit analysis, which has been developed by J. W. Griffith, provides a useful approach.

\section{ANALYSIS}

A major obstacle to daylighting design is a continuing lack of simple and accurate design analysis methods. These methods can be computational or graphic solutions; they can be in the form of graphic tables and computer programs; they include protractors and physical models. All of these exist, but none provides the combination of reliability, accuracy, and dynamic response that daylight design requires. The designer must therefore choose among them according to specific program and design objectives and use the results with caution.

Calculations are at best a representation, or simplification, of reality. All computer programs are a model of reality; what they do and do not measure is frequently more important than how well they measure a given element. The daylight designer must therefore approach all such programs and calculations as useful but not conclusive information. Daylight is a visual phenomenon; one should believe one's eyes and use them to challenge calculations. Because daylight is an instantaneous event and cannot be stored, averages can be very misleading. 
Physical modeling of a daylight design is therefore critical. Such a model is valuable for predicting both the quality and quantity of daylight and can reveal lighting gradients, specific glare problems, and the effects of building form and finishes. Whereas a mathematical model may work for a standard design condition, a physical model will provide information on complex, unusual, and specific design performance.

The built model should be tested outdoors, under naturally varying conditions. An artificial sky allows testing under more controlled conditions but implies stable conditions and exact numbers that belie actual daylight conditions. Preferably, the model should be tested at the proposed building site so that it can model such local conditions as reflection from landscaping or adjacent buildings. Outdoor testing suggests the limitations of real time, but the passage of seasons can be simulated by tilting the model to obtain the proper relationship to the Sun.

A daylight model can be simple, "quick and dirty," compared to a conventional architectural model. In the early stages of design, the model may simply deal with basic dimensions, openings, and surfaces; later in the design process, specific architectural features and furnishings must be modeled.

The model must be large enough to use with a meter and camera, or other instruments, but small enough to carry to the site (approximately 1:20 scale). In an assignment to his students at MIT, lighting designer William Lam notes that a model need not be painstakingly detailed; it needs to be accurate only in terms of room proportions, opening sizes, and reflectance and transmission values of plus or minus $10 \%$. He warns that some model materials will transmit light and must be covered with chipboard, aluminum foil, or paint to make them completely opaque. If adjacent surfaces, such as roofs and pavement, reflect enough light into the model to affect measurements, they should be included in the model and have an accurate reflectance. The plan orientation of the space in relation to north should be noted, and the model should have hatches in the floor and walls for taking measurements and photographs. If there is no glazing in the model itself, measurements must be factored to reflect actual glazing conditions.

Numerical calculations complement the physical model design evaluation. They allow the comparison and tradeoffs and an overall assessment of design performance. All but a miniscule fraction of buildings are daylit buildings. But not all of them are good daylit buildings that use daylight to provide useful illumination, an environment of good quality, and energy efficiency. Ask most architects to design a room to provide 50 footcandles on a desk for $80 \%$ of working hours by using daylight and you are likely to get a puzzled look and a fast shuffle through papers and textbooks. The problem is not a lack of methods but a lack of accessible, simple, and appropriate methods.

There are, in fact, about 60 recognized daylight design methods. But most were developed in Europe, where overcast skies prevail, and few are well suited to this country, where clear skies prevail. All of these techniques, however, can be divided into two main categories: the lumen method and the daylight factor method.
The lumen method was developed by J. W. Griffith at Southern Methodist University for Libbey-Owens-Ford Co. on the basis of extensive model studies under an artificial sky. The method was adopted by the Illuminating Engineering Society and has been the most widely used method in the United States.

The lumen method allows a comparison of various window wall schemes and their economic tradeoffs with HVAC and electrical lighting values. The effects of various glass transmittances, ground reflectances, wall reflectances, diffusing shades, Venetian blinds, overhangs, clear and overcast skies, and direct solar radiation are included in the calculation, which can evaluate them for energy or return on investment.

The method is limited to schemes of maximum utilization of daylight and it predicts illumination levels on a center line from the windows, according to intervals of $5 \mathrm{ft}$ $(1,500 \mathrm{~mm})$ from the back of the room. The technique was designed to evaluate schemes of variable window management, as well as fixed controls, to obtain the total benefits of daylight utilization, rather than meeting a minimum requirement. The method is applicable to a limited range of window configurations and accurate only for points situated along the center line from the window; it is also limited to vertical glazing.

The daylight factor method was developed in Great Britain to meet a minimum code requirement. It predicts the daylight anywhere in the room for a standard sky condition without sun incident on the window. The method, which is recommended by the Commission Internationale de 1'Eclairage, is used in Europe. Britain has a well-developed set of design aids such as diagrams, graphs, tables, and protractors to deal with daylighting at various stages of the design process. The daylight factor method is an essentially analytical process.

The daylight factor is described as a percentage of diffuse light received at a point of reference. The percentage expresses the ratio of interior illumination at a given point to the available illumination from an unobstructed sky outdoors. The point of reference is a horizontal plane.

The method allows nonunifor'm sky luminance distribution and is sensitive to the position of a window in a wall. There is no limit to room size or shape, and it accommodates nonvertical glazing. Its capacity to respond to shading devices is limited, as is its capability to deal with clear sky conditions. Direct sun is essentially excluded. The deylight factor, however, does provide a relative measure of all daylight, not only light directly from the sky (including losses from glass, dirt, window bars, etc.), but also the contributions from light reflected directly to a reference point from visible exterior surfaces and from light interreflected between the room's interior surfaces.

Both the lumen and daylight factor methods can be used in the early stages of design to evaluate alternative schemes without a computer. If the window schemes are on the east, west, or south, the lumen method allows tradeoff evaluations with variable sun controls.

Computer models have also been developed for daylight calculations: to compute illumination levels and equivalent sphere illumination (ESI) levels in daylit rooms, (ESI is a useful, or nonglare foot-candle. 
Specifically, it is the foot-candle illumination in a sphere that gives equal visual performance to the illumination, of whatever foot-candles, in a specific lighting system. Daylight from side windows provides two or three times more ESI than typical overhead light sources. ESI cannot be effectively measured in a physical daylight model because the measurement instruments are too large.) Available computer models, however, cannot easily model specific architectural details or such information as the placement and nature of room furnishings. The computer models also must still rely on essentially static analysis of a dynamic design problem.

Lumen II Daylight is a computer progrem for predicting daylight illumination and ESI for a simple task anywhere in the room. It is relatively expensive and therefore of limited usefulness in the early stages of design. The value of the ESI component is also being studied; Blackwell, the originator of ESI, has questioned the method he used to obtain calculation factors.

The physical and mathematical daylight analysis methods discussed deal only with the illumination aspects of daylight design. Daylight implies thermal tradeoffs that also need evaluation. The sizing and placement of windows to maximize daylighting benefits need to be considered in the context of thermal performance and overall energy performance.

A number of computer programs have been developed for energy analysis, but they are based on certain mechanical assumptions about the thermal design of a building. And none deals with daylight. Most concentrate on thermal design and deal with illumination by using standardized operating profiles for installed lighting.

Some of these programs are relatively complex and can model a building's performance hour by hour throughout the year. Daylight performance has been incorporated experimentally into severgl of these, but the resul ts have yet to be validated by comparison with actual conditions. None is at a state where an architect could use it with confidence to obtain accurate information.

The pressures for an integrated thermal/illumination model incorporating daylight continue to build. New energy performance standards will generate more pressure to incorporate daylight into existing energy analysis programs. But the problems of validation and the implications of the simplified data used in a computer program have yet to be resolved. Such programs also need to be user-oriented, accessible, and inexpensive.

The issues surrounding the illumination aspects of daylight and how to provide the designer with accurate information continue also to be the subject of intensive research: Daylight availability is so variable that trying to predict absolute values is not cost effective; therefore the precision of any measurement may be less important than in other cases. The lumen or daylight factor methods will give the architect a relative evaluation of alternative schemes useful for early design decisions. The physical model remains the most cost-effective way to approach absolute values for specific design solutions, allowing both qualitative and quantitative evaluation, and perceptual as well as analytical insights.

\section{CODES}

The issue of solar access has become a critical concern as architects and planners start to address the uses of solar energy at community scale. Ralph Knowles has done the pioneer research into the use of a solar envelope as a basis for solar access zoning. This envelope defines the maximum volume of development possible for a given site and set of time constraints without shadowing the neighboring surround. The issue of daylight access in a legal context raises some parallel issues when applied at urban design scale.

J.W. Griffith addressed the issue of daylight in building codes in 1962 when he prepared a model residential ordinance for Chicago. The code was not implemented, but the concept has gained new relevance today. The purpose of the daylight code was to establish minimum standards of daylight for habitable rooms where the Chicago building code already required a window. The scope of the task also included the development of workable techniques for applying and testing compliance with the code, and it included an examination of the impact of daylight controls in a variety of locations and situations. The Griffith report noted that the Chicago building code already required effective clear glass areas of "not less than $10 \%$ of a room area." But a window specification is not a daylight specification. So the code further states that the minimum amount of glass should be increased to $25 \%$ if the window was obstructed. The code also included dimensional requirements for courts and side yards for daylight purposes.

Griffith's proposed regulation called for 10 foot-candles of daylight in habitable rooms. Since this was a worstcase condition, it was assumed that most rooms would have higher daylight illumination levels. A version of the British daylight factor measurement technique was recommended to determine compliance. Based on an average room depth of $14 \mathrm{ft}(4,200 \mathrm{~mm})$, Griffith chose a penetration of $7 \mathrm{ft}(2,100 \mathrm{~mm})$ at a height of $30 \mathrm{in}$. $(760 \mathrm{~mm})$ as a measurement point of reference.

The implications of the daylight code are of interest today. Sites in desirable locations for daylight could increase density to the limits of existing floor-area ratios and economic parameters. The regulation, however, would encourage orientations, at either the building or apartment unit scale, that would maximize the potential for daylight and minimize obstructions.

Open space requirements would vary with building height and bulk. In very congested areas, the residential use of lower floor areas could be restricted if obstructions prohibited minimal daylight penetration. The relationships between buildings, including new and old construction, would become critical.

Where conformance to the daylight code was based on sky conditions, the maximum density and bulk of a building could be determined by conventional floor-area ratios. Where a reflective component is necessary, the daylight control would fix the height of a building. (Taller buildings may block the light from an obstruction and therefore decrease reflected light.) 
The daylight code would affect the orientation of buildings and the dwelling units within them in relation to the surround, but would not require unusual or undesirable building shapes. Griffith noted that the lower residential floors present the most restricted daylight condition and that codes for vertically stepped buildings therefore offer little daylight advantage.

The issue of daylight in relation to building codes is especially critical in this era of energy regulation. Component performance standards, such as ASHRAE 90-75, which has been adopted by many states, are based on assumptions about the thermal performance of windows that have resulted in strict limitations on window area. These assumptions relate to the concept that windows are a source of uncontrolled heat loss and heat gain and therefore a burden to mechanical heating and cooling systems. Such assumptions, however, not only ignore the potential for passive solar design to achieve thermal comfort, but they also limit the potential for daylight. Less glass area means less exposure to skylight, sunlight, and other daylight sources. Energy peformance standards that relate to the performance of a whole building and do not specify the performance of individual building components are far more sympathetic to daylight design strategies. These standards do not specify the design of a building, but only its performance; and skillful use of daylight promises significant improvement in the performance of a building, not only in energy terms, but in human terms.

There are situations where design strategies for daylight would seem to conflict with design strategies for efficient thermal performance. These conflicts, however, are greatest when the designer assumes mechanical solutions to thermal comfort. While daylighting may result in tradeoffs with the version of energy conservation that dictates compact buildings, small surface-to-volume ratios and minimal windows, it is thoroughly compatible with many aspects of passive solar design.

Daylighting implies large window areas that can be oriented and controlled to admit solar heat and light in heating seasons, or only light in cooling seasons. It implies high ceilings, which complement natural ventilation. It implies controls that respond to the Sun dynamically. It implies asymmetrical building forms and differentiation by orientation, as does passive solar design.

Daylight also implies an urban design concern for a public right to light that is slightly different but nonetheless consistent with the concept of solar access. And daylight implies a relationship between the user and the natural variations and tempos of day and season, something that has been lacking in most modern urban environments. For many people concerned with the quality of urban life, the bond that daylight can forge between people and natural cycles is its most critical contribution.

Certainly energy is one of the justifications for renewed interest in daylighting. But the energy argument frequently put forward in its defense may not be the correct one. The most frequent argument is that daylight can offset large electrical demands for artificial lighting systems. This is subject to a number of important qualifications, however. One is that natural lighting cannot reduce energy consumption if the electrical lighting system is not responsive to daylight conditions. Many highly publicized daylit buildings have artificial lighting systems that are designed and operated with no regard for daylight contributions to illumination. Another qualification is that daylight must be considered an integral part of the building design, an important consideration in the location and form of the building. Separating the daylight elements from the overall building and assessing them by a conventional cost/ benefit analysis may lead to false conclusions about their cost and energy efficiency.

Steve Selkowitz of Lawrence Berkeley Laboratories (LBL) has been particularly concerned with current justifications for daylighting. He cautions that daylighting must be justified on human and environmental grounds as well as improved visual performance. He has also developed some strong energy arguments, but they are not the conventional arguments.

At LBL, Selkowitz has been involved with some of the research into more efficient artificial lighting systems and components. He is concerned that if people justify daylighting solely on the basis of reduced electrical demand, predicted improvements in artificial systems will make comparative daylight "energy savings" appear insignificant. Task/ambient lighting systems are now available that operate in the range of 1 to $1.5 \mathrm{~W} / \mathrm{sq} \mathrm{ft}$ $(10.8$ to $16.2 \mathrm{~W} / \mathrm{sq} \mathrm{m}$ ) of installed power. If one projects the introduction of electronic ballasts and improved fluorescent lamps with improved phosphors and higher efficacy, and small HID systems indoors with improved color rendition, one can expect to see indoor lighting systems with efficiencies of 100 lumens/W. This is roughly a $50 \%$ improvement over the typical 65 lumens/W for conventional fluorescent systems. Improved lighting practices will further reduce electrical demand.

With these changes, lighting electrical power demands could be reduced from 7.5 to a range of 1 to $3 \mathrm{kWh} / \mathrm{sq} \mathrm{ft}$ (10.8 to $32.4 \mathrm{~W} / \mathrm{sq} \mathrm{m})$ per year. The 1 to $2 \mathrm{kWh} / \mathrm{sq} \mathrm{ft}$ $(10.8$ to $21.6 \mathrm{~W} / \mathrm{sq} \mathrm{m})$ per year now achieved with daylighting seems less impressive in this context. By that criteria alone, daylight contributions to energy conservation might make daylight design seem superfluous. But Selkowitz does offer strong energy justifications for daylighting that are not compromised by advanced artificial systems. One argument relates to peak power demands; the other relates to power system failures.

Peak power demands remain a critical issue for utilities, and lighting demands frequently coincide with peak heating and cooling loads. Charges for peak power may represent a significant fraction of a firm's total electric bill. Many utilities are now implementing selective rates to penalize peak power consumption. One utility in the state of Washington is now campaigning for the use of daylight as a way to reduce peak power demand.

The significance of peak power demand can be seen in the following example. Consider a typical all-electric office building in which half of the energy load results from lighting. Assume that one-third of the usable floor space is close enough to a window to benefit from natural light. The maximum potential daylighting savings is this one-third of electrical demand for lighting, or about $15 \%$ 
of total energy demand. If $50 \%$ of that is achieved by a dimming system, the daylight contribution is only about $8 \%$. The peak power situation is quite different, however.

Under summer peak conditions, typical cooling loads amount to 5 to $10 \mathrm{~W} / \mathrm{sq} \mathrm{ft}(54$ to $108 \mathrm{~W} / \mathrm{sq} \mathrm{m})$, of which 3 (32) $\mathrm{W}$ represent lighting. With a net coefficient of performance of 2 , the cooling power requirement is that 2.5 to $5 \mathrm{~W} / \mathrm{sq} \mathrm{ft}(27$ to $54 \mathrm{~W} / \mathrm{sq} \mathrm{m}$ ). If we turn the lights off in one-third of the building area, we reduce the power consumption by $1 \mathrm{~W} / \mathrm{sq} \mathrm{ft}(10.8 \mathrm{~W} / \mathrm{sq} \mathrm{m})$ and also produce a reduction in cooling requirements equivalent to $0.5 \mathrm{~W} / \mathrm{sq} \mathrm{ft}(5.4 \mathrm{~W} / \mathrm{sq} \mathrm{m})$. Under these circumstances, daylight saves $1.5 \mathrm{~W} / \mathrm{sq} \mathrm{ft}(16.2 \mathrm{~W} / \mathrm{sq} \mathrm{m})$, or roughly 10 to $20 \%$ of the building's peak power demand.

The cost of new power plant construction is frequently $\$ 1$ to $\$ 2$ per peak watt of installed power. In a new building, a $150-\mathrm{sq}-\mathrm{ft} \quad(13.89 \mathrm{sq} \mathrm{m})$ office with $3 \mathrm{~W} / \mathrm{sq} \mathrm{ft}$ $(32.4 \mathrm{~W} / \mathrm{sq} \mathrm{m})$ of lighting requires a utility investment of $\$ 450$ to $\$ 900$ in new generating capacity. Although this analysis is greatly simplified, it would seem that dimmable controls or other strategies to increase daylight contributions would be a sound investment. In the case of the Washington utility mentioned earlier, the argument is even stronger. It currently relies on hydropower to produce relatively inexpensive electricity; should additional generating capacity become necessary, it would have to turn to nuclear power and electrical rates in the area would soar.

Selkowitz's second energy argument for daylighting concerns the high cost of power disruption. As power has become increasingly centralized, power failures become more critical; and in recent years, we have experienced city, state, and regional power system failures. Daylighting is a design option that, at the scale of a single building, can reverse the trend toward greater reliance on remote centralized systems. As such, it has a flexibility and degree of failure tolerance that appears to be important, although it is difficult to quantify.

It is possible, however, to quantify the effects of disruption on worker productivity. High light levels have been sold on the basis of productivity. Assume that an office worker, with appropriate indirect and overhead charges, costs a company $\$ 40,000$ per year. The worker occupies $100 \mathrm{sq} \mathrm{ft}(9.29 \mathrm{sq} \mathrm{m})$ of space, works 250 days, and thus costs $\$ 160$ per day, or $\$ 0.20 / \mathrm{sq} \mathrm{ft}(\$ 2.16 / \mathrm{sq} \mathrm{m})$ per hour. Lighting, at $\$ 0.04 / \mathrm{kWh}$ costs $\$ 0.25$ to $\$ 0.30 / \mathrm{sq} \mathrm{ft}$ ( $\$ 2.70$ to $\$ 3.24 / \mathrm{sq} \mathrm{m}$ ) per year. If a daylit office building is able to continue productive work for even one hour during a blackout or power loss, the dollar savings are equivalent to an entire year's worth of energy savings.

Energy arguments for daylighting are particularly persuasive as we face rising costs and shortages of fossil fuels. Energy has certainly brought new financial support to daylight research and new enthusiasm for the potential of daylight as a design strategy. But energy shortages are not the reason that daylight is important. Far more important is the complement between the natural and artificial environment that daylight facilitates and far more important is the improved quality of design it promises. Daylight is a fundamental architectural form issue. Wright, Aal to, Kahn, Corbusier, and other masters knew the functional and aesthetic promise of natural light; we are rediscovering it. 
7

Other Solar Options:

Solar Industrial Process Heat

Wind Energy

Photovoltaics

Biomass 
7. Other Solar Options

A. Solar Industrial Process Heat

Collectors

Solar applications in IPH

Industrial process heat field tests

B. Wind Energy

Wind machine configurations

Energy storage

Large-scale power generation

C. Photovoltaics

Solar cells

Solar modules

Power systems

Photovoltaic applications

Economies

Future prospects

D. Biomass

Farms and forests: Today's energy resources

Biomass at work today

Benefits from biomass

F or the future

Gasohol 
OTHER SOLAR OPTIONS:

\section{A. SOLAR INDUSTRIAL PROCESS HEAT}

Whereas $36.3 \%$ of the U.S. energy demand is for commercial and residential uses, $41.2 \%$ is used by industry as shown in Fig. 7-1. Of that amount, $68.4 \%$ is direct thermal use which presents a potential market for solar application.

Using solar energy to supply industrial process heat (IPH) offers several potential advantages when compared to solar heating and cooling applications:

- Loads are of ten constant throughout the year allowing for better use of solar energy.

- Industrial plants usually have maintenance crews which can attend to the solar energy systems.

- Large collector arrays have the potential for yielding economies of scale.

- The total potential impact on the nation's energy use is greater.

\section{U.S. Energy Use}

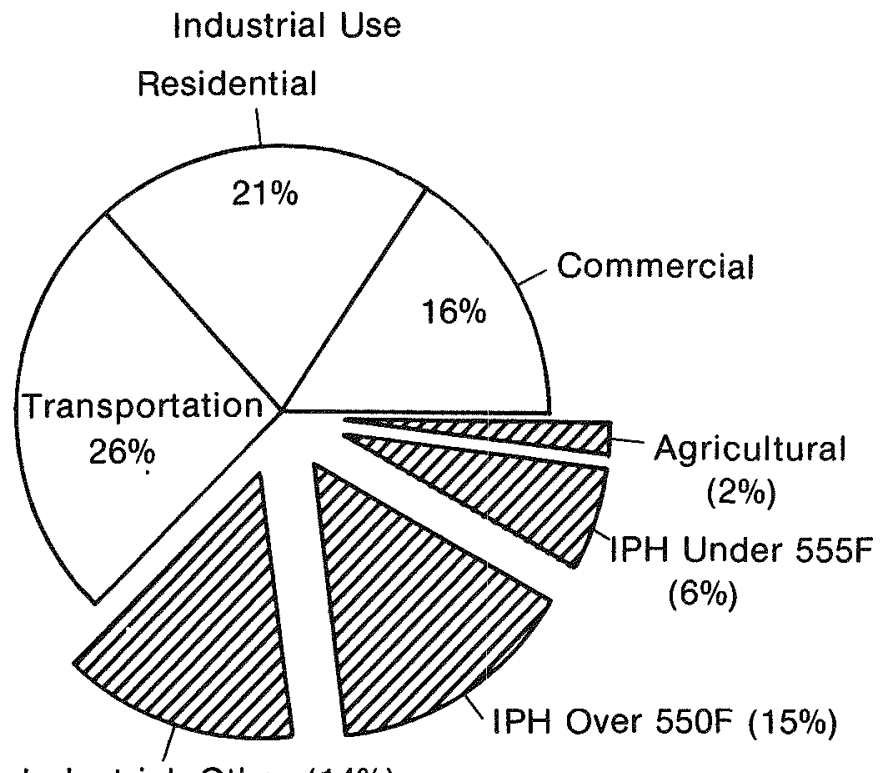

Industrial, Other (14\%)

Fig. 7-1. U.S. energy demand by sector
When compared to al ternate industrial fuels, solar energy offers the advantages of being nonpolluting and not subject to outside supply interruptions. Lead times for the construction of solar energy systems are also reasonably short.

of course, certain impediments to the use of solar energy in IPH also exist:

- Land availability. In most climates with high insolation, roofs are inadequate for supporting collector arrays. Either added supports must be buil t or land must be used. In the latter case, commercial land is of ten expensive and scarce.

- Industrial effluents. In an industrial environment, contamination of collectors is a greater problem than for commercial or residential buildings. Concentrating collectors which require high specular reflectivity are particularly suscep tible.

- Non-constant energy source. The plant must be able to adapt to the variable solar energy delivery.

- Availability of conservation al ternatives. Many plants have simple and inexpensive opportunities for energy conservation which should precede any commitment to solar. These include the use of waste heat from hightemperature processes to supply low-temperature processes (such as boiler feedwater preheat).

- Cost. Industry often requires payback periods of less than 5 years. Solar energy systems are currently too expensive to provide such paybacks.

The suitability of solar energy in a particular application depends upon a number of factors such as climate, economics, process temperature, and availability of space. In 1977, ERDA, the predecessor of DOE, commissioned two major studies (by InterTechnology Corporation and Battelle Laboratories) to determine the potential application of solar energy in IPH. Fig. 7-2 shows one result from the study done by InterTechnology Corporation (ITC) [1]. A computer simulation compared the performance of a flat plate collector system designed to deliver 1,000 gal. $(3,785 \mathrm{l})$ of $140 \mathrm{~F}\left(60^{\circ} \mathrm{C}\right)$ hot water per day in various cities in the United States. The figure shows the relative performance in different regions of the United States. This took both insolation and ambient temperature into account. As one might expect, the Southwest is an ideal location for such a plant. Table 7-1 shows where industry is located. The states are compared on the basis of fuel sales. Eighty percent of the energy used by industry is consumed in 13 states. California, which is an excellent candidate for solar 
Reproduced From the Survey Report by Intertechnology Corporation.

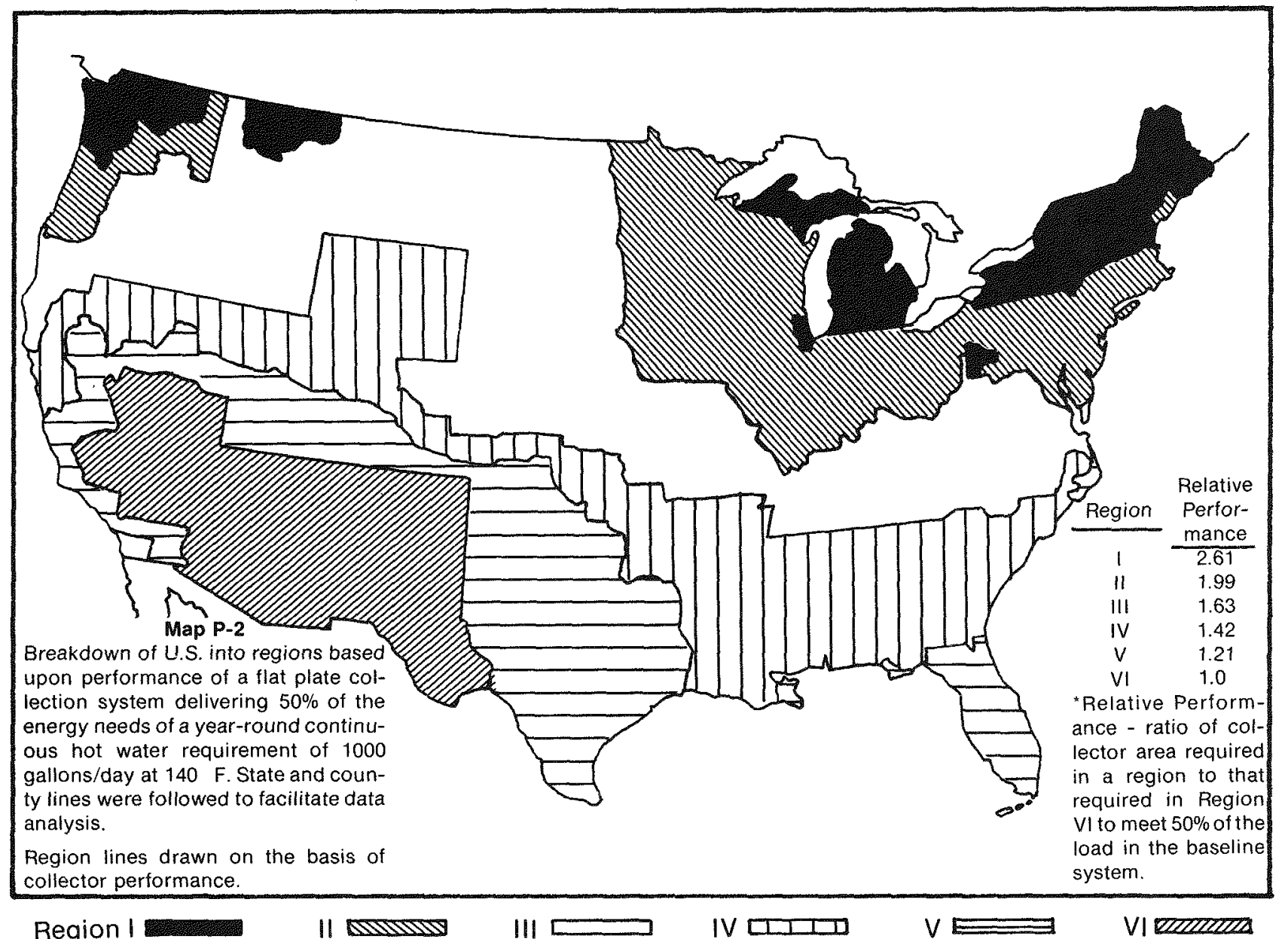

Fig. 7-2. Regional performance by reference IPH hot water system

Table 7-1. LOCATION OF INDUSTRY

( $80 \%$ in 13 States)

$\%$ of U.S. Total

\section{Texas}

Louisiana

Pennsylvania

Ohio

California

IIlino is

Michigan

Indiana

New York

Alabama

New Jersey

West Virginia

Wisconsin energy, is ranked fifth with $6 \%$ of the total. Texas, which is ranked first, has some very good areas for solar application.

Whether solar energy is practical depends to a great extent on which fuel it must compete against. Table 7-2 shows the percentages of each type of fuel input to the industrial sector in 1976. Oil and natural gas, which can be expected to rise in price, accounted for $68.8 \%$ of the energy use. Coal can be expected to remain fairly inexpensive (although the cost and extent of use will depend greatly on pollution requirements). Electricity will remain expensive unless it is generated by coal.

The temperature at which energy is used is also of vital importance in assessing the solar option. The higher the temperature needed, the greater will be the extent to which solar collectors lose their collected heat to the outdoor environment and thus the lower will be their efficiency. ITC [1] plotted the percentage of total IPH consumption versus process temperature. As shown in Fig. $7-3,27 \%$ of the energy consumed is at temperatures below $550 \mathrm{~F}\left(275^{\circ} \mathrm{C}\right)$-the approximate limit for current production collectors. 
Table 7-2. FUEL USE BY INDUSTRIAL SECTOR (1976)

\begin{tabular}{lc}
\hline & $\%$ \\
\hline Coal & 18.0 \\
Oil & 29.2 \\
Natural Gas & 39.6 \\
Elec tricity & 13.2 \\
\hline
\end{tabular}

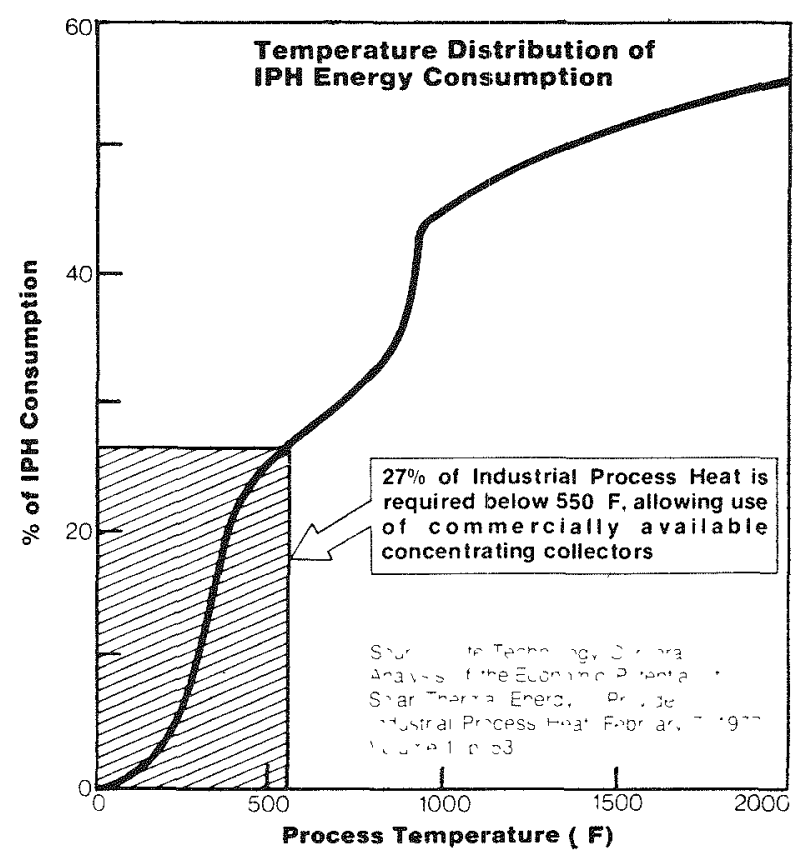

Fig. 7-3. Distribution of IPH requirements by temperature

Based largely on process temperature, Battelle Laboratories rated the qualitative potential for solar application to various industries as shown in Table 7-3 [2]. Fig. 7-4 shows the energy use of major industrial groups. Note that $80 \%$ of the energy is used by six major industries. Currently, detailed case studies of individual industrial plants are being performed at the Solar Energy Research Institute (SERI) to more accurately determine application feasibility.

\section{COLEECTORS}

The type of collector to be used depends on the process temperature required. Fig. 7-5 shows the approximate operating range for various types of collectors.

\section{Solar Ponds}

These are basically of two types. Shallow ponds developed by Lawrence Livermore Laboratory consist of bags of water which are heated by the Sun during the day and drained at night. Because they are mounted horizontally they perform best at lower latitudes. They can supply heat at temperatures below $125 \mathrm{~F}\left(50^{\circ} \mathrm{C}\right)$ at relatively low cost.
Salt gradient ponds developed extensively in Israel can supply considerably higher temperature water. These ponds work on the principle that solar heated water will dissolve salt and remain in the bottom of the pond by virtue of its higher density. A salt pond has the advantage of supplying long-term storage in addition to serving as a solar collector. Studies are currently being performed on how best to achieve and maintain pond stability.

\section{Flat Plates}

This, the most common design for a solar collector, can supply hot water or hot air at temperatures of up to about $200 \mathrm{~F}\left(93^{\circ} \mathrm{C}\right)$, though temperatures above $160 \mathrm{~F}$ $\left(71^{\circ} \mathrm{C}\right)$ result in relatively low efficiency. Advantages include no moving parts (flat plates are rarely designed to track the Sun), good durability, and collection of both direct and diffuse radiation. More details on these collectors can be found in Chapter 5 of this workbook.

\section{Evacurted Tubes}

The design of tubular collectors with an evacuated region around the absorber pipe cuts down on thermal losses sufficiently to supply temperatures of up to $300 \mathrm{~F}$ $\left(154^{\circ} \mathrm{C}\right)$ at reasonable efficiency. They have similar advantages as flat plates but cost more and are somewhat more prone to failure. (See Chapter 5.)

\section{Linear Concentrators}

Fresnel lens collectors, which focus light through refraction onto an absorber tube, and parabolic troughs or multiple reflector types, which concentrate by means of reflection, are used to supply temperatures of up to $500 \mathrm{~F}$ $\left(260^{\circ} \mathrm{C}\right)$. Parabolic troughs can yield higher concentrations than the Fresnel lens types and have been shown to operate at higher efficiencies than the multiple reflector types. As a result, they are the most common choice in the 300 to $500 \mathrm{~F}\left(154-260^{\circ} \mathrm{C}\right)$ temperature range. All of these must track the Sun, however, and will not collect any significant amount of diffuse radiation. Because of the strict requirements on focusing accuracy, they are also relatively susceptible to contaminants such as dust. The compound parabolic concentrator alleviates some of these problems but is suitable only for low concentrations. (See Chapter 5.)

\section{Point Focus Receivers}

Concentrators can achieve good efficiency at high temperatures because of the reduced receiver area for heat loss. Parabolic dish collectors take this advantage to the extreme by focusing sunlight onto a point. Temperatures of up to $2000 \mathrm{~F}\left(1095^{\circ} \mathrm{C}\right)$ can be supplied. This requires two-axis (azimuth and altitude) tracking of the Sun. Like the line focus collectors, point focus collectors can use only direct radiation. Because of collector shape and tracking requirements, they do not use land space as efficiently as the previously mentioned collectors. However, at temperatures much higher than $500 \mathrm{~F}\left(260^{\circ} \mathrm{C}\right)$, they and central receivers are the only choices. 
Table 7-3. POTENTIAL OF SOLAR APPLICATION FOR VARIOUS INDUSTRIES

\begin{tabular}{lll}
\hline \multicolumn{1}{c}{ Excellent } & \multicolumn{1}{c}{ Good/Marginal } & \multicolumn{1}{c}{ Poor } \\
\hline Food Processing & Aluminum & Cement \\
Textiles & Auto/Truck Manufacturing & Ceramics \\
& Concrete Block and Brick & Coal Mining and Cleaning \\
& Gypsum & Copper \\
& Gaper and Pulp \\
& Lumber and Wood Products & Petroleum Refining \\
& Mining & Plastics/Selected Polymers \\
& Rubber/Styrene-Butaline & Steel and Iron \\
Very small contributions by: & Rubber Manufacturing & \\
& Chemicals (inorganic) & \\
& Electronics & \\
\hline
\end{tabular}

Primary Metals

Petroleum and Coal Products

Chemicals and Allied Products

Paper and Allied Products

Stone, Clay and Glass Products

Food and Kindred Products

Textile Mill Products

Lumber and Wood Products

Mining

\section{Process Heat Requirements} in Major Industrial Groups

$10^{15} \mathrm{Btu} / \mathrm{yr}$, quads
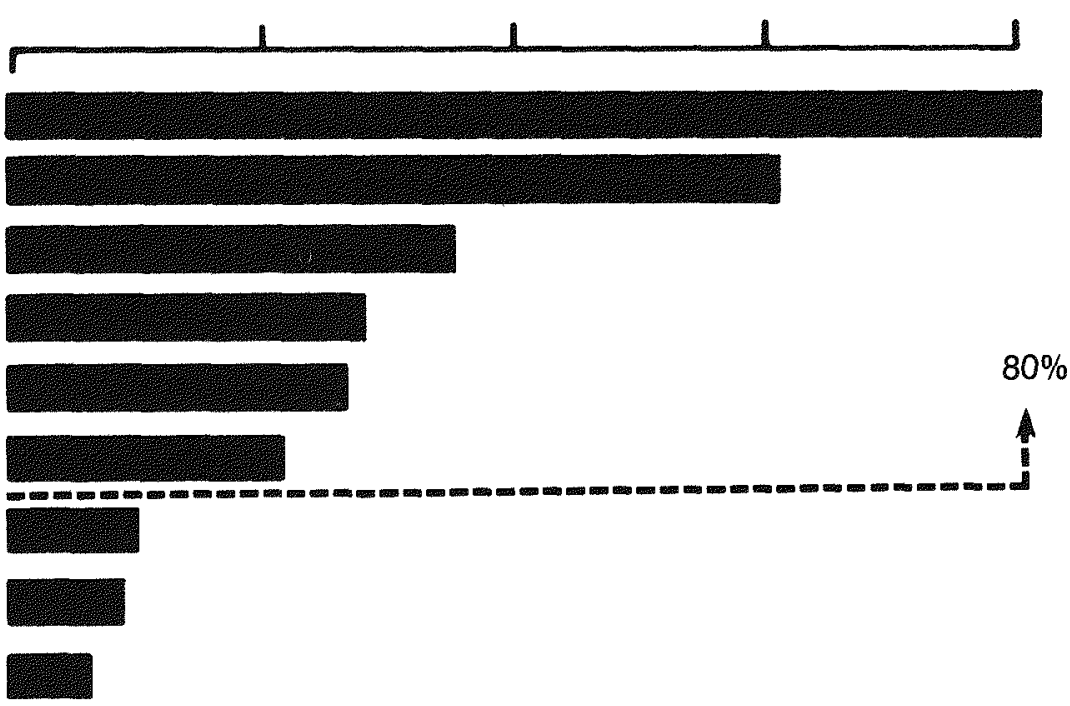

Other

Fig. 7-4. Energy use by major industrial groups 


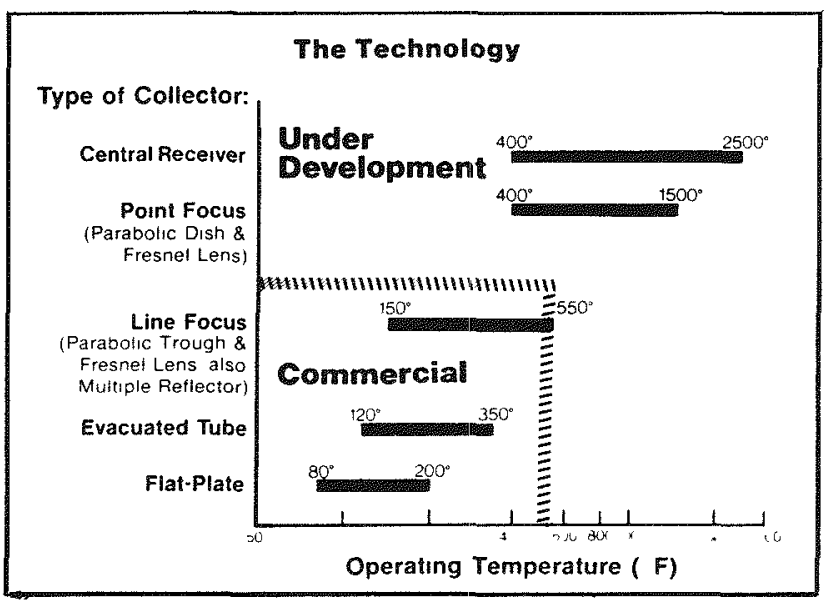

Fig. 7-5. Operating temperature ranges of
collector types

\section{Central Receivers}

By using a centrally located receiver on a tower surrounded by a field of carefully aimed individual reflectors (called heliostats) very high concentration and thus high temperatures can be achieved. Since all of the energy is transmitted to one central receiver in the form of light, the piping losses associated with distributed receivers are eliminated. Drawbacks include tower support costs, rigorous tracking requirements, and use of only direct insolation. Central receivers are still in an early development phase.

\section{SOLAR APPLCATIONS IN IPH}

The three main areas of solar application in industry are in the areas of:

- process hot water

- drying/dehydration

- process steam

Hot water is used in large amounts between 120 and $212 \mathrm{~F}\left(50-100^{\circ} \mathrm{C}\right)$ for cooking, washing, bleaching, and anodizing and represents about $2 \%$ of the IPH demand or 0.2 quad ( 1 quad $=10^{15}$ Btu). The preheat of boiler feedwater accounts for another 3 quads, but this can of ten be supplied by associated higher temperature waste heat. Either water can be heated directly in a collector loop, or a separate fluid can be used in conjunction with a heat exchanger. The latter approach can minimize freezing and corrosion problems but resul ts in somewhat higher collector temperature and thus reduced efficiency.

An example of an industrial process heat hot water system is shown in Fig. 7-6. This particular system supplies over $400 \mathrm{gal} . / \mathrm{min}(1,514 \mathrm{l} / \mathrm{min})$ of hot water in the range of 130 to $180 \mathrm{~F}\left(55-83^{\circ} \mathrm{C}\right)$ to the York Building Products concrete block curing plant in Harrisburg, $\mathrm{Pa}$. The collector array consists of $9,216 \mathrm{sq} \mathrm{ft}(829 \mathrm{sq} \mathrm{m})$ of multiple reflector type linear concentrators. A shelland-tube heat exchanger is used to transfer heat from the water and ethylene glycol collector loop to the process water. A unique feature of this application is that the large underground concrete curing area or "rotoclave" contains about 50,000 gallons of water and serves as built-in storage.

Drying and dehydration consume about 1.4 quads supplied as hot air below $350 \mathrm{~F}\left(177^{\circ} \mathrm{C}\right)$. Most of this is used for crop drying. The two most common ways to supply solar heated air are to heat air directly in the collectors or to heat a liquid in collectors and use a liquid-to-air heat exchanger.

An example of the first type of system is shown in Fig. 7-7. In this system, $21,000 \mathrm{sq} \mathrm{ft}(1,890 \mathrm{sq} \mathrm{m})$ of air collectors supply $140 \mathrm{~F}\left(60^{\circ} \mathrm{C}\right)$ air to a prune and raisin drying tunnel at the Lamanuzzi and Pantaleo Foods plant in Fresno, Calif. A 14,000-cu ft $(420 \mathrm{cu} \mathrm{m})$ rock bin is used for storage. A unique aspect of this plant is a heat recovery wheel which transfers heat from the tunnel exhaust to the collector array inlet. Although this raises the collector array temperature and thus lowers collector array efficiency, the heat recovered more than makes up for the lowered collector efficiency. The heat recovery wheel has a payback period of less than 1 year, and its success emphasizes the importance of preceding solar applications with conservation al ternatives.

An example of heating water to ultimately supply hot air is shown in Fig. 7-8, which illustrates the system at the J. A. LaCour lumber drying kiln in Canton, Miss. At this plant $2,500 \mathrm{sq} \mathrm{ft}(225 \mathrm{sq} \mathrm{m})$ of flat plate collectors heat water to $140 \mathrm{~F}\left(60^{\circ} \mathrm{C}\right)$ which then supplies hot air to two hardwood lumber kilns via finned-tube heat exchangers. Although this system results in higher collector temperatures than in a direct air approach, pumping power for the liquid loop is generally less than fan power for an air loop. To increase collected energy at the LaCour plant, $2,400 \mathrm{sq} \mathrm{ft}(216 \mathrm{sq} \mathrm{m})$ of reflectors are included in the collector array.

A third alternative for using solar heat in drying should be mentioned. Rather than using collectors at all, drying houses can be constructed in such a fashion that sunlight impinges directly upon the product to be dried. This approach results in relatively low temperatures and long drying times and will generally require that the product be spread out over a larger area. However, it can be a cost-effective approach.

Steam usage represents about 6 quads of energy consumption, $80 \%$ of which is below $350 \mathrm{~F}\left(177^{\circ} \mathrm{C}\right)$. Three possible ways to supply steam with solar collectors are:

- Use of a high-temperature fluid in the collectors with heat transferred to an unfired boiler.

- Circulation of pressurized water in the collectors with subsequent flashing to steam in a flash tank.

- Boiling of water in collectors.

The first type of system is shown in Fig, 7-9. In this example Therminol 55 is heated to $475 \mathrm{~F}\left(246^{\circ} \mathrm{C}\right)$ in an array consisting of $10,000 \mathrm{sq} \mathrm{ft}(900 \mathrm{sq} \mathrm{m})$ of parabolic trough collectors. The hot Therminol then boils water in an unfired boiler with steam supplied at 125 psi. The particular system shown here is being built for the Southern Union Oil Refinery in Hobbs, N. Mex. 


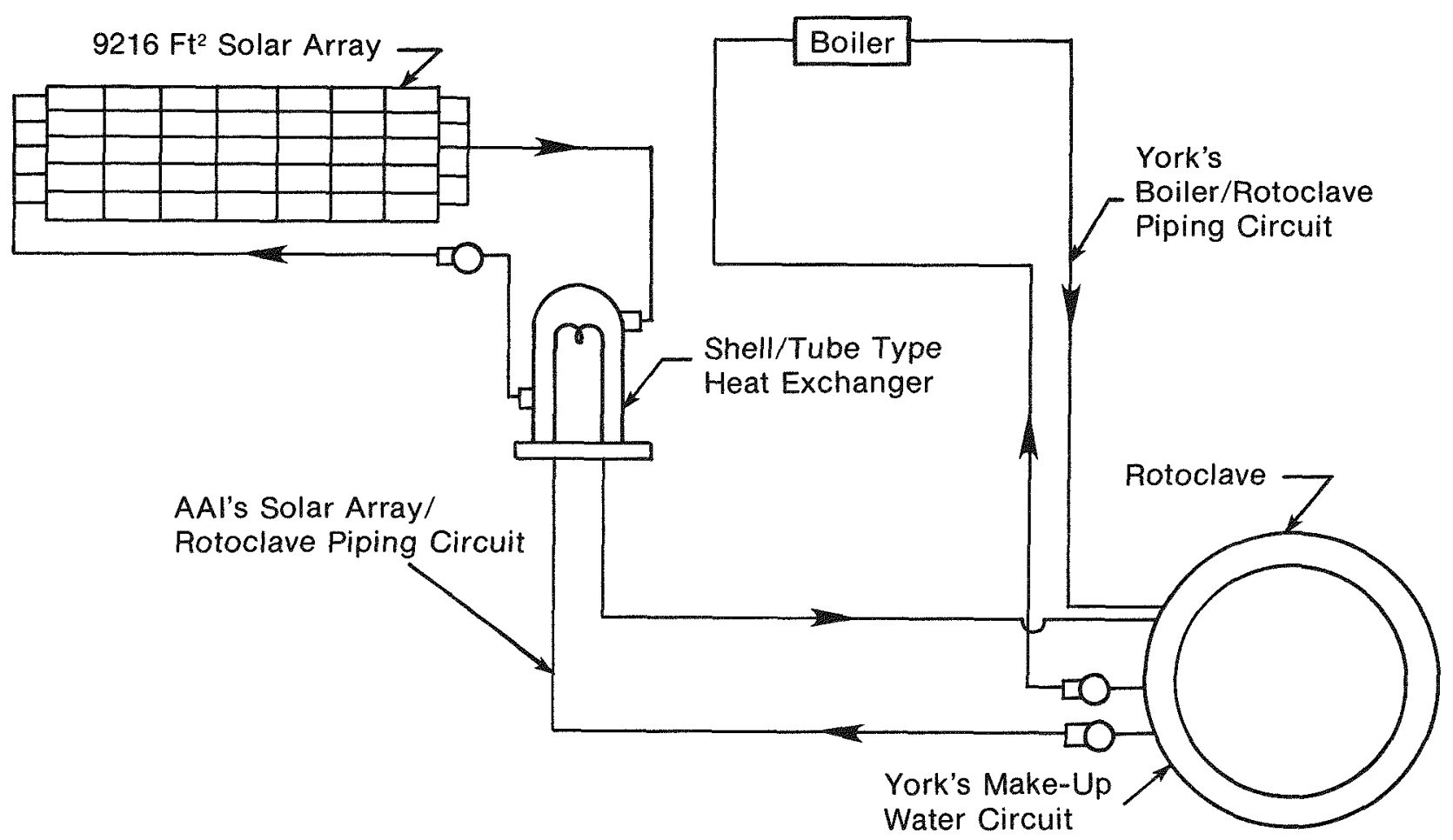

Fig. 7-6. York Building Products solar hot water system

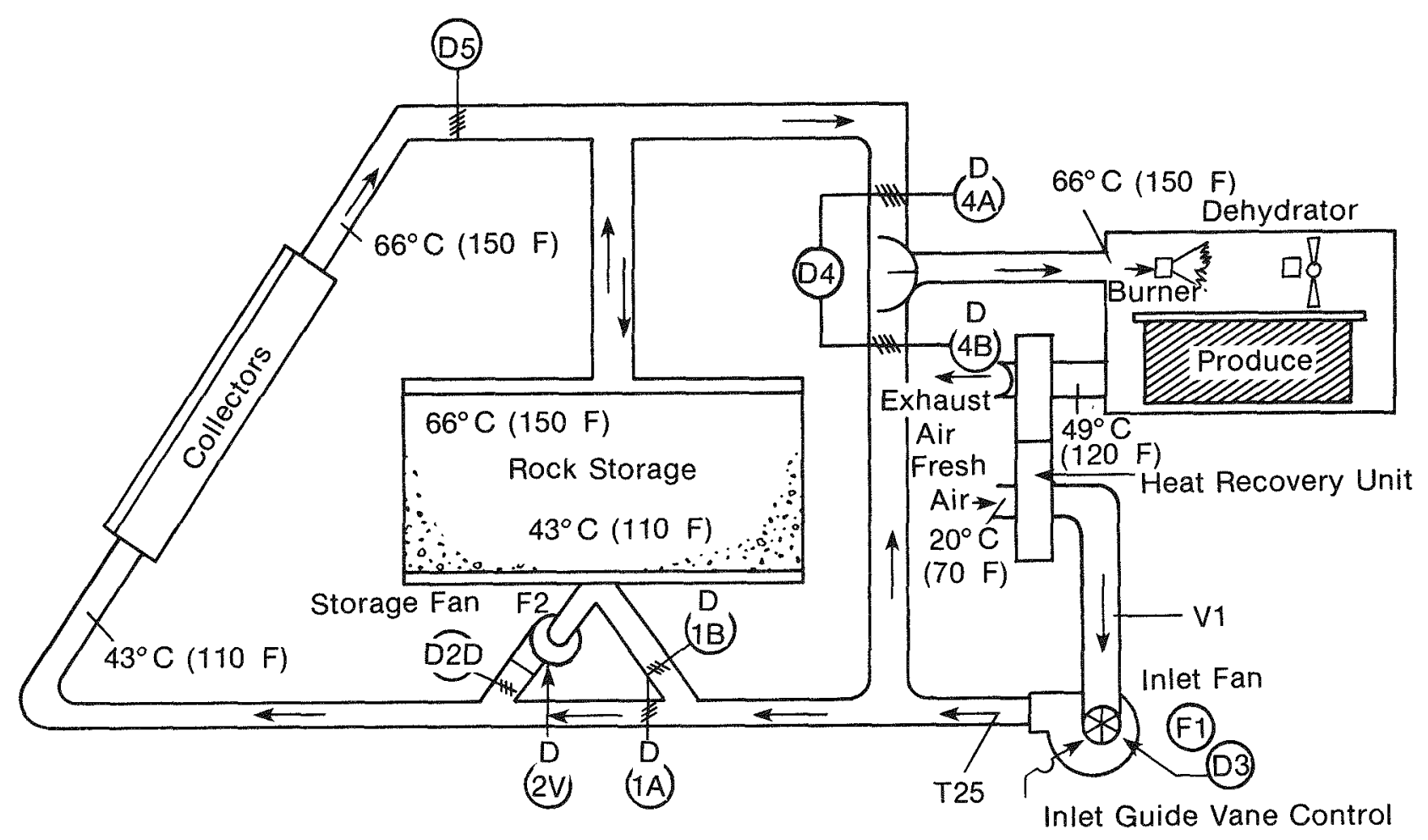

Fig. 7-7. Lamanuzzi \& Pantaleo Foods solar air system 


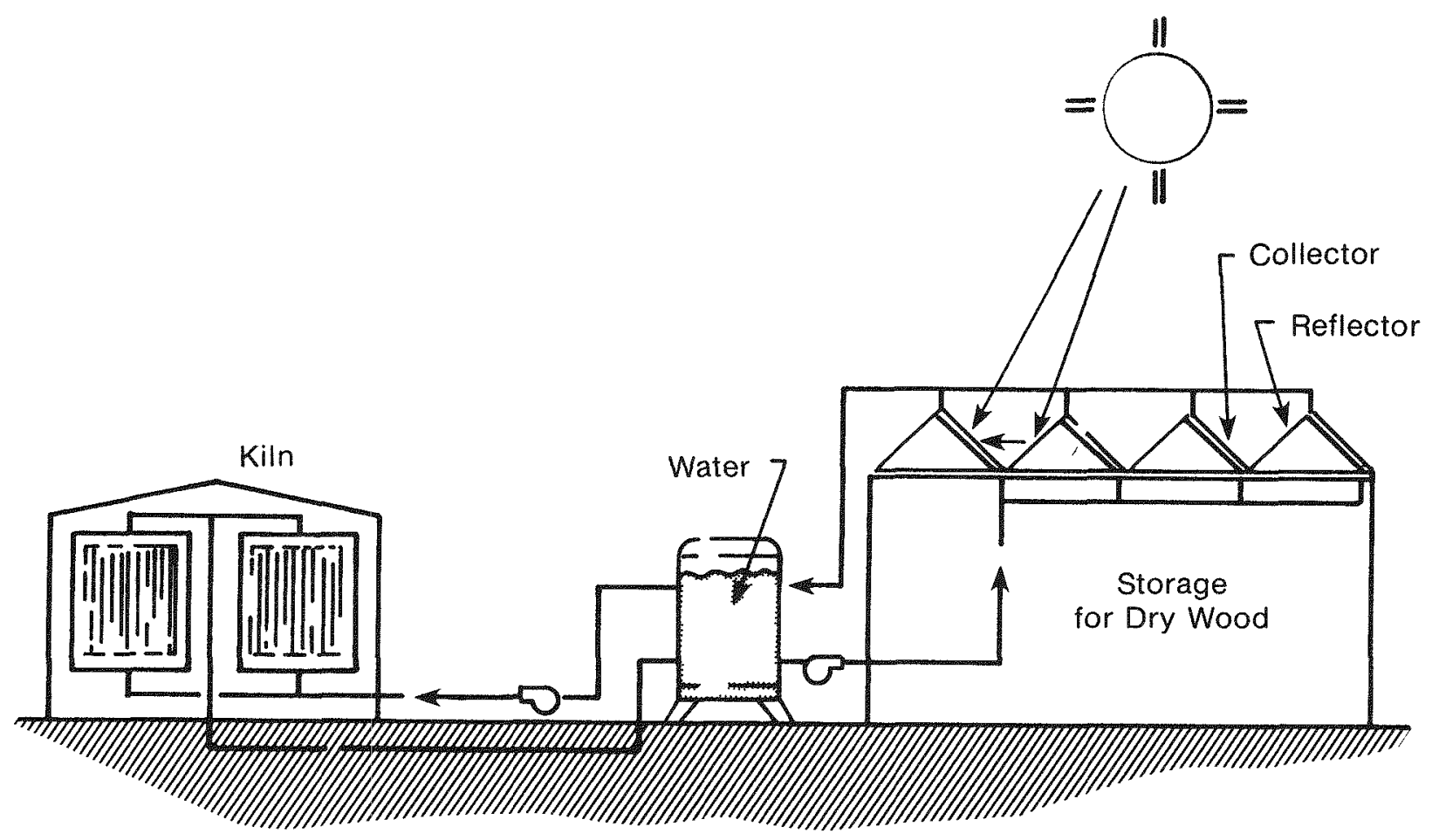

Fig. 7-8. LaCour Lumber kiln solar hot water-to-air system

\section{Heat Exchange System}

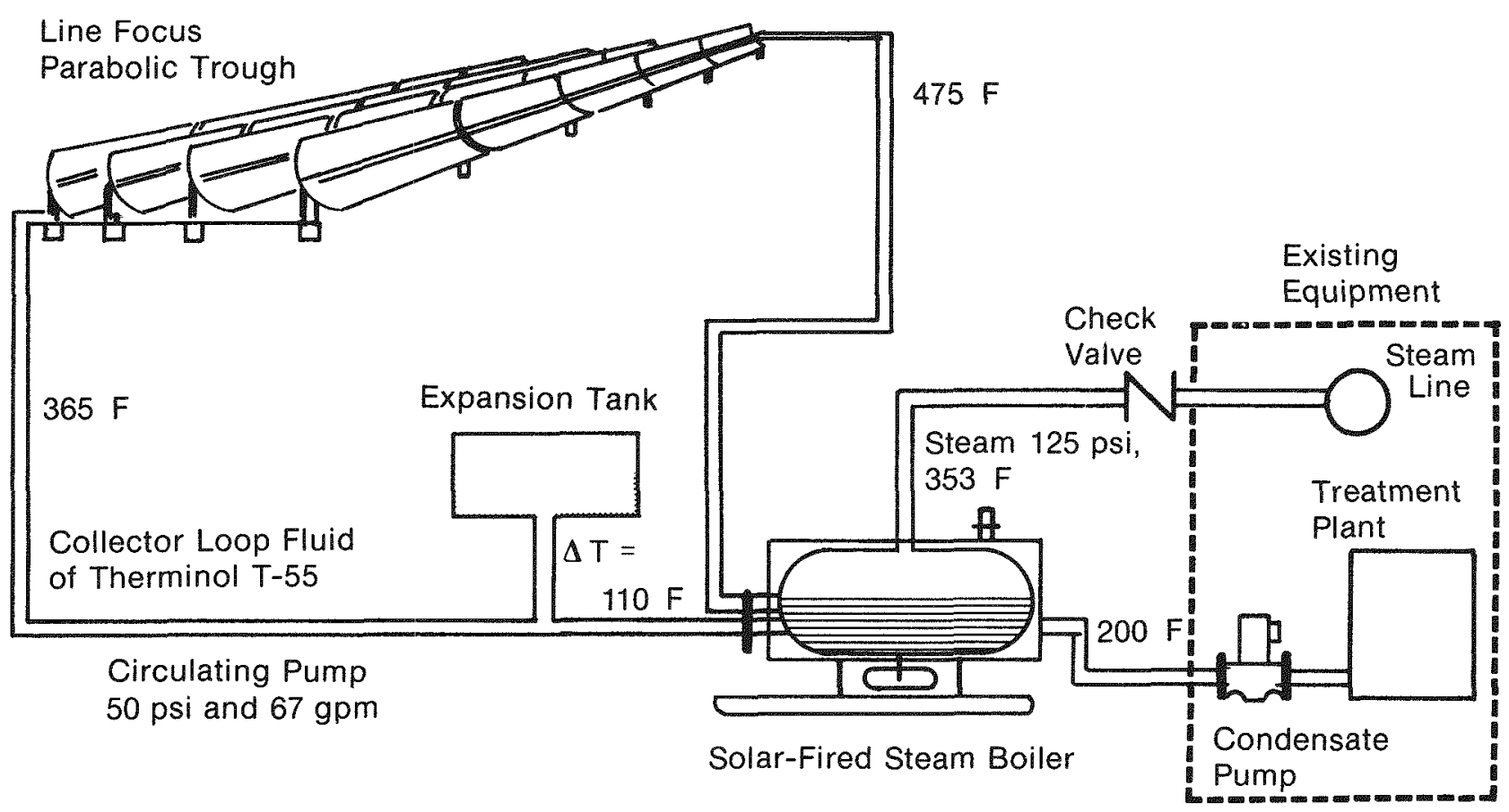

Fig. 7-9. Solar steam supply using unfired boiler 
In designing the solar system for the oil refinery, the flash system shown in Fig. 7-10 was considered as an alternative. In that system, water would be heated directly to $477 \mathrm{~F}\left(247^{\circ} \mathrm{C}\right)$ and 600 psi in the collector loop and then flashed to steam. This eliminates the need for an expensive unfired boiler and can provide more collected energy since the temperature difference across the heat exchanger is eliminated. On the other hand, freeze protection is required, and considerable pumping power must be provided to supply the pressure difference across the flash valve. A flash system similar in principle to the one shown is being buil t at the Ore-Ida Foods, Inc., french-fried pota to plant in Ontario, Oreg.

The third al ternative of boiling water in the collectors has not yet been attempted. Potential problems such as corrosion, tube burnout, and destructive temperature fluctuations must first be overcome.

Although steam is widely used in industry to transport heat, solar energy can probably be combined better with hot water. If hot water is used to supply heat to a process, solar collectors can be used without need for an unfired boiler and without having to suffer the disadvantages of a flash system. Thus, if solar energy is being considered for a new plant, some consideration should also be given to the use of pressurized hot water in place of steam.

\section{INDUSTRIAL PROCESS HEAT FIELD TESTS}

In an effort to advance the state of the art in solar industrial process heat, the U.S. Department of Energy has funded a number of field tests throughout the United States. These have been funded in cycles with each new cycle testing a different area for solar application: hot water $\left[<212 \mathrm{~F},\left(100^{\circ} \mathrm{C}\right)\right]$, hot air, low-temperature steam $\left[212-350 \mathrm{~F} \quad\left(100-177^{\circ} \mathrm{C}\right)\right]$, and intermediatetemperature steam $\left[350-550 \mathrm{~F}\left(177-275^{\circ} \mathrm{C}\right)\right]$. In addition, two new cycles are currently being funded for large collector area $[50,000 \mathrm{sq} \mathrm{ft}(4,500 \mathrm{sq} \mathrm{m})]$ projects both above and below $212 \mathrm{~F}\left(100^{\circ} \mathrm{C}\right)$ in order to investigate economies of scale. A list of the projects, several of which have been mentioned earlier, is given in Table 7-4.

Much has already been learned from the existing field tests. Six projects that have been operating for a year or longer were the subjects of a report by the Solar Energy Research Institute [3]. Table 7-5 excerpted from that report lists the major problems which were encountered at each site. System efficiencies have ranged from 8 to $33 \%$ for the first year of operation. With corrective actions taken to solve the problems, these numbers can be expected to increase considerably. As newly designed projects benefit from the experiences of earlier field tests, reliability and performance can be expected to increase.

Although six projects provide a very limited statistical basis on which to make generalizations, some basic conclusions can be drawn that should prove useful in future projects. These are:

- Collectors can prove to be a major problem in field application of solar projects. Degradation of absorber surfaces and glazings is still relatively common.

- Problems similar to those encountered in the solar heating and cooling of buildings program occur in IPH applications. Better education in system design is needed to prevent the occurrence of problems such as thermal shocking of evacuated tube collectors, heat exchanger freezing due to thermosyphon heat loss, improper pump selection, etc.

Flash System

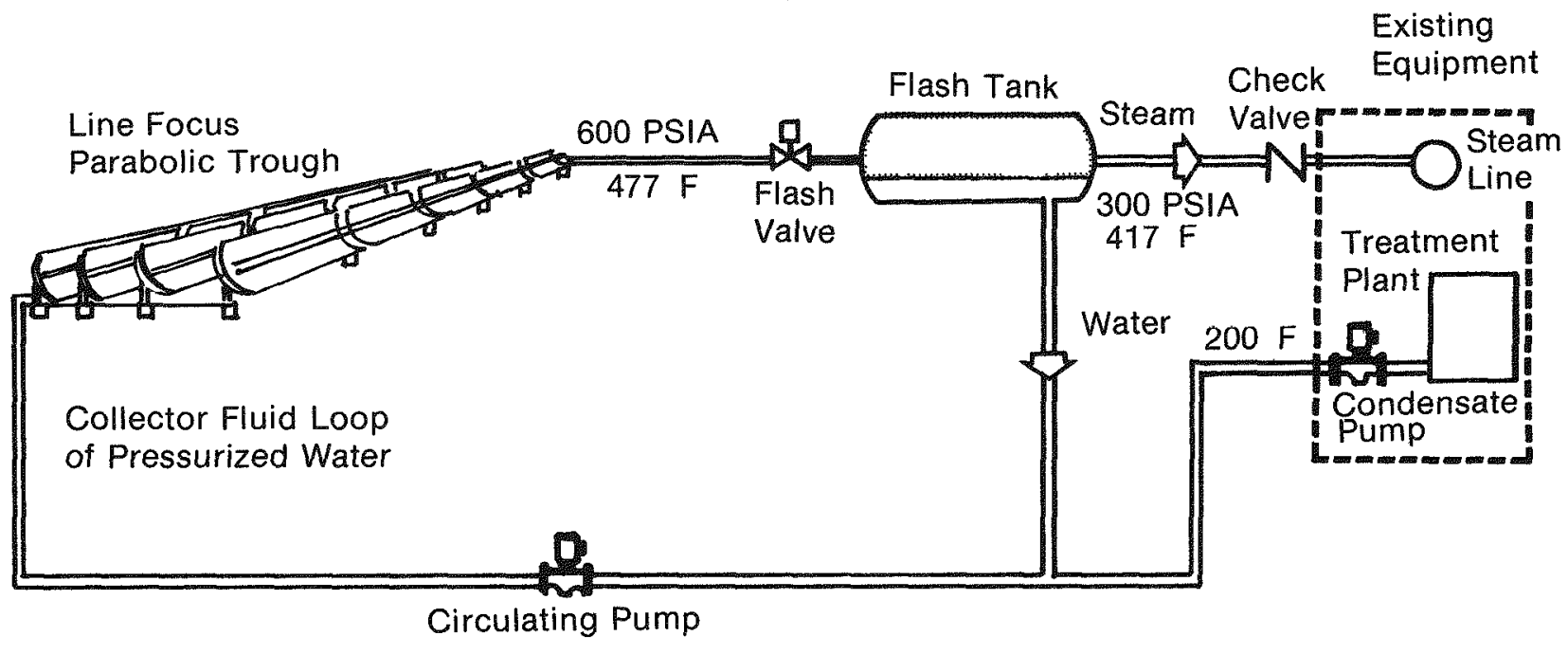

Fig. 7-10. Solar steam supply using flash tank 
Table 7-4. DOE-SPONSORED INDUSTRIAL PROCESS HEAT FIELD TESTS

\begin{tabular}{|c|c|c|c|c|}
\hline Location & Process & Collectors & Owner & Status \\
\hline \multicolumn{5}{|c|}{ HOT WATER (140-212 F) } \\
\hline $\begin{array}{l}\text { Sacram ento, } \\
\text { Calif. }\end{array}$ & $\begin{array}{c}\text { can } \\
\text { washing }\end{array}$ & $\begin{array}{c}\text { flat plate } \\
\text { \& parabolic trough }\end{array}$ & $\begin{array}{l}\text { Campbell } \\
\text { Soup Co. }\end{array}$ & $\begin{array}{l}\text { operational } \\
\text { (April 1978) }\end{array}$ \\
\hline $\begin{array}{l}\text { Harrisburg, } \\
\text { Pa. }\end{array}$ & $\begin{array}{c}\text { concrete } \\
\text { block curing }\end{array}$ & $\begin{array}{l}\text { multiple } \\
\text { reflector }\end{array}$ & $\begin{array}{l}\text { York Building } \\
\text { Products }\end{array}$ & $\begin{array}{l}\text { operational } \\
\text { (Sept. 1978) }\end{array}$ \\
\hline $\begin{array}{l}\text { LaFrance, } \\
\text { S.C. }\end{array}$ & $\begin{array}{l}\text { textile } \\
\text { dyeing }\end{array}$ & $\begin{array}{l}\text { evacuated } \\
\text { tube }\end{array}$ & $\begin{array}{l}\text { Riegel Textile } \\
\text { Corp. }\end{array}$ & $\begin{array}{l}\text { operational } \\
\text { (June 1978) }\end{array}$ \\
\hline \multicolumn{5}{|c|}{ HOT AIR (140-212 F) } \\
\hline $\begin{array}{l}\text { Fresno, } \\
\text { Calif. }\end{array}$ & $\begin{array}{l}\text { fruit } \\
\text { drying }\end{array}$ & flat plate & $\begin{array}{l}\text { Lamanuzzi \& } \\
\text { Pantaleo Foods }\end{array}$ & $\begin{array}{l}\text { operational } \\
\text { (May 1978) }\end{array}$ \\
\hline $\begin{array}{l}\text { Canton, } \\
\text { Miss. }\end{array}$ & $\begin{array}{l}\text { kiln drying } \\
\text { of lumber }\end{array}$ & flat plate & $\begin{array}{l}\text { LaCour Kiln } \\
\text { Services, Inc. }\end{array}$ & $\begin{array}{l}\text { operational } \\
\text { (June 1978) }\end{array}$ \\
\hline $\begin{array}{l}\text { Decatur, } \\
\text { Ala. }\end{array}$ & $\begin{array}{l}\text { soybean } \\
\text { drying }\end{array}$ & flat plate & Gold Kist, Inc. & $\begin{array}{l}\text { operational } \\
\text { (May 1978) }\end{array}$ \\
\hline $\begin{array}{l}\text { Gilroy, } \\
\text { Calif. }\end{array}$ & $\begin{array}{l}\text { onion } \\
\text { drying }\end{array}$ & $\begin{array}{l}\text { evacuated } \\
\text { tube }\end{array}$ & $\begin{array}{l}\text { Gilroy Foods, } \\
\text { Ine. }\end{array}$ & $\begin{array}{l}\text { operational } \\
\text { (Sept. 1979) }\end{array}$ \\
\hline \multicolumn{5}{|c|}{ LOW TEMPERATURE STEAM (212-350 F) } \\
\hline $\begin{array}{l}\text { Fairfax, } \\
\text { Ala. }\end{array}$ & $\begin{array}{l}\text { fabric } \\
\text { dryying }\end{array}$ & $\begin{array}{l}\text { parabolic } \\
\text { trough }\end{array}$ & $\begin{array}{l}\text { WestPoint } \\
\text { Pepperell }\end{array}$ & $\begin{array}{l}\text { operational } \\
\text { (Sept. 1978) }\end{array}$ \\
\hline $\begin{array}{l}\text { Sherman, } \\
\text { Tex. }\end{array}$ & $\begin{array}{l}\text { gauze } \\
\text { bleaching }\end{array}$ & $\begin{array}{l}\text { parabolic } \\
\text { trough }\end{array}$ & $\begin{array}{l}\text { Johnson \& } \\
\text { Johnson }\end{array}$ & $\begin{array}{l}\text { operational } \\
\text { (Feb. 1978) }\end{array}$ \\
\hline $\begin{array}{l}\text { Pasadena, } \\
\text { Calif. }\end{array}$ & laundry & $\begin{array}{l}\text { parabolic } \\
\text { trough }\end{array}$ & $\begin{array}{l}\text { Home Cleaning } \\
\text { \& Laundry }\end{array}$ & construction \\
\hline $\begin{array}{l}\text { Bradenton, } \\
\text { Fla. }\end{array}$ & $\begin{array}{l}\text { orange juice } \\
\text { pasteurization }\end{array}$ & $\begin{array}{l}\text { evacuated } \\
\text { tube }\end{array}$ & $\begin{array}{l}\text { Tropicana } \\
\text { Products, Inc. }\end{array}$ & construetion \\
\hline \multicolumn{5}{|c|}{ INTERMEDIATE TEMPERATURE STEAM (350-550 F) } \\
\hline $\begin{array}{l}\text { Mobile, } \\
\text { Ala. }\end{array}$ & oil heating & $\begin{array}{l}\text { parabolic } \\
\text { trough }\end{array}$ & Ergon, Inc. & design \\
\hline $\begin{array}{l}\text { Dalton, } \\
\text { Ga. }\end{array}$ & $\begin{array}{c}\text { latex } \\
\text { production }\end{array}$ & $\begin{array}{l}\text { multiple } \\
\text { reflector }\end{array}$ & Dow Chemical & construction \\
\hline $\begin{array}{l}\text { Newberry } \\
\text { Springs, Calif. }\end{array}$ & $\begin{array}{l}\text { hec torite } \\
\text { processing }\end{array}$ & $\begin{array}{l}\text { parabolic } \\
\text { trough }\end{array}$ & $\begin{array}{l}\text { Nat'l Lead } \\
\text { Industries }\end{array}$ & design \\
\hline $\begin{array}{l}\text { Hobbs, } \\
\text { N. Mex. }\end{array}$ & oil refinery & $\begin{array}{c}\text { parabolic } \\
\text { trough }\end{array}$ & $\begin{array}{l}\text { Southern } \\
\text { Union Co. }\end{array}$ & construction \\
\hline $\begin{array}{l}\text { San Antonio, } \\
\text { Tex. }\end{array}$ & brewery & $\begin{array}{l}\text { parabolic } \\
\text { trough }\end{array}$ & $\begin{array}{l}\text { Lone Star } \\
\text { Brewing Co. }\end{array}$ & design \\
\hline $\begin{array}{l}\text { Henderson, } \\
\text { Nev. }\end{array}$ & $\begin{array}{c}\text { chlorine } \\
\text { manufacturing }\end{array}$ & $\begin{array}{l}\text { parabolic } \\
\text { trough }\end{array}$ & $\begin{array}{c}\text { Stauffer } \\
\text { Chemical Co. }\end{array}$ & design \\
\hline $\begin{array}{l}\text { Ontario, } \\
\text { Ore. }\end{array}$ & $\begin{array}{l}\text { potato } \\
\text { processing }\end{array}$ & $\begin{array}{l}\text { parabolic } \\
\text { trough }\end{array}$ & Ore-Ida Co. & construction \\
\hline \multicolumn{5}{|c|}{ PRIVATELY FUNDED } \\
\hline $\begin{array}{l}\text { Youngstown, } \\
\text { Ohio }\end{array}$ & $\begin{array}{l}\text { aluminum } \\
\text { anodizing }\end{array}$ & $\begin{array}{l}\text { fixed half- } \\
\text { parabolic }\end{array}$ & $\begin{array}{c}\text { General } \\
\text { Extrusions, Ine. }\end{array}$ & $\begin{array}{l}\text { operational } \\
\text { (Sept. 1977) }\end{array}$ \\
\hline $\begin{array}{l}\text { Jacksonville, } \\
\text { Fla. }\end{array}$ & $\begin{array}{c}\text { beer } \\
\text { pasteurization }\end{array}$ & $\begin{array}{l}\text { evacuated } \\
\text { tube }\end{array}$ & $\begin{array}{l}\text { Anheuser- } \\
\text { Busch, Inc. }\end{array}$ & $\begin{array}{l}\text { operational } \\
\text { (Feb. 1978) }\end{array}$ \\
\hline
\end{tabular}


Table 7-5. PROBLEMS ENCOUNTERED AT OPERATIONAL FELD TESTS

\begin{tabular}{|c|c|c|}
\hline Project & Problems & Corrective Action \\
\hline Campbell Soup & $\begin{array}{l}\text { Data logger failure } \\
\text { Magnetic tape recorder failure } \\
\text { Nonoperative flowmeter } \\
\text { Broken glass cover tubes } \\
\text { Wind damage } \\
\text { Shutdown of can line while } \\
\text { changing soup type }\end{array}$ & $\begin{array}{l}\text { Exhaust fan installed } \\
\text { None } \\
\text { Replaced with Kates control valve, as yet uncali- } \\
\text { brated } \\
\text { Will be replaced } \\
\text { Repaired damage } \\
\text { None }\end{array}$ \\
\hline Riegel Textile & $\begin{array}{l}\text { Contamination of reflectors } \\
\text { by boiler stack effluents } \\
\text { Excessive night losses } \\
\text { Thermal shock tube breakage } \\
\text { Low flow rate through collector } \\
\text { Poor insulation in collector } \\
\text { headers }\end{array}$ & $\begin{array}{l}\text { None, effeet is being studied } \\
\text { Replace supply pipe with smaller diameter pipe } \\
\text { to reduce thermal mass } \\
\text { Installed over-temperature indicator; circuit box } \\
\text { made less accessible } \\
\text { Will install larger manifold fittings and will } \\
\text { increase impeller diameter of pump } \\
\text { Will replace leaky grommets and add more } \\
\text { insulation }\end{array}$ \\
\hline York Building Products & $\begin{array}{l}\text { Failure of black chrome coating } \\
\text { Thermosyphon freezeup } \\
\text { Mirror breakage--thermal } \\
\text { Insufficient wire size for motors } \\
\text { Drive motor grease too thick } \\
\text { Data logger not compatible with } \\
\text { tape drive } \\
\text { Mirror desilvering } \\
\text { Dust problems with data logger }\end{array}$ & $\begin{array}{l}\text { Painted rusted areas with flat black paint } \\
\text { Installed check valves in collector loop piping; } \\
\text { replaced heat exchanger tube bundle } \\
\text { Mirrors will be replaced } \\
\text { Replaced wires with heavier gauge } \\
\text { Replaced grease with low-temperature grease } \\
\text { Replaced data logger with different brand } \\
\text { None, effect is being studied to determine nec- } \\
\text { essary number of coats of epoxy to mirror } \\
\text { backs } \\
\text { Relocated to building lobby }\end{array}$ \\
\hline Gold Kist & $\begin{array}{l}\text { Collector contamination by } \\
\text { soybean chaff } \\
\text { Data logger failure due to low } \\
\text { temperature } \\
\text { Water seepage into insulation } \\
\text { Plant operation schedule calling } \\
\text { for maintenance during daytime }\end{array}$ & $\begin{array}{l}\text { Developed automatic sprinkler systems } \\
\text { Defective card replaced; heater repaired } \\
\text { None } \\
\text { Changed operation schedule to use solar } \\
\text { equipment more effectively }\end{array}$ \\
\hline LaCour Kiln Service & $\begin{array}{l}\text { CPVC pipe failure due to over- } \\
\text { heating during nonload conditions } \\
\\
\text { Gravel in collector loop piping } \\
\text { Flood damage to data acquisition } \\
\text { system } \\
\text { Dust in disk drive } \\
\text { Erratic water flowmeters } \\
\text { Poor turndown ratio on } \\
\text { conventional heaters } \\
\text { Inadequate collector pipe } \\
\text { slope to ensure draindown }\end{array}$ & $\begin{array}{l}\text { Replaced all CPVC with steel pipe; installed } \\
\text { high-temperature cutoff; installed larger } \\
\text { pressure relief valve } \\
\text { Replaced flowmeters; installed screens } \\
\text { Damage being repaired } \\
\text { Placed computer in fil ter-equipped, air- } \\
\text { conditioned room } \\
\text { Replaced flowmeters; added turbine flowmeters } \\
\text { None } \\
\text { Wooden supports added to prop up pipe }\end{array}$ \\
\hline $\mathrm{L}$ and $\mathrm{P}$ Foods & $\begin{array}{l}\text { Rain leakage into damper housings } \\
\text { Nonuniform rock storage bed } \\
\text { Timeclock failures in data } \\
\text { acquisition system } \\
\text { Lexan stress failure and yellowing } \\
\text { Vandalism }\end{array}$ & $\begin{array}{l}\text { Repaired damper motors } \\
\text { None } \\
\text { Isolated clock with capacitors } \\
\text { None } \\
\text { None }\end{array}$ \\
\hline
\end{tabular}


- Parasitic power has proved to be a major contributor to low system performance in those systems employing air collectors.

- Both operational and overnight piping losses can be very significant in solar IPH applications.

- Data acquisition systems have generally been very unreliable.

- Solar energy application to industrial process heat is not yet cost effective when the typical payback periods required by industrial owners are considered. Although industrial managers are concerned with fuel curtailments, most do not yet view solar energy as a profitable investment.

- A considerable investment in maintenance is needed to approach predicted performance in first generation projects.

- Environmental contaminants can seriously affect solar collec tor perf ormance.

- Certain adjustments in plant operation schedules, hardware, and control logic are of ten needed to optimize the use of a solar energy system.

- Energy conservation opportunities are abundant in industry, and many have much more rapid payback periods than solar energy systems. Just as in the solar heating and cooling of buildings, energy conservation should precede solar implementation.

- In some applications, solar energy may improve the quality of a final product in addition to saving fossil fuel.

More details on the Iow-temperature field tests including total costs can be found in Ref. 3 .

In its role as manager of several large-scale IPH field tests, SERI has compiled a list of topics which contractors are expected to address in their conceptual designs. This list is given in Table 7-6. An effort is currently underway to publish \& set of "Solar Industrial Process Heat Design Guidelines." These will draw on the experiences of operating projects and hopefully prevent contractors from repeating errors which have been made in the past.

The future of solar energy in industrial process heat depends on a number of factors. Increased costs of fossil fuel will certainly make solar more attractive. Unavailable or interrupted fossil-fuel supplies would have even a greater impact. As collectors become mass produced, it is expected that costs can drop substantially. Improvements in both collector efficiency and reliability will also accelerate solar implementation. Finally, cost studies have shown that government tax incentives can play a large part in bringing solar costs in line with what industry is willing to pay. (Details on the economics of solar IPH systems can be found in Ref. 4.)

\section{REFRRENCES}

1. InterTechnology Corporation. 1977. Analysis of the Economic Potential of Solar Thermal Energy to Provide Industrial Process Heat. 3 Vols., Warrenton, Va.

2. Battelle Columbus Laboratories. 1977. Survey of the Applications of Solar-Thermal Energy Systems to Industrial Process Heat. 3 Vols., Columbus, Ohio.

3. Kutscher, C. F. and R. Davenport, Preliminary Results of the Operational Industrial Process Heat Field Tests, SERI/TR-34-385, Solar Energy Research Institute, Golden, Colo., for theoming.

4. Dickinson, W. C. and K. Brown, Economic Analysis of Solar Industrial Process Heat Systems: A Methodology to Determine Annual Required Revenue and Internal Rate of Return, UCRL-52814, Lawrence Livermore Laboratory, Livermore, Calif. 
I. Choice of Solar Inter face

Process location relative to solar array

Process energy requirements, temperature, and schedule

Conservation measures or alternatives (other fuels, cogeneration)

Ability of process to accommodate variations in solar energy output

Process modifications needed

Process storage

Room for expansion of array

Seasonal and annual patterns of fuel and energy use (utility recorđis)

Energy prices and projections into future

Existing energy source (efficiency, fuel used, backup, fuel curtailm ents)

General description of plant operations

Economic criteria for energy investments

Availability of work force for maintenance of solar system

Energy intensity of process operations (fuel cost as $\%$ of value added, Btu/lb product, etc.)

II. Choice of Collector

Source of performance data

Potential annual energy delivery

Cost $(\$ / \mathrm{MBtu} / \mathrm{yr})$

Ability to tolerate stagnation conditions

Maintenance and installation requirements

Field experience

III. Collector Location/Mounting

Orientation ( $\mathrm{E}-\mathrm{W}$ versus $\mathrm{N}-\mathrm{S}$ )

Ground versus roof mounting

Wind load considerations

Hail, snow, and other environmental considerations

Roof penetrations and building modifications

Provision for washing and other maintenance

Shading considerations

Access for maintenance

Security of site

IV. Overall System Design Tradeoffs

Open loop versus closed loop

Collector operating temperature

Storage

Choice of heat transfer fluid (heat exchange system)

- fire considerations

- pumping power versus heat transfer capability

- cost

- corrosion, degradation, safety

Optimum flow rate (performance versus parasitics)

Choice of collector area

V. Piping and Subsystem Components

Applicable codes and standards

Direct return versus reverse return

Optimum pipe size (tradeoff between cost, parasitics, steady state, and overnight losses)

Insulation (optimum thickness, fire considerations, closed cell, open cell)

Thermal stress consi derations
Pump selection

Heat exchanger design (if any)

Valve selection

Flanges, connections, expansion loops, bellows, flex hose, etc.

Expansion tanks

Pressure relief valves (location, handling of discharge, etc.

Corrosion protection

VI. Electrical Subsystem and Components

Area classification

Backup power source (if required)

Applicable codes and standards

Grounding

VII. Controls

Operator control panel; alarm panel

Constant versus variable flow

Result of partial collector shading, tracking collector misalignment, flow blockage, etc.

Prevention of thermal shock (if a problem)

Emergency shutdown system

Startup procedures

Controller tuning

Operator training

Freeze protection

Recommended equipment types

Integration of solar and conventional systems

Sensor location and type

Tracker system (if present)

VIII. Energy Delivered by Solar System

Insolation data used

Maximum potential annual and monthly system energy delivery and efficiency (considering thermal losses, parasitics, realistic performance assumptions)

Expected annual energy utilization by process

Computer simulation methods

Conventional fuel savings; solar fraction for process.

IX. Data Acquisition (should follow SERI Data Acquisition Guidelines)

X. Documentation for Conceptual Design (may not be all-inclusive)

Preliminary design drawings (i.e., field layout)

System schematic

Control scenarios

DAS diagrams

Physical layout of solar/industrial process piping - and interface

Conceptual Design Report 


\section{OTHER SOLAR OPTIONS:}

\section{B. WIND ENERGY*}

Wind and air movement are the results of the Sun's warming of different layers of the atmosphere and parts of the Earth's surface. As solar radiation strikes the Earth, areas near the equator are heated more than areas near the poles. This causes equatorial air to $r$ ise to upper levels of the troposphere (the atmospheric zone closest to the Earth's surface). Cold polar air moves to the equator to replace the air that has risen, and sets up circulating planetary wind patterns. The rotation of the Earth has an effect on these winds, in what are known as Coriolis forces (after the French civil engineer who identified them in 1843): cooler air moving along the Earth's surface toward the equator is diverted toward the west, while the warmer air at the upper levels of the troposphere tends toward the east. These effects initiate large counterclockwise circulation of the air around low pressure areas in the northern hemisphere and clockwise circulation in the southern hemisphere. Topological features, day-night heating and cooling cycles, and manmade structures further complicate airflow patterns and generate microclimatic winds.

Localized wind movement and direction depend on the location of high and low pressure areas (equalization of pressure areas), the density of air (barometer readings), the amount of cloud cover (temperature differentials caused by shade or sun), topography (shape and contour of the land), land/water formations, and the position and tilt of the Earth with respect to the Sun.

Man has utilized wind energy for many thousands of years but has never taken advantage of its full potential. Wind has not been used to propel large ships since the early $1900 \mathrm{~s}$, although its use for the propulsion of sailing vessels dates back to the Egyptians, circa 3000 B.C. The development of the steam engine and other mechanical systems gradually supplanted the use of wind energy to propel large sailing vessels.

Wind can propel many types of vehicles; sails are even available for bicycles. The movement of the air exerts a pressure on any surface with which it comes in contact. With a constant wind speed, the force acting perpendicular to a surface increases at the same rate as the are of the surface increases. The surface can either be stationary such as the side of a building, which must transfer the force of the wind to the ground; or movable, and be set in motion by the force of the wind.

*This discussion is taken from Sun-Earth: How to Use Solar and Climatic Energies Today. Richard L. Crowther, et al., Denver: Crowther/Solar Group, 1977.
Wind energy may be harnessed for the movement of a sail or a blade. Many old windmills (for milling grain) in Europe used sails stretched over wooden frames to generate mechancial movement. The movement of the rotating sails was then transformed to useful work by wooden gears and shafts. Windmills are generally thought of as producing direct mechanical energy, and wind generators and wind turbines produce electrical energy. The majority of the wind machines being developed today are for the generation of electricity, yet most units presently operating pump water.

The theoretical maximum amount of kinetic energy (the energy possessed by virtue of an object's motion) which can be extracted by a wind machine from the windstream is only $59.26 \%$ This factor is known as the Betz Coefficient, first derived in 1972 by the German engineer, A. Betz. His calculations assumed $100 \%$ efficiency within the wind machine system itself. Since no machine can be perfect in construction and operation, and since energy is lost in electrical transmission lines, only about $40 \%$ of the wind's kinetic energy can be practically utilized in buildings.

The amount of available wind energy varies depending on the location, elevation, and orientation of a wind machine. Climatic data have been collected on the force of wind and its direction for many areas of the United States. For some locations the wind speed and direction are plotted on a polar axis graph (graph with North, South, East, and West indicated) in terms of wind strength and frequency. The resulting plot is called a wind rose map (Fig. 7-11) in reference to the shape most of ten generated; percentages indicate the portion of time (annually in this example) during which wind speeds reach the figures shown. Also helpful in determining the approximate amount of power which can be extracted from the wind are calculations for monthly average wind speeds and annual average velocity duration curves.

The quality of wind also affects the amount of power that can be extracted from it. There are significant amounts of shear and compression in a horizontal windstream flowing over the surface of the Earth. This shear resul ts in lower wind speeds elose to the Earth's surface than at al titudes at which free flow occurs. Laminar flow is the movement of air in parallel layers over an even landscape or calm body of water. An interruption in topography causes turbulence in the wind pattern. A tree, a house, or a hill can cause multiple redirections of wind in a manner which would cause instabilities in a poorly located wind machine. 


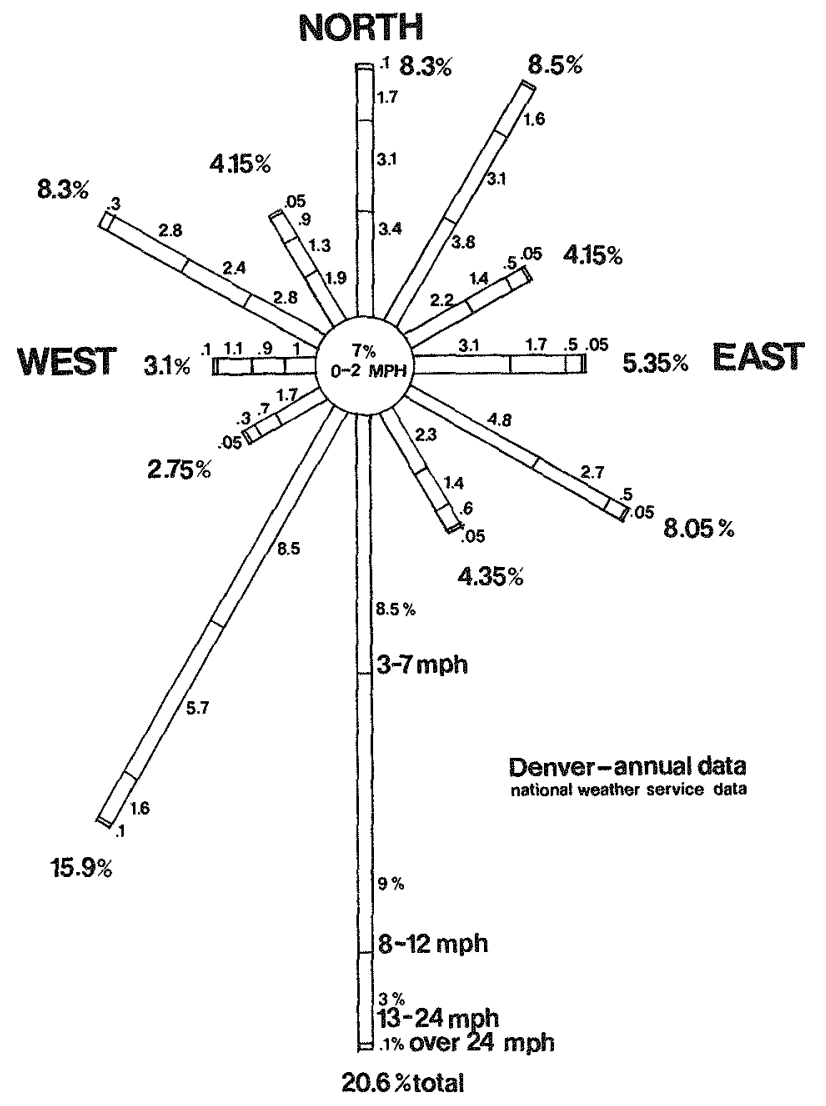

Fig. 7-11. Wind rose map

Source: Richard Crowther, Sun/Earth, 1977

Therefore, it is usually suggested that wind machines be placed as high as possible off the ground to eliminate surface effects. A customary minimum distance is $33 \mathrm{ft}$ $(10 \mathrm{~m})$ from ground level to the bottom of a turbine or airfoil. In nearly all geographic locations, winds become laminar above this height, and their velocity increases sharply. (The power of the wind increases as the cube of the velocity.) For large-scale wind generators, heights may reach $213 \mathrm{ft}(65 \mathrm{~m})$ or more.

Great care must be taken in choosing a suitable site for a wind machine. It is possible to increase the average power output by siting a machine to take advantage of local topographic features. Flow is accelerated as it passes over a rounded hill or through a narrow valley. Because of local anomalies, it is worthwhile to make a detailed wind survey before choosing a site for a wind machine. The effect of topography upon wind velocity is shown in Fig. 7-12.

Wind machines convert the horizontal force of wind into rotary or oscillatory mechancial motion. Limitations on the mechancial efficiency as mentioned above restrict the amount of energy which can be removed from the wind. One important principle in the design of wind machines is the tip speed ratio, the relationship between blade tip speed and actual wind velocity perpendicular to the plane of rotation. The higher the tip speed ratio is, the more efficient the machine will be. Many old style windmills produce tip speeds ratios of 1 to 2 and develop more torque (turning power) than is necessary for electrical generation. The most recently developed wind turbines and generators usually feature tip speed ratios between $6: 1$ and $8: 1$ facilitating more efficient electrical generation than is possible with lower tip speed ratios.

Wind machines produce useful power between certain minimum and maximum rotational speeds. Most machines need at least 7.5 to $10 \mathrm{mph}(12$ to $16 \mathrm{~km} / \mathrm{h}$ ) wind to generate electricity. Older windmills can use wind speeds as slow as 1.87 to $2.5 \mathrm{mph}$ ( 3 to $4 \mathrm{~km} / \mathrm{h}$ ) to pump water. The top utilization speed of wind machines averages approximately $41 \mathrm{mph}(65 \mathrm{~km} / \mathrm{h})$. No additional useful power can be extracted, without adjustments, from winds above that speed. Some wind machines will let the turbine, blades, or rotors spin on a free clutch system or centrifugal governor in high velocity winds; others have blades which can be mechanically modified to maintain a constant rotational speed in variable winds.
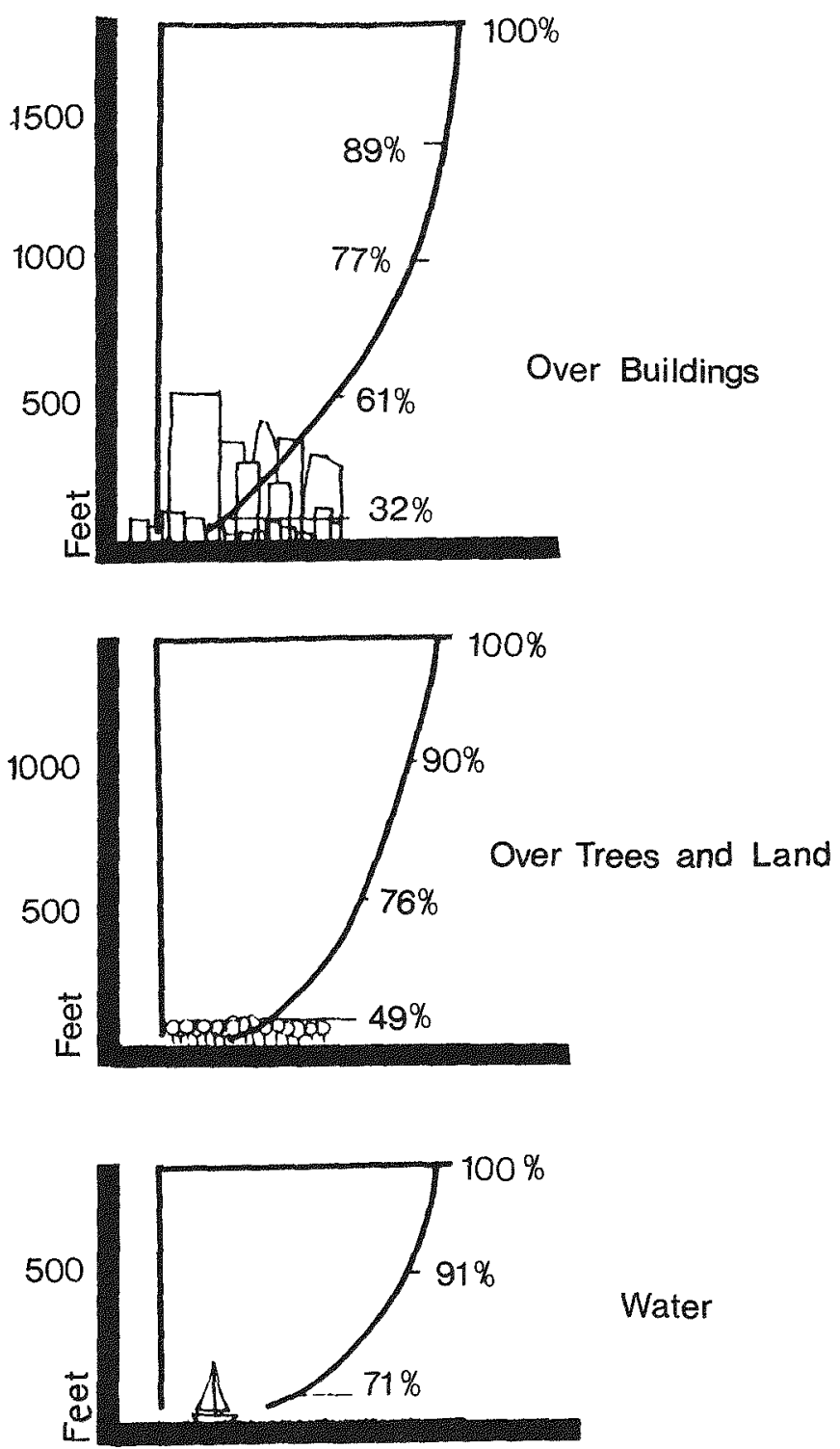

Fig. 7-12. Wind velocity profiles

Source: Richard Crowther, Sun/Earth, 1977 


\section{WIND MACHINE CONFIGURATIONS}

Much research has recently been done on airfoils, sail winds, hoops, rotors, single propellors, paired contrarotating propellors, and turbines to determine their suitability as part of a wind machine system. Each of these mechanisms may be categorized as either a horizontal or vertical axis device.

\section{Horizontal Axis}

Horizontal axis machines are typified by old windmills, in which the plane of rotation is, ideally, always perpendicular to the prevailing wind direction. These machines must be equipped with a mechanism to turn them when the wind direction changes. This can only be accomplished via the tracking process in which axis and blades all pivot into the wind. Because of tracking, some mechanical energy is lost. Horizontal axis devices have nonetheless enjoyed popularity for centuries, and they require only a low wind speed for fairly successful operation.

Horizontal axis wind machines vary greatly in their performance and design. Wind turbines consist of many blades which convert wind power into rotary motion. They can have an electrical generator connected to the central shaft or one positioned to ride the outside circumference of the wheel. The speed of the central shaft is generally too slow to power a generator without gearing upward at some cost in efficiency. By contrast, generators operating on the outer circumference of the wheel can take advantage of the high velocity of the blade tips. Figs. 7-13 through 7-18 show a variety of horizontal axis wind machines.

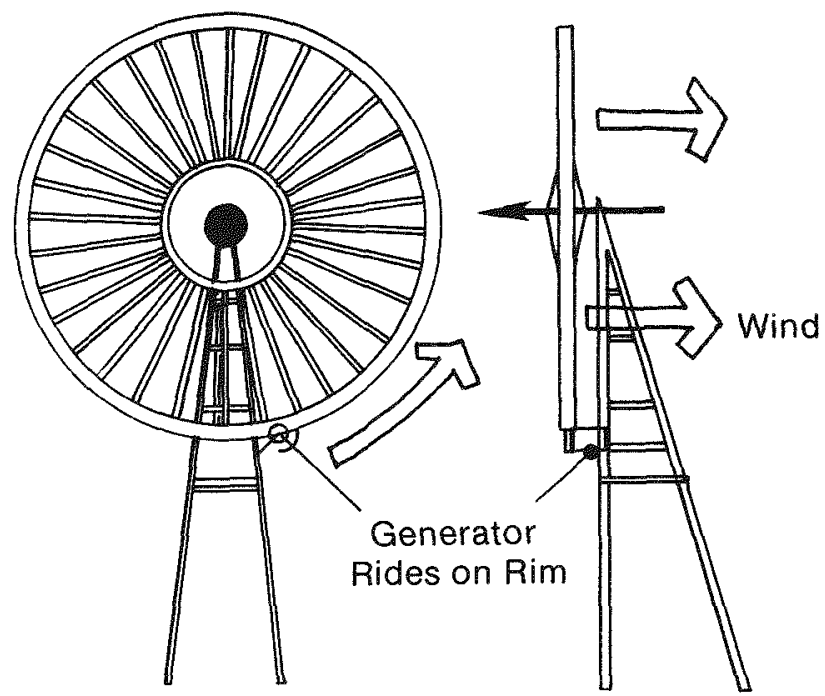

Fig. 7-13. Bicycle wheel turbine Source: Richard Crowther, Sun/Earth, 1977

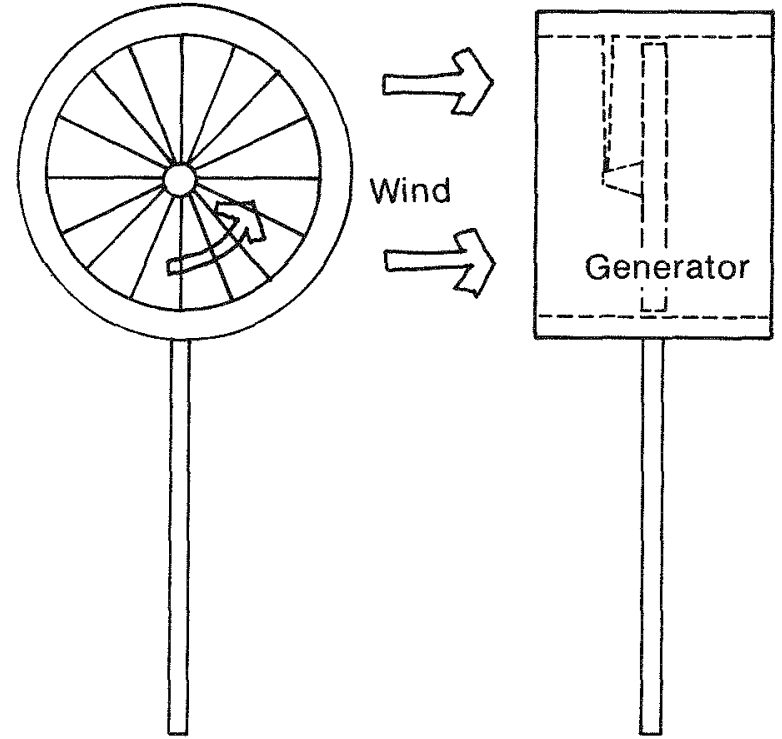

Fig. 7-14. Gillette wind turbine Source: Richard Crowther, Sun/Earth, 1977

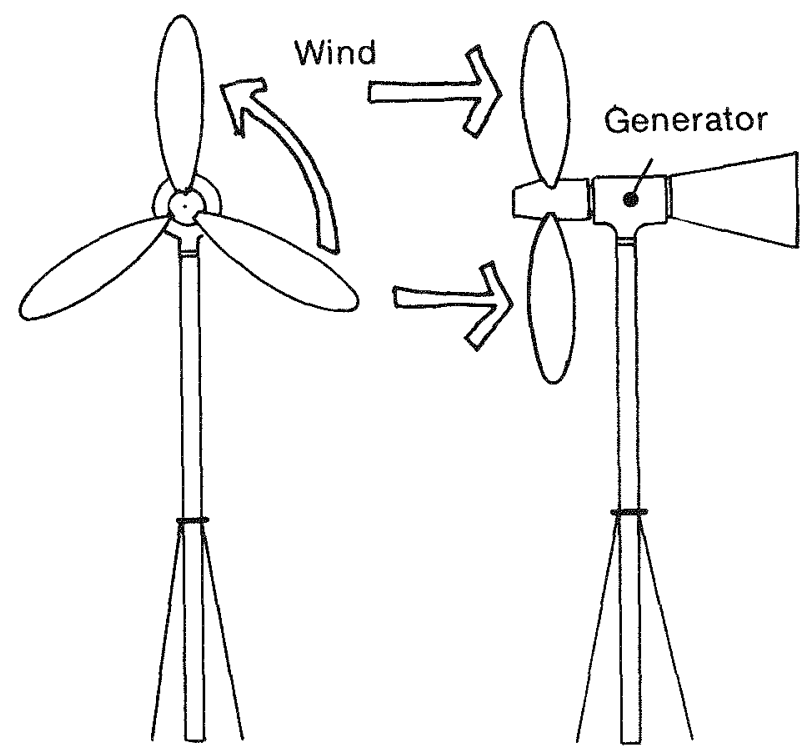

Fig. 7-15. Three-propellor wind machine Source: Richard Crowther, Sun/Earth, 1977 


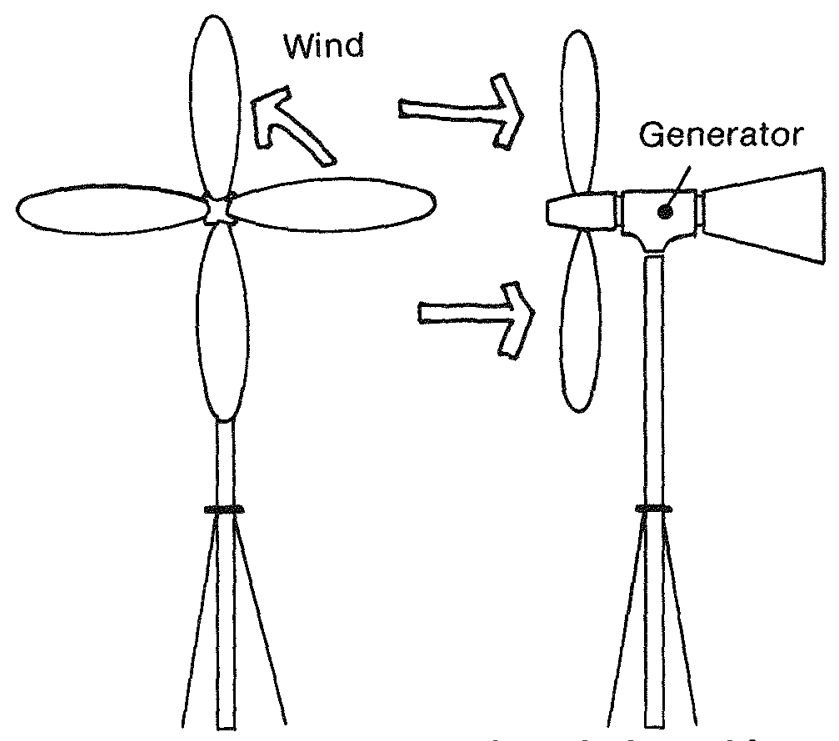

Fig. 7-16. Four-propellor wind machine Source: Richard Crowther, Sun/Earth, 1977
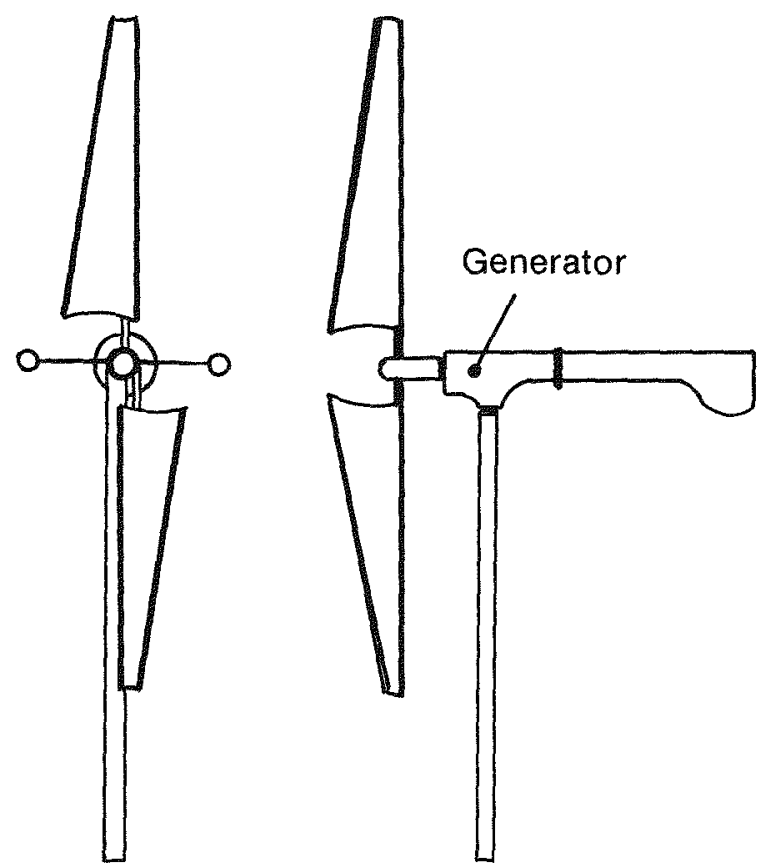

Fig. 7-17. Sailwing rotor

Source: Richard Crowther, Sun/Earth, 1977
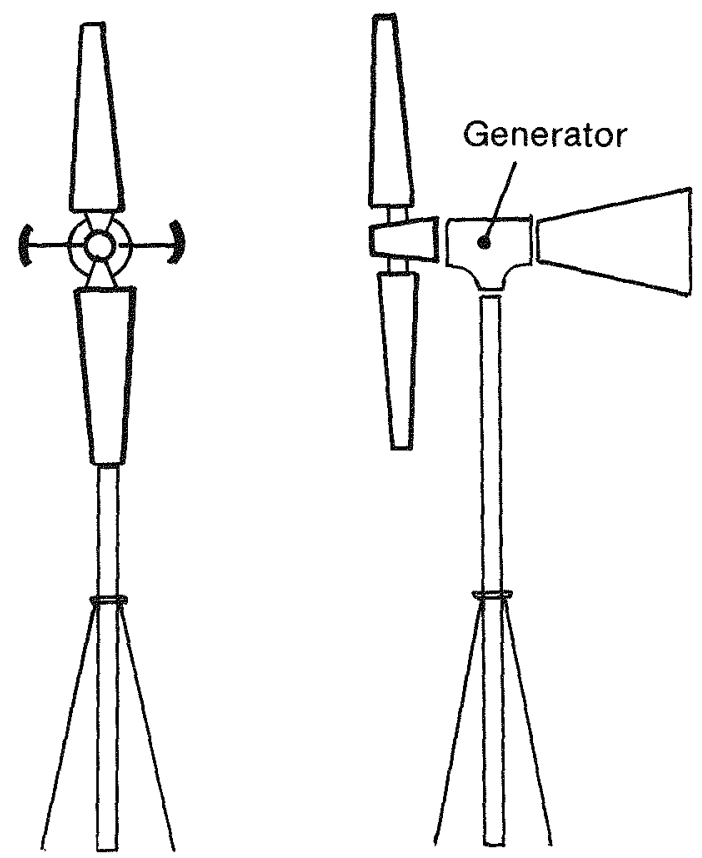

Fig. 7-18. Two-blade rotor.

Source: Richard Crowther, Sun/Earth, 1977

\section{Vertical Axis}

The rotor of a vertical axis wind machine revolves in a horizontal plane. Because of this orientation, the machine does not have to pivot to face into the wind. This feature is a distinct advantage on wind machines being used in areas where sudden changes in the wind direction occur, because high stability is exhibited and little "adjustment energy" is lost to any wind direction or velocity change. Therefore, wind gusts would cause power surges rather than disruptions.

Vertical axis machines have been used intermittently for centuries but have been less applicable to small installations than to large-scale milling operations and water pumping.

Many vertical axis wind machines produce high torque at a low speed. This is useful for operating an irrigation pump but is too slow to directly power an electrical generator. Some wind machines, of both the vertical and horizontal axis varieties, use gearing mechanisms to convert high torque, slow speed rotary motion into low torque, high speed motion sufficient to power an electrical generator. Advancements have recently been made in the development of electrical generators which operate at low speeds.

The two most established types of vertical axis wind machines are the Darrieus hoop rotor and the Savonius rotor (also known as the S-rotor). These are illustrated in Figs. 7-19 and 7-20. 


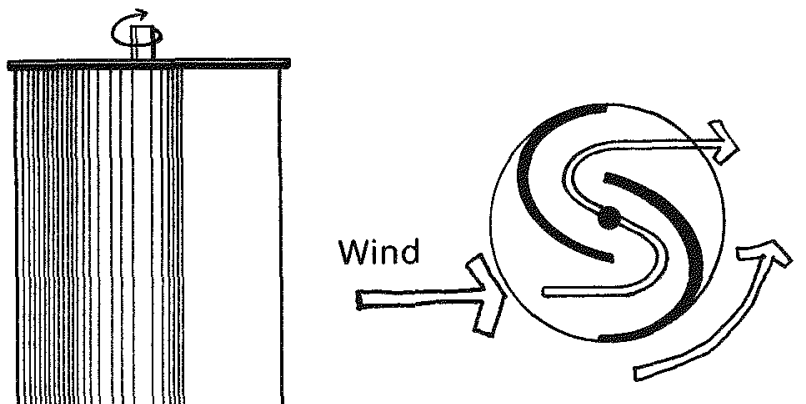

Plan View engineer, S. J. Savonius. This is predominantly a drag device though it does provide some lift. The vanes of the rotor catch the wind, striking the back of the vane and exiting behind the rotor shaft. A single rotor can have more than two vanes, in which case the torque may become more constant and the axial balance more refined. Another configuration accomplishing this result is the stacking of several two vane S-rotors at different angles, along a central shaft. The S-rotor operates at a maximum efficiency of $31 \%$ with a tip speed ratio of 0.8 to 1.8. The S-rotor can be economically built from oil drums cut in half vertically, then welded between end caps to form scoops; these in turn are mounted on a central shaft and the shaft connected to a diaphragm pump or electrical generator.

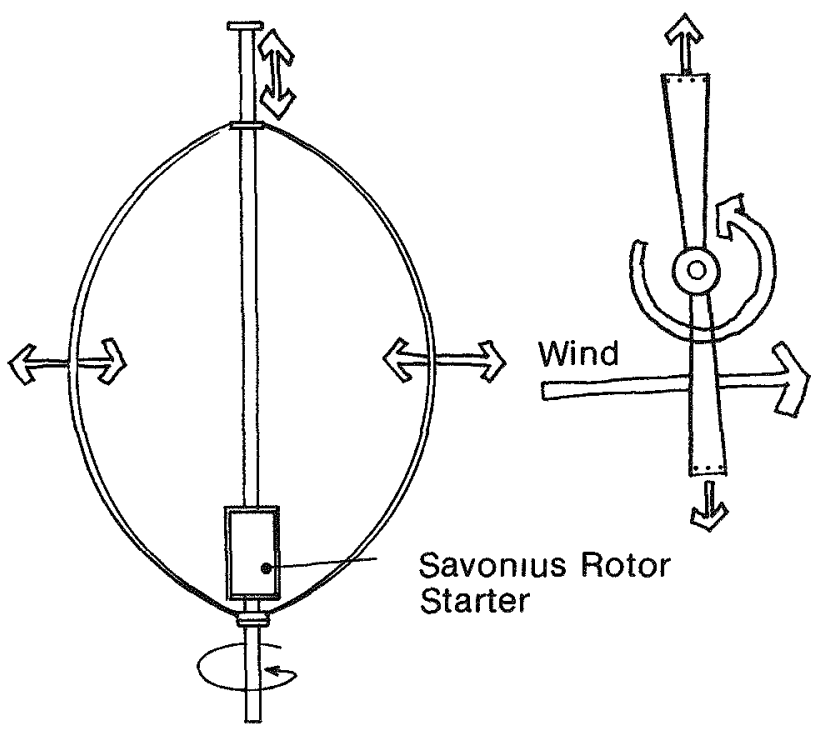

Fig. 7-20. Darrieus hoop rotor Source Rıchard Crowther, Sun/Earth, 1977
The Darrieus hoop rotor was patented in 1931 by the Frenchman, G. J. M. Darrieus. Research has been conducted recently on the rotor by NASA and by the National Research Council of Canada. Both teams have found high potential efficiency in this configuration within a certain windspeed range. The blades of the rotor are flexible and bend in response to the wind. Darrieus rotors are lift devices, which are characterized by curved blades with airfoil cross sections. They have relatively low starting torques, but relatively high tip-to-wind speeds and high power output for a given rotor size, weight, and cost. Usually the rotor needs some type of starter system to initiate its rotation. Frequently, a small S-rotor is mounted at the base of the central shaft to start the Darrieus rotor spinning. Such an addition increases the weight and cost of a system, so tradeoffs between maximum power output, starting efficiency, and cost must be considered in developing an optimum design for a given application. The efficiency of the Darrieus rotor is approximately $35 \%$ with a tip speed ratio of 6 to 8 , depending on the type of rotor. The main advantage of this type of system is its low cost.

\section{ENERGY STORAGE}

One of the main problems facing the use of wind for small-scale electrical generation is the present limited ability to store the energy. Batteries are the most efficient chemical storage system now available, but banks of batteries are costly to install and to maintain. The power generated by a wind machine is not constant enough to guarantee a reliable quantity of electricity or a stable a.c. (al ternating current) frequency. Therefore, most wind generators produce d.c. (direct current) voltage. Electricity in this form is compatible with storage in batteries (see Fig. 7-21), which themselves yield only d.c. voltage. Resistance appliances, such as heaters, toasters, and incandescent light bulbs, can be operated on d.c. current; but most large appliances contain induction motors which will operate only on a.c. It is possible to use an inverter to change d.c. to a.c., al though these devices are quite expensive. Some authorities foresee a possible resumption of the general use of d.c. motors to power large appliances.

Two of the most promising developments for wind energy storage appear to be the flywheel storage system and the electrolysis/hydrogen fuel storage system.

A flywheel, as shown in Fig. 7-22, can store a much higher quantity of energy per mass weight than a battery can. The principle of the flywheel system is that a spinning wheel can store and accumulate energy as momentum and release it for later use. Advances in material technology and low-friction bearings have made the flywheel principle feasible for energy storage. Flywheels can be mounted in a vacuum to decrease air friction. As the mass of a flywheel increases and the speed at the rim increases, there is an increase in the amount of stored energy.

The amount of energy that can be stored in a flywheel is a function of the material from which the flywheel is made, its size and shape, and its speed of rotation. Some heavy materials develop greater internal stresses than lighter materials do at a given speed of rotation. But, lightweight flywheels must be spun faster to store the same amount of energy as the heavy ones. A multi-ring 


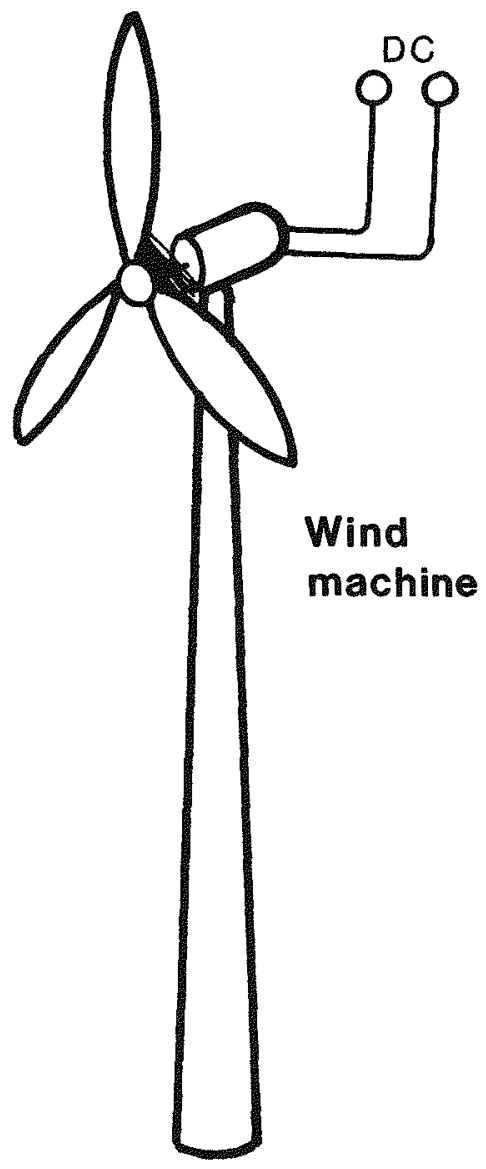

or radial fiber composite material flywheel could store from 30 to 40 times as much energy per pound as a leadacid battery. The flywheel would be attached to a motor/generator unit to recover the energy.

A motor powered by electricity from a wind machine can spin a flywheel and continue to add energy as long as the wind blows. When the wind speed is sufficient to generate continuous electricity, the motor can turn off and the flywheel will continue to spin. When electrical needs could no longer be met directly by the wind generator, the flywheel could then spin its own generator. It is estimated that a flywheel sealed in a partial vacuum and riding on extremely low-friction bearings (possibly magnetic suspension) could store energy for months, though this has not yet been demonstrated.

The electrolysis of water to produce hydrogen and oxygen is another alternative for energy storage, in which electricity generated by the wind machine breaks down the water into its two components, hydrogen and oxygen (Fig. 7-23). These two gases are then stored in tanks for future use. Energy is released as electricity in a hydrogen fuel cell, where the hydrogen and oxygen are recombined in giving off water vapor as they produce electricity.

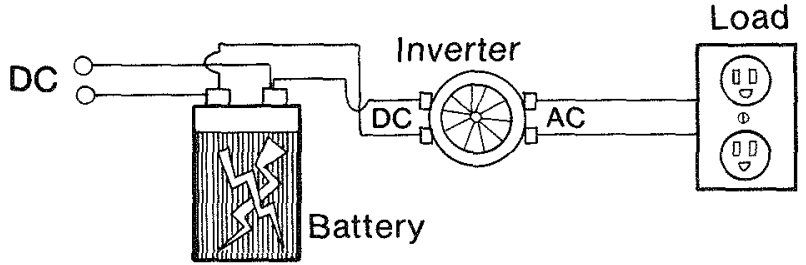

Fig. 7-21. Battery storage system

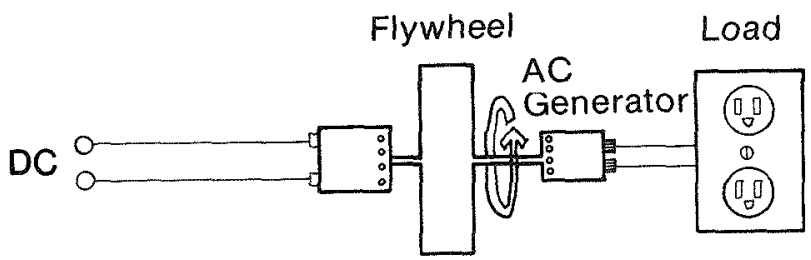

Fig. 7-22. Flywheel storage system

DC

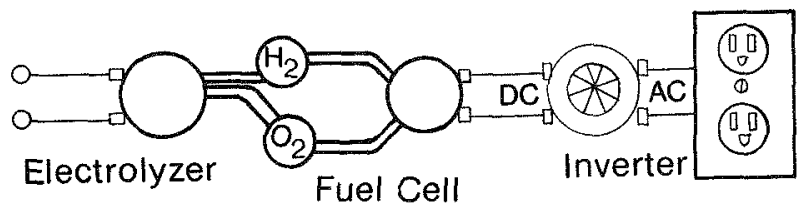

Fig. 7-23. Fuel cell storage system

Source: Richard Crowther, Sun/Earth, 1977

\section{LARGE-SCALE POWER GENERATION}

The use of wind energy is by no means limited to smallscale applications. It is theoretically possible to build wind generators that can deliver several megawat ts of power. There are certain constraints on the size and power output of wind machines because of limitations in the strength of materials, which in turn limit the allowable stresses for blades, bearings, towers, and other components of the system. Cost is also a limiting factor. In certain applications, it may be cheaper to build two small machines rather than one large one of equivalent total output.

The most effective application of wind energy would be to use it directly to pump water for irrigation or to generate electrical power. Wind systems without energy storage could be used in conjunction with a fossil-fuelpowered generating plant to save fuel when the wind is blowing. However, for most applications, energy storage would be required so that uninterrupted power could be delivered. Storage could be accomplished by the use of pumped water systems, compressed fluids, stored electrolytic hydrogen, flywheels, and other forms mentioned above.

Three types of wind machines would be suitable for largescale applications: those having open horizontal axis rotors, open vertical axis rotors, or vortex generators. (Small-scale vortex generators may also be practical in the future.) 
Wind machines with horizontal axis rotors for large-scale applications are similar in form to the ones already discussed for small-scale applications. In a $17 \mathrm{mph}$ $(27 \mathrm{~km} / \mathrm{h})$ wind, a machine with a $59 \mathrm{ft}(18 \mathrm{~m})$ diameter rotor has a rated output of 100 kilowatts $(\mathrm{kW})$. One with a $164 \mathrm{ft}(50 \mathrm{~m})$ diameter rotor is rated at 1 megawatt (MW), and one with a $446 \mathrm{ft}(136 \mathrm{~m})$ diameter rotor is rated at $10 \mathrm{MW}$, but would entail the height of a 45-story building in addition to its mounting height. The safety of life and property in the vicinity of a wind machine of such scale is a primary design consideration. In case of a rotor failure, buffer zones would have to be established in which occupancy is limited. Ultra-large machines could be placed in remote areas or in the ocean, where structural rigidity would not be as critical as on land. Smaller machines could be used near populated areas and possibly arranged in sizable arrays.

Vertical axis wind machines of the Darrieus type could also be used for large-scale applications. In a $17 \mathrm{mph}$ $(27 \mathrm{~km} / \mathrm{h})$ wind, a rotor with a $69 \mathrm{ft}(21 \mathrm{~m})$ diameter rotor has a rated output of $100 \mathrm{~kW}$. One with a $190 \mathrm{ft}(58 \mathrm{~m})$ diameter rotor is rated at $1 \mathrm{MW}$, and one with a $518 \mathrm{ft}$ $(158 \mathrm{~m})$ diameter rotor is rated at $10 \mathrm{MW}$. It is also necessary to take safety precautions and properly locate this type of machine, although sudden wind reorientation is far less a challenge than with horizontal axis turbines.

Another concept in wind machines is the vortex generator. These machines spin the wind to increase the power output of a turbine located in or near the vortex. Two varieties are presently under study. They are the unconfined and confined vortex type. One type employs wing-like structures to deflect the wind and create an unconfined vortex around the turbine. It is estimated that an unconfined vortex generator ean be designed to provide up to six times the power output of a conventional system, with the same diameter rotor.

Grumman Aerospace Corporation is developing a confined vortex system in which the pressure drop across a ducted turbine and the wind velocity through it are augmented by using additional ambient wind to produce a confined tornado-like vortex in a tower located at the exit of the duct. For a typical confined vortex system (Fig. 7-24), the diameter of the tower might be three times the diameter of the turbine. Dr. James Yen of the Grumman Aerospace Corporation estimates that large-scale wind energy systems, which have ducted turbines interconnected to vortex generators, may be designed to have power outputs that are 100 to 1,000 times those of conventional systems, of the same rotor diameter, operating at the same ambient free-flow wind speed.

With these systems, smaller high-speed turbines can be used to obtain the same output power as the large-bladed conventional systems, thus avoiding the large weight and inherent stresses on the blades of the conventional systems.

These concepts can yield significant improvements in the design of wind machines. They indicate that high power output can be derived from relatively small installations, and that the structure needed to deflect the wind can also shroud the turbine, decreasing potential dangers.

The cost of generating electricity with wind-vortex systems can be markedly reduced by incorporating the vortex tower in a multipurpose building.

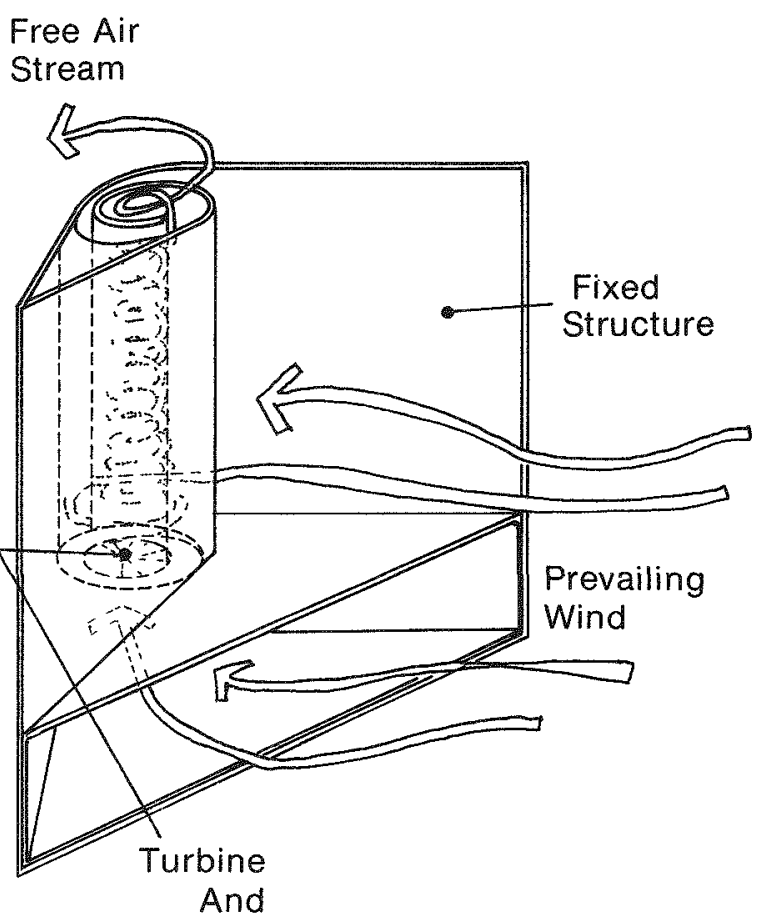

Generator

Fig. 7-24. Confined vortex wind generator Source Richard Crowther, Sun/Earth, 1977

There are a number of additional ways to store the energy produced by large-scale wind machines; most require interconnecting the machines with other systems.

In pumped water storage systems, the wind machines are used in conjunction with a hydroelectric system. Water from below the dam is pumped into storage behind it, using wind power. This can be accomplished with direct mechanical pumping or with electric powered pumps. The water behind the dam flows through turbines, generating electric power, and is retained in a holding basin. The water is then pumped behind the dam again, using wind machines, and the cycle starts over. With this type of system a steady supply of electric power can be supplied.

Although wind machines are among the simplest energy conversion devices, the wind is an unpredictable force. The selection of an optimum site for a wind machine and the choice of optimum designs for particular applications are of ten difficult and complex problems. Much research and development is currently underway on wind machines; undoubtedly innovative designs will continue to emerge. Wind machines, varying with geographical location, appear to have a high potential for making significant contributions to the goal of meeting our future energy needs.

Wind energy is derived from the Sun's energy, and its use has no discernible ill effects on the environment. Harnessing the wind's energy produces no thermal pollution, no air pollution, no radioactivity, and no byproducts which are dangerous to populations. 


\section{OTHER SOLAR OPTIONS:}

\section{PHOTOVOLTAICS}

\section{INTRODUCTION}

Electricity has become a widely used form of energy in the 20th century. In recent times, consumption in the United States has been increasing at about $7 \%$ per year, which is almost double the overall rate of increase in energy consumption. Because of its many advantagesconvenience, versatility, safety, and, at least until recently, low cost-its use is expected to continue to increase. Its drawback is the roundabout way it is generated: heat, usually from the burning of fossil fuels, is used to make steam that drives mechanical engines which activate generators that manufacture electricity. (Concentrating the Sun's rays with mirrors or lenses-a process called solar thermal conversion-is another way of making heat for generating electricity.) However, there is a simpler way: generating electricity directly from sunlight with no inherently energy-wasting steps in between.

\section{SOLAR CELLS}

A solar cell is a device which converts sunlight directly into electricity. Solar cells are made from semiconductor materials (a material having an electrical conductivity intermediate between an insulator such as glass, and a metal such as copper), such as silicon. A typical solar cell contains two very thin layers of silicon with an outside wire attached. In a silicon cell such as the one illustrated in Fig. 7-25, a junction called a pn junction is formed between the p-type silicon and n-type silicon. The p-type is made by replacing a few silicon atoms in the crystal with boron atoms. In the n-type, phosphorus atoms are substituted for silicon a toms. When sunlight strikes a solar cell, electrons are released in the silicon crystal. These electrons then migrate to the electrode in the n-layer. Simultaneously, the holes created by this energy transfer migrate toward the player. A flow of current from the $n$ to $p$ electrodes is thereby created through the external circuit.

\section{SOLAR MODULES}

Solar cell modules are the basic building blocks of solar electric power systems. These modules are made by interconnec ting solar cells in series-parallel combinations to deliver power at a desired voltage. It takes 40 cells connected in series to charge a 12-volt lead-acid battery. When solar cells are connected in series, the total voltage equals the sum of the solar cell voltages, while the current remains equal to the current from a

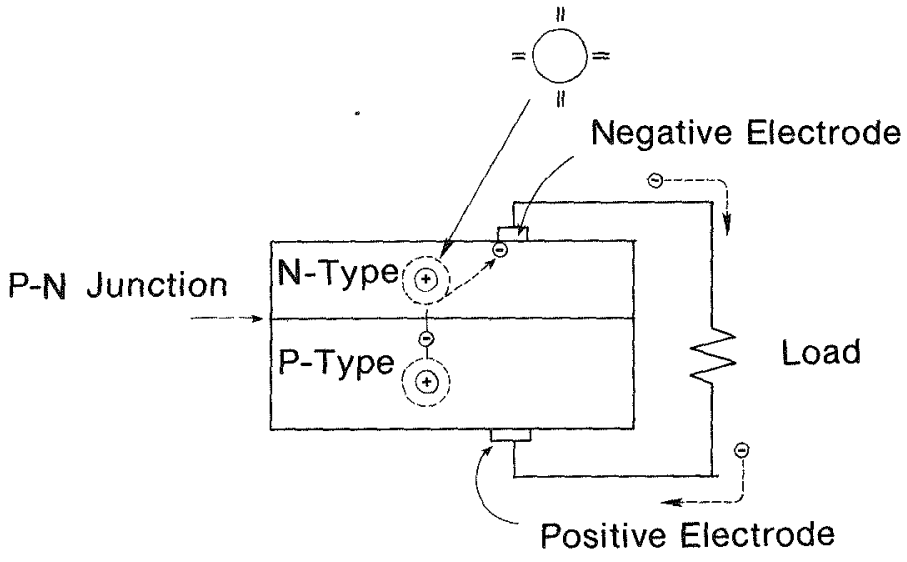

Fig. 7-25. Schematic diagram of the photovoltaic process in a silicon cell

single cell. When solar cells are connected in parallel, the total current equals the sum of the solar cell currents, while the voltage remains equal to the voltage from a single cell.

\section{POWER SYSTEMS}

Virtually any power output can be supplied by combining solar modules into a solar array. A regula tor is needed to control the voltage and also to direct it to a storage battery, if one is required. Since solar cells generate d.c. electrical energy, a power conditioner is necessary to convert it to a.c. power to make solar electricity compatible with the existing distribution system in the United States. A solar array is rated in peak power, which is the wattage it delivers at noon on a clear day.

\section{PHOTOVOLTAIC APPLICATIONS}

Solar arrays have been fabricated for a wide variety of applications where power requirements are relatively modest. Solar arrays provide the $15 \mathrm{~kW}$ needed to operate the transmitter at a daytime, AM radio station in Ohio. Two U.S. Forest Service lookout towers in Calif ornia have all their electrical power supplied by PV arrays, which produce $294 \mathrm{~W}$ each. On an 80 -acre farm in Nebraska, a photovoltaic power system provides $25 \mathrm{~kW}$ used for irrigation, crop drying, and fertilizer 
manufacturing. And in the Papago Indian village of Schuchuli, Arizona, the world's first village PV power system supplies $3.5 \mathrm{~kW}$ for needs selected by the residents: 15 refrigerators, a communal washing machine and a sewing machine, an electric water pump, and 47 fluores cent lights for the village's 15 homes, feast house, church, and community building. The world's largest system currently is a $60 \mathrm{~kW}$ facility at $\mathrm{Mt}$. Laguna Air Force Station in California. Systems capable of supplying up to $350 \mathrm{~kW}$ are in the planning stages.

In the future, solar cells may generate electricity in central power plants in a utility network or for individual homes or buildings. A $20 \times 30-\mathrm{ft}$ panel of solar cells, operating at $10 \%$ efficiency and with a peak output of 5,000 watts at midday in the northeastern United States, would yield an average of more than 1,000 watts over the entire year. This is more than enough to meet the electrical power needs of the average house. For larger houses, the area of the panels could be correspondingly increased. However, it will probably not be economically attractive to store electricity on a large scale to provide power during periods of darkness or when power demand exceeds the capacity of the solar cells. Consequently, a backup source of electricity would be needed.

\section{ECONOMICS}

Despite the promise of electricity generated by solar cells, economics remain a serious barrier to its more widespread use. In 1976, solar cell modules suitable for use on land were priced at $\$ 15$ to $\$ 20$ per peak watt. This is substantially lower than the $\$ 80$ price in the space program, where higher quality control standards are necessary, because land-based equipment can be maintained periodically and repaired when necessary.

At $\$ 15$ to $\$ 20$, a $20 \times 30-\mathrm{ft}$ panel of solar cells would cost $\$ 75,000$ to $\$ 100,000$, but these costs have already been reduced drastically, and cells for residential purposes may be economical by the mid-1980s. While initial costs are high, operating costs for solar electric systems would be relatively low. There would be no fuel bills, and the cells have a high potential for reliability and long life. Maintenance requirements are extremely low-rain, for example, helps take care of cleaning the solar cell surfaces.

Solar cells are expensive because their fabrication is largely a handcrafting process. A single crystal of extremely pure silicon is artificially grown in the form of an ingot; wafers cut from the ingot are polished and trimmed; the impurities are diffused into the silicon in an oven; electrical connections are added, and the finished cells are mounted in arrays. Some improvements have already been made in manufacturing methods and quality control, and the outlook seems good for further progress.

It has been found that silicon cells will inerease current output with increased levels of solar intensity without serious deterioration from the greater internal heat generation. So it appears that one of the more promising solutions to reducing the cost of photovoltaic applications is to replace some of the expensive semiconductor area with reflectors that increase the amount of sunlight striking the cell. If the heat generated by a photovol taic array were then used, rather than being discarded into the atmosphere, chances are far greater that it will become a cost-effective application.

\section{FUTURE PROSPECTS}

The goal of DOE's program in photovoltaic conversion is to solve the technical and economic problems standing in the way of widespread use of solar cells. For remote applications of 10 to 100 watts, they are already economically competitive. The cost of cells presently being marketed ranges from $\$ 8$ to $\$ 15$ per peak watt. Larger seale applications will require much lower prices. DOE's eff orts are aimed at bringing the price of solar cells down to $\$ 0.70$ per peak watt by the mid1980s. At this price, electricity from solar cells might well make a substantial contribution to meeting the nation's energy needs, especially since the cost of present methods of generating energy will probably also be rising. 


\section{OTHER SOLAR OPTONS:}

\section{BIOMASS}

\section{INTRODUCTION}

The use of biomass for energy is not a new idea. In the mid-1800s wood supplied over $90 \%$ of our energy needs; and, as late as 1940,20\% of the homes in the United States used wood for space heating. In the past several years, homeowners have shown a renewed interest in using woodburning stoves to supplement or replace conventional space heating systems; it is estimated that in Maine alone about $40 \%$ of the homes use woodstoves.

Today, several industries and utilities are using biomass to supply about 1.4 quads of energy a year for electricity, process heat, and space conditioning. Since the total national consumption of all forms of energy resources is 75 quads, this means biomass already provides almost $2 \%$ of the U.S. needs. One quad of energy equals a quadrillion $\left(10^{15}\right) \mathrm{Btu}$, or enough energy to heat 500,000 homes for 20 years.

The use of biomass holds much promise for the future. The world now produces billions of tons of biomass each year. Al though not all of this resource can be used for energy production, enough may be available to supply several additional quads of the nation's yearly energy by the end of this century. The great diversity of sources, conversion processes, and end products makes biomass a highly flexible energy option for industry, agriculture, utilities, and the homeowner. (See Table 7-7.)

\section{FARMS AND FORESTS: TODAY'S ENERGY RESOURCE}

Every day a valuable resource is thrown away. The forest products industry, the agricultural and food processing industries, and municipalities dispose of tons of biomass that could be used to produce energy. Most biomass now available for energy is material left over from other processes and falls into one of two categories: wastes or residues.

Wastes are byproducts of various manufacturing processes. For instance, wood shavings and scrap from making furniture are wastes. They are produced mostly by the forest products industry, agricultural processes, and municipalities. Other examples of wastes from different processes are:

\section{Forest Produets}

Sawdust

Bark

Paper pulp

Wood shavings

Scrap lumber

Wood dust

Paper

Table 7-7. ENERGY OPTIONS FROM BIOMASS

\begin{tabular}{llll}
\hline Energy Consum er & Energy Product & $\begin{array}{c}\text { Example of } \\
\text { Resources Used }\end{array}$ & $\begin{array}{c}\text { Example of } \\
\text { Conversion Process }\end{array}$ \\
\hline $\begin{array}{l}\text { Paper and Lumber Com- } \\
\text { panies }\end{array}$ & Steam, Electricity, Heat & $\begin{array}{l}\text { Forest residues, slash, } \\
\text { sawdust, bark }\end{array}$ & $\begin{array}{l}\text { Direct combustion, } \\
\text { Gasification, } \\
\text { Pyrolysis }\end{array}$ \\
\hline $\begin{array}{lll}\text { Municipalities } \\
\text { Homeowners, Space }\end{array}$ & Electric power and gas & $\begin{array}{l}\text { Wood wastes, sewage, solid } \\
\text { municipal waste }\end{array}$ & $\begin{array}{c}\text { Anaerobic digestion } \\
\text { Gasification }\end{array}$ \\
\hline $\begin{array}{lll}\text { Heating Users } \\
\text { Cars, Trucks }\end{array}$ & Heat & Wood, biomass residues & $\begin{array}{l}\text { Direct combustion } \\
\text { in wood stoves }\end{array}$ \\
\hline Utilities & Gasohol & Agricultural surplus & Fermentation \\
\hline
\end{tabular}


Agricul tural and Food Processing

Fruit pi ts

Citrus skins

Walnut shells

Rice hulls

Corn cobs

Manures

Sugarcane bagasse

Sugar beet refuse

Municipal

Sewage

Solid wastes

Residues are another source of biomass. Forest and agricultural harvesting operations leave residues that are available for conversion to energy. An example of a residue is the woody material or "slash" left in the forest after cutting and harvesting operations. Some other residues are:

\section{Forest}

Noncommercial timber

Diseased trees

Slash

\section{Agricul tural \\ Straw from: \\ rice \\ wheat \\ barley \\ oats \\ Corn stalks}

Wastes and residues are available for energy today, but the contribution that biomass can make to our national energy requirements will not depend entirely on the amount that can be collected. Biomass cannot be used for energy until it can be converted at a cost which will make it competitive with conventional fuels.

\section{THE CONVRRSION PROCESS}

Fortunately, a wide variety of methods can be used to convert available biomass wastes and residues into energy. Conversion techniques range from relatively simple to quite complex. Basically, there are two types of biomass energy (bioenergy) conversion processes:

- Thermochemical conversion

- Biological conversion

\section{Thermochemical Conversion}

The thermochemical conversion process uses heat (sometimes in the absence of air) to produce chemical reactions in biomass. Examples of such conversions include:

- Direct combustion

- Gasification

- Pyrolysis

\section{Direct Combustion}

This is the simplest and best developed biomass conversion process. Forest and agricultural wastes and residues can be burned to produce steam, electricity, or heat.

Wood and lumbermill wastes have been used suceessfully in boilers for process steam and electricity production for some time. It has been estimated that the forest products industry uses biomass to supply at least 1.I quads, or about $45 \%$, of its total energy needs per year. This industry has the potential to become virtually energy self-sufficient by using more of the biomass already available to it.

Other industries, such as textiles and paper products, that require heat in the preparation and treatment process of goods can also use the direct combustion conversion process. Hot water, steam, and hot air are required for many manufacturing processes; and a large percentage of this energy could be supplied by direct combustion.

Another use of direct combustion is in woodburning stoves. Woodstoves can meet all or part of the heating needs in a carefully designed and well-insulated building.

\section{Gasification}

Gasification is another bioenergy conversion process. This process releases bioenergy by heating wastes in limited amounts of air or oxygen. Forest wastes and wastes from food processing operations can be converted by this process. Gasification can produce synthetic natural gas (SNG), methanol, ammonia, hydrogen, carbon monoxide, or synthetic gasoline.

Sawmills and wood products manufacturing plants can use their wastes to generate gas for use in natural gas-fired kilns and for electricity generation.

Wastes such as corn cobs, fruit pits, walnut shells, and rice hulls can also be used to produce low- or medium-Btu gas. Normally, wastes create disposal problems; but, if used in the gasification process, wastes can be converted to a valuable energy resource for the food products industry. Also, some agricultural processing facilities such as cotton gins and feed processing plants produce wastes that can be gasified.

\section{Pyrolysis}

The pyrolysis process also breaks down biomass with heat but in the absence of oxygen and at a lower temperature than is required for gasification. The biomass resources used in this process include manure, agricultural and wood wastes, papermill wastes, and municipal solid wastes. Pyrolysis yields oil, charcoal, and synthetic gas.

Industries that produce biomass wastes can use the pyrolysis process. In addition, pyrolysis may be a good method of converting municipal solid wastes (after removal of inorganic materials) to usable fuels. 


\section{Cogeneration}

Cogeneration is not a biomass conversion process, but a way of using a conversion process to simultaneously produce electricity and process heat. For example, a sugar processing plant can use its own wastes to produce both electricity to operate plant machinery and steam for various heating and evaporating processes. Industrial use of cogeneration can reduce fossil fuel requirements and provide significant cost savings for the user.

\section{Biological Conversion}

Biological conversion (bioconversion) is a chemical reaction caused by treating biomass with enzymes, fungi, or micro-organisms. These conversion techniques produce either liquid or solid fuels. Two processes are used today:

- Anaerobic digestion

- Fermentation

\section{Annerobic Digestion}

This bioconversion process is the controlled decay of organic material in the absence of oxygen. Manures, agricul tural wastes, sewage, paper, seaweed, and algae all can be converted to produce methane gas.

Sewage treatment plants have used anaerobic digestion for many years to generate methane gas. With natural gas prices on the rise, large-scale anaerobic digesters at sewage treatment plants will become more economically attractive in some urban areas.

Since World War II, small-scale digesters have been used on farms, primarily in Europe and Asia. Recent estimates indicate that thousands of small biogas facilities in Korea and perhaps one-half million units in China are used today. Many U.S. farms have biomass available and could use small-scale digesters to supply valuable onsi te energy.

Any appliance or utility that uses natural gas could use synthetic methane gas instead. The average U.S. citizen uses about $60 \mathrm{cu} \mathrm{ft}(1.7 \mathrm{cu} \mathrm{m})$ of natural gas per day; the methane equivalent could be had from $20 \mathrm{lb}(9.07 \mathrm{~kg})$ of horse manure or $10 \mathrm{lb}(4.54 \mathrm{~kg})$ of chicken or pig manure.

\section{Fermentation}

This is a well-established process in which carbohydrates (such as sugar in the form of sugar cane juice, molasses, and other cellulosic materials) are fermented and distilled to produce ethyl alcohol (ethanol).

A mixture of $10 \%$ ethanol and $90 \%$ gasoline (known as gasohol) is usable in any internal combustion engine without modification to the carburetor. The gasohol now being widely used is made primarily from grain in conventional distilleries, using methods originally developed for beverage alcohols. This use of biomass could lessen our dependence on imported oil.

\section{BIOMASS AT WORK TODAY}

Al though bioenergy is mainly used by the forest products industry to provide steam, there is no reason why its use has to be limited to this industrial application. Manufacturers, homeowners, utilities, and food processors are showing an increasing interest in biomass as an energy source; and they all have the capacity to increase their use of this resource. Bioenergy is technically and economically ready today for numerous applications. The following facilities are examples of biomass conversion processes at work.*

\section{A Manufaeturer}

A company in Sheboygan, Wisconsin, that produces and distributes wooden parts for the automotive, toy, and furniture industries has a $91,000 \mathrm{sq} \mathrm{ft}(8,454 \mathrm{sq} \mathrm{m})$ manufacturing plant and warehouse heated by burning surplus materials. Particleboard and hardwood scraps are burned in a recently developed incinerator that uses the pyrolysis conversion process (Fig. 7-26).

Pyrolytic conversion takes place in two distinct steps. First, a mechanical loader feeds residue material into a pyrolysis chamber where gasification takes place. Combustible gases in the chamber pass to a thermal reactor where they are ignited and completely burned. The resulting hot gases are then passed through a boiler where heat is given up to produce steam for the plant's heating system.

The system's capital costs totaled $\$ 100,000$, and initial indications are that it will pay for itself within 2 years. The company will save $\$ 18,000$ each year on scrap disposal and $\$ 45,000$ annually by not having to buy fuel.

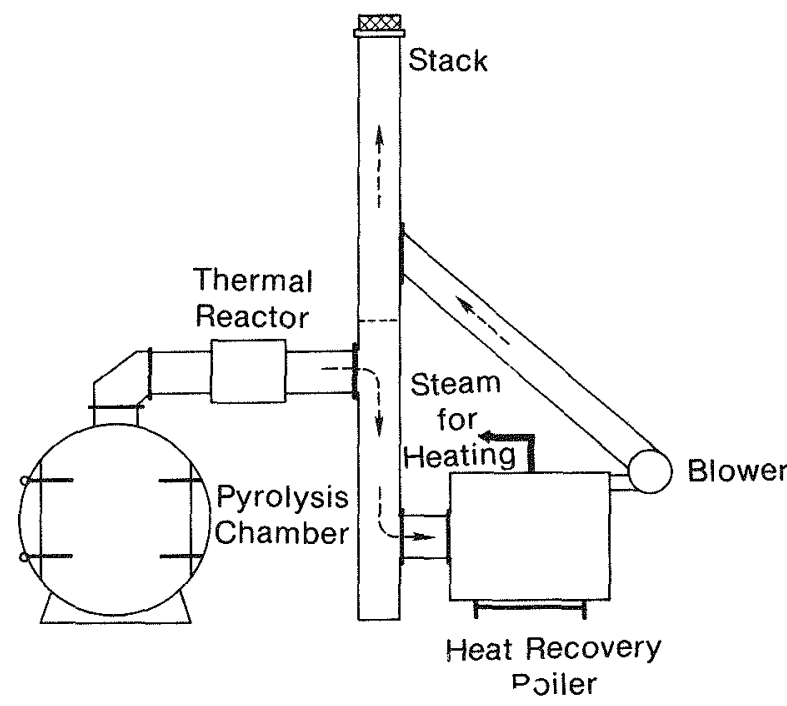

Fig. 7-26. Pyrolytic incinerator with heat recovery boiler

\footnotetext{
*Taken from U.S. Department of Energy, "Biomass Energy Success Stories-A Portfolio Illustrating Current Economic Uses of Renewable Biomass Energy," HCP/TO285-01, March 1978.
} 


\section{A Residence}

A $1,600 \mathrm{sq} \mathrm{ft}$ (148 sq $\mathrm{m}$ ) home in northern Minnesota is heated entirely by a small airtight woodstove burning a mixture of birch and aspen logs. Careful design allows heat to be distributed throughout the house without using ductwork or fans. The system has performed well over several winters, maintaining average temperatures of 70 to $75 \mathrm{~F}\left(21-24^{\circ} \mathrm{C}\right)$ throughout the house. Energy conservation measures were taken to increase the efficiency of the woodstove.

The heating system's cost was extremely low- $\$ 50$ for structural reinforcement around the air circulation holes and less than $\$ 200$ for the woodstove. Four cords of mixed aspen and birch (at $\$ 23$ per cord) are required annually to heat the house and an adjacent shop (Fig. 7-27).

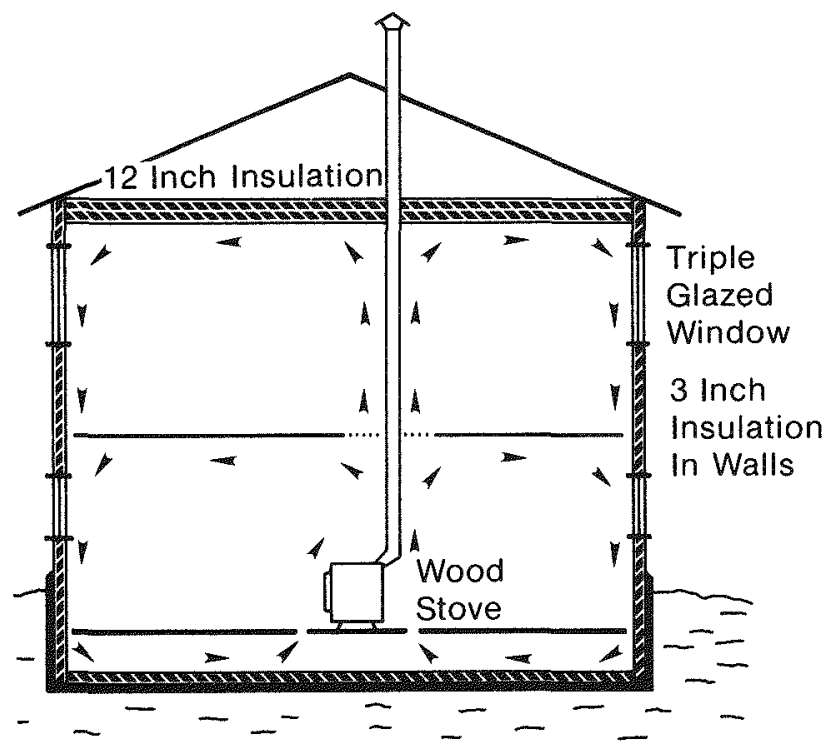

Fig. 7-27. Heat distribution by natural convection in a Minnesota house heated with a woodburning stove

\section{A Utility}

The city of Eugene, Oregon, with a population of 175,000 , owns water, steam, and electric power utilities. Elec tric power is supplied by three hydroelectric plants of 128 megawatt total capacity, plus a steam-electric plant generating 33.8 megawatts. This latter plant is fueled with surplus forest residues from the surrounding area. The plant also supplies steam heat service to a business district, a large hospital, a college campus, a large cannery, and a 16 -acre $(0.065 \mathrm{sq} \mathrm{km})$ greenhouse complex, all located within a 2-sq $\mathrm{m}(5.18 \mathrm{sq} \mathrm{km})$ area.

Assembled between 1931 and 1951 , the power plant houses three boilers with a combined steam generating capacity of $450,000 \mathrm{lb} / \mathrm{hr}(204,120 \mathrm{~kg} / \mathrm{hr})$. The wood residues, mostly bark, are delivered by truck to an outdoor storage pile from" nearby wood products mills.
Under normal conditions, the utility is operated yearround. During 8 months of the year, the balance of the steam capacity is used to generate electric power; the plant is on standby for electric power for the remaining 4 months (Fig. 7-28).

By using surplus forest residues for fuel, there has been a substantial savings over using oil. The operation of the plant has proven very successful from a utility standpoint. At the same time, it reduces air pollution and contributes to the solution of wood residue disposal problems in the Eugene area.

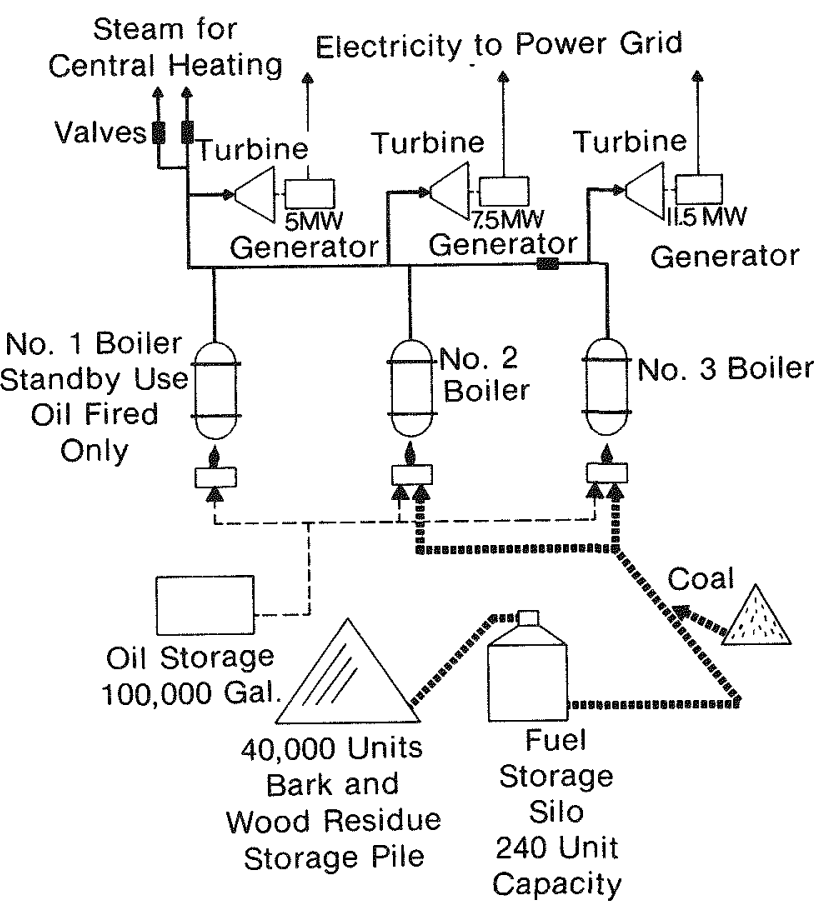

Fig. 7-28. Simplified diagram for the Eugene Water and Electric Board heating and electric utility

\section{Agricultural Processing Plant}

An Oahu, Hawaii, sugar company produces energy from sugarcane wastes to cogenerate low-pressure steam and electricity. The steam is used in various heating and evaporating processes in the sugar mill, and the electricity is used to operate plant machinery and drive large irrigation pumps. Internally generated electricity accounts for $75 \%$ of the electric power consumed annually by the mill (Fig. 7-29).

The sugar cane is cleaned and pressed to extract its juices and the remaining fiber (bagasse) is conveyed to the power plant where it is used to fire steam boilers for the cogeneration process.

Based on a cost of $\$ 0.03 / \mathrm{kWh}$ for purchased electricity, the value of bagasse burned would amount to $\$ 3.6$ million annually. These costs can be expected to remain 


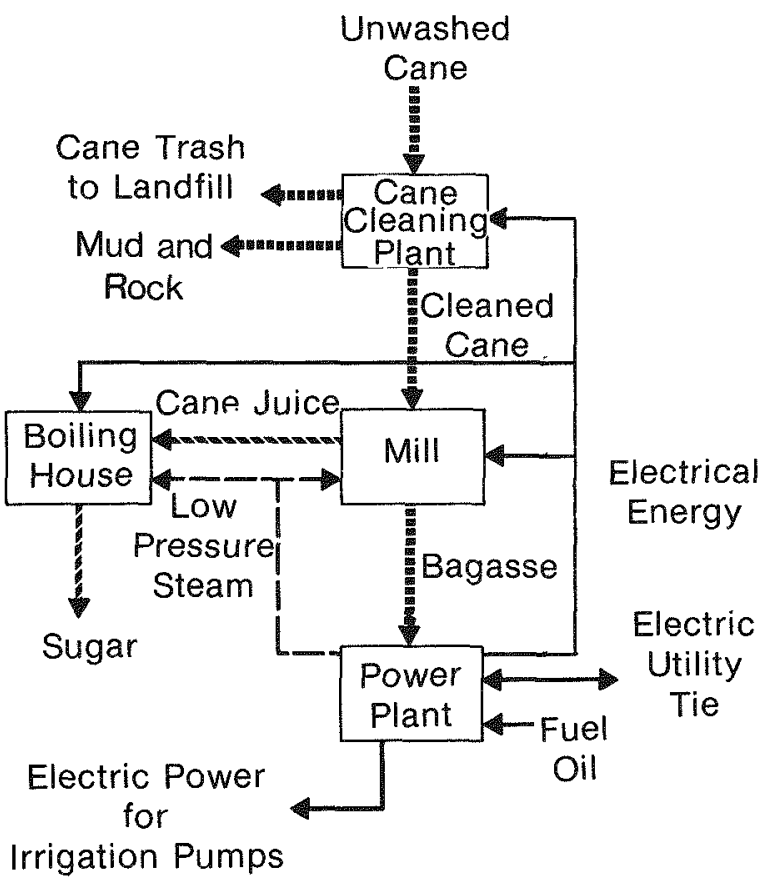

Fig. 7-29. Flow of material and energy at the Oahu Sugar Company

relatively stable compared to the rapidly escalating cost of petroleum-derived electricity in Hawaii. The energy from bagasse has helped the sugar industry in Hawaii to survive despite depressed sugar prices and rising petroleum costs.

\section{BENERTRS FROM BIOMASS}

Although certain technical and institutional conditions are limiting the extensive use of some biomass conversion processes, other processes are ready to use now. Whatever the stage of development, using biomass offers us many benefits. Among these are:

- There is a great deal of biomass, both in terms of current wastes and potential energy crops.

- It is a renewable and nondepleting resource if properly managed.

- Some uses of residues and wastes could lessen environmental problems. Wood wastes, garbage, and agricul tural residues are frequently burned or used in landfills; they could instead be used to produce energy with an environmental benefit. Using logging residues to produce energy can also reduce fire hazard, tree disease, and insect infestation.

- Biomass is safer and cleaner than several other energy sources. Organic waste is typically sulfur-free, and air emissions can be lower in biomass combustion systems than in systems that use some conventional fuels. Furthermore, biomass conversion does not carry the risks of spent fuel disposal or oil tanker spillage.
- It competes economically today in some applications (forest products and food processing) and makes a significant contribution to the national energy budget.

- Certain biomass conversion processes are highly efficient. In most cases, it is more economical to use residues onsite for electricity production even on a small-scale than to transport coal from the mine to the generating plant.

- It is a flexible resource because of its variety of sources, conversion processes, and energy endproducts.

\section{FOR THE FUTURE}

\section{Growing Our Fuel}

Biomass wastes and residues are abundant today, but there is a need to investigate methods of renewing biomass resources for the future. The concept of growing crops specifically cultivated for their high energy yield per acre and short growth cycles is being explored. Four types of energy farms are presently being studied:

- The cultivation of trees (silvicul ture) for the specific purpose of fuel production. These farms would contain trees which grow quickly and are planted in closely spaced rows. The time from planting to harvest would be about 4 to 7 years.

- Agricultural energy farms to cultivate crops such as corn, wheat, sugarcane, and grasses for conversion to fuels.

- Fresh water energy farms to grow various algae, duckweed, and water hyacinth for their fuel value.

- Marine energy farms to produce food, fuel, and material for bioenergy conversion processes. The development of certain marine plants, such as the giant Calif ornia kelp, is being studied intensively.

\section{GASOHOL}

Gasohol is probably the most familiar "clean fuel from biomass." Although methanol (known as "wood alcohol," and carrying warnings against crinking) and ethanol ("grain alcohol," the beverage alcohol) were widely used for fuels in the last century, low-cost oil relegated them to premium uses such as cooking (familiar as Sterno or for fondue pots) and on the auto race track where high performance is more critical than cost.

Now that oil costs are rising, we may turn back to these clean fuels. Ethanol from grain starch and sugars now costs about $\$ 1.20$ per gallon (bulk), and methanol from wood or residues is estimated to cost from $\$ 0.50$ to $\$ 1.35$ per gallon, depending on the size of the plant and cost of the material used for the conversion process. Since the alcohols have never been produced as fuels, these prices can be expected to drop as production increases and the technology is improved. 


\section{CONCLUSION}

Biofuels can only become more widely used as they become more competitive with conventional energy sources. This competitiveness includes not only the costs connected with transportation and the conversion process but also issues involving resource availability and al ternative uses for the resources (such as fertilizers and animal feeds). Some of these issues are:

- Although data are limited on the economics of all biomass conversion processes, enough is known so that several biomass applications are now competitive with conventional energy sources. Direct combustion and gasification (in some applications) are two such processes. The costs of these are comparable to or less than the costs of some conventional fuels in many uses.
- As with any energy option, environmental effects must be carefully investigated to ensure the intelligent use and management of the biomass resource. Overuse of this resource could affect its future availability and have a detrimental effect on the quality of our soil, air, and water.

- Finally, new technologies sometimes require changes in attitude and conventional practices. Present industrial fuel users may be comfortable with the convenience of conventional fuels even with recent price increases. These factors may keep them from thoroughly investigating other sources of renewable energy such as biomass.

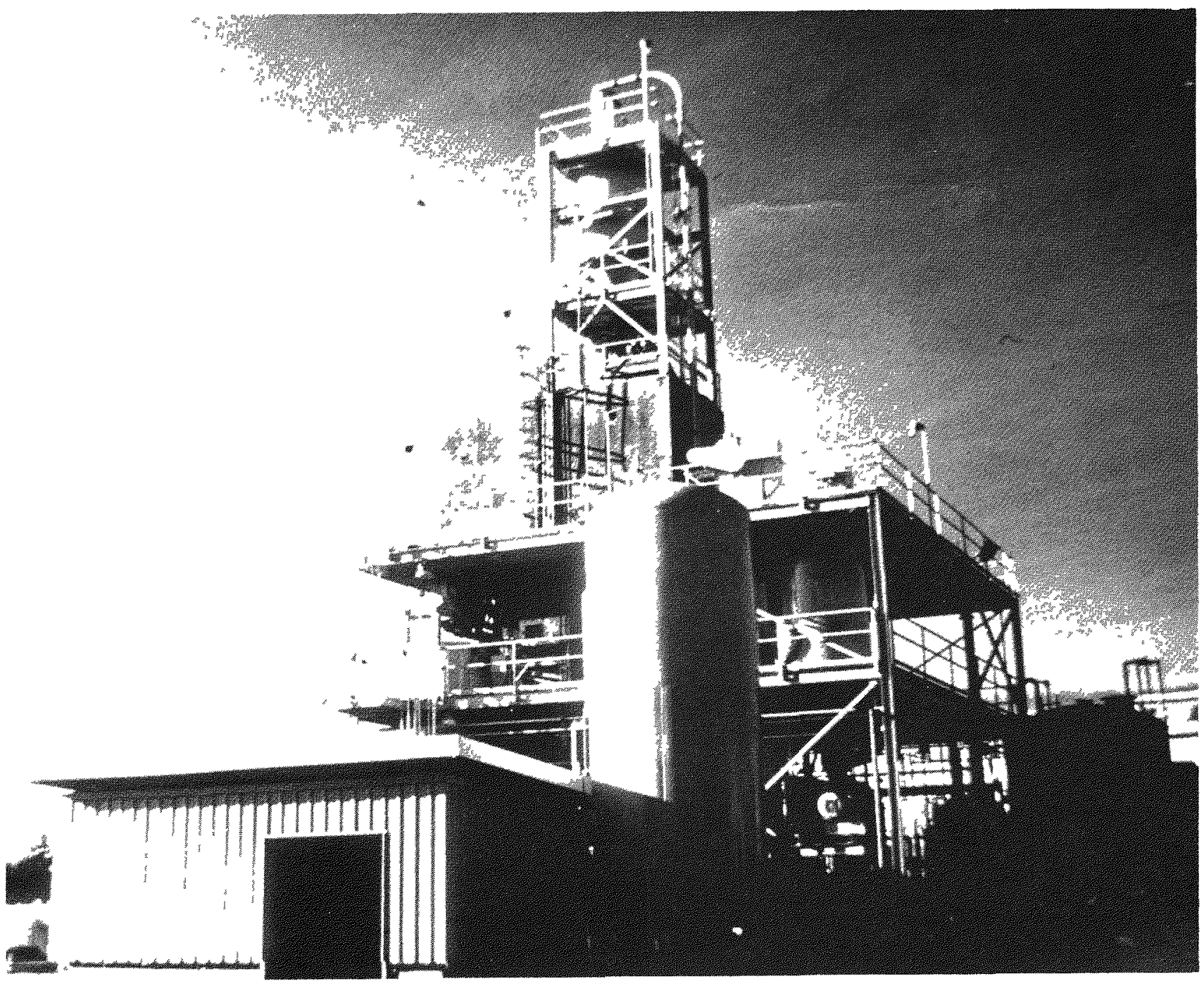

Fig. 7-30. An Albany, Oregon, plant uses biomass. 
Section II.

Solar System Evaluation 


\section{cotrintis}

\section{Chapter}

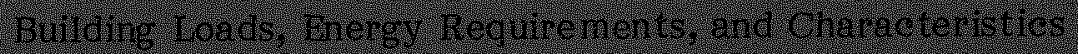

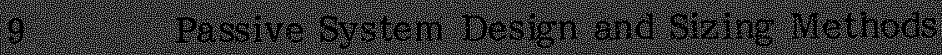

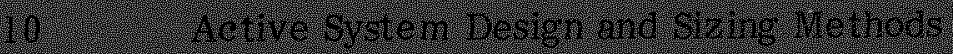

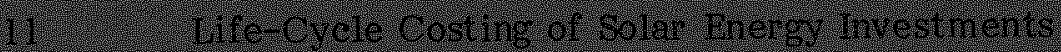

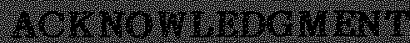

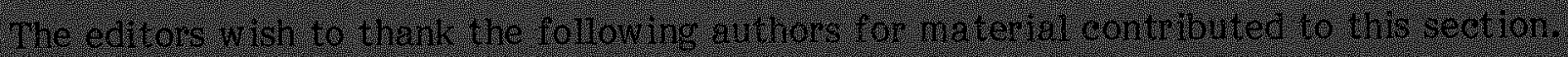

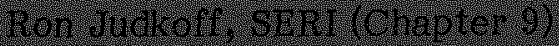

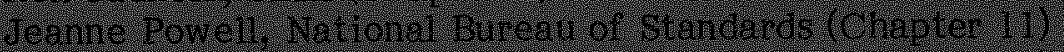

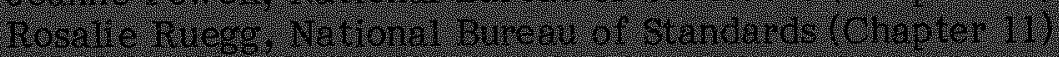

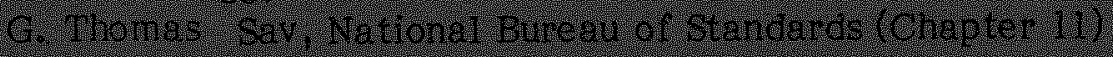

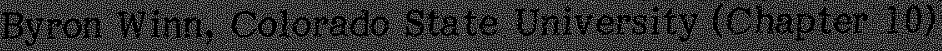


8

Building Loads, Energy Requirements, and Characteristics 
8. Building Loads, Energy Requirements, and Characteristics

Effect of building thermal load characteristics on solar system performance Determination of monthly and annual building loads

Building energy requirements 


\section{BULLDING LOADS, ENERGY REQUIREMENTS, AND CHARACTERISTICS}

\section{INTRODUCTION}

As opposed to design heating or cooling load calculations based on steady-state, peak load conditions, solar system design and component selection must be based on annual system performance. This annual performance can be predicted by use of correlations based on either the monthly or annual energy demand of the building thermal load. In the collector sizing and performance determination procedures that follow (Chapters 9 and 10), both monthly and annual building heating and cooling demands (those imposed on the building plant) must be known. These space conditioning demands, besides being influenced by the weather, are also influenced by the building envelope, internal loads, and the operation of the HVAC system.

In the cases where hourly solar system simulation computer programs are used, the hourly space and Building Service Hot Water (BSHW) loads are usually calculated in the program itself. These internally calculated loads are then used as input to the solar system simulation. If the solar simulation program does not generate its own loads, any of the computer dynamic energy analysis programs (see below) can be used to generate the hourly loads required as input.

\section{EFFECT OF BUILDING THERMAL LOAD CHARACTER- ISTICS ON SOLAR SYSTEM PERFORMANCE}

Because the building thermal load, in conjunction with the storage characteristics, influences the temperature of the fluid in the collectors, the seasonal load variations strongly influence annual system performance. Furthermore, the performance of particular types of solar systems (BSHW, space heating, space cooling, heat pump, or combination thereof) is strongly influenced by the building thermal load.

Because monthly BSHW loads are relatively uniform, properly sized BSHW systems can operate effectively despite monthly weather and insolation fluctuations. Furthermore, because BSHW collector systems can preheat the supply water, there is no month when they are rendered inoperative by low collector temperatures. Because of their fairly uniform monthly loads, such systems should be designed to operate effectively at collector temperatures of approximately 120 to $130 \mathrm{~F}$ $\left(50-54^{\circ} \mathrm{C}\right)$ year-round.
Likewise, combined space heating and cooling systems must meet a fairly uniform monthly load and can be used effectively year-round. During the winter heating season, collector temperatures of approximately $170 \mathrm{~F}$ $\left(77^{\circ} \mathrm{C}\right)$ are needed for conventional duct heating coils $\left[150 \mathrm{~F}\left(66^{\circ} \mathrm{C}\right)\right.$ inlet temperature], although heating coils that use from 120 to $140 \mathrm{~F}\left(50-60^{\circ} \mathrm{C}\right)$ inlet water could be selected to improve collector efficiency. During the summer cooling season, 180 to $210 \mathrm{~F}\left(82-99^{\circ} \mathrm{C}\right)$ collector temperatures are needed to drive absorption chillers.

Because of their fairly uniform load characteristics throughout the year, the performance of BSHW systems and combined heating and cooling systems can be predicted using annual load parameters.

On the other hand, the size of space heating or combined space and water heating systems is based on winter heating loads, so the collectors are oversized for the summer months. This requires dumping of excess heat during the summer and the mild spring and fall seasons when both heating and cooling loads are minimal. For such systems, weather and insolation fluctuations are important in winter but not in summer. This fact, coupled with the varying length of the heating season with location, requires that the performance of these systems be predicted using monthly load parameters.

\section{DETERMINATION OF MONTHLY AND ANNUAL BUIEDING LOADS}

Load models at two basic levels of sophistication and accuracy are recommended, depending on the design phase involved and the analytical tools available.

Steady-state models are moderately accurate in that they are based on daily or monthly average weather and insolation data. Transient models, which account for hourly data variations, are more accurate, but they require more detailed input in their use. Hcrrly calculations account for the variation in solar loadi:' varying occupant and equipment schedules, and th: thermal capacity of the building and its contents, the effects of which are averaged in daily or monthly calculations. Because capacitance can introduce time lags in the heating or cooling loads on the HVAC system, it must be accounted for if the energy consumption calculation is to be accurate. This is especially true if thermal storage tanks are available to redistribute the loads. Transient effects often are important, resulting in reduced loads and possible changes in operating techniques. 
The two basic model levels are described below. The load imposed on the heating and cooling coils is always the end computation goal.

\section{Steady-State Models}

During the conceptual design phase, when only estimates of solar system performance, size, and fuel savings are needed, a steady-state load model may be used. Unfortunately, the simplest method, the modified degreeday procedure [1], is restricted to small, single-story, envelope-dominated structures. For larger commercial or industrial buildings, where internal cooling-only zones are prevalent, the bin method [1] should be used. These steady-state calculative procedures are unable to account for energy requirements of HVAC systems employing reheat, mixing boxes, and other central HVAC equipment providing for individual room control [2].

The Cooling Degree-Days and Equivalent Full-Load Hours [1] procedures, applicable to residences only, are not recommended because there have been insufficient verification data to enable use of either method with any confidence [3].

\section{Modified Degree-Day Procedure}

Space heating loads in envelope-dominated structures, without internal-heating-only zones, can be estimated using the traditional degree-day procedure [1] Residences and warehouses are in this category. This procedure assumes that the steady-state heat loss or building heat load, $\mathrm{Q}_{\text {, }}$, is proportional to the equivalent heat loss coefficient ( $\mathrm{t} A$ factor) of the building envelope; that is

$$
\mathrm{Q}_{\mathrm{L}}=(\mathrm{UA})\left(\mathrm{T}_{\mathrm{B}}-\mathrm{T}_{\mathrm{A}}\right),
$$

where $T_{B}$ is the building temperature (reduced to account for internal heat generation and called the base temperature) and $\mathrm{T}_{\mathrm{A}}$ is the ambient temperature.

Traditionally, for residential-type buildings, $\mathrm{T}_{\mathrm{B}}=65 \mathrm{~F}$ $\left(18^{\circ} \mathrm{C}\right)$ has been used. Recent research, however, indicates that monthly average internal and solar heat gains offset residential heat loss at a mean daily temperature slightly below $65 \mathrm{~F}\left(18^{\circ} \mathrm{C}\right)$. Furthermore, for commercial buildings characterized by relatively large internal loads, $\mathrm{T}_{\mathrm{B}}$ may be closer to 50 to $60 \mathrm{~F}$ $\left(10-16^{\circ} \mathrm{C}\right)$. Therefore, use of the modified degree-day procedure described in Ref. 1 is recommended.

The building heat loss coefficient, UA in Eq. (8-1), is the space heating loss (in $\mathrm{Btu} / \mathrm{hr}$ or $\mathrm{kJ} / \mathrm{hr}$ ) at design conditions, estimated by ASHRAE procedures [4], divided by the design temperature difference. Where ventilation is significant, UA should include the ventilation load based on the design temperature difference, calculated by traditional methods. Degree-days at 50,55, 60 and $65 \mathrm{~F}\left(10,13,16\right.$ and $\left.18^{\circ} \mathrm{C}\right)$ base temperatures are tabulated in Ref. 20.

The building heat loss coefficient may also be expressed in $\mathrm{Btu} / \mathrm{DD}-\mathrm{sq} \mathrm{ft}(\mathrm{kJ} / \mathrm{C}$-day-sq $\mathrm{m})$ of building. Multiplying UA in Btu/hr-F by 24 and dividing by the building area in square feet ( $\mathrm{sq} \mathrm{m}$ ) gives the heat loss parameter in $\mathrm{Btu} / \mathrm{DD}$-sq $\mathrm{ft}\left(\mathrm{kJ} /{ }^{\circ} \mathrm{C}\right.$-day-sq $\left.\mathrm{m}\right)$. The building thermal load is then given by the heat loss parameter, times the building area, times the heating degree-days either per month or per year. Heating degree-days, referenced to a base temperature of $65 \mathrm{~F}$ $\left(18^{\circ} \mathrm{C}\right)$, are given by ASHRAE [1] or the Climatic Altas of the United States [5]. If $65 \mathrm{~F}\left(18^{\circ} \mathrm{C}\right)$ base degree-day data are used for a building with large internal heat sources (occupants, lights, or equipment), the internal heat gained from these sources should be subtracted from the heating load. Likewise, if large south-facing glass is present, the solar heat gain should also be taken as a credit against the heat load.

For residential and light commercial (envelope dominated) structures, a building heat loss coefficent of 6 to $12 \mathrm{Btu} / \mathrm{DD}$-sq ft $\left(123-245 \mathrm{~kJ} /{ }^{\circ} \mathrm{C}\right.$-day-sq $\left.\mathrm{m}\right)$ is typical. For an existing building, the load can be determined from past monthly and annual utility bills and degree-day values. The energy consumption can then be derived with corrections for furnace and refrigeration equipment efficiency and for nonspace heating energy uses.

\section{Bin Method}

Both heating and cooling loads can be estimated using the bin (temperature frequency) method. The bin method consists of making instantaneous energy calculations at many different outdoor dry-bulb temperatures and multiplying the results by the number of hours of occurrence of each temperature bin. The bins are usually $5 \mathrm{~F}\left(2.8^{\circ} \mathrm{C}\right)$ in size, and they are collected into three daily 8 -hour shifts. Because this method is based on hourly weather data rather than daily averages, it is considerably more accurate than the degree-day method. In addition, the bin method takes into account both occupied and unoccupied building conditions and gives credit for internal loads by adjustment of the balance point. The average coincident wet-bulb temperatures in the bins should be used to calculate the enthalpy of outdoor air for ventilation and the infiltration loads for cooling. Weather data for the bin method are given in Air Force Manual 88-29 [6].

A simplified energy calculation procedure called Energy Graphics [21] has recently been developed. It is a steadystate load analysis procedure to which empirical HVAC system and plant performance factors are applied. An advantage of this method is that it uses a graphical display format that allows the designer to examine the simultaneous interaction of various load components for typical days for each season.

\section{Building Service Water Heating Load Estimation}

Hot water loads vary according to building type, use, and occupany; but an average hot water demand in residential buildings has been established [7]. Furthermore, ASHRAE has published average hot water demand schedules for several types of commercial and/or institutional buildings (see Ref. 1, Chap 37).

The required temperature rise for the heated water is $\left(\mathrm{T}_{\mathrm{HW}}-\mathrm{T}_{\mathrm{M}}\right)$, where $\mathrm{T}_{\mathrm{HW}}$ is the minimum hot water supply temperature and $\mathrm{T}_{M}$ is the temperature of available main supply water. The available supply water temperature can be approximated on a monthly schedule by ground temperatures at the site. Such temperatures are given for selected cities in Ref. 8 . 


\section{Transient Models}

Massive buildings, commercial buildings with complex HVAC systems and controls, and those in the design development or construction document phase require more sophisticated load determination procedures. In such cases, the hourly differences in building thermal capacity (transients); solar loading on the building envelope; and heat generated internally by lights, equipment, and occupants significantly affect the building energy consumption. The diversity and sophistication of modern energy distribution and control systems, particularly solar energy systems, further contribute to energy consumption differences that can be found only by hourly calculation of the loads on the system and its response to them [1]. However, some approaches to transient space heating and cooling load determinations approximately include the transient effects by treating only selected hourly periods (usually one period per season). Some computer programs calculate loads for two conditions on one day in each month and extrapolate for annual loads. Most computer dynamic methods include calculations for the full 8,760 hours/year.

\section{Modified Bin Method}

The Carrier Corporation has developed a noneomputerized Rational Energy Analvsis Procedure [9] that accounts for solar gains; weather data collected in temperature bins; ventilation rates; HVAC system configuration and control; and building use, occupancy, and operating characteristics. Building dynamics (transients) are taken into account using ASHRAE response and weighting factors [4] for a 7-hour day each season. Both heating and cooling loads, on a monthly or annual basis, can be determined using this procedure. Where computer access is difficult or too expensive, the manual REAP method can be used. The improved procedure is at the expense of a considerably more complex calculation than for the bin method.

ASHRAE Technical Committee 4.7 (Energy Calculations) has recently developed a simplified manual procedure for estimating building loads and energy consumption that is a modification of the Bin Method. This procedure is expected to become available sometime in 1981 .

\section{Energy Graphics}

A simplified energy calculation procedure called Energy Graphics [21] has recently been developed. It is a steadystate load analysis procedure to which empirical HVAC system and plant performance factors are applied. An advantage of this method is that it uses a graphical display format that allows the designer to examine the simultaneous interaction of various load components for typical days for each season.

\section{Computer Dynamic Analysis}

Building heating and cooling loads can be determined using computer dynamic analysis techniques. Several computer programs that predict hourly, monthly, and annual loads on the basis of hourly weather data are available in both the public and private domain. These programs also predict the peak monthly and annual loads.

To date, the most widely used public domain programs have been NBS's NBSLD [10] and NASA's NECAP [11]. NBSLD is strictly a load program and primarily a research tool, whereas NECAP is a full energy analysis program containing load, system, and equipment simulations. Both give good results; but the input is rather involved, and computer run times are long.

In response to this less-than-satisfactory state of public domain building load and energy analysis computer programs, Lawrence Berkeley Laboratory and the Los Alamos Scientific Laboratory, under DOE sponsorship, have developed a fast, easy-to-use, and flexible building energy analysis computer program called DOE-2 $[12,13,14]$. (Earlier versions were called Cal-ERDA and DOE-1.) DOE-2 only operates on large, main-frame computers.

Another public domain building energy analysis computer program that can be used to calculate hourly, monthly, or annual loads is the BLAST program developed by the U.S. Army Construction Engineering Research Laboratory [15].

Other programs, some load and some both load and energy analysis programs, are privately available. Some examples are AXCESS, TRACE, ECUBE, and ESP-1. Because some are designed to compute annual heating and cooling energy requirements, they may have to be modified to give re-uirements on a monthly basis. Bibliographies of building energy analysis and loads programs have been published by ASHRAE [16] and SERI [17].

All of the computer dynamic analysis programs require the input of weather data of some sort. The more complex programs accept an input of NOAA weather data either in card form or on magnetic tape. These raw data are generally for hourly observation periods before 1965 and for 3-hour observation periods after 1965 (except for a few stations that have continued with hourly observations). Although hourly data are available for specific weather years, it is preferable to use edited or composite weather years that are representative of longterm weather conditions for the geographic location in question. The Test Reference Year (TRY); SOLMET; and, most recently, Typical Meteorological Year (TMY) data are examples of these edited or composite weather years $[18,19]$. They are available from NOAA. Some programs have a subroutine for processing these data and reducing them to a series of typical days ranging from one per month to one per week while others use hourly readings directly for one representative year.

The less complex programs use weather data from ASHRAE tables [4] or bin data from Ref. 6. These sources deal with weather conditions averaged over the year, thus reducing the precision of the simulation.

\section{BUIL.DING ENERGY REQUIREMENTS}

The above discussion has dealt with the thermal load imposed upon the building plant for space conditioning or BSHW. The actual energy requirements of the building (at the building boundary) will be the energy input to the 
plant equipment, as it reacts to meet the load, plus the energy input for lights, equipment, and other energy uses. All building energy analysis methods simulate the total operation of the building and its HVAC system, including their reaction to weather, occupancy, and equipment use, by first calculating the loads and then simulating the operation of the plant equipment (including part-load efficiencies) to meet those loads. Finally, the hourly or monthly plant energy consumption is integrated over the year to obtain the annual energy consumption.

One end result in computation is a prediction of energy expended per building area per year. As a general guideline for a new office building, the Federal Energy Administration, Office of Energy Conservation and Environment, has suggested an energy budget target of less than $55,000 \mathrm{Btu} / \mathrm{gross} \mathrm{sg} \mathrm{ft}-\mathrm{yr}(625,000 \mathrm{~kJ} / \mathrm{sq} \mathrm{m}-\mathrm{yr})$. A realistic energy budget goal for retrofitting existing office buildings is 75,000 Btu/gross sq $\mathrm{ft}-\mathrm{yr}$ $(850,000 \mathrm{~kJ} / \mathrm{sq} \mathrm{m}-\mathrm{yr})$. Buildings designed for solar energy herting and/or cooling should at least meet these guidelines.

It is expected that Building Energy Performance Standards (BEPS) promulgated by DOE will soon be issued. These may be used as a guide for a large number of building types.

\section{REFERENCES}

1. ASHRAE Handbook and Product Directory, Systems, Chapter 43, ASHRAE, 1980.

2. I. Sud, R. W. Wiggins, Jr., J. B. Chaddock, and T. D. Butler, "Development of the Duke University Building Energy Analysis Method (DUBEAM)," Duke University Center for the Study of Energy Conservation, Durham, North Carolina, November 1979.

3. E. Stamper, "Air-Conditioning Usage StudyEquivalent Rated Load Hours, "ASHRAE Journal, June 1979.

4. ASHRAE Handbook of Fundamentals, ASHRAE, 1977.

5. U.S. Department of Commerce, Environmental Sciences Services Administration, Environmental Data Services, Climatic Atlas of the United States, 1968.

6. Air Force Manual AFM 88-29, "Engineering Weather Data," Departments of the Air Force, Army, and Navy, July 1978.

7. J. J. Mutch, "Residential Water Heating: Fuel Consumption, Economics, and Public Policy," Rand Corporation report $R$ 1498-NSF, National Science Foundation, May 1974.

8. C. Strock, Handbook of Air Conditioning, Heating and Ventilating, The Industrial Press, New York, 1959.
9. W. W. Treichler, "A Non-Computerized Rational Energy Analysis Procedure," Proc. Conf. on Improving Efficiency and Performance of HVAC Equipment and Systems for Commercial and Industrial Buildings, April 12-14, 1976, School of Engineering, Purdue University, Purdue Research Foundation, 1976, Vol. 1, pp. 214-224.

(A REAP handbook will soon be available from the Carrier Corporation, Syracuse, New York.)

10. T. Kusuda, "NBSLD, Computer Program for Heating and Cooling Loads in Buildings," National Bureau of Standards report NBSIR 74-574, November 1974.

11. "NECAP-NASA's Energy-Cost Analysis Program" Part I-User's Manual and Part II-Engineering Manual, R. H. Henniger, ed., NASA CR-2590, Parts I and II, September 1975.

12. M. Lokmanhekim, Z. Cumali, F. C. Winkelmann, A. H. Rosenfeld, G. S. Leighton, and H. D. Ross, "CalERDA, A New State-of-the-Art Computer Program for the Energy Utilization Analysis of Buildings," paper presented at the Third International Symposium on the Use of Computers for Environmental Engineering Related to Buildings, Banff, Alberta, Canada, May 10-12, 1978.

13. H. L. Horak, B. D. Hunn, J. L. Peterson, M. A. Roschke, E. F. Tucker, and D. A. York, "DOE-2 Reference Manual," Los Alamos Scientific Laboratory report LA-7689-M, Lawrence Berkeley Laboratory Report LBL-8706, February 15, 1979. Available from NTIS.

14. S. C. Diamond, H. L. Horak, B. D. Hunn, J. L. Peterson, M. A. Roschke, and E. F. Tucker, "DOE-2 Program Manual," Los Alamos Scientific Laboratory report LA-7688-M, Lawrence Berkeley Laboratory report .LBL-8705, February 15, 1979. Available from NTIS.

15. D. C. Hittle, "BLAST, The Building Loads Analysis and Systems Thermodynamics Program, Vol. I, Users Manual," U.S. Army Construction Engineering Research Laboratory report CERL-TR-E-119, December 1977.

16. ASHRAE, "Bibliography on Available Computer Programs in the General Area of Heating, Refrigeration, Air Conditioning, and Ventilation," Research Project report GRP 153, October 1975.

17. "Analysis Methods for Solar Heating and Cooling Applications," SERI Report SP-35-232, Solar Energy Research Institute, January 1980.

18. E. A. Arens, D. H. Nall, and W. L. Carroll, "The Representativeness of TRY Data in Predicting Mean Annual Heating and Cooling Requirements," ASHRAE Symposium paper PH-79-8, No. 1, presented at the ASHRAE Semi-Annual Meeting, Philadelphia, Pennsylvania, January 1979. 
19. I. J. Hall, R. R. Prairie, H. E. Anderson, and E. C. Boes, "Generation of Typical Meteorological Years for 26 SOLMET Stations," ASHRAE Symposium paper DE-79-2, No. 3, presented at the ASHRAE Annual Meeting; Detroit, Michigan, June 1979.

20. "Passive Solar Design Handbook, Vol. 2, Passive Solar Design Analysis," U.S. Department of Energy report DOE/CS-0127/2, January 1980.

21. "Energy Graphics," Booz-Allen and Hamilton, Inc., undated report. 
9

Passive System Design and Sizing Methods 
9. Passive System Design and Sizing Methods

Design tool levels

Specific examples of design and analysis tools

The LASL manual methods

Sample problem 


\section{INTRODUCTION}

Energy efficient buildings can be built without the use of quantified design tools (Fig. 9-1). However, with the average cost of a single family detached residence in the United States now over $\$ 70,000$, we cannot afford to proceed by a process of trial and error (Fig. 9-2). For this reason the Department of Energy with the assistance of the Solar Energy Research Institute (SERI) and some of the national laboratories has supported the development of a number of passive design and analysis tools ranging from detailed hourly simulations to the simplest rules of thumb. The private sector has also been active in this area, and the Design Tool Group at SERI maintains a continuing survey of these methods.

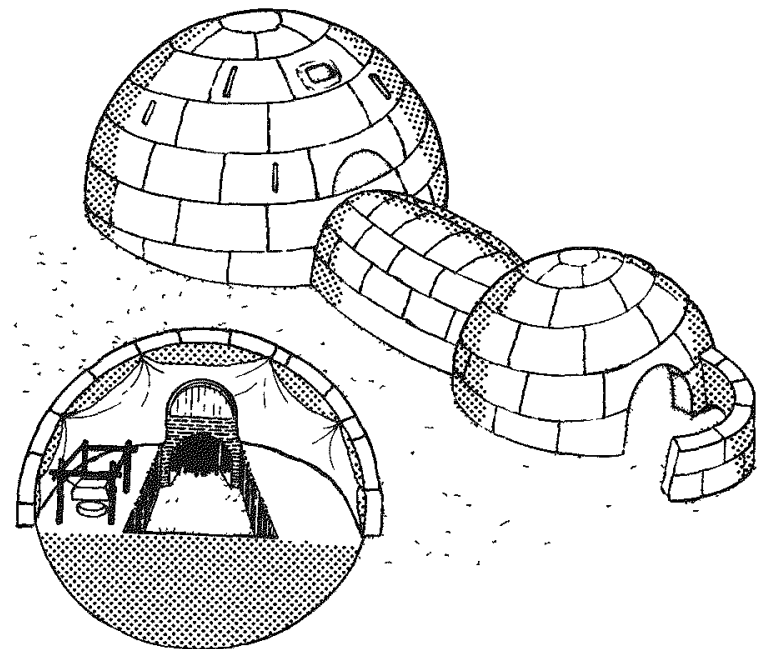

Fig.9-1. Eskimo igloo. Source; J.M. Fitch, American Building: The Environmental Forces That Shape It.

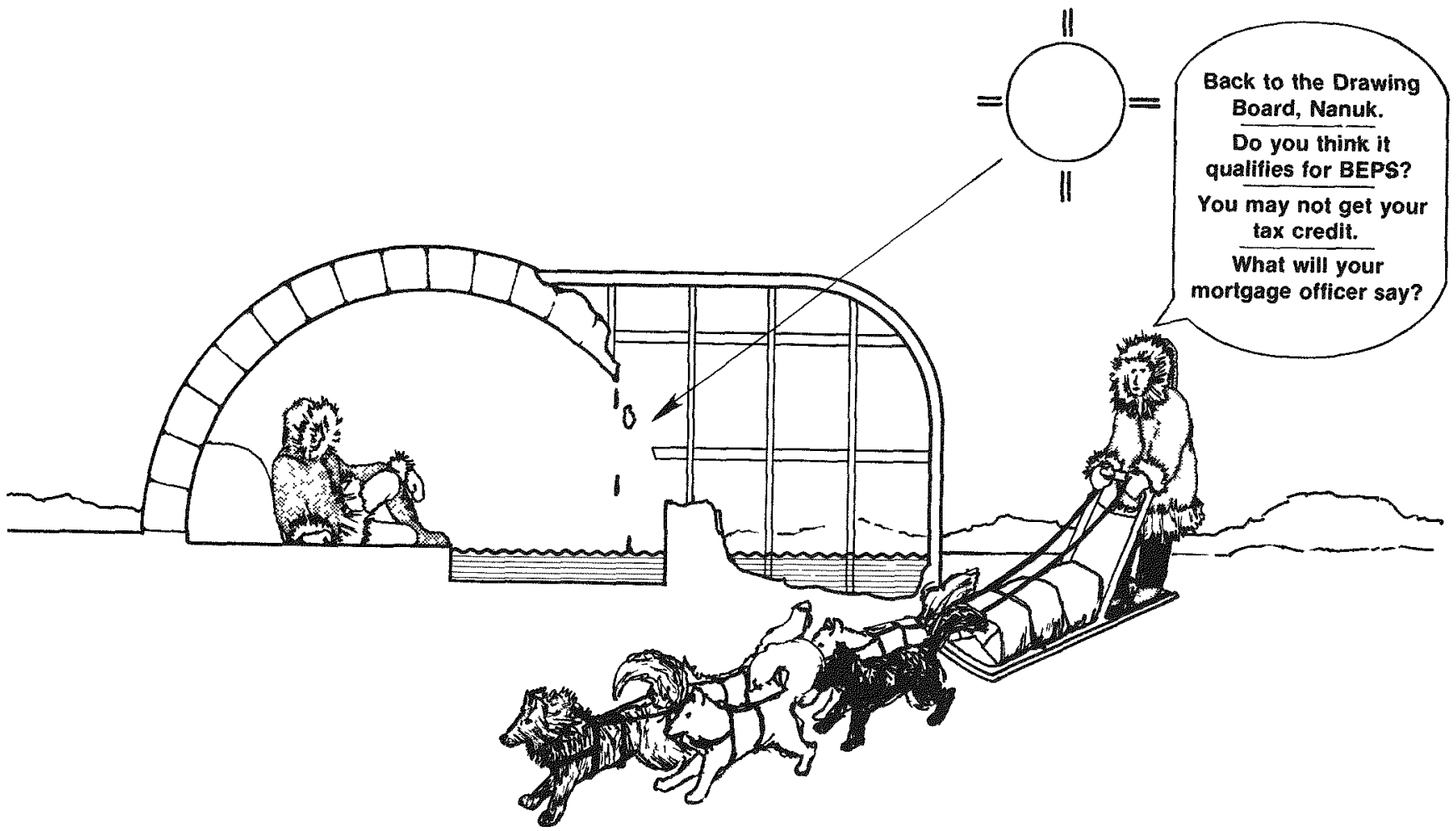

Fig.9-2. Eskimo igloo retrofitted with attached greenhouse 
The purpose of these design and analysis tools is threefold:

- To assist us in defining the problem at the programmatic level of design so that we know where the greatest energy savings potential resides. For example, in a typical $10,000 \mathrm{sq} \mathrm{ft}(926 \mathrm{sq} \mathrm{m})$ department store in Denver, annual lighting costs were $\$ 8,000$; annual cooling costs were $\$ 1,000$, and annual heating costs were only $\$ 500$.

- To assist us in sizing the various elements that affect the energy performance of the building.
- To assist us in predicting how successfully the elements of the system function together to minimize energy consumption while maintaining an acceptable level of comfort. This prediction of energy consumption is necessary to determine if the solution is cost effective; that is, if the future cost of fuel saved justifies the capital outlay necessary to achieve that savings. Such analyses also help us determine which design solution saves the most energy per dollar spent.

Design and analysis tools may be categorized into a number of levels which correspond in complexity and detail to the phases of the design process and the type of building under consideration. (See Tables 9-1 and 9-2.)

Table 9-1. DESIGN AND ANALYSIS TOOL CATEGORIES BY COMPLEXITY

Level I: Detailed Hourly Simulations

DEROB (Ūniv. of Texas, Austín)

BLAST (LBL, CERL)

DOE 2.1 (LASL, LBL)

TRNSYS (Univ, of Wisconsin)

UWENSOL (Univ. of Washington)

UWLIGHT (Univ. of Washington)

Mainframe

Computer

Required

Level II: Simplified Simulations and Correlations

SUNCAT (NCAT)

SOLAR V (UCLA)

Parts of DEROB (Univ, of Texas)

SLR

Level III: Automated Hand Methods, Correlations, Extremely Small Simulations

TEA-NET (Total Environmental Action)

PEG-FIX, PEG-FLOAT (Princeton Energy Group)

SEEC VI (Solar Environmental Engineering Corp.)

SOLARCON (Solarcon)

Level IV: Manual Methods

Solar Load Ratio Method (LASL)

Load Collector Ratio Method (LASL)

Rules of Thumb (LASL)

Thermal Inertia Method (Univ. of Texas, Austin)

Table 9-2. DESIGN AND ANALYSIS TOOIS CATEGORIZED BY DESIGN PHASE USE AND BUILDING TYPE

\begin{tabular}{|c|c|c|c|}
\hline \multirow[b]{2}{*}{$\begin{array}{c}\text { Phase in Design } \\
\text { Process }\end{array}$} & \multicolumn{3}{|c|}{ Building Type } \\
\hline & Residential & $\begin{array}{l}\text { Heavy Residential } \\
\text { Light Commercial }\end{array}$ & Heavy Commercial \\
\hline Design Development & $\begin{array}{c}\text { SEEC VI } \\
\text { SLR } \\
\text { SUNCAT } \\
\text { DEROB } \\
\text { TEA-NET }\end{array}$ & $\begin{array}{c}\text { SUNCAT } \\
\text { DEROB } \\
\text { DOE } 2.1 \\
\text { BLAST }\end{array}$ & $\begin{array}{l}\text { DOE } 2.1 \\
\text { BLAST }\end{array}$ \\
\hline Schematic Design & $\begin{array}{c}\text { LCR } \\
\text { TEA-NET }\end{array}$ & SUNCAT & DEROB \\
\hline $\begin{array}{l}\text { Programming and } \\
\text { Conceptual Design }\end{array}$ & $\begin{array}{l}\text { Rules of } \\
\text { Thumb }\end{array}$ & AlA Tables & AIA Tables \\
\hline
\end{tabular}

For use on a

Hanc-held

Programmable

Calculator

\section{icrocomputers Costing}

Possible on

less than $\$ 1,000$ 
In Tables 9-1 and 9-2, we see that the rules of thumb and manual methods tend to be most appropriate in the early phases of design, and the automated methods are most useful in the latter stages. We also see that the detailed simulations tend to be most appropriate in the large, more complex building types with the simpler, less expensive methods finding greatest utility in the design of smaller buildings. This is as we would expect because of the tighter budgetary constraints on smaller projects. It should also be noted that the tools for light residential applications are more highly developed than those for larger building types. Work is currently underway to further develop design and analysis tools for commercial buildings.

Eventually the Department of Energy hopes to provide design tools with full hybrid capability, tools capable of addressing passive and active heating and cooling, conventional HVAC systems, daylighting, and skin loads. Presently our capabilities are somewhat more limited than this. Some methods have extensive capability in one area but little or no capability in another. This is why it is necessary to list so many different techniques in order to cover the subject.

The remainder of this chapter is divided into three sections. The first section considers the various levels of design and analysis tools in general terms; Section 2 presents a representative method from each level. Section 3 looks at two manual methods in terms of an actual design sample problem.

The methods chosen as representative in Section 2 were selected on the basis of being most flexible in terms of passive design. This does not imply, however, that some other tool wouldn't be more appropriate for any particular application. The user must decide on a building-by-building basis. For example, the DEROB simulation emphasizes passive design more than the DOE-2 program does. However, there are many commercial buildings in which skin loads are relatively insignificant compared to internal loads. In such cases, the DOE-2 program, which has considerable systems capability but limited passive capability, would probably be more appropriate than the DEROB model which has considerable passive capability but limited systems and plant capability.

\section{DESIGN TOOL LEVEIS}

\section{Level I: Detailed Hourly Simulations}

The detailed hourly simulation programs require large main-frame computers. However, they are the most flexible for considering a wide variety of design strategies and the effects on the whole building performance of various parameter changes and interactions. These programs tend to be most useful for analyzing the design once it is well defined since they depend on detailed input information. These codes may be used in a number of different ways to:

- Generate design indicators, guidelines, and rules of thumb for the early phases of design;

- Generate simplified methods which do not require large computers (generally done by developing monthly or annual correlations based on hourly results);
- Verify independently developed simplified methods;

- Design and analyze innovative designs, repetitive building units, or large buildings (wherever the cost of use is justified);

- Generate building energy performance standards;

- Generate guidelines for the equitable administration of credits and incentives;

- Plan long-term government policy;

- Prove compliance with Building Energy Performance Standards (BEPS).

Some of these programs are already being used by building energy consultants and a few forward-looking architectural and engineering firms. Their further development is absolutely essential to generalize new knowledge about buildings gained from experimental studies.

\section{Level II: Mierocomputer Methods}

Ideally, simulation is the preferred design tool. Unfortunately, the expense and expertise required currently prohibit use of large computers. The microcomputer may soon change this situation. Already there are units costing less than $\$ 1,000$ which can accommodate some of the smaller simulations.

Work is currently under way at the National Center for Appropriate Technology (NCAT) to adapt the SUNCAT program for the microcomputer. In addition, SERI is nearing completion on a project to provide the Solar Load Ratio method in a basic software package for microcomputers. If the trend continues toward ever cheaper microcomputer power, it may soon be possible to fit even the most detailed simulations on these machines.

\section{Level m: Programmable Caleulator}

Almost all of the magnetic card programs for hand-held calculators represent the automation of hand methods based on monthly or annual correlations. The automated versions are faster and easier to use; however, they are only applicable within the restricted range of assumptions made for the correlation. Many innovative designs will fall outside these assumptions or will use a combination of strategies beyond the flexibility of these simple tools. For those designs falling within the correlation assumptions, the programmable calculator represents a convenient tool at minimal cost. In 1980, a TI-59 with printer costs about $\$ 350$. Without the printer (which is unnecessary for most of the available card programs) the price of the TI- 59 is about $\$ 200$.

SERI is nearing completion of a project to put the updated version of the Load Collector Ratio and Solar Load Ratio methods on magnetic program cards for the TI-59 calculator. These should be available along with publication of the Passive Solar Design Handbook by LoS Alamos Laboratory and Total Environmental Action by June 1980.

In at least one instance, the programmable calculator has been used for an actual hourly simulation. This use is discussed further in the section of this chapter dealing with TEA-NET. 


\section{Level IV: Manual Methods}

Manual methods are most useful for rules of thumb, design indicators, and guidelines which can be summarized in a few pages of graphs, charts, or nomograms. As soon as a procedure becomes lengthy or repetitive, it loses its utility by discouraging the analysis of many design alternatives. The Load Collector Ratio method, used in a sample problem later in this chapter, probably represents an upper limit for complexity and length of a hand procedure. There is no easy solution to this problem since beyond a certain point simplification must always involve a reduction in flexibility. Automation of these hand methods as previously discussed may be the only answer.

\section{SPECIFIC EXAMPLES OF DESIGN AND ANALYSIS TOOLS}

\section{DEROB: Dynamic Energy Response of Buildings}

DEROB is a series of modular programs under joint development by SERI and the Numerical Simulations Laboratory at the University of Texas in Austin. The program has extensive passive and general skin load modeling capabilities. The thermal solution technique is based on a finite difference or network* approach; however, specialized knowledge beyond that of the architect is not necessary for its use. Input data consist of geometric information defining the building as a threedimensional object and a physical description indicating the materials of which the building is composed. The program has a preprocessor which determines the network connections and places nodes to ensure stability. DEROB calculates exterior and interior shadowing and places solar radiation on building surfaces according to the geometric definition of the building. Table 9-3 summarizes inputs to the DEROB program, and Table 9-4 lists some of the various output options avail able.

Table 9-5 shows part of the materials library for defining floors, walls, and roofs.

DEROB lends itself to both computer graphic techniques and daylighting analysis because it models the building as a three-dimensional object and traces visible and infrared radiation very carefully through the building. Experimental versions of DEROB have been used to generate studies on (1) the optimization of daylighting and thermal energy use, (2) computer graphic evaluation of solar rights in a complex urban block (Fig. 9-3a, b), and (3) computer graphic design of shading devices (Fig. 9-4).

DEROB has been run against empirical data from the Los Alamos test cells, the Doug Balcomb residence, and the Bruce Hunn residence.
Table 9-3. SUMMARY OF INPUTS TO DEROB (FIXED FORMAT INPUT)

1. Interzonal natural convective connections (defined by height between inlet and outlet, and area of smallest opening).

2. Geometry of building (defined by an $x, y, z$ coordinate scheme).

3. Window type (single glazed, double glazed, etc.).

4. Glazing material (reflecting glass, regular glass, etc.).

5. Radiation absorptivity of opaque wall surfaces.

6. Movable insulation ( $R$-value and schedule of operation).

7. Wall section composition (material library included in program).

8. Thermostat control strategies (free float, deadband, set point).

9. Venting, heating, and air conditioning options and capacity.

10. TMY weather tapes.

11. Schedule of internal heat generation.

Table 9-4. SUMMARY OF DEROB OUTPUT OPTIONS

1. Hourly output of space air temperatures and heating and cooling energy supplied to space.

2. Monthly summaries of heating and cooling energy supplied to space.

3. Hourly instantaneous heat transfer and temperature at any node.

*For further explanation of nodal networks, see the section of this chapter dealing with TEA-NET. 
Table 9-5. MATERIALS LIBRARY FROM DEROB PROGRAM

\begin{tabular}{|c|c|c|c|c|c|}
\hline $\begin{array}{l}\text { acoustical tile } \\
\text { adobe } \\
\text { air spaces at about } 70 \mathrm{~F} \\
\text { aluminum } \\
\text { asphalt } \\
\text { brick } \\
\text { buil t-up roof } \\
1 / 2^{\prime \prime} \text { carpet with } 1 / 4^{\prime \prime} \text { pad } \\
\text { cellular glass insulation } \\
\text { cellulose } \\
\text { celotex insulation board } \\
\text { cement asbestos tile } \\
\text { cement plaster } \\
\text { concrete } \\
\text { concrete block } \\
\text { concrete slab } \\
\text { corkboard }\end{array}$ & $\begin{array}{r}42 . \\
38 . \\
7 . \\
14 . \\
29 . \\
1 . \\
40 . \\
44 . \\
18 . \\
23 . \\
9 . \\
27 . \\
12 . \\
5 . \\
41 . \\
31 . \\
10 .\end{array}$ & $\begin{array}{l}\text { dry clay } \\
\text { dry sand } \\
\text { glass wool } \\
\text { gypsum board } \\
\text { gypsum plaster } \\
\text { hardwood } \\
\text { limestone } \\
\text { marble } \\
\text { metal lath and plaster } \\
\text { mineral fiberboard } \\
\text { mortar cement } \\
\text { packed earth } \\
\text { particle board } \\
\text { plywood } \\
\text { polystyrene insulation } \\
\text { polyurethane insulation } \\
\text { pressed wood chips }\end{array}$ & $\begin{array}{l}17 . \\
34 . \\
4 . \\
2 . \\
11 . \\
26 . \\
28 . \\
33 . \\
30 . \\
19 . \\
39 . \\
8 . \\
45 . \\
25 . \\
20 . \\
21 . \\
22 .\end{array}$ & $\begin{array}{l}\text { reinforced concrete } \\
\text { rockwool insulation } \\
\text { sawdust } \\
\text { slate } \\
\text { soft wood } \\
\text { solid gypsum } \\
\text { stainless steel } \\
\text { steel } \\
\text { stucco } \\
\text { water } \\
\text { wool asbestos }\end{array}$ & $\begin{array}{r}37 . \\
43 . \\
24 . \\
35 . \\
3 . \\
32 . \\
15 . \\
16 . \\
6 . \\
36 . \\
13 .\end{array}$ \\
\hline
\end{tabular}

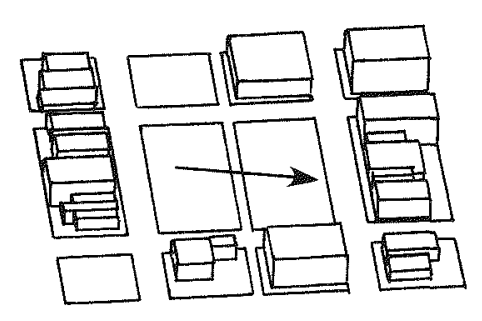

8 A.M.

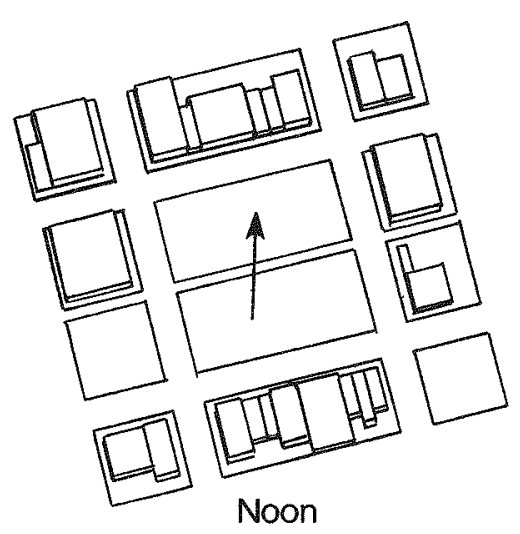

June 22

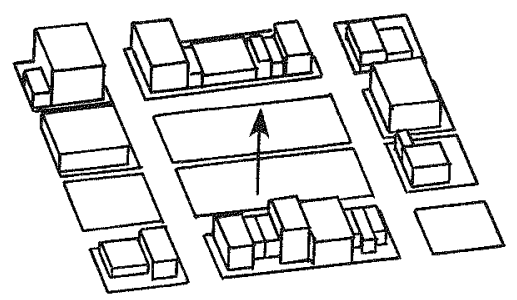

Noon

December 22
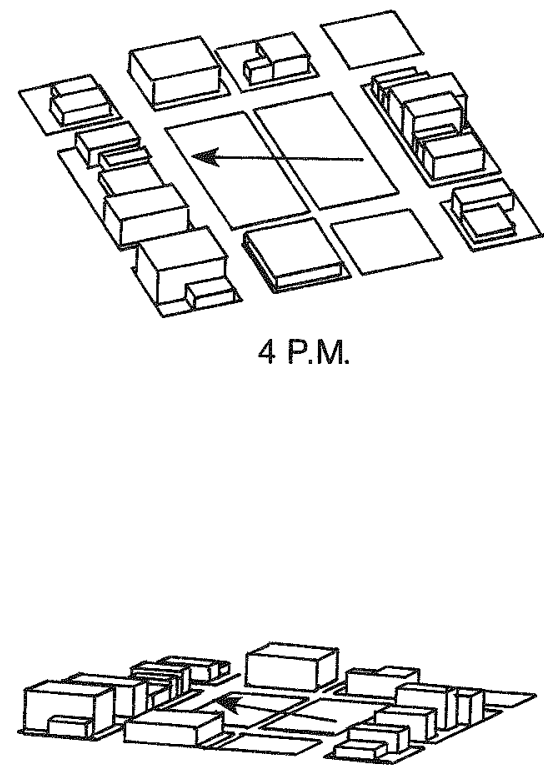

4 P.M.

Fig.9-3a. Solar views of an urban site during the summer and winter solstices 


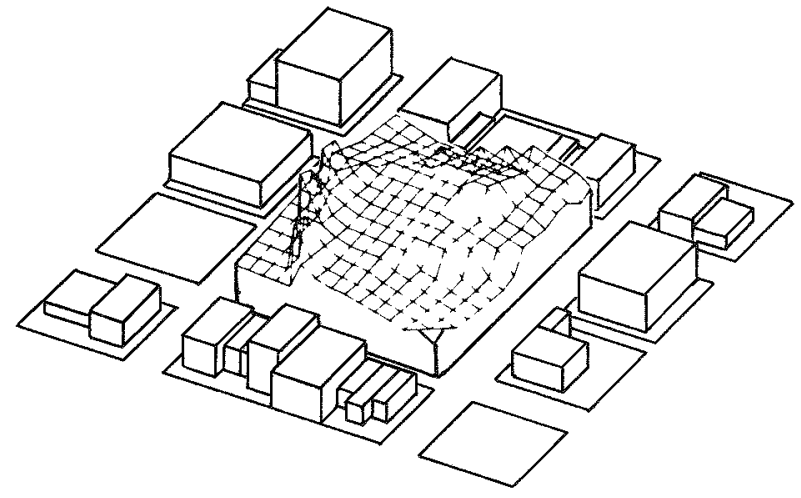

Fig. 9-3b. Vertical property boundaries that
respect the solar rights of neigh-
bors

\section{SUNCAT}

SUNCAT, developed at the National Center for Appropriate Technology, is a smaller, less detailed hourly simulation than DEROB. Its thermal solution is also based on a network approach. However, in SUNCAT, a small generic network is preprogrammed in, and portions of it are zeroed out depending on user input. (See Fig. 9-5.)

This approach limits the configurational flexibility of the program to situations that match the predefined network. Care has been taken, however, to allow for analysis of most common spatial arrangements in small passive buildings. Fig, 9-6 is a plan view of the most general configuration allowable in SUNCAT.

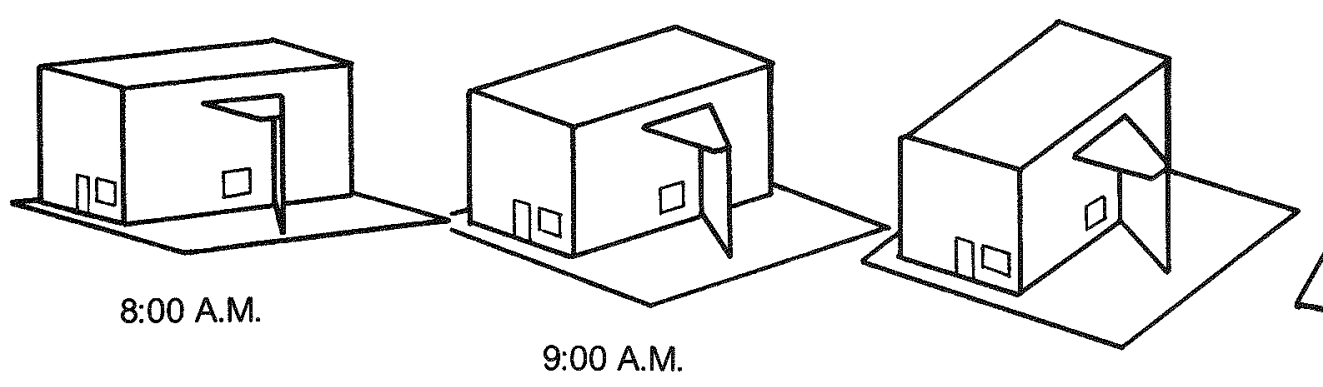

Latitude: 31

Month: 12

Day: $\quad 15$
10:00 A.M.

4. Solar views of the window and its shading device from 8:00 a.m. through 11:00 a.m. illustrating graph. ically the performance of the shading device according to the design. The figures were generated by the program ALKAZAM.

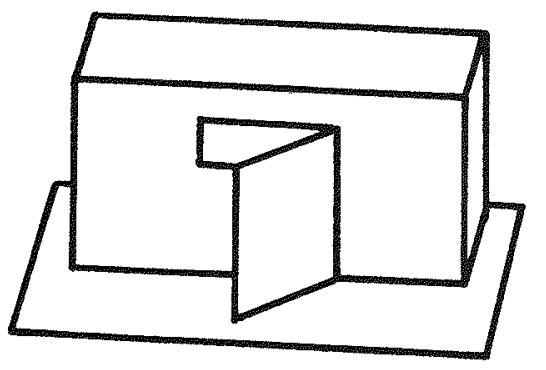

7:00 A.M.

Latitude: 31

Month: 8

Day: $\quad 15$

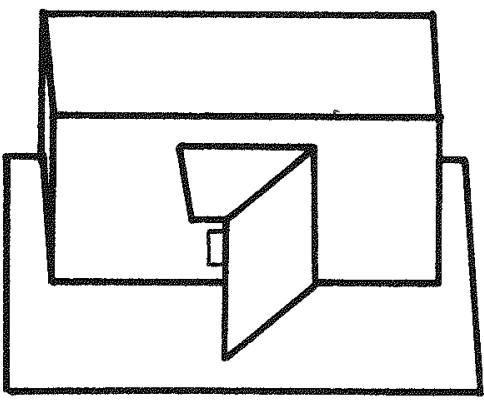

8:00 A.M.

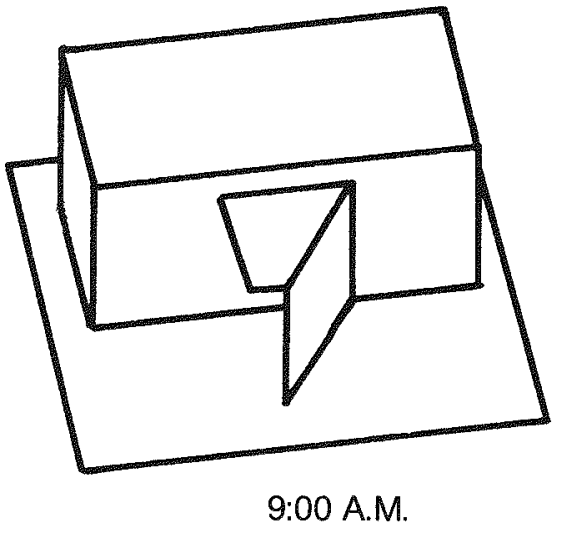

5. Solar views of the window and its shading device from 7:00 a.m. through 9:00 a.m. At 8:00 the window is partially exposed to the sun. The figures were generated by the program ALKAZAM.

Fig.9-4. Solar views of a window and shading device 


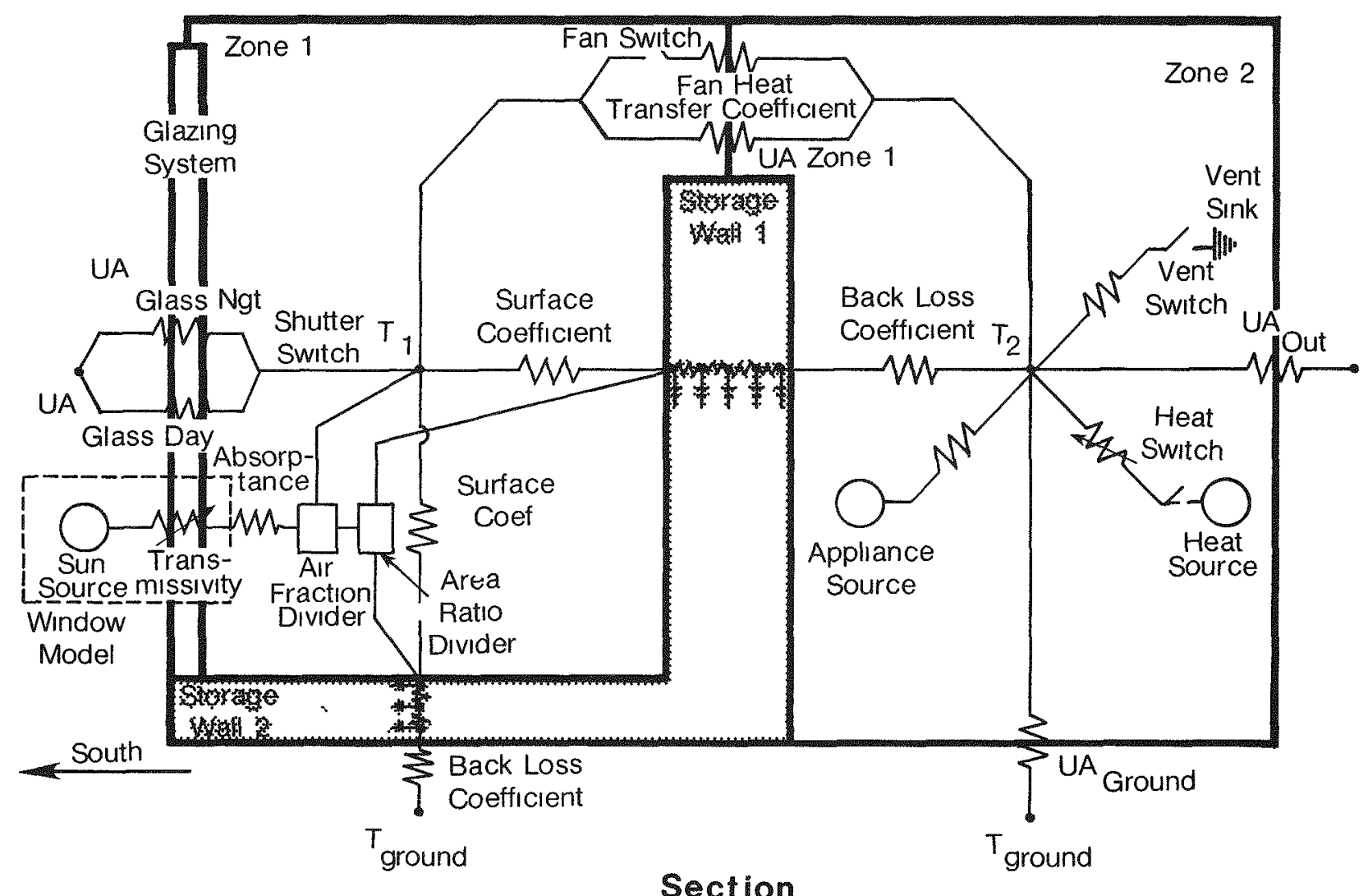

Section

Fig.9-5. Approximate electrical analog of a sample configuration of the NCAT passive solar model

Plan

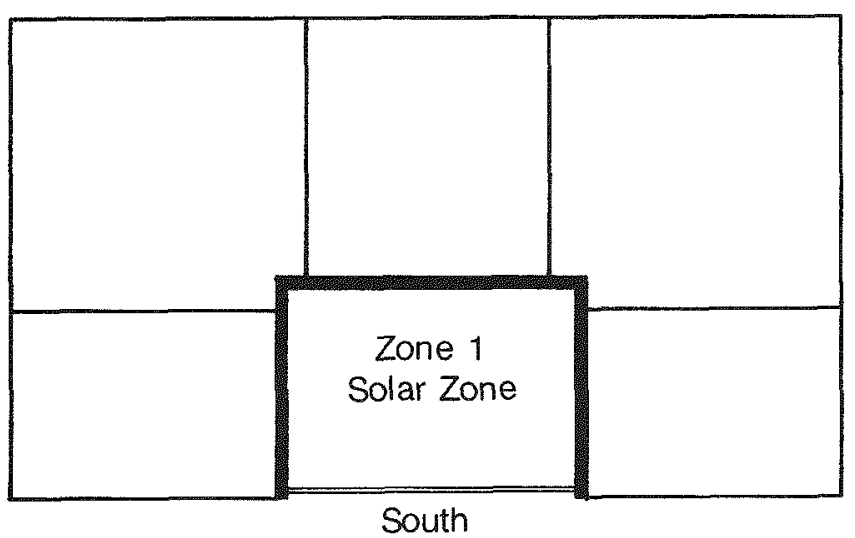

Fig.9-6. Plan view of the most general configuration allowable in SUNCAT
The model has the following characteristics:

- There can be just one solar recelving zone. (The program is currently being modified so that all zones may recelve sunlight.)

- Heat can flow from the recelving zone to back zones only via the mechanism of conductive transfer, or forced ventlation, except in the special case of the Trombe wall where natural convective flow through the vents is modeled as well as conduction through the wall.

- There is no heat flow between back zones.

- Shading is calculated exclusively on exterior glazed surfaces.

- No internal shading is calculated so the user must define those walls which receive direct sunlight. Energy is apportioned to recelving walls as an area weighted average.

Unlike DEROB, SUNCAT requires that the user have some specialized knowledge. The inputs are in the form of lumped thermal and physical parameters which would not normally be part of the working vocabulary of the designer. Some "magic numbers" must be chosen according to best professional judgment. To lllustrate, DEROB calculates the amount of incoming solar radiation 
stored and the quantity going immediately into raising the room air temperature based on where the radiation is falling in the room with respect to lightweight and massive surfaces and the solar absorptance of the finishes on those surfaces. SUNCAT, on the other hand, distributes incoming radiation evenly over the sunlit surfaces, requiring the user to pick according to his best judgment the percentage of energy which goes toward raising the room air temperature.

In general, the tradeoff for abbreviating the program is either less flexibility or increased judgmental and calculational responsibility on the part of the user. On the other hand, SUNCAT runs about 10 times faster than DEROB and is small enough to fit on a microcomputer.

Tables 9-6 and 9-7 summarize SUNCAT inputs and outputs, respectively. They are intended to give the reader an idea of the kind of knowledge necessary to use the program.

\section{TEA-NET}

TEA-NET was developed originally by Total Environmental Action for in-house use by its own design studio. It is now offered commercially. It is a 7-node hour-byhour simulation for use on the TI-59 hand-held programmable calculator with printer. Its primary use is for a design-day type analysis in which the user specifies the weather conditions and lumps all building parameters into several nodes. Because of the limited number of nodes available and the relatively slow run time, only a very simple range of building cases can be analyzed. It runs about $1 / 50$ th real time, so a 24-hour simulation takes approximately $1 / 2$ hour. This technique is most appropriate for analyzing the comfort and energy performance of a single room or zone under extreme or average conditions for several days representing critical seasons throughout the year.

The user must construct a nodal network representing the situation to be modeled; however, detailed instructions and examples are contained in the user's manual.

Fig. 9-7 shows a somewhat distorted section of a direct gain room with a concrete masonry wall for thermal storage. The section is distorted because it is drawn to detail what is important thermally.. The storage wall is not really so thick with respect to the room; it is "blown up" to allow inspection of its thermal behavior, which is relatively more complex than other portions of the building. The dots $\mathrm{T}_{1}-\mathrm{T}_{5}$ represent nodes which can be thought of as temperature and heat flow sensors. Associated with each sensor is a certain amount of mass storage or capacitance. $\mathrm{T}_{1}$, for example, the room air node, has a capacitance $C_{1}$ associated with it which represents the lumped storage capacity of the air plus all the lightweight materials in the room (e.g., gypsumboard, flooring, furniture, etc.). $\mathrm{C}_{2}$ is the storage capacity associated with the node on the mass wall surface. It represents a slice of the storage wall containing $1 / 6$ of the thermal storage capacity of the wall. (See Fig. 9-8.)
The "G's" (Fig. 9-7) represent the total heat transfer coefficient between any two nodes as a conductance. For example, $\mathrm{G}_{12}$ is the sum total coefficient accounting for mechanisms of conduction, convection, and radiation between the room air $\left(\mathrm{T}_{1}\right)$ and the storage wall surface $\left(\mathrm{T}_{2}\right)$ represented as a single conduc tance term.

Once all these terms have been entered as input, the program calculates energy flows and resultant temperatures hourly as a function of exterior ambient temperature, solar energy through the south collection area, and internal loads. A thermostat high and low cutoff may be set so that the amount of auxiliary energy necessary to maintain the room air temperature node within the deadband may be calculated.

Tables 9-8 and 9-9 show the kinds of input used by TEA-NET. The user's manual explains how they are derived.

Table 9-10 indicates the hourly output available from TEA-NET.

The utility of TEA-NET is most constrained by the limited Random Access Memory (RAM) of the calculator (996 steps in the TI-59). Substantial improvement in versatility could be realized with all the hand-held programmable tools if the 5,000 step Read Only Memory (ROM) chip which plugs into all TI-59s were used as a solar algorithm and subroutine library module. This would free up the RAM memory for enhancing input/ output characteristics and calculational capability.

\section{THE LASL MANUAL METHODS}

The LASL manual methods include:

- Rules of Thumb

- LCR (Load Collector Ratio Method)

- SLR (Solar Load Ratio Method)

These three methods are primarily intended to be used on small, skin-dominated buildings. To be strictly correct these methods apply most directly to situations in which collection, storage, and distribution all occur in a single volumetric zone. DOE is currently funding basic physical studies investigating the phenomena surrounding interzonal convective transport so that we may understand the thermal performance of multizone buildings. Until better information becomes available, the three methods mentioned above represent a useful set of tools matching the needs of the different phases of the design process. The rules of thumb are intended to give a "ball-park" indication of how much collection area to use in the programming and conceptual design phase. The LCR method, intended for the schematic phase of design, indicates quickly which design alternatives give better annual performance. A number of sensitivity studies have been done which greatly increase the flexibility and utility of LCR. 
I. Window Model Parameters

A. Glazing Type Parameters

Number of Layers $=$ number of layers of similar glazing material.

Total Thickness = total thickness of all glazing layers (in same units as extinction coefficient)

Extinction Coef $=$ extinction coefficient of glazing material per unit thickness

Index of Refraction = index of refraction of glazing material

Diffuse Angle = the equivalent angle of incidence in degrees used to approximate diffuse radiation transmissivity

Ground $\operatorname{Reflect}=$ ground reflectance multiplier

B. Window Unit Parameters

Height $=$ height of window unit, measured in plane of window

Length $=$ length of window unit

Til $t=$ til $t$ from horizontal of window unit in degrees ( 0 to 90)

Azim = azimuth angle of window unit in degrees (south=0, east positive, west negative)

C. Shading Device Parameters

$A=$ horizontal projection of overhang beyond plane of window

$B=$ vertical height of overhang above top of window unit

$\mathrm{C}=$ height of side fin above plane of window unit

$\mathrm{D}=$ dis tance from edge of window unit to side fin

$E=$ thickness of mullions (mullions assumed to have a square cross-section)

$\mathrm{NH}=$ number of horizontal mullions

$\mathrm{NV}=$ number of vertical mullions

\section{Building Model Parameters}

A. Glass Parameters

$\mathrm{U}$-values = air-to-air conductance of glazing in $\mathrm{Btu} / \mathrm{sq} \mathrm{ft}-\mathrm{hr} \mathrm{F}$

For Day = air-to-air conductance of glazing

For Night $=$ air-to-air conductance of glazing plus shutter system

Operation Schedule of Movable Insulation

B. Zone Parameters

Loss Coefficients = from zone air to ambient, to zone 1 air, and to ground.

Appliance Rate $=$ appliance input rate to zone air

Heating and Venting

Thermostat Control Strategy

C. Mass Parameters

Conduct $=$ thermal conductivity of mass type

Density $=$ density of mass type

Spec Heat $=$ specific heat of mass type

D. Wall Parameters

Mass Area $=$ area of mass wall in sq $\mathrm{ft}$

Thickness $=$ thickness of wall in $\mathrm{ft}$

Surf Coef $=$ Surface-to-air heat transfer coefficient of zone 1 side (sunlit side) of mass wall in $\mathrm{Btu} / \mathrm{sq} \mathrm{ft}-\mathrm{hr} \mathrm{F}$

Back Loss Coef $=$ surface-to-air heat transfer coefficient of backside

Shade Cntl = control switch for selecting type of shading wall

$=0$ for al ways shaded

Number of Nodes

$$
=1 \mathrm{f} \text { or al ways sunlit }
$$

III. Run Parameters

A. Fraction of Radiation to Air = value between 0 and 1 indicating the fraction of radiation which is input directly to the zone 1 air node.

B. Fraction of Radiation Lost = value between 0 and 1 indicating the fraction of transmitted radiation which is lost from the building due to rereflection through glass (ete.). 

C. Shutter Control Switch = switch to select mode of operation of shutters:
$=0$ for no shutters
$=1$ for shutters to open for first full hour of sun and close after last full hour of sun
$=2$ for shutters to open and close at the times shown in zone parameters
$=3$ for shutters to be open if there will be a net energy gain during the coming hour, and to be closed otherwise

D. Convective Loop Option

E. Forced Convection Heat Transfer Coefficient

F. Wall Height between Vents

G. Area of One Row of Vents

H. Time Increment $=$ time increment for finite differencing in hours $(0$ to 1$)$

Table 9-7. SUMMARY OF SUNCAT OUTPUTS

I. A summary of monthly and annual averages for the total building and for each zone for the following daily total energy flows in Btu/sq $\mathrm{ft}$ of glass/day:
A. Solar
$=$ total transmitted solar radiation minus solar losses. Solar input possible only in Zone 1.
B. Auxiliary
$=$ auxiliary energy supplied to main
C. Ambient by a $100 \%$ efficient air heater
D. Vented
= energy gain from ambient air when the outside temperature is above the inside temperature
= energy which must be vented or supplied by a cooling device to maintain the zone air temperature at the specified upper set point
E. Glass Loss
= outward heat flow through the glazing system (ambient contains the inward heat flow)
F. Bldg Loss
$=$ outward heat flow from the exterior skin of the nonsolar components to outside air
G. Total Loss
H. Storage
$=$ sum of $\mathrm{E}$ and $\mathrm{F}$ above
$=$ net energy stored in the mass walls curing the month
I. Convect
= energy transfer
J. In Temp
K. Out Temp
L. Sol Fr
$=$ daily average zone temperature $(\mathrm{F})$
$=$ daily average ambient temperature $(F)$
= solar fraction as 1 - (auxiliary fraction), where the auxiliary fraction is calculated as the ratio of auxiliary energy used in the solar building (variable "auxiliary") to the reference auxiliary (variable "ref aux")
M. Useful Heat = reference auxiliary minus auxiliary used in solar building
N. Ref Aux = auxiliary energy used in reference building

II. Hourly Output

The hourly output is formatted with one physical record per hour. The variables are:

1) Day number

2) Hour

3) Solar radiation input to zone 1

4) Ambient temperature

5) Inside air temperatures for each zone

6) Measured test cell air temperature

7) Area-weighted average of modeled mass wall interior (sunlit) surface temperatures

8) Area-weighted average of measured test cell mass wall interior surface temperatures

9) Area-weighted average of modeled mass wall exterior surface temperatures

10) Area-weighted average of measured test cell mass wall exterior surface temperatures 


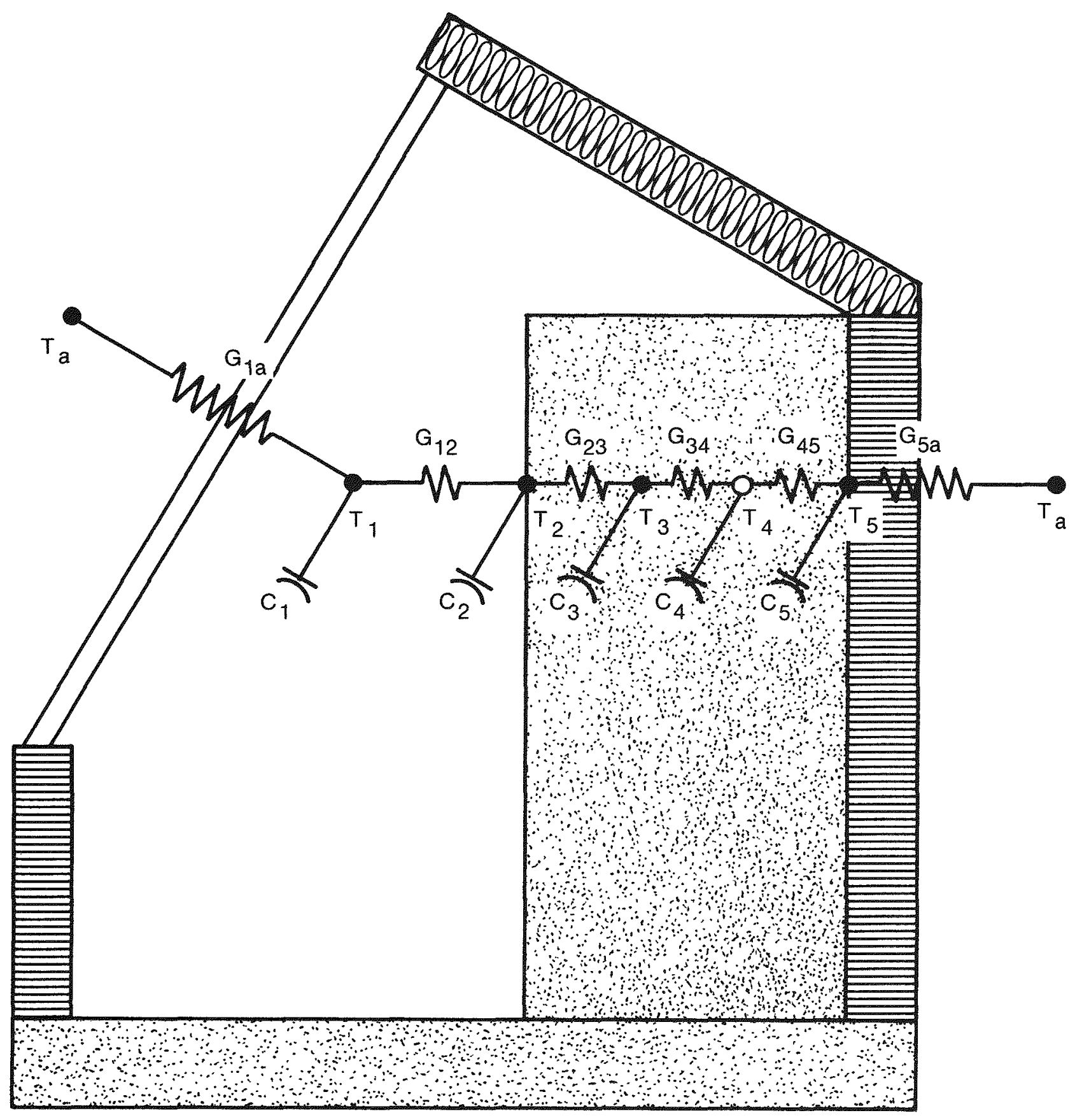

Fig.9-7. Nodal network of TEA-NET 


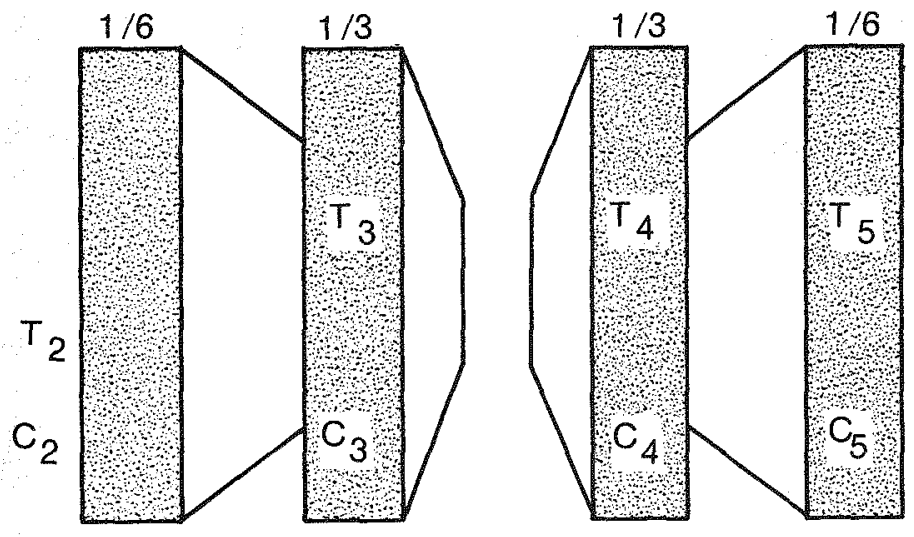

Fig. 9-8. Lumped nodal capacitance in TEA-NET

Table 9-8. BUHLDNG AND THERMAL CHARACTERISTICS USED IN TEA-NET EXAMPLE INPUT

\begin{tabular}{|c|c|c|c|c|}
\hline & $\mathrm{A}$ & $\mathrm{U}$ & UA & C \\
\hline & $\left(f t^{2}\right)$ & $\begin{array}{l}\text { Bty/hr } \\
\mathrm{ft}^{2} \mathrm{~F}\end{array}$ & $\underset{\mathrm{F}}{\mathrm{Btu} / \mathrm{hr}}$ & Btu/F \\
\hline $\begin{array}{l}\text { South-facing } \\
\text { glazing (without } \\
\text { shutters) }\end{array}$ & 250 & 0.50 & 125 & - \\
\hline $\begin{array}{l}\text { South-facing } \\
\text { glazing (with } \\
\text { shutters) }\end{array}$ & 250 & 0.10 & 25 & - \\
\hline $\begin{array}{l}\text { Roof, sides, front, } \\
\text { floor }\end{array}$ & 600 & 0.04 & 24 & - \\
\hline $\begin{array}{l}\text { Masonry wall air } \\
\text { film }\end{array}$ & 200 & 1.47 & 294 & \\
\hline $\begin{array}{l}\text { Masonry wall insula- } \\
\text { tion }\end{array}$ & 200 & 0.04 & 8 & - \\
\hline Masonry wall & 200 & & & 4000 \\
\hline $\begin{array}{l}\text { Greenhouse capaci- } \\
\text { tance (excluding } \\
\text { masonry wall) }\end{array}$ & & & & 500 \\
\hline $\begin{array}{l}\text { Infil tration } \\
\text { ( } 3 / 4 \mathrm{ac} / \text { hour })\end{array}$ & & & 27 & \\
\hline
\end{tabular}

\begin{tabular}{|c|c|c|}
\hline Mass wall conduc tivity & $\mathrm{k}$ & $=0.8 \mathrm{Btu} / \mathrm{hr}$ ft F \\
\hline Mass wall density & $\rho$ & $=150 \mathrm{lb} / \mathrm{ft}^{3}$ \\
\hline Mass wall heat capacity & $\mathrm{C}_{f}$ & $=0.2 \mathrm{Btu} / \mathrm{lb} \mathrm{F}$ \\
\hline Glazing transmittance & $\tau$ & $=0.76$ \\
\hline Mass wall absorptance & $\alpha$ & $=0.95$ \\
\hline
\end{tabular}

Clear day radiation on a $60^{\circ}$ surface is $306 \mathrm{Btu} / \mathrm{ft}^{2}$ on January 21 at $40^{\circ} \mathrm{N}$ latitude. A design day average temperature of $0 \mathrm{~F}$ with a diurnal temperature swing of $14 \mathrm{~F}$ is assumed.

Initial temperatures are arbitrarily assumed to be $70 \mathrm{~F}$ at all nodes for the purpose of this example problem. It should be noted that initial temperatures have a significant impact on performance and care should be taken to insure that realistic values are used in real problems.

Table 9-9. INPUT VALUES FOR EXAMPLE PROBLEM FROM TEA-NET PROGRAM

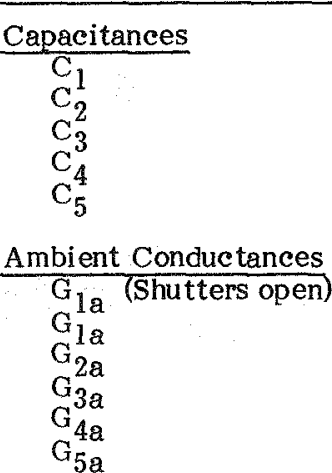

Nodal Conductances

$$
\begin{aligned}
& G_{12} \\
& G_{13} \\
& G_{14} \\
& G_{15} \\
& G_{23} \\
& G_{24} \\
& G_{25} \\
& G_{34} \\
& G_{35} \\
& G_{45}
\end{aligned}
$$

$\frac{\text { Internal Gain }}{\mathrm{Q}}$

$$
\begin{gathered}
\text { Solar Inputs } \\
\hline \text { node } 1 \\
\text { node } 2 \\
\text { node } 3 \\
\text { node } 4 \\
\text { node } 5
\end{gathered}
$$

Weather
$\mathrm{S}_{\max }$
$\mathrm{T}_{\mathrm{av}}$
$\mathrm{T}_{\mathrm{SW} / 2}$

Start and Stop Time

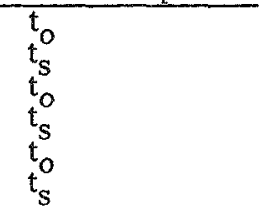

Initial Temperatures node 1

node 2

node 3

node 4

node 5

Thermostat

$\min$
$\max$
Room Capacitance

\begin{tabular}{c}
$\mathrm{Btu} / \mathrm{F}$ \\
\hline 500 \\
667 \\
1333 \\
1333 \\
667
\end{tabular}

$\underline{B t u / h r F}$ 176

76

0

0

8

Btu/hr F 294

0

0

720

0

720

0

720

$0 \mathrm{Btu} / \mathrm{hr} \mathrm{F}$

$$
\begin{gathered}
\frac{\mathrm{ft}^{2}}{29} \\
116 \\
0 \\
0 \\
0
\end{gathered}
$$

$306 \mathrm{Btu} / \mathrm{hr} \mathrm{ft} \mathrm{t}^{2}$

$0 \mathrm{~F}$

$7 \mathrm{~F}$

0 (12 midnight)

7
8
16
17
22

$\frac{\mathrm{F}}{70}$
70
70
70
70

$0 \mathrm{~F}$
$120 \mathrm{~F}$
$0 \mathrm{Btu} / \mathrm{F}$




\begin{tabular}{lc}
\hline Hour & 12 noon \\
T outside & $6 \mathrm{~F}$ \\
Insolation & $306 \mathrm{Btu}$ \\
Aux. for hour & $0 \mathrm{Btu}$ \\
Aux. subtotal & $0 \mathrm{Btu}$ \\
$\mathrm{T}_{1}$ & $72 \mathrm{~F}$ \\
$\mathrm{~T}_{2}$ & $102 \mathrm{~F}$ \\
$\mathrm{~T}_{3}$ & $80 \mathrm{~F}$ \\
$\mathrm{~T}_{4}$ & $70 \mathrm{~F}$ \\
$\mathrm{~T}_{5}$ & $67 \mathrm{~F}$ \\
\hline
\end{tabular}

The Solar Load Ratio method indicates monthly and annual performance and is useful for fine tuning during design development once a good deal of information is known about the building. The method is somewhat repetitious and tedious; however, SERI will soon issue it on magnetic cards for the TI-59 calculator, as well as in BASIC for use on microcomputers. This will greatly increase the utility of the SLR method. All three of these methods are correlations based on multiple runs of the hour-by-hour simulation program, PASOLE. Table 9-11 lists the passive system design assumptions made for purposes of the correlation.

\section{Definitions}

A number of terms unfamiliar to the designer will recur throughout these methods. It is important to understand these terms in a qualitative as well as quantitative sense in order to properly interpret the data and results which these methods contain.

The terms to be discussed in this section are SSF, BLC, and LCR.

\section{Solar Savings Fraction (SSF)}

Solar savings fraction (SSF) is the percentage of energy saved by a passive solar building as compared to a "conventional building." The conventional building is identical to the passive solar building in all respects except that the solar collection area has been removed and replaced by conventional construction. LASL defines this conventionally constructed wall or roof area which replaces the solar collection area as adiabatic, that is, having no net heat transfer.

To illustrate, let us imagine the following experiment. (See Fig. 9-9).

First, we construct a passive solar building with lots of windows for collection area on the south wall. We install electric resistance heating so that we can determine directly from the electric meter the amount of energy used in the building. We set a special thermostat such that the heating comes on whenever the room air temperature falls below $65 \mathrm{~F}\left(18^{\circ} \mathrm{C}\right)$ and the building is vented or cooled whenever the room air temperature rises above $75 \mathrm{~F}\left(24^{\circ} \mathrm{C}\right)$. We monitor this building for a year, and at the end of that year we find that 20 million $\mathrm{Btu}(21 \mathrm{GJ})$ were used to heat the building.
TABLE 9-11. Design Assumptions of SLR Method

Thermal Storage Wall Assumptions

Thermal Storage:

Building Mass:

Double Glazing:

$45 \mathrm{Btu} / \mathrm{F}-\mathrm{sq}$ ft of glazing

Negligible

Normal solar trans-

mittance $=0.747$

Air Temperature Range

in Building:

\section{$65 \mathrm{~F}$ to $75 \mathrm{~F}$}

Night Insulation:

R9 when used. Insulation in place from 5 p.m. to 8 a.m.

Wall to Room Conductance: $1.0 \mathrm{Btu} / \mathrm{hr}-\mathrm{sq} \mathrm{ft} \mathrm{F}$

Trombe Wall Properties:

$\mathrm{k}=1.0 \mathrm{Btu} / \mathrm{hr}-\mathrm{sq} \mathrm{ft} \mathrm{F}$

$\mathrm{C}_{\mathrm{p}} *=30 \mathrm{Btu} / \mathrm{cu} \mathrm{ft}-\mathrm{F}$

Trombe Wall has vents with backdraft dampers.

Transmitted solar radiation evenly distributed on storage mass.

Direct Gain Assumptions

Thermal Storage:

$45 \mathrm{Btu} / \mathrm{F}-\mathrm{sq} \mathrm{ft}$ of glazing

Mass Distribution:

6 in. thick layer of concrete on floor and north, east, or west walls. Mass surface area is three times the glazing area.

Other Building Mass:

Negligible

Double Glazing:

Normal solar transmittance $=0.747$

Air Temperature Range in Building:

$65 \mathrm{~F}$ to $75 \mathrm{~F}$

Night Insulation:

$\mathrm{R} 9$ when used. Insulation in place from 5 p.m. to 7 a.m.

Mass-Surface-to-Room

Air Conductance:

1.0 Btu/hr-sq ft F

Storage Mass Properties:

$k=1.0 \mathrm{Btu} / \mathrm{hr}-\mathrm{sg} \mathrm{ft} \mathrm{F}$

$\mathrm{C}_{\mathrm{p}}{ }^{*}=30 \mathrm{Btu} / \mathrm{cu} \mathrm{ft}-\mathrm{F}$

Glazing Orientation:

Vertical and south facing

Mass Surface Solar

Absorptance:

Overhang:

None

Mass Area/Glass Area: $\quad 3$

Transmitted solar radiation evenly distributed on storage mass.

${ }^{*} \mathrm{C}_{\mathrm{p}}=$ Volumetric heat capacity. 


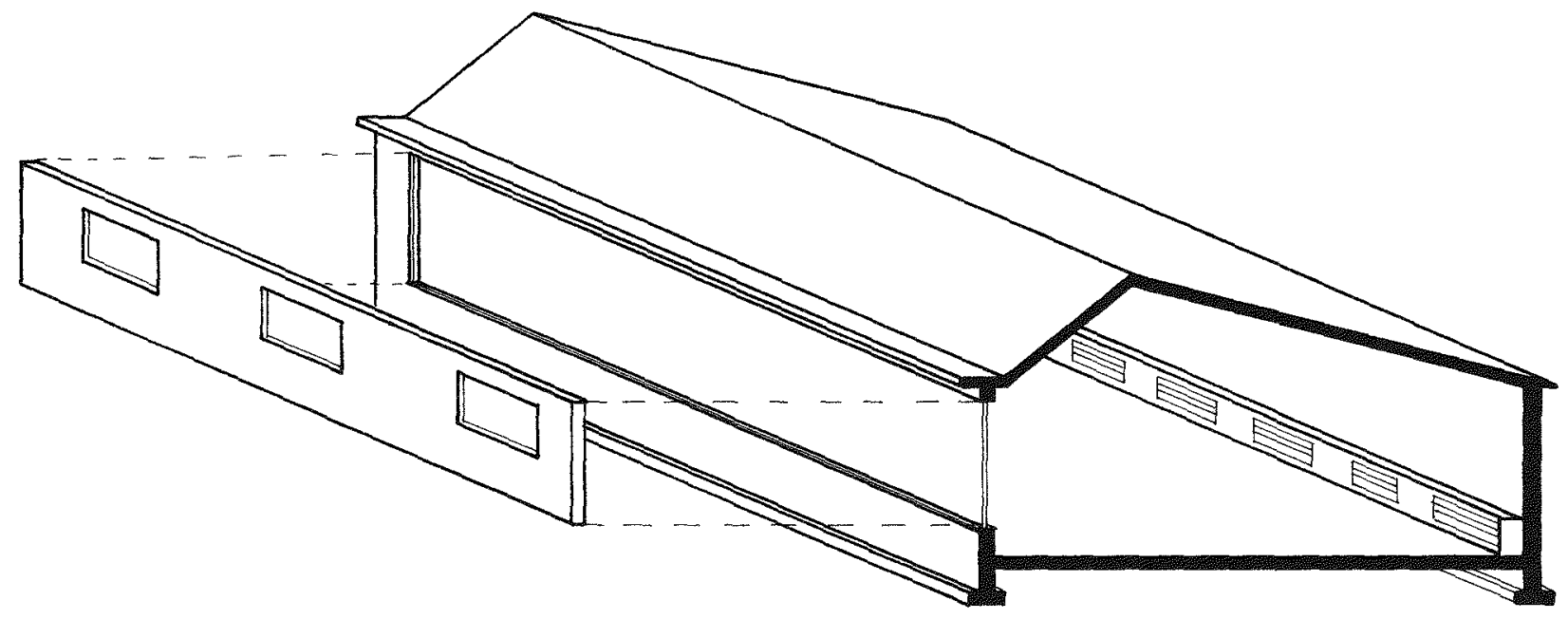

Fig.9-9. Solar Savings Fraction house

Next, because we have excellent contacts in high places, we are able to roll back the calendar and repeat the previous year's weather. We modify our solar building in the following way: over the solar collection area, we place a perfectly insulating piece of material such that no heat can flow into or out of the building through it. We now monitor the building again and find that the nonsolar building uses 60 million Btu ( $63 \mathrm{GJ}$ ) for heating. The 40 million Btu ( $42 \mathrm{GJ})$ difference in heating energy required by the solar building as compared to the nonsolar building was supplied by the Sun. The solar savings fraction (SSF) is, therefore,

$$
\frac{40 \times 10^{6}}{60 \times 10^{6}}=66 \%
$$

In general terms

$$
\mathrm{SSF}=1-\frac{\text { Furnace heat required by solar building }}{\begin{array}{l}
\text { Furnace heat required by comparable nonsolar } \\
\text { building }
\end{array}}
$$

$$
\mathrm{SSF}=\frac{\text { Furnace heat replaced by solar energy }}{\begin{array}{c}
\text { Furnace heat required by comparabie nonsolar } \\
\text { building }
\end{array}}
$$

\section{Building Load Coefficient (BLC)}

In order to use the LCR method it is first necessary to find the BLC. The building load coefficient is similar to a standard ASHRAE steady-state building load calculation as represented by the well-known formula $Q=U A \Delta T$, except that it is in terms of Btu/DD instead of Btu/hr and the steady-state loss through the solar collection area is not counted.

\footnotetext{
Where $Q=$ heat loss in $B$ tu/hr

$U=$ Conductance in Btu/hr-sq ft F

$\mathrm{A}=$ Area in sq ft

$\Delta \mathbf{T}=$ Temperature difference between indoors and outdoors
}

The most general way of deriving the BLC is to simply do an ASHRAE steady-state design heat loss ealculation with the addition of several steps.

$$
Q=U A \triangle T
$$

Find:

(1)

$\begin{array}{ll} & \text { UA (walls above grade) } \\ + & \text { UA (walls below grade) } \\ + & \text { UA (floor) } \\ + & \text { UA (doors) } \\ + & \text { UA (ceiling) } \\ + & \text { Infiltration }=\text { ach } \times .018 \\ & \text { x } \Delta \mathrm{T}, \\ + & \text { UA* (windows) }\end{array}$

*Not counting the UA $\Delta \mathrm{T}$ through solar collection area

Divide $\Sigma$ UA $\Delta \mathrm{T}$ by $\triangle \mathrm{T}($ Design). Btu/F-hr

Multiply $\frac{\mathrm{UA} \triangle \mathrm{T}}{\Delta \mathrm{T}(\mathrm{Design})}$ by $24 \mathrm{hr}$

To get $\mathrm{Btu} / \mathrm{F}-$ day $=\mathrm{BLC}$

If the $\Delta T$ s are all equal as might be the case in a building with a vented crawl space and no attic, then the procedure may be shortened by simply calculating the UA (overall) for the building as follows:

$\mathrm{UA}$ (walls) + UA (floor) + UA (roof) + UA (doors) + infil tration + UA (windows) not counting UA solar collection area $=\mathrm{UA}$ (overall) in $\mathrm{Btu} / \mathrm{F}-\mathrm{hr}$

UA (overall) $\times 24 \mathrm{hr}=\mathrm{BLC}$ in Btu/F-day. 


\section{Load Collector Ratio (LCR)}

The Load Collector Ratio (LCR) is simply a measure which compares the conservation portion of the building, as expressed by the building load coefficient, with the size of the solar collection area. LCR is defined as BLC divided by solar collection area expressed in units of Btu/DD per square foot of collection area. For example, if we have a very tightly buil t and well-insulated building, this implies a relatively smaller BLC than if we have a leaky building with no insulation. For a given collector area the more conservative building will therefore have a relatively smaller LCR than the poorly insulated building.

These terms will be further clarified in the following example.

\section{SAMPLE PROBLEM}

The following sample problem is for a $1,200 \mathrm{sq} \mathrm{ft}$ single family residence in Boston, Mass. We will trace this sample problem through programming, conceptual design, and schematic design by using the LASL Passive Solar rules of thumb and Load Collector Ratio method. The tables and graphs referenced in the sample problem are from Passive Solar Design Analysis by J. Douglas Balcomb and the $\mathrm{Q}-11$ branch at Los Alamos Scientific Laboratory.

We will follow our sample problem through the following steps as an integral part of the design process.

\section{Programming, Conceptual Design}

\section{Rules of Thumb}

Step 1: Use rule of thumb to derive a design indicator for sizing the collection area.

Step 2: Use rule of thumb to derive a design indicator for sizing and placing the thermal storage.

\section{Schematic Design}

\section{LCR Method}

Step 1: Recalculate collection area based on real design constraints and economic considerations.

Step 2: Recalculate storage mass size based on new collection area.

Step 3: Calculate Buil ding Load Coefficient (BLC).

Step 4: Calculate Load Collector Ratio (LCR).

Step 5: Calculate Solar Savings Fraction (SSF).

Step 6: Determine average interior temperature for a clear day in January.

Step 7: Estimate interior air temperature savings.

Step 8: Calculate annual auxiliary and the useful solar energy supplied to the house.

\section{SAMPLE PROBLEM RULES OF THUMB}

Location: Boston, Mass.

Latitude: $40^{\circ} \mathrm{N}$

Annual Degree Day (DD) Heating: 5,621 Cooling: 661

where $D D=65-\frac{\mathrm{T}_{\operatorname{Max}}+\mathrm{T}_{\text {Min }}}{2}$

$\mathrm{T}_{\text {Max }}=$ daily maximum ambient temperature

$\mathrm{T}_{\text {Min }}=$ daily minimum ambient temperature
Average January Temperature: $29 \mathrm{~F}$

Average January Max. Temp.: $36 \mathrm{~F}$

Average January Min. Temp.: $22 \mathrm{~F}$

Average July Temperature: $73 \mathrm{~F}$

Average July Max. Temp.: $81 \mathrm{~F}$

Average July Min. Temp.: $65 \mathrm{~F}$

Proposed Floor Area: $1,200 \mathrm{sq} \mathrm{ft}$

\section{STEP 1-Sizing Colleetion Area}

Look in rule of thumb table (Table 9-12) for Boston, Mass.

South glass area should be $15 \%$ to $29 \%$ of floor area to attain $17 \%$ to $25 \%$ solar savings fraction (SSF) without night insulation or $40 \%$ to $64 \%$ SSF with night insulation (NI).

Choosing to aim for the relatively high Solar Savings Fraction of $64 \%$, we can include in our programming the requirement for approximately: $0.29 \times 1,200 \mathrm{sq}$ ft floor area $=350 \mathrm{sq} f t$ collection area.

350 square feet of solar collection area. 
Table 9-12. SAMPLE RULES OF THUMB

\begin{tabular}{|c|c|c|c|c|c|c|}
\hline \multirow[b]{2}{*}{ City } & \multicolumn{2}{|c|}{$\begin{array}{c}\text { Ratio of } \\
\text { Glass Area/Floor Area }\end{array}$} & \multicolumn{2}{|c|}{$\begin{array}{l}\text { SSF Without } \\
\text { Night Insulation }\end{array}$} & \multicolumn{2}{|c|}{$\begin{array}{c}\text { SSF With } \\
\text { Night Insulation }\end{array}$} \\
\hline & Lower Limit & Upper Limit & Lower Limit & Upper Limit & Lower Limit & Upper Limit \\
\hline & R1 & $\mathrm{R} 2$ & Sl & \$2 & S3 & $\mathrm{S} 4$ \\
\hline Boston, Mass. & .15 & .29 & 17 & 25 & 40 & 64 \\
\hline
\end{tabular}

\section{STEP 2-Sizing and Placing Thermal Storage Mass}

How much? How thick? Where?

The sizing of storage is important to prevent overheating on elear winter days and to provide sufficient energy at night when it is needed most.

\section{Rule of Thumb for Storage}

$\begin{array}{lcl}\text { Water Storage } & 0.6 \times \mathrm{SSF} & \text { in units of } \mathrm{lb} / \mathrm{sg} \mathrm{ft} \\ \text { Masonry Storage } & 3 \times \mathrm{SSF} & \text { of south glass }\end{array}$

From the rule of thumb for collection area we know that we should get approximately $64 \%$ SSF. So from the rule of thumb for masonry storage we need $3 \times 64=192 \mathrm{lb}$ of masonry per sq ft of south glass.

At this point in the design we probably have not yet decided whether we will use a Trombe wall system, a direct gain system, or some combination of systems. The ultimate design will depend on aesthetic, siting, and functional issues. If the south side of the lot faces a superhighway, it may be advantageous to protect the occupants acoustically and visually, as well as thermally, with a thick concrete Trombe wall. On the other hand, if to the south is a wonderful view of the Berkshire Mountains, direct gain may be more in order. Likewise, the client may prefer visual privacy with respect to bedrooms and an indoor-outdoor connection for the living room/dining room. Whatever the final resolution, it is important to begin designing with some idea of the quantity and placement of thermal storage.

\section{For Trombe Wall Storage}

From rule of thumb we need $190 \mathrm{Ib}$ of storage for each square foot of collection area.

Concrete weighs $\simeq 150 \mathrm{lb} / \mathrm{cu} \mathrm{ft}$. Therefore, a $16 \mathrm{in.}(1.33 \mathrm{ft}$ ) thick wall will give $1.33 \mathrm{cu} \mathrm{ft} \times 150 \mathrm{lb} / \mathrm{cu} \mathrm{ft}=200 \mathrm{lb} \mathrm{of}$ storage for each square foot of collection area.

Table 9-12A. THERMAL LAG

\begin{tabular}{ccc}
$\begin{array}{c}\text { Wall } \\
\text { Thickness } \\
\text { (Inches) }\end{array}$ & $\begin{array}{c}\text { Inside Surface } \\
\text { Temperature Swing } \\
(\mathrm{F})\end{array}$ & $\begin{array}{c}\text { Time of Temperature } \\
\text { Peak at Inside } \\
\text { Surface }\end{array}$ \\
\hline 8 & 27 & $6: 00 \mathrm{pm}$ \\
12 & 13 & $8: 00 \mathrm{pm}$ \\
16 & 6.5 & $10: 30 \mathrm{pm}$ \\
20 & 3.0 & $1: 30 \mathrm{am}$ \\
24 & 1.3 & $4: 30 \mathrm{am}$ \\
\hline
\end{tabular}

Referring to Table 9-12A we see that a 16-in. thickness insures that energy falling on the outer surface of the wall during the day reaches the interior surface of the wall in the evening when it is most needed.

\section{For Direet Gain Storage}

Direct gain storage is more dependent on the geometry and interior organization of the building.

Direct gain storage placement rules:

- In direct sunlight as much as possible.

- In the same space with the solar collection area. 
- Not obscured by extensive carpets or wall hangings.

- As much surface area as possible.

- No more than about 4 in. thick except for water storage which can be almost any thickness.

If we use direct gain and an interior masonry or ceramic finishing material 4 in. thick, then we will need approximately $1,300 \mathrm{sq} \mathrm{ft}$ of surface area in the same space as the solar collection to attain about $190 \mathrm{lb}$ of storage for each square foot of south glass.

A $1 \mathrm{ft} \times 1 \mathrm{ft} \times 4$ in. section of masonry weighs $.333 \times 150 \mathrm{lb} / \mathrm{cu} \mathrm{ft}=50 \mathrm{lb} .190 \mathrm{lb} \div 50 \mathrm{lb}=3.8 \mathrm{sq} \mathrm{ft}$ of $4 \mathrm{in}$. thick masonry for each square foot of south glass. Therefore, $3.8 \times 350 \mathrm{sq} f \mathrm{ft}$ of collection area $=1,300 \mathrm{sq} \mathrm{ft}$ of mass surface area.

\section{LCR METHOD}

\section{SAMPLE PROBLEM}

The rules of thumb were something we used before we had any idea of how our building would appear. It gave us information which could help us ensure that whatever form the building took would allow enough room for collection area and thermal storage. Now let us assume that we have completed conceptual design, and we are enough into the schematic design phase to have chosen a pure direct gain system and to have drawn some plans, sections, and elevations for the building. (See Figs. 9-10 to 9-15).

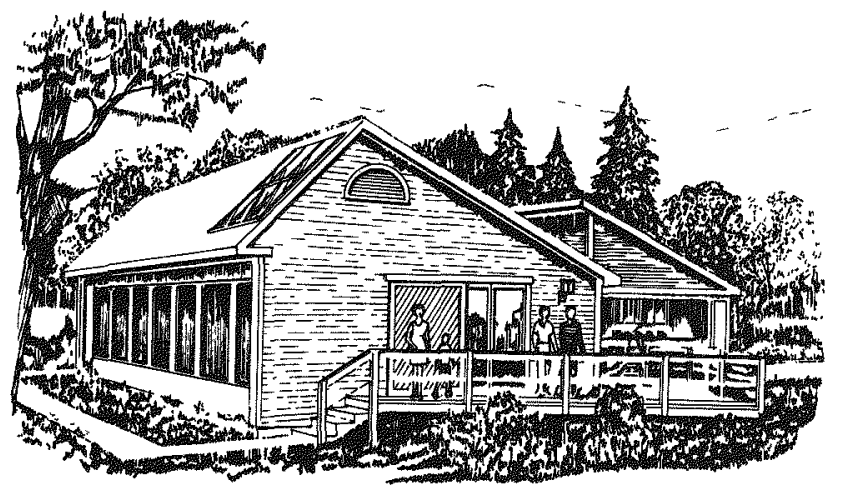

Fig. 9-10. Perspective of direct gain sample problem house

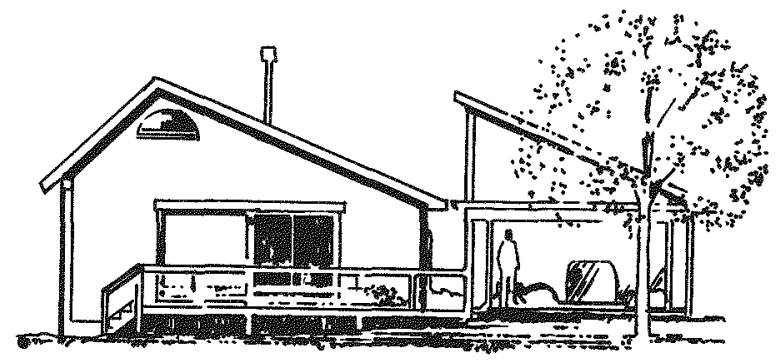

Fig. 9-12. East elevation

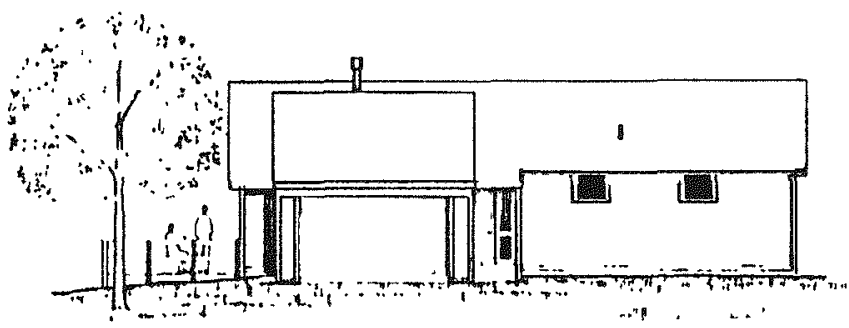

Fig. 9-11. North elevation

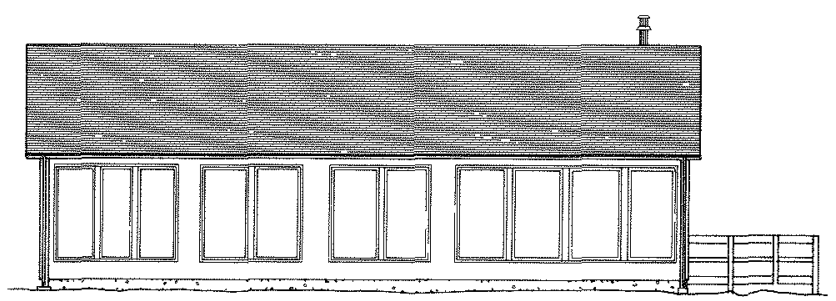

Fig. 9-13. South elevation 


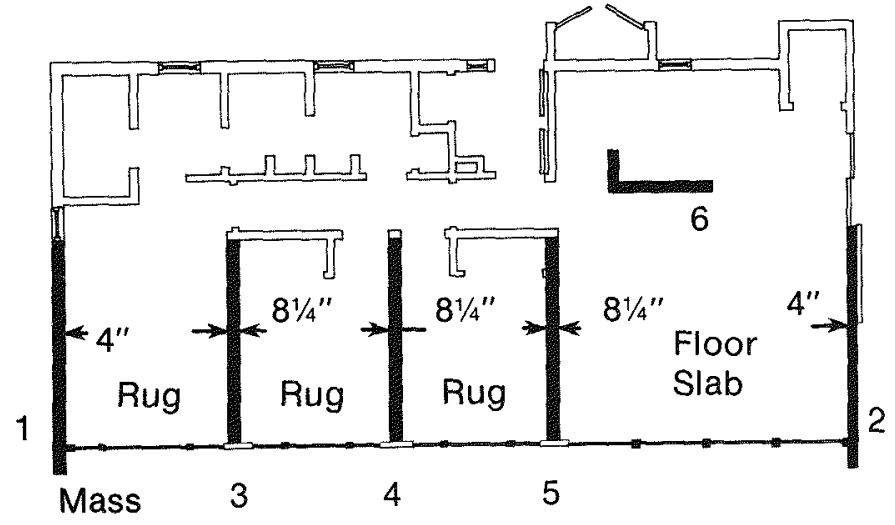

Fig. 9-14. Plan

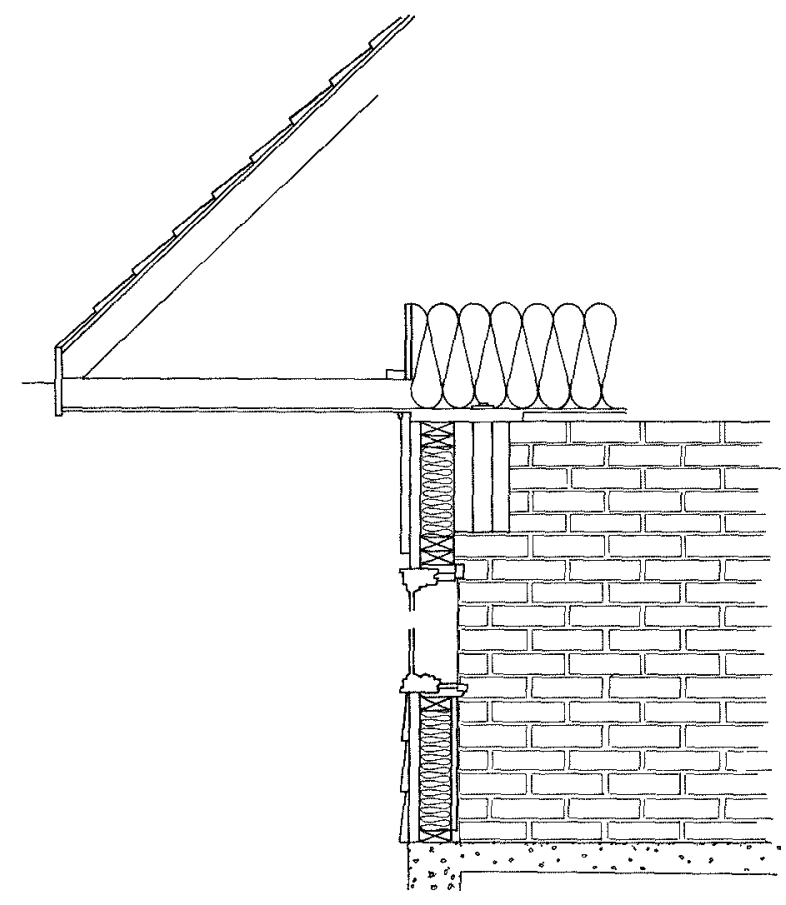

Fig. 9-15. Window wall section

\section{STEP 1-Re-size Colleetion Area Aceording to Real Design Constraints and Economics}

Having done the drawings we realize that if we wish to stick to a fairly conventional house configuration and structural system, and if we want to use off-the-shelf window sizes, it will be more practical to reduce the glass area on the south wall from the $350 \mathrm{sq} \mathrm{ft}$ in the rule of thumb to $250 \mathrm{sq} \mathrm{ft}$. (This is still within the range suggested by the rule of thumb.)

Since we have reduced the collection area to $250 \mathrm{sq} \mathrm{ft}$ then by interpolation, the rule of thumb predicts a solar savings fraction (SSF) of about $53 \%$.

\section{STEP 2-Re-size Storage Mass Based on New Collection Area}

Based on the $250 \mathrm{sq} \mathrm{ft}$ collector area, the storage rule of thumb for masonry asks for $53 \times 3=160 \mathrm{lb}$ of masonry in thicknesses of no more than $4 \mathrm{in}$. for each square foot of collection area. If we assume our masonry storage has an thicknesses of no more than $4 \mathrm{in}$. for each square fority of $130 \mathrm{lb} / \mathrm{cu} \mathrm{ft}$, then we need approximately $900 \mathrm{sg} \mathrm{ft} \mathrm{of} \mathrm{storage} \mathrm{area} \mathrm{at} \mathrm{a} \mathrm{thickness} \mathrm{of} 4$ in. By using 4 -in. comm on brick interior finishing on walls 1 and 2 (Fig. 9-14), and by using double-wythe brick walls ( 8 in. \pm thick total) for walls $3,4,5$, and 6 , we can accommodate this storage requirement and still allow carpets on the bedroom and living room floor slabs.

Our design now has the following characteristics: (See Fig. 9-16.)

Location: Boston, Mass.

Latitude: $40^{\circ} \mathrm{N}$

$\mathrm{HDD}=5,621$

Average January Temperature: $29 \mathrm{~F}$

Area: $1,200 \mathrm{sq} \mathrm{ft}(24 \mathrm{ft} \times 50 \mathrm{ft})$

Slab on Grade

Single Story

Wall R 30

\section{Roof R 40}

Perimeter Insulation: 2 in. $\times 12$ in. $U=0.2$

Windows (Triple Glazed 1/2" air gap) $U=0.31$

Infil tration: $0.6 \mathrm{AC} / \mathrm{hr}$

Volume: $9,600 \mathrm{cu} \mathrm{ft}$

South Glass: $250 \mathrm{sq} \mathrm{ft}$

Non-south Glass: $72 \mathrm{sq} \mathrm{ft}$

External Wall Area: $762 \mathrm{sg} \mathrm{ft}$

Slab Perimeter: $148 \mathrm{ft}$ 
$384 \mathrm{ft}^{2}$ Opaque Wall

$24 \mathrm{ft}^{2}$ Glass

$150 \mathrm{ft}^{2}$ Opaque
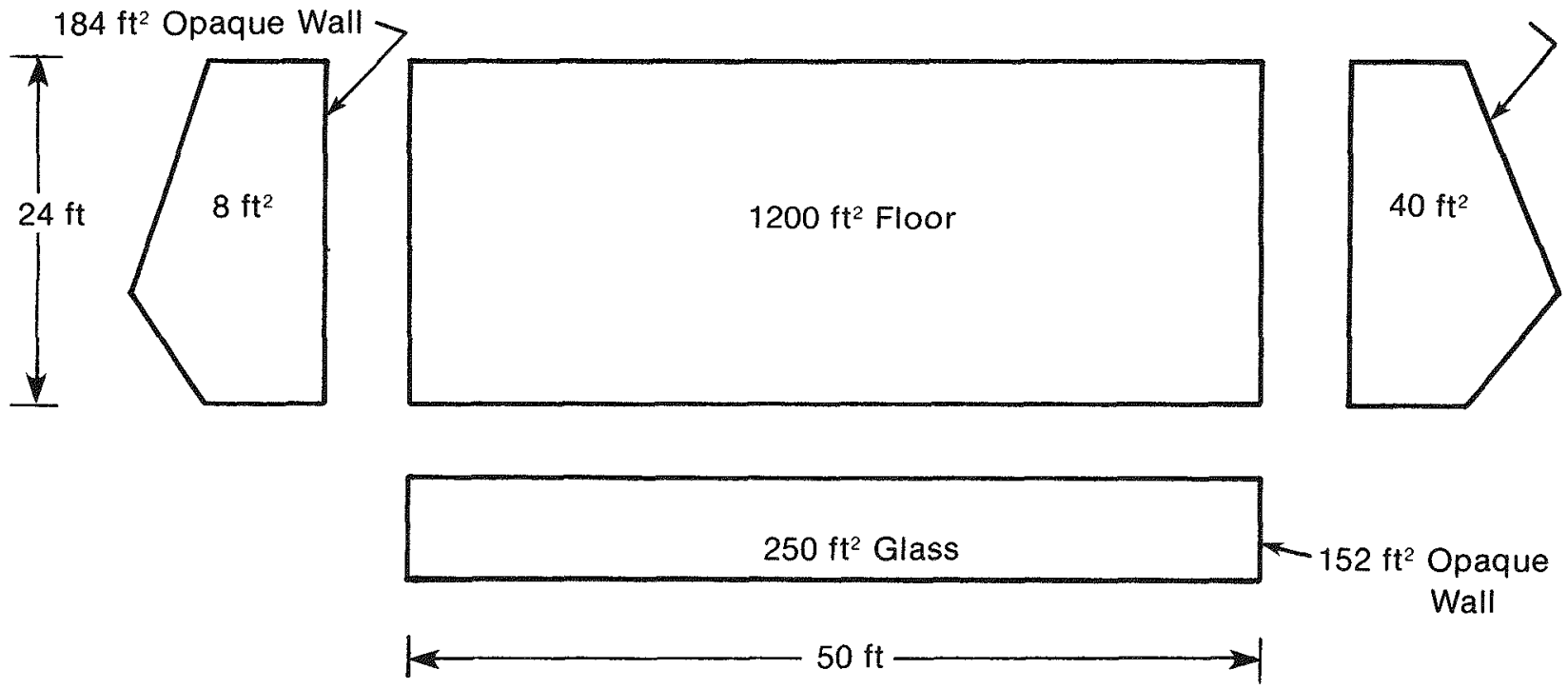

Fig. 9-16. Area take-off

STEP 3-Find Building Load Coefficient (BLC)

\begin{tabular}{lccccc}
\hline & $\mathrm{U}\left(\mathrm{Btu} / \mathrm{hr} / \mathrm{F} / \mathrm{ft}^{2}\right)$ & $\mathrm{A}\left(\mathrm{ft}^{2}\right)$ & $\mathrm{UA}(\mathrm{Btu} / \mathrm{hr} / \mathrm{F})$ & $\%$ \\
\hline Walls & .033 & $(\mathrm{R} \mathrm{30})$ & 762 & 25 & 12 \\
Roof & .025 & $(\mathrm{R} \mathrm{40)}$ & 1200 & 30 & 14 \\
Slab & .20 & $(\mathrm{R} 5)$ & $148(\mathrm{ft})$ & 30 & 14 \\
Triple Glazed & .31 & $(\mathrm{R} \mathrm{3.2)}$ & 72 & 22 & 10 \\
$\quad$ Non-South Glass & & & & \\
Infil tration & $(.6 \mathrm{AC} / \mathrm{h})\left(.018 \mathrm{Btu} / \mathrm{ft}^{3}-\mathrm{F}\right)\left(9600 \mathrm{ft}^{3}\right)=104^{*}$ & 50 \\
& & & & 211 & 100 \\
\hline
\end{tabular}

Total UA + Infil tration $=211 \mathrm{Btu} / \mathrm{hr} / \mathrm{F}$

$\mathrm{BLC}=211(24)=5,064 \mathrm{Btu} / \mathrm{F}-$ day

\section{STEP 4-Calculate LCR}

$\mathrm{LCR}=\frac{\mathrm{BLC}}{\text { South Glass Area }}=\frac{5,064(\mathrm{Btu} / \mathrm{F}-\text { day })}{250\left(\mathrm{ft}^{2}\right)}=20$

\section{STEP 5-Calculate SSF}

Look in LCR Table (Table 9-13) for Boston under direct gain with night insulation (DGNI).

For $\mathrm{LCR}=20$

$\mathrm{SSF}=53 \%$

Comparing to rule of thumb SSF $=52.8 \%$ with glass area to floor area ratio of $21 \%$. 
Table 9-13. LCR TABLE FOR SAMPLE PROBLEM

\begin{tabular}{l||crrrrrrrrr}
\hline \multicolumn{1}{c||}{ City } & System Type & \multicolumn{1}{c}{.1} & .2 & .3 & .4 & .5 & .6 & .7 & .8 & .9 \\
\hline Boston & WW & 81 & 35 & 20 & 13 & 9 & 5 & - & - & - \\
Lat: $40^{\circ} \mathrm{N}$ & WWNI & 159 & 73 & 46 & 32 & 24 & 19 & 15 & 11 & 3 \\
HDD: 5,621 & TW & 85 & 36 & 21 & 13 & 8 & 4 & - & - & - \\
T(Jan): $29 \mathrm{~F}$ & TWNI & 150 & 69 & 43 & 30 & 23 & 17 & 13 & 10 & 6 \\
& DG & 49 & - & - & - & - & - & - & - & - \\
& DGNI & 158 & 72 & 44 & 30 & 22 & 16 & 11 & 3 & 4 \\
\hline
\end{tabular}

We used ratio of $21 \%$.

The SSF predicted by LCR will differ from that predicted by the rules of thumb depending on whether the building load coefficient (BLC) used for the LCR method agrees with that assumed in the rules of thumb. In other words, if the house in question is better insulated and tighter than the house assumed in the rule of thumb, then LCR will predict a higher SSF than the rule of thumb. In this case the skin load of our sample problem house was very close to the assumption in the rule of thumb, so we got very close agreement in the predicted solar savings fraction (SSF).

\section{STEP 6-Determine Average Interior Temperature for a Clear Day in January}

$\overline{\mathrm{T}}_{\text {int }}=\Sigma \overline{\mathrm{T}}_{\text {out }}+\Delta \mathrm{T}_{\text {int loads }}+\Delta \mathrm{T}_{\text {solar }}$

where:

$\overrightarrow{\mathrm{T}}_{\text {int }}=$ average interior temperature

$\Delta \mathrm{T}_{\text {int loads }}=$ change in interior temperature due to internal heat generation

$\overline{\mathrm{T}}_{\text {out }}=$ average outside temperature for the month

$\Delta T_{\text {solar }}=$ change in interior temperature due to solar gain

$\Delta \mathrm{T}_{\text {int loads }}=5 \mathrm{~F}-7 \mathrm{~F}$

$\overline{\mathrm{T}}_{\text {out }}$ (Use Table $9-13$ ) $=29 \mathrm{~F}$

$\Delta \mathrm{T}_{\text {solar }}$ (Use Fig. 9-17) $=35 \mathrm{~F}$

So for Boston:

$\mathrm{LCR}=20$

Latitude $=40^{\circ} \mathrm{N}$

$\Delta \mathrm{T}_{\text {solar }}=35 \mathrm{~F}$

So average interior temperature on a clear January day $=29 \mathrm{~F}+7 \mathrm{~F}+35 \mathrm{~F}=71 \mathrm{~F}$.

In the case where movable insulation is used, the average temperature will be somewhat higher than that predicted by this calculation.

\section{STEP 7-Estimate Temperature Swings}

For a direct gain system the magnitude of the temperature swing will depend on the quantity and surface area of the storage. Table 9-14 gives clear winter day interior air temperature swings for direct gain storage of various surface area to glass area ratios.

In our case we met the storage requirement by putting 4 in. of interior finish brick on walls 1 and 2 (Fig. $8-14$ ) and by using $8 \mathrm{in}$. of double wythe brick in walls 3,4 , and 5 . This gave us approximately $900 \mathrm{sq} \mathrm{ft}$ of storage surface area.

$900 \mathrm{sq} \mathrm{ft}$ storage area $\div 250 \mathrm{sq} \mathrm{ft}$ collection area $=3.6$.

This would give us a temperature swing of about $0.7 \times \Delta \mathrm{T}$ (solar) $=0.7 \times 35 \mathrm{~F}=24.5 \mathrm{~F}$. 


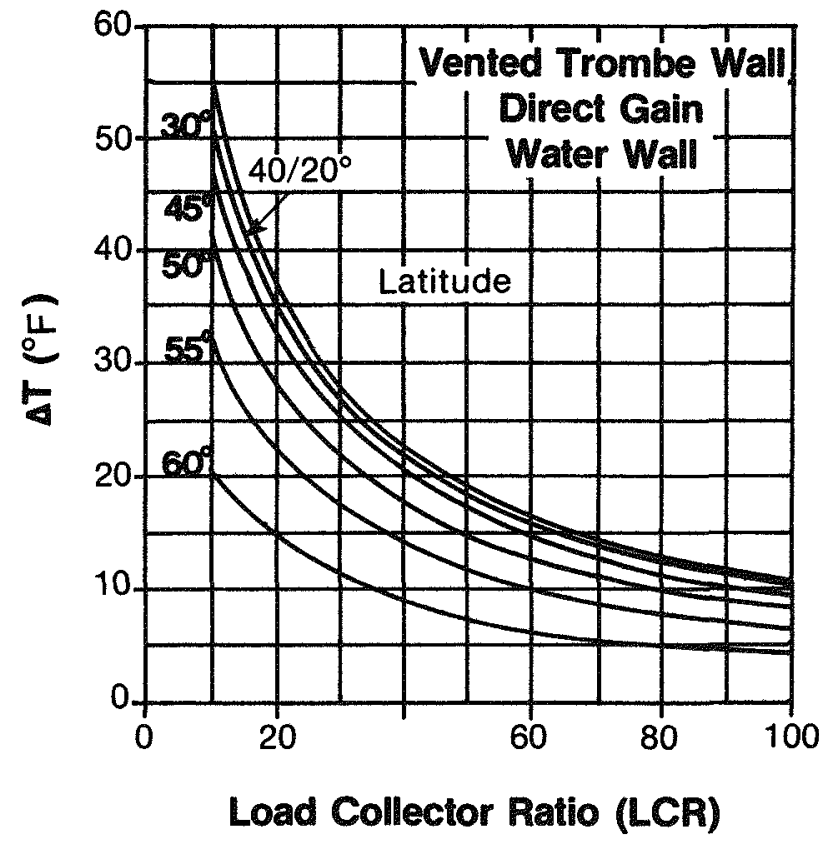

The temperature difference to be expected on a clear January day between the average inside temperature and the average outside temperature ( $\Delta T$ (solar)). This curve applies to the situation of a direct gain, water wall, or vented Trombe wall passive design. The curve marked $40 / 20^{\circ}$ applies at both a $40^{\circ}$ latitude and a $20^{\circ}$ latitude.
Table 9-14. CLEAR WIHTER DAY INTERIOR AIR TEMPERATURE SWINGS FOR DIRECT GAIN STORAGE

\begin{tabular}{|c|c|c|}
\hline Ratio: & $\frac{\text { Mass Surface }}{\text { Glazing Area }}$ & $\begin{array}{l}\text { Formula for } \\
\text { Temperature Swing }\end{array}$ \\
\hline & 1.5 & $1.11 \times \Delta \mathrm{T}_{\text {solar }}$ \\
\hline & 3 & $0.74 \times \Delta T_{\text {solar }}$ \\
\hline & 6 & $0.55 \times \Delta \mathrm{T}_{\text {solar }}$ \\
\hline & 9 & $0.37 \times \Delta \mathrm{T}_{\text {solar }}$ \\
\hline
\end{tabular}

\section{Fig. 9-17. Increase in interior tempera- ture due to solar gains}

Thus our average interior minimum and maximum temperatures if we allowed the house to "free float" would be

Maximum $=71+12=83 \mathrm{~F}$.

Minimum $=71-12=59 \mathrm{~F}$.

If we cared to reduce these temperature excursions, we could either add water storage or attempt to use the slab in the living room, kitchen, and bedrooms as storage. The practical limit for structurally incorporated mass in this house configuration would probably be about $1,500 \mathrm{sq} \mathrm{ft}$, which would give a mass area to collection area ratio of 6 and thus a temperature swing of $0.55 \times 35=19 \mathrm{~F}$.

Maximum average temp. $=71+9.5=80.5 \mathrm{~F}$.

Minimum average temp. $=71-9.5=61.5 \mathrm{~F}$.

It is evident that the difference in temperature swing between the design which allows free use of floor area (wall to wall carpet if desired) and that which requires thermal coupling of the floor slab to the space is relatively minor in this case. However, through the use of additional water storage or Trombe walls, interior temperature swings can be reduced considerably. 


\section{STEP 8-Calcelating Annual Auxiliary}

Annual Auxiliary $=[(1-$ SSF $) \times$ Conventional House Heating Load $]$

Annual Conventional Heating Load $=\mathrm{BLC}$ (Conv) $\times 5,621 \mathrm{DD}$ $=5,064 \mathrm{Btu} / \mathrm{DD} \times 5,621 \mathrm{DD}=29 \times 10^{6} \mathrm{Btu}$

$\left[(1-.53) \times 29 \times 10^{6}\right]=14 \times 10^{6} \mathrm{Btu}$

So: Annual Auxiliary Required $=14$ million $\mathrm{Btu}$

and

the amount of useful solar energy supplied is $29-14=15$ million Btu.

\section{CONCLUUSION}

Location: Boston, Mass.

$H D D ; 5,621$

Floor Area: $1,200 \mathrm{sq} \mathrm{ft}$

Collection Area: $250 \mathrm{sq} \mathrm{ft}$

Collection Area/Floor Area $=21 \%$

Walls: R 30

Roof: R 40

BLC: 5,064 Bru/F-day

LCR: BLC/Collection Area $=20 \mathrm{Btu} / \mathrm{F}-$ day $/ \mathrm{sq} \mathrm{ft} \mathrm{s} . \mathrm{gl}$.

Avg. Int. January Temp。 $=71 \mathrm{~F} \pm$

Temperature Swing $=24 \mathrm{~F}$

Avg. Maximum Int. January Temperature $=83 \mathrm{~F}$

Avg. Minimum Int. January Temperature $=59 \mathrm{~F}$.

$\mathrm{SSF}=53 \%$

Amnual Energy Savings $=15$ million Btu

To keep this sample problem as simple as possible, a pure direct gain system was used. It should be noted, however, that when relatively high solar saving fractions are desired, it is generally most beneficial in terms of comfort, Iuminance, and whole building thermal performance to use some mix of systems (e.g., a combination of direct gain to meet day time loads and assist in early morning warm-up, and Trombe wall to meet nighttime loads).

\section{Author's Note:}

It has not been within the scope of this chapter to discuss natural cooling, earth sheltering, use of wind breaks, or economics. Material on these subjects is currently being prepared. All of the above considerations can have a significant effect on whole building thermal and comf ort perf ormance and should be addressed by the responsible building designer. 
10

Acrive System Design and Sizing Methods 
10. Active System Design and Sizing Methods

Solar system sizing characteristics

Solar system simulation

Classification of design methods

Manual methods

Computer methods

Summary 


\section{ACTIVE SYSTEM DESIGN AND SIZING METHODS}

\section{INTRODUCTION}

In this chapter we will discuss methods that have been developed for the analysis and design of active solar heating, cooling, building service hot water (BSHW), and industrial process heat (IPH) systems. The methods span the spectrum between manual methods, hand-held calculator methods, and detailed computer simulations. The emphasis will be on methods that have been tested against actual installed solar systems.

There are several purposes to be served by active solar system analysis and design methods. First, they are needed to determine the appropriate size of the collector array. This decision should be made on an economic basis where the life-cycle cost of the solar system is compared with that of the fuel saved in its lifetime. To determine the future cost of fuel saved, the system performance, in terms of the fraction of the energy consumption met by solar (the solar contribution), must be ascertained using a design method. Furthermore, a space conditioning system has two aspects-supplying heat (or cooling) to a space and conserving the heat (or cooling) that is supplied. An economical system design is based on a balance of these two aspects. Thus, design methods are needed to balance quantitatively the energy supply and conservation costs, leading to lower life-cycle costs than those resulting from supply systems designed for loads that are considered constant [1].

Second, having selected the collector size, the components in the system (e.g., storage, heat exchangers) must be selected and sized; and the system configuration and control strategy, selected. These decisions are normally made through performance or cost optimization studies. Such studies are done by analyzing the dynamic performance of systems using tools that predict system behavior, usually computer programs. Integrated energy quantities over long periods (usually a year) can be computed, such as useful solar energy supplied to the load and the amount of auxiliary energy needed. Information on the times when these energy flows occur can also be obtained. The results of such evaluations can then be generalized for generic system types through a series of parametric studies that examine the sensitivity of system performance to various design parameters (e.g., collector tilt, storage size, control strategy). Such a process has been accomplished in developing the F-CHART design methodology. For new or unusual systems or for unusual applications, detailed simulation studies should be accomplished during the design process. However, for the majority of applications, the generalized results of previous analysis may be used in graphical or tabular form to make most component sizing decisions.

Third, analysis and design methods are used to determine the economic feasibility of a proposed solar design using a life-cycle cost analysis. Results of such studies cannot readily be generalized because they are specific to the local weather, system design, and time-dependent system and fuel costs.

\section{SOLAR SYSTEM SIZING CHARACTERISTICS}

Solar energy systems differ from conventional systems in three key respects that relate to system performance and collector-sizing requirements [2].

First, incident solar energy is not available continuously; and it may not be available at all during peak demand periods at night or in cloudy weather. Because solar energy may not be able to meet all demands economically, auxiliary energy supply systems must be provided. Sizing of solar systems components is therefore based on overall system performance, rather than on peak load calculations. The auxiliary system is still sized for peak loads.

Second, both the energy demand and the thermal storage mass influence the operating temperature of the solar collectors, and therefore influence the amount of incident solar energy that a given collector array can collect. Consequently, seasonal building heating and cooling load variations strongly influence the annual performance of a solar energy system.

Third, solar energy is typically collected and delivered over a large temperature range. This influences the performance of heating coils and absorption chillers. For these reasons, conventional "peak load" design methods are not acceptable. 


\section{SOLAR SYSTEM SIMULATION}

Whether used as a manual, hand-held calculator, or computer technique, virtually all design methods in use today were developed using simulation models. The application of simulation in the development of design tools is discussed next.

The performance of any solar heating or cooling system depends on the solar radiation available to the collector, the outside ambient air temperature and wind condition, the collector design, the inlet fluid temperature from storage, and the thermal load on the system. General understanding of how the above factors affect system performance in various locations requires a system simulation. Prediciting system performance is difficult because solar systems always operate in transient modes, they are driven by constantly varying weather, the relationship among system components is complex, and the systems are nonlinear in their response to solar radiation. Thus, it is not possible to analyze systems based on their response to average weather conditions. Short term performance information can be helpful in selecting components. The long-term performance can be predicted fairly accurately by using a digital computer program on an hour-by-hour basis. A series of parametric runs can be accomplished to estimate design parameter sensitivity (See Fig. 10-1 ). Sound design tools will result if these simulations are backed up by laboratory and field verifications.

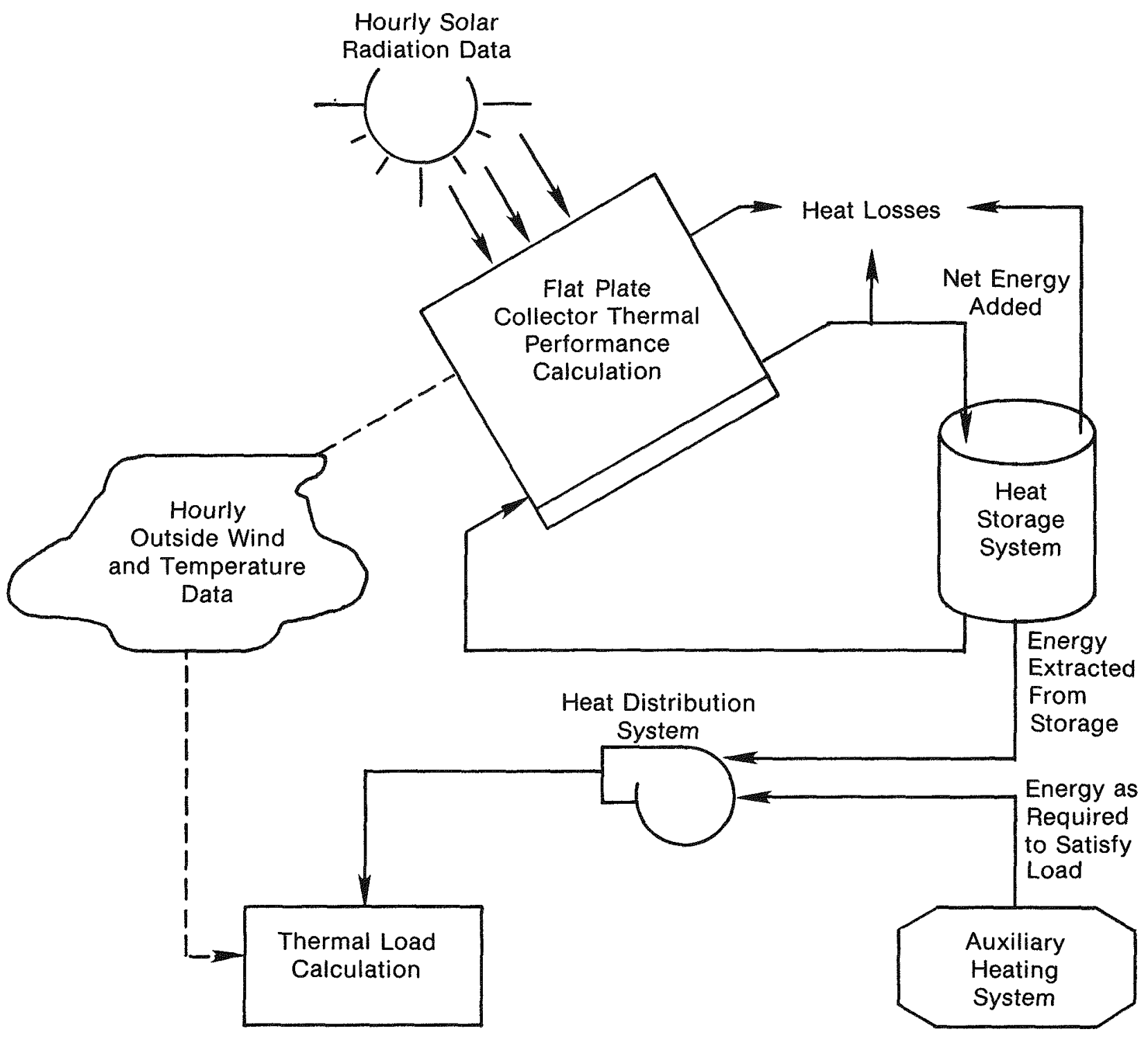

Fig. 10-1. Typical simulation model 
The general approach to development of simulation programs is to first formulate mathematical models for components. These component formulations may be based on first principles, or they may be empirical in nature; they may be simple models, or they may be highly detailed. Next, a means is developed for simultaneously solving these models, using time-dependent weather data as forcing functions. These simulation programs may be general, versatile, and applicable to a range or processes; or they may be special purpose programs useful for simulation of specific processes. The level of detail appropriate is based on the cost of the simulation and the purposes intended $[3,4]$.

The results of many simulations can be used to develop generalized performance data that correlate the performance of a particular type of system with its design parameters and the weather. Furthermore, these results can be used to develop design methods that do not require the further aid of a computer.

\section{CLASSIFICATION OF DESIGN METHODS}

Two basic types of design methods will be presented: manual and computer methods. Although distinction along these lines is not always clear, most designers will find it useful. Though it is true that most of the manual methods have resulted from computer analysis, the key consideration here is how the designer executes the method. Design methods that are executed on hand-held calculators or by graphs, tables, and manually solved equations are classified as manual methods. Those executed on desktop minicomputers or main-frame computers are classified as computer methods. Generally, the computer methods use hour-by-hour computation for the full year; however, this is not always the case. By and large, the manual methods are referred to as simplified methods, although some are by no means simple to use.

The main rule governing the selection of a manual or computer design method is that the tool should be appropriate to the task. That is, in the early design phases when little is known about the building and the proposed solar system, and quick performance estimates are needed, simplified manual methods are appropriate. However, in advanced stages of design optimization, or in the design of unusual systems, computer methods are more appropriate.

Comprehensive compendia of both types of solar system design/analysis methods are in Refs. 5, 6, and 7 . Descriptions of available public and private domain methods are included. The SERI models data base can provide information concerning most commonly used design programs.

The major advantages in the use of simplified manual methods are simplicity in use, computational speed and low cost for use, rapid turnaround (especially important in iterative phases of design), and the ability to be used by persons with little technical experience [5] Disadvantages of such methods include the limited ability to use them for design optimization, the lack of control over assumptions made, and the limited selection of systems that can be simulated. Simplified manual methods have been developed mainly for direct space heating and BSHW applications; very few such methods have been developed for heat pump, cooling, or IPH applications. Furthermore, simplified manual methods are limited to standard system configurations and load characteristics. Combined solar-heat pump systems, for example, are not presently covered by simplified design methods. Thus, if the system under consideration is significantly nonstandard in application, configuration, or load characteristics, computer methods are required to achieve accurate and detailed results.

Computer simulation methods may be used for design and optimization studies and, in some cases, for HVAC system tradeoff analyses and peak load and energy use (demand) analyses [5]. The advantages to their use are the ability to simulate accurately the details of complex systems, the incorporation of a large variety of system types, and the flexibility in doing optimization studies. Disadvantages include the complexity of program input, long running times and high costs, accessibility of computing facilities, and requirements for learning a complex program to perform accurate simulations.

\section{MANUAL METHODS}

A large number of manual design methods have been developed for active solar heating/cooling systems. Representative methods are described in Refs, 8-19, and a detailed listing is given in Ref. 6 .

Because solar system performance, whether heating or cooling, is strongly dependent on the design water temperature (or minimum base for storage below which auxiliary energy must be used) of the load and, to a lesser extent, on the load profile, these characteristics must be considered in selecting a design method. Most of the simplified methods in use have been developed for residential buildings where the major loads occur at night. These methods do not explicitly take into account variation in design water temperature, which is a significant parameter in commercial building space heating systems, as well as cooling and IPH systems. Design water temperatures are about the same for residential space and domestic hot water (DHW) systems but can be considerably higher for commercial building space and BSHW (domestic and process) heating. The methods developed for residential space and $\mathrm{DHW}$ systems generally use a design temperature of $75 \mathrm{~F}$ $\left(24^{\circ} \mathrm{C}\right)$. Recently, other methods, namely $\bar{\Phi}-$ F-CHART [17] and those developed by Lunde [18], have been developed for the prediction of solar performance over a range of system design temperatures and can therefore be applied to cooling and IPH systems. 
Virtually all methods developed for residential space heating can also be applied to DHW systems. However, Ref. 20 briefly deseribes design/sizing methods developed specifically for solar DHW systems.

Although many manual design methods are available, only three will be presented here: F-CHART (and its derivatives), SLR (or SBLR), and U.S. Army Construction Engineering Research Laboratory (CERL) methods. These are the most usable methods for nonresidential buildings applications.

\section{The F-CHART Method}

The most comprehensive and widely used of the simplified methods is the F-CHART method [8]. It was developed by the University of Wisconsin using the TRNSYS computer program [21,22] that is discussed in a later section of this chapter. F-CHART was developed by using the TRNSYS program to simulate representative types of solar heating and BSHW systems in several different geographical locations, using either air or water as the transport fluid. Correlations were determined between the monthly solar fraction and two dimensionless quantities that are particular to a given system being analyzed. One is a measure of the monthly solar radiation absorbed by the collector, and the other is a measure of the collector thermal energy losses. The result of this is a graph (or chart) showing the solar fraction, $f$, as a function of these two dimensionless quantities. The F-CHART for a liquid system is shown on Fig. 10-2 and that for an air system is shown on Fig. 10-3. The curves shown in Figs. 10-2 and 10-3 may be represented analytically as follows. The equation that gives the solar fraction $f_{w}$ as a function of the dimensionless quantities, $\mathrm{X}$ and $\mathrm{Y}$, for a liquid system is

$$
\begin{aligned}
f_{W}= & 1.029 Y-0.065 X-0.245 Y^{2} \\
& +0.0018 X^{2}+0.025 Y^{3}
\end{aligned}
$$

The equation for the solar fraction, $f_{a}$, for an air system is

$$
\begin{aligned}
f_{Q}= & 1.04 Y-0.065 X-0.159 Y^{2} \\
& +0.00187 X^{2}-0.0095 Y^{3}
\end{aligned}
$$

One may determine the solar fraction for each month of the year for a given solar system by calculating the $X$ and $Y$ values and then either using one of the above equations or referring to the appropriate F-CHART and reading the solar fraction directly from the F-CHART.

\section{Effeets of Parameter Changes}

The correlation curves and equations that were developed for the F-CHART program were based on certain values for design parameters. For example, the storage size was assumed to be 0.75 cubic feet of rocks per square foot of collector $(0.25 \mathrm{cu} \mathrm{m} / \mathrm{sq} \mathrm{m}$ of collector) for air systems and 2 gallons of water per square foot of collector ( $80 \mathrm{l} / \mathrm{sq} \mathrm{m}$ of collector) for liquid systems. In addition, the load heat exchanger was assumed to have a value of 2 for the quantity $\epsilon_{\mathrm{L}}\left(\mathrm{m} \mathrm{c}_{\mathrm{p}}\right)_{\mathrm{min}} / \mathrm{UA}$, where $\epsilon_{\mathrm{L}}$ is the heat exchanger effectiveness, $\left(m c_{p}\right)_{\min }$ is the minimum fluid capacitance rate, and $\mathrm{UA}$ is the area conductance product of the building, which represents the load. Also, the collector flow rate for air systems was assumed to be $2 \mathrm{cfm}$ per square foot of collector $(10 \ell / \mathrm{s}-\mathrm{sq} \mathrm{m}$ of collector). These values were selected because they are considered to be nominal design values for solar systems. However, not every solar system is going to be designed strictly to these values. The question then is how do we take into account the sensitivity of the solar fraction to changes in these design values. One approach would be to rerun the TRNSYS program for changes in these design parameters and then develop sensitivity curves showing the effect of changes in these design parameters on solar system performance. Another approach would be to determine the effect of parameter changes on the $X$ and $Y$ values in the F-CHART correlation equation. This is the approach that was followed with respect to the F-CHART program. The results are shown in Figs. 10-4, 10-5, and 10-6. The curves shown in these figures may be used by the solar system designer to determine the correction factors that should be applied to the $\mathrm{X}$ or $\mathrm{Y}$ values when necessary.

\section{Availability}

The F-CHART calculations may be performed manually, or with the aid of a programmable hand-held calculator, or with a desktop calculator, or with a large-scale computer. Performing the calculations manually is tedious and time consuming and is not recommended except on a one time basis in order to gain a more complete understanding of the method. The central site computer approach is the most efficient in terms of time; this is particularly true when several different systems are to be analyzed. However, the central site computer is not always available, and the overhead costs tend to be rather high. For designers who wish to make use of the F-CHART program on a central site computer, the program may be ordered from the Solar Energy Laboratory of the University of Wisconsin-Madison. The cost is $\$ 200$. The program is also available on several commercial computer service bureaus. The latest version, Version 4, includes life-cycle cost analysis capability. Version 4 uses a variation of the F-CHART METHOD ( $\bar{\phi}-F-C H A R T)$ for liquid systems and the above displayed method for air systems. Version 3 uses solely the F-CHART METHOD. Both programs are available on most time-sharing networks.

For designers who wish to make use of the F-CHART method on programmable hand-held calculators or small desktop computers, there are several organizations from which the F-CHART program may be ordered. The 


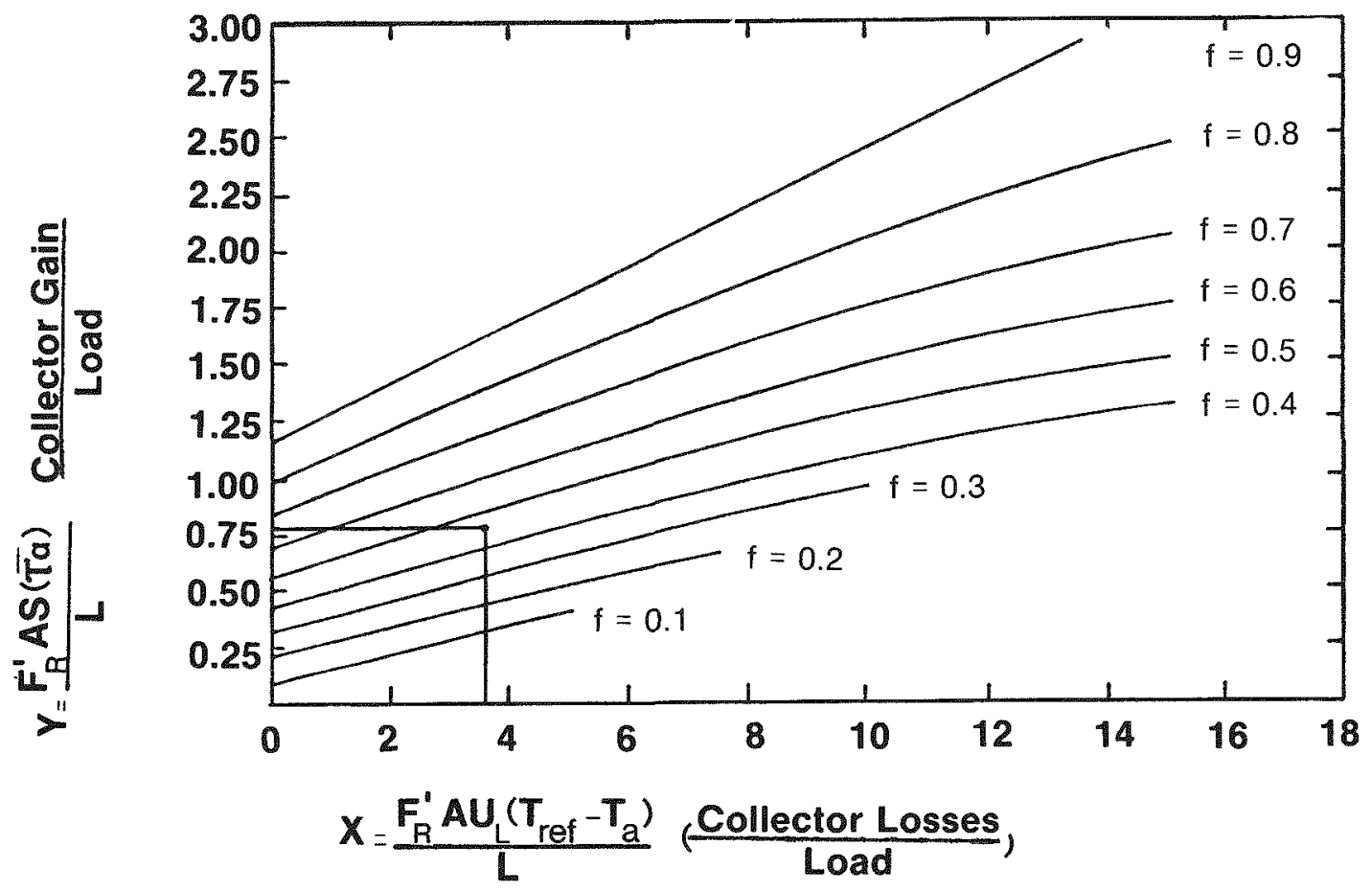

Fig. 10-2. F-CHART for a liquid system

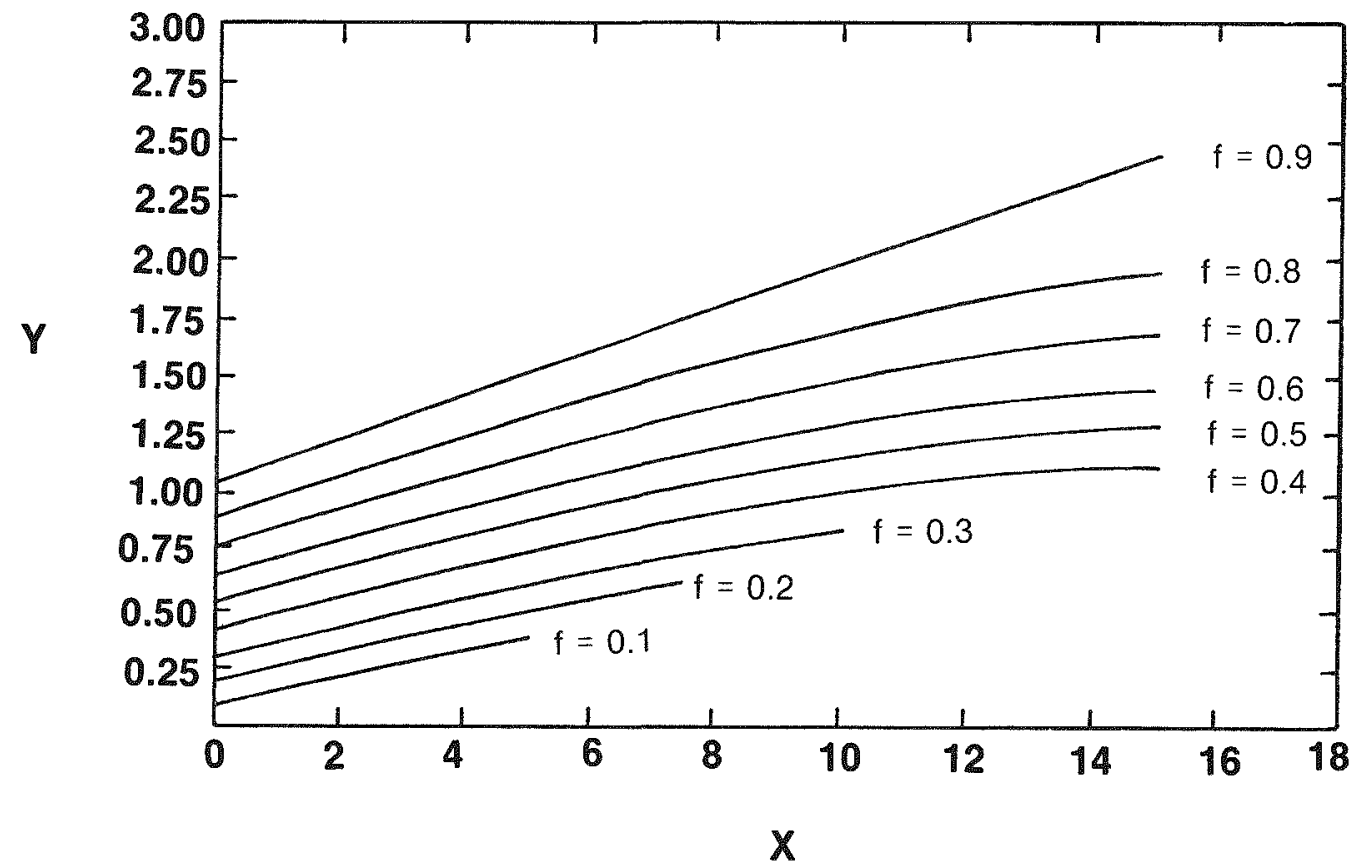

Fig. 10-3. F-CHART for a solar air-heating system 


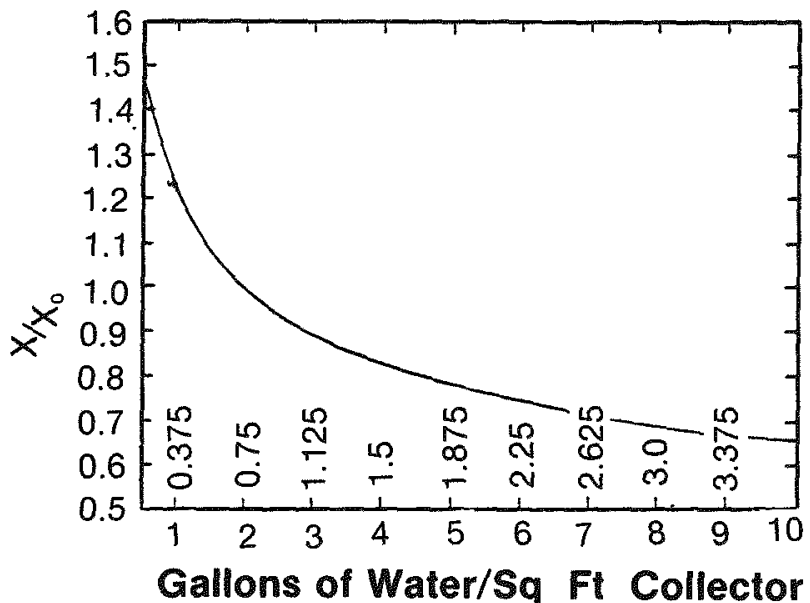

Fig. 10-4. Storage size correction factor for F-CHART

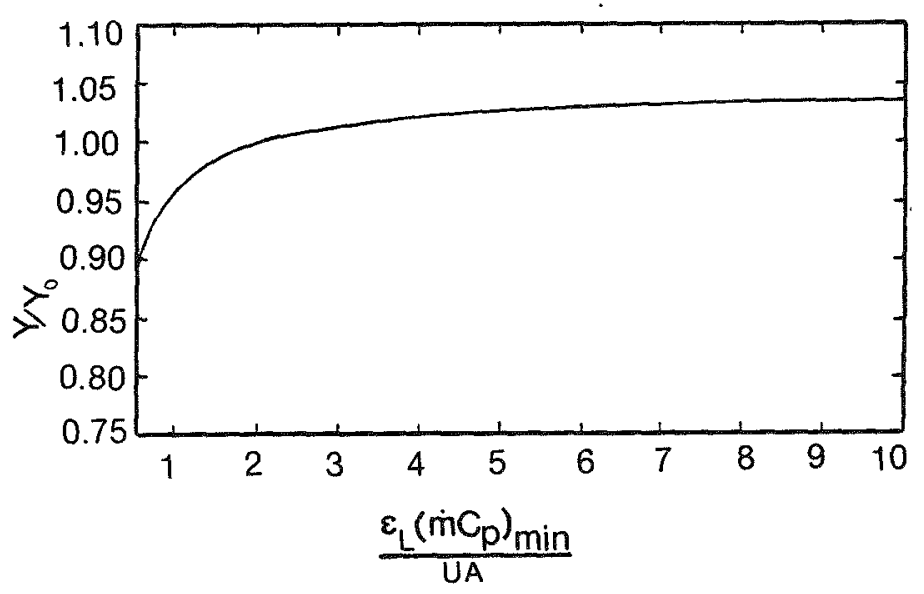

Fig. 10-5. Load heat exchanger correction factor for F-CHART

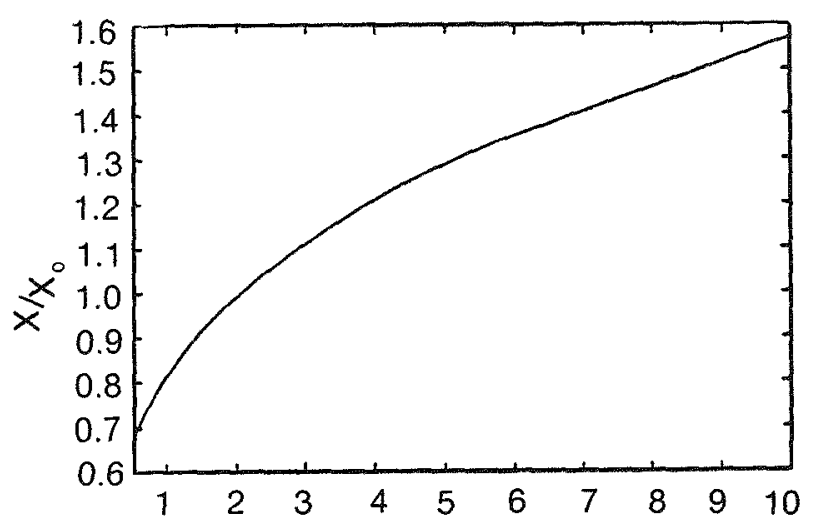

SCFM/Sq ft of Collector interested party may contact SERI for further information regarding these sources of the F-CHART method. Programs like F-CHART have also been used by manufacturers and others to develop "second-tier" design methods, incorporating design parameters of particular collectors or systems supplied by the manufacturer. The results of the design programs are presented in the simplest possible terms for use by dealers and distributors in sizing systems based on the parameters of the products at hand.

The $\bar{\Phi}-F-C H A R T$ METHOD include methods for handling new system configurations such as solar-heat pump systems and methods for designing systems to deliver energy at temperatures other than $70 \mathrm{~F}\left(20^{\circ} \mathrm{C}\right)$, for example, for use in designing systems with absorption coolers [17].

\section{Validation Results}

The agreement between F-CHART results and TRNSYS results has been shown to be very good. This is to be expected since F-CHART is based upon a correlation to results obtained from the TRNSYS program. The question of interest is "How well do results obtained from the F-CHART program agree with results observed in practice?" The following material that addresses that question has been taken from Ref. 23. Additional validation results, obtained by a utility company, are presented in Ref. 24.

The F-CHART program has been used to model several existing solar systems, and the results obtained from the program were compared with results obtained from the actual systems. These systems included the Colorado State University Solar House II, the Eco-Era \#2 House, the SEECO House, and several HUD demonstration houses. The results obtained from these comparison studies are presented below.

CSU Solar House II. The agreement between F-CHART results and CSU Solar House II observed results is shown in Table 10-1. These results are for an air system and are for the year 1977. Based on that rather limited sample, the mean error in the monthly fractions of the load supplied by solar is $2 \%$, and the standard deviation is $7 \%$ between the F-CHART results and the observed results. This agreement is considered to be excellent.

Fig. 10-6. Air flow rate correction factor for F-CHART 
Table 10-1. CSU SOLAR HOUSE II*

\begin{tabular}{lcccccc}
\hline Month & $\begin{array}{c}\mathrm{H}_{\mathrm{T}} \\
\left(\mathrm{Btu} / \mathrm{Ft}^{2} \text {-Day) }\right.\end{array}$ & $\mathrm{DD}$ & $\begin{array}{c}\mathrm{T}_{\mathrm{a}} \\
(\mathrm{F})\end{array}$ & $\begin{array}{c}\mathrm{L}_{\text {phw }} \\
10^{6} \text { Btu }\end{array}$ & $\mathrm{F}_{\text {meas }}$ & $\mathrm{F}_{\text {fchart }}$ \\
\hline NOV & 1259 & 690 & 42 & 1.06 & 0.65 & 0.73 \\
DEC & 1409 & 899 & 36 & 1.64 & 0.69 & 0.69 \\
JAN & 1398 & 1240 & 25 & 2.12 & 0.58 & 0.52 \\
FEB & 1478 & 756 & 38 & 2.21 & 0.79 & 0.76 \\
MAR & 1793 & 806 & 39 & 2.21 & 0.82 & 0.85 \\
APR & 1096 & 510 & 48 & 1.74 & 0.88 & 0.77 \\
\hline
\end{tabular}

$F_{R} \tau \alpha=0.57, F_{R} U_{L}=1.30 \mathrm{Btu} / \mathrm{hr}-\mathrm{ft}^{2}-\mathrm{F}$

Area $=722 \mathrm{ft}^{2}\left(690 \mathrm{ft}^{2}\right.$ effective)

*Data from Ref. 25.

Table 10-2. COMPARISON BETWEEN F-CHART CALCULATIONS AND MEASURED RESULTS FOR 2 YEARS OP OBSERVATIONS: AIR SYSTEM, FORT COLLINS, COLORADO

\begin{tabular}{lcc}
\hline \multicolumn{1}{c}{ Month } & $\mathrm{F}^{*}$ obs & $\mathrm{F}_{\text {fchart }}$ \\
\hline October & 0.81 & 0.91 \\
November & 0.68 & 0.55 \\
December & 0.60 & 0.42 \\
January & 0.44 & 0.46 \\
February & 0.46 & 0.53 \\
March & 0.66 & 0.59 \\
April & 0.69 & 0.74 \\
\hline
\end{tabular}

*Ineludes pilot lights

Eco-Era \#2. A single family residence in Fort Collins, Colorado, was constructed as part of the Cycle 1 of the HUD Demonstration Program. The house has been occupied since early in 1977, and auxiliary energy use has been monitored since that time. The observed values of energy use have been used to calculate the solar fraction provided by the air solar system. These results, for 2 years of observation, are shown in Table 10-2. The mean and standard deviation between F-CHART and observed results are $2 \%$ and $11 \%$, respectively. Again, this agreement is considered to be quite good.

SEECO House. A liquid-based solar system was also installed in 1976 in Fort Collins, Colorado, as part of Cycle 1 of the HUD Demonstration Program. The auxiliary energy use in this house has also been monitored since the time the house has been occupied, and the solar fraction has been determined. The comparison between the F-CHART studies and observations on the liquid system is shown in Table 10-3. In this case the mean error is $0 \%$ and the standard deviation is $12 \%$, again representing very good agreement between the F-CHART program and measured results.
Table 10-3. COMPARISON BETWEEN F-CHART CALCULATIONS AND MEASURED RESULTS FOR 2 YEARS OF OBSER VATIONS, LIQUTD SYSTEM, FORT COLILNS, COLORADO

\begin{tabular}{lcc}
\hline \multicolumn{1}{c}{ Month } & $F_{\text {obs }}^{*}$ & $F_{\text {fchart }}$ \\
\hline October & 0.75 & 0.99 \\
November & 0.66 & 0.68 \\
December & 0.65 & 0.54 \\
January & 0.67 & 0.58 \\
February & 0.65 & 0.65 \\
March & 0.82 & 0.72 \\
April & 0.82 & 0.86 \\
\hline
\end{tabular}

*Includes pilot lights

Based on the results presented above, one may logically conclude that the F-CHART program provides an accurate design tool for systems representative of those for which the F-CHART program was developed; that is, for liquid- and air-based solar systems of conventional design. Results obtained from the F-CHART program are not considered to be valid for solar systems using a heat pump in series with the solar supply, solar cooling systems, long-term storage systems, and the like. The F-CHART procedure is being continually updated, however, so that it will accommodate additional system types.

F-CHART Comparisons for Improperly Designed or Installed Solar Systems. The F-CHART program will not provide accurate results for systems not represented by the F-CHART program or for systems where installation problems exist. A survey of 12 systems that were part of the HUD Demonstration Program has been conducted by the Solar Environmental Engineering Company. The results of comparisons between the F-CHART predictions and estimates of the solar fraction are shown in Fig. 10-7. We observe from this figure that the F-CHART program tends to overpredict in most of the 
cases shown. However, in each ease for which F-CHART overpredicts the solar performance, it has been determined that there were either design problems or installation problems or both. We may reasonably conclude, with some degree of confidence, that if a solar system is properly designed and properly installed, the results obtained from the F-CHART program will be in close agreement with measured results.

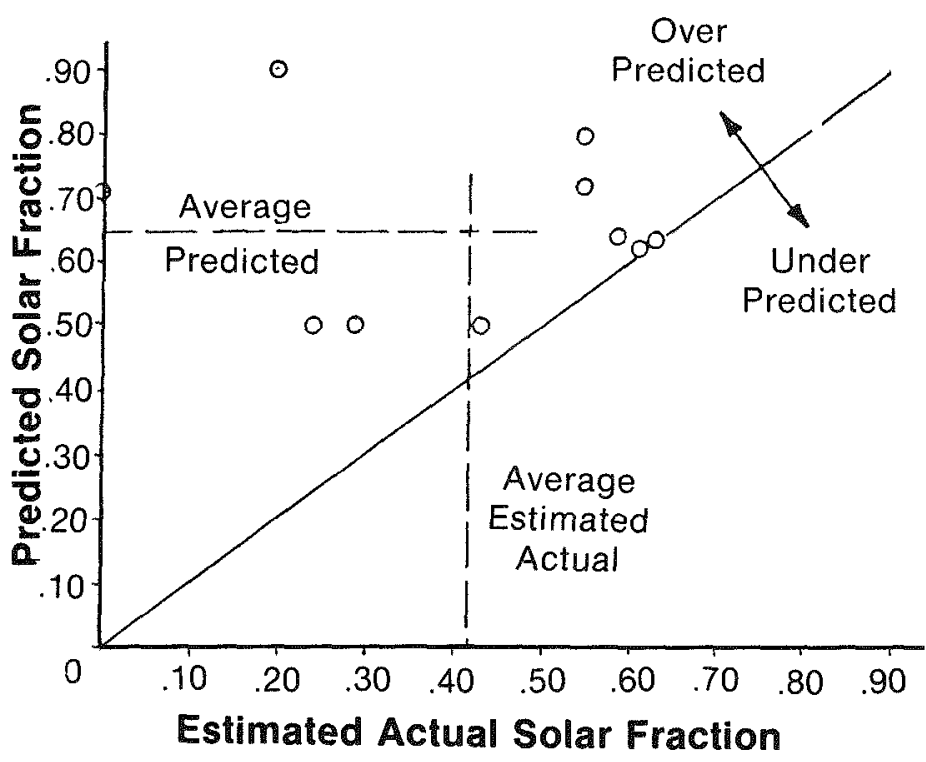

Fig. 10-7. Measured solar fraction vs. estimated solar fraction from $F$. CHART, improperly designed or installed systems

3

\section{Derivatives of the F-CHART Method}

\section{Relative Areas Method}

Recall that the F-CHART method is based on a correlation with results obtained from the TRNSYS program. The correlations are performed on a monthly basis. That is, the user of the F-CHART must calculate solar fractions for each month of the year. These results are then used to determine an annual solar fraction of the energy provided by the solar system. The figure of interest is typically the annual solar fraction. Therefore, if a method were available that provided directly the annual solar fraction, then perhaps a time savings could be realized. This was the motivation behind the development of the Relative Areas program. The Relative Areas program, developed at Colorado State
University, provides a method by which the solar system designer can calculate directly the optimal collector area for a given application and the corresponding solar fraction for the solar system. These calculations can be performed very rapidly with the aid of a programmable hand-held calculator, or they can be performed manually in a very short time (a matter of a few minutes).

The relationship between collector area and annual solar load fraction obtained from F-CHART calculations is similar for virtually all collectors and locations. The differences observed for different collector types and locations may be virtually eliminated by plotting the solar fraction as a function of relative collector area, defined as A/A .5 , where $\mathrm{A}_{.5}$ is equal to the collector area corresponding to an annual solar load fraction of 0.5. By defining the abseissa in this way the curves of solar fraction as a function of relative collector area are forced to intersect at the point $\mathrm{A} / \mathrm{A}_{.5}=1, \mathrm{f}=.5$; and since the curves have similar shapes, they are closely grouped for all practical values of relative area. These curves may be represented analytically by the equation

$\mathrm{f}=\mathrm{C}_{1}+\mathrm{C}_{2} \ln (\mathrm{A} / \mathrm{A} .5)$

that gives the solar fraction as a function of relative collector area and two location-dependent parameters, $\mathrm{C}_{1}$ and $\mathrm{C}_{2}$. The parameters $\mathrm{C}_{1}$ and $\mathrm{C}_{2}$ have been calculated for the 172 locations included in Version 2.0 of the F-CHART program. The values are tabulated in Ref. 13 and in a hand-held calculator program report available from the Solar Environmental Engineering Company. They are tabulated for liquid- and air-based solar space heating and BSHW systems. By reading the values for $\mathrm{C}_{1}$ and $\mathrm{C}_{2}$ from the tables in the above-mentioned reports, the solar system designer can very quickly determine the solar fraction, $f$, as a function of relative collector area. If the value for $A_{.5}$ is known, then the solar fraction as a function of collector area can also be determined very quickly. An equation for $A_{.5}$ has been derived and is given as

$\left.\mathrm{A}_{.5}=\mathrm{A}_{\mathrm{S}}(\mathrm{UA}) / \mathrm{F}_{R} \tau \alpha-\mathrm{F}_{R} \mathrm{U}_{\mathrm{L}} \mathrm{Z}\right)$

where $A_{S}$ and $Z$ are also location-dependent parameters that have been tabulated in the above-mentioned reports. It has been shown that the standard deviation in A from the value given by F-CHART is on the order of $1 \%$.

Eqs. $10-3$ and $10-4$, for $f$ and $A_{.5}$, provide a very simple method by which one can calculate the solar fraction as a function of collector area. The optimal collector area, that is, the collector area that results in minimizing the life-cycle cost of the solar system, can be calculated in an equally simple manner. The total cost of purchasing and operating a solar heating system over its lifetime can 
be expressed analytically as

$$
\begin{aligned}
C_{T}= & \left(C_{b}+A C_{a}\right) E_{1}+A C_{o} E_{2}+C_{m} E_{3} \\
& +(1-f) L C_{f} E_{4}
\end{aligned}
$$

where

$\mathrm{C}_{\mathrm{b}}=$ solar heating system base cost, $\$$

$\mathrm{C}_{\mathrm{a}}=$ collector area dependent first cost, $\$ \mathrm{ft}^{-2}$

$\mathrm{C}_{\mathrm{o}}=$ collector area dependent operation cost, $\$ \mathrm{ft}^{-2} \mathrm{yr}^{-1}$

$\mathrm{C}_{\mathrm{m}}=$ maintenance cost, $\$ \mathrm{yr}^{-1}$

$\mathrm{C}_{\mathrm{f}}=$ fuel price, $\$ /$ million $\mathrm{Btu}^{-1}$ delivered by furnace

$\mathrm{L}=$ total (space $+\mathrm{DHW}$ ) annual heat load, million Btu $\mathrm{yr}^{-1}$, and

$\mathrm{E}=$ factors for converting cash flows to present worth.

For minimum total cost,

$\frac{\partial C_{T}}{\partial A}=0=C_{a} E_{1}+C_{o} E_{2}-L_{f} E_{4} \frac{\partial f}{\partial A}$

Since we have an equation for $f$ as a function of collector area, A, we can determine that

$$
\partial \mathbf{f} / \partial \mathrm{A}=\mathrm{C}_{2} / \mathrm{A}
$$

Therefore, the optimal collector area may be expressed as

$$
A_{\text {opt }}=\frac{\left(C_{2}\right)(L)\left(C_{f}\right)(31)}{\left(C_{a}\right)+\left(C_{o}\right)(18)}
$$

Hence, one can calculate the optimal collector area directly from knowing the load and the locationdependent curve fit parameter $\mathrm{C}_{2}$.

\section{GFL Method}

Another method for directly calculating the annual solar fraction is the GFL method [26]. It was developed to meet a need of the architectural, contracting, and construction industries. This method, which is in essence a correlation of F-CHART runs, is applicable to both liquid- and air-residential systems. It is used to calculate the annual solar heating fraction and the energy supplied to the load by the solar energy system under consideration. The inputs are the optical and thermal characteristics of the collector, the collector type (air or liquid) and area, the combined space and DHW load, and the geographic location. Results of the GFL method correlate very well with F-CHART results; differences are typically less than $2 \%$, and never more than $5 \%$.

Although the GFL method is easy to use and requires only the solution of several simple algebraic equations, it is restricted to the same standard solar heating system configurations as F-CHART.

\section{The Solar-Load Ratio (SLR) Method}

\section{Residential Systems}

An hourly simulation program, developed by the Los Alamos Scientific Laboratory (LASL) [27] but not documented in detail, has been used to develop the "Monthly Solar-Load Ratio" (SLR) method, a simplified design and sizing procedure for residential systems [9]. Detailed hour-by-hour computer simulations have been run for 25 U.S. and Canadian cities for up to 12 years of weather data for each city. On the basis of these simulations, a method has been devised to allow the designer to estimate system performance based on monthly data of horizontal solar radiation and heating degree-days. The results of this method agree reasonably well with the hour-by-hour computer simulations. This SLR method has also been extended to nonresidential buildings for a range of design water temperatures [15] Note that the method of Ref. 19 is quite similar to the SLR method.

The basic difference in approach between the F-CHART method and the SLR method is that while F-CHART includes the basic solar collector characteristics as variables in the input parameters of the method, the SLR method presents performance for reference liquid and air systems. The liquid ref erence system characteristics are given in Table 10-4. Thus, the system designer can use the results of parametric studies [29], in which each system and collector characteristic is varied singly, to determine performance of systems differing from the reference systems.

Tables of sizing results have been developed only for the ref erence liquid system. Although other researchers [28] have found that air and liquid system performance can differ substantially, depending on the climate, system characteristics, and the fraction of the load met by solar, the LASL simulations [9] indicated very little difference between the two reference system types. Thus, the same simplified method presented here can be used for either system type. However, Ref. 29 recommends that air system performance be approximated by adjusting the liquid system results using a small correction factor.

It should be noted that the SLR method gives comparable results on an annual basis when compared to the results of F-CHART [30], the design method in most widespread use. Furthermore, in a comparison of several solar system computer simulation programs, the parent programs of F-CHART and the SLR method were also shown to be in substantial agreement, although the formulation of the programs is somewhat different [31] .

Use of the SLR Method. Collector array sizing information is presented here, for the reference liquid system, in two formats. The first is in the form of tables of the ratio of building heating load-to-collector area required for selected solar fractions in the U.S. and 
Table 10-4. THE STANDARD LQUID SYSTEM

Values of parameters used for the "standard" solar heating system that includes liquid-heating solar collectors, a heat exchanger, and water tank thermal storage. The values are normalized to $1 \mathrm{sq} f \mathrm{f}$ of collector ( $\mathrm{sq} \mathrm{ft}_{\mathrm{c}}$ ).

\begin{tabular}{|c|c|}
\hline Parameter & Nominal Value \\
\hline \multicolumn{2}{|l|}{ Solar Colleetor } \\
\hline 1. Orientation & Due south \\
\hline 2. Tilt (from horizontal) & Lat $+10^{\circ}$ \\
\hline 3. Number of glazings & 1 \\
\hline 4. Glass transmissivity (at normal incidence) & 0.86 (6\% absorption* $8 \%$ reflections) \\
\hline 5. Surface absorptance (solar) & 0.98 \\
\hline 6. Surface emittance (IR) & 0.89 \\
\hline 7. Coolant flow rate $\left(\mathrm{mC}_{\mathrm{p}} / \mathrm{sq} \mathrm{ft} \mathrm{c}_{\mathrm{c}}\right)$ & $0.04 \mathrm{gpm}$ water/sq $\mathrm{ft}_{\mathrm{c}}(20 \mathrm{Btu} / \mathrm{hr}-\mathrm{F}-\mathrm{sq} \mathrm{ft} \mathrm{c})$ \\
\hline 8. Heat transfer coefficient to coolant (UA/sq $\mathrm{ft}_{\mathrm{c}}$ ) & $30 \mathrm{Btu} / \mathrm{hr}-\mathrm{F}-\mathrm{sq} \mathrm{ft}$ \\
\hline 9. Back insulation U-value (UA/sg $\mathrm{ft}_{\mathrm{e}}$ ) & $0: 083 \mathrm{Btu} / \mathrm{hr}-\mathrm{F}-\mathrm{sq} \mathrm{ft_{c }}$ \\
\hline 10. Coolant heat capacity rate $\left(\mathrm{mC}_{\mathrm{p}} / \mathrm{sq} \mathrm{ft}_{\mathrm{c}}\right)$ & $1 \mathrm{Btu} / \mathrm{hr}-\mathrm{F}-\mathrm{sq} \mathrm{ft}_{\mathrm{c}}$ \\
\hline \multicolumn{2}{|l|}{ Collector Piping } \\
\hline 11. Heat loss coefficient, to ambient (UA/sq $f t_{c}$ ) & $\begin{array}{l}0: 04 \mathrm{Btu}-\mathrm{hr}-F-\mathrm{sq} f \mathrm{t}_{\mathrm{c}}(\mathrm{U} \approx 0.3 \mathrm{Btu} / \mathrm{hr}-\mathrm{F}=\mathrm{sq} \mathrm{ft} \text { pipe } \\
\text { or } 1 \mathrm{in} \text {. insulation of } k=0.025 \mathrm{Btu} / \mathrm{hr}-\mathrm{ft}-\mathrm{F}\end{array}$ \\
\hline \multicolumn{2}{|l|}{ Heat Exchanger } \\
\hline 12. Heat transfer coefficient (UA/sg $\mathrm{ft}_{\mathrm{c}}$ ) & $10 \mathrm{Btu} / \mathrm{hr}-\mathrm{F}-\mathrm{sq} \mathrm{ft}_{\mathrm{c}}$ \\
\hline \multicolumn{2}{|l|}{ Thermal Storage } \\
\hline 13. Heat capacity & $1.8 \mathrm{gal}$ water/sq $\mathrm{ft}_{\mathrm{c}}\left(15 \mathrm{Btu} / \mathrm{F}-\mathrm{sq} \mathrm{ft_{c }}\right)$ \\
\hline $\begin{array}{l}\text { 14. Heat loss coefficient (UA/sq } \mathrm{ft}_{\mathrm{c}} \text { ), assuming all } \\
\text { heat loss is to heated space }\end{array}$ & $0 \mathrm{Btu} / \mathrm{hr}-\mathrm{F}-\mathrm{sq} \mathrm{ft}$ \\
\hline \multicolumn{2}{|l|}{ Controls } \\
\hline $\begin{array}{l}\text { Building maintained at } 70 \mathrm{~F} \\
\text { Collectors on when advantageous }\end{array}$ & \\
\hline
\end{tabular}

*These values apply for normal incidence on ordinary double-strength glass ( $1 / 8$ in.). For other angles of incidence, the Fresnel equation is used. 
Canadian cities studied. Since $100 \%$ solar heating, though feasible in some locations, will rarely be cost effective, results are presented for 25,50 , and $75 \%$ solar heating fractions to cover the range most likely to be useful to the designer. A set of supplementary solar-load ratio maps for the United States and southern Canada is presented in Ref. 9. The results enable one to determine collector sizes for the cities analyzed. The second format presents the results as a universal performance curve for use in the SLR method, which enables the prediction of system performance for any city for which average monthly horizontal solar radiation and heating degree-days are available.

Both performance prediction formats require the use of average monthly horizontal insolation and monthly building load. In the tabulated data, the insolation is built into the entry for each city; in the universal curve format, the monthly isolation is entered explicitly as a parameter. Methods of determining monthly insolation are discussed in Chapter 3 . In both cases, the building load is generally entered in terms of monthly degreedays; however, a number of alternate load determination techniques are available. Note that for buildings with heating, ventilating, and air-conditioning (HVAC) systems, it is the load imposed on the heating coil that must be determined. Several methods of computing building thermal loads are presented in Chapter 8 .

The SLR results are presented in terms of the ratio of building load to collector area for liquid systems in Tables 10-5a (English units) and 10-5b (SI units). These tables present the ratio in terms of the solar heating percentage of the total space heating requirement. The Load-Collector Ratio (LC) is defined as:

$$
\mathrm{LC}=\frac{\text { Building Load (Btu/F-day) }}{\text { Collector Area }\left(\mathrm{ft}^{2}\right)}
$$

$\mathrm{LC}=\frac{\text { Building Load }\left(\mathrm{kJ} /{ }^{\circ} \mathrm{C} \text { day }\right)}{\text { Collector Area }\left(\mathrm{m}^{2}\right)}$

To use the building load/collector area (LC) ratio for determining the size of the collector for one of the cities listed (or an equivalent location), one must (1) determine the building thermal load and (2) decide what percentage of solar heating the system is to provide.

Changes in Design Parameters. Changing any one of the design parameters for the reference liquid or air systems will have some effect on system performance. The effect of changing these design parameters can be determined from the data presented in Ref, 29.
However, it should be noted that the data in Ref. 29 reflect changes occurring when only one parameter is varied at a time. Because of nonlinear effects, the result of changing more than one parameter may be quite different from the algebraic sum of the results for each individual parameter change. Application of these parametric results to systems much different from the reference systems should be made with caution.

Domestic Hot Water Add-On. The addition of a domestic hot water preheat capability is an almost universal feature of a space heating system. This is a good marriage because it allows the installed solar collectors to serve a large load in the winter, thus increasing their effectiveness, and to be used in the summer when they would otherwise be idle.

The LC values given in Table 10-5 do not include the effect of this additional load-the reference liquid or air systems studies are for space heating only. It is no longer possible to characterize the performance in terms of a single parameter, like LC, when the hot water capability is added because different buildings will have a different thermal load balance. A whole set of different maps or tables could be generated for different proportions of space and hot water heating loads, but this complication would defeat the intent of the simple approach taken.

The designer of a combined system may choose to estimate collector area requirements, based on the space heating load only using the values of LC given here or to resort to the somewhat more complex Monthly Solar Load Ratio method to obtain a more accurate estimate.

Year-to-Year Variations at a Fixed Location. One can expect year-to-year variations in solar heating fraction of $\pm 5 \%$ resulting from variations in climate.

The Monthly Solar-Load Ratio (SLR) Method. For locations not covered by the cities given in Table 10-5, the SLR method can be used. It is based on correlations developed for many hour-by-hour computer simulations for a variety of locations.

This method is a five-step process that can be performed on hand calculators with exponential functions. The steps are as follows:

Step 1. Obtain the following data for each month of the year for the site where the solar heating system is to be located.

a. Heating degree days, per month

b. Total solar radiation on a horizontal surface, per month 
Table 10-5a. VALUES OF LC FOR REFERENCE LIQUID SYSTEM FOR SELECTED CTTIES

\begin{tabular}{|c|c|c|c|c|c|c|}
\hline \multirow[b]{2}{*}{ Location } & \multirow[b]{2}{*}{$\begin{array}{l}\text { Latitude } \\
{ }^{\circ} \mathrm{N}\end{array}$} & \multirow[b]{2}{*}{$\begin{array}{c}\text { Elevation } \\
\mathrm{Ft}\end{array}$} & \multirow[b]{2}{*}{$\begin{array}{l}\text { Degree } \\
\text { Days }\end{array}$} & \multicolumn{3}{|c|}{$\begin{array}{c}\text { LC where solar provides } 25 \%, 50 \%, 75 \% \\
\text { of heating load }\end{array}$} \\
\hline & & & & $\begin{array}{c}25 \% \\
\text { Btu/ } \\
\mathrm{DD} \mathrm{ft}_{\mathrm{c}}{ }^{2}\end{array}$ & $\begin{array}{c}50 \% \\
\text { Btu/ } \\
\mathrm{DD} \mathrm{ft}_{\mathrm{c}}{ }^{2} \\
\end{array}$ & $\begin{array}{c}75 \% \\
\text { Btu/ } \\
\mathrm{DD} \mathrm{ft}_{\mathbf{c}}{ }^{2} \\
\end{array}$ \\
\hline \multicolumn{7}{|l|}{ UNITED STATES } \\
\hline \multicolumn{7}{|l|}{ ARIZONA } \\
\hline $\begin{array}{l}\text { Page } \\
\text { Phoenix } \\
\text { Tucson }\end{array}$ & $\begin{array}{l}37 \\
33 \\
32\end{array}$ & $\begin{array}{l}4280 \\
1139 \\
2440\end{array}$ & $\begin{array}{l}6632 \\
1765 \\
1800\end{array}$ & $\begin{array}{l}128 \\
300 \\
301\end{array}$ & $\begin{array}{r}48 \\
118 \\
118\end{array}$ & $\begin{array}{l}23 \\
59 \\
59\end{array}$ \\
\hline \multicolumn{7}{|l|}{ ARKANSAS } \\
\hline $\begin{array}{c}\text { Little Rock } \\
\text { CALIFORNIA }\end{array}$ & 35 & \multicolumn{5}{|c|}{ CALIFORNIA } \\
\hline $\begin{array}{l}\text { Davis } \\
\text { El Centro } \\
\text { Fresno } \\
\text { Inyokern } \\
\text { Los Angeles } \\
\text { Riverside } \\
\text { Santa Maria }\end{array}$ & $\begin{array}{l}39 \\
33 \\
37 \\
36 \\
34 \\
34 \\
35\end{array}$ & $\begin{array}{r}50 \\
12 \\
336 \\
2186 \\
540 \\
1050 \\
289\end{array}$ & $\begin{array}{l}2502 \\
1458 \\
2492 \\
3528 \\
2061 \\
1803 \\
2967\end{array}$ & $\begin{array}{l}198 \\
547 \\
195 \\
232 \\
416 \\
391 \\
353\end{array}$ & $\begin{array}{r}72 \\
206 \\
70 \\
88 \\
157 \\
152 \\
142\end{array}$ & $\begin{array}{l}33 \\
97 \\
32 \\
42 \\
75 \\
74 \\
67\end{array}$ \\
\hline \multicolumn{7}{|l|}{ COLORADO } \\
\hline $\begin{array}{l}\text { Grand Junction } \\
\text { Grandby }\end{array}$ & $\begin{array}{l}39 \\
40\end{array}$ & $\begin{array}{l}4832 \\
8340\end{array}$ & $\begin{array}{r}5641 \\
10,000\end{array}$ & $\begin{array}{l}119 \\
119\end{array}$ & $\begin{array}{l}46 \\
47\end{array}$ & $\begin{array}{l}22 \\
23\end{array}$ \\
\hline \multicolumn{7}{|l|}{ FLORIDA } \\
\hline $\begin{array}{l}\text { Apalachicola } \\
\text { Tallahassee }\end{array}$ & $\begin{array}{l}30 \\
30\end{array}$ & $\begin{array}{l}46 \\
64\end{array}$ & $\begin{array}{l}1308 \\
1485\end{array}$ & $\begin{array}{l}324 \\
283\end{array}$ & $\begin{array}{l}129 \\
113\end{array}$ & $\begin{array}{l}65 \\
57\end{array}$ \\
\hline \multicolumn{7}{|l|}{ GEORGIA } \\
\hline $\begin{array}{l}\text { Atlanta } \\
\text { Griffin }\end{array}$ & $\begin{array}{l}34 \\
33\end{array}$ & $\begin{array}{l}1018 \\
1001\end{array}$ & $\begin{array}{l}2961 \\
2136\end{array}$ & $\begin{array}{l}154 \\
217\end{array}$ & $\begin{array}{l}59 \\
84\end{array}$ & $\begin{array}{l}29 \\
42\end{array}$ \\
\hline \multicolumn{7}{|l|}{ IDAHO } \\
\hline $\begin{array}{l}\text { Boise } \\
\text { ILLINOIS }\end{array}$ & \multicolumn{5}{|c|}{ ILLINOIS } & 17 \\
\hline $\begin{array}{l}\text { ANL, Lemont } \\
\text { IN DIANA }\end{array}$ & 42 & 750 & 6155 & 79 & 30 & 14 \\
\hline $\begin{array}{l}\text { Indianapolis } \\
\text { KANSAS }\end{array}$ & 40 & 819 & 5699 & 86 & KANSAS & 15 \\
\hline $\begin{array}{l}\text { Dodge City } \\
\text { LOUISIANA }\end{array}$ & 38 & 2625 & 4986 & 126 & 49 & 24 \\
\hline $\begin{array}{l}\text { Lake Charles } \\
\text { Shreveport }\end{array}$ & $\begin{array}{l}30 \\
32\end{array}$ & $\begin{array}{r}60 \\
220\end{array}$ & $\begin{array}{l}1459 \\
2184\end{array}$ & $\begin{array}{l}244 \\
179\end{array}$ & $\begin{array}{l}96 \\
70\end{array}$ & $\begin{array}{l}48 \\
35\end{array}$ \\
\hline \multicolumn{7}{|l|}{ MAINE } \\
\hline \multicolumn{7}{|l|}{ MARYLAND } \\
\hline $\begin{array}{l}\text { Silver Hill } \\
\text { MASSACHUSETTS }\end{array}$ & \multicolumn{5}{|c|}{ MASSACHUSETTS } & 21 \\
\hline $\begin{array}{l}\text { Blue Hill } \\
\text { Boston } \\
\text { East Wareham }\end{array}$ & $\begin{array}{l}42 \\
42 \\
42\end{array}$ & $\begin{array}{r}670 \\
157 \\
50\end{array}$ & $\begin{array}{l}6368 \\
5624 \\
5891\end{array}$ & $\begin{array}{l}82 \\
86 \\
97\end{array}$ & $\begin{array}{l}31 \\
33 \\
37\end{array}$ & $\begin{array}{l}15 \\
16 \\
18\end{array}$ \\
\hline \multicolumn{7}{|l|}{ MICHIGAN } \\
\hline $\begin{array}{l}\text { East Lansing } \\
\text { Sault Ste. Marie }\end{array}$ & $\begin{array}{l}43 \\
46\end{array}$ & $\begin{array}{l}878 \\
724\end{array}$ & $\begin{array}{l}6909 \\
9048\end{array}$ & $\begin{array}{l}76 \\
74\end{array}$ & $\begin{array}{l}28 \\
27\end{array}$ & $\begin{array}{l}13 \\
12\end{array}$ \\
\hline \multicolumn{7}{|l|}{ MINNESOTA } \\
\hline $\begin{array}{l}\text { Saint Cloud } \\
\text { MISSOURI }\end{array}$ & 46 & 1062 & 8879 & 71 & 27 & 13 \\
\hline $\begin{array}{c}\text { Columbia } \\
\text { MONTANA }\end{array}$ & \multicolumn{5}{|c|}{ MONTANA } & 18 \\
\hline $\begin{array}{l}\text { Glasgow } \\
\text { Great Falls }\end{array}$ & $\begin{array}{l}48 \\
47\end{array}$ & $\begin{array}{l}2109 \\
3692\end{array}$ & $\begin{array}{l}8996 \\
7750\end{array}$ & $\begin{array}{r}105 \\
93\end{array}$ & $\begin{array}{l}41 \\
35\end{array}$ & $\begin{array}{l}20 \\
16\end{array}$ \\
\hline \multicolumn{7}{|l|}{ NEBRASKA } \\
\hline Lincoln & 41 & 1316 & 5864 & 104 & 39 & 19 \\
\hline North Omaha & 41 & 1323 & 6612 & 89 & 34 & 16 \\
\hline
\end{tabular}


Table 10-5a. VALUES OF LC FOR REFERENCE LIQUID SYSTEM FOR SELECTED CITIES (continued)

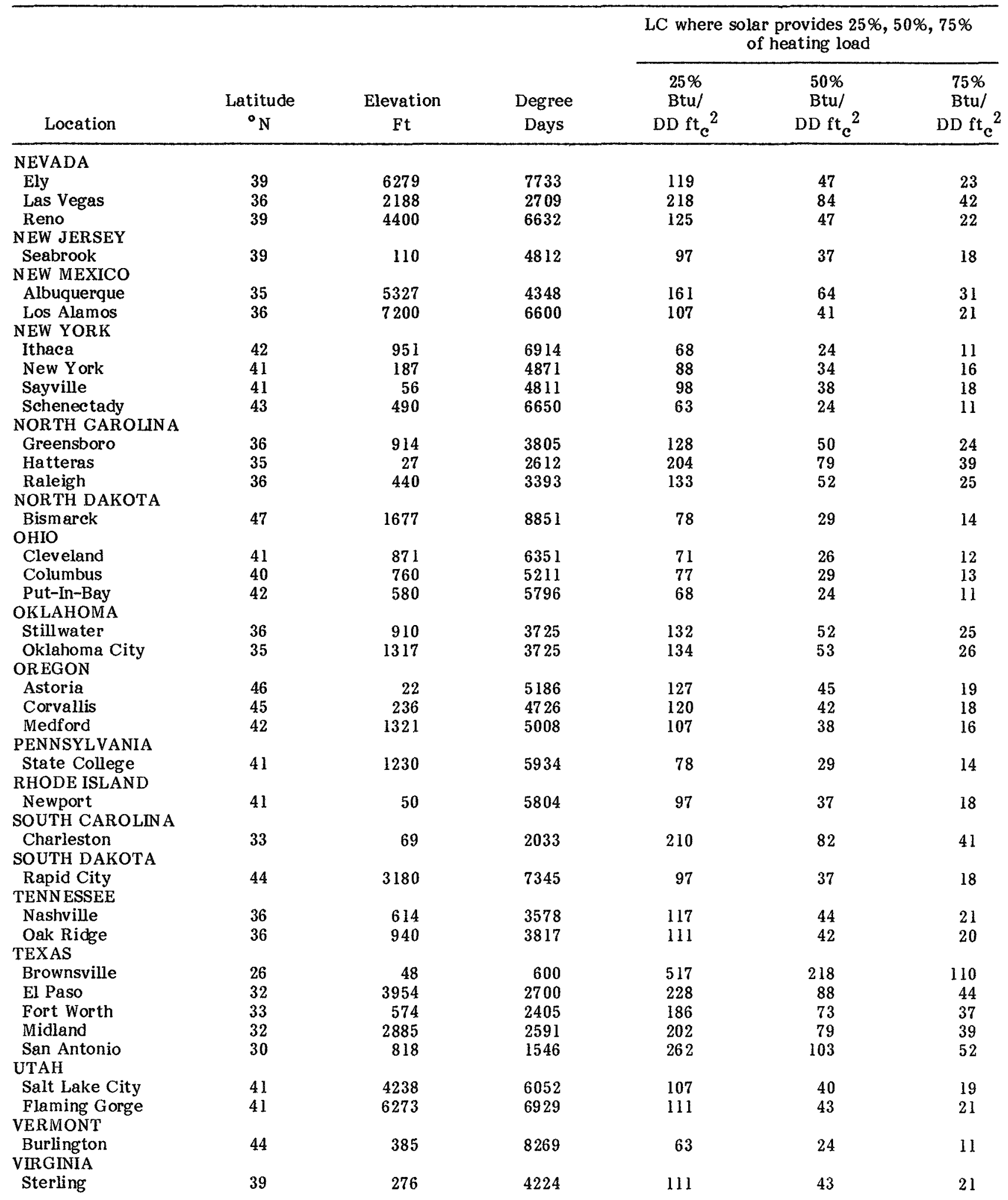


Table 10-5a. VALUES OF LC FOR REFERENCE LQUID SYSTEM FOR SELECTED CITIES (concluded)

\begin{tabular}{|c|c|c|c|c|c|c|}
\hline \multirow[b]{2}{*}{ Location } & \multirow[b]{2}{*}{$\begin{array}{l}\text { Latitude } \\
{ }^{\circ} \mathrm{N}\end{array}$} & \multirow[b]{2}{*}{$\begin{array}{c}\text { Elevation } \\
\text { Ft }\end{array}$} & \multirow[b]{2}{*}{$\begin{array}{c}\text { Degree } \\
\text { Days }\end{array}$} & \multicolumn{3}{|c|}{$\begin{array}{c}\text { LC where solar provides } 25 \%, 50 \%, 75 \% \\
\text { of heating load }\end{array}$} \\
\hline & & & & $\begin{array}{c}25 \% \\
\text { Btu/ } \\
\text { DD ft }_{c}^{2}\end{array}$ & $\begin{array}{c}50 \% \\
\text { Btu/ } \\
\text { DD ft }{ }_{c}^{2}\end{array}$ & $\begin{array}{c}75 \% \\
\text { Btu/ } \\
\text { DD ft }_{\mathrm{c}}{ }^{2}\end{array}$ \\
\hline \multicolumn{7}{|c|}{ WASHINGTON } \\
\hline Prosser & 46 & 840 & 4805 & 117 & 41 & 18 \\
\hline Pullman & 47 & 2583 & 5542 & 100 & 36 & 16 \\
\hline Richland & 47 & 731 & 5941 & 100 & 35 & 15 \\
\hline Seattle & 48 & 110 & 4785 & 94 & 33 & 13 \\
\hline Spokane & 48 & 2356 & 6655 & 90 & 31 & 14 \\
\hline \multicolumn{7}{|l|}{ WISCONSIN } \\
\hline $\begin{array}{l}\text { Madison } \\
\text { WYOMING }\end{array}$ & 43 & 889 & 7863 & 76 & 28 & 13 \\
\hline Lander & 43 & 5574 & 7870 & 108 & 42 & 21 \\
\hline Laramie & 41 & 7240 & 7381 & 106 & 42 & 21 \\
\hline \multicolumn{7}{|l|}{ CANADA } \\
\hline Toronto & 44 & 443 & 6827 & 72 & 27 & 13 \\
\hline Winnipeg & 50 & 820 & 10629 & 63 & 23 & 11 \\
\hline
\end{tabular}


Table 10-5b. VALUES OF LC FOR REFERENCE LIQUID SYSTEM FOR SELECTED CITIES

(SI Units)

\begin{tabular}{|c|c|c|c|c|c|c|}
\hline \multirow[b]{2}{*}{ Location } & \multirow[b]{2}{*}{$\begin{array}{l}\text { Latitude } \\
{ }^{\mathrm{N}} \mathrm{N}\end{array}$} & \multirow[b]{2}{*}{$\begin{array}{l}\text { Elevation } \\
\mathrm{m}\end{array}$} & \multirow[b]{2}{*}{$\begin{array}{l}\text { Degree } \\
\text { Days }\end{array}$} & \multicolumn{3}{|c|}{$\begin{array}{c}\text { LC where solar provides } 25 \%, 50 \%, 75 \% \\
\text { of heating load }\end{array}$} \\
\hline & & & & $\mathrm{kJ} /{ }^{\circ} \mathrm{C}-\mathrm{day}-\mathrm{m}_{\mathrm{c}}{ }^{25}$ & $\mathrm{~kJ} /{ }^{\circ} \mathrm{C}-$ day- $\mathrm{m}_{\mathrm{c}}{ }^{2}$ & $\mathrm{~kJ} /{ }^{\circ} \mathrm{C}-\mathrm{day}-\mathrm{m}_{\mathrm{c}}{ }^{2}$ \\
\hline \multicolumn{7}{|l|}{ UNITED STATES } \\
\hline \multicolumn{7}{|l|}{ ARIZONA } \\
\hline Page & 37 & 1304 & 3684 & 2615 & 981 & 470 \\
\hline Phoenix & 33 & 347 & 981 & 6129 & 2411 & 1205 \\
\hline Tueson & 32 & 683 & 1000 & 6149 & 2411 & 1205 \\
\hline \multicolumn{7}{|l|}{ ARKANSAS } \\
\hline Little Rock & 35 & 84 & 1788 & 2574 & 981 & 490 \\
\hline \multicolumn{7}{|l|}{ CALIFORNIA } \\
\hline Davis & 39 & 15 & 1390 & 4045 & 1471 & 674 \\
\hline El Centro & 33 & 4 & 810 & 11175 & 4209 & 1982 \\
\hline Fresno & 37 & 102 & 1384 & 3984 & 1430 & 654 \\
\hline Inyokern & 36 & 666 & 1960 & 4740 & 1798 & 858 \\
\hline Los Angeles & 34 & 165 & 1145 & 8499 & 3208 & 1532 \\
\hline Riverside & 34 & 320 & 1002 & 7988 & 3105 & 1512 \\
\hline Santa Maria & 35 & 88 & 1648 & 7212 & 2901 & 1369 \\
\hline \multicolumn{7}{|l|}{ COLORADO } \\
\hline Grand Junction & 39 & 1473 & 3134 & 2431 & 940 & 449 \\
\hline Grandby & 40 & 2542 & 6,000 & 2431 & 960 & 470 \\
\hline \multicolumn{7}{|l|}{ FLORIDA } \\
\hline Apalachicola & 30 & 14 & 727 & 6619 & 2635 & 1328 \\
\hline Tallahassee & 30 & 20 & 825 & 5782 & 2309 & 1165 \\
\hline \multicolumn{7}{|l|}{ GEORGIA } \\
\hline Atlanta & 34 & 310 & 1645 & 3146 & 1205 & 592 \\
\hline Griffin & 33 & 305 & 1187 & 4433 & 1716 & 858 \\
\hline \multicolumn{7}{|l|}{ IDAHO } \\
\hline Boise & 44 & 882 & 3227 & 2206 & 797 & 347 \\
\hline \multicolumn{7}{|l|}{ ILLINOIS } \\
\hline ANL, Lemont & 42 & 229 & 3419 & 1614 & 613 & 286 \\
\hline \multicolumn{7}{|l|}{ IN DIANA } \\
\hline Indianapolis & 40 & 250 & 3166 & 1757 & 654 & 306 \\
\hline \multicolumn{7}{|l|}{ KANSAS } \\
\hline Dodge City & 38 & 800 & 2770 & 2574 & 1001 & 490 \\
\hline \multicolumn{7}{|l|}{ LOUISIANA } \\
\hline Lake Charles & 30 & 18 & 811 & 4985 & 1961 & 981 \\
\hline Shreveport & 32 & 67 & 1213 & 3657 & 1430 & 715 \\
\hline \multicolumn{7}{|l|}{ MAINE } \\
\hline Caribou & 47 & 195 & 5426 & 1389 & 531 & 245 \\
\hline MARYLAND & & & & & & \\
\hline Silver Hill & 39 & 89 & 2347 & 2268 & 878 & 429 \\
\hline MASSACHUSETTS & & & & & & \\
\hline Blue Hill & 42 & 204 & 3538 & 1675 & 633 & 306 \\
\hline Boston & 42 & 48 & 3124 & 1757 & 674 & 327 \\
\hline East Wareham & 42 & 15 & 3273 & 1982 & 756 & 368 \\
\hline MICHIGAN & & & & & & \\
\hline East Lansing & 43 & 268 & 3838 & 1553 & 572 & 266 \\
\hline Sault Ste. Marie & 46 & 221 & 5027 & 1512 & 552 & 245 \\
\hline MINNESOTA & & & & & & \\
\hline Saint Cloud & 46 & 324 & 4933 & 1451 & 552 & 266 \\
\hline MISSOURI & & & & & & \\
\hline Columbia & 39 & 248 & 2803 & 2084 & 776 & 368 \\
\hline MONTANA & & & & & & \\
\hline Glasgow & 48 & 643 & 4998 & 2145 & 838 & 409 \\
\hline Great Falls & 47 & 1125 & 4306 & 1900 & 715 & 327 \\
\hline
\end{tabular}


Table 10-5b. VALUES OF LC FOR REFERENCE LQUID SYSTEM FOR SELECTED CITIES (continued) (SI Uni ts)

\begin{tabular}{|c|c|c|c|c|c|c|}
\hline \multirow[b]{2}{*}{ Location } & \multirow[b]{2}{*}{$\begin{array}{l}\text { Latitude } \\
{ }^{\circ} \mathrm{N}\end{array}$} & \multirow[b]{2}{*}{$\begin{array}{l}\text { Elevation } \\
\mathrm{m}\end{array}$} & \multirow[b]{2}{*}{$\begin{array}{l}\text { Degree } \\
\text { Days }\end{array}$} & \multicolumn{3}{|c|}{$\begin{array}{c}\mathrm{LC} \text { where solar provides } 25 \%, 50 \%, 75 \% \\
\text { of heating load }\end{array}$} \\
\hline & & & & $\mathrm{kJ} /{ }^{\circ} \mathrm{C}-$ day $-\mathrm{m}_{\mathrm{c}}{ }^{2}$ & $\mathrm{~kJ} /{ }^{\circ} \mathrm{C}-\mathrm{day}-\mathrm{m}_{\mathrm{c}}{ }^{2}$ & $\mathrm{~kJ} /{ }^{\circ} \mathrm{C}-$ day $-\mathrm{m}^{2} \mathrm{c}^{2}$ \\
\hline \multicolumn{7}{|l|}{ NEBRASKA } \\
\hline Lineoln & 41 & 401 & 3258 & 2125 & 797 & 388 \\
\hline North Omaha & 41 & 403 & 3673 & 1818 & 695 & 327 \\
\hline \multicolumn{7}{|l|}{ NEVADA } \\
\hline Ely & 39 & 1914 & 4296 & 2431 & 960 & 470 \\
\hline Las Vegas & 36 & 667 & 1505 & 4454 & 1716 & 858 \\
\hline Reno & 39 & 1341 & 3684 & 2554 & 960 & 449 \\
\hline \multicolumn{7}{|l|}{ NEW JERSEY } \\
\hline Seabrook & 39 & 34 & 2673 & 1982 & 756 & 368 \\
\hline \multicolumn{7}{|l|}{ NEW MEXICO } \\
\hline Albuquerque & 35 & 1624 & 2416 & 3289 & 1308 & 633 \\
\hline Los Alamos & 36 & 2194 & 3667 & 2186 & 838 & 429 \\
\hline \multicolumn{7}{|l|}{ NEW YORK } \\
\hline Ithaca & 42 & 290 & 3841 & 1389 & 490 & 225 \\
\hline New York & 41 & 57 & 2706 & 1798 & 695 & 327 \\
\hline Sayville & 41 & 17 & 2673 & 2002 & 776 & 368 \\
\hline Schenec tady & 43 & 149 & 3694 & 1287 & 490 & 225 \\
\hline \multicolumn{7}{|c|}{ NORTH CAŘOLINA } \\
\hline Greensboro & 36 & 279 & 2114 & 2615 & 1022 & 490 \\
\hline Hatteras & 35 & 8 & 1451 & 4168 & 1614 & 797 \\
\hline Raleigh & 36 & 134 & 1885 & 2717 & 1062 & 511 \\
\hline \multicolumn{7}{|l|}{ NORTH DAKOTA } \\
\hline Bismarek & 47 & 511 & 4917 & 1594 & 592 & 286 \\
\hline \multicolumn{7}{|l|}{ OHIO } \\
\hline Cleveland & 41 & 265 & 3528 & 1451 & 531 & 245 \\
\hline Columbus & 40 & 232 & 2895 & 1573 & 592 & 266 \\
\hline Put-In-Bay & 42 & 177 & 3220 & 1389 & 490 & 225 \\
\hline \multicolumn{7}{|l|}{ OKLAHOMA } \\
\hline Still water & 36 & 277 & 2069 & 2697 & 1062 & 511 \\
\hline Oklahoma City & 35 & 401 & 2069 & 2738 & 1083 & 531 \\
\hline \multicolumn{7}{|l|}{ OREGON } \\
\hline Astoria & 46 & 7 & 2881 & 2595 & 919 & 388 \\
\hline Corvallis & 45 & 72 & 2626 & 2452 & 858 & 368 \\
\hline Medf ord & 42 & 403 & 2782 & 2186 & 776 & 327 \\
\hline \multicolumn{7}{|l|}{ PENNSYLVANIA } \\
\hline State College & 41 & 375 & 3297 & 1594 & 592 & 286 \\
\hline \multicolumn{7}{|l|}{ RHODE ISLAND } \\
\hline Newport & 41 & 15 & 3224 & 1982 & 756 & 368 \\
\hline SOUTH CAROLI & & & & & & \\
\hline Charleston & 33 & 21 & 1129 & 4290 & 1675 & 838 \\
\hline SOUTH DAKOTA & & & & & & \\
\hline Rapid City & 44 & 969 & 4081 & 1982 & 756 & 368 \\
\hline TENNESSEE & & & & & & \\
\hline Nashville & 36 & 187 & 1988 & 2390 & 899 & 429 \\
\hline Oak Ridge & 36 & 286 & 2121 & 2268 & 858 & 409 \\
\hline TEXAS & & & & & & \\
\hline Brownsville & 26 & 15 & 333 & 10562 & 4454 & 2247 \\
\hline El Paso & 32 & 1205 & 1500 & 4658 & 1798 & 899 \\
\hline Fort Worth & 33 & 175 & 1336 & 3800 & 1491 & 756 \\
\hline Midland & 32 & 879 & 1439 & 4127 & 1614 & 797 \\
\hline San Antonio & 30 & 249 & 859 & 5353 & 2104 & 1062 \\
\hline UTAH & & & & & & \\
\hline Sal t Lake City & 41 & 1292 & 3362 & 2186 & 817 & 388 \\
\hline Flaming Gorge & 41 & 1912 & 3849 & 2268 & 878 & 429 \\
\hline VERMONT & & & & & & \\
\hline Burlington & 44 & 117 & 4594 & 1287 & 490 & 225 \\
\hline
\end{tabular}


Table 10-5b. VALUES OF LC FOR REFERENCE LIQUID SYSTEM FOR SELECTED CITIES (concluded)

(SI Units)

\begin{tabular}{|c|c|c|c|c|c|c|}
\hline \multirow[b]{2}{*}{ Location } & \multirow[b]{2}{*}{$\begin{array}{c}\text { Latitude } \\
{ }^{\circ} \mathrm{N}\end{array}$} & \multirow[b]{2}{*}{$\begin{array}{c}\text { Elevation } \\
\mathrm{m}\end{array}$} & \multirow[b]{2}{*}{$\begin{array}{c}\text { Degree } \\
\text { Days }\end{array}$} & \multicolumn{3}{|c|}{$\begin{array}{c}\text { LC where solar provides } 25 \%, 50 \%, 75 \% \\
\text { of heating load }\end{array}$} \\
\hline & & & & $\mathrm{kJ} / /^{\circ} \mathrm{C}-\mathrm{day}-\mathrm{m}_{\mathrm{c}}{ }^{25 \%}$ & $\mathrm{~kJ} / /^{\circ} \mathrm{C}-\mathrm{day}-\mathrm{m}_{\mathrm{c}}{ }^{2}$ & $\begin{array}{c}75 \% \\
\mathrm{~kJ} /{ }^{\circ} \mathrm{C}-\text { day }-\mathrm{m}_{\mathrm{c}}{ }^{2}\end{array}$ \\
\hline \multicolumn{7}{|l|}{ VIR GINIA } \\
\hline Sterling & 39 & 84 & 2347 & 2268 & 878 & 429 \\
\hline Prosser & 46 & 256 & 2669 & 2390 & 838 & 368 \\
\hline Pullman & 47 & 787 & 3079 & 2043 & 735 & 327 \\
\hline Richland & 47 & 223 & 3301 & 2043 & 715 & 306 \\
\hline Seattle & 48 & 34 & 2658 & 1920 & 674 & 266 \\
\hline Spokane & 48 & 718 & 3697 & 1430 & 633 & 286 \\
\hline \multicolumn{7}{|l|}{ WISCONSIN } \\
\hline $\begin{array}{c}\text { Madison } \\
\text { WYOMING }\end{array}$ & 43 & 271 & 4368 & 1553 & 572 & 266 \\
\hline Lander & 43 & 1699 & 4372 & 2206 & 858 & 1287 \\
\hline Laramie & 41 & 2207 & 4101 & 2166 & 858 & 1287 \\
\hline . & & & & & & \\
\hline \multicolumn{7}{|l|}{ CANADA } \\
\hline Toronto & 44 & 135 & 5905 & 1471 & 552 & 266 \\
\hline Winnipeg & 50 & 250 & 3793 & 1287 & 470 & 225 \\
\hline
\end{tabular}


Step 2. Correct the solar radiation to a collector for tilt angle of latitude plus $10^{\circ}$, using the following approximate formula.

$\left[\begin{array}{l}\text { Total monthly radiation } \\ \text { on tilted surface, } \mathrm{Btu} / \mathrm{ft}^{2 *}\end{array}\right]$

$$
1.025 Y-8200
$$

Total monthly radiation on

$\mathrm{Y}=\quad$ horizontal surface, $\mathrm{Btu} / \mathrm{ft}^{2}$ *

cos(latitude - solar declination at mid-month)

Solar declination at mid-month $23.45^{\circ} \cos$ (30 M-187);

$M=\quad$ month number $($ January $=1$, December $=12)$.

The resulting values are the monthly solar radiation on a plane surface tilted at an angle equal to the latitude plus $10^{\circ}$ and oriented due south.

Step 3. Determine the building thermal load in units of $\mathrm{Btu} / \mathrm{F}$-day or $\mathrm{kJ} /{ }^{\circ} \mathrm{C}$-day. This is the total heat required by the building per day for a $1^{\circ}$ difference between the inside and outside temperatures.

Step 4. Determine the "Solar Load Ratio" (SLR) for each month from the following formula:

Solar Collector Area $\mathrm{x}$ Total Radiation on Tilted Surface

SLR $=$ Building Thermal Load x Heating Degree-Days per Month

The solar load ratio is dimensionless. It is the ratio of the total solar energy incident on the collectors to the total energy required to heat the building.

Step 5. The annual heating fraction can then be estimated from the following formula:

$$
\left[\begin{array}{l}
\text { Annual } \\
\text { Solar } \\
\text { Heating } \\
\text { Fraction }
\end{array}\right]=\frac{\sum_{m o=1}^{12} \text { (Degree-Days) }(\mathrm{X})}{\sum_{m=1}^{12} \text { (Degree-Days) }}
$$

where

$$
\begin{aligned}
X= & 1.06-1.366 \mathrm{e}^{-0.55} \text { SLR }+0.306 \mathrm{e}^{-1.05 \mathrm{SLR}}, \\
& (\text { f or SLR } 5.66) ; \\
X= & 1(\text { f or SLR } 5.66)
\end{aligned}
$$

The function $\mathrm{X}$ is shown plotted in Fig. 10-8. Note that $\mathrm{X}$ is not a very good estimate of the monthly solar heating fraction because it is designed to compensate (on an annual basis) for the fact that the heating load based on degree-days per month is lower than the heating load based on hour-by-hour calculations.
The key to the accuracy of the method is the determination of the function $X$ used in Step 5. This function has been carefully determined so that the resulting error in predicting the solar heating fraction (compared to the simulation result) will be minimized without using a different function for each locality.

The determination of $\mathrm{X}$ is based on hour-by-hour computer simulations of a "test year" for 25 locations for five different collector sizes in each location. The standard deviation of the prediction error is $4.4 \%$ solar heating. Predicted vs. simulated results for the 125 cases are given in Ref. 29 .

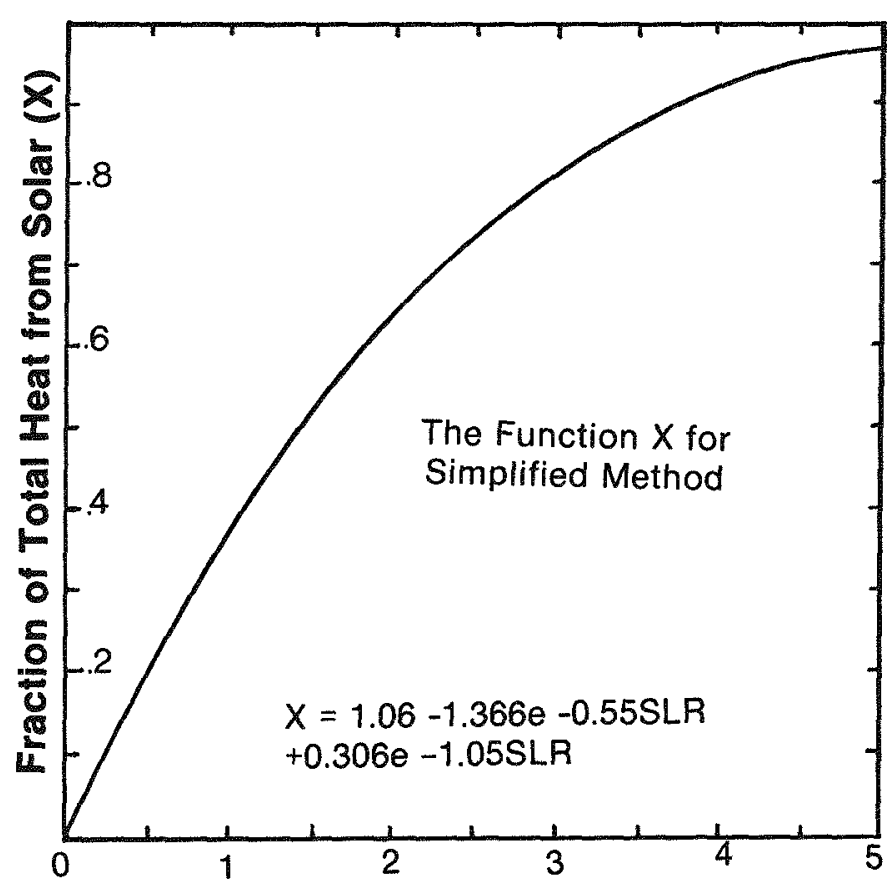

Solar Load Ratio

\section{Nonresidential Buildings}

Using hour-by-hour simulations, LASL has extended the SLR sizing procedure described above to nonresidential (commercial) buildings [15]. Liquid solar heating systems were considered for combined space and building service hot water (BSHW). Commercial building space and BSHW loads were simulated for a reference liquid system (Table 10-4), incorporating a heating coil supply temperature governed by an ambient air schedule.

$* \mathrm{Btu} / \mathrm{ft}^{2} \times 11.35=\mathrm{kJ} / \mathrm{m}^{2}$. 
The building thermal loads were modeled for a "typical" three-story office building with offices on the north and south sides, a corridor in between, and an unheated stairwell at each end. The building envelope heat loss coefficient, UA, was estimated by taking the actual annual envelope heat losses generated by an hour-by-hour analysis of the building and normalizing them to a per degree-day per building area basis. Thus, the dynamics of the building envelope, with respect to the envelope losses, were partially accounted for. A single-zone model was used in which the load was characterized by three parameters: one representing the envelope and ventilation loads that are degree-day dependent; one, the BSHW load and its appropriate profile of occurrence; and one, the internal generation load with its profile. The internal generation load was taken as a eredit against heating load at each hour. These three load components were varied independently over a range expected in most office buildings in a simulation using 1974 hourly weather data for Los Alamos, New Mexico. The result was a performance characterized by virtually identical curves of fraction of load met by solar energy vs. SLR, regardless of load characters.

Although performance was found to be essentially independent of load characteristics, two system parameters were significant: the average temperature of water supplied to the heating coil and the collector characteristics. A family of curves was produced by using four heating coil supply temperature schedules for a nonselective, double-glazed collector. A further family of curves was produced, based on three generic collector types (nonselective single and double-glazed, and selective single-glazed) for a given heating coil temperature schedule. The curves, based on these design parameter perturbations and their use in a sizing procedure, are discussed below.

Load Model Limitations. Although the model accounts for envelope, ventilation, and internal generation loads, it assumes that these loads are intimately coupled at each hour. The implication is that loads generated internally at a given hour can be applied directly to meet the envelope and ventilation heat losses during that hour. Although the envelope loss term includes dynamic eff ects with respect to envelope losses, the dynamics of thermal storage in the building shell and furnishings are not fully accounted for.

Furthermore, the single-zone lumping assumes that heat generated in interior zones can be taken as a direct credit against envelope losses in the perimeter zones.

Despite these limitations, the load model is adequate for generating performance and sizing curves to be used in preliminary design and solar system feasibility assessment. Year-to-year weather variations and uncertainties in modeling of the solar system components are likely to introduce greater uncertainties in the results than those resulting from inaccuracies in the load model. Moreover, the model is quite accurate for small, single-zone, envelope-dominated buildings.

The Simulations and Their Results. The typical office building was modeled for eight U.S. cities using weather data for each city chosen from 10-year records. The specific year was that in which the solar performance was nearest the average for the 10-year period.

The results of these simulations are a set of universal sizing curves. All are expressed as the fraction of demand met by storage vs. the SLR on a monthly basis. For given collector and system characteristics, the simulation data from the eight cities all fall very close to the appropriate universal curve.

In addition to the universal curves, results from a series of residential system perturbations of the solar design parameters are given in summary form. These were produced by varying each key system parameter singly through simulated yearly loads based on actual weather data to determine how such variations affected system performance. Detailed graphical results are presented in Ref. 29. For each calculation, only the parameter under study was varied, so the complex system interactions that result from changing that particular parameter have been taken into account.

The results of these studies are intended to give information on system performance trends as a function of parametric variation, rather than to be taken as absolutes. The effects of the parameter variations shown are expected to give a reasonable approximation of commercial building performance in all climatic zones.

BSHW Heating-Design and Sizing Curves. A typical office building BSHW load was examined using a domestic hot water profile, Fig. 10-9, based on ASHRAE data; average usage was 1 gal/day $(3.78 \ell /$ day $)$ per person.

A two-tank system was used; that is, the solar-heated storage tank acts as a preheater for a conventional BSHW how water tank. A control scheme was adopted in which auxiliary heat was provided to the BSHW tank as necessary to keep the water at preset temperatures ranging from 110 to $170 \mathrm{~F}\left(43-77^{\circ} \mathrm{C}\right)$. Thus, the nominal collector operating temperature ranged from 120 to $180 \mathrm{~F}\left(49-82^{\circ} \mathrm{C}\right)$. A solar storage tank capacity of $15 \mathrm{lb}$ $(1.8 \mathrm{gal})$ of water $/ \mathrm{sq} \mathrm{ft} \mathrm{c}_{\mathrm{c}}\left(72 \mathrm{~kg} / \mathrm{sq} \mathrm{m_{ \textrm {c } }}\right)$ was assumed, with a tank heat loss coefficient of $U \stackrel{\mathrm{c}}{=} 0.17 \mathrm{Btu} / \mathrm{hr}-\mathrm{F}-\mathrm{sq} \mathrm{ft}$ $\left(0.98 \mathrm{~W} /{ }^{\circ} \mathrm{C}-\mathrm{sq} \mathrm{m}\right)$ of tank. This system configuration and nominal parameter values represent an optimal, or near optimal, system for commercial buildings. 


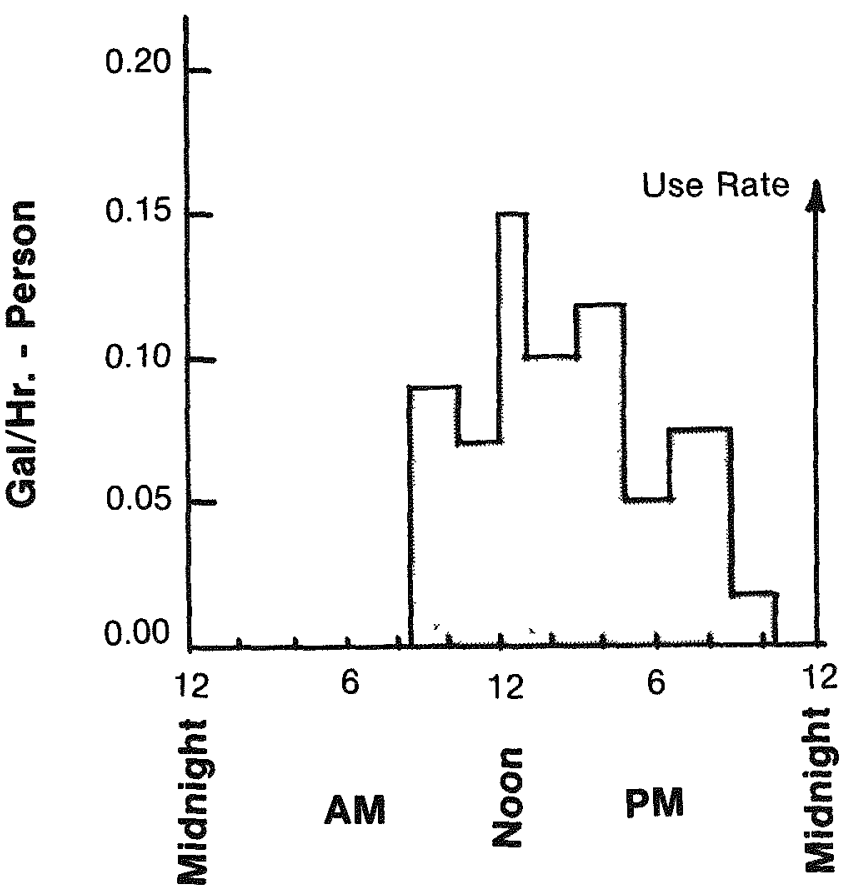

Fig. 10-9. Assumed BSHW use profile

The resulting universal curves are shown in Figs. 10-10 and 10-11. Each curve on these figures is described by an equation of the form

$f=a_{1} \times$ SLR, SLR $<1.2$.
$f=1-b_{1} e^{\left(-c_{1} \times S L R\right)}, S L R \geq 1.2$.

where $a_{1}, b_{1}$, and $c_{1}$ are constants for a given curve. Here $f$ is the fraction of demand met by the solar system, and the ratio of the available solar radiation to the building load (SLR) is defined by

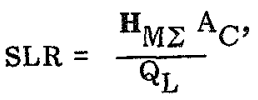

where

$\mathbf{H}_{\mathrm{M} \Sigma}=$ monthly insolation per unit area on a collector tilted at angle $\Sigma$ from horizontal,

$\mathrm{A}_{\mathrm{C}}=$ collector area, and

$\mathrm{Q}_{\mathrm{L}}=$ monthly thermal load.

Using values of $Q_{L}$ and $\mathbf{H}_{M \Sigma}$ obtained as specified in Chapter 8 and Chapter 3 , respectively, one can compute the SLR, and Eq. (10-11) reduces to $f$ as a function of collector area, $\mathrm{A}_{\mathrm{C}}$, alone. This equation can then be used for collector sizing and economic feasibility calculations. Although the curves were generated assuming a tilt of lat $+5^{\circ}$, the insolation on a collector tilted at lat $+10^{\circ}$ is entirely adequate.
The universal curves for an office building BSHW system with a double-glazed, nonselective collector are shown in Fig. 10-10 for four design water temperatures. Note the marked effect of setpoint temperature on performance. The sensitivity of system performance to variations in the daily use profile has not yet been studied. However, in the absence of information to the contrary, these curves should provide a reasonably good approximation of system performance in office and laboratory buildings with process hot water loads.

Fig. 10-11 shows universal BSHW curves for three generic flat plate collector types: single-glazed, nonselective surface; double-glazed, nonselective surface; and singleglazed, selective surface. These curves apply to a design water temperature of $100 \mathrm{~F}\left(43^{\circ} \mathrm{C}\right)$.

Although the curves in Figs. 10-10 and 10-11 represent a monthly data base, they may be applied with little error on an annul basis. This is because the BSHW load is not seasonally dependent.

BSHW Heating-Design Parameter Variations. Using the "standard" liquid collector system, whose parameters are listed in Table $10-4$ as a reference case, a parameter variation of a residential DHW load profile in Fresno, California, has been performed using both one- and twotank systems. The two-tank system performed best thermally because of the lower operating temperatures possible for its solar-heated portion. Economic considerations often justify the use of a single tank system. The significant results are as follows:

1. Collector Tilt. Because the load is constant over the year, the effect of collector tilt is quite different from that in combined space and water heating. The optimal tilt is about lat $+5^{\circ}$ for a two-tank system and equal to the latitude for a one-tank system. One-tank system performance drops rapidly if the tilt is more than $20^{\circ}$ from optimum, but two-tank system performance is less sensitive.

2. Storage Mass. Performance drops rapidly at storage parameter values below $10 \mathrm{Btu} / \mathrm{F}$-sq $\mathrm{ft}_{\mathrm{c}}$ or $1.2 \mathrm{gal}$ water $/ \mathrm{sq} \mathrm{ft} \mathrm{c}_{\mathrm{c}}\left(48 \mathrm{~kg} / \mathrm{sq} \mathrm{\textrm {m } _ { \mathrm { c } }}\right)$ for both one- and two-tank systems. However, there is little to be gained by storage mass increases beyond $15 \mathrm{Btu} / \mathrm{F}-\mathrm{sq} \mathrm{ft}_{\mathrm{c}}$ or $1.8 \mathrm{gal}$ water $/ \mathrm{sq} \mathrm{ft} t_{c}(72 \mathrm{~kg} / \mathrm{sq} \mathrm{m})_{c}$; this is the recommended design value. It corresponds to about 1 to 2 days' storage.

3. Hot Water Design Temperature. The effect of hot water design temperature on system performance is shown in Fig. 10-10. Thus, it is important to keep the set point temperature as low as possible when using solar energy. 


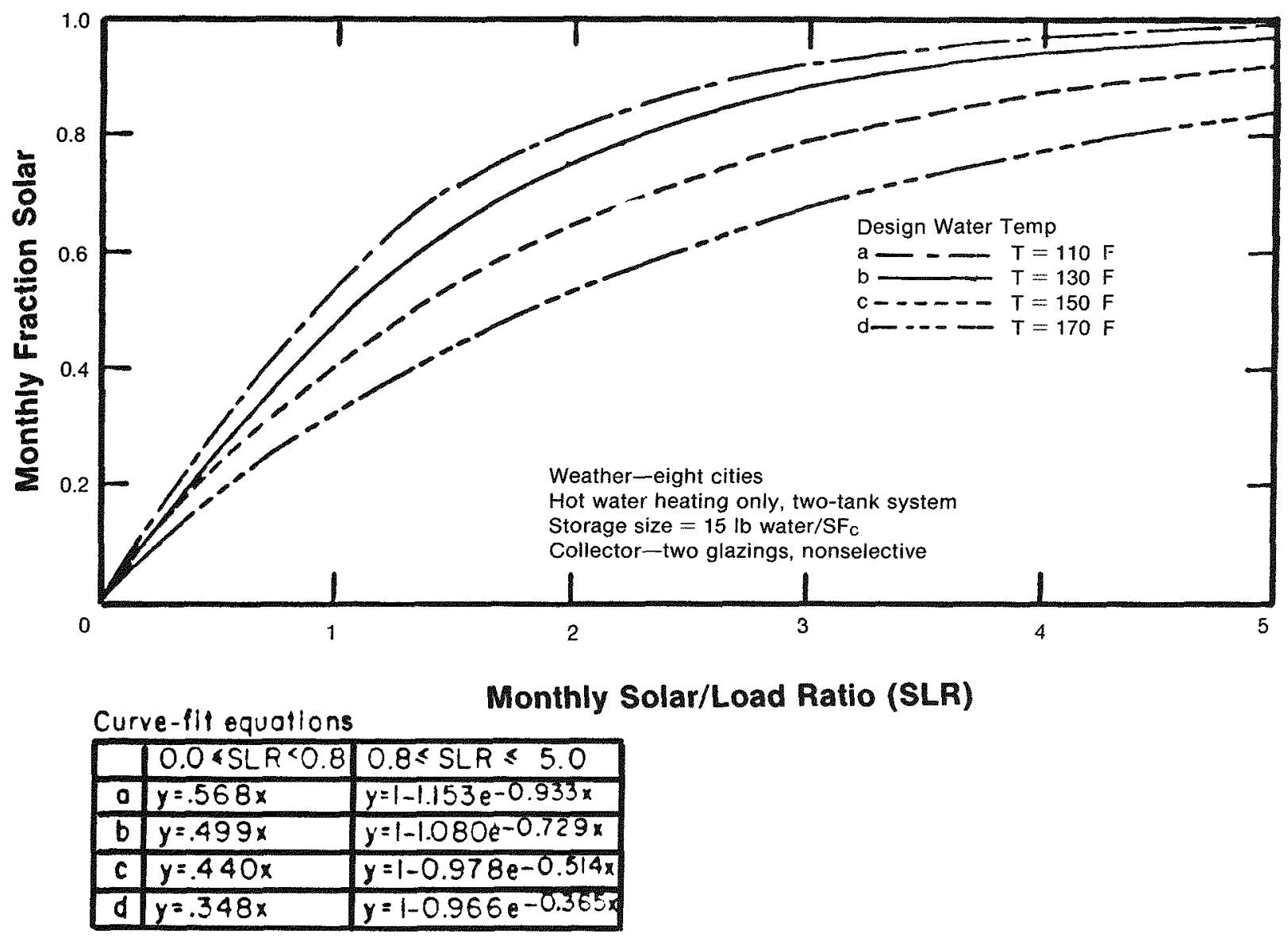

Fig. 10-10. Universal performance curves. Commercial BSHW only, at various design temperatures 


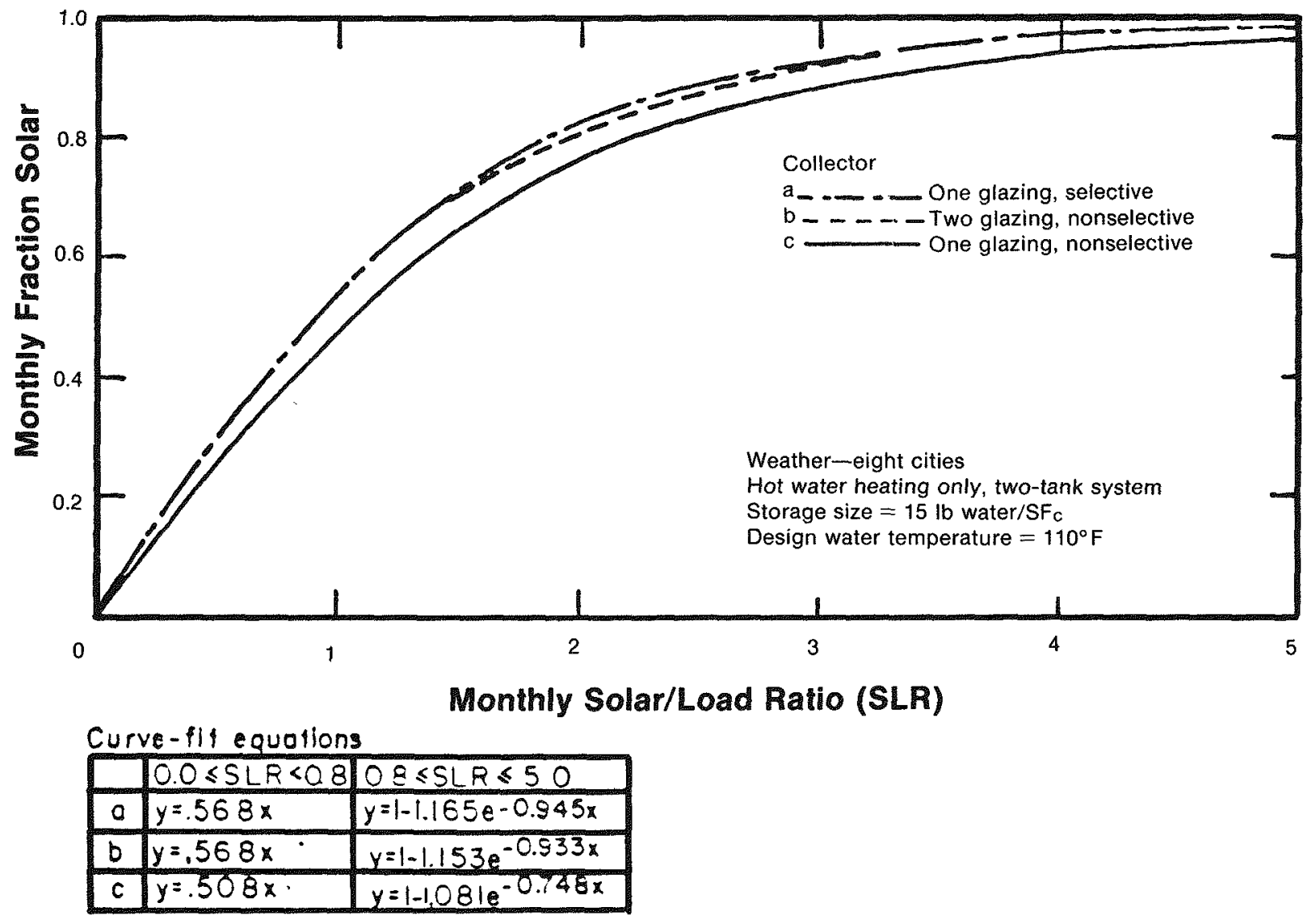

Fig. 10-11. Universal performance curves. Commercial BSHW only, by various collector types 

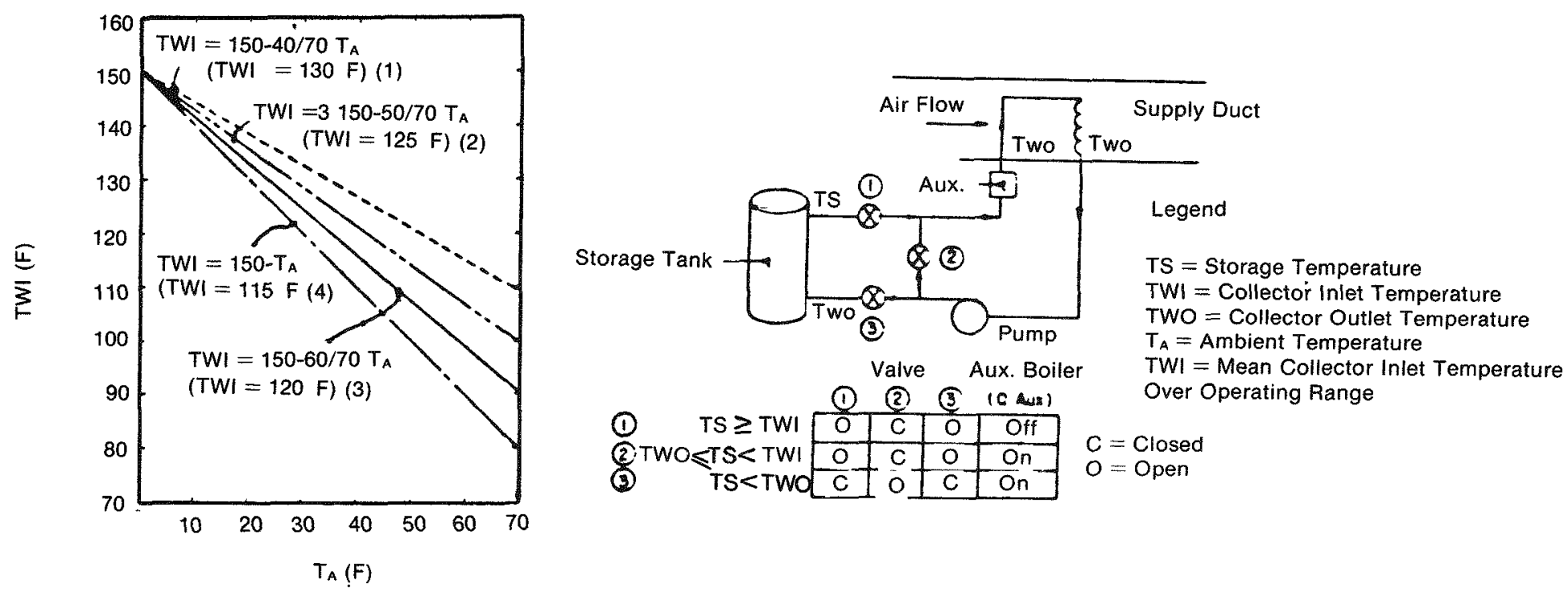

Fig. 10-12. Heating coll model used in simulation

The effect of other system parameters is essentially the same as in combined space and water heating (see below).

Combined Space and BSHW Heating-Design and sizing Curves. As described earlier, the typical office building was simulated using a single-zone model. Hourly heating loads were based on the following nominal values of the load param eters.

Envelope and ventilation load $=5$ Btu/DD-sq $\mathrm{ft}_{\mathrm{b}}$ $\left(100 \mathrm{~kJ} /{ }^{\circ} \mathrm{C}\right.$-day-sq $\left.\mathrm{m}_{\mathrm{b}}\right)$

Hot water load $=5 \mathrm{Btu} /$ day-sq $\mathrm{ft}_{\mathrm{b}}\left(57 \mathrm{~kJ} /\right.$ day-sq $\left.\mathrm{m}_{\mathrm{b}}\right)$ by hourly profile

Internal generation load $=10 \mathrm{Btu} / \mathrm{hr}-\mathrm{sq} \mathrm{ft}_{\mathrm{b}}\left(32 \mathrm{~W} / \mathrm{sq} \mathrm{m}_{\mathrm{b}}\right)$ during occupied hours only.

The heating coil model used is shown in Fig. 10-12. Solar energy supplies the load when the storage tank temperature is high enough; otherwise, auxiliary energy brings the temperature to the required heating coil supply temperature. Four heating coil supply temperature schedules varying with ambient air temperature, Fig. 10-12, were run for a base case, nonselective, double-glazed collector. Because the heating coil supply temperatures ranged from 150 to $80 \mathrm{~F}\left(66-27^{\circ} \mathrm{C}\right)$, the nominal collector operating temperature was from 125 to $140 \mathrm{~F}\left(52-60^{\circ} \mathrm{C}\right)$. A solar storage tank capacity of $15 \mathrm{lb}$ $(1.8 \mathrm{gal})$ of water $/ \mathrm{sq} \mathrm{ft} /\left(72 \mathrm{~kg}\right.$ water $\left./ \mathrm{sq} \mathrm{m}_{\mathrm{c}}\right)$ was assumed. Because of the large collector area available, all BSHW loads were assumed to be met by solar heating. This system configuration and the nominal parameter values used represent a typical office building.
Fig. 10-13 shows the resulting universal curve for combined space and water heating, given the four heating coil schedules and a nonselective, double-glazed collector. These curves approximate system performance in all office and laboratory buildings at all sites reasonably well. Note that because collectors are more efficient at lower temperatures, operating at lower heating coil temperatures improves performance significantly. Thus heating coils should be designed to operate at 120 to $140 \mathrm{~F}\left(49-60^{\circ} \mathrm{C}\right)$, rather than at the higher temperatures used in conventional systems.

Fig. 10-14 shows performance of three collector types, given a heating coil supply schedule characterized by $115 \mathrm{~F}\left(46^{\circ} \mathrm{C}\right)$ average supply temperature.

Each curve in Figs. 10-13 and 10-14 is described by an equation of the same form as the equation for $f$, except that the curves are linear below and exponential above SLR $=1.2$, rather than 0.8 . The SLR is calculated as described above to give $f$ as a function of collector area. The heating coil supply temperature schedule and collector types that represent the application under consideration dictate which curve to use.

An example shown later illustrates the use of the universal combined space and water heating curves of Figs. 10-13 and 10-14.

Combined Space and BSHW Heating-Design Parameter Variations. Studies conducted by Los Alamos Scientific Laboratory [29], which simulated performance of residential buildings in several cities, indicate the effects on performance when parameters are varied from their nominal values. The major results are as follows: 


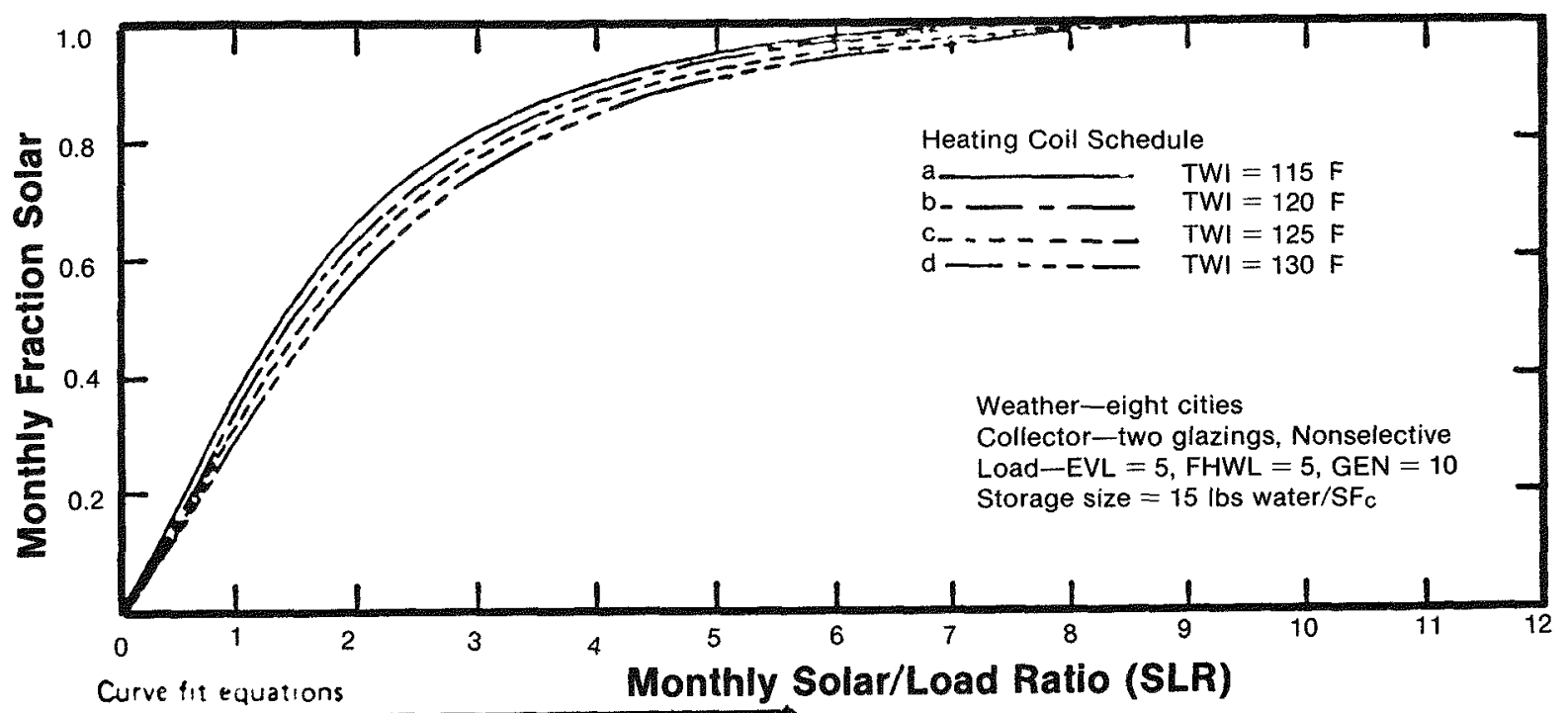

Curve fit equations

\begin{tabular}{|l|l|l|}
\hline & $0.0 \leqslant S L R<1.2$ & $1.2 \leqslant S L R \leqslant 12.0$ \\
\hline$a$ & $y=362 x$ & $y=1-1.173 e^{-0.609 x}$ \\
\hline$b$ & $y=349 x$ & $y=1-1.153 e^{-0.575 x}$ \\
\hline$c$ & $y=334 x$ & $y=1-1.146 e^{-0.541 x}$ \\
\hline$d$ & $y=.318 x$ & $y=1-1.132 e^{-0.504 x}$ \\
\hline
\end{tabular}

Fig. 10-13. Universal performance curves. Commercial building space and BSHW heating at various design temperatures

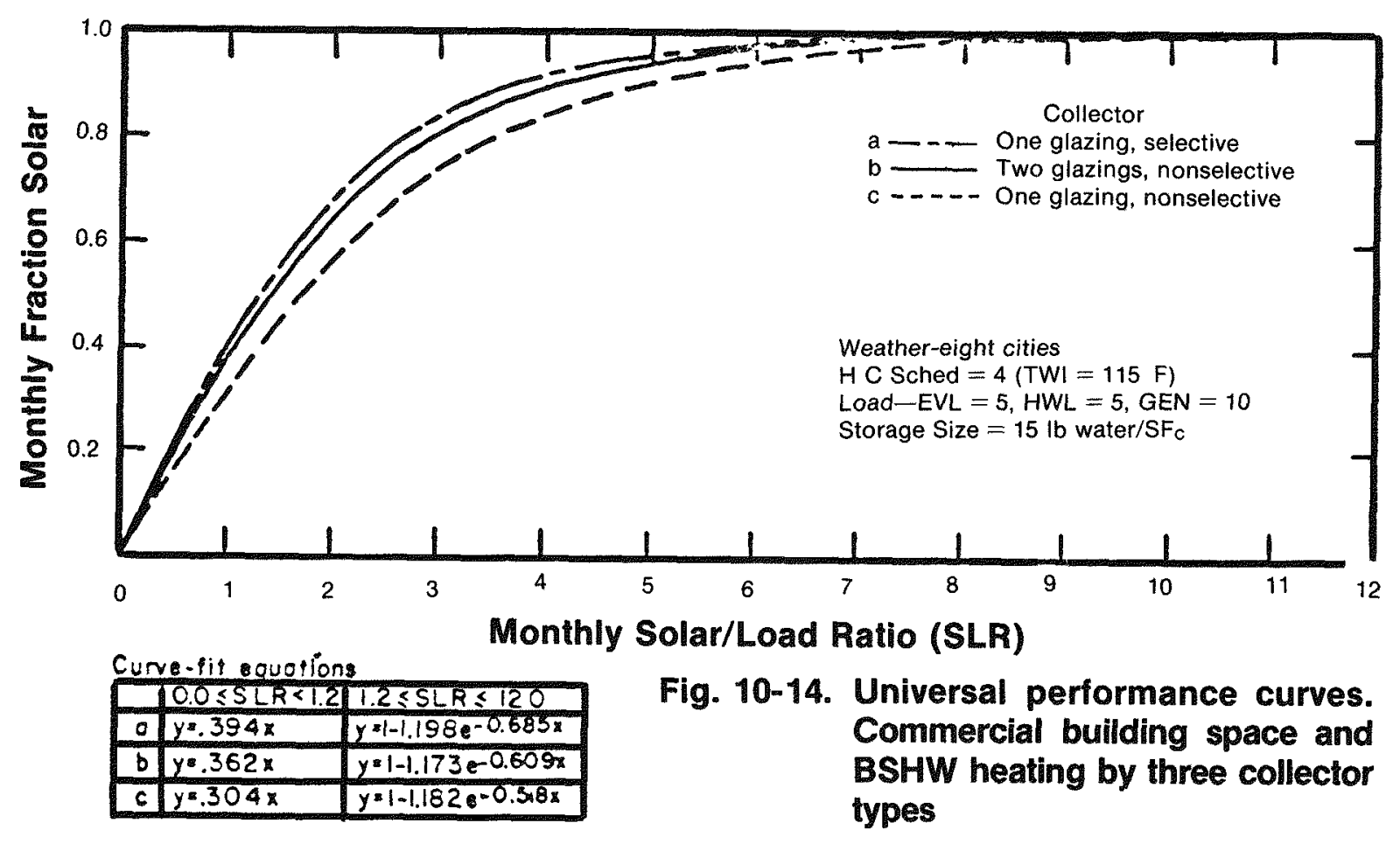




\section{Liquid Space Heating/Hot Water System}

1. Collector Orientation. Due south collector orientation is optimum. Variations of up to $30^{\circ}$ east or west reduce performance by only about $3 \%$ in all except the coldest climate (Bismarck), where variations should be less than $20^{\circ}$.

2. Collector Tilt. Collector tilt angle is important. The of $t$-quoted lat $+15^{\circ}$ rule of thumb applies in some locations, but not all. Optimum tilt also is influenced by the monthly distribution of the heating load, whether it is concentrated in a short period of 2 or 3 months or spread out over half the year. Relatively major deviations from the optimum tilt affect performance only slightly.

Many other considerations, such as ease of assembly and repair, shedding of snow and rain, architectural integration, and avoidance of potential overheating, may be more important than maximizing performance. A vertical collector may well be best in some situations.

3. Heat Exchanger Heat Transfer Coefficient. A heat exchanger coefficient of at least $10 \mathrm{Btu} / \mathrm{hr}-\mathrm{F} \mathrm{sq} \mathrm{ft}$ $\left(60 \mathrm{~W} /{ }^{\circ} \mathrm{C}-\mathrm{sq} \mathrm{m}_{\mathrm{c}}\right)$ should be achieved. For example, if the total amount of energy being collected at a particular time is $100 \mathrm{Btu} / \mathrm{hr}^{-\mathrm{sq} \mathrm{ft}} \mathrm{c}\left(300 \mathrm{~W} / \mathrm{sq} \mathrm{m}_{\mathrm{c}}\right)$, then a temperature difference between one side of the heat exchanger and the other of 5 to $10 \mathrm{~F}\left(3-6^{\circ} \mathrm{C}\right)$ is practical, and the exchanger should be sized to give it.

Some collector liquids that have poor heat transfer characteristics, such as paraffinic oils, can cause relatively difficult problems in achieving this kind of heat exchanger effectiveness. On the other hand, water is a relatively good heat transfer fluid.

4. Thermal Storage Heat Capacity. A water tanks for thermal storage is considered part of the standard liquid system. The nominal storage capacity is $15 \mathrm{Btu} / \mathrm{F}-\mathrm{sq} \mathrm{ft}$ or $1.8 \mathrm{gal}$ of water $/ \mathrm{sq} \mathrm{ft}_{c}\left(72 \mathrm{~kg} / \mathrm{sq} \mathrm{m}_{c}\right)$. For a $50-50$ ethylene glycol and water solution, the corresponding thermal storage capacity is $2.05 \mathrm{gal} / \mathrm{sq} \mathrm{ft}_{\mathrm{c}}\left(82 \mathrm{~kg} / \mathrm{sq} \mathrm{m}_{\mathrm{c}}\right)$.

The simulation analysis indicates that having enough thermal storage to counteract more than 1 day of poor weather does not improve the yearly performance very much. However, fairly severe performance losses are predicted if the storage capacity is less than $10 \mathrm{Btu} / \mathrm{sq} \mathrm{ft}_{\mathrm{c}}$ or $1.2 \mathrm{gal}$ water $/ \mathrm{sq} \mathrm{ft}_{\mathrm{c}}\left(48 \mathrm{~kg} / \mathrm{sq} \mathrm{\textrm {m } _ { \mathrm { c } }}\right)$.

5. Number of Glazings. Double glazing usually does not reduce heat losses enough to justify its added cost. single glazing with a selective absorber surface is preferred. However, for low-temperature applications [ $120 \mathrm{~F}\left(49^{\circ} \mathrm{C}\right)$ collector temperature], as in solarassisted heat pump systems, a nonselective, single-glazed collector may be appropriate.

6. Heat Losses from Storage. The best location for the heat storage tank is within or beneath the space to be heated. Then, any heat lost from storage simply goes into the heated space, and there is no net penalty to the system performance. The tank should be insulated for times when the living space does not require heat and when heat losses from the tank would contribute to overheating. A $U$ value of less than $0.2 \mathrm{Btu} / \mathrm{hr}-\mathrm{F}-\mathrm{sq} \mathrm{ft}$ (1.1 W/ $/{ }^{\circ} \mathrm{C}$-sq $\mathrm{m}$ ) of tank is recommended.

If the storage tank is located outside the occupied space, heat lost to the environment through the tank insulation can degrade the performance severely.

7. Collector Glazing Transmittance. A $1.0 \%$ reduction of glass transmittance reduces performance by only $0.25 \%$.

8. Collector Surface Absorptance. Surface absorption should not be less than $90 \%$.

9. Collector Surface Emittance. A highly selective surface can increase performance of single-glazed collectors significantly; but it offers less advantage to double-glazed collectors, and durability is still a problem.

10. Collector Coolant Flow Rate. The flow rate should be designed to keep the peak coolant temperature rise to about $20 \mathrm{~F}\left(11^{\circ} \mathrm{C}\right)$. This generally corresponds to a flow rate of $10 \mathrm{lb} / \mathrm{hr}-\mathrm{sq} \mathrm{ft} \mathrm{c}$ or $0.02 \mathrm{gpm}$ water/ sq ft $\mathrm{c}$ $\left(49 \mathrm{~kg} / \mathrm{hr}-\mathrm{sq} \mathrm{m}_{\mathrm{c}}\right.$ ).

11. Collector Heat Transfer Coefficient. A heat transfer coefficient (UA/sq ft $\mathrm{c}_{\mathrm{c}}$ ) greater than $10 \mathrm{Btu} / \mathrm{hr}-\mathrm{F}-\mathrm{sq} \mathrm{ft} \mathrm{c} \quad\left(57 \mathrm{~W} /{ }^{\circ} \mathrm{C}-\mathrm{sq} \mathrm{m}_{\mathrm{c}}\right)$ will give near maximum performance.

12. Collector Back Insulation. $\mathrm{UA} / \mathrm{sq} \mathrm{ft} c$ values of 0.1 $\mathrm{Btu} / \mathrm{hr}-\mathrm{F}$-sq ft $\left(0.6 \mathrm{~W} /{ }^{\circ} \mathrm{C}-\mathrm{sq} \mathrm{m}_{\mathrm{c}}\right)$ should be integrated into the collector design. This corresponds to 3 in. $(76.2 \mathrm{~mm})$ of insulation that has a thermal conductivity (k) of $0.025 \mathrm{Btu} / \mathrm{hr}-\mathrm{ft} F(\simeq 0.25 \mathrm{Btu}-\mathrm{in} . / \mathrm{hr}-\mathrm{sq} \mathrm{ft}-\mathrm{F})$.

13. Collector Heat Capacity. Collector design should minimize the metal mass and fluid inventory in the collector.

14. Distribution Pipe Insulation. Collector-to-storage distribution pipe heat losses can be kept relatively low by insulating to a $U$ value $\simeq 0.15 \quad \mathrm{Btu} / \mathrm{hr}-\mathrm{F}-\mathrm{sq} \mathrm{ft}$ $\left(0.9 \mathrm{~W} /{ }^{\circ} \mathrm{C}-\mathrm{sq} \mathrm{m}\right)$ of pipe or 2 in. $(50.8 \mathrm{~mm})$ of insulation that has a $k$ of $0.025 \mathrm{Btu} / \mathrm{hr}-\mathrm{ft}-\mathrm{F} \quad(\simeq 0.25 \mathrm{Btu}-\mathrm{in.} /$ hr-sq $f t-F$ ).

Air Space Heating/Hot Water System. The above remarks about the standard liquid system generally apply to an analogous "standard" air system. An air collector, coupled with a rock bed, was simulated using the same locations and weather data. The design parameters, and the effects of varying them, are essentially the same for both the liquid and air systems, except for those listed below. 
Table 10-6. RECOMMENDED SOLAR SYSTEM DESIGN PARAMETERS

\begin{tabular}{|c|c|}
\hline Parameter & $\begin{array}{l}\text { Recommended } \\
\text { Design Value }\end{array}$ \\
\hline 1. Collector area & Determined by life-cycle cost analysis \\
\hline 2. Collector tilt & $\begin{array}{l}\text { Lat }+5^{\circ} \text { (water heating only) } \\
\text { or lat }+15^{\circ} \text { (space and water heating) }\end{array}$ \\
\hline 3. Collector orientation & Due south \\
\hline 4. Storage mass & $\begin{array}{l}15 \mathrm{lb} \text { water } / \mathrm{sq} \mathrm{ft}_{\mathrm{c}}=1.8 \mathrm{gal} / \mathrm{sq} \mathrm{ft}_{\mathrm{c}} \text { (liquid system) } \\
\text { or } 15 \mathrm{Btu} / \mathrm{F}-\mathrm{sq} \mathrm{ft}_{\mathrm{c}}=75 \mathrm{lb} \text { rocks } / \mathrm{sq} \mathrm{ft}_{\mathrm{c}} \text { (air system) }\end{array}$ \\
\hline $\begin{array}{l}\text { 5. Heat exchanger heat transfer } \\
\text { coefficient }\end{array}$ & $10 \mathrm{Btu} / \mathrm{hr}-\mathrm{F}-\mathrm{sq} \mathrm{ft} \mathrm{c}_{\mathrm{c}}(5-15 \mathrm{~F}$ approach) \\
\hline 6. Collector heat transfer & $\begin{array}{l}10 \mathrm{Btu} / \mathrm{hr}-\mathrm{F}-\mathrm{sq} \mathrm{ft} \mathrm{e}_{\mathrm{e}} \text { (liquid system) } \\
\text { or } 4 \mathrm{Btu} / \mathrm{hr}-\mathrm{F}-\mathrm{sq} \mathrm{ft} \text { (air system) }\end{array}$ \\
\hline 7. Number of glazings & 1 \\
\hline 8. Collector surface absorptance & $\geq 0.9$ with selective surface \\
\hline 9. Collector coolant flow rate & $\begin{array}{l}10 \mathrm{lb} / \mathrm{hr}-\mathrm{sq} \mathrm{ft} \mathrm{c}_{\mathrm{c}}=0.02 \mathrm{gpm} \text { water } / \mathrm{sq} \mathrm{ft} \mathrm{c}_{\mathrm{c}} \text { (liquid system) } \\
\text { or } 2 \mathrm{cfm} / \mathrm{sq} \mathrm{ft} \text { (air system) }^{\text {(air }}\end{array}$ \\
\hline 10. Collector back insulation & $\mathrm{U}=0.1 \mathrm{Btu} / \mathrm{hr}-\mathrm{F}-\mathrm{sq} \mathrm{ft}_{\mathrm{c}}$ \\
\hline 11. Distribution pipe insulation & $\mathrm{U}=0.15 \mathrm{Btu} / \mathrm{hr}-\mathrm{F}-\mathrm{sq} \mathrm{ft_{c }}$ of pipe \\
\hline
\end{tabular}

1. Collector Heat Transfer Effectiveness (product of the heat transfer coefficient times the heat transfer area divided by the collector area). This should be approximately $4 \mathrm{Btu} / \mathrm{hr}-\mathrm{F}-\mathrm{sq} \mathrm{ft}_{\mathrm{c}}\left(23 \mathrm{~W}^{\circ} \mathrm{C}-\mathrm{sq} \mathrm{m}_{\mathrm{c}}\right)$.

2. Collector Air Flow Rate. Performance drops severely at air flow rates below $1 \mathrm{efm} / \mathrm{sq} \mathrm{ft}_{\mathrm{c}}\left(5 \mathrm{l} / \mathrm{s}-\mathrm{sq} \mathrm{m}_{\mathrm{c}}\right)$; $2 \mathrm{cfm} / \mathrm{sq} \mathrm{ft}_{\mathrm{c}}\left(10 \mathrm{l} / \mathrm{s}-\mathrm{sq} \mathrm{m}_{\mathrm{c}}\right)$ is recommended.

3. Thermal Storage Heat Capacity. The capacity of the thermal storage is not very important beyond a value of about $10 \mathrm{Btu} / \mathrm{F}-\mathrm{sq} \mathrm{ft}_{\mathrm{c}}\left(200 \mathrm{~kJ} /{ }^{\circ} \mathrm{C}-\mathrm{sq} \mathrm{m}_{\mathrm{c}}\right)$, corresponding to $50 \mathrm{lb}$ or rock/sq ft $\mathrm{c}\left(230 \mathrm{~kg} / \mathrm{sg} \mathrm{m}_{\mathrm{c}}\right)$.

4. Rock-Bed Temperature Distribution. A short air flow path in the rock bed is preferable to a long one for pressure drop reasons, but it should be longer than about 12 rock diameters to take advantage of spatial temperature distribution benefits. (Detailed rock-bed design information is given in Ref. 43 of Chapter 5 of this workbook.)

Recommended Solar System Design Parameters. The above results of parametric studies can be summarized by identifying recommended solar system design parameters. These nominal design parameters (Table 10-6) are recommended for the standard system configurations studied. For example, these parameters are not applicable to combined solar-heat pump or solar cooling systems.

\section{Solar Cooling Systems}

Although LASL has not developed performance curves for combined solar space heating and cooling systems, CERL has studied such systems [14]. The CERL method is recommended for feasibility assessment of such systems, but hourly computer simulation is recommended for system design.

CERL investigated a modular barracks and a headquarters and classroom building. An hourly computer simulation program, coupled with loads determined using hourly weather tapes, was used in parametric studies of liquid solar systems in Fort Worth, Texas; Columbia, Missour i; Madison, Wisconsin; Washington, D.C.; and Los Angeles, California. 


\section{Design and Sizing Curves}

The modular barracks and headquarters office and classroom buildings simulated had typical envelope and ventilation characteristics, used a limited economy cycle, and had large cooling loads.

It was assumed that a solar-driven absorption chiller provided the cooling. The model was based on a 3-ton $\mathrm{LiBr}$ water unit $(\mathrm{COP}=0.65)$ designed to use water at $210 \mathrm{~F}\left(99^{\circ} \mathrm{C}\right)$, but capable of operation down to $170 \mathrm{~F}$ $\left(77^{\circ} \mathrm{C}\right)$ at significantly reduced capacity. Thus, the nominal collector operating temperature was about $200 \mathrm{~F}$ $\left(93^{\circ} \mathrm{C}\right)$. Heating was provided by a heating coil in the air supply duct that was driven by water from the solar storage and boosted by an auxiliary heater if the supply temperature fell below a specified level.

The resulting universal performance curves, Fig. 10-15, are applicable to nearly all buildings, regardless of site, that have dominant cooling loads, and for which the annual heating and cooling load and the annual insolation at the site are known. These universal curves correlate the data on the basis of annual, rather than monthly, parameters, because the combined heating and cooling load is fairly uniform on an annual basis. However, this performance-estimating method should not be applied to lightweight or uninsulated buildings or those with large glass areas, because their thermal properties may differ greatly from those studied.

Note also that the simulation used to develop these curves is limited. A particular outside air schedule and a single storage tank with auxiliary boost and a fixed heating coil design temperature were used, along with several other assumptions. Therefore, care must be taken in extrapolating these results to other applications.

Fig. 10-15 shows solar system operation, given storage capacities of 16,31 , and $62 \mathrm{Btu} / \mathrm{F}-\mathrm{sq} \mathrm{ft} \mathrm{c}(325,630$, and $\left.1260 \mathrm{~kJ} /{ }^{\circ} \mathrm{C}-\mathrm{sq} \mathrm{m}_{\mathrm{c}}\right)$. Each curve is described by the general equation

$f=B\left(r-0.082 r^{2}\right)$,

where $f$ is the annual load fraction supplied by solar energy; $B$ is a parameter (see Fig. 10-15); and $r$ is a modified SLR that corrects for different collector types.

$r=\frac{H_{M \Sigma} A_{C}}{Q_{L} M}$

$\mathrm{H}_{M \Sigma}, A_{C}$, and $Q_{L}$ have been defined earlier, and $M$ is the multiplying factor for various collectors given in Table 10-7. Note that proper operation of the absorption chiller requires a solar collector that achieves temperature of $180 \mathrm{~F}+\left(82^{\circ} \mathrm{C}\right)$. Thus, solar heating and cooling systems must include a high-performance collector, and a collector multiplying factor for a selective surface should be used in design evaluations.

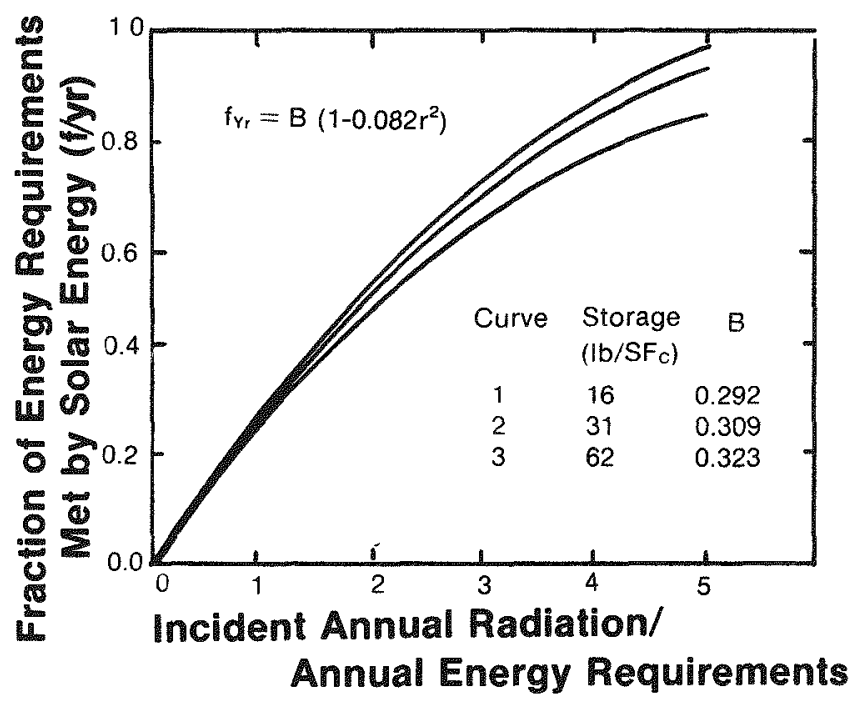

Fig. 10-15. Approximate universal perform-
ance curves for three storage ca-
pacities in a combined heating
and cooling system

\section{Design Parameter Variations}

Using hourly simulations based on the weather in the five cities that CERL studied, variation of selected system parameters has been studied. For a system of a given size, the use of solar-supplied energy varies greatly at the different sites [14] indicating the critical impact of building energy use on the overall performance of the solar energy system.

Comparison of the load fraction met by solar energy and the thermal storage capacity shows that performance is improved greatly by increasing storage from 8 to $15 \mathrm{lb}$ of water $/ \mathrm{sq} \mathrm{ft}_{\mathrm{c}}\left(40-80 \mathrm{~kg} / \mathrm{sq} \mathrm{m}_{\mathrm{c}}\right)$, but improved considerably less by increasing it further.

Table 10-7. COLLECTOR AREA MULTIPLYING PACTOR, M, FOR DIFPERENT COLEECTOR CHARACTERISTICS

$$
\begin{aligned}
\alpha & =\text { Absorptance } \\
\varepsilon & =\text { Emittance } \\
N & =\text { Number of glazings }
\end{aligned}
$$

\begin{tabular}{lllll}
\hline$\alpha$ & & 0.96 & 0.94 & 0.90 \\
$\varepsilon$ & 0.96 & 0.30 & 0.10 \\
\hline \multirow{2}{*}{$\mathrm{N}$} & 1 & 1.55 & 1.09 & 1 \\
& 2 & 1.09 & 0.97 & 0.93 \\
\hline
\end{tabular}


The effect of collector tilt on performance of a solar heating and cooling system shows that optimum tilt is approximately lat $-10^{\circ}$. This is quite different from BSHW only or space heating only systems which optimize at higher tilt angles, because the dominant cooling loads occur during the summer when lower tilt angles are more effective.

\section{Other Methods}

The solar design methods of Refs. 17 and 18, which include the effects of different design water temperatures, can be applied to solar cooling systems if the minimum load temperature is set appropriate to absorption cooling equipment.

\section{IPH Systems}

Most IPH systems are characterized by the high temperatures required for energy supply to the load. Thus, IPH systems often use concentrating collectors that have highly nonlinear performance curves. To account for higher temperatures used with flat plate collectors, the methods of Refs. 17 and 18 can be used. Where concentrating collectors are used, computer analysis methods are recommended.

\section{COMPUTER METHODS}

Computer simulation programs applicable to solar system design are of two basic types. First, there are the full building energy analysis computer programs that also have solar simulation capabilities. Examples are DOE-2, BLAST, ACCESS, and TRACE. The other type is the detailed programs developed specifically for solar system simulation. These programs generally have limited load and HVAC system capabilities. Examples are TRNSYS, SOLCOST, SIMSHAC, and WATSUN. For envelopedominated buildings, where the loads are readily computed using the degree-day method, the latter type of program is appropriate. However, for most comm ercial buildings, which are interior-load dominated and require that coupled heating and cooling loads be calculated, the full building energy analysis programs are the most appropriate. Compendia of solar simulation computer programs are given in Refs. 5-7. The SERI models data base can also be used when selecting computer programs for specific tasks.

Two basic approaches are used in the computer simulation of active solar heating/cooling systems: the fixed-schematic approach and the component-based approach [5]. The fixed-schematic (with options) approach is the most prevalent method in use. A set of system schematics is fixed with the user having certain options usually limited to equipment configuration and performance, control strategies, and auxiliary fuel types. Generally, not all of the program's capabilities are exercised in a given run. When modeling a system, the user only defines those parts required; the other components are deactivated. The fixed-schematic approach is less expensive to develop and execute than the component-based methods. However, distinct system schematics must be programmed separately; and as additional systems are added, the program size increases.

The component-based approach is organized around components rather than systems. The user input includes a definition of the system schematic that identifies the library components used and how these components are interconnected. Additional components may be added to the library. The advantage of this approach is its flexibility in simulating a variety of system types. On the other hand, the input data preparation is more complex, and run times are increased.

Solar hẹating/cooling simulation programs are available by purchase, lease, time-share, or batch processing. In addition, some programs are proprietary, in which case the user has limited access to program documentation and assumptions and limited opportunity to change the program to suit special needs.

The purchase of the source code (and documentation) is only useful if the user has access to computer facilities. Under a lease agreement, the program supplier will install the program on the user's system and provide instruction and documentation for a limited time period. Such an arrangement also requires the availability of inhouse computer facilities.

Time-share programs are available on national computer service bureau time-sharing networks. The costs are generally proportional to computer time used, and problems of initial implementation and maintenance are avoided. However, the user forfeits the flexibility to modify the program.

When programs are operated in the batch mode, the input data are submitted to the program developer for execution. Changes are usually based on computer time used. Turnaround may vary from a few hours to a few days.

Some programs are available on several bases. When selecting a program, the user must trade off the cost of setting up the program on the user's computer system, and the user convenience and access to the program algorithms afforded by owning the program. Often, the user has no access to computer facilities except through the batch or time-sharing mode. 


\section{Detailed Hour-by-Hour Simulation Programs}

\section{TRNSYS}

TRNSYS is a transient solar system simulation program developed at the Solar Energy Laboratory at the University of Wisconsin-Madison. The program has been under development since 1974, and a number of updated versions have been released since that time. Version 10.0 is the most recent. The program contains simulation models of various subsystem components, including solar collectors, thermal storage units, pumps, controllers, heat pumps, a building load model, etc. That is, all of the components which normally comprise a solar energy system have been modeled in TRNSYS. The user of the program may then "hook up" the components that are representative of a particular solar system to be analyzed and, by so doing, simulate the performance of a given solar energy system. The level of detail can be selected by the user.

TRNSYS was developed to fill the need for a flexible, component-based, public domain computer program for the analysis and design of a wide variety of solar heating and cooling systems [20,22]. An additional use of a transient system simulation program such as TRNSYS is to develop design methods and design handbooks that may be used for the design of representative types of solar energy systems. This was done in the case of the development of the F-CHART design method using TRNSYS. Once this step has been accomplished, it is no longer necessary to execute the detailed computer simulations for the design of systems for which the design methods or handbooks have been developed.

Inputs 4

Outputs 5

Parameters 7

Derivatives 0

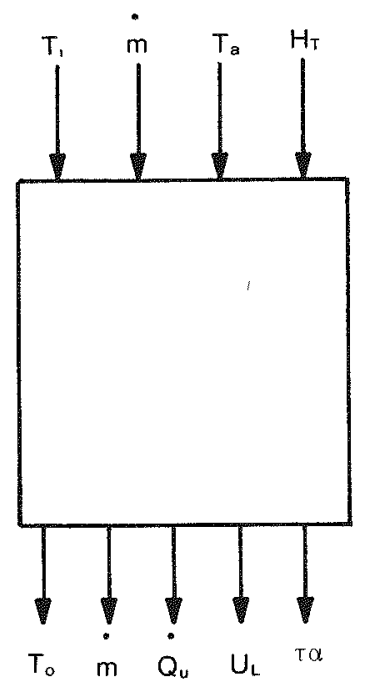

\section{Parameters}

1. Mode: 1
2. $\mathrm{A}$
3. $\mathrm{F}^{\prime}$
4. $\mathrm{C}_{\mathrm{p}}$
5. $\mathrm{d}$
6. $\mathrm{U}_{\mathrm{L}}$
7. $\mathrm{T}$

Fig. 10-16. Component diagram for a mode 1 collector
Program Description. The first step in setting up a simulation using TRNSYS is to develop an information flow diagram. The information flow diagram is simply a way in which the solar system may be described in order to simulate the systems using TRNSYS. The information flow diagram conveys to the program the components used in the solar system and the manner in which they are connected. There must be an information flow diagram for each subsystem component utilized in the solar system. These are typically referred to as component diagrams. A component diagram for a Type 1 collector is shown in Fig. 10-16. The inputs are the temperature of the fluid entering the collector, the mass flow rate, the ambient temperature, and the radiation on the tilted collector surface. The outputs are the temperature of the fluid leaving the collector, the mass flow rate, the time rate of change of useful energy collected, the transm issivity-absorptivity product, and the collector loss coefficient. Parameters used in modeling the subsystem components include the collector area, the effectiveness factor, the specific heat of the transport fluid, the absorptivity of the collector, the loss coefficient of the collector, and the transmissivity of the collector covers.

Suppose that we wish to simulate the performance of the service hot water system shown schematically in Fig. 10-17. The subsystem components include a collector, a pump, and a controller. Suppose that the controller turns the pump on whenever the difference between the temperature of the fluid coming from the collector and the temperature of the fluid going into the collector exceeds $0.9 \mathrm{~F}\left(0.5^{\circ} \mathrm{C}\right)$ and that the controller turns the pump off whenever the temperature difference is equal to $0 \mathrm{~F}$. Suppose, furthermore, that the supply water is at a constant temperature of $68 \mathrm{~F}\left(20^{\circ} \mathrm{C}\right)$. Also, suppose that the mass flow rate is constant at $0.9 \mathrm{gpm}(200 / \mathrm{hr})$ whenever the pump is turned on. An information flow diagram for the system is shown in Fig. 10-18. The manner in which outputs of some components are connected to inputs of other components is illustrated in this diagram. For example, the output $T_{0}$ from the collector becomes input $\mathrm{T}_{1}$ to the controller.

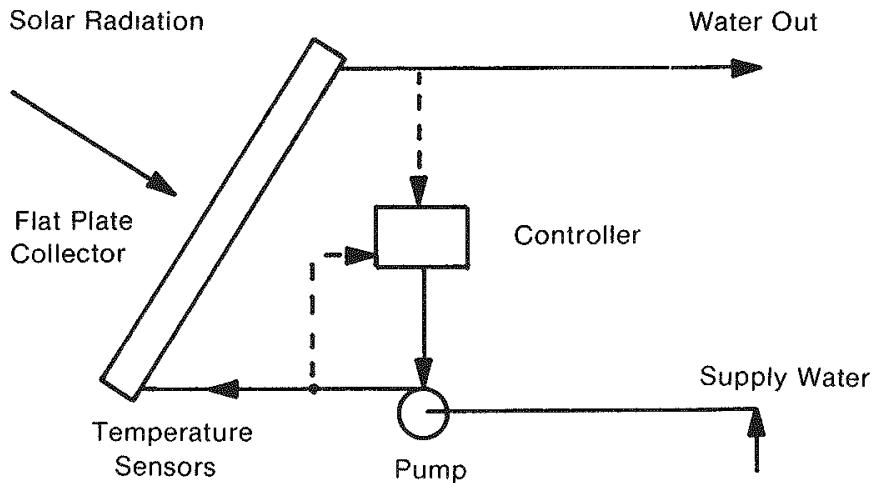

Fig. 10-17. Schematic diagram of a simple solar water heating system 


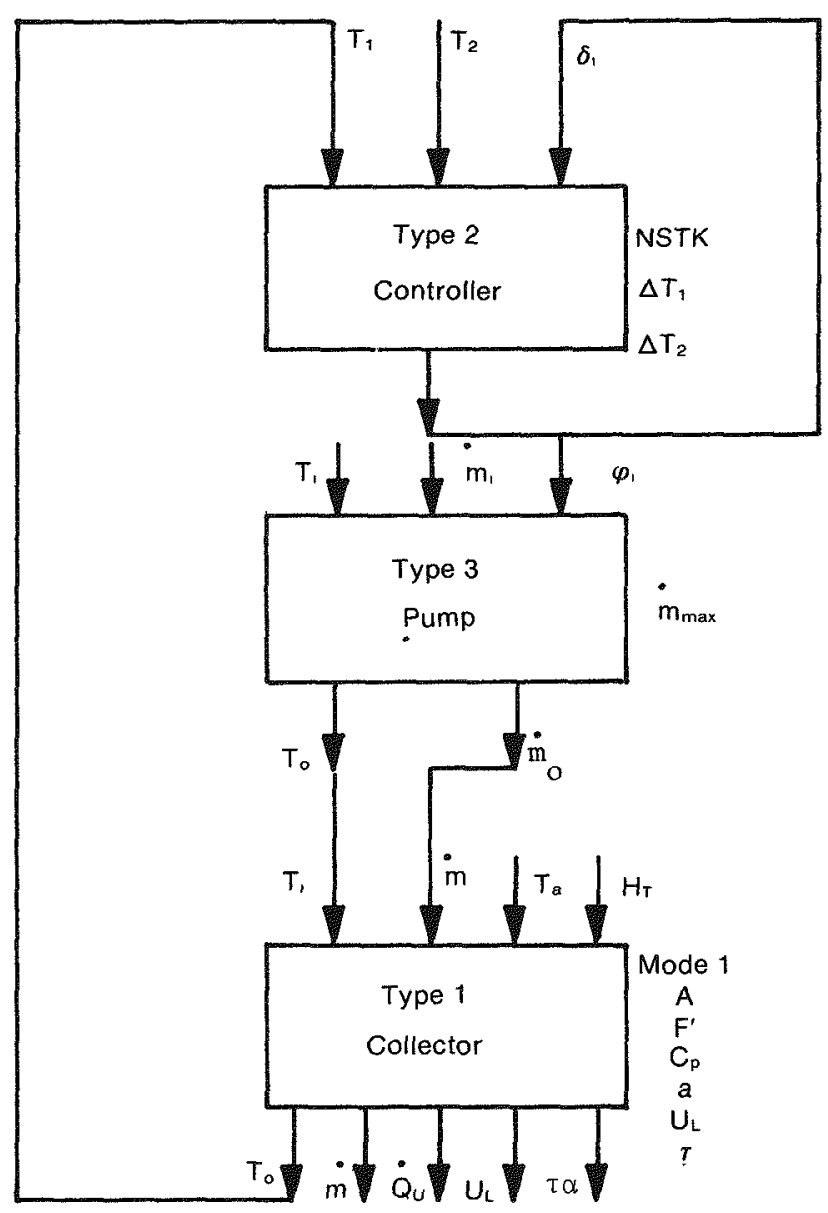

Fig. 10-18. Information flow diagram for a
solar water heating system

What would happen if we were to try to execute the TRNSYS program for this system? Nothingt There is no input to drive the system. Hence, we must read some input data. This is provided by a data reader, which may be modeled as simply another subsystem component. The data reader for TRNSYS has no inputs but has up to 20 outputs. The inputs for this system include the radiation on the tilted surface, $\mathrm{H}_{\boldsymbol{L}}$, and the ambient temperature, $T_{A}$. Suppose that this information is recorded on cards at hourly intervals. The data reader may then be used to read this information from the cards and provide it to the program. If we were to include the data reader in the information flow diagram, connecting $\mathbf{H}_{\Sigma}$ and $T_{A}$ to the inputs of the collector component diagram, then we would be able to make the system operate. However, we would still not learn anything as we have made no provision for obtaining any output. Just as there are provisions for reading input data into TRNSYS, there are also provisions for getting information out of TRNSYS. These components include integrators, printers, and plotters. Suppose that we are interested in determining the average daily efficiency of the collector. This would be provided by

$$
\eta=\frac{Q_{u}}{\Sigma \bar{H}_{\Sigma}}
$$

The useful energy, $Q_{u}$, and the total radiation may be determined by integrating the instantaneous values over the 24-hour time period. These integrations are performed in TRNSYS by using a quantity integrator. Finally, tabular results may be obtained by using a printer subsystem, and/or graphical results may be obtained by using a plotter subsystem. The component diagrams for these subsystems may be added to the information flow diagram to obtain a complete information flow diagram for this example, as shown in Fig. 10-19.

Although this appears to be somewhat complicated, it really is quite simple; and it is relatively easy to construct information flow diagrams for reasonably complex solar systems such as those found in the Colorado State University Solar Houses, which include cooling as well as heating and service hot water components.

In the event that a user wishes to include a subsystem component that is not presentiy included in the component library in the TRNSYS program, then the user must write the subroutine and develop an information flow diagram for that particular subsystem component. This is of ten a straightforward process but at times can develop into a rather significant problem. Components currently included in the TRNSYS library include a collector component using the Hottel-Whillier-Bliss equations; a differential controller; a pump having a fixed flow rate; a liquid storage tank including stratification; counterflow, parallel flow, or crossflow heat exchangers; an on-off auxiliary heater with set temperature and deadband; a space load and air conditioner; a three-stage room thermostat; a data reader; a packed bed energy storage tank; flow controllers for air or water; a space heating load; relief valves; time-dependent forcing functions; algebraic operations; a solar radiation processor; building components used to model heating and cooling loads; a heat pump; a quantity integrator; and a printer and a plotter. 


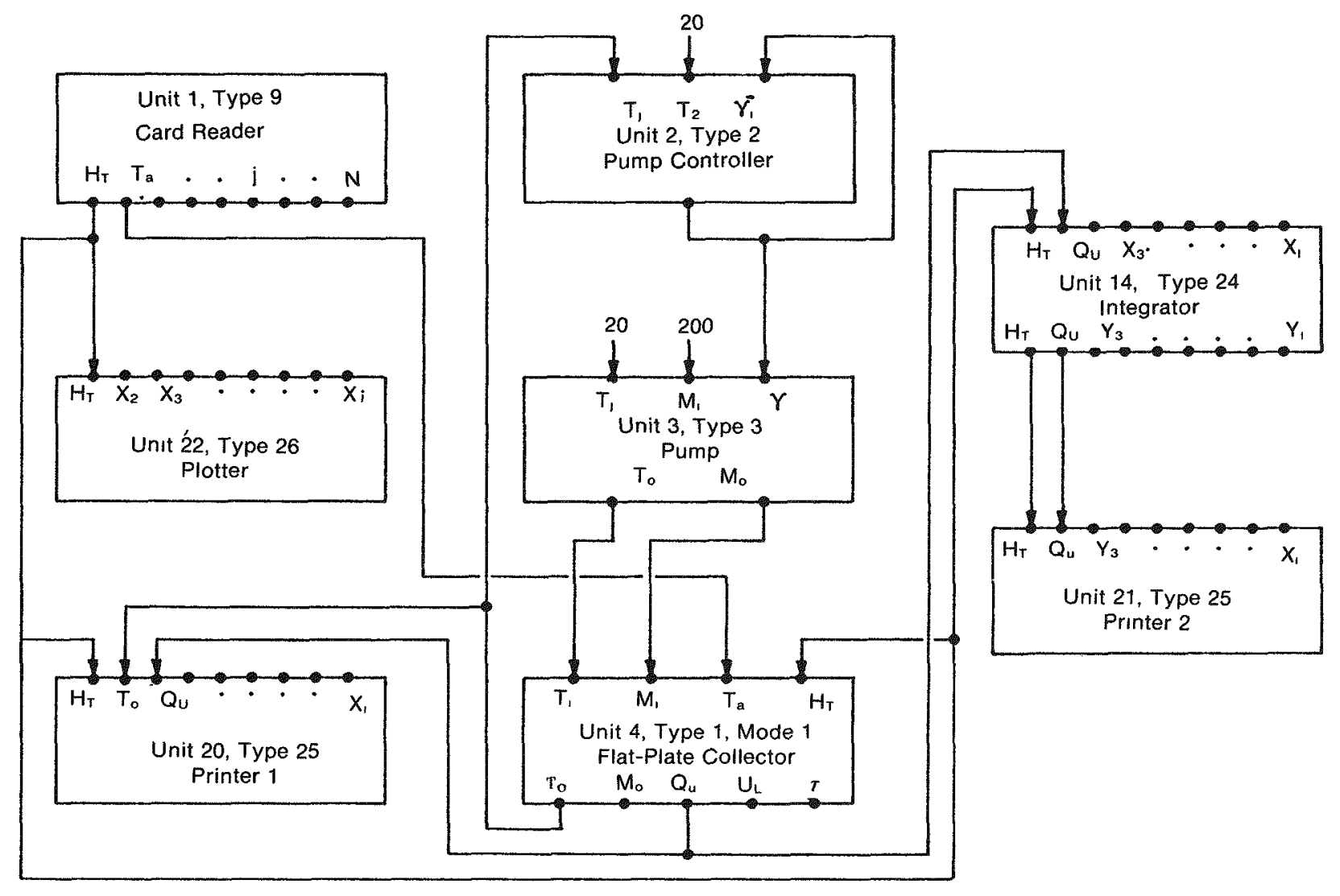

Fig. 10-19. Complete information flow diagram for a solar water heating system

Validation Results. If it can be shown that the results obtained from a simulation program are accurate, then that program may be used to study the performance of different systems subjected to varying climatological conditions. The program may also be used to develop simplified tools. This was the process that was followed relative to the TRNSYS program. Validation studies of TRNSYS have been conducted by the Solar Environmental Engineering Company [23, 32]. Data obtained from Colorado State University Solar House I were used to determine the validity of the TRNSYS program. That is, measured values of the outputs of various subsystem components, including the solar radiation, the ambient temperature, the storage tank temperature, the enclosure temperature, the collector inlet and outlet temperatures, the collector flow rates, the useful energy collected, the auxiliary energy supplied, etc., were compared with simulated values obtained from TRNSYS. The differences between the observed states and the simulated states were then analyzed statistically. Results obtained from a simulation of Solar House I during the cooling season are shown on Table 10-8. It is apparent from these results that TRNSYS provides a very accurate tool for analyzing systems such as that in CSU Solar House I.
Additional comparisons of measured and simulated performance for CSU Solar House I are reported in Ref. 34. This study also showed that agreement between measured and simulated data was on the average quite good. This further suggests that the TRNSYS simulation model adequately represents the physical system.

Based on these and similar results, one may proceed with confidence to analyze similar type systems in different geographic locations. In fact, if one uses only validated subsystem components in TRNSYS, then one may have confidence in the accuracy of results obtained from TRNSYS for any type of system subjected to any climatological conditions. TRNSYS has been used to model a wide variety of system types including space heating and cooling systems in both residential and commercial buildings, industrial process heat applications, grain drying applications, etc.

Future Developments. The major developments planned for TRNSYS involve component subroutines. New models are being developed for new kinds of systems, including advanced solar-heat pump systems, absorption chillers, and heat and mass transfer devices. 
Table 10-8. TRNSYS VAIDDATION RESULTS - TESTING PERIODS CSU SOLAR HOUSE I

\begin{tabular}{|c|c|c|c|c|c|c|c|c|c|}
\hline \multirow[b]{3}{*}{ Component } & \multicolumn{6}{|c|}{ Month } & \multirow{2}{*}{\multicolumn{2}{|c|}{$\begin{array}{l}\text { Summer } \\
\text { Average }\end{array}$}} & \multirow{3}{*}{$\begin{array}{l}\text { Percent } \\
\text { Error }\end{array}$} \\
\hline & \multicolumn{2}{|c|}{ June } & \multicolumn{2}{|c|}{ July } & \multicolumn{2}{|c|}{ August } & & & \\
\hline & Mean & STDV & Mean & STDV & Mean & STDV & Mean & STDV & \\
\hline $\begin{array}{l}\text { Storage Tank } \\
\text { (F) }\end{array}$ & 1.4 & 2.8 & 1.6 & 5.7 & -2.0 & 5.9 & 0.4 & 4.8 & $\sim 1 \%$ \\
\hline $\begin{array}{l}\text { Enclosure } \\
\text { (F) }\end{array}$ & -0.1 & 2.1 & 6.1 & 3.1 & -4.8 & 3.0 & 0.4 & 2.7 & $\sim 1 \%$ \\
\hline $\begin{array}{l}\text { Collector Inlet } \\
\text { (F) }\end{array}$ & 0.6 & 2.3 & 0.5 & 1.6 & 0.7 & 2.4 & 0.6 & 2.1 & $\sim 1 \%$ \\
\hline $\begin{array}{l}\text { Collector Outlet } \\
\text { (F) }\end{array}$ & 0.5 & 1.8 & -1.2 & 2.8 & 0.5 & 1.7 & -0.1 & 2.1 & $\sim 1 \%$ \\
\hline $\begin{array}{l}\text { Collector Flow } \\
\text { Rate }(\mathrm{lbm} / \mathrm{min})\end{array}$ & 0.4 & 2.5 & 0.5 & 1.8 & 0.4 & 1.5 & 0.4 & 1.9 & $\sim 1 \%$ \\
\hline $\begin{array}{c}\text { Energy Collected } \\
\text { (Btu/Day) }\end{array}$ & 8524 & 24506 & 7812 & 22609 & 6279 & 21725 & 7538 & 22946 & $\sim 2.5 \%$ \\
\hline $\begin{array}{l}\text { Cooling Load } \\
\text { (Btu/Day) }\end{array}$ & -25178 & 43517 & -68253 & 62785 & 89753 & 90286 & 1226 & 65529 & $\sim 1 \%$ \\
\hline $\begin{array}{c}\text { Aux. Energy } \\
\text { Supply (Btu/Day) }\end{array}$ & -32271 & 44952 & -75843 & 86597 & 113603 & 127314 & 5489 & 86287 & $\sim 2 \%$ \\
\hline $\begin{array}{l}\text { Solar Insol }\left(45^{\circ}\right) \\
\quad\left(\mathrm{Btu} / \mathrm{ft}^{2} / \mathrm{hr}\right)\end{array}$ & 9.9 & 13.9 & 7.6 & 11.6 & 7.6 & 10.8 & 8.4 & 12.1 & $\sim 4 \%$ \\
\hline
\end{tabular}

Note: The numbers presented represent the mean of the differences between the simulated and measured performance statistics.

\section{DOE-2/CBS}

DOE-2 is a full hour-by-hour building energy analysis program that also has extensive active solar systems simulation capabilities. The main DOE-2 program was developed by the Lawrence Berkeley Laboratory (LBL) with the assistance of the Los Alamos Scientific Laboratory (LASL). LASL has developed the solar system simulator. The latest version of the program, DOE-2.1 [35] is accessible in the batch mode at LBL (for DOE contractors). It is available on several computer service networks and at SERI. (SERI access is only available to governmental agencies or their contractors.) It also may be purchased from NTIS.

Program Description. Four programs, LOADS, SYSTEMS, PLANT, and ECONOMICS, form the heart of DOE-2. The LOADS program uses hourly weather data to perform hourly and design, or peak, energy-use calculations of the heating and cooling loads on the building's HVAC system. The LOADS program takes into account the type of building construction; the accupancy; the equipment used in the building; the hours of the day and days of the week of occupancy and equipment use; the solar radiation through walls and windows; and the thermal mass of interior walls, floors, and furniture in which heat is stored. It also takes into account the effects on the building of shading by trees, attached balconies, overhangs, fins, or other nearby buildings.
The SYSTEMS program takes the results of the hourly LOADS calculations and simulates one or more of 21 HVAC systems such as a variable-volume air system, floor-panel or baseboard heating, or a constant-volume air system. The SYSTEM program also includes in its calculations the effects of variations in thermostat settings such as adjusting thermostats for seasonal changes, or lowering thermostat settings at night.

The PLANT program uses the hourly calculations from SYSTEMS to simulate the heating and cooling plant. This plant might include boilers, chillers, gas or steam turbines, and electricity from a utility company. The newest element in the PLANT program is the solar simulator package called Component-Based Simulator (CBS), a set of subprograms that simulates elements of a solar heating or cooling system.

Finally, the ECONOMICS program uses the PLANT program results to calculate and compare the costs of installation, maintenance, and fuel use of alternative systems over the lifetime of the building.

The DOE-2 solar simulator, CBS [36] is a multilevel analysis and design tool for both liquid (see Fig. 10-20) and air (see Fig, 10-21) active solar heating and/or cooling systems. CBS contains many simulation models or components. The user may assemble a system using these components to suit his own special requirements or 
may select a preassembled, standard liquid or air system from among several stored in the DOE-2 library. To save time, most users will use a preassembled system. Both commercial and residential building systems, including space heating and cooling, process hot water, and combined solar-heat pumps are modeled. TRNSYS was used as the basis when developing CBS.

Validation Results. CBS includes many of the concepts (simulation and organizational) of TRNSYS. A component-based structure and methodology enable the CBS user to assemble a large number of systems, while code redundancy is kept to a minimum. CBS employs a streamlined input and component-connection procedure and has greatly reduced calculation times, as compared with TRNSYS. To verify the relative accuracy of CBS compared with TRNSYS, several comparative test runs have been made for space and domestic hot water heating systems $[31,36]$. Both hourly and monthly results were examined. The solar fraction results of the two programs agreed to within 3.2 percentage points on a monthly basis and to within 0.8 percentage points on an annul basis.

Future Developments. Future developments in DOE-2/CBS will include a mixed storage tank model, an improved concentrating collector model, an improved solar-absorption chiller model, and a solar-Rankine chiller model.

\section{Other Computer Simulation Programs}

\section{SOLCOST}

The SOLCOST program was developed by the MartinMarietta Corporation in 1976 with support from DOE [37]. SOLCOST lies between F-CHART and TRNSYS in terms of ease of use and versatility. It differs from F-CHART in that, whereas F-CHART is a correlation program, SOLCOST is a simulation program similar to TRNSYS. That is, SOLCOST actually simulates the performance of representative types of solar systems. It is not as flexible as TRNSYS, however, in that it is not modular; and the user of the SOLCOST program does not have the freedom to build a simulation model of his own solar system. It is more flexible than F-CHART, however, in that it includes several types of solar systems that are not included in F-CHART. The SOLCOST program includes tracking and concentrating collectors, solar cooling systems, solar-assisted heat pump systems, and mixed heating and cooling systems in addition to the conventional types of heating systems that are included in F-CHART. It follows that sinee the SOLCOST is more complex than F-CHART, it is also more difficult to run. However, for many people who have been thoroughly exposed to both programs, the increased versatility of SOLCOST is desired. The SOLCOST program is on several national time-sharing networks and may be

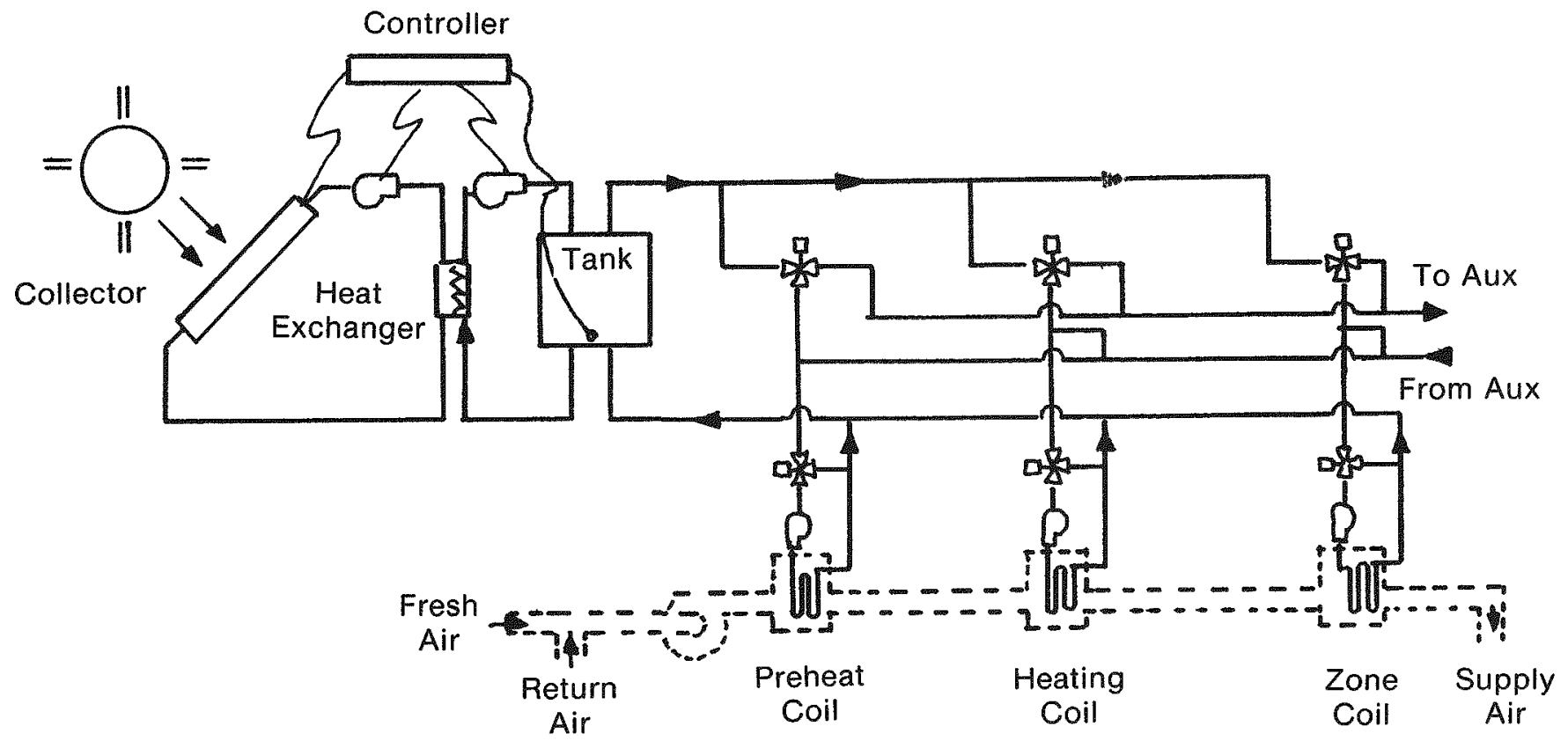

Dashed equipment items are not simulated in CBS.

Fig. 10-20. DOE-2/CBS commercial liquid solar system schematic 


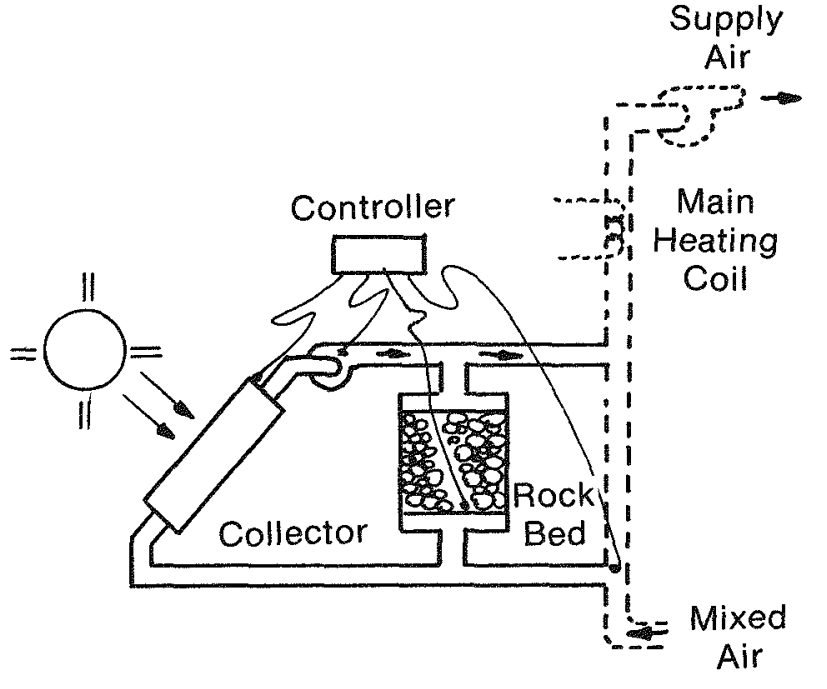

Dashed equipment items are not simulated in CBS.

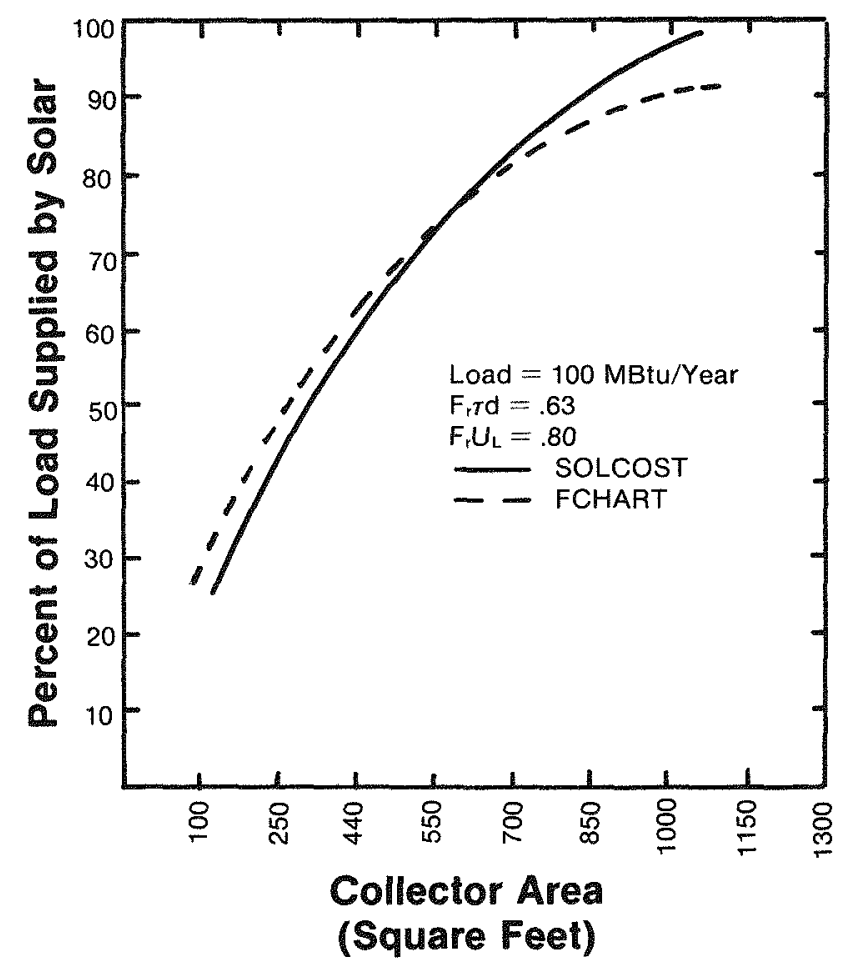

Fig. 10-22 Typical comparison between FCHART and SOLCOST results

accessed from virtually anywhere in the United States. For those designers who wish to obtain SOLCOST and install it on their own computational facilities, the program may be ordered from the Solar Environmental Engineering Company. The cost of the program is $\$ 200$. Both SOLCOST and F-CHART include life-cycle cost analyses in addition to the solar system performance analyses.

Comparisons Between SOLCOST and F-CHART. It is of interest to compare results obtained from both SOLCOST and F-CHART. Thousands of comparisons between the two programs have been made by the Solar Environmental Engineering Company. Some of the results of these studies are presented below.

Shown in Fig. 10-22 is a typical result obtained from comparing SOLCOST and F-CHART. These results are shown for a space heating system in Denver, Colorado. For solar fractions between 0.3 and 0.8 the results obtained from the two programs are in very close agreement. Results obtained from several additional comparison studies for several additional locations are shown in Table 10-9. Again, we see that the two programs give closely comparable results. Still additional comparisons between F-CHART and SOLCOST results are shown in Fig. 10-23. The conclusion that may be drawn from these studies is that when the same climatological data are used in the SOLCOST and F-CHART programs, and when the programs are used correctly, the two programs produce results that agree to within $\pm 10 \%$

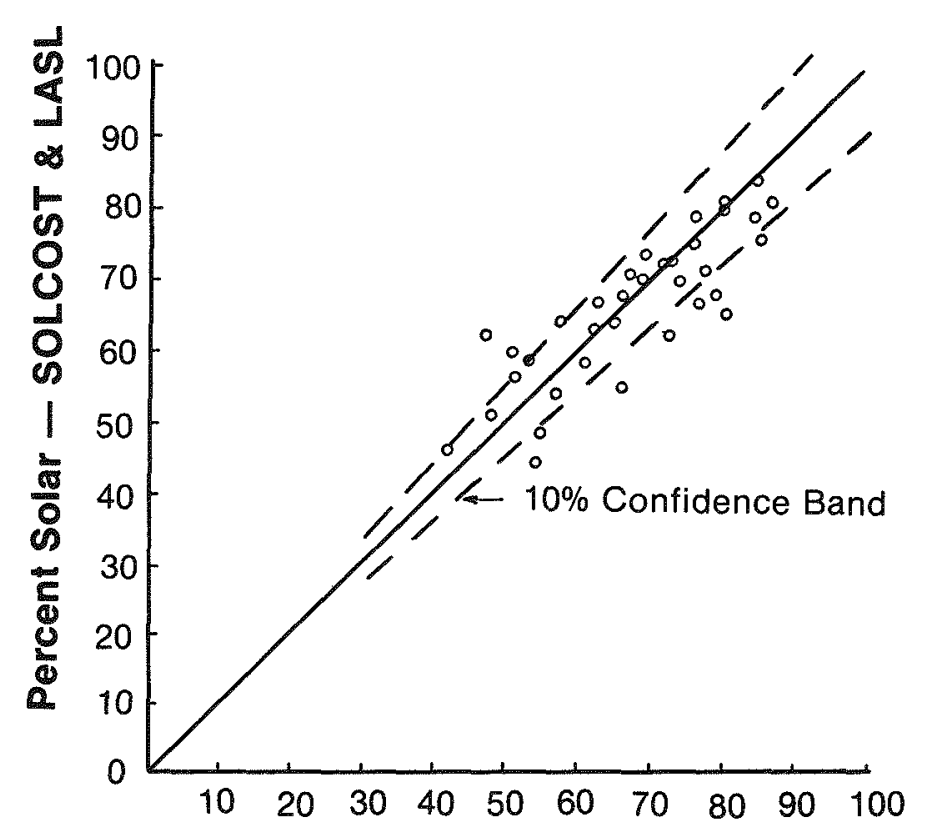

Percent Solar - FCHART

Fig. 10-23. F-CHART-SOLCOST comparisons

greater than $90 \%$ of the time. This agreement is considered to be well within the accuracy of the program, when they are applied to the design of actual systems. 
In addition to these comparisons between results obtained from both the F-CHART and SOLCOST programs, results obtained from SOLCOST have been compared with measurements of actual system performance in a manner similar to that previously described for F-CHART. As should be expected, the results obtained between SOLCOST and measured system performance figures were comparable to those previously reported for comparisons between F-CHART results and measured system results. For more information, see Ref. 32, and Figs. 10-24 and 10-25.

SolcosT" Service Centers. For designers who do not have access to SOLCOST but who would prefer having the program executed by someone else and then having the results delivered, the SOLCOST Service Center (Solar Environmental Engineering Company, 2524 E. Vine Dr., Ft. Collins, CO 80524) has been established. Forms may be obtained from the Government Printing office (Ref. 37), which, when completed by the solar system designer, may be submitted to the nearest SOLCOST Service Center for processing. The results obtained from the SOLCOST program will then be mailed to the solar system designer. For further information regarding this procedure, contact International Business Services.

Figure 10-23 shows the monthly comparison of predicted versus measured solar fractions for a National Bureau of Standards test to determine performance of standard BSHW systems.
Figure 10-24 shows the monthly comparisons for the Hogate and Aratex systems. The annual measured solar fraction for Aratex was 0.16 and the SOLCOST prediction was 0.18. Data for the Hogate system were insufficient to compute the annual fraction.

\section{Other Programs}

There are many other special purpose computer programs, both proprietary and public domain, for solar system simulation. These programs, which include BLAST, ACCESS, HISPER, RSVP, SIMSHAC, and TRACE, among others, can be quite useful in the design of certain solar systems. However, most of these programs have not been validated. For descriptions of these and other programs, as well as accessibility information, the reader should see Refs. 5-7.

\section{SUMMARY}

\section{Manual Methods}

\section{F-CHART (and its Derivatives)}

Most valid for solar heating and hot water systems on envelope-dominated buildings (i.e., buildings in which internal loads due to lights, occupants, etc, are not dominant). Can be used with nontracking collectors only. Can be done by hand and is also available as an

Table 10-9. SUMMARY OF SOLCOST - F-CHART COMPARISONS

\begin{tabular}{|c|c|c|c|c|c|}
\hline \multirow[b]{2}{*}{ Location } & \multirow[b]{2}{*}{$\begin{array}{l}\text { System } \\
\text { Type* }\end{array}$} & \multicolumn{2}{|c|}{$\begin{array}{c}\text { Difference } \\
\text { SOLCOST - F-CHART }\end{array}$} & \multicolumn{2}{|c|}{$\begin{array}{c}\text { Difference** } \\
\text { SOLCOST - F-CHART }\end{array}$} \\
\hline & & Mean & $\begin{array}{l}\text { Standard } \\
\text { Deviation }\end{array}$ & Mean & $\begin{array}{l}\text { Standard } \\
\text { Deviation }\end{array}$ \\
\hline Boston & $\begin{array}{l}1 \\
2\end{array}$ & $\begin{array}{r}7.03 \\
11.44\end{array}$ & $\begin{array}{l}3.72 \\
6.00\end{array}$ & $\begin{array}{l}0.84 \\
6.66\end{array}$ & $\begin{array}{l}3.06 \\
4.68\end{array}$ \\
\hline $\begin{array}{l}\text { San } \\
\text { Francisco }\end{array}$ & $\begin{array}{l}1 \\
2\end{array}$ & $\begin{array}{r}-1.60 \\
4.97\end{array}$ & $\begin{array}{l}1.93 \\
5.57\end{array}$ & $\begin{array}{l}0.84 \\
5.74\end{array}$ & $\begin{array}{l}1.83 \\
5.73\end{array}$ \\
\hline Miami & $\begin{array}{l}1 \\
2\end{array}$ & $\begin{array}{l}7.53 \\
6.82\end{array}$ & $\begin{array}{l}6.82 \\
5.48\end{array}$ & $\begin{array}{l}5.71 \\
6.62\end{array}$ & $\begin{array}{l}6.16 \\
5.48\end{array}$ \\
\hline Denver & $\begin{array}{l}1 \\
2\end{array}$ & $\begin{array}{r}-10.06 \\
-3.88\end{array}$ & $\begin{array}{l}4.46 \\
4.10\end{array}$ & $\begin{array}{r}-0.68 \\
6.03\end{array}$ & $\begin{array}{l}2.59 \\
6.53\end{array}$ \\
\hline $\begin{array}{l}\text { Washington } \\
\text { D.C. }\end{array}$ & $\begin{array}{l}1 \\
2\end{array}$ & $\begin{array}{l}3.14 \\
9.44\end{array}$ & $\begin{array}{l}3.45 \\
5.82\end{array}$ & $\begin{array}{l}0.50 \\
6.70\end{array}$ & $\begin{array}{l}2.40 \\
5.03\end{array}$ \\
\hline Madison & $\begin{array}{l}1 \\
2\end{array}$ & $\begin{array}{r}-4.00 \\
3.20\end{array}$ & $\begin{array}{l}3.63 \\
3.15\end{array}$ & $\begin{array}{l}0.79 \\
7.40\end{array}$ & $\begin{array}{l}3.66 \\
3.79\end{array}$ \\
\hline $\begin{array}{l}\text { All Cities } \\
\text { Combined }\end{array}$ & $\begin{array}{l}1 \\
2\end{array}$ & $\begin{array}{r}.37 \\
5.33\end{array}$ & $\begin{array}{l}7.44 \\
6.97\end{array}$ & $\begin{array}{l}1.36 \\
6.53\end{array}$ & $\begin{array}{l}3.93 \\
5.05\end{array}$ \\
\hline
\end{tabular}

*Type 1 is a BSHW system and Type 2 is a combined BSHW and space heating system.

**F-CHART executed using SOLCOST weather data. 
easy-to-use computer program. Similar limitations apply to the various simplified F-CHART techniques such as GFL, Relative Areas, etc.

SLR

The commercial buildings version of this method is most valid for solar heating/hot water applications in which space heating is the major load, and for office and other type buildings with large internal loads. The method accounts for a range of design water temperatures. Is not valid for concentrating collectors. In this method performance curves are also available for BSHW heating applications.

\section{CERL}

Is applicable to commercial building BSHW, combined space and BSHW heating, and combined heating and cooling systems.

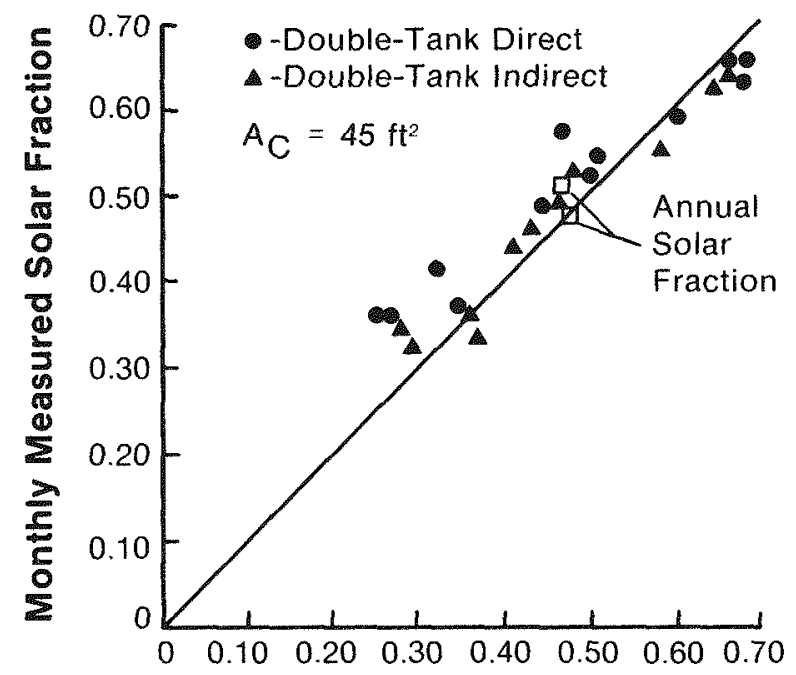

SOLCOST Predicted Solar Fraction

Fig. 10-24. SOLCOST predictions compared with measured data, NBS hot water systems

\section{Computer Methods}

\section{TRNSYS}

A computer simulation that can include cooling, as well as space heating/hot water applications. Is not subject to any of the limitations of the other methods but requires greater sophistication on the part of the user to develop an accurate computer model. Widely accessible.

\section{DOE-2/CBS}

Combines a general building energy/analysis program with a sophisticated solar heating/cooling system simulator that includes both preassembled and userconnected system configurations. Is easier and faster to use than TRNSYS but requires large, main-frame computers for execution.

\section{SOLCOST}

A computer simulation for solar heating/hot water applications and envelope-dominated buildings that includes a life-cycle cost analysis. Will handle all collector types. The user need only fill out input forms.

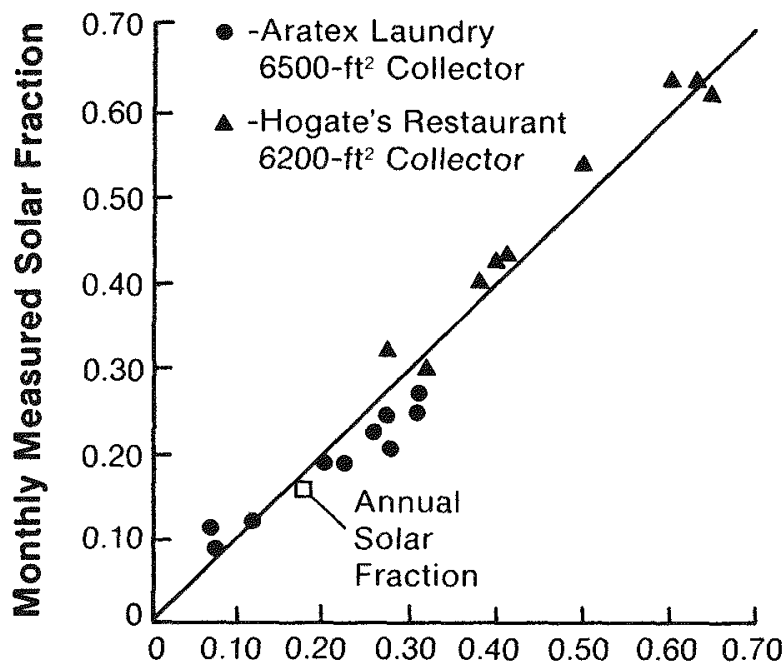

SOLCOST Predicted Solar Fraction
Fig. 10-25. SOLCOST predictions compared with measured data, large hot water systems




\section{REFRRENCES}

1. C. D. Barley, "Load Optimization in Solar Space Heating Systems," Solar Energy, Vol. 23, No. 2, 1979.

2. D. Hittle, D. Holshouser, and G. Walton, "Interim Feasibility Assessment Method for Solar Heating and Cooling of Army Buildings," U.S. Army Construction Engineering Research Laboratory technical report E-91, May 1976.

3. J. A. Duffie, "Simulation and Design Methods," Proceedings of the 1978 Annual Meeting of the American Section of the International Solar Energy Society, Ine., Denver, Colorado, August 1978.

4. R. C. Jórdan and B. Y. H. Liu, eds., "Application of Solar Energy for Heating and Cooling of Buildings," Chapter IX, ,ASHRAE GRP 170, 1977.

5. S. J. Feldman and R. L. Merriam, "Solar Heating and Cooling System Simulation Programs: Draft Reference Manual," report prepared for Research Project 1269 by Arthur D. Little, Inc., Cambridge, Massachusetts, February 1979.

6. "Analysis Methods for Solar Heating and Cooling Applications," Solar Energy Research Institute, January 1980.

7. P. L. Versteegen, "Survey of Currently Used Simulation Methods," Final Report to DOE, Science Applications, Inc., McLean, Virginia, November 17, 1978.

8. W. A. Beckman, S. A. Klein, and J. A. Duffie, Solar Heating Design by the F-CHART Method, WileyInterscience, New York, 1977.

9. J. D. Balcomb and J. C. Hedstrom, "A Simplified Method for Calculating Required Solar Collector Array Size for Space Heating," Proceedings of the Joint Conference of the American Section of the International Solar Energy Society and the Solar Energy Society of Canada, Inc., Vol. 4, Winnipeg, Manitoba, August 1976.

10. J. C. Ward, "Minimum Cost Sizing of Solar Heating Systems," Proceedings of the Joint Conference of the American Section of the International Solar Energy Society and the Solar Energy Society of Canada, Vol. 4, Winnipeg, Manitoba, August 1976.

11. G. H. Strickford, "An Averaging Technique for Predicting the Performance of a Solar Energy Collector System," Proceedings of the Joint Conference of the American section of the International Solar Energy Society and the Solar Energy Society of Canada, Inc., Vol. 4, Winnipeg, Manitoba, August 1976.
12. P. J. Lunde, "Prediction of Monthly and Annual Performance of Solar Heating Systems," Solar Energy, Vol. 20, No. 3, 1978.

13. C. D. Barley and C. B. Winn, "Optimal Sizing of Solar Collectors by the Method of Relative Areas," Solar Energy, Vol. 21, No. 4, 1978.

14. D. C. Hittle, G. N. Walton, D. F. Holshouser, D. J. Leverenz, "Predicting the Performance of Solar Energy Systems," U.S. Army Construction Engineering Research Laboratory interim report E-98, January 1977.

15. "DOE Facilities Solar Design Handbook," U.S. Department of Energy report DOE/AD-0006/1, January 1978.

16. S. R. Swanson and R. F. Boehem, "Calculation of Long-Term Solar Collector Heating Performance," Solar Energy, Vol. 19, No. 2, 1977.

17. S. A. Klein and W. A. Beckman, "A General Design Method for Closed-Loop Solar Energy Systems," Solar Energy, Vol. 22, pp. 269-282, 1979.

18. P. J. Lunde, "Prediction of the Performance of Solar Heating Systems Over a Range of Storage Capacities," Solar Energy, Vol. 23, No. 2, 1979.

19. "Heating and Air Conditioning Systems Installation Standards for One and Two Family Dwellings and Multifamily Housing Including Solar," Sheet Metal and Air Conditioning Contractors' National Association, Ine., 8224 Old Courthouse Road, Vienna, Virginia 22180, 1977.

20. D. E. Cassel, R. E. Hedden, and W. L. Glennie, "Survey of Solar Domestic Hot Water Calculation Methods," Proceedings of the Conference of Systems Simulation and Economic Analysis for Solar Heating and Cooling, San Diego, California, June 1978.

21. "TRNSYS: A Transient Simulation Program - Report No. 38-9," Solar Energy Laboratory, University of Wisconsin-Madison, February 1978.

22. S. A. Klein, W. A. Beckman, and J. A. Duffie, "TRNSYS - A Transient Simulation Program," ASHRAE Transactions, Vol. 82, Part 1, 1976.

23. "Model Validation Studies of Solar Systems, Phase III," Final report, prepared by Solar Environmental Engineering Company for the U.S. Department of Energy, December 1978.

24. W. M. Gary, "Performance Comparison Between F-CHART Simulations and Several Operating Solar Systems," Proceedings of the Conference on Systems Simulation and Economic Analysis for Solar Heating and Cooling, San Diego, California, June 1978. 
25. S. Karaki, P. R. Armstrong, and T. N. Bechtel, "Evaluation of a Residential Solar Air Heating and Nocturnal Cooling Systems," CCMS report Co02868-3 submitted by the Solar Energy Applications Laboratory, Colorado State University, to the U.S. Department of Energy, December 1977.

26. G. F. Lameiro and P. Bendt, "The GFL Method for Designing Solar Energy Space Heating and Domestic Hot Water Systems," Vol. 2.1, Proceedings of the 1978 Annual Meeting of the American Section of the International Solar Energy Society, Inc., Denver, Colorado, August 1978.

27. J. D. Balcomb, J. C. Hedstrom, S. W. Moore, and B. T. Rogers, "Solar Heating Handbook for Los Alamos," Los Alamos Scientific Laboratory report LA-5967-MS, May 1976 .

28. R. I. Oonk, G. O. G. Lof, L. E. Shaw, and B. E. ColeAppel, "A Method of Comparing Flat-Plate Air and Liquid Solar Collectors for Use in Space Ileating Applications," Proceedings of the Joint Conference of the American Section of the International Solar Energy Society and the Solar Energy Society of Canada, Vol. 2, Winnipeg, Manitoba, August 1976.

29. "ERDA's Pacific Regional Solar Heating Handbook," 2nd Fd., prepared by the Los Alamos Scientific Laboratory, Solar Energy Group, for the U.S. Department of Energy, San Francisco Operations Office, November 1976. (Superintendent of Documents, Washington, D.C., Stock No. 060-000$0024-7$.)

30. Unpublished minutes of the Solar Heating and Cooling System Simulation and Economic Analysis Working Group Meeting, Sponsored by the U.S. Department of Energy, Office of Conservation and Solar Applications, Solar Heating and Cooling R\&D Branch, Golden, Colorado, November 14-15, 1977.

31. T. L. Freeman, M. W. Maybaum, and S. Chandra, "A Comparison of Four Solar Simulation Programs in Solving a Solar Heating Problem, "Proceedings of the Conference on Systems Simulation and Economic Analysis for Solar Heating and Cooling, San Diego, California, June 1978.

32. "The Validation of Solar House Design Programs, Phases I and II," Final Report, prepared by Solar" Environmental Engineering Company for the U.S. Department of Energy, September 1976.

33. "SHACOB - Design of Systems," Training Course, Solar Energy Applications Laboratory, Colorado State University, 1977. GPO \#003-011-00084-4.
34. J. W. Mitchell and W. A. Beckman, "Comparísons of Measured and Simulated Performance for CSU House I," Proceedings of the Conference on Systems Simulation and Economic Analysis for Solar Heating and Cooling, San Diego, California, June 1978.

35. "DOE-2 Reference Manual," Los Alamos Scientific Laboratory report LA-7689-M (Lawrence Berkeley Laboratory report LBL-8706), March 1980.

36. M. A. Roschke, B. D. Hunn, and S. C. Diamond, "A Component-Based Simulator for Solar Systems," proceedings of the Conference on Systems Simulation and Economic Analysis for Solar Heating and Cooling, San Diego, California, June 1978.

37. "SOLCOST: Space Heating Handbook with Service Hot Water and Heat Loads Calculations," DOE/CS0042/3, July 1978. GPO \#061 -000 00148 -4, \$1.25.

38. D. E. Hun and R. T. Giellis, "Solcost: A Solar Energy Design Program." Proceedings, Systems Simulation and Economic Analysis, SERI/TP-351-431, Jan. 23-25, 1980, San Diego, CA. 
11

Life-Cycle Costing of Solar Energy Investments 
11. Life-Cycle Costing of Solar Energy Investments

Life-cycle costing (LCC) method

Dis counting

LCC modes of analysis

Energy analysis

Project design and sizing

Graphical depiction of cost tradeoffs

Project priority 


\section{LIFE-CYCLE COSTING OF SOLAR ENERGY NNVESTMENTS}

\section{INTRODUCTION}

This chapter provides an overview of the life-cycle costing method of evaluating investments in solar energy. It describes the use of the method in detemining the economically efficient design and size for a solar energy system, the cost effectiveness of a given system, and the establishment of project priorities.

In introducing the life-cycle costing method, the emphasis of this chapter is on promoting a general understanding of the approach. At the level presented, the life-cycle costing method is applicable to most-if not all-solar energy projects. For more detailed economic models providing for in-depth analysis of investments in active and passive solar energy systems for commercial buildings, the reader is directed to Refs. 2 and 5; for models that treat solar investments for buildings of state and local governments and nonprofit organizations, the reader is directed to Refs. 4 and 5; and for models that treat solar investments for federally owned or leased buildings, to Ref. 3 .

An easy-to-use, interactive computer program, called FEDSOL, and economic optimization guide have been prepared for the life-cycle cost evaluation and sizing of solar energy projects for Federal buildings. The user's manual and guide that accompanies the program (Ref.6) describes in detail the specific requirements that Federal agencies should follow in establishing assumptions, data, and evaluation measures for proposed solar projects. It provides a number of examples of the use of life-cycle cost analysis in sizing projects.

Alternatively, the life-cycle cost worksheets for solar energy projects contained in the Cost Data Forms (A-2) for the Solar Federal Buildings Program and in the Life-Cycle Cost Manual for the Federal Energy Management Programs (Ref. 3) may be used as an aid in performing the life-cycle cost calculations required of solar energy projects undertaken in the Federal sector.

\section{LIPE-CYCLE COSTING (LCC) METHOD}

Life-cycle costing (LCC) is a term commonly used to describe a general method of economic evaluation by which all relevant costs over the life of a project are accounted for when determining the economic efficiency of the project. With its emphasis on costs, it is a suitable method for evaluating the economic feasibility of projects such as energy conservation or solar energy which realize their benefits primarily through fuel cost avoidance. Applied to tax-exempt solar energy investment decisions, the method requires an assessment of the following kinds of solar-related costs: (1) system acquisition and installation costs (capital costs); (2) system replacement costs; (3) maintenance and repair costs; (4) energy costs; and (5) salvage or resale value net of removal and disposal costs. These costs are required for all components necessary for the solar energy system's operation including (1) solar collectors; (2) thermal storage; (3) distribution system; (4) controls, motors, pumps, fans, and other ancillary equipment; (5) special building features such as roof and wall modifications; and (6) the auxiliary energy system. As a basis for comparison, an assessment of the same kinds of costs is also needed for the nonsolar energy system which would be used in lieu of a solar energy system.

\section{DISCOUNTWMG*}

In accounting for project costs, life-cycle costing requires that dollar costs occurring at different calendar times be adjusted to a common time basis, taking into account the cost of money over time. This technique is referred to as discounting. Discounting is necessary for a valid economic comparison because if money in hand can be invested in financial assets or real assets to yield a return over time, an expenditure or receipt that occurs at

*For a more detailed description of the discounting procedure see Refs. 1,3 , and 4 . 
some future date does not have the same value as if it occurred today. This is true whether or not there is price inflation that changes the value of money over time.

Discounting is accomplished by applying discount formulas-or multiplicative factors pre-calculated from the formulas-to each item of cost. There are formulas or factors that can be used to discount each of the various patterns of cash flow-single future amounts such as replacement costs, recurring future amounts such as maintenance and repair costs, and escalating future amounts such as energy costs. Discount formulas and discount factors are contained in most engineering economics textbooks. The most commonly used formulas for treating energy conservation and solar investment analyses, together with discount factors for a range of discount rates, are given in Ref. 1. Those specific factors needed for the Solar in Federal Buildings Program are given in Ref. 3 .

Discounting requires the selection of a discount rate that reflects the time value of money. The discount rate is used either directly in the discounting formulas or-if factors are used-to select the appropriate factor from discount factor tables. If inflation is included in estimates of future costs and savings, then it must also be included in the discount rate. Alternatively, if all costs and savings are expressed in constant dollars, inflation should not be included in the discount rate. The Office of Management and Budget (OMB) prescribes that all costs and savings for federal solar and energy conservation projects be evaluated on the basis of constant dollars (i.e., inflation removed) and that a real discount rate of $7 \%$ per annum be used.

Working with constant dollars and a real discount rate, present prices can be used as estimates of future prices in constant dollars for those items whose prices can be expected to inflate at about the same rate as prices in general.

For future amounts that are expected to change at a rate different from the general rate of inflation, present prices will require adjusting in order to serve as estimates of future prices. In the case of future amounts that are not subject to price inflation, such as services fixed by contractual agreement, a price deflator index can be used to convert the future amounts to constant dollars prior to discounting. In the case of future amounts that are expected to increase faster than the rate of general price inflation, such as energy costs, differential price escalation rates can be used to find the future constant dollar equivalents. Differential energy price escalation rates have been developed by the Energy information Administration (EIA) of DOE for the various types of energy used by the residential, commercial, and industrial sectors in different regions of the country. Discount factors based on a $7 \%$ discount rate and the EIA-projected differential escalation rates are given in Ref. 3 .

\section{LCC MODES OF ANALYSIS*}

A life-cycle costing approach can be implemented by applying any or all of the following several specific evaluation techniques or "modes of analysis": (1) total life-cycle cost (TLCC) analysis, which sums the discounted value of all of the equivalent costs over the investor's time horizon; (2) net savings (NS) analysis, which finds the difference between the TLCCs of a proposed project and its alternative as a dollar measure of the project's net profitability; (3) savings-toinvestment ratio (SIR) method, which indicates by a numerical ratio the size of savings relative to costs; and (4) internal-rate-of-return (IRR) technique, which gives the percentage yield on an investment.

Often these life-cycle costing techniques are supplemented by additional techniques of economic evaluation which focus on some particular aspect of the investment, such as the time to payback. Not a full lifecycle costing technique itself, the payback measure indicates the elapsed time until cumulative savings (or receipts) are sufficient to cover cumulative costs. There are two versions of the payback measure that are often used. Discounted Payback (DPB) takes into account the cost of money through discounting. Simple Payback (SPB) does not include discounting, nor does it necessarily include future escalation in energy prices. (The Solar in Federal Buildings Program uses SPB without future energy price escalation as a supplemental measure to the required life-cycle costing evaluation.)

Each of these evaluation techniques has its advantages and disadvantages that make it particularly appropriate for some purposes and less appropriate for others [1]. In brief, the TLCC and NS techniques are especially useful for designing and sizing projects, and the SIR and IRR techniques are particularly useful for assigning priority to projects when the budget is limited. The PB technique is useful when project life is very uncertain or when a speculative investment requires quick recovery of funds. Collectively, they form tools of analysis which can be

* Simplified explanations and formulas for these modes of analysis are given in Refs. 1 and 3. Detailed formulas for evaluating solar and energy conservation investments for residential and commercial buildings are given in Refs. 2 and 6. 
used in determining the cost-effective design and size of solar energy systems, the type of auxiliary energy system, the kinds and amounts of other energy conservation investments to use in conjunction with solar energy, and, when the budget is limited, the economic priorities that should be assigned to competing projects. For the purpose of providing an overview and introduction to the LCC method, the focus of this chapter is on the TLCC and NS techniques.

\section{ENERGY ANALYSIS}

Regardless of the specific LCC technique used, an essential task in the analysis of solar energy investments is to determine the end-use energy requirements of the process to which solar energy is to be applied and the potential performance of the proposed solar energy system in meeting the energy requirements. The process might be space heating, domestic hot water, space cooling, or some combination thereof. Energy requirements and measures of system performance are data inputs into the LCC analysis.

Energy load calculations are usually done on a monthly basis and summed to an annual value. Once the annual energy load is known, the annual quantity of nonsolar energy required to meet the load can be calculated based on the energy content of conventional fuel and the conventional energy equipment efficiency. Algebraically, the annual quantity of conventional energy required $(E)$ is calculated as follows:

$$
E=\frac{L}{B \cdot e} \text {, }
$$

where $L$ represents the annual load, B the energy content of conventional fuel, and $e$ the annual efficiency of conventional energy equipment.

For example, assume that the space heating load of a building is 800 million Btu per annum, the conventional fuel is oil with a Btu content of approximately 140,000 Btu per gallon, and the average annual efficiency of the furnace is 0.6 , then,

$$
E=\frac{800 \cdot 10^{6}}{(140,000)(0.6)}=9,524 \text { gallons. }
$$

Thus, it is estimated that 9,524 gallons of oil per annum are required for space heating purposes. Of course, if $\mathrm{E}$ is known it is also possible to work backwards to determine $\mathrm{L}$.
Several packaged computer programs exist for the purpose of estimating solar energy system performance. Hand calculation techniques are also available. In addition to estimating solar performance, many of the computer programs can accomplish the dual task of estimating building thermal loads and domestic hot water loads. For those programs or hand calculation techniques that do not accomplish this dual task, both monthly and annual loads must be known. The uitimate objective is to determine the annual amount of useful energy which the solar energy system is capable of supplying to the building.

Solar performance can best be incorporated into the economic analysis by expressing the useful output of the solar energy system as a fraction of the total load. Thus, if the solar energy system is estimated to deliver a total quantity of useful Btu per annum (S), then the annual fraction ( $F$ ) of total load (L) met by solar is

$$
\mathbf{F}=\frac{\mathbf{S}}{\mathrm{L}} \text {. }
$$

Continuing with our previous example $(L=800$ million Btu), suppose a solar energy system of a particular design and size is expected to deliver 500 million Btu of use ful energy during the space heating season. Then,

$$
F=\frac{500 \cdot 10^{6}}{800 \cdot 10^{6}}=0.625 \text {, }
$$

and the solar energy system is expected to provide $62.5 \%$ of the building's required space heating load.

If the auxiliary heating system is assumed to be the same type and to have the same operating efficiency as the nonsolar energy system used alone (i.e., a $100 \%$ nonsolar energy system), the annual quantity of nonsolar (conventional) energy required would be reduced from 9,254 gallons of oil to 3,571 by using this solar energy system. That is, the annual quantity of conventional energy required by this solar auxiliary system $\left(E_{A}\right)$ is

$E_{A}=\frac{L(1-F)}{B \cdot e}=\frac{800 \cdot 10^{6} \cdot(1-0.625)}{(140,000)(0.6)}=3,571$,

for a savings of 5,953 gallons of oil per annum. (A detailed analysis would also consider the energy required to operate the solar energy system components, such as electrical energy required to operate the pumps or fans and the control system. Energy costs to operate the solar energy system would reduce the overall savings in fuel from the solar energy system.) 
In the above example, the solar auxiliary system and the $100 \%$ nonsolar energy system are, for simplicity, assumed to be identical. This, of course, need not be the case. If the energy system used as an auxiliary to solar is different from the $100 \%$ nonsolar energy system, it may use a different type of fuel and have a different operational efficiency, as well as different investment and nonfuel operation and maintenance costs.

Furthermore, even if the two systems are identical, the part-load contribution of the auxiliary solar energy system may cause it to have a lower efficiency than the $100 \%$ system. For example, if, in the above example, the system efficiency dropped from $e_{N}=0.6$ for the $100 \%$ nonsolar energy system to $e_{A}=0.5$ for that same system used as the solar auxiliary, the annual oil savings (S) would decrease from 5,953 gallons to 5,238 , i.e.,

$$
S=\frac{L}{B}\left(\frac{1}{e_{N}}-\frac{(1-F)}{e_{A}}\right)=\frac{800 \cdot 10^{6}}{140,000}\left(\frac{1}{0.6}-\frac{(1-0.625)}{0.5}\right)
$$$$
=5,238
$$

\section{PROJECT DESIGN AND SIZING}

To design and size solar energy systems and to select auxiliary energy systems for maximum cost effectiveness, the TLCC for each alternative design and size to be considered can be calculated and compared. The alternative with the lowest TLCC is the most costeff ective choice, provided possible differences in comfort and other effects not quantified in the cost equations do not outweigh the results of the life-cycle cost evaluation.

Similarly, projects can be designed and sized on the basis of their comparative NS. The NS of a solar energy system of a given design and size can be found by taking the difference between the TLCC of the alternative $100 \%$ nonsolar energy system and the TLCC of the combined solar energy/auxiliary system in question. If a project has a positive NS, it recovers its full costs plus a surplus, and, hence, is economically desirable. The system with the highest NS relative to the base (nonsolar) case is the most cost-effective choice, other things being the same.

By repeating the comparison of TLCC or NS across many solar design and size alternatives and auxiliary systems, the economically optimal solar design, size, and auxiliary system can be determined. Given a specified level of building energy requirements, the problem is to find that energy system-nonsolar or combined solar energy/ auxiliary energy system-which minimizes TLCC or maximizes NS of the total energy-related costs of the building.* As implied above, solar energy systems will generally be used in conjunction with an auxiliary energy system (electricity, natural gas, oil, etc.), rather than alone. This is the reason that it is necessary to compare the TLCC of the combined solar energy/auxiliary energy system ( $\mathrm{TLCC}_{\mathrm{s}, \mathrm{a}}$ ) to the TLCC of a $100 \%$ nonsolar energy system $\left(\mathrm{TLCC}_{\mathrm{w}}\right.$ ) which would be used in lieu of solar. If $\mathrm{TLCC}_{\mathrm{S}, \mathrm{a}}$ is lower than $\mathrm{TLCC}_{\mathrm{w}}$, the solar energy/auxiliary energy system is more cost effective than the nonsolar energy system alone.

Assuming that an auxiliary system for the solar energy system is required, NS is computed for a given thermal load by subtracting $\mathrm{TLCC}_{\mathrm{s}, \mathrm{a}}$ from $\mathrm{TLCC}_{\mathrm{W}}$, i.e.,

$$
\mathrm{NS}=\mathrm{TLCC}_{\mathrm{w}}-\mathrm{TLCC}_{\mathrm{s}, \mathrm{a}}
$$

TLCC $_{W}$ may be calculated as follows:

$$
\begin{aligned}
\mathrm{TLCC}_{w}= & \mathrm{P}_{w} \cdot \frac{\mathrm{L}}{B_{w} \cdot e_{w}} \cdot \mathrm{UPW}_{\mathrm{w}}^{*}+I_{w} \\
& +\left(\sum_{\mathrm{t}=1}^{\mathrm{n}} \mathrm{R}_{\mathrm{t}} \cdot \mathrm{SPW}_{\mathrm{t}}\right)+\left(\mathrm{M}_{\mathrm{w}} \cdot \mathrm{UWW}_{\mathrm{n}}\right) \\
& -\left(\mathrm{S}_{\mathrm{w}} \cdot \mathrm{SPW}_{\mathrm{n}}\right)
\end{aligned}
$$

where the subscript " $W$ " designates costs of the $100 \%$ nonsolar energy system; $P_{W}$ represents the current price per unit of fuel used in the $100 \%$ nonsolar energy system (e.g., $\$ / \mathrm{kWh}$, $\$ /$ gal of oil, $\$ /$ cu ft of natural gas); $\mathrm{L}$, the annual heating load; $B_{W}$, the energy content of the fuel used in this system; $e_{w}$, the average annual efficiency of this system; UPW ${ }_{W}$, the uniform present worth factor for the specified discount rate and period of study, $n$, modified to include projected price escalation rates for the fuel used in this system; $I_{W}$, the initial investment costs for this system; $n$, the number of years in the study period; $R_{w}$, the costs of replacements to this system net of salvage value of components replaced in year $t ; s P W_{t}$, the single present worth factor for the specific discount rate and the year, $t$, in which the replacement is expected to occur; $M_{W}$, the annually recurring nonfuel operation and maintenance cost for this system; UPW the uniform present worth discount factor for the specified discount rate and period of study; $S_{w}$, the estimated salvage value of this system net of disposal

\footnotetext{
* In some cases, it may be deemed desirable to invest in a solar energy system even when it is not the cost-effective choice based on a life-cycle cost evaluation. In this case, the economic analysis is nevertheless useful for designing and sizing the solar energy system to minimize economic losses.
} 
costs at the end of the study period; and SPW ${ }_{n}$, the single present worth discount factor for the specified discount rate and last year in the study period.

$\mathrm{TLCC}_{\mathrm{S}, \mathrm{a}}$ is mathematically determined as follows:

$$
\mathrm{TLCC}_{\mathrm{s}, \mathrm{a}}=\mathrm{LCC}_{\mathrm{s}}+\mathrm{LCC}_{\mathrm{a}}
$$

where $\mathrm{LCC}_{\mathrm{S}}$ represents the life-cycle costs of the solar energy system, and $\mathrm{LCC}_{\mathrm{a}}$ represents the life-cycle costs of the auxiliary system in a combined system.

$\mathrm{LCC}_{\mathrm{S}}$ may be calculated in the following manner:*

$$
\begin{aligned}
L C C_{s}= & C_{s}+\left(v_{s} \cdot A_{s}\right)+\left(M_{s} \cdot U P W_{n}\right)+\left(P_{s} \cdot Q_{s} \cdot U P W_{s_{n}}^{*}\right) \\
& +\left(\sum_{j=1}^{n} R_{s_{t}} \cdot S P W_{t}\right)-\left(S_{s} \cdot S P W_{n}\right)
\end{aligned}
$$

where $C_{S}$ represents the fixed costs of the solar energy system; $v$, the variable costs of the solar energy system per unit of solar collector area, $A_{S} ; M_{S}$, the annually recurring costs of maintaining the solar energy system; $U P W_{n}$, the uniform present worth factor for the specified discount rate and study period, $n ; P_{S}$, the price of electricity per sales unit; $Q_{S}$, the quantity of electricity required annually to operate the fans, pumps, and controls of the solar energy system; UPW, the uniform present worth factor for the specified discount rate and study period, $n$, modified to include a set of projected energy price escalation rates for electricity; $R_{s_{t}}$, the costs of major replacements to the solar energy system net of salvage value of components replaced in year t; $\mathrm{SPW}_{t}$, the single present worth factor for the specified discount rate and year, $t$, in which the repair or replacement is expected to occur; $S_{\mathrm{S}}$, the estimated salvage value of the system at the end of the study period net of removal and disposal costs; and $\mathrm{SPW}_{\mathrm{n}}$, the single present worth factor for the specified discount rate and the last year in the study period.

\footnotetext{
*Eq. (11-8) assumes that solar storage volume and all other variable system components increase proportionately with installed collector area. Therefore, the variable cost component $\left(v_{S}\right)$ includes the cost of storage per unit of collector area, as well as all other variable system costs which increase proportionately with collector area.
}

$\mathrm{LCC}_{8}$ may be calculated as follows:

$$
\begin{aligned}
I_{a}= & P_{a} \cdot \frac{L(1-F)}{B_{a} e_{a}} \cdot U P W_{a}^{*}+I_{a} \\
& +\left(\sum_{j=1}^{n} R_{a_{t}} \cdot S P W_{t}\right)+\left(M_{a} \cdot U W_{n}\right) \\
& -\left(S_{a} \cdot S P W_{n}\right),
\end{aligned}
$$

where the subscript " $a$ " designates costs of the auxiliary energy system; $\mathrm{P}_{\mathrm{a}}$ represents the current price per unit of fuel consumed in the auxiliary system; $L$, the annual heating load; $\mathrm{B}_{\mathrm{a}}$, the energy content of the auxiliary fuel; $e_{a}$, the average annual efficiency of the auxiliary heating system; $F$, the annual fraction of the heating load supplied by solar; UPW $a_{n}^{*}$, the uniform present worth factor for the specified discount rate and period of study, $n$, modified to include projected energy price escalation rates for the auxiliary fuel; $I_{a}$, the initial investment costs for the auxiliary backup system; $R_{a_{t}}$, the costs of replacements to the auxiliary system net of salvage in year $t$; $S P W_{t}$, the single present worth factor for the specified discount rate and the year, $t$, in which the replacement is expected to occur; $M_{a}$, the annually recurring nonfuel operation and maintenance cost of the auxiliary system; UPW $n$, the uniform present worth discount factor for the specified discount rate and study period, $n ; S_{a}$, the estimated salvage value of the auxiliary system net of disposal costs at the end of the study period; and $S P W_{n}$, the single present worth discount factor for the specified discount rate and the last year in the study period.

\section{GRAPHICAL DEPICTION OF COST TRADEOFFS}

A tradeoff is made between lower auxiliary energy costs $\left(\mathrm{LCC}_{\mathrm{a}}\right)$ and higher solar energy system costs $\left(\mathrm{LCC}_{\mathrm{S}}\right)$ as the size of a solar energy system of a given design is increased or, usually, as the system design is made more technically efficient.

Consider the tradeoff between solar energy system size and auxiliary energy cost for a system of a given design, as depicted graphically in Fig. 11-1. Collector area, as an indicator of overall system size, is shown along the horizontal axis. Present value costs are shown along the vertical axis. As collector area increases, the amount of energy supplied by the solar energy system increases. Thus, auxiliary energy usage and $\mathrm{LCC}_{\mathrm{a}}$ decreases as $\mathrm{LCC}_{\mathrm{S}}$ increases. The $\mathrm{LCC}_{\mathrm{a}}$ line is curved toward the origin because additional units of $\mathrm{A}$ generally increase the fraction of the load supplied by solar by ever smaller 
amounts. Therefore, as additional units of $A$ are installed, the $\mathrm{LCC}_{\mathrm{a}}$ curve declines at a decreasing rate. $\mathrm{LCC}_{S}$, in contrast, is shown to increase linearly with $\mathrm{A}$ in Fig. 11-1. This would be the case if each additional unit of A were to add the same amount of total solar energy system costs as did the previous unit of $A . C_{s}$ on the vertical axis indicates those system costs that are relatively insensitive to system size, that is, the "fixed costs."

The tradeoff depicted in Fig. 11-l suggests that there may be a solar energy system size which just balances the decreases in $\mathrm{LCC}_{a}$ with the increase in $\mathrm{LCC}_{\mathrm{s}}$ as additional units of collector area (A) are installed. That is, there is some point at which $\mathrm{TLCC}_{\mathrm{S}, \mathrm{a}}$ reaches a minimum value. This is depicted in Fig. $11-2$, which is identical to Fig. 11-1 with the exception of the addition of the $\mathrm{TLCC}_{\mathrm{s}, \mathrm{a}}$ curve. The $\mathrm{TLCC}_{\mathrm{s}, \mathrm{a}}$ curve, obtained by adding $\mathrm{LCC}_{\mathrm{a}}$ and $\mathrm{LCC}_{\mathrm{s}}$ vertically, is a U-shaped (although other shapes are possible, depending upon the shapes of $\mathrm{LCC}_{\mathrm{a}}$ and $\left.\mathrm{LCC}_{\mathrm{s}}\right)$. TLCC $\mathrm{s,a}$ is shown as first decreasing, reaching a minimum value at $A^{*}$, and thereafter increasing. The system size represented by $A^{*}$ collector area is the economically optimal size for the solar energy system. It is economically optimal in the sense that it minimizes the total life-cycle costs of the combined system, $\mathrm{TLCC}_{\mathrm{s}, \mathrm{a}^{*}}$. Any other size would result in greater $\mathrm{TLCC}_{\mathrm{s}, \mathrm{a}^{*}}$

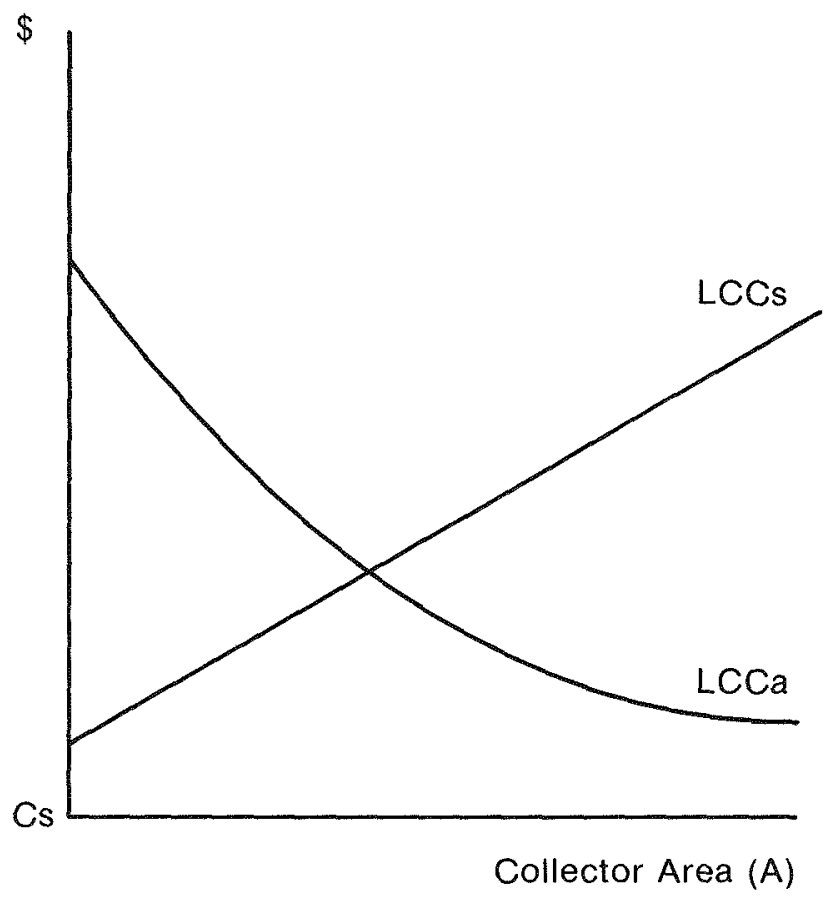

Fig. 11-1. LCC Tradeoff between conventional energy and solar energy

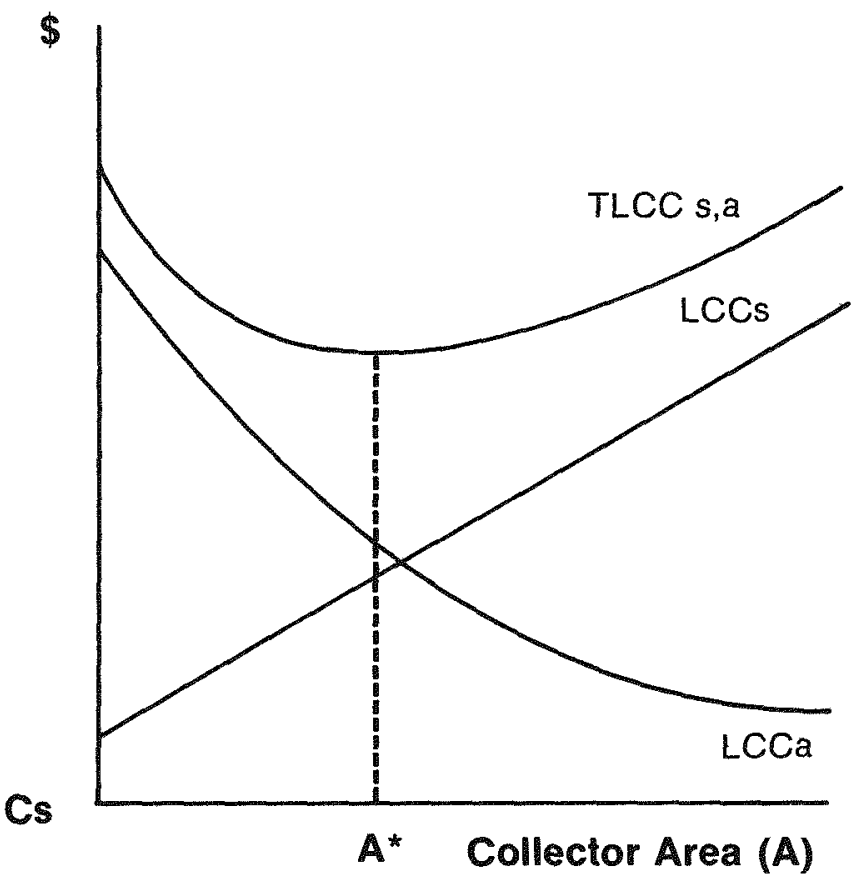

Fig. 11-2. Determining the economically optimal system size through minimizing $\operatorname{TLCC}_{\mathrm{S}, \mathrm{a}}$

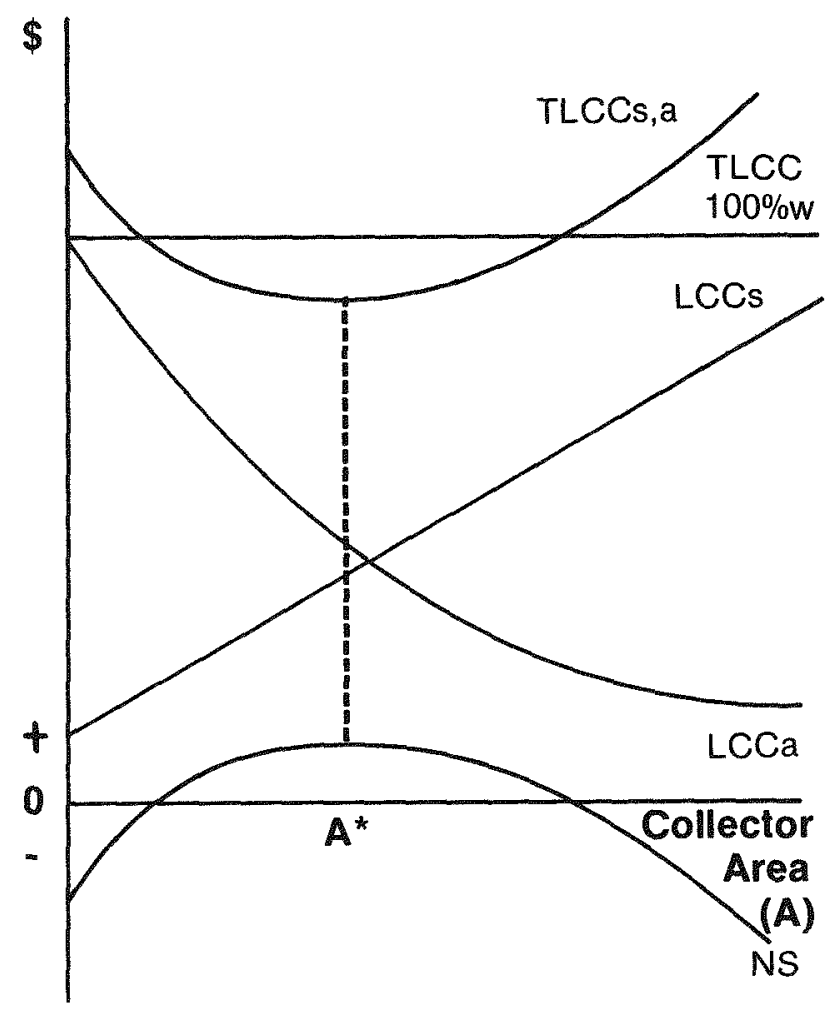

Fig. 11-3. Determining cost effectiveness of solar investment 
Thus far we have considered tradeoffs between $\mathrm{LCC}_{Q}$ and $\mathrm{LCC}_{\mathrm{S}}$ in order to determine the total costs of various size combinations of the solar/auxiliary energy system. Now we examine the cost effectiveness of the combined solar/auxiliary energy system relative to a $100 \%$ nonsolar energy system. Fig. 11-3 shows the TLCC curve for the $100 \%$ nonsolar energy system $\left(\mathrm{TLCC}_{100 \% \mathrm{~W}}\right.$ ), in addition to the curves of Fig. 11-2. TLCC $\mathrm{W}_{\mathrm{W}}$ is independent of collector area because it represents the total life-cycle cost without the solar energy system. Fig. 11-3 also shows the NS curve for the combined solar/auxiliary energy system of alternative sizes. The NS curve is found by taking the difference between the $\mathrm{TLCC}_{100 \% \mathrm{~W}}$ curve and the $\mathrm{TLCC}_{\mathrm{S}, \mathrm{a}}$ curve. NS is shown to be initially below the horizontal axis, indicating higher life-cycle costs for small sizes of the combined solar/auxiliary energy system than for the $100 \%$ nonsolar energy system. NS then increases, rises above the horizontal axis, and reaches a maximum value for the solar energy system size designated $A^{*}$. NS decreases thereafter and losses are incurred for the largest system sizes. (Other shapes of the NS curve are possible, depending on the shapes of $\operatorname{LCC}_{a}, \operatorname{LCC}_{\mathrm{S}}$, and $\operatorname{TLCC}_{\mathrm{S}, \mathrm{a}}$ ).

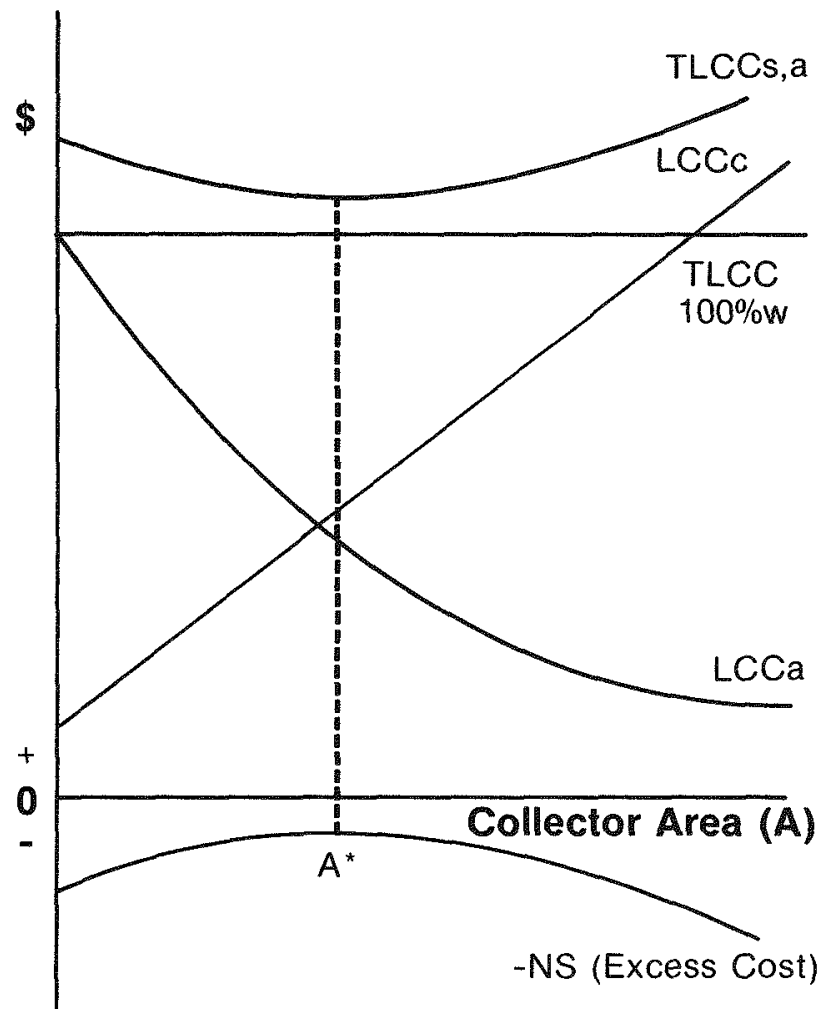

Fig. 11-4. Minimizing losses (-NS) associated with solar installations
It is important to note that NS reaches a maximum value at $A^{*}$ coincident with the minimum value of $\operatorname{TLCC}_{S, a^{*}}$ Maximizing $\mathrm{NS}$ is identical to minimizing $\mathrm{TLCC}_{\mathrm{S}, \mathrm{a}}$ in determining the optimal system size, $A^{*}$. Only by selecting the economically optimal size (A*) of the solar energy system will the maximum cost effectiveness of the system be obtained.

In the graphical exposition of Fig. 11-3, NS is positive at $A^{*}$ and, therefore, the solar energy system is cost effective. It recovers its full cost over the life-cycle plus some surplus, NS. The value of the surplus is over and above the opportunity cost of money, since all costs and savings are assumed to have undergone the discounting procedure.

The collector area which minimizes $\mathrm{TLCC}_{\mathrm{S}, \mathrm{a}}$ will not necessarily produce a positive NS. That is, the minimumcost solar energy system may not be cost effective relative to the $100 \%$ nonsolar energy system. This situation is depicted graphically in Fig. 11-4. The collector size $A^{*}$ in Fig. 11-4 minimizes $T_{L C C}, a$, but results in a negative $\mathrm{NS}$, which means a higher life-cycle cost of supplying energy to the building.

If a solar energy system is to be installed regardless of its cost effectiveness, $A^{*}$ (as depicted in Fig. $11-4$ ) is the optimally sized system to install, based on economic efficiency considerations. Although it is not cost effective, $A^{*}$ is optimal in the sense of minimizing total life-cycle losses (-NS), or "excess cost," from using solar energy. Any other size for this solar energy system, other than zero, would result in greater excess cost over the life of the system than size $A^{*}$.

This same tradeoff procedure could be applied to alternative system designs, for example, flat plate collectors versus advanced technology collectors and air systems versus water systems. The system design and size with the highest net savings, or the lowest $-\mathrm{NS}$, excess cost, is the economically preferred solar energy system, other things being equal.

\section{PROJECT PRIORITY}

In addition to determining if a given solar energy project is cost effective and to designing and sizing projects for maximum cost effectiveness, it may be necessary to assign priorities to projects competing for a limited budget. The economic objective in setting priorities across all potential projects is to obtain the maximum net savings from available funds. To set project priorities, the savings-to-investment (SIR) ratio or the internal- 
rate-of-return (IRR) is needed to rank projects in descending order of their return per dollar cost. Selecting projects on this basis until the available budget is exhausted will result in maximum net economic benefits from the total of projects undertaken. (See Refs. 3 and 4 for a discussion of project ranking.)

\section{SUMMARY}

This chapter has described in brief the objectives of lifecycle costing and has provided an overview of life-cycle costing procedures for evaluating solar energy investment projects. Included in the overview were the discounting procedure, the modes of analysis, the analysis of the building's energy requirements and the solar system's performance, the design and sizing of solar energy projects, and the priority ranking of competing projects for a limited budget. The emphasis was on the analysis of cost tradeoffs between increased use of solar energy versus decreased use of nonsolar energy.

The specific requirements for carrying out these lifecycle procedures for projects proposed for Federal Buildings are described in the Life-Cycle Costing Manual for the Federal Energy Management Program, Ref. 3, and FEDSOL: Program User's Manual and Economic Optimization Guide for Solar Federal Buildings Projects, Ref. 6.

\section{REFRRENCES}

1. Marshall, Harold E. and Ruegg, Rosalie T., Simplified Design Economics: Principles of Economics Applied to Energy Conservation and Solar Energy Investments in Buildings (Washington, D.C.: National Bureau of Standards, 1980) NBS Special Publication 544.

2. Powell, Jeanne W., An Economic Model for Passive Solar Designs in Commercial Environments (Washington, D.C.: National Bureau of Standards, 1980) NBS Building Science Series 125.

3. Ruegg, Rosalie T., and MeConnaughey, John S., LifeCycle Costing Manual for the Federal Energy Management Program (Washington, D.C.: National Bureau of Standards, 1980) NBS Handbook 135.

4. Ruegg, Rosalie T.; McConnaughey, John S.; Sav, G. Thomas; and Hockenbery, Kimberly A., Life-Cycle Costing: A Guide for Selecting Energy Conservation Projects for Public Buildings (Washington, D.C.: National Bureau of Standards 1978) NBS Building Science Series 113.

5. Ruegg, Rosalie T.; Petersen, Stephen $R_{\circ}$, and Marshall, Harold E., Recommended Practice for Measuring Life-Cycle Costs of Buildings and Building Systems (Washington, D.C.: National Bureau of Standards, 1980) NBS Interagency Report 80-2040.

6. Powell, Jeanne W., and Rodgers, Jr., Richard C., FEDSOL: Program User's Manual and Economic Optimization Guide for Solar Federal Buildings Projects (Washington, D.C., National Bureau of Standards, 1981) NBS Interagency Report, In Press. 
Section III.

The Solar Design Process 


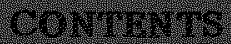

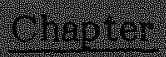

12 - Solat Design Process OVenview

13.t. - Bre-besign Phase

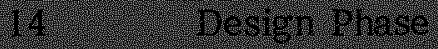

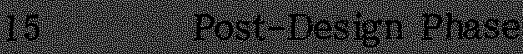

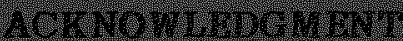

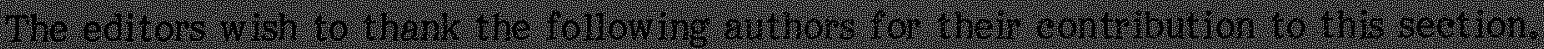

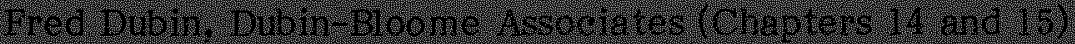

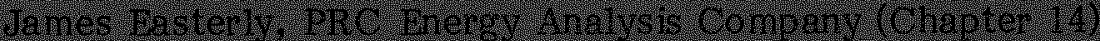

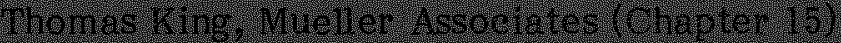

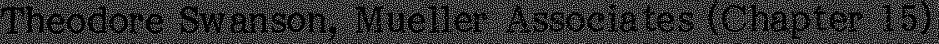

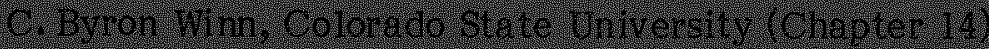


12

Solar Design Process Overview 
12. Exploring the Range of Possible Solutions

Incremental change solutions

Redesign solutions

Three-dimensional solutions

Unique solutions

Summary

Recommended Energy Related Design Process Tasks

Pre-design tasks

Design tasks

Post-design tasks 


\section{Editors' Note:}

Section III is incomplete at this time. Research is currently underway at SERI which will be used as the basis for this section. This section is scheduled for completion in late 1981 and will be included in the final edition of the Solar Design Workbook. A working outline of the Section is reproduced here to show what material is included. A blackened box next to the topic indicates that the material included is essentially complete. A partially blackened box $\square$ denotes the inclusion of some material in that section, and an open box $\square$ indicates total absence of material. 


\section{Section III. Working Outuline}

Chapter

12 Solar Design Process Overview

A. Part I - Exploring the Range of Possible Solutions

B. Part II - Recommended Energy Related Design Process Tasks

1. Pre-Design Tasks

2. Design Tasks

3. Post-Design Tasks

13

* Pre-Design Phase

A. Characterizing Expected Energy Needs of Proposed Building

B. Characterizing Potential Energy Types Available

C. Matching Energy Needs and Energy Types

D. Translating Energy Strategies into Architectural Design Indicators

* Rough graphics only

14

Design Phase

A. Schematic Design

B. Testing Schematic Design Alternatives

C. Design Development

1. Component Design Guidelines and Details

2. Architectural and Engineering Concerns in Solar System Design and Operation (Passive and Active)

3. Standards

Post-Design Phase

A. Construction Contracts

B. Contract Documents

C. Guideline Specifications

D. Procurement Procedures

E. Instrumentation and Monitoring

F. System Performance Evaluation and Acceptance Testing

G. Operation and Maintenance 


\section{SOLAR DESIGN PROCESS OVERVIEW}

\section{INTRODUCTION}

Section I of this workbook looked the fundamentals of technology specific options available for use in energy efficient buildings. Section II introduced methods that are available to calculate the expected performance and economics of these strategies. Such information is an important educational base for the designer of energy efficient buildings. The next "hurdle" for the designer, and the purpose of this section, is to develop a procedure to accurately find appropriate energy related solutions for a given building problem.

The usual response by building designers to a "bombardment" of numerous new energy options is to narrow down the information to a few, select "good ideas." Such conclusions by the inexperienced solar designer can be very limiting, if not dangerous. A much better approach is to think of all the options as part of an arsenal, to be called upon as the particular building problem unfolds and demonstrates a well defined need for specific options held there. This is the essence of a procedure to select appropriate energy related building strategies: to allow the most appropriate solution to evolve from the architectural programmatic needs and the energy potential and constraints of the site.

Chapter 12 explores two major process related issues which must be addressed before work commences on a specific building project. First, what is the range of possible solutions the design team should consider? A range of solutions is not a list of technology specific options, but rather a conceptual definition of the deviation from standard practice procedures and building solutions appropriate for a given problem. This range extends from maximizing the efficiency of mechanical equipment in a "typical" building to searching for unique architectural forms that satisfy building energy needs by physically responding to the dynamics of nature. The architectural and energy goals of a specific project, the time available for analysis, and the experience and abilities of the design team will greatly influence this decision. Part I of this chapter explores the possible range of solutions and the design processes that generate them.

Once an appropriate range of possible solutions has been defined for a project, it remains to orchestrate the design team to meet that challenge effectively. Part II of this chapter presents a suggested sequence of important energy related design process tasks for the design team to consider. These tasks are flexible to suit the range of solutions to be addressed.
The material in this chapter assumes a commercial (nonresidential) building design problem. The commercial building problem is addressed since it is much more complex and, therefore, makes a better example. Much of the information could be used for other building types, if desired. The participation of a design team (i.e., people of different skills usually including an arehitect, mechanical engineer, and/or a solar consultant) is also assumed. This consideration is primarily included to help orchestrate the interactions of these team members, not because the process can only be utilized with these specialists.

There is no "perfect" solution for a specific building design problem. The attempt is to make the decisionmaking process more accurate and the results more beneficial. Likewise, there is no single energy related design process applicable to every building problem. The tasks presented later in this chapter are intended to aid the design team but require modification to suit specific goals, building problems, or design team capabilities.

\section{PART Is EXPLORING THE RANGE OF POSSIBLE SOLUTIONS}

Organizing a design team to develop an energy conserving building design is not an easy task. Typically, there is much confusion among team members concerning which alternatives to consider for any given building problem. Just what is an energy efficient building? All too of ten, individual design team members will have different, if not opposing, answers to this question. Some people perceive energy efficient buildings as a mechanical systems selection and efficiency problem. Others believe that solar collectors and tanks are the answer. Still others may see it as an architectural problem where the need is to maximize building form or shape.

Because of these different visions, it is critical for the project leader to establish from the very beginning what "range of solutions" will be investigated by the design team, and what approach or procedure will be used to orchestrate the team members toward this common goal.

It is all but impossible to separate a range of solutions from the procedure used to generate that result. A limited procedure will produce a building with a limited amount of variation from standard practices. Likewise, to search for innovative and aggressive new building solutions is impossible without a comprehensive, well organized design team procedure plan. 
Four examples are presented to demonstrate the wide range of possible solutions. Fundamental to this discussion will be the procedures used to generate these solutions. Each Solution/Approach example is appropriate for various design problems. The suitability of each is primarily dependent on the abilities of the design team, the project goals, and the time available to explore the problem. However, a noticeable increase in the comprehensiveness of each example is obvious.

\section{Example Approach 1: Ineremental Change Solutions}

At first, the design of energy efficient buildings may seem like a simple problem. One could design a building and then singularly "add" or "incorporate" each of the strategies presented in Section $I$. The changing energy performance and economics of each option could then be calculated using the tools and data in Section II of this workbook. A simple comparison of the first cost and the energy savings of each option could lead to the selection of the "best" solutions.

Such an approach is well exemplified by an excellent DOE-funded study undertaken by The Ehrenkrantz Group of New York. The report, entitled "Cost Benefit Analysis of Passive Solar Design Alternatives: New Office Building/Temperate Climate" is regrettably not available to the public at this time. This report singularly addresses "passive" options, but, as will be explained, the procedure is very useful for exploring a range of active solar systems and mechancial equipment selection.

The procedure in this report begins with a set building form as shown in Figs. 12-18 through 12-1f.

The energy needs and construction cost of this base building were then determined as presented in Tables 12-1a and 12-1b. All costs are determined on cost per net square foot and total costs.

Energy consumption of the base building is shown by items and expressed in Btu. Where appropriate, gallons of oil and kilowatt hours are also shown. Dollar figures are calculated per "onsite" energy costs.

A list of "changes" to be tried on the building was then developed as shown in Table 12-2.

Each modification was then singularly analyzed by computer to determine the resulting energy savings and any changes in first cost and life-cycle costs.

Figs. 12-2a through 12-2e are example results from the Ehrenkrantz Group incremental change approach. Perimeter daylighting replacing artificial lighting was found to be the most cost-effective alternative.

The incremental change procedure is very well suited to the design and selection of active solar systems and mechanical equipment. For a given building (building loads are set), several mechanical options can be tried to see which systems offer maximum economy in terms of first cost and life-cycle costs. Options such as off peak heating and cooling are also easily compared. Control strategies can also be investigated to indicate the probable savings of options such as deadband thermostats. Several computer programs are available to mechanical engineers for these studies, and their use is becoming quite common.

The incremental change approach actually works best when applied to retrofitting older buildings. After all, this is the only architectural problem where the building form is actually "set" or "unchangeable" as the ineremental change approach generally assumes. Applied to new buildings, the incremental change approach is often called The New Building Retrofit Approach. The architectural design options, in particular the passive design strategies, are not seriously considered since they will have little impact on a building not designed to optimize their potential. Nonetheless, energy savings can definitely be achieved by using the incremental change approach; and this method should be the minimum consideration given to the energy performance of new buildings.

Another interesting characteristic of the incremental change approach can be found in the Ehrenkrantz Group results shown in Tables $12-3 \mathrm{a}$ through $12-3 \mathrm{e}$. Note that only one of these "passive" options makes any significant impact on the total building energy needs. Does this imply that there is little opportunity to save substantial amounts of energy in this building type?

The answer to this question is really quite simple. Larger office buildings, such as the Ehrenkrantz base building, are dominated by their "internal" energy loads. That is why building orientation or insulation thickness has a much smaller energy impact than the attempt to satisfy an internal load such as lighting. This brings us to our first major need for energy-related design procedures. The process must allow us to determine the real energy needs of a proposed building at the earliest time possible so that these needs may be addressed rather than options which are less appropriate. Undirected, the incremental change approach does not fulfill that need.

As a conceptual approach to our problem, the incremental change procedure is severely limited by the base building. Base buildings are usually closed, mechanically tempered environments. Such buildings have evolved as a response to a fossil-fuel-rich culture and have purposely become dependent on mechanical climate control and artificial illumination. Alternative energy strategies applied to such buildings will only work if they "feed" that dependence within the energy needs and physical constraints of the closed building box. Therefore, all alternative energy options are reduced to "applique" to be bolted to the building or inserted into the mechanical equipment room. If our goal is to develop building designs that minimize fossil fuel dependence, is the best approach to "inerementally improve" an energy addict?

In conclusion, the incremental change approach is an appropriate "minimum" consideration for the design of new buildings. This approach can lead to energy savings, particularly in the selection of appropriate mechanical systems. As an educational exercise, this approach will help a design team identify the major building energy problems by showing "sensitivity" to options that address these major needs. The solutions that result from this approach are best summarized as standard practice base building dependent or improvements in the energy efficiency of a typical building. 


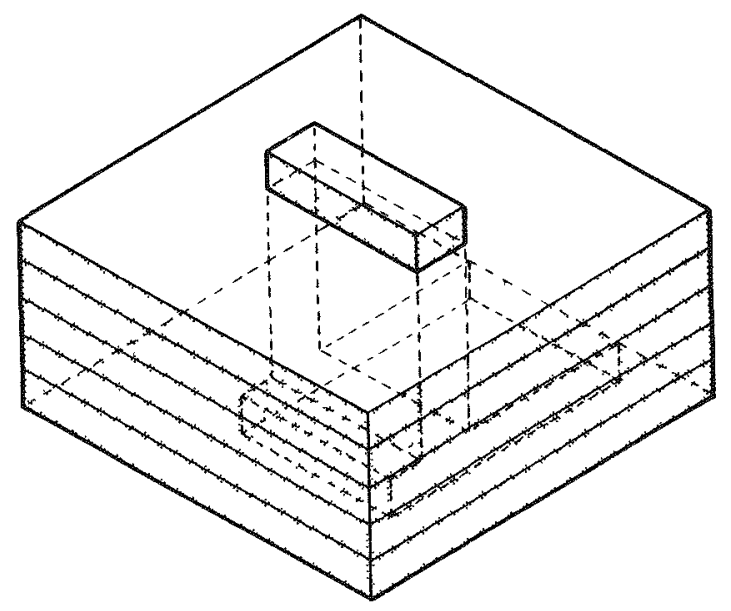

Fig. 12-1a. Configuration of base building

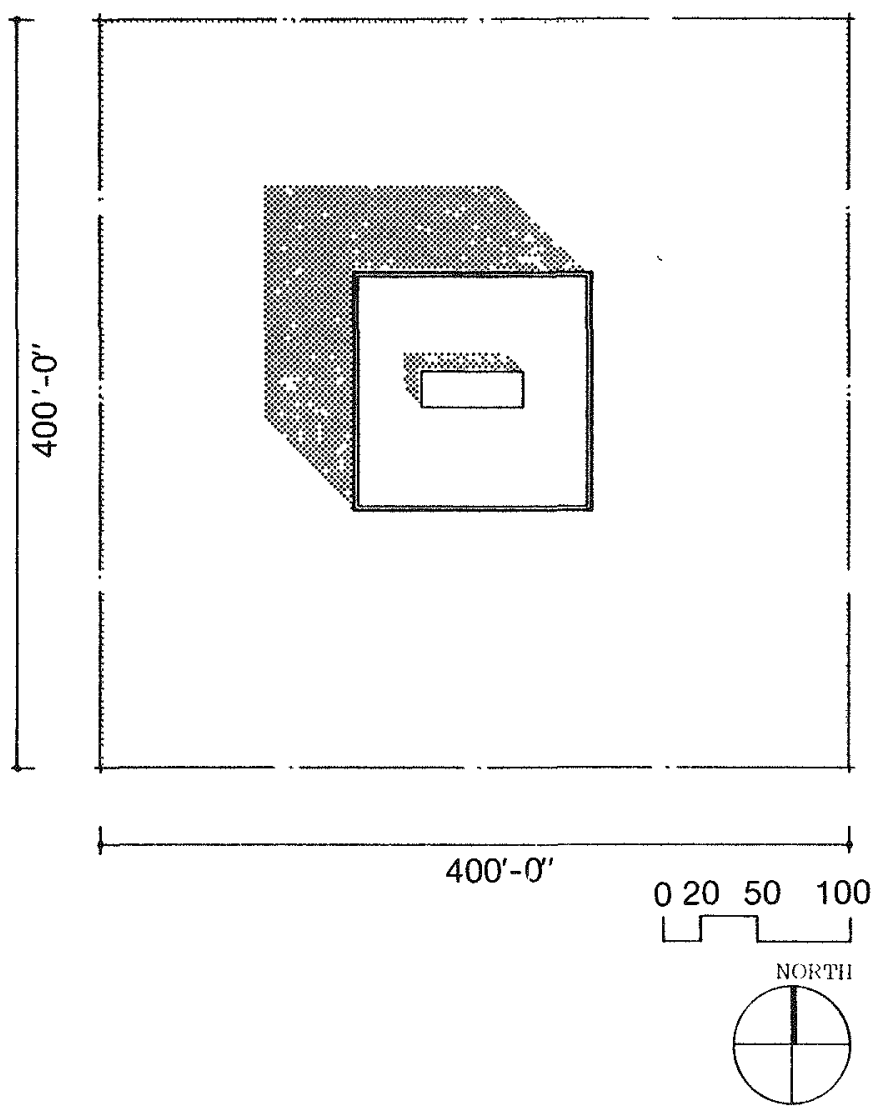

Fig. 12-1b. Site plan of base building
The Base Building is a five-story square plan building with 16,641 gross $\mathrm{sq}$ ft $(1,541 \mathrm{sq} \mathrm{m})$ per floor. There is a partial basement and a mechanical penthouse. Total height of the building is $60 \mathrm{ft}(18 \mathrm{~m})$, excluding penthouse, giving an aspect ratio of height to width of $1: 2.1$ and surface to volume ratio of $1: 21$.

\begin{tabular}{lll} 
Gross Area & office floors & $-83,205 \mathrm{sq} \mathrm{ft}$ \\
penthouse & -990 \\
& basement & $-4,675$ \\
\cline { 2 - 3 } Total & $-88,870 \mathrm{sq} \mathrm{ft}$
\end{tabular}

Site Surface

Reflectance

Area $400 \mathrm{ft} \times 400 \mathrm{ft}$

Building line to site line
- Grass/Asphalt

$-6-7 \%$

- $160,000 \mathrm{sq} \mathrm{ft}$

- 3.673 acres

$-136 \mathrm{ft}$ 


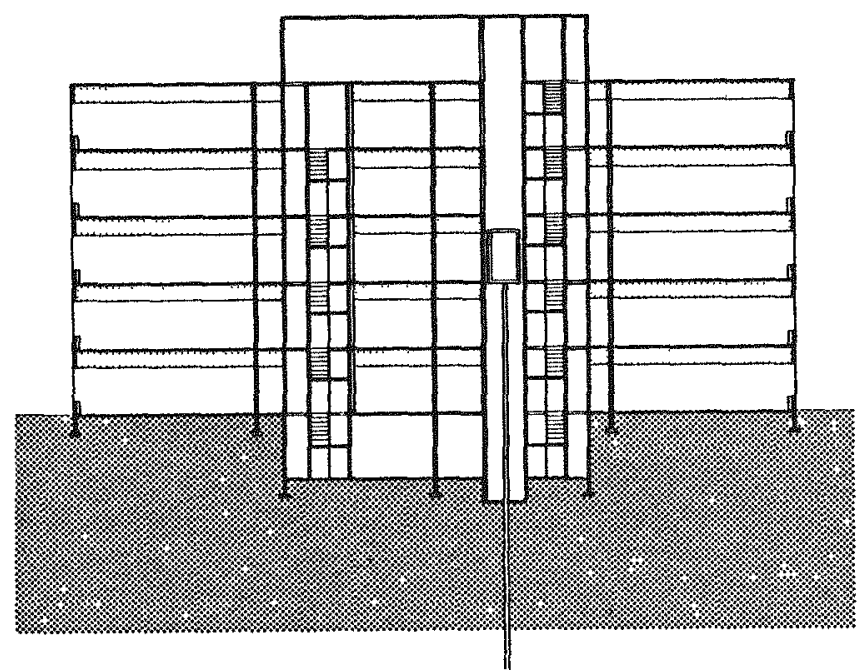

05102030

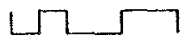

Fig. 12-1c. Section of base building

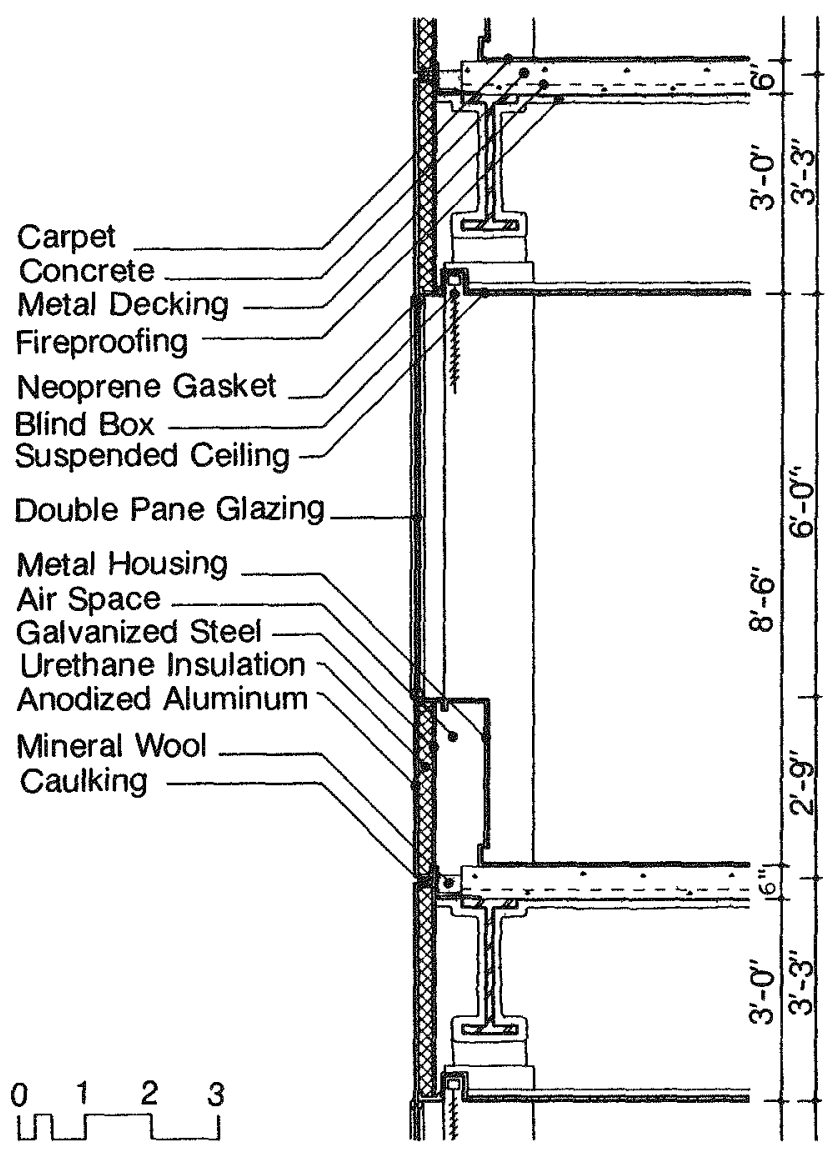

Fig. 12-1d. Wall section of base building
The structure is a steel frame with poured concrete floors over a corr ugated steel deck. Floor to floor height is $12 \mathrm{ft}(3,658 \mathrm{~mm})$ for all floors. The ceiling plenum is $3 \mathrm{ft}(914 \mathrm{~mm})$. The steel structure is fireproofed with a coating of spray applied vermiculite, thickness as required by code.

Struc tural bays

- $32 \mathrm{ft}, 3 \mathrm{in} . \times 32 \mathrm{ft}, 3 \mathrm{in}$.

The wall of the base building is composed of insulated metal panels with continuous insulated glass windows. This "skin" is connected to the structure at points only to prevent excess thermal bridging. It is assumed that a fan coil unit under the window would provide heat to the perimeter zone. Venetian blinds are used as interior shading devices. Window lites are secured to the panels by resilient neoprene gaskets at their perimeter and mullions. 


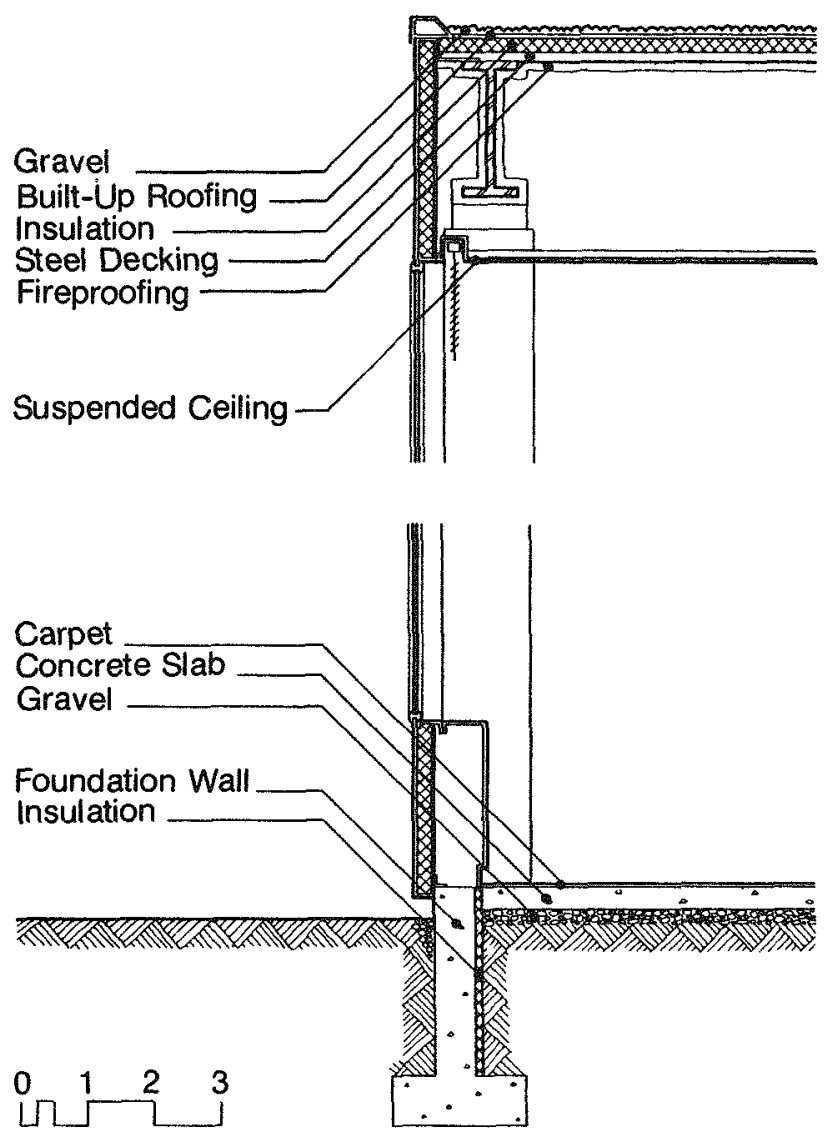

Fig. 12-1e. Roof and ground slab of base building

The ground floor, except over the basement, is a poured concrete slab over gravel. The frost wall is poured concrete with $1-i n .(25 \mathrm{~mm})$ insulation on the inside.

The roof system is a steel deck with a rigid insulation and built-up roofing on the exterior.
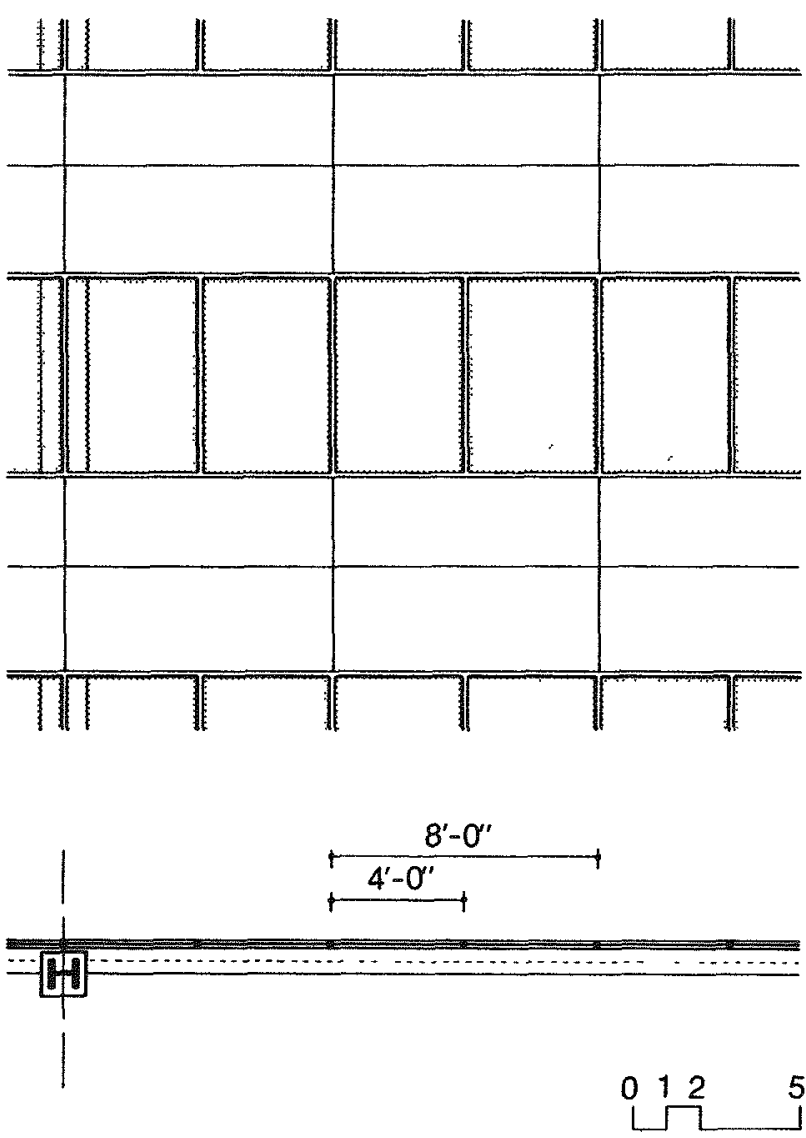

Fig. 12-1f. Elevation and window plan of base building

The wall panel system is expressed on the elevation as continuous wall and window bands around the building. Panels of clear anodized aluminum have a reflective metallic surface. Windows are clear insulating glass and are joined with neoprene gaskets. All four elevations are identical.

Opaque wall to window ratio is $50 \%(1: 1)$.

Glass and wall are on the same plane; there is no shading on the windows.

Glass area

Opaque wall area

Total wall area
- $15,480 \mathrm{sq} \mathrm{ft}$ total

- 15,480 sq ft total

$-30,960 \mathrm{sq} \mathrm{ft}$ 
Table 12-1a. COST SUMMARY

\begin{tabular}{|c|c|c|}
\hline Item & $\$ /$ net sq ft & Total Cost \\
\hline 1. Site & 2.35 & $\$ 213,703$ \\
\hline 2. Sub-structure & 2.64 & 131,279 \\
\hline 3. Structure & 11.72 & 849,356 \\
\hline 4. Exterior Wall & 4.67 & 338,559 \\
\hline 5. Glazing & 3.57 & 258,509 \\
\hline 6. Roofing & 0.68 & 49,569 \\
\hline $\begin{array}{l}\text { 7. Doors, Frames \& } \\
\text { Hardware }\end{array}$ & 0.26 & 18,608 \\
\hline 8. Fireproofing & 0.54 & 38,939 \\
\hline 9. Stairs \& Railings & 0.59 & 43,050 \\
\hline 10. Interior Partitions & 0.09 & 6,409 \\
\hline 11. Fin is hes & 4.07 & 294,797 \\
\hline $\begin{array}{l}\text { 12. Toilet Partitions } \\
\text { \& Access. }\end{array}$ & 0.21 & 15,426 \\
\hline 13. Venetian Blinds & 0.24 & 17,750 \\
\hline 14. Vertical Transportation & 2.50 & 180,820 \\
\hline 15. Plumbing & 0.26 & 18,627 \\
\hline 16. HVAC & 5.96 & 432,000 \\
\hline 17. Electrical & 7.95 & 575,773 \\
\hline Total & 48.91 & $\$ 3,543,180$ \\
\hline
\end{tabular}

Table 12-1b. ENERGY CONSUMPTION SUMMARY

\begin{tabular}{lrcrrr}
\hline \multicolumn{1}{c}{ Item } & Btu & Gallons & kWh & Dollars & $\%$ \\
\hline Heating & 1,184 & 8,457 & & 3,806 & 7.8 \\
Cooling & 568 & & 166,422 & 8,321 & 17.0 \\
Lighting & 1,503 & & 433,420 & 21,371 & 43.7 \\
F ans \& Pumps & 406 & & 118,957 & 5,948 & 12.2 \\
Domestic Hot & 286 & 2,044 & & 920 & 1.9 \\
$\quad$ Water & & & & & \\
Office Equip. & 404 & & 113,438 & 5,975 & 12.2 \\
Elevators & 133 & & 38,969 & 1,948 & 4.0 \\
\hline Total & 4,484 & 10,501 & 883,266 & 48,889 & \\
\hline
\end{tabular}

Energy Consumption/Net Sq Ft $=61,891 \mathrm{Btu} / \mathrm{sq} \mathrm{ft}$
Table 12-2. EHRENKRANTZ LIST OF ALTERNATTVS

\begin{tabular}{|c|c|}
\hline $\begin{array}{l}1 \\
1.1 \\
1.2 \\
1.3 \\
1.4 \\
1.5\end{array}$ & $\begin{array}{l}\text { STTE } \\
\text { Orientation } \\
\text { Ground Reflectance } \\
\text { Berming } \\
\text { Shading } \\
\text { Wind Breaks }\end{array}$ \\
\hline $\begin{array}{l}2 \\
2.1 \\
2.2 \\
2.3\end{array}$ & $\begin{array}{l}\text { OUTSIDE OF WALL } \\
\text { Horizontal Overhang Shading } \\
\text { Vertical Fin Shading } \\
\text { Horizontal and Vertical Shading }\end{array}$ \\
\hline $\begin{array}{l}3 \\
3.1 \\
3.2 \\
3.3 \\
3.4 \\
3.5 \\
3.6 \\
3.7 \\
3.8 \\
3.9 \\
3.10 \\
3.11\end{array}$ & $\begin{array}{l}\text { WALL } \\
\text { Opaque Wall/Low Mass } \\
\text { Opaque Wall/Medium Mass } \\
\text { Opaque Wall/High Mass } \\
\text { Opaque Wall/Exterior Absorptance } \\
\text { Opaque Wall/Vented Walls } \\
\text { Opaque Wall/Trombe Walls } \\
\text { Opaque Wall/Set-back } \\
\text { Glazing } \\
\text { Vented Windows } \\
\text { Window/Wall Ratio } \\
\text { Beam Lighting }\end{array}$ \\
\hline $\begin{array}{l}4 \\
4.1 \\
4.2 \\
4.3 \\
4.4\end{array}$ & $\begin{array}{l}\text { ROOF } \\
\text { Roof Construction } \\
\text { Roof Absorptance } \\
\text { Water Cooled Roofs } \\
\text { Skylights }\end{array}$ \\
\hline $\begin{array}{l}5 \\
5.1 \\
5.2 \\
5.3 \\
5.4 \\
5.5 \\
5.6\end{array}$ & $\begin{array}{l}\text { INTERIOR } \\
\text { Insulating Shutters } \\
\text { Blinds } \\
\text { Photoelec tric Light Controller } \\
\text { Structure Mass } \\
\text { Interior Planning } \\
\text { Core Location }\end{array}$ \\
\hline
\end{tabular}




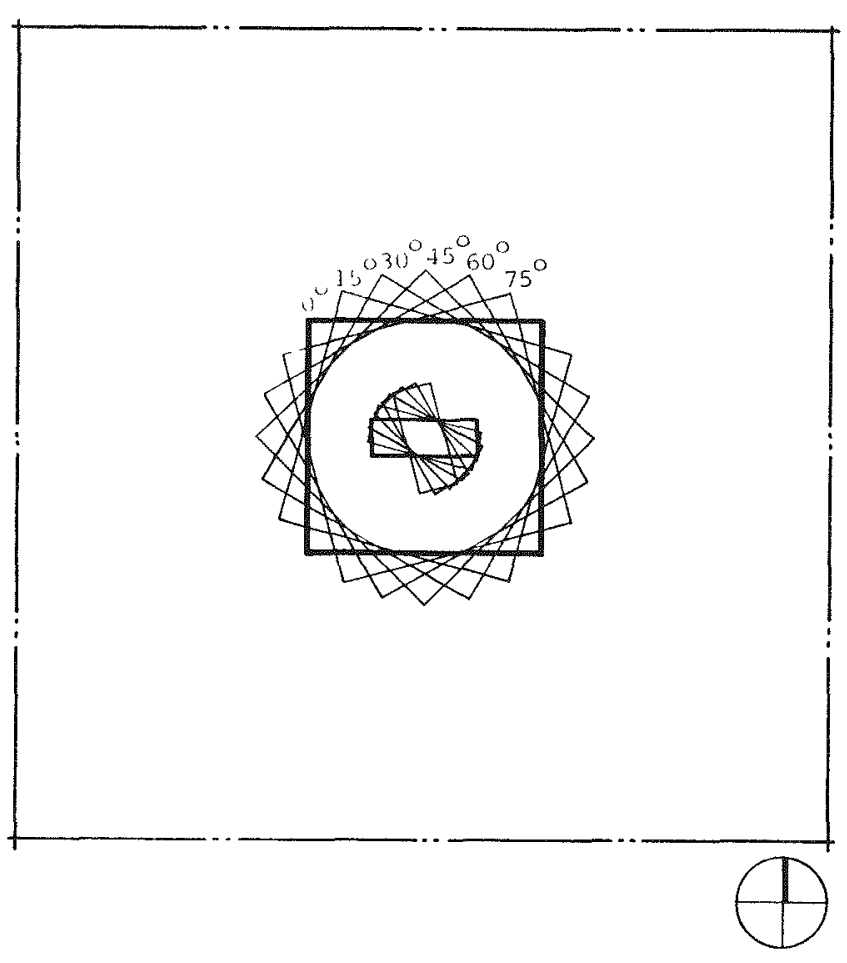

The base building is assumed to face the four compass orientations and is labeled as $0^{\circ}$ from south.

To test effects of changing orientation, the base building is rotated in $15^{\circ}$ increments to reach a maximum shift of $75^{\circ}$.

Since all four elevations on the base building are the same, a rotation of $90^{\circ}$ or more is equivalent to alternatives already tested.

Fig. 12-2a. Rotation of building

Table 12-3a. EHRENKRANTZ BUILDING EXAMPLE: ORENTATION OPTION

\begin{tabular}{|c|c|c|c|c|}
\hline \multirow[b]{2}{*}{ Benefits Data } & \multirow[b]{2}{*}{ Units } & \multicolumn{3}{|c|}{ Degrees from South } \\
\hline & & $30^{\circ}$ & $45^{\circ}$ & $60^{\circ}$ \\
\hline Investment Tax Credit at $10 \%$ & $\$$ & 0 & 0 & 0 \\
\hline Energy Tax Credits & $\$ / \mathrm{yr} 0$ & 0 & 0 & 0 \\
\hline Straight Line Depreciation at 0 yr schedule & $\$ / y r$ & 0 & 0 & 0 \\
\hline Salvage Value in year 30 & $\$$ & 0 & 0 & 0 \\
\hline \multicolumn{5}{|l|}{ Energy Savings: } \\
\hline Heating & $\begin{array}{r}\$ / \mathrm{yr} 0 \\
\text { Gallons/yr }\end{array}$ & $\begin{array}{c}\$ 29.00 \\
64.4\end{array}$ & $\begin{array}{c}\$ 26.00 \\
57.7\end{array}$ & $\begin{array}{c}\$ 36.00 \\
80\end{array}$ \\
\hline Cooling & $\begin{array}{r}\$ / y^{\prime} 0 \\
k W h / y r\end{array}$ & $\begin{array}{c}\$ 58.00 \\
1160\end{array}$ & $\begin{array}{c}\$ 15.00 \\
300\end{array}$ & - \\
\hline Lighting & $\begin{array}{r}\$ / \mathrm{yr} 0 \\
\mathrm{kWh} / \mathrm{yr}\end{array}$ & $\begin{array}{l}0 \\
0\end{array}$ & $\begin{array}{l}0 \\
0\end{array}$ & $\begin{array}{l}0 \\
0\end{array}$ \\
\hline Mechanical (fans, pumps, central plant) & $\begin{array}{r}\$ / \mathrm{yr} 0 \\
\mathrm{kWh} / \mathrm{yr}\end{array}$ & $\begin{array}{c}\$ 53.00 \\
1060\end{array}$ & $\begin{array}{c}\$ 38.00 \\
760\end{array}$ & $\begin{array}{c}\$ 23.00 \\
460\end{array}$ \\
\hline Total & $\$ /$ yr 0 & $\$ 140.00$ & $\$ 79.00$ & $\$ 59.00$ \\
\hline
\end{tabular}




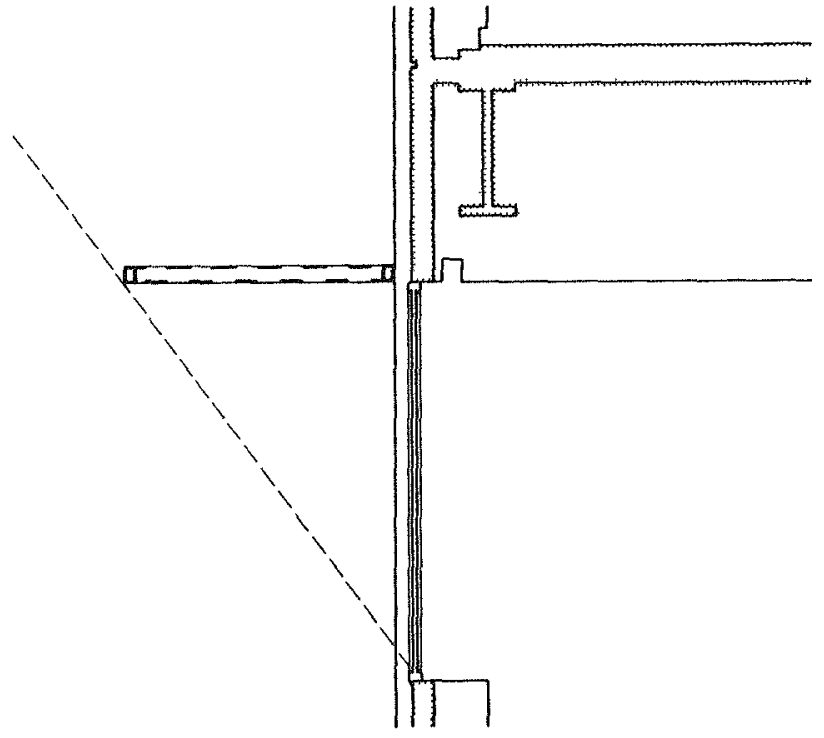

Fig. 12-2b. Horizontal window overhang
The window area of the base building is shaded by a single overhang, 1,2 , and $3 \mathrm{ft}(305,610,914 \mathrm{~mm})$ wide.

The overhangs are prefabricated with $4-i n .(102 \mathrm{~mm})$ wide metal strips attached to a metal frame. The spaces between strips allow hot air usually trapped below the overhang to escape without transmitting its heat to the interior. Only the low winter sun is able to pass between strips.

Shading devices are tested one elevation at a time, with resulting energy changes calculated for the total building. Only selected combinations of shading devices and elevation orientations are tested.

All shading alternatives are compared to the base building design with no shading.

Table 12-3b. EHRENKRANTZ BUILDING EXAMPLE: OPTION-3-FT .OVERHANG ON THE SOUTH ELEVATION

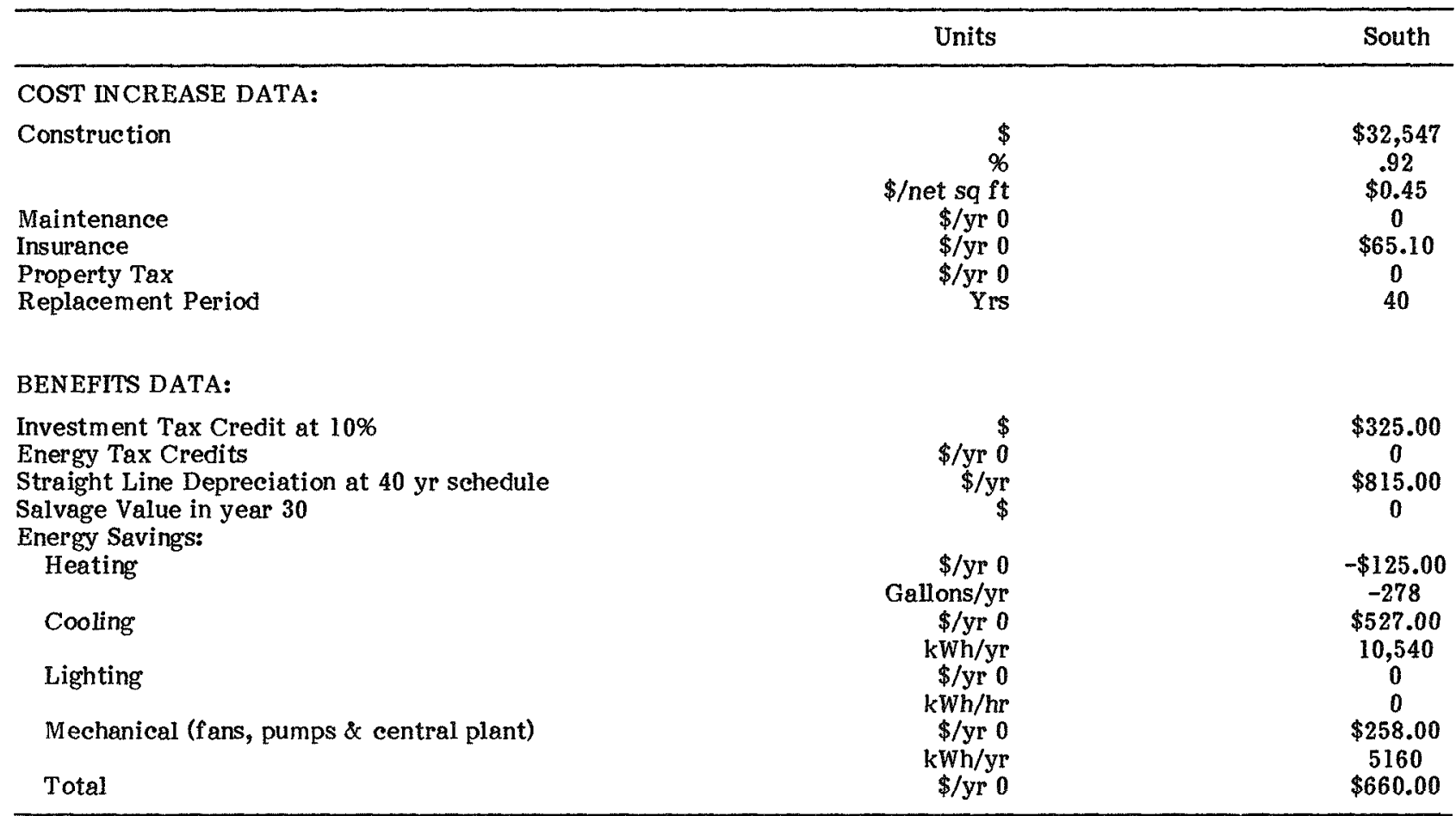




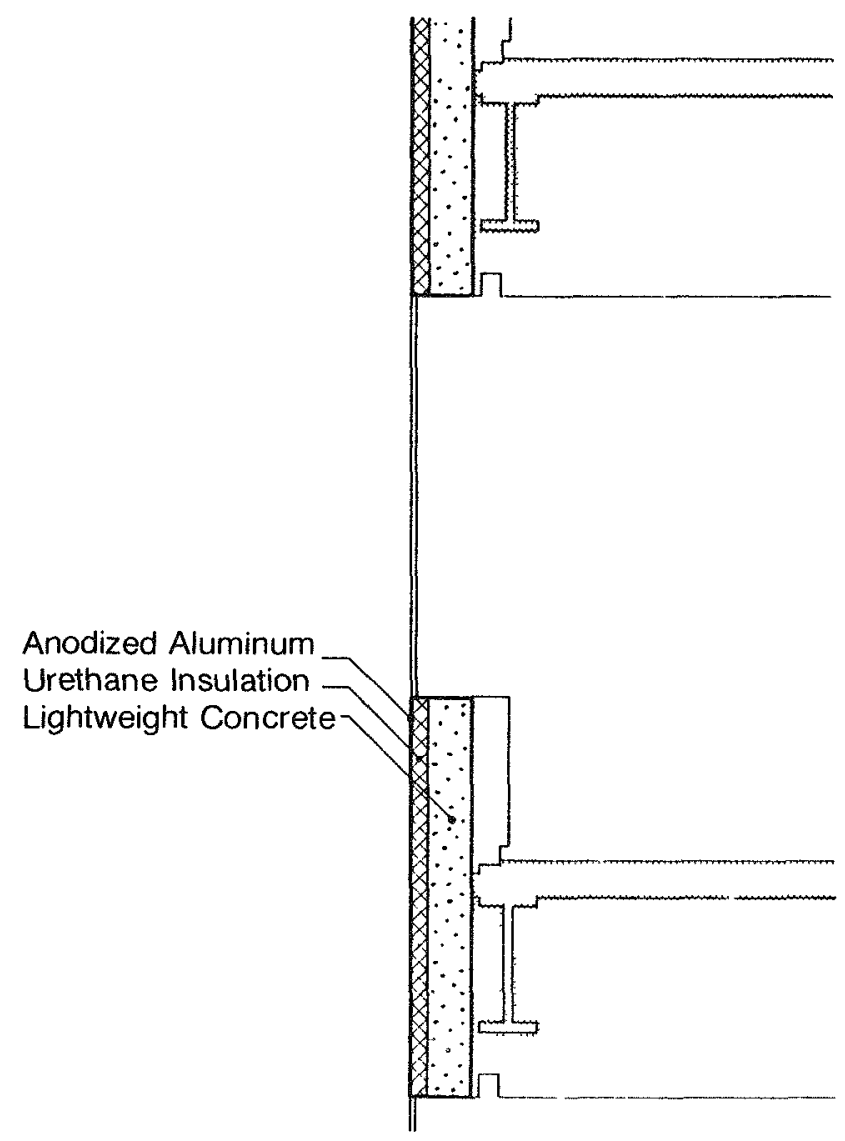

Prefabricated panels of lightweight concrete are tested with 1,2 , and 4 in. $(25,51,102 \mathrm{~mm})$ of insulation located on the outside of the panel. Insulation is covered with anodized aluminum skin for exterior finish.

Outside insulation alternatives are tested with double glazing of clear glass and compared to the base building's low mass sandwich panel of $3-\mathrm{in} .(76 \mathrm{~mm})$ insulation.

Fig. 12-2c. Test panel

Table 12-3c. EHRENKRANTZ BUHDING EXAMPLE: OPTION-2-IN. POLYURETHANE OUTSIDE INSULATION

\begin{tabular}{|c|c|c|}
\hline & Units & Total \\
\hline \multicolumn{3}{|l|}{ COST INCREASE DATA: } \\
\hline Construction & $\begin{array}{r}\$ \\
\% \\
\$ / \text { net so ft }\end{array}$ & $\begin{array}{c}\$ 1928 \\
.05 \\
\$ 0.027\end{array}$ \\
\hline Maintenance & $\$ / \mathrm{yr} 0$ & 0 \\
\hline Insurance & $\$ /$ yr 0 & $\$ 3.86$ \\
\hline Property Tax & $\$ /$ yr 0 & 0 \\
\hline Replacement Period & Yrs & 40 \\
\hline \multicolumn{3}{|l|}{ BENEFITS DATA: } \\
\hline Investment Tax Credit at $10 \%$ & $\$$ & $\$ 193.00$ \\
\hline Energy Tax Credits & $\$ / y r 0$ & 0 \\
\hline Straight Line Depreciation at 40 yr schedule & $\$ / \mathrm{yr}$ & $\$ 48.00$ \\
\hline Salvage Value in year 30 & $\$$ & 0 \\
\hline \multicolumn{3}{|l|}{ Energy Savings: } \\
\hline \multirow[t]{2}{*}{ Heating } & $\$ /$ yr 0 & $-\$ 13.00$ \\
\hline & Gallons/yr & -29 \\
\hline \multirow{2}{*}{ Cooling } & $\$ /$ yr 0 & $\$ 58.00$ \\
\hline & $\mathrm{kWh} / \mathrm{yr}$ & 1160 \\
\hline \multirow[t]{2}{*}{ Lighting } & $\$ / y r 0$ & 0 \\
\hline & $\mathrm{kWh} / \mathrm{yr}$ & 0 \\
\hline \multirow[t]{2}{*}{ Mechanical (fans, pumps \& central plant) } & $\$ /$ yr 0 & $\$ 38.00$ \\
\hline & $\mathrm{kWh} / \mathrm{yr}$ & 760 \\
\hline Total & $\$ / \mathrm{yr} 0$ & $\$ 83.00$ \\
\hline
\end{tabular}




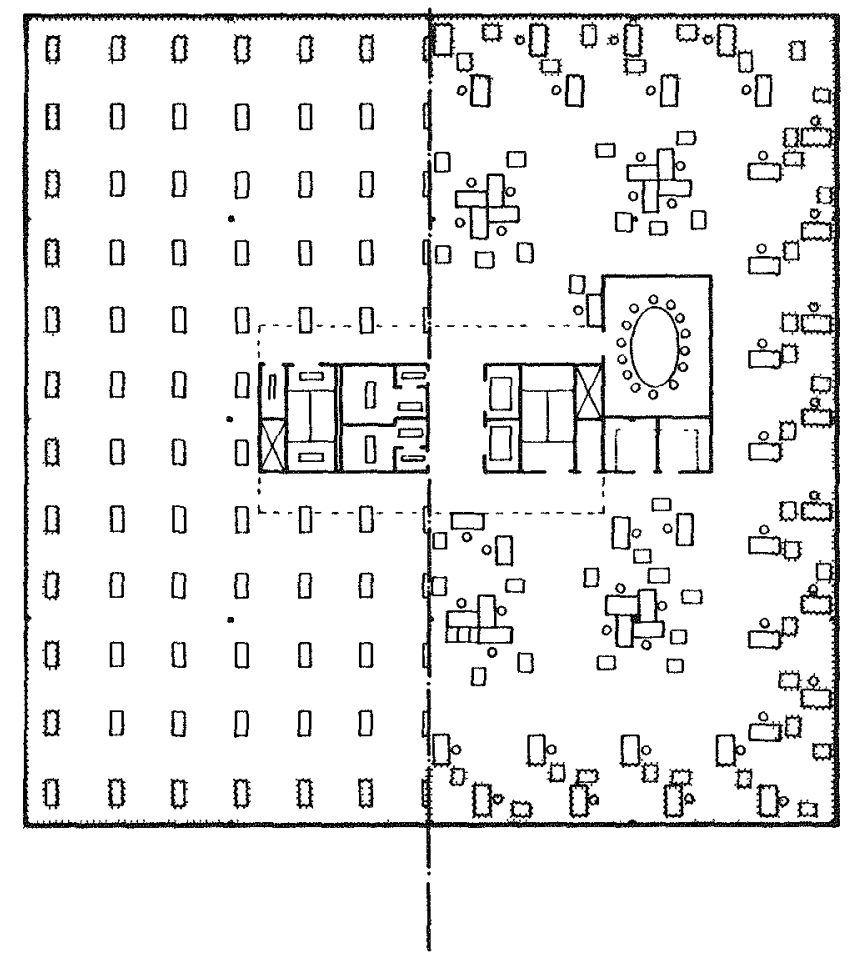

Fig. 12-2d. Lighting control of perimeter area
Perimeter artificial lighting is controlled by an automatic photoelectric light dimmer system.

The controlled zone is $10 \mathrm{ft}(3,048 \mathrm{~mm})$ and one fixture deep.

The system is designed to dim or switch off artificial lighting when good lighting levels are available from daylight penetration through windows. Each zone is controlled separately.

The computer simulation assumes a venetian blind in the down position whenever direct sunlight falls on the window area.

The base building has no photoelectric system. 
Table 12-3d. EHRENKRANTZ STUDY EXAMPLE: OPTION-PERIMETER DAYLIGHTING WITH PHOTOELECTRIC CONTROLLER

\begin{tabular}{|c|c|c|c|c|c|c|}
\hline & Units & South $^{2}$ & East $^{a}$ & North ${ }^{2}$ & West $^{a}$ & Total $^{\mathrm{b}}$ \\
\hline \multicolumn{7}{|l|}{ COST INCREASE DATA: } \\
\hline $\begin{array}{l}\text { Construction } \\
\text { Maintenance } \\
\text { Insurance } \\
\text { Property Tax } \\
\text { Replacement Period }\end{array}$ & $\begin{array}{r}\$ \\
\% \\
\$ / \text { net sq ft } \\
\$ / \mathrm{yr} 0 \\
\$ / \mathrm{yr} 0 \\
\$ / \mathrm{yr} 0 \\
\text { Yrs }\end{array}$ & $\begin{array}{c}\$ 2847 \\
.08 \\
\$ 0.039 \\
0 \\
\$ 5.69 \\
0 \\
20\end{array}$ & $\begin{array}{c}\$ 2816 \\
.08 \\
\$ 0.039 \\
0 \\
\$ 5.63 \\
0 \\
20\end{array}$ & $\begin{array}{c}\$ 2945 \\
.08 \\
\$ 0.041 \\
0 \\
\$ 5.89 \\
0 \\
20\end{array}$ & $\begin{array}{c}\$ 2798 \\
.08 \\
\$ 0.039 \\
0 \\
\$ 5.60 \\
0 \\
20\end{array}$ & $\begin{array}{c}\$ 11,780 \\
.33 \\
\$ 0.16 \\
0 \\
\$ 22.81 \\
0 \\
20\end{array}$ \\
\hline \multicolumn{7}{|l|}{ BENEFITS DATA: } \\
\hline $\begin{array}{l}\text { Investment Tax Credit at } 10 \% \\
\text { Energy Tax Credits } \\
\text { Straight Line Depreciation at } 15 \mathrm{yr} \text { schedule } \\
\text { Salvage Value in year } 30\end{array}$ & $\begin{array}{r}\$ \\
\$ / y r 0 \\
\$ / y r \\
\$\end{array}$ & $\begin{array}{c}\$ 285.00 \\
0 \\
190^{\mathrm{c}} / 735^{\mathrm{d}} \\
\$ 750.00\end{array}$ & $\begin{array}{c}\$ 282.00 \\
0 \\
188^{c} / 727^{d} \\
\$ 750.00\end{array}$ & $\begin{array}{c}\$ 295.00 \\
0 \\
196 c^{c} / 760^{d} \\
\$ 750.00\end{array}$ & $\begin{array}{c}\$ 280.00 \\
0 \\
188^{c} / 721^{d} \\
\$ 750.00\end{array}$ & $\begin{array}{c}\$ 118.00 \\
0 \\
785^{\mathrm{c}} / 3040^{\mathrm{d}} \\
\$ 3000\end{array}$ \\
\hline \multicolumn{7}{|l|}{ Energy Savings: } \\
\hline Heating & $\begin{array}{r}\$ / y r 0 \\
\text { Gallons/yr }\end{array}$ & $\begin{array}{c}-\$ 122.00 \\
-271\end{array}$ & $\begin{array}{c}-\$ 167.00 \\
-371\end{array}$ & $\begin{array}{c}-\$ 275.00 \\
-611\end{array}$ & $\begin{array}{c}-\$ 176.00 \\
-391\end{array}$ & $\begin{array}{c}-\$ 740.00 \\
-1644\end{array}$ \\
\hline Cooling & $\begin{array}{r}\$ / \mathrm{yr} 0 \\
\mathrm{kWh} / \mathrm{yr}\end{array}$ & $\begin{array}{c}\$ 483.00 \\
9660\end{array}$ & $\begin{array}{c}\$ 469.00 \\
9380\end{array}$ & $\begin{array}{c}\$ 337.00 \\
6740\end{array}$ & $\begin{array}{c}\$ 513.00 \\
10,260\end{array}$ & $\begin{array}{c}\$ 1802 \\
36,040\end{array}$ \\
\hline Lighting & $\begin{array}{r}\$ / \mathrm{yr} 0 \\
\mathrm{kWh} / \mathrm{yr}\end{array}$ & $\begin{array}{c}\$ 1923 \\
38,460\end{array}$ & $\begin{array}{l}\$ 1946 \\
38,920\end{array}$ & $\begin{array}{c}\$ 1949 \\
38,980\end{array}$ & $\begin{array}{l}\$ 1948 \\
38,960\end{array}$ & $\begin{array}{c}\$ 7766 \\
155,320\end{array}$ \\
\hline $\begin{array}{l}\text { Mechanical (fans, pumps \& central plant) } \\
\text { Total }\end{array}$ & $\begin{array}{r}\$ / y r 0 \\
k W h / y^{2} \\
\$ / y r 0\end{array}$ & $\begin{array}{l}\$ 238.00 \\
4760 \\
\$ 2522\end{array}$ & $\begin{array}{l}\$ 215.00 \\
4300 \\
\$ 2463\end{array}$ & $\begin{array}{l}\$ 124.00 \\
2480 \\
\$ 2135\end{array}$ & $\begin{array}{l}\$ 228.00 \\
4560 \\
\$ 2513\end{array}$ & $\begin{array}{l}\$ 805.00 \\
16,100 \\
\$ 9633\end{array}$ \\
\hline \multicolumn{7}{|l|}{ LIFE CYCLE COST/BENEFIT DATA: } \\
\hline $\begin{array}{l}\text { Dis counted Payback } \\
\text { Internal Rate of Return } \\
\text { Net Present Value }\end{array}$ & $\begin{array}{r}\text { Yrs } \\
\% \\
\$\end{array}$ & $\begin{array}{c}1.75 \\
72.17 \\
\$ 98,002\end{array}$ & $\begin{array}{c}1.78 \\
71.44 \\
\$ 95,681\end{array}$ & $\begin{array}{c}2.11 \\
61.66 \\
\$ 82,438\end{array}$ & $\begin{array}{c}1.73 \\
72.97 \\
\$ 97,697\end{array}$ & $\begin{array}{c}1.89 \\
67.73 \\
\$ 373,414\end{array}$ \\
\hline
\end{tabular}

aption applied to this zone only

boption applied to all zones

CYears 1 through 15

$d_{Y}$ ears 20 through 30 


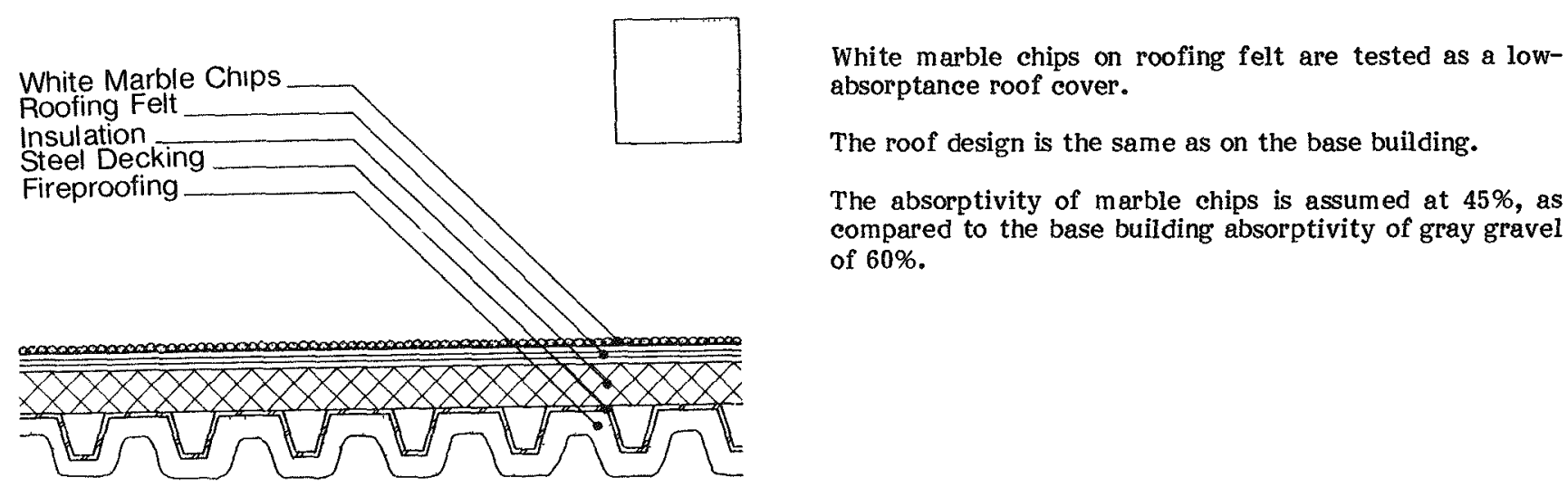

Fig. 12-2e. Low-absorptance roof cover

Table 12-3e. EHRENKRANTZ BUILDING EXAMPLE: OPTION-LOW ABSORPTANCE ROOF COVER

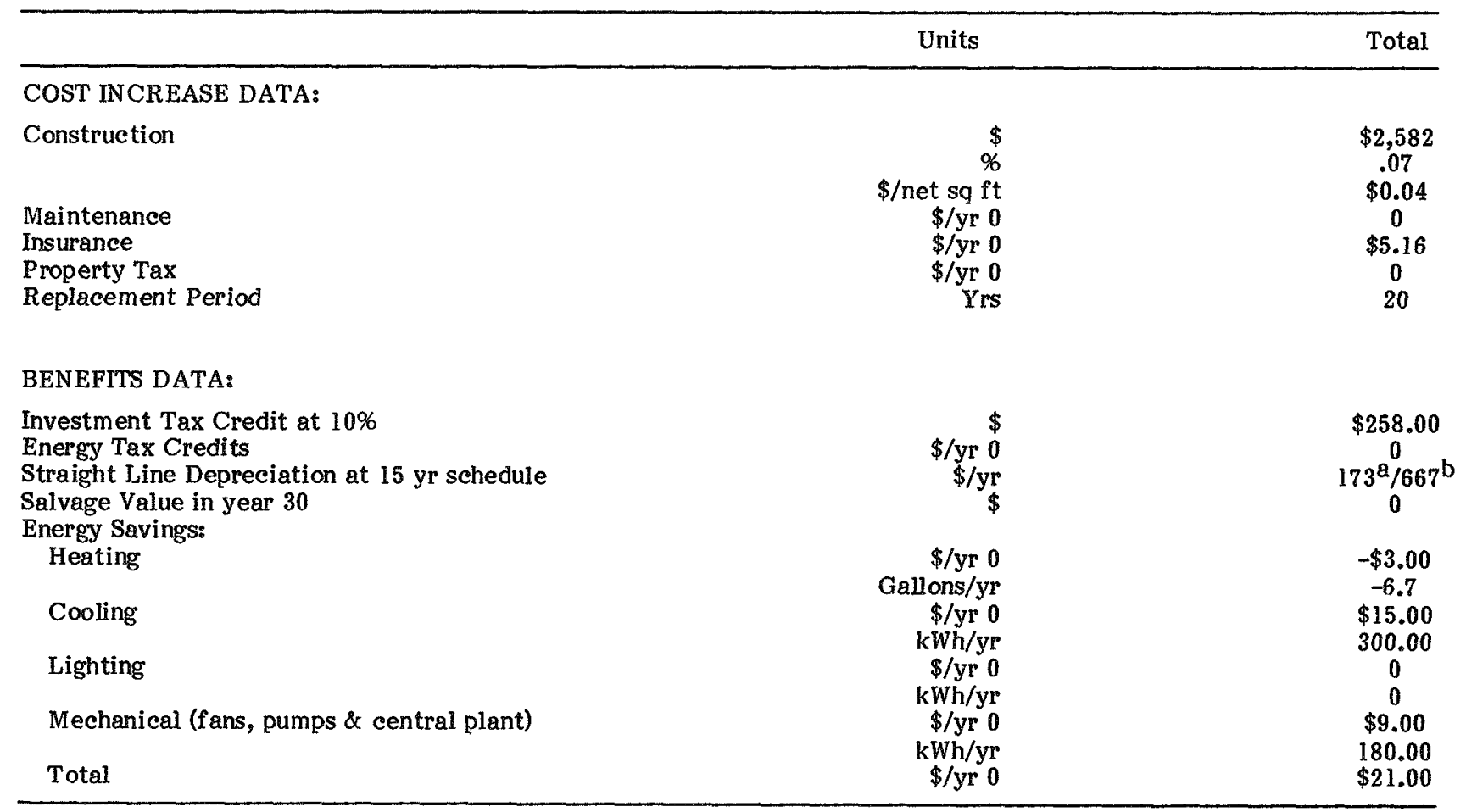

aY ears 1 through 15

bYears 20 through 30 


\section{Example Approach 2: Redesign Solutions}

For purposes of this discussion, the next level of design approach will be characterized by Redesign Solutions. Redesign solutions evolve by considering all the increm ental change approach options but also include an exercise to "redesign" the building and improve the base box. Architectural redesign considerations dwell primarily on the exterior form of the building box, allowing it to become longer or narrower to optimize thermal or illumination exposures, etc. These considerations enhance perimeter energy exchanges without greatly altering internal architectural forms. Hence, the solutions are typically called "twodimensional."

An excellent example of the Redesign Approach is the AIA/RC report "Life Cycle Cost Stucy of Commercial Buildings." This report was funded by DOE as a portion of the work related to the proposed Building Energy Performance Standards (BEPS). The primary intent was to identify the minimum yearly energy needs and minimum life-cycle cost for the buildings analyzed, and determine if a predictable relationship exists between these two variables. (None was found.)

Three office buildings were analyzed in the report. They are located in Denver, Minneapolis, and Raleigh. Architectural redesign options were intentionally held to the two-dimensional range to provide solutions similar to the original buildings as constructed.

The study starts with the three base buildings as originally designed and constructed for real clients. Figs. 12-3, 12-5, and 12-7 document these buildings. As in the incremental change procedure, a list of changes or options to be tried was developed. The list is quite extensive, covering numerous mechanical and architectural incremental changes. Regrettably, strategies such as electric demand limiters and passive solar techniques were eliminated since the loads analysis computer program used could not model them.

Note that the reference point in this analysis is once again the "base building." The major difference between this analysis and the incremental change approach is visually shown in Figs. 12-4, 12-6, and 12-8. The redesign efforts were limited in number compared to the many system and component changes tried, but they represent an attempt to modify architecturally building energy loads. Eventually, the redesigned buildings with apropriate mechanical systems became the new base buildings in the study.

A brief summary of the yearly energy needs for each building with various options applied is given in Tables $12-4,12-5$, and 12-6. Note that the most significant reduction is the initial redesign. The redesign represents modest architectural considerations and the selection of appropriate mechanical systems, the latter having the largest impact. These two considerations reduce building energy dependency by nearly $50 \%$ in all three cases. This significant energy savings is achieved by straightforward, intelligent, professional practice-not by major alternative energy strategies or exotic mechanical systems. It demonstrates the great amount of energy "fat" which can be eliminated from standard practice designs through the use of presently available professional knowledge.
Using the redesign energy performance as the new base, the study shows that an additional $20 \%$ or more of the building's energy needs can be eliminated with additional strategies such as perimeter daylighting, deadband thermostats, additional offpeak thermal storage, etc. These additional savings were all achieved without aggressively altering the architectural box. Figs. 12-9 through 12-11 document a few of the options tried on the three buildings.

The study strongly supports and states the following conclusion: "Substantial energy reduction can be achieved through building design techniques without materially affecting first cost or sacrificing occupant comfort and with a reduction of the life-cycle cost." Not surprisingly, the two design strategies that appeared especially promising (after sound professional practice) are the deadband thermostatic control system and perimeter daylighting with automatic controls in the artificial lighting system.

The AIA/RC study is extremely valuable because of the monumental number of alternatives tried. It also is a good example since it considers both architectural and mechanical issues. Note that architectural form is not identified as a "most promising" strategy, but the two listed strategies can be decisively addressed by architectural design (more on this later). Threedimensional problems are not solved by two-dimensional solutions. Therefore, we have not yet reached the end of the possible range of solutions. How much can the building itself respond to the dynamics of energy flows?

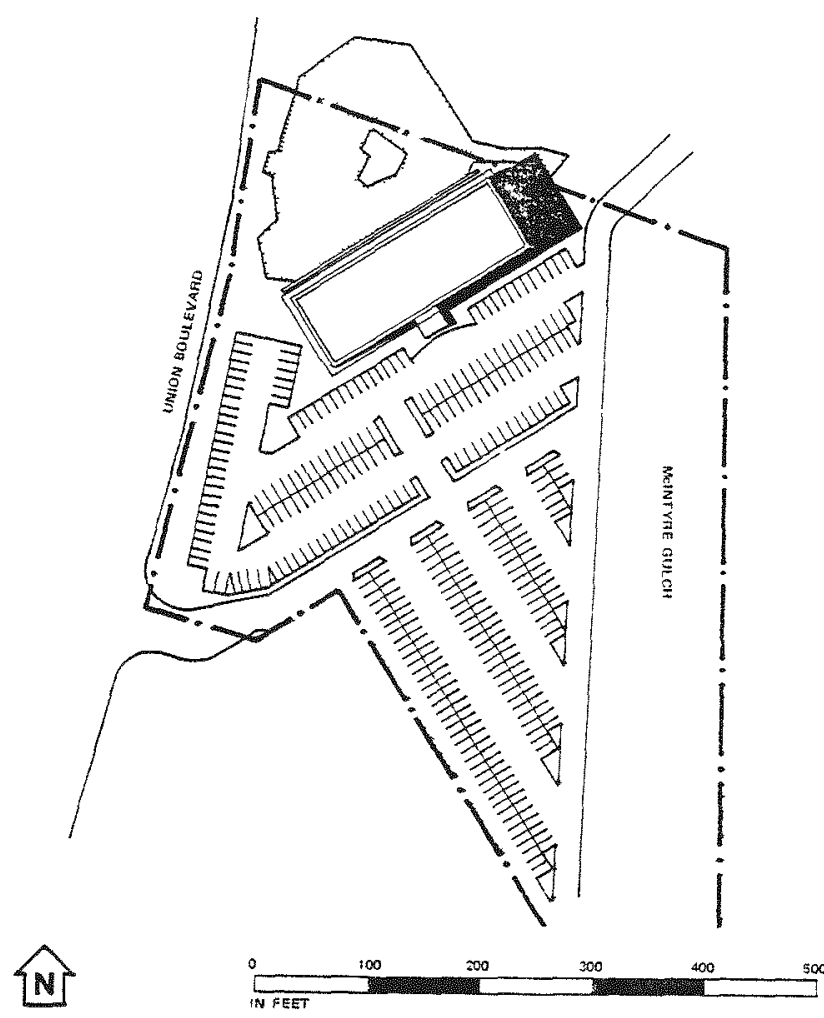

Fig. 12-3a. Site plan, original building, Denver 


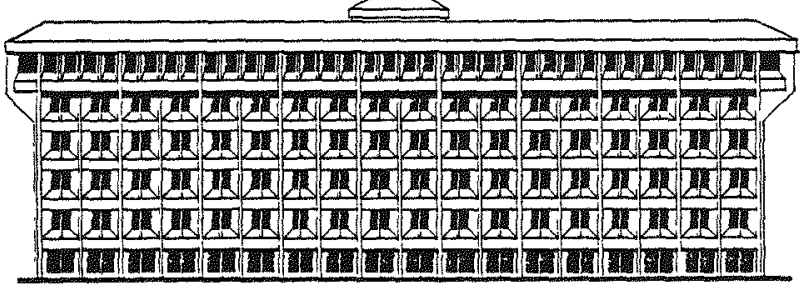

Fig. 12-3b. Southeast elevation, original building, Denver

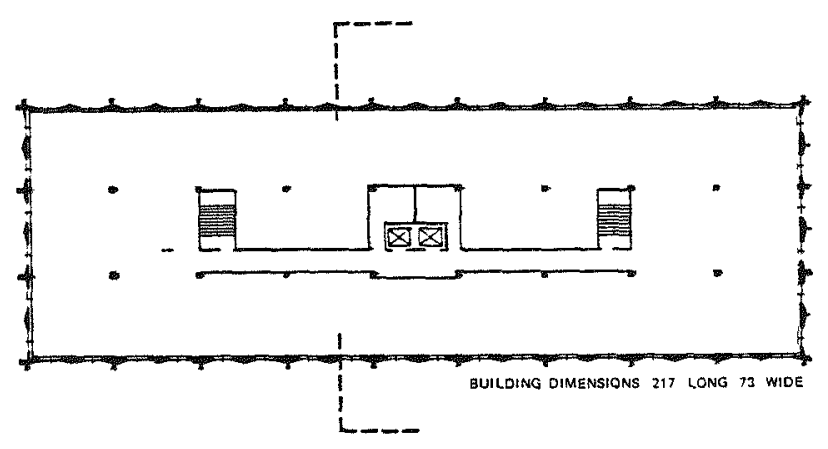

Fig. 12-3c. Typical floor plan, original building, Denver

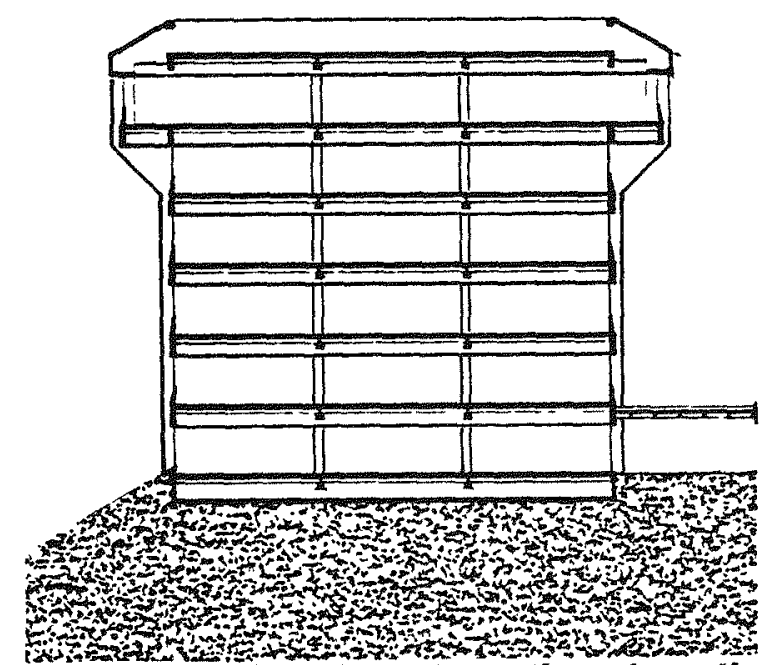

Fig. 12-3d. Northwest-southeast section, original building, Denver

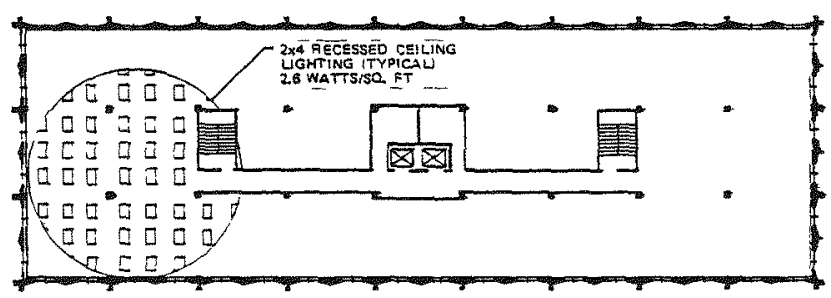

Fig. 12-3e. Typical lighting layout, original building, Denver

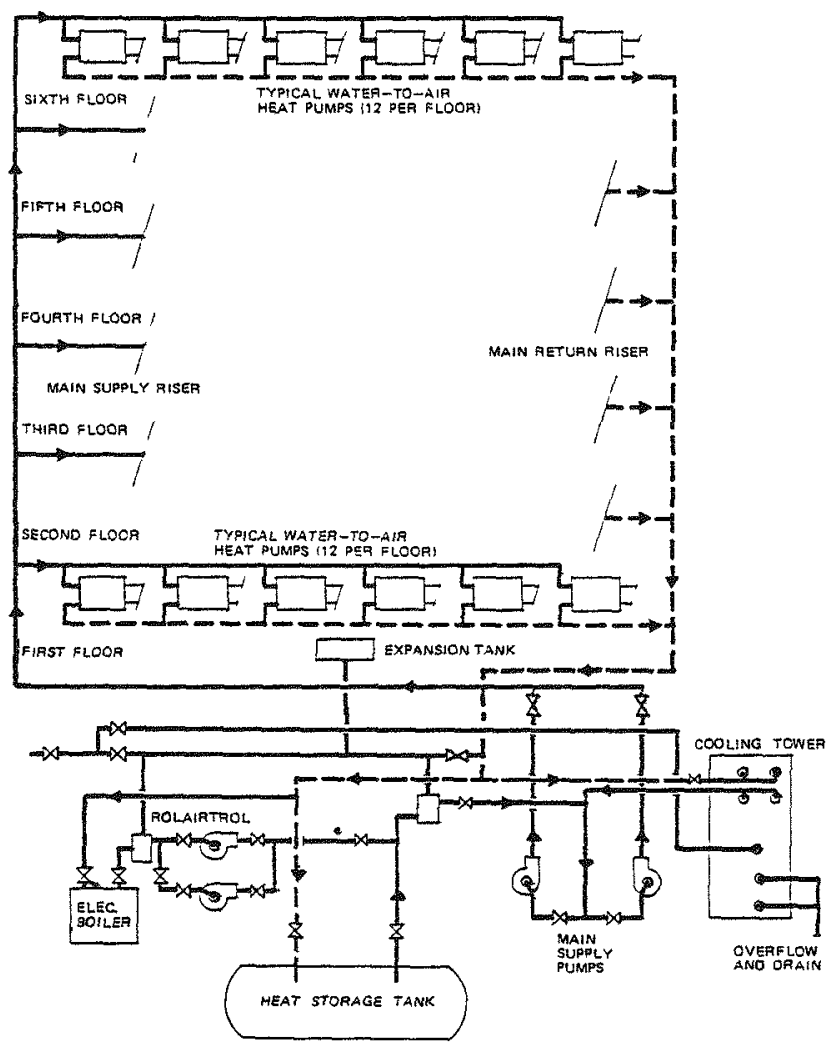

Fig. 12-3f. HVAC schematic, original building, Denver 


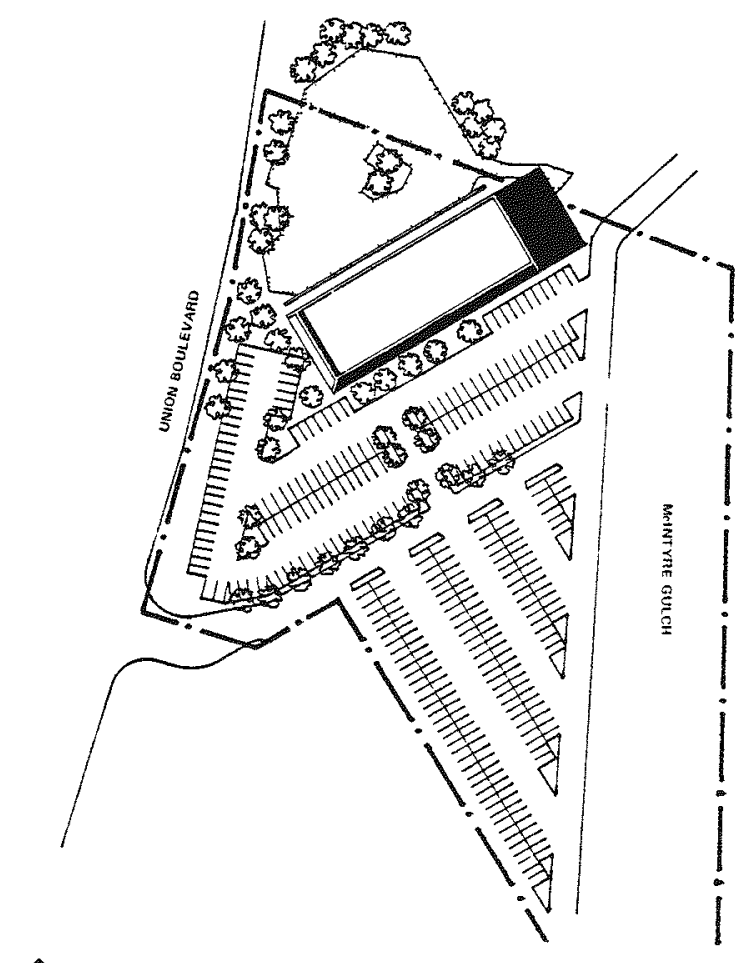

N

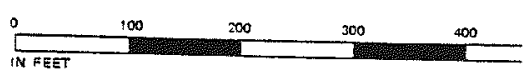

Fig. 12-4a. Site plan, redesign building, Denver

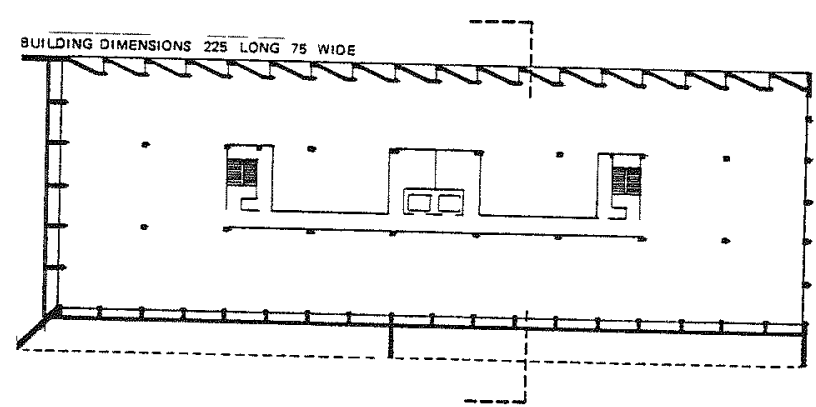

Fig. 12-4c. Typical floor plan, redesign building, Denver

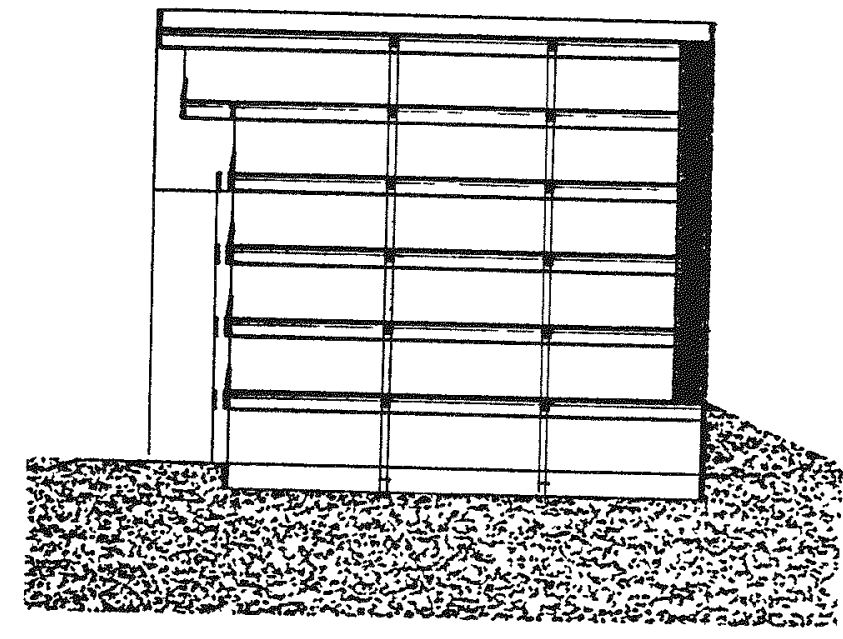

Fig. 12-4d. Northwest-southeast section, redesign building, Denver

Fig. 12-4b. Southeast elevation, redesign building, Denver 


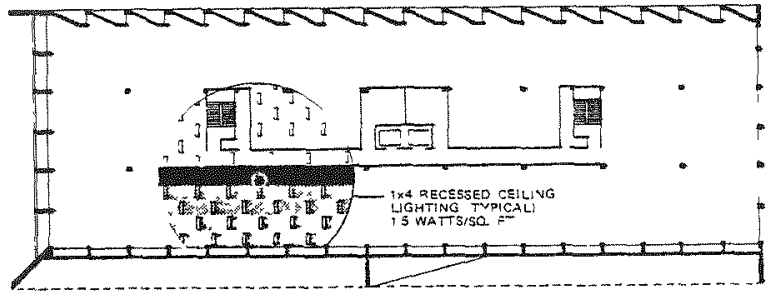

Fig. 12-4e. Typical lighting layout, redesign building, Denver

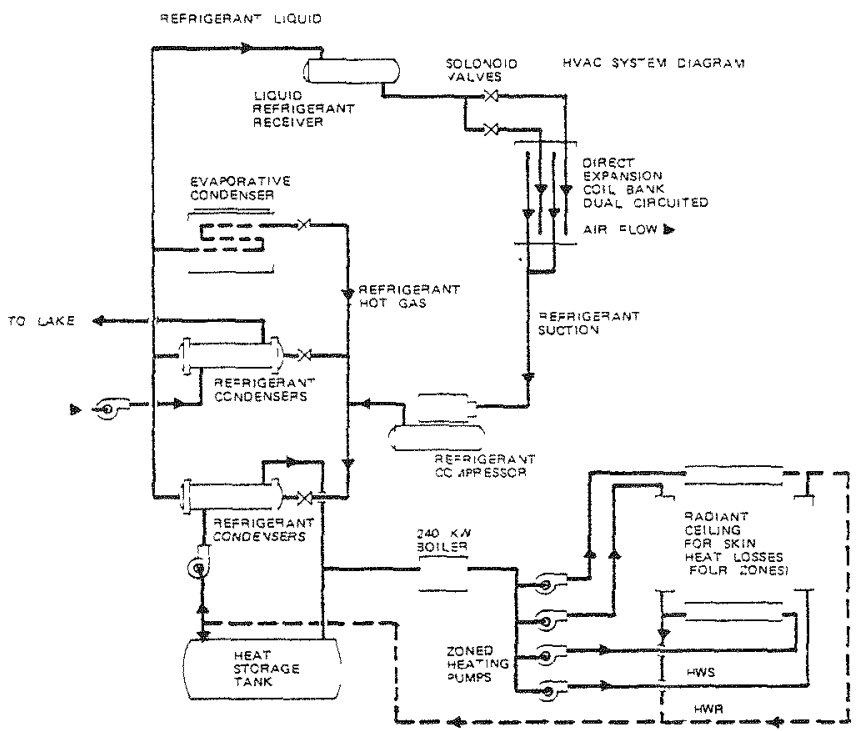

Fig. 12-4f. HVAC schematic, redesign building, Denver

Table 12-4. AIA/RC STUDY: COMPARISON OF DESIGNED ENERGY PERPORMANCE, DRSIGN ENERGY CONSUMPTION, AND DESIGN ENERGY BUDGET FOR THE DENVER OFFICE BUILDING

\begin{tabular}{|c|c|c|c|}
\hline & DEPa & $\mathrm{DEC}^{\mathrm{b}}$ & $\mathrm{DEB}^{\mathrm{C}}$ \\
\hline \multicolumn{4}{|c|}{ DEO1 Original Building } \\
\hline Electric & 49.4 & 152.2 & 109 \\
\hline Natural Gas & 53.4 & 137.0 & 109 \\
\hline \multicolumn{4}{|c|}{ DE10 ASHRAE 90-75R Upgrade and Downgrade } \\
\hline \multicolumn{4}{|c|}{ Modification of DEOL } \\
\hline Electric & 31.9 & 98.3 & 109 \\
\hline Natural Gas & 34.9 & 86.8 & 109 \\
\hline \multicolumn{4}{|c|}{ DE15 ASHRAE 90-75R Upgrade only } \\
\hline \multicolumn{4}{|c|}{ Modification of DEOI } \\
\hline Electric & 27.7 & 85.3 & 109 \\
\hline Natural Gas & 30.1 & 75.8 & 109 \\
\hline \multicolumn{4}{|c|}{ DE25 Redesign of DE01 (with corrected data) } \\
\hline Electric & 26.5 & 81.6 & 109 \\
\hline Natural Gas & 29.0 & 72.0 & 109 \\
\hline \multicolumn{4}{|c|}{ DE30 Redesign (DE25) plus 3 zone daylighting } \\
\hline Electric & 24.5 & 75.5 & 109 \\
\hline Natural Gas & 27.2 & 65.2 & 109 \\
\hline \multicolumn{4}{|c|}{$\begin{array}{l}\text { DE54 Redesign (DE25) plus dimming daylighting } \\
\text { (DE31), deadband thermostat (DE40), and hot } \\
\text { water storage (DE45) }\end{array}$} \\
\hline Electric & 20.4 & 62.7 & 109 \\
\hline Natural Gas & 22.4 & 54.7 & 109 \\
\hline
\end{tabular}

a Designed Energy Performance in thousands of Btu/gross sq $\mathrm{ft} / \mathrm{yr}$ measured at the building line.

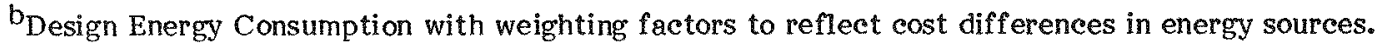

CDesign Energy Budget from NOPR, November 1979 (proposed BEPS).

"Electric" stands for an all-electric building.

"Natural Gas" stands for natural gas for DHW and space heating; the rest of the building is electric.

Note: Natural gas efficiencies of the appliances were determined by the design teams and differed for each building. The efficiency used for the Denver building was $70 \%$. 


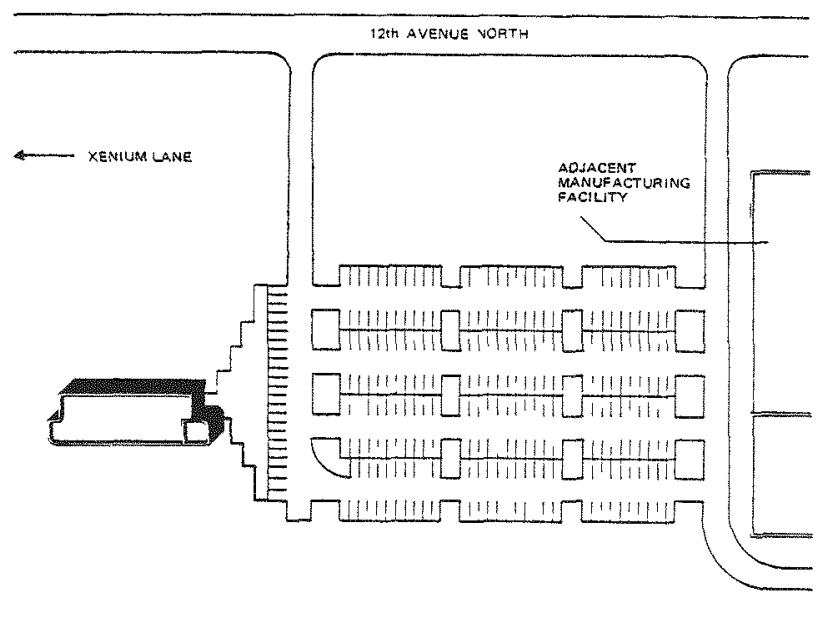

YN

Fig. 12-5a. Site plan, original building, Minneapolis

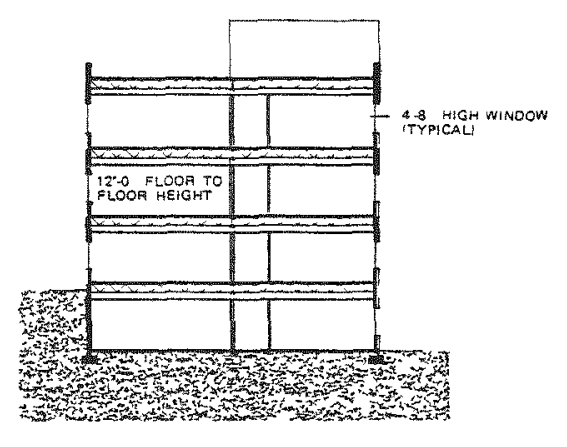

Fig. 12-5d. North-south section, original building, Minneapolis

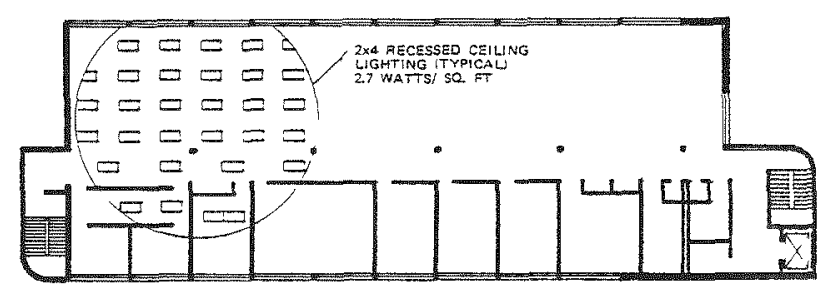

Fig. 12-5e. Typical lighting layout, original building, Minneapolis

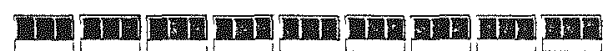

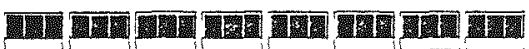

Fig. 12-5b. South elevation, original building, Minneapolis
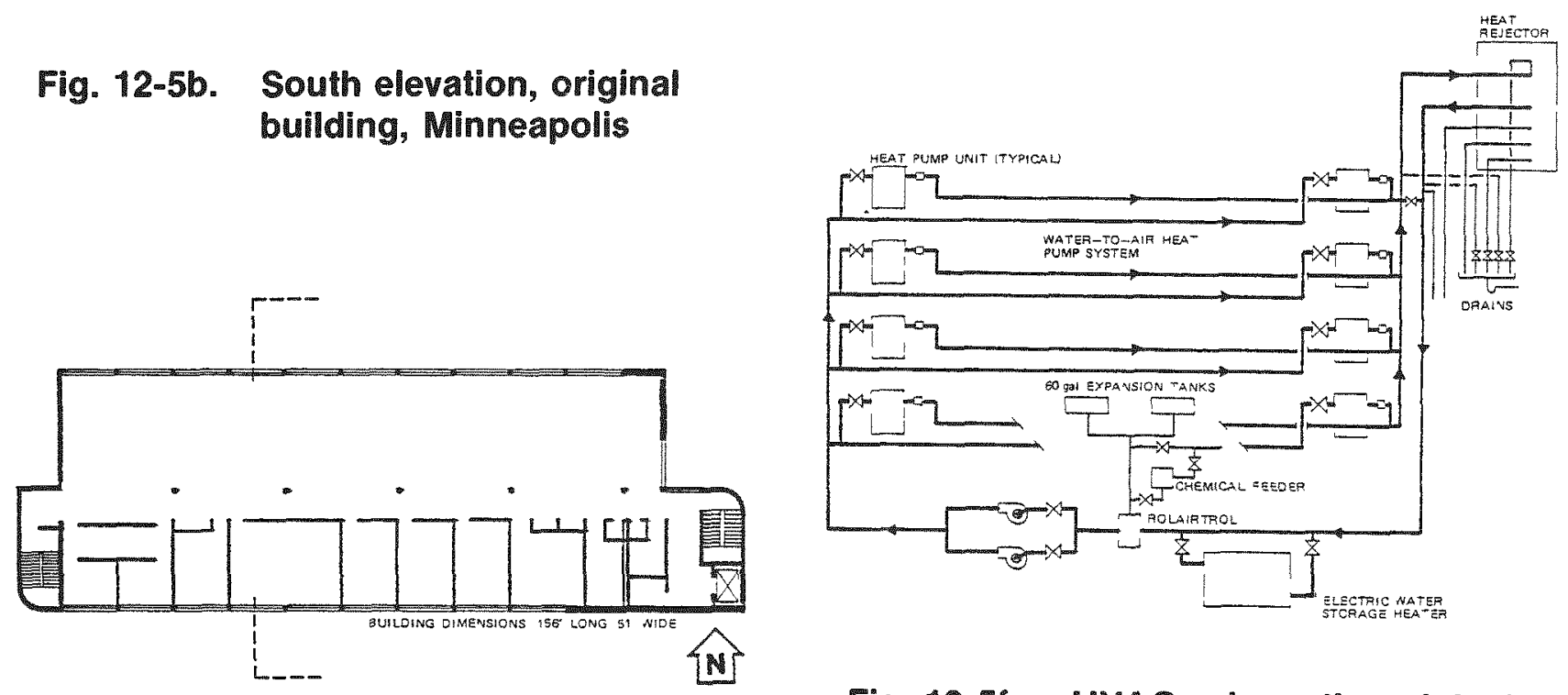

Fig. 12-5f. HVAC schematic, original

Fig. 12-5c. Typical floor plan, original building, Minneapolis building, Minneapolis 


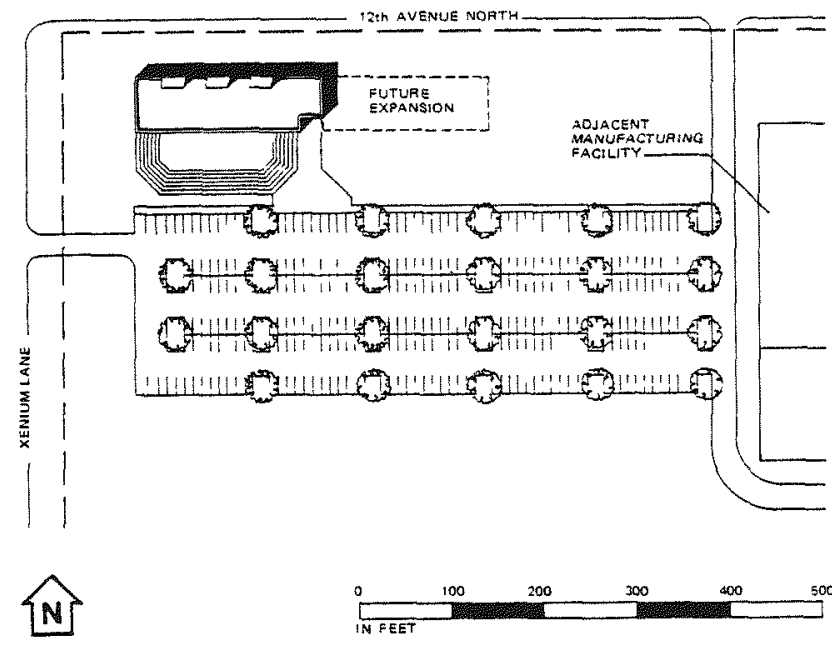

Fig. 12-6a. Site plan, redesign building, Minneapolis

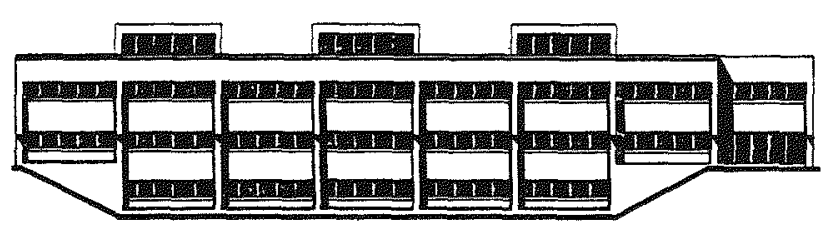

Fig. 12-6b. South elevation, redesign building, Minneapolis

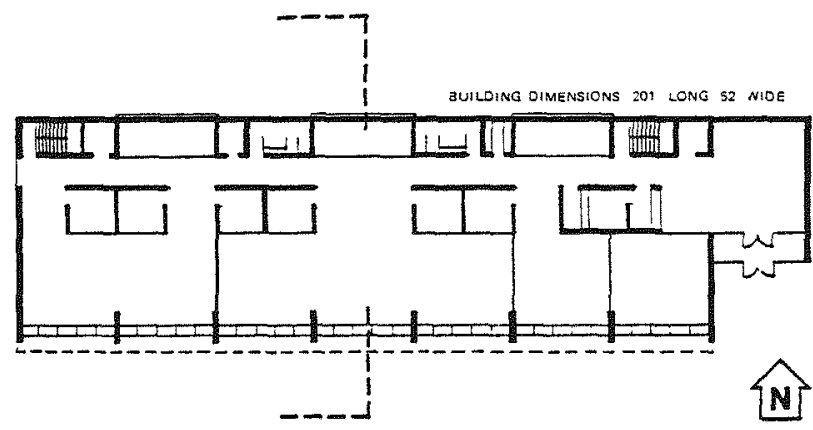

Fig. 12-6c. Typical floor plan, redesign building, Minneapolis

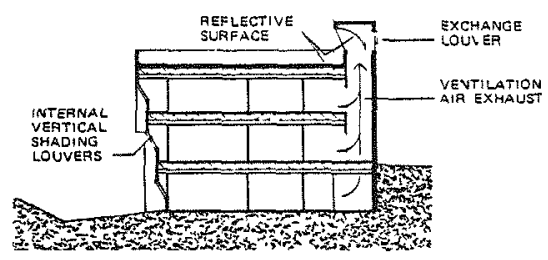

Fig. 12-6d. North-south section, redesign building, Minneapolis

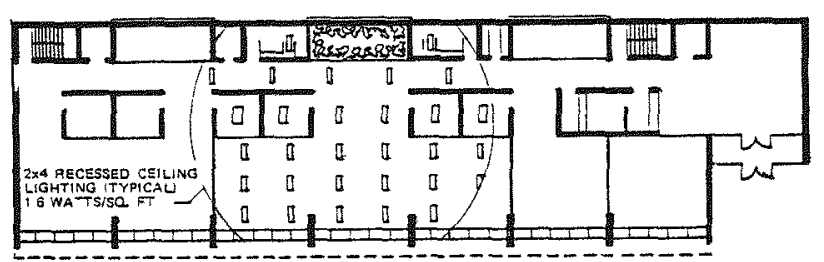

Fig. 12-6e. Typical lighting layout, redesign building, Minneapolis 
Table 12-5. AIA/RC STUDY: COMPARISON OF DESIGNED ENERGY PERFORMANCE, DESIGN ENERGY CONSUMPTION, AND DESIGN ENERGY BUDGET FOR THE MINNEAPOLIS OFFICE BUILDING

\begin{tabular}{|c|c|c|c|}
\hline & DEPa & $\mathrm{DEC}^{\mathrm{b}}$ & $\mathrm{DEB}^{\mathrm{c}}$ \\
\hline \multicolumn{4}{|c|}{ MN01 Original Building } \\
\hline Electric & 70.1 & 215.8 & 117 \\
\hline Natural Gas & 85.1 & 199.5 & 117 \\
\hline \multicolumn{4}{|c|}{ MN10 ASHRAE 90-75R Upgrade and Downgrade } \\
\hline \multicolumn{4}{|c|}{ Modification of MNO1 } \\
\hline Electric & 59.8 & 184.2 & 117 \\
\hline Natural Gas & 77.3 & 165.3 & 117 \\
\hline \multicolumn{4}{|c|}{ MN15 ASHRAE 90-75R Upgrade only } \\
\hline \multicolumn{4}{|c|}{ Modification of MNOI } \\
\hline Electric & 51.9 & 159.8 & 117 \\
\hline Natural Gas & 69.3 & 141.1 & 117 \\
\hline \multicolumn{4}{|c|}{ MN25 Redesign of MN01 (with corrected data) } \\
\hline Electric & 40.1 & 123.4 & 117 \\
\hline Natural Gas & 49.7 & 113.1 & 117 \\
\hline \multicolumn{4}{|c|}{$\begin{array}{l}\text { MN50 Redesign (MN25) plus zoned daylighting } \\
\text { (MN30) and deadband thermostat (MN40) }\end{array}$} \\
\hline Electric & 35.6 & 109.7 & 117 \\
\hline Natural Gas & 44.0 & 100.7 & 117 \\
\hline \multicolumn{4}{|c|}{$\begin{array}{l}\text { MN58 Redesign (MN25) plus zoned daylighting } \\
\text { (MN30), deadband thermostat (MN41), increased } \\
\text { insulation for internal heat balance (MN37), and } \\
\text { VAV/DX system (MN43) }\end{array}$} \\
\hline Electric & 25.3 & 77.9 & 117 \\
\hline Natural Gas & 28.4 & 74.6 & 117 \\
\hline
\end{tabular}

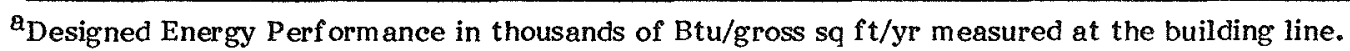

${ }^{b}$ Design Energy Consumption with weighting factors to reflect cost differences in energy sources.

${ }^{c^{C}}$ Design Energy Budget from NOPR, November 1979 (proposed BEPS).

"Electric" stands for an all-electric building.

"Natural Gas" stands for natural gas for DHW and space heating; the rest of the building is electric.

Note: Natural gas efficiencies of the appliances were determined by the design teams and differed for each building. The efficiency used for the Minneapolis building was $50 \%$. 


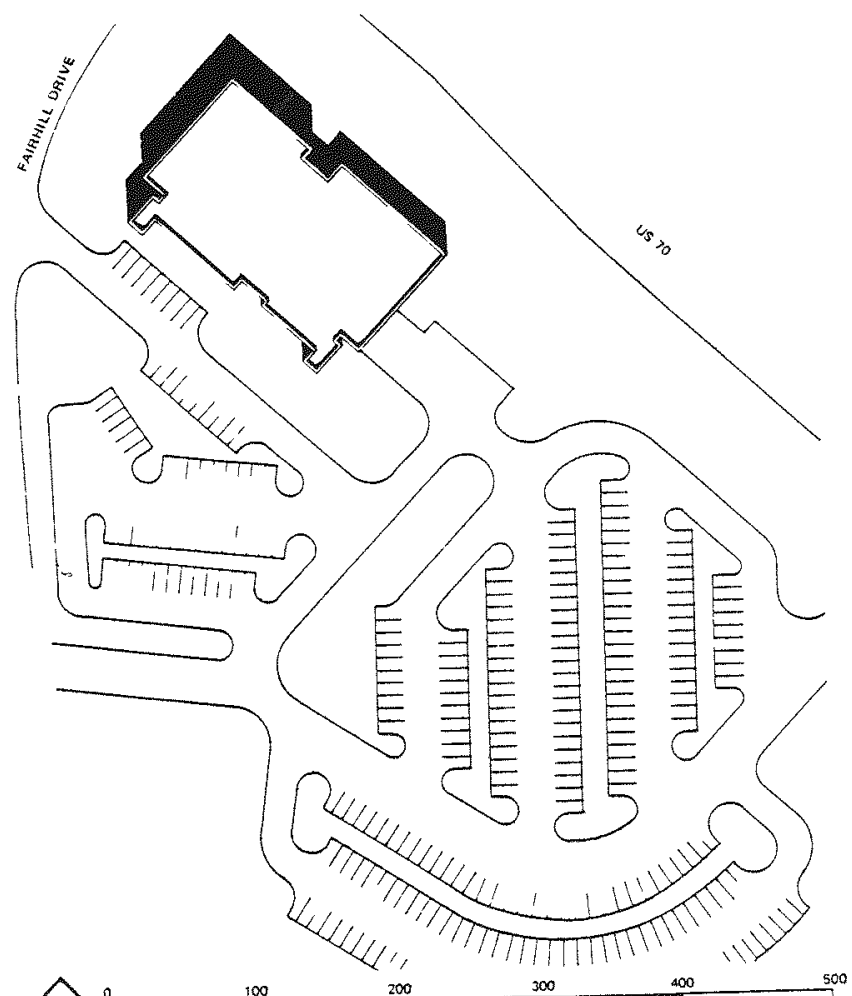

NO Fig. 12-7a. Site plan, original building,
Raleigh

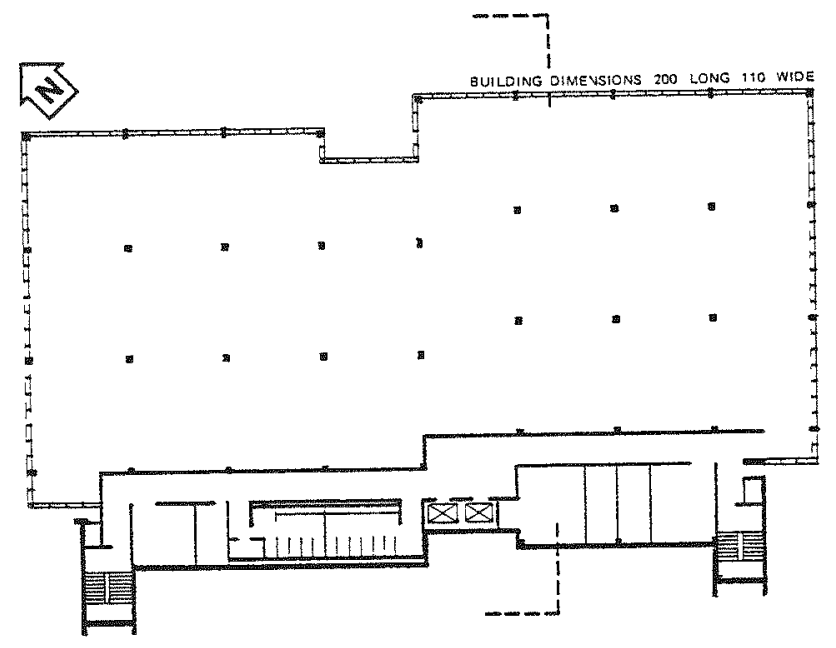

Fig. 12-7c. Typical floor plan, original building, Raleigh

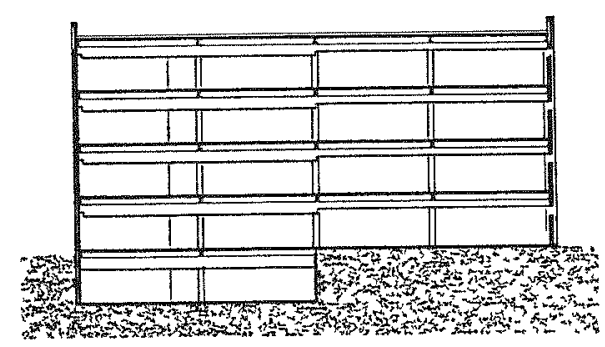

Fig. 12-7d. Northeast-southwest section, original building, Raleigh

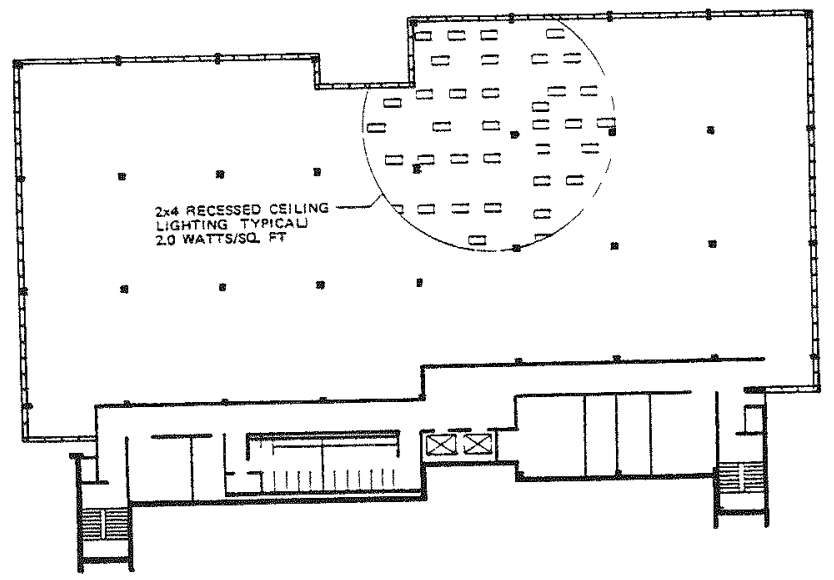

Fig. 12-7e. Typical lighting layout, original building, Raleigh 


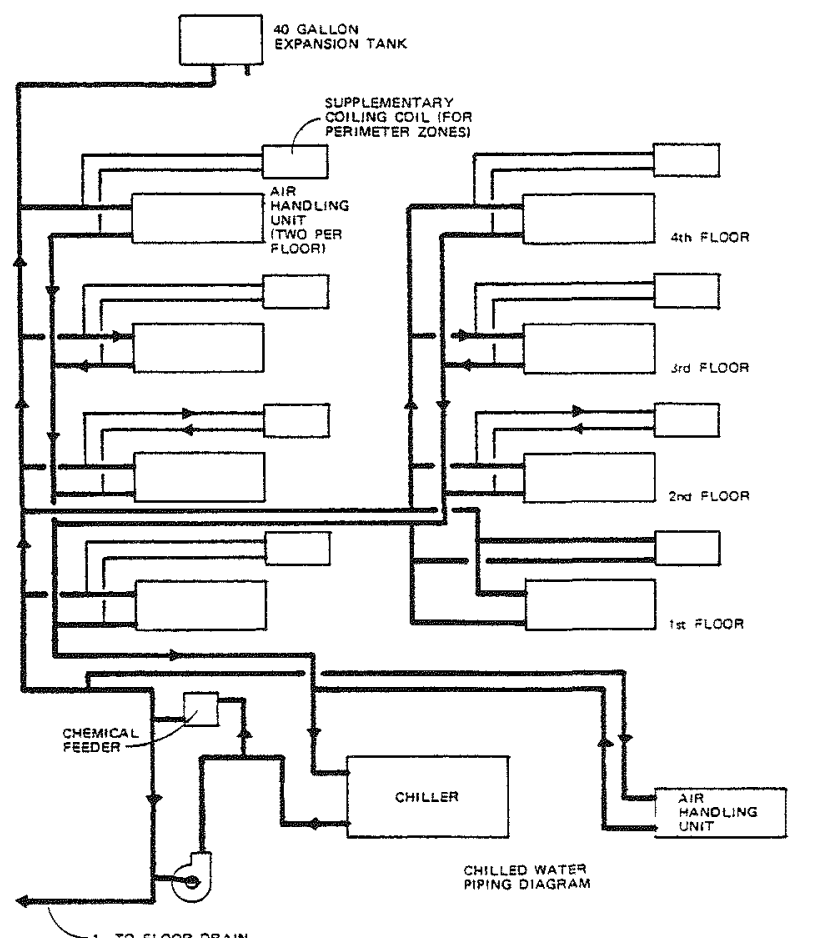

Fig. 12-7f. HVAC schematic, original building, Raleigh

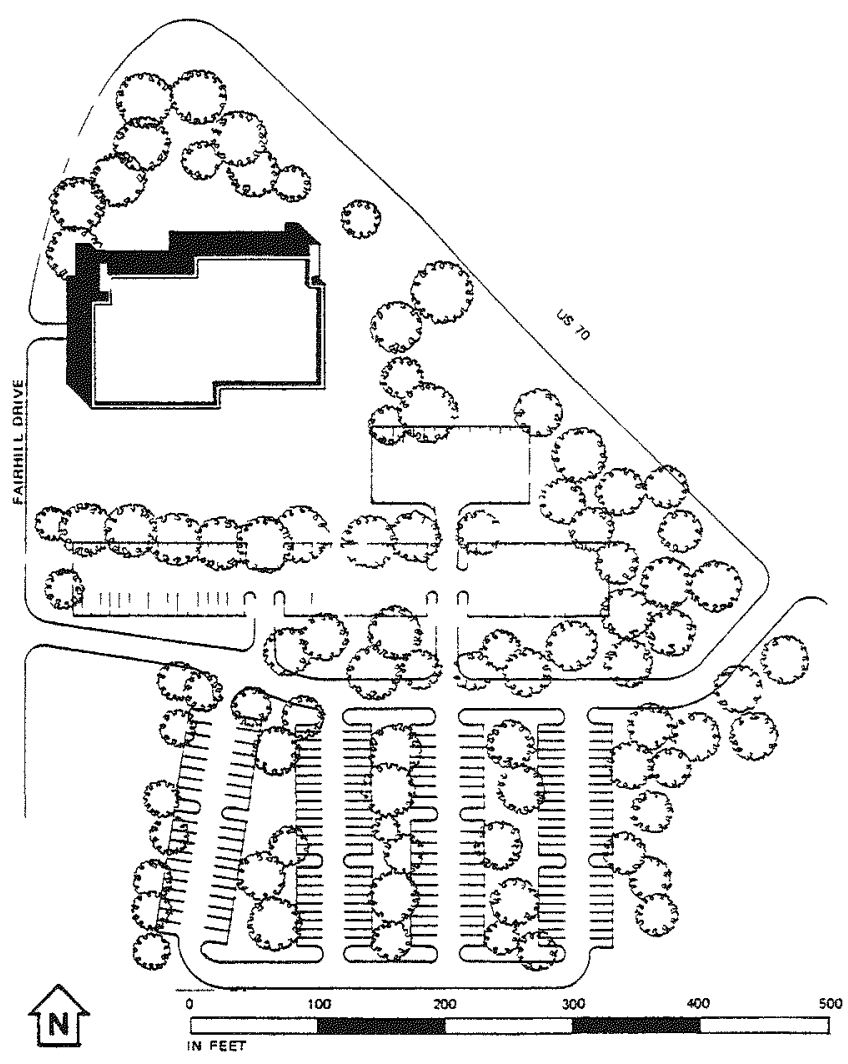

Fig. 12-8a. Site plan, redesign building, Raleigh

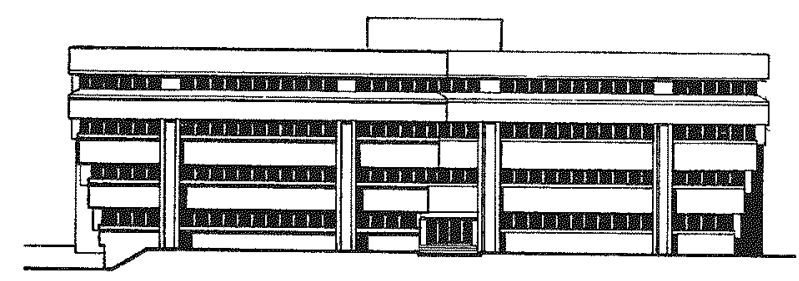

Fig. 12-8b. South elevation, redesign building, Raleigh

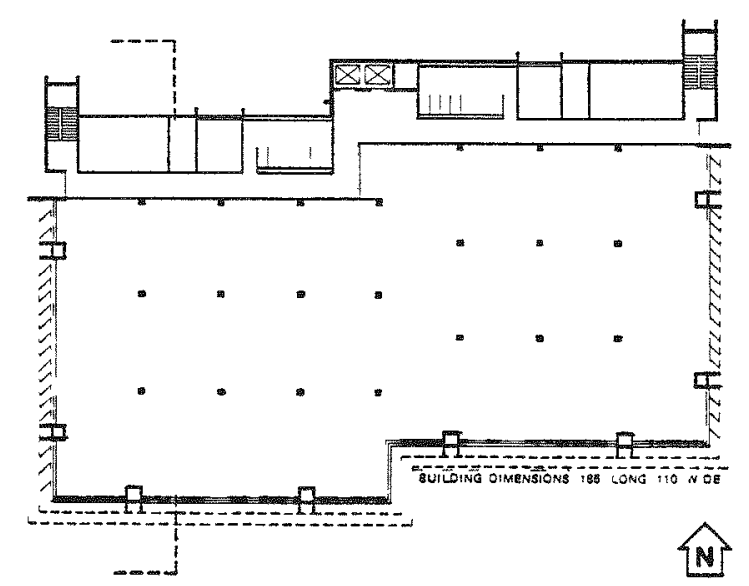

Fig. 12-8c. Typical floor plan, redesign building, Raleigh

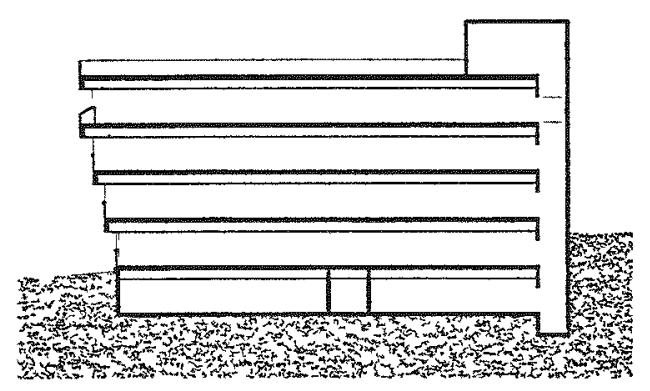

Fig. 12-8d. North-south section, redesign building, Raleigh 


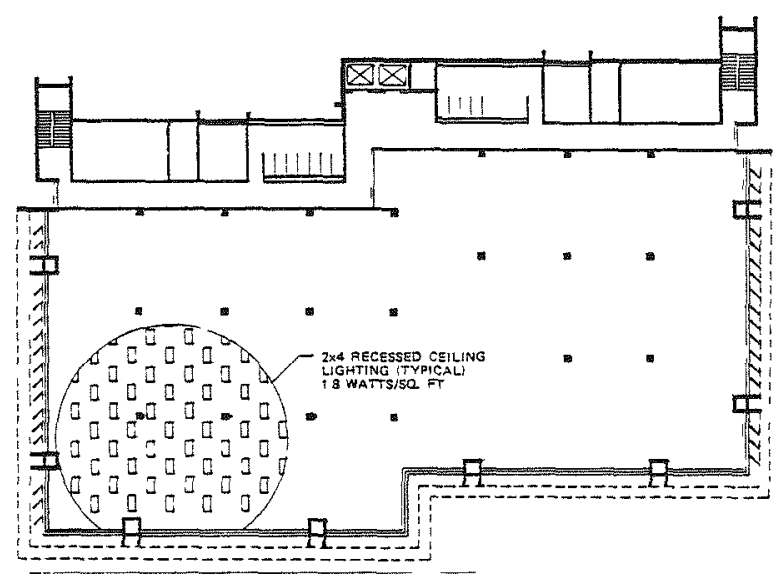

Fig. 12-8e. Typical lighting layout, redesign building, Raleigh

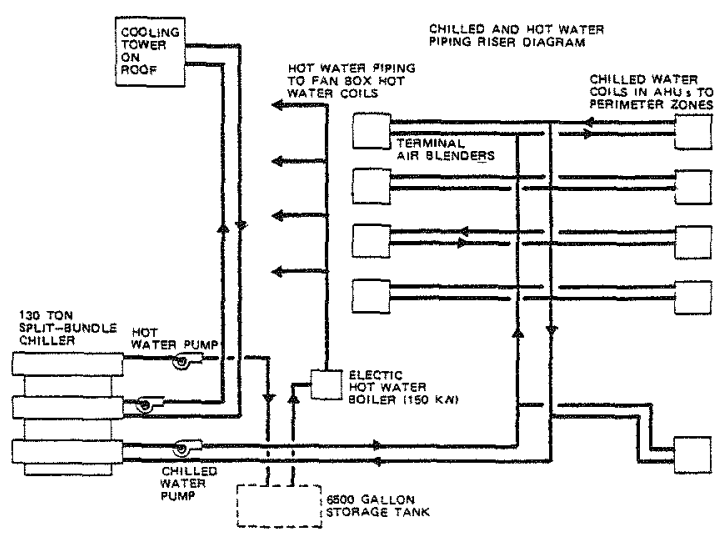

Fig. 12-8f. HVAC schematic, redesign building, Raleigh

Table 12-6. AIA/RC STUDY: COMPARISON OF DESIGNED ENERGY PERFORMANCE, DESIGN ENERGY CONSUMPTION, AND DFSIGN ENERGY BUDGET FOR THE RALEIGH OFFICE BUHDING

\begin{tabular}{|c|c|c|c|}
\hline & $\mathrm{DEP}^{\mathrm{a}}$ & $\mathrm{DEC}^{\mathrm{b}}$ & $\mathrm{DEB}^{\mathrm{C}}$ \\
\hline \multicolumn{4}{|c|}{ RA01 Original Building } \\
\hline Electric & 70.7 & 217.8 & 113 \\
\hline Natural Gas & 91.9 & 173.0 & 113 \\
\hline \multicolumn{4}{|c|}{ RA10 ASHRAE 90-75R Upgrade and Downgrade } \\
\hline \multicolumn{4}{|c|}{ Modification of RA0l } \\
\hline Electric & 50.2 & 154.5 & 113 \\
\hline Natural Gas & 56.3 & 141.5 & 113 \\
\hline \multicolumn{4}{|c|}{ RA15 ASHRAE 90-75R Upgrade only } \\
\hline \multicolumn{4}{|c|}{ Modification of RA01 } \\
\hline Electric & 32.6 & 100.5 & 113 \\
\hline Natural Gas & 36.1 & 93.0 & 113 \\
\hline \multicolumn{4}{|c|}{ RA25 Redesign of RA01 (with corrected data) } \\
\hline Electric & 30.0 & 92.5 & 113 \\
\hline Natural Gas & 36.1 & 88.6 & 113 \\
\hline \multicolumn{4}{|c|}{$\begin{array}{l}\text { RA50 Redesign (RA25) plus zoned daylighting } \\
\text { (RA30) and deadband thermostat (RA40) }\end{array}$} \\
\hline Electric & 26.2 & 80.8 & 113 \\
\hline Natural Gas & 27.8 & 75.0 & 113 \\
\hline \multicolumn{4}{|c|}{$\begin{array}{l}\text { RA105 New Concept Design (RA100) plus solar } \\
\text { assist for DHW and space heating (RA43) }\end{array}$} \\
\hline Electric & 22.8 & 70.2 & 113 \\
\hline Natural Gas & 25.3 & 64.9 & 113 \\
\hline
\end{tabular}

${ }^{a}$ Designed Energy Performance in thousands of Btu/gross $\mathrm{sg} \mathrm{ft} / \mathrm{yr}$ measured at the building line.

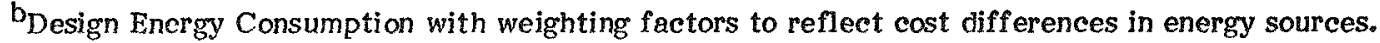

'Design Energy Budget from NOPR, November 1979 (proposed BEPS).

"Electric" stands for an all-electric building.

"Natural Gas" stands for natural gas for DHW and space heating; the rest of the building is electric.

Note: Natural gas efficiencies of the appliances were determined by the design teams and differed for each building. The efficiency used for the Raleigh building was $60 \%$. 

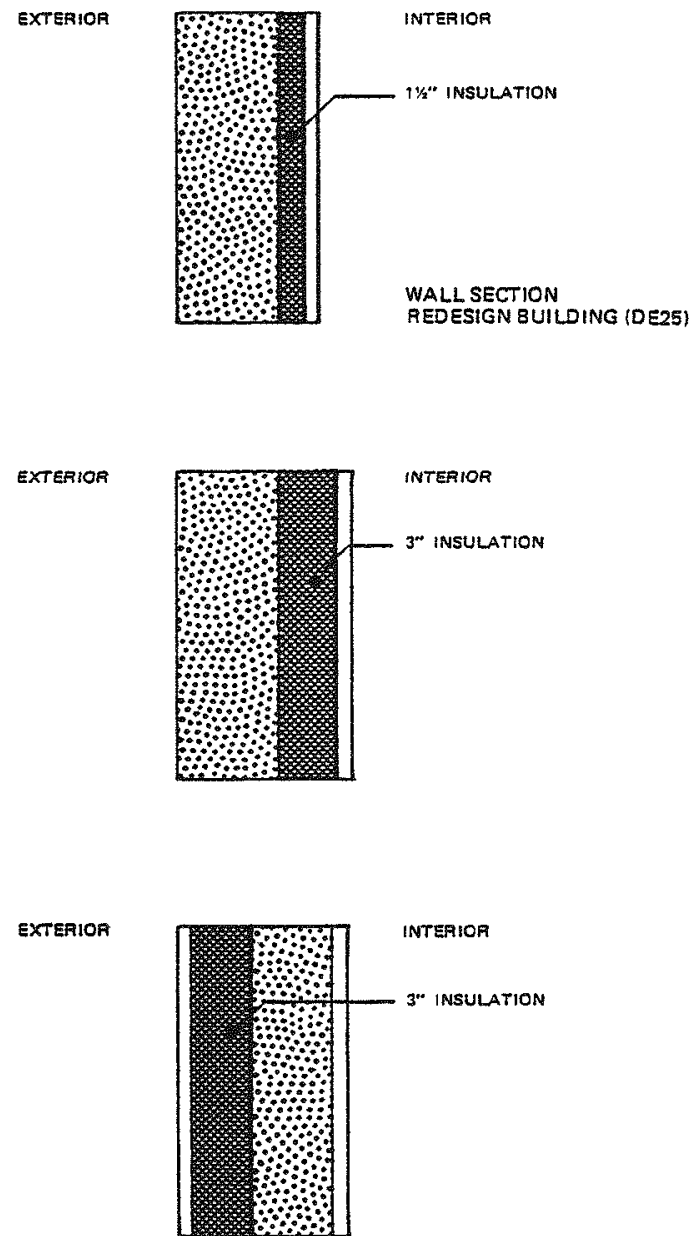

Fig. 12-9a. AIA/RC study-example options-wall sections showing insulation location and thickness, redesign building, Denver

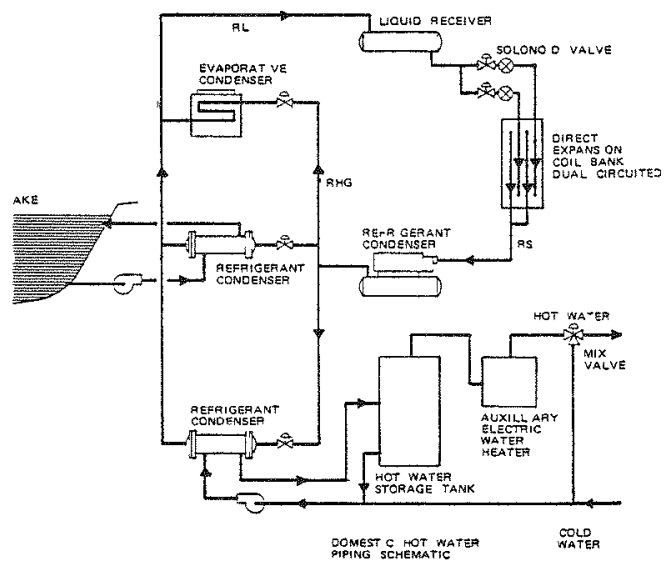

Fig. 12-9b. AlA/RC study-example option - HVAC schematic, DHW preheated by water-cooled condenser waste heat, redesign building, Denver

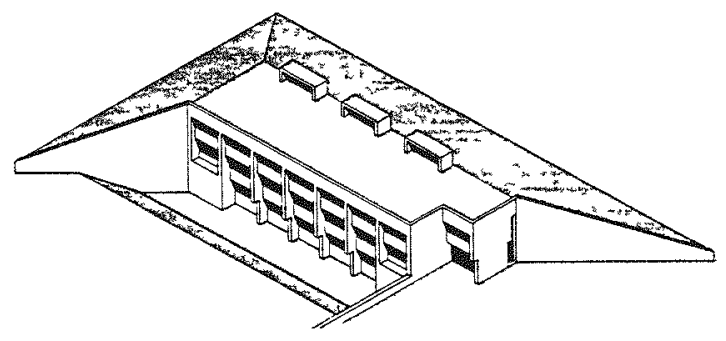

Fig. 12-10a. AlA/RC study-example option -axonometric, new concept design of three-story, concrete frame and partial earth shelter, Minneapolis

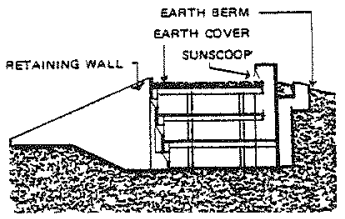

Fig. 12-10b. Building section 


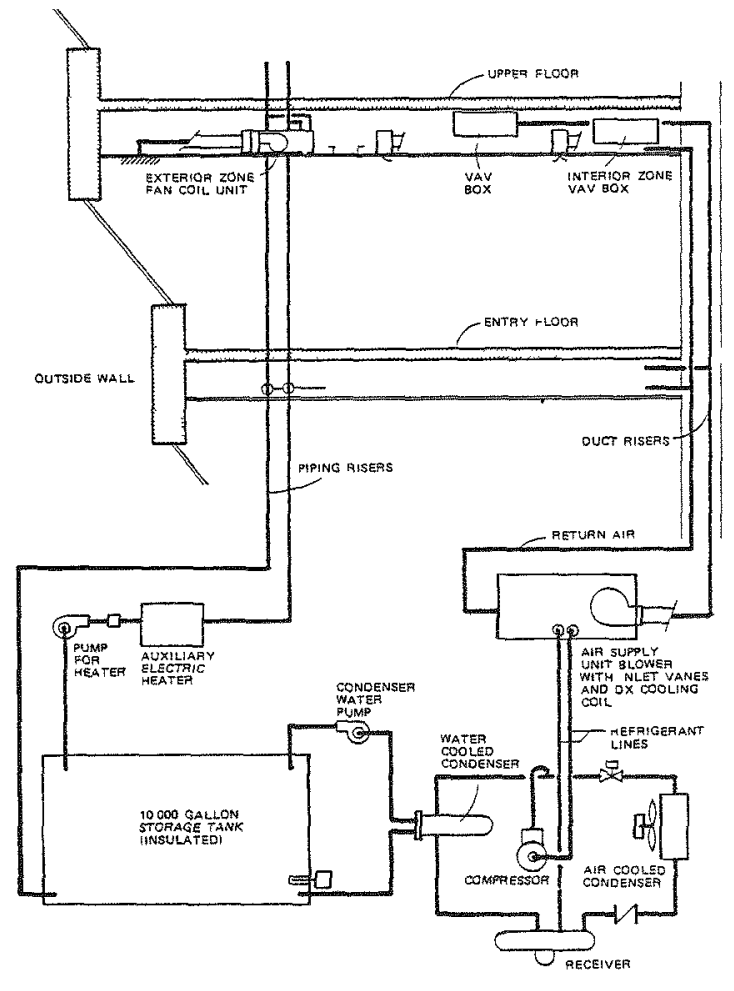

Fig. 12-10c. AlA/RC study-example option - HVAC schematic, VAV/DX system with dual, air and watercooled, condensers, redesign building, Minneapolis

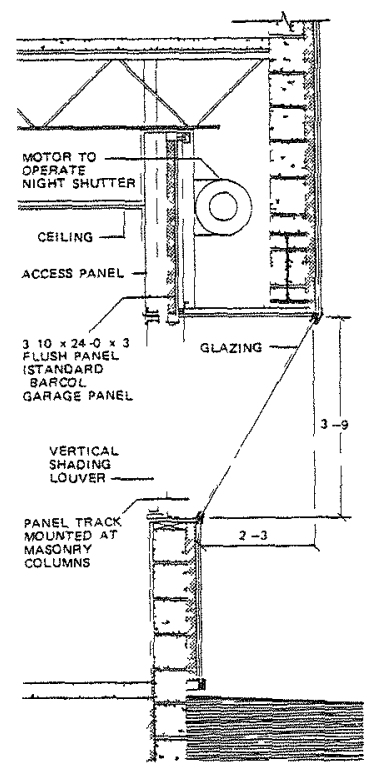

Fig. 12-10d. AlA/RC study-example option -wall section, night shutter window insulation, redesign building, Minneapolis

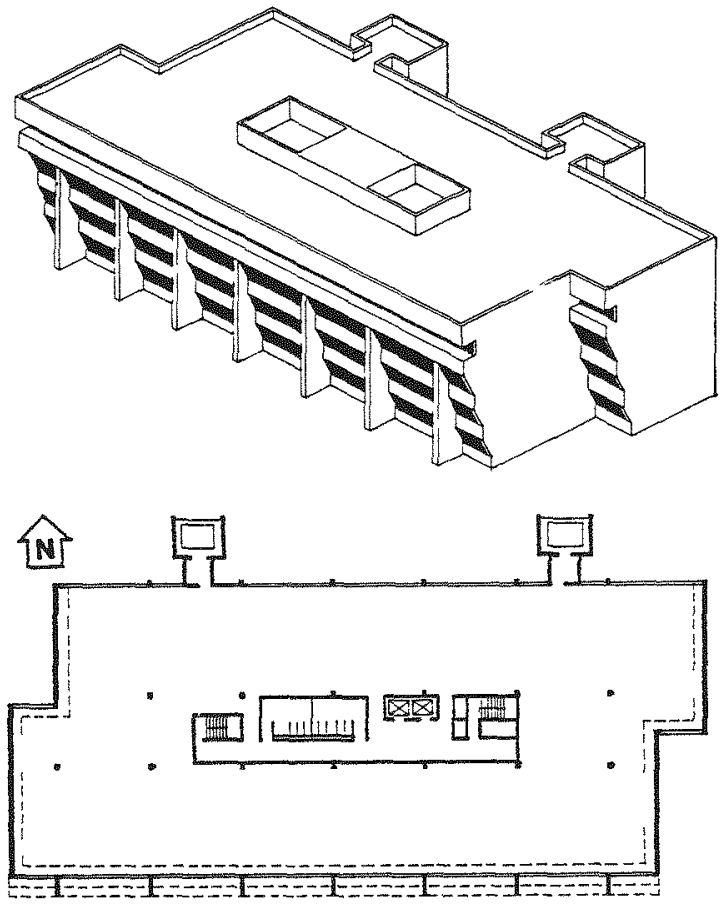

Fig. 12-11a. AlA/RC study-example option -axonometric and typical floor plan, new concept design, Raleigh

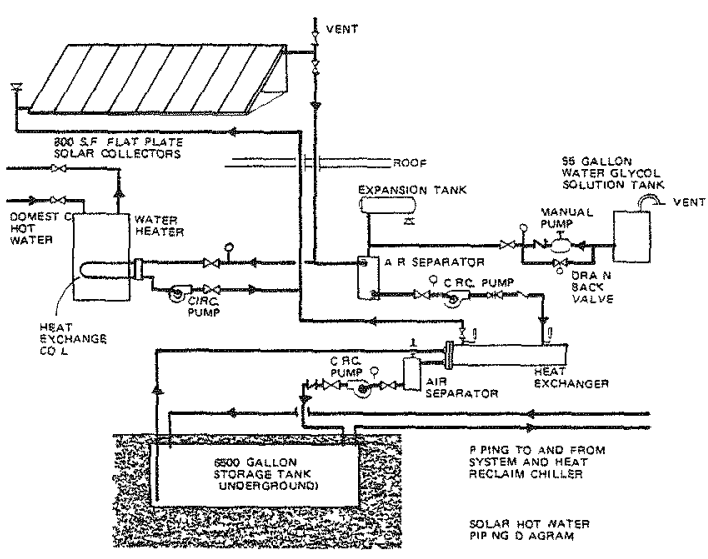

Fig. 12-11b. AlA/RC study-example option -schematic, solar assist for DHW and space heating, redesign building, Raleigh 


\section{Example Approach 3: Three-Dimensional Solutions}

To this point, it is apparent that considerable energy savings are possible in the design of commercial buildings. The present goal is to explore the range of possible solutions to educate and to help prepare you to define the tasks necessary for a design team to address. The architectural range of solutions has so far been limited to two-dimensional considerations. What possibilities are available to us if we give up the classical closed box and attempt to solve our energy problem with three-dim ensional architectural solutions?

A major philosophical shift must oceur in order for us to explore this option. Energy conservation must not be viewed as a mechanical, component, or facade problem and must now be addressed as an additional major architectural design element.

Alvar Aalto, Le Corbusier, and other great architects used daylighting for reasons other than energy efficiency. Natural light was used for quality reasons, to enhance the experience of the interior spaces. The changing movement and quality of sunlight give plasticity to interior spaces, as well as a psychological connection to the outside. The human eye has evolved as a response to sunlight, so sunlight is a very desirable illumination source. This does not mean the great masters of light were not solving an energy problem; it means they were prim arily solving a hum an need.

Approaching three-dimensional architectural solutions for energy efficient buildings requires a reinterpretation of building spatial requirements and human needs. As a design element, energy strategies must enhance the human experience by adding quality and function to the environment. Otherwise, the resulting solution will be an unacceptable compromise between energy requirements and hum an needs.

The separation of building design and energy strategies becomes very thin at this point. Now the architectural, structural, and mechanical expertise of the design team must truly mesh in order to find appropriate solutions. Few design teams have achieved this reguired level of communicative skills. It is no longer a matter of an architect doing architecture and the mechanical engineer providing suitable environmental systems. The job responsibilities will remain the same, but the request for information among the design team members will be greatly al tered.

Of greatest concern is the language barrier between the two key team professionals. Most engineers are amused by the term "space," and few architects consider a "Btu" to be relative to architectural design. Solar consultants may prove to be an effective transitional link for design teams, since they generally have background in both fields. We will address this problem in more detail later in this chapter. For now, let's look at two examples where this communication problem was overcome, and the resul ts proved delightfully interesting.
Figs. 12-12a through 12-12g show an office complex design for the Tennessee Valley Authority in downtown Chattanooga, Tennessee. The design team for the project is Caudill Rowlett Scott, architects (Sizemore/CRS, Bickle/CM); The Architects Collaborative, Ine., architects; Van der Ryn/Calthorpe \& Partners, architects; TVA Architectural Design Branch, architects; Syska \& Hennessey, Inc, engineers; Bolt, Beranek \& Newman, Inc, acoustics; Le Messurier/SCI, structural; William Lam Associates, Inc. lighting; Travis Price, energy. More information on this project can be found in the excellent article "Daylighting as a Central Determinant of Design" by Scott Matthews and Peter Calthorpe, AIA Journal, September 1979.

TVA instructed the design team to advance the state of the art in energy conscious building design while emphasizing the need for sensitivity to human needs, the urban context, and environmental quality. The results are an extremely good example of the synthesis of energy strategies with architectural and functional goals.

As an architectural solution, the design fulfills inportant goals such as maximum year-round use of exterior spaces (atriums), respect for the scale and character of the surrounding urban buildings, the provision for mixed-use spaces, a sensitivity to pedestrian scale and amenity, and respect for the sun rights of all neighbors by adhering to the concept of the solar envelope.

As an energy solution, the design architecturally stresses the same two "promising strategies" of the AIA/RC report. The building box has been broken into a series of narrow sections separated by atriums. The atriums act as a buffer zone, allowing the introduction of passive lighting, heating, and cooling strategies into a space which has greater comfort limits than the adjacent office sprees they serve. In effect, this zone is the architectural equivalent to a mechanical system "deadband" control strategy. All functions that could tolerate larger comfort limits are grouped into this area. The transfer of daylight from exterior to atrium to offices was one of the predominant design determinants.

The atrium solution allows the use of natural energy in a way that a box building cannot. The fluctuating intensity of natural energies makes them difficult to use on a box with holes or penetrations cut into it for direct application to offices. An atrium can be used to modulate these fluctuations or as a control device. The atrium also increases the potential to use more daylighting by greatly increasing the "perimeter" zone.

The SERI Permanent Facility Building is another good example of an attempt to synthesize energy strategies with architectural goals. This building is a case study in Chapter 18. Figs. $12-13 \mathrm{a}$ and 12-13b show the central nature of the atrium to the overall design. Once again, by breaking up the "box" a great number of opportunities are available to solve the three-dimensional energy needs of this building. 
Needless to say, the TVA and SERI designs were not developed by using "typical" design process or teaming arrangements. A commitment to explore energy issues by attacking the architectural box requires a reassessment of intent and process. The process-related tasks overviewed later in this chapter will explain one way this may be done.

These two examples are by no means the limits of threedimensional energy efficient architecture. Commercial buildings tend to have unique energy needs so "standard" al ternative solutions will probably not be possible. These solutions indicate the start of a search for new architectural forms that are humane, yet respectful of an energy-limited world. Added to the numerous other energy options, the inclusion of architectural considerations can only increase the likelihood of finding new, appropriate, built environment solutions.

How far can we go in the reinterpretation of architecture that serves our needs? What other range of solutions exists?

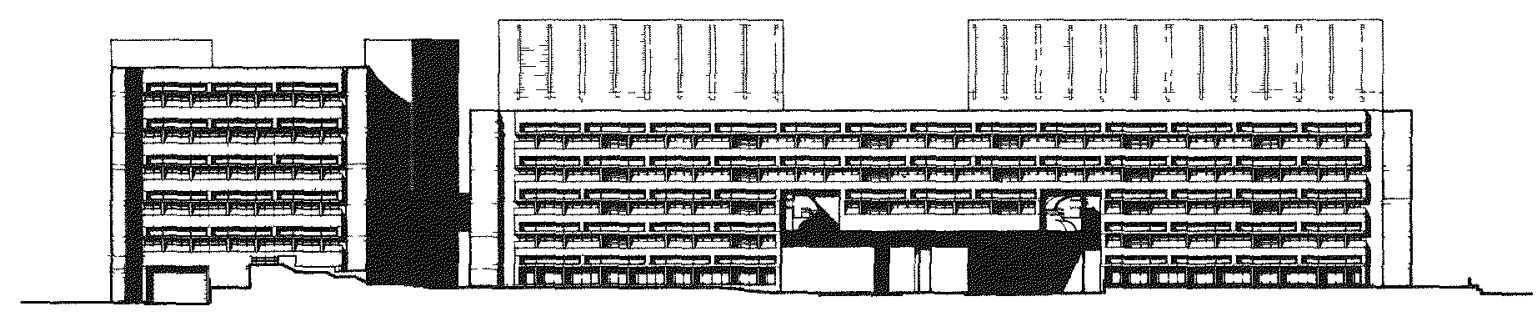

Fig. 12-12a. TVA building, south elevation (courtesy of TVA)

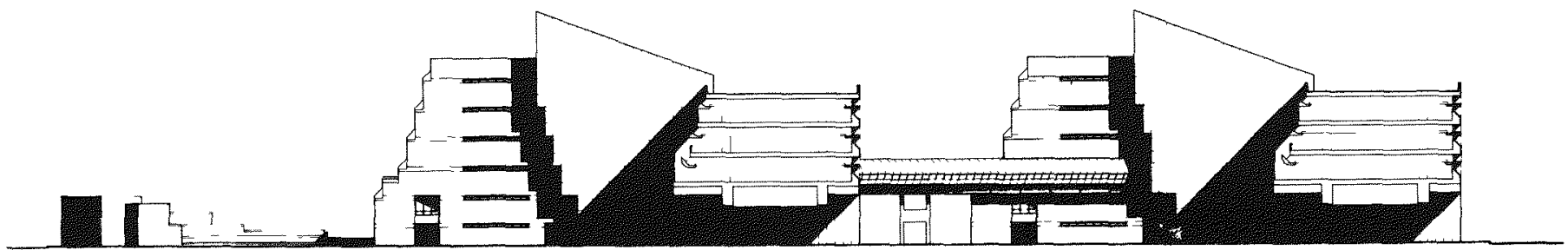

Fig. 12-12b. TVA building, Broad street elevation (courtesy of TVA) 


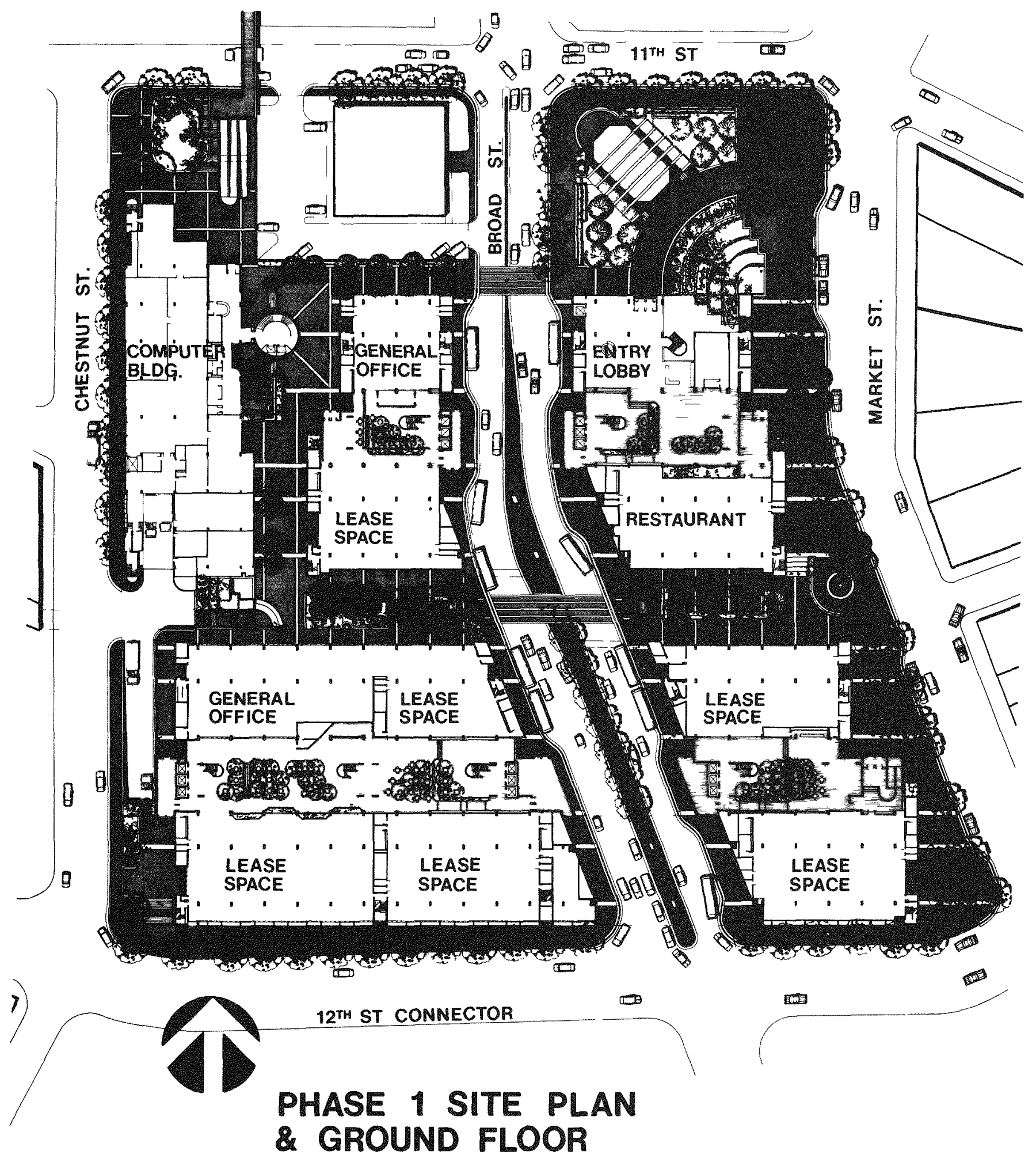

Fig. 12-12c. TVA building (courtesy of TVA) 


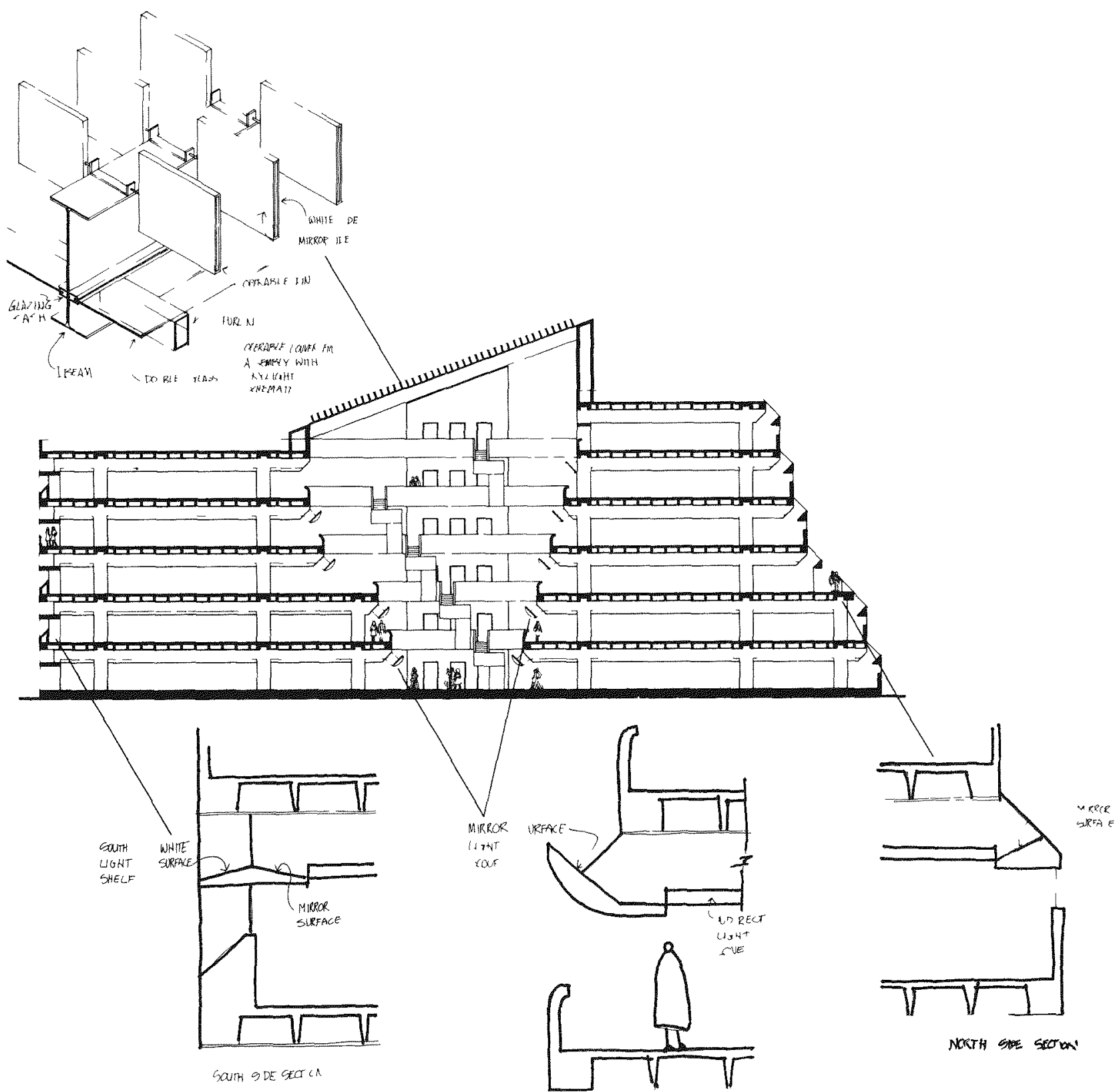

ATRIUM SECTION

Fig. 12-12d. TVA building section and day lighting details (courtesy of Van der Ryn/Calthorpe) 


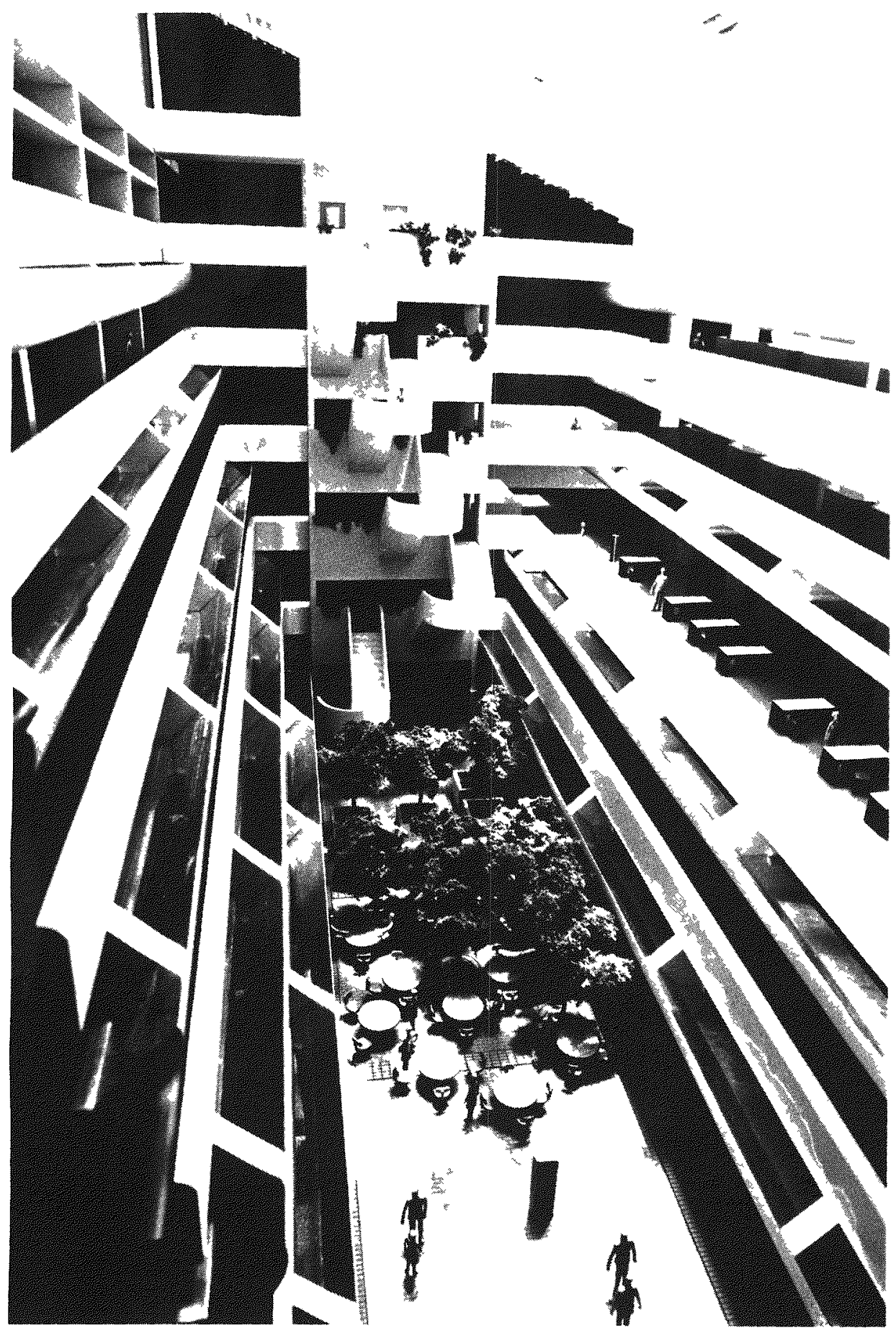

Fig. 12-12e. TVA building atrium (courtesy of TVA) 


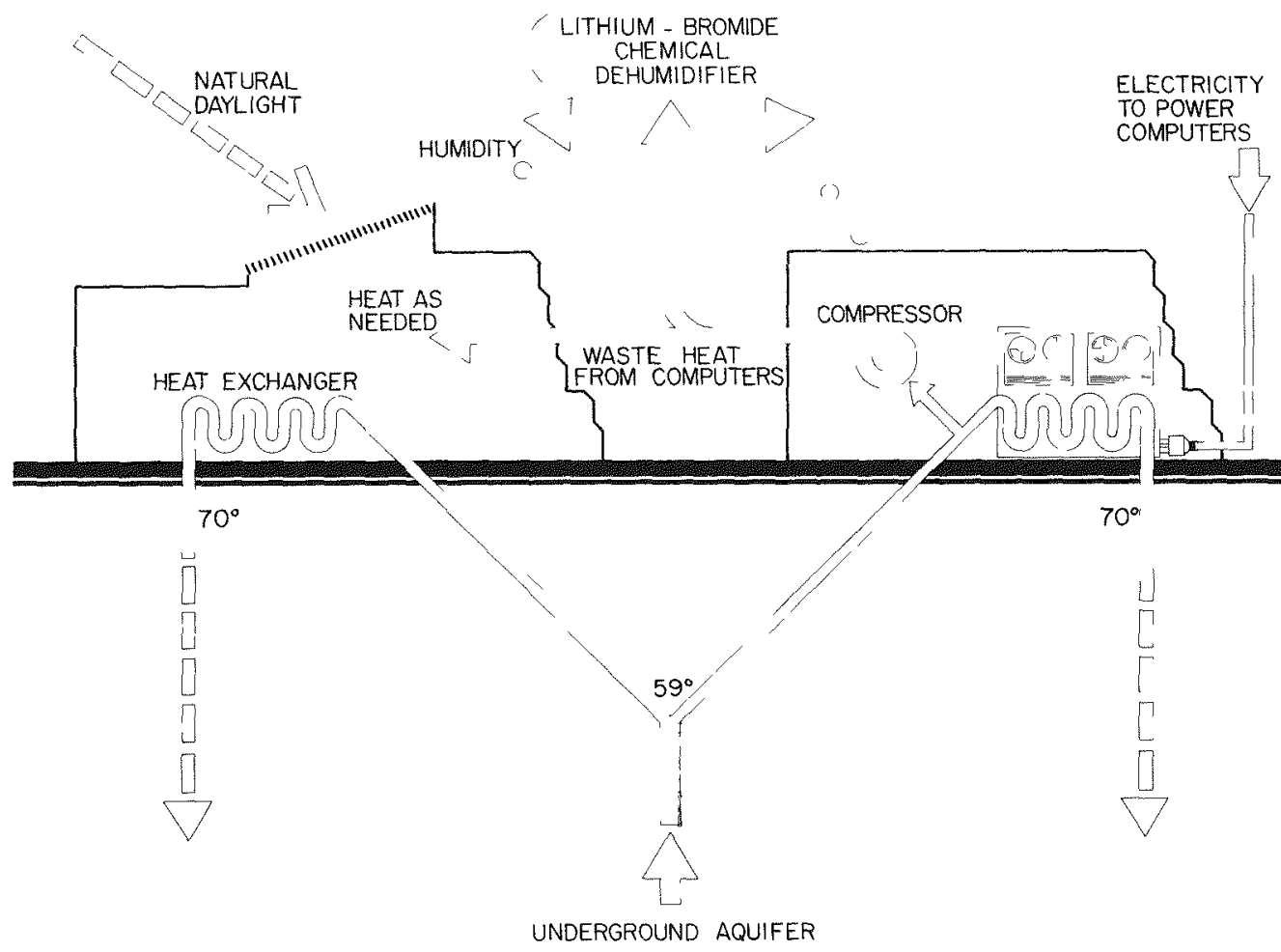

Fig. 12-12f. TVA building groundwater cooling and chemical dehumidification (courtesy of TVA)

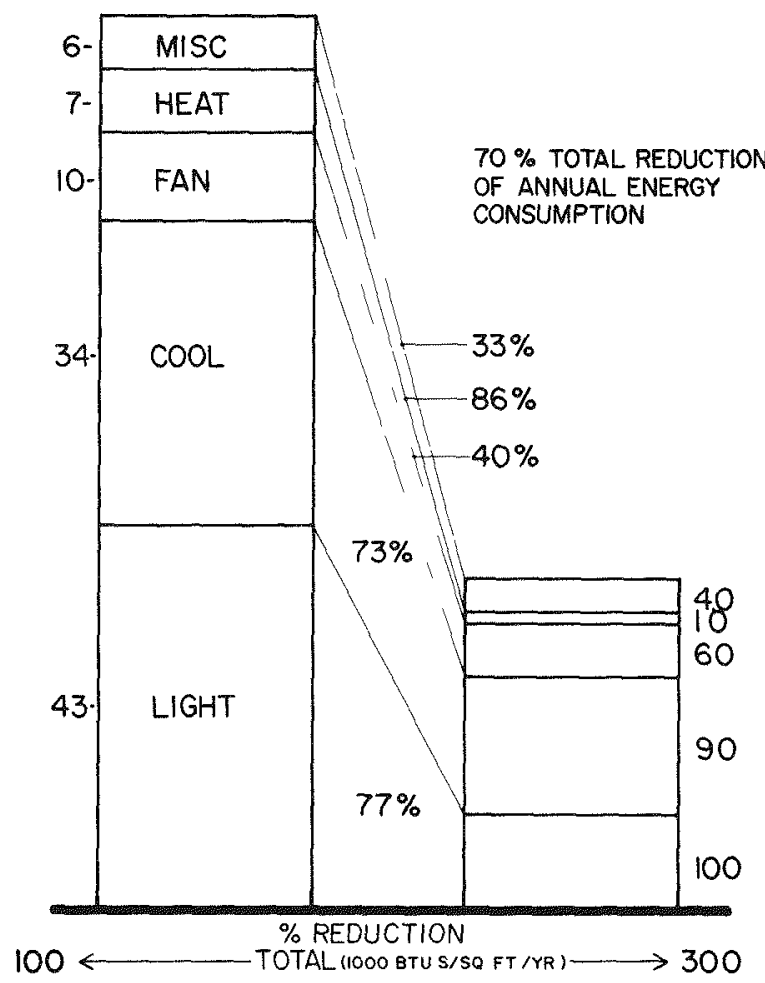

Fig. 12-12g. TVA building energy needs (courtesy of TVA) 


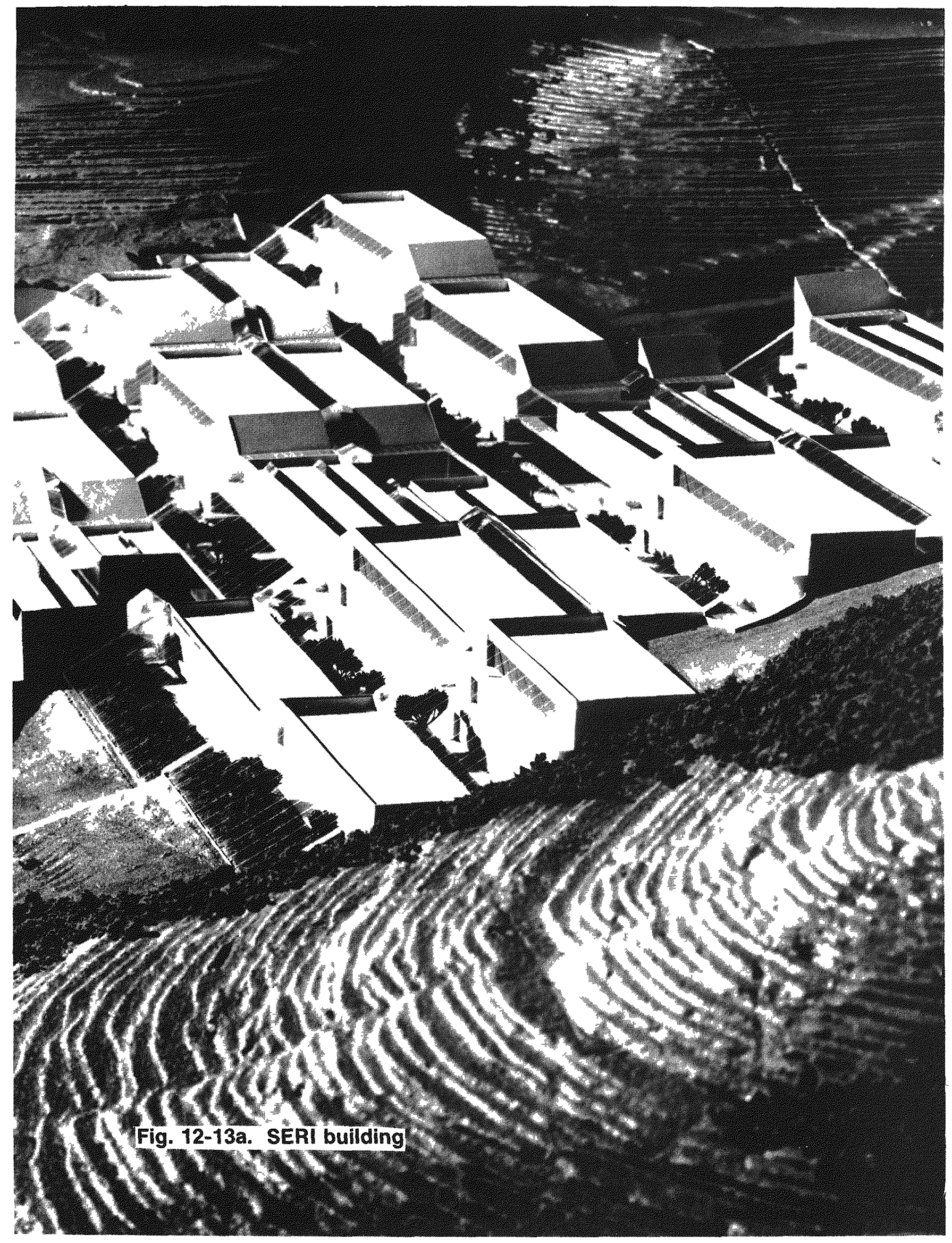


Typical Building Section

1 Light Court

2 Water Tanks

3 Black Attic (Interstitial)

4 Solar Court Ventilator

5 Trombe Wall

6 Labroatory

7 Interstitial

8 Laboratory Office

9 Walkway

10 Solar Court

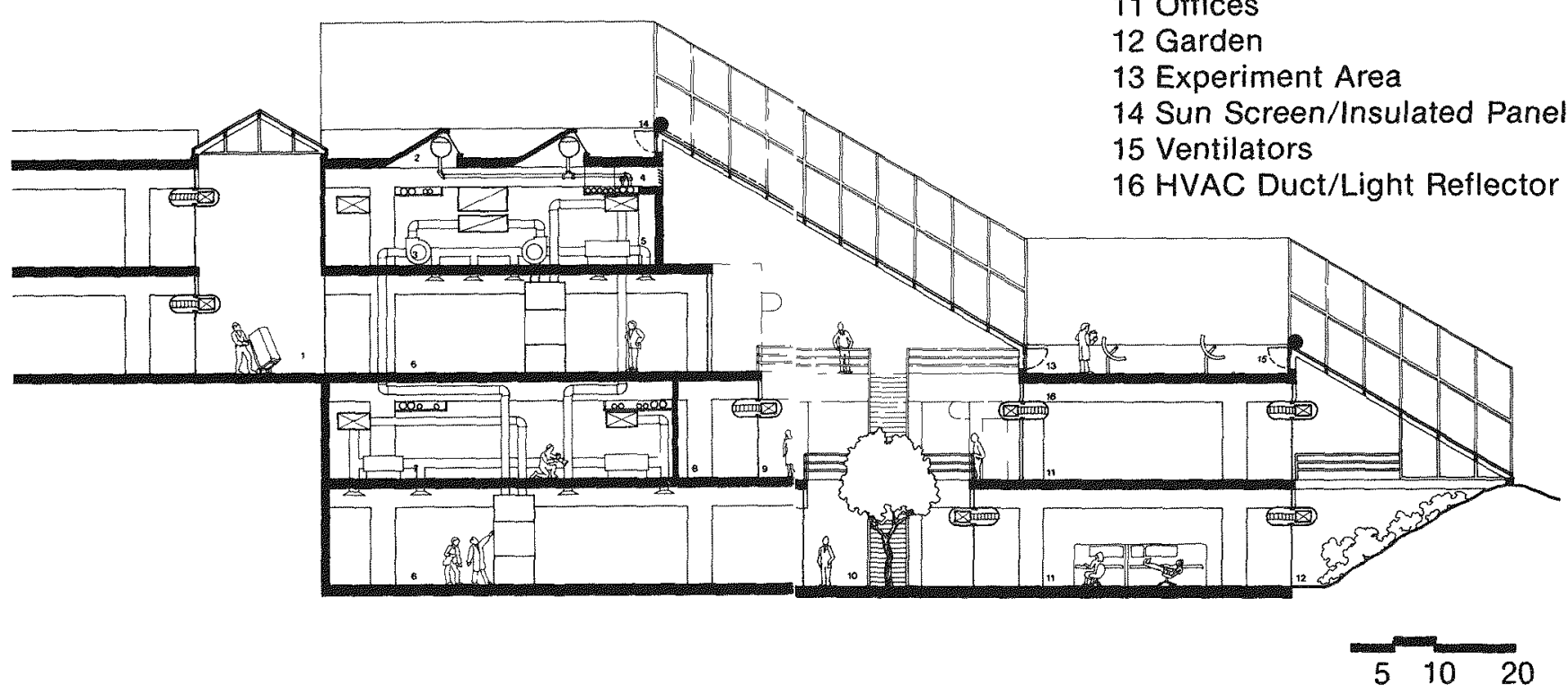

Fig. 12-13b. SERI building section 


\section{Example Approach 4: Unique Solutions}

The next level of possible solutions is presently undefinable. What will be the ultimate solutions to energy efficient architecture? With our new building materials and modern cultural needs, it is hard to believe that our future buildings will simply digress to historical solutions of past energy-limited societies. The existence of 4.5 billion people makes that all but impossible without accepting a very high mortality rate. It is also unlikely that our future needs can be met by improving an architecture that evolved through decades of energy overabundance. Therefore, our fourth example is presented to provoke thought, rather than to state an absolute additional range of solutions. The following scenario could be slanted many different ways; ours is but one of these.

The three-dimensional solutions aggressively attack the architectural box by breaking it into smaller pieces. The opportunities this strategy provided greatly increased the potential for natural energy usage. Conceptually, the intent was to make a load-dominated building skindominated. By increasing the amount of "perimeter," natural energies could be used to offset internal energy needs. As these needs were reduced, the larger perimeter began demanding more energy until the tradeoff between increased skin loads for reduced internal loads achieved an optimum balance. This approach assumed the classical box, but was not afraid to break it up. What would happen if there were no box?

If breaking the box by an atrium makes sense, what would happen if the box disappeared and the space became totally enclosed by the atrium? All the interior spaces would become free-form pavilions or small encapsulations within the atrium. The natural energy flows could then be brought into the "pavilions" from all directions, rather than from just one or two sides. Vertical and horizontal spatial distribution could then be adjusted within the atrium for maximum natural energy flows and functional reasons. The pavilions themselves need not be constructed of weather resistant materials and could be reformed easily as functional needs change. Spaces around the pavilions could be used for support and amenity needs which allow greater deadband comfort limits.

A very interesting theoretical study funded by the General Services Administration (GSA) in 1975 looked at such a scenario. The study, "Megastructure: A New Concept of Federal Office Building Design," had the following primary participants: Building Sciences, Inc.; Cambridge Seven Associates, Inc.; Davis Brody \& Associates; Weidlinger Associates; Geiger Berger Associates, P.C.; Cosentini Associates; and Tishman Research Corporation. Further information on this feasibility study can be obtained by contacting the General Services Administration, Public Buildings Service (PCD), Washington, D.C. 20405.

The study sought to provide a stimulating and pleasant working environment for federal employees. Of critical importance was the need for flexibility (government agencies tend to be constantly reorganizing, evolving, and changing in staff size) and to demonstrate significant energy savings. The design team responded to this challenge by developing a triple-layered, pneumatic, clear span roof that admits solar light and heat when desired, and reflects direct solar heat when conditions warrant. Within this enclosed space are "work platforms" which accommodate office functions. "Open" areas under the canopy are landscaped in a park setting and include small gardens, walkways, exhibit space, and other amenities. Figs. 12-14a through 12-14d exhibit the proposed design and some of the more interesting details.

The energy and architectural issues surrounding this study are very though provoking. Is the atrium engulfing the building the best solution? Will clients be satisfied with architecture that is inward focusing? Will future needs even allow us to build suburban office parks? How much of this solution is practical today, and what parts are dreams of the future? Is this project another attempt to conquer nature, or to join and work with her? Without sufficient supporting data, unique solutions currently must be classified as research.

\section{Summary}

The intent of the preceding four examples was to challenge your ideas on just what is the range of possible solutions for energy efficient buildings and to gain insight into how a design team must be organized in response to the options you decide to investigate. The examples are limited since they address only one building type and one point of view. The principles should apply to other building problems, and certainly, it should now be clear that individual design team members very likely have different ideas of "what is an energy efficient building." For this reason, as stated earlier in this section, it is critical for the project leader to establish from the very beginning what range of solutions will be investigated by the design team, and what procedure will be used to orchestrate the team members toward this common goal.

The amount of time available to the design team will greatly influence the range of solutions investigated. The minimum suggested effort is to maximize the efficiencies of all artificial comfort and illumination systems. Substantial energy savings are possible for modest investments in time.

Further investigations may be dependent on design team capabilities as well as time constraints. The application of active or passive strategies "to" the building may provide the next level of improvement. Breaking away from the base building box has much potential but will require additional time.

Once the design team leader determines the level of investigations or solutions he feels to be appropriate for a particular project, it remains to enumerate the tasks that will facilitate that end. The remainder of this chapter will overview a suggested procedure that can be modified according to the range of solutions you intend to investigate. 


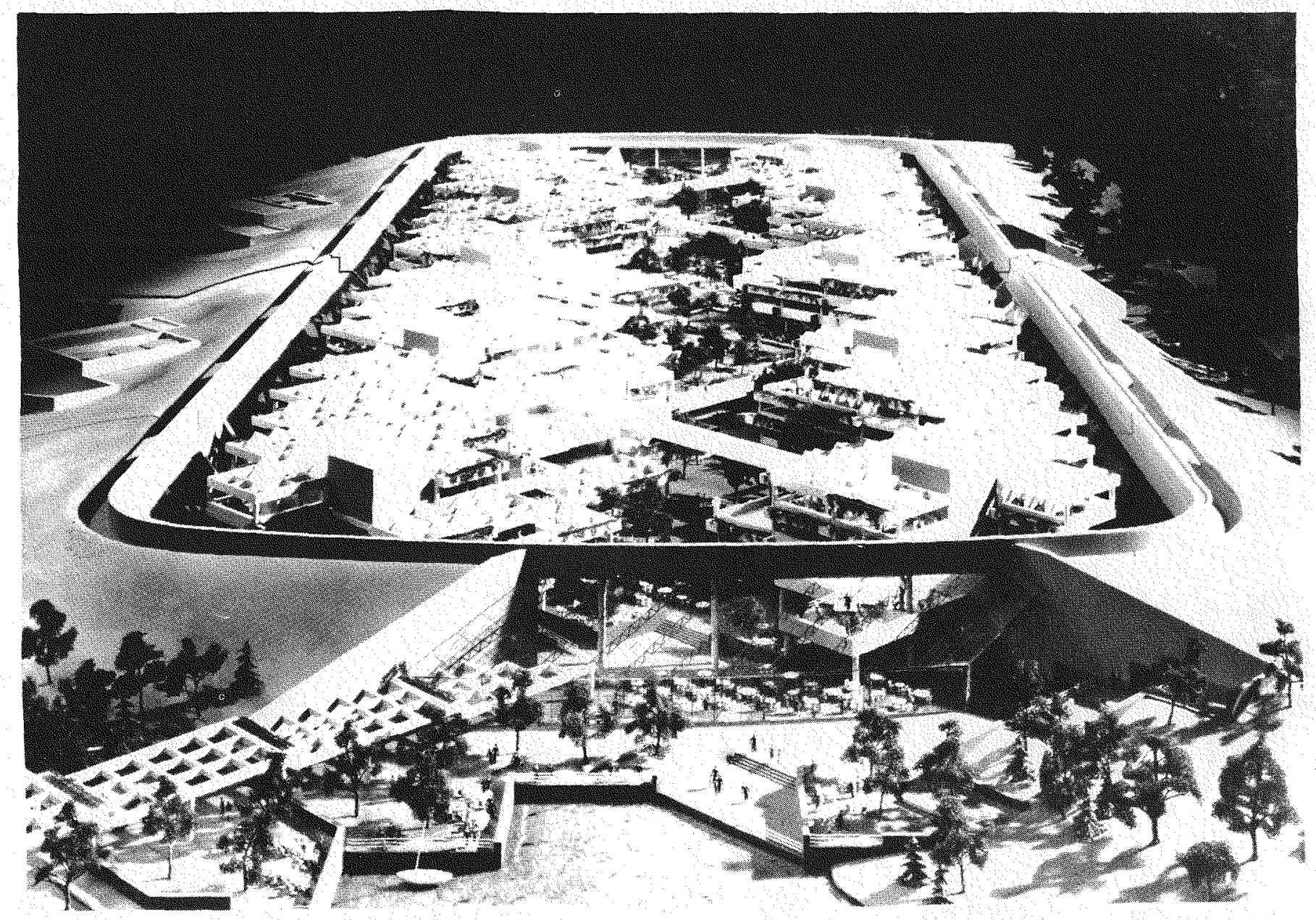

Fig. 12-14a. GSA megastructure model with the roof removed (courtesy of GSA) 


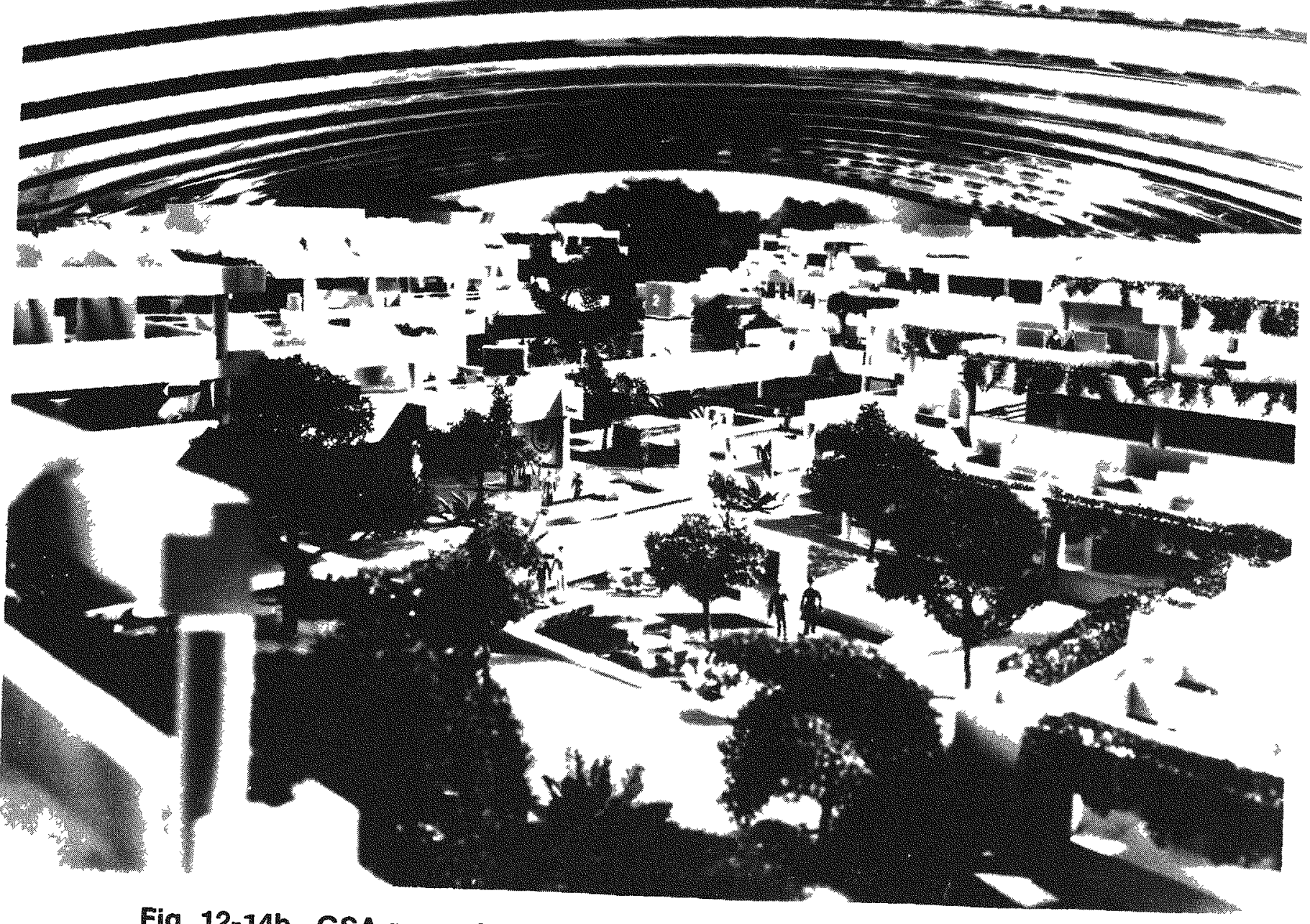

Fig. 12-14b. GSA megastructure interior (courtesy of GSA) 

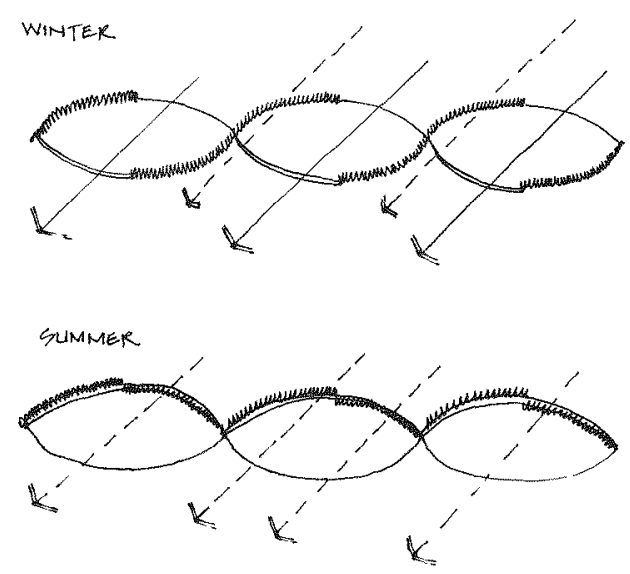

Fig. 12-14c. GSA megastructure 3-membrane roof operation (courtesy of GSA)

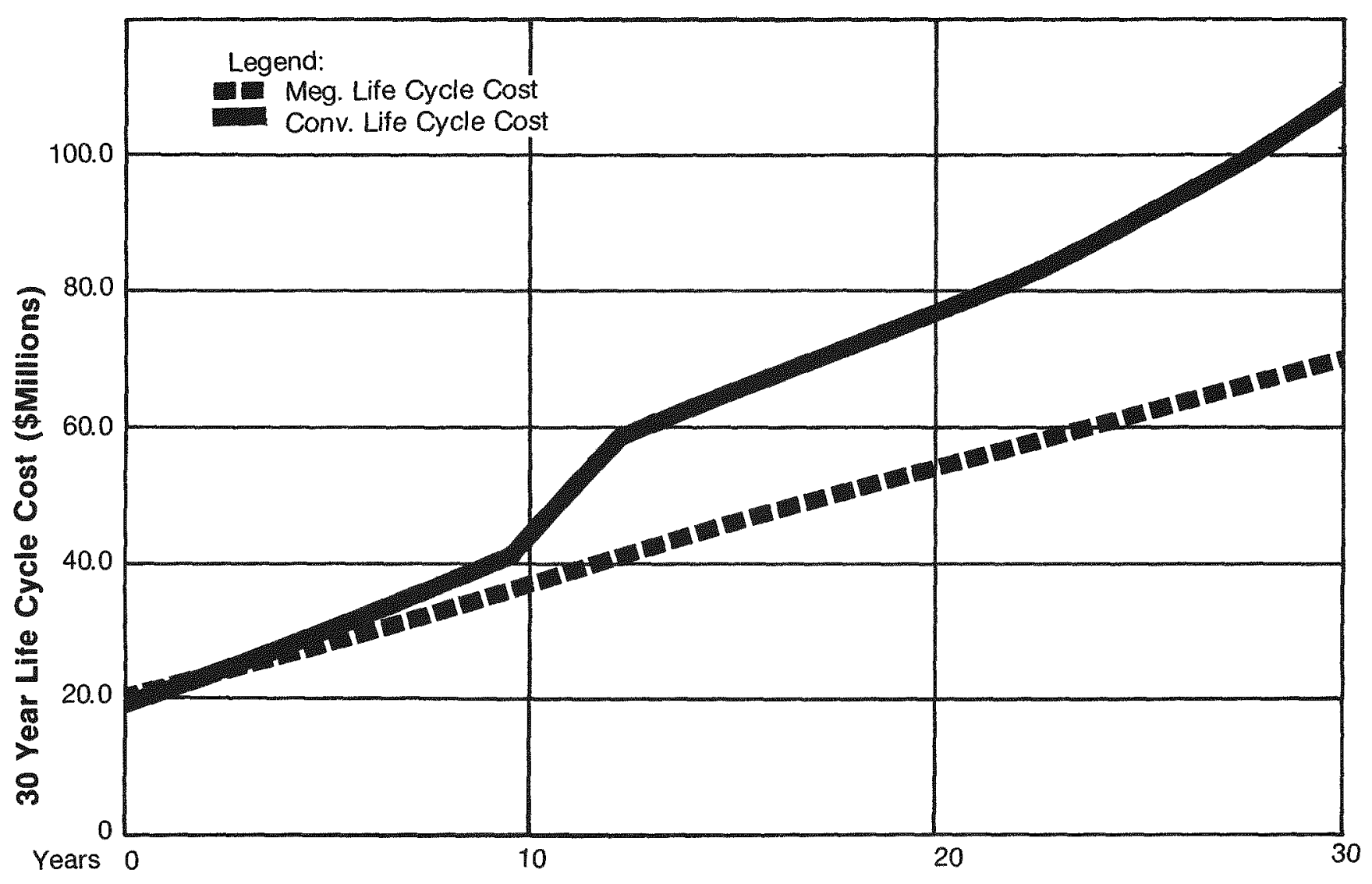

Fig. 12-14d. GSA megastructure life-cycle cost comparison (courtesy of GSA) 


\section{PART II: RECOMMENDED ENERGY RELATED DESIGN PROCRSS TASKS}

Once the range of solutions to be investigated for a building is established by the project leader, a detailed design team plan should be formulated. This plan will coordinate and properly time the efforts of all individuals to ensure a successful energy efficient design.

The design tasks suggested in this section attempt to define the energy problem of a given project and carefully narrow down the myriad of energy related concepts and strategies available to those which will have the most positive results. These tasks are intended to complement the existing architectural design process. Undoubtedly, it will be necessary to modify these tasks to better suit the specific range of solutions, design team capabilities, building type or complexity, time available for the effort, etc. Therefore, review the present tasks as the fundamental issues relating to this problem rather than as absolute, set requirements.

The purpose of this section is to overview recommended energy related design process tasks by discussing their importance and defining their scope. Chapter 14 will provide specific detailed and examples on the execution of these activities.

For clarity, the tasks are divided into three categories. The categories are (1) Pre-Design Tasks, (2) Design Tasks, and (3) Post-Design Tasks. Pre-Design Tasks are completed before any building design work begins. These tasks are intended to provide a clear statement of the energy problem and to indicate the best potential energy strategies.

Design Tasks use the above information to generate and develop schematic design(s). The tasks address the tradeoffs involved with competing or conflicting energy related concepts (strategies), and the primary need to satisfy the architectural program. In most cases, multiple building designs will be in order at this time to see how the tradeoffs can best be solved.

Post-Design Tasks are concerned with the fine-tuning of the selected design, material/construction problems, and post-occupancy user and performance evaluations.

\section{Pre-Design Tasks}

Pre-Design Tasks formulate a statement of the energy problem, analyze available energy sources (conventional and alternative) that could solve these needs, match/ select appropriate energy sources for specific energy needs, and translate this handful of prospective concepts/ strategies into design indicators for the architect to use in the schematic design phase. These efforts do not result in a building design, but rather generate a list of appropriate, most promising strategies that could be integrated into the building design.

These tasks will typically require the participation of all design team members. For example, a mechanical engineer may best formulate the statement of the energy problem. A solar consultant can look at the benefits of strategies such as building shape or form. The architect could eliminate some energy strategies because of architectural programmatic considerations. In general, all design team members should participate in these tasks so that the results are clearly the most appropriate strategies.

There are four Pre-Design Tasks. They are as follows.

\section{Characterize the Expected Energy Needs of the Proposed Building}

The expected energy needs of the project should be determined and characterized in a format that will facilitate the solving of this design problem. How much energy would a conventional building of this type need, at what times, for which specific end use, and at what yearly cost per end use?

These questions are critical for the use of alternative energy sources and strategies in commercial buildings. In particular, most of these strategies have been demonstrated on residential buildings and require specific design changes to be useful to commercial buildings. It is not appropriate to assume automatically that heating strategies are the most important. Far too many designers make this mistake and end up attacking the wrong problem and achieving only modest energy savings. Commercial buildings generally must address combined heating, cooling, and lighting strategies. The statement of the dynamic energy needs is critical to successful solution of this problem.

Three major issues surface in the performance of this task. First, what building should be used to characterize the energy problem? Without the final design available, a different building must be used. This building could be the latest similar building in the area, such as the last school built in the district, the shopping center across the street, or the last office building you designed in the area. Existing buildings are excellent, particularly if the utility bills are available. However, use care to pick a "good" building (energy-wise). Your final solution will look impressive if you start with an energy "hog," but the definition of the problem and the selection of appropriate alternative energy strategies will suffer by using a building with inflated energy needs.

The second important issue to consider in this task is which accounting system should be used. There are three possibilities. End Use Btu is the most common but probably the least useful. End Use Btu equates all consumed energy to the heat content it represents. For example, $1 \mathrm{Btu}$ of electricity is equal to $1 \mathrm{Btu}$ of wood or natural gas. The prices paid per Btu may vary by a factor of four, but this accounting system would present them as equal.

Another energy accounting system is called Primary Energy. This system uses multipliers [resource utilization factors (RUF) or fossil-fuel work equivalents (FFWE)] to convert End Use Btu to more realistic values that include hidden energy subsidies such as the efficiency of electrical generation. One Btu of electricity at the building requires approximately $3.6 \mathrm{Btu}$ of fossil fuel at the generator-henee, the greater cost of a Btu of electricity versus natural gas or fuel oil. The major problem with this accounting system is to find accurate and generally accepted multipliers. 
The last, and generally the best, accounting system is the dollar. This unit ineludes all hidden subsidies, social and economic value. For each building end use (lighting, heating, cooling, fans, elevators, etc.) all costs can be defined to get a better statement of the energy problem. Since this system easily allows the inclusion of demand charges, taxes, etc., it is the most complete accounting system.

The importance of this issue is demonstrated in Fig. 12-15. In this figure are two pie charts. The area of each chart represents total energy use by restaurants (100\%). The charts are from the same data base, but one is based on End Use Btu and the other on resource utilization factors (Primary Energy). Note that the energy problem statement would be substantially different depending on the accounting system used. Heating, the major problem in End Use Btu, is the smallest problem in the Primary Energy accounting system. If dollars were used, the results would be close to the resource utilization chart, but the effects of demand charges and tax benefits/ detriments would make a better problem definition.

The third important issue under this task is the necessity to characterize dynamically the energy requirements of the building. Typically, daily profiles for each season and for peak load conditions are a must. Such a characterization lends itself to daily energy availability profiles in the next task. See Fig. 12-16 for an example. Information in this format will facilitate the finding of solutions. A simple example of this is a building that requires more energy for lighting than for any other end use, but the daily profiles show that $90 \%$ of that demand is at night. Daylighting would quickly be eliminated as a major energy strategy in such a case.
In summary, the purpose of this task is to state the energy problem of the proposed building by documenting the amount of energy (dollars) needed for each end use on a yearly basis and by finding the dynamic profiles of these energy needs under seasonal and peak conditions.

\section{Characterize the Potential Energy Types Available at} the Site (Natural and Conventional)

Once the approximate energy needs of a building are characterized, it remains to investigate the alternative and conventional energy sources available to satisfy that need. How much energy is available at the site, at what times and regularities, and at what cost?

This investigation begins with the site in general by attempting to investigate how the microclimate can be altered to produce natural comfort and amenity. Then, for each significant energy need (end use) uncovered in Task 1 above, information is gathered on each possible al ternative to meet that need. For instance, if heating is a major energy need of the building and is required during the four coldest winter months, how much gas, electricity, solar radiation, biomass, or other source of energy is available at that time, for that use, and at what approximate cost? If there is no solar radiation available at the site during these months, then this strategy may be eliminated.

The dynamic availability of the energy sources is best plotted in a similar format to the energy needs in Task 1 above. Yearly, monthly, and daily availability and regularity are important to document.

\section{RESTAURANTS: 5,782 mean square feet}
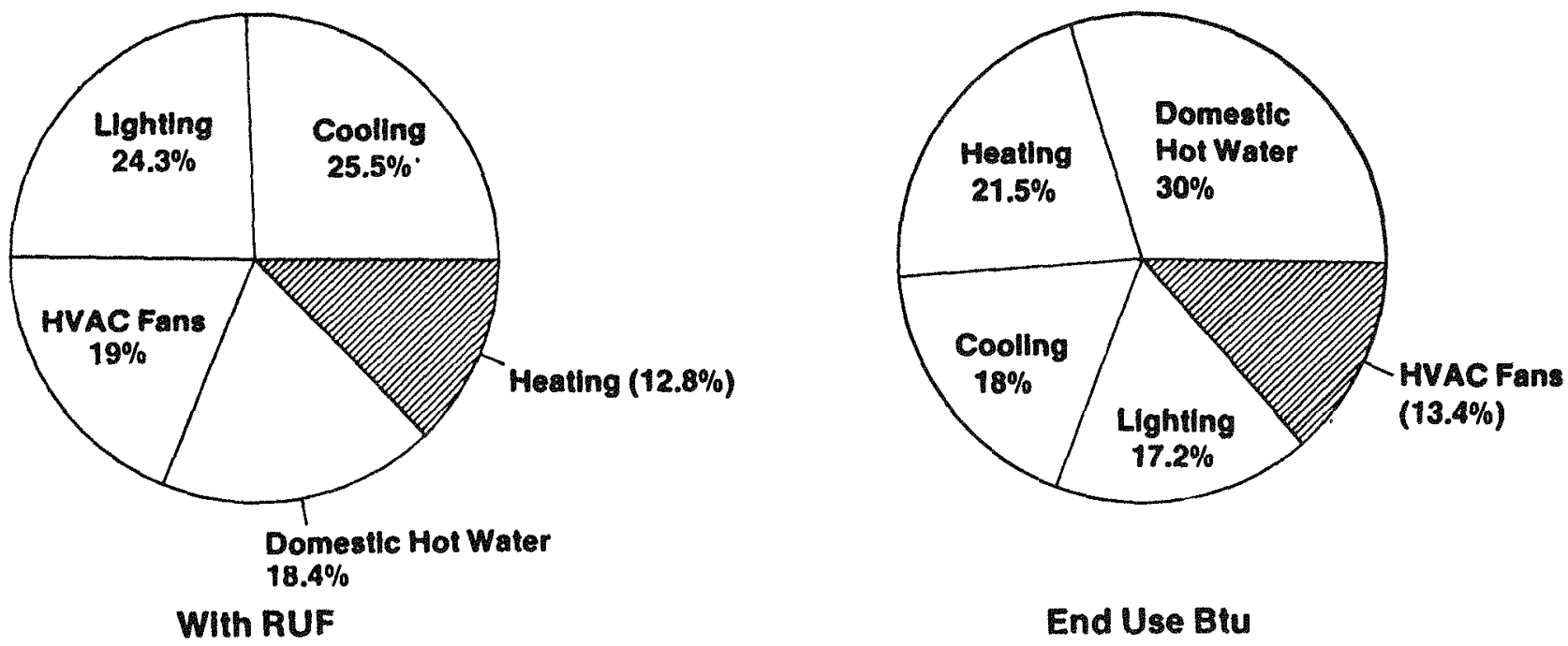

Fig. 12-15. EneRgY acCOUNTING SYSTEMS 
Bickle/: '

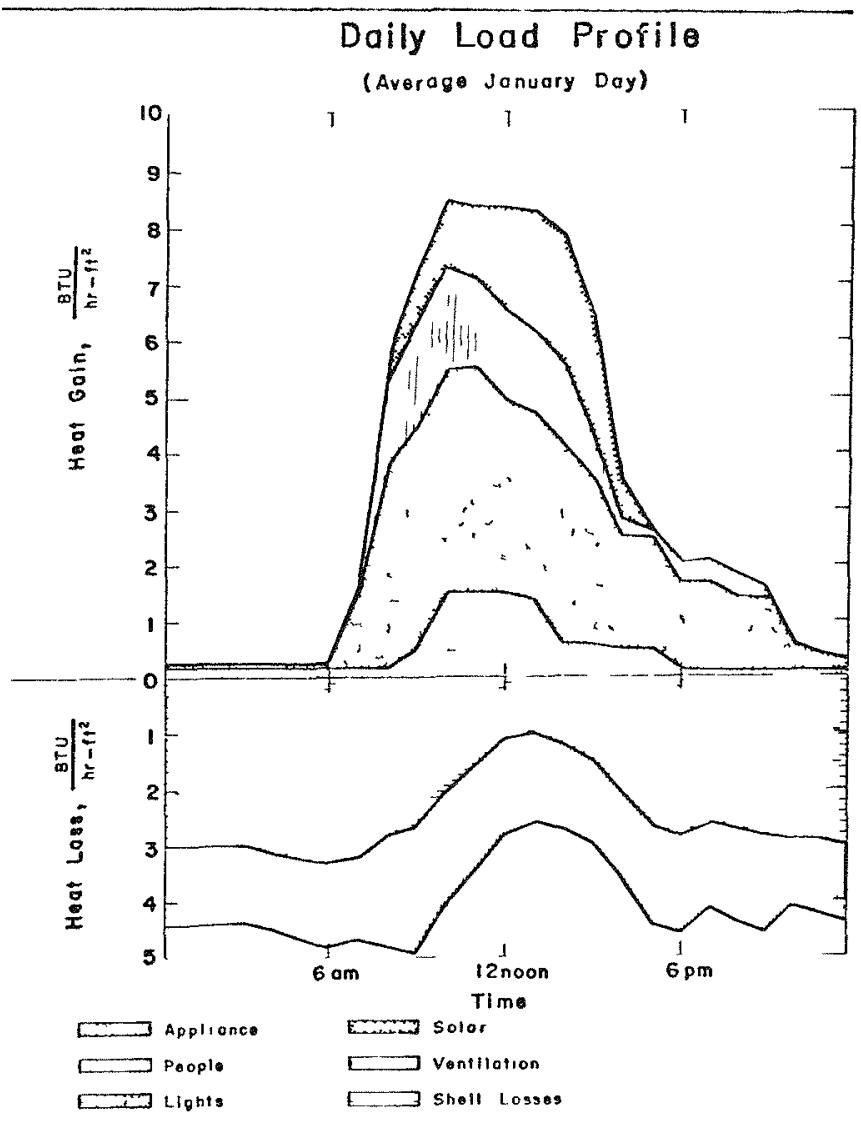

TiG, 12-1E. DAILY LOAD PROFILE.

Commercial energy sources are best characterized by their availability and by economic issues such as hookup charges and rate structure.

The architectural advantages and disadvantages of the site with respect to energy use should be identified. This information should relate directly to the architectural program.

Also, architectural needs may provide potential energy sources. Computer rooms and kitchens, for example, may be used as sources of heat.

In summary, this task attempts to identify and document potential energy sources at the site that exhibit the ability to satisfy specific energy needs of the building. The results of this investigation should be similar in format to the results of Task 1 .

\section{Matching Energy Needs and Available Energy Types (Concepts/Strategies)}

According to the energy needs and available energy sources, which concepts or strategies are worth pursuing in terms of performance, economics, and architectural compatibility? These activities "narrow-down" the alternative strategies to the ones that seem appropriate to the specific project.

The performance matches are made by determining the potential of each al ternative energy source or strategy to offset nonrenewable energy use in the building. The issues here are twofold. First, what energy can be saved by component or system? Secondly, what energy needs can be avoided by design? Conflicting strategies may be found such as the conservation potential of a square building (minimize surface area) and the passive solar advantages of a building oriented toward the Sun (with greater total surface area as a result). Such conflicts are appropriate at this time.

Fundamental to this task are appropriate, simple performance and economic design tools and data. The matching process must be done on a conceptual basis since the building design is not yet complete. The simple tools necessary to do this need only be aceurate enough to choose between systems, not to give exact solar heating fractions, yearly daylighting fractions, etc. The designer wants to know if active heating is worth considering or if daylighting is even reasonable. To answer these questions, each strategy must be tested in terms of performance, economies, and architectural compatibility.

\section{Translating Energy Strategies into Architectural Design Indicators}

Typically, the majority of pre-design work will be completed by "technically oriented" experts. It is their responsibility to assess the energy needs of the proposed building and to identify an appropriate range of the most viable energy related strategies. These strategies are not building solutions in themselves, but they represent the most promising energy options that can be used by the building designer. The task now is to bridge this gap between the completed pre-design analysis work and the remaining design efforts (analysis to synthesis).

Two levels of architectural design indicators can be developed for the architectural designer. The first is a component, or singular, strategy. An example of this is daylighting. Information on the many ways to provide daylighting for the particular building type under consideration can be prepared and given to the designer. This information could also contain daylighting rules of thumb and geometric considerations, or other basic design information. The idea is to provide enough information to the designer so that he understands the fundamentals of the strategy's application.

The second level of architectural design indicator is scenarios of combined strategies. The major indicator is the overall architectural impact. For instance, a combination of specific cooling, heating, and daylighting strategies may produce a constricted, square building envelope, while other strategy combinations may require 
low, single-story envelopes or long, narrow envelopes of multiple stories. Rather than just a component by component concern, these indicators describe basic architectural form scenarios of combined strategies.

The preparation of architectural design indicators must be careful not to suggest singular, exact solutions. The indicators must be informative and provide useful data, but not be so constrictive that design latitude is lost. The energy issues are only one major concern of architectural design. Other design issues seldom permit an architecture form optimized solely for energy reasons.

Design indicators must interpret the most promising energy strategies in a designer's language. The information should deal with approximate sizes, shapes, and relationships, and not Btu or footcandle needs. This will better suit the skills of most architectural designers. This task is primarily a matter of successful communication.

\section{Design Tasks}

Design Tasks represent the overall solution to the energy efficient building problem. Starting at the schematic design phase, the design team works in a direct response mode to the project designer. A variety of solutions may be generated and tested, with the end result being the selection and development of the best overall solution.

The Design Tasks are broken down into three major increments of work numbered as 5,6 , and 7 in this presentation.

\section{Sehematic Design}

Armed with the appropriate energy related concepts (strategies and the design indicators that convey the architectural impact of each), the project designer may now attempt to put the entire project together. This task deals with the tradeoffs involved with competing or conflicting concepts/strategies and the primary need to satisfy the architectural program. In most cases, multiple building designs will be in order at this time to see how the tradeoffs can best be solved.

Critical to this process is a constructive feedback loop from the other members of the design team to the project designer concerning the realities of any proposed energy systems. Within the context of the complete architectural program, the project designer will need to massage the energy related strategies to achieve an integrated "whole." The degree of interaction among team members at this point is important to establish to avoid intra-team conflicts. Some architects perceive the feedback loop as a "threat," when in actuality it is intended to aid and support him/her.

The schematic design effort should result in several potential building solutions. The present knowledge concerning appropriate energy efficient commercial buildings is limited, and no singular, ultimate solution should prove too obvious. Once the design team feels comfortable with the proposed designs, it remains to test their performance, economic, and architectural merit.

\section{Testing the Schematic Design Alternatives}

Accurate assessments of the building solutions can now be developed since actual building designs are now available for study. The alternative schematic design solutions can now be judged according to detailed performance, economic, and architectural analysis. The results of analysis can result in improvements or modifications to specific schematic designs and/or the selection of the best design for entry into the design development phase.

Most obvious is the ability to test the schematic designs for energy performance. Using the tools presented in Section II of this workbook, the buildings can now be assessed in great detail. Such results should prove extremely useful in comparing conflicting strategies and in finding ways to improve each particular schematic design.

Tied closely to the comparative performance of each design is the comparative economics of the solutions. A detailed cost takeoff is possible now since complete building forms are available. The project specific economic criteria should now be applied so that each solution can be assessed according to these needs/goals.

The uitimate comparative test for the proposed designs is the overall solution of the architectural program. Since the designs may vary substantially, the client's needs, feelings, and approval must be tested. All energy related strategies must pass this architectural compatibility test.

The results of this effort may range from retuming to Pre-Design Task 3 to the selection of the most appropriate schematic design to enter design development.

\section{Design Development}

By this stage in the design process, the most appropriate schematic design has been selected. The building designers must now focus their efforts on working out the details which will convert the selected schematic design into a real building. Construction documents describing the energy aspects of the building must be prepared coincident with the conventional construction documents. Details and specifications must be designed to (1) enhance the energy efficiency of the energy system and components, (2) be cost effective, and (3) allow for ease of construction.

It is very important to have the details and specifications clear and non-confusing in order to obtain accurate cost estimates, bids, and workmanship, for the details and specifications are of ten foreign to most contractors. 


\section{Post-Design Tasks}

The post-design phase includes all aspects related to the construction, occupancy, and operation of the building. Cost estimates and bids often vary greatly for innovative energy designs, for contractors are unfamiliar with the final design. Construction supervision is of the utmost importance to obtain the desired results and reiterates the importance of the contract documents.

When completed, the energy system(s) must be thoroughly inspected and checked to assure proper operation. Guildelines for proper operation and maintenance must be given to the building owners, occupants, and/or maintenance personnel. The architect/engineer should make followup visits to the building after occupancy, again to assure proper system operation and maintenance.

System performance testing and acceptance testing are also included as post-design tasks. Proper system instrumentation and monitoring can be very helpful in improving the energy efficiency of the existing building and providing a sound basis for future design. 
13

Pre-Design Phase 
PRE-DESIGN PHASE

The material in this section is to come from a future SERI publication, The Design of Passive Commercial Buildings. This material is not yet available. 
TROMBE WALL COMCEPT
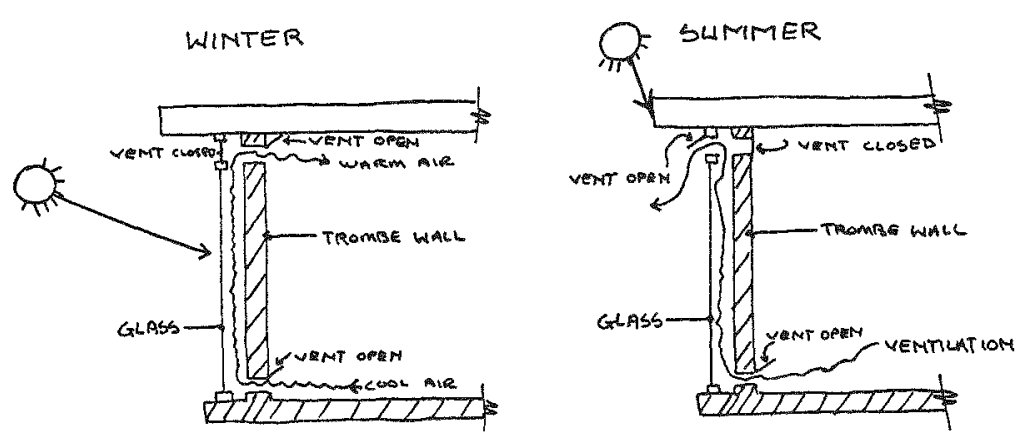

Fig. 1. New Mexico Tech Dormitory

HEAT RECOVERY CONCEPT

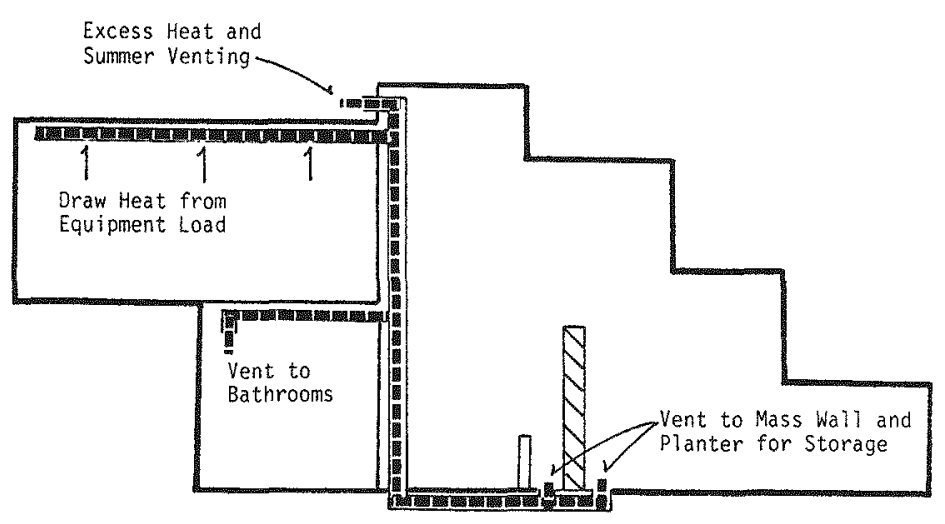

Fig. 2. KQEO-KZZX Radio Station 

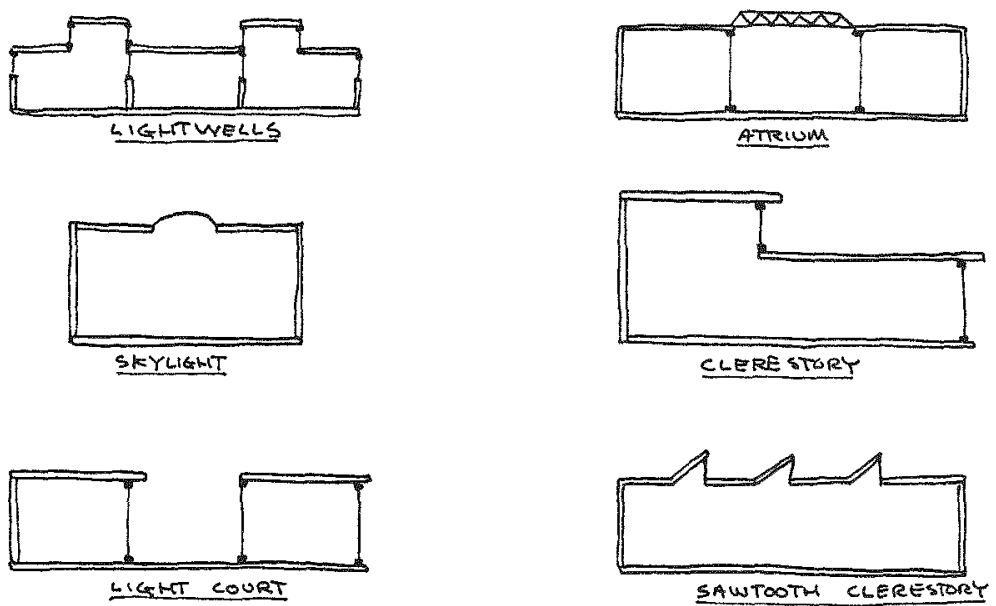

Fig. 3. New Mexico Tech Dormitory

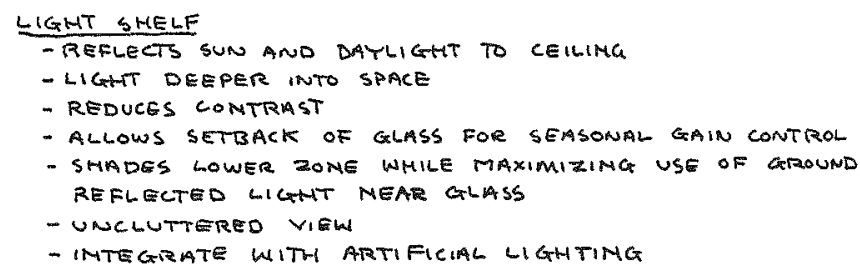

- integrate with artificial lighting

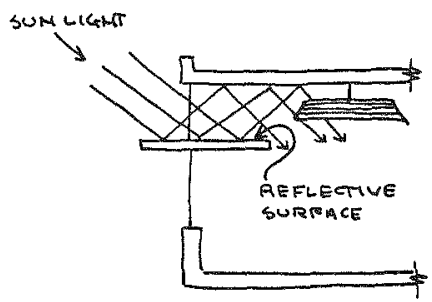
Fig. 4. New Mexico Tech Dormitory daylighting
concept 

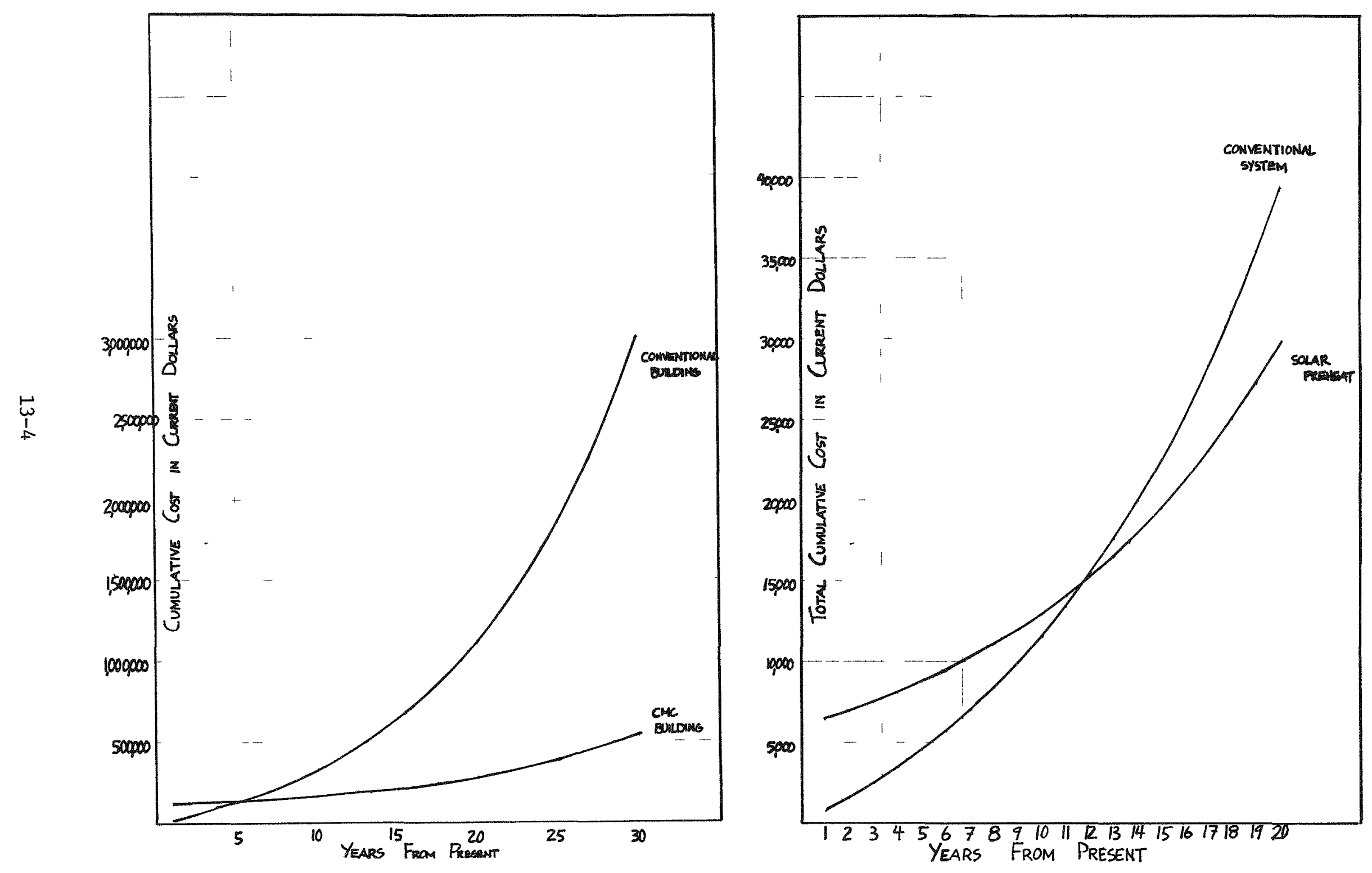

Fig. 6. Heating

Fig. 5. Solar preheat 

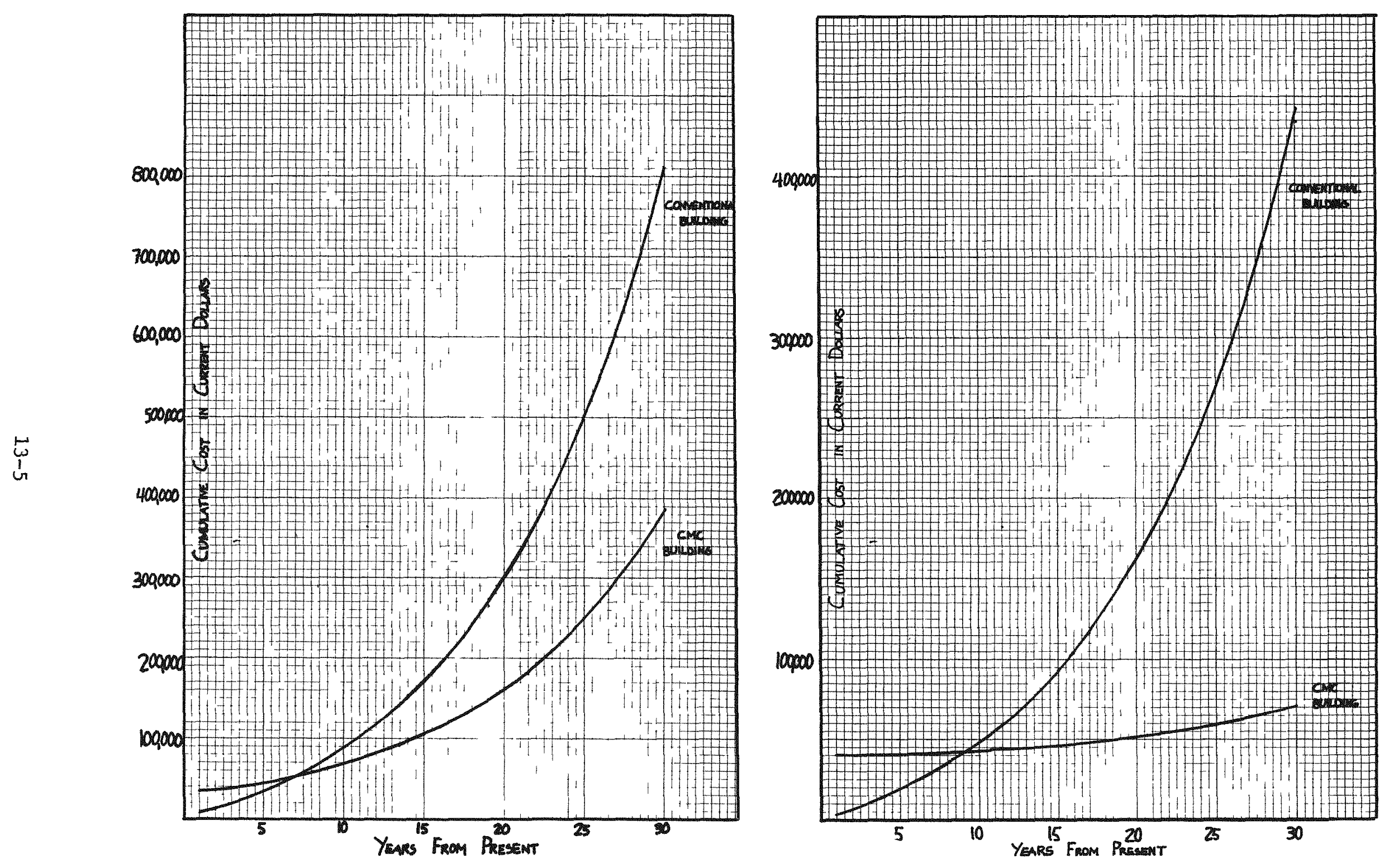

Fig. 7. Lighting

Fig. 8. Cooling 


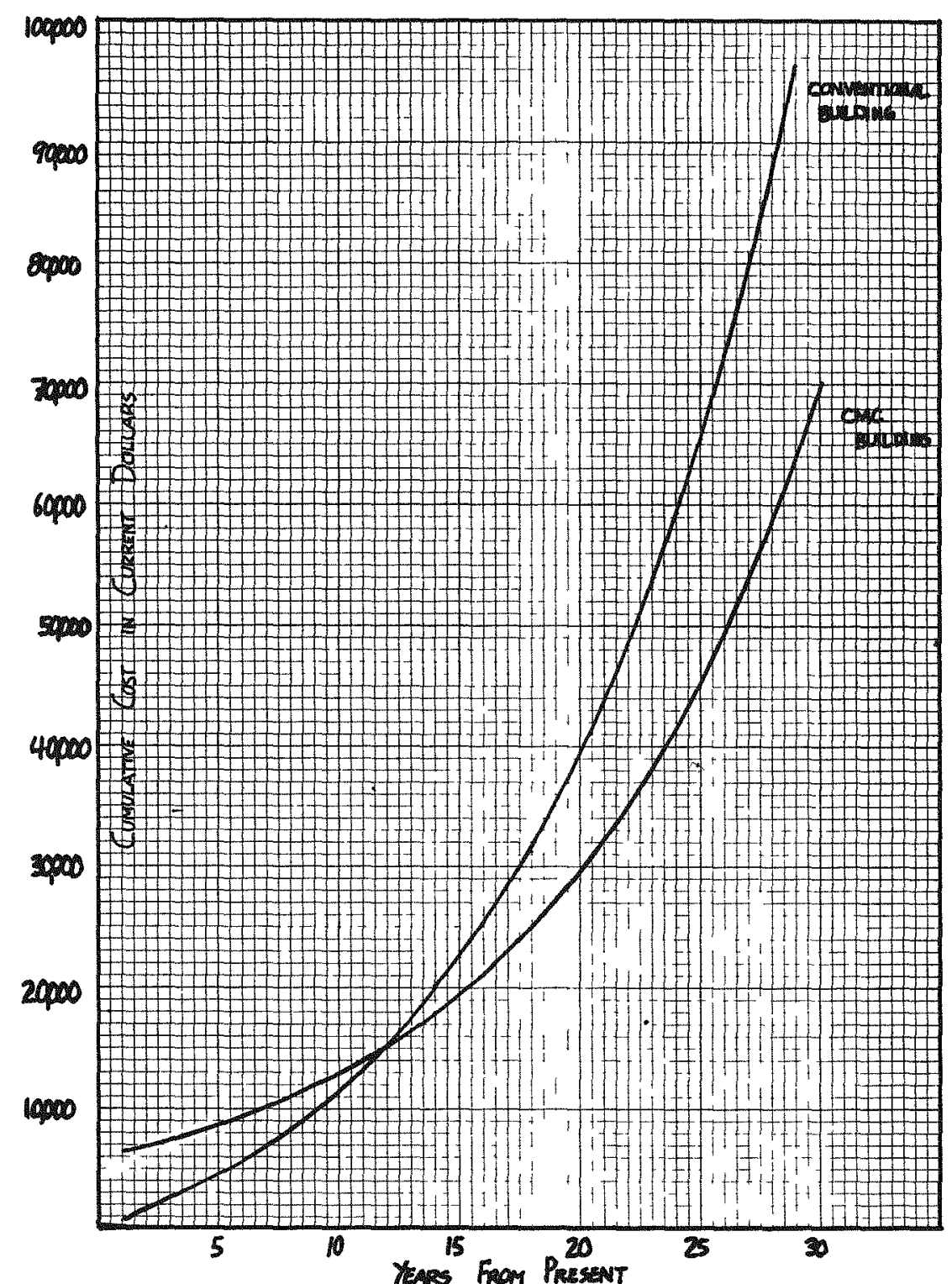

Fig. 9. Hot water 


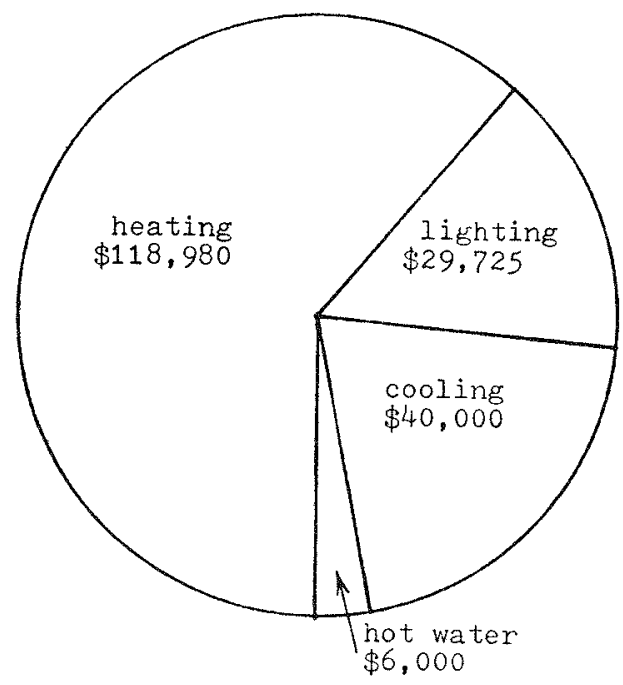

Additional Construction Cost

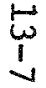

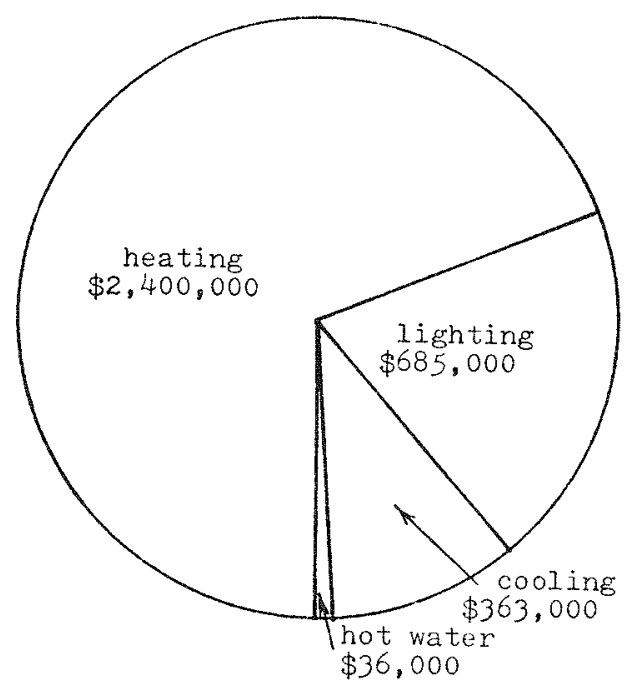

Savings in 30 years in 1980 Dollars (based on all electric at $4 \Phi / K W H$ )

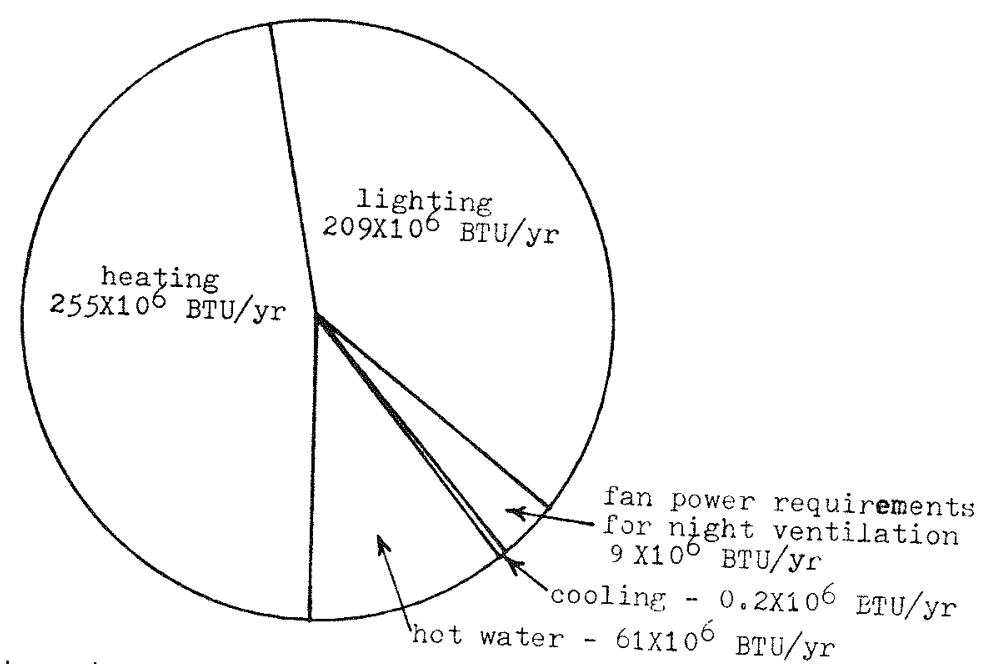

Colorado Mountain College Building 17,174 BTU/s.f./yr

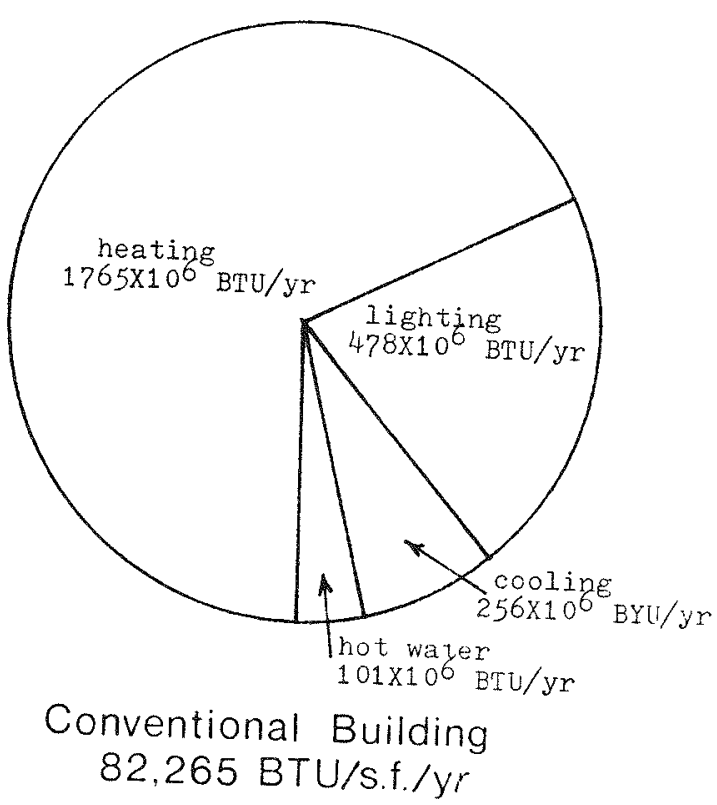

Fig. 11. Energy use profile charts
Fig. 10. Cost profile charts, Colorado Mountain College 


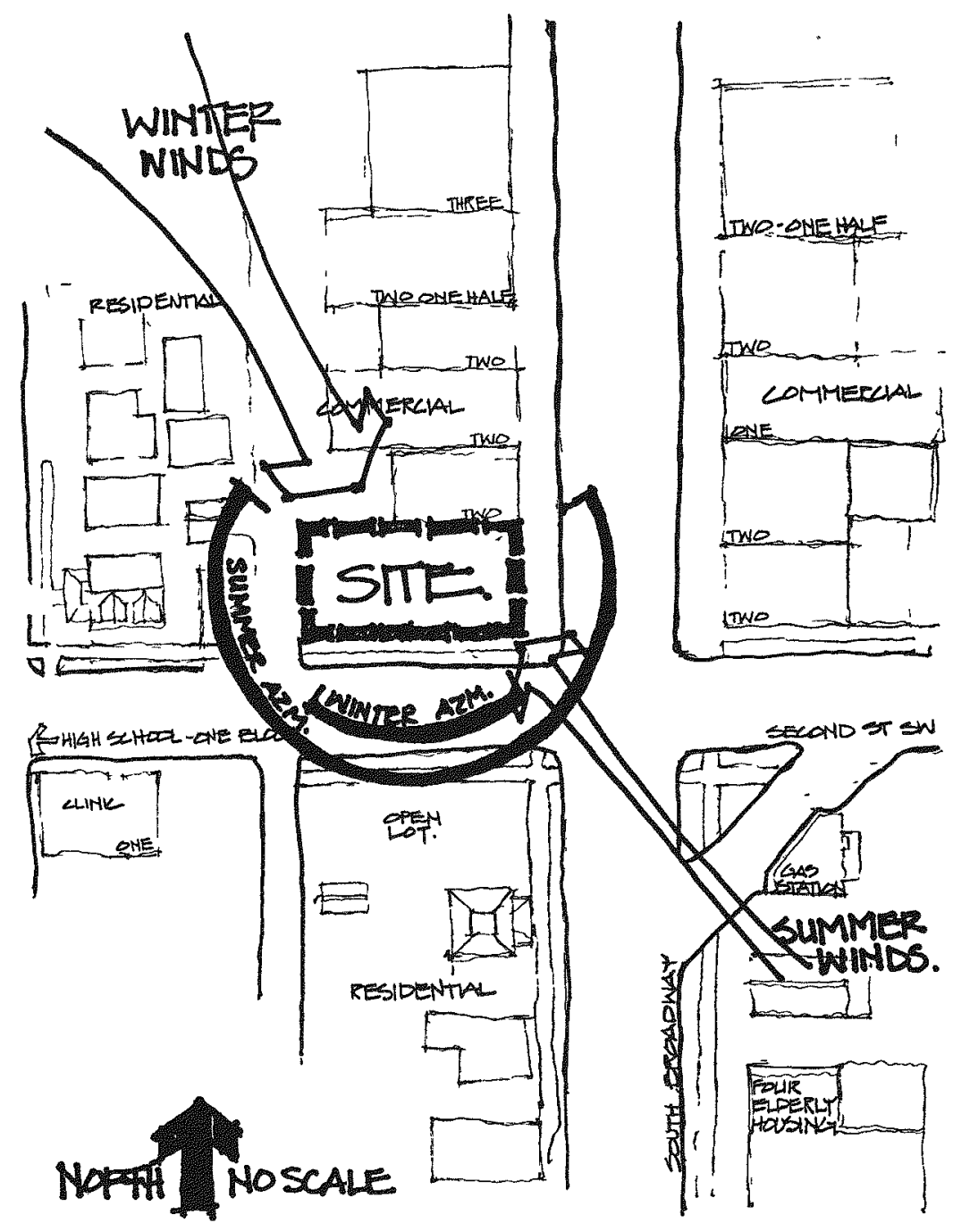

Fig. 12. Site analysis, Security State Bank of Wells, Minnesota (courtesy of John Weidt Associates, Inc.) 

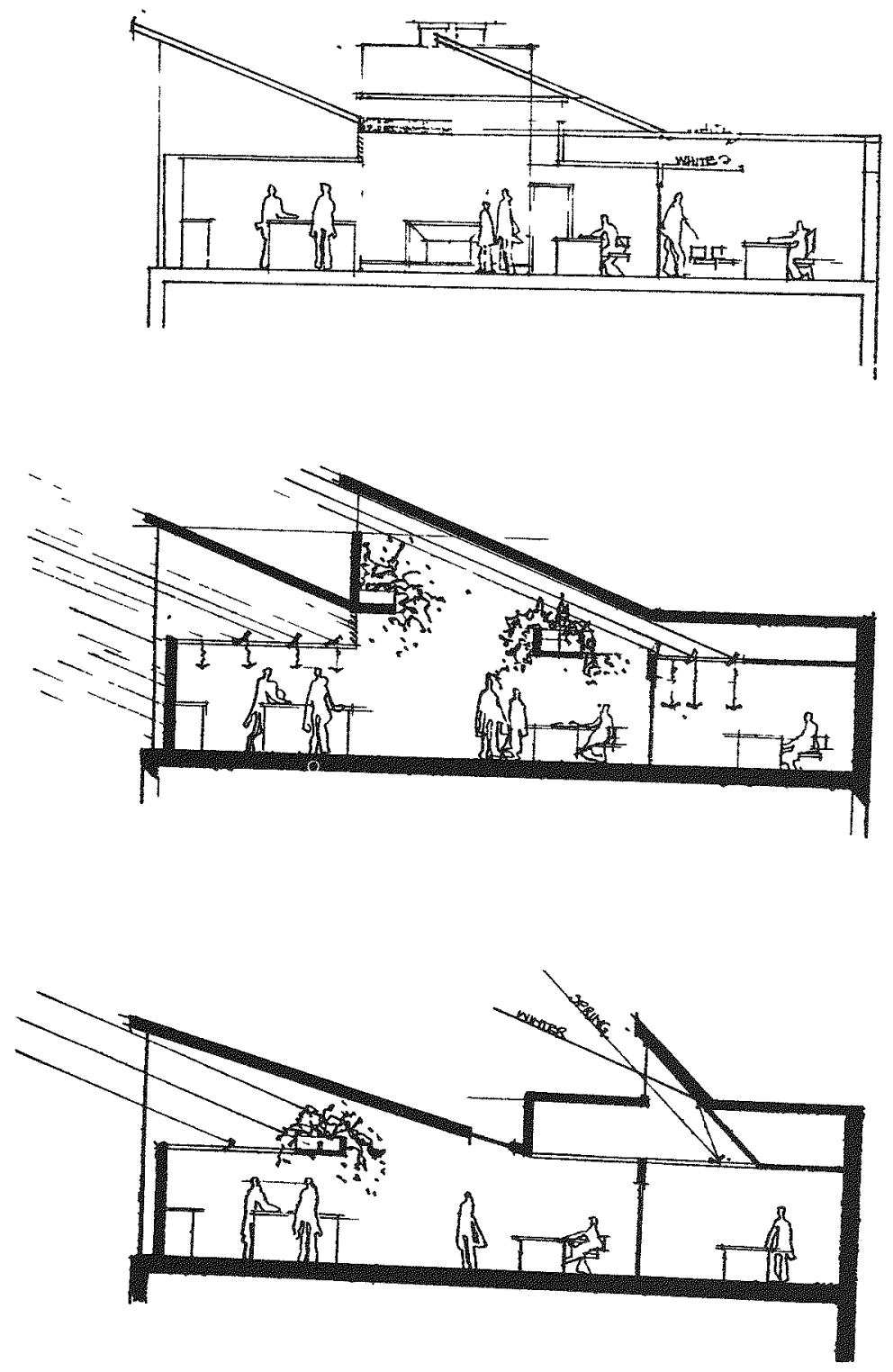

Fig. 13. Early schematic design, Security State Bank of Wells, Minnesota (courtesy of John Weidt Associates, Inc.) 

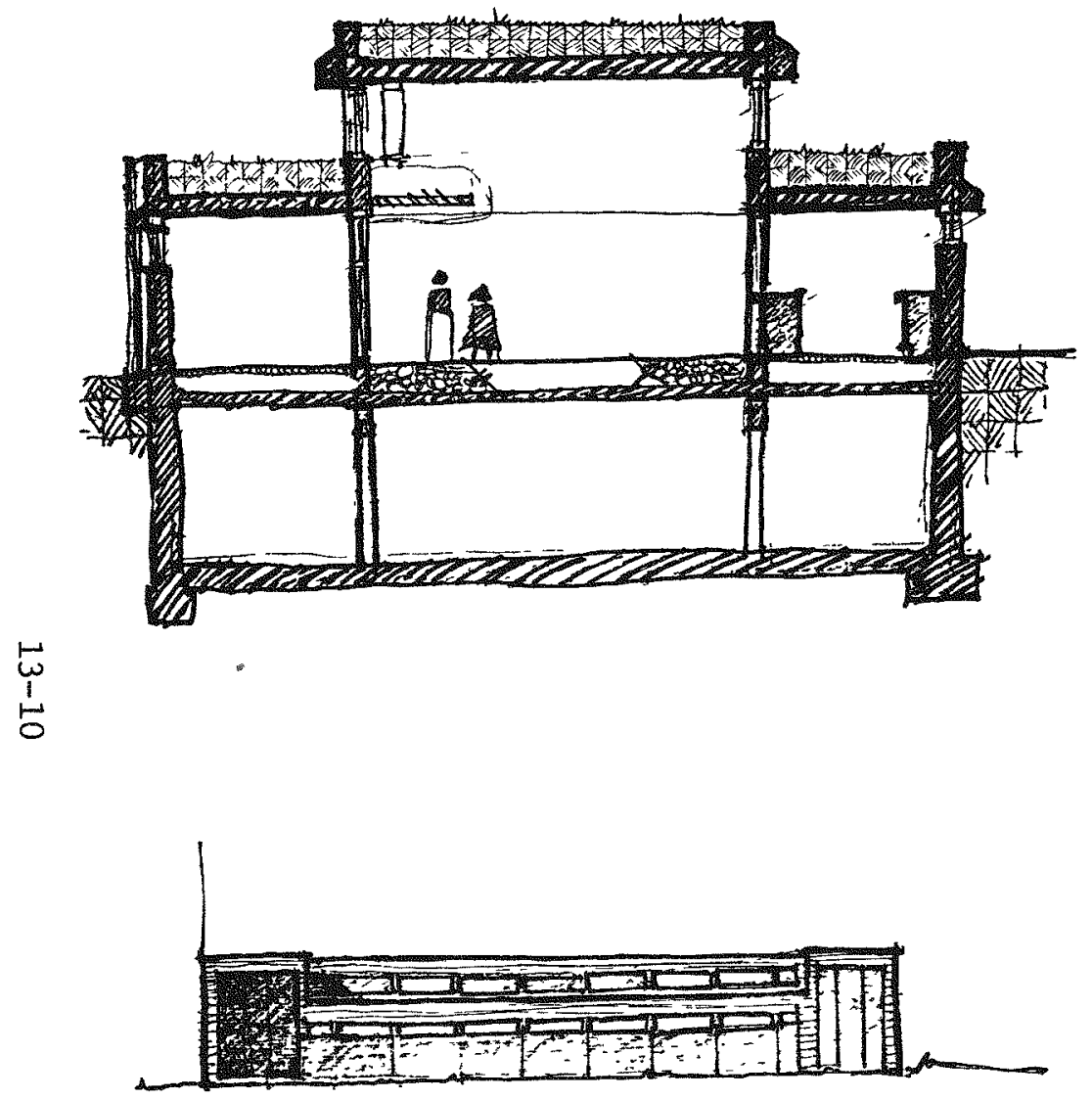

Fig. 14. Early schematic design, Security State Bank of Wells, Minnesota (courtesy of John Weidt Associates, Inc.)
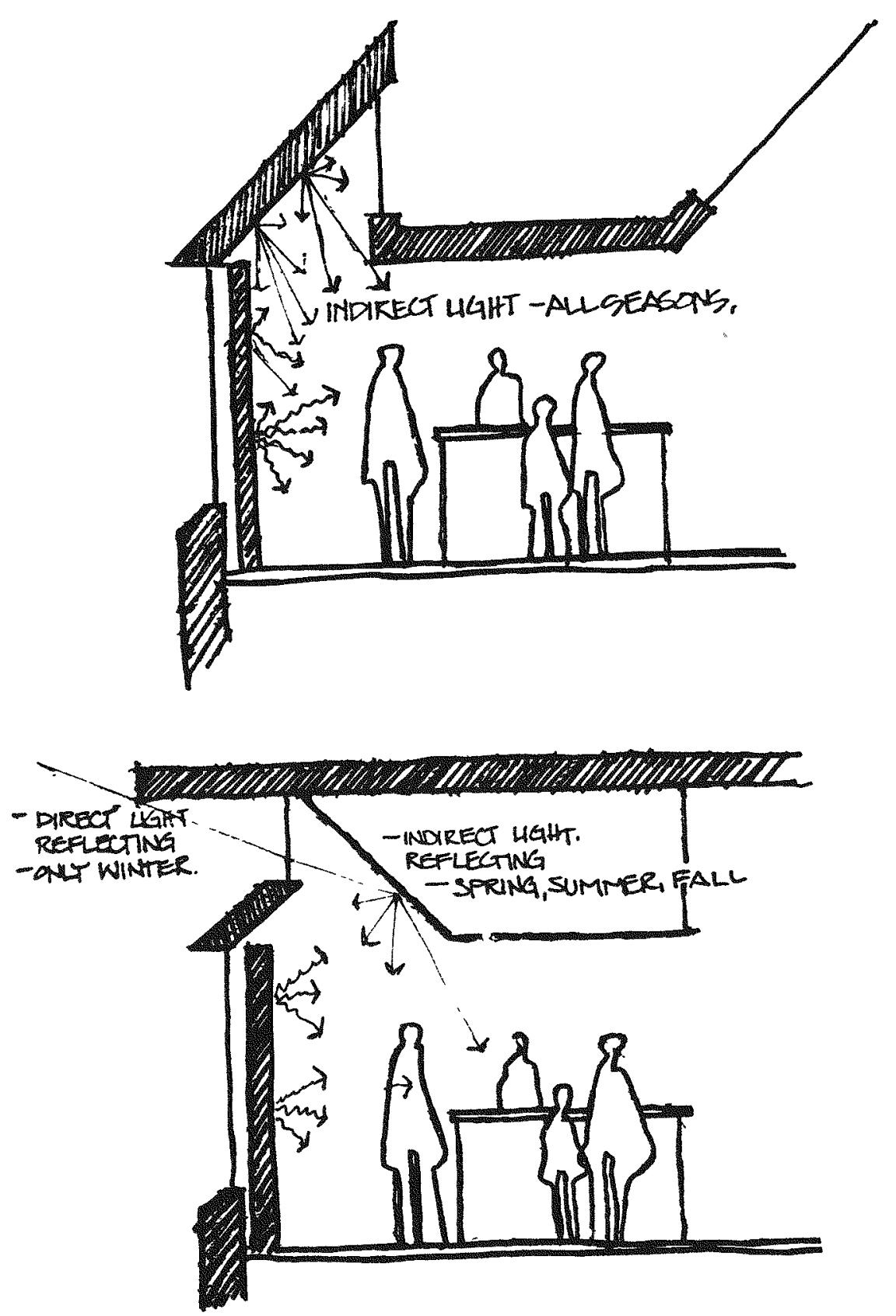

Fig. 15. LIGHT/HEAT Studies, early schematic design, Security State Bank of We1ls, Minnesota (courtesy of John Weidt Associates, Inc.) 


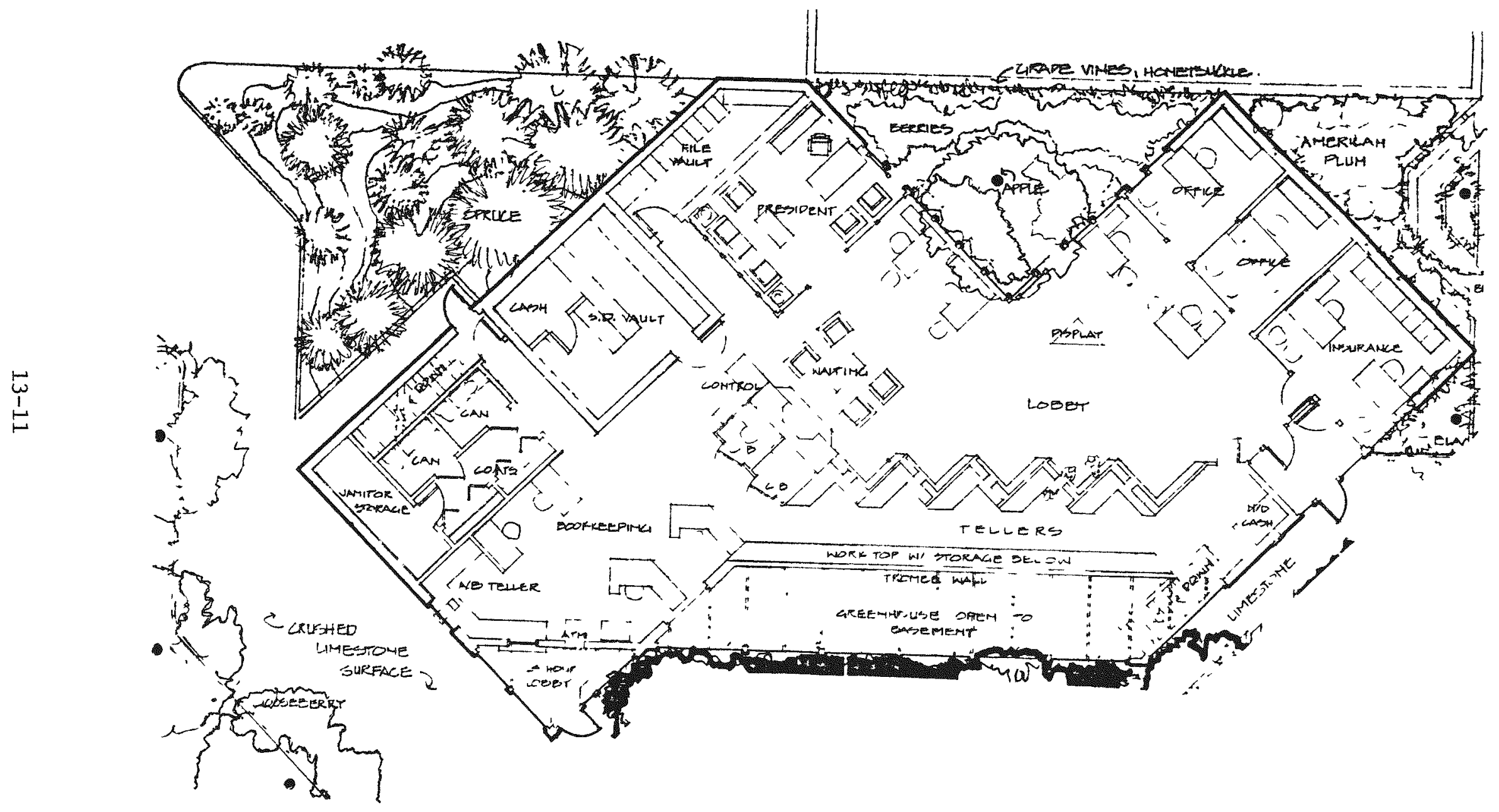

Fig. 16. Early schematic design, Security State Bank of Wells, Minnesota (courtesy of John Weidt Associates, Inc.) 


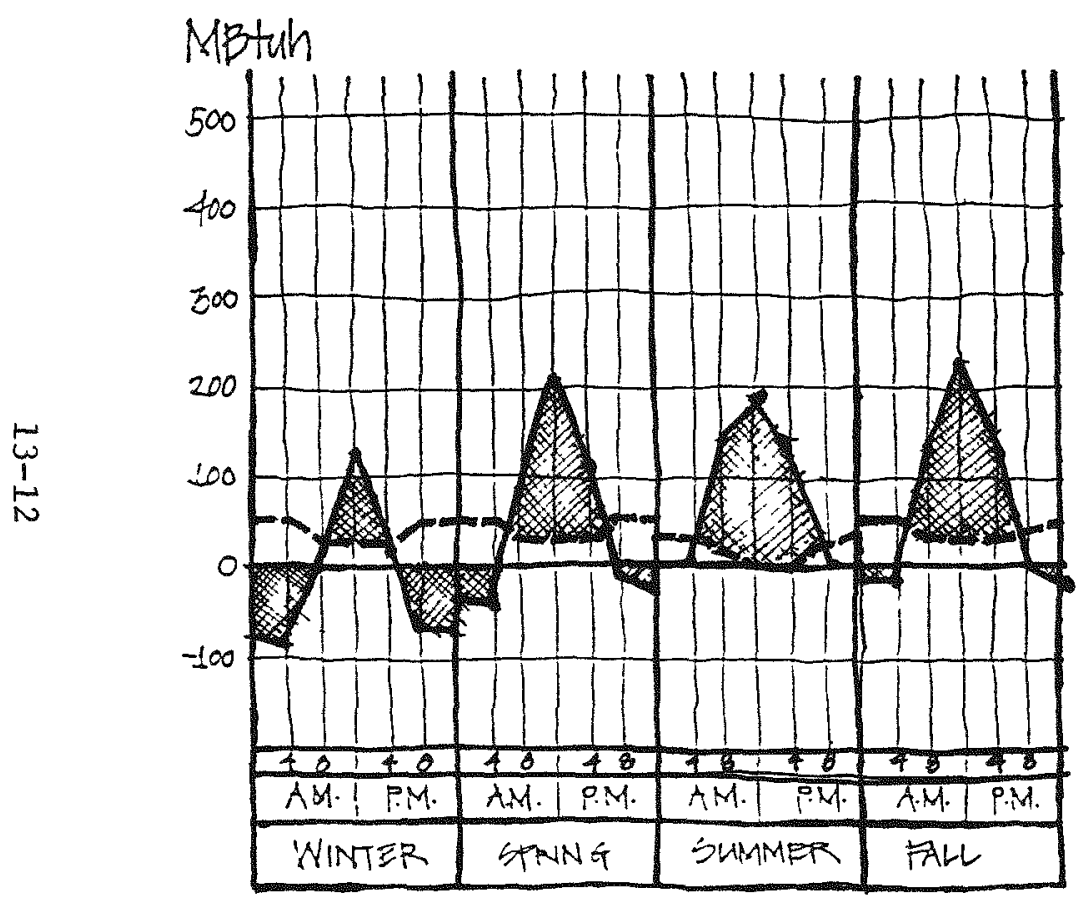

Fig. 17. Total heat gain and loss study for Security State Bank of Wells, Minnesota (courtesy of John Weidt Associates, Inc.)

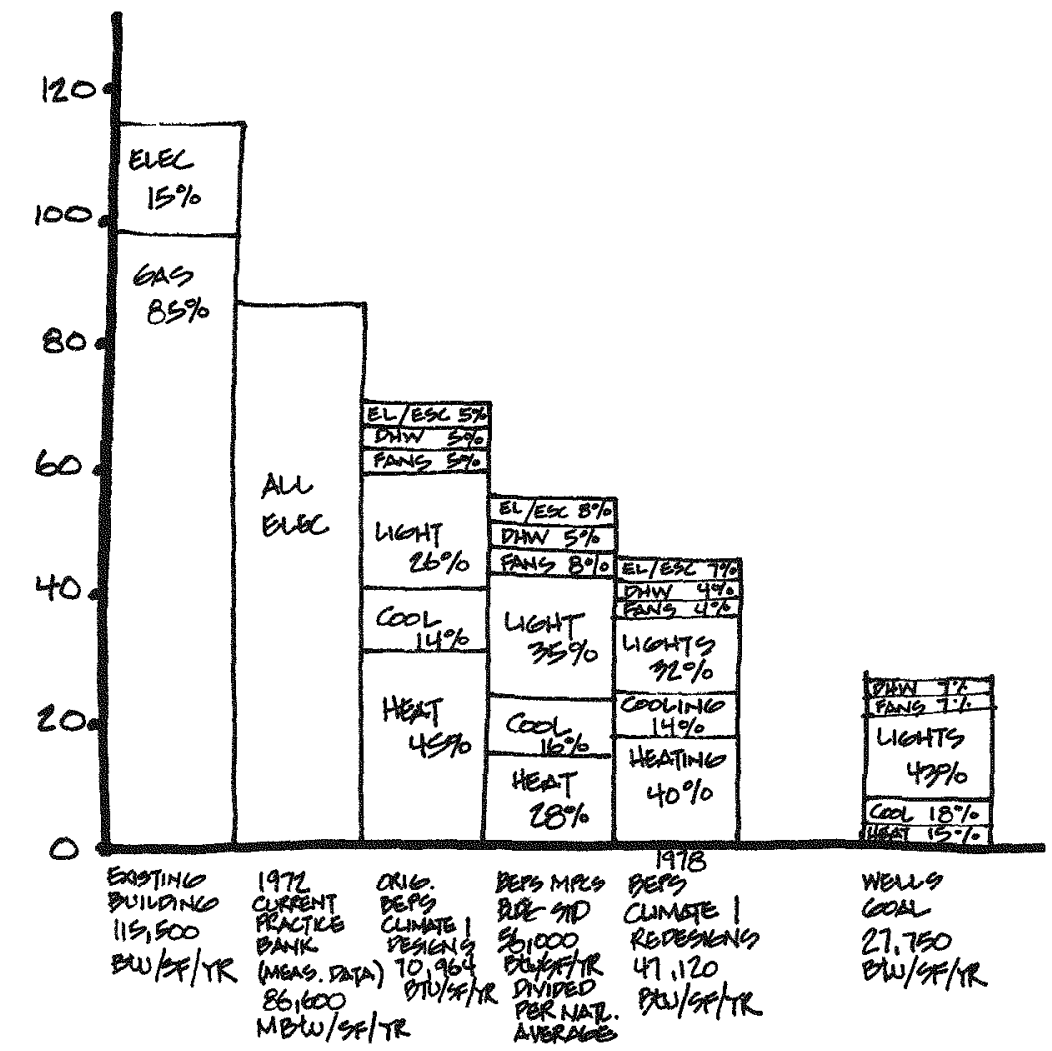

Fig. 18. Security State Bank of Wells, Minnesota. Energy needs and goals breakdown. (courtesy of John Weidt Associates, Inc.) 


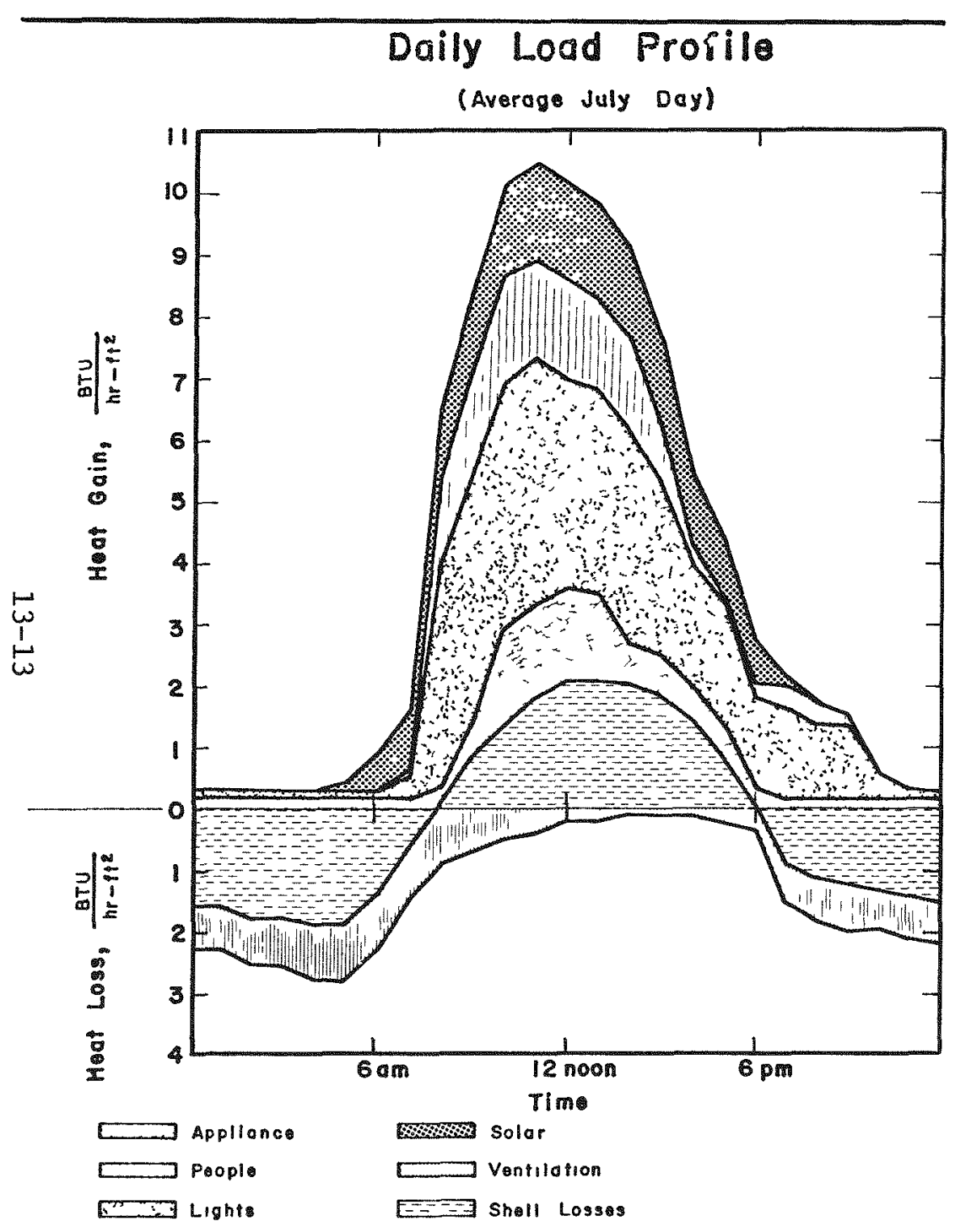

Fig. 19. Daily load profile

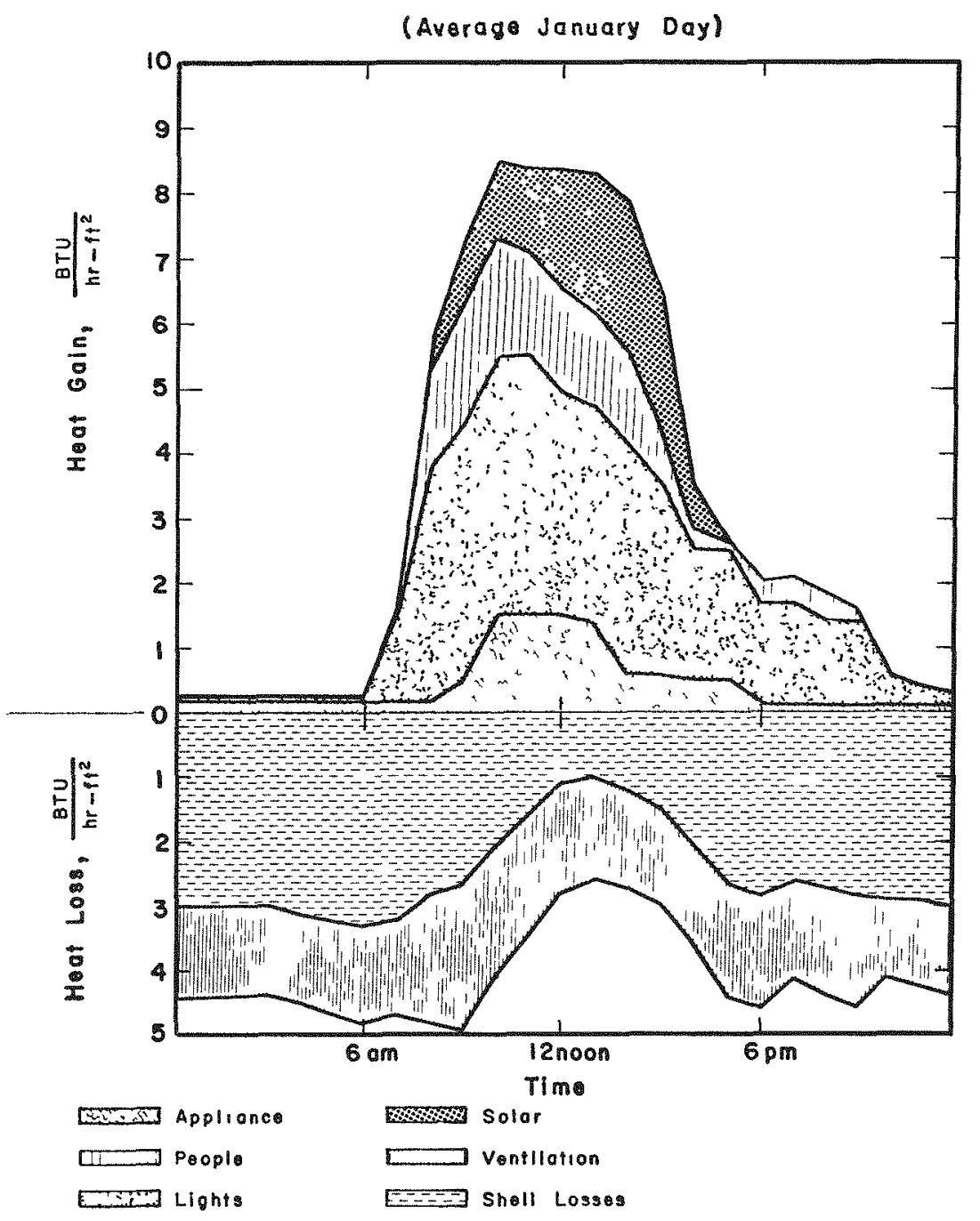

Fig. 20. Daily load profile 
BICKLE /CM

Douglas County High School

ENERGY GOALS

- Minimize the use of non-renewable resources

- Showcase the utilization of natural resources: Solar, Wind, Site, Daylight

- Create areas which provide transition between outdoors and indoors - but are unconditioned Ex: Vestibule, Atrium, Courtyard

Typical Annual Energy Consumption for High Schools in Denver Area

- Range on Average: 80,000-120,000 Bulg. ft.

- New Schools built at: 50,000 B tulsa. ft.

- Goal for this Project: 40,000 Btu/sq. ft.

- Can meet goal with passive solar, natural lighting, and energy conscious design

End - Use Breakdown

* Heating

$31 \%$ of total

* Lighting

$40 \%$ of total

- Appliances छ Misc. Electrical $24 \%$ of total

- Domestic $5 \%$ of total

* Can be reduced by utilizing passive solar and daylighting where possible

$13-14$ 


\section{SITING}

- Utilize Trees to North $\& N W$ for Winter Wind Protection

- Put Paved Areas on $N$ to carry heat buildup into building for winter and away from building in summer

- Utilize slope for thermal barrier on north as well as wind barrier

- Provide flow paths to effectively utilize natural ventilation

- Allow for maximum solar exposure on South and Southeast

BUILDING FORM

- 1 story vs. 2 story

- 2 story requires $10-20 \%$ less heating energy due to more wall space for glass

- Compoct va. Finger

- with identical glass aveas, compact E finger plans use about the same total amount of energy - Earta Berm

- Gain in insulation on wall almost neqated by loss in glass area

\section{WINDOWS}

- Because the major energy use is for heating and lighting, intelligent use of window area will reduce total energy consumption

- Glass areas should not be greater than $50 \%$ of wall area

- Glass should be oriented towards the East, Southeast, South, and Southwest

- Minimize glass area on West and North wes't 
- Use North and Northeast glozing to provide natural lighting

- Horizontal windows are more beneficial than vertical when providing daylight and passive solar heat qain

- Light shelves should be used to pull light into deep rooms-not large glazing areas

- All windows used for passive gain must be justified with proper placement of mass or prompt surface

\section{LIGHTING}

- Extensive use should be made of available daylight

- Particularly useful from North

- Light shelves and clerestories (see Concept Cards)

- Controls must be implemented which will effectively integrate natural lighting with artificial lighting

\section{CONOEPTS}
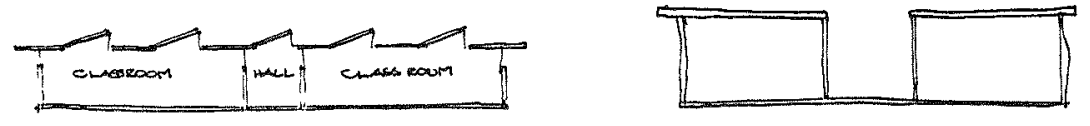

Clar STRT

LIGHT COURT

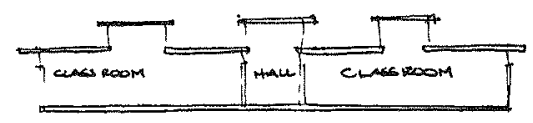

LIGHT WESLS
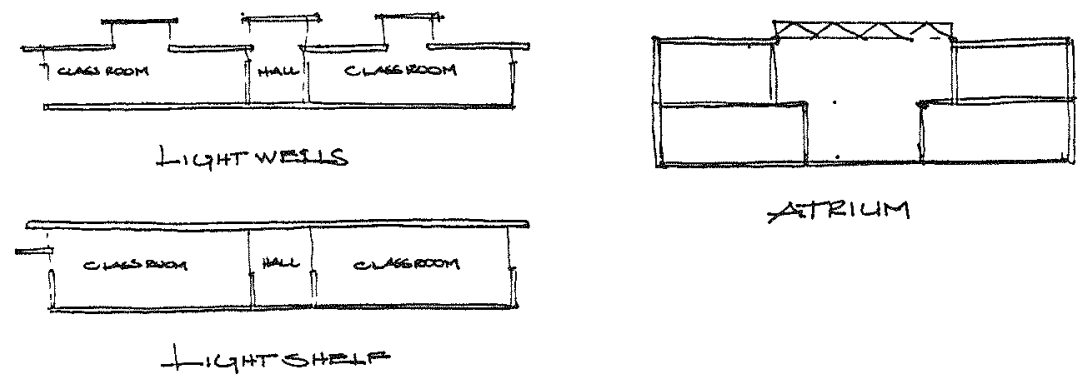


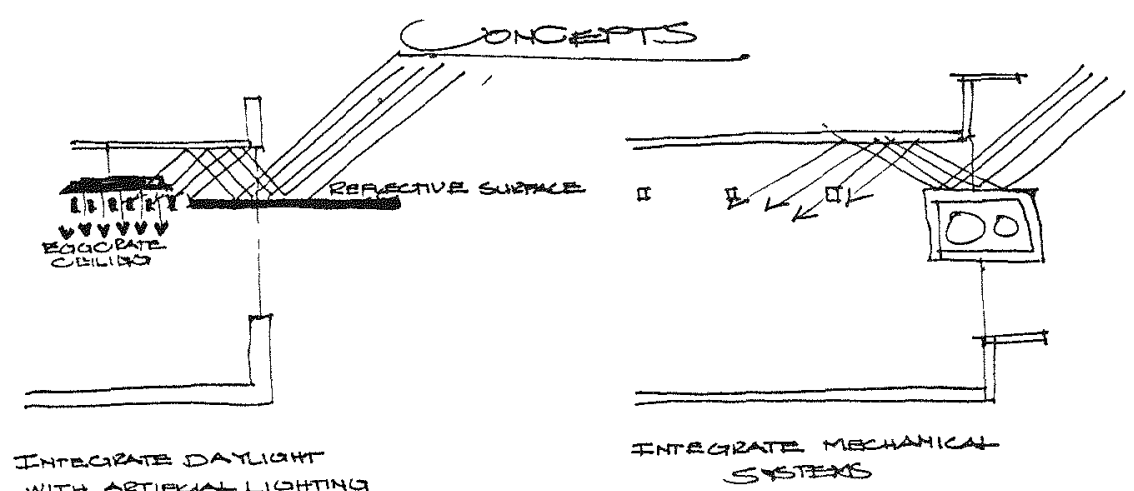

Fig. 21. Douglas County High School Concepts.

\section{PASSIVE Solar \\ - Primarily used to reduce heating \\ loads in perimeter zones}

- Utilize a "Prompt Wall" for quick heatup in morning after night setback

- Direct Gain onto storage walls in hall ways

- Use operable windows to provide for ventilation cooling

- Building should be oriented with major wall surfaces towards

south and Southeast to take advantage of morning sun

- Use courtyard or atrium as buffer against elements with deciduous trees to provide shade in swing months 


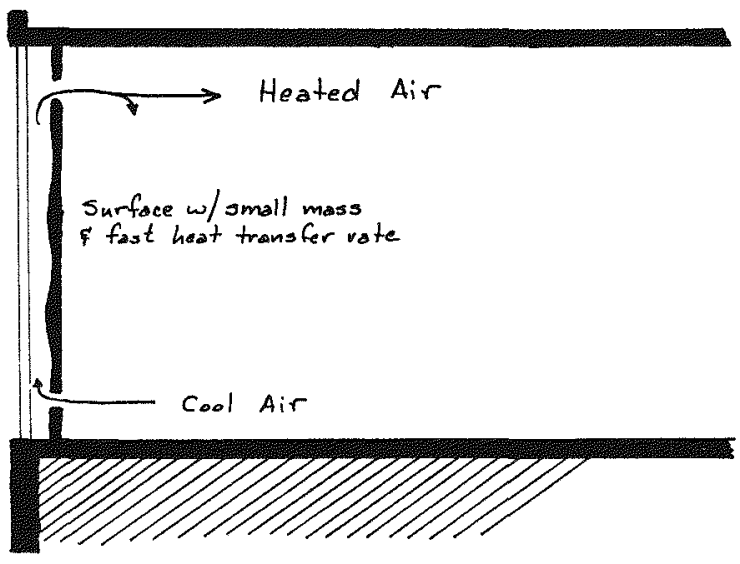

Fig. 22. Douglas County High School prompt wal1.

DIRECT GAIM CONCEPT
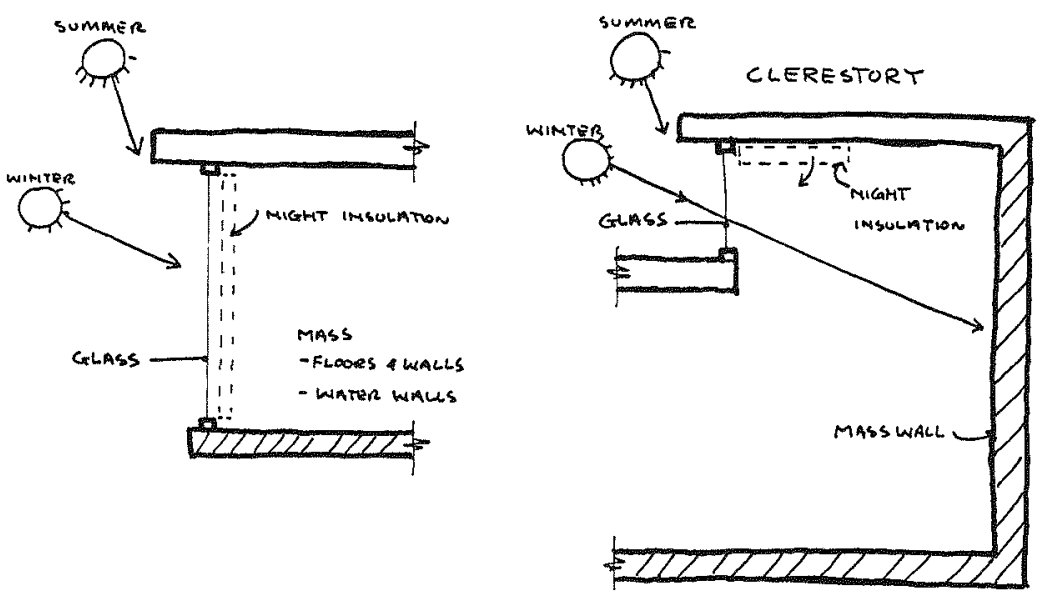

Fig. 23. Douglas County High School direct gain concept.

Storage for Energy / Utility Constraints

- Peoples gas - max. 4500 cfh

- Can use a central hydronic heating system with hot water storage

- Charge storage with off-peak gas

- Also provides for easy addition of active solar heating 


\section{BICKLE CNR}

\section{KQEO-KZZX RADIO STATION}

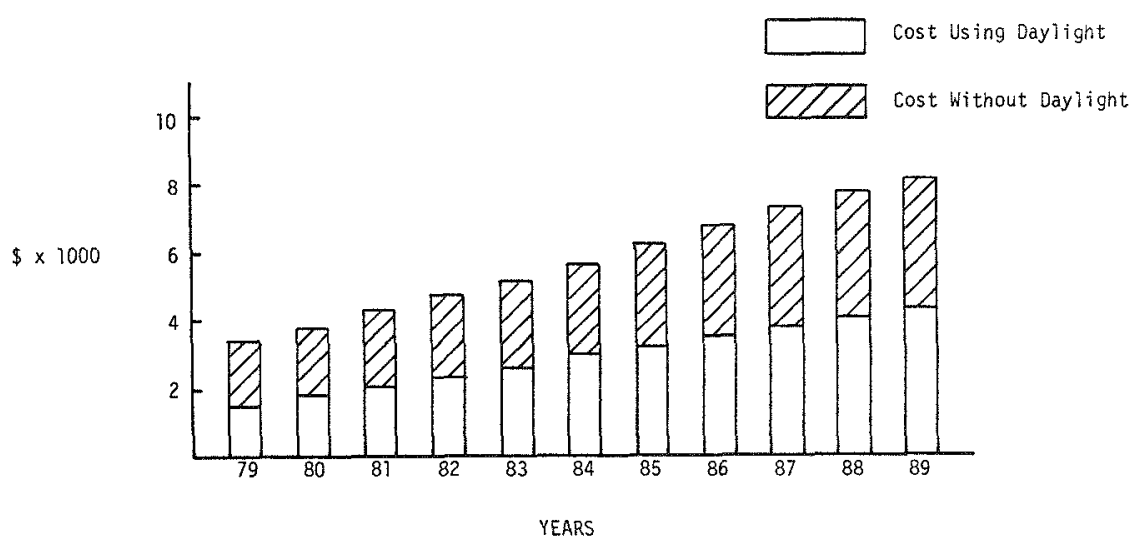

Fig. 24. Yearly savings with daylighting

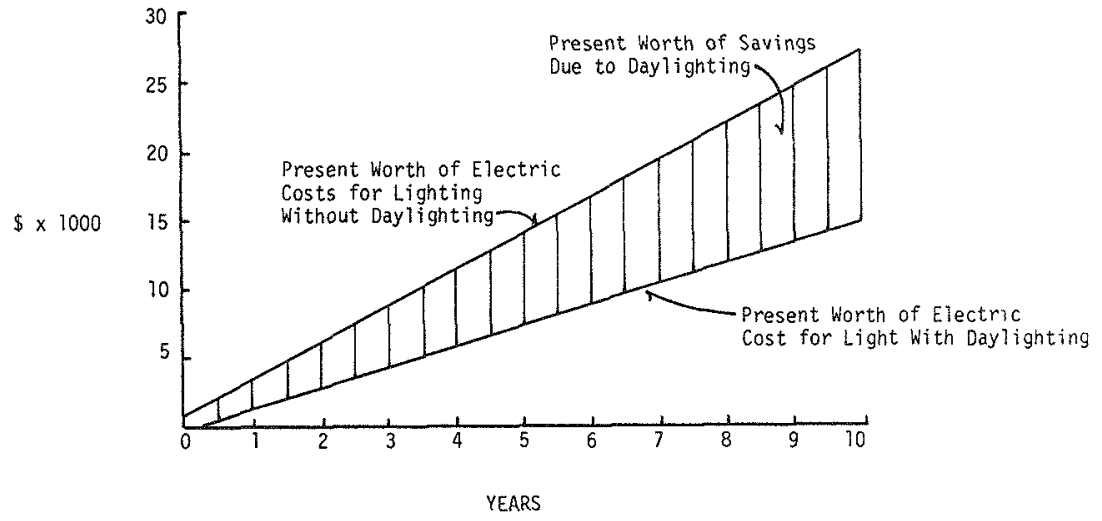

Fig. 25. Cumulative savings with natural lighting 


\section{BICKLE CN}

\section{KQEO - KZZX RADIO STATION}

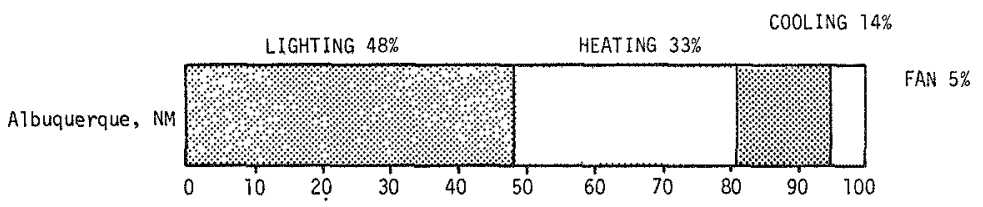

Fig. 26 Energy end use breakdown for a typical office* (identifies priorities for future energy design)

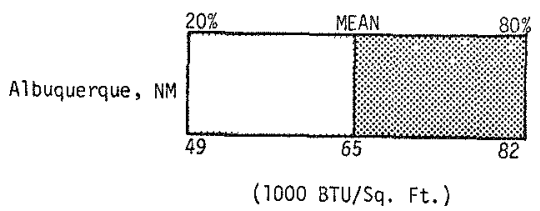

* From AIA/RC Research on Building Energy Performance Standards

Fig.27 Annual energy use for a typical office* 
IUIAL ANNUAL ENERGY CONSUMPTION $33,095 \mathrm{BTU} / \mathrm{SQ}$.FT.

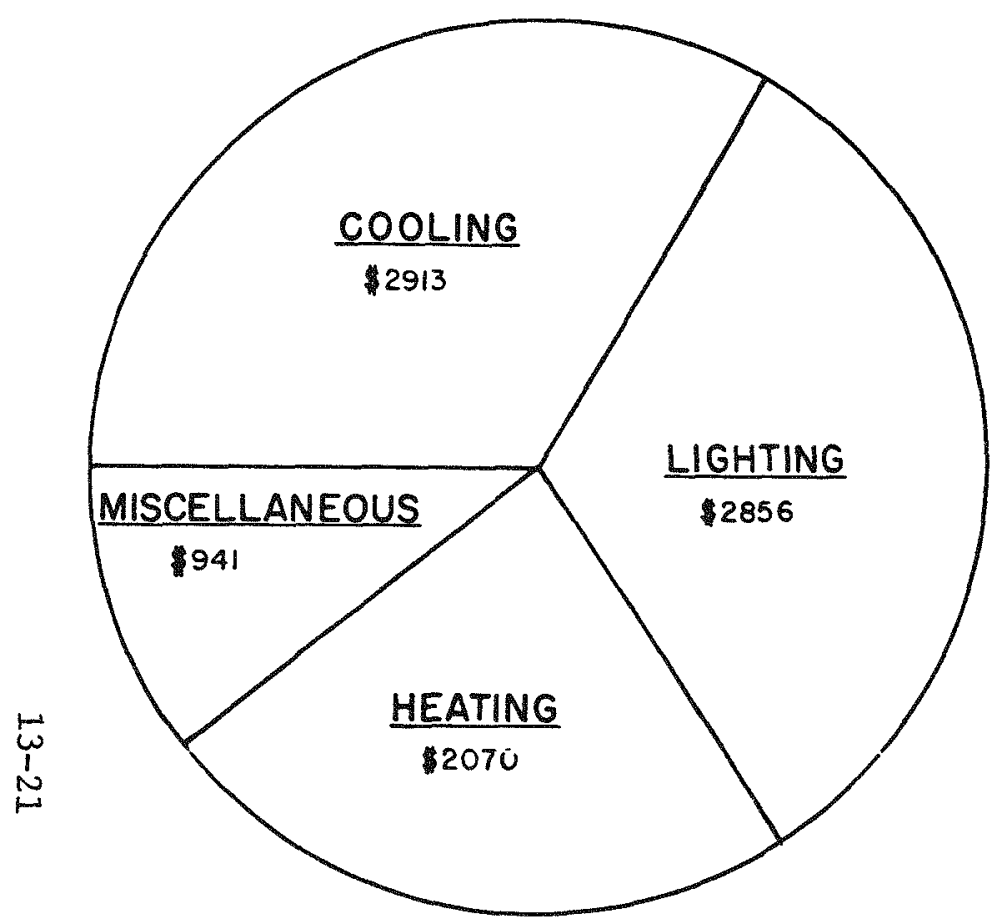

\section{ORIGINAL BUILDING ENERGY COST}

ELECTRICAL RATE -

$\begin{array}{rrr}0-500 \mathrm{KWH} & \$ .04294 \\ 501-15,000 \mathrm{KWH} & \$ .03634 \\ 15,001-40,000 \mathrm{KWH} & \$ .02268 \\ 40,001-100,000 \mathrm{KWH} & \$ .02098 \\ 100,001-500,000 \mathrm{KWH} & \$ .01998 \\ \text { Above }-500,000 \mathrm{KWH} & \$ .01958\end{array}$

DEMAND RATE -

$\begin{array}{rrr}0 & 50 \mathrm{KW} & \$ .00 \\ 51- & 100 \mathrm{KW} & \$ 3.45 \\ \text { Above }- & 100 \mathrm{KW} & \$ 3.65\end{array}$

GAS RATE -

$\begin{array}{rlr}0- & 150 \text { THERMS } & \$ .4133 \\ 151- & 750 \text { THERMS } & \$ .3252 \\ \text { Above }- & 750 \text { THERMS } & \$ .3012\end{array}$

GROSS FLOOR AREA

$26,593 \mathrm{SQ} . \mathrm{FT}$.

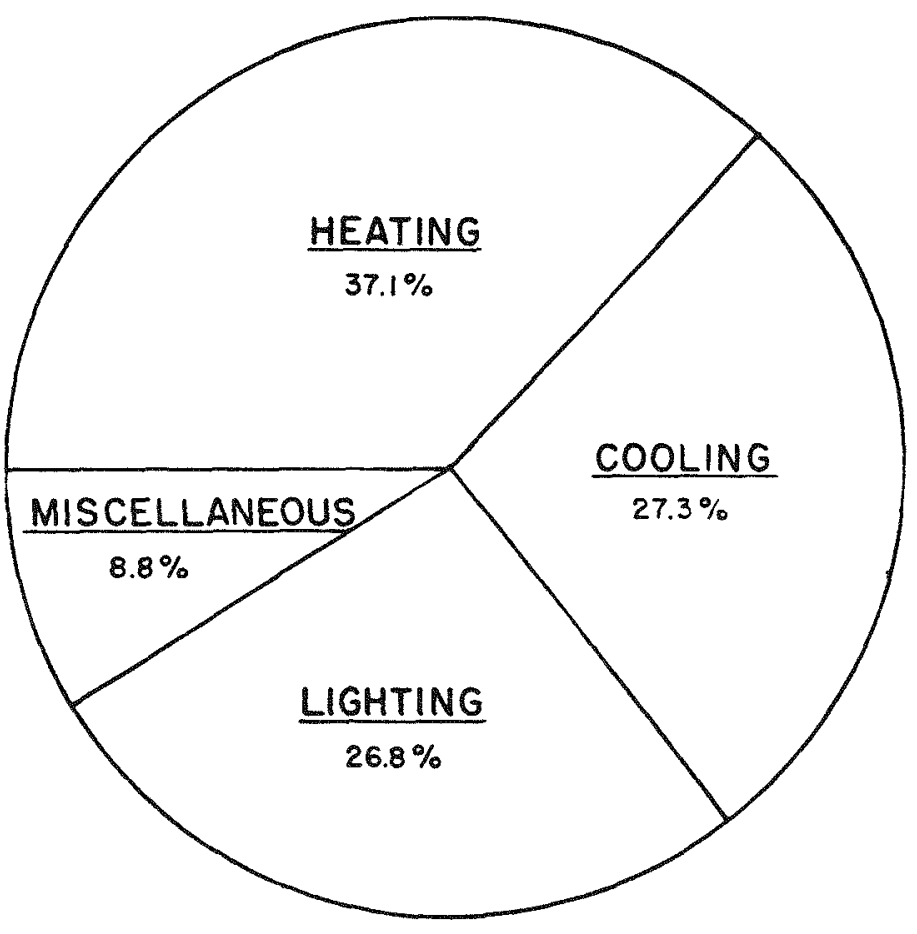

ORIGINAL BUILDING ENERGY CONSUMPTION

HVAC SYSTEM -

Packaged single-zone rooftop air conditioning units with gas heating complement (62.5 tons total cooling capacity).

LIGHTING SYSTEM -

$2 \times 4$ Lay-in fluorescent fixtures $(1.7 \mathrm{w.} / \mathrm{sq} . \mathrm{ft}$.$) .$

Skylights provide daylighting supplement.

Fig. 28. Statement of energy needs in end use Btu's and dollars. Abrams Primary School for Bessemer, Alabama, board of education (courtesy of Cobb/Adams/Benton, Inc.) 


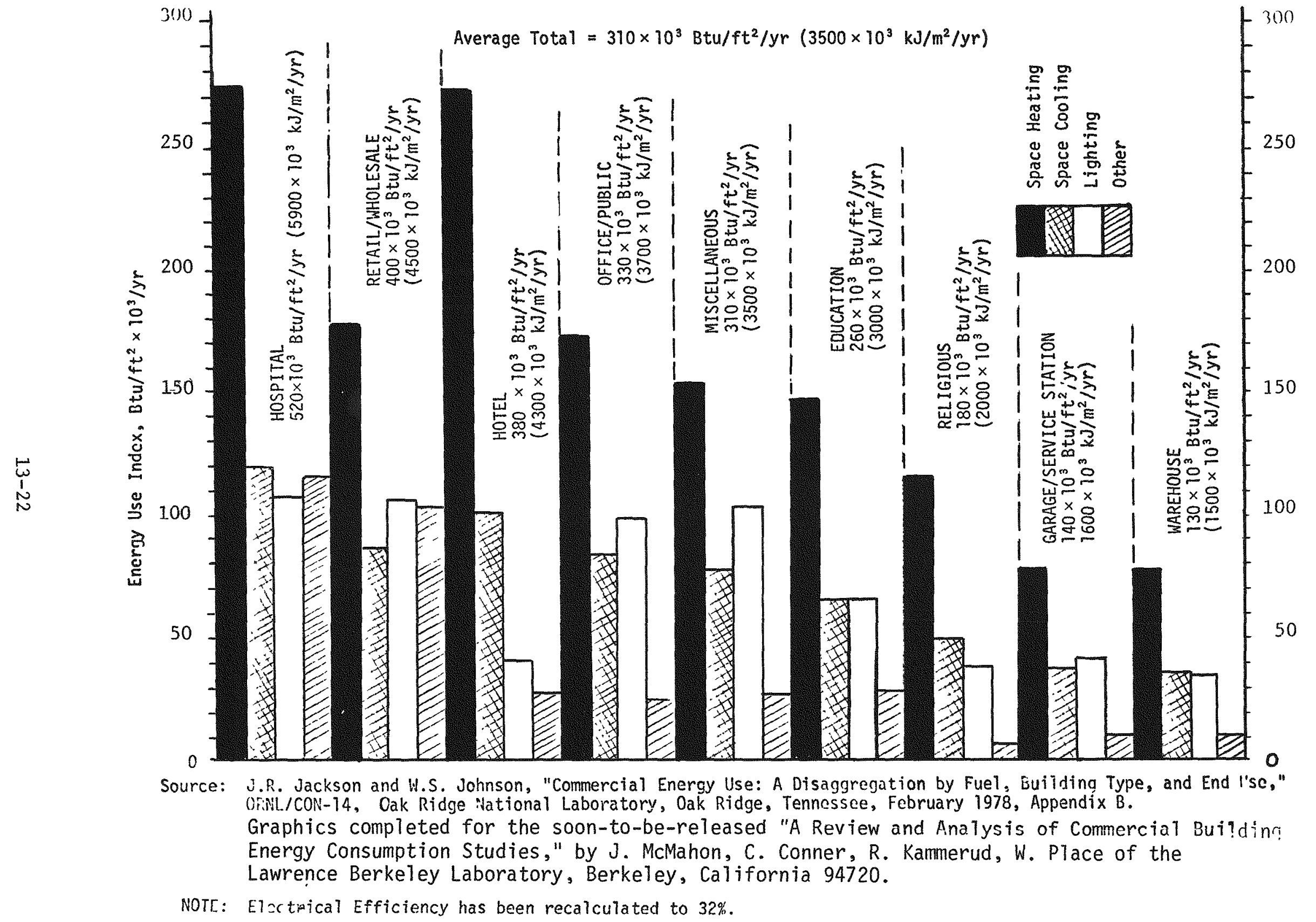

Fig. 29. Energy use index by building type, 1975 


\section{Douglas County High School}

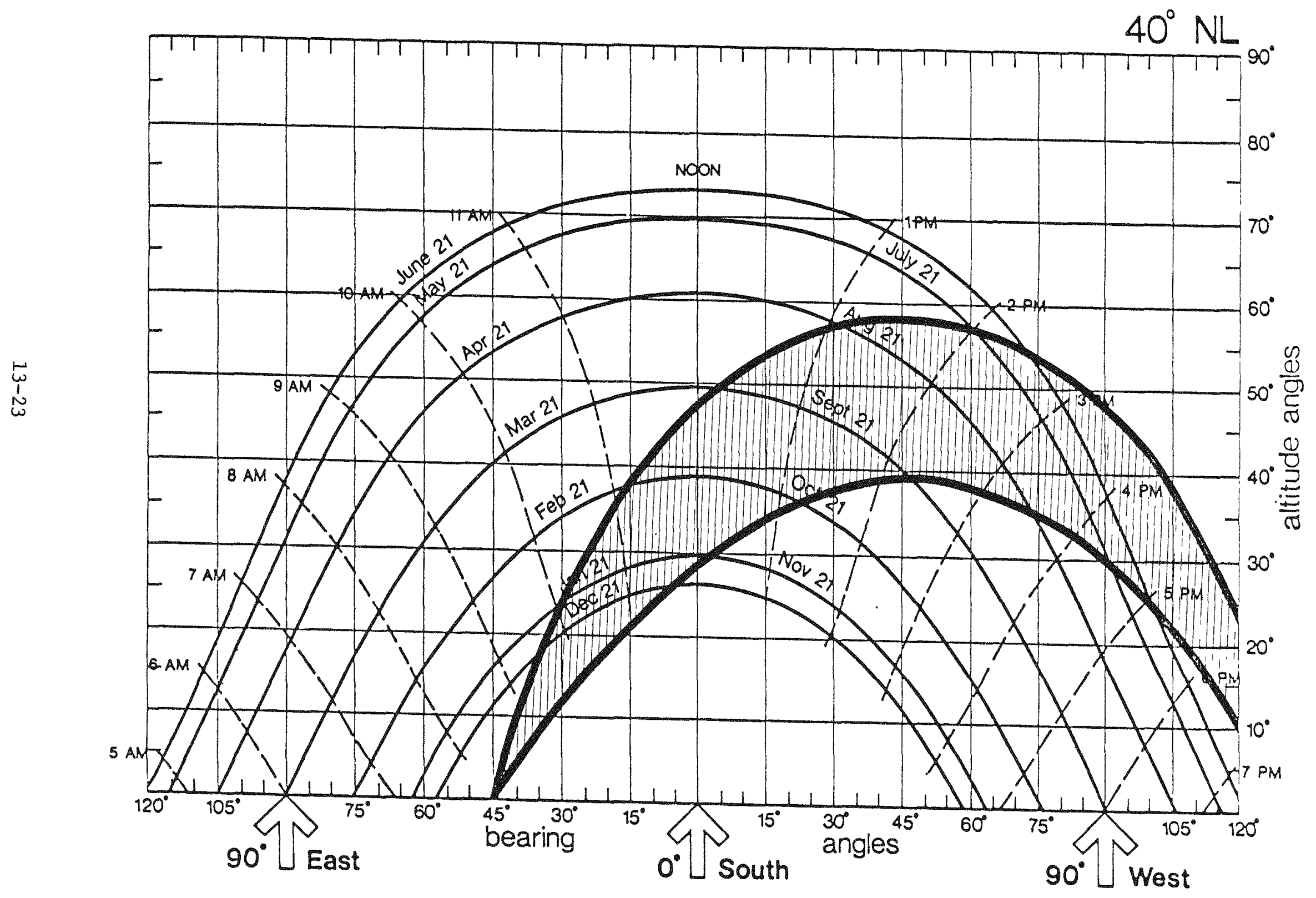

Fig. 30. Shading mask 


\section{STORES:}

\section{0,171 mean square feet}

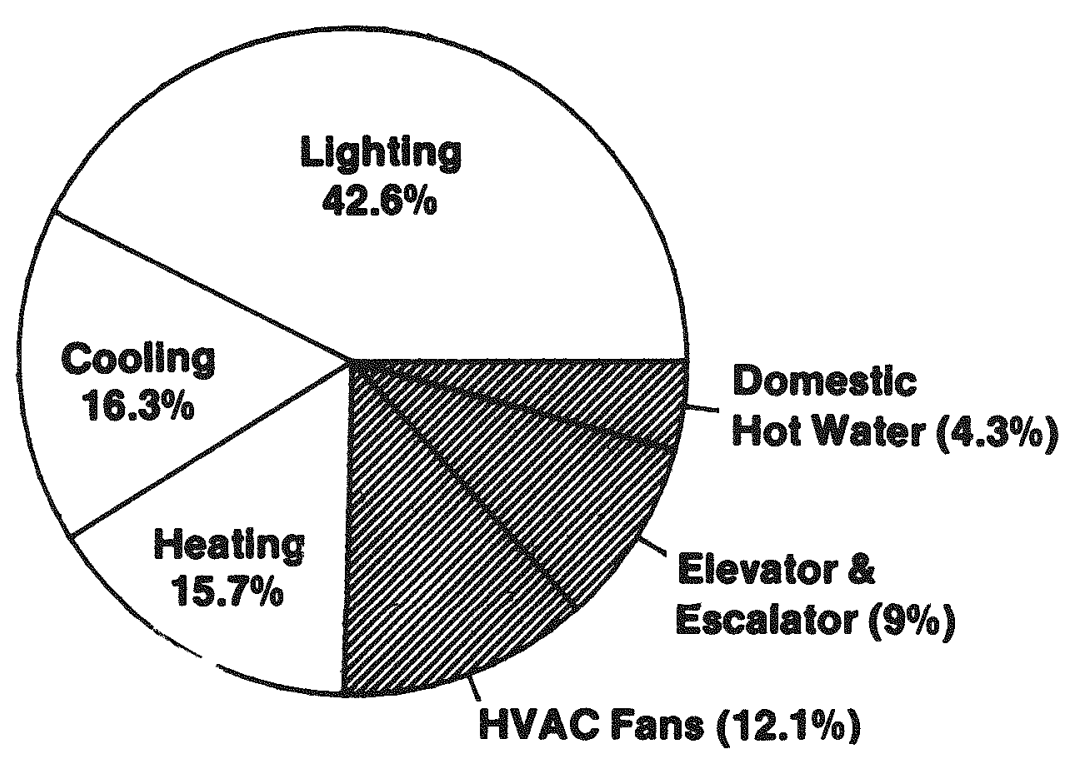

With RUF's

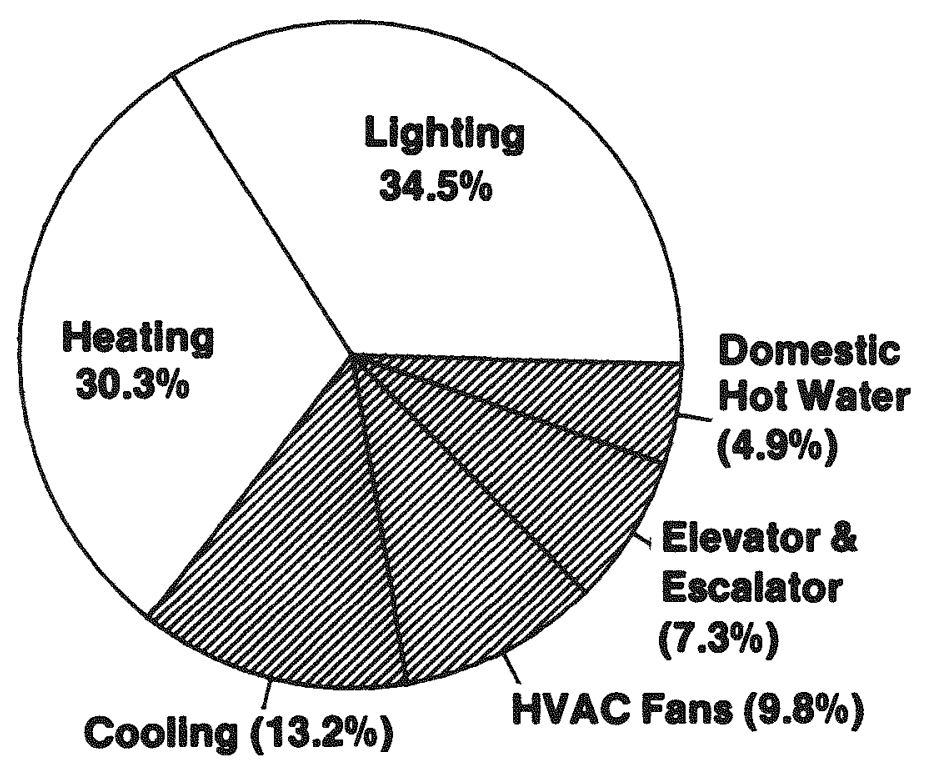

End Use Btu's 


\section{SHOPPING CENTERS:}

\section{7,898 mean square feet}

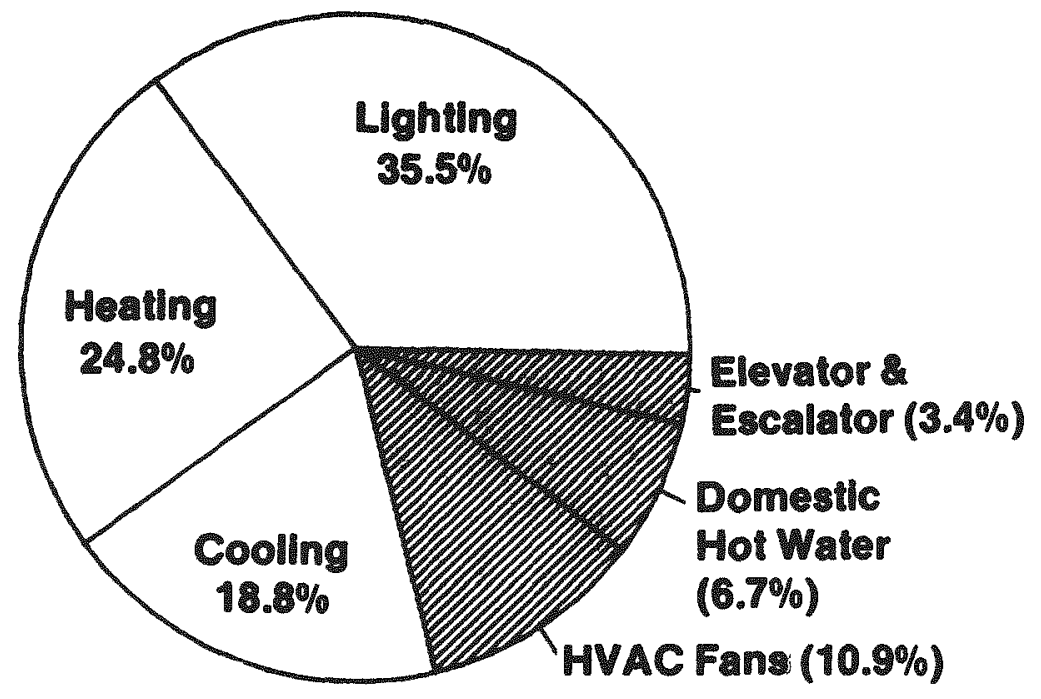

With RUF's

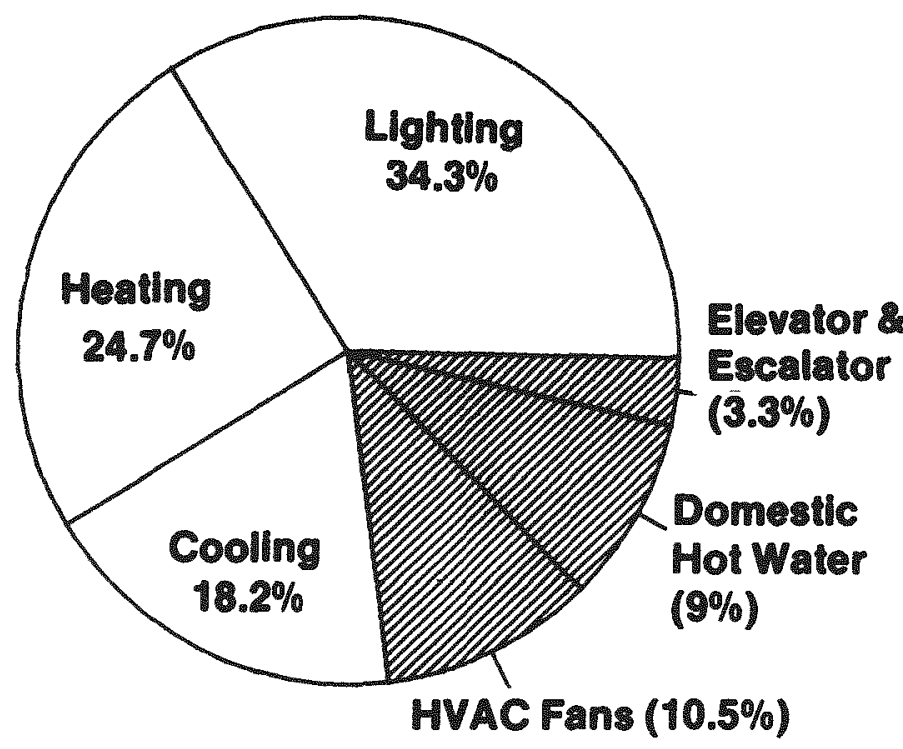

End Use Btu's 


\section{SMALL OFFICES:}

\section{7,311 mean square feet}

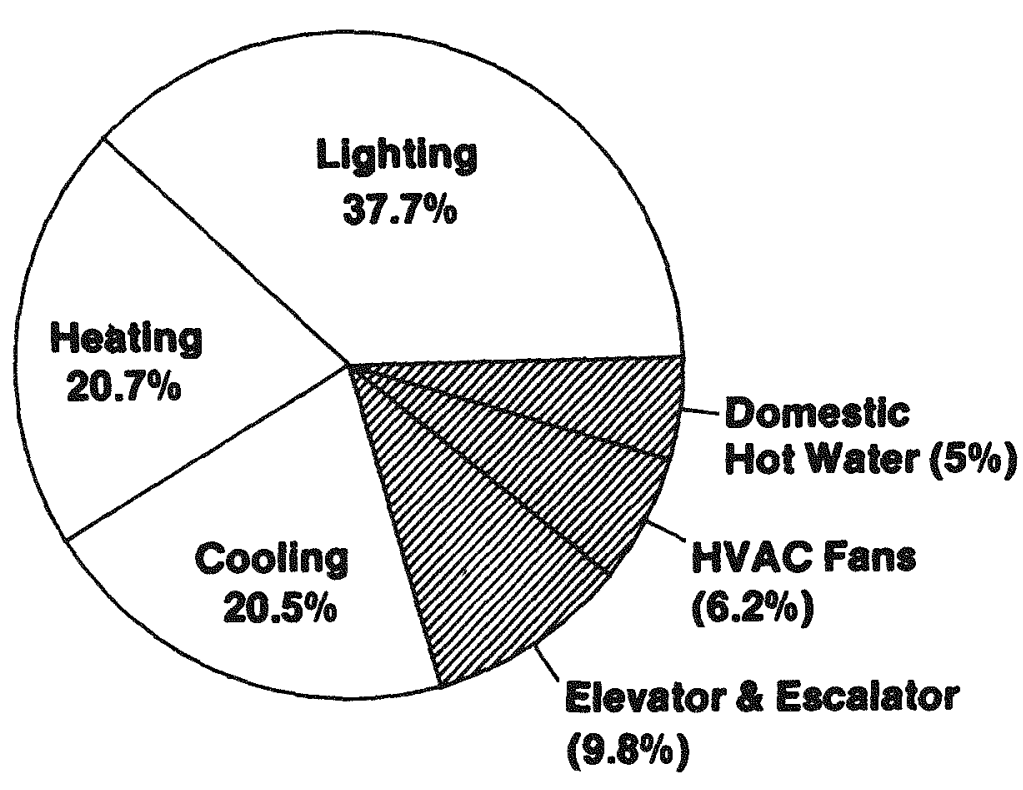

With RUF's

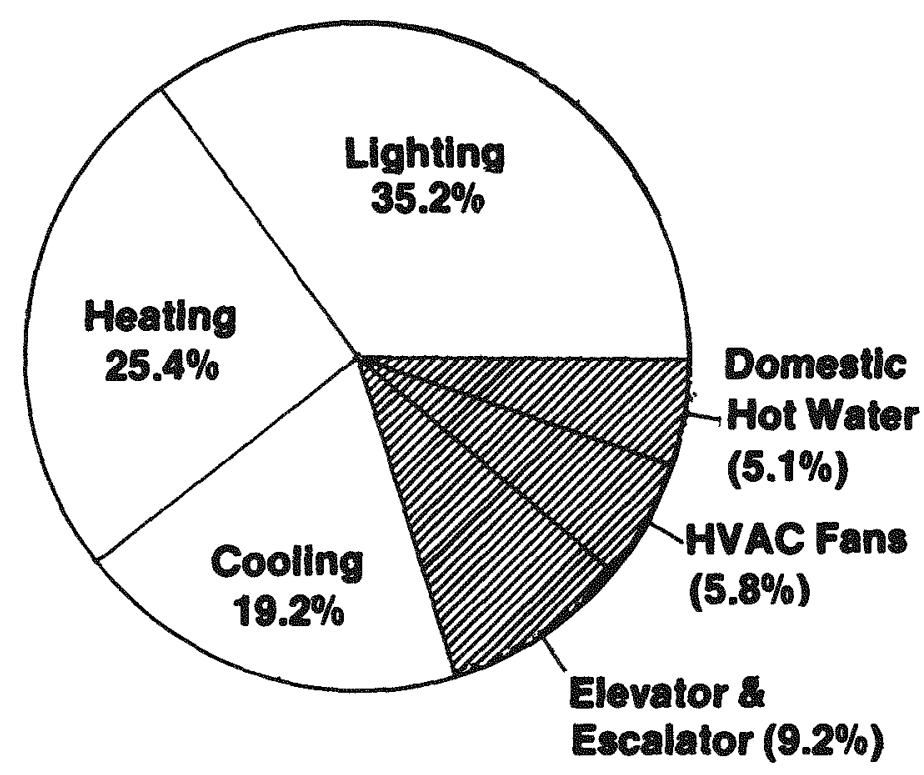

End Use Btu's 


\section{LARGE OFFICES:}

174,894 mean square feet

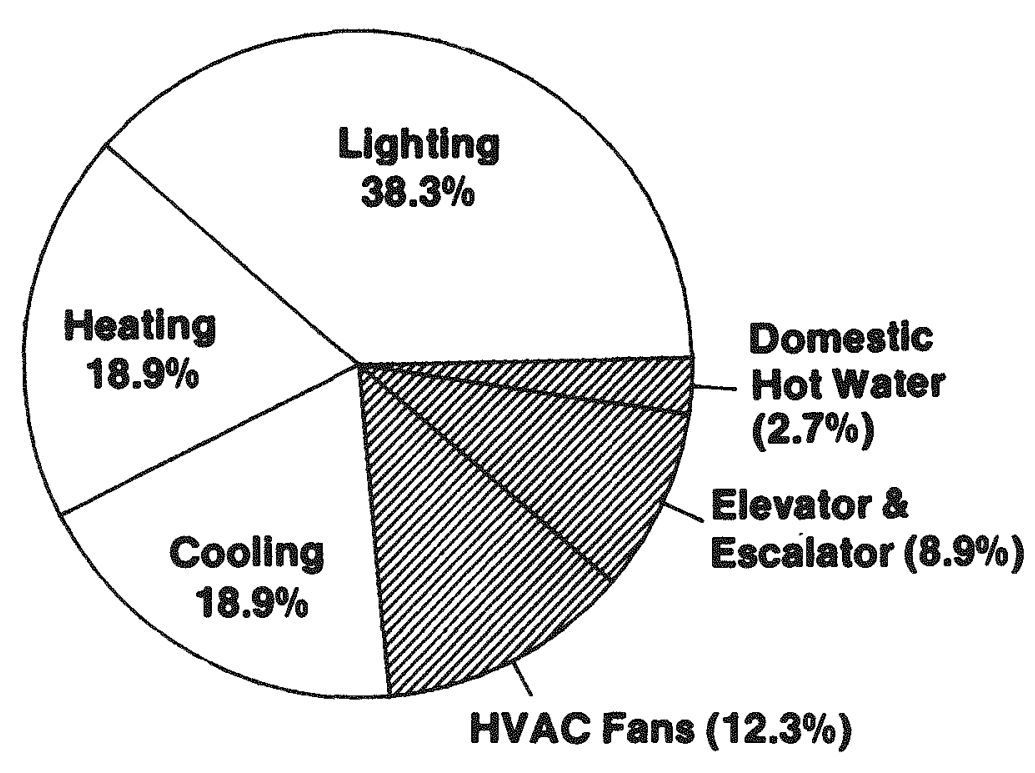

With RUF's

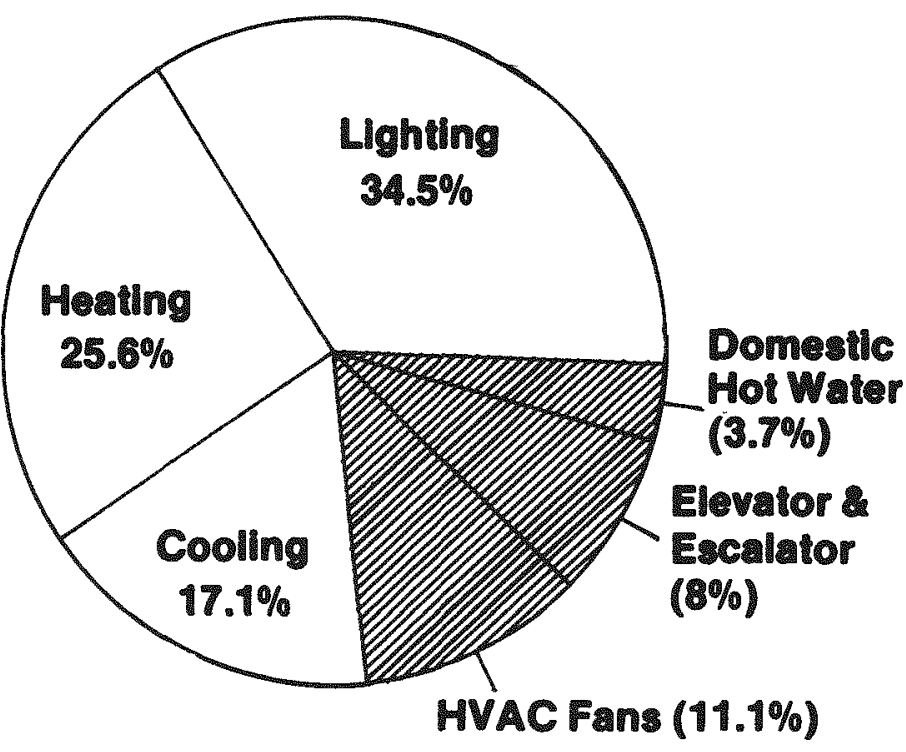

End Use Btu's 


\section{ELEMENTARY SCHOOLS: 51,018 mean square feet}

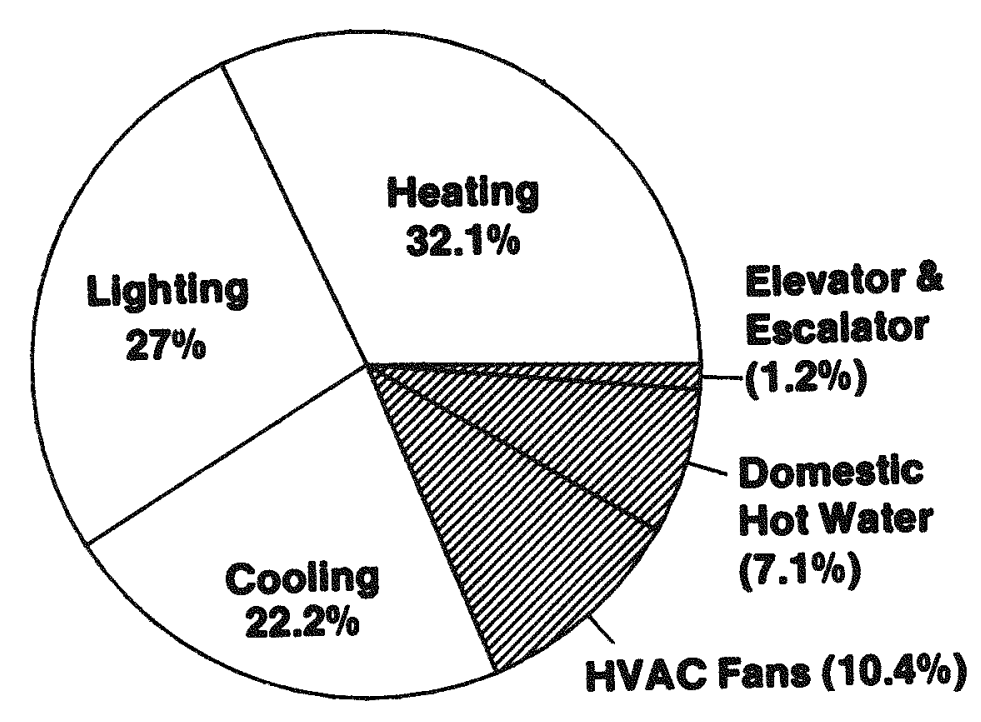

With RUF's

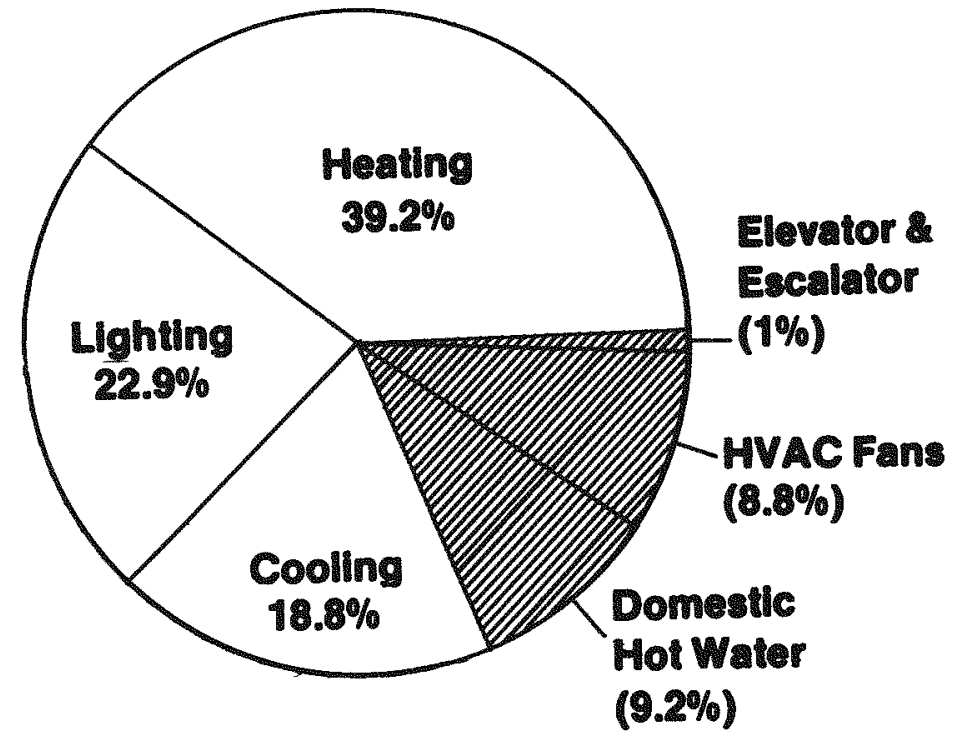

End Use Btu's 


\section{SECONDARY SCHOOLS:}

106,784 mean square feet

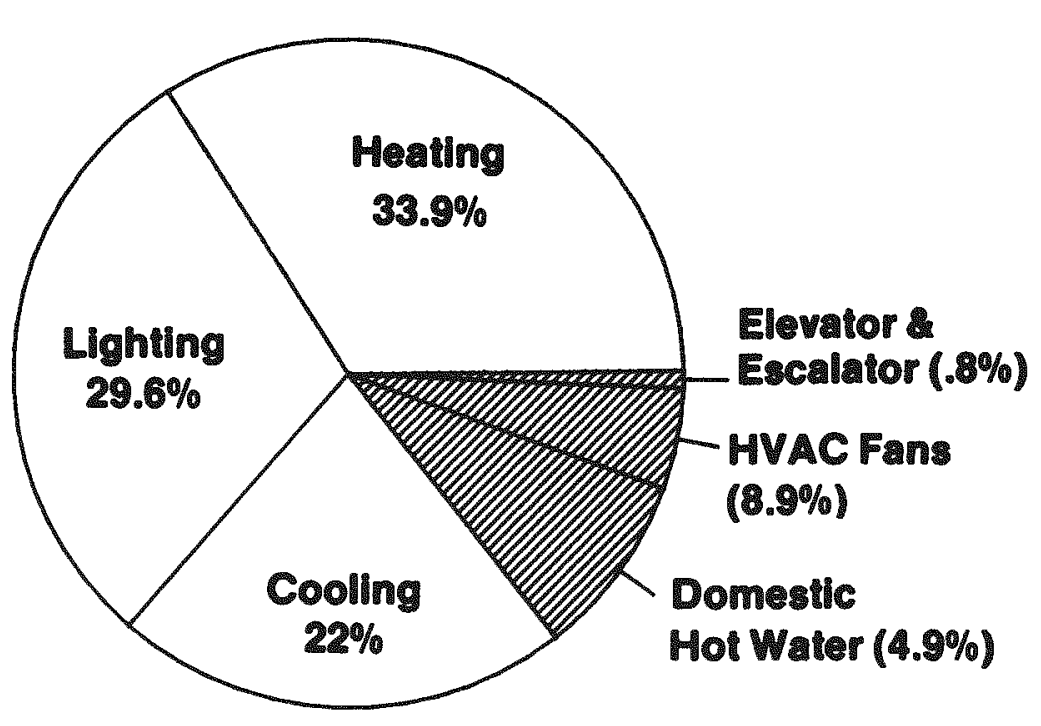

With RUF's

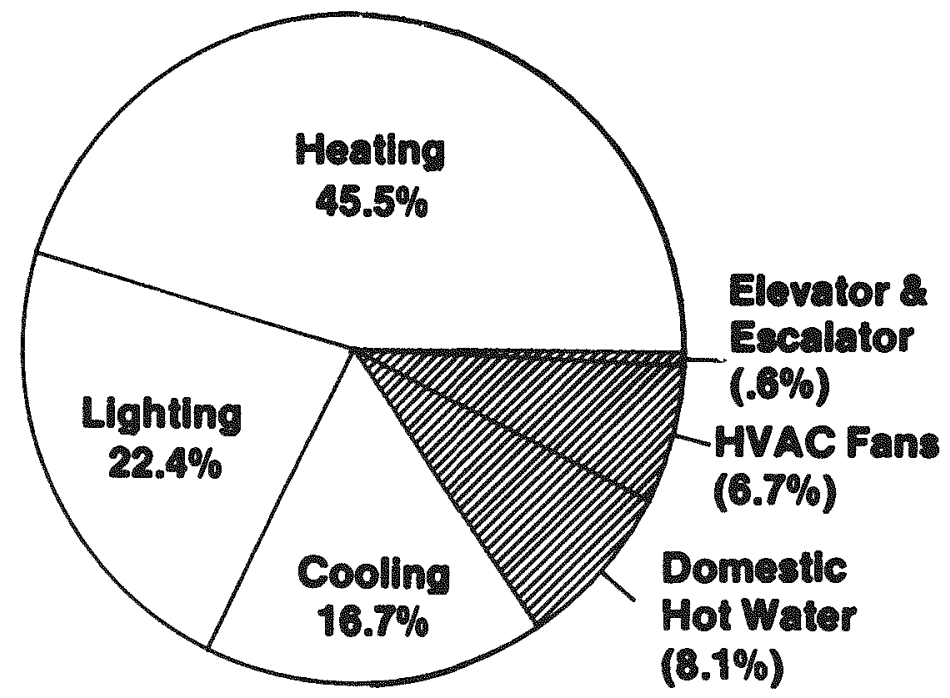

End Use Btu's 


\section{CLINICS:}

\section{6,980 mean square feet}

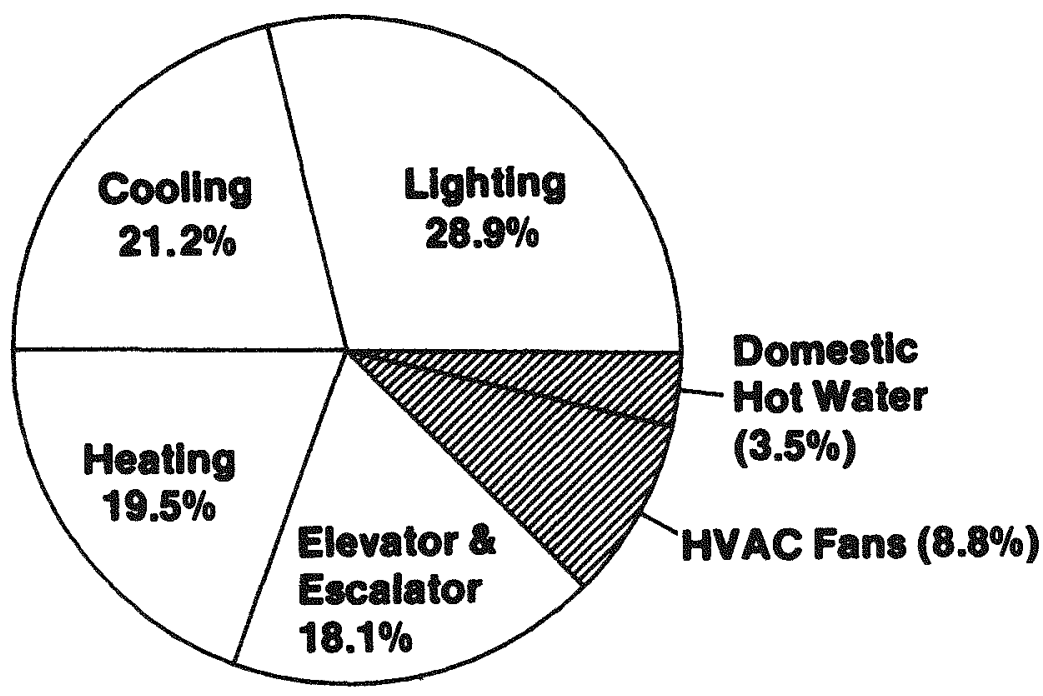

With RUF's

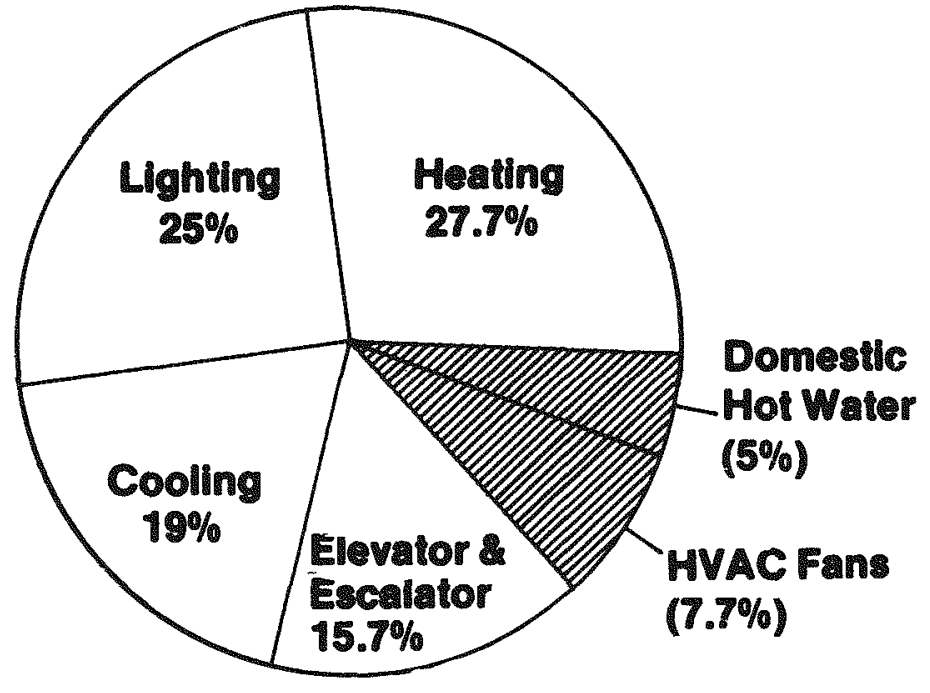

End Use Btu's 


\section{HOSPITALS:}

\section{6,321 mean square feet}

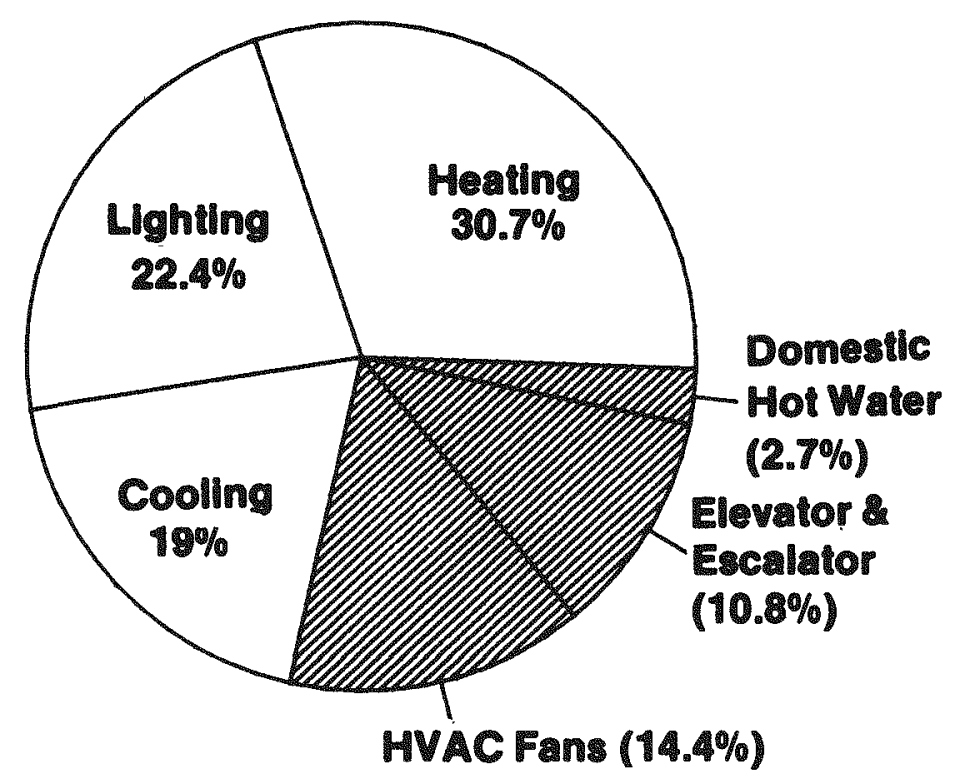

With RUF's

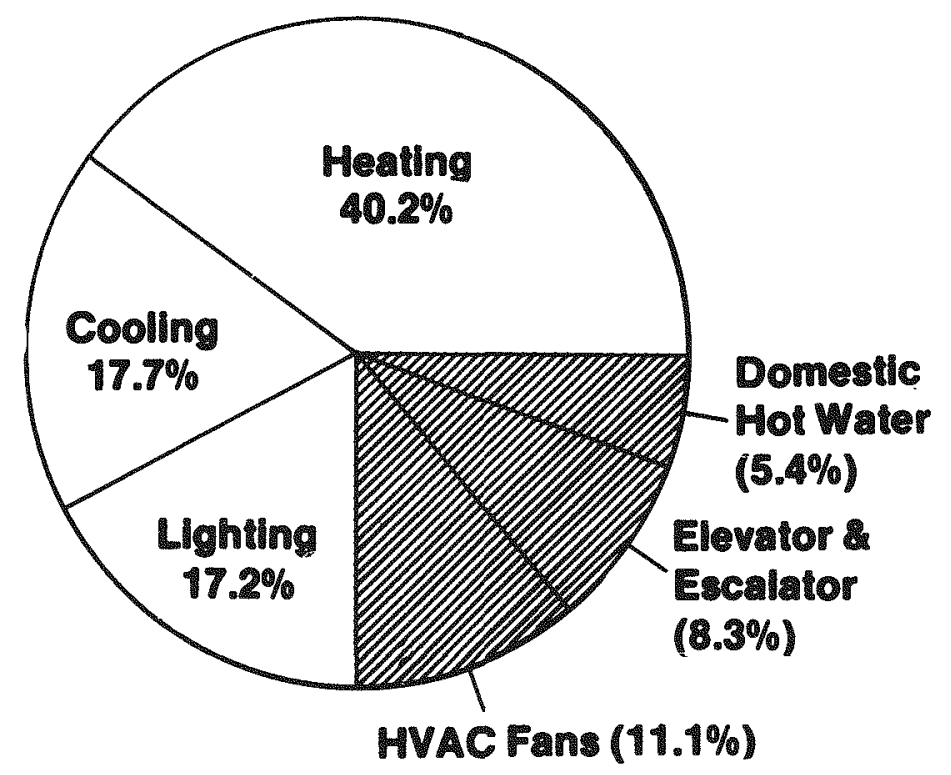

End Use Btu's 


\section{RESTAURANTS:}

\section{5,782 mean square feet}
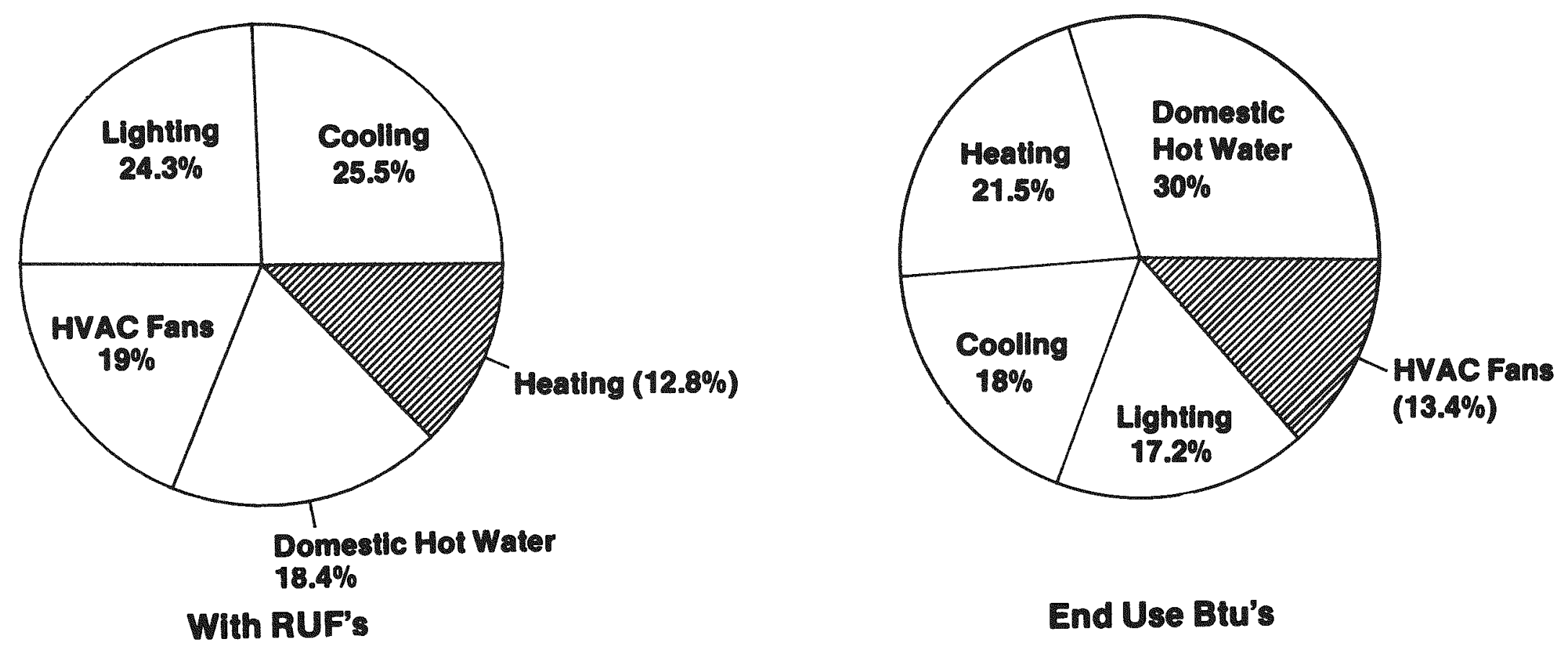

End Use Btu's 


\section{FAST FOOD:}

\section{2,300 mean square feet}

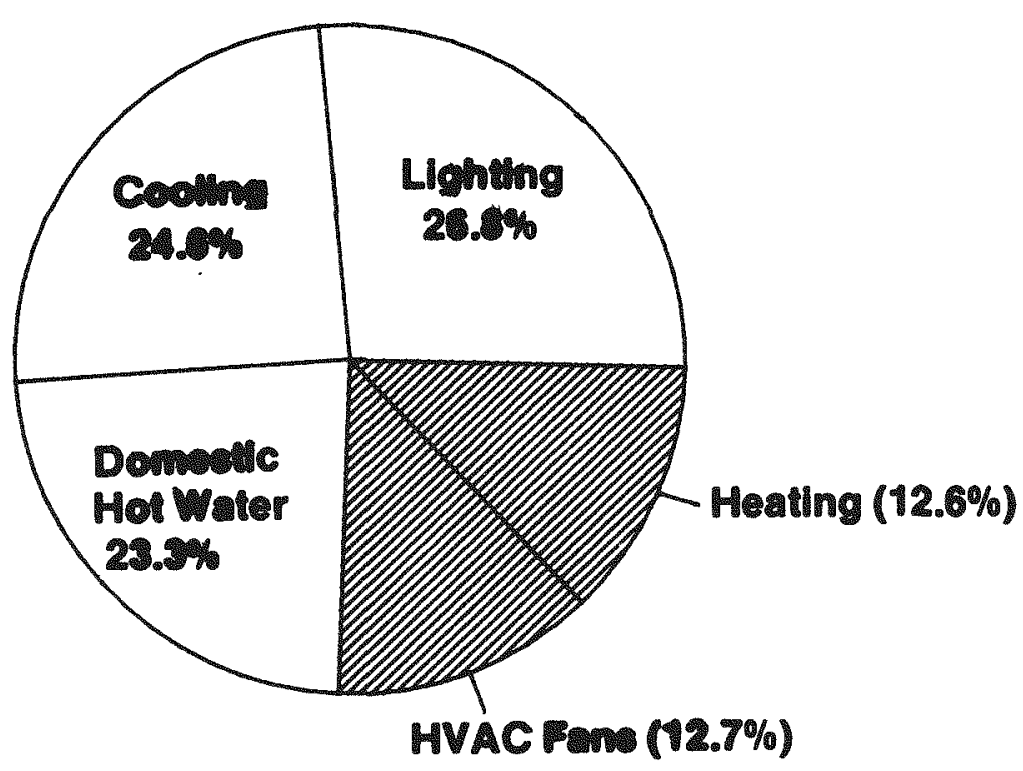

With RUF's

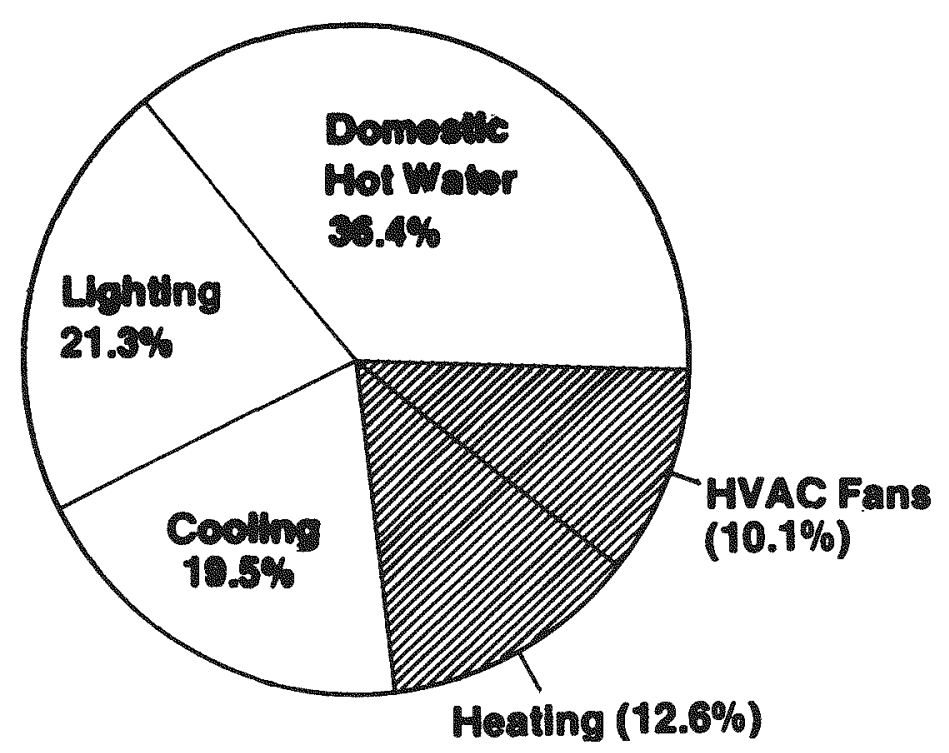

End Use Btu's 


\section{ASSEMBLY:}

\section{6,801 mean square feet}

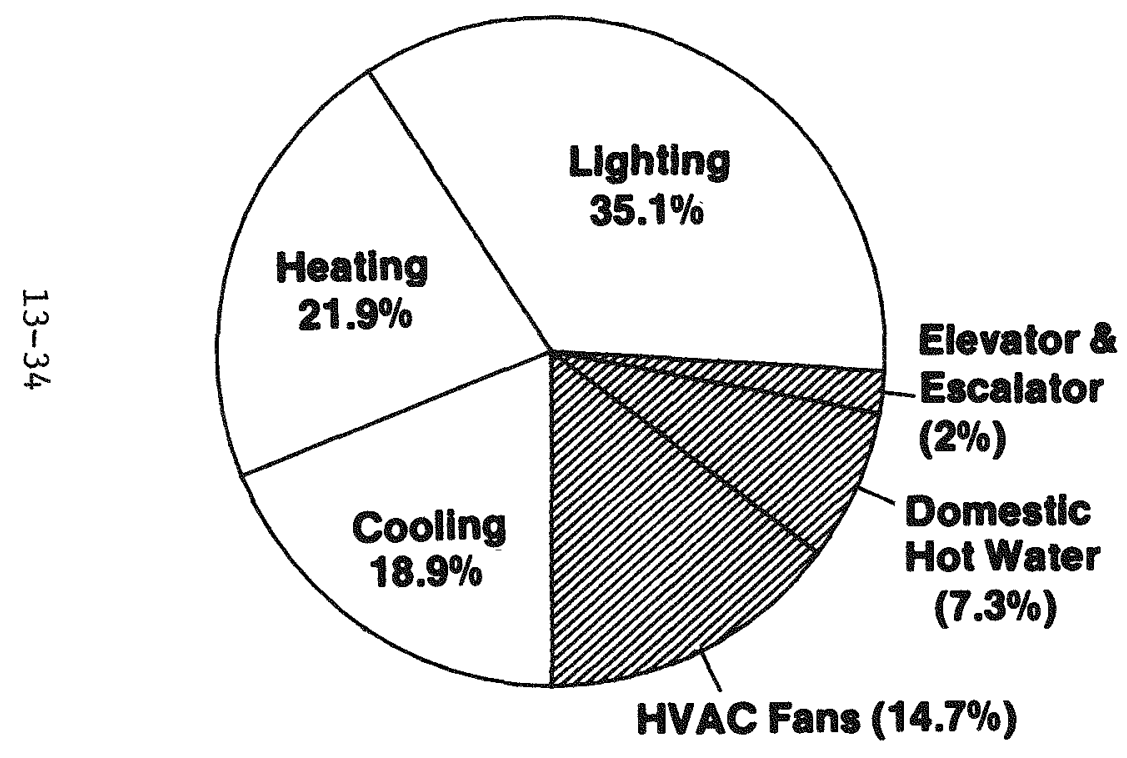

With RUF's

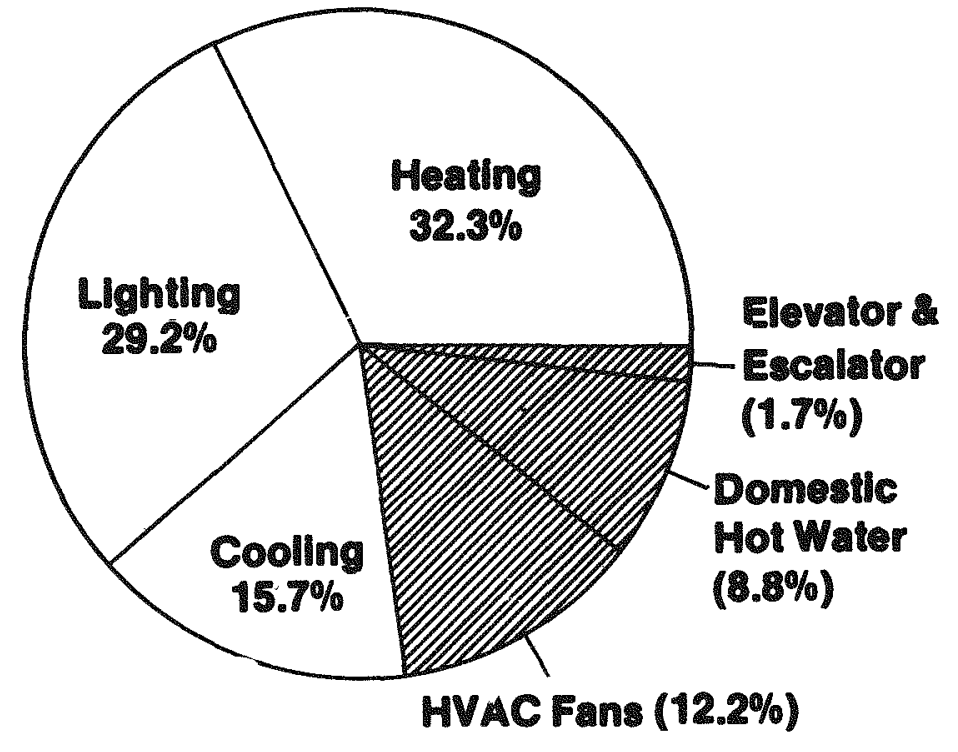

End Use Btu's 


\section{STORAGE:}

41,796 mean square feet
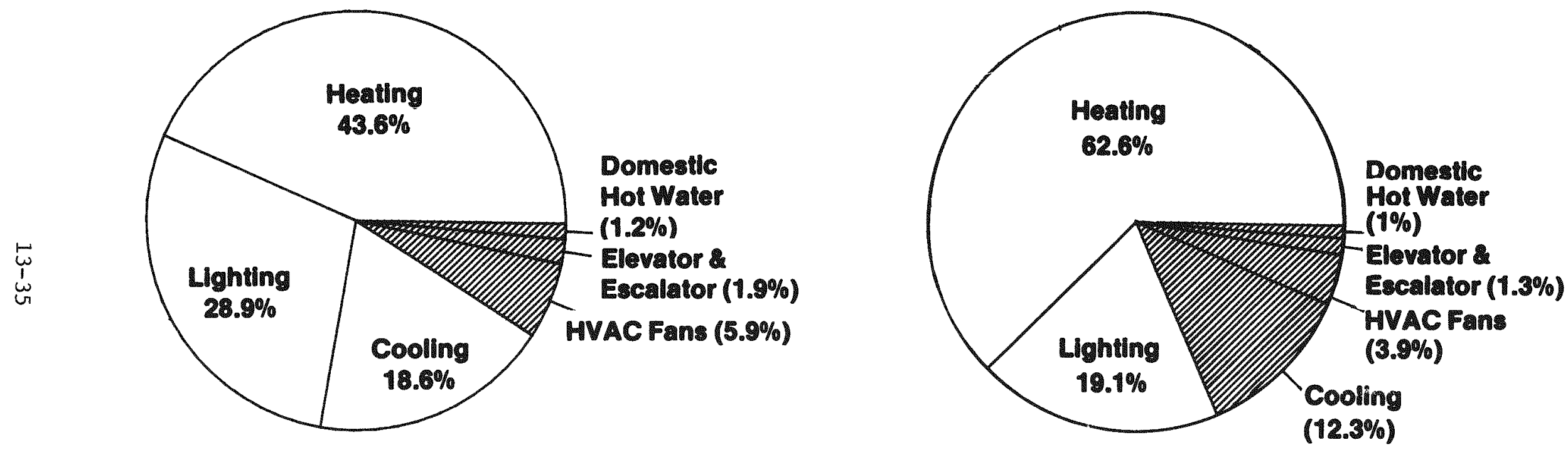

With RUF's

End Use Biu's 


\section{HOTELS/MOTELS:}

\section{2,396 mean square feet}

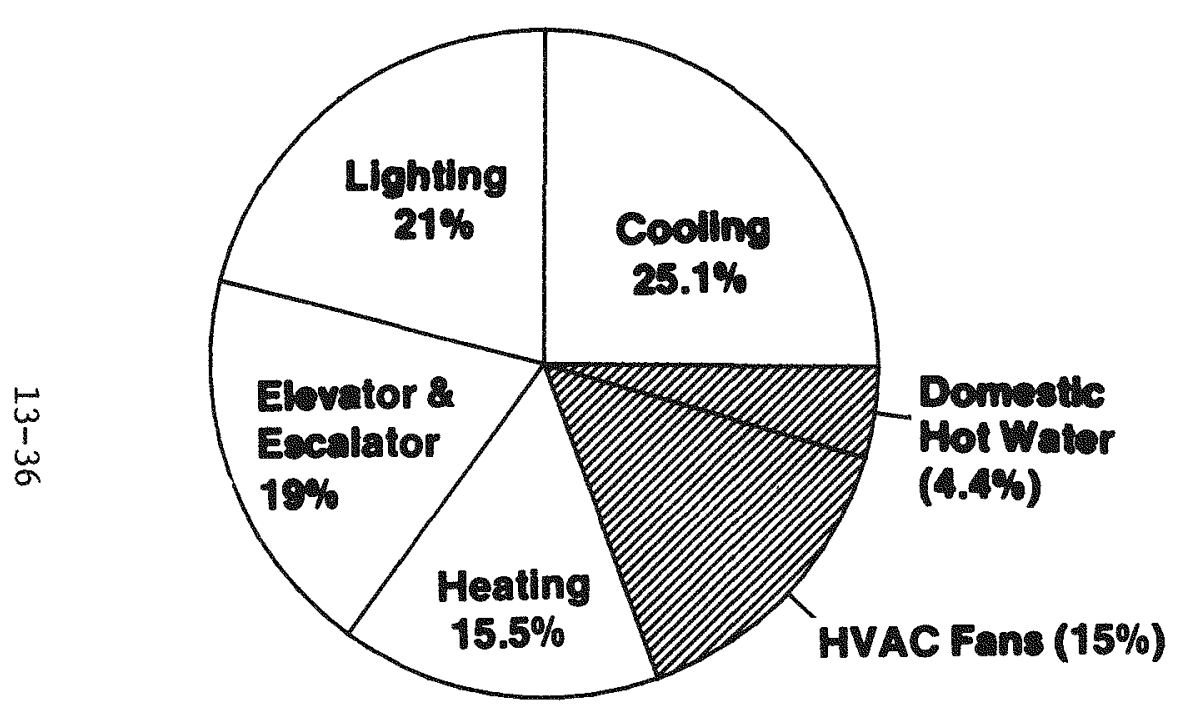

With RUF's

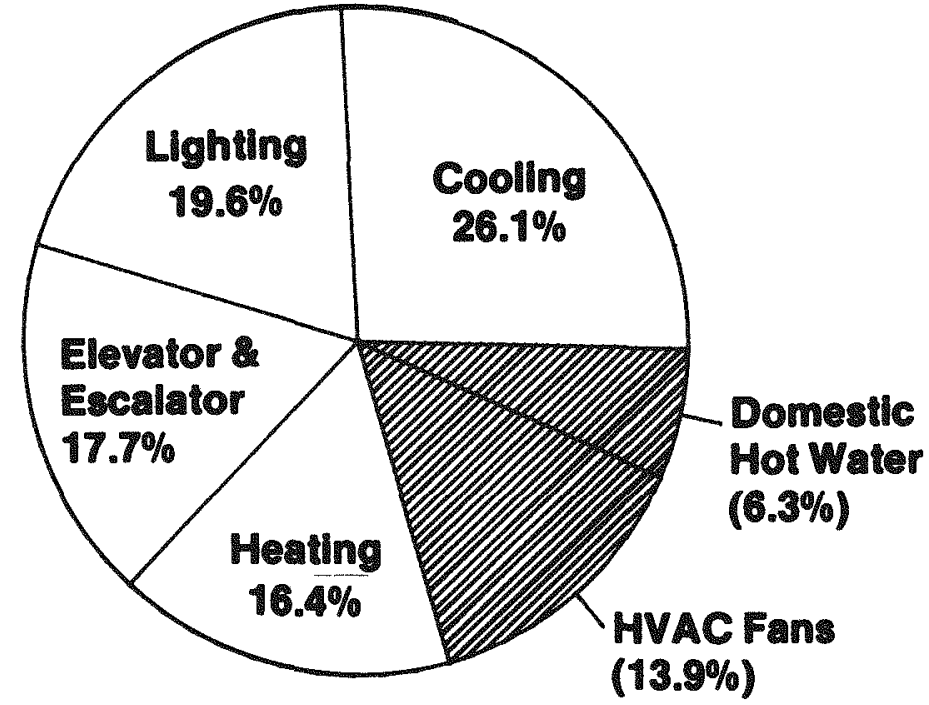

End Use Btu's 
NURSING HOMES/DORMS:

45,773 mean square feet

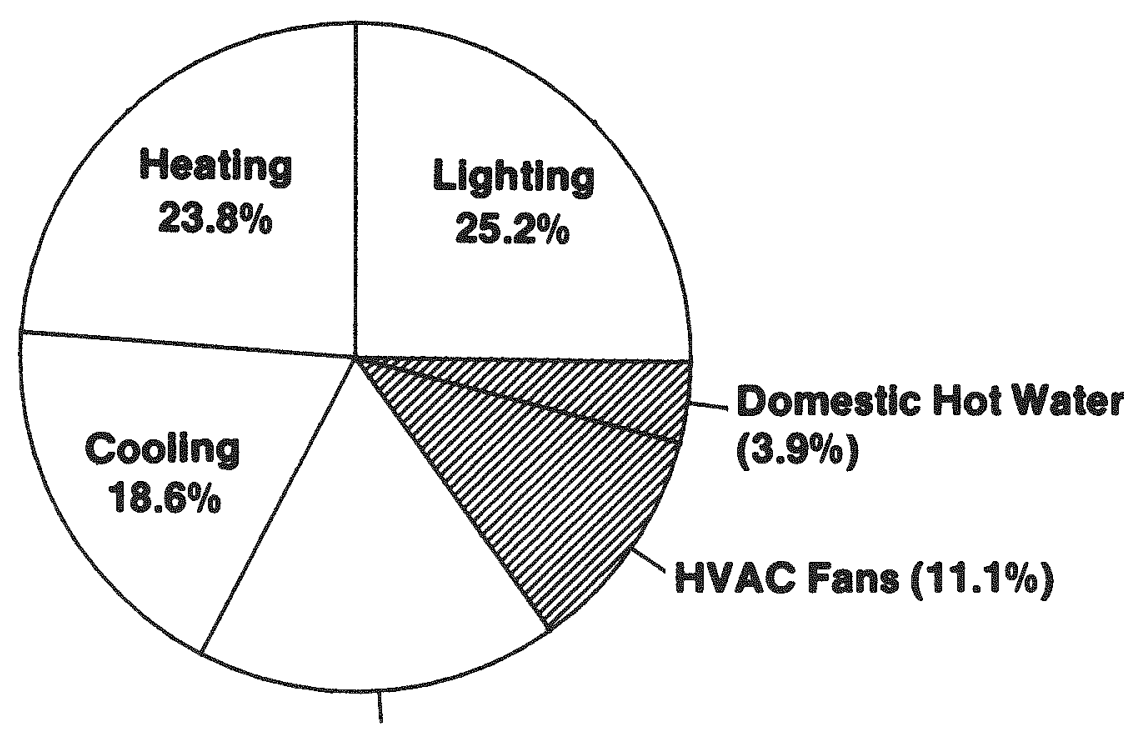

Elevator Escalator $17.5 \%$ With RUF's

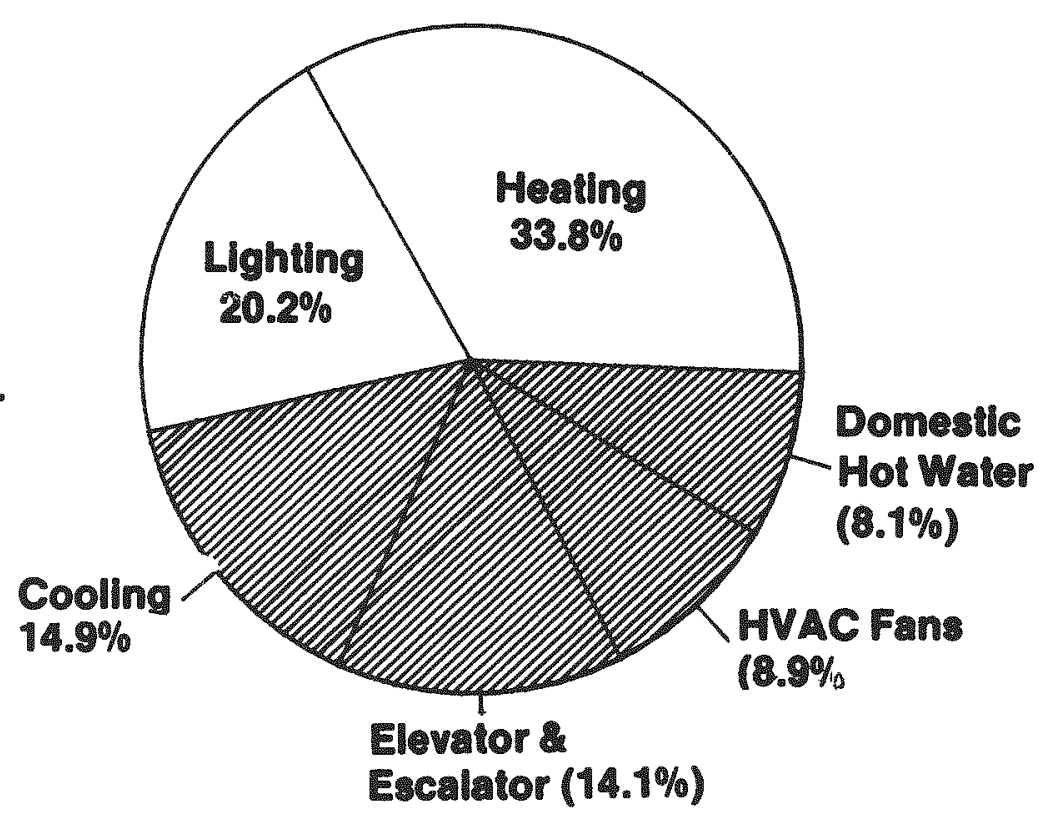

End Use Btu's 


\section{MULTI-FAMILY LOW RISE:}

57,730 mean square feet

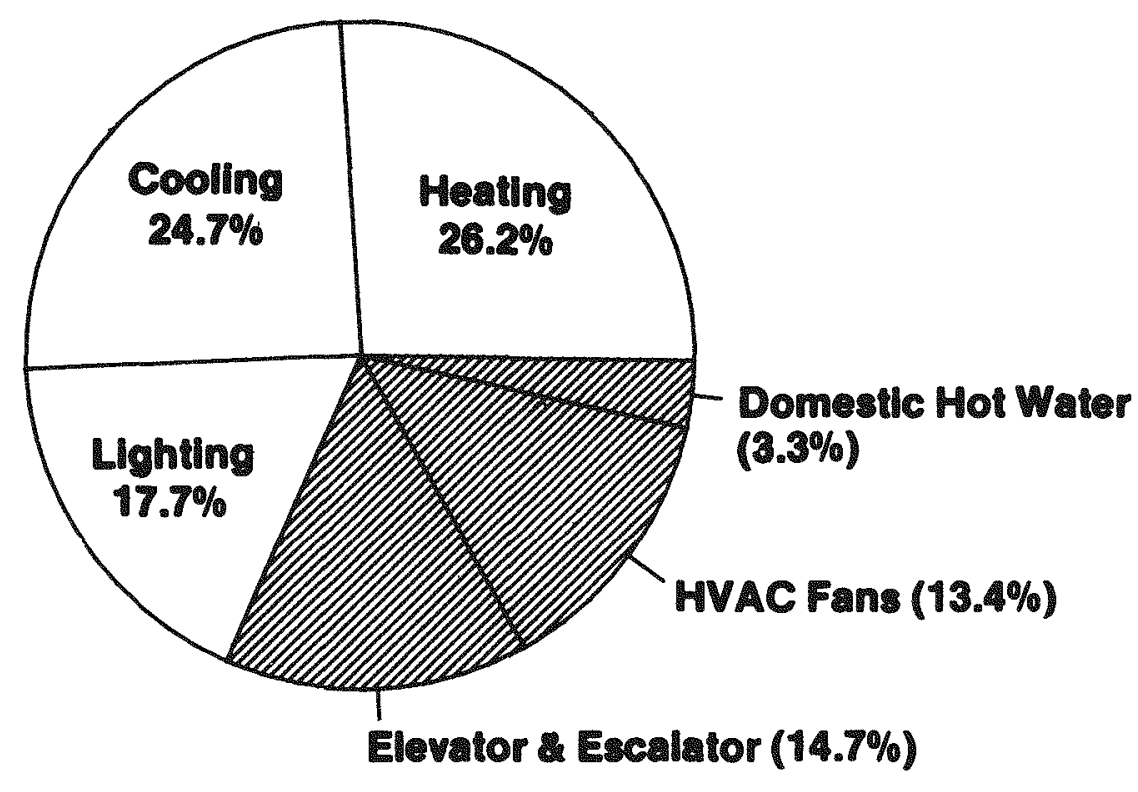

With RUF's

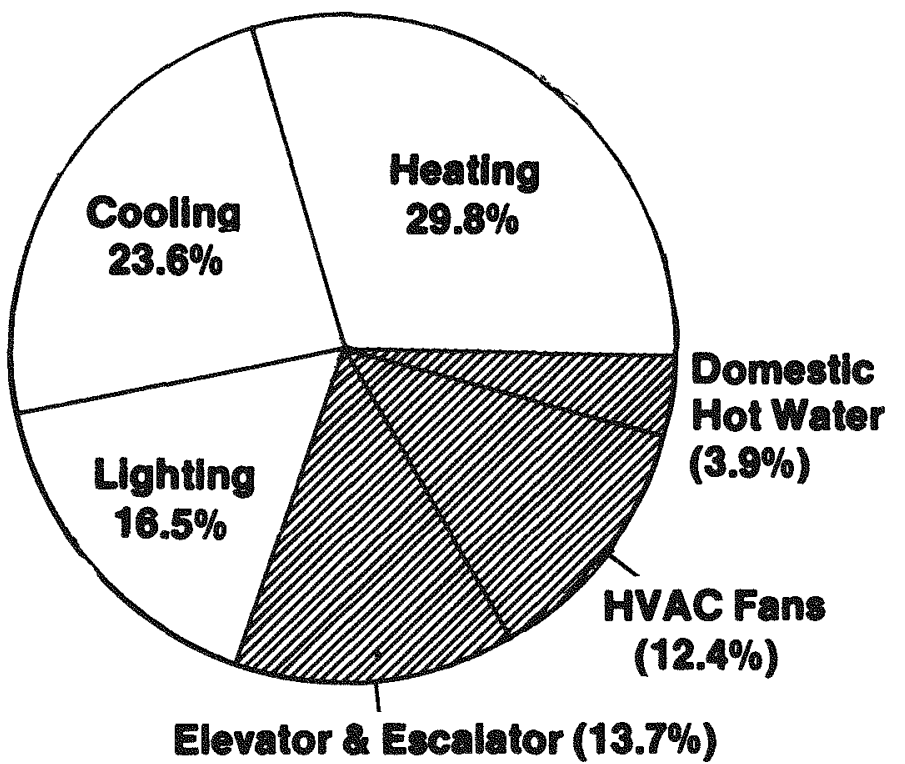

End Use Btu's 


\section{HIGH RISE APARTMENTS:}

\section{4,242 mean square feet}

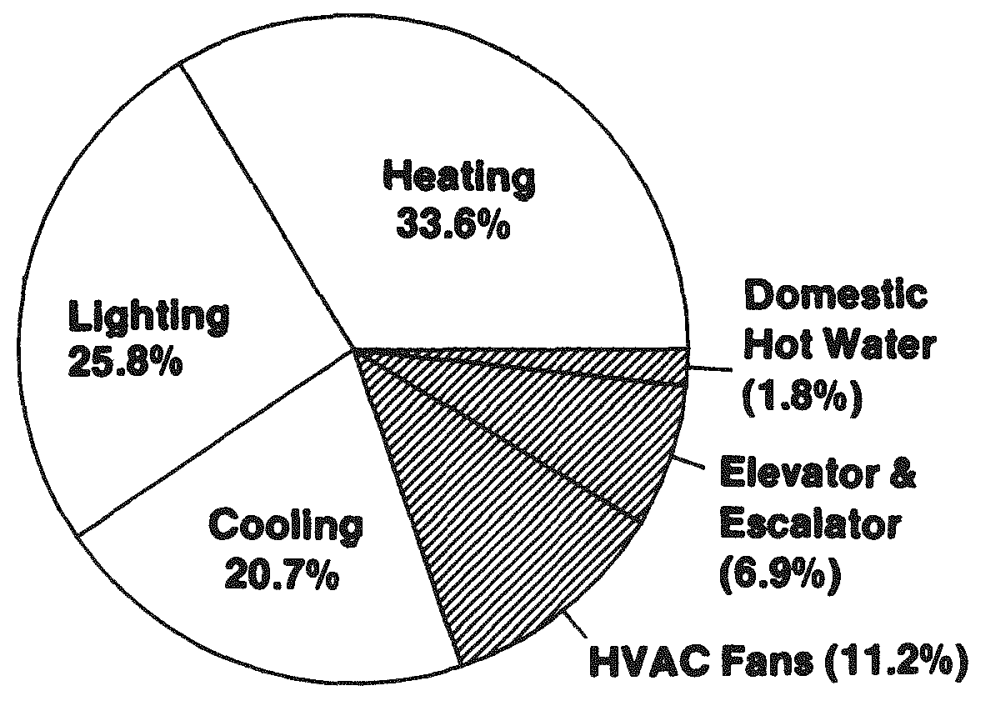

With RUF's

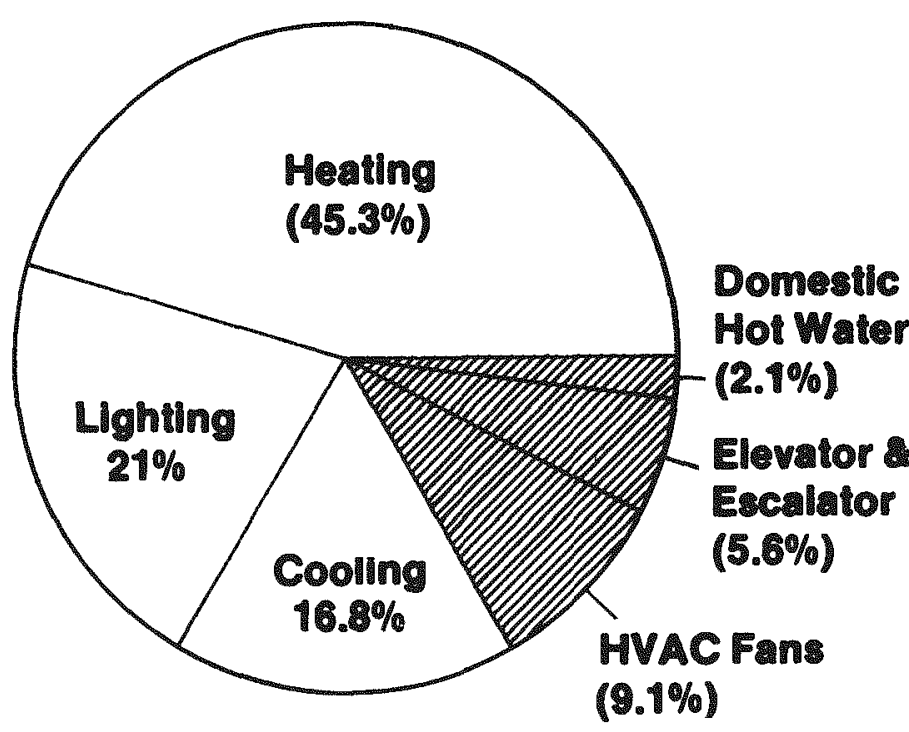

End Use Btu's

Fig. 31. AIA/RC phase I redesign data (courtesy of $\mathrm{AIA} / \mathrm{RC}$ ) 
14
Design Phase 
14. Collectors

Heat Transfer Fluids

Storage

Liquid storage design

Rockbed storage design

Controllers

Heat exchangers

Manifolding

Pipe sizing

Duet sizing

Air removers

Expansion tanks

Valves

Dampers

Gauges

Pumps

Fans

Insulation

Architectural and Engineering Concerns in Solar System Design

Standards 


\section{DESIGN PHASE}

\section{INTRODUCTION}

A solar heating or cooling system is comprised of a collector array and various subsystem components, including the storage, controls, pumps or tank heat exchangers, and pipes or ducts. It is essential that these subsystem components be selected properly in order that the solar system perform as desired. A poor selection of a heat exchanger between the collector and storage in a liquid system could result in extremely poor system performance even if all other components are properly designed. Many of these components are standard components in conventional heating or cooling systems. However, their application to a solar heating or cooling system may require a different selection procedure than that which is normally used. The purpose of this chapter is to present the information necessary so that the solar system designer may be aware of the appropriate procedures to be applied to the selection of subsystem components in solar heating and cooling systems.

The design process consists of first determining the collector array size and then selecting subsystem components based upon that size. The collector array size is typically based on some economic considerations, as discussed in Chapter 11 of this workbook. Once a given collector has been selected and the appropriate array size has been determined, then the collector flow rate may be determined. This flow rate is then used in the selection process for pumps and heat exchangers in the collector loop in a liquid system and for fans and ducts for an air system. The procedures that should be followed in the selection of these components are described in this chapter. It is not intended that this chapter serve to provide details for the design of components such as heat exchangers. There is a great deal of literature on this subject elsewhere. It is, however, the intent that the material in this chapter serve as a guide for selection of off-the-shelf type components to be used in solar heating or cooling systems.

\section{COMPONENT DESIGN GUIDELINES, DETAILS, AND RULAS OF THUMB}

\section{Collectors}

The collector area should be determined by applying the economic considerations discussed in Chapter 11. This is illustrated in Fig. 14-1.

The total life cycle cost consists of the sum of the first cost and the auxiliary heating cost. The first cost will increase as the collector array size increases, but a larger collector array will provide for more solar heating and thereby provide for a lower auxiliary heating cost.

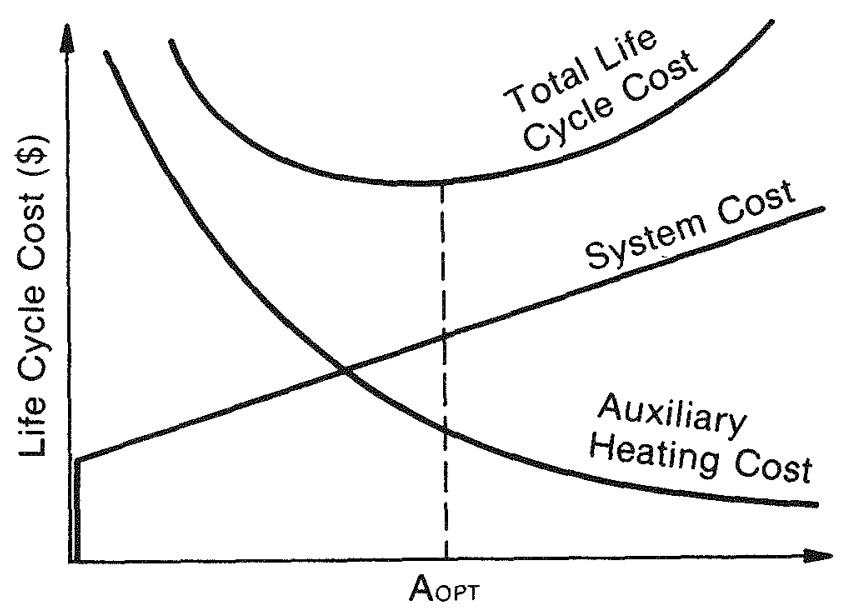

Collector Area $\left(\mathrm{m}^{2}\right)$

Fig. 14-1. Life Cycle Cost vs. Collector area
Editor's note: This chapter focuses on procedures and guidelines for designing and sizing active solar heating and cooling systems. The equivalent information on passive systems is being prepared and will be included in a later edition of this workbook.
The best collector area would be the area that minimizes the total life cycle cost. Although the procedures for determining this collector area have been discussed in Chapter 11, there are some very approximate rules of thumb that may be applied in order to serve as a check on a given design. These are as follows: 
Heating and Cooling - collector area of $1 / 5$ to $1 / 2 \mathrm{sq} \mathrm{ft}$ of floor area

Domestic Hot water - 15-20 sq ft per person

Cooling only $-1 / 3$ to $2 / 3 \mathrm{sq} \mathrm{ft}$ of collector per sq $\mathrm{ft}$ of floor area.

Additional guidelines associated with collectors are listed below.

\section{Design Loads}

All structural design should be based on generally accepted engineering practice and should be in compliance with ANSI A58.1. Collector support structures may be fixed or have an adjustable tilt angle.

Wind loads are usually based on hurricane velocities. Design wind loads should be ealeulated according to the procedures in ANSI A58.1. Flat plate collectors mounted flush with the roof surface should use design loads that would have been imposed on the roof area they cover. Collectors mounted at an angle to or parallel to the roof surface on open racks can be lifted by wind striking their undersides. This wind load is in addition to the equivalent roof-area wind loads, and it should be determined according to accepted engineering procedures. Although wind load may not lift an array of the structure, it might promote vibration which can lead to leaks through pitch boxes and other mounting points. Negative pressures induced by wind can and often do exceed pressure loadings. Cover plate retainers must be adequately designed to prevent separation from the collector frame and to prevent glazings from popping out of collectors.

Solar system components are subject to seismic forces generated by their mass. The design of all connections between components and the structure should allow for anticipated movements of the structure.

\section{Other Factors to be Considered}

- Collector azimuth: Optimum azimuth is true south; $\pm 20^{\circ}$ variation is not of major significance.

- Check match between collector tilt angle, latitude, and collector end use. A $10^{\circ}$ variation from optimum tilt angle is insignificant. Initial guidelines are:

$\begin{array}{ll}\text { Heating: } & \text { Latitude }+10^{\circ} \text { to }+15^{\circ} \\ \text { Cooling: } & \text { Latitude }-10^{\circ} \\ \text { Domestic Hot Water: } & \text { Latitude to Latitude }+5^{\circ}\end{array}$

Domestic Hot Water: Latitude to Latitude $+5^{\circ}$

- Collector area should match temperature application and percentage solar participation required.

- A $10 \%$ or greater decrease in collector thermal efficiency should not be indicated by before and after testing procedure outlined in IMPS. Determine that a graph showing both pre-test and post-test thermal performance is provided.

- Outgassing: Problems with outgassing can be caused by the resin binder in some fiberglass insulation. Use resin-free insulation. Both black paint surface coatings and sealants around the cover plates have outgassed. Use surface coatings and sealants with high vaporization temperatures.

- For the most cost effective selection of collectors, the parameter $P$ should fall within the following Instantaneous Efficiency Guidelines:
Parameter, $P=\frac{T_{\text {in }}-T_{a m b}}{I}$

Domestic Hot Water 0.1 to 0.3

Pre-Heating

Heat Pump

Direct Heating

0.1 to 0.3

Cooling

0.2 to 0.6

- Absorber Surfaces: Aluminum flow passages are not compatible with copper piping. Steel absorber plates may corrode in a drain-down system unless nitrogen is used as a refill gas when the system is drained.

- Cover Plates: To prevent cover plate breakage, some collectors come with a protective adhesive paper. Remove this paper in moderate temperatures; otherwise, the glue will be frozen or melted and become difficult to remove.

- Inner Condensation: Be sure the collectors have vent holes or weep holes to allow condensed moisture to escape. They must be placed in such a way as to allow moisture to drain from the collector box.

- Insulation: Always use proper high-temperature insulation to protect wood. Even single glazed collectors can produce stagnation temperatures of $250 \mathrm{~F}$ or more, high enough to ignite wooden roof members.

- Large flashed arrays should have gutters or provisions for runoff. Asphalt roofing is designed for an evenly dispersed flow of water, and reinforcement is necessary if this normal flow is increased.

- Collectors should be mounted with a minimum 1-1/2" space for air circulation to disperse moisture buildup and to prevent the growth of fungus under collectors.

- Consider glare problems where collectors are mounted near high traffic areas. This problem can cause public annoyance and opposition to installation. Collectors with black anodized aluminum and stippled finish on the glass are the least reflecting.

- Consider lightning protection for the collectors and the system.

- Room for expansion between modular collectors must be provided (1/4 to $1 / 8$ in. minimum). Consult manufacturer for recommended flashing details.

- On site-built collectors, avoid securely fastening metal absorbers to rafters. Expansion may place undue stress on structure, ducting, or pipe connections.

- Wherever possible, absorbers should be allowed to "float," compensating for expansion across the entire array.

\section{Collector Support Structure}

- Choose structural mounting elements based on design live and dead loads imposed (including contained fluid, piping, valves and accessories, snow, seismic, and wind loading up to $150 \mathrm{mph}$ ).

- Standard struetural shapes used may be I-beam, box beam, angle, channel, or pipe of adequate size (steel or aluminum).

- Minimum support size should be 2 in. diameter or 2 -in. $\times 2$-in. $\times 1 / 4$-in structural shape. (Adequate up to $300 \mathrm{lb} / \mathrm{sq} \mathrm{ft}$ loading.)

- Method of connection should be bolting or welding, sized for loads imposed. 
- Supporting structure should be anchored to suitable structural members of building or foundations.

\section{Liquid Systems - General Guidelines}

- Check on provisions to prevent moisture buildup in the collector. Desiccants, weep holes, and/or breather plugs may be used.

- Review provisions made for high stagnation temperatures. Are liquid collectors drained or left filled in summer with no service de mand?

- Make provisions for expansion of system's headers and collectors.

- Systems using either ethylene glycol or propylene can not be permitted to stagnate without draining and flushing the collection loop.

- Some systems use boil out as a means of drain down. Assure that fluid is not permitted to escape from the system or that provisions are made to recapture fluid.

- If a system uses pulsed flow for frost protection (use of solar storage to prevent freezing), check that the system will not freeze if pump or power supply fails. Pump failure should activate an alarm, and a normally open solenoid valve should drain antifreeze solution to a holding tank. Check that heat loss from collectors at night does not exceed heat collected during the day due to pulsed flow of warm fluid through cold collector.

- Care should be taken in the design and layout of the fluid transport system to prevent conditions in which locally excessive pressures are developed as a result of flow restrictions. Precautions must be taken to assure that heat transfer liquids do not discharge on asphalt base roofing materials or other types of roofing or at locations which may be hazardous, cause structural damage, discolor building finish, or damage plant materials or pose health hazards to animals or humans.

- Fill connections for non-potable fluids should be labeled "Danger-Water Not Drinkable" with fluid name, date filled, installer's name, and a warning not to connect to potable water.

- The Uniform Plumbing Cole requires that any fluid circuit be separated from the municipal supply by a backflow prevention device. However, antifreeze circuits should not have provisions for automatic makeup as this could result in dilution of the antifreeze solution to the point where freezing could occur. Refill should be manual so as to assure proper fluid ratios.

- Weld or sweat joints should be used on all collection loops and other piping where applicable, and tightly drawn teflon taped joints should be made where needed. Some pipe dopes, butyl rubber expansion tank diaphragms, valve seats, discs, and sealants are not compatible with most glycols. Use $95 / 5$ tin/lead solder on all collector-manifold sweat joints.

- For drain-down systems, vacuum breaker must be located at the top of the collector to allow the fluid to drain automatically and thus prevent freeze damage. The piping must be circuited to permit positive air purging during pump startup and sloped to ensure that all pipe ruses in unconditioned spaces are completely drained.

- The drain-back volume must be allowed for in the storage tank, and the pipes must be sized for drain down.
- Three-port automatic valves and reversible flows can cause severe hydraulic and control problems. If possible, use industrial grade two-way automatic valves giving tight shut-off.

- Provide adequate expansion joints and loops in piping and at equipment to permit free movement. Loops are preferable to joints. Guides and anchors are required.

- Galvanized piping has given problems when the temperature of the fluid is higher than about $130 \mathrm{~F}$. It is recommended that galvanized piping should not be used in solar energy systems.

- Pump cavitation can occur if the expansion tank is not located at the inlet side of the pump. Positive suction head is ensured by this configuration.

- Piping should be arranged to provide for air purgingwater velocities in collectors are low and usually not sufficient to carry air to elimination devices; flow should always be in the direction of natural air movement. Piping should be sloped to assist air movement and to provide for collector drainage.

- Collector manifolding resistance should be low compared to tube resistance to maintain even tube flow distribution. (Keep manifold resistance to about $10 \%$ of tube resistance.)

- Velocities in copper piping should be less than $4 \mathrm{ft} / \mathrm{s}$ to minimize erosion.

- Hose should be avoided when possible. If hose must be used for collector or system piping should be high temperature, reinfor ced elastomers, preferably silcone rubber.

- Pipe slopes for inlet and outlet manifolds and all piping in unconditioned space on drain-down systems should be at least $1 / 4$ in. per foot.

- Exterior piping losses should be designed to limit thermal losses to less than $5 \%$.

\section{Heat Transfer Fluids}

- Fluid should be suitable for use in panel fluid passages of aluminum, copper, or steel. (Copper is less sensitive than steel or aluminum. Aluminum should never be exposed to chlorinated swimming pool water.)

- Fluid should be selected for freezing point and boiling point considering geographical location, minimum temperature, and maximum stagnation temperature.

- System must include provision for manual filling with correct heat transfer/antifreeze solution.

- Fill points for heat transfer/antifreeze fluid should be tagged, indicating type of fluid to be used.

"WARNING - Use Only - - . . . - Fluid."

Also indicate date filled, installer's name, and a warning not to connect to potable. Removal of handle, or lock wiring, is advisable if located in public areas.

- To help prevent possible freezeup, raw water makeup should be manual.

- Piping hookups must comply with local code rulings to prevent backflow and possible contamination of city water.

- With an antifreeze system, use of automatic makeup water should be avoided. An overdilution of the solution can lead to freezing problems. A tank of pre- 
mixed antifreeze is preferable, or a low-level alarm in the expansion tank indicating a need for the manual addition of antifreeze.

- Leakage is more likely to occur with antifreeze and silicone oil transport fluids than with water. Care should be taken in pump and seal selection to assure compatibility with the transport fluid. Threaded fittings should be avoided.

- Antifreeze boiloff should be prevented. The residual sludge deposited by boiling antifreeze will eventually cause flow restrictions inside the collectors. Boiling of glycol fluids also cause fluid properties to become acidic.

\section{Storage}

Thermal storage may be one of three types:

- Sensible storage

- Latent storage

- Chemical storage.

Sensible storage is the most common type used in the industry today. It is based upon the heat capacity of various materials such as water, rocks, steel, oil, etc. The amount of heat stored in a sensible heat storage medium is the mass of the material times the specific heat of the material times the temperature difference which the material undergoes. Water and rocks are the most commonly used materials for sensible heat storage.

Latent heat storage is based upon the heat of fusion of various materials. This is the amount of energy required to change the state of a material from solid to liquid phase and vice versa. For example, the amount of energy required to change sodium sulfate decahydrate from the solid to the liquid state is approximately $108 \mathrm{Btu}$ per pound of material. The most commonly used phase change materials are salt hydrates (sometimes incorrectly referred to as eutectic salts) such as sodium sulfate decahydrate and calcium chloride hexahydrate.

The advantages of using latent heat storage over sensible heat storage are significant reductions in the volume of storage required and a more uniform operating temperature. The principal disadvantages involve: separation of the salts from the solution after repeated changes of phase; supercooling, and low conductivity. Mechanical or chemical means must be used to prevent separation, and this leads to either higher original costs or higher maintenance costs or both.

* Material on Rock Bed Storage Design and Storage in Liquid-Based Systems was taken from the Design and Installation Manual for Thermal Energy Storage, By $\mathrm{R}$. Cole, K. Nield, R. Rohde, and R. Wolosewicz of Argonne National Lab.
Chemical storage is not presently considered to be viable for solar heating and cooling systems. Further research and development are required in this area in order that this be a viable choice. It is presently more appropriate to industrial process heat applications, although more research is needed there too. The remaining material in this section will be devoted to sensible heat storage using water or rocks as the heat storage medium. Additional storage-related material is presented in Chapter 5 .

\section{Rock Bed Storage Design*}

Depending on the temperature of stored heat, and on the timing and control of its release to the space, rock-bed storage systems can either be thermally coupled to heated spaces or isolated from them. By intentionally coupling the rock bed to the heated space, stored heat will be conducted to a surface within the space and will then be radiated and convected to the space. The conductance of the material separating the bed from the space (usually a floor or wall panel) determines the rate and delay of heat release to the space. The floor or wall surface temperature will only be a few degrees above the room temperature. If the design is correct, the net result will be a comf ortable situation, with slow heating from a large radiant panel. Such an arrangement is usually desirable in the case of low-temperature [65-90 F $\left.\left(18-32^{\circ} \mathrm{C}\right)\right]$ rock beds characteristic of passive or hybrid systems. When the rock bed is isolated from the space, one has greater control over heat delivery. In isolated rock beds, the bed is discharged with an air flow. (See Chapter 5.) However, in coupled rock beds, the air flow is usually in one direction only, to charge the bed. Delivery of heat to the space is by conduction through the floor slab or wall panel. Fig. 14-2 illustrates a spacecoupled rock bed configuration. "Passive Solar Design Analysis," by J. D. Balcomb (DOE/CS-0127/2), January 1980 , Chapter $G$, describes the design of space-coupled rock beds for passive and hybrid applications.

\section{Isolated Rock Bed Flow Configurations}

Several different rock-bed configurations have been used. The most common are vertical and horizontal flow designs. A third approach, known as the U-shaped rock bed, has been used; however it has significant disadvantages, and not much data on the performance of this type are available so its use is not recommended.

A vertical flow rock bed (Fig: 14-3) provides the best thermal characteristics, since it can best take advantage of warm air's natural tendency to rise. Air flows vertically through the rockbed, downward in the charging mode and upward when heat is taken from the rock bed. The main disadvantage of this approach is that considerable vertical space is required, and the rock bed must be designed carefully to fit into the space available.

Horizontal flow rock beds (Fig. 14-4) require less vertical space than vertical flow rock beds, but they also have some disadvantages. If the rocks settle over a period of time, an air gap might be formed between the top of the rocks and the rock-bed cover, unless some precautions are taken. 


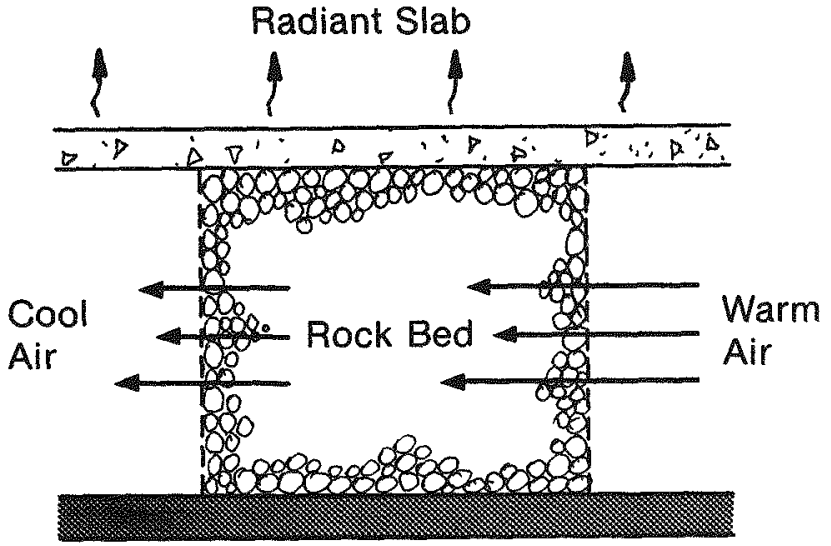

Fig. 14-2. Space-coupled rock bed
arrangement

(Source Design and Installation Manual for Thermal Energy Storage, Argonne National Lab)

Second, as the warm air is distributed in the inlet plenum, it will rise and heat the rocks on the top of the bin more than those on the bottom. When the flow is reversed for space heating, part of the air will pass through the warmer rocks at the top while the rest of the air passes through the cooler rocks at the bottom. The mixed warm and cool air will be delivered to the building at a temperature significantly lower than that of the warmest rocks.

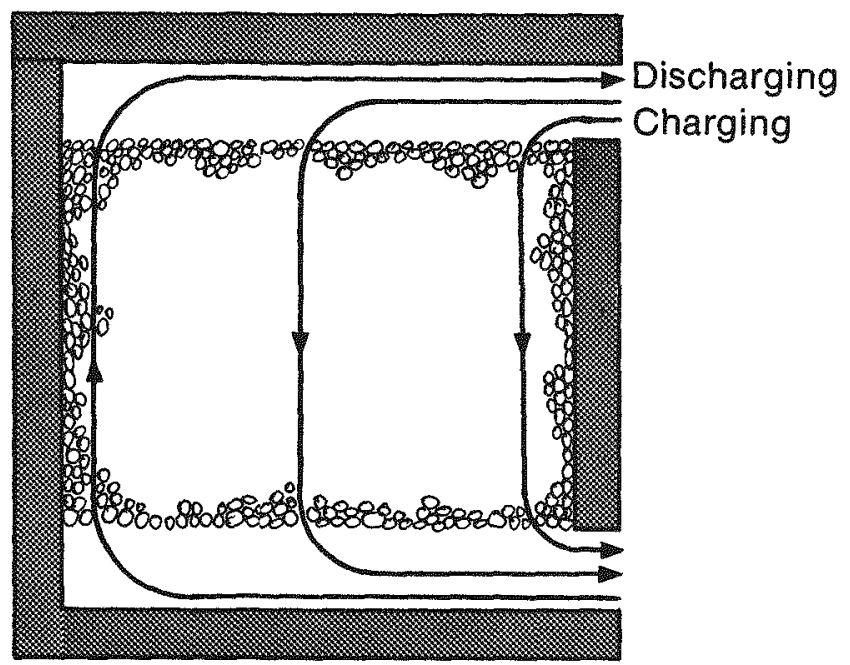

Fig. 14-3. Vertical flow rock bed

(Source Design and Installation Manual for Thermal Energy Storage, Argonne National Lab)

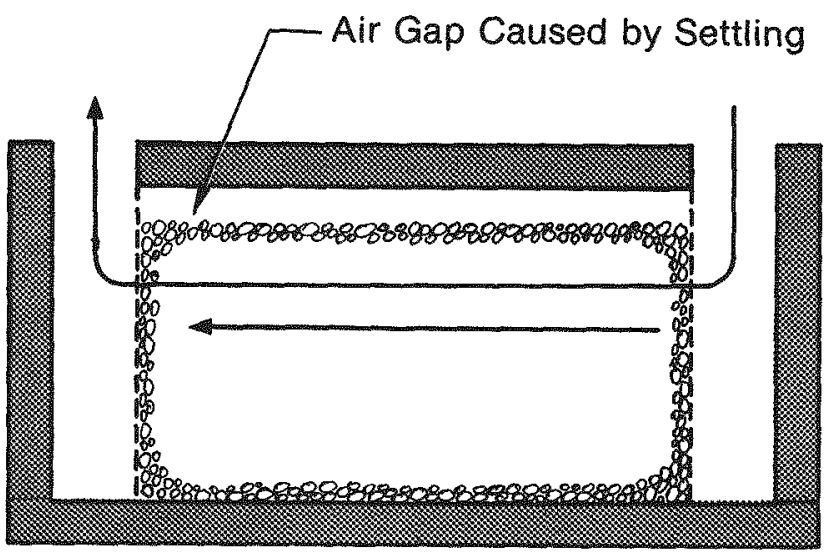

Fig. 14-4. Horizontal flow rock bed

(Source Design and Installation Manual for Thermal Energy Storage, Argonne National Lab)

Research on improved designs for horizontal rock beds is being conducted in Japan and the United States. One experimental design is shown in Fig. 14-5.

\section{Rock-bed Design Guidelines}

Of primary importance to the performance of the rock bed are its volume, the face velocity, the pressure drop across the rock bed, and the size of the rocks in relation to the depth of the rock bed.

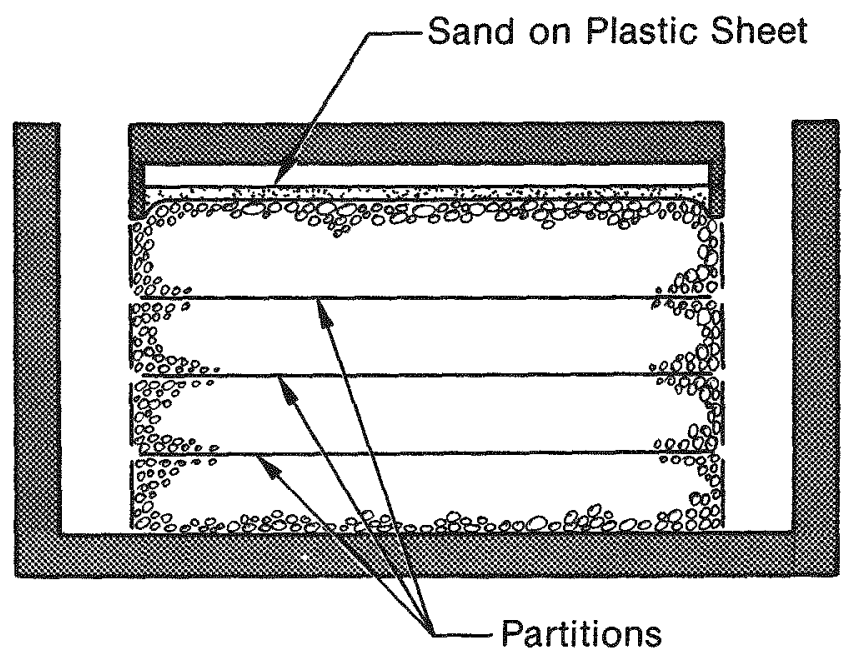

Fig. 14-5. Horizontal flow rock bed with partitions and floating cover

(Source Design and Installation Manual for Thermal Energy Storage, Argonne National Lab) 
Heat Storage Capacity. Recommended storage volumes are in the range of 0.50 to $0.75 \mathrm{cu} \mathrm{ft} / \mathrm{sq} \mathrm{ft}(0.15$ to $0.20 \mathrm{cu} \mathrm{m} / \mathrm{sq} \mathrm{m}$ ) of collector (see Chapter 5). With rock of $160 \mathrm{lb} / \mathrm{cu} \mathrm{ft}(2600 \mathrm{~kg} / \mathrm{cu} \mathrm{m})$ density, $0.2 \mathrm{Btu} / \mathrm{lb} \mathrm{F}$ $\left(0.9 \mathrm{~kJ} / \mathrm{kg}^{\circ} \mathrm{C}\right)$ specific heat, and a typical void fraction of 0.4 , a typical midwinter collection of $800 \mathrm{Btu} / \mathrm{sq} \mathrm{ft}$ $(9 \mathrm{MJ} / \mathrm{sq} \mathrm{m})$ of collector will result in an average bed te mperature rise of:

$$
\Delta \mathrm{T}=\frac{\mathrm{Q}}{\mathrm{mC}}
$$$$
\Delta \mathrm{T}=\frac{800 \mathrm{Btu} / \mathrm{ft}^{2} \mathrm{c}}{\left(160 \mathrm{lb} / \mathrm{ft}^{3} \text { rock }\right)\left(0.6 \frac{\mathrm{ft}^{3} \text { rock }}{\mathrm{ft}^{3} \text { bed }}\right)\left(0.75 \frac{\mathrm{ft}^{3} \text { bed }}{\mathrm{ft}^{2} \mathrm{c}}\right)\left(0.2 \frac{\mathrm{Btu}}{1 \mathrm{~b} F}\right)}
$$$$
\Delta \mathrm{T}=55 \mathrm{~F}
$$

Face Velocity. The face velocity is the volumetric air flow rate divided by the cross-sectional flow area of the rock bed. It measures the air's velocity immediately before it enters the rocks. (Some texts call it the superficial velocity.) Increasing the face velocity increases the pressure drop across the rock bed.

Pressure Drop. The pressure drop across the rock bed is important in ensuring proper air distribution and in determining fan energy requirements. Designing the rockbed for a minimum pressure drop of .15 inches of water ( 38 pascals) will provide for an even distribution of air flow through the rock. By ensuring that the resistance to air flow in the plena is much less than that occuring in the rock, bypassing a major portion of the storage volume (as depicted in Fig. 14-6) will be avoided. It is also recommended that the rock box be designed for a maximum pressure drop of .30 inches of water (75 pascals) in order that the fan does not use an excessive amount of power.

Dividing the pressure drop by the bed depth (for a vertical-flow rock bed) yields the pressure gradient, which will be used in later calculations.

Rock Size and Type. The fourth parameter affecting performance is the rock diameter. Increasing the rock diameter decreases the pressure drop across the rock bed, because the larger spaces between large rocks have less resistance to air flow than the spaces between small rocks.

Another more subtle effect of increasing the rock diameter is that it increases the time required for each rock to reach its equilibrium temperature with the air. If this time is more than the time required for air to traverse the rock bed, the rocks will be unable to absorb all the heat in the air by the time the air leaves the rock bed. Thus, air will be returned to the collector at a temperature that is warmer than the coolest rocks, the benefit of thermal stratification will be lost, and the collectors will lose some efficiency.

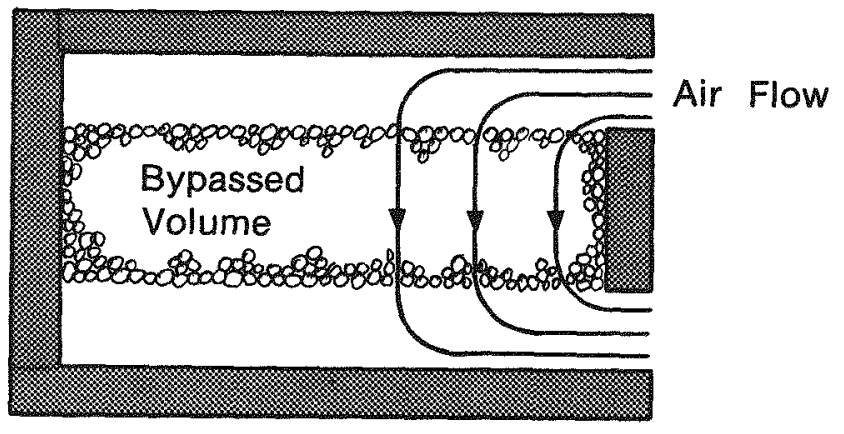

Not Enough Pressure Drop

Fig. 14-6. Air flow pattern when the pressure drop is too low or the plena are too small

(Source: Design and Installation Manual for Thermal Energy Storage, Argonne National Lab)

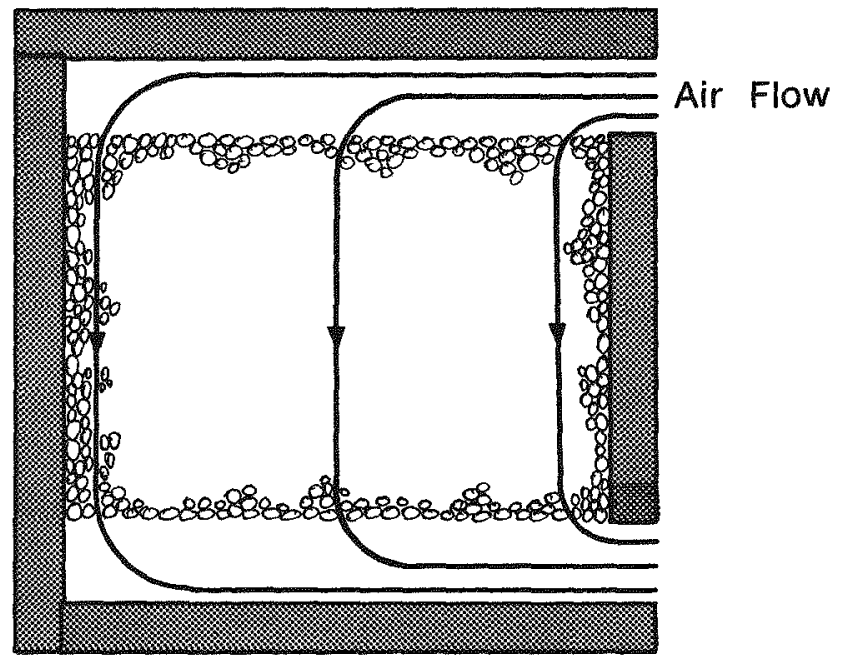

Adequate Pressure Drop

Fig. 14-7. Air flow pattern when the pressure drop and plenum size are adequate.

(Source: Design and Installation Manual for Thermal Energy Storage, Argonne National Lab) 
Face Velocity (meters/second)

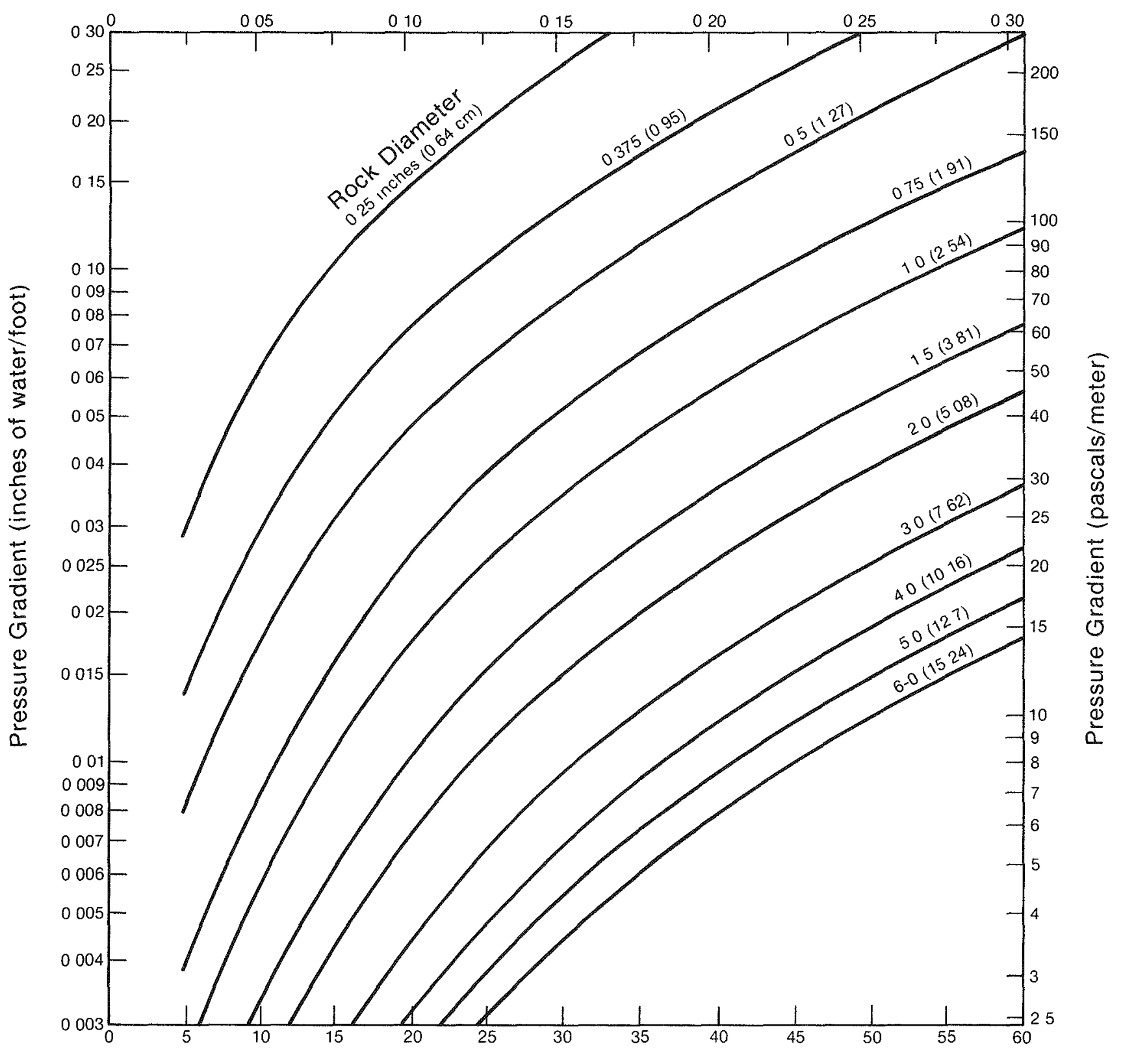

Face Velocity (feet/minute)

Fig. 14-8. Rock bed performance map

(Source: Design and Installation Manual for Thermal Energy Storage, Argonne Natıonal Lab) 
However, if the equilibration time of the rock is much less than the time required for air to traverse the rockbed, the air temperature emerging the rockbed will approach the temperature of the coolest rocks. The rockbed will remain thermally stratified, with higher temperatures at the top and cooler temperatures at the bottom. Ideally, the air temperature leaving the rock box will continue to be close to the temperature of the coolest rocks until the rockbed is almost fully charged. For the rockbed to behave in the manner described above, it should be designed with a depth of at least 20 times the rock diameter if the rocks are less than 4 inches $(100 \mathrm{~mm})$ in diameter, and 30 times the rock diameter if the rocks are larger than 4 inches $(100 \mathrm{~mm})$ in diameter. Rocks in the range of .5 to 3 inches $(13-76 \mathrm{~mm})$ in diameter are preferred.

The ideal rocks to use in a rock bed are the rounded ones typically found in river beds because this will create an even distribution of air voids through the rock bed. However, crushed rock will work nearly as well. Rocks that conform to ASTM C 33, "Specifications for Concrete Aggregates," are generally acceptable and have been washed to remove dust and dirt. Be certain that rocks are clean and dry before they are put in the rock bin.

The rocks should be about the same size-within $3 / 4$ to 1$1 / 2$ times the average rock diameter. Rocks are usually sorted into specific sizes by being passed through screen meshes.

Several types of rock are unacceptable for use in rock beds. Rocks that crumble, such as schist and softer varieties of limestone and sandstone, should not be used. Marble, limestone, and dolomite, which are acceptable for heating systems, react with water and carbon dioxide and may therefore cause problems in systems that are used for nighttime cooling in the summer. In addition, some rocks of volcanic origin will smell of sulfur when they are cracked. Test for this before you buy the rocks by breaking several open.

Rock Bed Performance Map. The rock bed performance map shown in Fig. 14-8 provides a relationship among face velocity, pressure gradient, and rock diameter. The vertical axis represents the pressure gradient in inches of water per foot of depth (pascals per meter) and the horizontal axis represents the face velocity in feet per minute (meters per second). The curved lines show the relationship between pressure gradient and face velocity for various rock diameters. Two typical calculations using the rock bed performance map are:

- Given the air flow rate and the rock bin dimensions, determine the rock size necessary for adequate performance.

- Given the air flow rate and the available rock size, determine the necessary dimensions of the rock bin.

Use of the performance map will be demonstrated in the rock bed design example.

Rock Bin. Rock bins must be strong enough to withstand the outward pressure of the rocks. This pressure, already great when the bin is first filled, increases as the rocks expand, contract, and settle with the heating and cooling of the bed. Typical materials for rock bins include wood, concrete, and cement blocks. Appendix F of Ref. I shows details for construction of a wooden bin. Construction of a poured concrete bin is similar to that of the cast-inplace water tank described in Appendix $\mathrm{H}$ of Ref. 1, except that no lining is needed, and air inlet and outlet openings must be provided.

Plena. The function of the plena is to distribute the air uniformly over the top and bottom of the rocks. To do this, the plena must resist air flow much less than the rocks. It is recommended that the cross-sectional area of each plenum, as shown in Fig. 14-9, be at least $8 \%$ of the cross-sectional area of the rock bin. That is, the plenum height times the plenum width should be at least $8 \%$ of the rock bin width times the length. If a plenum is partially obstructed by supports for the rock bed such as bond beam blocks, the plenum area should be increased to $12 \%$ of the cross-sectional area of the rock bed.

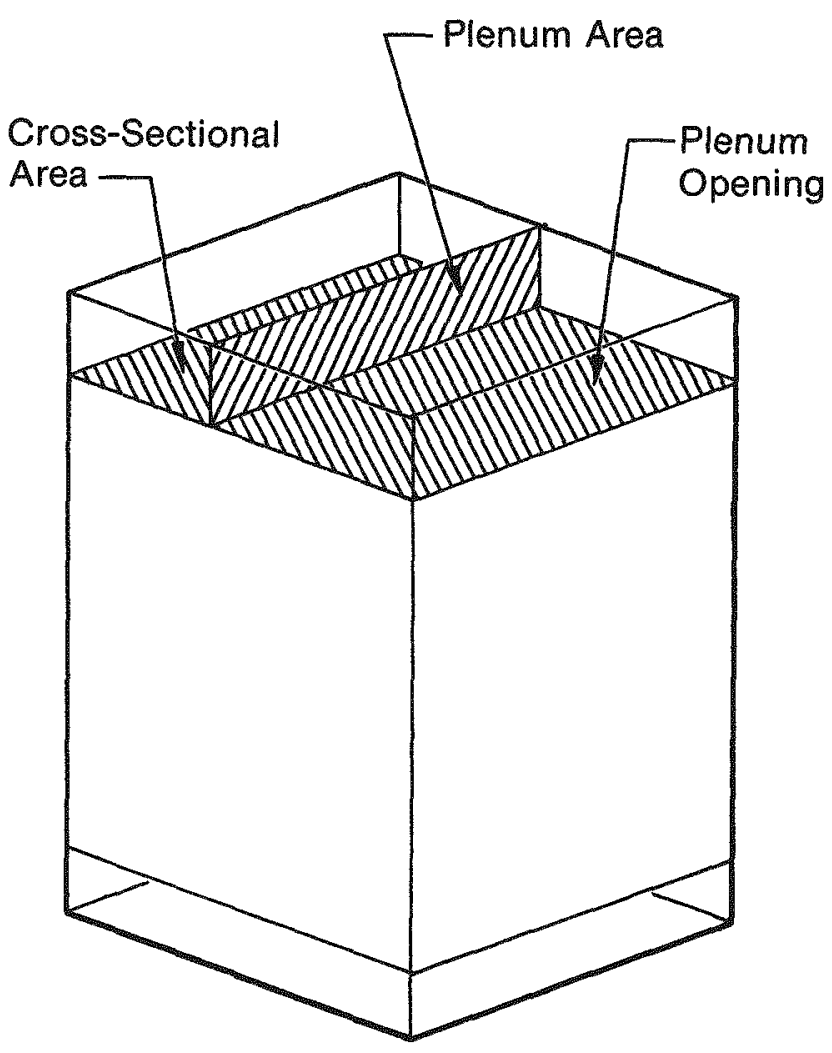

Fig. 14-9. Definition of plenum area and cross-sectional area in a rock bed

(Source: Design and Installation Manual for Thermal Energy Storage, Argonne National Lab) 
Other Considerations. Common sense and building codes dictate a number of considerations that a designer should keep in mind when designing a rock bed.

- Do a thorough job in designing the first few systems. Many details of these designs can be incorporated in later systems.

- Have a structural engineer design a rock-bed foundation that will meet building code requirements and ensure the safety of the building.

- Choose materials that can withstand high temperatures for the life of the system. Fire codes generally outlaw placing flammable materials in contact with the hot air system, so fire-retardant gypsum board must be specified as the interior lining of wooden rock bins.

- Consider such constraints as space restrictions and available rock sizes.

- Use standard materials and dimensions. This will save both time and labor.

- Use flexible silicone caulk for sealing the rock bin. Silicone caulk will not dry out and crack.

- Design for easy maintenance. All components (blowers, filters, and so on) must be accessible for repair and maintenance.

- Install a drain that is not trapped to a sewer. The drain will allow any water in the bed (from accidents or condensation in nighttime cooling systems) to escape. A trap in the drain will dry out in normal use, so the drain cannot be connected directly to a sewer.

- Failure to provide for removal of moisture from the rockbed can result in the growth of harmful bacteria which can lead to illness such as Legionaires Disease.

- Design to reduce summer cooling loads. For rock beds located within the heated area, provide a bypass for summer domestic hot water heating so the rock bed can be kept cool. Install the rock bed in a space that can be manually vented when heat is needed at night but not during the day.

\section{Rock Bed Design Bxample}

It is desired that an air-based solar space heating system be installed in a new house. The following has been determined:

- $400 \mathrm{sg} \mathrm{ft}(37 \mathrm{sq} \mathrm{m}$ ) of solar collector is needed.

- The collector manufacturer has recommended an air flow rate of $2 \mathrm{cu} \mathrm{ft} / \mathrm{min}-\mathrm{sq} \mathrm{ft}(0.01 \mathrm{cu} \mathrm{m} / \mathrm{s}-\mathrm{sq} \mathrm{m})$ of collector area, for a total air flow rate of $800 \mathrm{cu}$ $\mathrm{ft} / \mathrm{min}$. $(0.38 \mathrm{cu} \mathrm{m} / \mathrm{s})$.

- The rock bed eill be installed in the basement of a building, which has a floor-to-joist height of $7 \mathrm{ft}(2,130$ $\mathrm{mm}$ ).

- A recessed floor for the rock bed can be poured no lower than $1 \mathrm{ft}(300 \mathrm{~mm})$ below the nominal basement floor level in order for the rock-bed drain to go to the sump well.

From that information the following design parameters can be calculated.
A. Depth. The total height of the rock bed, including insulation and plena, is limited to 96 in. $(2,438 \mathrm{~mm})$. Because space will be needed to put the cover on, allow 2 in. $(50 \mathrm{~mm})$ of working space, limiting the height to 94 in. $(2,388 \mathrm{~mm})$.

It is planned to make the cover of $2 \times 6$ studs (to allow room for insulation) with $3 / 8-i n .(9 \mathrm{~mm})$ plywood sheathing, so the cover will be $61 / 4 \mathrm{in}$. (155 $\mathrm{mm}$ ) thick.

Because the bond beam blocks used to support the rocks come in a standard 7-5/8-in. $(193 \mathrm{~mm})$ size, it is assumed that the bottom plenum, which will contain the bond beam blocks, will be $7-5 / 8$ in. high and that the top plenum will be $5-1 / 8$ in. $(130 \mathrm{~mm})$ high.

The bond beam blocks will be placed on a piece of 2-in. $(51-\mathrm{mm})$ rigid fiberglass insulation.

The total height of all of these components is $20.75 \mathrm{in}$. $(527 \mathrm{~mm})$, which leaves $94 \mathrm{in} .-20.75 \mathrm{in} .=73.25 \mathrm{in}$. $(1,861 \mathrm{~mm})$ for the rocks. For convenience it is assumed that we will use 72 in., or $6 \mathrm{ft}(1,829 \mathrm{~mm})$, of rocks will be used.

B. Volume limits. Using the rule of thumb for the volume of the rock bed, it is found that for $400 \mathrm{sq} f t$ of collector the minimum rock volume is:

$$
400 \times 0.5=200 \mathrm{ft}^{3}\left(5.66 \mathrm{~m}^{2}\right)
$$

and the maximum rock volume is:

$$
400 \times 0.75=300 \mathrm{ft}^{3}\left(8.50 \mathrm{~m}^{2}\right) \text {. }
$$

Therefore, any volume between 200 and $300 \mathrm{cu}$ ft will satisfy the rule of thumb requirement.

If $\mathrm{f}$-Chart or some other design tool is available to the designer, it should be used at this point to calculate the optimum storage volume before proceeding with the following calculations.

C. Cross-sectional Area. The cross-sectional area of the rock bed is the volume divided by the height. Using the volume limits from Step $B$ and the height from Step A, it is determined that the minimum cross-sectional area is:

$$
\frac{200 \mathrm{ft}^{3}}{6 \mathrm{ft}}=33.3 \mathrm{ft}^{2}\left(3.09 \mathrm{~m}^{2}\right)
$$

and the maximum cross-sectional area is:

$$
\frac{300 \mathrm{ft}^{3}}{6 \mathrm{ft}}=50 \mathrm{ft}^{2}\left(4.65 \mathrm{~m}^{2}\right) \text {. }
$$

To obtain one of the dimensions (the length as defined previously in Fig. 14-9, the rule of thumb regarding plenum sizing will be used. The rule of thumb for the bottom plenum, which will contain bond beam blocks, says that the plenum area must equal at least $12 \%$ of the cross-sectional area. The minimum plenum area is:

Minimum Plenum Area $=0.12 \times$ Cross-sectional Area, 
which can be written as:

Plenum Height $\mathrm{x}$ Width $=0.12 \mathrm{x}$ Maximum Length $\mathrm{x}$ Width .

Since "Width" is common to both sides of the equation, it can be factored out, leaving:

$$
\text { Plenum Height }=0.12 \times \text { Maximum Length . }
$$

Therefore, since a plenum height of $7-5 / 8$, or 7.62 in. (194 $\mathrm{mm}$ ) has been specified, a maximum length can be computed thus:

$$
\begin{aligned}
\text { Maximum Length } & =\frac{7.62}{0.12} \\
& =63.5 \mathrm{in} .(1,613 \mathrm{~mm})
\end{aligned}
$$

Therefore, a length of $63 \mathrm{in} .(1,600 \mathrm{~mm})$ is chosen, which is less than the maximum length permitted by the rule of thumb. The top plenum height is to be about two-thirds $(8 \% / 12 \%)$ of the size of the bottom plenum which satisfies the rule of thumb.

Anticipating that the walls will be made from $2 \times 6$ studs with $1-$ in. $(25-\mathrm{mm})$ plywood outside and $1 / 2-\mathrm{in}$. $(13-\mathrm{mm})$ gypsum board inside, the other dimension will be 82 in. $(2,083 \mathrm{~mm})$.

The cross-sectional area is then:

$$
\frac{62 \times 82}{144}=35.9 \mathrm{ft}^{2}\left(3.33 \mathrm{~m}^{2}\right),
$$

which is within the limits of 33.3 to $50.0 \mathrm{sq} \mathrm{ft}$ as calculated above.

D. Face Velocity. The face velocity is the velocity of the air immediately before it enters the rocks. It is calculated by dividing the air flow rate by the crosssectional area of the rock bin. In this case the face velocity will be:

$$
\frac{800 \mathrm{ft}^{3} / \mathrm{min}}{35.9 \mathrm{ft}^{2}}=22.3 \mathrm{ft} / \mathrm{min}(0.11 \mathrm{~m} / \mathrm{s}) .
$$

This number will be used later to help determine the rock size and the pressure drop in the rock bed.

E. Pressure Gradient Limits. The pressure gradient is the pressure drop per unit length through the rock bin. It is calculated by dividing the total pressure drop by the depth of the rocks. Using the second rule of thumb given earlier, the minimum pressure gradient is:

$$
\frac{0.15 \text { in. of water }}{6 \mathrm{ft}}=0.025 \mathrm{in} \text {. of water } / \mathrm{ft}(20.4 \mathrm{~Pa} / \mathrm{m})
$$

and the maximum pressure gradient is:

$$
\frac{0.30 \mathrm{in} \text {. of water }}{6 \mathrm{ft}}=0.05 \text { in. of water } / \mathrm{ft}(40.8 \mathrm{~Pa} / \mathrm{m}) \text {. }
$$

These limits will now be used to help determine the rock size and the pressure drop in the rock bed.
F. Rock Size. The rock bed perfor mance map in Fig. 1410 and the numbers which were calculated in Steps D and $E$ will be used to determine the rock size suitable for the system.

First, a vertical line is drawn at the face velocity of $22.3 \mathrm{ft} / \mathrm{min}(0.11 \mathrm{~m} / \mathrm{s})$. Next, two horizontal lines are drawn at the pressure gradient li mits of 0.025 and 0.05 in. of water $/ \mathrm{ft}(20.4$ to $40.8 \mathrm{~Pa} / \mathrm{m})$.

Any of the curved lines corresponding to various rock sizes that cross the face velocity line between the pressure gradient limit lines is a suitable choice. In this case, only the curve that corresponds to $3 / 4$-in.-diameter (19 mm-diameter) rock is indicated, so that is the rock size which will be used. Only washed rocks whose average diameter varies from $3 / 4$ to $1-1 / 2$ times the nominal diameter, or from $5 / 8$ in. to $1-1 / 8$ in. (16 to $28 \mathrm{~mm}$ ) will be accepted.

To check the fourth rule of thumb, it is noted that 20 $x 3 / 4$ in. $=15$ in. $(381 \mathrm{~mm})$, which is much less than the rock bed depth of $6 \mathrm{ft}(1,700 \mathrm{~mm})$. That means thermal stratification in the rock bed will be good.

G. Pressure Drop. The design point of the rock bed is the point on the rock bed performance map where the line representing the pressure gradient crosses the curve representing the rock size. In this case, the design point is at a pressure gradient of $0.032 \mathrm{in}$. of water/ft $(26.1$ $\mathrm{Pa} / \mathrm{m})$. Multiplying this value by the rock bed depth gives a total pressure drop of:

$$
0.032 \times 6=0.19 \mathrm{in} \text {. of water }(47.3 \mathrm{~Pa}) \text {. }
$$

This number will be used with the other pressure drops in the system to size the blower.

H. Volume and Floor Loading. The total volume of rocks will be:

$$
6 \mathrm{ft} \times 35.9 \mathrm{ft}^{2}=215 \mathrm{ft}^{3}\left(6.09 \mathrm{~m}^{3}\right) .
$$

If the rocks have a $30 \%$ void fraction, they will weigh:

$$
0.7 \times 167 \mathrm{lb} / \mathrm{ft}^{3} \times 215 \mathrm{ft}^{3}=25,234 \mathrm{lb}(11,470 \mathrm{~kg}),
$$

or almost 13 tons. The loading on the floor will be:

$$
\frac{25,134 \mathrm{lb}}{35.9 \mathrm{ft}^{2}}=700 \mathrm{lb} / \mathrm{ft}^{2}\left(3,425 \mathrm{~kg} / \mathrm{m}^{2}\right) \text {. }
$$

Since most basement floors can support only 150 to $400 \mathrm{lb} / \mathrm{sq} \mathrm{ft}(734$ to $1,957 \mathrm{~kg} / \mathrm{sq} \mathrm{m})$, a structural engineer must determine the load capacity and if design reinforcements are necessary. Failure to do this may lead to a building code violation and structural damage to the building.

Note that the design point which was selected is not unique. If the maximum and minimum values of the face velocity are calculated by using the minimum and maximum values of the area, respectively, from Step $C_{\text {, }}$ it is determined that the face velocity can be anywhere between 16.0 and $24.0 \mathrm{ft} / \mathrm{min}(0.081-0.122 \mathrm{~m} / \mathrm{s})$. Lines corresponding to these values as well as the pressure 
Face Velocity (meters/second)

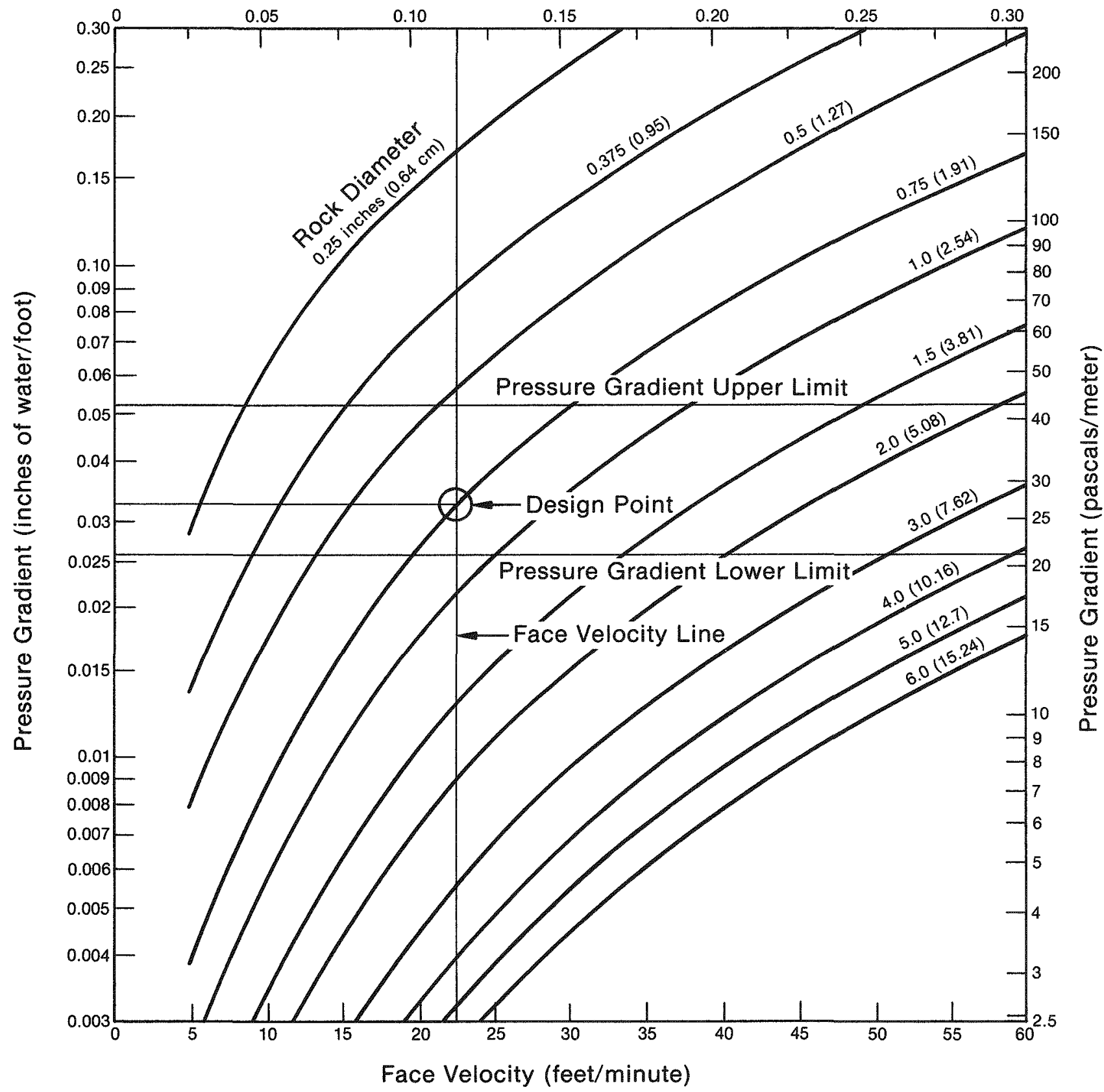

Fig. 14-10. Rock bed performance map for design example

(Source: Design and Installation Manual for Thermal Energy Storage, Argonne National Lab) 
Face Velocity (meters/second)

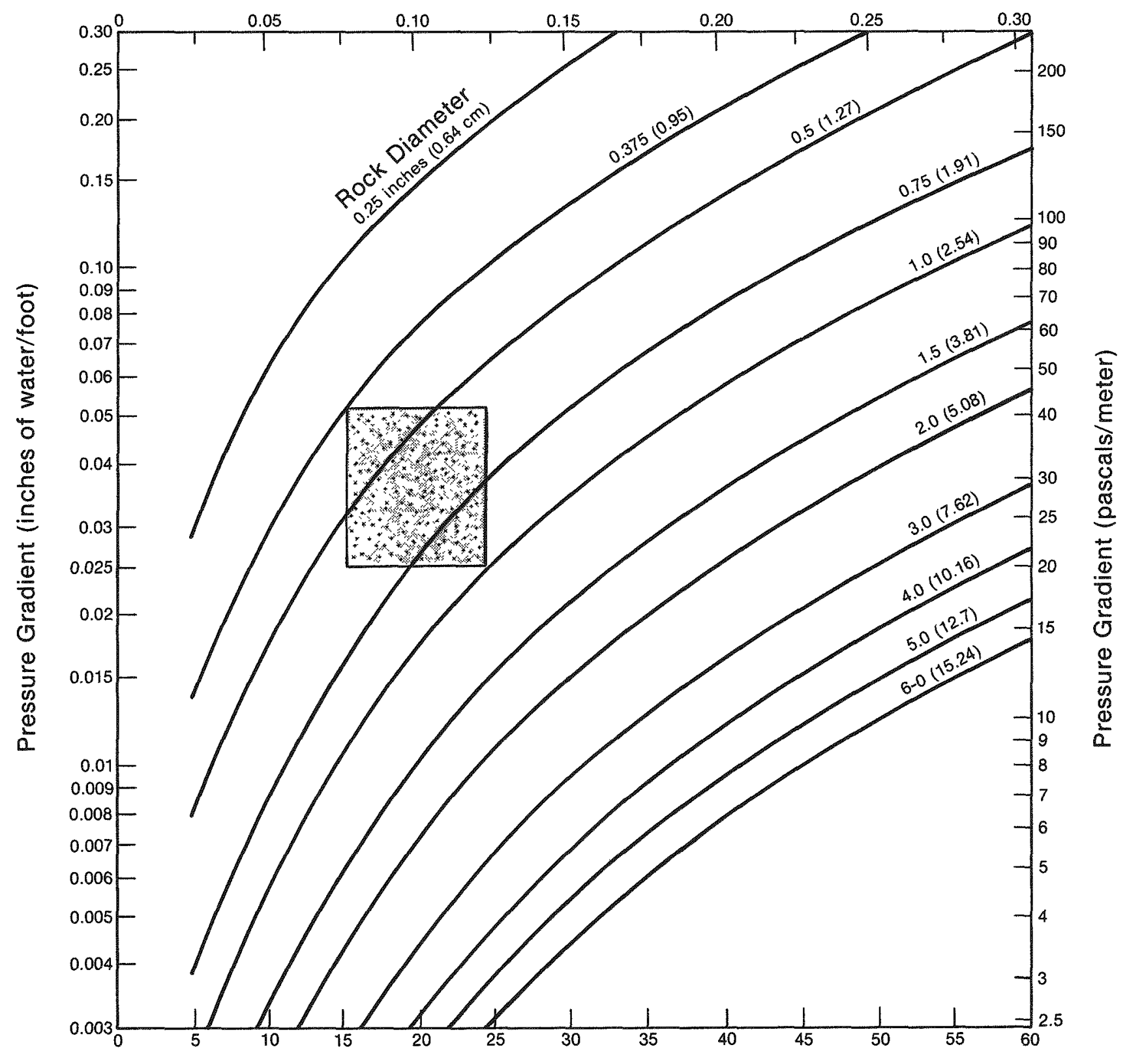

Face Velocity (feet/minute)

Fig. 14-10b. Allowable design area on rock bed performance map.

(Source: Design and Installation Manual for Thermal Energy Storage, Argonne National Lab) 
gradient limits are shown in Fig. 14-10b. Any point within the allowable design area is a valid design point in that it falls within the limits set by the rule of thumb for volume and pressure drop corresponding to the rock bed depth which was initially chosen. The allowable design area could be changed by using a different rock bed depth.

\section{Duet Sizing}

\section{Sizing Criteria}

In order to design a system with minimum initial and operating expenses, while supplying optimal flow rates for the collector array(s), several factors must be considered. Initial system cost can be reduced through the use of smaller ducts. However, as air velocity and friction losses increase, operating expenses will also increase due to higher fan power requirements.

It is important to analyze duct sizing with these factors in mind. The minimum life cycle cost will be penalized when the sum of the power and system costs is lowest (see Fig. 14-11). Thus by satisfying these economic criteria as well as other system constraints, such as space availability and noise levels, the optimal design parameters will be defined.

Recommendations for duct system design are:

- Minimize the length of all duct runs

- Keep elbows and transitions (e.g., diffuses) to a minimum

- Use turning vanes in all elbows

- Use collector panel configurations which use no more than 2 or 3 panels in series

- Attempt to minimize connections used in the supply and retum loops so that air losses are reduced

- Carefully tape and insulate ductwork. Air flow and thermal losses have severely reduced system performance in many air systems.

\section{Duct Design Method}

The most common methods of air duct system design are (1) equal friction; (2) velocity reduction; (3) static regain and variations thereof such as total pressure; and (4) constant velocity. of these four methods the equal friction method is by far the most commonly used for active solar air heating systems. Several reasons for this preference include its simplicity in calculation, the availability of diagrams for rough calculations, and its applicability to low flow rates which are commonly found in solar heating systems.

In the equal friction method, the ductwork in a system (including manifolds and collectors) is sized for a constant pressure loss per running foot of duct. Reducers, fittings, and elbows must be represented in terms of equivalent length of straight duet. However, total equivalent length in the critical path of flow must be estimated from the total pressure loss coefficients which are given for most fittings, reducers, and elbows in the ASHRAE Handbook of Fundamentals.

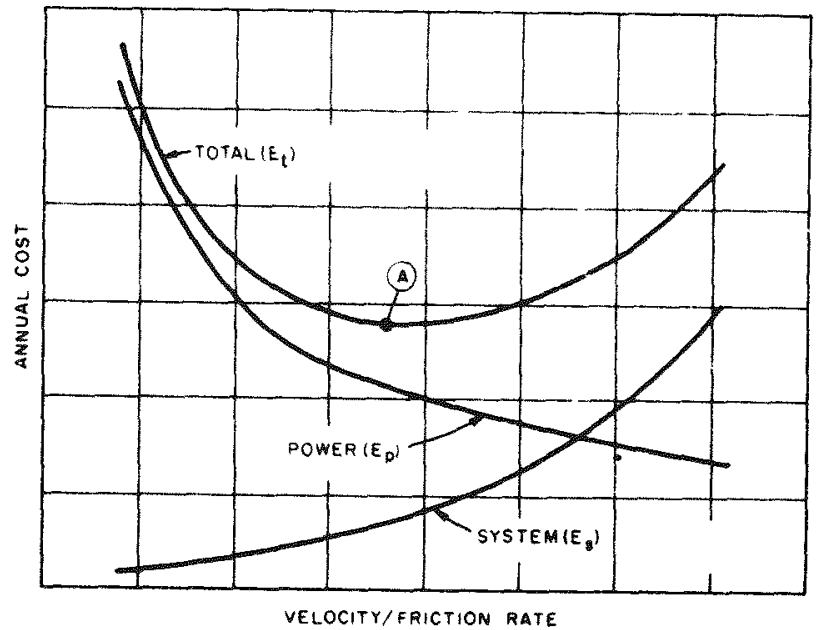

\section{Fig. 14-11. System economic analysis (Source: ASHRAE Handbook of Fundamentals)}

For an initial design it may be desirable to refer to a graph such as Fig. 14-12 and attempt to size a duct which lies within the design band. In some cases, especially where higher air flow rates are anticipated, it will become necessary to analyze possible noise generation problems and appropriately place sound attenuators in the system.

After the system has been initially sized, total pressure drops are calculated for the main manifold, heat exchanger (if any), and system storage (if any) sections. Then, using flow rates as suggested by the collector manufacturer, it is possible to establish a total pressure grade line (see Fig. 14-13). Note that we will want the total pressure $\left(\mathrm{P}_{\mathrm{T}}\right)$ to change from positive to negative when it goes through the collector. This will help to reduce air leakage (both infiltration and exfiltration) in the collector, which is generally the location of the greatest system air loss. Then a redesign of the appropriate sections and fittings to approximately balance the system without entirely relying on dampers is done. After installation, it is usually desirable to test, adjust, and balance the inlet air flow among the arrays being fed from a central trunkline.

When the system has been sized, balanced (approximately), and accounted for altitude, temperature, and maximum velocity concerns (see section below on basic engineering concepts) we may then determine the appropriate fan size needed to supply the required CFM at the calculated friction loss for the loop. The details of fan selection are covered later in this section.

\section{HVAC Engineering Concepts}

\section{Standard Air}

Standard air is used as a basis for rating equipment, but 


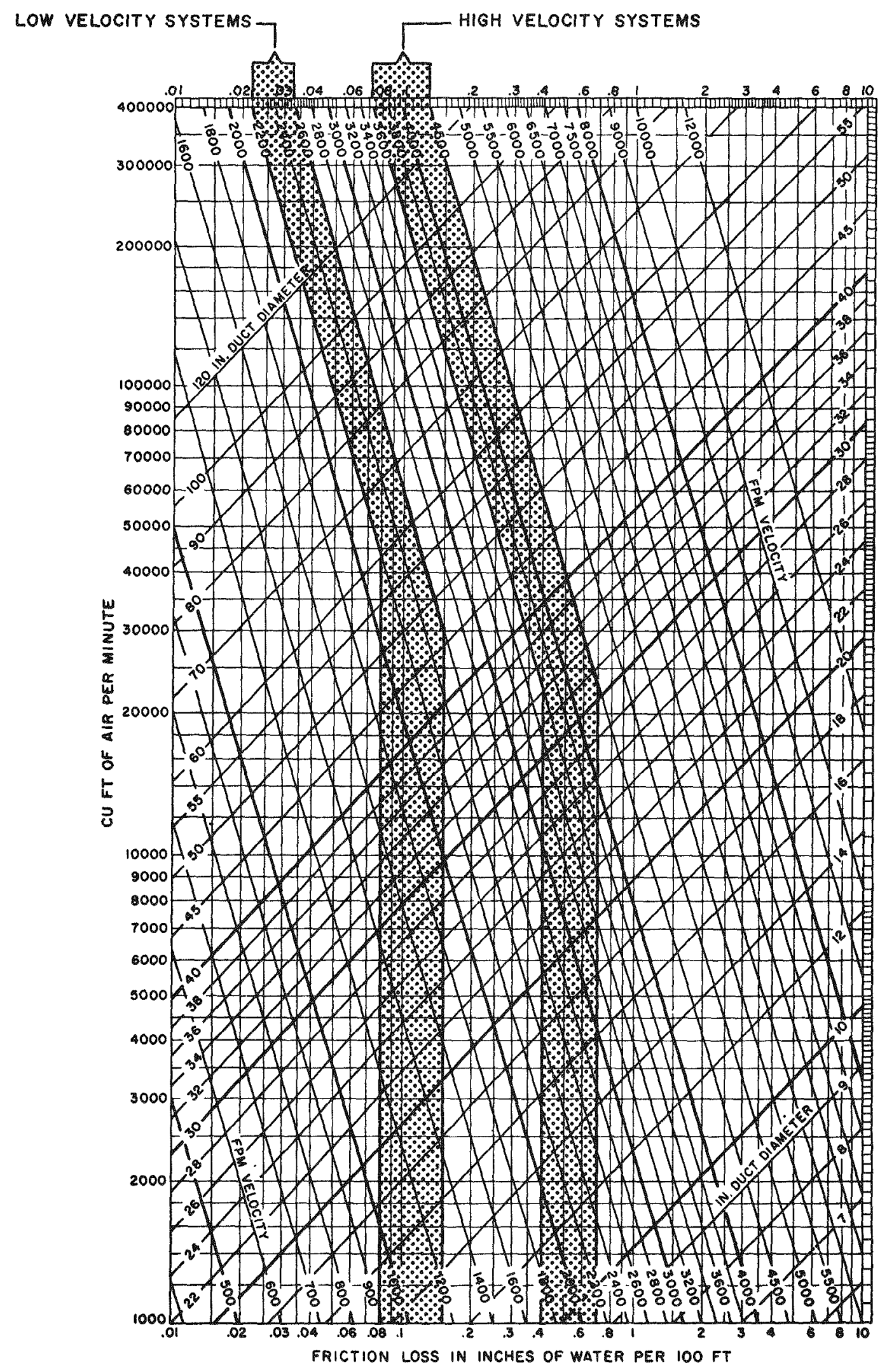

Fig 14-12. Suggested Velocity and Friction Rate Design Limits 
nonstandard air is most often encountered in actual systems. Standard air refers to daytime air at $14.7 \mathrm{psia}$, $\mathrm{T}=70 \mathrm{~F}, \rho=0.75 \mathrm{lbm} / \mathrm{cu} \mathrm{ft}$.

\section{Air Density}

Air density ratio (ADR) is the ratio of the actual air density to standard air density.

$$
\mathrm{ADR}=\frac{\rho}{\rho_{\mathrm{STD}}}
$$

We can calculate from

$$
\rho=\frac{39.75}{(460+T) e^{h / 27000}}\left(1 \mathrm{bm} / \mathrm{ft}^{3}\right)
$$

where

$$
\begin{aligned}
& \mathrm{h}=\text { altitude }(\mathrm{ft}) \\
& \mathrm{T}=\text { temperature }\left({ }^{\circ} \mathrm{F}\right)
\end{aligned}
$$

Similarly, ADR may be calculated directly from its definition:

$$
\mathrm{ADR}=\frac{\rho}{\rho_{\mathrm{STD}}}
$$

But from the Ideal Gas Law pv $=R T_{1}$

where the specific volume

$$
V=1 / \rho
$$

then,

$$
\rho_{\text {std }}=\frac{\rho_{\text {std }}}{\text { RTstd. }}
$$

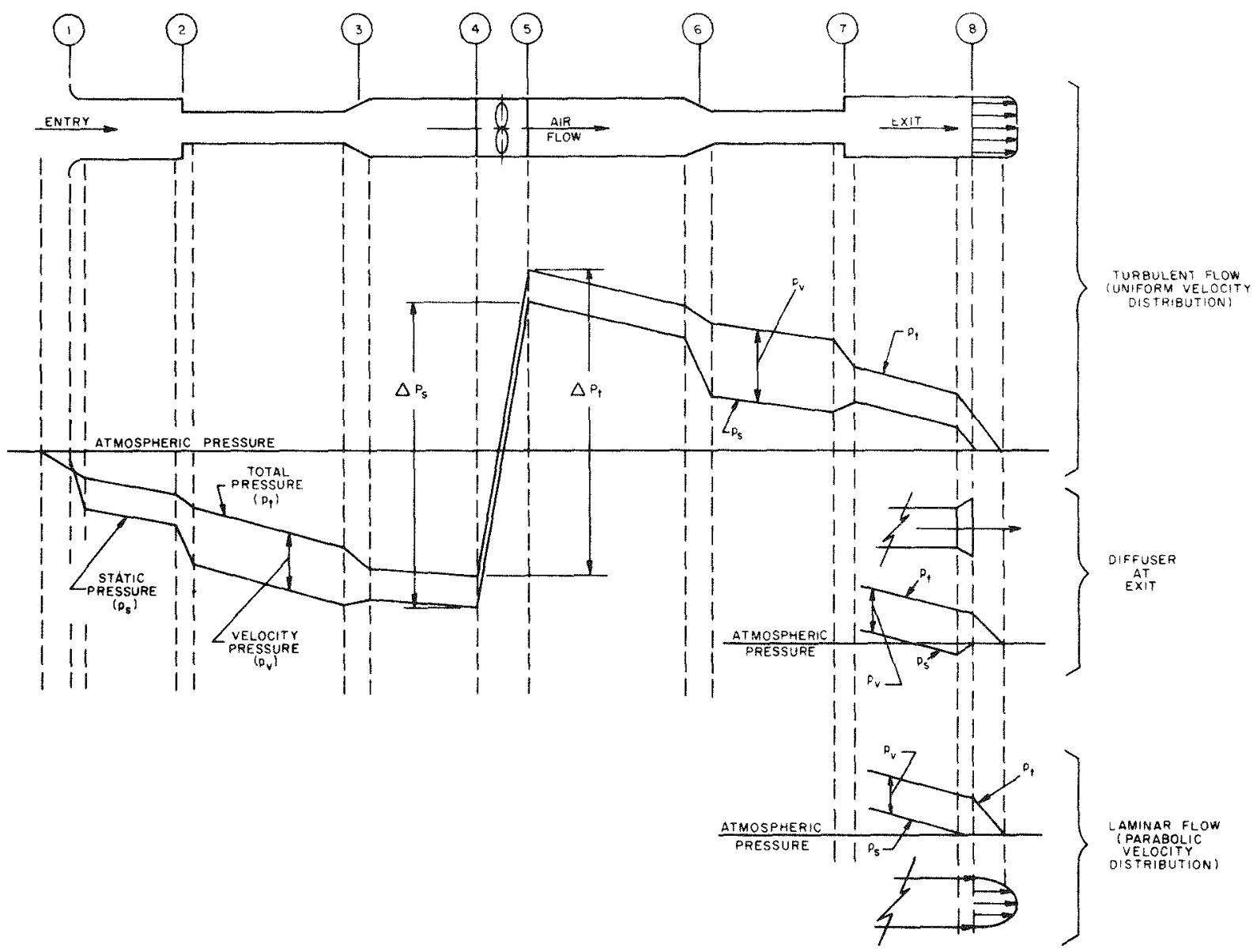

Fig. 14-13. Pressure changes during flow in ducts. (Source: ASHRAE Handbook of Fundamentals) 
Therefore

$$
\begin{aligned}
\mathrm{ADR} & =\left(\frac{\mathrm{RT}_{\mathrm{STD}}}{\mathrm{p}_{\mathrm{STD}}}\right) \rho \\
& =\left(\frac{\mathrm{RT}_{\mathrm{STD}}}{\mathrm{P}_{\mathrm{STD}}}\right) \frac{39.75}{(460+\mathrm{T}) \mathrm{e}^{\mathrm{h} / 27000}} \\
& =\frac{530}{(460+\mathrm{T}) \mathrm{e}^{\mathrm{h} / 27000}}
\end{aligned}
$$

Example. Calculate the average air properties for a solar system duct design near Denver where altitude $=5000 \mathrm{ft}$ and $\mathrm{T}=120 \mathrm{~F}$.

$$
\begin{aligned}
\operatorname{ADR} & =\left(\frac{530}{(460+120)}\right) e^{-\frac{5000}{27000}} \\
& =0.76 \\
\text { Then } \rho & =(0.76) \text { STD } \\
& =\left(0.76 \times 0.075 \mathrm{lbm} / \mathrm{ft}^{3}\right) \\
& =0.06 \mathrm{lbm} / \mathrm{ft}^{3}
\end{aligned}
$$

\section{Air Hlow Rates}

Standard Cubic Feet per Minute (SCFM) is a measure of air flow expressed in terms of standard air. ACFM refers to actual CFM. These are related through ADR as follows:

$$
A C F M=\frac{S C F M}{A D R}
$$

Example. Suppose we have 1000 ACFM flowing in a duct for the previous example, for which $A D R=0.76$. Then

$$
\begin{aligned}
\text { SCFM } & =(A C F M)(A D R) \\
& =(1000)(0.76) \\
& =760
\end{aligned}
$$

$1000 \mathrm{ACFM}$ and 760 SCFM describe the same air flow when $\mathrm{ADR}=0.76$. This becomes important when we talk about sizing equipment and duets.

\section{Air Velocity}

Air velocity in a duct is also described in terms of standard conditions or actual conditions.

$$
w(C F M)=V(f t / \min ) A\left(f t^{2}\right) \text {. }
$$

Therefore the actual air velocity $(\mathrm{ft} / \mathrm{min})$ is given by

$$
V=\frac{A C F M}{A \overline{R E A}}
$$

For a rectangular duct with dimensions $A$ and $B$ (in inches)

$$
V=\frac{(\mathrm{ACFM})(144)}{\mathrm{A} \times \mathrm{B}} \mathrm{ft} / \mathrm{min}
$$

For a round duct with diameter $D$ (in.)

$$
\begin{aligned}
V & =\frac{(A C F M \times 144)}{\frac{\pi D^{2}}{4}} \\
& =\frac{(183.35)(A C F M)}{D^{2}}(\mathrm{ft} / \mathrm{min})
\end{aligned}
$$

For standard air, replace ACFM by SCFM.

Bxample. Again consider the earlier problem for which we had $1000 \mathrm{ACFM}$ at $\mathrm{ADR}=0.76$; suppose this flow is in a duct of dimensions 12 in. $x 14$ in.

The actual air velocity is

$$
\begin{aligned}
\mathrm{V}(\mathrm{ft} / \mathrm{min}) & =\frac{(144)(1000)}{12 \times 14} \\
& =857 \mathrm{ft} / \mathrm{min} .
\end{aligned}
$$

If this same air flow were carried in a 12 in. diameter round duct, the actual air velocity would be

$$
\begin{aligned}
V & =\frac{(183.35)(1000)}{12^{2}} \\
& =1273 \mathrm{ft} / \mathrm{min} .
\end{aligned}
$$

If we express the air velocity in terms of standard air, we would have (for the rectangular duct)

$\mathrm{V}_{\mathrm{STD} A I R}=\frac{(144)(\mathrm{SCFM})}{12 \times 14}$

But $S C F M=A C F M \times A D R$.

Therefore

$$
\begin{aligned}
V_{\text {STD AIR }} & =\frac{(144)(760)}{12 \times 14} \\
& =651 \mathrm{ft} / \mathrm{min} .
\end{aligned}
$$

\section{Static Head $\left(\mathrm{H}_{\mathrm{S}}\right)$}

Static head refers to the pressure that pushes the air through a system. 


\section{Veloeity Head $\left(\mathrm{H}_{\mathbf{V}}\right)$}

Velocity head is the pressure associated with the movement of air. (Velocity head does not create air flow but is the result of air flow.)

Recall Bernoulli's equation:

$$
\mathrm{p}_{\mathrm{t}}=\mathrm{p}_{\mathrm{s}}+1 / 2 \rho \mathrm{V}^{2}
$$

or

$$
\mathrm{H}_{\mathrm{T}}=\mathrm{H}_{\mathrm{S}}+\mathrm{H}_{\mathrm{V}} \text {. }
$$

Therefore

$$
\mathrm{H}_{\mathrm{v}}=1 / 2 \rho \mathrm{V}^{2} \text {. }
$$

Therefore for standard air

$$
\begin{aligned}
\mathrm{H}_{\mathrm{V}} & =1 / 2 \rho \mathrm{V}^{2} \\
& =(1 / 2)\left(0.75 \mathrm{lbm} / \mathrm{ft}^{3}\right)[\mathrm{V}(\mathrm{ft} / \mathrm{min})]^{2} .
\end{aligned}
$$

Now we normally express head in inches water column (W.C.)

$$
1 \mathrm{ft} \mathrm{H}_{2} \mathrm{O}=0.433 \mathrm{lbf} / \mathrm{in}^{2}
$$

Therefore

$$
H_{V}=(V / 4005)^{2} \text { (in. W. C.) . }
$$

For nonstandard air, the velocity head is

$$
H_{V}=(0.83) \rho(V / 1000)^{2}
$$

where

$$
.83=(1 / 2)(1 / .144)(1 / 3.600)(1 / 32.174)(12 / .433) .
$$

\section{Total Head $\left(\mathrm{H}_{\mathrm{T}}\right)$}

$$
\mathrm{H}_{\mathrm{T}}=\mathrm{H}_{\mathrm{S}}+\mathrm{H}_{\mathrm{V}}
$$

\section{Static Regain}

Static regain is the conversion from velocity head to static head.

\section{Head Loss}

We need to calculate the head loss (due to friction) in order to size the air handling unit.

Use Fig. 14-14 (from ASHRAE Handbook of Fundamentals) to determine head loss in round duct. The figure is for standard air only! Hence we proceed as follows:

1. Find nominal head loss using ACFM.

2. Multiply the nominal head loss by the duct friction correction factor where duct friction correction factor $\left(F_{D F}\right)$

$$
=0.182+10.911 \rho\left(1 \mathrm{bm} / \mathrm{ft}^{3}\right) \text {. }
$$

Example. Find the head loss in a $12 \mathrm{in}$, round duct carrying 1000 SCFM of air at $6000 \mathrm{ft}$ elevation and $150^{\circ} \mathrm{F}$.

First we must determine the ACFM. Recall that

$$
\mathrm{ADR}=\frac{\mathrm{SCFM}}{\mathrm{ACFM}}
$$

and that

$$
\begin{aligned}
\mathrm{ADR} & =\frac{\rho}{\rho_{\mathrm{STD}}} \\
& =\frac{530}{(460+\mathrm{T})} \mathrm{e}^{-\frac{\text { ALT }}{27000}} \\
& =\frac{530}{460+150} \mathrm{e}^{-\frac{6000}{27000}} \\
& =0.696 .
\end{aligned}
$$

Then

$$
A C F M=\frac{1000}{0.696}=1437 .
$$

From Fig. 14-15 the nominal head loss is

$$
\mathrm{H}_{\text {nom }} \approx 0.38 \mathrm{in.} \mathrm{W.C.} / 100 \mathrm{ft} .
$$

Now correct to get actual head loss.

At $6000 \mathrm{ft}$ and $150^{\circ} \mathrm{F}$

$$
\begin{aligned}
\rho & =0.696 \rho_{\text {STD }}=(0.696)\left(0.075 \mathrm{lb} / \mathrm{ft}^{3}\right) \\
& =0.052 \mathrm{lbm} / \mathrm{ft}^{3} .
\end{aligned}
$$

Then

$$
\begin{aligned}
F_{D F} & =0.182+(10.911)(0.052) \\
& =0.749 .
\end{aligned}
$$

Therefore the actual head loss is

$$
\begin{aligned}
\mathrm{H}_{\text {ACT }} & =0.38 \times 0.749 \\
& =0.285 \mathrm{in} \mathrm{W.C.} / 100 \mathrm{ft} .
\end{aligned}
$$

A correlation equation has been developed for duct head loss and is as follows:

$$
H=\frac{(0.027)\left(\mathrm{H}_{.} \mathrm{F}_{\odot}\right)(\mathrm{L})(\mathrm{ADR})^{0.845}}{\left(D_{\mathrm{e}}\right)^{4.92}}(0.184 \times \mathrm{ACFM})^{1.85}
$$




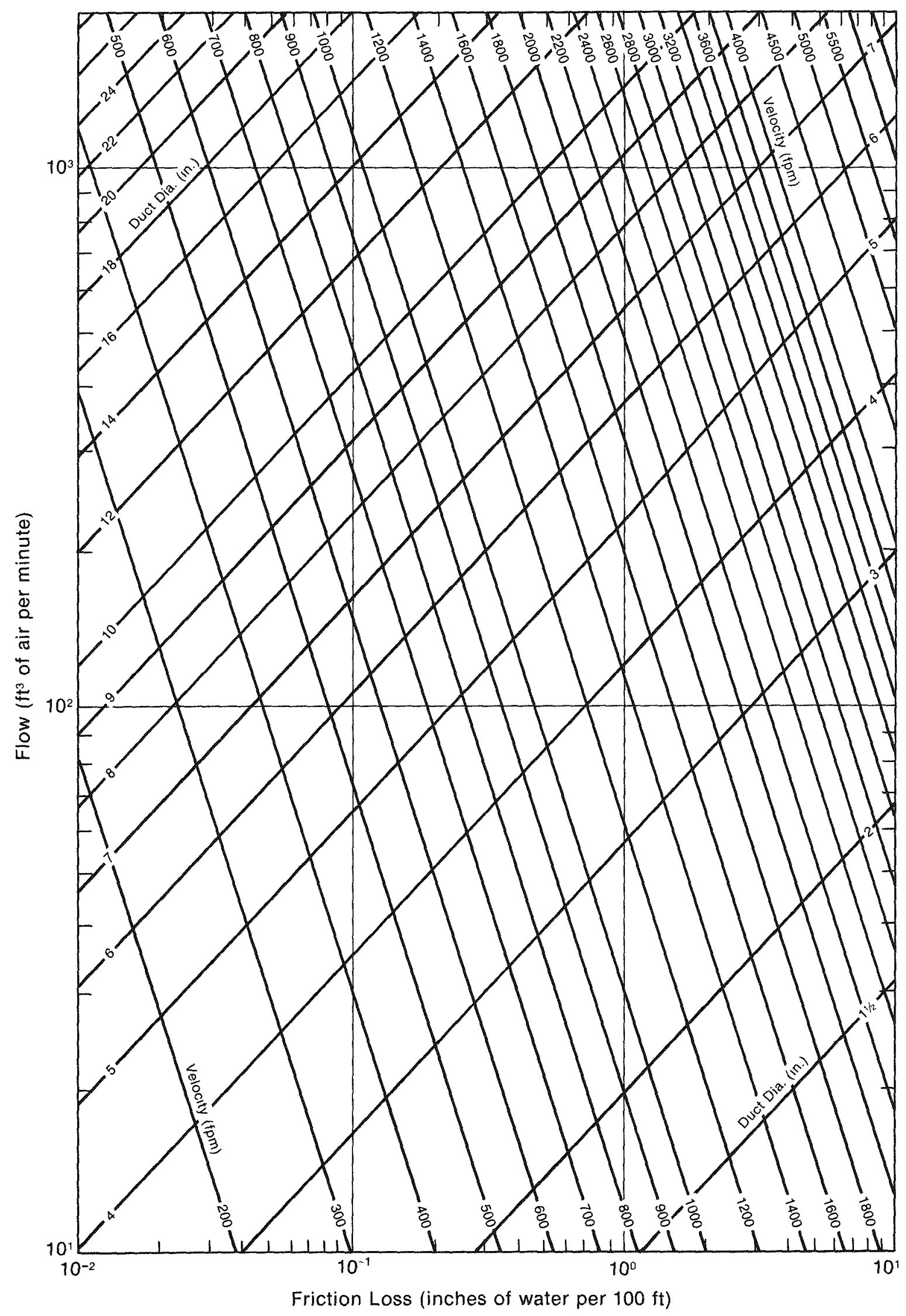

Fig. 14-14. Friction Loss in a Straight Duct

(Source: ASHRAE Handbook of Fundamentals) 


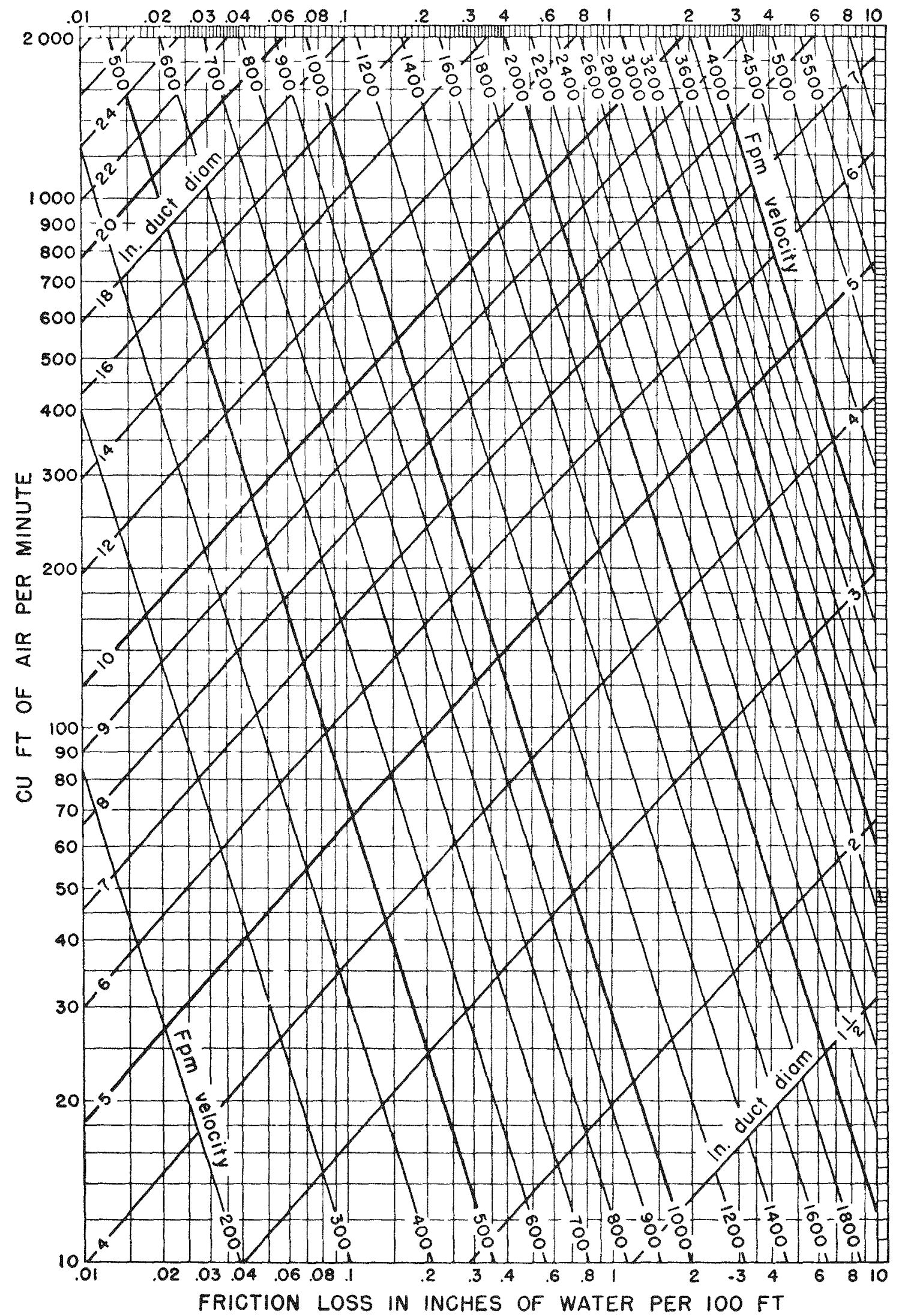

Based on Standard Air of $0075 \mathrm{lb} / \mathrm{ft}^{3}$ densty flowing through average, clean, round, galvanized metal ducts having approximately 40 jounts per $100 \mathrm{ft}$ ) Caut

Fig. 14-15. Friction of air in straight ducts for volumes of 10 to $2000 \mathrm{cfm}$.

(Source: ASHRAE Handbook of Fundamentals) 
where

$$
\begin{aligned}
\mathrm{H} & =\text { head loss, in. W.C. } \\
\mathrm{L} & =\text { equivalent duet length, } \mathrm{ft} \\
\mathrm{ADR} & =\text { air density ratio, lbm/cu ft } \\
\mathrm{D}_{\mathrm{e}} & =\text { equivalent round duct diameter, in. } \\
\mathrm{ACFM} & =\text { actual air flow rate, } \mathrm{cu} \mathrm{ft} / \mathrm{min} \\
\mathrm{IF} & =\text { insulation friction factor }
\end{aligned}
$$

Compare with earlier result:

$$
\begin{gathered}
H=\frac{(0.027)(1)(100)(0.696)^{0.845}}{12^{4.92}}(0.184 \times 1437)^{1.85} \\
=0.295 \text { in. W.C. } / 100 \mathrm{ft} .
\end{gathered}
$$

Compared at 0.285 in. W.C. from earlier result, it is very good agreement.

\section{Equivalent Length}

Equivalent length is the actual length of duct plus an amount added for each elbow. This is because elbows have a higher head loss than a straight piece of duct of the same length. Hence an elbow is considered to be a straight duct with an equivalent length greater than its actual length. Graphs of equivalent lengths of round and rectangular ducts have been developed and are presented in Chapter 25 of the ASHR AE Handbook of Fundamentals. Equivalent leng ths for elbows are shown in Fig. 14-16. Table 14-1 showing equivalent length values is also included.

Example. Consider a 10 in. round duct $152 \mathrm{ft}$ long. It has seven $90^{\circ}$-piece elbows. What is the equivalent length? Say $R / D=1.5$.

From the Graph

$$
\frac{\mathrm{L}}{\mathrm{D}}=12 \text {. }
$$

Hence the equivalent length is 12 times the diameter; that is

$$
L=12 \times 10 \mathrm{in},=120 \mathrm{in.} \text { or } 10 \mathrm{ft} .
$$

Hence the equivalent length of the entire duct system is

$$
\begin{aligned}
\mathbf{L} & =152+(7 \times 10) \\
& =222 \mathrm{ft} .
\end{aligned}
$$

Hence if $\mathrm{H}=0.285$ in $W . C . / 100 \mathrm{ft}$, then the head loss in

\begin{tabular}{|c|c|c|c|c|c|c|c|c|c|c|c|c|c|c|c|}
\hline Vel. Fps & $1 / 2$ & $3 / 4$ & 1 & $11 / 4$ & $11 / 2$ & 2 & $21 / 2$ & 3 & $31 / 2$ & 4 & 5 & 6 & 8 & 10 & 12 \\
\hline $\begin{array}{l}1 \\
2 \\
3 \\
4 \\
5\end{array}$ & $\begin{array}{l}12 \\
14 \\
15 \\
15 \\
16\end{array}$ & $\begin{array}{ll}1 & 7 \\
1 & 9 \\
2 & 0 \\
21 & 1 \\
22\end{array}$ & $\begin{array}{l}22 \\
25 \\
27 \\
28 \\
29\end{array}$ & $\begin{array}{l}30 \\
33 \\
36 \\
37 \\
39\end{array}$ & $\begin{array}{l}35 \\
39 \\
42 \\
44 \\
45\end{array}$ & $\begin{array}{l}45 \\
51 \\
54 \\
56 \\
59\end{array}$ & $\begin{array}{l}54 \\
60 \\
64 \\
67 \\
70\end{array}$ & $\begin{array}{l}67 \\
75 \\
80 \\
83 \\
87\end{array}$ & $\begin{array}{r}77 \\
86 \\
92 \\
96 \\
100\end{array}$ & $\begin{array}{r}86 \\
95 \\
102 \\
106 \\
111\end{array}$ & $\begin{array}{l}105 \\
117 \\
125 \\
131 \\
136\end{array}$ & $\begin{array}{l}122 \\
137 \\
148 \\
152 \\
158\end{array}$ & $\begin{array}{l}154 \\
173 \\
184 \\
192 \\
198\end{array}$ & $\begin{array}{l}187 \\
208 \\
223 \\
232 \\
242\end{array}$ & $\begin{array}{l}222 \\
248 \\
265 \\
276 \\
288\end{array}$ \\
\hline $\begin{array}{r}6 \\
7 \\
8 \\
9 \\
10\end{array}$ & $\begin{array}{l}17 \\
17 \\
17 \\
18 \\
18\end{array}$ & $\begin{array}{ll}2 & 3 \\
2 & 3 \\
2 & 4 \\
2 & 4 \\
2 & 5\end{array}$ & $\begin{array}{ll}3 & 0 \\
3 & 0 \\
3 & 1 \\
3 & 2 \\
3 & 2\end{array}$ & $\begin{array}{l}40 \\
41 \\
42 \\
43 \\
43\end{array}$ & $\begin{array}{l}47 \\
48 \\
49 \\
50 \\
51\end{array}$ & $\begin{array}{l}60 \\
62 \\
63 \\
64 \\
65\end{array}$ & $\begin{array}{l}72 \\
74 \\
75 \\
77 \\
78\end{array}$ & $\begin{array}{l}89 \\
91 \\
93 \\
95 \\
97\end{array}$ & $\begin{array}{l}103 \\
105 \\
108 \\
110 \\
112\end{array}$ & $\begin{array}{l}114 \\
117 \\
119 \\
122 \\
124\end{array}$ & $\begin{array}{l}140 \\
143 \\
146 \\
149 \\
152\end{array}$ & $\begin{array}{l}163 \\
167 \\
171 \\
174 \\
177\end{array}$ & $\begin{array}{l}205 \\
210 \\
215 \\
219 \\
222\end{array}$ & $\begin{array}{l}249 \\
255 \\
261 \\
266 \\
270\end{array}$ & $\begin{array}{ll}29 & 6 \\
30 & 3 \\
31 & 0 \\
31 & 6 \\
32 & 0\end{array}$ \\
\hline
\end{tabular}
this system would be $(0.285$ in W.C. $)(222 / 100)=0.63$ in. W.C.
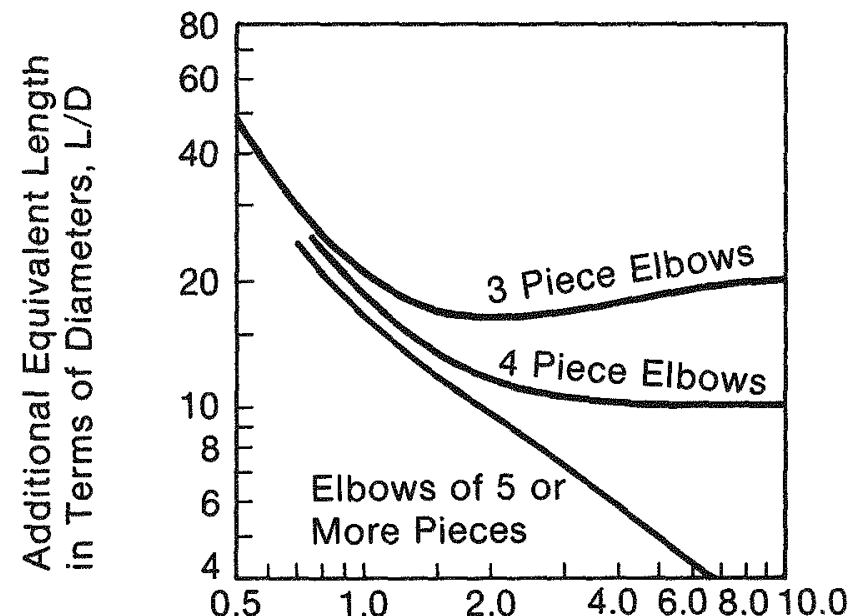

Radius Ratio, R/D

Fig. 14-16. Loss in 90-Deg Elbows of Round Cross Section

(Source: ASHRAE Handbook of Fundamentals)

Table 14-1. Equivalent Length of Pipe for 90-Deg Elbows Pipe Size

(Source: ASHRAE Handbook of Fundamentals) 


\section{Insulation Friction Factor}

The insulation friction factor accounts for added friction due to duct liners; if no insulation is used (bad practice) or it is placed on the outside (looks bad), then the insulation friction factor (IF) is equal to 1. Good designs will have $\mathrm{IF}=1.05$ but others will have IF as high as 1.4 .

\section{Bquivalent Duets}

For every rectangular duct with dimensions $A$ and $B$ there is a round duct with diameter $D$ which will have the same head loss when the same volume of air flows through each.

The ASHRAE Handbook of Fundamentals has a table in Chapter 25 showing equivalent ducts. This table is duplicated here (Table 14-2). Equivalent duct diameters may also be computed according to:

$$
D_{E}=\frac{1.30(A B)^{0.625}}{(A+B)^{0.25}} \text {. }
$$

Check: A 10 in. $\times 12$ in. duct has, from the equation,

$$
D_{E}=\frac{1.3(120)^{0.625}}{(22)^{0.25}}=11.96 \mathrm{in} \text {. }
$$

Compared at 11.9 in. from Table.

It should be noted that although these ducts have equal friction or head loss at equal air flow rates, the air velocity is always greater in a round duct than in the rectangular equivalent.

\section{Solar System Design Constraints}

Two parameters:

- Air Velocity $\leq 1000 \mathrm{ft} / \mathrm{min}$

- $\mathrm{H} \approx 0.08$ in. $\mathrm{H}_{2} \mathrm{O/100 \textrm {ft }}$

These are based on extensive experience with residential solar and air distribution systems; they are good values to use in order to provide quiet and cost effective systems.

\section{Solar System Duet Design}

The following information is needed:

- Site elevation

- Design air te mperature

- Typically $70 \mathrm{~F}$ for retum air from building or supply air to the collectors.

- Typically $120 \mathrm{~F}$ for heated air going to the building or return air from the collectors.

- Insulation friction factor

- $F=1$ if no insulation is used inside ducts.

- Obtain from insulation manufacturer interviews; normally IF is 1.05 , to 1.40 .

- Maximum duct friction factor, $F_{\text {max }}$ Normally, $F_{\text {max }}=0.08$ in. $\mathrm{H}_{2} 0 / 100 \mathrm{ft}$.

- Maximum duct air velocity, $\mathrm{V}_{\text {max }}$ Normally, $\mathrm{v}_{\max }=1000 \mathrm{ft} / \mathrm{min}$.
These inputs and the basic air engineering concepts are sufficient information for proper duct sizing.

Example. Size the supply and retum duets for a solar collector array of $300 \mathrm{sq} \mathrm{ft}$; assume $2.0 \mathrm{SCFM} / \mathrm{sq} \mathrm{ft}$ of collector area. Use a rectangular duct at $\mathbf{F}=1.05$. The system is to be located near Ft. Collins, Colorado (elevation $=5000 \mathrm{ft}$ ).

Solution. We could size the supply and return ducts separately from one another. However, in practice these are usually made the same size. Hence it is common practice to size the return air duct (carrying the hotter air-hopefully) and then make the supply air duct the same size.

First ealculate the air density ratio, $A D R$.

$$
\begin{aligned}
\text { ADR } & =\frac{530 e^{-\frac{\text { ALT }}{27000}}}{(460+T)} \\
\text { use } T & =120 \mathrm{~F} ; \text { hence } \\
\text { ADR } & =0.76 .
\end{aligned}
$$

The collector flow rate is

$$
\begin{aligned}
m_{C} & =(2.0 \mathrm{SCFM} / \mathrm{sq} \mathrm{ft})(300 \mathrm{sq} \mathrm{ft}) \\
& =600 \mathrm{SCFM} .
\end{aligned}
$$

Hence the actual air flow rate is

$$
\mathrm{ACFM}=600 / .76=790 \text {. }
$$

$$
\mathrm{H}=\mathrm{F}_{\max }=.08 \text { inches } \mathrm{W} . \mathrm{C} \text {. }
$$

We could use the chart (Fig. 14-14) to size the duct required to carry 790 ACFM at a specified head loss but that figure is for standard air only.

We can either correct the friction factor and use Fig. 14-14 or we can use the equation derived earlier. Recall that

$$
H=\frac{(0.027)(\mathrm{IF})(\mathrm{L})(\mathrm{ADR})^{0.845}}{\mathrm{D}_{\mathrm{E}}^{4.92}}(0.184 \mathrm{ACFN})^{1.85} \text { or }
$$

$$
\begin{aligned}
\left(D_{\mathrm{E}}\right)^{4.92} & =\frac{(0.027)(\mathrm{IF})(\mathrm{L})(\mathrm{ADR})^{0.845}(0.184 \times \mathrm{ACFM})^{1.85}}{\mathrm{H}} \\
& =\frac{(0.027)(1.05)(100)(0.76)^{0.845}(0.184 \times 790)^{1.85}}{.08}
\end{aligned}
$$

$$
\left(D_{E}\right)^{4.92}=281367 \text {. }
$$

Therefore

$$
D_{E}=(281367)^{1 / 4.92}=12.8 \mathrm{in} .
$$




\section{Table 14-2.Circular Equivalents of Rectangular Ducts for Equal Friction and Capacity}

(Source: ASHRAE Handbook of Fundamentals) Dimensions in Inches

\begin{tabular}{|c|c|c|c|c|c|c|c|c|c|c|c|c|c|c|c|c|c|c|c|c|c|}
\hline $\begin{array}{l}\text { Side } \\
\text { Rec- } \\
\text { tan- } \\
\text { gular } \\
\text { Duct }\end{array}$ & 6 & 7 & 8 & 9 & 10 & 11 & 12 & 13 & 14 & 15 & 16 & 17 & 18 & 19 & 20 & 22 & 24 & 26 & 28 & 30 & $\begin{array}{l}\text { Slde } \\
\text { Rec- } \\
\text { tan- } \\
\text { gular } \\
\text { Duct }\end{array}$ \\
\hline $\begin{array}{r}6 \\
7 \\
8 \\
9 \\
10\end{array}$ & $\begin{array}{l}66 \\
71 \\
75 \\
80 \\
84\end{array}$ & $\begin{array}{l}77 \\
82 \\
86 \\
91\end{array}$ & $\begin{array}{l}88 \\
93 \\
98\end{array}$ & $\begin{array}{r}99 \\
104\end{array}$ & 109 & & & & & & & & & & & & & & & & $\begin{array}{r}6 \\
7 \\
8 \\
9 \\
10\end{array}$ \\
\hline $\begin{array}{l}11 \\
12 \\
13 \\
14 \\
15\end{array}$ & $\begin{array}{r}88 \\
91 \\
95 \\
98 \\
101\end{array}$ & $\begin{array}{r}95 \\
99 \\
103 \\
107 \\
110\end{array}$ & $\begin{array}{l}102 \\
107 \\
111 \\
115 \\
118\end{array}$ & $\begin{array}{l}108 \\
113 \\
118 \\
122 \\
126\end{array}$ & $\begin{array}{l}114 \\
119 \\
124 \\
129 \\
133\end{array}$ & $\begin{array}{l}120 \\
125 \\
130 \\
135 \\
140\end{array}$ & $\begin{array}{l}131 \\
136 \\
142 \\
146\end{array}$ & $\begin{array}{r}142 \\
147 \\
153\end{array}$ & $\begin{array}{r} \\
153 \\
158\end{array}$ & 164 & & & & & & & & & & & $\begin{array}{l}11 \\
12 \\
13 \\
14 \\
15\end{array}$ \\
\hline $\begin{array}{l}16 \\
17 \\
18 \\
19 \\
20\end{array}$ & $\begin{array}{l}104 \\
107 \\
110 \\
112 \\
115\end{array}$ & $\begin{array}{l}114 \\
117 \\
119 \\
122 \\
125\end{array}$ & $\begin{array}{l}122 \\
125 \\
129 \\
132 \\
135\end{array}$ & $\begin{array}{l}130 \\
134 \\
137 \\
141 \\
144\end{array}$ & $\begin{array}{l}137 \\
141 \\
145 \\
149 \\
152\end{array}$ & $\begin{array}{l}144 \\
149 \\
153 \\
156 \\
159\end{array}$ & $\begin{array}{l}151 \\
155 \\
160 \\
164 \\
168\end{array}$ & $\begin{array}{l}157 \\
161 \\
166 \\
171 \\
175\end{array}$ & $\begin{array}{l}163 \\
168 \\
173 \\
178 \\
182\end{array}$ & $\begin{array}{l}169 \\
174 \\
179 \\
184 \\
188\end{array}$ & $\begin{array}{l}175 \\
180 \\
185 \\
190 \\
195\end{array}$ & $\begin{array}{l}186 \\
191 \\
196 \\
201\end{array}$ & $\begin{array}{l}197 \\
202 \\
207\end{array}$ & $\begin{array}{l}208 \\
213\end{array}$ & 219 & & & & & & $\begin{array}{l}16 \\
17 \\
18 \\
19 \\
20\end{array}$ \\
\hline $\begin{array}{l}22 \\
24 \\
26 \\
28 \\
30\end{array}$ & $\begin{array}{l}120 \\
124 \\
128 \\
132 \\
136\end{array}$ & $\begin{array}{l}131 \\
136 \\
141 \\
145 \\
149\end{array}$ & $\begin{array}{l}141 \\
146 \\
152 \\
156 \\
161\end{array}$ & $\begin{array}{l}150 \\
156 \\
162 \\
167 \\
172\end{array}$ & $\begin{array}{r}159 \\
166 \\
172 \\
177 \\
\cdot 183\end{array}$ & $\begin{array}{l}167 \\
175 \\
181 \\
187 \\
193\end{array}$ & $\begin{array}{l}176 \\
183 \\
190 \\
196 \\
202\end{array}$ & $\begin{array}{l}183 \\
191 \\
198 \\
205 \\
211\end{array}$ & $\begin{array}{l}191 \\
198 \\
206 \\
213 \\
220\end{array}$ & $\begin{array}{l}197 \\
206 \\
214 \\
221 \\
229\end{array}$ & $\begin{array}{l}204 \\
213 \\
221 \\
229 \\
237\end{array}$ & $\begin{array}{l}210 \\
219 \\
228 \\
236 \\
244\end{array}$ & $\begin{array}{l}217 \\
226 \\
235 \\
244 \\
252\end{array}$ & $\begin{array}{l}223 \\
232 \\
241 \\
250 \\
259\end{array}$ & $\begin{array}{l}229 \\
239 \\
248 \\
257 \\
267\end{array}$ & $\begin{array}{l}241 \\
251 \\
261 \\
271 \\
280\end{array}$ & $\begin{array}{l}262 \\
272 \\
282 \\
293\end{array}$ & $\begin{array}{l}284 \\
295 \\
305\end{array}$ & $\begin{array}{l}306 \\
316\end{array}$ & 328 & $\begin{array}{l}22 \\
24 \\
26 \\
28 \\
30\end{array}$ \\
\hline $\begin{array}{l}32 \\
34 \\
36 \\
38 \\
40\end{array}$ & $\begin{array}{l}140 \\
144 \\
147 \\
150 \\
153\end{array}$ & $\begin{array}{l}153 \\
157 \\
161 \\
164 \\
168\end{array}$ & $\begin{array}{l}165 \\
170 \\
174 \\
178 \\
182\end{array}$ & $\begin{array}{l}177 \\
182 \\
186 \\
190 \\
194\end{array}$ & $\begin{array}{l}188 \\
193 \\
198 \\
203 \\
207\end{array}$ & $\begin{array}{l}198 \\
204 \\
209 \\
214 \\
219\end{array}$ & $\begin{array}{l}208 \\
214 \\
219 \\
225 \\
230\end{array}$ & $\begin{array}{ll}21 & 8 \\
22 & 4 \\
23 & 0 \\
23 & 5 \\
24 & 0\end{array}$ & $\begin{array}{l}227 \\
233 \\
239 \\
245 \\
251\end{array}$ & $\begin{array}{l}236 \\
242 \\
248 \\
254 \\
260\end{array}$ & $\begin{array}{l}244 \\
251 \\
258 \\
264 \\
270\end{array}$ & $\begin{array}{l}252 \\
259 \\
266 \\
273 \\
279\end{array}$ & $\begin{array}{l}260 \\
26 \quad 7 \\
274 \\
281 \\
288\end{array}$ & $\begin{array}{l}267 \\
275 \\
283 \\
290 \\
297\end{array}$ & $\begin{array}{l}275 \\
283 \\
290 \\
298 \\
305\end{array}$ & $\begin{array}{l}289 \\
297 \\
305 \\
314 \\
321\end{array}$ & $\begin{array}{l}301 \\
310 \\
320 \\
328 \\
336\end{array}$ & $\begin{array}{ll}314 \\
32 & 3 \\
33 & 0 \\
342 \\
351\end{array}$ & $\begin{array}{l}326 \\
336 \\
346 \\
355 \\
364\end{array}$ & $\begin{array}{l}338 \\
348 \\
358 \\
367 \\
376\end{array}$ & $\begin{array}{l}32 \\
34 \\
36 \\
38 \\
40\end{array}$ \\
\hline $\begin{array}{l}42 \\
44 \\
46 \\
48 \\
50\end{array}$ & $\begin{array}{l}156 \\
159 \\
162 \\
165 \\
168\end{array}$ & $\begin{array}{l}171 \\
175 \\
178 \\
181 \\
184\end{array}$ & $\begin{array}{l}185 \\
189 \\
192 \\
196 \\
199\end{array}$ & $\begin{array}{l}198 \\
202 \\
216 \\
209 \\
213\end{array}$ & $\begin{array}{l}211 \\
215 \\
219 \\
223 \\
227\end{array}$ & $\begin{array}{ll}22 & 3 \\
22 & 7 \\
23 & 2 \\
23 & 6 \\
24 & 0\end{array}$ & $\begin{array}{l}234 \\
239 \\
243 \\
248 \\
252\end{array}$ & $\begin{array}{l}245 \\
250 \\
255 \\
260 \\
264\end{array}$ & $\begin{array}{l}256 \\
261 \\
267 \\
272 \\
276\end{array}$ & $\begin{array}{l}266 \\
272 \\
277 \\
282 \\
287\end{array}$ & $\begin{array}{l}276 \\
282 \\
287 \\
292 \\
298\end{array}$ & $\begin{array}{l}285 \\
291 \\
297 \\
302 \\
308\end{array}$ & $\begin{array}{l}294 \\
300 \\
306 \\
312 \\
318\end{array}$ & $\begin{array}{l}304 \\
310 \\
316 \\
322 \\
328\end{array}$ & $\begin{array}{l}312 \\
319 \\
325 \\
331 \\
337\end{array}$ & $\begin{array}{l}328 \\
335 \\
442 \\
349 \\
355\end{array}$ & $\begin{array}{l}344 \\
352 \\
359 \\
366 \\
373\end{array}$ & $\begin{array}{l}359 \\
367 \\
374 \\
382 \\
389\end{array}$ & $\begin{array}{l}373 \\
381 \\
389 \\
397 \\
404\end{array}$ & $\begin{array}{l}386 \\
395 \\
403 \\
412 \\
420\end{array}$ & $\begin{array}{l}42 \\
44 \\
46 \\
48 \\
50\end{array}$ \\
\hline $\begin{array}{l}52 \\
54 \\
56 \\
58 \\
60\end{array}$ & $\begin{array}{l}170 \\
173 \\
176 \\
178 \\
181\end{array}$ & $\begin{array}{l}187 \\
190 \\
193 \\
195 \\
198\end{array}$ & $\begin{array}{l}202 \\
205 \\
209 \\
211 \\
214\end{array}$ & $\begin{array}{ll}21 & 6 \\
22 & 0 \\
22 & 4 \\
22 & 7 \\
23 & 0\end{array}$ & $\begin{array}{l}231 \\
234 \\
238 \\
242 \\
245\end{array}$ & 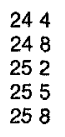 & $\begin{array}{l}256 \\
261 \\
265 \\
269 \\
273\end{array}$ & $\begin{array}{l}268 \\
273 \\
277 \\
282 \\
287\end{array}$ & $\begin{array}{l}281 \\
285 \\
289 \\
293 \\
298\end{array}$ & $\begin{array}{l}292 \\
297 \\
301 \\
305 \\
310\end{array}$ & $\begin{array}{l}303 \\
308 \\
312 \\
317 \\
322\end{array}$ & $\begin{array}{l}314 \\
319 \\
324 \\
329 \\
334\end{array}$ & $\begin{array}{l}324 \\
329 \\
334 \\
339 \\
345\end{array}$ & $\begin{array}{l}334 \\
339 \\
345 \\
350 \\
355\end{array}$ & $\begin{array}{l}343 \\
349 \\
355 \\
360 \\
365\end{array}$ & $\begin{array}{l}362 \\
368 \\
374 \\
380 \\
386\end{array}$ & $\begin{array}{l}380 \\
387 \\
393 \\
398 \\
404\end{array}$ & $\begin{array}{l}396 \\
403 \\
410 \\
417 \\
423\end{array}$ & $\begin{array}{l}412 \\
420 \\
427 \\
434 \\
440\end{array}$ & $\begin{array}{l}428 \\
436 \\
443 \\
450 \\
458\end{array}$ & $\begin{array}{l}52 \\
54 \\
56 \\
58 \\
60\end{array}$ \\
\hline $\begin{array}{l}62 \\
64 \\
66 \\
68 \\
70\end{array}$ & $\begin{array}{l}183 \\
186 \\
188 \\
190 \\
192\end{array}$ & $\begin{array}{l}201 \\
203 \\
206 \\
208 \\
210\end{array}$ & $\begin{array}{l}217 \\
220 \\
223 \\
225 \\
228\end{array}$ & $\begin{array}{l}233 \\
236 \\
239 \\
242 \\
245\end{array}$ & $\begin{array}{l}248 \\
252 \\
255 \\
258 \\
261\end{array}$ & 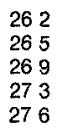 & $\begin{array}{l}276 \\
279 \\
283 \\
287 \\
291\end{array}$ & $\begin{array}{l}290 \\
293 \\
297 \\
301 \\
304\end{array}$ & $\begin{array}{l}302 \\
306 \\
310 \\
314 \\
318\end{array}$ & $\begin{array}{l}314 \\
318 \\
322 \\
326 \\
331\end{array}$ & $\begin{array}{l}326 \\
331 \\
335 \\
339 \\
343\end{array}$ & $\begin{array}{l}338 \\
342 \\
347 \\
351 \\
356\end{array}$ & $\begin{array}{l}350 \\
355 \\
359 \\
363 \\
368\end{array}$ & $\begin{array}{l}360 \\
365 \\
370 \\
375 \\
379\end{array}$ & $\begin{array}{l}371 \\
376 \\
381 \\
386 \\
391\end{array}$ & $\begin{array}{l}392 \\
397 \\
402 \\
407 \\
413\end{array}$ & $\begin{array}{l}410 \\
416 \\
422 \\
428 \\
433\end{array}$ & $\begin{array}{l}429 \\
435 \\
441 \\
447 \\
453\end{array}$ & $\begin{array}{l}447 \\
454 \\
460 \\
466 \\
472\end{array}$ & $\begin{array}{l}465 \\
472 \\
478 \\
484 \\
490\end{array}$ & $\begin{array}{l}62 \\
64 \\
66 \\
68 \\
70\end{array}$ \\
\hline $\begin{array}{l}72 \\
74 \\
76 \\
78 \\
80\end{array}$ & & & & & & & & & & & & & & & $\begin{array}{l}396 \\
400 \\
405 \\
409 \\
413\end{array}$ & $\begin{array}{l}418 \\
423 \\
428 \\
433 \\
438\end{array}$ & $\begin{array}{l}438 \\
444 \\
449 \\
455 \\
460\end{array}$ & $\begin{array}{l}478 \\
484 \\
470 \\
475 \\
480\end{array}$ & $\begin{array}{l}497 \\
503 \\
490 \\
495 \\
501\end{array}$ & $\begin{array}{l}497 \\
503 \\
508 \\
515 \\
520\end{array}$ & $\begin{array}{l}72 \\
74 \\
76 \\
78 \\
80\end{array}$ \\
\hline $\begin{array}{l}82 \\
84 \\
86 \\
88 \\
90\end{array}$ & & & & & & & & & & & & & & & $\begin{array}{l}418 \\
422 \\
426 \\
430 \\
434\end{array}$ & $\begin{array}{l}442 \\
446 \\
450 \\
454 \\
459\end{array}$ & $\begin{array}{l}464 \\
469 \\
474 \\
479 \\
483\end{array}$ & $\begin{array}{l}486 \\
492 \\
496 \\
501 \\
506\end{array}$ & $\begin{array}{l}506 \\
511 \\
516 \\
522 \\
528\end{array}$ & $\begin{array}{l}526 \\
532 \\
537 \\
543 \\
548\end{array}$ & $\begin{array}{l}82 \\
84 \\
86 \\
88 \\
90\end{array}$ \\
\hline $\begin{array}{l}92 \\
96\end{array}$ & & & & & & & & & & & & & & & $\begin{array}{l}438 \\
446\end{array}$ & $\begin{array}{l}463 \\
472\end{array}$ & $\begin{array}{l}487 \\
495\end{array}$ & $\begin{array}{l}511 \\
520\end{array}$ & $\begin{array}{l}534 \\
544\end{array}$ & $\begin{array}{l}554 \\
563\end{array}$ & $\begin{array}{l}92 \\
96\end{array}$ \\
\hline
\end{tabular}

Equation for Circular Equivalent of a Rectangular Duct ${ }^{10}$

$\mathrm{De}=130\left[(a b)^{0625} /(a+b)^{0250}\right]=130 \sqrt[8]{\left.(a b)^{5 /(a+b}\right)^{2}}$

where

$a=$ length of one side of rectangular duct inches

$b=$ length of adjacent side of rectangular duct inches

$D_{\theta}=$ circular equivalent of rectangular duct for equal friction and

capacity, inches 
Therefore select a 13 in. diameter duct.

Altemative Method. Calculate a modified design friction factor from

$$
\text { MDFF }=\frac{\text { Desired Friction Rate }}{F_{\text {DF }} \times \text { IF }}
$$

where

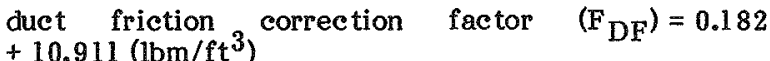

insulation friction factor (IF) .

\section{Fan Selection}

When you select a fan for your system your main concern will be matching the fan's pumping characteristies to the system's pressure drop characteristics. The fan's diameter, type (axial flow or centrifugal), blade angles, and operating speed (RPM) all affect its pumping characteristics. Fan manufacturers publish data giving flow rate versus static pressure for their products. If the fan can operate at more than one speed, data for several speeds will be published. Typical curves for three different $f$ an speeds are shown in Fig. 14-17.

The designer must calculate the pressure drop of the system at the operating flow rate and select a fan and operating speed that will give a static pressure equal to the system pressure drop at the operating flow rate. (Fig. 14-17 shows the operating flow rate.) For the fan data shown in the figure, the fan should operate at $1100 \mathrm{RPM}$ to provide the operating flow rate required by the system.

To illustrate what will happen if the designer makes the wrong choice of fan or fan speed, a curve labeled "system pressure drop" has been drawn on Fig. 14-17. If the fan is to large or the fan speed too fast, the system will operate at Point $\mathrm{A}$. Both the air flow rate and the system pressure drop will be greater than planned for, and the, fan will consume more electric power than a properly sized fan.

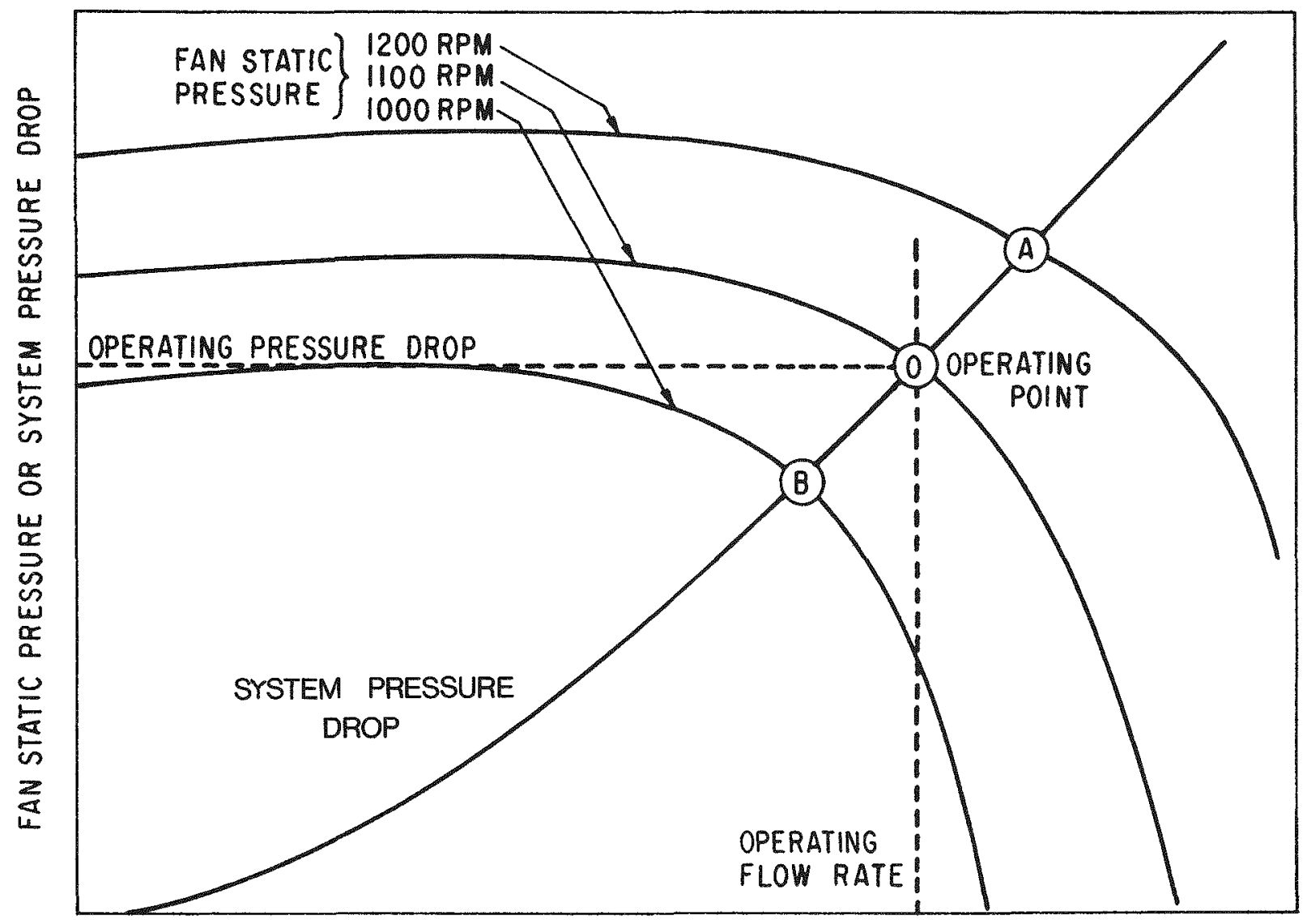

AIR FLOW RATE

Fig. 14-17. Typical fan and system characteristics.

(Source: Design and Installation Manual for Thermal Energy Storage, Argonne National Lab) 
If the fan is too small or the fan speed too slow, the system will operate at Point B. The system pressure drop will be lower than it should be for normal operation; but, more importantly, the air flow rate will be lower than it should be. The low air flow rate will degrade the performance of the system.

\section{System Pressure Drops}

The system pressure drop is the sum of several component pressure drops:

- Rock bed pressure drop.

- Collector pressure drop.

- Filter and damper pressure drops.

- Duct losses, including allowance for bends, branch ducts, and expansions or contractions.

Rock bed pressure drops have been discussed previously. Information about collector, filter, and damper pressure drops should be obtained from the various manufacturers. Procedures for calculating duct losses can be found later in this section of the workbook and in the ASHRAE Handbook of Fundamentals, Chapter 25, "Air Duct Design Methods." The pressure drops caused by expansion from the air duct into the plenum of the rock bed and the corresponding contraction at the opposite end of the rock bed should not be overlooked. The method for calculating these pressure drops is also given in the ASHRAE Handbook of Fundamentals.

\section{Power Requirements}

Having selected the fan, the designer must choose a motor to power it. If the motor is too small, the fan will not be able to pump the necessary amount of air, and frequent motor burnouts will be likely. An oversized motor will draw only slightly more power than a motor of exactly the proper size (unless the motor is grossly oversized). Thus, it is better to select a slightly oversized motor than an undersized one. Belt drives must be rated for one and a half times the motor power and should include an adjustable sheave on the motor.

Many fan manufacturers publish the motor requirements with the fan performance curves, as shown in Fig. 14-18a. If the manufacturer's data is presented in this way, select the larger of the two motors indicated by the dashed lines on either side of the operating point. For example, in Fig. 14-18a dashed lines corresponding to $3 / 4$ and 1 horsepower lie on either side of the operating point (Point 0 ). Choose the 1 horsepower motor.

Sometimes the manufacturer presents fan efficiency, as shown in Fig. 14-18b, instead of motor horsepower. A short calculation is required to determine the minimum motor power, $\mathbb{P}_{\mathrm{min}}$ in horsepower (kilowatts):

$$
\mathrm{P}_{\min }=\frac{1.25 q \Delta \mathrm{p}}{\mathrm{en}}
$$

where

$\mathrm{q}=$ volumetric air flow rate in cubic feet per minute (cubic meters per second).

$1.25=a$ safety factor contant included to ensure that motors will not be undersized.
$\Delta p=$ system pressure drop in inches of water (pascals).

$\eta=$ fan efficiency in percent.

$c=a$ unit conversion constant. Use $c=63.46$ to convert cubic feet per minute, inches of water, and percent to horsepower; use $c=10$ to convert cubie meters per second, pascals, and percent to kilowatts.

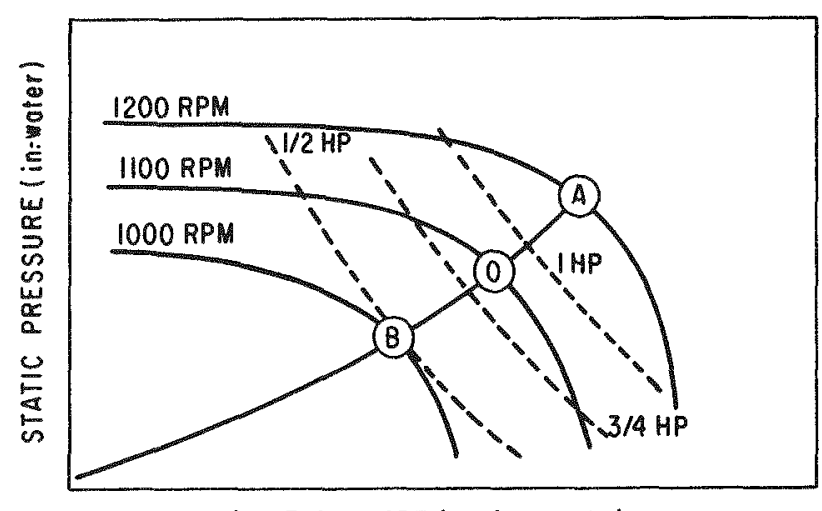

AIR FLOW RATE (cu fl. per min)

\section{Fig. 14-18a. Typical tan performance curves showing motor power requirements}

(Source: Design and Installation Manual for Thermal Energy Storage, Argonne National Lab)

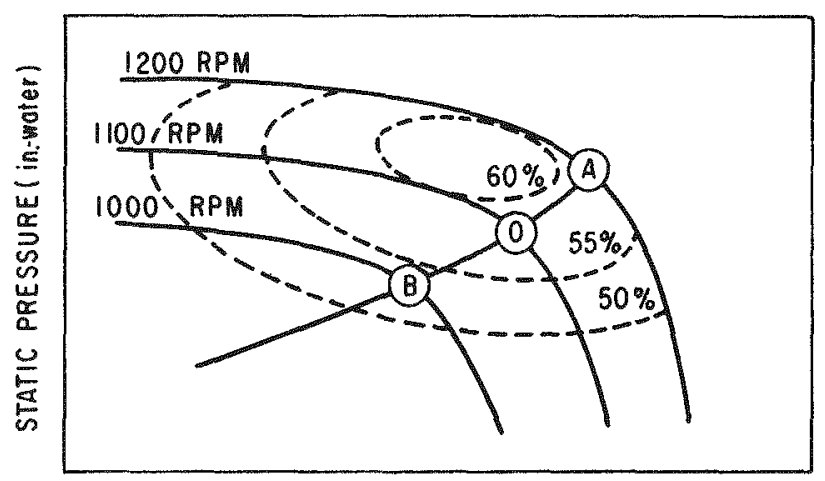

AIR FLOW RATE (cu.ft per min.)

Fig. 14-18b. Typical fan performance curves showing fan efficiency.

(Source: Design and Installation Manual for Thermal Energy Storage, Argonne National Lab) 


\section{Fan Installation}

The temperature of the air a fan must handle in a solar system can sometimes present a problem not of ten encountered in conventional heating systems. Study your system carefully and determine the maximum air temperature the fan will encounter. If that temperature exceeds $100 \mathrm{~F}\left(38^{\circ} \mathrm{C}\right)$, the fan must meet the following specifications.

- The fan bearings must be able to operate continuously at the maximum air temperature. Special bearings may be required. Alternatively, the bearings can be located outside the stream of hot air and shaft seals specified to minimize leakage.

- The motor and drive belts must be outside the stream of heated air, or a Type B motor connected directly to the fan must be used.

- The fan should be selected on the basis of a modified operating point (Point $M$ in Fig. 14-19) instead of the previously defined operating point (Point $O$ ). To find the modified operating point multiply both the air flow rate and the fan static pressure at the operating point by the factor $\mathrm{F}$.

$$
F=\frac{T+T_{O}}{T_{r}+T_{0}}
$$

where

$$
\begin{aligned}
& \mathrm{T}=\text { air temperature in the duct in degrees } \\
& \text { Fahrenheit (degrees Celsius). } \\
& \mathrm{T}_{0}=\text { conversion to absolute temperature scale. } \\
& \mathrm{T}_{\mathrm{r}}=\text { room temperature. Use } \mathrm{T}_{\mathrm{r}}=70 \mathrm{~F} \text { or } \\
& \mathrm{T}_{\mathrm{r}}=20^{\circ} \mathrm{C} \text {. }
\end{aligned}
$$

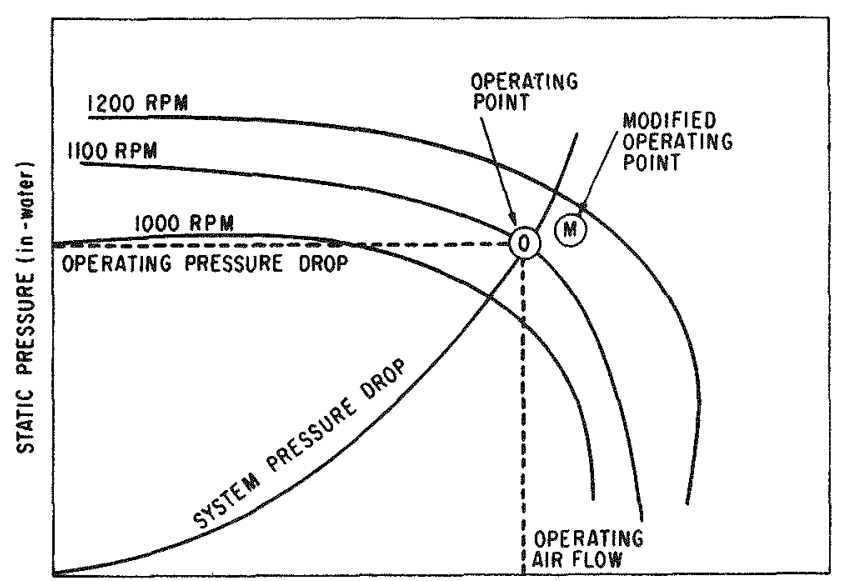

AIR FLOW RATE (cu.ft. per sec)

Fig. 14-19. Modified operating point.
The modified operating point applies only to fan selection and should not be used for other calculations.

Since the major operating expense of an air-based system is the cost of electricity, it is important to install the fan so that it will operate at its highest efficiency. We recommend connecting the inlet of the fan to the ductwork with a straight section of duct at least five duct diameters long. The duct should match the diameter of the fan inlet so that there will not be a sudden contraction or expansion as the air enters the fan. If a transition from a rectangular duct to a round fan inlet must be made, the transition slope should not exceed 4 in 12 inches $\left(18^{\circ}\right)$. It is especially important to avoid using bends or elbows near the fan inlet, because the turbulence they cause reduces fan efficiency. Use similar care in designing the outlet ductwork.

\section{Other Components}

Filters. Filters for the air-based solar system should be located at both the rock bin inlet and outlet where they are easily accessible for service or replacement. Filter mounts must minimize the amount of leakage bypassing the fil ter and leakage escaping the duct.

The face velocity of the filter (air flow rate divided by filter area) should not exceed 300 feet per minute (1.5 meters per second). If the filter is larger than the cross-section of the duct, a transition to the full filter size, with a slope not exceeding 4 in 12 inches $\left(18^{\circ}\right)$, must be made.

Install a filter replacement indicating gauge at each filter. The gauge can be self-indicating or remoteindicating, but in either case the indicating part of the gauge must be located where it will be easy to see.

Dampers. Since dampers have proven to be the least reliable component in existing air-based systems, it is worthwhile to invest in high-quality dampers for your system. Automatically controlled dampers are essential to control the direction of air flow through the rock bed and to control the collector and space heating loops. A spring-loaded, motor-driven damper can provide failsafe operation in case of a power failure. Backdreft dampers should be installed in the ducts between the collectors and the rock bed to prevent thermosiphoning at night-a major source of heat loss to the system. Choose a grood backdraft damper with seals made of felt or other resilient material such as silicone rubber. The backdraft dampers must close by either gravity or springs and must remain tightly closed until the blower opens them.

Air Hrandlers. Air handlers, including a fan and as many as four motorized dampers in one package, are available. The main advantages of an air handling unit are:

- Air handlers require less installation labor than separa te components.

- Air handlers specifically designed for solar applications can be purchased.

We recommend choosing an air handler in preference to individual components if an air handler that meets your system's flow rate and control requirements is available. 
Temperature Sensors. Use the type of temperature sensor recommended by the controller manufacturer.

Two temperature sensors should be placed in the rock bed, one 6 in. $(15 \mathrm{~cm})$ below the top of the rocks and the other 6 in. $(15 \mathrm{~cm})$ above the bottom of the rocks. Low temperature readings by both sensors indicate that little heat remains in the rock bed, and the auxiliary heater must supply heat. High temperature readings by both sensors indicate that the rock bed is fully charged. A high temperature reading at the top and a low temperature reading at the bottom indicate that the rock bed is partially charged.

To avoid damaging temperature sensors and to make replacement simple, we recommend that the sensors be placed inside pipes that extend from outside the rock bin's inner wall to the center of the rock bed. The sensor leads are then run from the pipe out through the insulation to an electrical box for connection to the controller.

\section{Thermal Energy Storage in Liguid-Based Systems}

Before selecting a particular type of storage tank, you must consider a number of variables:

- Size and shape.

- Material.

- Location.

- Insulation.

- Corrosion.

- Cost.

- Leak protection.

- Protective coating.

- Installation.

- Pressure and temperature limits.

Each individual liquid-based storage system has different requirements. The temperatures listed below are subject to variation and are intended only as a general guide. Direct space heating usually requires storage temperatures no higher than $160 \mathrm{~F}\left(71^{\circ} \mathrm{C}\right)$, although some hydronic heating systems require higher temperatures. Most direct space heating systems use unpressurized tanks. Solar-assisted heat pump systems typically operate at less than $100 \mathrm{~F}\left(38^{\circ} \mathrm{C}\right)$, which dramatically reduces the amount of insulation required on the tank. Absorption air conditioning systems use hot storage at temperatures above $170 \mathrm{~F}\left(77^{\circ} \mathrm{C}\right)$ or cold storage at temperatures below $55 \mathrm{~F}\left(13^{\circ} \mathrm{C}\right)$. A pressure vessel may be required for the hot storage.

Storage for load management may resemble storage for direct space heating systems if the tank is heated electrically at off-peak rates. If a load management system uses heat pumps to move heat from one part of the building to another or to air condition during the day and heat at night, the temperature require ments will be similar to the temperature requirements for a solarassisted heat pump.

Direct heating of potable water usually requires temperatures of less than $140 \mathrm{~F}\left(60^{\circ} \mathrm{C}\right)$ and a pressurized tank. Preheating the water usually requires temperatures under $120 \mathrm{~F}\left(49^{\circ} \mathrm{C}\right)$. The preheat tank may be pressurized or unpressurized, depending on the system configuration. It is not unusual for domestic hot water systems to operate at higher temperatures than those listed here.

Various tank materials that can meet these temperature and pressure requirements are available. Use tested materials, such as steel, fiberglass, concrete, or wood with plastic lining, to avoid the risks inherent in using materials that have not been proven. Advantages and disadvantages of each type of tank are shown in Chapter 5. All types of tanks can be purchased or constructed in any size likely to be used in storage systems.

Normally, only one tank is used for storage in space heating systems. Where the properly sized tank is unavailable, or where space restrictions dictate the use of smaller tanks in place of a larger one, two or more storage tanks can be used. Two small tanks cost more than a large one, however, and a multiple tank system requires more insulation because it exposes a larger surf ace area than a single tank.

\section{Tank Types}

\section{Steel Tanks}

The principal advantages of steel tanks are the relative ease of fabricating them to ASME Pressure Vessel Code requirements, the ease of attaching pipes and fittings, and the amount of experience available with steel tanks. The main problem with steel tanks is corrosion, although the difficulty of installing them in enclosed buildings and their cost are also problems.

Four types of corrosion present the greatest threat to steel tanks: electrochemical corrosion, oxidation (rusting), galvanic corrosion, and pitting. Six methods of protection, which can be used singly or in combination, are sealing the system, adding chemical corrosion inhibitors (see Table 14-3), using protective coatings or liners, using cathodic protection, increasing the metal's thickness, and using noncorroding alloys. Since corrosion rates double with each $20 \mathrm{~F}\left(10^{\circ} \mathrm{C}\right)$ inerease in temperature, limiting the maximum temperature will prolong the tank's life.

Electrochemical Corrosion. Electrochemical corrosion of a metal is mainly governed by two conditions: the $\mathrm{pH}$ of the liquid (electroly te) and the electric potential of the metal. The $\mathrm{pH}$ is a measure of acidity or alkalinity of the liquid; and acid solution has a pH lower than 7 , an alkali has a pH higher than 7 , and a neutral solution has a pH of 7. The electric potential of the metal is usually given relative to that of hydrogen, which is always present in water.

Marcel Pourbaix has produced diagrams showing corrosion conditions for various metals as functions of $\mathrm{pH}$ and electric potential. Fig. $14-20$ is the Pourbaix diagram for iron at $77 \mathrm{~F}\left(25^{\circ} \mathrm{C}\right)$. In addition to corrosion conditions for the metal, the figure shows two lines, a and $b$. Below Line $a$, decomposition of water and evolution of hydrogen is possible; above Line b, decomposition of water and evolution of oxygen is possible. 
Table 14-3. CORROSION INHIBITORS

\begin{tabular}{|c|c|c|c|}
\hline $\begin{array}{c}\text { Generalized } \\
\text { Categories }\end{array}$ & $\begin{array}{l}\text { Metals } \\
\text { Protected }\end{array}$ & $\begin{array}{l}\text { Specific } \\
\text { Compounds }\end{array}$ & $\begin{array}{l}\text { Acute } \\
\text { Oral } \\
\text { Toxicity }\end{array}$ \\
\hline Nitrate Salts & Iron, Aluminum & $\begin{array}{l}\text { Lithium Nitrate, } \\
\text { Sodium Nitrate }\end{array}$ & High \\
\hline Sulfate Salts & All Metals & Sodium Sulfate & $?$ \\
\hline Sulfite Salts & All Metals & Sodium Sulfite & Mod \\
\hline Borate Salts & $\begin{array}{l}\text { Iron and Iron } \\
\text { Alloys }\end{array}$ & Sodium Borate & Mod \\
\hline Phosphate Salts & Iron, Aluminum & $\begin{array}{l}\text { Potassium Hydrogen } \\
\text { Phosphate, Trisodium } \\
\text { Phosphate }\end{array}$ & $\begin{array}{l}\text { Mod } \\
\text { Low }\end{array}$ \\
\hline Silicate Salts & $\begin{array}{l}\text { Copper, Iron, } \\
\text { Aluminum }\end{array}$ & Sodium Metasilicate & Mod \\
\hline Triazoles & $\begin{array}{l}\text { Primary Cuprous } \\
\text { Metals }\end{array}$ & Benzoltriazole & $?$ \\
\hline Benzoate Salts & Iron & Sodium Benzoate & Mod \\
\hline
\end{tabular}

Under normal conditions the $\mathrm{pH}$ is 7 , and iron has an electric potential of $\mathbf{- 0 . 4 4}$ volts relative to hydrogen. This state is shown as Point $X$ in Fig. 14-20. As you can see, Point $X$ is in a region where corrosion can take place.

Three methods of preventing corrosion can move Point $X$. Cathodic protection can move it down, alkalinization can move it to the right, and anodic protection can move it up.

The most reliable method is cathodic protection, which can be used effectively to protect either the inside or the outside of the tank. The steel tank is given a negative electric potential by being connected either to a source of direct current or to a bar of a more reactive metal.

If a source of direct current is used, the tank must be connected to the negative $(-)$ terminal, and an electrode in contact with the water but insulated from the tank must be connected to the positive $(t)$ terminal. Pourbaix recommends using the following voltages:

- For $\mathrm{pH}$ less than $10, \mathrm{E}=-0.62$ volts.

- For pH between 10 and $13, \mathrm{E}=-0.08-\mathrm{pH} \times 0.059$ volts.

The electrode should be an inert material such as carbon. This type of cathodic protection has the disadvantage of requiring electrical equipment and a power source that must be checked periodically.

A more common method of cathodic protection is using a sacrificial anode. This method has the advantage of not requiring an external power source. The anode must be submerged in the water and electrically connected to the

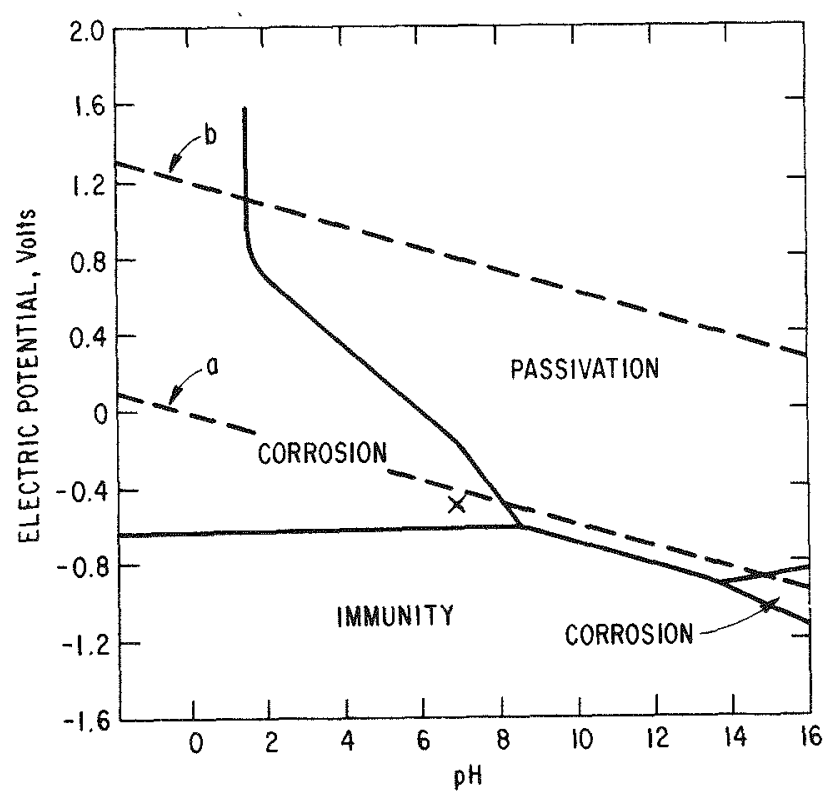

Fig. 14-20. Pourbaix diagram for iron at $77^{\circ} \mathrm{F}\left(25^{\circ} \mathrm{C}\right)$

(Source: Design and Installation Manual for Thermal Energy Storage, Argonne National Lab) 
tank. Since protection ends when the anode has completely dissolved, the anode should be inspected annually and replaced if necessary.

In choosing a sacrificial anode, you must choose a metal that is more reactive than the steel tank as shown in Table 14-4. The most commonly used anodes are made of magnesium, aluminum, or zinc. We recommend choosing a magnesium bar as the anode for most storage tanks. Aluminum has a tendency to form a protective coating over itself, reducing the effectiveness of the protection. Zinc, whether as a metal bar, as galvanizing, or as an additive to epoxy or paint, is not recommended for most thermal energy storage applications. At temperatures above approximately $155 \mathrm{~F}\left(68^{\circ} \mathrm{C}\right)$, the roles of zinc and steel reverse, so that the steel is sacrificed instead of being protected. Zinc can provide effective protection if the maximum allowable tank temperature is kept below about $140 \mathrm{~F}\left(60^{\circ} \mathrm{C}\right)$, however.

Either method of cathodic protection works particularly well if the tank is lined with epoxy, glass, or hydraulic stone. The coating protects most of the steel and leaves only a few small uncoated areas. Since the current required for cathodic protection is proportional to the area of the exposed steel, the coating allows a smaller current source to be used or allows the anode to last longer.

In most situations, cathodic protection should not be combined with strong alkalinization. In one case the alkalinization may cause a protective coating to form over the anode, but in another it may cause rapid consumption of the anode. In both cases the effectiveness of the protection will be decreased.

Table 14-4. ELECTROMOTTVE FORCE SERIES OF METALS

$\begin{array}{ll}\text { MOST REACTIVE: } & \text { Magnesium } \\ & \text { Beryllium } \\ & \text { Aluminum } \\ \text { Manganese } \\ \text { Zine } \\ \text { Chromium } \\ \text { Iron } \\ \text { Cadmium } \\ \text { Nickel } \\ & \text { Tin } \\ & \text { Lead } \\ & \text { Hydrogen } \\ & \text { Copper } \\ & \text { Mercury } \\ & \text { Silver } \\ & \text { Palladium } \\ & \text { Platinum } \\ \text { LEAST REACTIVE: } & \text { Gold }\end{array}$

Source: Theodore Baumeister and Lionel S. Marks, editors. Standard Handbood for Mechanical Engineers. MeGraw-Hill, seventh edition 1967.

The relative positions of the metals depend on the electrolyte solution in which they are immersed, the temperature, and the surface condition of the metals.
Steel is relatively inactive in an alkaline environment; adding lime, caustic soda, or trisodium phosphate to maintain a pH of 9.5-12 will protect steel from electrochemical corrosion. Increasing the $\mathrm{pH}$ of the water also moves iron into the region of passivation, in which a protective film forms over its surface. The $\mathrm{pH}$ of the water must be tested periodically to maintain the required alkalinity. Alkalinization cannot ordinarily be used to protect domestic hot water tanks, but it works well for vented or sealed tanks in other applications. Do not use alkalinization if aluminum parts will be exposed to the water, since aluminum corrodes quickly in an alkaline environment.

Anodic protection is rarely used because it does not stop corrosion completely, because increased corrosion rates can ocur if the potential of the steel is raised too high, and because imperfections in the passivated surface can lead to pit corrosion. For these reasons, anodic protection is not recommended.

Oxidation. Oxygen can enter a tank in two ways: it can be dissolved in water that enters the tank, or it can enter through the tank's air vent. Besides causing rust, oxygen tends to catalyze other types of corrosion.

One method of stopping oxidation is to seal the system so that no air or water can enter it. The oxygen initially present in the system will quickly be removed as it reacts with parts of the system. Although minor rusting may occur at that time, no further rusting can take place after the oxygen has reacted. Sealing the system requires that all of the components be able to withstand the pressure generated when the system is heated. The tank must be designed to the American Society of Mechanical Engineers' (ASME) Pressure Vessel Code or local code requirements and provide it with a pressure relief valve. With some system configurations, an expansion tank may also be required. The main disadvantage of a sealed system is its cost; but if the system must operate close to or above the normal boiling point, sealing it provides effective protection from oxidation.

Oxygen dissolved in water flows continuously into domestic hot water tanks. Thus, even though the tank is pressurized, oxygen cannot be excluded from it. Linings of glass or hydraulic stone limit the contact of steel and oxygen, thus limiting the extent of rusting. In tanks larger than 120 gallons (454 liters), glass or hydraulic stone can be expensive. For these tanks, four interior coatings of baked-on phenolic epoxy are recommended.

Vented tanks are exposed to oxygen from the air that enters the vent. We recommend four eoats of baked-on phenolic epoxy to protect the tank interior. If a baked-on treatment is unavailable, four coats of two-part epoxy can be specified, although it is less effective than the baked-on coating. Sodium sulfite added to the water will scavenge oxygen; it must be periodically tested and replenished.

If the tank is to be located underground, we recommend two coats of coal-tar epoxy on the outside. For indoor or aboveground locations, a coat of primer followed by two coats of enamel provides adequate outer protection. 
Galvanic Corrosion. Galvanic corrosion occurs when dissimilar metals in an electrolyte are in electrical contact with each other. This of ten occurs when a copper fitting is screwed into a steel tank. The water in the tank serves as the electrolyte. The more reactive metal (steel) dissolves in the vicinity of the less reactive metal (copper), and the usual result is a leak in the system.

Galvanic corrosion can be minimized by electrically insulating dissimilar metals from each other. Use dielectric bushings to connect pipes to tanks, and gaskets or pads to insulate other components. Be careful to eliminate other electrical conneetions between dissimilar metals. A common ground, for example, would defeat the effort to insulate dissimilar metals from each other. Use a volt-ohm meter (VOM) to measure the electrical resistance between components before the system is filled with water. A resistance of more than $1000 \mathrm{ohms}$ indicates adequate insulation, but a resistance of less than $100 \mathrm{ohms}$ means that an electrical connection still exists. Because the dissimilar metals plus the electroly te form a battery, testing after the system has been filled with water will give false resistance measurements.

The dissimilar metal combinations encountered most frequently in solar systems are iron-copper (or brass), aluminum-iron, aluminum-copper (or brass), and zinciron. The more reactive metal is listed first in each case except for the zine-iron combination. Zine is more reactive than iron below about $155 \mathrm{~F}\left(68^{\circ} \mathrm{C}\right)$ but less reactive above that temperature.

Pitting. Pitting is a localized form of corrosion in which small-diameter holes penetrate the base metal. One type of pitting is believed to be caused by ions or particles of a less reactive metal plating onto a more reactive metal. Localized galvanic corrosion produces a pit that can quickly penetrate the more reactive metal. In a storage system, a typical source of the less reactive metal ions is a copper pipe. The copper ions circulate in the water until they plate out on the steel tank and cause a pit.

Another type of pit corrosion is beli eved to be caused by small imperfections in a passivated.surface. As the pit grows, the chemistry of the solution changes locally so that the passivating agents become deficient within the pit, accelerating pit growth. A similar type of corrosion occurs in crevices and screw threads. Cathodic protection is more effective against pitting than alkalinization or anodic protection. The presence of some ions, especially chloride ions, tends to encourage this form of pitting.

Other Methods of Protection. Occasionally the thickness of the walls in steel tanks is increased for corrosion protection. Although the use of thicker metal does not stop corrosion, it does increase the length of time before the corrosion causes system failure. Use of thicker metal is often combined with alkalinization.

Stainless steel alloys are rarely encountered in solar energy storage systems because of their high first cost. Stainless steels form a passivated surface condition that protects the metal from corrosion. Cathodic protection will destroy that surface condition and should not be used with stainless steel.

Recommendations for Steel Tanks. Following are recommendations for most steel tanks used in space hesting applications:

- Use four coats of baked-on phenolic epoxy on the inside of the tank.

- Use a magnesium bar as cathodic protection.

- Electrically insulate dissimilar metals, except the magnesium anode, with dielectric bushings, gaskets, or pads.

- Use sodium sulfite to scavenge oxygen.

- Do not use chromate-type corrosion inhibitors. They are highly toxic and carcinogenic, cause damage to a common type of pump seal, and are difficult to dispose of properly. Since chromates act by passivating the steel surface, their effectiveness is much reduced when combined with cathodic protection.

- If possible, limit the maximum tank temperature to $160 \mathrm{~F}\left(71^{\circ} \mathrm{C}\right)$ or less.

- Protect the outside of a buried tank with two coats of cosl-tar epoxy and a magnesium anode. Use a coat of primer and two coats of enamel to protect the outside of aboveground tanks.

- If the tank will be pressurized, it must comply with Seetion VIII of the ASME Boiler and Pressure Vessel Code or local codes.

- Do not install large steel tanks in basements, crawl spaces, or other locations where building modifications would be necessary to replace them.

\section{Fiberglass-Reinforced Plastic Tanks}

Both factory-insulated and on-site-insulated fiberglassreinforced plastic (FRP) tanks are available and have been successfully used in solar energy installations. The main advantage of FR P tanks is that they do not corrode.

It is recommended that the designer use factory-insulated FRP tanks, which are designed specifically for solar energy storage and are available in convenient sizes and shapes. A typical factory-insulated FRP tank consists of an inner FRP shell covered with 2 to $4 \mathrm{in}$. (5 to $10 \mathrm{~cm}$ ) of urethane insulation. An outer FRP shell protects the insulation. Factory-insulated FRP tanks can be used outdoors above or below grade or in a garage. Do not install an FRP tank in a location where major building modifications would be necessary to replace it.

Installation of on-site-insulated FRP tanks requires much more eare than that of factory-insulated FRP tanks. Since the fiberglass is thin, the tanks must be protected from punctures and must be carefully supported to prevent rupture.

The extra labor required to insulate and install an onsite-insulated tank may make a factory-insulated tank less expensive. Some installations, however, can benefit from the greater variety of sizes and shapes that are avail able in on-site-insulated tanks. 
Nearly all FRP tanks have two limitations.

- FRP tanks must not be pressurized or subjected to a vacuum inside the tank unless they are specifically designed for it. A vent will ensure that the tank is not subjected to these conditions.

- Operating temperatures must never exceed the limit specified by the manufacturer. Exceeding the limit will void the warranty and damage the tank. Since the temperature limit is nearly always below the boiling point, the system controller must stop heat addition to the tank before the manufacturer's temperature limit is reached. Adjust the cutoff point on the controller to $5 \mathrm{~F}\left(3^{\circ} \mathrm{C}\right)$ below the temperature limitation on the tank. Since many controllers do not have a provision for limiting the tank temperature, the designer must select the controller carefully.

The temperature limitation is determined by the type of resin used to make the tank. Ordinary polyester resins have a limitation of $160 \mathrm{~F}\left(71^{\circ} \mathrm{C}\right)$-suitable only for lowtemperature tanks. With premium quality resins, the temperature limitation can be raised to $180-200 \mathrm{~F}$ $\left(82-93^{\circ} \mathrm{C}\right)$. Consult the tank manufacturer for details.

Before accepting delivery of an FRP tank, the designer should inspect it carefully. Do not accept delivery of a tank that has been dropped or shows any signs of physical damage. Before installing the tank, inspect the gel coat on its inner surface. If the gel coat is cracked or if fibers are exposed, hot water can break the bond between the glass fibers and the resin, which will lead to premature tank failure.

\section{Concrete Tanks}

Concrete tanks for solar energy storage can be divided into two categories: cast-in-place tanks and precast tanks, including tanks designed primarily to be used as septic tanks and utility vaults. Major advantages of concrete tanks are that they are relatively inexpensive as long as their shape is kept simple, the mass of concrete becomes part of the storage system, and concrete is a readily available construction material. Concrete also has considerable resistance to underground loads. Because concrete can be cast in almost any shape, it is a good material for retrofit installations. Conerete is also fireproof and corrosion resistant.

Concrete does have several disadvantages, however. It is subject to capillary action, so water can seep through cracks and joints unless the tank is lined. Leakproof conections through the tank walls are often difficult to make. Plaster coatings, which are adequate for cisterns, have a tendeney to crack with the fluctuating temperatures of thermal storage materials. Seepage that can be tolerated in a cistern or swimming pool will degrade the insulation around a tank. It is recommended that either a spray-on butyl rubber coating 30 to 50 mils $(0.75$ to $1.25 \mathrm{~mm})$ thick on the inside of the tank or a replaceable liner of the type used for wooden tanks be used.

The weight of a concrete tank may be either an advantage or a disadvantage, depending on the situation. Special footings may be required to carry the weight, particularly if the tank is close to a load-bearing wall. It is possible to design the tank into a corner of a basement wall if the foundation and wall are designed to carry the added load. This technique is more amenable to new construction than to retrofitting.

The weight of concrete is an advantage in underground storage containers, since it can help prevent the tank from being buoyed out of the ground by high groundwater.

Do not install precast concrete tanks in locations where major building modifications would be required to install or replace them. Cast-in-place tanks can be installed in some locations that do not permit installation of precast tanks.

\section{Wooden or Multicomponent Tanks with Plastic Liners}

Wooden or multicomponent tanks can be purchased as kits or can be custom designed. Their main advantages are low cost and easy indoor installation. The disadvantages are that the plastic liners have temperature limitations, and the tanks are usually intended for indoor locations only.

One available kit makes a vinyl-lined, 2000-gallon (7600-liter) eylindrical tank.* According to the manufacturer's instructions, the tank, made of $3 / 8$ in. CDX plywood and reinforced with steel bands, can be installed with simple hand tools. The kit includes insulation for the bottom, sides, and cover, as well as a 1-in. PVC compression fitting. The maximum allowable temperature inside the tank is $160 \mathrm{~F}\left(71^{\circ} \mathrm{C}\right)$.

Another type of kit uses lock-together panels of 4-in. $(10-\mathrm{cm})$ thick urethane form sandwiched between steel facings.** The plastic liner is rated for $180 \mathrm{~F}\left(82^{\circ} \mathrm{C}\right)$ continuous service, and an aluminum roof is available for outdoor containers. Sizes from 500 to 2000 gallons (1900 to 7600 liters) are available.

It is passible to construct a wooden tank by modifying the rock bin described in Appendix F of the Argonne Design and Installation Manual for Thermal Energy Storage. The gypsum board or sheet metal lining, tie rods, caulking, and openings for air ducts can be deleted from the design, but otherwise construction of a water tank is similar to construction of a rock bin. Custom fabricators of plastic linings can be found in most major U.S. cities, since the technology is similar to that used for water beds and swimming pools. Consult the yellow pages of your telephone book or the Thomas Register for names of fabricators.

\section{Liners \\ Liners should be about 1 to 3 percent larger than the inside of the container to avoid the possibility of stressing the seams. With some types of plastic it may be difficult to fabricate corners; however, corners can be folded from a flat sheet, if necessary. When installing the liner, care must be taken to remove all sharp edges,

\footnotetext{
*Acorn Structures, Ine., Concord, Massachusetts 01742.
} \\ **Bally Case and Cooler, Inc., Bally, Pennsylvania 19503.}


burrs, splinters, and debris that might puncture it. Avoid working inside the tank with the liner in place; if work must be done there, remove shoes, belt buckles, tools, and other objects that could puncture the liner. Properties of several plastics are listed below.

Polyvinyl Chloride (PVC). PVC is one of the least expensive and easiest liner materials to work with, and there is considerable experience with it in solar systems, industrial hot water processes, swimming pools, and water beds. Seams can be made by dielectric sealing, a more reliable process than heat sealing or cementing. Repairs can be made with patches and adhesives.

Specify a material thickness in the range of 30 to 60 mils $(0.75$ to $150 \mathrm{~mm})$, and make liners slightly oversized to avoid stressing the seams. The maximum tank temperature should be limted to $160 \mathrm{~F}\left(71^{\circ} \mathrm{C}\right)$, although a few special compositions can tolerate a water temperature of $180 \mathrm{~F}\left(82^{\circ} \mathrm{C}\right)$. Lifetime varies from 6 to 15 years, with about 8 years being typical. Failure is finally caused by leaching of plasticizers. When this occurs, the plastic becomes brittle and cracks appear, usually at the corners.

Ethylene Propylene Diene (EPDM). EPDM is a rubberlike material that can withstand boiling water. It is more expensive than PVC and more difficult to fabricate, since dielectric sealing cannot be used. There may be some difficulty in finding a fabricator who will make corners, although flat EPDM sheets are available. EPDM can be patched with adhesives, but patching is more difficult than for PVC. A thickness in the 30 to $60 \mathrm{mil}(0.75$ to $1.50 \mathrm{~mm}$ ) range should be specified.

Butyl Rubber. Butyl rubber is a reasonably durable material that is less expensive than EPDM but more expensive than PVC. Seams can be vulcanized, but the process is more difficult than dielectric sealing. Butyl rubber can be patched with adhesives. The sheet form is more durable than the spray-on form.

Polyethylene and Polypropylene. Polyethylene and polypropylene are inexpensive in flat sheets, but joints are difficult to fabricate, and patching is difficult at best. Adhesives perform poorly since polyethylene and polypropylene are unaffected by most ordinary solvents. The materials tend to be stiff in thickness of greater than 30 mils $(0.75 \mathrm{~mm})$. Polypropylene is capable of withstanding higher temperatures than polyethylene, but there is little experience with using these materials in solar systems.

Chlorosulfonated Polyethylene. Chlorosulfonated polyethylene is usually laminated with a serim (a mesh fabric) of another material to give it dimensional stability. Flat sheets are generally available, but fabricated corners may be difficult to obtain. Some users have reported separation of the material from the scrim.

Chlorinated Polyvinyl Chloride (CPVC). Like PVC, CPVC is normally rigid, but it can be made flexible by adding plasticizers. The plasticizers are subject to leaching, as they are with PVC; therefore, CPVC has no advantages over PVC.

\section{Tank Costs}

Factors that affect tank installation costs include the tank size, whether it is being installed in a new building or has to be built into an existing one, the location, the temperature requirements, insulation requirements, and the materials used.

\section{Size}

Tank size is the most important factor affecting cost. Generally, the cost per gallon decreases as the size of the tank increases, as shown in Chapter 5. Because system performance is not extremely sensitive to tank size (unless the tank is considerably undersized), the best approach is to select a standard size close to the optimum size.

\section{New Building oxisting Building}

Whether the tank is to be installed in a new or an existing building limits the choice of tank materials and location. It may be possible to design access to a steel, fiberglass, or precast concrete tank into a new building, but the lack of access in an existing building may require choosing an outdoor location or a different tank materiai.

Reinforcements to the foundation can be specified before a new building is built, but in an existing building part of the basement floor may have to be removed before a reinforeed section of floor can be installed. The greater flexibility in choosing tank materials, tank location, and foundation reinforcement generally gives a solar system in a new building a cost advantage over a solar system in an existing building.

\section{Location}

The location which a storage tank is to be placed will have an impact on the various requirements which it must be designed to meet. Each special requirement will add to system cost. "Some of these requirements include water proof insulation, extra-thick insulation, freeze protection long-life components, limitations on materials and protection from groundwater (i.e., tie-down straps, exterior corrosion protection, provisions for drainage of ground water, etc.).

Underground tanks generally have the most special requirements. The insulation should be waterproof and should have extra thickness because of the possible presence of groundwater, which reduces its insulating value. Tie-down straps are required to prevent flotation of a partly filled tank. Provisions for draining groundwater and rainwater away from the tank and exterior corrosion protection for steel tanks should also be included. Because access to them is difficult, underground tanks should be designed for a long lifetime. Steel, fiberglass, and concrete can be used for underground tanks, but wood is not recommended because of its short lifetime when in contact with earth. 
Basement locations generally impose few special requirements on the storage tank. Weatherproof and extra-thick insulation, freeze protection, and protection from groundwater are not needed when the tank is indoors. Steel and fiberglass tanks are not recommended for existing buildings because they ordinarily will not fit through the doors. If a steel or fiberglass tank is to be installed in a new building, it should last the lifetime of the building. Both wooden and cast-in-place concrete tanks are suitable for basement installation.

The requirements for tanks in besements also apply to tanks in crawl spaces. In addition, since most crawl spaces are unheated, extra insulation and a means of protecting the tank from freezing are needed.

Garages are excellent location for steel or fiberglass tanks. The large door allows for easy installation or replacement of the complete tank. Since most garages are unheated, extra insulation and a means of protecting the tank from freezing are needed.

The requirements for outdoor, aboveground storage tanks are the same as for those in garages, except that the tank must also be protected from the weather. Some factoryinsulated fiberglass tanks are adequately protected against weathering and do not need additional protection.

When a tank is placed indoors, whether in the basement or on a slab within the living space, a drain should be provided to accomodate the "leak that should not have happened while the occupants were on vacation."

\section{Temperature Requirements}

High storage temperatures are undesirable for the following reasons.

- High temperatures decrease collector efficiency.

- High temperatures increase insulation requirements.

- High temperatures require better quality lining and material for all types of tanks.

- High temperatures increase corrosion rates.

Each of these effects of high storage temperature tends to increase costs.

\section{Insulation Requirements}

Insulation requirements are primarily determined by the tank's location. Indoor tanks in heated areas require the least insulation, and protection of the insulation can consist of a simple cover. Tanks in unheated indoor locations need extra insulation thickness, but a simple cover is sufficient protection for the insulation. Outdoor tanks have the most severe insulation requirements. Aboveground tanks require extra insulation thickness and protection from weather. Underground tanks require waterproof insulation and extra thickness to compensate for the presence of groundwater. The cost of insulating an outdoor tank is about two to four times the cost of insulating an indoor tank. The costs of materials and labor frequently make a factory-insulated tank less expensive than an on-site-insulated tank.

Attention should be given to the type of insulation material used in indoor storage installations. When insulation such as urethane foams (an isocyanurate compound) are ignited, the toxic fumes of cyanide gas are emitted. If this material is used it should be sealed or protected from direct ignition. This is required by some building safety codes.

\section{Materials}

Steel tanks rated for 100 psi $(690 \mathrm{kPa})$ are generally the most expensive type of tank. When the tank, lining, insulation and sheath, and installation costs are added, you can expect the total to be about $\$ 2.50$ per gallon (\$0.66 per liter) for an indoor, 1000 - to 2000 -gallon ( 3800 to 7600 -liter) tank. This figure should be considered a rough guide and not a precise estimate, since shipping, labor cost and skill, inflation, and availablity of tanks influence the total cost. The premium for a pressurerated tank is generally about $\$ 0.50$ per gallon $(\$ 0.13$ per liter), although in some areas the premium can be much less.

The installed cost for a 1000- to 2000-gallon (3800- to 7600-liter) FRP tank without a high-temperature resin for direct space heating is about $\$ 1.75$ per gallon $(\$ 0.53$ per liter). On-site-insulated and factory-insulated tanks are similar in cost, since the more difficult and laborintensive installation procedure for the on-site-insulated tank tends to bring its installed cost up to the installed cost of a factory-insulated tank. As with steel tanks, the choice of manufacturer, shipping, labor cost and skill, inflation, and availability of tanks can significantly affect the installed cost. The cost of high-temperature resin (recommended for direct space heating; unnecessary for a solar-assisted heat pump) is about $\$ 0.25$ to $\$ 1.25$ per gallon ( $\$ 0.07$ to $\$ 0.33$ per liter), varying widely from manufacturer to manufacturer.

The installed cost of a 1000- to 2000-gallon (3800- to 7600 -liter) precast concrete tank is about $\$ 1.50$ per gallon ( $\$ 0.40$ per liter). Shipping costs can add a significant amount if the distance to the manufacturer is more than 100 miles ( 160 kilometers). Because of the difficulty of shipping these large, heavy objects, manufacturers tend to be local, and prices and availability vary from one part of the country to another. Installed costs of cast-in-place concrete tanks are highly variable, and there is a tendency to neglect cost considerations when designing tanks. With careful design the installed cost of a 1000- to 2000-gallon (3800to 7600 -liter) tank can be less than about $\$ 1.50$ per gallon $(\$ 0.40$ per liter). If the tank can be designed into a corner of a building and the tank is poured at the same time the building walls are poured, lower cost is possible. Since this type of construction is labor intensive, costs will vary from one part of the country to another.

Plastic-lined wooden or multicomponent tanks installed in sheltered locations are the least expensive type of tank. The installed cost of a 1000 - to 2000-gallon (3800- to 7600 - liter) tank of this type can be less than $\$ 1.00$ per gallon ( $\$ 0.26$ per liter), although some may cost about $\$ 1.50$ per gallon $(\$ 0.40$ per liter). Some liner types require periodic replacement, which increases costs. 


\section{Thermal Stratification in Tanks}

A storage system with perfect thermal stratification can perform 5 to 10 percent better than a thermally mixed system. Although perfect stratification cannot be achieved in a liquid-based system, partial stratification can be encouraged by the methods shown in Figs. 14-21a, $b$, and c. Using a horizontal inlet and outlet and low-velocity flows (Figs. 14-2la and b) is so easy to do that it should be standard practice in liquid-based systems. Baffles (Fig. 14-21c) are most easily installed by the manufacturer. Avoid the design mistakes illustrated in Figs. 14-22a, b, and c.

protection).

\section{Additional Considerations for Liquid Storage Systems}

- When tanks which are insulated with such materials as urethane foams, which when ignited produce highly toxic fumes, are contained within equipment rooms or living spaces, the insulation must be coated. Avoid using paints that have an oil or an aluminum base as they will attack such insulation. It is best to check with the manufacturer for compatibility.

- Liquid storage tanks should be leak tested at 1.5 times the design pressure. Automatic relief valves should be incorporated to protect the tank against overpressurization (some codes require underpressurization protection).

- It is better to dump excess heat by boiling storage tank water than to vaporize the collector fluid. Boiling the collector fluid could cause its loss or put the glycol and water mixture into an improper chemical balance.

- A vented storage tank can create pumping difficulties when operating temperatures approach the boiling point of the storage water. Cavitation can occur at the pump intake, especially if storage is below ground, unless positive suction head pressure is maintained.

- Unsheltered, aboveground storage tanks should be designed to resist snow, wind, hail, and seismic loads. Completely enclosed tanks need only be designed to resist seismic loads.

- Storage units should be accessible for routine maintenance and repair.

- Tanks should be provided with means for emptying the liquid. Those above grade or floor level should have a valve at the lowest point, and buried tanks should have provision for pump or syphon the fluid from the tank.

- Tanks should have liquid-level indicators-preferably sight glasses-to indicate whether the fluid is at the appropriate level. Tanks requiring makeup water from the potable water system but containing nonpotable water should be filled using an air gap or comparable means of separation.

- If flammable materials are used as storage media or in the storage container, they must conform to existing standards and fire codes.

- Thermal storage system materials should be chemically compatible to prevent corrosion and deterioration.

- Tanks should be insulated so that the thermal losses do not exceed $5 \%$ of their maximum thermal energy capacity over a 24-hour winter design day. This generally requires about 3 to 4 in. of fiberglass batts or 2 to 3 in. of rigid styrofoam insulation (at least $R-14$ ) for indoor installation. At least $R-28$ is recommended

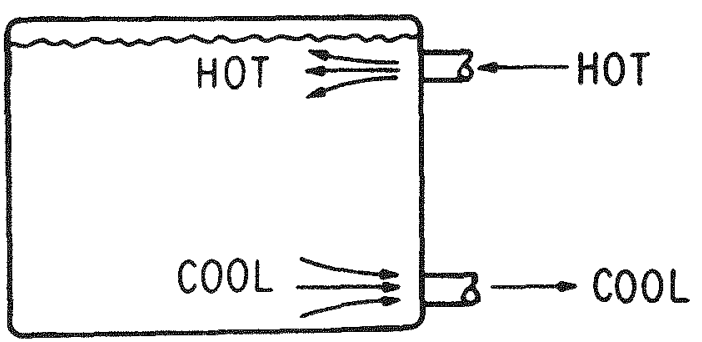

a. Horizontal Flow

Hot water should

enter or leave at

the top; cold

water should

enter or leave at

the botton.

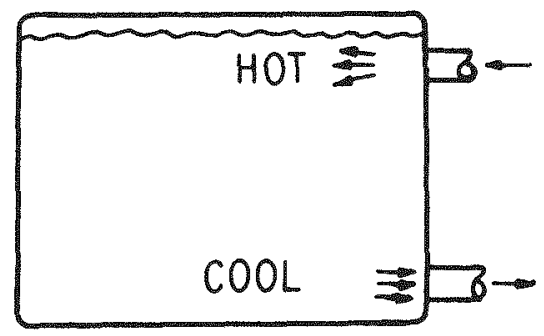

b. Low-Velocity Flow

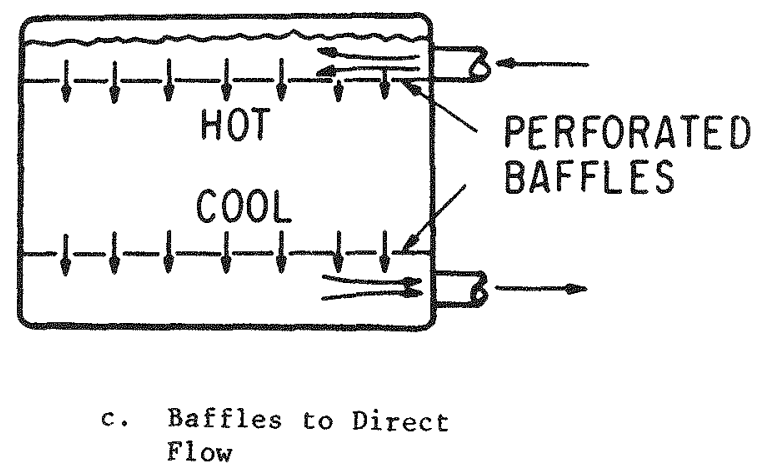

Fig. 14-21. Methods for promoting thermal stratification in water tanks.

(Source: Design and Installation Manual for Thermal Energy Storage, Argonne National Lab)

for outdoor installation. The entire perimeter of the storage, including top and bottom, should be insulated. There is strong indication of high heat losses through conerete foundations which act as thermal bridges when inadequately insulated, therefore the bottom should be more heavily insulated. 


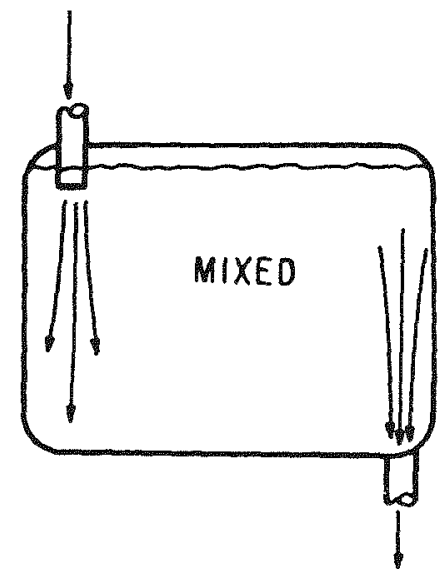

a. Vertical flow disrupts thermal stratification.

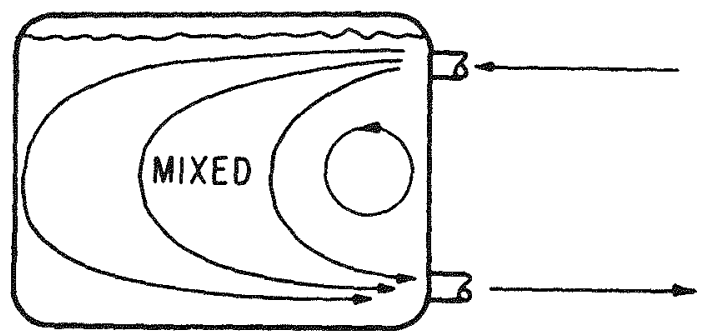

b. High-velocity flow causes turbulence, mixing, and short-circuiting.

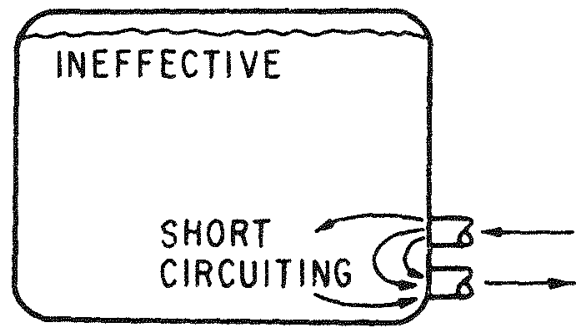

c. Inlet and outlet close together causes shortcircuiting. Parts of storage medium far from inlet and outlet may be ineffective.

Fig. 14-22. Water tank design mistakes. (Source: Design and Installation Manual for Thermal Energy Storage, Argonne National Lab)
- Heat losses from thermal storage containers, which are usually placed in basements or equipment rooms, must be accounted for when determining the thermal loading of these spaces.

- Where the water table is near the surface, heat from below-grade storage will diffuse into the adjacent earth, and the thermal losses from storage will increase considerably. Do not place storage tanks in ground water.

- Thermal storage for much more than overnight does not improve the yearly system performance very appreciably. Fairly severe performance losses are predicted if the storage provides less than $10 \mathrm{Btu} / \mathrm{sq} \mathrm{ft}$ of collector-F ( 1.2 gal. of water $/ \mathrm{sq} \mathrm{ft}$ of collector).

- For most commercial buildings, tank sizes are 1.5 to 2 $\mathrm{gal} / \mathrm{sq} \mathrm{ft}$ of collector and may range from 5,000 to $20,000 \mathrm{gal}$. The storage tank water is heated directly if water is the heat transfer medium or indirectly through a heat exchanger if other fluids are used.

- Concrete tanks are generally not usable in pressurized systems. The lining of a concrete tank must be leakproof and must be able to withstand temperatures of 180 to $200 \mathrm{~F}$ over long periods of time.

- In drain-down systems, be certain to allow adequate room for the fluid to drain back.

- Where water storage is vented to the atmosphere, auto fill or low water level indicators (sight glasses) are essential. Vented storage may well evaporate excessive moisture into living or equipment areas.

- Flow channeling in liquid storage tanks may actually be desirable between two different thermal loops, such as the solar loop and the building heating loop. In this case, if the supply of solar-heated liquid is located adjacent to the point where water is drawn from the storage tank to heat the building, the hottest water in storage is delivered directly to the load whenever solar heat is collected.

- All storage connections for liquid and air systems should be installed so as to enhance thermal stratification. On liquid systems, baffles should be considered where very large volumes and flow rates are involved.

- Capacity: water - 1 to $3 \mathrm{gal} / \mathrm{sq} \mathrm{ft}$ of collector area.

rock -0.5 to $1.0 \mathrm{cu} \mathrm{ft} / \mathrm{sq} \mathrm{ft}$ of collector area.

salt $\quad-5$ to $20 \mathrm{lb} / \mathrm{sq} \mathrm{ft}$ of collector hydrates area.

Insulation: minimum - R-11

optimum $-R-19$ to $R \sim 30$

\section{Controllers}

The primary purpose of the controller component is to control the action of the fluid movers (pumps or fans) in the solar heating or cooling system. In the collector loop the pump or fan should be turned on in order to circulate fluid through the collector whenever it is advantageous to collect energy. The fluid movers in the distribution loop 
should be turned on whenever the building thermostat calls for heating or cooling.

The typical controller is comprised of three component subsystems. These are the sensor subsystem, the comparators, and the output devices. The purpose of the sensors is to sense temperatures at various points in the system, for example, in the thermal storage unit, in the building, and at the collector outlet. The purpose of the comparator subsystem is to compare the differences between temperatures at various points and certain setpoint temperatures in order to determine whether or not the fluid mover should be turned on. The purpose of the ou tput subsystem is to send a signal to the fluid mover in order to control it. The Controller subsystem is shown in Fig. 14-23.

The differential control is used to control the fluid movers and electronic valves in most (i.e., more than $99 \%)$ active solar systems. This differential control is popular because of its energy management capability and functional simplicity. The controller produces a typical daily system temperature history as illustrated in Fig. 14-24. This controls the fluid mover (pump or blower) by comparing the temperature dependent signals from the collector and storage sensors to initiate appropriate flow whenever the temperature in the collectors is sufficiently high to economically transfer energy to the storage tank, i.e., it switches power "on" when $\mathrm{T}_{\text {coll }} \geq\left(\mathrm{T}_{\text {storage }}+\Delta \mathrm{T}_{\mathrm{ON}}\right)$. A "Dead band," or hysteresis, is required to minimize the on-off cycling. This cycling results from the thermal transients that exceed the system's thermal time constant, such as the rapid collector cool-down experienced upon initiating flow with low temperature storage water.

More than 50 firms offer differential thermostats for sale to the solar industry. While there is variation in design, all are functionally similar in that they have:

1) Collector and storage sensors,

2) Low voltage solid state control logic,

3) Line voltage input, and

4) Logically switched line voltage outputs.

\section{Flow Control Techniques}

The solar industry uses two types of differential controller outputs. The first type provides make-orbreak power switching so as to operate the collector pump either full on or off. The second modulates the power supplied to the pump during the "on" time so as to vary the flow rate of the pump as a function of the collector-to-storage tempergture difference. The flow characteristies of both types of operation are illustrated in Figs. 14-25 and 14-26.

The hysteresis function for an on-off controller is illustrated in Fig, 14-25. If the pump is off, it will remain off until the temperature difference between the collector and the storage reaches the value $\Delta T_{O N}$. At that point the controller will turn the pump on and the temperature difference will begin to decrease. Then the temperature difference becomes less than $\Delta \mathrm{T}_{\mathrm{OFF}}$, the controller will turn the pump off.

The flow characteristics of a variable flow rate pump are illustrated in Fig. 14-26. The dashed line indicates the theoretical flow rate as a function of the temperature difference, $\Delta T$. As indicated, the theoretical flow rate is a linear function of $\Delta \mathrm{T}$. In reality, however, the actual flow rate is a nonlinear function of $\Delta \mathrm{T}$ as illustrated by the solid line on the figure.

\section{On-Off Flow}

On-off operation of a fixed flow rate collector pump is the most widely used pump and control configuration. The make/break power switching implemented within the controller is familiar to the installer, electrician, etc. On-off control can be used to switch any motor of appropriate voltage and current rating. Manufacturers use both electromechanical (relays) and solid-state outputs in these controllers.

As shown in Fig. 14-27, the choice of the on and off temperature difference is critical if excessive pump eycling is to be avoided without significantly reducing the system collection duty cycle and COP. The coefficient of performance (COP) is defined as the ratio between

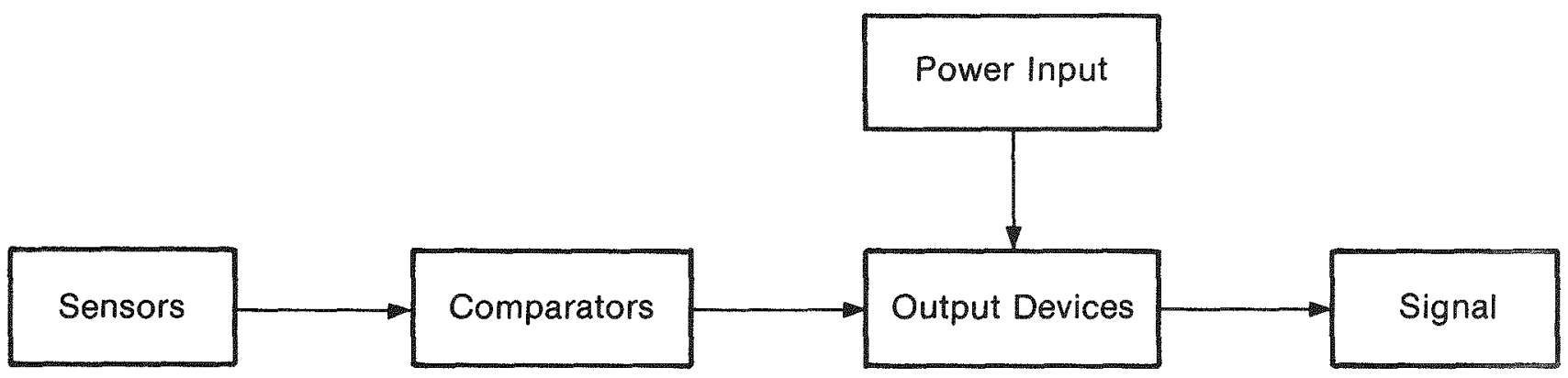

Fig. 14-23. Schematic representation of controller subsystem 

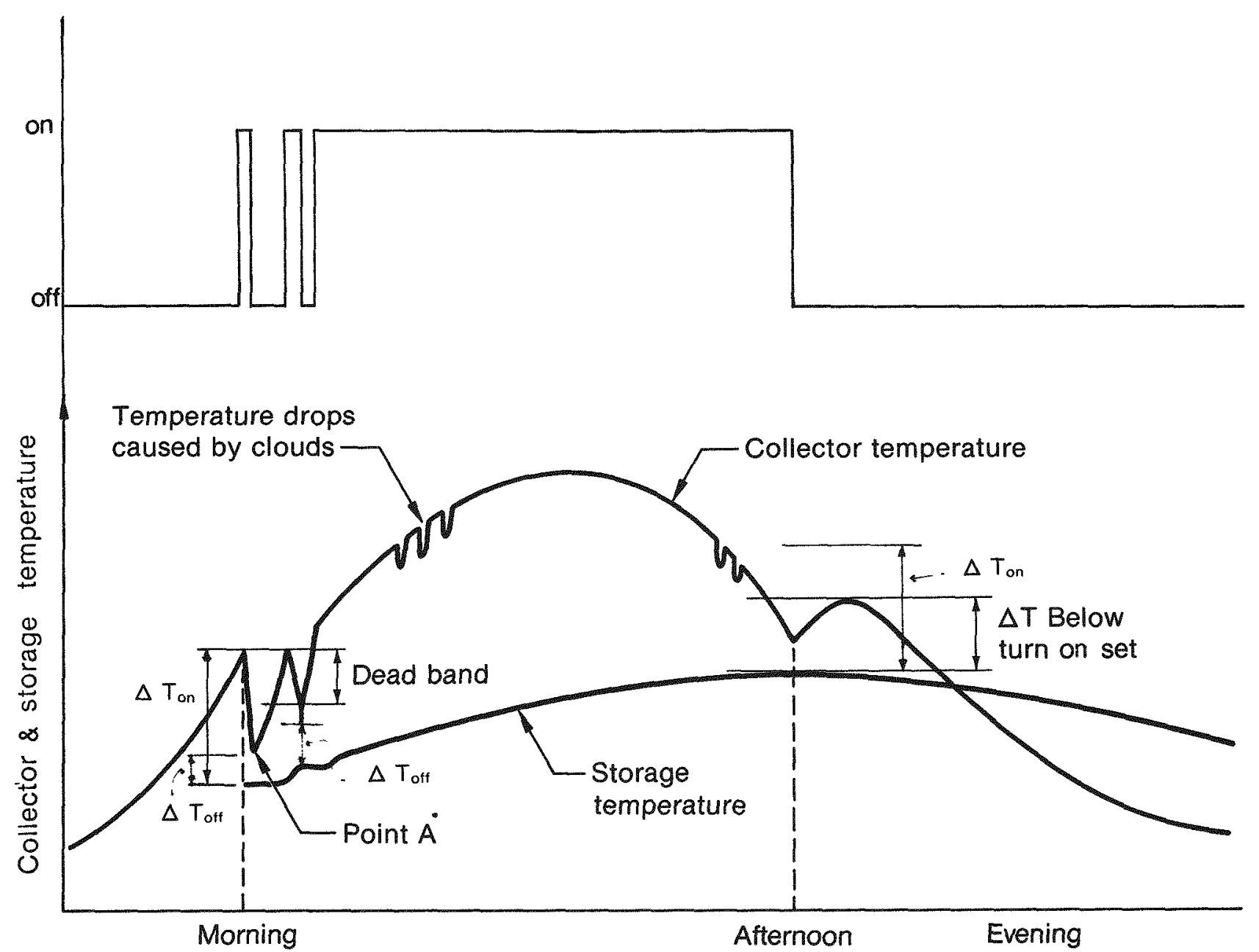

Fig. 14-24. Typical daily system temperature

energy collected per unit time by the fluid in the collectors and external power delivered to the pump or fan motor. That is

$$
\operatorname{COP}=\frac{\dot{\mathrm{Q}}_{\mathrm{u}}(\mathrm{kW})}{\mathrm{P}(\mathrm{kW})}
$$

where $\dot{Q}_{u}$ represents the time rate at which energy is collected and $P$ represents the power input to the fluid mover. Obviously, if $\mathrm{COP} \leq 1$, it is not worthwhile to have the fluid mover turned on. A COP of 1 is equivalent to electric resistance heating. Unless that is the backup, you would want COP $>1$, say 2 or 3 .

The preferred on-off temperatures to be used in "bangbang" (or on-off) control depend on many characteristics. These include the collector characteristics, the heat exchanger features, the piping thermal capacitance, the system's flow rate, the system loss characteristics, probe placement, probe accuracy, etc. Collector probe placement is particularly critical in its effect upon the system's transient thermal performance. Analytic results, generally confirmed by field experience and illustrated in Fig. 14-28, show that for high efficiency collection operation the collector probe should be near the collector outlet, i.e., $90 \%$ of the leng th of the flow path. If the sensor is located downstream of this region it turns the fluid mover on later, and if it is located too far upstream, then the effects of either boundary layer heat losses and/or natural convection are exaggerated and excessive cycling will be introduced. An exception to this general rule is that location further downstream may be preferable for a single collector probe system, located in a high solar radiation climate that experiences large amounts of radiation to the night sky.

The dead band (hysteresis) between the off settings and the "on" temperature settings minimizes pump cycling, i.e., frequent turn on and off, during morning start-up and afternoon shut-down or intermittent cloud conditions.

The "off" setting must be sufficiently high to accommodate normal sensor inaccuracies, but low enough to otherwise allow collection of as much solar energy as 


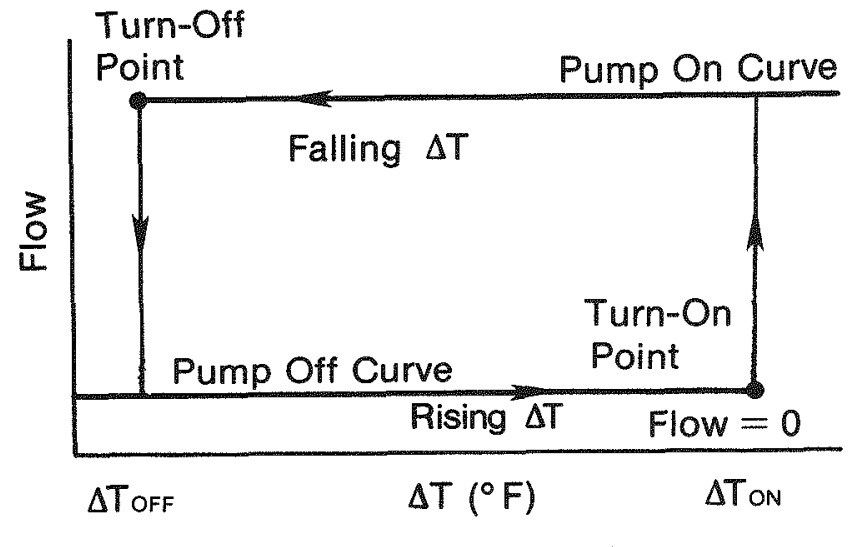

On-Off Flow Controller its upper range of values. Thus the hysteresis in liquid systems is normally in the range of $12 \mathrm{~F}$ to $16 \mathrm{~F}$, with some systems as high as $20 \mathrm{~F}$.

Air transport systems normally require $\Delta T$ temperatures of $10 \mathrm{~F}$ and as high as $20 \mathrm{~F}$ with a $15 \mathrm{~F}$ to $25 \mathrm{~F}$ hysteresis. This slightly wider range for hysteresis is required if a COP $>1$ is to be maintained, in order to compensate for the effects of higher pressure drops in air systems, the relatively low specific heat of air and the relatively low efficiency of blowers (as compared to pumps). It may be shown that $\triangle \mathrm{T} O F F$ for which $C O P=1$ is proportional to the pressure drop in the collector loop and inversely proportional to the product of the efficiency of the fluid mover (fan or pump) and the specific heat of the transport fluid. Because of the low specific heat of air, an "on" temperature twice the "off" temperature is usually adequate to satisfactorily reduce cycling.

\section{Location of Control Sensors}

The collector manufacturer should provide sensors, for use with the differential controller, in one out of every 10 collector panels supplied.

The differential control sensor for use with the solar collector differential controller and any high te mperature limit sensors should be located within $10 \mathrm{in}$. of the bottom of the tank. On the other hand, the differential control sensors for use with the heating circuit and with the building service hot water should be located near the top of the tank.

System Alarms. High and low level alarm switches should be provided on expansion tanks. Alarm switches should be float actuated, packless construction with syphon bellows.

Electrode two-probe type liquid level alarm switches should be provided for water storage tanks.

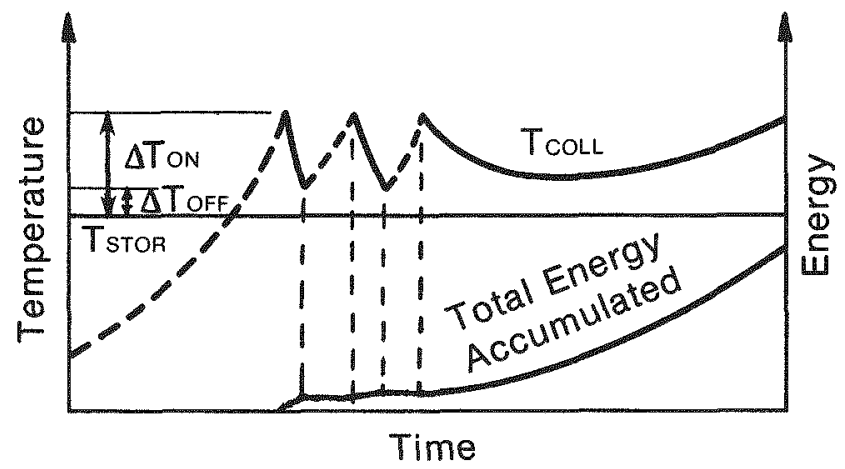

Fig. 14-27. Representative Behavior due to On-Off Controller

possible while assuring that collection will be stopped when parasitic power for the pumps exceeds the value of the solar energy gain; that is, if the COP is less than or equal to 1 , collection should be stopped. It has been determined from experience that if an on-to-off $\triangle$ temperature ratio of from $4: 1$ up to $6: 1$ is maintained with $\triangle T_{O F F}$ temperature ranging from $2 \mathrm{~F}$ to $4 \mathrm{~F}$, satisfactory operation will result in most types of flat pla te liquid transport systems. It is usually found that the higher ratio of $\Delta \mathrm{T}_{\mathrm{ON}}$ to $\Delta \mathrm{T}_{\mathrm{OFF}}$ is applied when $\Delta T_{O F F}$ is at its lower range of values. That is, if $\Delta T_{O F F}$ is approximately $2 \mathrm{~F}$, then $\Delta \mathrm{T}_{\mathrm{ON}}$ would be approximately $12 \mathrm{~F}$. Similarly, the lower value of the ratio of on-to-off temperature differentials is applied when $\Delta T_{O F F}$ is near 
Flow switches with electrical contacts should be provided to actuate alarms for all pumped circuits. These switches should signal alarms only in the event that the corresponding pump is electrically energized, but no flow results.

Guidelines. For final design, verify that:

- Control philosophy matches the desired modes of operation.

- Collector loop controls recognize solar input, collector temperature, and storage temperature.

- Controls allow the collector loop and the utilization loop to opera te independently.

- Control sequences are reversible and will always revert to the most economical mode.

- All controls are "fail safe."

- Where a light sensor (i.e., solar cell) is used to initiate circulation of antifreeze to a heat exchanger, low ambient temperature operation can cause freezing of that heat exchanger. Where light sensors are necessary, as with tubular collectors, a low limit cutout should be installed in series to prevent circulation of below $35 \mathrm{~F}$ antifreeze through heat exchangers containing water.

\section{Accessories}

The following accessories are required:

- Solar collector connections suitable for use with specific antifreeze coolant used. Typical materials specified include:

- Aeroquip FC252 fiberglass reinforced silicone heater hose, inside diameter equal to the inside diameter of the header pipe.

- Anaconda chemical transfer hose type CT16 and CT21 stainless steel, or bronze flexible transfer hose.

- Vacuum breakers of float or dise type with shutoff valve. The solar energy system, including collectors, pipes, tanks, and heat exchangers, should be designed for protection against possible collapse, by design or by provision of vacuum relief valves.

- Automatic pressure relief devices, adequately sized and installed in those parts of the energy transport subsystem containing pressurized fluids. Each section of the system should have a pressure relief device so that no section can be valved off or otherwise isolated from a relief device.

- Antifreeze loss indicator in antif reeze loops to indicate antif reeze loss; these can be pressure gauges or sight tubes in conjunetion with colored antif reeze.

- Strainers in the line at the inlet to pumps, control valves, or other types of equipment. Strainers for pump protection should be no less than 40 mesh and be made of bronze. A control valve needs greater protection than a pump does and, therefore, requires a finer mesh strainer.

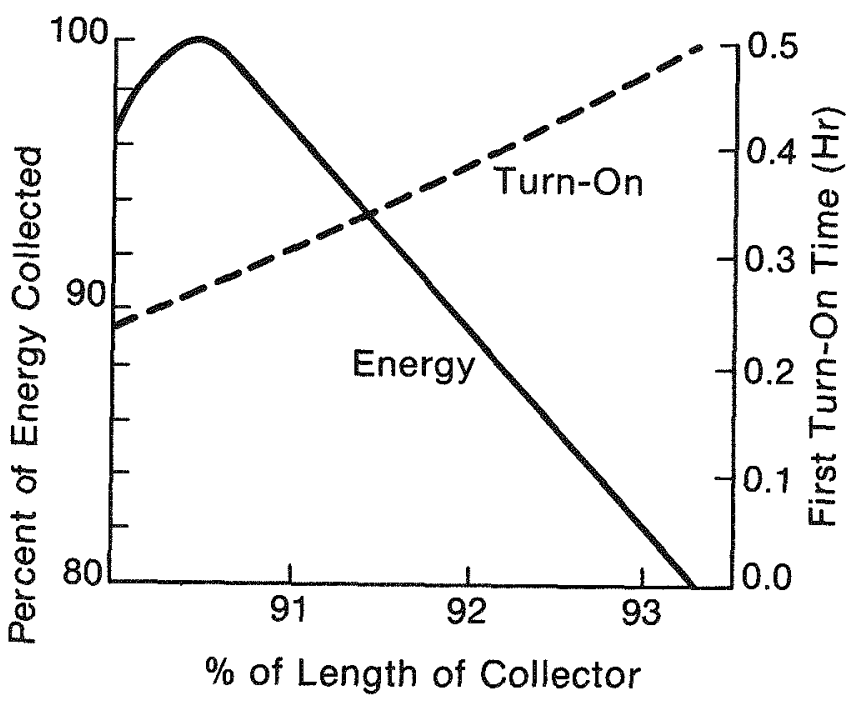

Fig. 14-28. Collected Energy and First
Turn-On Time vs. Sensor
Location

- Air vents at the high points of all mains and risers. Vents in solar and heating coil piping should be suitable for antif reeze when used.

- Thermometers and gauges to monitor the water temperature as it enters and as it leaves the collectors, storage, and heat exchangers are usually considered to be essential; monitoring the pump suction pressure and discharge pressure is also essential.

\section{HEAT EXCHANGER COMPONENT DESIGN}

Nom enclature:

$$
\begin{aligned}
C_{p} & =\text { Specific heat at constant pressure, Btu/lb-F } \\
D & =\text { Inside or outside tube diameter, } \mathrm{ft} \\
\mathrm{g} & =\text { Acceleration of gravity, } 32.2 \mathrm{ft} / \mathrm{sec} \\
\mathrm{h} & =\text { Film coefficient for convection, Btu/hr-sq } \mathrm{ft}-\mathrm{F} \\
\mathrm{K} & =\text { Thermal conductivity, Btu/hr-sq } \mathrm{ft}-\mathrm{F} \\
\mathrm{t} & =\text { Temperature } \mathrm{F} \\
\Delta t & =\text { Temperature difference, } \mathrm{F} \\
V & =\text { Linear Velocity, } \mathrm{ft} / \mathrm{hr} \\
\beta & =\text { Thermal coefficient of expansion, } \mathrm{F}^{-1} \\
\mu & =\text { Absolute viscosity, } \mathrm{lb} \mathrm{m}^{-1} / \mathrm{hr}-\mathrm{ft}
\end{aligned}
$$




$$
\begin{aligned}
\mathrm{V} & =\text { Kinematic viscosity, } \mathrm{sq} \mathrm{ft} / \mathrm{hr} \\
\rho & =\text { Density, } \mathrm{Ib}_{\mathrm{m}} / \mathrm{cu} \mathrm{ft} \\
\mathrm{U}= & \text { Overall coefficient of heat transfer, } \\
& \mathrm{Btu} / \mathrm{hr} \text { sq } \mathrm{ft}-\mathrm{F}
\end{aligned}
$$

Dimensionless Groups:

$\begin{array}{ll}\text { Reynolds Number } & R_{e}=\frac{\rho V D}{\mu}=\frac{V D}{V} \\ \text { Grashof Number } & G_{r}=\frac{D^{3} \rho^{2} \beta g \Delta t}{\mu^{2}} \\ \text { Prandlt Number } & \mathrm{Pr}=\frac{\mu C_{p}}{K} \\ \text { Nusselt Number } & \mathrm{Nu}=\frac{\mathrm{hD}}{\mathrm{K}}\end{array}$

\section{Sizing a Heat Exchanger}

For preliminary sizing of a heat exchanger for normal heating applications, the primary concern is to provide sufficient area of heat exchanger tube surface. Heat exchangers require a temperature differential in order to effect heat transfer; the size of that temperature differential affects the operating temperature of the system. Thus, heat exchanger sizing has a direct bearing on overall collection efficiency. Generally, the collector outlet temperature must be at least $10 \mathrm{~F}$ above the temperature of the heating system for each heat exchanger between the collector and the heating system fluid.

The familiar heat transfer equation used in heat exchanger selection is:

$$
\mathrm{Q}=\mathrm{U} \cdot \mathrm{A} \cdot \mathrm{MTD}
$$

$$
\begin{aligned}
Q= & \text { Total heat transfer rate, Btu/hr } \\
U= & \text { Overall coefficient of heat transfer between } \\
& \text { fluids, Btu/hr-sq } \mathrm{ft}-\mathrm{F} \\
\mathrm{A}= & \text { Surface area of the tubing, sq } \mathrm{ft} \\
\text { MTD = } & \text { Mean temperature difference between the } \\
& \text { fluids, degrees } \mathrm{F}
\end{aligned}
$$

In solving for the overall coefficient of heat transfer $U$, both the classic textbook equations approach and the "shortcut" chart approach based on the theoretical equations are presented. In addition, assumed $U$ factors are also shown for general information which may be useful for fast design estimates.

Generally, the primary concern of the project engineer is whether there is sufficient area of heat exchanger tube surface for the particular solar application. The above equation is used to show:

$$
\mathrm{A}=\frac{\mathrm{Q}}{\mathrm{UMTD}}
$$

Since $Q$ is usually known from previous solar collector calculations, the two unknowns are the $U$ factor and the MTD.
For normal heating type applications, three summary checks have been used to evaluate heat exchanger designs.

1. The fluids "approach" temperature should be between 5 and $15 \mathrm{~F}$. (For counterflow heat exchangers (HXs), the approach temperature is the difference between the hot fluid inlet and cold fluid outlet. For parallel flow HXs it is the difference between the hot fluid outlet and the cold fluid outlet).

2. The heat exchanger effectiveness should be not less than 0.50 , and preferably 0.70 . Effectiveness is defined in a later section.

3. The ratio of the solar collector aperture area and the heat exchanger tube surface area should be between 5 and 15 , (i.e., $5\left\langle\mathrm{~A}_{\text {coll. }} / \mathrm{A}_{\mathrm{HX}}\langle 15\right.$ ).

\section{Overan Heat Transfer Coefficient}

The overall heat transfer coefficient $U$ (Btu/hr-sq ft-F) of the heat exchanger tubes can be shown either of two ways:

Based on inside area:

$$
\mathrm{U}_{\mathrm{i}}=\frac{1}{\frac{\mathrm{I}}{\mathrm{h}_{\mathrm{i}}}+\frac{\mathrm{L}}{\mathrm{K}}+\frac{\bar{D}_{\mathrm{i}}}{\mathrm{h}_{\mathrm{O}} \mathrm{D}_{\mathrm{o}}}}
$$

or

Based on outside area:

$$
\mathrm{U}_{\mathrm{O}}=\frac{1}{\frac{1}{\mathrm{~h}_{\mathrm{o}}}+\frac{\mathrm{L}}{\overline{\mathrm{K}}}+\frac{\mathrm{D}_{\mathrm{O}}}{\mathrm{h}_{\mathrm{l}} \mathrm{D}_{\mathrm{i}}}}
$$

Where $U_{i}$ and $U_{0}=$ Coefficients based on the inside and outside tube areas, respectively, $\mathrm{Btu} / \mathrm{hr}$-sq ft-F

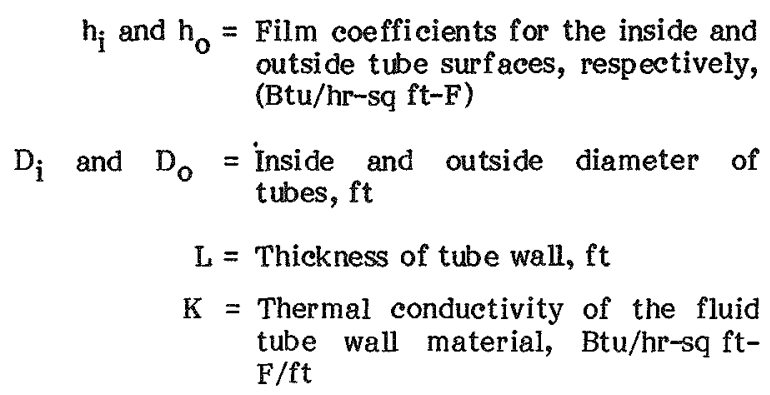

For practical purposes in the early design stages the $U$ factor equation for thin-wall tubes free from scale may be approximated as

$$
\mathrm{U}=\frac{1}{\frac{1}{\mathrm{~h}_{\mathrm{j}}}+\frac{1}{\mathrm{~h}_{\mathrm{o}}}}
$$

However, during normal heat exchanger operation fluid impurities are deposited on the tubes as a thin film. This film is quantified by a scale factor $F_{0}$ which is tabulated for various applications. For solar systems that have relatively clean heat transfer fluids, the overall $U$ factor equation becomes: 


$$
\mathrm{U}=\frac{1}{\frac{1}{\mathrm{~h}_{\mathrm{i}}}+\frac{1}{\mathrm{~h}_{\mathrm{O}}}+\frac{1}{\mathrm{~F}_{\mathrm{O}}}}
$$

For normal solar system design, an acceptable $F$ factor is $1,000 \mathrm{Btu} / \mathrm{hr}-\mathrm{sq} \mathrm{ft}-\mathrm{F}$ or $0.001 \mathrm{hr}-\mathrm{sq} \mathrm{ft-F/Btu}$ as normally published in handbooks (ASHRAE Equipment Handbook, Ch. 17, and the Standards of Tubular Exchange Manufacturers Association).

\section{Mean Temperature Difference}

For a multipass heat exchanger the mean temperature difference MTD is simply the $\log$ mean temperature difference LMTD of the fluids modified by a correction factor $K$ :

$$
M T D=L M T D \times K
$$

Where a single pass shell and tube heat exchanger is used, the LMTD correction factor $K$ is equal to 1.0 for either the parallel- or counter-flow arrangements.

In the counter-flow exchanger, the cold fluid outlet temperature can exceed the hot fluid outlet temperature; in the parallel-flow, it cannot. Most important, counterflow will require less tube surface area for an equal heat transfer rate than will parallel-flow (see Fig. 14-29).

The equation for calculating the LMTD is:

$$
\text { LMTD }=\frac{\Delta \mathrm{T}_{1}-\Delta \mathrm{T}_{2}}{\log _{10} \frac{\Delta \mathrm{T}_{1}}{\Delta \mathrm{T}_{2}}}
$$

Where

$\Delta \mathrm{T}_{1}=$ Greater temperature difference, degrees $\mathrm{F}$ $\Delta \mathrm{T}_{2}=$ Lesser temperature difference, degrees $\mathrm{F}$

Fig. 14-30 can be used to determine the LMTD directly instead of using the above equations. Also, where the ratio of $\Delta \mathrm{T}_{1} / \Delta \mathrm{T}_{2}$ is less than two, the arithmetic mean of $\Delta T_{1}$ and $\Delta T_{2}$ can be used for the MTD with an error less than $4 \%$.

For normal solar system multipass heat exchangers, the correction factor $K$ can be determined from Fig. 14-31 solving for the MTD:

$$
\text { MTD }=\text { LMTD } \times \mathbf{K}
$$

Other multipass arrangements can be found in the TEMA standard, Standards of Tabular Exchange Manuf acturers Association Manual.

\section{Heat Exchanger Effectiveness}

By definition, the heat exchanger effectiveness $(\mathcal{E})$ is defined as the ratio of the actual rate of heat transfer in a given heat exchanger to the maximum possible rate of heat transfer (see Fig. 14-32).

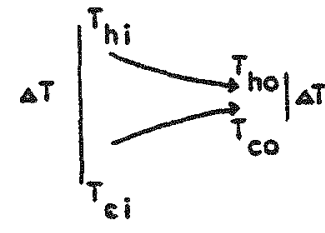

Parallel-Flow<smiles>[Te][Te][Te]</smiles>

Counter-Flow

\section{Fig. 14-29. Typical temperature gradients for parallel and counter flow heat exchangers.}

Where

$$
\begin{aligned}
& C_{h}=\text { Hot fluid capacitance rate }=\mathrm{lb} / \mathrm{hr} \times \mathrm{sp} h \mathrm{~h} \text {, } \\
& \mathrm{C}_{\mathrm{c}}=\text { Cold fluid capacitance rate }=\mathrm{lb} / \mathrm{hr} \times \mathrm{sp} \mathrm{ht} \text {, } \\
& \mathrm{T}_{\text {hí }}=\text { Hot fluid in, } \mathrm{F} \\
& \mathrm{T}_{\text {ho }}=\text { Hot fluid out, } \mathbf{F} \\
& \mathrm{T}_{\mathrm{ci}}=\text { Cold fluid in, } \mathrm{F} \\
& \mathrm{T}_{\text {co }}=\text { Cold fluid out, } \mathrm{F}
\end{aligned}
$$

The effectiveness may be calculated by one of the two following equations, depending upon which fluid has the minimum fluid capacitance rate.

$$
\begin{aligned}
& \varepsilon=\frac{C_{h}\left(T_{h i}-T_{h o}\right)}{C_{\min }\left(T_{h i}-T_{c i}\right)} \text { where } C_{c} \text { is minimum } \\
& \varepsilon=\frac{C_{c}\left(T_{c o}-T_{c i}\right)}{C_{\min }\left(T_{h i}-T_{c i}\right)} \text { where } C_{h} \text { is minimum }
\end{aligned}
$$

\section{Calculating the Overall Heat Transfer Coefficient-Three Methods}

Three methods are presented here to calculate the overall heat transfer coefficient $U$ of the heat exchanger. As discussed previously, the equation for solving for the $U$ factor is

$$
U=\frac{1}{\frac{1}{h_{i}}+\frac{1}{h_{0}}+\frac{1}{F_{o}}}
$$

where $h_{i}=$ inside film coefficient

$h_{0}=$ outside film coefficient

$F_{0}=$ fouling factor 


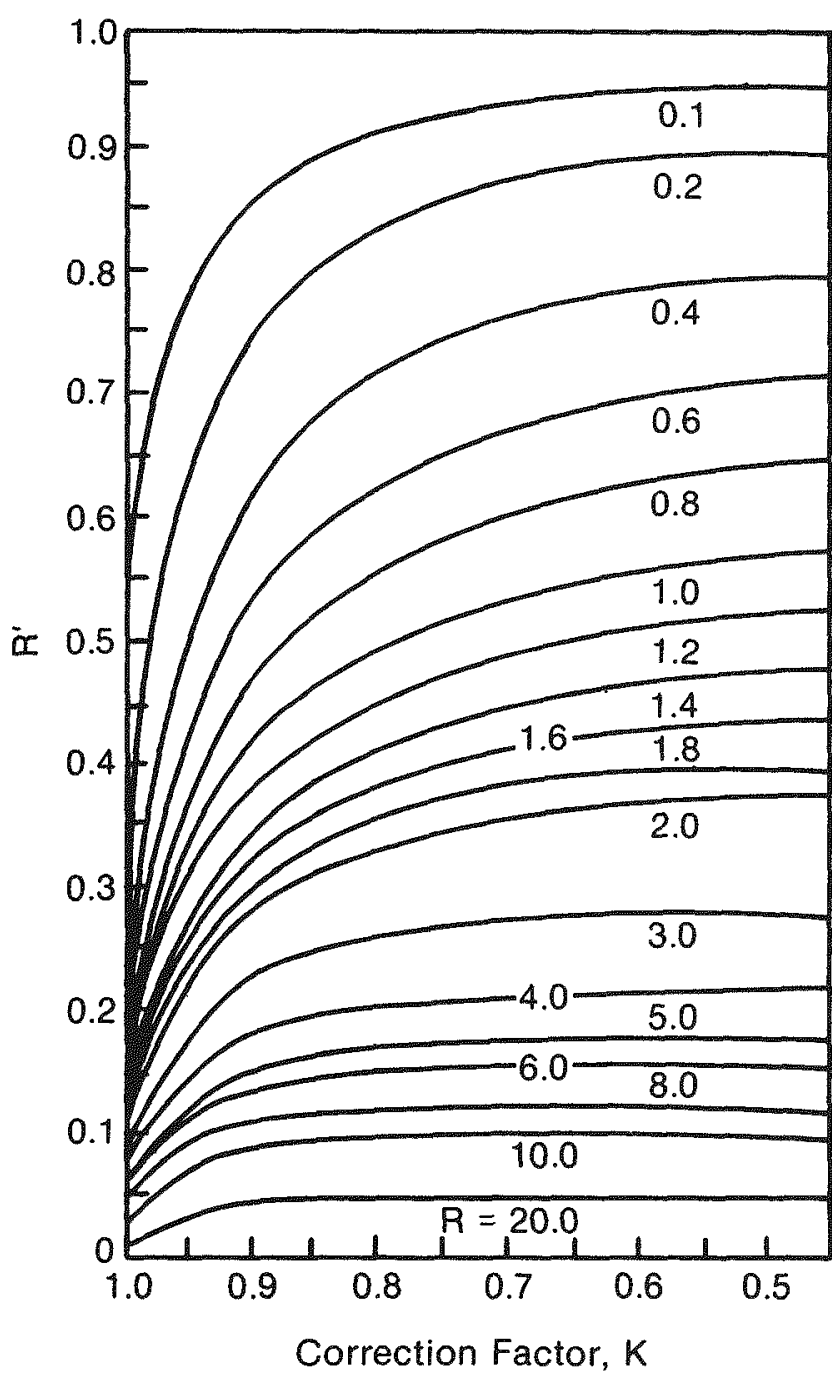

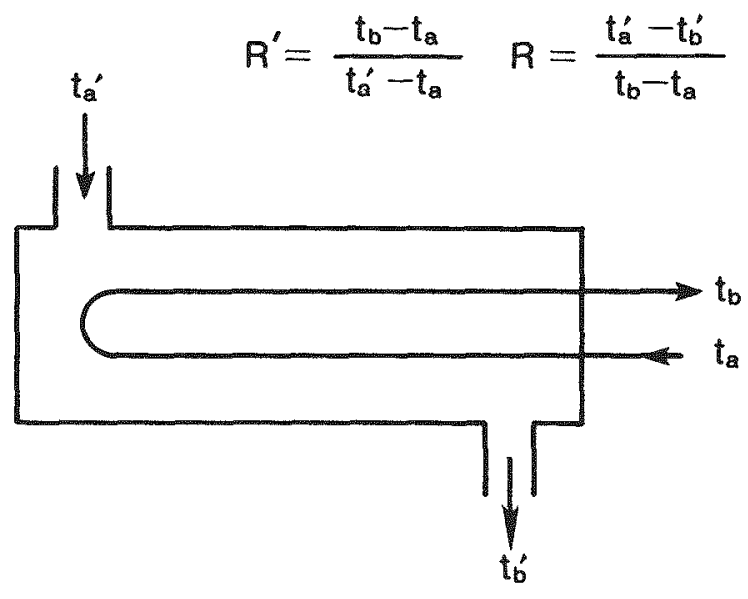

$t_{a}^{\prime}=$ Inlet Temperature, Shell Side

$t_{b}^{\prime}=$ Outlet Temperature, Shell Side

$t_{a}=$ Inlet Temperature, Tube Side

$t_{b}=$ Outlet Temperature, Tube Side

Fig. 14-30. Correction factors for LMTD, one shell pass, two or a multiple of two tube passes. 


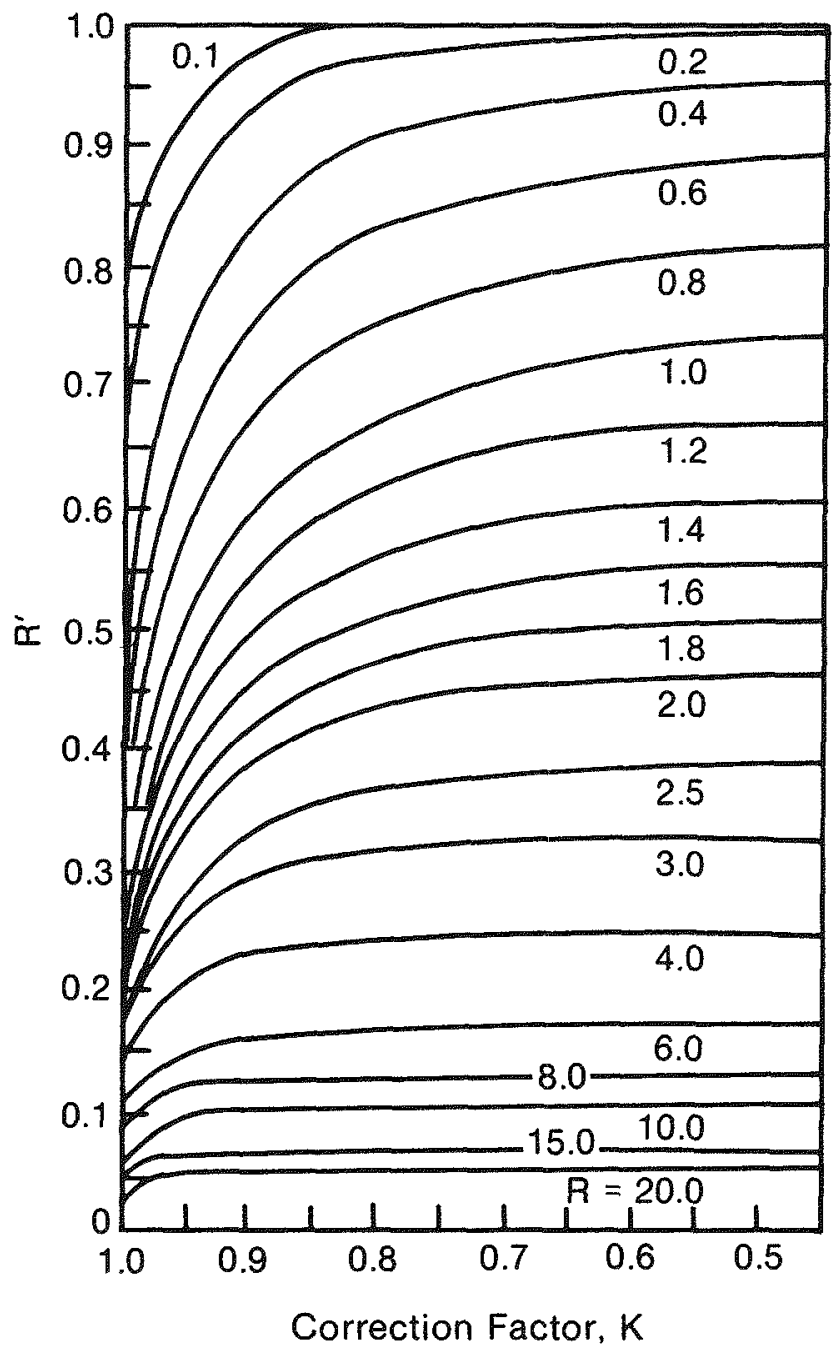

$$
R^{\prime}=\frac{t_{b}-t_{a}}{t_{a}^{\prime}-t_{a}} \quad R=\frac{t_{b}^{\prime}-t_{a}^{\prime}}{t_{b}-t_{a}}
$$

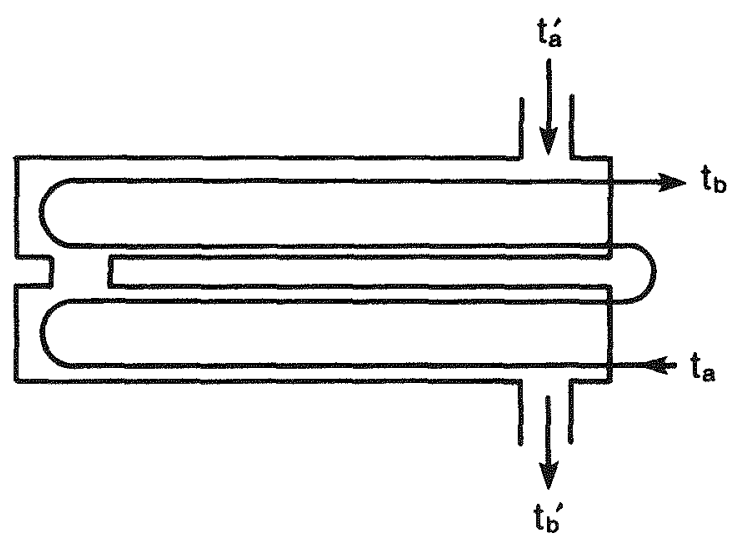

$t_{a}=$ Inlet Temperature, Shell Side

$t_{b^{\prime}}{ }^{\prime}=$ Outlet Temperature, Shell Side

$t_{a}=$ Inlet Temperature, Tube Side

$t_{b}=$ Outlet Temperature, Tube Side

Fig. 14-31. Correction factors for LMTD, two shell passes, four or a multiple of four tube passes. 


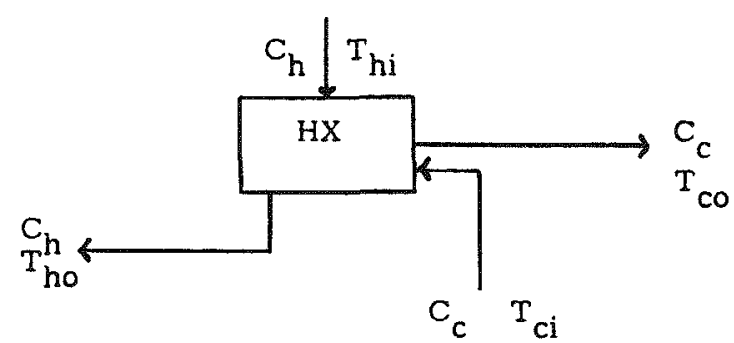

Fig. 14-32. Thermal flow parameters for heat exchangers.

Method 1: This approach uses the textbook approach to determine the film coefficient for both heat transfer fluids.

Tube Side -

Turbulent Flow $(\operatorname{Re}>2100)$

$$
\frac{\mathrm{hD}}{\mathrm{K}}=0.023 \mathrm{R}_{\mathrm{e}}^{0.8 \mathrm{p}_{\mathrm{r}} \mathrm{n}}
$$

where

$$
\begin{aligned}
\mathrm{n} & =0.4 \text { for heating } \\
& =0.3 \text { for cooling }
\end{aligned}
$$

Laminar Flow $\left(R_{e}<2100\right)$

$$
\frac{\mathrm{hD}}{\mathrm{K}}=1.86\left(\mathrm{R}_{\mathrm{e}} \times \mathrm{P}_{\mathrm{r}} \times \frac{\mathrm{D}}{\mathrm{L}}\right)^{0.33}
$$

Note: physical properties taken at average fluid temperature.

Reference: ASHRAE Handbook of Fundamentals

Shell side -

Turbulent Flow $\mathrm{R}_{\mathrm{e}}>2100$

$$
\frac{h \mathrm{D}}{\mathrm{K}}=0.36 \mathrm{R}_{\mathrm{e}}^{0.55} \mathrm{P}_{\mathrm{r}} 0.35
$$

In computing $R_{e}$, the equivalent diameter of various tube sizes and configurations are needed. The equivalent diameter in inches $d_{e}$ and feet $D_{e}$ are given in Table 14-5.
Table 14-5.

\begin{tabular}{llll}
\hline Tube OD, in. & \multicolumn{1}{c}{ Pitch } & $\mathrm{d}_{\mathrm{e}}{ }^{\prime \prime}$ & $\mathrm{D}_{\mathrm{e}}{ }^{\prime}$ \\
\hline $3 / 4$ & $1^{\prime \prime}$ square & 0.95 & 0.079 \\
1 & $1-1 / 4^{n \prime}$ square & 0.99 & 0.083 \\
$1-1 / 4$ & $1-9 / 16^{\prime \prime}$ square & 1.23 & 0.103 \\
$1-1 / 2$ & $1-7 / 8^{\prime \prime}$ square & 1.48 & 0.123 \\
$3 / 4$ & $15 / 16^{\prime \prime}$ triangle & 0.55 & 0.046 \\
$3 / 4$ & $1^{\prime \prime}$ triangle & 0.55 & 0.061 \\
1 & $1-1 / 4^{n}$ triangle & 0.72 & 0.06 \\
$1-1 / 4$ & $1-9 / 16^{\prime \prime}$ triangle & 0.91 & 0.076 \\
$1-1 / 2$ & $1-7 / 8^{\prime \prime}$ triangle & 1.08 & 0.09 \\
\hline
\end{tabular}

Reference: Donald Q. Kem, Process Heat Transfer, MeGraw Hill Co.

Note: Physical properties taken at average fluid temp.

Laminar Flow $\left(\mathrm{R}_{\mathrm{e}}<2100\right.$ ) (applicable to the tube bundle type heat exchanger)

$$
\frac{\mathrm{hD}}{\mathrm{K}}=0.56 \mathrm{G}_{\mathrm{r}}^{0.25} \mathrm{P}_{\mathrm{r}}^{0.25}
$$

where $G_{r} \times P_{r}=10^{4}$ to $10^{8}$, and

$$
\frac{\mathrm{hD}}{\mathrm{K}}=0.13 \mathrm{G}_{\mathrm{r}}^{0.33} \mathrm{P}_{\mathrm{p}}^{0.33}
$$

where $G_{p} \times P_{p}=10^{8}$ to $10^{12}$

Note: $G_{r} \times P_{r}=\frac{D^{3} \rho^{2} \beta g \Delta t C_{p}}{\mu K}$

is evaluated at the fluid temperature, all other properties evaluated at the average film temperature.

Reference: ASHRAE, Handbook and Product Directory, Chapter 2.

The fluid physical properties required to use these equations for water, $50 \%$ ethylene glycol, $50 \%$ propylene glycol, and silicon are tabulated in Tables 14-6 through 14-9.

Method 2: the second approach uses charts to solve for the fluid film coefficients. This method is simpler and is more adaptable for use in the early conceptual design stage. These charts (Tables 14-10, 14-11, 14-12) are taken from Herman J. Stoever, MeGraw Hill Book Co., 1941.

CASE 1. Table 14-10 is used to find the inside film coefficient, $h_{j}$, for turbulent flow in the tubes. For selection purposes an average tube fluid velocity of $4 \mathrm{fps}$ is adequate. The heat transfer coefficient equation used for this chart is

$$
\frac{\mathrm{hD}}{\mathrm{K}}=0.225\left(\mathrm{R}_{\mathrm{e}}\right)^{0.8}\left(\mathrm{P}_{\mathrm{r}}\right)^{0.4}
$$

Each of the physical properties is taken at the average fluid temperature. 
TABLE 14-6 PHYSICAL PROPERTIES. WATER

\begin{tabular}{|c|c|c|c|c|c|c|}
\hline $\begin{array}{l}\text { Temper- } \\
\text { arure } \\
T \\
o_{\mathrm{Y}}\end{array}$ & $\begin{array}{l}\frac{\text { Densit }}{P} \\
b_{m} / \hat{t}^{3}\end{array}$ & $\begin{array}{l}\text { Duname } \\
\text { Viscosity } \\
\mathrm{Ib}_{\mathrm{m}} / \mathrm{hr} \mathrm{ft}\end{array}$ & $\begin{array}{c}\text { Specific } \\
\text { Heat } \\
C \\
B / p_{\mathrm{m}} p_{-F}\end{array}$ & $\begin{array}{c}\text { Thermal } \\
\text { Conductrvity } \\
\mathrm{K} \\
\mathrm{B} / \mathrm{hr}-\mathrm{ft}^{2}-\mathrm{F} / \mathrm{ft}\end{array}$ & $\begin{array}{c}\text { Prandtl } \\
\text { Number } \\
\text { Pr }\end{array}$ & $\begin{array}{l}\text { Thermal } \\
\text { Coef oi Exp } \\
=\mathrm{F}-1\end{array}$ \\
\hline $\begin{array}{l}40 \\
50 \\
60 \\
70 \\
80 \\
90 \\
100 \\
110 \\
120 \\
130 \\
140 \\
150 \\
160 \\
170 \\
180 \\
190 \\
200 \\
210 \\
220 \\
230 \\
240 \\
250\end{array}$ & 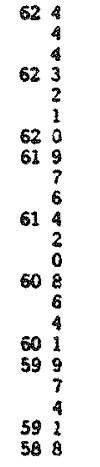 & 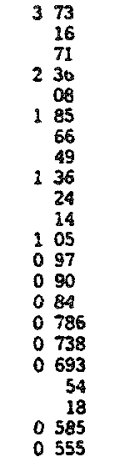 & $\begin{array}{ll}1 & 005 \\
1 & 0 \\
1 & 0 \\
1 & 0 \\
1 & 0 \\
1 & 0 \\
1 & 0 \\
1 & 0 \\
1 & 0 \\
1 & 0 \\
1 & 0 \\
1 & 0 \\
1 & 0 \\
1 & 0 \\
1 & 0 \\
1 & 005 \\
1 & 005 \\
1 & 005 \\
1 & 01 \\
1 & 015 \\
1 & 015 \\
1 & 01 \\
1 & 01 \\
1 & 015\end{array}$ & $\begin{array}{r}0 \quad 326 \\
32 \\
37 \\
0 \quad 343 \\
49 \\
494 \\
00359 \\
63 \\
67 \\
00372 \\
76 \\
80 \\
00383 \\
86 \\
88 \\
0 \quad 390 \\
92 \\
93 \\
0 \quad 394 \\
95 \\
96 \\
0 \quad 396\end{array}$ & $\begin{array}{rr}21 & 50 \\
9 & 51 \\
8 & 09 \\
6 & 88 \\
5 & 95 \\
5 & 23 \\
4 & 63 \\
4 & 11 \\
3 & 70 \\
3 & 33 \\
3 & 04 \\
2 & 7 \\
2 & 53 \\
2 & 34 \\
2 & 18 \\
2 & 02 \\
1 & 90 \\
1 & 80 \\
1 & 69 \\
1 & 58 \\
1 & 49 \\
1 & 42\end{array}$ & $\begin{array}{r}00020 \\
49 \\
85 \\
0012 \\
15 \\
18 \\
0020\end{array}$ \\
\hline
\end{tabular}

TABLE 14-7. PHYSICAL PROPERTIES 50\% ETHYLENE GLYCOL

Reference GLYCOLS, published by Union Carbide Corp. 270 Park Avenue NY, NY 10017

\begin{tabular}{|c|c|c|c|c|c|}
\hline $\begin{array}{l}\text { Temper. } \\
\text { ature } \\
T \\
{ }^{\circ}\end{array}$ & $\begin{array}{l}\text { Density } \\
\mathrm{l} \mathrm{b}_{\mathrm{m}} / \mathrm{f \textrm {q } ^ { 3 }}\end{array}$ & $\begin{array}{l}\text { y Dynamie } \\
\text { Viscosity } \\
1 \mathrm{~b}_{\mathrm{m}} / \mathrm{hr}\end{array}$ & $\begin{array}{c}\text { Specifie } \\
\text { Heat } \\
C_{\mathrm{B}} \\
\mathrm{P}_{\mathrm{m}}-\mathrm{F}\end{array}$ & $\begin{array}{l}\text { Thermal } \\
\text { Conduetuvity } \\
K{ }^{2}-F / f t \\
B / h r-f t^{2}-E\end{array}$ & $\begin{array}{l}\text { Prandtl } \\
\text { Number } \\
\text { Pr }\end{array}$ \\
\hline $\begin{array}{r}40 \\
50 \\
60 \\
70 \\
80 \\
90 \\
100 \\
110 \\
120 \\
130 \\
140 \\
150 \\
160 \\
170 \\
180 \\
190 \\
200 \\
210 \\
220 \\
730\end{array}$ & $\begin{array}{ll}65 & 83 \\
65 & 58 \\
65 & 33 \\
65 & 15 \\
65 & 15 \\
64 & 65 \\
64 & 40 \\
64 & 15 \\
63 & 90 \\
63 & 65 \\
63 & 46\end{array}$ & $\begin{array}{ll}5 & 57 \\
5 & 04 \\
4 & 5 \\
3 & 97 \\
3 & 43 \\
2 & 90 \\
2 & 54 \\
2 & 3 \\
2 & 18 \\
2 & 03 \\
1 & 82\end{array}$ & $\begin{array}{ll}0 & 78 \\
0 & 79 \\
0 & 79 \\
0 & 80 \\
0 & 81 \\
0 & 815 \\
0 & 82 \\
0 & 83 \\
0 & 835 \\
0 & 84 \\
0 & 845 \\
0 & 85 \\
0 & 86 \\
0 & 865 \\
0 & 87 \\
0 & 875 \\
0 & 88\end{array}$ & $\begin{array}{ccc} & 243 \\
& & 2 \\
& & 2 \\
0 & 241 \\
& 24 \\
0 & 24 \\
0 & 24 \\
& 4 \\
& 4 \\
& 4 \\
& 4 \\
& 4 \\
& 4 \\
& 4 \\
& 4 & 4 \\
0 & 24 \\
0 & 239 \\
0 & 2385 \\
0 & 238 \\
0 & 237 \\
0 & 235 \\
0 & 232 \\
0 & 231 \\
0 & 23\end{array}$ & $\begin{array}{rl}18 & 91 \\
17 & 22 \\
15 & 56 \\
13 & 81 \\
12 & 01 \\
10 & 21 \\
9 & 0 \\
8 & 24 \\
7 & 89 \\
7 & 40 \\
6 & 69\end{array}$ \\
\hline
\end{tabular}

TABLE 14-8 PHYSICAL PROPERTIES 50\% PROPYLENE GLYCOL

\begin{tabular}{|c|c|c|c|c|c|}
\hline \multirow{2}{*}{$\begin{array}{l}\text { Ref } \\
\text { Temper- } \\
\text { ature } \\
{ }_{T} \\
{ }_{\mathrm{O}}\end{array}$} & \multirow{2}{*}{$\begin{array}{l}\text { Deference } \\
\text { Density } \\
1 \mathrm{~b}_{\mathrm{m}^{\prime}} / \mathrm{ft}^{3}\end{array}$} & \multicolumn{4}{|c|}{$\begin{array}{c}\text { GLYCOLS published by Union Carbide corp } \\
270 \text { Park Avenue NY NY } 10017\end{array}$} \\
\hline & & $\begin{array}{l}\text { Dy namic } \\
\text { Viscosity } \\
\mathrm{Ib}_{\mathrm{m}} / \mathrm{hr} \mathrm{ft}\end{array}$ & $\begin{array}{c}\text { Specific } \\
\text { Heat } \\
C_{\mathrm{m}} \\
\mathrm{B} / \mathrm{b}_{\mathrm{m}} \mathrm{F}\end{array}$ & $\begin{array}{l}\text { Thermal P } \\
\text { Conductuvity } \\
\mathrm{K} \\
\mathrm{B} / \mathrm{hr}-\mathrm{ft}^{2}-\mathrm{F} / \mathrm{ft}\end{array}$ & $\begin{array}{l}\text { Prandtl } \\
\text { Number } \\
\text { Pr }\end{array}$ \\
\hline $\begin{array}{r}40 \\
50 \\
60 \\
70 \\
80 \\
90 \\
100 \\
110 \\
120 \\
130 \\
140 \\
150 \\
160 \\
170 \\
180 \\
190 \\
200 \\
210 \\
220 \\
230 \\
240\end{array}$ & $\begin{array}{ll}64 & 06 \\
63 & 77 \\
63 & 52 \\
63 & 27 \\
63 & 02 \\
62 & 77 \\
62 & 52 \\
62 & 28 \\
62 & 03 \\
61 & 78 \\
61 & 5\end{array}$ & $\begin{array}{ll}7 & 5 \\
6 & 29 \\
5 & 57 \\
4 & 84 \\
4 & 11 \\
3 & 51 \\
3 & 03 \\
2 & 66 \\
2 & 42 \\
2 & 06 \\
1 & 79\end{array}$ & $\begin{array}{ll}0 & 865 \\
0 & 87 \\
0 & 875 \\
0 & 88 \\
0 & 885 \\
0 & 89 \\
0 & 895 \\
0 & 90 \\
0 & 905 \\
0 & 91 \\
0 & 915\end{array}$ & \begin{tabular}{ll}
0 & 223 \\
0 & 221 \\
0 & 22 \\
0 & 2 \\
& 2 \\
& 2 \\
& 2 \\
& 2 \\
& 2 \\
& 2 \\
& \multicolumn{1}{c}{2} \\
0 & 219 \\
0 & 219 \\
0 & 218 \\
0 & 217 \\
0 & 217 \\
0 & 2165 \\
0 & 216
\end{tabular} & $\begin{array}{rl}29 & 5 \\
24 & 9 \\
22 & 2 \\
19 & 4 \\
16 & 6 \\
14 & 3 \\
12 & 4 \\
11 & 0 \\
10 & 1 \\
8 & 7 \\
7 & 6\end{array}$ \\
\hline 250 & 600 & 117 & 094 & 0215 & 512 \\
\hline
\end{tabular}

TABLE 14-9. PHYSICAL PROPERTIES

SILICONE (GE SF 81 (50))

Reference General Electric Corp Data

\begin{tabular}{|c|c|c|c|c|c|}
\hline $\begin{array}{l}\text { Temper } \\
\text { ature } \\
{ }_{T} \\
{ }_{F}\end{array}$ & $\begin{array}{l}-\frac{P}{P} \\
1 b_{m} / \mathrm{ft}^{3}\end{array}$ & $\begin{array}{l}\text { Dynamic } \\
\text { Viscosity } \\
1 \mathrm{~b}_{\mathrm{m}} / \mathrm{hr} \mathrm{ft}\end{array}$ & $\begin{array}{c}\text { Specific } \\
\text { Heat } \\
C_{\mathrm{B} / \mathrm{b}_{\mathrm{m}}}\end{array}$ & $\begin{array}{l}\text { Thermal } \\
\text { Conductivity } \\
\mathrm{K} \\
\mathrm{B} / \mathrm{hr}-\mathrm{ft}^{2}-\mathrm{F} / \mathrm{ft}\end{array}$ & $\begin{array}{c}\text { Prandtl } \\
\text { Number } \\
\text { Pr }\end{array}$ \\
\hline $\begin{array}{l}40 \\
50 \\
60 \\
70 \\
80 \\
90\end{array}$ & 615 & 1549 & 0356 & $0 \quad 0882$ & 62538 \\
\hline $\begin{array}{l}100 \\
110 \\
120 \\
130 \\
140 \\
150 \\
160 \\
170 \\
180 \\
190 \\
200 \\
210 \\
220 \\
230 \\
240 \\
250\end{array}$ & $\begin{array}{ll}60 & 0 \\
59 & 7 \\
59 & 3 \\
59 & 0 \\
58 & 7 \\
58 & 5 \\
58 & 1 \\
57 & 8 \\
57 & 5 \\
57 & 2 \\
57 & 0\end{array}$ & $\begin{array}{ll}93 & 0 \\
85 & 6 \\
78 & 2 \\
68 & 7 \\
66 & 0 \\
61 & 2 \\
57 & 5 \\
51 & 6 \\
46 & 9 \\
44 & 4 \\
42 & 0\end{array}$ & $\begin{array}{ll}0 & 378 \\
0 & 384 \\
0 & 388 \\
0 & 392 \\
0 & 396 \\
0 & 40 \\
0 & 405 \\
0 & 41 \\
0 & 414 \\
0 & 418 \\
0 & 422\end{array}$ & $\begin{array}{ll}0 & 086 \\
0 & 0855 \\
0 & 085 \\
0 & 0846 \\
0 & 0842 \\
0 & 0837 \\
0 & 0833 \\
0 & 0828 \\
0 & 0824 \\
0 & 082 \\
0 & 0815\end{array}$ & $\begin{array}{ll}408 & 80 \\
384 & 45 \\
356 & 96 \\
318 & 33 \\
310 & 40 \\
292 & 42 \\
279 & 56 \\
255 & 51 \\
235 & 64 \\
226 & 33 \\
217 & 47\end{array}$ \\
\hline
\end{tabular}


Table 14-10

\section{Tables for use in determining the heat transfer coefficient for liquids heated inside tubes, under turbulent flow}

$$
h=h_{0} \times F_{t} \times F_{d}
$$

where $h=$ the film coefficient, $\mathrm{Bt} \mathrm{u} /(\mathrm{sq} \mathrm{ft})(\mathrm{hr})\left({ }^{\circ} \mathrm{F}\right), h_{0}=$ the base value of the film coefficient, from Fig $22, F_{t}=$ the temperature-correction factor, from Table $8, F_{\alpha}=$ the diameter-correction factor, from Table 9

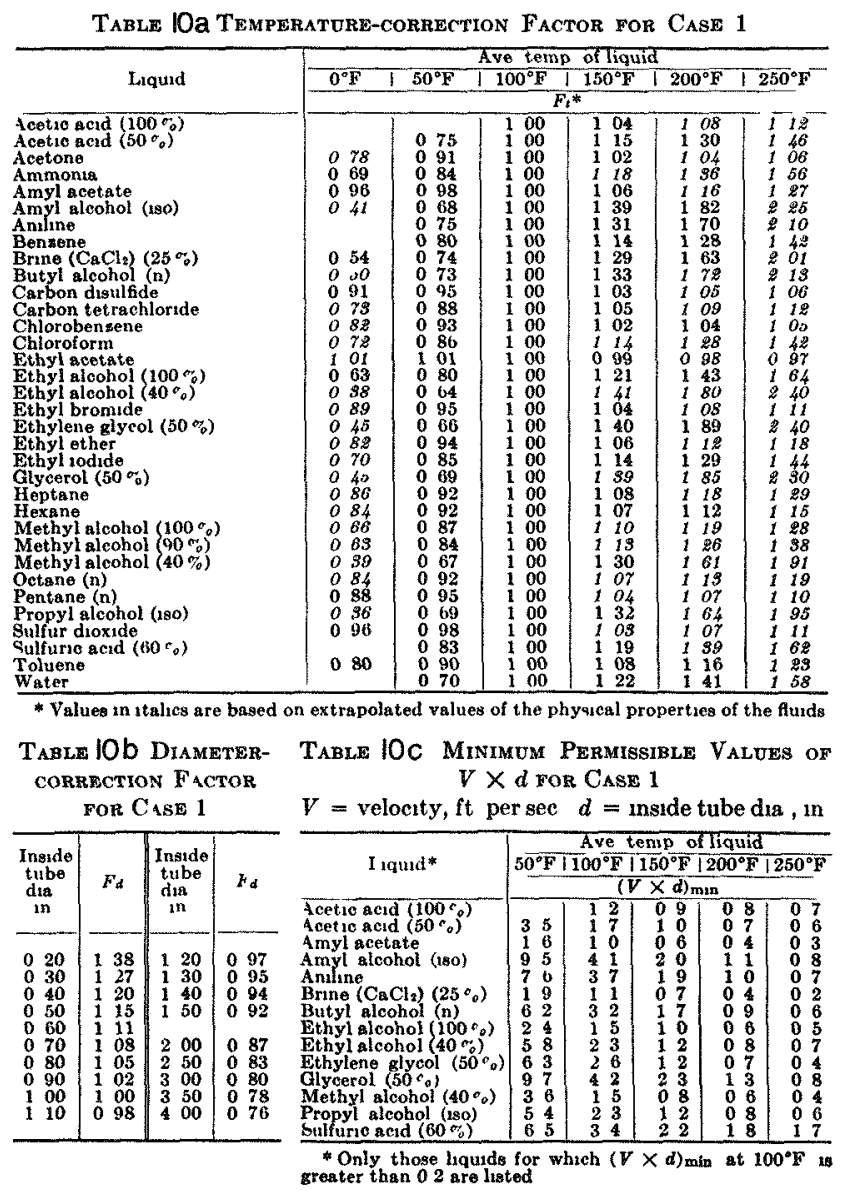

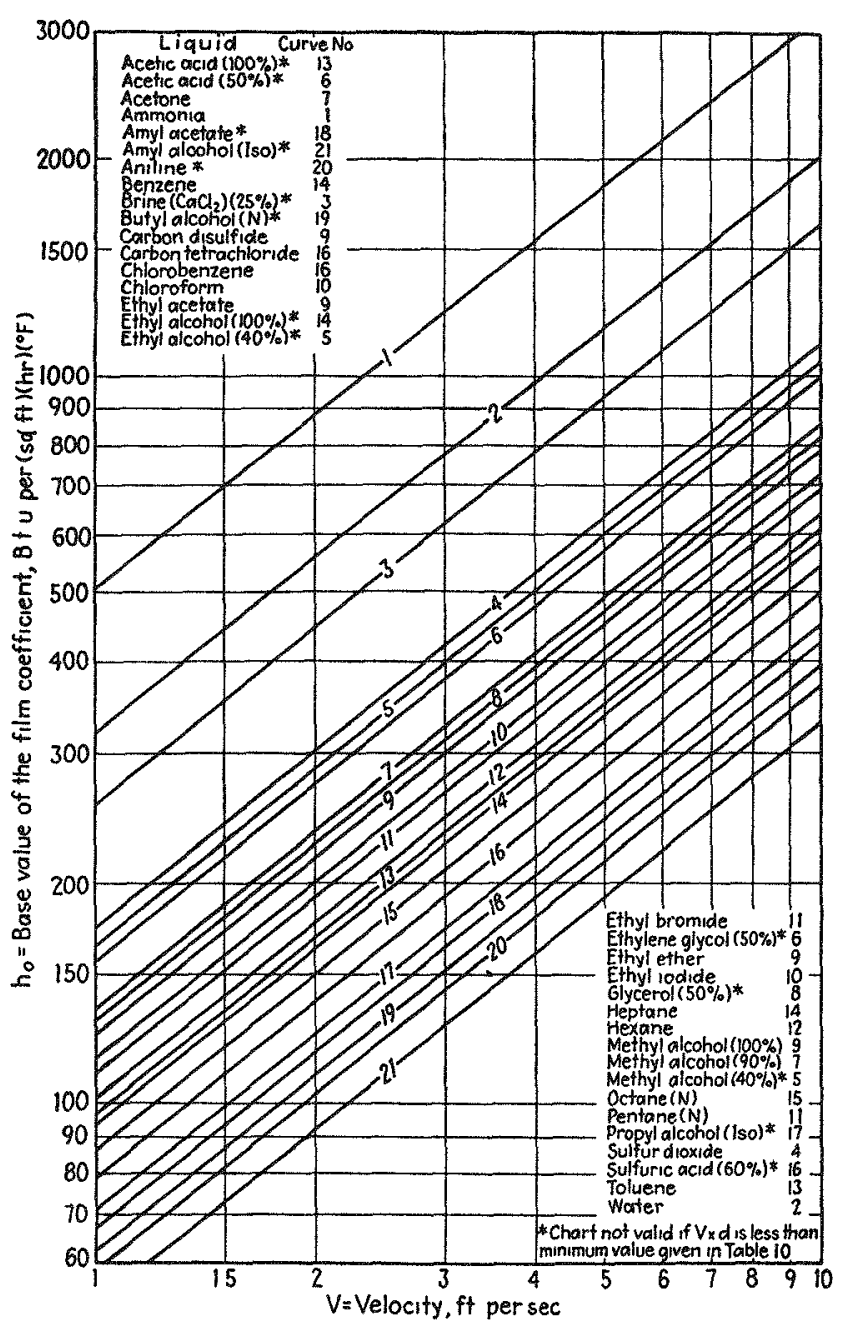

Fig. 14-34. Diagram used in determining the base value of the film coefficients 
CASE 2. Table 14-11 allows the selection of the outside film coefficient $h_{0}$ in the shell side of the heat exchanger with turbulent flow. An average shell fluid velocity of $2 \mathrm{fps}$ is recommended. This chart is based on the following equation:

$$
\frac{h \mathrm{D}}{\mathrm{K}}=0.385\left(\mathrm{R}_{\mathrm{e}}\right)^{0.56}\left(\mathrm{P}_{\mathrm{r}}\right)^{0.3}
$$

Each of the physical fluid properties is taken at the average film temperature.

CASE 3. Table 14-12 refers to the tube bundle type heat exchanger (a shell and tube heat exchanger without the shell) that has natural convective heat transfer on the outside tube surface area. This chart is used in the selection of the outside film coefficient $h_{0}$ for the tubes. The tube inside film coefficient would use Case 1 previously discussed. The heat transfer equation for this chart is:

$$
\frac{\mathrm{hD}}{\mathrm{K}}=0.525\left(G_{\mathrm{r}}\right)^{0.25}\left(\mathrm{P}_{\mathrm{r}}\right)^{0.25}
$$

Each of the physical fluid properties is taken at the average film temperature.

\section{Example A}

Determine the overall coefficient of heat transfer $U$ for a shell and tube heat exchanger using the three methods discussed.

\section{Method 1 - theoretical for mulae}

Method 2 - charts

Method 3 - assumed value

Given: Shell - $50 \%$ ethylene glycol, average temperature $130 \mathrm{~F}$ with $20 \mathrm{~F} \mathrm{t}$, flow velocity $2 \mathrm{fps}, 10 \mathrm{~F}$ approach. Tube - water, average temperature $120 \mathrm{~F}$ with $20 \mathrm{~F} \mathrm{t}$, flow velocity 4 fps (see Fig. 14-33).

Method 1: Theoretical Formulae. Find the shell outside film coefficient, $h_{0}$, assume turbulent flow at $2 \mathrm{fps}$.

$$
\frac{h_{0} D}{K}=0.36 R_{e}^{0.55} \mathrm{P}_{r}^{0.33}
$$

Physical properties for $50 \%$ ethylene glycol at $130 \mathrm{~F}$ average temperature. Assume $3 / 4$ in. OD copper tubing with equivalent diameter $d_{e}=0.55$ in. or $d_{e}=0.046 \mathrm{ft}$ with tubes on 15/16-in. triangular pitch. Refer to Table 14-4 for fluid physical properties.

$$
D_{\mathrm{e}}=0.046 \mathrm{ft}
$$

$$
\begin{aligned}
& V=2 \mathrm{fps}=(2)(3600)=7200 \mathrm{fph} \\
& \rho=65.15 \mathrm{lb} / \mathrm{cu} \mathrm{ft} \\
& \mu=3.97 \mathrm{lb}_{\mathrm{m}} / \mathrm{hr}-\mathrm{ft} \\
& \mathrm{K}=0.24 \mathrm{Btu} / \mathrm{hr}-\mathrm{sq} \mathrm{ft}-\mathrm{F} / \mathrm{ft} \\
& \mathrm{C}_{\mathrm{p}}=.835 \mathrm{Btu} / \mathrm{hb} \mathrm{m}^{\mathrm{F}} \\
& R_{e}=\frac{V D \rho}{\mu}=\frac{(7200)(0.046)(65.15)}{3.97}=5435 \\
& \mathrm{P}_{\mathrm{r}}=\frac{\mu \mathrm{C}_{\mathrm{p}}}{\mathrm{k}}=\frac{(3.97)(0.835)}{0.24}=13.81 \\
& h_{o}=\frac{K}{D} 0.36\left(R_{e}\right)^{0.55}\left(P_{r}\right)^{0.33} \\
& =\frac{0.24}{0.046}(0.36)(5435)^{0.55}(13.81)^{0.33} \\
& =(1.88)(113.33)(2.38) \\
& \mathrm{h}_{\mathrm{o}}=507 \mathrm{Btu} / \mathrm{hr}-\mathrm{sq} \mathrm{ft-F}
\end{aligned}
$$

Find the tube side film coefficient, $h_{i}$, assume turbulent flow at 4 fps.

$$
\frac{h_{i} D}{\bar{K}}=0.023\left(R_{e}\right)^{0.8}\left(P_{r}\right)^{0.4}
$$

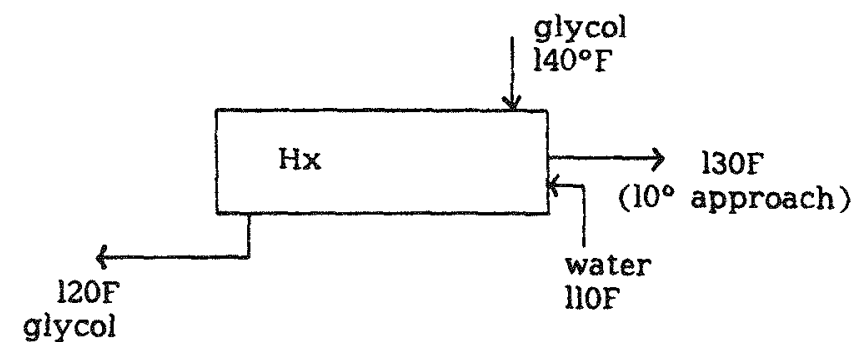

glycol

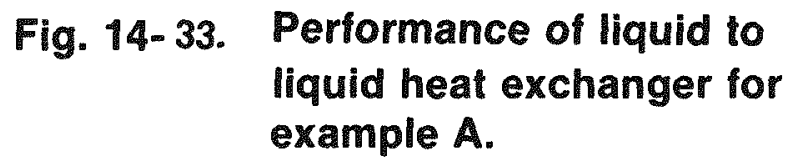


Table 14-11. Liquids heated or cooled outside single tubes, direction of flow normal to tube

$h=h_{0} \times F_{t} \times F_{d}$,

where $h=$ the film coefficient, $\mathrm{B} \mathrm{t} \mathrm{u} /(\mathrm{sq} \mathrm{ft})(\mathrm{hr})\left({ }^{\circ} \mathrm{F}.\right)$.

$h_{0}=$ the base value of the film coeffienent, from Fig 26 .

$F_{t}=$ the temperature-correction factor, from Table 20

$F_{d}=$ the dameter-correction factor, from Table 21

Table 14-11a Temperaturemcorrection Factor for Case 2

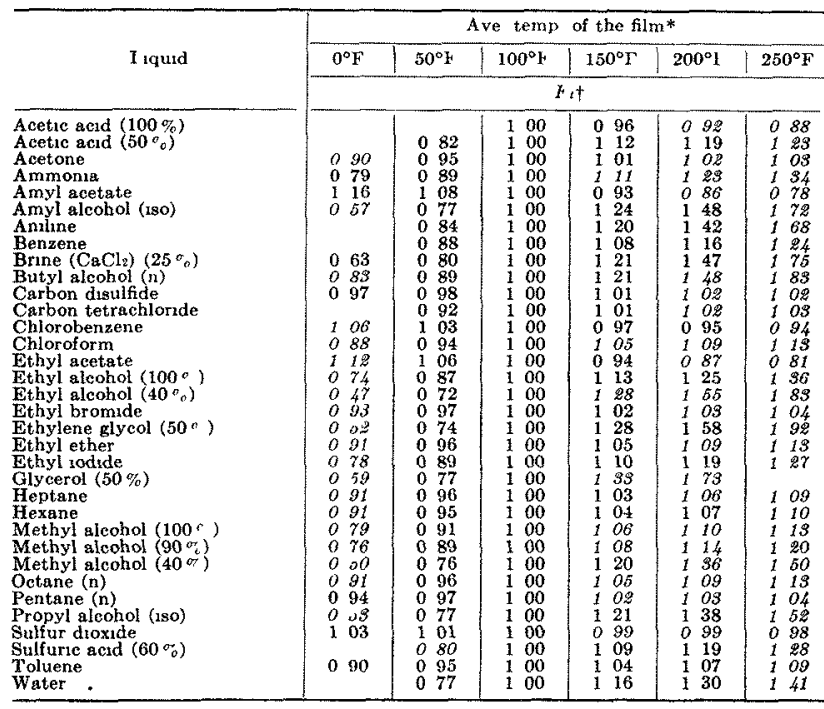

* Average temper uture of th him $=$ (temperatuse of the tube wall + temperature of the man body of the liquid) -2
$t$ Values in talics ate based on $x$ xtrapolated values of the physical properties of the funds

TaBLE $1411 \mathrm{~b}$ DIAMF' $\mathrm{H}$-CORRECTION FaCtor FOR CASE 2

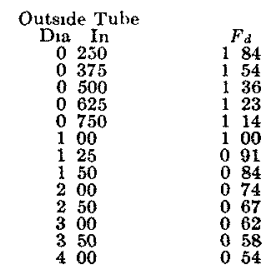

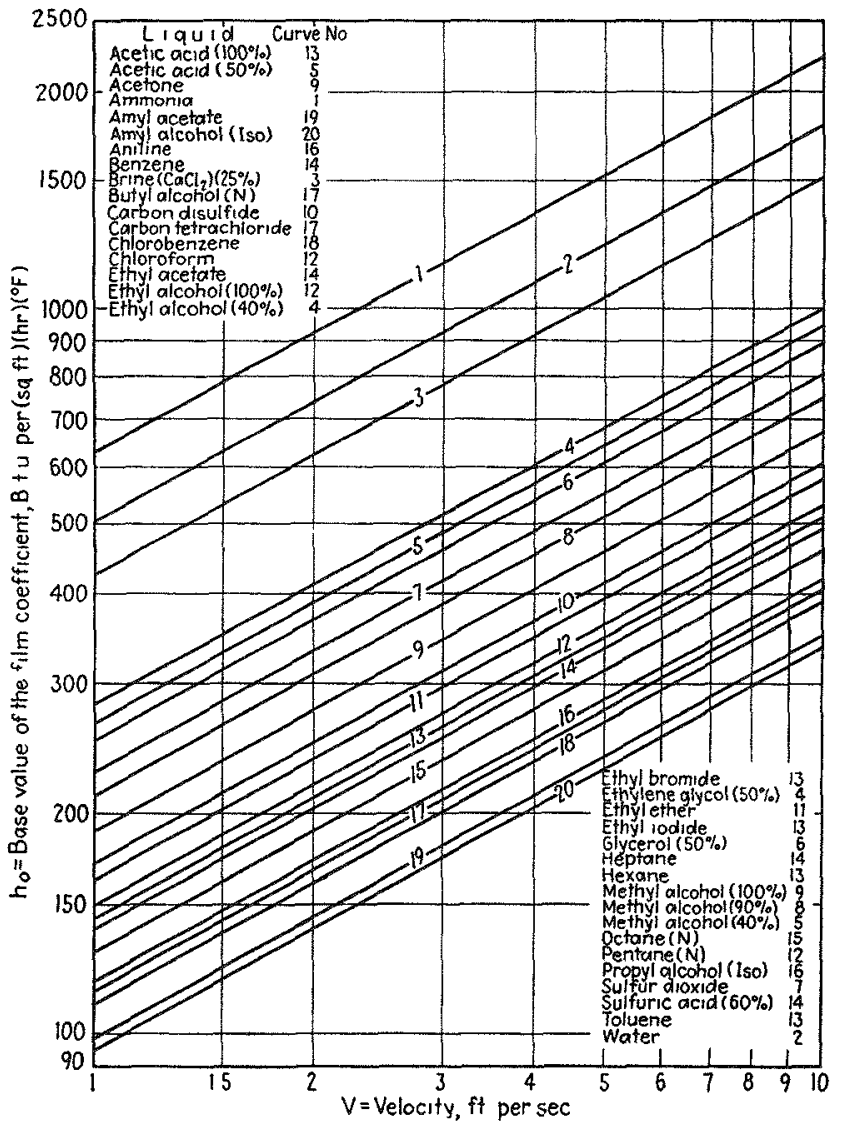

Fig. 14-35. 


\section{Table 14-12. Liquids heated outside horizontal tubes, natural convection}

$$
h=h_{0} \times F_{t} \times F_{d},
$$

where $h$ the film coefficient, $\mathrm{B} t \mathrm{u} /(\mathrm{sq} \mathrm{ft})(\mathrm{hr})\left({ }^{\circ} \mathrm{F}\right)$

$h_{0}=$ the base value of the film coefficient, from Fig 31

$F_{t}=$ the temperature-correction factor, from Table 26

$F_{d}=$ the diameter-correction factor, from Table 27

Table 14-12atemperatere-correction Factor yor Case 3

\begin{tabular}{|c|c|c|c|c|c|c|}
\hline \multirow{3}{*}{ Liqued } & \multicolumn{6}{|c|}{ Ave temp of the film* } \\
\hline & $0^{\circ} \mathrm{F}$ & $50^{\circ} \mathrm{F}$ & $100^{\circ} \mathrm{F}$ & $150^{\circ} \mathrm{F}$ & $200^{\circ} \mathrm{F}$ & $250^{\circ} \mathrm{F}$ \\
\hline & \multicolumn{6}{|c|}{$F_{t} \dagger$} \\
\hline 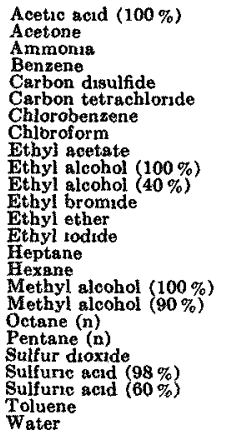 & 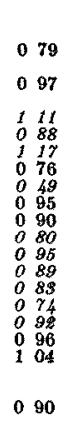 & 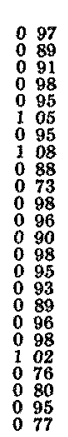 & $\begin{array}{ll}1 & 00 \\
1 & 00 \\
1 & 00 \\
1 & 00 \\
1 & 00 \\
1 & 00 \\
1 & 00 \\
1 & 00 \\
1 & 00 \\
1 & 00 \\
1 & 00 \\
1 & 00 \\
1 & 00 \\
1 & 00 \\
1 & 00 \\
1 & 00 \\
1 & 00 \\
1 & 00 \\
1 & 00 \\
1 & 00 \\
1 & 00 \\
1 & 00 \\
1 & 00 \\
1 & 00 \\
1 & 00 \\
1 & 00 \\
1 & 00\end{array}$ & $\begin{array}{ll}0 & 95 \\
1 & 02 \\
1 & 11 \\
1 & 08 \\
1 & 01 \\
0 & 01 \\
0 & 99 \\
0 & 95 \\
1 & 05 \\
0 & 92 \\
1 & 12 \\
1 & 89 \\
1 & 02 \\
1 & 03 \\
1 & 03 \\
1 & 08 \\
1 & 03 \\
1 & 04 \\
1 & 06 \\
1 & 09 \\
1 & 04 \\
1 & 02 \\
0 & 02 \\
0 & 99 \\
1 & 94 \\
1 & 17 \\
1 & 04 \\
1 & 0.5\end{array}$ & 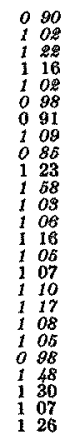 & 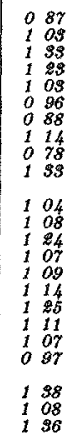 \\
\hline
\end{tabular}

*Average temperature of the film $=$ (temperature of the tube wall + temperature of the $\uparrow$ Values in italles are based on extrapolated values of the physical properties of the fluds

Table 14-12b Diameter-correction Factor for Case 3

\begin{tabular}{|c|}
\hline 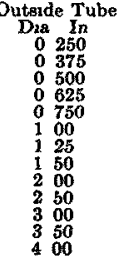 \\
\hline
\end{tabular}

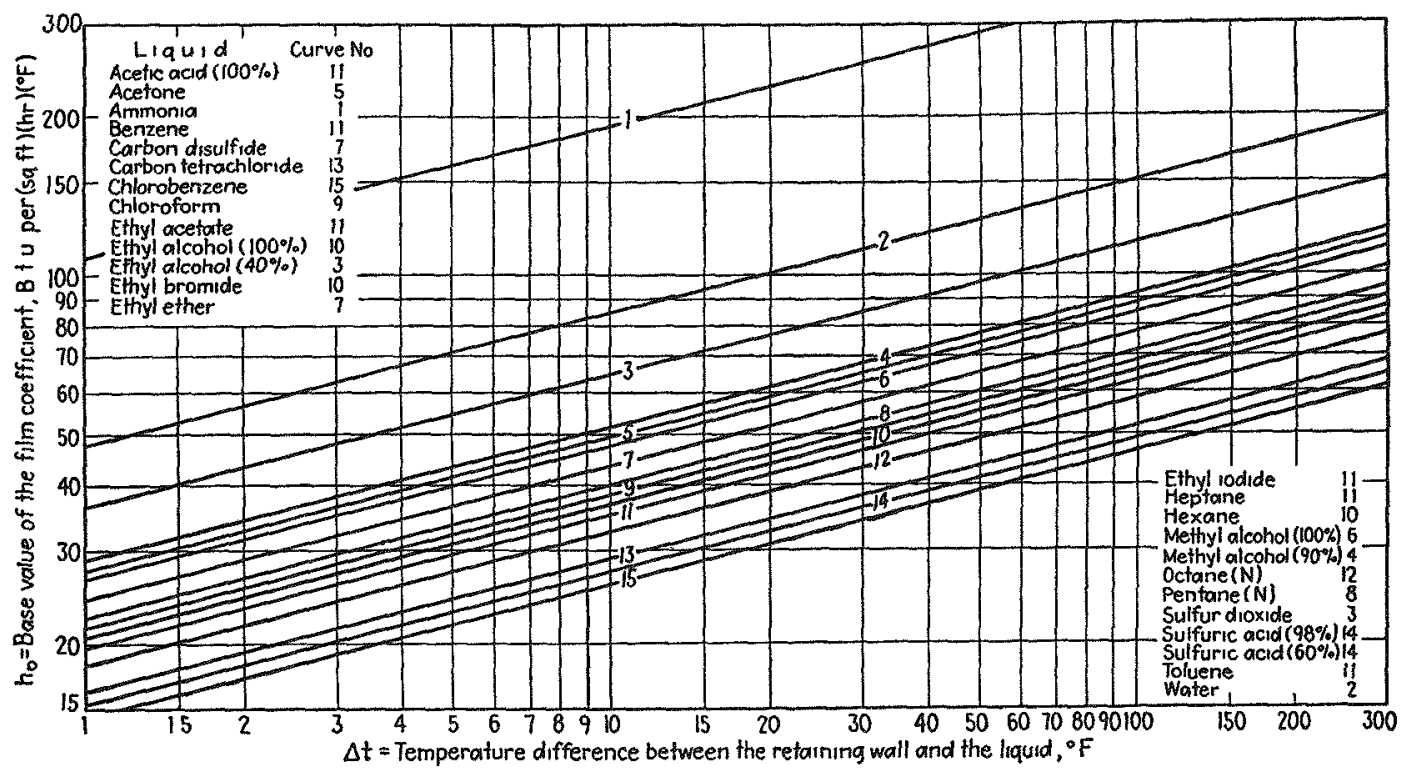

Fig. 14-36. 
Physical properties for water at $120 \mathrm{~F}$ average temperature with $3 / 4$ in. OD copper tube. Refer to Table 14-3 for fluid physical properties.

$$
\begin{aligned}
\mathrm{D} & =0.785 \mathrm{in.}=0.0654 \mathrm{ft} \\
\mathrm{V} & =4 \mathrm{fps}=(4)(3600)=14,400 \mathrm{fph} \\
\rho & =61.7 \mathrm{lb} / / \mathrm{cu} \mathrm{ft} \\
\mu & =1.367 \mathrm{lb}_{\mathrm{m}} / \mathrm{hr}-\mathrm{ft} \\
\mathrm{K} & =0.367 \mathrm{lb} \mathrm{m} / \mathrm{hr}-\mathrm{sq} \mathrm{ft}-\mathrm{F} / \mathrm{ft} \\
\mathrm{P}_{\mathbf{r}} & =3.7 \\
\mathrm{R}_{\mathrm{e}}=\frac{\mathrm{VD} \rho}{\mu} & =\frac{(14,400)(0.0654)(61.7)}{1.36}=42,725
\end{aligned}
$$

turbulent flow $42,725 \quad 2100$

$$
\begin{aligned}
\mathrm{P}_{\mathrm{r}} & =\frac{\mu \mathrm{C}_{\mathrm{p}}}{\mathrm{K}}=3.7 \\
\mathrm{~h}_{\mathrm{i}} & =\frac{0.367}{0.0654}(0.023)(42,725)^{0.8}(3.7)^{0.4} \\
& =(0.129)(5065) \times(.69) \\
\mathrm{h}_{\mathrm{i}} & =1104 \mathrm{Btu} / \mathrm{hr}-\mathrm{sq} \mathrm{ft}-\mathrm{F}
\end{aligned}
$$

Find overall $\mathrm{U}$ f actor - Method 1

$$
U=\frac{1}{\frac{1}{h_{i}}+\frac{1}{h_{o}}+\frac{1}{F_{o}}}=\frac{1}{\frac{1}{1104}+\frac{1}{507}+\frac{1}{1000}}
$$

assume fouling factor $\mathrm{F}_{\mathrm{o}}=1000$

$$
\begin{gathered}
=\frac{1}{0.00091+0.002+0.001}=\frac{1}{0.00391} \\
U=256 \mathrm{Btu} / \mathrm{hr}-\mathrm{sq} \mathrm{ft}-\mathrm{F}
\end{gathered}
$$

Method 2: Charts. Find the outside film coefficient, $h_{0}$ assume turbulent flow at 2 fps. Reference Table 14-18, Case 5 with $50 \%$ ethylene glycol at $2 \mathrm{fps}$ and $130 \mathrm{~F}$ average temperature, and $3 / 4$ in. type " $L$ " copper tubing.

From Table 14-10, $h_{o}=410 \mathrm{Btu} / \mathrm{hr}-\mathrm{sq} \mathrm{ft}-\mathrm{F}$

Correction factor $\mathrm{F}_{\mathrm{d}}$ for tube $\mathrm{OD}$ at $\mathbf{0 . 8 7 5}$ in. is $\mathbf{1 . 0 7}$.

Correction factor $F_{t}$ for average temperature at $130 \mathrm{~F}$ is 1.168 .

Therefore $h_{o}$ corrected $=(410)(1.07)(1.168)$

$$
h_{0}=512 \mathrm{Btu} / \mathrm{hr}-\mathrm{sq} \mathrm{ft}-\mathrm{F}
$$

Find the inside film coefficient, $h_{i}$, assume turbulent flow at 4 fps.
Reference Table 14-10, Case 1, with water at $4 \mathrm{fps}$ and $120 \mathrm{~F}$ average temperature and $3 / 4$ in. type $L$ copper tubing.

From Table 14-9,

$h_{i}=980 \mathrm{Btu} / \mathrm{hr}^{2}-\mathrm{sq} \mathrm{ft}-\mathrm{F}$

Correction factor $\mathrm{F}_{\mathrm{d}}$ for tube $\mathrm{OD}$ at $\mathbf{0 . 8 7 5}$ is 1.055 .

Correction factor $F_{t}$ for $120 \mathrm{~F}$ average temperature is 1.13.

Therefore corrected $h_{i}=(980)(1.055)(1.13)$

$$
h_{i}=1168 \mathrm{Btu} / \mathrm{hr}-\mathrm{sq} \mathrm{ft}-\mathrm{F} \text {. }
$$

Find overall U factor - Method 2.

$$
\begin{gathered}
U=\frac{1}{\frac{1}{1168}+\frac{1}{512}+\frac{1}{1000}}=\frac{1}{0.00381} \\
U=262 \mathrm{Btu} / \mathrm{hr}-\mathrm{sq} \mathrm{ft}-\mathrm{F}
\end{gathered}
$$

Method 3: Assume overall U factor for a glycol to water heat exchanger is $250 \mathrm{Btu} / \mathrm{hr}-\mathrm{sq} \mathrm{ft}-\mathrm{F}$. Comparison of the three methods for determining the overall coefficient of heat transfer for a shell and tube heat exchanger using glycol and water:

$$
\begin{array}{ll}
\text { Method 1 - theoretical } & 256 \mathrm{Btu} / \mathrm{hr}-\mathrm{sq} \mathrm{ft}-\mathrm{F} \\
\text { Method 2 - charts } & 262 \mathrm{Btu} / \mathrm{hr}-\mathrm{sq} \mathrm{ft}-\mathrm{F} \\
\text { Method 3- assumed } & 250 \mathrm{Btu} / \mathrm{hr}-\mathrm{sq} \mathrm{ft}-\mathrm{F}
\end{array}
$$

\section{Example B}

Determine the area of heating surface for a shell and tube heat exchanger with the operating conditions of Example A. Also, find the heat exchanger effectiveness.

Operating conditions from Example A:

shell - 50\% ethylene glycol, average temperature $130 \mathrm{~F}$, flow velocity 2 fps.

tube - water; average temperature $120 \mathrm{~F}$, flow vel city 4 fps.

Given - optimum solar collector area is $1000 \mathrm{sq} \mathrm{ft}_{\mathrm{c}}$ net aperture.

Find collector fluid flow rate - assume flow rate to be $10 \mathrm{Btu} / \mathrm{hr}-\mathrm{sq} \mathrm{ft} \mathrm{c}^{-\mathrm{F}} 130 \mathrm{~F}$.

$$
\begin{aligned}
& \mathrm{gpm}=\frac{10 \mathrm{Btu}}{\mathrm{hr}-\mathrm{sq} \mathrm{ft} \mathrm{c}_{\mathrm{c}}} \frac{1 \mathrm{bm}_{\mathrm{m}}}{\mathrm{sp}_{\mathrm{ht}}} \frac{\mathrm{hr}}{60 \mathrm{~min}} \frac{\mathrm{gal}}{8.3 \mathrm{sp} \times \mathrm{gr}} \\
& =0.23 \frac{\mathrm{ggm}}{\mathrm{sq} \mathrm{ft}} \\
& =0.23 \frac{\mathrm{ggm}}{\mathrm{sq} f \mathrm{t}_{\mathrm{c}}} \times 1000 \mathrm{sq} \mathrm{ft}_{\mathrm{c}}=23 \mathrm{gpm}
\end{aligned}
$$


Find solar collector $\Delta t$, assume peak solar load is 300 $\mathrm{Btu} / \mathrm{hr}-\mathrm{sq} \mathrm{ft}_{\mathrm{c}}$, collector efficiency is $60 \%$.

$$
\begin{aligned}
\Delta t & =\frac{1000 \mathrm{sq} f t_{\mathrm{c}} \frac{300 \mathrm{Btu}}{\mathrm{hr}-\mathrm{sq} \mathrm{ft}}(0.60)}{(23 \mathrm{gpm})(500)(0.84)(1.044)} \\
\Delta t & =18 \mathrm{~F}
\end{aligned}
$$

Find Log Mean Temperature Difference LMTD, assume 10 degrees approaches for heat exchanger (see Fig. 14-34).

Check for LMTD correction factor $F$,

$$
\begin{aligned}
& R=\frac{129-109}{139-109}=\frac{20}{30}=0.67 \\
& R^{\prime}=\frac{139-121}{129-109}=\frac{18}{20}=0.90
\end{aligned}
$$

from Fig. $14-30, K=1.0$.

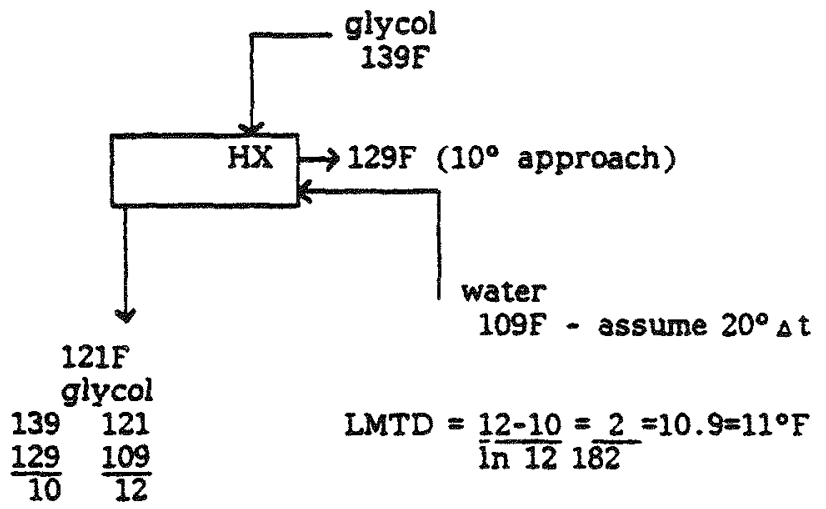

\section{Fig. 14-37. Performance of liquid to liquid heat exchanger for example $B$.}

Therefore the Mean Temperature Difference MTD is $L M T D \times F=11 \times 1.0=11 \mathrm{~F}$.

Find the total heat transfer from the collectors to the heat ex changer.

$$
\begin{aligned}
Q & =g p m \times 500 \times s p h t \times s p g r \times t \\
& =23 \mathrm{gpm}(500)(0.84)\left(1.044 \times 18^{\circ}\right) \\
Q & =181,530 \mathrm{Btu} / \mathrm{hr}
\end{aligned}
$$

Find the sq $\mathrm{ft}$ of heat exchanger tubing where the overall heat transfer coefficient $U$ is $262 \mathrm{Btu} / \mathrm{hr}-\mathrm{sq} \mathrm{ft}-\mathrm{F}$ (ref. Example A).

$$
\begin{aligned}
& \text { Area }=\frac{Q}{\mathrm{LMTD}}=\frac{181,530 \mathrm{~B} / \mathrm{hr}}{262 \mathrm{~B} / \mathrm{hr}-\mathrm{ft}^{2}-\mathrm{F} \times 11^{\circ}} \\
& \text { Area }=63 \mathrm{SF}
\end{aligned}
$$

Find heat exchanger eff ectiveness

$$
\text { shell flow rate } \quad=23 \mathrm{gpm} \text { from above }
$$

$$
\text { tube flow rate } \quad=\frac{181,530}{50020^{\circ}}=18 \mathrm{gpm}
$$

hot capacitance rate $\mathrm{C}_{\mathrm{h}}=$

$$
(23 \mathrm{gpm})(500)(1.044)(0.84)=10,085
$$

cold capacitance rate $\mathrm{C}_{\mathfrak{c}}=$

$$
\begin{aligned}
(18 \mathrm{gpm})(500)(1.0)= & 9,000 \\
& (\mathrm{C} \mathrm{min})
\end{aligned}
$$

therefore

$$
\begin{aligned}
& =\frac{C_{h}\left(T_{h i}-T_{h o}\right)}{C_{\min }\left(T_{h i}-T_{c i}\right)} \\
& =\frac{(10,085)(139 \mathrm{~F}-121 \mathrm{~F})}{(9,000)(139 \mathrm{~F}-109 \mathrm{~F})} \\
& =0.67
\end{aligned}
$$

\section{Guidelines}

When specifying the heat exchanger for a given system, the following items should be detailed: type, materials, construction, capacity, approach temperature, effectiveness factor, requirements on presure drop and flow rate, insulation, method of protection from high presure and temperature, single or double separation between potable water and nonpotable liquids. (See Fig. 14-38 for a detail of typical heat exchanger piping.)

Heat exchangers must be designed to withstand increased corrosion, with some heat transfer fluids at elevated temperatures (i.e., ethylene and propylene glycol). Two specific precautions should be taken when an antifreeze solution is used. These are: 1) System piping must be cleaned and flushed before it is filled, and 2) Reaction of the solution with the inhibitor, sealants, and piping materials must be prevented (e.g., galvanized piping and chromate-based inhibitors should not be used with glycols).

Heat exchangers should be designed and constructed in accordance with the ASME Code for Unfired Pressure Vessels and be so stamped. 
Heat exchangers should be designed for a maximum 50 psig on both the primary and secondary sides, should be tested to $100 \mathrm{psig}$, and should be provided with ASME relief valves and drain valves.

Solar heating systems should be designed so that leaky dampers and thermosiphoning will not cause freezing of heat exchangers or water piping.

\section{Manif olding}

The supply and return manifolding for the collector array should be sized to provide uniform flow through the collectors. Satisfactory flow distribution will usually be achieved if the head loss through each collector is about $70 \%$ of the total head loss from A to B (Fig. 14-35).

It is also recommended that reverse return manifolding, as shown in Fig. 14-39 be used. This will aid in achieving uniform flow through the collectors. If uniform flow is not present, then some collectors will not perform as well as expected.

\section{Expansion}

Expansion and contraction of manifolding due to temperature changes has led to many problems in solar installations. The linear expansion of copper tubing is shown in the following table.
Table 14-13. Linear Expansion of Copper Tubing

\begin{tabular}{cc}
\hline Temperature Change $\left({ }^{\circ} \mathrm{F}\right)$ & Expansion (in./100 $\mathrm{ft})$ \\
\hline 0 & 0 \\
50 & 0.56 \\
100 & 1.12 \\
$150^{*}$ & 1.69 \\
200 & 2.27 \\
\hline
\end{tabular}

*Typical value.

Example. One system had a run of nearly $60 \mathrm{ft}$ consequently the daily movement was on the order of

$$
\begin{aligned}
x= & (1.69 \mathrm{in} / 100 \mathrm{ft})(60 \mathrm{ft}) \\
& 1.01 \mathrm{in.}
\end{aligned}
$$

The roof penetration was as shown in Fig. 14-40.

The size of the penetration had inereased significantly after a period of several months. This was discovered when the roof leaked. This could also lead to leaks developing in the piping.

This can be prevented by the following:

- Provide expansion loops and offsets (see Fig. 14-41)

- Expansion joints

- Slip type (require periodic maintenance)

- Bellows type (don't use in draining type system.)

- Flexible Hoses

- Have reliability problems

- Avoid long runs ?

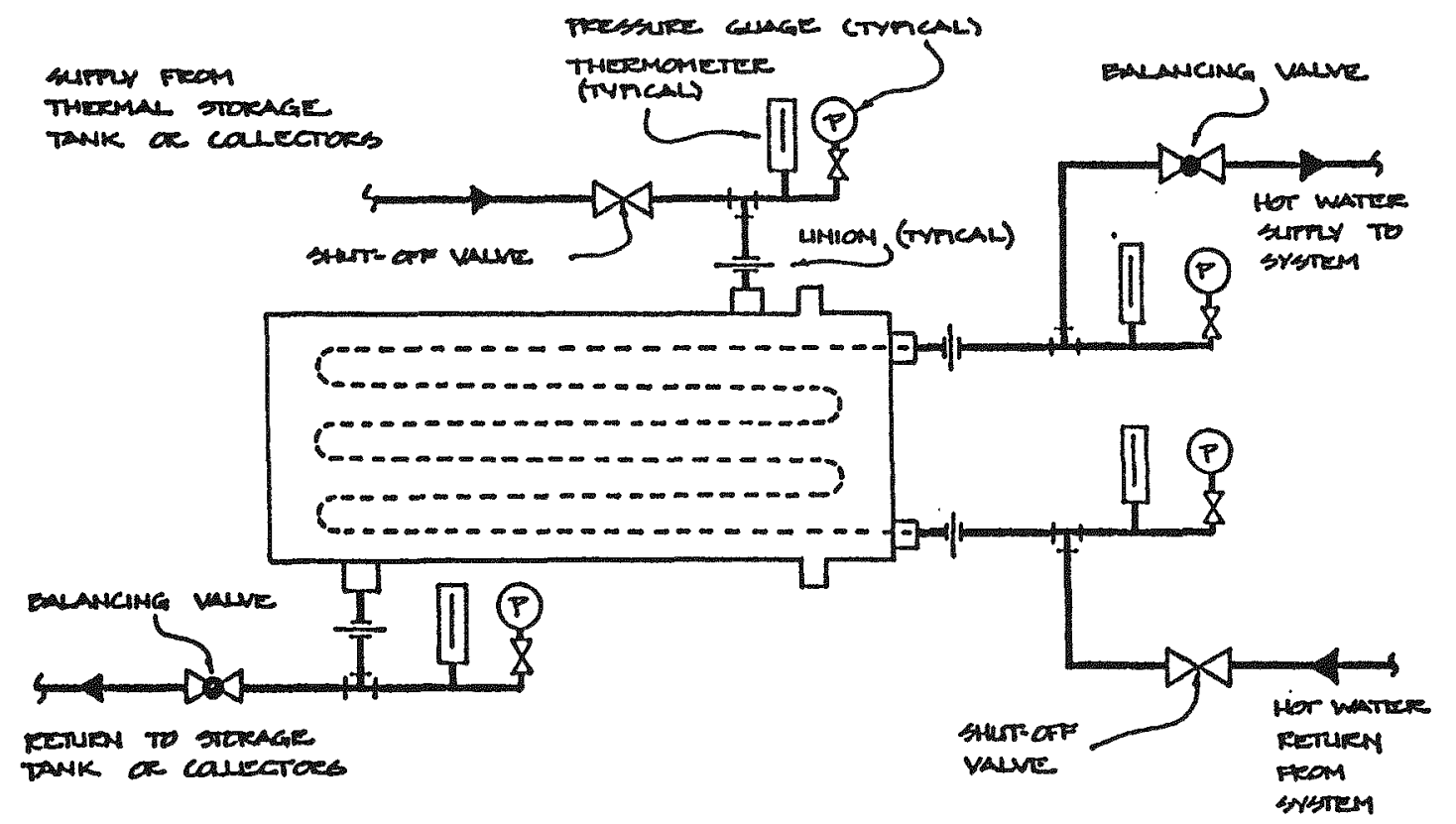

Fig. 14-38 . Heat exchanger piping detail. 


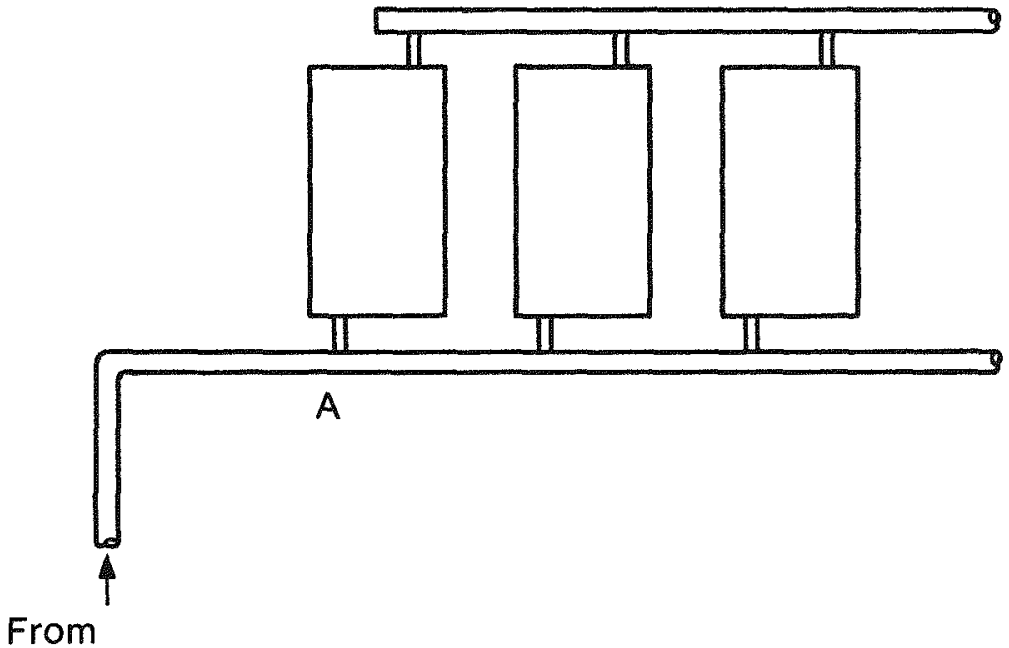

Equipment

Room

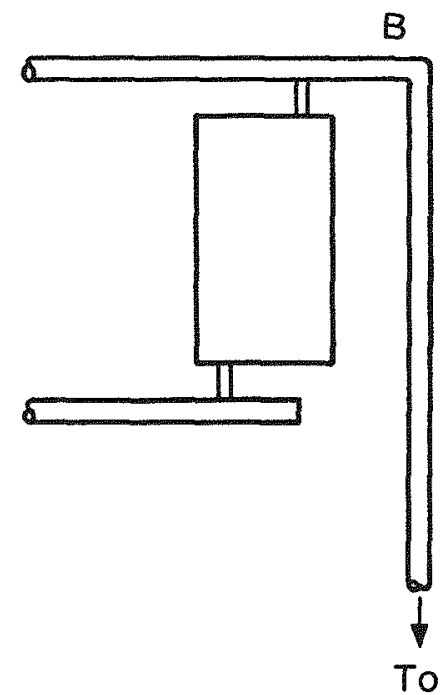

Equipment Room

Fig. 14-39 . Exterior manifolding

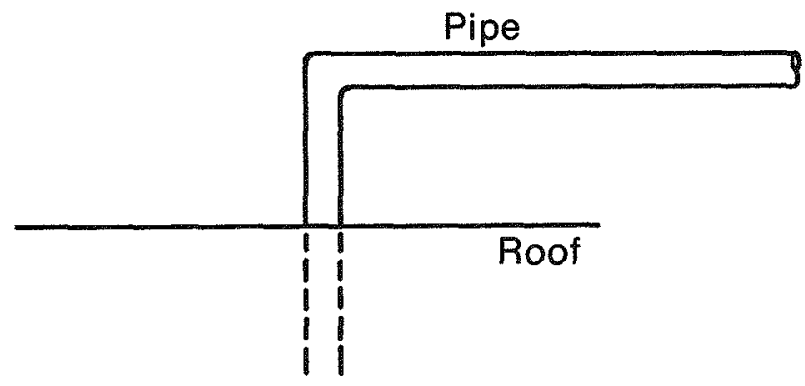

Fig. 14-40. Pipe without allowance for expansion

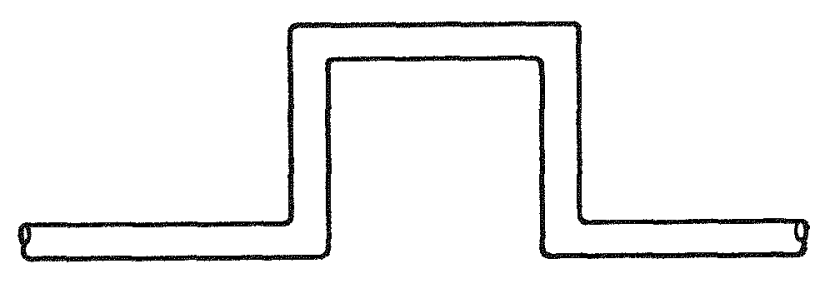

Fig. 14-41. Expansion loop in pipe 


\section{Pipe Sizing}

The sizing and arrangement of the piping in a liquid solar system can have 8 very important effect on its performance. In an active system it is critical that piping is sized correctly so that suitable velocities, mass flow rates, and pressure drops are achieved at specific points throughout the system with reasonable pump sizes. In certain passive systems, such as thermosiphon DHW layouts, the proper choice of piping sizes will, by itself, determine temperature differentials, flow rates, and collector efficiencies. In any system the improper selection of a pipe size can result in system noise, inefficiency, insufficient flow rates, air entrainment, and erosion problems.

The basis for calculating collector loop pipe size is derived from the mass flow rate requirement (as determined by collector flow rate recommendations) and the desired flow velocities through the pipe section. Note that throughout this section we will only be concerned with clean metal pipe (proper for most closed loop arrangements) and assume pressure drops as stated in the various sources of pressure drop data as listed in the ASHRAE Handbook of Fundamentals, 1977.*

The more popular method of determining piping sizes for solar systems is that of designing for now velocity. This will allow us to choose the fluid exchange time between the various components (e.g., heat exchangers and collectors) and assure even flow distribution in the manifolds, headers, and collectors without the need for balaneing valves. The lower and upper limits for design flow rates are: (1) no less than 2 fps in pipe sizes 2 in. and under, and minimum velocities corresponding to $0.75 \mathrm{ft}$ of water head per $100 \mathrm{ft}$ of pipelength for pipe sizes 2 in. and above; and (2) typically no more than 4 fps will be designed for sizes 2 in. and under, although higher velocities may be used for larger pipes. The lower velocity limits will be determined by free air purge requirements, particularly near areas of possible cavitation (formation of air pockets and bubbles), and

*1. Hydraulic Institute Pressure Drop Tables (available from the Hydraulic Institute), which are based on the Fanning equation with $60 \mathrm{~F}\left(15.5^{\circ} \mathrm{C}\right)$ water, and list gpm vs. pressure drop in feet of water head per $100 \mathrm{ft}$ of pipe length.

2. Pipe Head Loss Charts based on Hydraulic Institute data are shown in this chap ter. The charts are stated in English ( $\mathrm{ft} / 100 \mathrm{ft}$ vs. $\mathrm{gpm}$ ) and contain metric conversion (meter/100 meter vs. cubic meter per hour).

3. Copper Tubing Head Loss Charts are also shown in both English and metric units and are again based on $60 \mathrm{~F}\left(15.5^{\circ} \mathrm{C}\right)$ for a base viscosity reference.

4. Geisecke Chart, long used to express pressure drop for LTW systems, was developed by Dr. F. E. Geisecke in cooperative research with ASHVE at the University of Texas. The chart shows gpm or MBh heat conveyed at a $20 \mathrm{~F}$ drop vs. pressure drop in milinches per $\mathrm{ft}$. The chart compares numerically to the Hydraulic Institu te values for $60 \mathrm{~F}$ water. lower pressures (highest points in the system and in downcorner return mains). The upper limits are needed to reduce erosion and possible noise problems. Velocity noise in most systems is caused by free air, not water, in areas of sharp pressure drops and low static pressures. Where hydronic systems have been carefully designed to maintain high static pressures and remove entrapped air, the flow velocities may be increased.

When flow velocities and mass transfer rates have been determined, it is then possible to calculate piping friction losses which will be necessary for selecting the appropria te pump size and capacity.

Example. Say we have $16 \mathrm{gpm}$ flowing in the collector loop; use Type L (Residential).

$\begin{array}{ccc}\text { Tube Size (in.) } & \Delta p\left(f t \mathrm{H}_{2} 0 / 100 \mathrm{ft}\right) & \mathrm{V}(\mathrm{ft} / \mathrm{sec}) \\ 1.0 & 17 & \\ 1.5 & 2.8 & 6.5 \\ 2.0 & 0.66 & 3 \\ & & 1.7\end{array}$

It is also important to calculate the head loss in plumbing fittings and piping; a nomogram and chart that are useful for this purpose are shown in Figs, 14-39 to 14-41. The ASHR AE Handbook of Fundamentals also includes a table for this purpose.

A rule of thumb for head loss in a pipe elbow is:

$$
\Delta p(f t)=2 D(i n)
$$

e.g.g A $1.5^{\prime \prime}$ tube would have $v=3 \mathrm{ft} / \mathrm{sec}$.

Check with the nomogram: get $3.9 \mathrm{ft}$ of equivalent length.

Check Table (at $3 \mathrm{ft} / \mathrm{sec}$ ): $\quad \mathrm{p}=4.2 \mathrm{ft}$

\section{Air Removers}

Air should be removed for the following reasons:

- Prevent corrosion

- Prevent noise

- Prevent cavitation

- Prevent air locking which inhibits flow.

Also, a strainer sereen should be included to remove solid particles.

\section{Expansion Tanks}

Expansion tanks provide room for expansion due to thermal effects. When placed upstream of pumps, they provide a positive head to the suction side of the pump. This helps to prevent cavitation in the low pressure region on the suction side of the pump. Cavitation causes rapid deterioration of the pump impeller and housing due to erosion caused by vapor bubbles. 


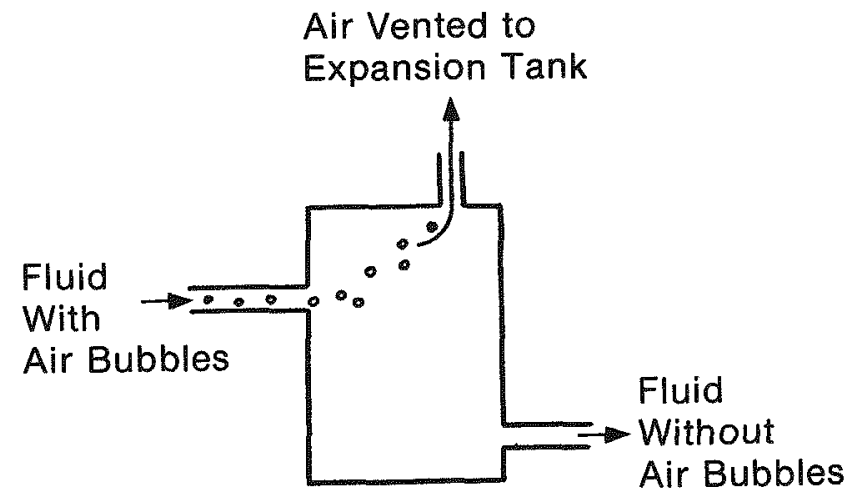

\section{Schematic diagram of an air remover}

\section{Considerations for Expansion Tanks}

- Provide for at least 3 to $5 \mathrm{psia}(21-34 \mathrm{kPa})$ at the top of the system for positive venting at initial fill.

- Allow a safety margin of $15 \mathrm{~F}$ above maximum operating temperature for flash protection.

- Calculate maximum operating pressures at system components with pump in operation (i.e, add or subtract pump pressures from maximum allowable pressures).

- Connect the expansion tank to the suction side of pump.

- Connect standard tanks to points of highest te mperature and lowest pressure.

- To reduce tank size:

- Increase the maximum allowable pressure,

- Reduce initial pressures (i.e., elevate the tank),

- Use diaphragm tanks,

- Mechanically pressurize standard tanks at initial fill, and

- Be certain the expansion tank is sized sufficiently to allow for thermal expansion of the particular fluid being used over the widest temperature range expected during system operation.

- Raise the initial fill temperature before sealing.

- Verify the pump suction pressure at maximum operating temperature.

- Do not install shutoff valves in connection lines.

- Do not insulate.

\section{Valves}

- Gate valves - used to isolate pipe sections or components. Have low $\Delta \mathrm{p}$ in normal mode.
- Control valves (circuit valves) - used to set flows at the specified flow rates.

- Check valves - used to prevent reverse flow and eliminate thermosiphoning.

- Pressure relief valves - used to protect system components from extreme pressures.

- Pressure and temperature relief valves are used to protect the system from extreme pressures and temperatures.

\section{Additional Considerations}

- Pressure relief valves should not discharge antifreeze fluids onto asphalt or built-up roofing. Relief valves should be piped to safe disposal locations.

- For drain-down systems, make sure that the type of balancing valve chosen will not trap water when partially closed for balancing. Make sure pipes are adequately supported to prevent sagging.

\section{Gauges}

Pressure and temperature gauges (or fittings for them) should be installed at several points throughout the system in order to make it easy to check the system performance.

\section{Pumps}

Centrifugal pumps are best suited for liquid-heating solar systems. Typical performance curves for a centrifugal pump are shown in Fig. 14-42.

The "head" is the pressure generated by the pump expressed in feet of water and is the difference in pressure between the suction and discharge sides. The head generated by the pump is also equal to the sum of the pressure drops across the piping and all other components of the circulation loop. The efficiency of the pump is the ratio of fluid (or brake) power generated by the pump, divided by the electrical power delivered to the motor. From the curves in Fig. 14-42 it is readily seen that pumps should be chosen to circulate the desired flow rate at required head to operate near peak efficiency (also covered in Chapter 5). The size of motor needed for the pump is determined by the brake horsepower and pump efficiency

Since the head produced by a pump is exactly balanced by the head losses in the system, it is necessary to estimate the head losses in the piping loops, across collectors, and through heat exchangers before selecting pumps. A chart for estimating friction losses in copper tubing is shown in Fig. 14-40. Similar charts are available for other types of piping from suppliers. A nomograph for estimating head losses across valves and fittings is shown in Fig. 14-39. Head losses for collectors and heat exchangers are given in manufacturer's catalogs and brochures.

To estimate head losses in a particular loop a piping layout (schematic) should be made with valves, fittings, filters, and other components shown in the loop. Pipe sizes should be selected so that flow velocities will not exceed about $7 \mathrm{ft} / \mathrm{sec}$. With discharges selected and pressure losses calculated for each circulation loop, pump, selections can be made from manufacturer's catalogs. 


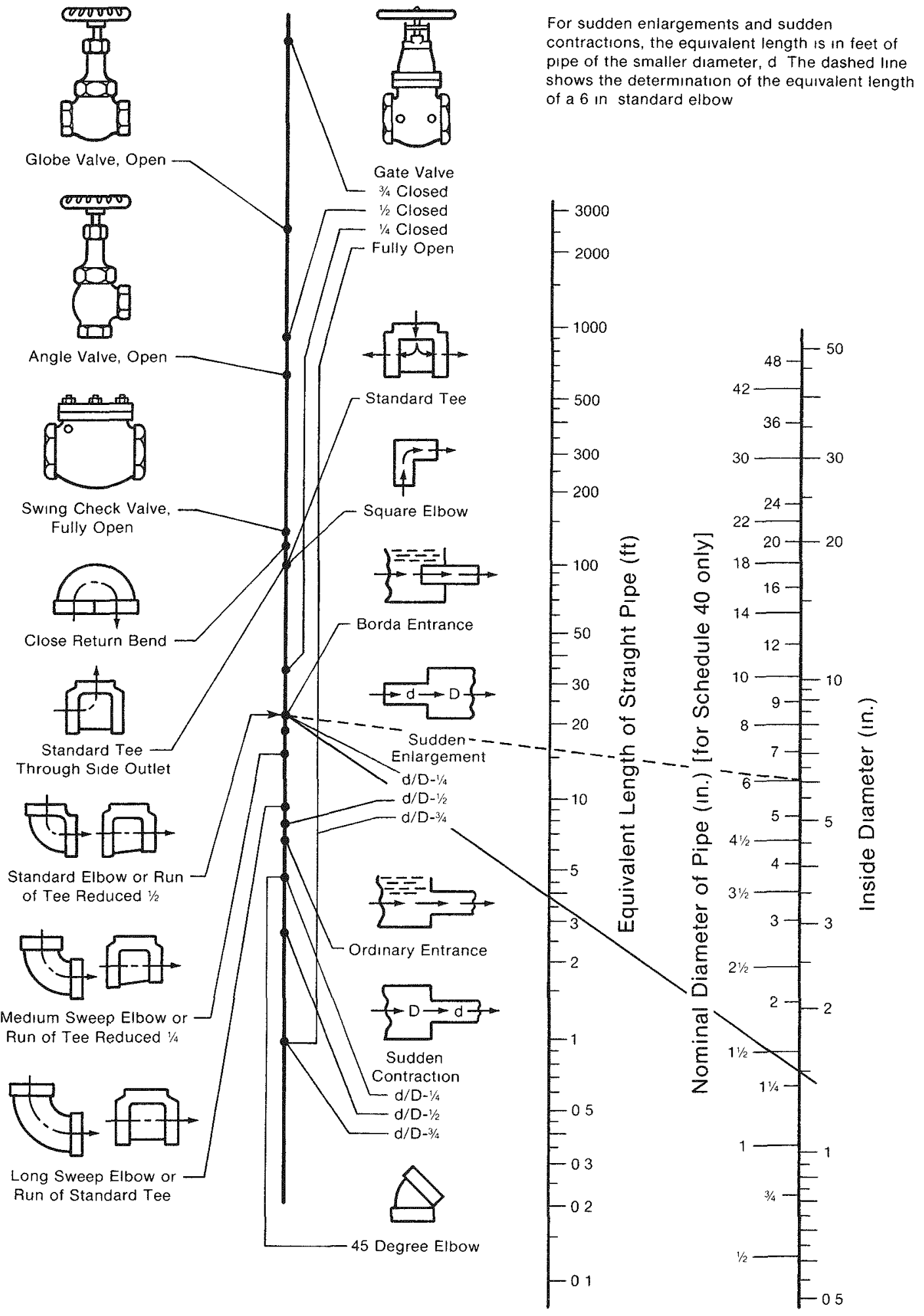

Fig. 14-42. Pressure Loss in Various Elements

(Source: Solar Heatıng and Coolıng of Residentıal Buıldıngs Desıgn of Systems) 


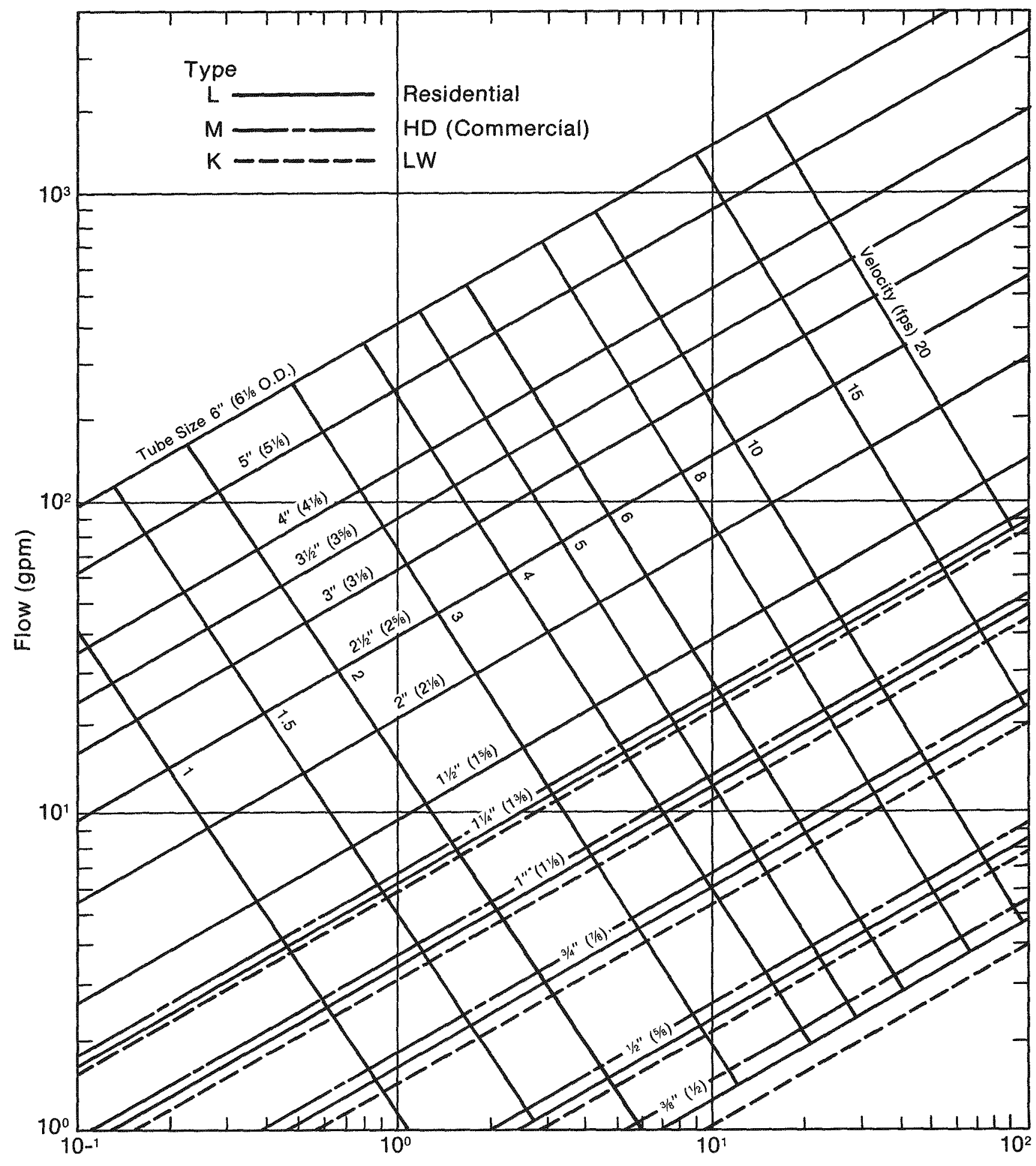

Friction Loss (feet of water per $100 \mathrm{ft}$ )

Fig. 14-43. Friction Loss in Copper Tubing 
Flow of Water in Gallons per Minute

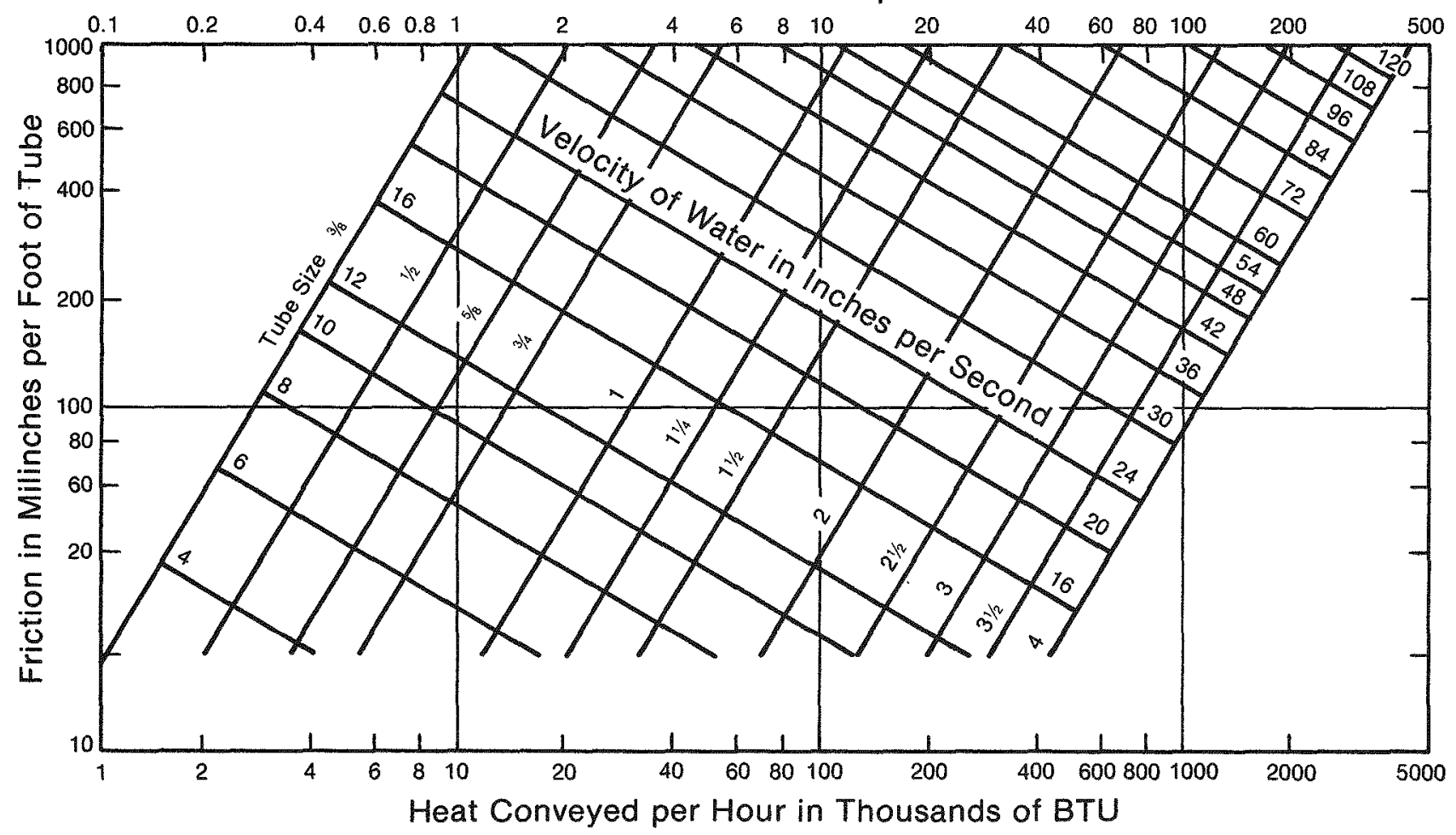

Lower scale of chart is based on 20-deg temperature difference between flow and return risers. To find friction when temperature drop is other than 20 deg, multiply the actual heat conveyed by $(20+$ actual temperature drop) and read the corresponding friction.

Conversion $\mathrm{Ft} /(100 \mathrm{Ft})$ to Milinches $/ \mathrm{Ft}$

Ft per $100 \mathrm{Ft} \quad 0.5 \quad 1 \quad 2 \quad \begin{array}{llll}3 & 4 & 5\end{array}$

Milinches per Ft $60 \quad 120 \quad 240 \quad 360 \quad 480 \quad 600$

Fig. 14-44. Friction Loss due to Flow of Water in Type L Copper Tube

(Source: ASHRAE Handbook of Fundamentals) 


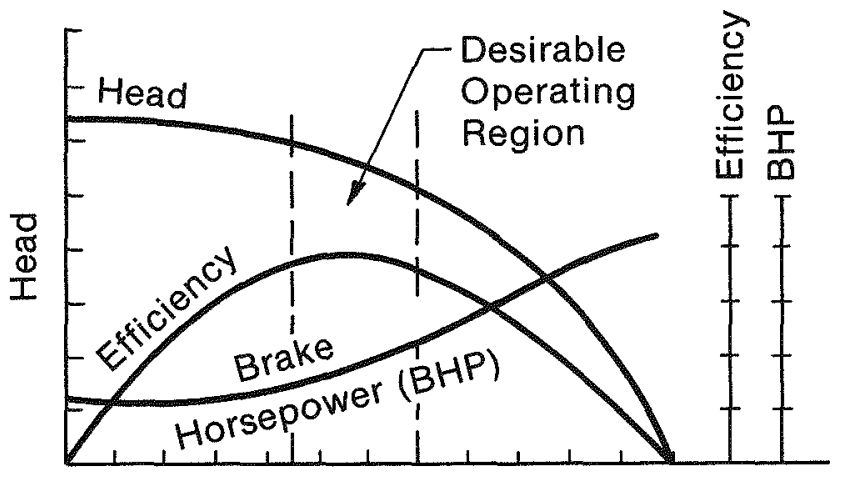

Discharge

\section{Additional Considerations}

- Closed loops may use a circulator pump with an iron housing, while open loop systems must incorporate a pump in which all parts in contact with water are manuf actured of stainless steel or bronze. The use of the stainless steel circulator has eliminated many of the rust corrosion problems of bronze-lined pumps used in open and potable systems. Stainless steel pumps now compete with bronze-lined pumps in cost.

- Close-coupled pumps should be avoided to prevent heat transfer from the fluid through the shaft to the motor, a factor which could cause motor overheating.

Table 14-15. INSULATION THICKNESS

\begin{tabular}{|c|c|c|c|}
\hline \multirow[b]{2}{*}{ Service } & \multicolumn{2}{|c|}{ Pipe Size } & \multirow{2}{*}{$\begin{array}{c}\text { Insulation } \\
\text { Density } \\
\text { (lb/cu ft) }\end{array}$} \\
\hline & $\begin{array}{l}1-1 / 4 \\
\text { (in.) }\end{array}$ & $\begin{array}{l}1-1 / 4 \\
\text { (in.) }\end{array}$ & \\
\hline Cold water & 1 & $1-1 / 2$ & 4 \\
\hline Hot water & 1 & $1-1 / 2$ & 4 \\
\hline Glyeol or equal & 2 & 2 & 4 \\
\hline Outdoors & 2 & 2 & 4 \\
\hline Chilled water & 1 & 2 & 4 \\
\hline \multirow{3}{*}{$\begin{array}{l}\text { Exposed in } \\
\text { mechanical room } \\
\text { Underground solar } \\
\text { piping }\end{array}$} & & & \\
\hline & $1-1 / 2$ & 2 & 7 \\
\hline & 2 & 3 & $\begin{array}{c}K=0.78 \text { or } \\
\text { less }\end{array}$ \\
\hline
\end{tabular}

Modular pumps for one-third to two-thirds of the load where the system permits reduction in water volume should be selected. The larger pump may be of variable volume to give complete modulation over the entire range of loads.

- Some pumps are not self-priming. They require a minimum of $3 \mathrm{ft}$ of static head on the inlet side at all times. This ensures adequate fluid for bearing lubrication. Failure to provide this static head will result in bearing seizure and pump failure.

- The following should be assured:

- That the pump be constructed of vertically split casing with screwed connections in connector sizes 2 in. and smaller, flanged in sizes $2-1 / 2$ in. and larger;

- That pressure gauge tappings are in all flanges;

- That internal parts be serviceable without disturbing piping;

TabIe 14-14. UPPER TEMPERATURE LMTTS FOR INSULATION MATERIAIS FOR COLLECTORS, TANKS, PIPE, AND FITTLNGS

\begin{tabular}{|c|c|c|c|}
\hline $\begin{array}{l}\text { Density } \\
\text { Material }\end{array}$ & $\begin{array}{l}\text { Thermal } \\
\text { Conductivity } \\
\text { at } 200 \mathrm{~F} \\
\text { (lb/cu ft) }\end{array}$ & $\begin{array}{c}\text { Temperature } \\
\text { (Btu/hr-sq ft-F/in.) }\end{array}$ & Limits (F) \\
\hline Fiberglass with Organic Binder & $\begin{array}{l}0.6 \\
1.0 \\
1.5 \\
3.0\end{array}$ & $\begin{array}{l}0.41 \\
0.35 \\
0.31 \\
0.30\end{array}$ & $\begin{array}{l}350 \\
350 \\
350 \\
350\end{array}$ \\
\hline Fiberglass with Low Binder & 1.5 & 0.31 & 850 \\
\hline Ceramic Fiber Blanket & 3.0 & 0.4 at $400 \mathrm{~F}$ & 2300 \\
\hline Mineral Fiber Blanket & 10.0 & 0.31 & 1200 \\
\hline Calcium Silicate & 13.0 & 0.38 & 1200 \\
\hline Urea-Formaldehyde Foam & 0.7 & 0.20 at $75 \mathrm{~F}$ & 210 \\
\hline Urethane Foam $\quad 2-4$ & 0.20 & $250-400$ & \\
\hline
\end{tabular}


- That the enclosed centrifugal impeller be balanced statically and dynamically;

- That the sleeve bearings be oil-lubricated;

- That the shaft be constructed of stainless steel;

- That mechanical seals be suitable for $225 \mathrm{~F}$ or maximum operating temperature, whichever is higher;

- That the coupling be of a spring type and flexible; and

- That the pump be factory tested to $150 \%$ of design pressure hydrostatically.

\section{Insulation}

Insulation should be applied after all piping, fittings, and equipment are pressure tested. fiberglass insulation is the preferred and most frequently used; but ureaf ormaldehyde foam, urethane foam, calcium silicate, and other materials where appropriate can be used. Refer to Table 14-14 for upper temperature limits of insulation materials.

\section{Pipe Insulation}

Based on fiberglass, all pipe insulation should have a $\mathrm{k}$ value (thermal conductivity) not to exceed $0.23 \mathrm{Btu}$ in./sq $\mathrm{ft} \mathrm{hr}-\mathrm{F}$ at a mean temperature of $75 \mathrm{~F}$ in accordance with the preceding schedule for thickness (Table 14-15).
Composite insulation, jacket, and adhesive should bear underwriter's label, have flame spread of 25 or less, and smoke developed rating of 50 or less, conforming to ASTM-E-84 and NF PA 225.

All exterior glycol solution supply and retum piping (other than buried) installed in connection with solar installation should be wrapped, after insulation, with two layers of $30 \mathrm{lb}$ roofing felt and finished with weatherprof plastic reinforced with glass membrane.

Fittings, valves, strainers, etc., should be insulated with flexible fiberglass blanket $2-4 \mathrm{lb}$ density, to thickness equal to adjoining pipe insulation and finished with a smoothing coat of insulating and finishing cement.

Underground piping should have sufficiently sealed closed-cell insulation to render it permanently waterproof. It should be protected against undue compaction. Backfilling with sand and keeping pipes below frost line and away from rocks and construction debris are standard practice.

\section{System and Component Details}

The following section includes diagrams illustrating typical detailing for liquid systems and components. It is far from complete. Included are details on drain-down system piping, collector piping, expansion tank piping, heat exchanger piping, in-line pumps, and water storage tanks. Details on air or passive systems are not included.

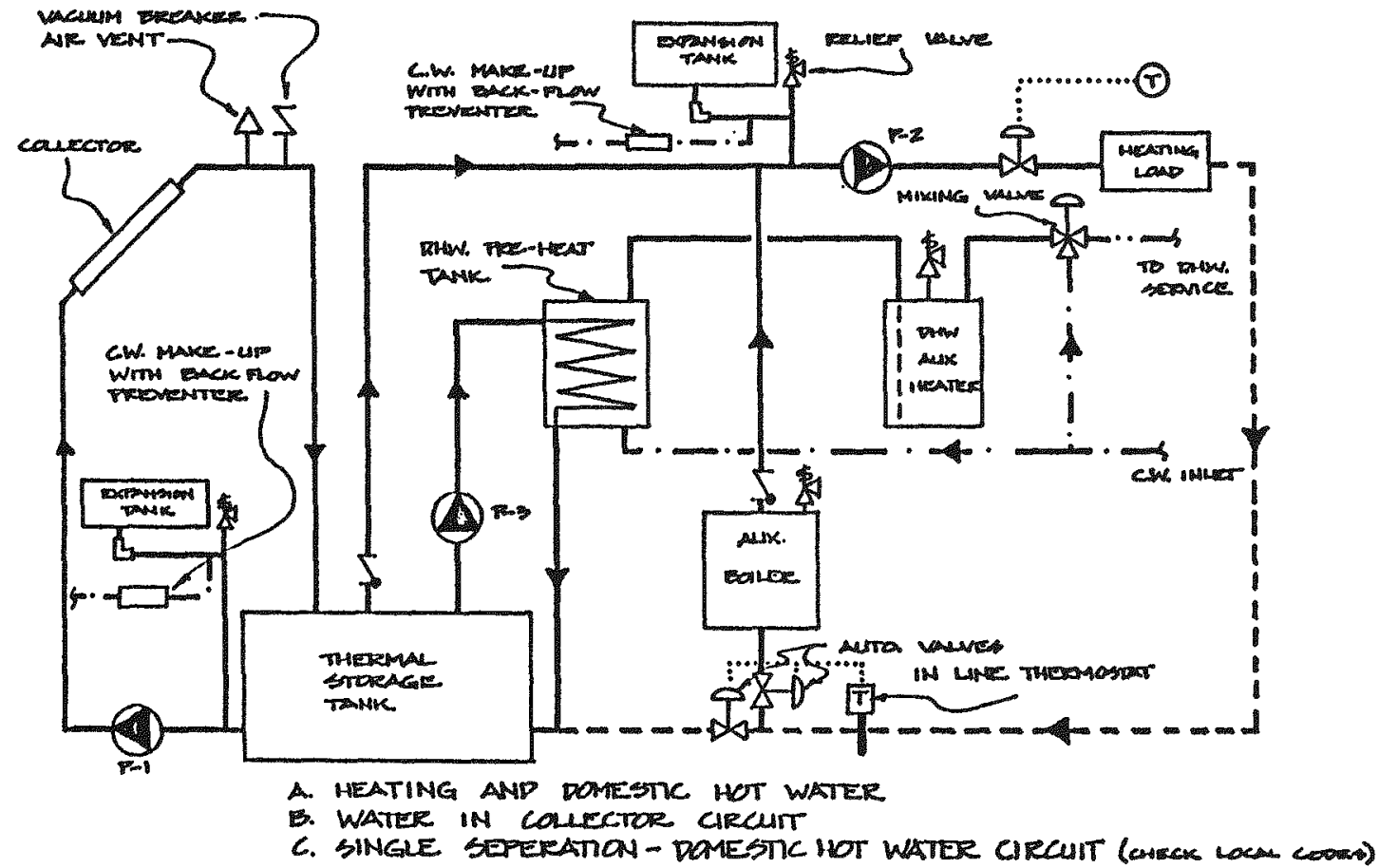

Fig.14-46 Schematic Solar System Flow 


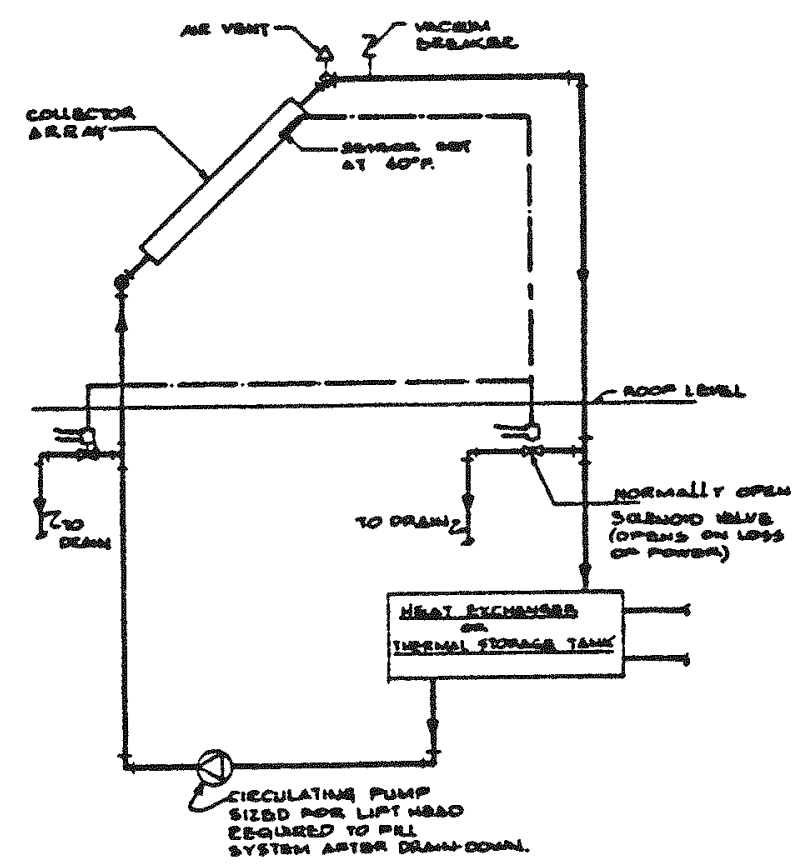

Fig. 14-47. Typical Drain-Down System Piping

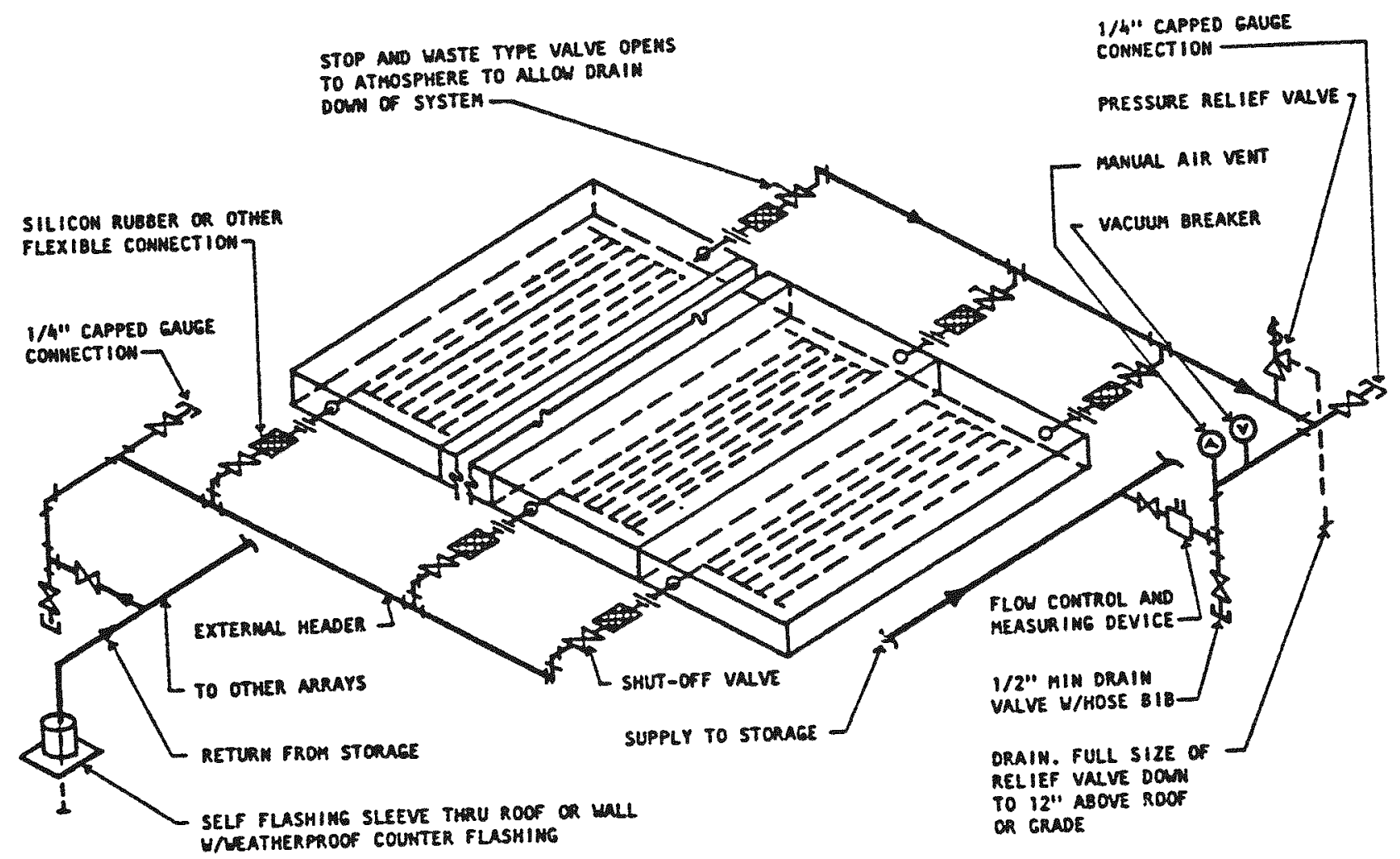

Fig. 14-48. Piping Detail of Solar Collectors with External Headers 

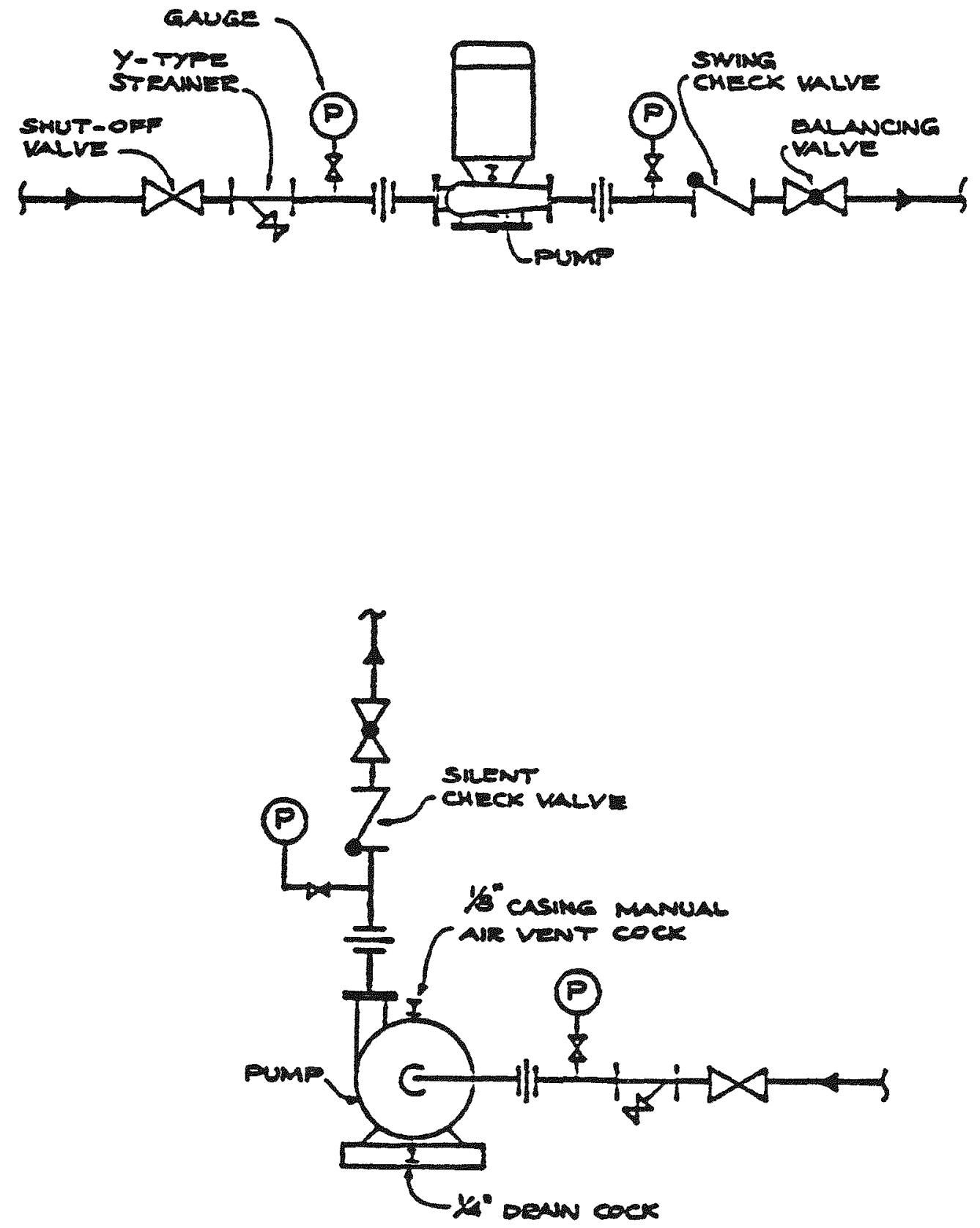

Fig. 14-49. Typical Piping Details of an In-Line Centrifugal Pump 


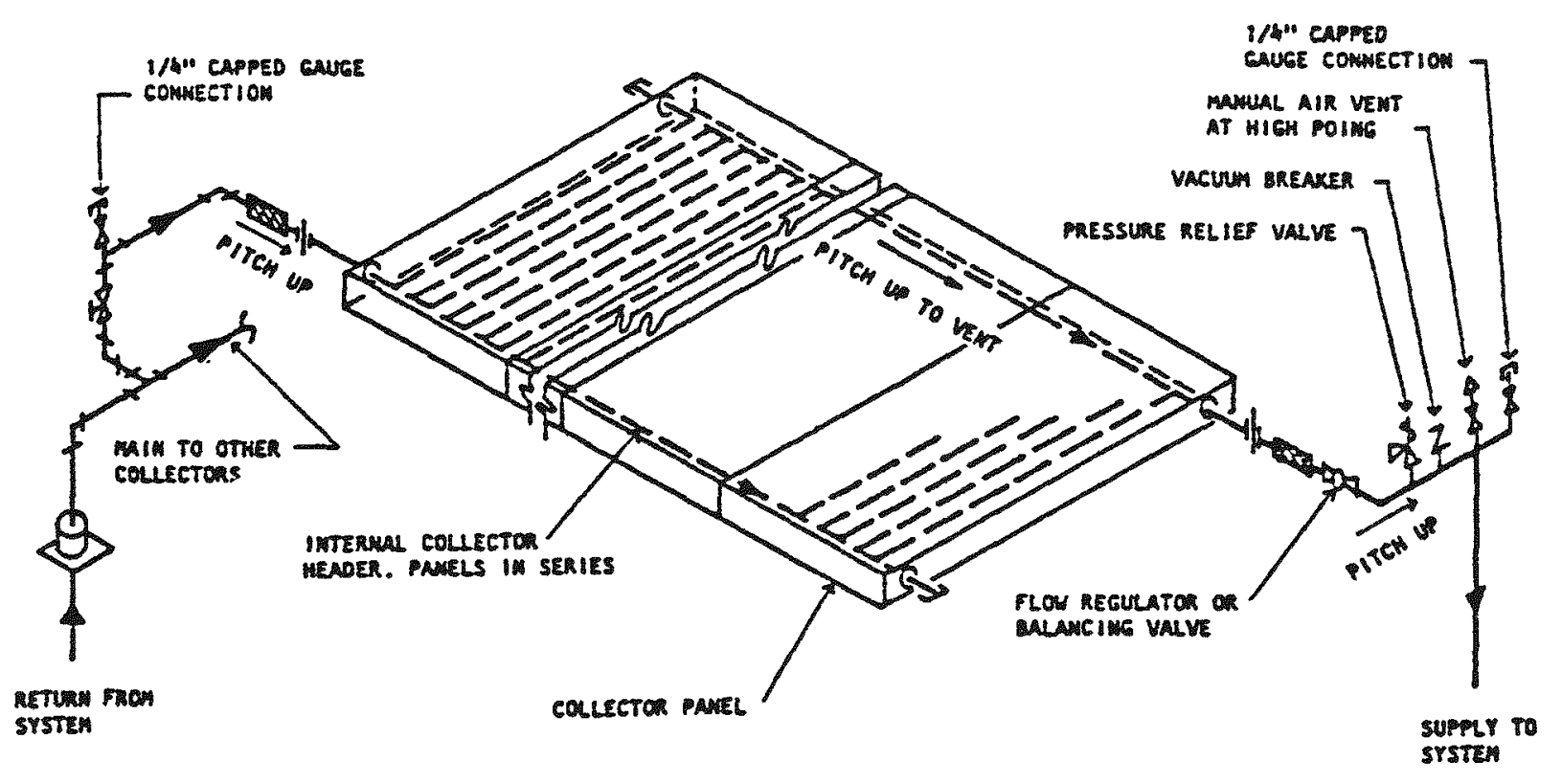

Fig. 14-50. Piping Detail of Solar Collectors with Internal Headers.

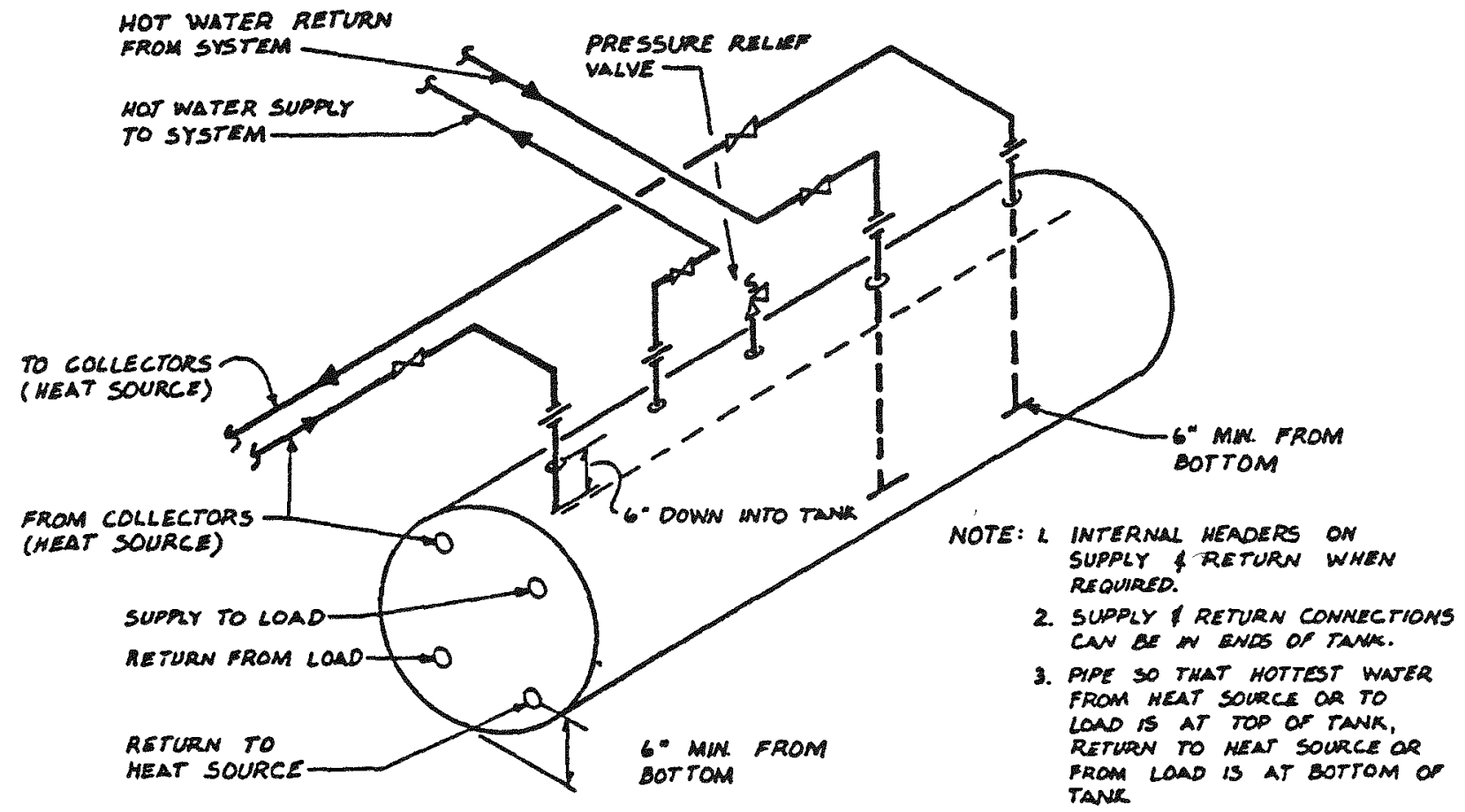

Fig. 14-51. Typical Thermal Storage Piping Detail 


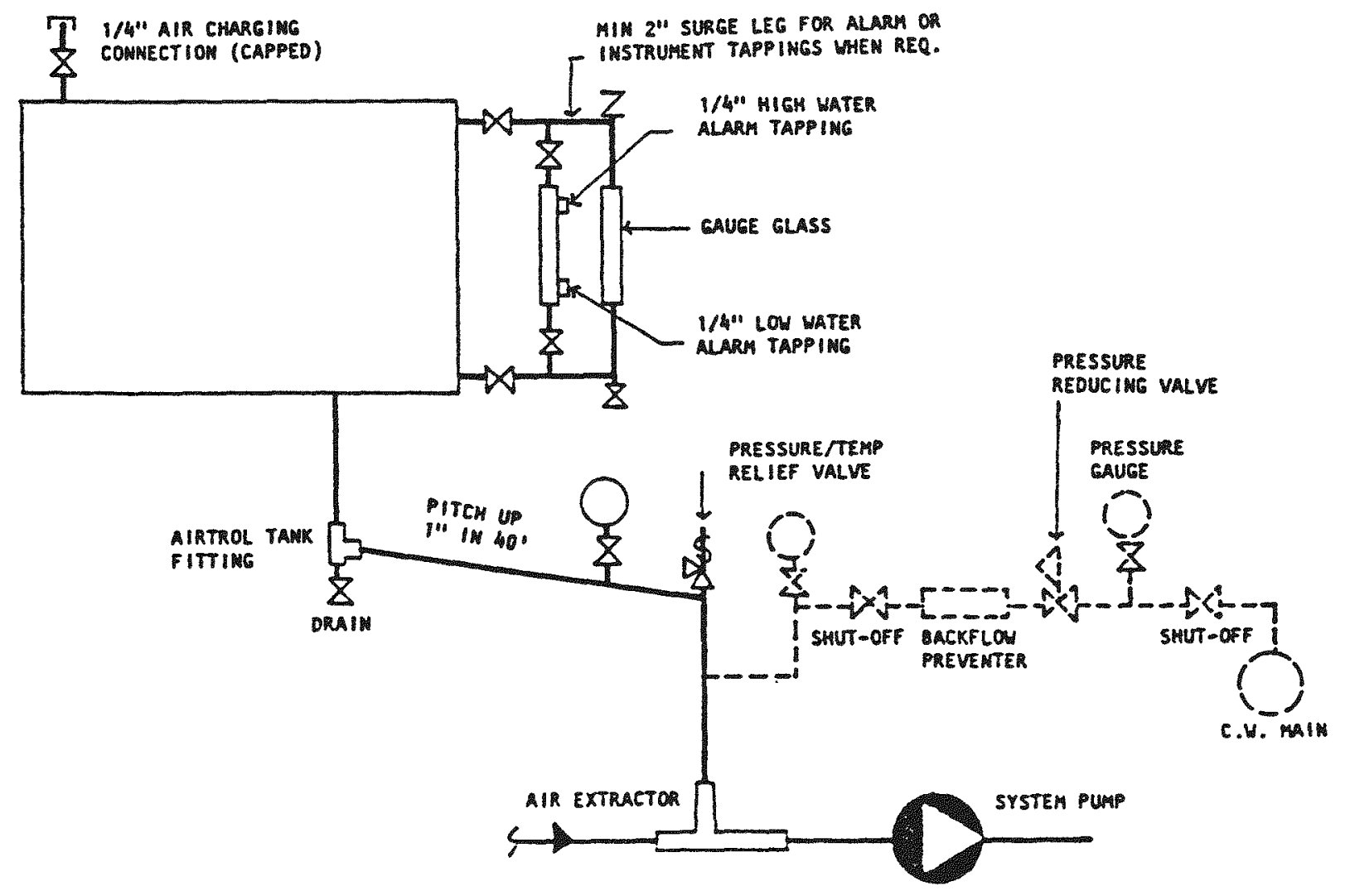

Fig. 14-52. Typical Closed Expansion-Tank Piping Details

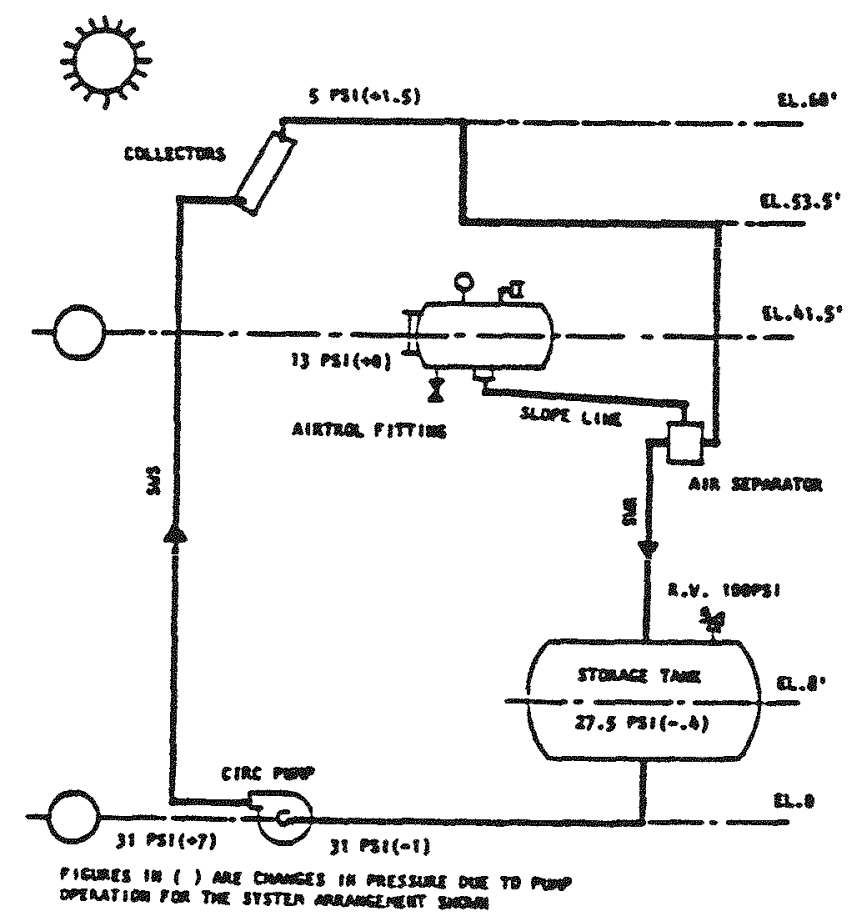

Fig. 14-53. Closed System Diagram with Typical Operating Pressures 
Architectural Concerns in Solar System Design and Installation

The Ehrenkrantz Group, Architects and Planners (TEG), has been active in the National Solar Data Program by participating in solar design research and analysis as subcontractors to PRC Energy Analysis Company in management support work for the Department of Energy (DOE). TEG has performed over 100 design reviews for DOE during the last 18 months. This has provided TEG the opportunity to witness, firsthand, the types of physical problems solar designers have been confronting in the design of solar energy systems. TEG's experience has included both the review of contract documents and onsite inspection of these facilities which have been sponsored by DOE's National Solar Heating and Cooling Demonstration Program.

This section articulates the physical (rather than the mechanical or electrical) aspects involved in the design and installation of solar systems. It also addresses the typical physical factors and problems encountered in design. In addition, it comments upon the cost effectiveness of various approaches.

This section discusses design characteristics of the collector and storage loops, using existing technology, and is unrelated to the specific application of the solar energy collected (i.e., the demand loop-whether building service hot water (BSHW), heating, or cooling-is not covered in this discussion). Rather, it details DOE's specific experience relative to what solar designers nationwide are designing in the installation of solar collectors, array structures, piping, and storage equipment, with particular emphasis on cost-effective alternatives.

It is anticipated that through the sharing of this knowledge of the state of the art in solar systems, there will be an increase in the use of solar energy throughout the United States.

\section{Collector Selection}

What factors must be considered in selecting the "best" collector for a project? Obviously, the overall collector efficiency, based on the expected load profile, is of prime importance. However, once the total net collector area requirement has been defined, there are still probably 10 to 50 different collectors available to fit these requirements.

What secondary attributes might affect collector choice? If cost is important, the decision should rest on the lowest cost per Btu of an installed collector.

The size and construction of different collectors can have considerable impact on their installed cost. For instance, collectors with larger areas usually cost less per square foot to install than smaller collectors because a greater net area is being installed with approximately the same amount of work. Depending on their location and support design, taller collectors tend to be cheaper to install because they require fewer vertical supports and, therefore, fewer roof penetrations into flat roofs and fewer footings for field-mounted installations.
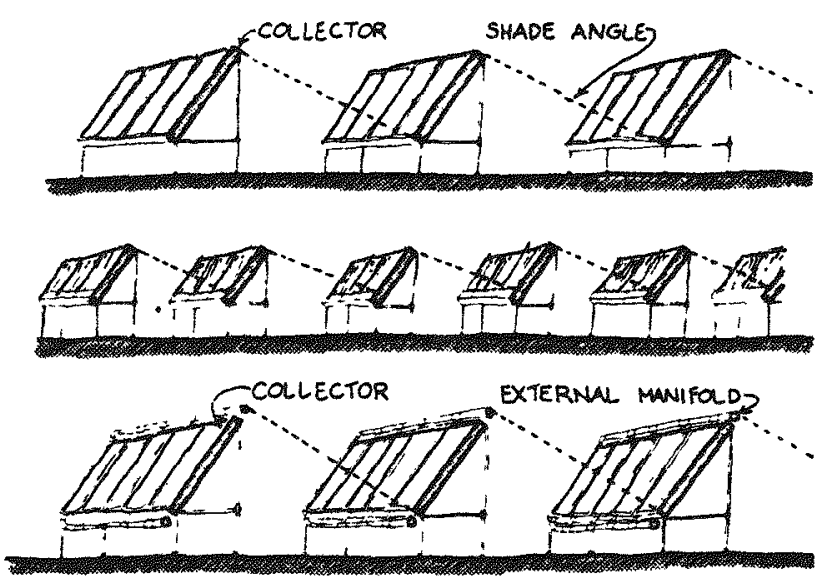

\section{Fig. 14-54. Collector size affects cost and row spacing}

A good rule of thumb for determining the distance between the rows seems to be that the shade angle should not greatly exceed the angle of the Sun on December 21, at noon. The highest continuous obstruction on the southern row shall not cast a shadow on the lower glass opening of the next row. This means that if exterior manifolds are used, the top of the manifold must be considered, not the top of the collector. Of economic interest is the fact that collectors with exterior $m$ anifolds tend to cost more to install than collectors with interior manifolds.

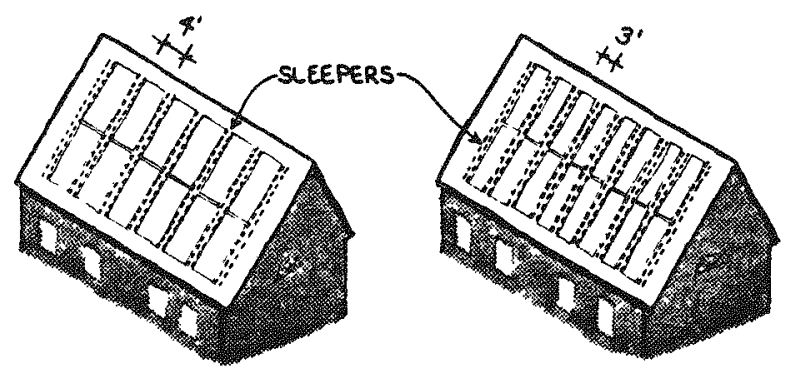

Fig. 14-55. Pitched roof considerations

On a pitched roof, wider collectors tend to require less wood blocking and can, therefore, be more cost effective.

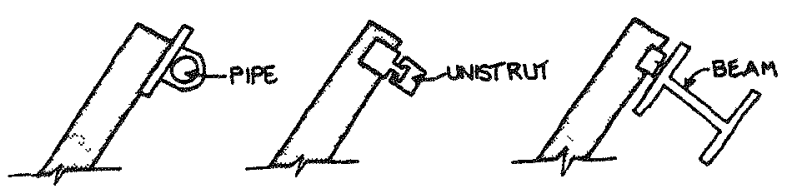

Fig. 14-56. Special attachment hardware 
Collector attachment details can also have a cost impact. Some collectors require special structural connections, such as pipe or Unistrut. If these special connections cannot be made integral parts of the structural support, they constitute extra cost. This will detract from the cost effectiveness of the particular collector. Therefore, it is important to review the connection requirements for the collector prior to designing the structure. Careful design can maximize the collector's capabilities (e.g., careful design can accommodate requirements such as type or location of supports).

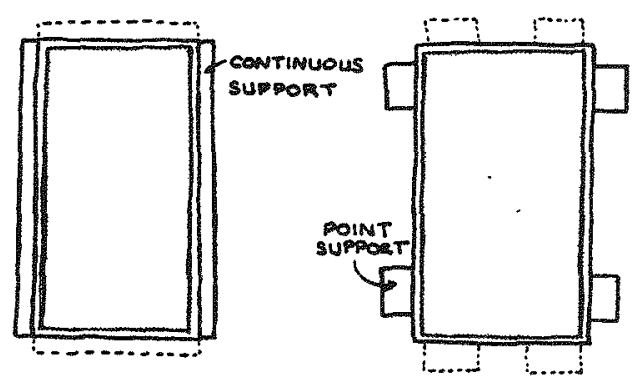

Fig. 14-57. Collector anchorage points

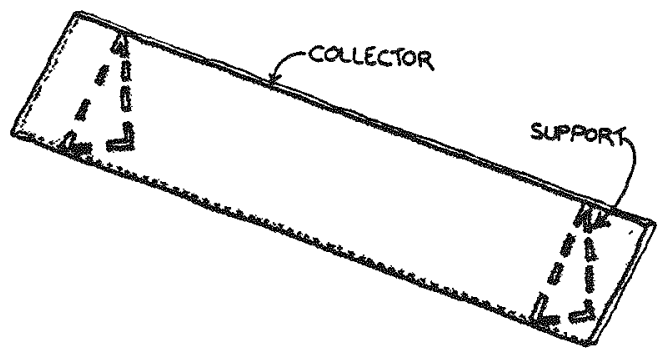

Fig. 14-58. Support requirements

Regardless of the type of collector and support used, you must prevent differential metals from coming in contact with each other and causing deterioration resulting from galvanic action. Place nonmetallic material between the different metals. Bitumastic materials, neoprene, and teflon are examples of materials that have been used successfully.

The designer should also consider the aesthetic implications of solar designs relative to scale, support design, and piping arrangement. Many designs we have reviewed did not include elevation drawings. The designers would receive a rather unpleasant surprise at the system's appearance if the system were built as designed.

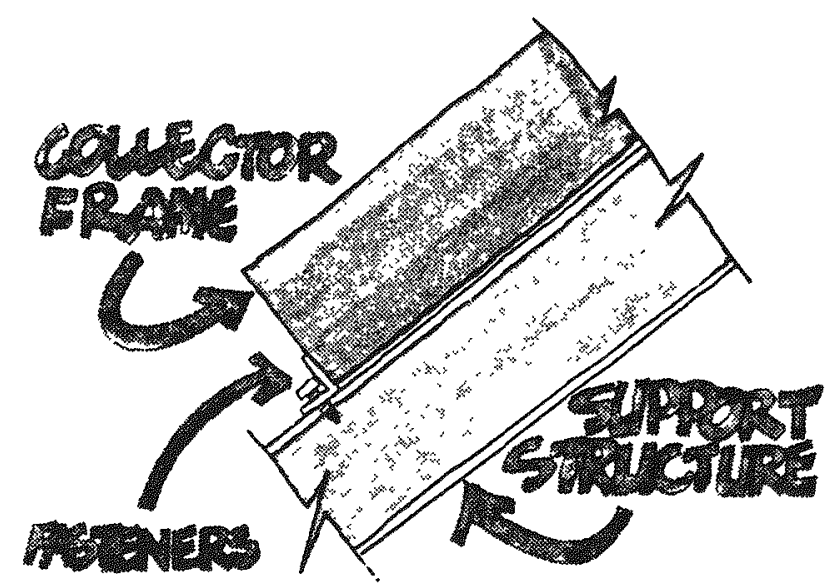

Fig. 14-59. Differential metals

A review of past performance is important if tracking collectors are being considered. These collectors do have substantially higher performance in direct sun, but they depend on motors and other moving parts. There are
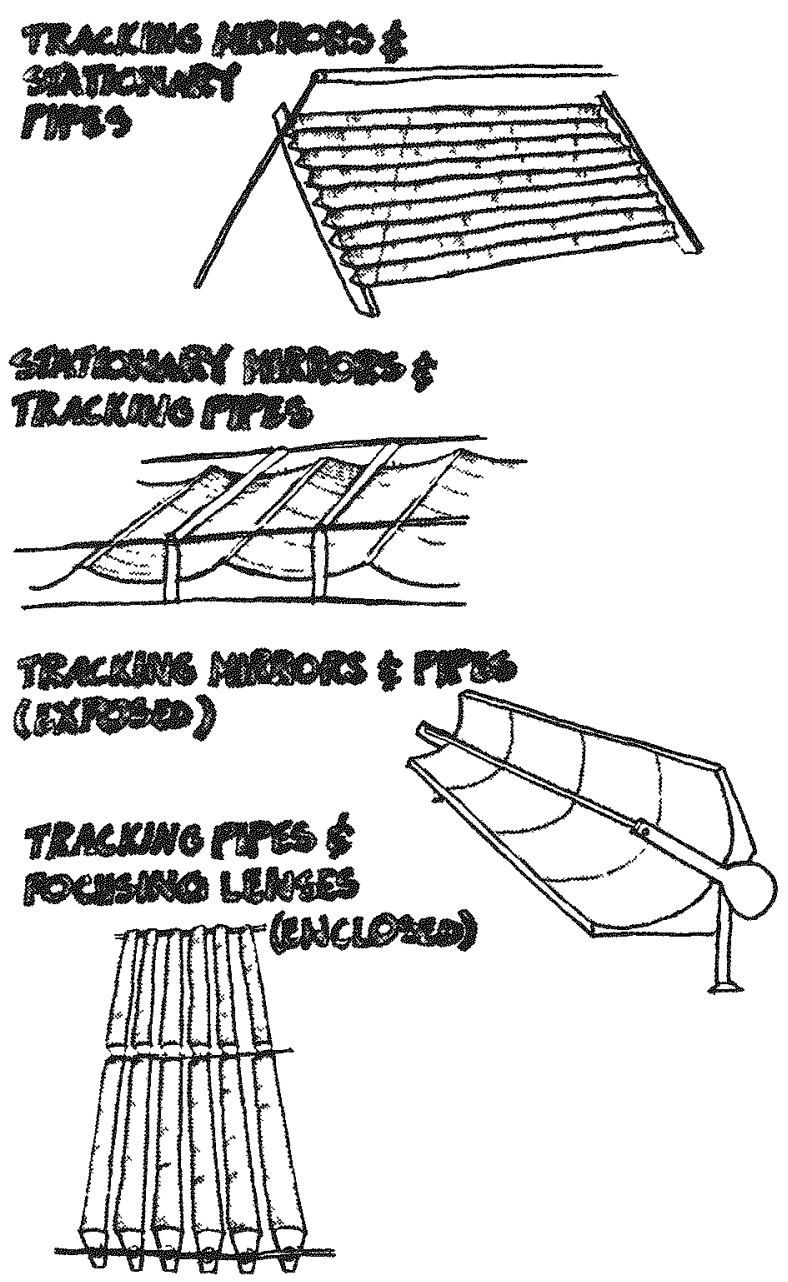

Fig. 14-60. Tracking collector alternatives 
many tracking collector al ternatives. Some collectors have tracking mirrors and stationary piping. Some have tracking piping and stationary mirrors. S till others have tracking piping and mirrors or focusing lenses. Whatever the makeup of the collector considered, remember that the two most common physical problems encountered are failure of the motors that drive the tracking mechanism and failure of the rotating pipe connection. In general, a system will be more dependable if you carefully scrutinize these two crucial areas and check with users regarding personal experience. In addition, review the "mirror" material for use in your particular area. Is there any air pollutant that would either deteriorate or coat the mirror material?

\section{Colleetor Mounting Locations}

In the designs reviewed by TEG, collectors have been mounted on either flat roofs or pitched roofs, or on the ground. Each location has its own installation requirements, advantages, and disadvantages.

Flat Roof Mounting. The most common collector location for the DOE Commercial Solar Demonstration projects has been on flat roofs. The following factors should be taken into account for this approach to be the most reliable and cost effective.

The distance between the vertical portions of the support structure attached to the roof will vary; the capacity of the structure to accommodate point loads will dictate actual support spacing. We have seen one design where the building structure could not accept point loads, so the collector support structures were designed with vertical legs of ondy $4 \mathrm{ft}(1.2 \mathrm{~m})$ on center, requiring 700 pitch pockets. Another design spanned more than $50 \mathrm{ft}$ $(15.2 \mathrm{~m})$ across a whole roof. The most economical spans seem to be approximately 10 to $50 \mathrm{ft}(3-15.2 \mathrm{~m})$.
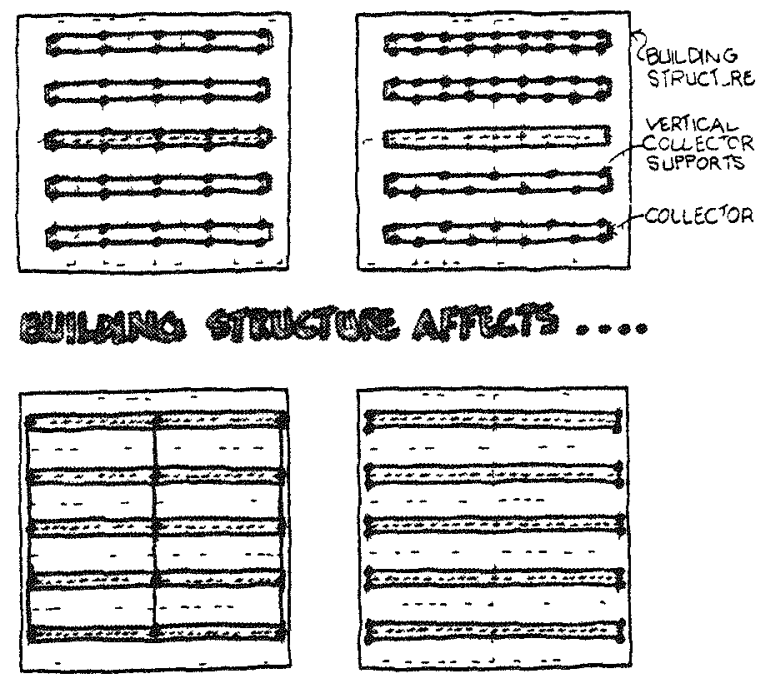

coustos superts

Fig. 14-61. Collector support structures
The relative orientation of the collectors to the building structure and, of course, the type of building structureconcrete, steel, or wood-will have an effect on the collector support. If the collectors run at right angles to the secondary building structure, there is the possibility of locating the legs of the collector support structure at regular intervals. If, however, the collectors run parallel to the secondary members, the collector vertical supports must be located directly over a single secondary member. This will mean that the member will be required to support the total load, or that an additional structural frame will be provided above the roof to carry the collector supports. The designer may elect to have the collector support span the whole roof. Thus, the structural orientation of the building has a major impact on the design and cost of the collector support structure. Obviously, if the collectors can be aligned with the building structure, the collector support legs can be set in a regular fashion. If, however, the collectors are set at an angle to the building, the support legs may have to be located in an irregular pattern in order to conf orm to the roof structure.

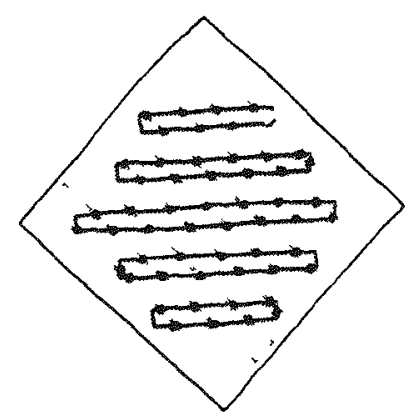

Fig. 14-62. Collectors set at an angle to the building structure

Some designers have been concerned with the dead load of the collectors. However, the collector weight is seldom a factor because the dead load of the collectors is really quite minor compared with the weight of the supports added to the wind loads, and most flat plate collectors weigh about the same.

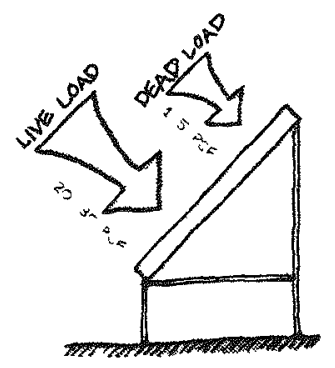

Fig. 14-63. Collector weight 
The decision whether to array the collectors in rows one, two, or more collectors high should be based on spans, struetural loads, roof area, obstructions, aestheties, and pipe configurations.

Distance between arrays is usually less than $10 \mathrm{ft}(3 \mathrm{~m})$ when the array is only one collector high, allowing piping to be supported off the collector supports. If collectors are spaced further apart than $10 \mathrm{ft}(3 \mathrm{~m})$ the piping will require special roof supports. In this case, the supports must be detailed. Even so, it is usually more economical to install collectors at least two collectors high, especially if the collectors are not tall. This approach of ten has greater visual impact and minimizes piping and structure requirements.
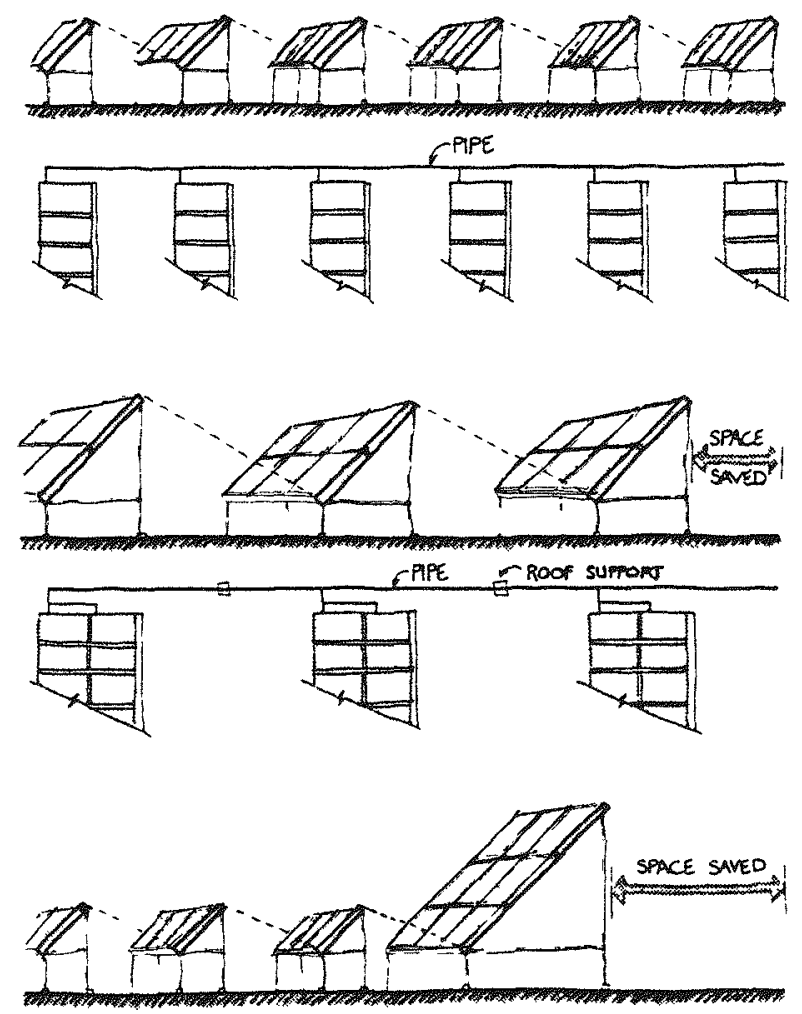

Fig. 14-64. Alternative array layouts

There is a common tendency to select aluminum or steel tubular space frames when long span, triangular shaped structures are required. This approach, although aesthetically pleasing, can be extremely costly and labor intensive. In general, simple, hot rolled steel, wide flanged beams, and steel angle structural support systems are less expensive. Complex space frames tend to cost more and are hard to come by. They may have their place, but be sure to cost compare different alternatives unless cost is no object.

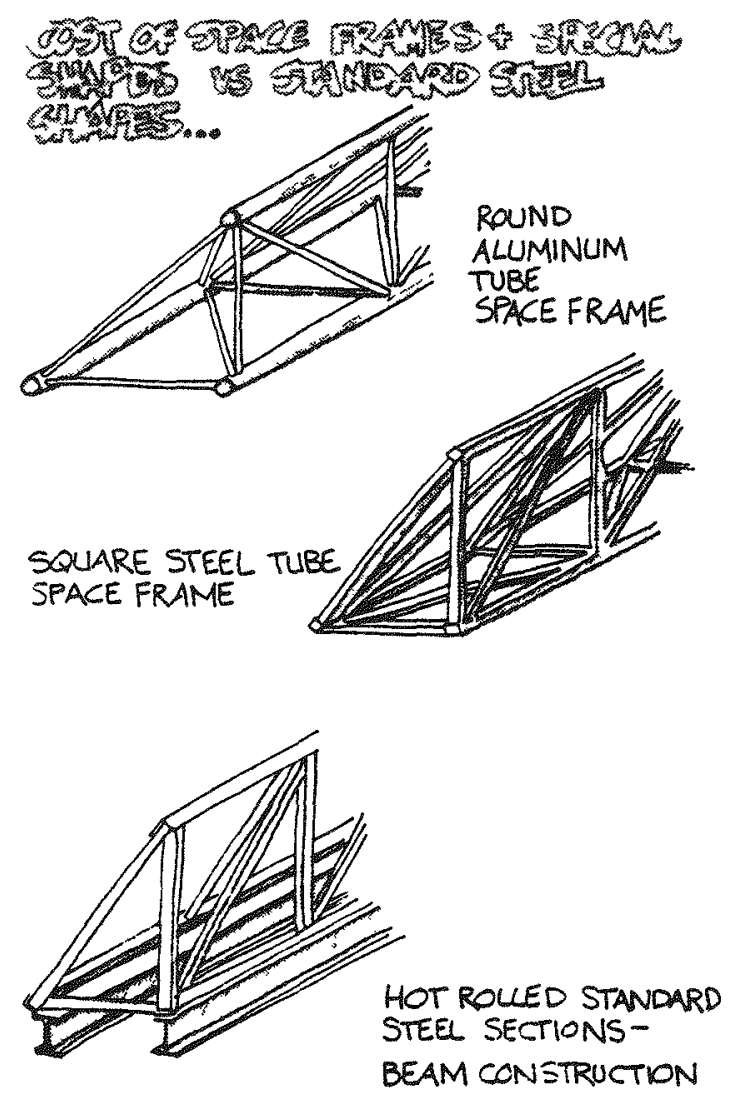

Fig. 14-65. Alternative frame structures

There are many ways of anchoring the collector support structure to the building. However anchorage is approached, the connection must be designed to support all the different loads that will be imposed on it, including dead loads, horizontal thermal movement, and live snow and wind loads. Failure of these anchorage details will result in roof leaks-if not worse problems.

Pitch pockets are one of the oldest and most common approaches. However, one must be careful to specify and install them correctly. If used for piping, do not install more than one pipe in each pocket or the differential movement may cause problems. The main problem with pitch pockets is that they require perpetual maintenance.

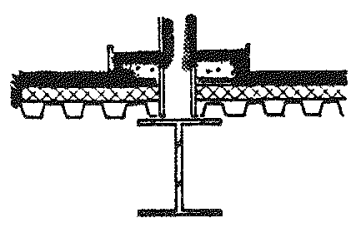

Fig. 14-66. Pitch pocket detail 
Curbs are also an old standby. If fabricated in the field, the construction and roof anchorage should be carefully specified to withstand the horizontal as well as vertical loads that will be applied.

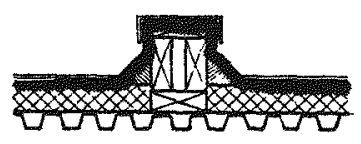

\section{Fig. 14-67. Field fabricated curb detail}

Manufactured curbs must also be selected and fastened to the roof to withstand future loads. If curbs are incorrectly installed, any movement that ensues could cause a roofing failure and leaks.

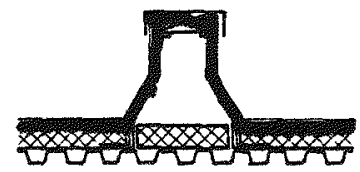

Fig. 14-68. Prefabricated curb detail

If the vertical collector support is a regular shape, round or square, there are manuf actured neoprene sleeve curbs that are available for use.
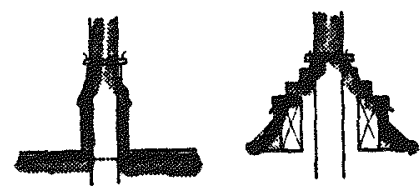

Fig. 14-69. Neoprene sleeve detail

In some designs there have been attempts to minimize or eliminate roofing penetrations. Sleepers bolted to the roof have often been used, especially in retrofits. They are cost effective but extremely unreliable. It is almost impossible to protect the bolt penetrations of the roofing. Another problem is that if the insulation under the roof's waterproof membrane is not sufficiently dense, the vertical load will tend to shear roofing and cause leaks. This problem can be prevented only by reducing point loading or cutting the roofing and replacing the insulation under the sleepers with blocking, and then patching the roof. To date, sleeper installations have caused a high proportion of leaky roofs.

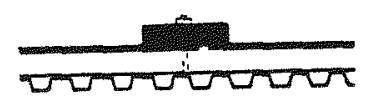

Fig. 14-70. Sleeper detail

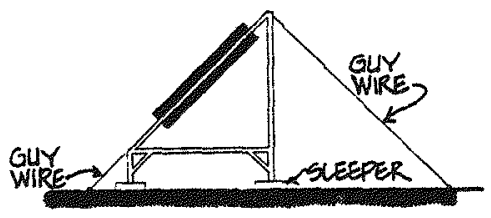

Fig. 14-71. Guy wire anchorage

A light frame structure design, using sleepers (not attached to the roof structure) and guy wires to anchor everything in place is shown above.

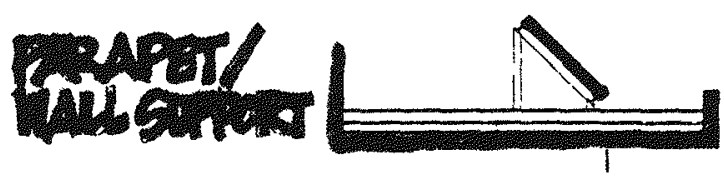

Fig. 14-72. Support between walls

This figure shows a design in which the structural members span the space between available vertical supports. However, this design was revised to simple pitch pockets because spanning was not economical. Sometimes it may be economical so one shouldn't discount it completely. If this approach is used, be sure to allow for temperature expansion.

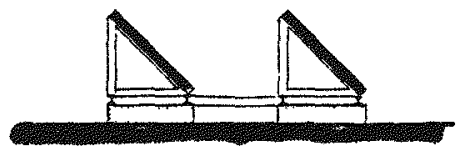

Fig. 14-73. Dead load anchorage

Another interesting approach uses heavy dead-load conerete blocks tied together with structural members to withstand the horizontal forces of the wind. If the roof can support this structurally, it is an interesting approach, but the extra roof structure required to handle the dead load is costly. 
Remember that flat roofs are not flat; they pitch for drainage. If a continuous curb or sleeper arrangement is used, be sure to consider the effect on the roof drainage system. If puddling will ensue, make certain that the roofing material will not deteriorate. In general, coal tar derivatives will withstand puddling slightly better than asphalt will. Neither, however, can be depended upon if submerged over long periods of time.

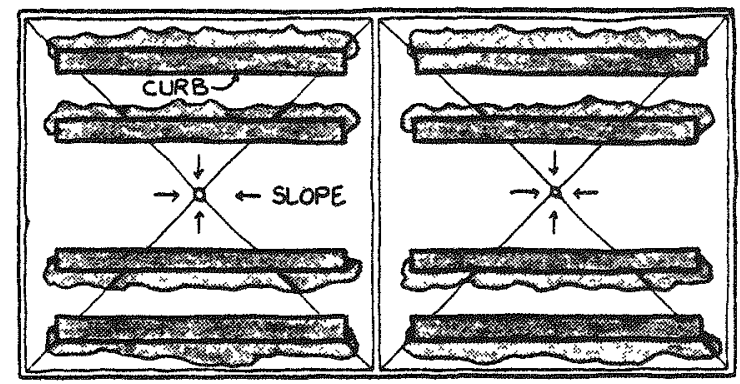

\section{Fig. 14-74. Puddling due to improperly placed curbs}

Also, be sure to take into account the continuously changing roof slopes when designing the vertical components of the collector support structure. Provide for shim ming.

In snowy areas, lifting the low point of the collector, collector support structure, and all piping sufficiently far off the roof (based upon the amount of snow) allows the wind-rather than maintenance personnel-to remove the snow. If there are continuous collector obstructions next to the roof instead, they will tend to act as a snow fence and actually precipitate additional snow. This creates greater loads and reduces collector efficiency; buried collectors do not collect too well.
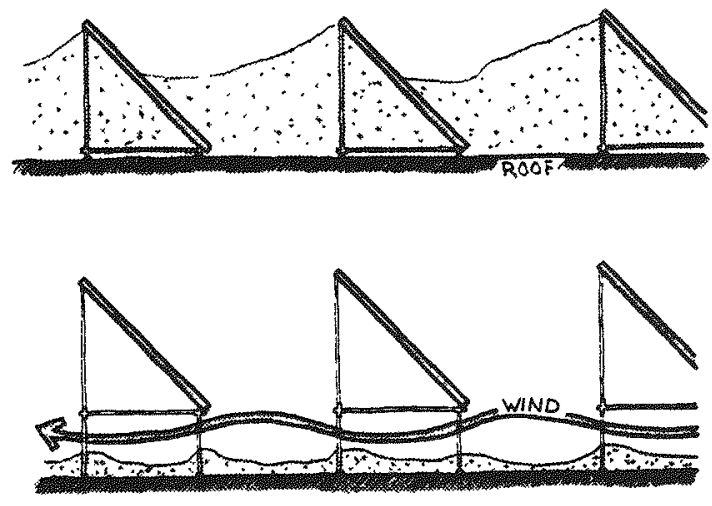

Fig. 14-75. Avoiding snow accumulation by raising collectors
Raising the collectors also allows for future roof maintenance and repair. This is particularly important in the south, where the collectors are installed at a very low angle for air conditioning.

If protection for the roofing in the form of commercially available walking surfaces is installed where people tend to walk, the need to repair the roof will be reduced.

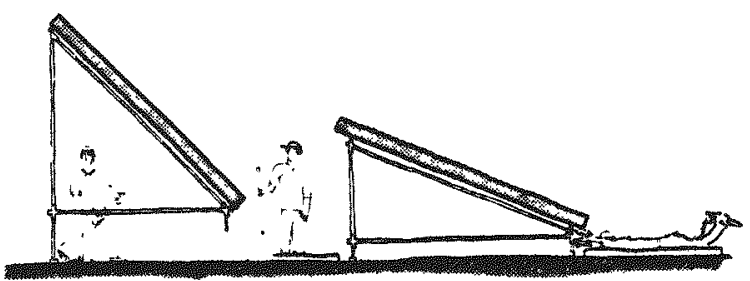

Fig. 14-76. Providing roof protection

There has been a lot of expensive overdesign to provide instant access to the collector pipes and valves, especially in conjunction with tubular collectors. When working platforms are provided as part of the collector support, they are expensive and not cost effective. The use of a ladder has to be cheaper for access, but the roof surface must be protected from the point loading that ladders will create. There are no emergencies that will require such instant attention that you cannot wait for a ladder. In fact, the condition will probably exist for a week before anyone notices it. If there is a real catastrophe, it is unlikely that the access walks will prove significant.
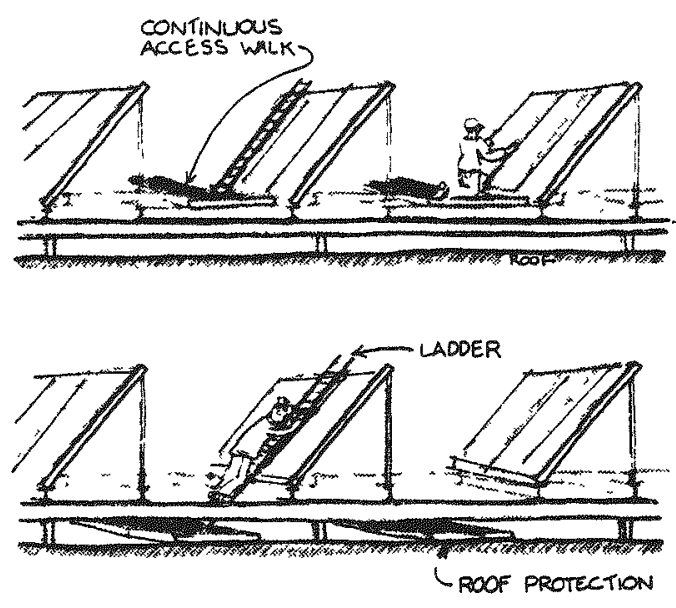

Fig. 14-77. Roof mounted locations 
Platforms on ground-mounted arrays make even less sense and can create unsafe conditions when used in conjunc tion with ladders.
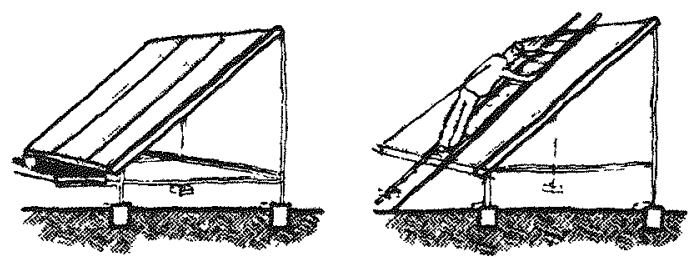

Fig. 14-78. Ground mounted locations

Pitched-Roof Mounting. If the pitch of the roof is less than the desired pitch of the collectors, many of the same spacing considerations that are encountered with flat roofs will exist; namely, shade angles, structural loading, and snow problems must be considered.

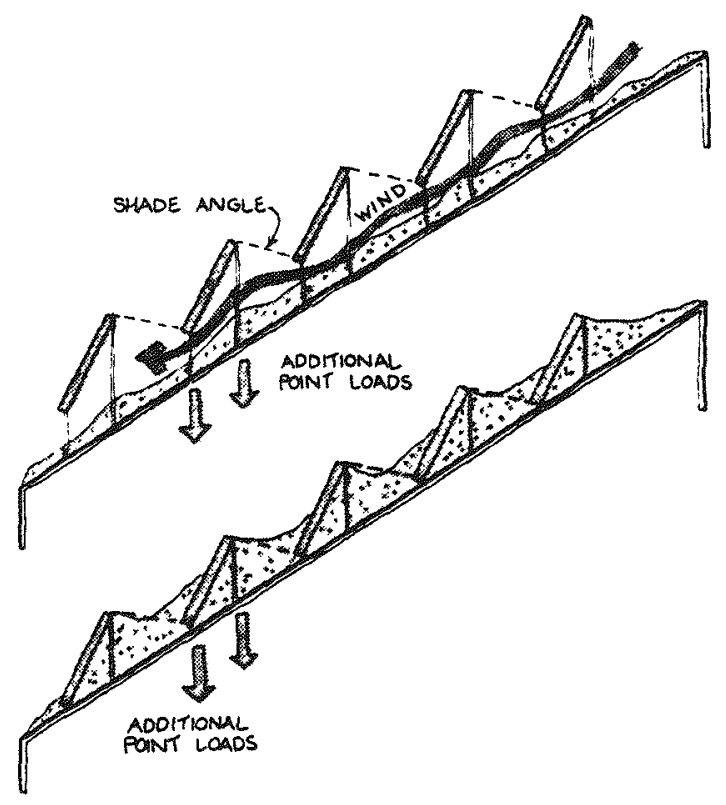

\section{Fig. 14-79. Spacing considerations on pitched roois}

If the pitch of the roof is acceptable for direct mounting of collectors, the design decisions are different because the collectors are mounted parallel to the roof. Spacing requirements are all but eliminated. The loading requirements are basically limited to the dead load of the collectors because the live load is not increased. Snow load is also no longer a problem, but avalanche protection must be provided for any unwary pedestrians who may exit from a building or walk by.

Roof replacement under collectors cannot be accomplished without removing trhe collectors. All that can be done to waterproof the installation is to protect the connection between the collector support and the roofing from water running down the roof.

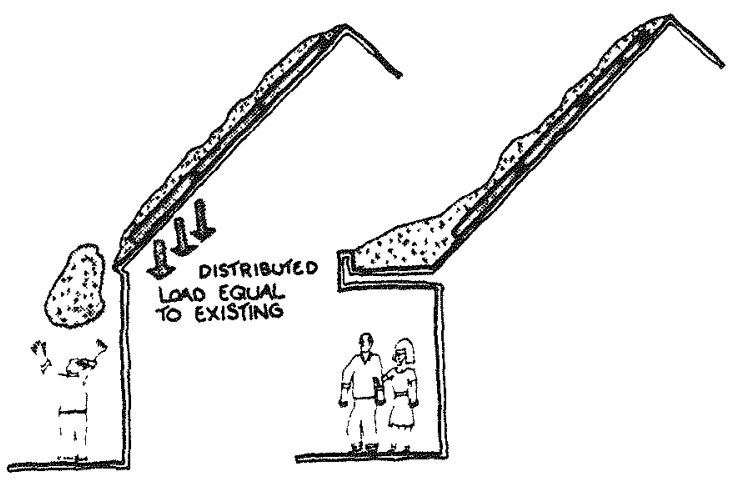

Fig. 14-80.

\section{Collector pitch same as roof pitch}

With shingle roofs, the collector support points can be anchored with a plate under the shingles so that the fasteners are flashed by the shingles. If sleepers are used directly on the roof, they should not run across the slope of the roof or they will create a dam, retaining runoff and allowing water to penetrate the shingles. The sleepers should run with the slope, and if roofing cement is applied between each layer of shingles, under the sleeper, and between the sleeper and the shingles, leaks should not occur.
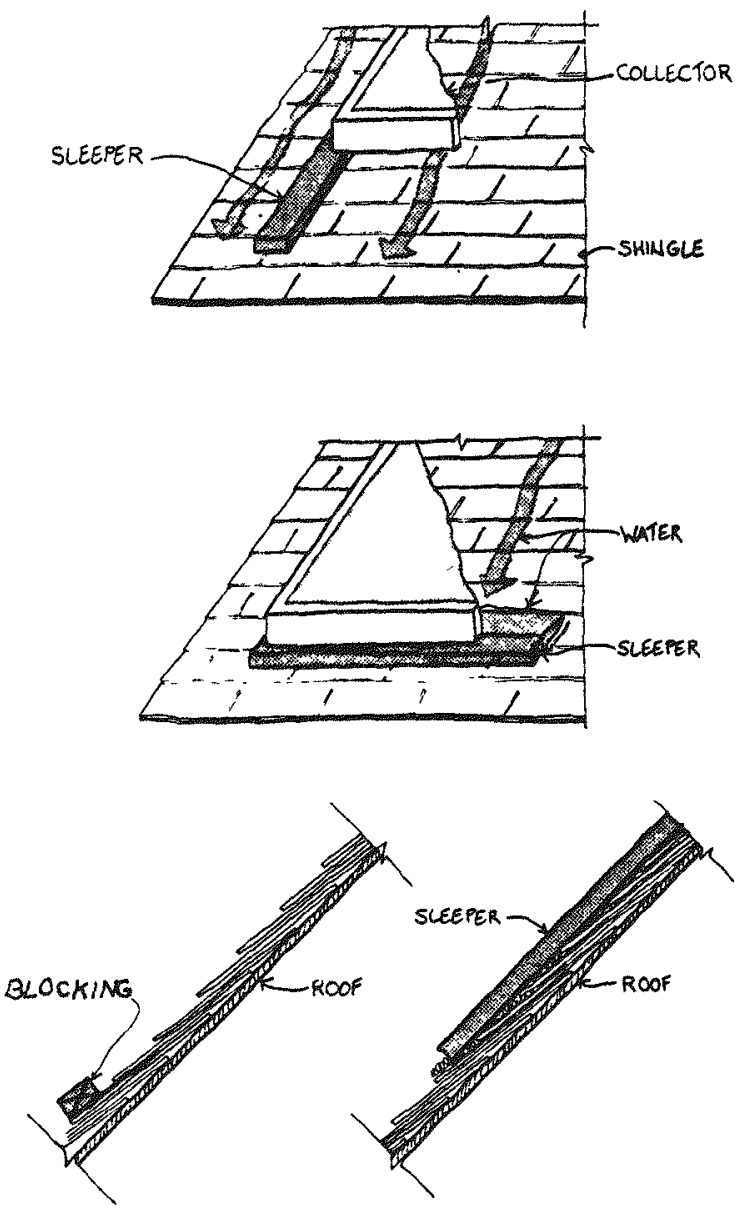

Fig.14-28 Sleeper locations 
Typical aesthetic concerns when designing collectors on pitched roofs are sloping collectors in drain-down systems, the sheer amount of exposed piping on the roof, and provision for pipe crossovers.

If a drain-down system is used, the collectors must be sloped to drain. Unfortunately, buildings do not slope; if the designer does not consider this fact, people may wonder why the building is crooked.

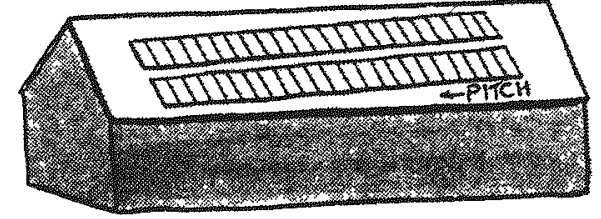

\section{Fig. 14-81. Sloped collectors to allow drain-down}

For that matter, all exposed piping should be considered in terms of aesthetic implications so that the final product does not look like an abandoned boiler factory.

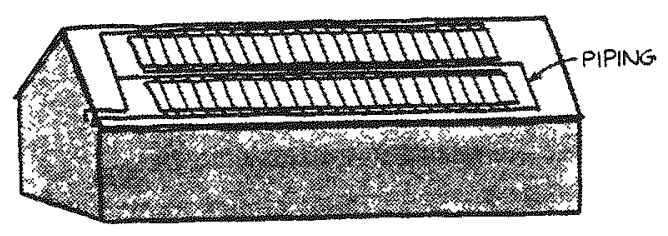

Fig. 14-82. Exposed piping

Pipe crossovers should be avoided or carefully detailed because there is little room between the roof surface and the top surface of the collectors. Pipe crossovers invariably protrude above the collector surface, making them both highly visible and unsightly.
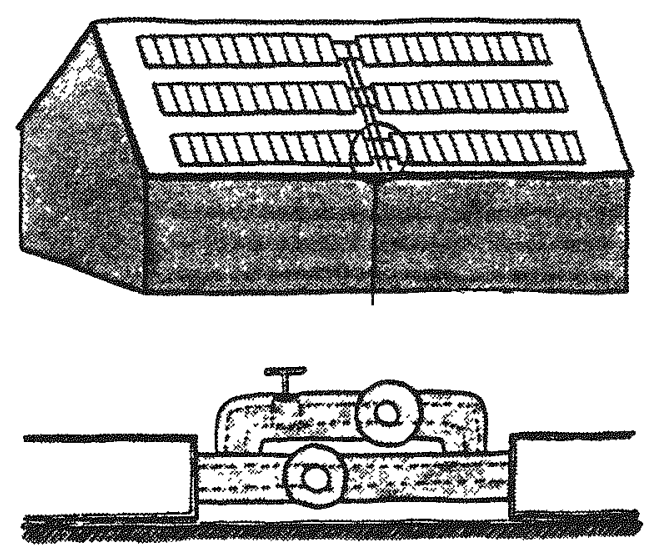

Fig. 14-83. Pipe crossovers
Ground-Mounted Collectors. Ground- or site-mounting raises the issue of buried piping versus above ground piping. In areas with a deep frost line or very wet soil conditions, locating piping above ground is much preferred. In fact, above ground locations are generally preferred to facilitate inspection and repair of piping, in spite of the thermal and water problems incurred. If piping is located above ground, however, the designer must contend with its appearance. In any case, when buried piping is used, try to minimize the amount of piping under paved areas.

When collectors are mounted on the ground, the spacing considerations are similar to those for collectors mounted on a flat roof. Instead of roof penetrations, one must contend with footings. In areas with little or no frost and good soil-bearing capacity, vertical supports are less costly than in deep frost areas because of the difference in footing requirements. Here again, the designer should arrive at a good balance between horizontal structural spans and vertical supports.
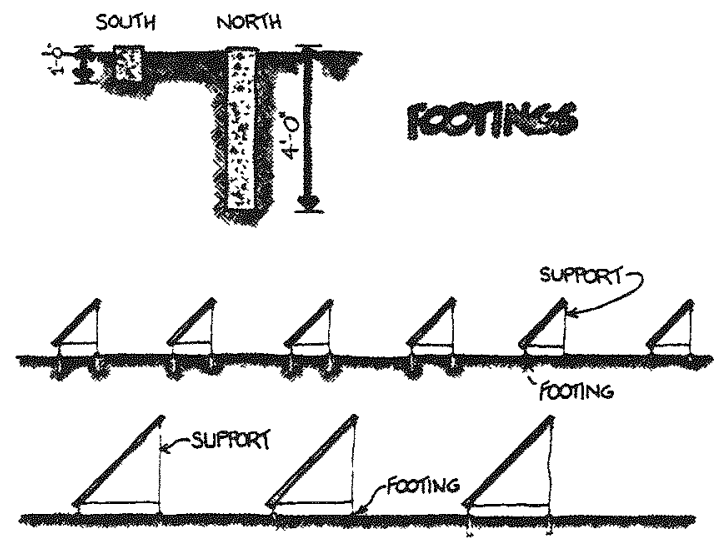

Fig. 14-84. Cost concerns in site supports

For materials, consider pressure-treated wood as well as metals. Wood is more cost effective. A prefabricated horizontal structure supported by site-fabricated vertical members is also a cost-effective approach.

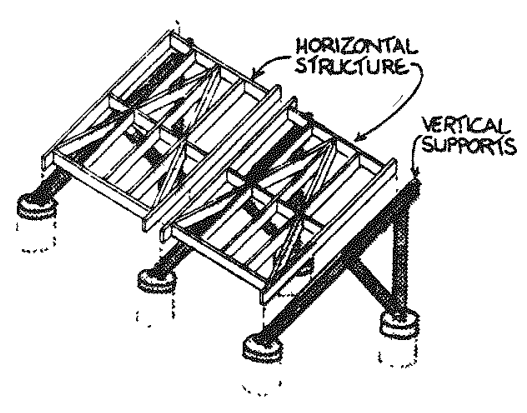

Fig. 14-85. Prefabing horizontal structure 
In one design, pole-barn-type vertical supports were least expensive. Because of the cost of footings, it has been found to be less expensive to install collectors in arrays two collectors high, again keeping the collectors off the ground for snow and "growing things" clearance.

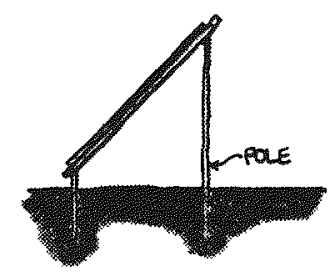

Fig. 14-86. Pole barn construction

Growing things, like weeds and trees, present a problem unique to site-mounted collectors. The cost and inconvenience of mowing the collector field could be considerable. Short of paving the area, one approach uses a chemical defoliant on the soil and follows with a covering of a plastic sheet and then gravel on the area.
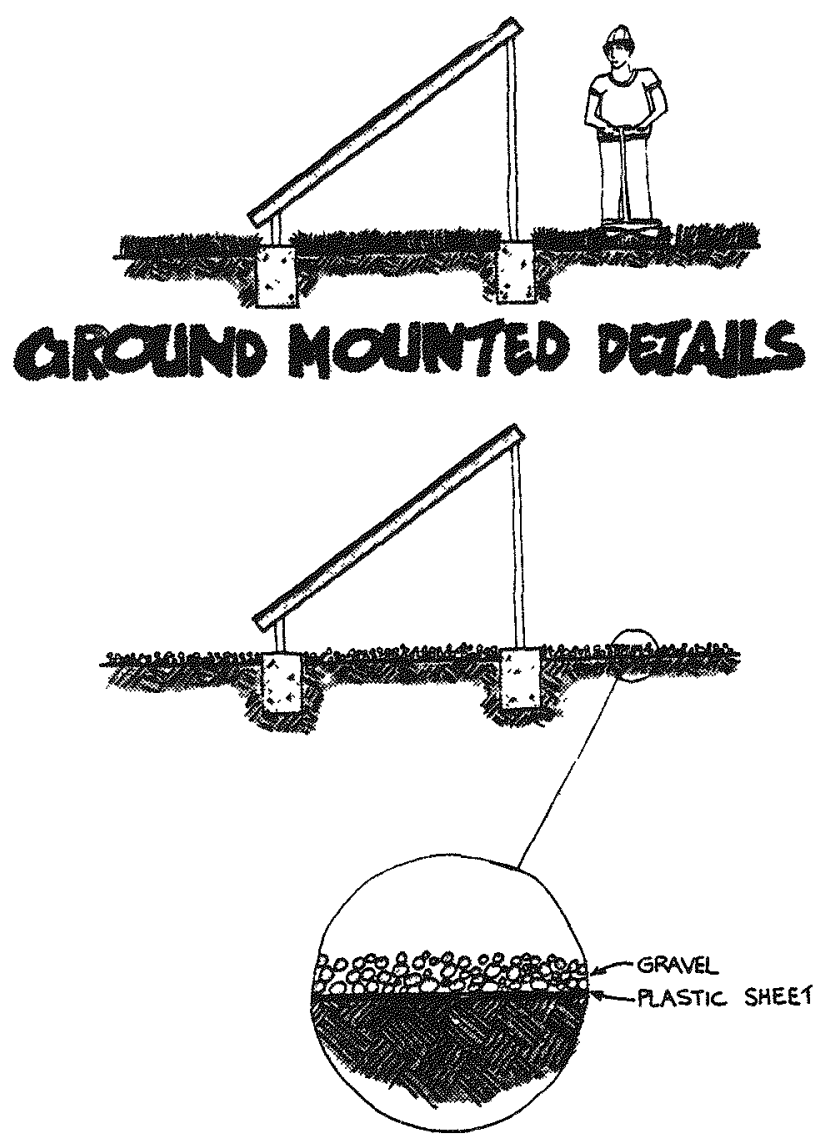

Fig. 14-87. Mow vs, no mow

\section{Storge Locations: Liquid and Air Systems}

For a long time we have known that a major loss of energy occurs through improper storage containers; IBM's data confirm our findings. Once the volume of storage and the area required are decided, the next decision to be made is the best available location. The choices are above or below grade inside of the building and above or below grade outside of the building.

Interior storage. Above grade storage inside of the building is, obviously, the simplest location, if room can be found. However, the space required may cost $\$ 30$ to $\$ 60 / \mathrm{sq} \mathrm{ft}(\$ 324-\$ 648 / \mathrm{sq} \mathrm{m})$ to build new construction, or it may take up valuable existing space. An interior installation is much easier to insulate and does not require waterproofing. Pipe runs also tend to be shorter.

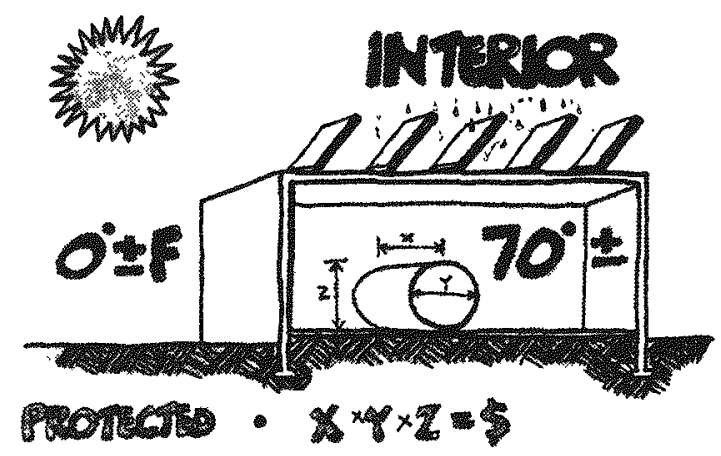

Fig. 14-88. Interior storage

Aside from the physical space required, the main problem encountered in interior storage locations concerns the insulation of the tanks. This can be a twofold problem because valuable energy will be lost, and, simul taneously, summer cooling loads will be increased. The most common source of heat loss is through radiation from the tank supports, from either legs or saddles, or the bottom of the tank. With tank saddles or tanks sitting directly on a slab, it would be advantageous to use high density insulation such as foam glass between the tank and the saddle or the slab. If the saddles or legs are integral with the tank, it is best to insulate the supporting members. Then the supports should be isolated from the slab by using the neoprene or cork pads normally used as vibration isolators. 

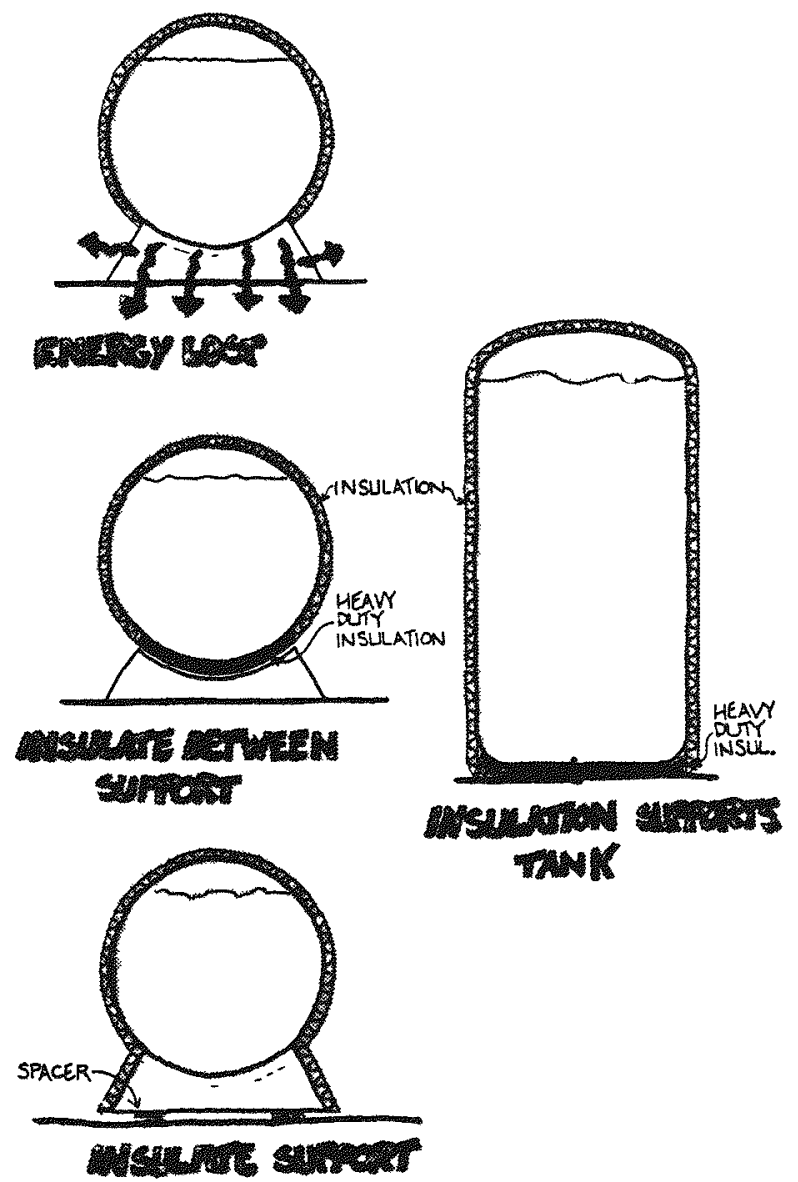

\section{Fig. 14-89. Insulating an interior storage tank}

We have not encountered liquid storage containers constructed of wood. How ever, our studies have shown that if properly lined with a sheet material such as reinforced EPDM, they should be cost effective and could solve many construction problems involving tight places for nonpressurized storage. Failures in liners have tended to occur at the corners. When the liner material is poorly fitted, tensile failure may occur.

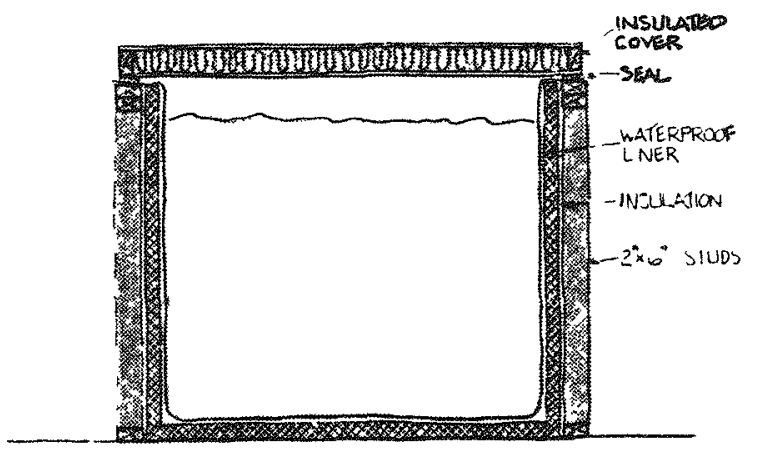

Fig. 14-90. Wood container for liquid storage
A number of designs have used either square or round concrete tanks with top, bottom, or mid-height joints. The major concerns with this type of tank are the construction joints and the porosity of the material. If the tank is supplied in two parts, be sure that the joint is well sealed. It is preferable that the two halves have grouted-in steel ties to prevent any movement that would cause leaks. In addition, the coating should be able to span minor cracks which of ten tend to develop. Cement and epoxy waterproofings would tend to be less desirable because they cannot span cracks. Liquid applied elastomerics or plastic liners are capable of spanning minor eracks and should be considered if the temperature and liquid water additives are compatible. Also, be sure to insulate the bottoms.

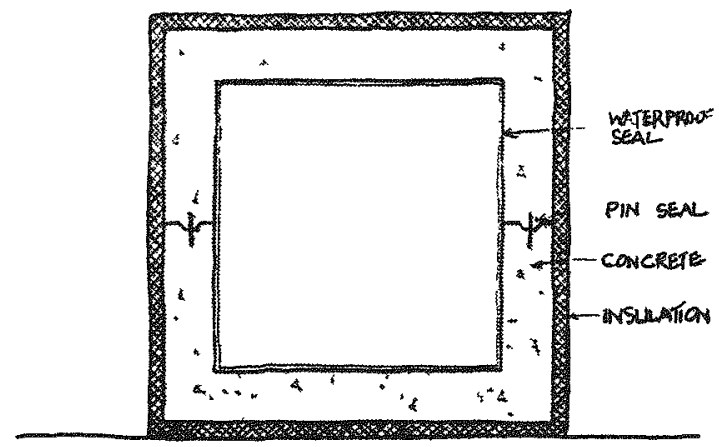

Fig. 14-91. Concrete container for liquid storage

Exterior Storage. Once storage is removed from the building, the cost of the occupied space may be minimized, but problems and the chance of energy losses through storage are considerably increased. There are a number of major physical factors related to exterior conditions which must be addressed:

- Insulation. Ambient outside temperatures require close attention to insulation. The insulation should be impervious to water in case a leak develops in the waterproofing. If the tank is supported by the insulation directly on the ground, insulation must be capable of supporting the load of the filled tank without being crushed. If the tank sits on supports, it is doubly important to either isolate the support or insulate it to minimize radiation losses.

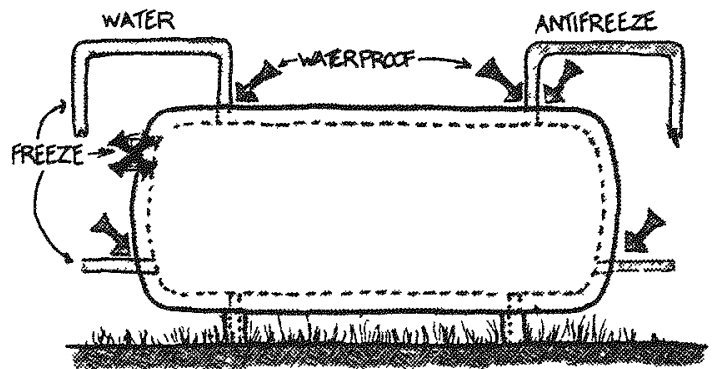

Fig. 14-92. Insulating an exterior storage lank 
- Waterproofing. Rain and snow demand close attention to waterproofing. If the waterproofing fails, the insulation can be severely affected. All penetrations for valves, supports, piping, sensor wires, etc., must be adequately waterproofed to preserve the waterproofing, and, therefore, the thermal integrity of the storage.

- Preeze Problems. Freezing can be a problem, not so much for the storage tank (because of its mass), but for water piping without antifreeze. Freezing precludes the use of normal tank sight levels for monitoring the water level. If the sight level can be drained, however, monitoring is always possible. During site visits by TEG staff, maintenance personnel at installations without some sort of level indicator unanimously bemoaned their inability to ascertain liquid levels in storage.

Aesthetic considerations of exposed storage tanks are unfortunately of ten neglected. The "Oh, it's in the back of the building, no one will see it" approach is often prevalent. Buildings have four elevations, and unless one is designing a plumbing warehouse, why make the building look like one?

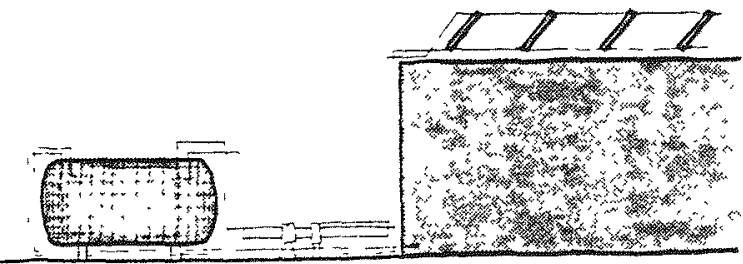

Fig. 14-93. Aesthetically poorly designed storage tank

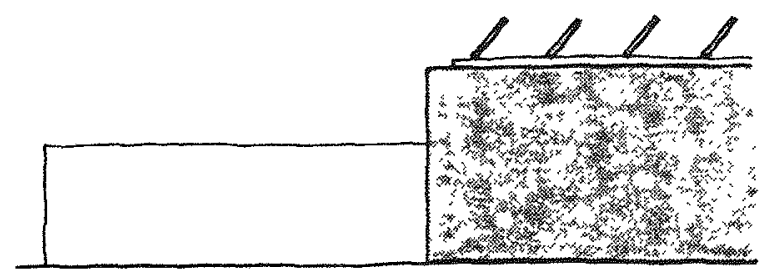

-212.

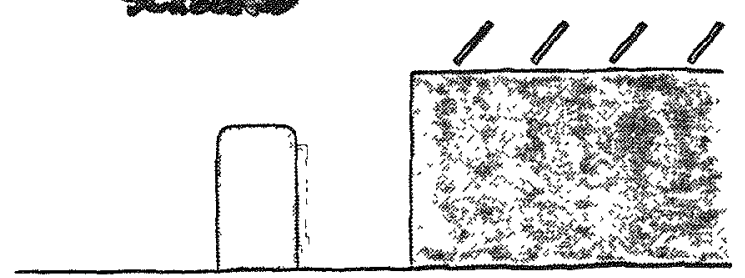

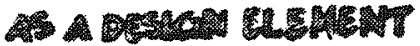

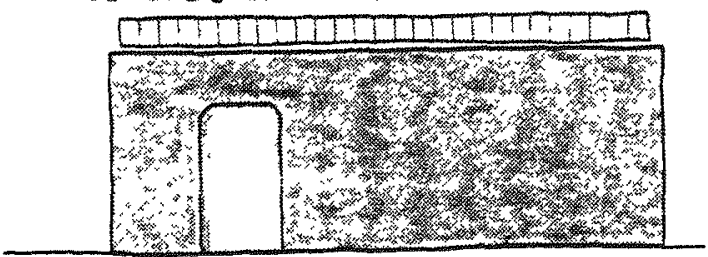

Fig. 14-94. Design options for storage tanks
Well-designed screens are passible; in one case, the storage waterproofing was white fiberglass reinforced epoxy, and it was attractive as a free--standing design element. Do not let solar components happen; design them into the building.

Below Grade Storage. Buried tanks can be an attractive alternative. However, the concept of "out of sight, out of mind" can be misleading. Buried tanks save building space because of their exterior location and also eliminate aesthetic problems. However, they have more than their own share of problems.

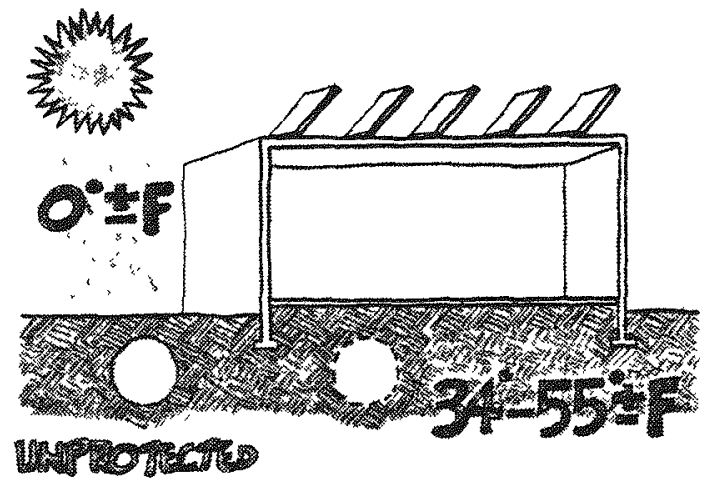

Fig. 14-95. Buried storage lanks

The first and foremost consideration prior to deciding on a buried location is elevation of the water table. If it is above the height of the bottom of the proposed tank, there are several problems which require a special holddown structure and waterproofing. It is best to avoid this condition. However, if there is no alternative, design the support so that the tank is held up when full, and down when empty. This is usually accomplished with a large concrete footing with tank saddles to hold up the tank and steel straps to hold down the tank. It is most important that the supporting members do not break the waterproof integrity of the tank. One way of doing this is to insulate and waterproof the tank prior to installation. Install high density insulation, such as foam and glass, capable of withstanding the point loads imposed by the supports and steel traps, and of strengthening the waterproofing in these areas. Remember that much as the support can crush the insulation and tear the waterproofing under the compression, the steel straps can do equal damage if the tank tends to float.

If there is no water table problem, there is probably no need for any concrete support, especially if the soil has good bearing and drainage. A common approach to installation is to pre-foam the tank with urethane, then wrap it with nylon fabric and a bitumastic material, and set it in a sand bed. If done carefully, this seems to work well. Another approach is to set the tank in granular insulation and place a plastic sheet over the top. If the surrounding ground is porous, this approach can work. However, if it is not, water will tend to back up into the insulation and extract the hard-won solar energy.

IF THERE IS A HIGH WATER TABLE DO NOT BURRY THE TANK. There is no way of adequately water roofing a tank in contact with free water. 


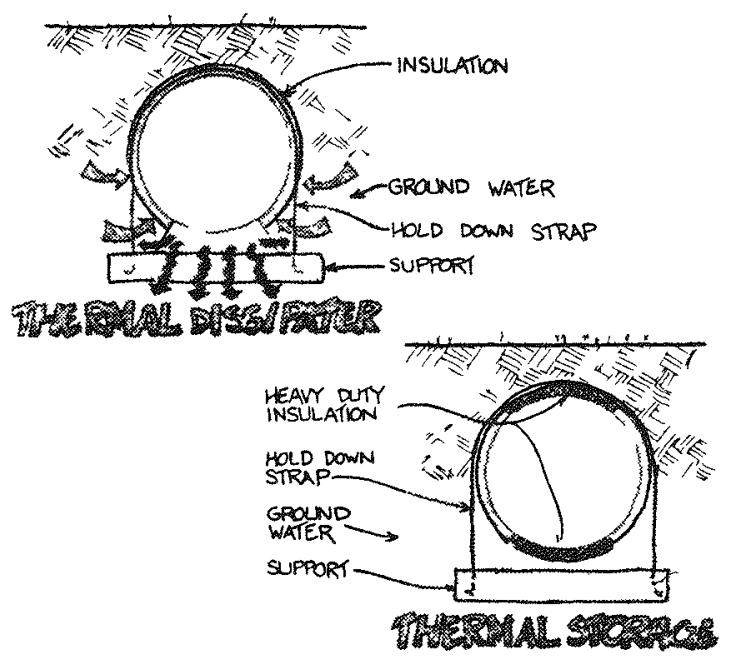

Fig. 14-96. Insulation and waterproofing

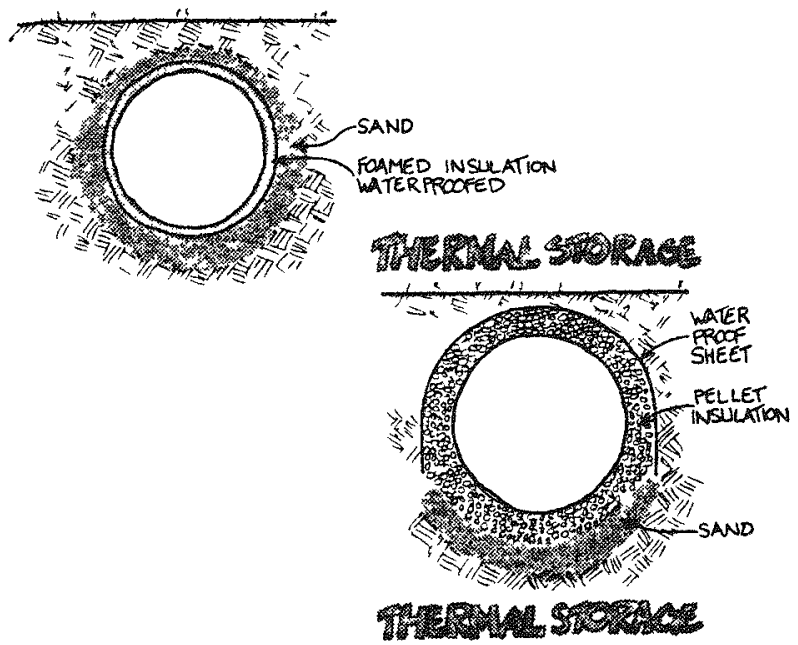

Fig. 14-97. Insulating tanks in dry soil

Access to buried tanks is another area that must be thought out carefully. If access is required, many of the same freezing problems encountered with exterior above ground installations will be encountered here and must be solved. Again, if access is provided, and if the existing pipes, etc., are bunched, the access area can be minimized. Provide drainage between the walls of the access enclosure and the tank waterproofing so that water will not be trapped here. Be sure that any access opening does in fact provide adequate access to all items requiring future attention such as; tank hatch, sensor penetrations, and possibly pipe penetrations.

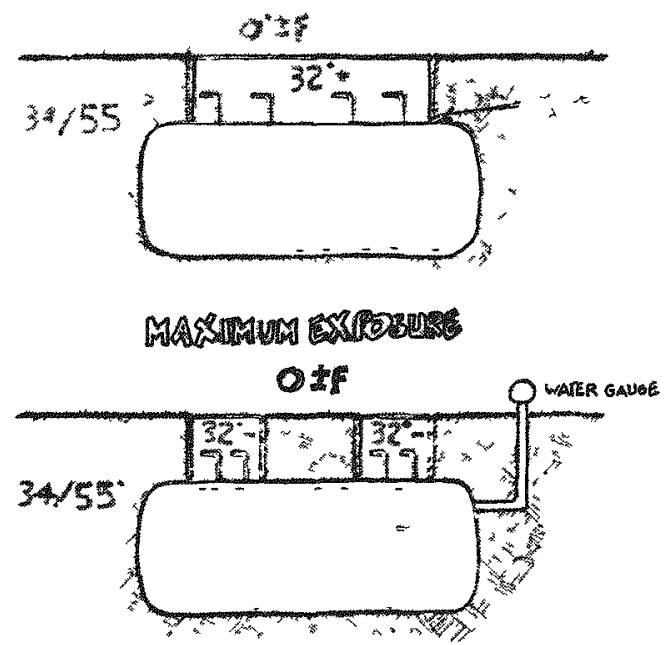

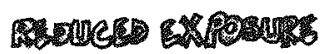

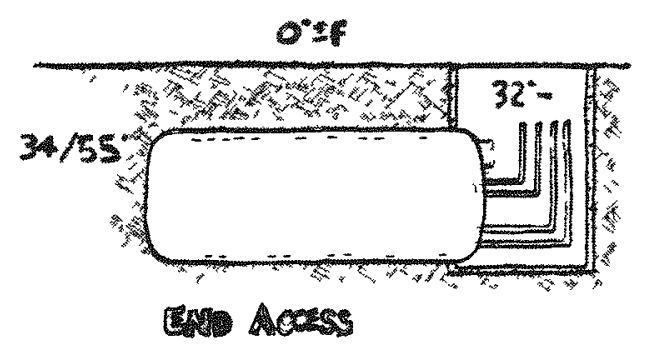

Fig. 14-98. Providing access to buried tanks

Be sure to locate the buried tank, especially in retrofits, sufficiently far from the building so as not to undermine the foundations or footings. If the tank is located under existing slabs or pavement, the same problem exists. If a slab is undermined, it will ul tim ately crack or break up.

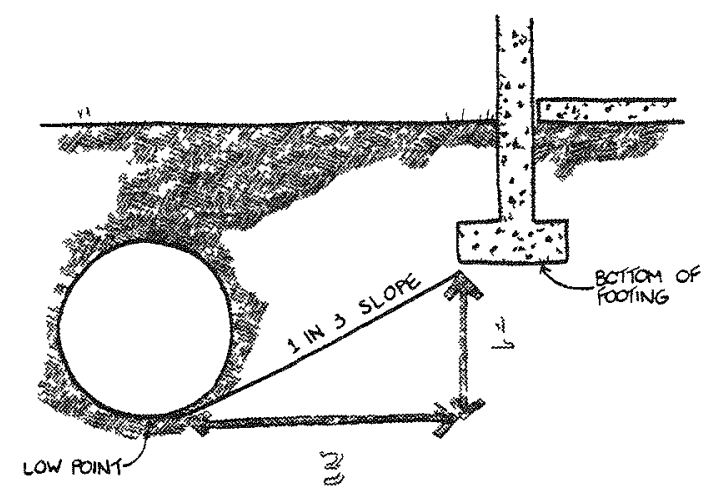

Fig. 14-99. Locating a lank near the building foundation 
A good rule of thumb is to locate the tank at least $3 \mathrm{ft}$ $(1 \mathrm{~m})$ away from the face of the building, for each foot $(.3 \mathrm{~m})$ below the footing. Excavate or provide slab openings of sufficient width, not only for the tank installation but also to prevent undermining. Check with the structural engineer for the particular site.

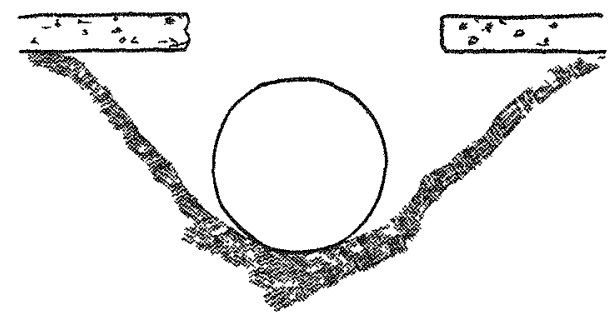

\section{Fig. 14-100. Locating a tank under concrete slabs}

In some cases designers have tried to integrate a concrete storage container into the general structure of the building by using the foundation walls and slab as the sides and bottom of the storage tank, while insulating only the outside of the tank inside the building. This approach, though possibly less expensive, has related drawbacks. One is that there is a tendency to draw off and dissipate the heat through conduction within the adjacent concrete walls; this wastes heat in winter and can add to the summer cooling demand by radiating heat into occupied spaces. This problem can be overcome only by first insulating the inside of the tank and then using a waterproof liner. Expansion joints must be provided between the storage tank and adjoining concrete slabs and walls.
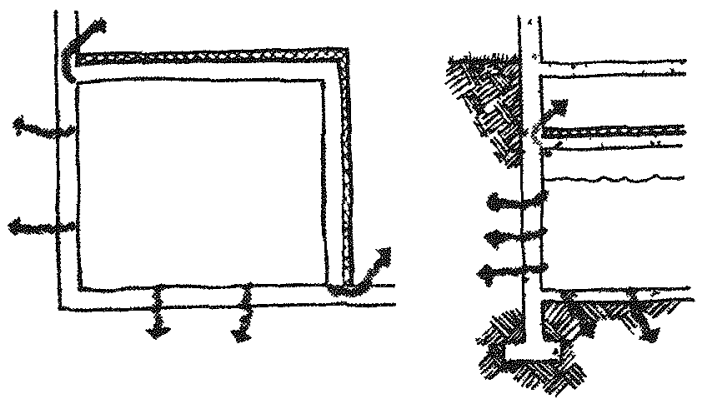

Fig.14-101. Heat loss from storage
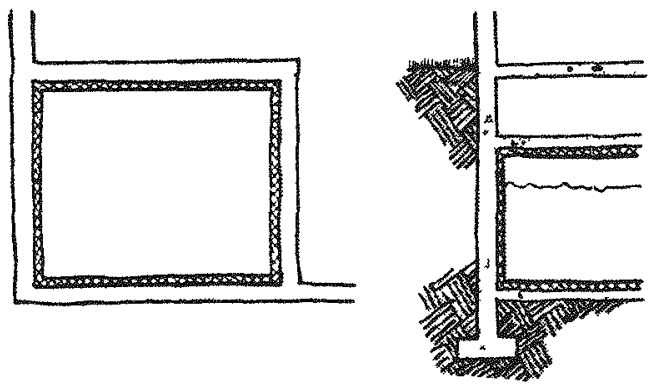

Fig. 14-102. Insulating structurally integrated concrete storage tanks

\section{Air Storage}

Drainage and Visual Inspection. The question of drainage and inspection at the bottom of a rock bed is often discussed. If a floor drain is provided, the liquid in the trap will evaporate allowing sewer gases to enter the heating system. A better approach is to provide an opening in the duct that extends to the bottom of the box or a separate 3 -in. $(76 \mathrm{~mm})$ diameter pipe, so that in emergencies a pump could be lowered. DO NOT PROVIDE DR AINS.

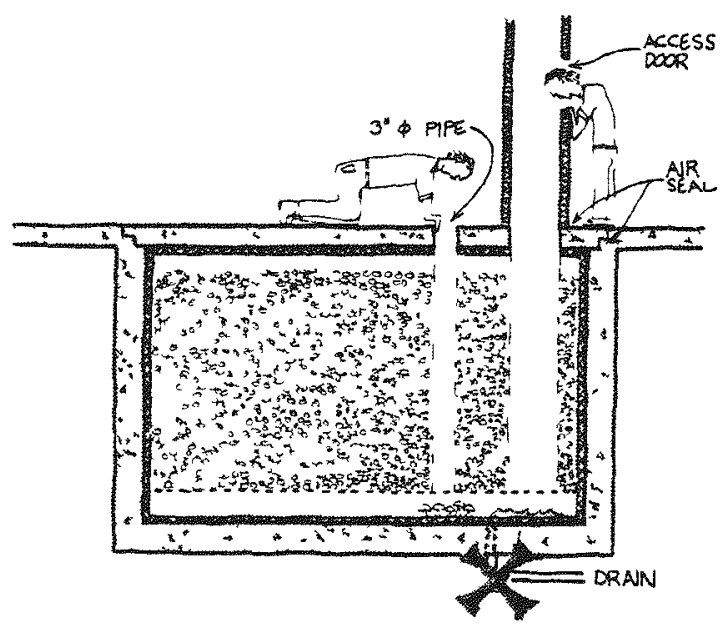

Fig. 14-103. Visual inspection of a rock bed

Insulating Concrete Tops. Another point that is not usually considered is how to insulate the concrete top of a concrete rock box. Be sure that there is sufficient space to get inside to remove the formwork and install the insulation or design the insulation to act as the form work.

Avoiding Air Leaks. The most common problem encountered with rock storage, both in design and installation, involves proper sealing of the wood cover to the storage box and of the duct penetrations. This problem is fairly easily overcome with a little detailing and thought. It is not sufficient to just run a bead of caulking around the duct penetration, especially if all one is caulking against is $1 / 2-\mathrm{in} .(12 \mathrm{~mm})$ plywood. Consider the paths that air can use to escape, and use some flashings, caulkings, glue, and ingenuity to prevent it.

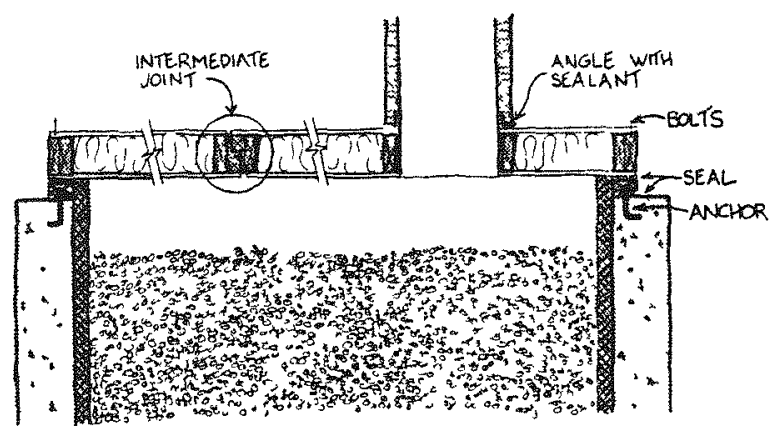

Fig. 14-104. Insulating a rock bed 


\section{Piping Concerns}

Pipe Expansion and Contraction. We know that there can be as much as 2 in. $(50 \mathrm{~mm})$ of movement on pipes resulting from temperature differential. These movements are either in opposite directions or at right angles to each other. Therefore, always allow for this movement at ties or in long pipe lengths.

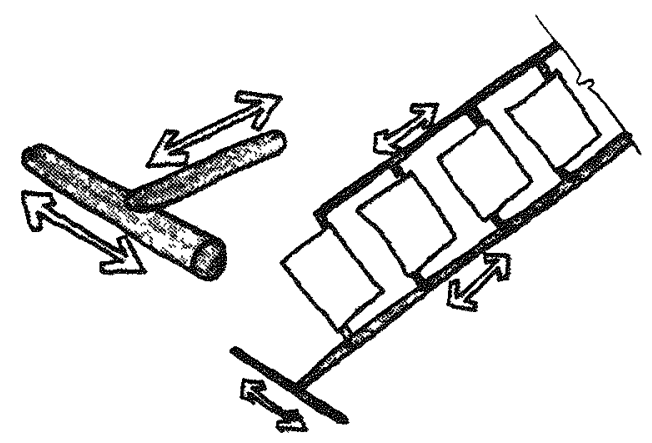

Fig. 14-105. Expansion in pipes

Some ways to compensate for these movements are with silicone bulbs, bellows, braided wire, pipe elbows, or swings. Whatever method is chosen, design it, show it, and specify it.

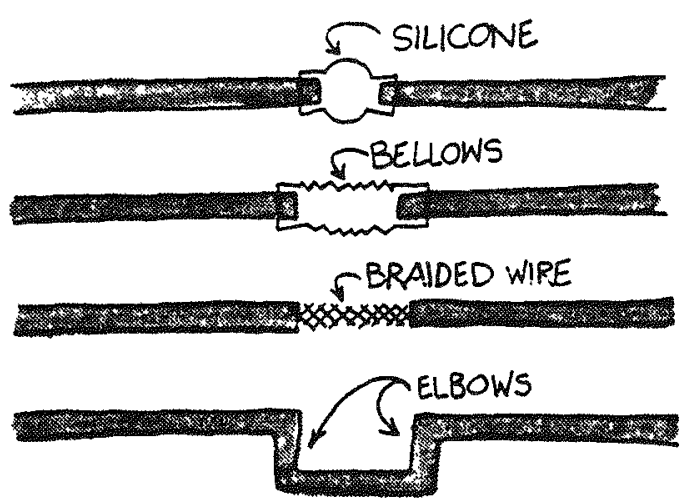

Fig. 14-106. Allowing for expansion

It is important to design the pipe support within the collector arrays. Pipes can be supported off the collector. This is normally done by the use of soldered copper nipples. Be very careful that the mechanic does not burn out the waterproof seals of the collector. This is a constant problem because the solder required flows at a particularly high temperature.

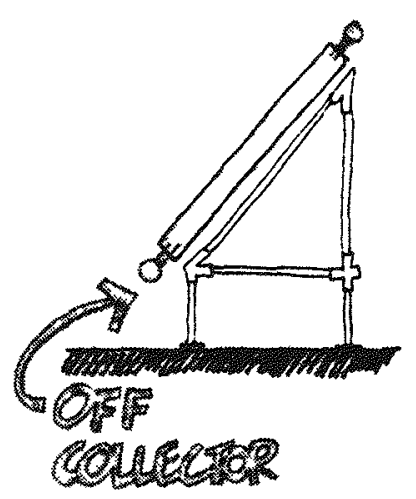

Fig. 14-107. Pipe support off the collector

If pipes are supported off the collector support, be sure to design space on the collector support to support the piping. Consider supporting the pipes off the back of the support as an alternative.

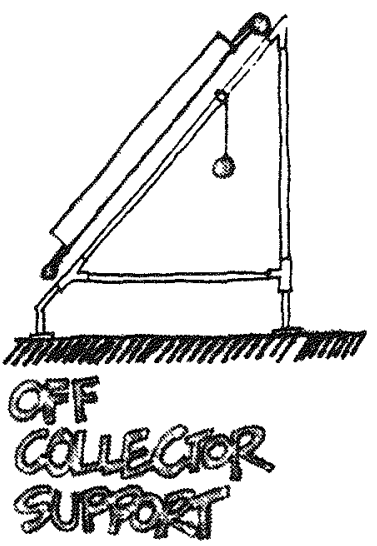

Fig. 14-108. Pipe support off the collector support

Sometimes, the pipes are just supported on the roof surface. If they are, be prepared to have the pipes used as a platform, with the concomitant problem of having the waterproofing destroyed.

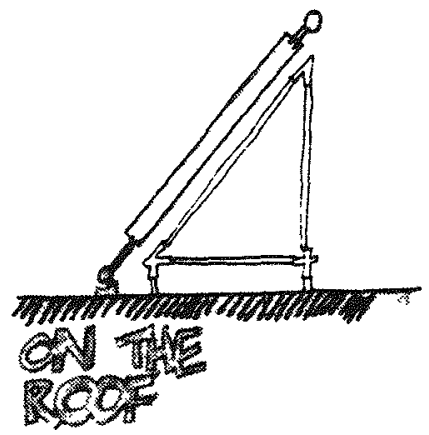

Fig. 14-109. Pipe support off the roof surface 
A fairly common way to support pipes is off other pipes, especially in reverse-return designs. In this case, be sure that the pipes are well supported, one from the other, and that they are both free to move independently. When supporting pipes, be sure to allow for thermal pipe movement. Do not restrain them by clamping pipes to waterproofing to the point where pipe movement will cause a tear in the waterproofing membrane. Pipe sleeves or shields should be considered to protect the waterproofing/insulation installation.

In addition to supporting the pipes, if a pipe anchor is provided, be sure that the structural member to which it is fixed is capable of resisting the design thrust resulting from the expansion compensator. Otherwise the structure rather than the compensator may do the moving.

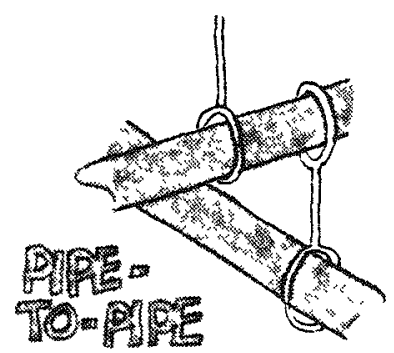

Fig. 14-110. Supporting pipes off other pipes

\section{Drain-Down Systems}

Drain-down systems are very enticing because of their improved thermal performance. However, there is one overriding physical requirement that must be met but is sometimes overlooked-all the piping and collectors must be adequately pitched to orain. Some designs have no provision, or even enough room on the collector support, for pitching the collector or piping. The specifications, however, state that all piping must pitch to drain. If the design requires drain down, then the detail must allow for pitch or it will not drain down.

Keep in mind, too, that collector supports are allowed to deflect under loading - so when designing the collector support allow sufficient space to adequately pitch piping. Also keep in mind that $1 / 8-\mathrm{in} . / \mathrm{ft}(10 \mathrm{~mm} / \mathrm{m})$ slope parallel to the collector slope is less than $3 / 32-\mathrm{in} .(2 \mathrm{~mm})$ in actual vertical drop. If possible, $1 / 4-i n . / f t(20 \mathrm{~mm} / \mathrm{m})$ pitch is a good slope to design.

\section{Pipe Insulation/Waterproofing}

Insulations. Most insulations that solar designers deal with were not developed for the solar field. They are being used and adapted to solar but are not really suitable in all cases.
Rigid fiberglass is a very common material. It is relatively low cost, varies in thickness up to 3 in. $(76 \mathrm{~mm})$ and resists high heat. On the other hand, it absorbs water like a sponge and once wet makes a better radiator than an insulator. Also, it cannot take the flexible shapes very often required by solar installations. This material is good for long runs of piping without too many joints and tees, but it is especially unsuitable for exterior manifolded collector installations because of the inherent problem of providing adequate waterproofing.

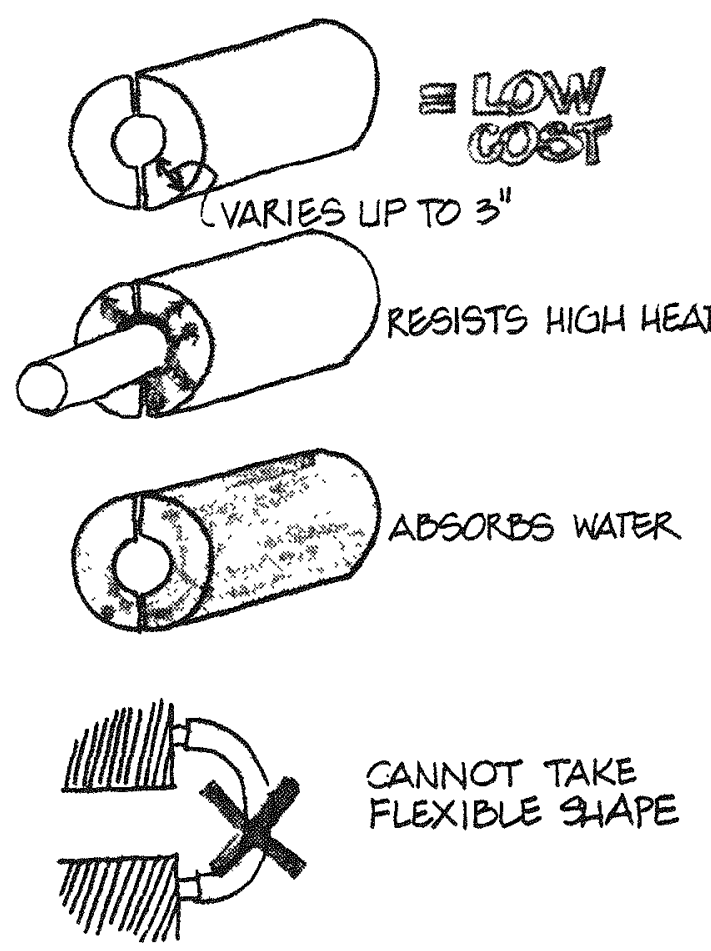

Fig. 14-111. Rigid fiberglass insulation

Rigid, foam is roughly comparable in cost to rigid fiberglass for the same $R$ value. Like fiberglass, it too varies up to about 3 in. $(76 \mathrm{~mm})$. However, it greatly deteriorates if exposed to the high heat associated with stagnation. Should stagnation be a possibility, consider some sort of pipe wrap as an inner protection. Rigid foam is not readily affected by water, but it is also not waterproof. As a matter of fact, water coming in contact with some rigid foams and pipe will create a mild acid which will deteriorate the pipe, so it must be well waterproofed. Rigid foam also cannot take the flexible shapes of ten required with solar. 


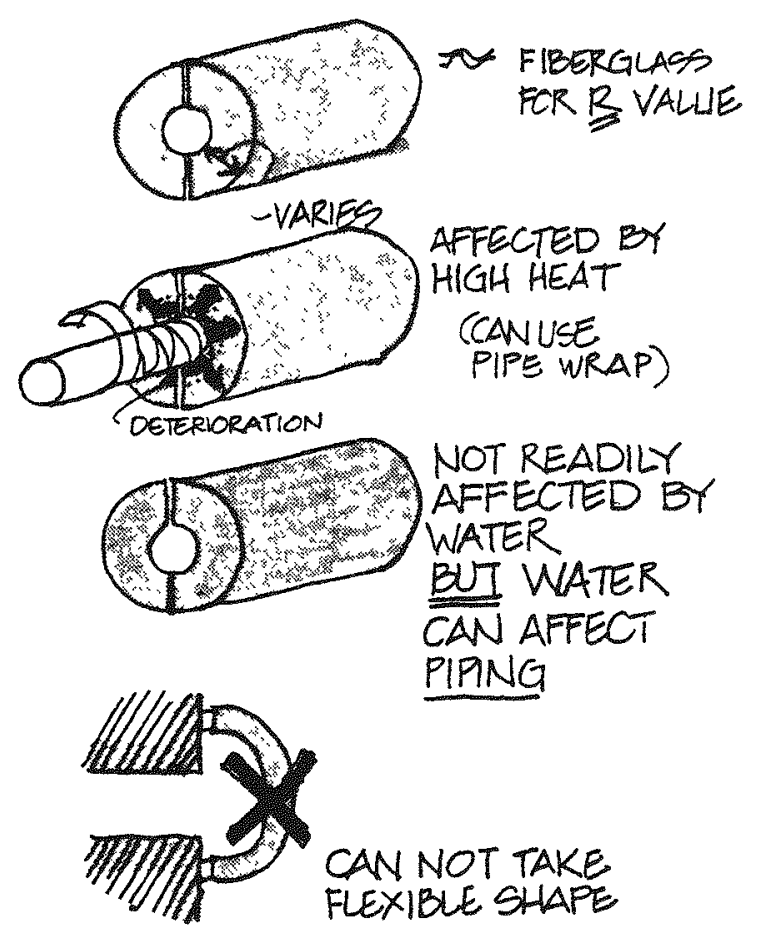

Fig. 14-112. Rigid foam insulation

Flexible foam is available in very limited thicknesses: only $1 / 2-i n$. or $3 / 4-i n .(12-19 \mathrm{~mm})$. To increase the $R$ value, put on a second layer at double the cost. It is affected by high heat; possibly, the use of pipe wrap would aid in this problem. It is not affected by water; it is waterproof and can be used as its own waterproofing. However, it is affected by the Sun's ultraviolet rays. It can be painted to protect against ultraviolet deterioration. If it is not painted, serious deterioration is of ten seen in 6 months with failure within a year. A final advantage of flexible foam is that it is capable of taking any shape necessary. This material is particularly suited to exterior uses involving many bends, short sections, or penetrators, such as those encountered with exterior manifolds or interconnecting collectors.

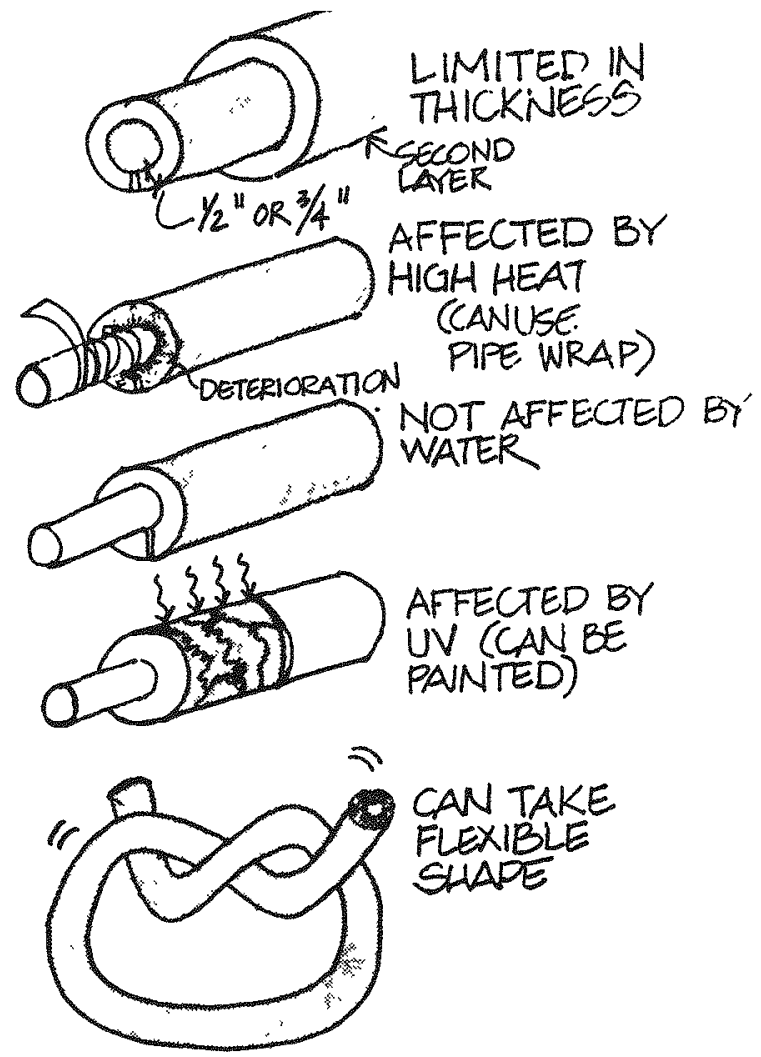

Fig. 14-113. Flexible foam insulation

Waterproofing. Common areas that require special provision for waterproofing are joints between collectors and piping, at changes of direction in pipes or pipe tees, and where valves or monitoring equipment protrude through the waterproofing. Be sure that the design and contract documents fully address these problems. Do not allow open seams in waterproofing. Provide joint protection at all elbows and tees.
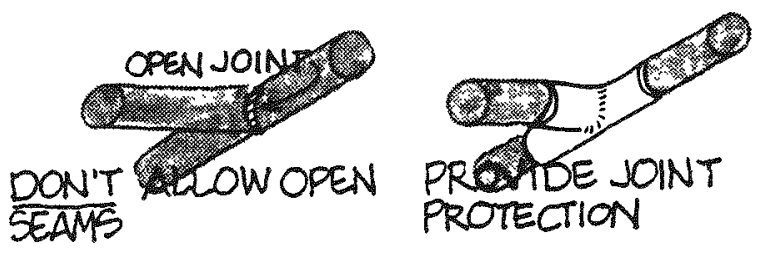

Fig. 14-114. Waterproofing joints 
Do not bind the pipes when supporting them. Be sure that the pipes are free to move or, with pipe movement, either the waterproofing or insulation will tear.

Do not support piping by puncturing the waterproofingespecially in terms of supporting the pipe directly. Not only do you puncture the waterproofing and wreak havoc with the insulation, but you also allow for a heat bridge to radiate additional energy. Support the pipe loosely on the outside of the waterproofing.
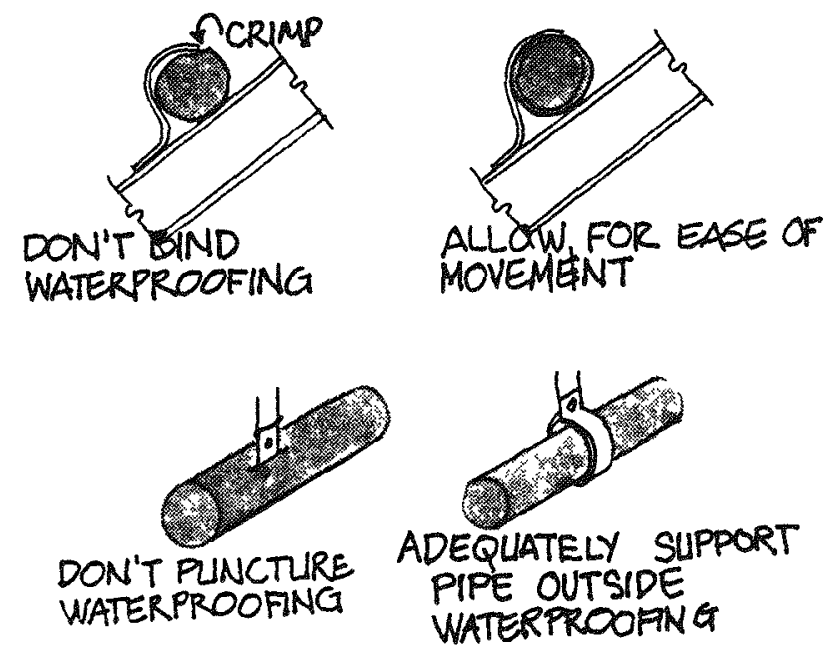

Fig. 14-115. Supporting pipes

Do not seal over the ends of sheet waterproofings. Seal between the seams or the sealant will fail with movement. Seals over waterproofing layers will fail; seals between waterproofing layers will tend not to fail.

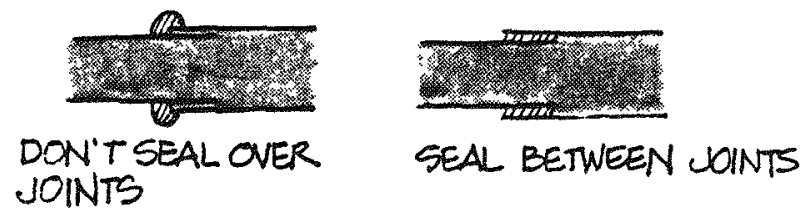

Fig. 14-116. Sealing joints

Lastly, avoid differential metals if aluminum waterproofing is used. And, if steel structures or steel clamps are used, include nonmetallic protection to prevent galvanic action. One installation had aluminum waterproofing with a sheet of galvanized steel under it but no galvanic protection between them. That waterproofing will fail. The final insulationwaterproofing approach selected should answer all the requirements of the installation factors of the design.

Flashing should be galvanically compatible with collector construction. This includes supports and fasteners. Proper dielectric insulation must be used where incompatibility exists.

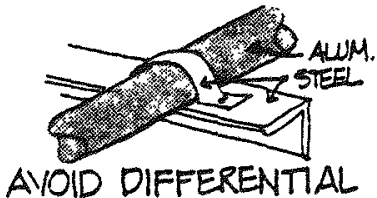

METALS...

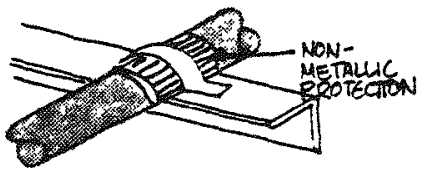

OR PROVIDE PROTECTION

Fig. 14-117. Differential metal contact

\section{Summary}

There is much more to designing an effective solarassisted mechanical system than just choosing the collector area and mechanical approach. A successful project demands a high level of attention to all details.

The designer of a solar installation does not necessarily have to trade off good aesthetic design for cost or vice versa, but one must consider each solar component and its ul timate impact on the function and appearance of the building and work toward an attractive and cost-effective solution. This solution must then be fully transmitted to the contractor.

\section{Conclusion}

Cost considerations: For solar projects to be cost-effective the architect/engineer must isolate the different cost tradeoffs and choose the most effective approach.

Construction considerations: The $\mathrm{A} / \mathrm{E}$ must isolate all construction problems and solve them. Details and specifications must address each problem. The $A / E$ must follow up with sufficient field visits so problems are not solved by the contractor.

\section{Acknowledgment}

The author wishes to thank the following persons for their help in the preparation of this document: Illustrations, by the Ehrenkraintz Group-Stephen Dalton, Stephannie Bartos, Christopher Burg, and Barry Donaldson; Editing, by the Ehrenkrantz Group-Anne Reynolds and Joan Goldberg.

Special appreciation is given to Ron Kirkpatrick of PRC Energy Analysis Company for his efforts. 
Engineering Concerns in Solar System Design and Operation

The National Solar Heating and Cooling Program is being conducted by the Department of Energy as mandated by the Solar Heating and Cooling Demonstration Act of 1974. The overall goal of this demonstration program is to assist in the establishment of a viable solar industry and to achieve a substantial reduction in fossil fuel use through widespread use of solar heating and cooling applications. An analysis and synthesis of the information gathered from this program are disseminated in site-specific reports and summary documents as products of the National Solar Data Program. These reports cover topies such as:

- Solar Project Description

- Project Costs

- Maintenance and Reli ability

- Operational Experience

- System Perform ance Evaluation

- Monthly Perform ance Reports

This section has been prepared to help architects and engineers avoid some of the problems which have typically been encountered in solar heating and cooling installations. The primary focus of the discussion is on engineering concerns associated with the startup and operation of solar systems. Recommendations are also made regarding the design and installation phases to help avoid these problems.

Some of the information for this section is based on PRC's extensive firsthand involvement with the Solar Demonstration Program, which includes over 100 design reviews, visits to $m$ any operational sites to collect information for solar project descriptions and cost documents, - and experiences gained in project management for a number of operational sites.

\section{Overview}

Use of solar energy involves a certain number of unique considerations not common to conventional heating and cooling systems. Once these considerations are understood, the vast majority of design factors associated with solar systems are the same as those for conventional systems. The primary difference between solar and conventional HVAC (heating, ventilating, and airconditioning) systems is that solar exaggerates the limits of certain operational parameters, especially in the areas of ambient and fluid temperatures. As a result, solar generally requires greater attention to detail during the design and installation phases. This point will become clearer as specific problem areas are discussed.

\section{Solgr System Startup (Solar Loop)}

Thermal Shock. In some cases, solar collectors have been damaged by thermal shock when the collectors were initi ally filled. On a sunny day, an empty (dry) collector can reach very high temperatures. The absorber may be $450 \mathrm{~F}\left(232^{\circ} \mathrm{C}\right)$ in a flat plate collector, $600 \mathrm{~F}\left(315^{\circ} \mathrm{C}\right)$ in an evacuated tube collector, and over $1000 \mathrm{~F}\left(538^{\circ} \mathrm{C}\right)$ in a concentrating collector. In this situation, the fluid entering the dry collectors on initial startup will be hundreds of degrees cooler than the absorbers. In situations where this has not been avoided, there have been cases of broken glazings and/or absorber warpage with flat plate collectors, and cracking or exploding of tubes in evacuated tube collectors. This situation can be easily avoided by ensuring that the initial system fill is done during the early morning, before the Sun has a chance to heat the collectors.

Thermal shock can be an ongoing operational concern with drain-down systems because they are emptied and filled routinely. If the solar pump is off during the morning for maintenance or because of a power failure and then turned on during the middle of a sunny day, the collectors will have reached a high stagnation temperature. To prevent the solar pump from starting whenever the maximum safe collector temperature is exceeded, a high limit temperature sensor connected to a pump lockout control should be installed on the collector absorber.

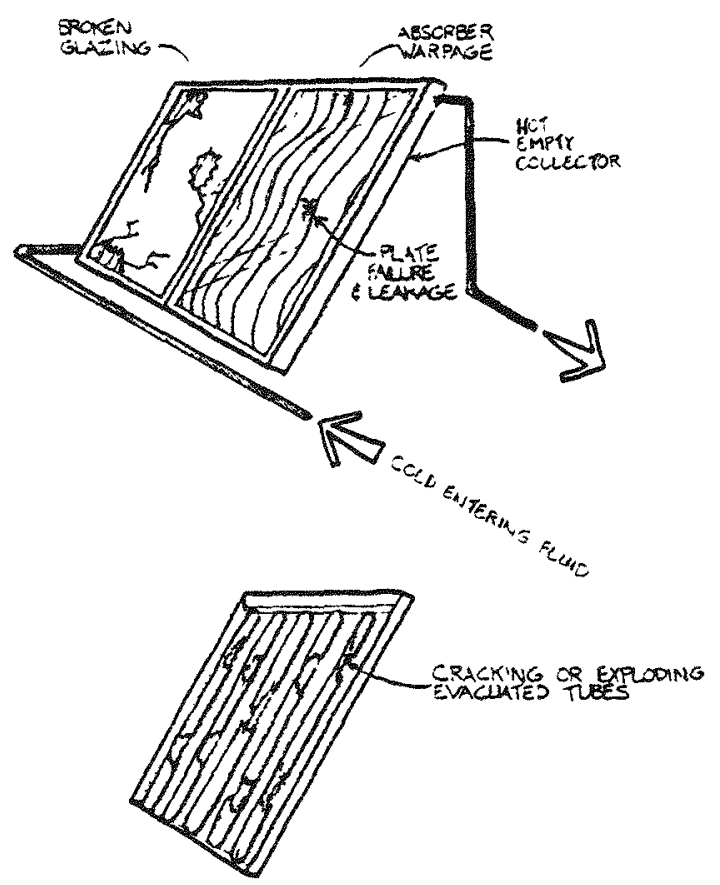

\section{Fig. 118. Damage to collectors due to thermal shock}

Cold Morming Startup. System perform ance can of ten be improved during winter morning startup of large antifreeze-filled collector arrays by adding a bypass warmup mode. When the Sun has heated the collectors above the storage tank temperature, the solar pump starts, yet a significant volume of very cold liquid is still contained in the piping external to the building. Heat can actually be removed from storage as cold liquid from external piping passes through the heat exchanger, delivering chilled water to the thermal storage tank. 
System performance can be improved by bypassing the heat exchanger until the entire solar loop has been warmed above the storage temperature.

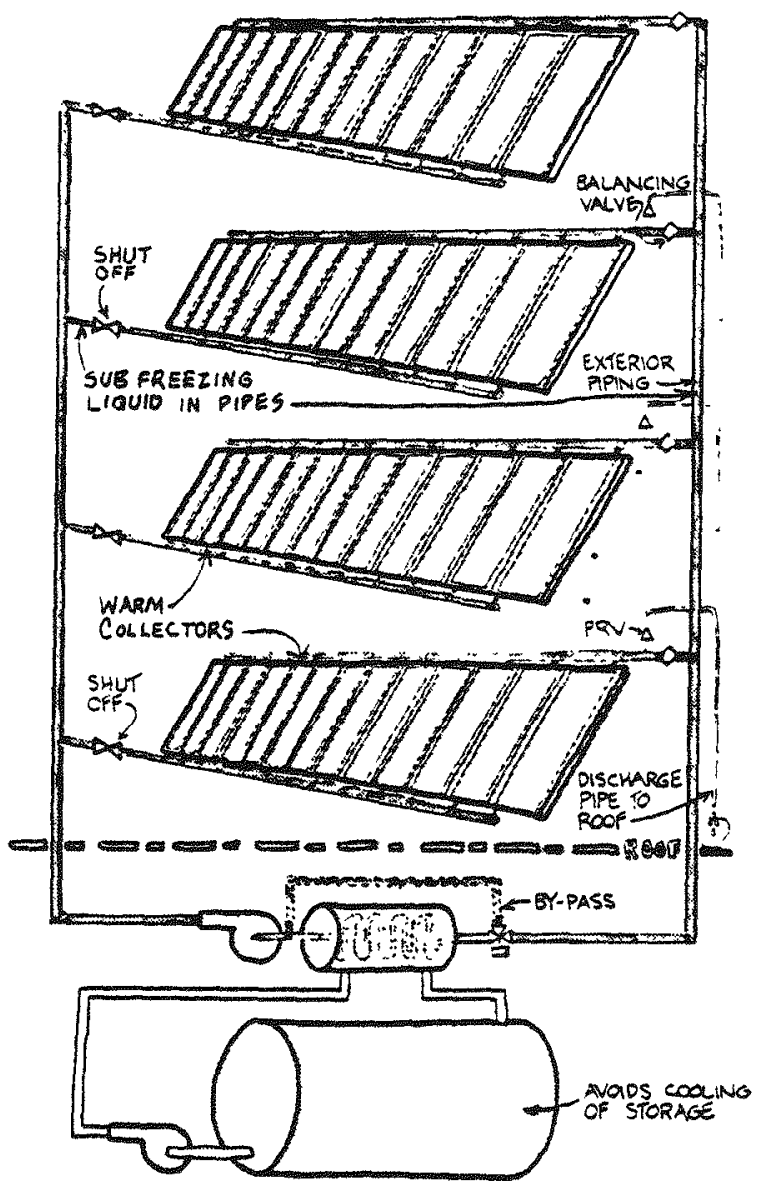

Fig. 14-119. Bypassing storage during cold morning startup

Piping and Ducting

Pressure Relief Valving. Each bank of collectors in a solar array usually has a valve in both the inlet and outlet piping. There have been cases where both of these valves were inadvertently closed while the collectors were full of liquid. The Sun heated the collectors, causing fluid expansion and generation of steam. Collectors ruptured (and exploded in one case) because a pressure relief valve was not installed between the inlet and outlet valves. This operational problem can be avoided by installing pressure relief valves (PRVs) on each collector bank. The discharge from each PRV should be piped to the roof level or to a roof drain to eliminate the possibility of scalding anyone who is next to the valve when it discharges hot fluid.

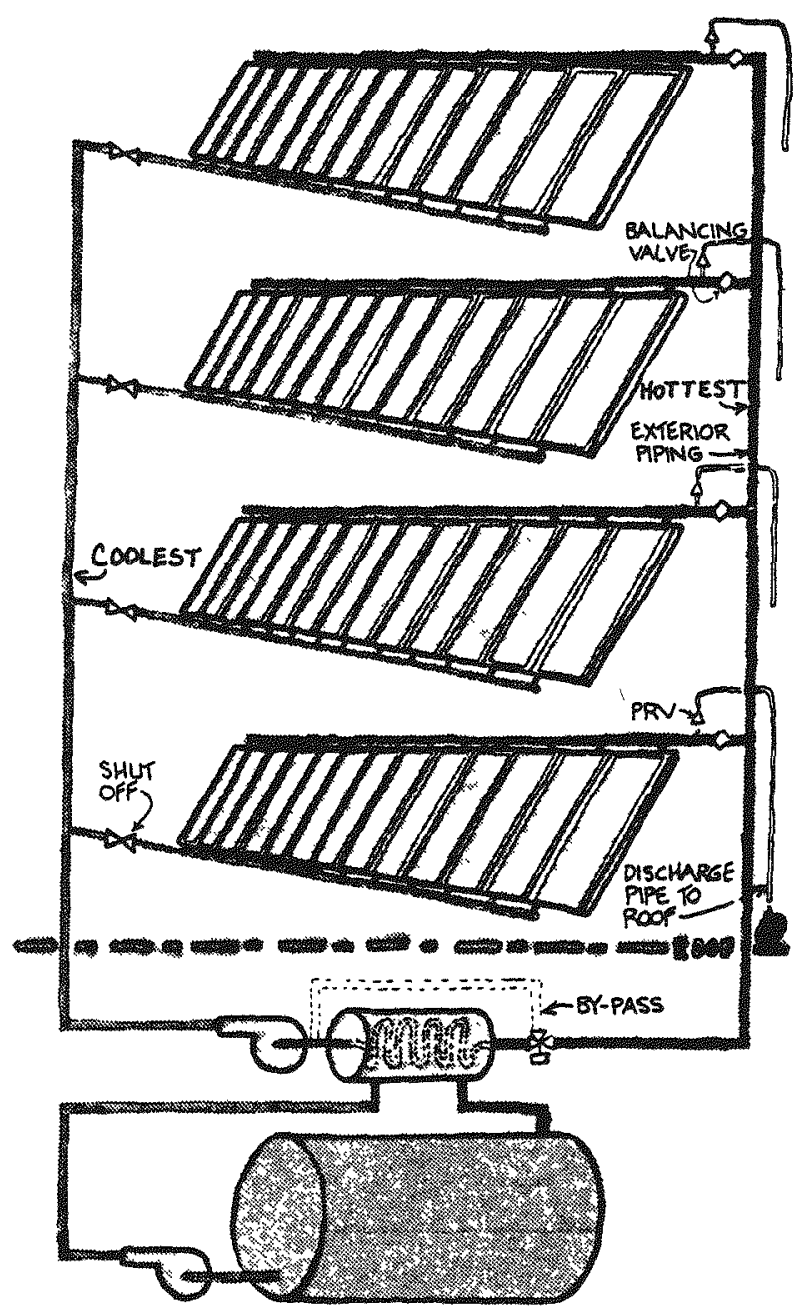

Fig. 14-120.l Location of pressure relief valves

Test Piping for Leaks. There have been cases where collector arrays were not pressure and water tested prior to insulating, waterproofing, and burying of the pipes and storage tank. Leaks were subsequently discovered at system startup. Insulation had to be removed and buried pipe uncovered to repair the system. Obviously, standard installation procedures should call for a pressure and water test of the system before the pipes and storage tanks are insulated and buried.

Collector Pipe Connections. The pipe connection to the solar collector is a critical area of concern. On long collector arrays, pipe expansion/contraction can result in more than 1 in. $(25 \mathrm{~mm})$ of travel on the supply and return headers, especially if expansion compensation is not adequate. If rigid pipe is used to connect the 
collector to the piping manifold, the absorber must be free to move. But, be careful not to rely too heavily on absorber movement; it can bind up or run out of room to move within the collector box. A "pigtail" or offset in the rigid connector should be considered to help isolate the collector from pipe expansion.

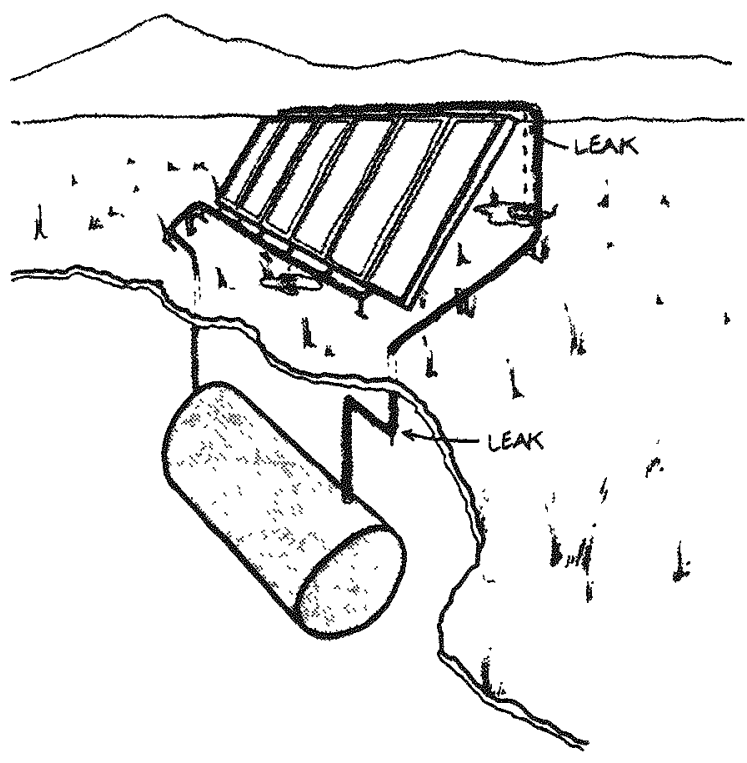

Fig. 14-121. Piping leaks
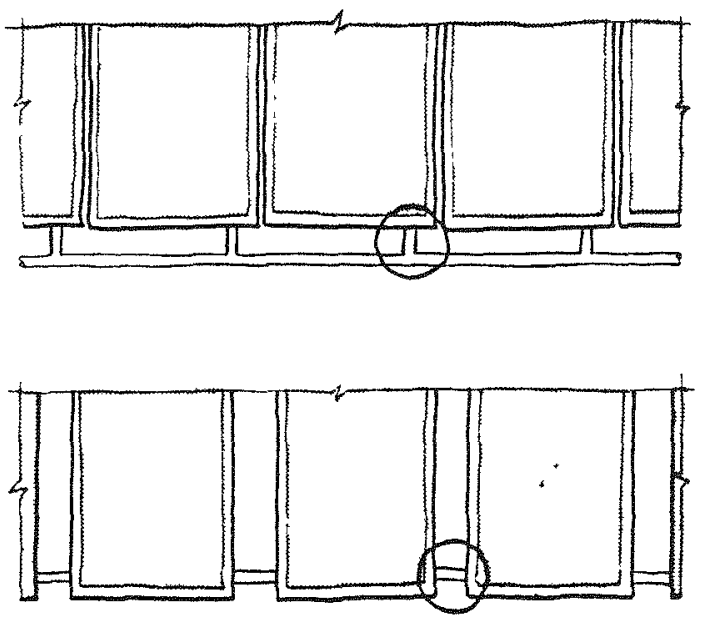

Fig. 14-122. Locations for expansion joints

Use of flexible hose is another approach often used to provide expansion compensation for the collector connectors.

A number of hose clamp types are used in this application. The screw type has occasionally sliced the hose when overtightening occurred. Smooth liners are available for screw clamps to help avoid this problem. A recommended screw torque should be considered for the specific hose material to be used. The hose may also take a "set" over time and require a yearly maintenance procedure to recheck elamp tightness.

Spring clamps have been successful in avoiding hose damage and in automatically compensating for any hose "set ting" which occurs. There have been cases, though, in which expansion cycling has gradually worked the hose loose, since a spring clamp generally has less clamping force than a screw clamp. This is of particular concern on straight hose connections between collectors with internal manifolds. A shoulder on the end of the pipe connection will help prevent this problem. Crimp clamps offer another option. Though not of ten used, they should be considered as a promising alternative.

A final precaution regarding hose connectors is to make sure the mating pipe has been deburred before installing the hose. There have been cases where small slits have been cut into the inside surface of flexible hoses (when deburring was not done), resulting in leaky connectors.
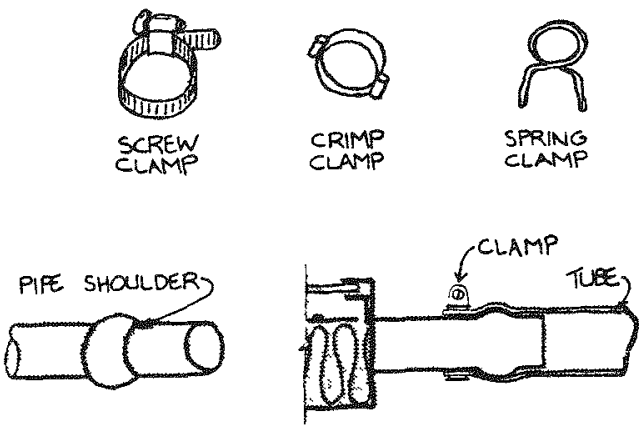

Fig. 14-123. Types of hose clamps

Air Leaks. Leaks have also been a serious concern in air collector systems. The performance of these systems has of ten been significantly degraded because of leaks in duct seams, damper shafts, collectors, and rock box joints. Duct seams should be caulked or taped (with top quality materials). Longitudinal seams should be caulked or taped prior to installation. Space should be allowed to get at cross seams after installation. Attention must be paid to tight, quality installation procedures to minimize air (and heat) losses.

Air systems have also encountered significant problems when leaky dampers have allowed unregulated flow to occur. Freezing of BSHW preheat coils has oceurred when cold air from the collectors has fallen through a loose-fitting damper across the duct-mounted coil. Loss of stored heat has also occurred when warm air has risen from rock storage up through a loose damper and into cold collectors during cloudy winter days or winter nights. Specify tight, low-leakage dampers and be certain that correct, high-quality installation procedures are followed. BSHW coils should be located so that they are protected by storage heat. 


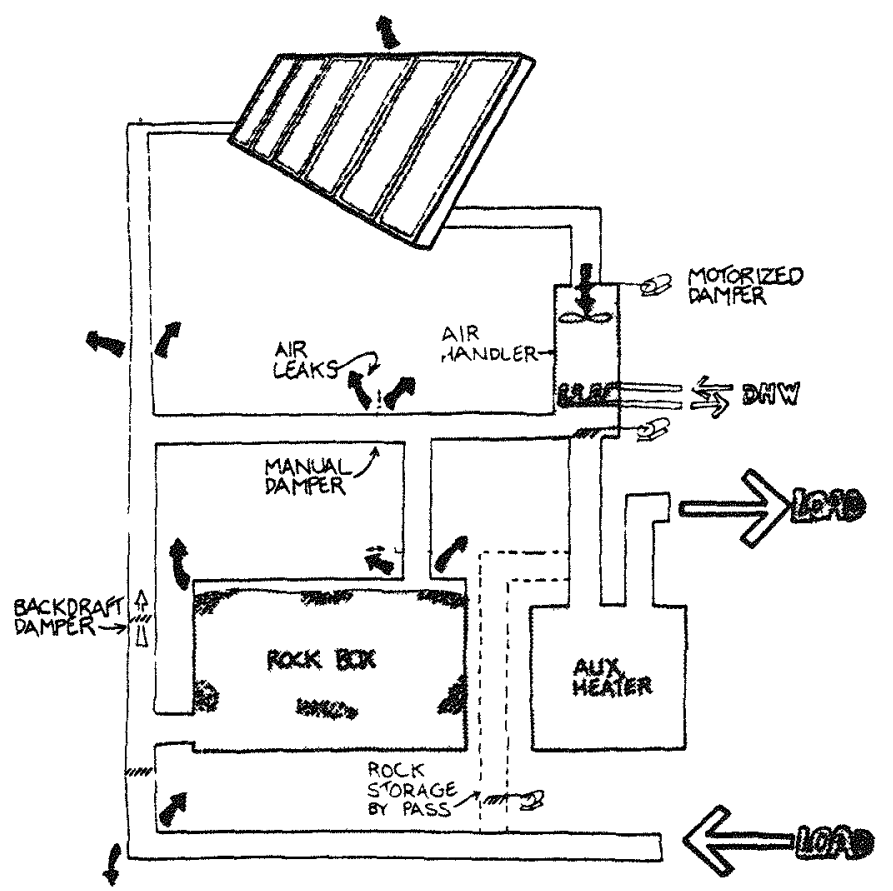

Fig. 14-124. Air system leaks

\section{Thermal Storage}

Rock Settlement. Though vertical air flow through rock storage boxes is generally the preferred configuration, air systems have occasionally used horizontal flow through the rock storage box. With this arrangement, there is a tendency for settling to occur over time, creating an air space above the rocks. If the rocks are tamped down and allowed to set for a few weeks before the top of the rock box is installed, the air gap will be minimized. If an air gap does occur, air will take the path of least resistance and pass over the top of the rocks, essentially bypassing storage. To be certain this will not occur, baffles should be installed from the top of the box into the rocks, perpendicular to the air flow.

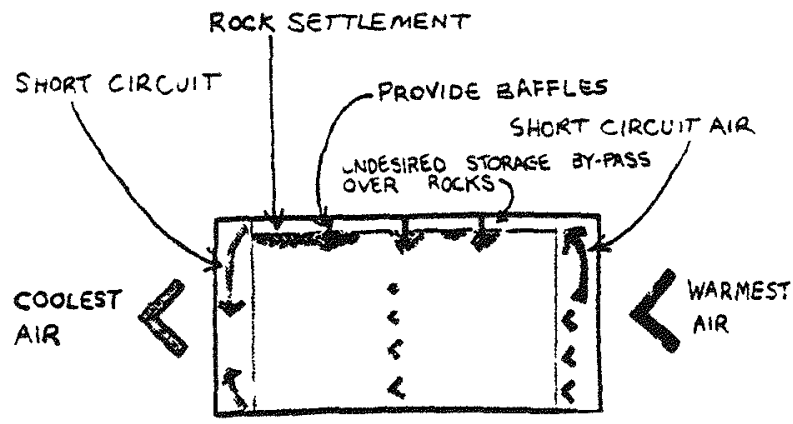

Fig. 14-125. Settling in a horizontal flow rock box
Flow Channeling. In a few cases, flow channeling has been inadvertently designed into the rock storage box. This occurs when the inlet and outlet plenums do not allow flow through the entire cross section of the rock box. When the plenums are open to the entire cross section of the box, the full volume of rock is active in the energy storage process.

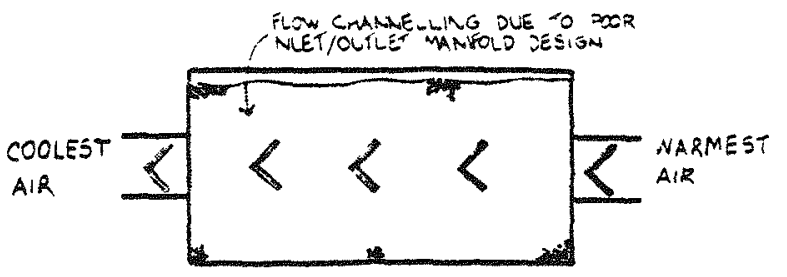

Poor Distribution

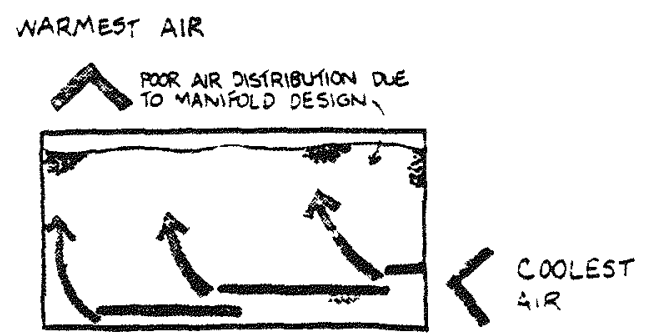

Fig. 14-126. Air flow through horizontal flow rock beds

Flow channeling has also occurred in liquid storage tanks. Sometimes this may actually be desirable between two different thermal loops, such as the solar loop and the building heating $100 \mathrm{p}$. In this case, if the supply of solar-heated liquid is located adjacent to the point where water is drawn from the storage tank to heat the building, the hottest water in storage is delivered directly to the load whenever solar heat is collected.

Flow channeling in liquid storage is also undesirable, though, if it occurs across the storage tank within one flow loop. For example, in some systems the inlet and outlet to the building heating loop were installed on the same end of the storage tank. Flow channeling between the inlet and outlet results in significant bypassing of available stored energy. The inlet outlet on any one flow loop should be installed at diagonal locations across the tank to improve flow distribution. A horizontal discharge pipe with many holes along its length will help greatly in assuring that flow channeling cannot occur within a given loop.

Stor Bypass. Unless Iow off-peak electric rates are available for an electric boiler, it is generally undesirable to use an auxili ary heat source to heat the storage tank. There is usually no benefit in storing auxiliary energy, 


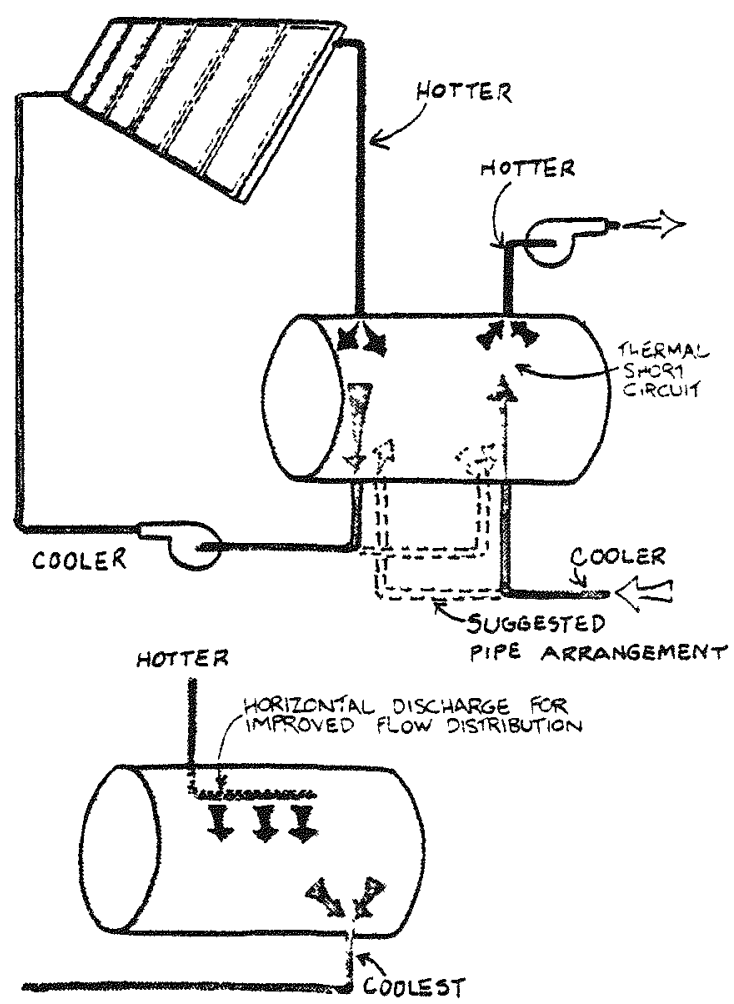

Fig. 14-127. Flow through a liquid storage
tank

since it is "always" available-unlike solar-while there is a penalty associated with energy storage due to standby heat losses. The flow loops should be carefully examined since there are of ten subtle paths which allow auxiliary heat to be supplied to storage.

\section{General Design Factors}

Heat Directly from Solar Loop. Try to allow for the capability of using heat directly from the solar loop to the building load. It appears that overall system efficiency is improved when the system includes this capacity. When the storage temperature is depleted on a partly cloudy day, a 2-hour period of sunlight may not be adequate to raise the storage to a usable temperature. Overnight standby losses from storage can significantly eliminate heat stored during the short collection period of the previous day. Whereas, if the collected solar energy is supplied directly to the load-bypassing storage-a net positive contribution from solar can be provided.

Absorption Cooling. Absorption chillers offer an attractive opportunity to use solar energy during the summer, but care should be taken in selecting the source of backup energy. Some systems that use a backup boiler to supply auxiliary energy for the absorption chiller use as much or more energy for backup as a conventional electric chiller would require to meet the entire cooling

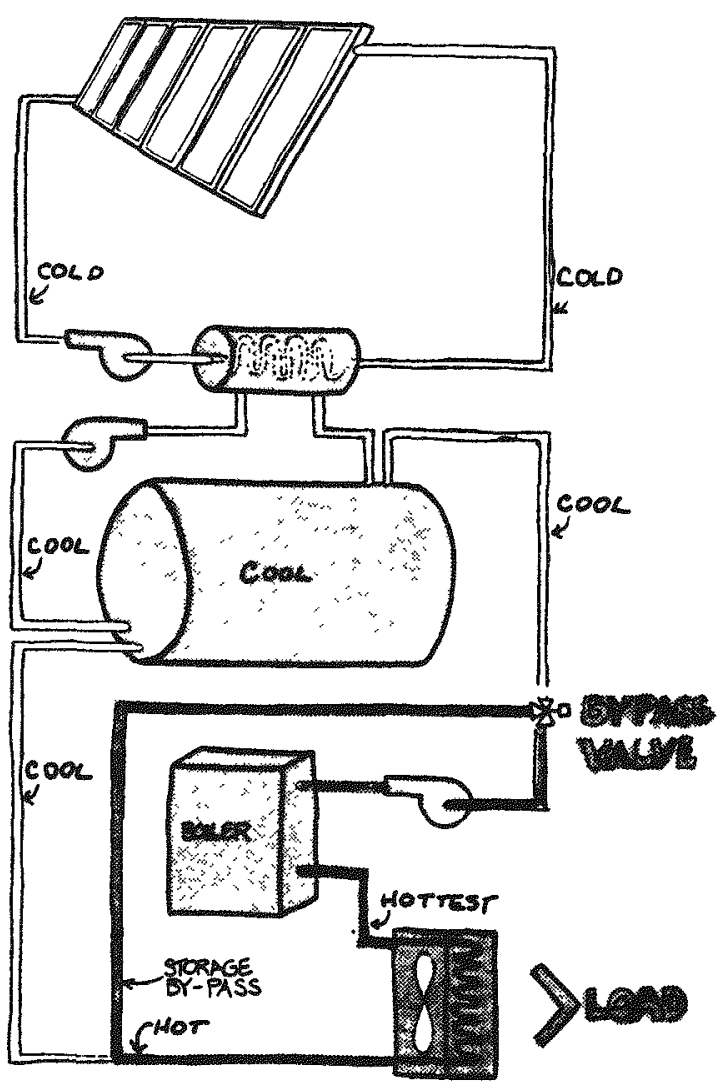

Fig. 14-128. Auxiliary heating system

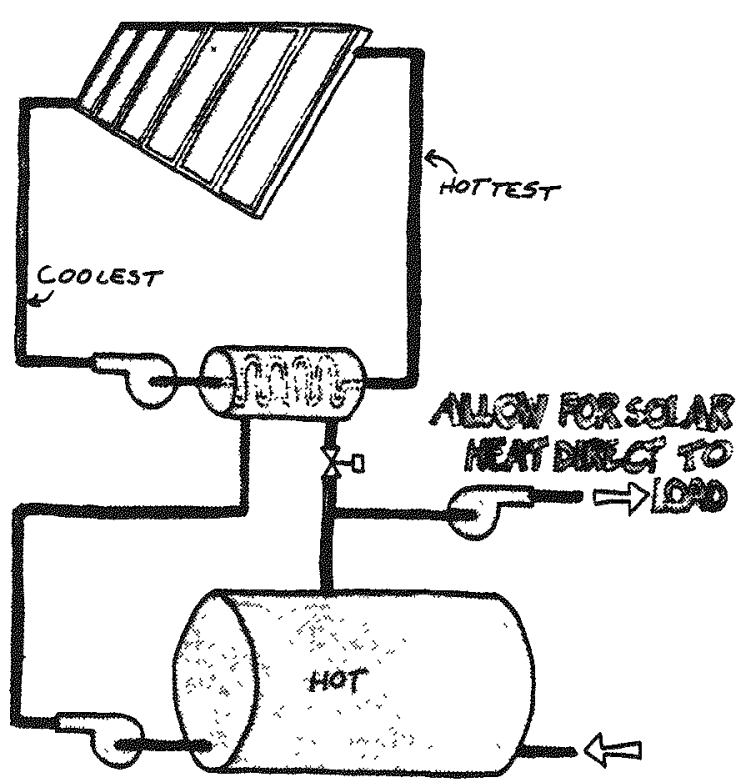

Fig. 14-129. Heating directly from the solar loop 
load. If solar energy provides approximately $80 \%$ of more of the annual input heat requirements for the absorption chiller, use of a backup boiler is acceptable. If the solar contribution is less than $80 \%$, an electric chiller should be considered as the backup for the absorption chiller. The reason for this is that an absorption chiller requires five units of input energy (in the form of solar heat) to provide three units of cooling energy out, while an electric chiller requires only one unit of input energy (in the form of electricity) to provide the same three units of cooling. The analysis becomes more complicated, though, if a consideration is made for the $33 \%$ fuel efficiency associated with electric generation.
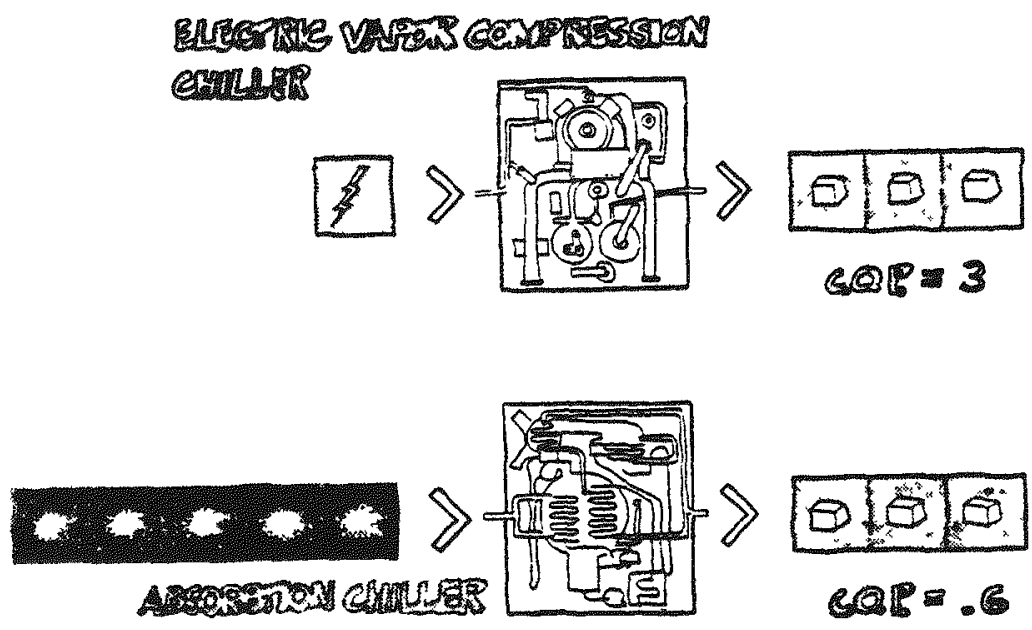

Fig. 14-130. COP of an electric vapor compression chiller vs. an absorption chiller

Proper Equipment Sizing. The need for correct sizing of equipment is obvious in any heating and cooling system. With solar systems, the impact of incorrect sizing is substantial, because of the relatively large initial investment required for the solar array.

An oversized solar array will be costly; it will also require a method of heat rejection. If the array is undersized, a poor solar contribution resul ts.

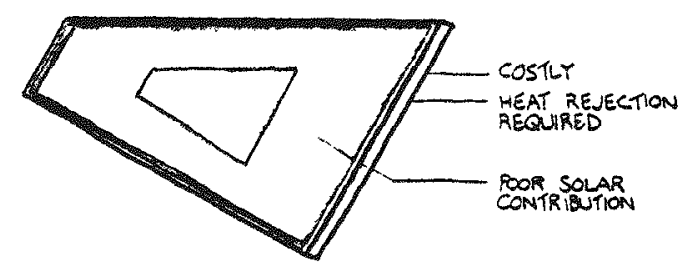
Fig. 14-131. Too large vs. too small of a
collector
Oversized pumps consume excess energy; turbulence and flow balance problems can also result. Undersized pumps have failed, requiring the installation of new, larger pumps. Higher collector temperatures and lower collector efficiency also result if the pump flow rate is too low for the collector array.

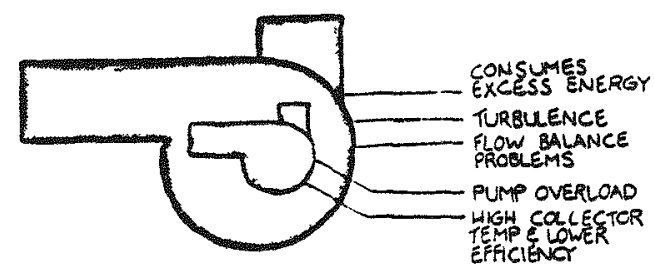

Fig. 14-132. Too large vs. too small of a pump

Correct sizing of heat exchangers is critical. If they are undersized, the sol ar system capacity is choked off at the heat exchanger, resulting in reduced system efficiency. An investment in added heat exchanger capacity is well worth the initial cost, considering the high relative cost of unused collector array capacity.

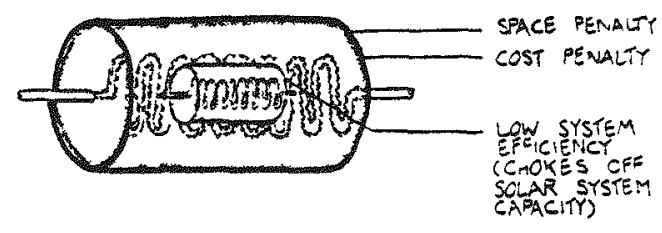

Fig. 14-133. Too large vs. too small of a heat exchanger

Storage tanks which are oversized of ten result in unusable low-grade heat, as well as adding both cost and space penalties. Undersizing storage can prevent the use of available solar energy once the maximum allowable storage temperature is reached. Heat rejection may also be required at this point. To achieve op timum efficiency during system operation, it is obvious (yet worth reemphasizing) that a thorough engineering analysis must be made during the design phase regarding building loads and optimum sizing for interrelated components.

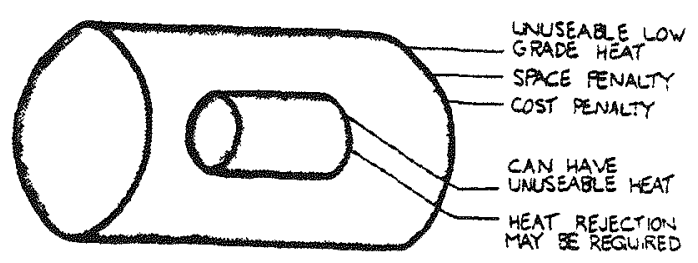

Fig. 14-134. Too large vs. too small of a storage tank 


\section{Controls and Sensors}

Night Setback Control. When night setback of building thermostats is used, an important yet simple means of improving solar system effectiveness has of ten been overlooked. Some systems use a two-stage thermostat to control both the solar and auxiliary heat. For example, if the building temperature drops below $68 \mathrm{~F}\left(20^{\circ} \mathrm{C}\right)$ heat is delivered from solar storage. If the solar system cannot keep up with the load and the building temperature drops to $65 \mathrm{~F}\left(18^{\circ} \mathrm{C}\right)$, the auxiliary heat comes on. When night setback of the building temperature is used in conjunction with this two-stage control approach, auxiliary heat will always go on when the thermostat is moved forward to the daytime setting. A time delay on activation of auxiliary heat at morning setup of the building thermostat will give the solar system a chance to satisfy the load without requiring backup energy.

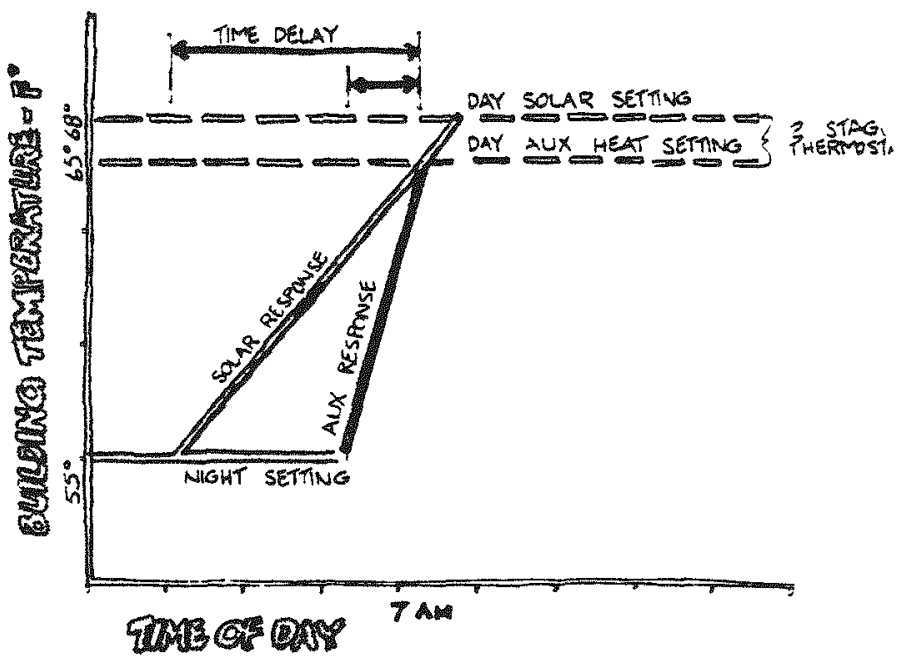

Fig. 14-135. Night setback control

Solar Sensors. The operating efficiency of solar systems has been degraded in some cases because of the improper location or installation of the collector temperature sensor. The sensor is a critical component because it is used to determine when solar energy is available. Collector temperature sensors provide more accurate control when located directly on the absorber, rather than in the return pipe above the collector. This is due to the fact that no flow passes the pipe-mounted sensor prior to startup, and it must rely on conduction and convection of heat up from the collectors for an indirect measurement of the collector temperature.

Make sure the temperature sensor for the collector is tightly mounted to the absorber surface. In one case, a loosely mounted sensor caused cooling of storage at the end of the day. The mass of the sensor retained enough heat after the solar input dropped off and the absorber had cooled to indicate falsely that solar heat was still available. Corrosion protection for these sensors should also be considered. In some instances, periodic condensation in the collector caused gradual corrosion of the collector temperature sensor, resulting in erroneous system control. Collector sensors should be installed in the factory, and backup sensors should be provided.
Occasionally, pyranometers are used to indicate when an adequate level of insolation is available for solar pump startup, particularly for evacuated tube systems. Even on cloudy days, heat gradually rises to a high level in the tube, and overheating can be a concern. To avoid this problem, the threshold limit for startup had to be reduced to a lower level of incoming Btu. When pyranometer controls are used, back up sensors in the return piping are mandatory if snow occurs.

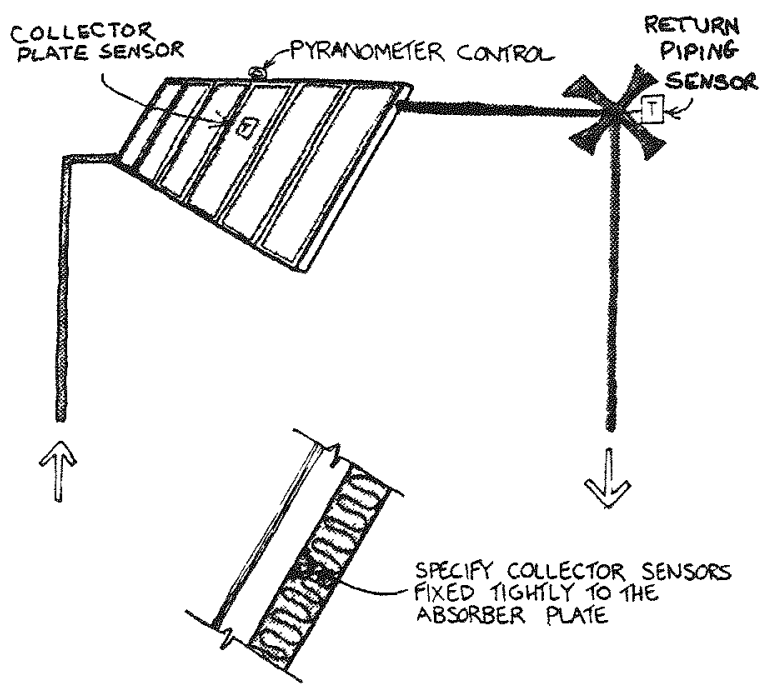

Fig. 14-136. Location of collector temperature sensor

Storage Tank Sensors. The location of the storage tank temperature sensor has not always been well thought out. This sensor should not be located too near the point where solar-heated liquid is supplied to the tank. If it is located too near this point, the sensor may indicate that the collectors are not substantially warmer than storage, and pump shutoff and cycling can occur. The potential effects of stratification within the tank must also be considered when locating this temperature sensor.

In some cases horizontal stratification has been achieved by using baffles to create chambers along the length of a tank. Again, if the temperature sensor in the storage tank is located in the hot end of the tank, it may falsely indicate that the collectors are not substantially warmer than storage, and pump shu toff and cycling can occur.

Visual Sensors for Monitoring. Make sure that an adequate number of sensors are installed to allow monitoring of solar system perfor mance. In many cases this has not been done, making it difficult to troubleshoot and evaluate system performance. Use of an adequate number of sensors should be a standard design practice with any heating and cooling system. As a minimum, temperature sensors should be installed at the inlet and outlet to collectors, heat exchangers, storage, and the building load, with pressure gauges at the inlet and outlet of the pumps. Also be sure that there is sufficient monitoring capability so as to enable the accurate setting of balancing valves within an array. 

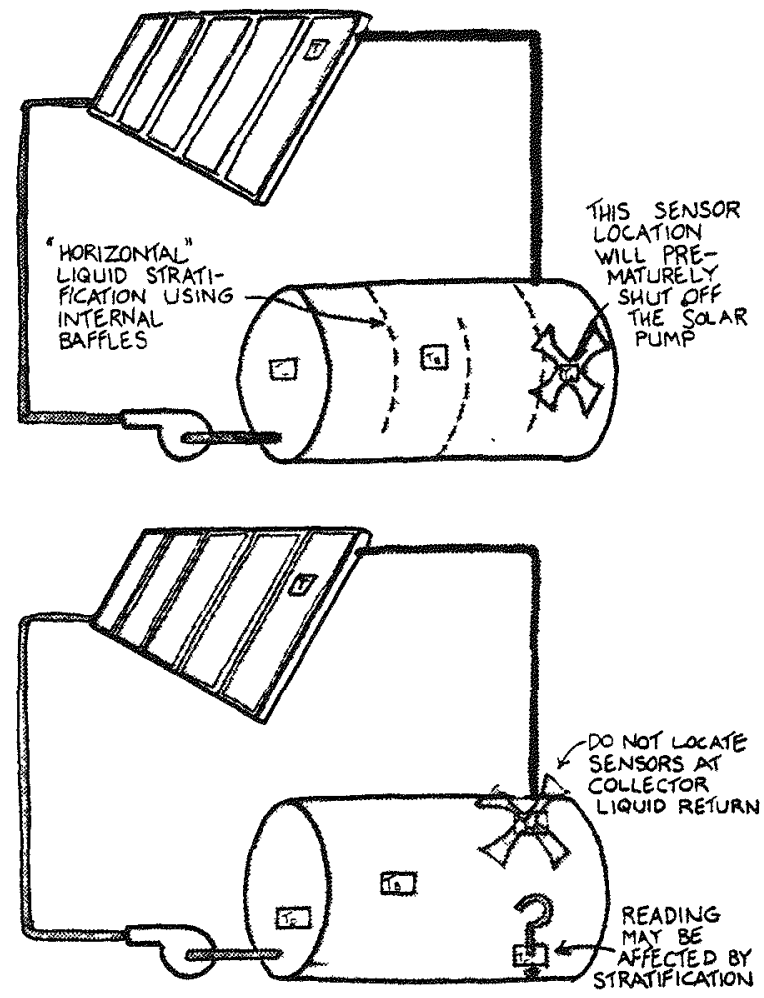

Fig. 14-137. Location of storage tank temperature sensor

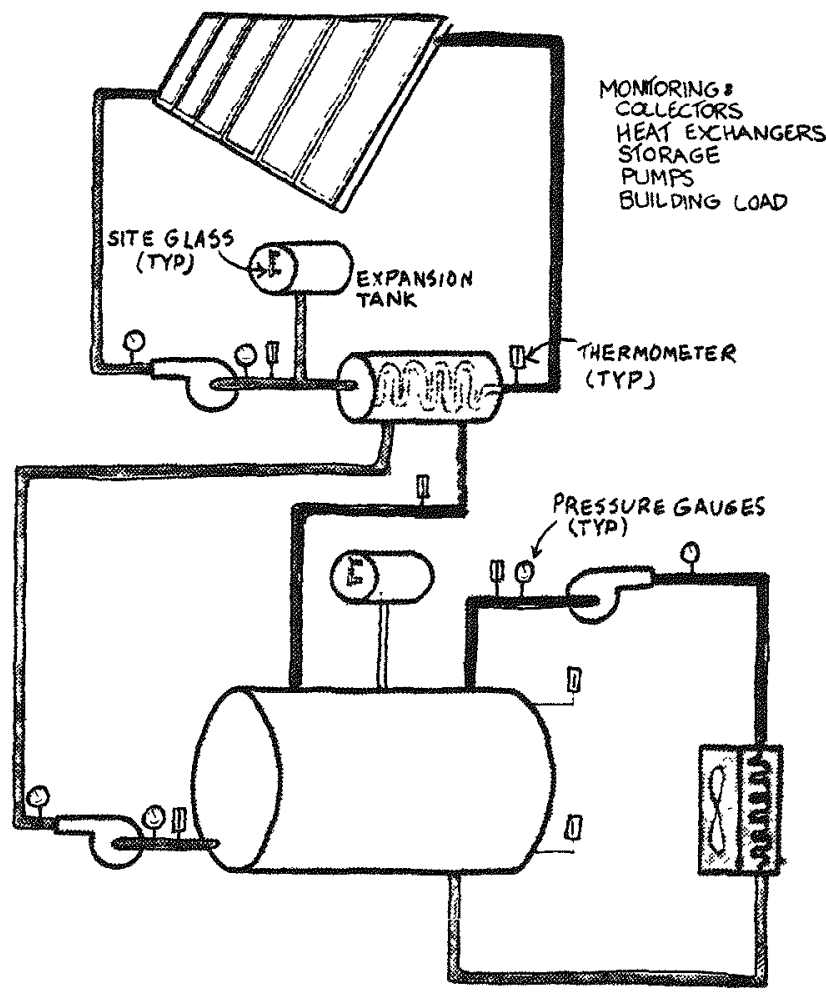

Fig. 14-138. Location of sensors throughout the system

\section{Transport Fluids}

Automatic Makeup Water. Use of automatic makeup water should generally be avoided in the sol ar loop. Some systems that use antifreeze as the solar transport fluid have frozen because of the use of automatic makeup water. This was due to reduction in the concentration of glycol as more and more water was added over a period of time. A makeup tank of premixed glycol or a lowlevel alarm in the expansion tank to signal the need for the manual addition of antifreeze is preferable. Automatic makeup water should also be avoided for drain-down systems. In one case the automatic makeup valve leaked and refilled a drained collector array. Unfortunately, the temperature was below freezing and the collectors froze.

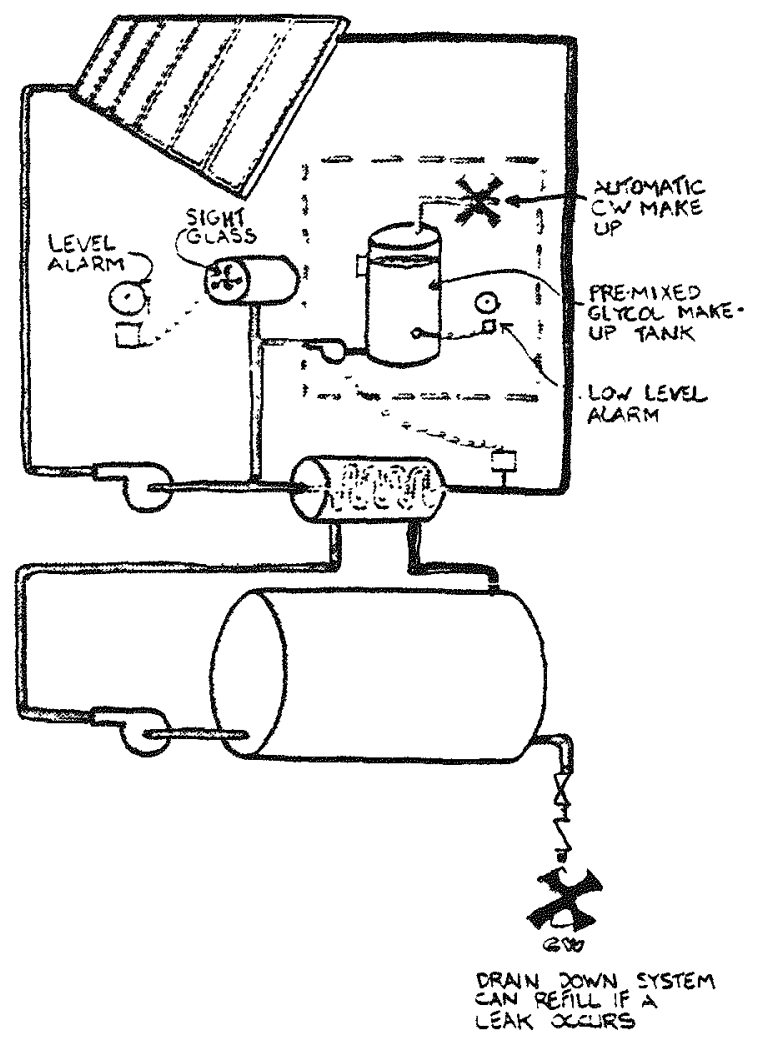

Fig. 14-139. System with automatic cold water makeup

Transport Liquid Chareteristics. When solar-heated hot water systems use a nonpotable fluid on the solar side of the loop, a double-walled heat exchanger must be used. With an all-water system it is questionable whether the water in the main storage tank is still potable after 2 years of operation. The water should be checked periodically and replaced if necessary to assure that it is potable; otherwise, a double-walled heat exchanger may be necessary. Antifreeze products range from highly toxic to potable. If potable antifreeze is used, valve tags and maintenance procedures should clearly identify the brand of fluid to be used for refilling. Oil transport fluids are generally nonpotable. Corrosion inhibitors range from highly toxic to potable. 
Acidity of glycol systems should be monitored over time. If high stagnation temperatures occur in the collectors [approxim ately $300 \mathrm{~F}\left(150^{\circ} \mathrm{C}\right)$ ] antifreeze tends to become acidic. When this occurs, chemicals can sometimes be added to correct the $\mathrm{pH}$ level, or the antif reeze may have to be replaced.

The HVAC industry has developed a standard practice of attempting to minimize the amount of suspended air in heat transfer fluids to reduce corrosion problems in piping systems. Solar drain-down systems have of ten ignored this precaution. It is possible to design a closedloop drain-down system that prevents the constant addition of new air into the system.

Leakage is more likely to occur with antifreeze and oil tranport fluids than with water. Care should be taken in pump and seal selection to assure compatibility with the transport fluid. Serewed fittings must be especially tight to prevent leakage.

Antifreeze boil-off should be prevented. A residual sludge can be left in the collectors if the antifreeze is allowed to boil, eventually causing flow restrictions inside the collectors.

\section{Freeze and Boil Protection}

Recirculation. There are three basic approaches to freeze and overheat protection for systems that use liquid in the collector loop. The first type uses circulation of warm water from storage to the collectors and exterior piping to prevent freezeups. Usually, this is considered for moderate climates where freezing is infrequent, or where evacuated tube collectors are used and collector losses are minimal. Some of these systems have paid a high price in reduced system efficiency as a result of the freeze protection made. A thorough analysis of total heat loss with this approach should be made in the design phase. Even though losses are minimal with evacuated tubes, extensive outdoor piping can drain off a substantial amount of energy.

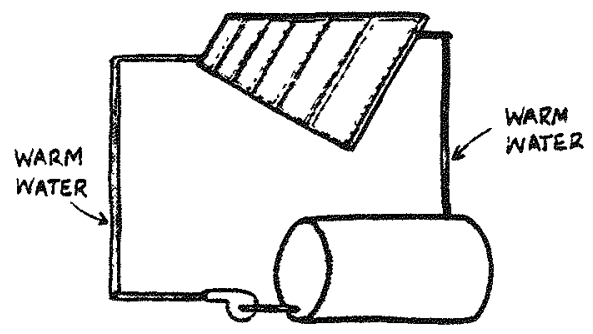

Fig. 14-140. Freeze protection through
recirculation of stored water

Drain Down. A second basic system type is the draindown system. With this approach, all water in the collectors and exterior piping is drained into the storage tank to prevent freezing. There have been a number of problems with these systems which will be discussed later in this section.

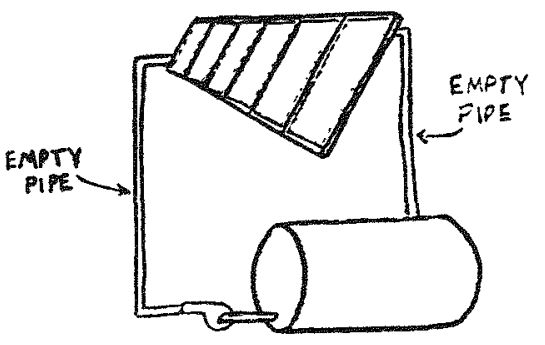

Fig 14-14-141. Drain down system

Antifreeze. The third freeze protection approach uses antifreeze in the collector loop. Make sure the glycol concentration is adequate to prevent freezeups. This seems quite obvious, yet problems have occurred in this area. Also, consider a heat dump for glycol systems when building loads do not meet the solar output. As discussed earlier, acidity and sludge formation can occur if the collector fluid is allowed to boil.

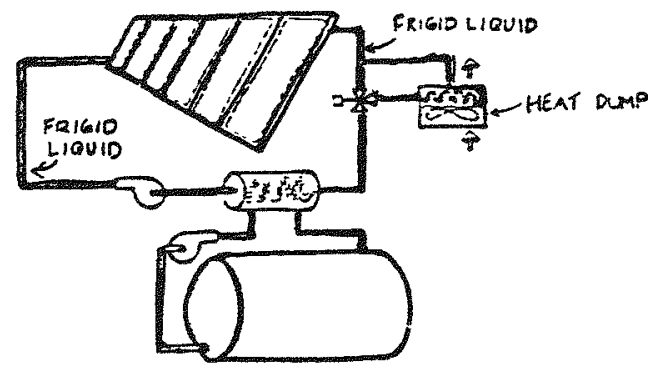

Fig. 14-142. Freeze protection with anti-
freeze

Provisions for Power Failures. Provisions for power failures are frequently overlooked. Water systems are sometimes designed for mild climates with no antifreeze and no drain-down capability. A mode in which city water is flushed through the collectors for freeze and overheat protection is occasionally used with these systems. In dry western states, this system can waste precious water resources. Separate battery-operated sensors may be used to measure collector overheat temperatures and freezing air temperatures. In this arrangement, water will only be flushed through the system when boiling or freezing of collectors is a danger. Another option which should be seriously considered is to install a small emergency generator to operate the solar pump and the heat dump blower whenever power is lost.

Drain-Down Preeautions. As mentioned above, draindown systems have been prone to a number of freezeup problems. Make sure that the type of balancing valve chosen will not trap water when partially closed for balancing. Make sure pipes are adequately supported to prevent sagging; freezing has occurred in pipes when this 


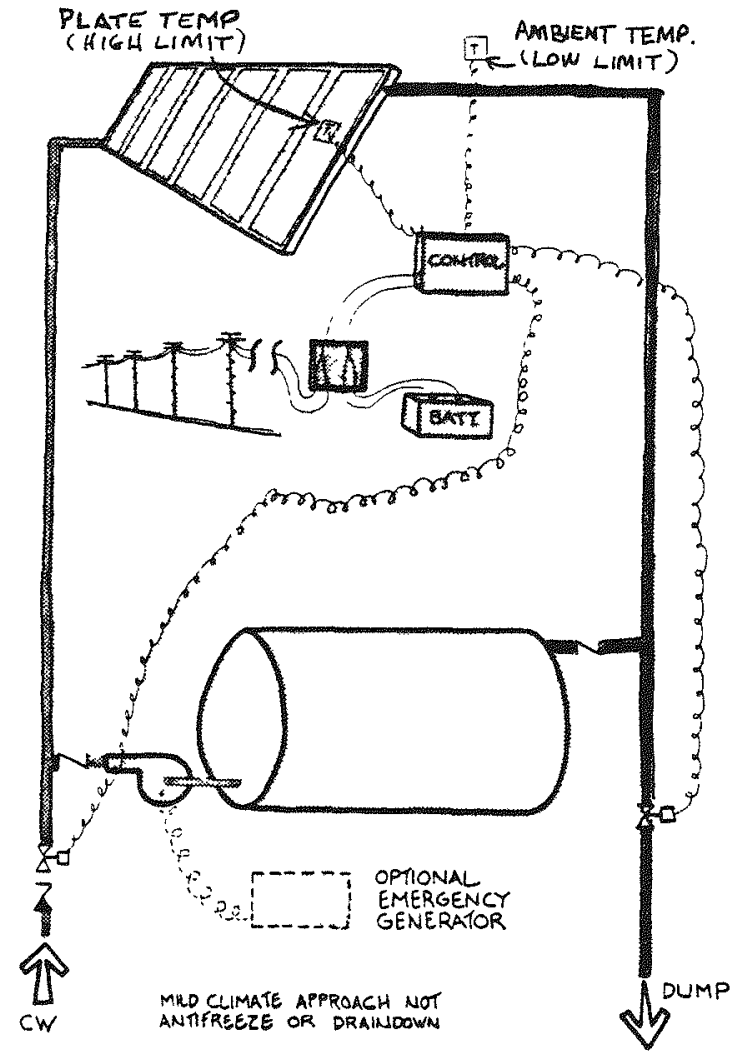

Fig. 14-143. Protection against overheating and freezing during power failures

was not done. After installation, inspect flexible hoses to ensure inat sagging low points are not present; water has collected and frozen in connectors when this was not checked.

\section{Conclusion}

The majority of problems associated with solar system startup and operation are actually common to the heating and cooling industry, although some are exaggerated in

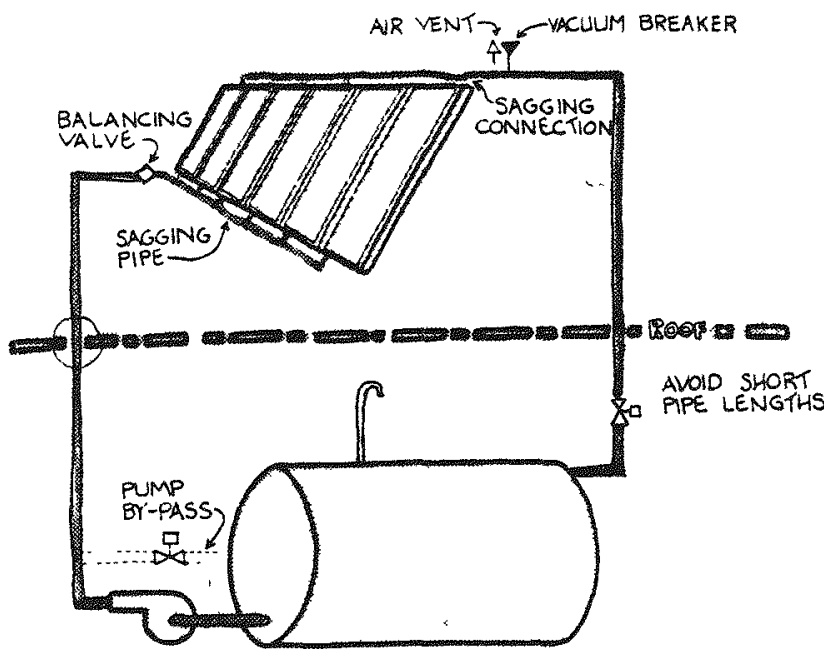

Fig. 14-144. Precautions in drain down systems

solar systems. Increased attention should be paid to areas such as sensor location, thermal shock, expansion/ contraction, leaks, and weathering.

Overall, most problems encountered with solar energy are not new. Many of the problems that have occurred were caused or intensified by excess system complexity; so keep the system as simple as possible. Trying to find "the problem" in a tangle of pipes, pumps, and control valves is a major headache. When problems do occur, it is very important to have an adequate number of sensors installed in the system to allow for trouble-shooting and monitoring. Finally, try not to reinvent the wheel with solar; the application of good HVAC practices is essential for successful system operation.

\section{Acknowledgment}

Graphics in this section were prepared by the Ehrenkrantz Group. 


\section{Standards}

Interim Performance Criteria for Solar Heating and Cooling Systems in Residential Buildings

Background. Public Law 93-409, the "Solar Heating and Cooling Demonstration Act of 1974," provides for demonstration within a three-year period of the practical use of solar heating technology, and ... the development and demonstration within a five-year period of the practical use of combined heating and cooling technology." Under the provisions of the Act, the Department of Housing and Urban Development (HUD) has utilized the services of the NBS to develop a document containing interim performance criteria for the design and evaluation of solar heating and cooling systems to be demonstrated by HUD in residential construction.

Objectives. These interim criteria have the following objectives:

- To provide designers, manufacturers, and evaluators with the technical performance criteria that will be used for the solar heating and cooling demonstration program.

- To establish technical performance levels that will be used for the evaluation and procurement of systems, subsystems, and components for the solar heating and cooling demonstration program.

- To provide a basis for the development of more definitive performance criteria at a later date.

Scope. The interim performance criteria given for hardware related items including space heating systems, hot water systems, space cooling systems, or combinations thereof*, and their various subsystems, components, and materials are intended to:

- establish minimum levels for health and saf ety that are consistent with those presently established for conventional systems used in residential applications; **

- ensure that the proposed heating, cooling, and hot water systems, or combinations thereof, are capable of providing levels of performance consistent with those provided by conventional systems used in residential applications; **

- verify that proposed systems, subsystems, and components are capable of providing their design performance levels; and

- ascertain that the systems, subsystems, and components are durable, reliable, readily maintainable, and generally constructed in accordance with good engineering practice.

*Although not specifically mentioned in PL 93-409, it is recognized in this document that not all cooling systems are combined with heating systems.

**(i.e., the HUD MPS and recognized building codes and standards).
The criteria given in the "Interim Performance Criteria for Solar Heating and Cooling Systems in Residential Buildings" document primarily consider aspects of planning and design that are different from conventional buildings by reason of the active solar energy systems under consideration. The performance requirements of the document are consistent with the requirements of the HUD MPS 4900.1, "Minimum Property Standards for One and Two Family Dwellings"; MPS 4910.1, "Minimum Property Standards for Multi-Family Housing; MPS 4920.1, "Minimum Property Standards for Care-Type Housing"; and MPS 4930.2, "Intermediate Minimum Property Standards Supplement for Solar Heating and Domestic Hot Water Systems."

The interim performance criteria are intended to be flexible to allow freedom of design and encourage innovation in keeping with the intent of Public Law 93-409.

Organization and Format. The interim document is organized on the basis of performance criteria dealing with heating and cooling systems and their integration into buildings.

Performance statement entries are presented in the Requirement, Criterion, Evaluation, and Commentary format. The Requirement is a qualitative statement giving the user need or expectation for the item being addressed. It is a general statement of what the system or its subassemblies shall be able to do. The Criterion is generally a quantitative statement giving the level of performance required to meet the application or expectation for the item being addressed. The one or more criteria associated with each requirement state those considerations which are necessary to meet the requirement. Because of limitations in the state of the art, a qualitative statement is not always contained in each criterion in the document. In addition, a quantitative statement is not always contained in each criterion in the document. Quantitative statements have been intentionally omitted in some criteria where these values will be provided by the designer. The Evaluation sets forth the methods of test and/or other information upon which an evaluative judgment of compliance with a criterion will be based. It states the standards, inspection methods, analyses, review procedures, historical documentations, and/or methods which may be used in evaluating whether the system and its subassemblies as designed comply with the eriterion. It is expected, in many cases, that the review of documentation of in-use performance, or professional judgment, will be used as evaluative tools in lieu of testing. The Commentary provides background for the reader and presents the rationale behind the selection of specific data presented in the Requirement, Criterion, or Evaluation. The commentary is intended for information purposes and is therefore only advisory.

The document is organized into chapters on the basis of the performance attributes listed below. Each of these should be addressed in a proper solar design process.

1) Thermal performance statements are used to evaluate the ability of systems and their subassemblies to operate and provide their rated output. The ability of the solar heating system to provide a predetermined 
quantity of domestic hot water is an example of a thermal consideration. Others include correct sizing of storage tanks, collector performance evaluations, and building energy load criteria.

2) Mechanical performance statements treat the mechanical design and performance of the solar energy systems and their subassemblies. Factors such as the ability of the system to withstand normal design service conditions (i.e., pressure, temperature, fluid flow, vacuum relief, and thermal expansion) are considered under this category.

3) Structural performance statements deal with the ability of systems and subassemblies to maintain their structural integrity under in-service and extreme ambient conditions. Factors such as wind, snow, and seismic live loads as well as the dead loads associated with additional hardware on a conventionally designed roof are considered under this category.

4) Safety deals with the mitigation of hazards that could result in property damage or injury and death. Hazards such as those related to fragile, toxic and/or flammable materials, conformity to codes and standards, and emergency access provisions are considered under this category.

5) Durability and Reliability relate to the ability of systems and their components to perform designed functions for a specific interval under designated use conditions. Corrosion, material degradation, thermal shock, freeze protection, and fluid compatibility are typical items for consideration under this category.

7) Building and Site Performance statements deal with the interactions between the solar energy system (or components of the building with a solar aspect) and its surrounding environment, the rest of the building, and its siting. These performance statements provide for integrating the building and site with the system and its components without seriously degrading the environment or impairing the normal function of the building and its components. In most cases, a careful review of the building's performance is required so as to size an appropriate and efficient solar design. For many situations, such as passive solar gain, this analysis will actually serve as a performance prediction of the solar design.

The Interim Performance Criteria Document is not final in nature. With the present state of the art, there will be a need for periodic updates to readjust levels of acceptability for both systems and components. A major reason for including a commentary in the presentation is to assure a workable process of updating these interim performance criteria by establishing the basis for selection of performance levels and methods of evaluation so that, when questions arise as to the basis for a particular criterion, the reader will have available the rationale behind the criterion.

\section{Energy Performance Standards for New Buildings}

The Department of Energy proposes to establish energy performance standards for new buildings to achieve the maximum practicable improvements in energy efficiency and increases in the use of renewable sources of energy. The standards will apply to the designs of new residential and commercial buildings.

The proposed standards ' consist of three fundamental elements:

- Energy Budget Levels for different classifications of buildings in different climates, expressed as an annual rate of energy consumption.

- A method for applying these Energy Budget Levels to a specific building design to obtain a specific annual rate of energy consumption, which is its Design Energy Budget.

- A method for calculating the estimated annual rate of energy consumption of a building design, which is referred to as its Design Energy Consumption.

The proposed rule requires that the Design Energy Consumption of a building design for a new building may not exceed its Design Energy Budget.

States and local governments will be encouraged to adopt, enforce, and implement the energy performance standards through their existing building codes, other construction control mechanisms, or an alternate approval process. Although such implementation is discussed in the preamble to the proposed rule, an implementation methodology is not formally proposed.

The Department anticipates that, after the final rule is promulgated, the standards will be revised periodically to reflect advances in energy conservation and renewable energy technologies, changes in energy prices and supplies, and knowledge gained from experience in administering the standards.

For further details, refer to Federal Register, Vol. 44, No. 230, Wednesday, November 28, 1979. (Proposed Rules.) 
15

Post-Design Phase 



\section{CONTRACT DOCUMENTS}

The contract documents detail the quality, quantity, and performance of passive components, equipment, and appurtenances, and the manner of installation. The format and content of the specifications should generally follow the prevalent procedures used by the construction industry. The Construction Specifications Institute (CSI) format is an industry standard; unfortunately, the specifications for solar energy systems are not so well developed or standardized. The following sample specifications for the major components of active systems are indicative of the detail that should be included in the full specifications.

\section{Solar Collectors: Sample Specification}

This guide specification is specific for flat plate collectors. Although many of the provisions are common for evacuated tube collectors, and focusing, concentrating, and tracking collectors, obviously each of the other type collectors has characteristics particular to the individual type.

- The solar collectors shall be delivered when requested by the government and 18 months from the date of the purehase order. Failure to perform within this period may result in cancellation of the purchase order.

- No sales tax is to be included in the bid price.

- The bidder shall include in the base bid the cost to provide 30 collectors in addition to the cost of the basic array. These are to be used as spares and replacements for units damaged during construction.

- Each bidder shall submit with his proposal complete details and information on the performance, installation, and construction of the submitted unit. In addition, all certifications called for in the detailed specifications and on the proposal must be included.

- The bidder is advised that in this solicitation low bid is not the sole criterion for selection. All factors requested in the proposal will be evaluated to determine the most appropriate collector for this project.

\section{Basis for Bid Evaluation and Award: (Others Can Be Substituted)}

- The lowest overall "Effective Cost" to the government will be the basis for making the award provided all other aspects of the specifications are met.

- The effective cost (E.C.) will be determined by the following formula: E.C. = Collector cost $\mathrm{x}$ Installation factor, where: Collector cost $=$ Total cost for the number of collectors required to provide the minimum output for each month as noted in Part 3 of the technical specifications, and Installation factor $=$ total number of collectors 450 .

- The "Bid Evaluation Form" shall be completed by all bidders and submitted with the bid proposal along with collector performance test report and other data listed therein. Failure to submit these forms will nullify the entire bid.

\section{General Conditions}

- Contractor shall submit a written warranty as follows: Manufacturer shall warrant the collector to be free from defects in material and workmanship for a period of 5 years.

- Collectors must remain free from the following defects during the warranty period:

- Condensation of water vapor or outgassing produced from internal components on inside of coverplate(s);

- Leakage of fluid or air passageway;

- Damage resulting from stresses induced by thermal cycling;

- Physical degradation of collector materials including visible corrosion, rust, and discoloration of absorbing surface or box enclosure;

- Leakage of gaskets.

- Effective date of the warranty shall be the date of completion of installation of the collectors.

- Collectors shall be the manufacturer's standard production model.

- The warranty shall include inspection by the manufacturer's field representative at no charge to verify failures, establish cause, and authorize corrective action.

- The warranty shall cover all costs to remedy a defect in the collector including cost, labor, shipping, and replacement of the collectors.

- Replacement collectors shall be warranted for the period of the unexpired warranty period of the original collector or 1 year, whichever is greater.

- Prior to commencing fabrication of the collectors, the contractor shall submit the following:

- Three copies of detailed shop drawings of the collectors.

- Sample collector or cutaway section showing all major components.

- Payment will be made in one lump sum after satisfactory delivery of all collectors and after submission of the following:

- Executed release of liens.

- Completed warranty form.

\section{General Collector Requirements}

- Flat plate type with cover plates, absorber, internal manifold, insulation, and enclosure in nominally $3 \mathrm{ft} x$ $7 \mathrm{ft}$ modules.

- Maximum operating weight: $15 \mathrm{lb} / \mathrm{sg} \mathrm{ft}$. 


\section{Coverplates}

- One or two as required to meet schedule performance criteria.

- Minimum transmittance for solar radiation:

- $85 \%$ at $0^{\circ}$ incidence angle in 0.3 to 2.5 micron band.

- $80 \%$ at $60^{\circ}$ incident angle in 0.3 to 2.5 micron band.

- $10 \%$ maximum deterioration over 20-year service life.

- Opaque to long wave radiation.

- Capable of withstanding temperatures from $-25 \mathrm{~F}$ $\left(-32^{\circ} \mathrm{C}\right)$ to stagnation temperature without warping, buckling, sagging, or breakage.

- Hail load resistance as per Section 3.1 .5 of NBSIR 76-1187.

\section{Absorber}

- Steel, copper, or aluminum plate with steel or copper fluid passages. Aluminum fluid passage will not be accepted.

- Performance shall not be affected by thermal expansion between $-25 \mathrm{~F} \quad\left(-32^{\circ} \mathrm{C}\right)$ and stagnation temperature. Provide provisions to prevent overstressing of supports, piping, and plate supports and between plate and collector enclosure.

- Maximum temperature difference between plate and fluid in nearest passage: $15 \mathrm{~F}\left(-9^{\circ} \mathrm{C}\right)$.

- Maximum fluid pressure drop: 1.5 psi at $20 \mathrm{lb} / \mathrm{hr}$ flow rate per square foot of collector area.

- Fluid passages:

- Drainable by gravity at any tilt angle.

- Insulated internal manifold with side inlet and outlet connections.

- Sized for turbulent flow at scheduled flow rate without causing erosion.

- Method of connection shall permit removal of collector from system without shutting down system.

- Surface coating:

- Selective or nonselective at vendor's option to meet scheduled performance criteria of use.

- To withstand temperatures from $-25 \mathrm{~F}\left(-32^{\circ} \mathrm{C}\right)$ to stagnation during 20-year service life.

- Absorptance and emittance shall not change by more than $5 \%$ over 20-year service life. Verify by accelerated life test or real time test of at least 500 hours.

- Shall not deteriorate because of condensation or other moisture in collector enclosure over 20 -year service life.

\section{Collector Supports: Sample Specification}

Collector supports can be fabricated of structural steel, aluminum, or, in some cases, wood treated with creosote. (See Table 15-1.) Specifications should include the following:
- The method of fabricating (e.g., welded or bolted).

- The method of anchoring (e.g., base plate, anchor bolts, or lag bolts).

- The location on the roof or grade.

- Foundations, if on grade.

- The material specification and protective coatings.

- Method of sealing penetrations of roof or structure.

- Method of securing the collectors to the mounting to permit easy removal.

- The design load upon which the mountings were designed.

- The shape of the members (e.g., box channel, angle tube) and the materials for bolts and other appurtenances.

\section{Thermal Storage: Sample Specification}

The following is an example of the information that should be included in the specifications for tanks handling an antifreeze-water mixture or nonpotable water.

- Location: Indoors exposed. Outdoors above grade exposed or buried below grade.

- Supports: Specify steel cradle supports if indoors. Specify the excavation, sand bed, backfill material, depth of cover, hold down slab, or concrete base with rods if underground.

- Tappings and Manhole: Specify location, size, and IPS of all tappings, and the manhole location, gasket, and fostering arrangement.

- Material: Sample guideline specifications below for specifications for steel and concrete tanks. Specify working pressure and hydraulic test pressure.

- Anti-Mixing Devices: Specify internal baffles, perforated headers, or other devices to create stratification. The devices should be made of steel with auto corrosion finish.

- Insulation: The material thickness, $\mathrm{R}$-value, waterproof covering, and method of application should be specified. The $R$-value selected must be in accordance with fluid temperatures and ambient temperatures.

- Lining: Specify the lining or coating to resist corrosion, especially for partially filled tanks.

- Size and Capacity: Specify the gallons of fluid, volume, and diameter, or length, width, and height.

\section{Steel Storage Tanks: Sample Specification}

(These specifications are taken from and everywhere meet or exceed the National Board of Underwriters' Standards and Underwriters' Laboratories, Inc. Requirements.)

- Material: Class A open-hearth or basic oxygen steel plate. Thickness of shells and heads are in accordance with Underwriters' specifications. All heads and shell rings shall be of one-piece construction.

- Construction: Lab-welded continuously on the outside and tack-welded on the inside according to 
Table 15-1. COLLECTOR SUPPORT STRUCTURAL MATERIALS

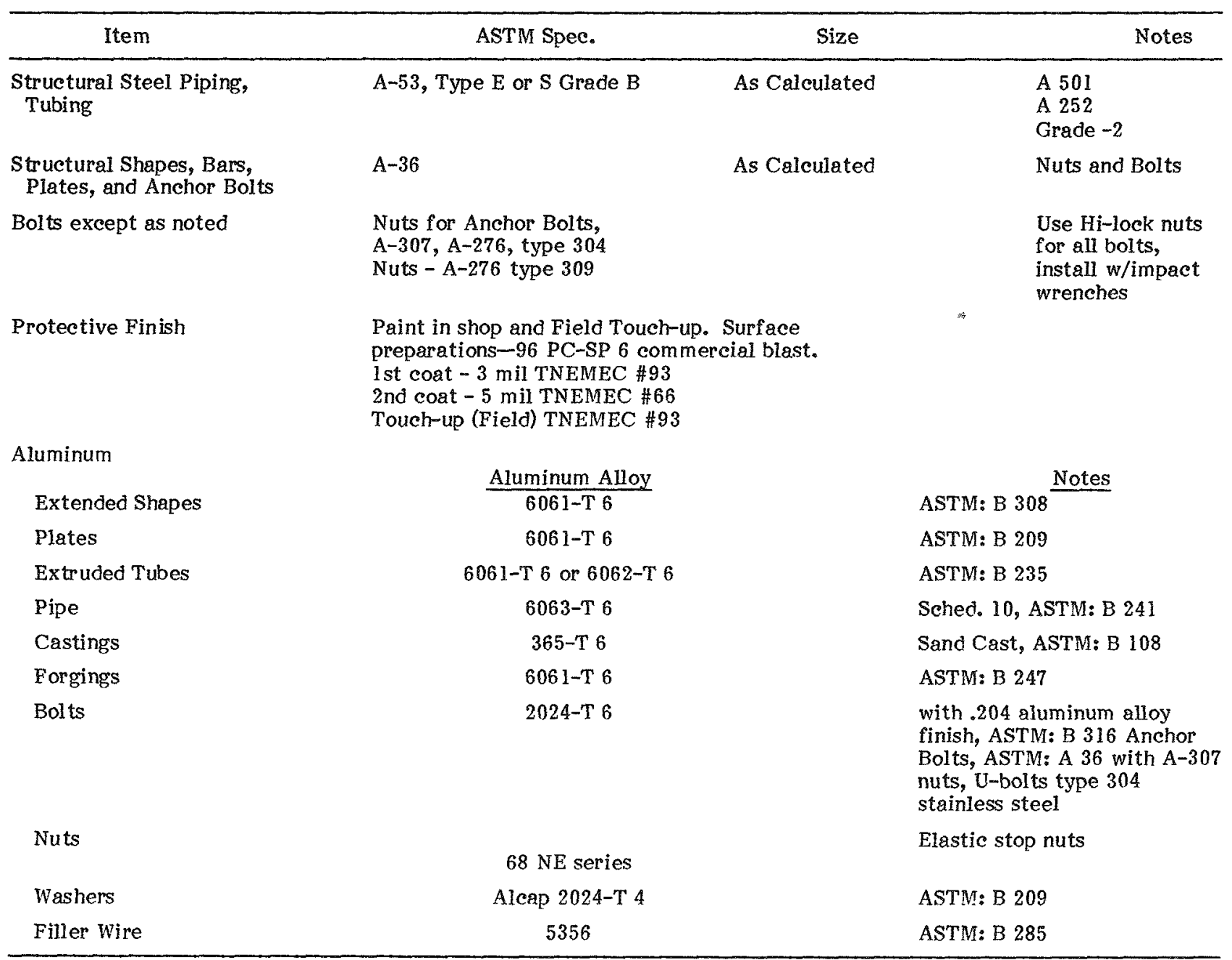

Underwriters' specifications. All welding shall be electric-arc.

- Paint: Underground tanks shall be covered with protective black asphalt paint. Aboveground tanks shall be primed with red-oxide paint. The exterior of the tank shall be sandblasted prior to the application of a protective coating.

- Testing: Before painting, all tanks are to be tested and proved tight against leakage under a test pressure of not less than 5 nor more than 7 psi. Tank shall be tested with ASME Code.

\section{Cast-in-Place Storage Tanks: Sample Specification}

- Details: American Concrete Institute Standards Manual of Standard Practice for Detailing Concrete Structures (AC 1315 ).

- Codes: Building Code Requirement for Reinforced Concrete (AC 1-31B-71).

- Materials: Cement - Standard Specification for Portland Cement (ASTM: C 150). Water - Free of acids, alkalies, organic materials. Aggregates -
(ASTM: C 33). Reinforced Steel (ASTM: A 615-68). Placing of Reinforcing Bars - C.R.S.I. Recommended Practice.

- Concrete Mixtures: Building Code of the American Concrete Institute Allowable Design Stresses on Minimum 28-Day Compressive Strength (AC 1-318-71).

- Testing: 4 Test Cylinders as per ASTM: C 31, 7-day Strength $65 \%$ of 28 -day Strength Compression Tests in accord with ASTM: C 39. Slump tests shall not exceed maximum of American C.I. Ready Mixed Concrete Standard Specification for ready mixed concrete (AST: C 94).

- Placing: Forms shall be wetted except when temperature is below $40 \mathrm{~F}\left(5^{\circ} \mathrm{C}\right)$.

- Curing: Forms shall be kept in place for 7-day curing period. Liquid Membrane Forming Compounds for Curing Concrete (ASTM: C 30).

- Hardening: Hardener shall be applied in no less than three coats.

- Protection: Protect concrete from sun, rain, water, and snow for 2-week period af ter placing.

- Cold Weather: All concrete shall be maintained at a temperature of $50 \mathrm{~F}\left(10^{\circ} \mathrm{C}\right)$ for not less than 4 days 
after depositing. During next 3 days protect concrete from freezing.

- Openings: All openings, except vent openings and those for valves or pipe connections communicating with the interior of the tank, shall be equipped with substantial covers. Thieving and gauging openings shall have approved self-closing covers, but manhole covers may be of either bolted or approved self-closing type. Pipe connections shall be standard threaded flanges or spuds. All openings in the tank are to be protected by metal covers, or their equivalent, while tank is in storage or in transit. Manholes shall be bolted-cover type with gasket not less than $1 / 8$ in. in thickness, or of a material required for this particular use. Aboveground tanks over 5,000 gal. capacity, and each compartment over 5,000 gal. capacity of compartment tanks must be provided with a manhole. Tanks shall be equipped with a permanently open vent. Vent valves or relief of tanks fitted with floating roofs of acceptable design, which leave no considerable space above the liquid in which vapors may accumulate, need not terminate in flame arresters. (The function of the breather vent is to permit the proper outflow and inflow of air during filling and emptying operations. Venting prevents the development of dangerous interior pressure, or possible collapse of the tank due to vacuum, and safely permits the normal expansion and contraction of the product due to varying temperatures.)

- Lining: Tank shall be lined with epoxy primer and epoxy finish.

- Insulation: Tank shall be insulated with fiberglass, $7 \mathrm{lb}$ density, minimum $R$-value of 20 and shall have a protective waterproof cover, wrapped with hot tar. Contractor to follow recommended standard for cold weather. Concrete (AC 1 604).

- Hot Weather Protection: The placing temperature concrete shall not be more than $90 \mathrm{~F}\left(32^{\circ} \mathrm{C}\right)$. Contractor to follow recommended standard for hot weather concrete (AC 1 605).

- Forms and Centering: Design of form work shall comply with AC 1347 .

\section{Heat Transfer Fluids: Sample Specification}

When antifreeze solutions are used, the fluid (often called the coolant) must be carefully specified as the solution in the solar loop (collector to storage or to heat exchanger) may be exposed to a wide range of temperatures over its annual cycle, ranging from $-50 \mathrm{~F}$ to over $400 \mathrm{~F}\left(-46^{\circ}\right.$ to $204^{\circ} \mathrm{C}$ ) during stagnation periods. Under these conditions, a premium heat transfer/antifreeze fluid requires $a$ high priority and careful selection. The percentage of antifreeze fluid to total fluid in the collector loop should be noted in the specifications. A sample:

- Trade name of the fluid

- Manufacturer

- Specific heat $(.7)$ at $200 \mathrm{~F}\left(93^{\circ} \mathrm{C}\right)$

- Freezing point $\left[-50 \mathrm{~F}\left(-46^{\circ} \mathrm{C}\right)\right]$

- Toxicity

- Compatibility with the parent metal
- Flash point $100 \mathrm{~F}\left(56^{\circ} \mathrm{C}\right)$ over stagnation temperature

- Interaction with shingles, wood, other roofing

- Color (dark)

- $\mathrm{pH}(6.0-8.5 \pm .5)$

- Boiling point [over $\left.450 \mathrm{~F}\left(232^{\circ} \mathrm{C}\right)\right]$

- Viscosity at $0 \mathrm{~F}$ and $250 \mathrm{~F}\left(-18^{\circ}\right.$ and $\left.120^{\circ} \mathrm{C}\right)$

- Density: lb/cu ft

- Vapor pressure: Indicate from $100 \mathrm{~F}\left(38^{\circ} \mathrm{C}\right)$ to stagnation temperature

- Coefficient of expansion

- Effectiveness ratio: $.7 \mathrm{~min}$.

\section{Heat Exchangers: Sample Specification}

- Type: Shell and tube, other

- Tube Material: Copper

- Shell Material: Bronze

- Flow, Shell Side: 4 gpm

- Fluid, Shell Side: 50/ethylene glycol and water

- Flow, tube bundle: $8 \mathrm{gpm}$

- Fluid, tube bundle: water

- Entering water temperature, shell side: $120 \mathrm{~F}\left(49^{\circ} \mathrm{C}\right)$

- Leaving water temperature, shell side: $100 \mathrm{~F}\left(38^{\circ} \mathrm{C}\right)$

- Entering water temperature, tube side: $90 \mathrm{~F}\left(32^{\circ} \mathrm{C}\right)$

- Leaving water temperature, tube side: $110 \mathrm{~F}\left(43^{\circ} \mathrm{C}\right)$

- Pressure drop, shell side: $10 \mathrm{ft}\left(\mathrm{H}_{2} \mathrm{O}\right)$

- Pressure drop, tube side: $8 \mathrm{ft}\left(\mathrm{H}_{2} \mathrm{O}\right)$

- Fouling factor, shell side: .0001

- Fouling factor, tube side: .0001

- Number of passes

- Surface area, shell side: $20 \mathrm{sq} \mathrm{ft}(1.9 \mathrm{sq} \mathrm{m})$

- Surface area, tube side: $28 \mathrm{sq} \mathrm{ft}(2.6 \mathrm{sq} \mathrm{m})$

- Shell dimensions diameter: $18 \mathrm{ft}(5.5 \mathrm{~m})$ length: $20 \mathrm{ft}(6 \mathrm{~m})$

- Working pressure shell side: $28 \mathrm{psi}$ tube side: $18 \mathrm{psi}$

\section{Pumps: Sample Specification}

- Type: In-line or base mounted centrifugal

- Capacity: As noted on the drawings (equipment schedules) includes: location, service, gpm, head, rpm, impeller size, efficiency, motor brake horsepower, motor horsepower, electrical characteristics, fluid pumped, and remarks

- Performance: Brake horsepower not to exceed motor horsepower at any point on curve

- Maximum Shutoff Head: 125\% of design head

- Minimum Flow at Break-Off: $125 \%$ of design flow 
- Construction: All bronze or stainless steel, vertically split casing with screwed connections in size 2 in. and smaller, flanged in sizes 2-1/2 in. and larger. Provide pressure gauge tappings in flanges. Internal parts to be serviceable without disturbing piping. Bronze enclosed centrifugal impeller, balanced statically and dynamically. Oil lubricated sleeve bearings. Provide oilers. Stainless steel shaft. Mechanical seals suitable for $225 \mathrm{~F}\left(107^{\circ} \mathrm{C}\right)$. Spring type flexible coupling.

- Factory test to $150 \%$ of design pressure hydrostatically

- Submittals to include characteristic curves indicating brake horsepower and total dynamic head.

\section{Testing and Balaneing: Sample Specification}

- The entire system, whether air or liquid, shall be "Tested and Balanced" to provide the scheduled performance.

- Labor, materials, instruments, and power required for testing shall be furnished by the contractor.

- Pressure tests shall be applied to piping only before connection of equipment. In no case shall piping, ducting, equipment, or accessories be subjected to pressures exceeding their rating.

- All defective work shall be promptly repaired or replaced, and the tests shall be repeated until the particular system and component parts receive approval.

- Equipment and systems which normally operate during certain seasons of the year shall be tested during the appropriate season. Tests shall be performed on the individual equipment, systems, and their controls.

- No piping or ducting in any location shall be closed up, furred in, or covered before testing.

- Water used for testing shall be drained from the system after tests are complete.

- The tests herein specified shall be applied in the presence of the user agency or its authorized representative, before the work is covered, concealed, or made inaccessible to testing, inspection, repair, correction, or replacement.

- The contractor shall furnish all supplies, equipment, materials, and labor for testing, except for the furnishing of water and electricity for making tests. Contractor shall make and remove all temporary piping or duct connections required for the tests and shall dispose of test water and all waste after tests.

- No item of equipment shall be subjected to a pressure exceeding the manufacturer's specified maximum. Low-pressure elements shall be isolated from highpressure tests or removed from the line during such tests.

- All piping for relief valve discharge, hot water, and solar water supply and return shall be tested with water and made tight under a pressure of $100 \mathrm{lb} / \mathrm{sq} \mathrm{in.}$ gauge maintained for 24 hours. Certified shop test records for all pressure vessels installed and tested at full operating pressures and temperatures for 1 hour shall be furnished. All pressure control, relief, and safety devices shall be set and tested.

\section{Start Up}

The contractor shall flush until clean all system pipelines prior to starting up the system. System pipelines shall be flushed in sections, with a final flushing after the entire system is connected, prior to system operations.

\section{Test Log}

The contractor shall submit for approval to the user agency three copies of a complete tabulated log of all tests and readings of design and delivered quantities for the following:

\begin{tabular}{ll}
\hline \multicolumn{1}{c}{ Item } & \multicolumn{1}{c}{ Readings } \\
\hline $\begin{array}{l}\text { All motors and belt } \\
\text { driven equipment }\end{array}$ & Amps, voltage, rpm, hp \\
All fans and pumps & $\begin{array}{l}\text { Inlet and outlet pressure } \\
\text { flow rates, cfm, gpm or gph } \\
\text { Inlet and outlet temperatures } \\
\text { on both air and water sides } \\
\text { face velocities, pressure drop }\end{array}$ \\
All solar and system & $\begin{array}{l}\text { Supply and return } \\
\text { temperatures }\end{array}$ \\
Hot water systems & $\begin{array}{l}\text { Supply and return } \\
\text { pressures and temperatures, } \\
\text { flow rates }\end{array}$ \\
$\begin{array}{l}\text { Converters, heat } \\
\text { pump, auxiliary } \\
\text { boilers }\end{array}$ & $\begin{array}{l}\text { Supply and return pressures, } \\
\text { temperatures, flow rates, } \\
\text { Solar collector array }\end{array}$ \\
& and solar insolation \\
\hline
\end{tabular}

The test log shall contain the time of day and the outside air temperature at the time the tests and readings were made.

\section{Other: Sample Specification}

Standard heating, ventilating, air conditioning, plumbing, and electrical work industry standards should be specified. Specifications for DOE installations at the following facilities can be obtained from DOE as guidelines for similar project specifications. These installations were started or completed in 1978 and 1979.

- Brookhaven National Laboratory, Animal Quarantine Labs, Upton, New York

- Lawrence Berkeley Laboratory, Building 90, Berkeley, California

- Grand Junction Office Cafeteria, Grand Junction, Colorado

- Bartlesville Energy Research Center, Bartlesville, Oklahoma 
- Argonne National Laboratory Cafeteria, Argonne, Illinois

- University of California Laboratory, Davis, California

For complete information write:

U.S. Department of Energy

Office of Construction \& Facility Management

Attention: Mr. David Barr

Washington, D.C.

\section{PROCUREMENT PROCEDURES}

\section{Design Phase}

Design services for solar energy systems may be obtained through a number of procedures. The use of in-house personnel, a consulting engineering firm, or a design and build contractor are common approaches. However, both Federal programs and private projects have demonstrated the plethora of pitfalls for the novice, so use of experienced solar design engineers is recommended for anything other than very straightforward applications. The design services of consulting engineers are of ten best procured through negotiation with selected firms.

In new construction, it is common practice to employ an architect. Under these circumstances, it is traditional for the (solar) engineer to be subcontracted to the architect. However, it is important to remember that the solar system may impose some special requirements on the building's form. The HVAC system can no longer be considered as an "add-on" that must fit within the building's predetermined form. In passive solar design, particular attention must be given to integrating engineering and architectural considerations.

In retrofit situations, the solar design engineer normally has prime responsibility for the project. In these cases, architectural and structural engineering services can be subcontracted to him. For either new or retrofit applications it is often very beneficial to obtain construction supervision services from the engineer.

\section{Construction Phase}

It is possible to use in-house personnel for actual construction of the solar system, but it is much more common to contract this work. Competitive bidding for procurement of this work is important to obtain the lowest system cost. At least three bids should be obtained to help assure the reasonableness of the bids received.

The competitive bidding procedure should include:

- consideration of experience as well as price in selecting the lowest qualified bidder,

- a prebid conference, and

- the passible use of a split bid package.
In all construction projects, both a contractor's price and his ability to perform are important. This is particularly true for solar systems. The idea is to select the lowest qualified bidder. It should be possible to restrict bidding to only those contractors/manufacturers meeting some set of reasonable criteria. Though bidding should not, in most cases, be limited to contractors with solar energy experience, it should be recognized that experience and familiarity with these systems can result in labor savings and faster installation with fewer problems. Studies have shown that a significant learning curve exists for the installation of collectors. In addition to previous solar experience, exposure to government contracting procedures would also be helpful. Maintaining open communications during the bidding process will help facilitate a more trouble free project.

A prebid conference should be held to explain recommended installation procedures and to allow the contractors to ask questions. It may be beneficial to have a sample collector available. In this way, the contractors' fear of the unknown will hopefully be alleviated somewhat, thus resulting in more and lower bids. The purpose and scope of the project should be discussed, and the similarity to conventional systems stressed. Procedures for changes, delays, inspection, and such should also be reviewed.

It may be advantageous to split the bid package into several parts. The solar system may be segregated from the nonsolar portion, and the solar system may be further broken down into the collector array and the remainder of the solar system. There are a number of advantages to split bidding:

- Competition is increased by encouraging more bidders/ suppliers.

- Solar costs can be segregated.

- Prebidding of collectors is possible which permits designing the remainder of the array for a specific collector.

It is thus obvious that split bidding may provide increased flexibility. However, there are also disadvantages associated with this approach:

- Delays may snowball uncontrollably.

- Warranty enforcement may be more difficult.

- Acceptance testing is more complicated.

\section{Solar Contracting Strategy Example}

There are many variations in solar contracting procedures. One that has worked well with previous Federal demonstration projects is to use a split bid package and also prebid the collector array.

Solar collectors are usually the most visually prominent component of a solar energy system on a building. Selection of the collectors can be the most difficult step encountered during the design/bidding process because of the variations in cost, size, performance, durability, mounting and piping methods, and appearance of the many collectors manufactured. 
Writing a "tight" specification around a single collector will frequently preclude competition and increase costs by preventing other collector manufacturers from bidding. However, a system is usually designed around a specific collector so that the designer will know that the system can indeed "work." If a less restrictive specification is written, it frequently occurs that a very different collector is selected through bidding. As a result, the required piping for connections to the collectors might require modification, the support structure may need redesign, the recommended flowrates may be different, and the collectors might not fit in the available space. Prebidding the solar collectors will of ten lessen many of these problems.

The goal of prebidding the array is to select a collector based on a combined cost/performance factor. The difficulty is in developing a procedure to do this that is fair, reasonably accurate, and can be followed by the prospective bidders. Considerations include:

- Total installed cost-delivery, collectors, mounting, and associated piping.

- Performance at normal operating point(s).

- Requiring a minimum array output at the normal operating point.

Once a collector has been selected, the engineer can then design the remainder of the solar system based on a specific collector design. This approach facilitates structural and piping design and permits early ordering of long lead time items. Bidding on the remainder of the system is thus easier.

An example of the benefits of this approach follows. Suppose that a designer wishes to specify a collector with a certified performance greater than or equal to that indicated in Fig. 15-1. Depending on what value of collector parameter is chosen as the "normal operation point" (NOP), either/both collector $A$ and/or collector B will suffice. However, perhaps neither will be satisfactory. When the cost factor is plugged in, the decision is even less clear. Although a computer analysis could be employed to make a decision, it is of ten best for the designer to specify the value of the collector parameter at the NOP and to require a minimum collector efficiency at that number. The solar engineer should determine the NOP based on such considerations as application and climate. It might be appropriate to select a NOP for each season and then determine a weighted average annual NOP based on seasonal loads.

It is possible that collector $B$ could be more cost effective than collector A, even if B costs more. Simply specifying minimum performance will not optimize system cost effectiveness. In determining maximum cost effectiveness, the total installed subsystem cost should be used. This includes delivery, the collectors themselves, mounting costs, and any additional piping costs. Collector performance is the other major parameter in determining cost effectiveness.

Most collectors have different mounting schemes and requirements for piping or support structures. As an example, consider a collector that offers an internal manifold at a cost slightly higher than another collector that requires external manifold piping. For fairness, the

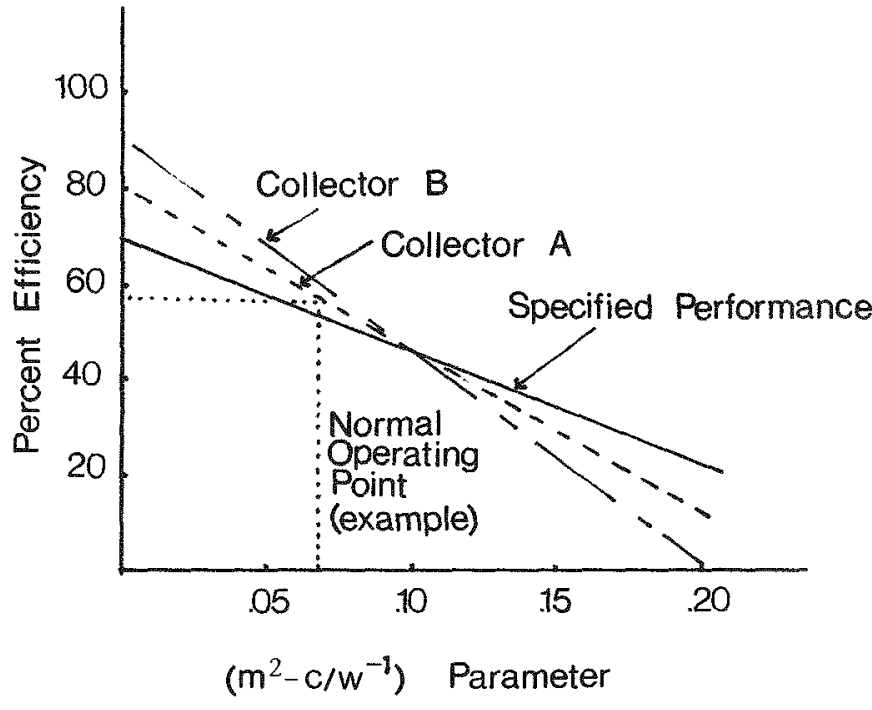

Fig. 15-1. Selection of a collector based
upon performance

cost of "extra" piping and labor required for the collector without internal manifolds should be included in its "total installed cost." Some designers predetermine costs per linear foot of piping or for added support structure so that two very different collector systems can be compared more equitably. However, this process can be tedious and not necessarily accurate.

It is generally appropriate to consider use of simple economic parameters for evaluation/selection of bids. One such simple equation is as follows:

"Energy Cost" $=\frac{\text { Total Installed Cost }}{\text { Collector Efficiency (@NOP) x Area }}$

This "energy $\cos t^{\text {" }}$ parameter cannot be used to compare solar to conventional fuels, but it can be used to compare various solar options. In addition, it is necessary to insure that the array delivers a sufficient quantity of energy. Thus, a system requirement should be:

\section{Collector Efficiency (@NOP)x Area Minimum Energy}

Evaluating evacuated tube or concentrating collectors may be somewhat more difficult, especially when comparing them to flat plate collectors. Under these circumstances, particular care should be given to using gross collector area and total system cost. The "winning" collector bid would thus be the array that provides the lowest "energy cost" and delivers at least the minimum amount of energy.

When performing this simple analysis, it is imperative that a consistent approach be taken. Collector efficiency should be as determined by an independent laboratory 
using a standard test procedure and based on gross (or effective) area. The area used in the above equations should thus be the gross (or effective) value.

\section{Additional Considerations}

Contracting for construction of a solar system requires several additional considerations.

\section{Aestheties}

On some buildings, the visual appearance of the collectors is very important. Tracking collectors might be precluded from the bidding based on this criterion. Also, some special type finishes or flashing may be required. The use of internal manifolding or other special piping requirements could be necessary. However, care should be taken not to eliminate too many collector manufacturers from bidding.

\section{Support Structure}

Frequently, the maximum dimensions of a collector must be specified because of support structure or shading limitations. Support structures should be designed to ensure that a number of manufacturers can meet the size requirements.

\section{Other Collector Considerations}

Specifications and selection criteria directly related to thermal performance and cost are discussed above. Selection and specification may also be based in part on the following additional considerations:

- Warranty: Many collector manufacturers provide a 5 -year limited warranty on materials and workmanship. Unlimited warranties providing more complete coverage are offered by some manufacturers for an additional charge per collector.

- Testing Procedure: Consideration should be given to whether the collector test data provided conform to standard collector testing procedures (ASHRAE 93-77 or other) and to whether the testing was done by an independent laboratory.

- Manufacturer's History: The designer may specify that the collector manufacturer must have already produced a certain number of collectors and that these collectors have been installed and operated successfully for a certain minimum time period. Local representation is also desirable.

- Working Pressure: The maximum safe working pressure of the collector and the pressure drop across the collector at a specified flow should be considered.

- Durability: Particular areas of concern include condensation on the cover plates, leaking of collector fluid, strain caused by thermal cycling of collector materials, outgassing of collector materials, and physical degradation of materials resulting from high stagnation temperatures and ultraviolet exposure.

- Cover Plates: The cover plate should be able to withstand wind suction loading, hail, and ultraviolet exposure for the system life. Consideration should be given to the ease with which cover plates can be replaced.

- Frame: The structural integrity and weatherproofing of the frame may be specified. Consideration should be given to whether the collector can support wind and snow loads, whether the collector can support its own weight during handling and installation without twisting and breaking the cover plate, and whether the frame is waterproof at all joints and fixtures.

- Interim Performance Criteria: (IPC) The specification should require that the collectors satisfy the IPC as developed by the National Bureau of Standards. 


\section{INSTRUMENTATION AND MONITORING}

\section{Instrumentation Systems}

\section{Levels of Instrumentation}

A wide variety of sensor types and data collection systems is currently available on the commercial market. This equipment ranges from simple thermometers to sophisticated solid-state devices capable of energy monitoring and control functions previously thought impossible or very difficult. Although many sensors and systems serve both energy monitoring and control functions, this discussion will be confined to their monitoring aspect.

When designing an energy monitoring system, engineers are often tempted to specify the latest and most sophisticated equipment. However, such an approach of ten results in an unnecessary expenditure of money. Understanding just what level of information is appropriate and necessary to satisfy the intended purpose is important. The system and type of sensors specified should be the simplest equipment that will provide the type of information required at an acceptable level of accuracy and detail.

The various types of energy monitoring systems may be considered as belonging to one of a number of roughly defined levels of sophistication. For the purposes of this discussion, seven levels have been identified. Four of these involve manual data collection over both short and long time spans. The remaining three levels use automatic data collection over long time periods. These seven levels are discussed below in order of increasing sophistication and capability.

1. No sensors or recorder. Estimates of system conditions are made by independent calculations, valve positions, touch, sound, previous experience, or by other such means. This approach can only provide gross estimates and is not very useful for most purposes.

2. Visual monitors. Sensors such as thermometers, flowmeters, and multimeters are used to obtain instantaneous values of the system parameters. Data collection over a period of time is performed by visually reading and recording values. Depending on their purpose, these sensors may or may not be permanently installed in the system. Data readings may be taken nonintrusively (i.e., thermowells or surface measurements) or by inserting probes directly into the flowstream. This latter approach is facilitated by providing appropriate fittings in the piping or duct system. Depending on the probes used, the data may be quite accurate for steady-state conditions.

3. Energy meters. These devices monitor and report the time integrated quantity of energy passing through a pair of pipes or wires. By measuring the flow rate and temperature difference between the fluid in a particular pair of pipes, Btu meters provide an indication of the accumulated energy flow over time. They generally do not require any electrical power for operation. Wattmeters may be used to provide the same information for electrical energy use. Most energy meters must be read manually, but some provide an output to a recorder. The accuracy of these devices is reasonably good. However, they are of ten expensive.

4. Energy meters and visual monitors. The combination of these two approaches provides both instantaneous and time integrated data. This approach is very versatile and may serve many purposes.

5. Datalogging. This procedure involves the automatic recording of data from a number of remote sensors. Although it is possible to accomplish this by using a number of recorders, it is generally most practical to employ one centralized recorder. The sensors used at this level typically provide data in the form of an electronic signal. Sensor lead wires often must be magnetically shielded and mechanically protected by conduit. Signal processing may be required before recording. Equipment compatibility is an important concern here. The data may be recorded in analog (e.g., strip chart recorder) or in digital (e.g., paper tape) form. Processing of the data is generally done manually. The data sampling rate must be consistent with the typical behavior of the system and the level of accuracy required. Depending on the specific sensors employed, the accuracy of this type of system may be quite good. Because of the type of sensors required, the sensor leads, and the central recorder, these systems are generally more expensive than those discussed previously.

6. Data recording with local processing. This approach basically involves all elements of the datalogging system discussed above plus an onsite data processor. The typical processor will be electronic, will provide some means of integrating the data readings over a specified time interval, and will perform the required data reduction and manipulation. Depending on the specific unit, the processing may involve only simple algebraic manipulations or more advanced calculations. The output may be stored on paper or electronically on magnetic tape or discs. As indicated above, accuracy of the data is dependent primarily on the specific sensors chosen, the signal conditioning, and the sampling rate. The data processor adds to the total cost, but the relative increase may not be too great.

7. Data recording with remote processing. This approach also uses all elements of a datalogger system, but the data are generally stored electronically for only a relatively short time. The datalogging device may or may not perform simple preprocessing. Once again, accuracy is dependent primarily on the specific sensors, signal conditioning, and data collection rate. A disadvantage of this type of system is that performance data are often not available locally until after remote processing is completed. A typical system of this type stores the data on a cassette tape and periodically transmits it to a central computer for processing. This approach offers considerable computational power for large amounts of data. It is the most reasonable approach when a large number of separate sites are to be monitored. This type of system is used by DOE in the National Solar Data Network, which is discussed later. 


\section{Sensors and Equipment}

Choice of a specific energy monitoring system is inevitably a compromise between the desired accuracy, cost, versatility, reliability, and other constraints. The various types of sensors, recorders, and processing equipment appropriate for common solar applications are discussed below. When discussing price, it should be noted that first cost is not a correct indication of total price. Installation, sensor leads, and signal conditioning equipment may add significantly to the total cost. Many standard sensors are not suitable for solar application because of the flow and temperatures encountered. Within reasonable economic boundaries, reliability and accuracy are generally most important. Economic considerations should also include the level of personnel required for analysis. A detailed breakdown of the more important characteristics of each type of sensor is presented in Tables 15-2 through 15-6.

\section{Data Recording and Processing}

There are several ways of recording analog electrical signals from the various probes in the system. Probably the oldest method is strip chart recording. Chart recorders provide excellent trend indication, but the output is difficult to format for numerical analysis. Wide fluctuations in the recorded flows and temperatures tend to lower the accuracy of the recorded information. Chart recorders also require extensive maintenance and adjustment. They range in price from about $\$ 500$ to $\$ 1,500$, depending on the number of input channels. Dataloggers are another type of data recording device which has become very popular in recent years. Several different manufacturers now provide a variety of models. Many machines will either print data on paper or record it on magnetic tape. Some models do both. Others are capable of relaying data to a remote computer when called. Some have a limited analysis capability and can convert inputs into engineering units or compute energy flows. Variable data sampling rates may also be possible with some machines. The specific datalogger specified should match the user's needs and the type of sensors employed.

The data sensors specified should be capable of the accuracy required by the type of analysis to be done. Data quality is generally not limited by the recording device but by the probes and how well they are installed.

Automatic - data analysis can provide very useful information on system operation and performance. Data are input to a computer which may be either local or remote. A wide variety of numerical analyses may be performed on large quantities of data. Both long-term and transient behavior may be observed, and the results outputted to the users. Although this approach can provide very detailed information, personnel familiar with computer programming are required for analysis.

\section{Levels of Instrumentation for Each Purpose}

The four primary purposes for energy monitoring are debugging, acceptance testing, system maintenance, and performance evaluation. Each purpose may be served, to varying degrees, by many of the seven levels of instrumentation discussed above. Table 15-7 presents a subjective summary of the compatibility of each instrumentation level for each purpose.

\section{Instrumentation for Specific Purposes}

The level of instrumentation and type of sensors most generally appropriate for each purpose are discussed below. These system descriptions are not intended to be definitive but merely to describe what might be a typical cost-effective installation for each purpose.

\section{Debugging}

To perform the numerous adjustments and modifications of ten necessary to get a new system operational, some sort of instrumentation is highly desirable. The data collected should indicate instantaneous values and be in a form immediately available to local personnel. Accordingly, the most cost-effective system for this type of purpase would probably be a set of portable visual monitors (thermometers, pressure gauges, flowmeters, and multimeters or wattmeters). Provisions should be made at appropriate locations in the piping system to allow for intrusive measurement of fluid temperature. With proper care, a reasonably accurate temperature reading may also be taken from the surface of a pipe. Flow measurements are more difficult but may be done by using many of the sensor types discussed previously. The use of orifice plates or variable area type flowmeters is common. The accuracy of the data depends primarily on the sensors used. Rugged, high-quality equipment is recommended since it may be removed and reused for numerous applications. Fig. 15-2 indicates what might be a typical selection of sensor locations for a solar heating and hot water installation.

\section{Acceptance Test}

Before putting a new system into permanent operation, it is necessary to verify that it is operating as designed. In addition to monitoring the system at selected points, it is often necessary to determine the energy flows through a component or subsystem. For example, in a solar system it might be desirable to know how much energy the collector loop is delivering or what the energy flows into and out of the tank are. For instantaneous values these objectives may be accomplished by use of a sufficient number of visual monitors. Data collected in this manner must be manually processed. Since it may be desirable to evaluate performance over both instantaneous and short time intervals, both instantaneous and totalizing sensors are desirable. Energy meters may be very useful but are prohibitively expensive if used only for this purpose. These devices are generally much less portable than visual monitors.

\section{Maintenance Monitoring}

A data monitoring system may be used to assist in the routine maintenance and repair of a solar energy system. It may be useful both for isolating problems and preventive maintenance. With these purposes in mind, it 
Table 15-2. SOLAR RADIATION PROBES

\begin{tabular}{|c|c|c|c|c|c|c|c|c|}
\hline $\begin{array}{l}\text { TYPE OF } \\
\text { SENSOR }\end{array}$ & $\begin{array}{l}\text { APPROXIMATE } \\
\text { COST }\end{array}$ & ACCURACY & RANGEABILITY & MAINTENANCE & CONVENIENCE & $\begin{array}{l}\text { TYPE OF } \\
\text { OUTPUT }\end{array}$ & $\begin{array}{l}\text { DATALOGGER } \\
\text { CAPABILITY }\end{array}$ & SPECIAL COMMENTS \\
\hline Pyranometer & $\$ 150-\$ 300$ & $\begin{array}{l}1 \%-3 \% \text { of } \\
\text { instantaneous }\end{array}$ & Adequate & Little & High & $\begin{array}{l}\text { Analog } \\
\text { Electrical }\end{array}$ & Yes & $\begin{array}{l}\text { Mounting point must } \\
\text { be unshaded. Some } \\
\text { models increase error } \\
\text { by tilting. }\end{array}$ \\
\hline $\begin{array}{l}\text { Integrating } \\
\text { Pyranometer }\end{array}$ & $\$ 150$ & $\begin{array}{l}5 \% \text { of } \\
\text { integrated } \\
\text { value }\end{array}$ & $\begin{array}{c}\text { Adequate } \\
.\end{array}$ & Some & High & $\begin{array}{l}\text { Mechanical } \\
\text { Totalizer } \\
\text { (and analog } \\
\text { electrical } \\
\text { on some } \\
\text { models) }\end{array}$ & Some Models & $\begin{array}{l}\text { Some models provide } \\
\text { instantaneous reading. }\end{array}$ \\
\hline
\end{tabular}

Table 15-3. THERMAL SENSORS

\begin{tabular}{|c|c|c|c|c|c|c|c|c|}
\hline $\begin{array}{l}\text { TYPE OF } \\
\text { SENSOR }\end{array}$ & $\begin{array}{l}\text { APPROXIMATE } \\
\text { COST }\end{array}$ & ACCURACY & RANGEABILITY & MAINTENANCE & CONVENIENCE & $\begin{array}{l}\text { TYPE OF } \\
\text { OUTPUT }\end{array}$ & $\begin{array}{l}\text { DATALOGGER } \\
\text { CAPABILITY }\end{array}$ & SPECIAL COMMENTS \\
\hline $\begin{array}{l}\text { Bimetallic Dial } \\
\text { Thermometer }\end{array}$ & $\$ 25$ & $\begin{array}{l}\text { Low, } 1 \% \text { of full } \\
\text { seale }\end{array}$ & Adequate & Little & $\begin{array}{l}\text { Good, when } \\
\text { installed } \\
\text { correctly }\end{array}$ & Visual & No & $\begin{array}{l}\text { Not reliable for } \\
\text { differential } \\
\text { temperature due } \\
\text { to low accuracy }\end{array}$ \\
\hline $\begin{array}{l}\text { Bulb Type } \\
\text { Thermometer }\end{array}$ & $\$ 25$ & High & Adequate & Little & $\begin{array}{l}\text { Difficult to } \\
\text { read because } \\
\text { of small seale }\end{array}$ & Visual & No & Very fragile \\
\hline $\begin{array}{l}\text { Digital } \\
\text { Thermometer }\end{array}$ & $\$ 100$ & $\begin{array}{l}\text { Depends on } \\
\text { type of } \\
\text { probe(s), } \\
\text { typically } 1^{\circ} \mathrm{F}\end{array}$ & Adequate & Little & $\begin{array}{l}\text { Excellent; one } \\
\text { indicator can } \\
\text { serve several } \\
\text { locations (probes) }\end{array}$ & $\begin{array}{l}\text { Visual } \\
\text { (digital) }\end{array}$ & As an option & $\begin{array}{l}\text { Probes typically cost } \\
\$ 50 \text {. }\end{array}$ \\
\hline Thermocouple & $\$ 25-\$ 30$ & Fair, $2^{\circ} \mathrm{F}$ & Adequate & $\begin{array}{l}\text { Some, periodic } \\
\text { recalibration }\end{array}$ & $\begin{array}{l}\text { Excellent, when } \\
\text { coupled with } \\
\text { indicator }\end{array}$ & $\begin{array}{l}\text { Analog } \\
\text { electrical }\end{array}$ & $\begin{array}{l}\text { Must be } \\
\text { amplified } \\
\text { increased cost } \\
\text { and error) }\end{array}$ & $\begin{array}{l}\text { Not reliable for } \\
\text { differential } \\
\text { temperatures. } \\
\text { Requires special wire } \\
\text { for installation. }\end{array}$ \\
\hline $\begin{array}{l}\text { Resistance } \\
\text { Temperature } \\
\text { Detectors (RTD) }\end{array}$ & $\$ 60$ & High, $0.5^{\circ} \mathrm{F}$ & Adequate & Little & $\begin{array}{l}\text { Excellent, when } \\
\text { coupled with } \\
\text { indicator }\end{array}$ & $\begin{array}{l}\text { Analog } \\
\text { electrical }\end{array}$ & Yes & $\begin{array}{l}\text { Matehed differential } \\
\text { pairs can be accurate } \\
\text { to } 0.1^{\circ} \mathrm{F} \text {. }\end{array}$ \\
\hline Thermistors & $\$ 10-\$ 15$ & $\begin{array}{l}\text { Moderate, } \\
1^{\circ} \mathrm{F}\end{array}$ & Limited & Little & $\begin{array}{l}\text { Excellent, when } \\
\text { coupled with } \\
\text { indicator }\end{array}$ & $\begin{array}{l}\text { Analog } \\
\text { electrical }\end{array}$ & Yes & $\begin{array}{l}\text { Not available in proper } \\
\text { housing. Can be } \\
\text { damaged by high } \\
\text { temperature. }\end{array}$ \\
\hline
\end{tabular}


Table 15-4. LIQUID FLOW SENSORS AND INDICATORS

\begin{tabular}{|c|c|c|c|c|c|c|c|c|}
\hline $\begin{array}{l}\text { TYPE OF } \\
\text { SENSOR }\end{array}$ & $\underset{\text { COST }}{\text { APPROXIMATE }}$ & ACCURACY & RANGEABILITY & MAINTENANCE & CONVENIENCE & $\begin{array}{l}\text { TYPE OF } \\
\text { OUTPUT }\end{array}$ & $\begin{array}{l}\text { DATALOGGER } \\
\text { CAPABILITY }\end{array}$ & SPECIAL COMMENTS \\
\hline $\begin{array}{l}\text { Pressure } \\
\text { Gauges }\end{array}$ & $\$ 50$ & $\begin{array}{l}\text { Strictly a } \\
\text { flow indicator }\end{array}$ & Adequate & $\begin{array}{l}\text { Little, very } \\
\text { reliable }\end{array}$ & Low & Visual & No & \\
\hline Variable Area & $\$ 500$ & $\begin{array}{l}\text { Low, } 2 \% \text { of } \\
\text { full scale }\end{array}$ & Moderate, 12:1 & $\begin{array}{l}\text { Little, very } \\
\text { reliable }\end{array}$ & Moderate to High & Visual & No & $\begin{array}{l}\text { High pressure drop } \\
\text { increases pump sizing } \\
\text { and energy require-- } \\
\text { ments. }\end{array}$ \\
\hline $\begin{array}{l}\text { Differential } \\
\text { Pressure with } \\
\text { Orifice }\end{array}$ & $\$ 800$ & $\begin{array}{l}\text { Fair, } 1 \% \text { of } \\
\text { full scale }\end{array}$ & Poor, 5:1 & $\begin{array}{l}\text { Little, very } \\
\text { reliable }\end{array}$ & High & $\begin{array}{l}\text { Visual or } \\
\text { analog } \\
\text { electrical }\end{array}$ & & $\begin{array}{l}\text { Strictly visual indi- } \\
\text { cation available at } \\
\text { greatly reduced cost. } \\
\text { High pressure drop } \\
\text { increases pump sizing } \\
\text { and energy require- } \\
\text { ments. }\end{array}$ \\
\hline Turbine & $\begin{array}{l}\$ 1,000, \$ 1,500 \mathrm{w} / \\
\text { instantaneous } \\
\text { flow indicator }\end{array}$ & $\begin{array}{l}\text { High, } 0.25 \% \text { of } \\
\text { instantaneous } \\
\text { flow }\end{array}$ & Excellent, 20:1 & $\begin{array}{l}\text { Not reliable for } \\
\text { continuous } \\
\text { operation due to } \\
\text { bearing wear }\end{array}$ & Low & Pulsed & $\begin{array}{l}\text { Requires time- } \\
\text { base integrator }\end{array}$ & $\begin{array}{l}\text { Portable insertion } \\
\text { turbines are very } \\
\text { convenient for flow } \\
\text { balancing at greatly } \\
\text { reduced cost. Prone } \\
\text { to damage from high } \\
\text { flows and debris. }\end{array}$ \\
\hline Target or Impact & $\$ 1,000$ & $\begin{array}{l}\text { Moderate, } 0.5 \% \\
\text { of full scale }\end{array}$ & Moderate, $10: 1$ & $\begin{array}{l}\text { No wearing parts, } \\
\text { (see comments) }\end{array}$ & Moderate & $\begin{array}{l}\text { Analog } \\
\text { electrical }\end{array}$ & Yes & $\begin{array}{l}\text { Transmitters prone } \\
\text { to failure. Fluid must } \\
\text { be kept free of debris. }\end{array}$ \\
\hline Vortex & $\begin{array}{l}\$ 800-\text { Analog } \\
\$ 1,000-\text { Digital } \\
\$ 500-\text { Indicator } \\
\text { and totalizer }\end{array}$ & $\begin{array}{l}\text { High, } 1 \% \text { of } \\
\text { instantaneous } \\
\text { flow }\end{array}$ & Excellent, 20:1 & $\begin{array}{l}\text { Very good, no } \\
\text { wearing parts }\end{array}$ & Low & $\begin{array}{l}\text { Analog or } \\
\text { digital } \\
\text { electrical }\end{array}$ & Yes & $\begin{array}{l}\text { State-of-the-art } \\
\text { flowmeter }\end{array}$ \\
\hline Magnetic & $\$ 3,000$ & $\begin{array}{l}\text { High, } 1 \% \text { of } \\
\text { instantaneous } \\
\text { flow }\end{array}$ & Excellent, 30:1 & $\begin{array}{l}\text { Very good, no } \\
\text { wearing parts }\end{array}$ & Low & $\begin{array}{l}\text { Analog } \\
\text { electrical }\end{array}$ & Yes & Very expensive \\
\hline $\begin{array}{l}\text { Positive } \\
\text { Displacement }\end{array}$ & $\$ 500$ & High & Low & Prone to failure & Moderate to high & $\begin{array}{l}\text { Mechanical } \\
\text { totalizer }\end{array}$ & $\begin{array}{l}\text { As an option; } \\
\text { requires time- } \\
\text { base integrator }\end{array}$ & $\begin{array}{l}\text { Good for greatly } \\
\text { varying flow rates, } \\
\text { i.e., domestic water } \\
\text { supply }\end{array}$ \\
\hline
\end{tabular}


Table 15-5. AIR FLOWMETERS

\begin{tabular}{|c|c|c|c|c|c|c|c|c|}
\hline $\begin{array}{l}\text { TYPE OF } \\
\text { SENSOR }\end{array}$ & $\begin{array}{l}\text { APPROXIMATE } \\
\text { COST }\end{array}$ & ACCURACY & RANGEABILITY & MAINTENANCE & CONVENIENCE & $\begin{array}{l}\text { TYPE OF } \\
\text { OUTPUT }\end{array}$ & $\begin{array}{l}\text { DATALOGGER } \\
\text { CAPABILITY }\end{array}$ & SPECIAL COMMENTS \\
\hline $\begin{array}{l}\text { Hot Wire } \\
\text { Anemometer }\end{array}$ & $\$ 600-\$ 1,000$ & $\begin{array}{l}\text { Moderate, } 2 \% \\
\text { of full scale }\end{array}$ & Moderate, $15: 1$ & Some & Low & $\begin{array}{l}\text { Analog } \\
\text { electrical }\end{array}$ & Yes & $\begin{array}{l}\text { Some models easily } \\
\text { damaged by debris } \\
\text { and improper handling. } \\
\text { Must be properly } \\
\text { located in order to } \\
\text { determine mean flow. }\end{array}$ \\
\hline Turbine & $\$ 300$ & $\begin{array}{l}\text { Good, } 1 \% \text { of } \\
\text { flow }\end{array}$ & Moderate, $15: 1$ & Little & Low & $\begin{array}{l}\text { Analog } \\
\text { electrical }\end{array}$ & Yes & $\begin{array}{l}\text { Must be properly } \\
\text { located in order to } \\
\text { determine mean flow. }\end{array}$ \\
\hline
\end{tabular}

$\stackrel{\leftrightarrow}{\mathfrak{w}}$

Table 15-6. ENERGY METERS

\begin{tabular}{|c|c|c|c|c|c|c|c|c|}
\hline $\begin{array}{l}\text { TYPE OF } \\
\text { SENSOR }\end{array}$ & $\begin{array}{l}\text { APPROXIMATE } \\
\text { COST }\end{array}$ & ACCURACY & RANGEABILITY & MAINTENANCE & CONVENIENCE & $\begin{array}{l}\text { TYPE OF } \\
\text { OUTPUT }\end{array}$ & $\begin{array}{l}\text { DATALOGGER } \\
\text { CAPABILITY }\end{array}$ & SPECIAL COMMENTS \\
\hline Btu Meter & $\$ 400-\$ 700$ & $\begin{array}{l}\text { Moderate, } 1 \% \text { of } \\
\text { full scale }\end{array}$ & $\begin{array}{l}\text { Dependent on type } \\
\text { of flow sensor }\end{array}$ & Unproven & High & $\begin{array}{l}\text { Mechanical } \\
\text { totalizer }\end{array}$ & No & \\
\hline $\begin{array}{l}\text { Electrical } \\
\text { Wattmeter } \\
\text { (Hall Probe) }\end{array}$ & $\$ 200$ & High & Very & Excellent & High & $\begin{array}{l}\text { Analog } \\
\text { electrical }\end{array}$ & Yes & \\
\hline $\begin{array}{l}\text { Electrical } \\
\text { Wattmeter } \\
\text { (Induction) }\end{array}$ & $\$ 100$ & $\begin{array}{l}\text { Moderate } 1 \% \text { of } \\
\text { full scale }\end{array}$ & Good & Excellent & High & $\begin{array}{l}\text { Analog } \\
\text { electrical }\end{array}$ & Yes & $\begin{array}{l}\text { Requires special } \\
\text { installation }\end{array}$ \\
\hline $\begin{array}{l}\text { KWatt Demand } \\
\text { Meter }\end{array}$ & $\$ 150$ & $\begin{array}{l}\text { Moderate } 1 \% \text { of } \\
\text { full scale }\end{array}$ & Good & Excellent & High & $\begin{array}{l}\text { Mechanical } \\
\text { totalizer }\end{array}$ & $\begin{array}{l}\text { An option } \\
\text { with timebase } \\
\text { integrator }\end{array}$ & \\
\hline
\end{tabular}


Table 15-7. LEVETS OF INSTRUMENTATION FOR EACH PURPOSE

\begin{tabular}{|c|c|c|c|c|}
\hline & Debugging & Acceptance Test & Maintenance & Performance Monitoring \\
\hline Data Time Base & Short & Short & Long & Long \\
\hline None & $\begin{array}{l}\text { Very } \\
\text { Difficult }\end{array}$ & $\mathrm{N} / \mathrm{A}$ & $\begin{array}{l}\text { Very } \\
\text { Difficult }\end{array}$ & $\mathrm{N} / \mathrm{A}$ \\
\hline Visual Monitors & Adequate & Difficult & Adequate & Difficult \\
\hline Energy Meters & Difficult & Adequate & Difficult & Adequate \\
\hline $\begin{array}{l}\text { Energy Meters } \\
\text { Plus Visual } \\
\text { Monitors }\end{array}$ & Adequate & Adequate & Adequate & Adequate \\
\hline $\begin{array}{l}\text { Data Logging \& } \\
\text { Local Processing }\end{array}$ & Good & Good & Good & Adequate \\
\hline $\begin{array}{l}\text { Data Logging \& } \\
\text { Rem ote Processing }\end{array}$ & Difficult & Difficult & Adequate & Very Good \\
\hline
\end{tabular}

Key

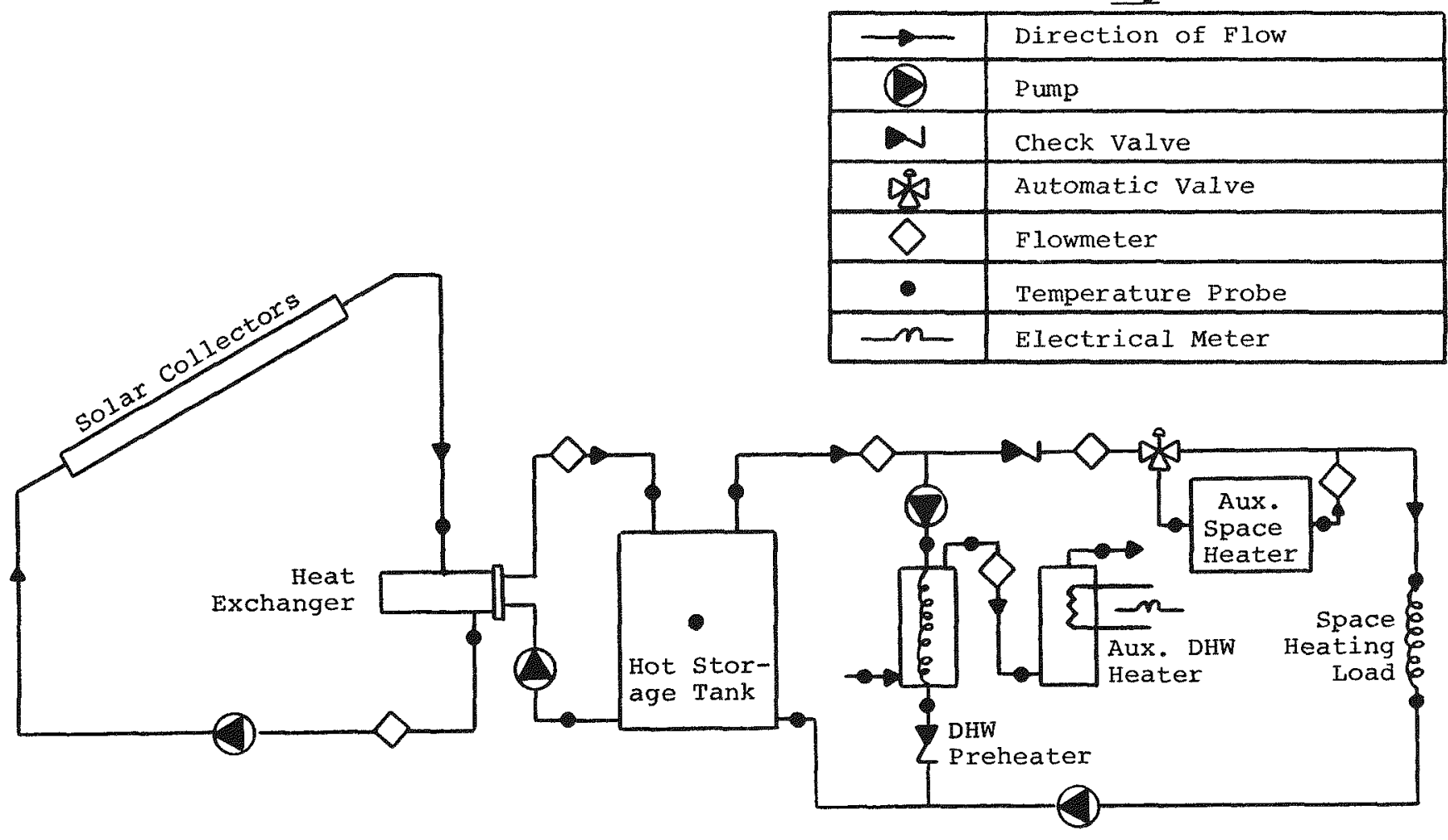

Fig. 15-2. Typical selection of visual monitors for solar heating and hot water systems 
is desirable to have the sensors permanently installed. Data recording, although useful, is generally not necessary. The simplest method of providing the necessary data is to use visual monitors of the types discussed previously. Both instantaneous and totalizer types may be useful. Measurement of intermittent flows such as service hot water generally requires use of totalizer meters. When used for a purely maintenance function, the sensor's ruggedness and reliability are more important than its accuracy.

\section{Performance Monitoring}

Performance monitoring over time requires a more elaborate system than those discussed above. Although some instantaneous data readings are still useful, the need now is primarily for time integrated values. This purpose may be achieved with either a manual or automatic type system. A manual system involves use of Btu meters and wattmeters. An automatic system requires electronic sensors and some type of datalogger. With quality sensors, both approaches may provide accurate and reliable information. Manual systems are generally less expensive but are decentralized and do not provide an output amenable to sophisticated processing. Although automatic electronic systems may overcome these problems, they are currently more expensive (depending on the specific application). The cost of many electronic sensors and dataloggers continues to drop, but there is still the cost of running signal wires from the sensors to the central recorder. A manual system of Btu meters and wattmeters should be completely adequate for many applications. Measurement of integrated solar flux is most reliably done with electronic devices. However, this information may not be necessary, or approximate values may be obtained from nearby weather stations.

The appropriate locations for energy meters in a typical solar heating and hot water installation are presented in Fig. 15-3. The goal here is to determine the net solar contribution to the load(s). For the system presented in Fig. 15-3, the solar contribution to the total load is computed as follows:

- Fraction of total load from solar $=$ meter 2 reading $\div$ (meter 3 reading + meter 6 reading)

It may be desirable to know the separate solar contribution to the space heating and service hot water loads. The following equations apply for a system instrumented as in Fig. 15-3.

- Fraction of total space heating load from solar = (meter 6 reading - meter 5 reading) $\div$ meter 6 reading

- Fraction of total BSHW load from solar $=$ (meter 3 reading - meter 4 reading $\div$ meter 3 reading

The installation of all six energy meters provides some redundancy. However, this allows system performance to be checked by performing an energy balance. Heat losses through pipes and other sources may thus be evaluated. For total solar contribution to the gross load, at least three energy monitors (numbers 2, 3, and 6) are required. To determine a separate solar contribution to the heating and BSHW loads, a minimum of four energy

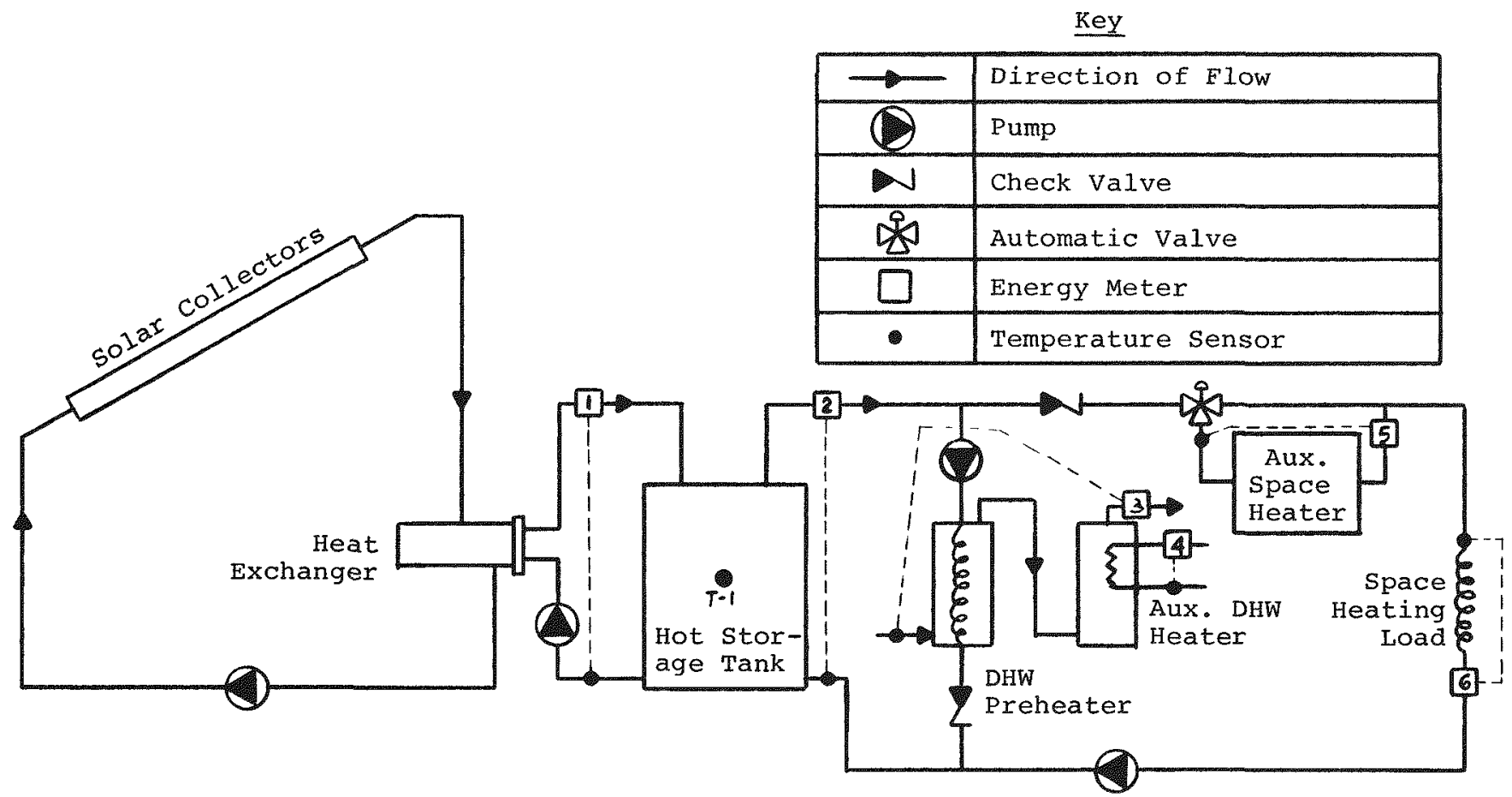

Fig. 15-3. Typical selection of energy meters for a solar heating and hot water system 
monitors (numbers 3,6 , and any two of 2,4 , and 5 ) is required.

It is interesting to evaluate the performance of the storage tank. Its energy loss may be calculated as follows:

- Heat lost from tank $=$ meter 1 reading - meter 2 reading - change in internal energy of tank calculated from temperature sensor $T-1$ readings.

Neglecting pipe losses, the following energy balance applies:

- Meter 6 reading + meter 3 reading $=$ meter 2 reading + meter 4 reading + meter 5 reading.

This equation may be used for an approximate check on energy balance and to determine thermal losses from pipes downstream of the storage tank.

\section{Typical Installation Problems}

Most problems with temperature probes occur from poor calibration or mislocation of the sensor. Extraneous heat flows between the probe extension/weatherhead and external environment can also be a problem. Insulating the extension may help. Another source of extraneous heat flow is thermosyphoning within a pipe under no-flow conditions. Better sensor placement or check valves may be useful in correcting this problem. The dials and scales of visual probes must be located above the insulation. Thermocouples in particular suffer from difficulties in calibration. Dual thermowells are recommended for sideby-side in-place calibration with a standard thermometer.

Problems with flowmeters occur primarily from failures resulting from improper application of the specific type of flowmeter. Many types of flowmeters require long lengths of straight pipe (or duct) upstream and downstream of the sensor. Turbine meters are subject to failure from bearing wear. Impact meters suffer from strain gauge failure. Vortex meters have a relatively sound track record. Orifice/differential pressure flowmeters increase line pressure drop and thus pump size and power requirements. Strainers should be placed upstream from turbine meters for protection. All flowmeters should be calibrated in place whenever possible. Air flow measurements are particularly difficult because of nonuniform flow within the duct or variable air conditions.

Remote analysis of system data is undesirable for the debugging process unless provision is made for immediate onsite availability of data. Slow turnaround time hampers debugging. All sensors should be installed where they can be easily reached and read. Thermal probes should be installed in a manner which allows removal for recalibration or repair. Provisions should be made for electromagnetic interference suppression if high gain amplifiers are to be used (i.e., thermocouples). Flowmeters ideally should have bypass circuits to allow for system operation during repair and maintenance periods.
Compatibility of system components is very important. The data recorder should accept the type of signals that will be provided. Care should be taken to insure that the proper type of sensor wire is used and that it is adequately shielded from electromagnetic interference and physical damage. Shielded strand wire in rigid conduit may be required.

\section{Energy Monitoring Equipment}

Table $15-8$ is a partial list of manufacturers of instrumentation and monitoring equipment.

\section{The National Solar Data Network}

The National Solar Data Network (NSDN) is a major component of the National Solar Data Program. The purpose of the NSDN is to evaluate the performance of instrumented DOE solar demonstration projects. Over 200 solar sites located throughout the country are to be monitored in an effort to obtain a large data base on solar system performance. The data monitoring system employed is an excelient example of a full-scale data recording with remote processing system. The NSDN consists of the following components:

1. Site Instrumentation (e.g., sensors, gauges, etc.)

2. Site Data Aequisition Subsystem (SDAS)

3. Communications Link

4. Central Data Processing System (CDPS), consisting of a communications processor with suitable sof tware to control the data collection from the instrumented sites, and a Host (or main) Computer with appropriate software and sufficient data storage to process the collected data.

The NSDN system is presented conceptually in Fig. 15-4.

\section{Site Implementation}

The solar energy system at each site is instrumented to provide sufficient data to support a subsystem level thermal performance analysis. This instrumentation generally includes sensors to monitor the following conditions:

- Total insolation (in the plane of the collector array)

- Outdoor ambient temperature

- Internal building temperature

- Collector lnop flow rate and temperatures

- Storage inlet flow rate and temperatures

- Storage outlet flow rate and temperatures

- Internal storage temperatures

- Load subsystem flow rates and temperatures

- Auxiliary fuel flow rates and values 
Table 15-8. PARTIAL LIST OF MONTTORING EQUIPMENT MANUFACTURERS

Orifice and Differential Pressure Flowmeters

Fisher and Porter Co., Inc.

Warminster, $\mathrm{Pa}$.

Budget Meter Co.

Mil waukee, Wis.

Foxboro Company

Foxboro, Mass.

\section{Vortex Flowmeters}

Fisher and Porter Co., Inc.

Warminster, $\mathrm{Pa}$.

Brooks Instrument Div.

Emerson Electric Co.

Hatfield, Pa.

Foxboro Company

Foxboro, Mass.

\section{Magnetic Flowmeters}

Brooks Instrument Div.

Emerson Electric Co.

Hatfield, $\mathrm{Pa}$.

Fisher \& Porter Co., Inc.

Warminster, $\mathrm{Pa}$.

Robert Shaw Controls

Long Beach, Calif.

Positive Displacement Flowmeters

Budget Meter Co.

Mil waukee, Wis.

Brooks Instrument Div.

Emerson Electric Co.

Hatfield, Pa.

ITT Barton

Monterey Park, Calif.

Bulb Thermometers

Mueller Inst. Co., Inc.

Ivoryton, Conn.

Kessler Co.

Westbury, N.Y.

Palmer Inst. Co.

Cincinnati, Ohio
Dial Thermometers

Marsh Inst. Co.

Skokie, IIl.

Reotemp Inst. Corp.

San Diego, Calif.

Tel-Tru Mifg. Div.

Germanow-Simon Mach. Co.

Rochester, N.Y.

\section{Digital Thermometers}

Bailey Instruments, Inc. Saddle Brook, N.J.

Leeds \& Northrup Co.

North Wales, $\mathrm{Pa}$.

Analog Devices

Norwood, Mass.

RTDs and Thermocouples

Leeds and Northrup

North Wales, Pa.

$R \& F$ Corp.

Hudson, N.Y.

Minco Produets, Ine.

Minneapolis, Minn.

\section{Dataloggers}

Fluke Mfg. Co.

Mountlake Terrace, Wash.

Consolidated Controls Corp.

Bethel, Conn.

Ecosol Ltd.

New York, N.Y. 


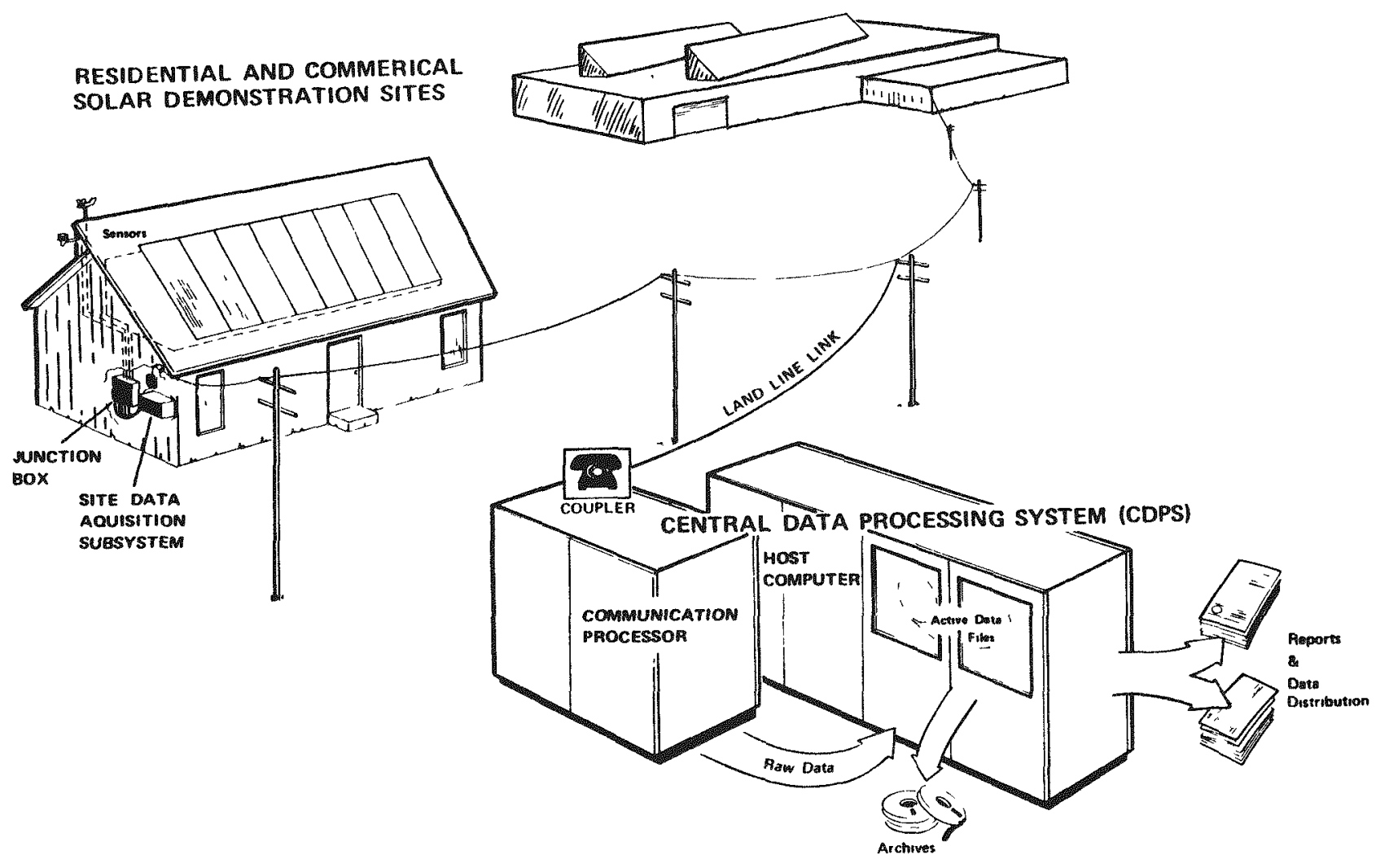

Fig. 15-4. National Solar Data Network

Each system is instrumented to the practical level required for calculation of the performance factors. (See NBSIR 76-1137, August 1976, National Bureau of Standards.) Some sites have additional instrumentation as a result of their unique requirements.

\section{Site Data Acquisition Subsystem}

Site data are locally recorded on an automatic basis by the Site Data Acquisition Subsystem (SDAS). This consists of a variety of sensors providing data (as an electrical signal) to a central site recorder. Periodically, these recorded data are transmitted to the Central Data Processing System (CDPS) at the IBM facility in Huntsville, Alabama.

\section{Communications link}

The communications link between each SDAS and the CDPS consists of voice-grade telephone lines and telephone data couplers. The recorded data at each remote site are collected periodically (usually daily) by the Communications Processor in the CDPS. The Communications Processor directs the calling of all sites, communicates with the SDAS, and temporarily stores the data until called for by the Host Computer for processing. For each site call, the Communications Processor establishes and verifies correct contact with the site by checking an address code transmitted from the SDAS. Also, the SDAS transmits the reading from its internal timer to insure that the data to be transmitted will be timetagged correctly.

\section{Central Data Processing System}

After the Communications Processor scans the data as received to determine if there are any apparent errors in the transmission process, the data are transferred to the Host Computer. Here the data are converted from the binary transmission format to appropriate values in engineering units. This conversion uses factors unique to each site location. The measurements are then checked to insure that they are reasonable (not beyond the known limits of the instrumentation, or erratic). Data that appear questionable are discarded.

For each site, equations that define the desired performance factors for the site-specific system configuration have been formulated and programmed. All valid data are processed by the Host Computer using these performance equations to generate hourly performance factors. As sufficient data are aceumulated, the hourly performance factors are combined to provide daily performance factors and, finally, monthly performance factors.

All performance factors are stored in the CDPS data files along with the measurements (in engineering units), site identification information (both numerical and textual), and certain site data which are used in processing and generating the performance factors. 


\section{Outputs of the NSDN}

Through the NSDN, monthly and seasonal performance reports are published on all operating systems. These reports are available from the DOE Technical Information Center. In addition to being used to evaluate the performance of the instrumented systems, the NSDN has been valuable in debugging systems and identifying operational problems and failures and their causes.

The NSDN has, for instance, alerted a commercial building owner that his collector circulating pump was activating in the middle of the night, thus causing an energy loss to the surrounding air. Onsite investigation located the source of and corrected this problem.

In several other cases, leaking air dampers could be identified as the cause of water freezing in BSHW heat exchangers. Analysis of the temperature readings in the duct showed below freezing temperatures near the heat exchanger on cold nights when that part of the system was deactivated. A bulletin has been distributed to alert owners of similar systems to this problem and to suggest corrective measures.
Similarly, the NSDN has identified air leaks in ducts as the primary source of heat loss in air systems. Special consideration beyond normal construction techniques must be applied to reduce such leaks.

The NSDN has provided sufficient information to permit analysis of collector array efficiency. This analysis has determined that the efficiency is of ten from 10 to $30 \%$ lower than single collector test efficiencies. Reasons for this include manifold piping heat losses and nonuniform flow distribution.

Excessive heat loss from storage, another problem area identified through the NSDN, has highlighted the importance of proper construction techniques.

Observations such as those discussed above are being used in the development of special reports from the NSDN to inform the solar community of lessons learned. These reports, when used together with other outputs of the Data Program, such as "Solar Project Descriptions" and "Solar Project Cost Reports" help provide an overall assessment of solar energy systems within the demonstration program. 
Section IV.
Case Studies 
contomitis

\section{chepter}

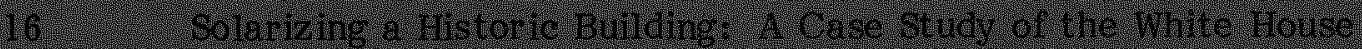

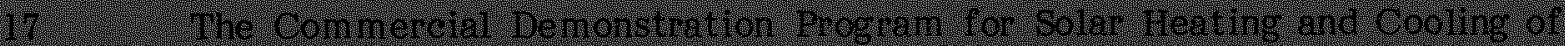
Commercial Butldings

\section{0}

The editors wish to thant the following authors for their contribution to this seption.

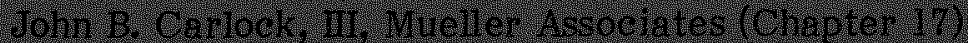

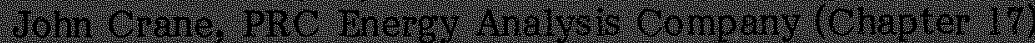

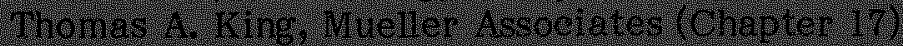

Pan A sabatiuk Wueller a ssociates (Chabter 17)

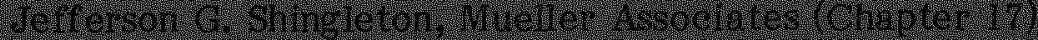

Steohen Weinstein, The whenkrantz Group (Chnpter 16 ) 
16

Solarizing a Historic Building:

A Case Study of the White House 
16. Solarizing a Historic Building: A Case Study of the White House

What is a historic building?

Special problems involved in the solarizing of historic buildings Design approach

Why solarize a historic building?

The White House as a demonstration project 


\section{SOLARIZING A HISTORIC BUILDING: A CASE STUDY OF THE WHTTE HOUSE}

\section{WHAT IS A HISTORIC BUILDING?}

According to the legal definition embodied in the Historic Preservation Act of 1966, any building over 50 years of age is eligible. However, only those buildings listed in The National Register of Historic Places are, in fact, "historic buildings." Once a building is designated "his toric," any alteration to the building involving federal funds must be approved by the Advisory Council for Historic Buildings or its approved agent, usually the state historic preservation officer.

\section{SPECIAL PROBLEMS INVOLVED IN THE SOLARIZING OF HIISTORIC BUILDINGS}

To understand the problems, one must first understand what makes a particular building historic. A building is normally designated "historic" if it has national, regional, or local significance or on the basis of its architectural, engineering, cultural, economic, or historic connotations. In other words, if a building had the first indoor plumbing in the nation, or if Washington slept there, it's historic. In addition, normally buildings are designated "historic" when a group of concerned eitizens pushes for it. We can now see that the potential problems have two sources: the conditions that make the building historic and the local interest groups who pushed for its designation. Usually, a carefully considered approach and a well thought-out aesthetic design will go a long way toward forestalling most problems by appeasing a majority of concerned people.

\section{DESIGN APPROACH}

Actually, every solar installation should be designed so as to enhance the project rather than appearing to be just stuck onto it. There really should be little difference between the design approaches to historic and nonhistoric buildings, except for this major one: the appearance of a historic building, from one or more vantage points, may not be altered. The "historic view" must remain unchanged. This requirement does not preclude the use of solar, but it can severely restrict the location and extent of its use. Of ten the answer to installing solar can be found within historic precedent for the building style involved. For instance, in Federal style buildings, balustrades often mask the slope of roofs. Similarly, a balustrade can mask collector installation. Very gingerbread-y buildings may have interior courtyards with simple sloped roofs that can be used without affecting the "historic view."

\section{WHY SOLARIZE A HISTORIC BUILDNG?}

This is an important question, and its answers will have a strong impact on the design approach. The White House was solarized to provide the nation with a highly visible example of the acceptance and use of solar energy. It is hoped that this example will lead to expanded application of solar energy, with consequent benefits that far exceed the energy savings of the White House alone.

But how strong a solar statement do you wish to make? A strong statement would enable passersby to get at least one clear view of the installation; hiding collectors in an inaccessible inside courtyard or behind a screen of some sort would make a very weak statement. At this stage of solar development, the concept needs a strong statement, which suggests an attempt to integrate, rather than hide, the solar installation whenever possible and architecturally appropriate.

\section{THE WHTTE HOUSE AS A DEMONSTRATION PROJECT}

A task team was formed to carry out the White House solarization project. Government team members included representatives from the then-ERDA Division of Solar Energy (now the Department of Energy), the White House staff, the National Park Service, and the General Services Administration. Planning Research Corporation and The Ehrenkrantz Group acted as solar engineering and architectural management support contractors to ERDA. Mueller Associates acted as mechanical engineers and cost consul tants.

The study defined the following:

- Possible areas that could be used for solar,

- Historic compatibility with the architectural style,

- Impact on the aesthetics of the complex,

- Potential visibility to the public,

- Ease of access for visiting dignitaries,

- The amount of energy that would be generated,

- Combinations of solar locations to provide increased energy for mul tiple uses,

- The economies involved, and

- Time required to complete the different alternatives. 


\section{Locations}

After an extensive review of the building and the grounds, the team selected eight possible locations (Fig. 16-1).
A. Ground Site
B. East Wing Roof
C. Residence Roof
D. Swimming Pool
E. West Terrace Roof
F. East Terrace Roof
G. Oval Office and Cabinet Room Roof
H. West Wing Main Roof

How Mueh Solar Could Be Provided, and How Would It Affect the Complex?

The next step was to review each site to ascertain how many collectors could actually be installed and how visible they would be to the public.

\section{Location A. Ground Site}

The area selected for a ground installation was a sloping portion of the south lawn just north of a transverse road that separates the upper and lower portions of the south lawn. The Ground Site could hold $6,340 \mathrm{sq}$ ft $(589 \mathrm{sq} \mathrm{m})$ of collectors, providing 2,176 million Btu (2,300 GJ) annually, or enough energy to provide $78 \%$ of the heating and $28 \%$ of the cooling for the second and third floors of the residence.

This location has one of the most important vistas of the White House, namely, the classic view of the south elevation over the smooth expanse of the south lawn. Therefore, the architectural handling of this location would be of the utmost importance. The scheme worked out would have allowed for any degree of visibility desired; by placing the collectors in a "ha-ha," the designers could have concealed them completely. Don't laugh; a "ha-ha" is simply a recess in the ground to accommodate a specific use without causing a visual obstruction (Fig. 16-2). The ha-ha was a typical landscaping device used at the time

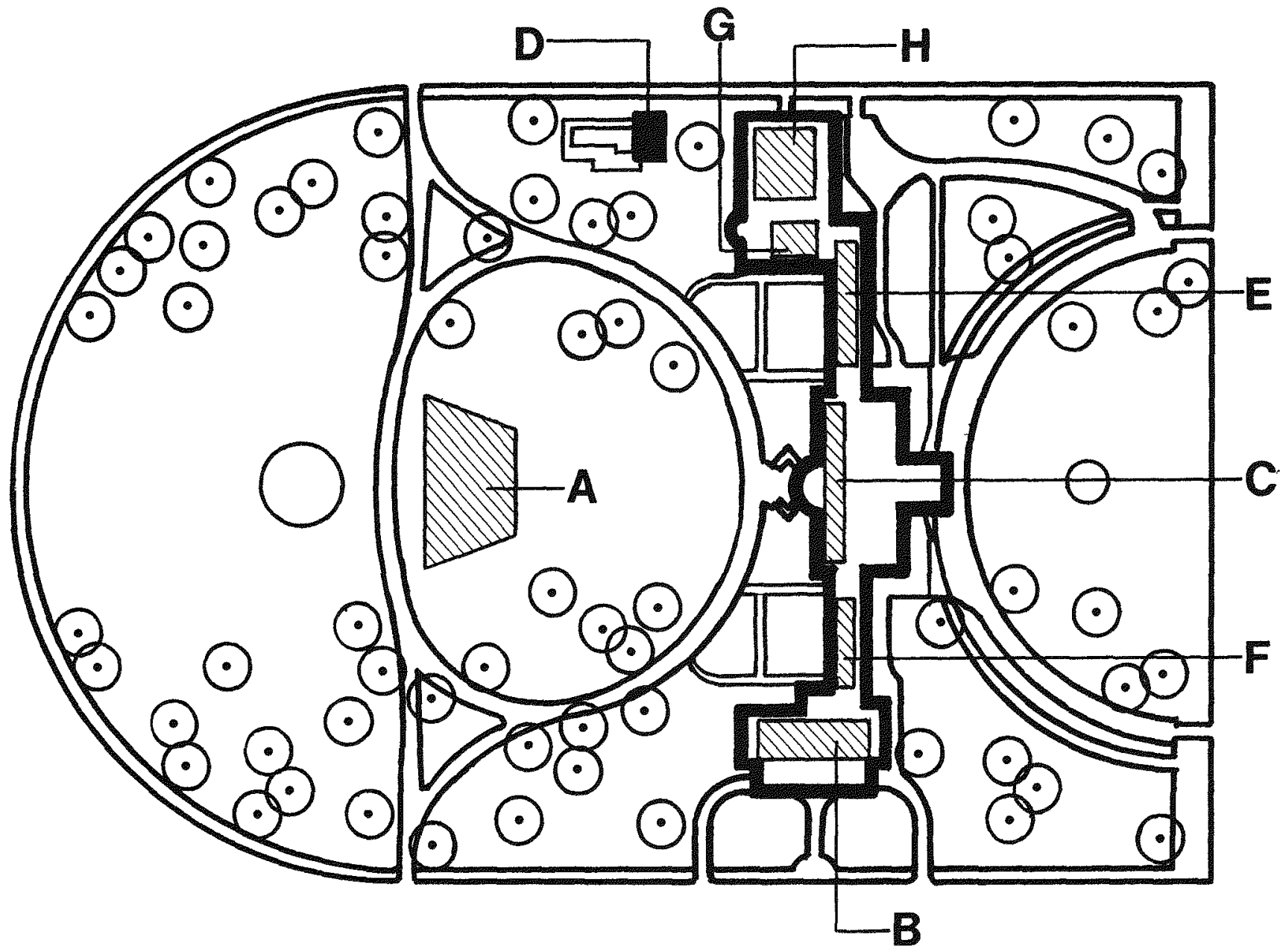

Fig. 16-1. Possible locations for installation of a solar system on the White House 


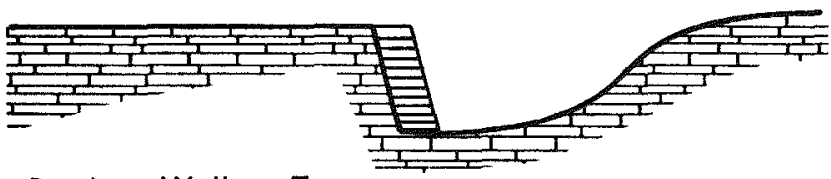

Sunken Wall or Fence

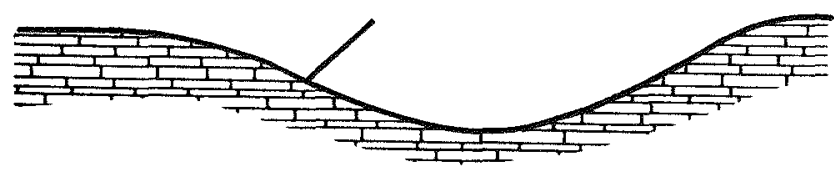

Sloping Invisible Iron Fence

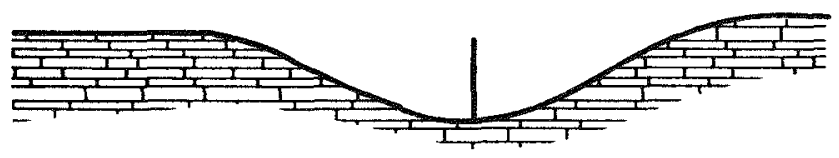

Common Wire Fence Sunken

\section{Fig. 16-2. Historical forms of "ha-ha's"}

the White House was built. As a matter of fact, the road that traverses the south lawn is in a ha-ha and cannot be seen from the south. This is an indication of historic precedent. Conversely, the collectors could be set only partially in the ground or above the ground to allow for greater visibility. It was felt that this location required the complete concealment of the collectors because of the importance of the "historic view." This site was not selected for many reasons, not the least of which was that it would have wreaked havoc on the Easter Egg Roll and other social events.

\section{Location B. East Wing Roof}

The East Wing could be an excellent location for solar. It is flat, completely unencumbered, and not part of any "historic view." In addition, visitors' tours of the White House line up along the street adjacent to the East Wing and enter through this wing; the collectors would be highly visible.

The East Wing Roof could hold $1,820 \mathrm{sq} f t$ ( $169 \mathrm{sq} \mathrm{m}$ ) of collectors, providing 365 million Btu ( $385 \mathrm{GJ})$ annually, or enough energy to provide $76 \%$ of the heating requirements of the second floor of the wing.

The East Wing would provide the most readily visible collector location within the complex, as it is the only place open to public viewing from the street. As in the first case, the collectors could either be left exposed or concealed, again according to historic precedent, by a masonry balustrade similar to the balustrade already designed into the Residence to conceal pitched roofs. Possibly a lighter, more modem enclosure might have been used. A disadvantage of this location is that it would not have provided the President and visiting dignitaries with ready access to the installation; the roof can be reached only by ladders.

\section{Location C. Residence Roof}

The Residence Roof is a very important part of the "historic" south view of the White House; furthermore, it has four chimneys that would create some shading.

The Residence Roof could hold $620 \mathrm{sq} \mathrm{ft}(57.6 \mathrm{sq} \mathrm{m})$ of collectors providing 116 million Btu $(122 \mathrm{GJ})$ annually, or about $60 \%$ of the domestic hot water for the residence.

Because of the importance of this elevation, it was felt that if collectors were to be located on this roof they should be set at the slope of the roof or $6.5 \%$ to minimize the visual impact of the collectors. Other minor, monumental problems would have arisen with collectors at this location in the attempts to run piping down through the Residence.

\section{Location D. Swimming Pool, Dressing Room Roof}

Since the end use of collectors in this location would be to heat the pool, and since the President doesn't have time for such frivolous things as swimming, this site was eliminated.

\section{Location R. West Terrace Roof}

The West Terrace Roof is over the old swimming pool, now the press room, and is outside the formal dining room. The roof of the terrace cannot be used as a direct pedestrian passage to the West Wing.

The Terrace could hold $600 \mathrm{sq} \mathrm{ft}(56 \mathrm{sq} \mathrm{m})$ of collectors and provide 112 million Btu (118 GJ) annually using only one row of collectors; it could accommodate up to three rows.

The collectors would not be seen by the public from any location other than the Washington Monument because of the solid terrace railings surrounding them. Plans were to set the collectors in a box that would normally be open, with a cover providing a reflecting surface for improved perform ance. To conceal the collectors during formal functions, the boxes could be closed.

\section{Location F. East Terrace Roof}

The East Terrace Roof is over the connection between the East Wing and the Residence, and the terrace can be used as a pedestrian connection.

This Terrace could hold $400 \mathrm{sq} \mathrm{ft}(37 \mathrm{sq} \mathrm{m}$ ) of collectors in one row, providing 74 million Btu (78 GJ) annually. Both Terraces were considered to work in conjunction with collectors on the respective wings for heating and cooling.

As with the West Terrace, the collectors not only could have been seen by the public but would also have been readily accessible from within the complex. 


\section{Location G. Cabinet Room Roof}

The Cabinet Room Roof is located just north of the Oval Office, east of the West Wing, and above the Rose Garden. It is flat and (was) unencumbered, and it measures about $96 \mathrm{ft}(29.3 \mathrm{~m})$ north and south, $25 \mathrm{ft}(7.6 \mathrm{~m})$ east and west. It is raised above the West Terrace by about $5 \mathrm{ft}(1,500 \mathrm{~mm})$ with a $10-\mathrm{ft}(3,000 \mathrm{~mm})$ tiled walkway along its east side, four steps above the Terrace.

The Cabinet Room Roof is now encumbered with 32 collectors of $611 \mathrm{sq} \mathrm{ft}(56.8 \mathrm{sq} \mathrm{m})$ and will provide 117 million Btu (123 GJ) annually, or about $68 \%$ of the domestic hot water for the West Wing.

The Cabinet Room Roof is partially visible from limited locations along Pennsylvania Avenue to the north and clearly visible from the top of the Washington Monument; it has easy access from within the complex. The collectors cannot be seen from either of the historic views of the White House (from the north or south). However, there are good views from the entrance to the West Wing and the Rose Garden. As in the design of the East Wing, the question of just how visible the collectors should be came up. Should they be exposed or concealed behind a balustrade or wall? They are, in fact, exposed.

One problem with this location was making certain that the roof dian't leak. As a result, we were forced to use clear spans and not penetrate the roofing except at the side walls.

\section{Location H. West Wing Roof}

The West Wing Roof is, at the present time, loaded with all sorts of mechanical equipment and covered skylights; installing collectors would require a considerable amount of work to remove and revise existing equipment.

The West Wing Roof could hold $2,400 \mathrm{sq} \mathrm{ft}(213 \mathrm{sq} \mathrm{m})$ of collectors providing 607 million Btu $(640 \mathrm{GJ})$ annually, or enough energy to provide $92 \%$ of the heating and $33 \%$ of the cooling loads for the West Wing.

The feeling was that the view of the roof of the West Wing could only be improved and that this location would therefore be good for the installation. As with the East Wing, collectors could have been either exposed or enclosed by a balustrade or low fence.

\section{Location of Mechanical Space}

As we all know, installing solar systems unfortunately entails more than just placing collectors on the roof or ground. There also is a lot of other mechanical equipment-tanks, heat exchangers, absorption chillers, etc.--that takes up a lot of space. One limiting factor in the selection of the final approach was that there was only a minimum of space available in the existing mechanical rooms-some in the West Wing and some under the South Portico of the Residence. Any major solar installation would have required the construction of additional underground mechanical space at considerable expense. You just don't add bumps or exposed storage tanks to historic buildings, especially the White House. As a matter of fact, the West Wing mechanical room is presently buried outside the building line.

\section{The Final Design}

The decision was made to provide domestic hot water for the West Wing, which includes numerous bathroom facilities and the Navy Mess that feeds the people who work in the West Wing. The required collector area coincided almost exactly with the available area on the Cabinet Room Roof and was easily accessible to the President and his guests; in addition, it has limited public visibility but did not affect the historic views of the White House. Also, it has easy pipe access to the mechanical room, and pipes could be run in an unobtrusive manner mounted on the West Terrace hand rail; they did not have to run through any occupied, finished spaces. There was enough space in the mechanical room to set three small 200-gallon (757 2 ) storage tanks, which were transported through the existing halls and easily set in place in about half an hour.

The system is a basic domestic hot water preheat system. A propylene glycol solution is heated by the collectors and then piped to a double wall heat exchang$\mathrm{er}$, where it transfers its heat to the domestic water. The storage tanks are piped in series, and the coldest water from the colder tanks goes to the heat exchanger and is returned to the hottest tank. City water is supplied to the coldest tank, and hot water is supplied to load from the hottest tank.

The collector installation had to be approved by the Washington, D.C., Fine Arts Commission. The first approved design was composed of a rigid welded box frame that framed the collectors and freespanned the roof; it was supported on the side by a welded steel box support that enclosed the piping. The collector support frame was cantilevered from the steel box pipe enclosure and had no back bracing members. This design was found to be too costly and was revised. The new design used a 10-in. (250 $\mathrm{mm}$ ) diameter pipe supported by two legs to clear span the roof. A simple angle frame surrounding the collectors was attached to the pipe with angle fins welded to the members and bolted together. Each frame has two back braces connected to the pipe behind. The horizontal piping is enclosed in a bent metal enclosure that is not structural.

\section{Bidding Approach}

The first approach was to convene a blue ribbon panel of experts composed of representatives from architectural, mechanical engineering, and solar societies to select a collector. However, that approach was deemed unacceptable, and the collectors had to be bid. There then followed a considerable amount of discussion as to whether the collectors should be prebid or bid as a part of the total construction package. The basic problem was time-the collector installation had to be functioning by April 30, 1979, in time for "Sun Day." It was felt that for the design team to keep complete control of cost, aesthetic design, and performance, it had to know, prior to design completion, what collector was to be used. If the collectors were bid as part of the total installation package, the team felt, the contractors would have had too much design latitude; and much time could have been lost in the shop drawing and construction phase, as inconsistencies and misunderstanding would have to be resolved. The "Blue Ribbon Panel" was convened, and its members were strongly in favor of prebidding the collectors. 
Ul timately, the collectors were prebid as a "small business set aside" through Commerce Business Daily (CBD) on the basis of a performance specification. The bid was won by InterTechnology Solar Corporation, and the general contracting was also bid through the CBD. It was won by Alternate Energy Industries and installed by its construction affiliate, Solar Processes, Inc.

\section{CONCLUSION}

Historic buildings do present one unique problem, namely, that "historic views" cannot be altered. However, an understanding of the historic import of the building under consideration, coupled with good architectural design, can make for a successful project. In ending, I would like to make the plea that any solar installation you are involved with be compatible with the architectural style of the building, whether it is historie or modern, old or new, and not look as if it has just been tacked on. 
17

The Commercial Demonstration Program for Solar Heating and Cooling of Commercial Buildings 
17. The Commercial Demonstration Program for Solar Heating and Cooling of Commercial Buildings

\section{Project examples}

Comparative system perf ormance

Supporting documentation

Cost effectiveness: an assessment based on commercial demonstration projects

Cost analysis

Subsystem cost analysis

Cost effectiveness analysis

Payback period

Rate of return analysis

First year solar energy costs

Summary and conclusions 


\section{THE COMMERCIAL DEMONSTRATION PROGRAM FOR SOLAR HEATING AND COOLING OF COMMERCIAL BULDINGS}

The purpose of this chapter is to familiarize those involved in developing solar heating and cooling systems for the Solar in Federal Buildings Program with similar efforts in the ongoing Commercial Demonstration Program for Solar Heating and Cooling of Commereial Buildings. This program currently has 275 projects (sites) located throughout the United States. The chapter is divided into two parts.

Two representative projects (Hogate's Restaurant, Washington, D. C., and the Santa Clara Community Center, Santa Clara, California) are described in Part A. Particular attention has been given to project experiences, performance, and cost.

Part A also contains a comparative analysis of various solar applications which is intended to point out the inherent capabilities and limitations to be considered by those involved in the Solar in Federal Buildings Program.

In Part $B$, detailed after-the-fact construction costs are presented for 24 of the projects. Cost analyses include an evaluation of the cost components and cost factors impacting solar systems. An economic assessment, including first year cost of energy, payback period, and rate of return is presented for nine operating systems in the dem onstration program.

The Commercial Demonstration Program is well documented. Solar Bulletins listing currently available National Solar Data Program reports are released periodically from the National Solar Heating and Cooling Information Center, P.O. Box 1607, Rockville, MD, and are available at nominal cost from the National Technical Information Service (NTIS), 5285 Port Royal Rd., Springfield, VA, 22161.

Many other reports are published annually on various aspects of the Commercial Demonstration program. Brief descriptions and availability information are included in the Appendix to this chapter.

\section{A. PROJECT EXAMPLES}

\section{INTRODUCTION}

Two operating, completely instrumented solar systems have been selected for discussion. The operation of the hot water system for Hogate's Restaurant has been fully documented, and the problems associated with this system appear to be representative of those in solar systems. The Santa Clara Community Center has a 2year history of operation for its heating, cooling, and hot water system. Although fully instrumented, the Santa Clara system is not part of the National Solar Data Network but is independently analyzed by the University of Santa Clara.

\section{Hogate's Restaurant}

\section{System Description [1]}

Hogate's Restaurant is located on the north bank of the Potomac River in Washington, D.C. It accommodates approximately 600 people and is equipped with a solar energy system for preheating process water. The solar energy system was retrofitted to the building during the summer and autumn of 1977.

The characteristics of the solar installation are as follows:

- Effective collector aperture area-5,840 sq ft $(542.5 \mathrm{sq} \mathrm{m})$

- Type of collector-liquid, flat plate;

- Collector manufacturer-Sunworks, Inc.;

- Collector orientation $-45^{\circ}$ west of south;

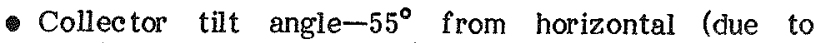
architec tural requirements);

- Instrumentation-part of the National Solar Data Network;

- Freeze protection-antifreeze;

- Storage-two 5,000 gallon (18.9 cu m) tanks;

- Auxiliary system-gas-fired hot water heater;

- Daily water demand-10,000 gallons (37.8 cu m) at $140 \mathrm{~F}\left(60 \mathrm{C}^{\circ}\right)$; and

- Solar contribution-approximately $55 \%$ of demand.

Fig. 17-1 is a highly simplified schematic of the Hogate's system.

It has been designed for three modes of operation:

Mode 1-Conventional Heating. When there is a hot water demand and solar radiation is insufficient, cold water from the inlet is directed through the storage tanks to the boiler where it is heated. 


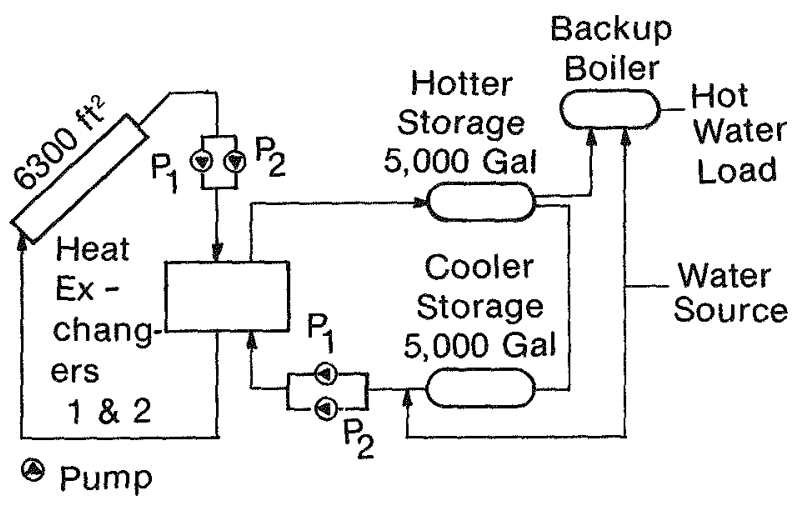

Fig. 17-1. Schematic diagram of solar sys-
tem at Hogate's Restaurant

Mode 2-Collector to Storage. This mode is invoked when there is sufficient solar energy to preheat water. The lead pump is turned on, causing water from the cold water supply to flow through the heat exchanger to the hotter storage tank. The preheated water in hotter storage is then available to the load. This mode is terminated when the temperature differential between the collectors and the cooler storage tank drops below a deactivate setting in the controller, or if the temperature of the hotter storage tank exceeds $180 \mathrm{~F}\left(82^{\circ} \mathrm{C}\right)$.

Mode 3-Regenerate. This mode is invoked when there is no hot water demand, but there is sufficient solar energy to preheat water. Water is circulated from the cooler storage tank through the heat exchanger to the hotter storage tank and, finally, back to the cooler tank. This mode can be terminated either by an insufficient solar radiation condition or by the temperature of the water in the hotter tank exceeding $180 \mathrm{~F}\left(82^{\circ} \mathrm{C}\right)$.

As one views this rather simple system, it would be easy to believe that such a system could be installed with virtually no problems. That is certainly not the case. This particular system experienced problems that resulted in additional costs and delays and that are generally representative of experiences in the Commercial Demonstration Program.

\section{Projeet Experiences}

Each of the following project experiences is discussed in terms of the problem encountered, the approach taken, and possible implications for the Solar in Federal Buildings Program.

F-CHART was used during the design phase to determine the performance of the system for various configurations and operating conditions. For 3 months of summer operation in 1978, the data on performance correlated closely with the F-CHART predictions. This gives some credence to the F-CHART method for calculating hot water usage, at least for the Washington, D.C., area and for the type of application encountered at Hogate's Restaurant.
During the design phase the original building construction drawings were used to determine the location and mounting of the collectors. At the time of installation it was found that the beams were not actually located as shown in the drawings. This resulted in redesign and associated delays and cost impacts. The fact that building drawings do not al ways agree with the structure $i$ tself has probably been experienced by many others, but it is a special problem for solar systems because of the unique factors that must be considered in mounting collectors. It is probably worth a few exploratory checks to be sure that, indeed, the supports for the building are as specified in the drawings.

The design of the Hogate's solar system was compromised to some degree to meet aesthetics and the Washington planning codes. One effect was to offset the orientation by $45^{\circ}$ west of south instead of using direct south orientation. In addition to the displacement in angle, additional costs were incurred for bracing, etc. It is always wise to consider aesthetics early in the design stages so that there are not surprises during the construction and operational periods when permits might be revoked and additional eff or ts required.

The design for Hogate's Restaurant called for a 10,000 gallon $(37.8 \mathrm{cu} \mathrm{m}$ ) storage tank which could not be obtained commercially or installed with reasonable ease, making it necessary to place two tanks in the garage area. In designing for a retrofit and placing the tanks in the parking area, additional costs were incurred because the tanks were located farther from the collectors, from the final usage point, and from the backup system located on the roof.

For storage tanks and components in general, there is a wealth of experience in the numerous projects funded for the Commercial Demonstration Program. Data on these components are available in several places, including the descriptive documents for the individual projects and the proceedings from the various conferences.

One negative characteristic of solar systems has been the numerous construction/checkout delays that one encounters. These delays are not necessarily due to the solar component being added, but often solar is a contributor to delay because it complicates the construction and checkout process.

Particular areas which caused delays in the Hogate's Restaurant project included the following:

1) A change in contractor was required since the original contractor discontinued his work in the area.

2) Leakage was experienced in the flexible copper couplings both between collector panels and in the long headers associated with the rows of collectors. The bellows type units used both for the connections between collectors and on the large header pipes at Hogate's were of a copper composition and failed so frequently that the situation became impossible. The large copper bellows in the header pipes were replaced with a stainless steel version, and the flexible couplings between collectors were replaced with a plastic coupling which provided the flexibility to accommodate the shifting resulting from the temperature changes. 
3) The additional soldering and heating of the pipes during the replacement of the flexible couplings between collectors caused the collector seals to degrade.

4) There was considerable damage to the insulation on the header pipes and associated plumbing because it was not designed to withstand the physical abuse of frequent repair activity. There are several considerations that one can address in this area. The first, of course, is to select reliable components which will not require frequent repair. This is becoming more possible with the advances in the collector area and the associated testing. Another is to design the system so that the fragile insulation is not damaged during repair operations.

5) The instrumentation monitoring equipment had to be relocated from the equipment room to a cooler area. Equipment rooms frequently have rather high temperatures; therefore, a check should be made before installation to preclude damage to the instrumentation or the need for relocation at a later date.

6) There is still some concern about discoloration at points on the collector panels where the internal headers were connected. This is under review with the collector manufacturer and is delaying final acceptance.

7) Special consideration had to be given to the placement of sensors in pipes. Flow meters should be placed in piping in such a way that there are prescribed straight runs on either side of the meter itself. This varies with the meter but is still an important consideration early in the layout of the system and planning for piping.

As the Hogate's system became operational, it was determined that low fluid in the collector loop was automatically being corrected with water makeup, thus diluting the antifreeze solution. A solution to this problem is to require an alarm which indicates low levels of fluid and causes a manual action to take place with prescribed procedures to insure that fluid is not so diluted that freezing might occur.

Instrumentation indicated that the gas-fired boiler was not operating efficiently and required repair to correct the inefficient combustion process. It is possible that this problem could have persisted from some time without being observed by the maintenance and operational personnel, and that it would bias the evaluation of solar. Consideration should be given to including some checks on backup performance.

The collector problems noted at Hogate's deserve some discussion because it appears that the most serious problems were corrected in subsequent production runs and are not necessarily the kind of thing that would be encountered in other installations. The major point to be made is that collectors should pass the tests required to meet current standards. Since the Commercial Demonstration Program demonstrated many of the wellknown collector types and representative manufacturers, it is possible for designers and builders to research the history of similar collectors. With the testing and certification programs, coupled with the experience for the different collectors that can be observed by visiting a

site and discussing these designs and installations with previous designers and owners, it seems that one can avoid serious long-term problems.

In connecting collectors at Hogate's using the bellows coupling, it was necessary that a rather intense soldering effort be made very close to the panel, causing degradation of the insulation around the pipes. Problems like this are best addressed by observing good installation practices. If attention is given during design to the interconnection process required for assembling a collector array, the need for resoldering and excessive installation work in the field can be minimized and thus cause less chance for damage to the collectors.

In summary, choosing a collector which has been qualified and meets the standards is a step required to get assurance of quality. Further confirmation can be had by looking at the systems already built using the collector in question. During the design, consider the installation process so that the collectors will not be damaged by excessive heat where soldering is required.

\section{Performance [2]}

A summary report from the National Solar Data Program for Hogate's covering June, July, and August 1978 revealed the following performance:

Total Incident Solar Energy

Collected Solar Energy

Collector Array Efficiency

Energy to Storage

Energy from Storage

Storage Efficiency

Transport Losses

Parasitic Energy

Auxiliary Thermal

Hot Water Load

Solar Fraction

*MBtu $=$ million $\mathrm{Btu}$

The array efficiency agrees with predicted values used in the F-CHART simulation applied during the design phase.

The high storage efficiency is attributed to the insulation of the tanks [6 in. $(150 \mathrm{~mm})$ of glass fiberboard sheathed with aluminum], the low storage temperatures, and the ideal phasing between the availability of energy collected and its utilization.

\section{$\operatorname{Cost}[3]$}

The total system cost in 1977 dollars is summarized in Table 17-1.

Costs (in 1977 dollars) per unit of collector unit area are as shown in Table 17-2.

\section{Santa Clara Community Center}

\section{System Description [4]}

The Santa Clara Community Recreation Center is a onestory facility with a $27,000-\mathrm{sq}-\mathrm{ft}(2,508 \mathrm{sq} \mathrm{m})$ net interior area used for arts and crafts classes and public 
Table 17-1. TOTAL SYSTEM CONSTRUCTON COST SUMMARY-HOGATES

\begin{tabular}{lccrr}
\hline \multicolumn{1}{c}{ Category } & Materials & Labor & Subcontract & Total \\
\hline Collector Array & $\$ 72,030$ & None & $\$ 16,023$ & $\$ 87,055$ \\
Support Structure & None & None & 46,415 & 46,415 \\
Piping & 21,140 & 27,375 & 2,500 & 51,015 \\
Insulation & None & None & 12,000 & 12,000 \\
Storage & 10,466 & 1,100 & 9,000 & 20,566 \\
Controls & None & None & 3,100 & 3,100 \\
Electrical Power & 1,000 & None & 1,000 & 2,100 \\
General Construction & 2,850 & 2,050 & 12,500 & 17,400 \\
Overhead and Profit (25\%) & 26,647 & 7,631 & - & 34,278 \\
Genergl Contractor Fee (10\%) & - & & 10,254 & 10,254 \\
& & & TOTAL COST & $\$ 284,183$ \\
\hline
\end{tabular}

Table 17-2. COSTS PER UNTT OF COLLECTOR AREA

\begin{tabular}{lcc}
\hline \multicolumn{1}{c}{ Category } & $\begin{array}{c}\text { Unit Cost, } \\
\text { \$/sq ft } \\
\text { Collector Area }\end{array}$ & $\begin{array}{c}\text { Percent of } \\
\text { Total System } \\
\text { Cost }\end{array}$ \\
\hline Collector Array & 18.20 & 37 \\
Support Structure & 8.70 & 18 \\
Piping & 10.40 & 22 \\
Insulation & 2.30 & 5 \\
Storage & 4.20 & 9 \\
Controls & 0.60 & 1 \\
Electrical Power & 0.40 & 1 \\
General Construction & 3.30 & 7 \\
\multicolumn{1}{c}{ TOTAL SYSTEM } & 48.70 & 100 \\
\hline
\end{tabular}

meetings. The facility serves the community on a yearround basis, with both day and evening schedules. The solar-driven heating and cooling system installed on this building began full operation in the second quarter of 1977. The system has the following significant features:

- Effective collector aperture area-7,085 sq $\mathrm{ft}$ $(658 \mathrm{sq} \mathrm{m})$

- Type of collector-liquid, flat plate;

- Collector manufacturer-Ametek Power Systems;

- Collector orientation-south;

- Collector tilt angle--18 from horizontal;

- Instrumentation-tailored for Santa Clara;

- Freeze protection-10\% propylene glycol solution in the collector loop:

- Storage-10,000 gallon (37.8 cu m) hot water heater, 50,000 gallon (189 cu m) cold water heater;

- Auxiliary system-gas-fired boiler;

- Annual demand-space heating - 265 million Btu (280 GJ), space cooling - 483 million Btu (510 GJ).

- Solar contribution-approximately $85 \%$ of heating demand, approximately $65 \%$ of cooling demand;

The system as shown in Fig. 17-2 has been designed for three modes of operation:
Mode 1-Auxiliary or Storage to Load. This mode is used when there is little or no solar energy available. Heating is supplied either from the stored hot water or from the boiler. Cooling is supplied from the cool storage which is maintained by the boiler/absorption chiller combination.

Mode 2-Collector to Storage Load. This mode is initiated when the solar flux is sufficient to provide efficient building heating and hot water storage but is insufficient to drive the absorption chillers. The system operates in this mode during most of the winter, and also in the summer during the early morning and late afternoon hours. Cooling is supplied as described for Mode 1.

Mode 3-Collector to Chillers. This mode is invoked when the insolation is adequate to provide efficient firing of one or both absorption chillers. The active periods for this mode center about solar noon in summmer. Chilled water is drawn from the bottom of the cold storage tank where it is coldest and deposited on the top of the tank on its return from the cold fan coils. If the temperature at the top of the cold reservoir rises above $55 \mathrm{~F}\left(13^{\circ} \mathrm{C}\right)$, the boiler comes on to fire the absorption chillers.

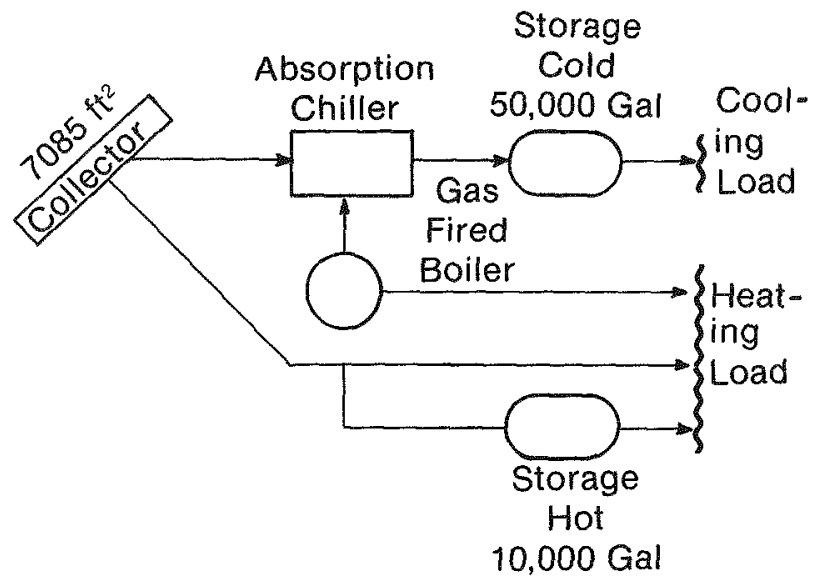

Fig. 17-2. Schematic diagram of solar system at the Santa Clara Community Center 


\section{Project Experiences}

There were some general problem areas associated with the design, installation, and instrumentation, along with a general concern for fossil fuel savings.

An example of a design problem was the case in which the cold storage tank failed to maintain stratification. During low cooling load conditions, the cooling-fan-coil loop returned the flow to the top of the tank at a temperature close to the temperature existing at the bottom of the tank (Fig. 17-3).

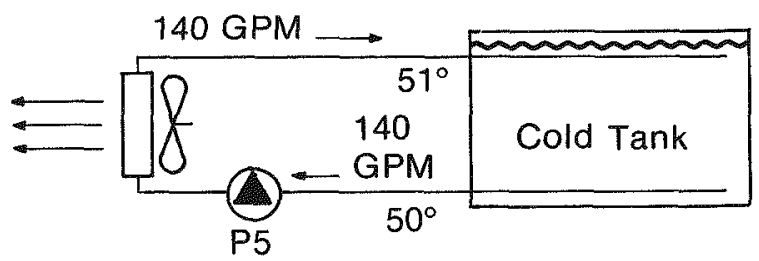

Fig. 17-3. Partial load condition before in-
stallation of cooling fan coil mo-
dulating valve

This problem was solved by installing a temperature modulating valve which maintains the output temperature at $55 \mathrm{~F}\left(13^{\circ} \mathrm{C}\right)$ by recirculating some of the flow as shown in Fig. 17-4.

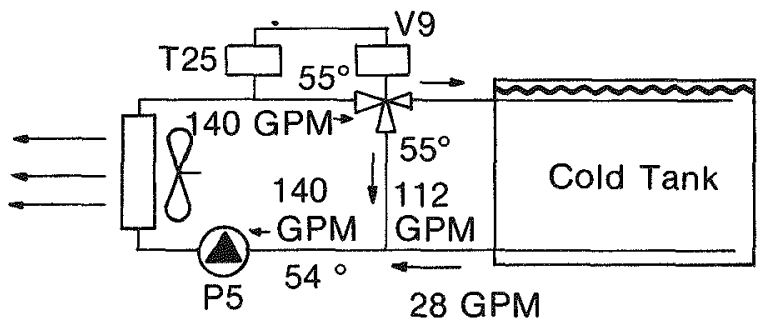

Fig. 17-4. Partial load condition after in-
stallation of cooling fan coil mo-
dulating valve

High energy loss from the storage tank due to convection through the pressure relief valve was corrected by adding a hinged cap and restrictor.

In regard to overall system performance, the analysis for the Santa Clara Community Recreation Center solar heating and cooling system verified the original design philosophy. Although the measured performance of the collectors and chillers is slightly lower than expected, the system has demonstrated an ability to collect solar energy at high temperatures for driving the absorption chillers and has provided a significant percentage of the thermal energy required to heat and cool the building.
The basic concept of using high performance flat plate solar collectors to drive solar absorption chillers has been verified. However, the performance calculations show a large auxiliary energy requirement for the system, both for natural gas and for electricity. For the 6-month cooling season, the solar energy system required more fossil fuel energy, in natural gas and fuel at the electric generating plant, than a conventional system would have used.

Significant natural gas demand was predicted by the systems simulation performed by Lockheed, and the actual use of natural gas closely follows the predicted values. Such large natural gas usage resul ts from the relative size of the collector/chiller system capacity and the building cooling load. Additionally, burning natural gas to provide thermal energy for an absorption chiller to produce cooling has an inherent low efficiency. The boiler operates at an average efficiency of $70 \%$, and the rated COP of the chillers is 0.67 . The combined result gives a net COP of 0.47 .

It was expected that the increase in natural gas use would be somewhat offset by a decrease in electric energy use. However, two factors worked against this offset. First, electric-driven vapor compression cooling has an inherently higher coefficient of performance. Assuming that a generating plant burns natural gas to produce electric energy at an efficiency of $35 \%$ and the vapor compression chiller operates at a COP of 3.0 , the net COP is 1.15 . This is 2.5 times more efficient than gasfired absorption cooling. Secondly, the electric power requirements of the many pumps in the solar energy system were found to be significant. Much of this electric power was not required to collect the solar energy but was required to drive the pumps necessary for the absorption chiller fluid loops.

\section{Performance}

An overall summary of performance for the period of April 1977 through March 1978 is as follows:
1. Incident solar energy

2. Solar energy collected

3. Solar delivered to hot fan coils

4. Total hot fan coil Ioad

5. Solar delivered to chillers

6. Total energy to chillers

7. Solar delivered to DHW load

8. Total DHW load

9. Boiler energy use

Solar percentage of total thermal load

$*$ MBtu $=$ million Btu

\author{
$4,297.8 \mathrm{MBtu}^{*}$ \\ 1,103.4 MBtu \\ 344.6 MBtu \\ $610.6 \mathrm{MBtu}$ \\ 497.8 MBtu \\ 867.2 MBtu \\ 64.8 MBtu \\ $78.1 \mathrm{MBtu}$ \\ 1,085.7 MBtu
}

$58.3 \%$
This results in a yearly collection efficiency of $25.7 \%$ (I $\div 2$ ) and the effective utilization of $21 \%$ of the total incident solar energy $[(3+5+7) \div 2)]$. A more detailed report of the cooling season (April - September 1977) has shown that the project has met one of its major objectives; namely, to demonstrate that flat plate collectors can drive an absorption chiller. Fig. 17-5 summarizes the performance during the 6 -month period. 


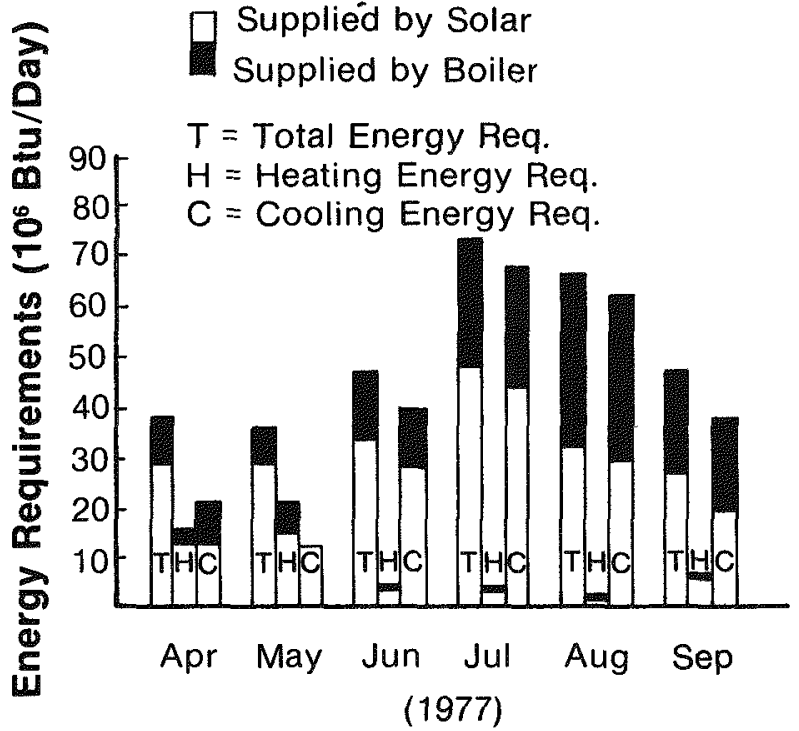

Fig. 17-5. Average daily thermal energy requirements for the Santa Clara Community Center during April through September 1977

The system generally met expectations, as shown in Fig. 17-6 even though the solar collector performance was poorer than predicted (attributed to dirt on the collectors, imperfect flow balance, line losses, etc.), and the absorption chiller capacities were approximately $20 \%$ lower than specified (due to accumulation of scale in the condenser portion of the chiller).

Interestingly, though the system performed essentially as intended, there were no effective fossil fuel savings for the solar design compared to the best conventional use of a compression chiller. Table 17-3 shows a 1,328 million Btu (1,381 GJ) fossil fuel requirement for the present solar design and an estimated 1,175 million $B$ tu $(1,239 \mathrm{GJ})$ for the conventional compression chiller originally envisioned for Santa Clara. As noted above, this resul ts from the low COP of the absorption chiller which is driven by a gas-fired boiler for a significant portion of the time. Another factor is the power required to drive the cooling tower fans. These performance data should be considered in any solar cooling design and are discussed in more detail in the Santa Clara, California, Community Center Commercial Solar Demonstration Progress Report-Six Months ${ }^{\prime}$ Data Acquisition and Analysis of Cooling Performance, SAN/1083-78/1, March 1978.

\section{Actual Insolation CY 1971 Insolation}
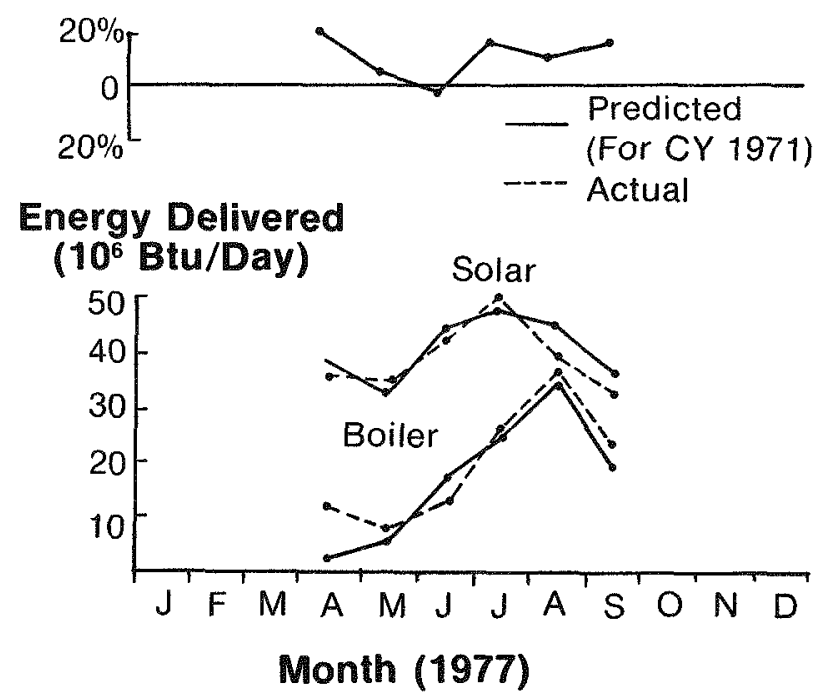

Fig. 17-6. Average daily energy delivered by the solar collector array and the gas-fired boiler for April through September 1977, Santa Clara Community Center

Table 17-3. FOSSIL ENERGY REQUIREMENTS FOR SOLAR AND NONSOLAR SYSTEMS* (APRIL-SEPTEMBER 1977)

\begin{tabular}{ccc}
\hline & System 1 & System 2 \\
$\begin{array}{c}\text { Present Solar } \\
\text { System }\end{array}$ & $\begin{array}{c}\text { Electric-Driven } \\
\text { Cooling }\end{array}$ \\
\hline
\end{tabular}

$\begin{array}{lrr}\text { Gas Energy Used: } & & \\ \text { Heating } & 60 & 233 \\ \text { Cooling } & 448 & 0 \\ \text { DHW } & \frac{9}{517} & \frac{56}{289} \\ \text { Total } & 517 & \end{array}$

Electric Energy Used:

$\begin{array}{lrr}\text { Cooling } & 0 & 126 \\ \text { Auxiliary } & 133 & 33 \\ \text { Air Handler } & 151 & 151 \\ \text { Total } & 284 & 310\end{array}$

Total Fossil Energy

Requirements** $^{* *} \quad 1,324 \quad 1,175$

*Unless otherwise noted, all quantities are reported in millions of Btu.

**An electric generating plant efficiency of $35 \%$ is assumed. 


\section{COMPARATIVE SYSTEM PERFORMANCE}

Although detailed performance data are available for only a very few representative commercial solar systems [5], it is possible to provide qualitative statements for the various applications (i.e., industrial hot water, space heating, space cooling, and combinations thereof) as follows:

1. Hot water systems operating throughout the year appear to be most attractive since they (a) require modest amounts of additional power (parasitic power) to handle the additional needs imposed by the solar system, (b) offer the least competition* with the auxiliary system, (c) exhibit the lowest purchase costs, and (d) are simpler to operate and maintain.

2. Solar space heating systems suffer since (a) their output is needed when the incident solar energy is lowest, (b) collector efficiencies are lower in cold weather, and (c) their useful period is only about 6 months of each year. Depending on the design approach, competition with the auxiliary may be a factor affecting system efficiency.

3. Solar space cooling systems benefit from the abundant solar energy but suffer seriously from (a) the need to furnish high temperature fluids with the attendant low collector ef ficiencies, (b) the low COP of absorption chillers, (c) competition between solar and auxiliary, (d) high cost, (e) complex maintenance and operation, (f) high parasitic power requirements, and $(\mathrm{g})$ a low usage factor (5 to 6 months per year for the systems considered).

4. Combined solar space heating and cooling systems overcome the usage penalty by employing common collectors year-round; however, the other penalties still exist.

5. Adding the hot water application to space heating and/or cooling has not shown much advantage in the systems considered since the hot water load is generally such a small fraction of the total load.

Since quantitative comparative data are not available at this time, complete guidance for the selection of the application for a given site is not possible. Instead, it is recommended that designers consult the performance data from the National Solar Data Program and the other sources identified to aid in the selection of a solar application and in comparing design alternatives. It is also recommended that for all applications the solar/auxiliary interface be reviewed to minimize the competition (without penalizing the rest of the design) between solar and auxiliary. For solar space cooling, particular attention is direeted to the need to minimize parasi tic power requirements.

* Solar hot water systems frequently preheat incoming water which is then "boosted" as required by the auxiliary system to the working temperature. This does not require that the solar contribution "compete" in a common hot water storage tank where fluid temperatures are raised by the auxiliary or some heat recovery system. Competition can also occur in solar space heating and cooling systems when either common hot storage or cold storage is utilized.

\section{SUMMARY}

Many projects in the DOE Commercial Demonstration program have reached an operational state; others are in various stages of implementation. Experiences from these projects are generally available for use in the Solar in Federal Buildings Program. Either documented experience or direet personal contact can be used to assure benefits from lessons already learned. There is an effort underway to determine absolute and comparative worth of various systems. Results are very tentative, but indications confirm the preference for hot water systems and the inherent difficulties in solar space cooling systems.

\section{ACKNOWLEDGMENT}

Appreciation is extended to Ms. Jaine Pendleton for her valuable assistance in developing the outline for this section and for her contributions in the analyses and presentation of the project data.

\section{REPERENCES}

1. Solar Project Description, Hogate's Restaurant, May 9, 1978 (SOLAR/2028-78/50).

2. V. S. Aquila, Thermal Performance of the Hogate's Restaurant Solar Energy Hot Water System, November 1978.

3. Solar Project Cost Report, Hogate's Restaurant, May 9, 1978 (SOLAR/2078/78/60).

4. W. Niemeyer, S. Ayraud, M. Hemsch, F. Brown, Progress Report - Six Months Data Acquisition and Analysis of Cooling Performance, Santa Clara Community Center Commercial Solar Demonstration (SAN/1083-78/1), March 1978.

5. Conference Proceedings-Solar Heating and Cooling Systems Operational Results, Colorado Springs, Colorado, 28 November - 1 December, 1978, pp. 147238. 


\section{B. COST EFFECTIVENESS: AN ASSESSMENT BASED ON COMMERCIAL DEMONSTRATION PROJECTS*}

\section{INTRODUCTION}

The use of solar energy systems for heating, cooling, or providing process water for commercial applications is commonly considered to be technically feasible. A question that remains regarding this overall feasibility is the degree of cost effectiveness and the relative importance of the many significant factors that impact it. This section reports on continuing work that has used the expanding data base within the National Solar Data Program to address the cost effectiveness of National Solar Demonstration projects.

The components of the investigation are system cost, system performance, and the selection of appropriate calculation methods and parameters to define cost effectiveness. Accurate total system construction costs have been obtained for 24 solar heating and cooling (SHAC) and 10 industrial process heat (IPH) demonstration projects to date. These total system costs for the SHAC systems are presented in this section along with cost breakdowns of major categories for each system. Results of analyses are presented that identify the major factors that impact total system and subsystem costs.

System performance has been determined by the National Solar Data Network (NSDN) for a number of SHAC demonstration projects. Only the summary parameters quantifying system performance are presented here. The cost effectiveness of nine SHAC demonstration projects as determined by a number of different procedures is presented and discussed at length. These analyses combine the cost and performance information for a more complete assessment of cost effectiveness. A complete analysis of the IPH system costs are not presented here, but it can be said that their costs are similar to SHAC hot water systems.

\section{COST ANALYSIS}

\section{General}

The selection of projects for which accurate total system and subsystem costs have been obtained includes a number of different system types as described in Table 17-4. The 24 projects are identified in Table 17-5, which also includes information on the type of application, location, type of construction, and collector area.

These sites were not selected to be representative of all solar energy systems. A very large sample of systems would be needed to understand completely all the operant factors. Nonetheless, the 24 sites listed do provide an adequate basis for some preliminary conclusions.

The fact that only one passive system is included in the

*Thomas A. King, P. E., Jefferson G. Shingleton, P. E., Paul A. Sabatiuk, and John B. Carlock, III. Mueller Associates, Ine., Baltimore, Maryland.

\section{Table 17-4. SUMMARY OF PROJECT TYPES}

\begin{tabular}{lc}
\hline \multicolumn{1}{c}{ Description } & Number of Sites \\
\hline Passive Heating & 1 \\
Active Heating & 10 \\
Process Water & 5 \\
Heating \& Cooling & 8 \\
& \\
New & 10 \\
Retrofit & 14 \\
Air Type Collectors & 5 \\
Liquid Type Collectors & 18 \\
\hline
\end{tabular}

selection reflects the fact that few of the SHAC demonstration projects use passive solar energy. Cost data is not yet available for passive systems constructed in the Passive Commercial Demonstration Program.

Cost data on the subject 24 sites are available in "Solar Project Cost Reports" from the DOE Technical Information Center (TIC). See Table 17-5 for specific report numbers.

The cost data were obtained during visits to the sites; discussions with system designers, construction contractors, and owners; and review of DOE vouchers. In the cost reports, construction costs are divided into cost categories that roughly parallel construction work categories as follows: collector array, support structure, piping, ductwork, insulation, heating and cooling equipment, storage, controls, electrical power, general construction. For the analyses here, piping, ductwork, and insulation costs are lumped in a single cost eategory as are electrical and controls costs. The cost reports described above present more detailed cost data.

The costs presented are normalized to account for differences in the contractual structures of the projects through the application of a standard overhead and profit rate to bare costs. In addition, all costs are expressed in 1977 dollars. Construction costs increased by 20 to 25 percent from 1977 to 1981 according to Engineering News Record.

The cost figures do not include the design, instrumentation, or auxiliary energy system costs. More information concerning the cost data collection and analysis process can be found in the cost reports. "Solar Project Descriptions" are also available from TIC for most of the 24 projects discussed in this paper.

The reader is reminded that in comparing the costs of various systems and subsystems, "cheaper" is not necessarily "better." Nine of the 24 projects are subjected to cost effectiveness analysis later in this section. That analysis includes the effect of system performance and is thus a better indicator of the overall cost effectiveness of a system. Nonetheless, terms employed here such as dollars per square foot of collector area can be very useful when the reader is aware of the limitations of their application. 
Table 17-5. BASIC INPORMATION FOR COST ANALYZED PROJECTS

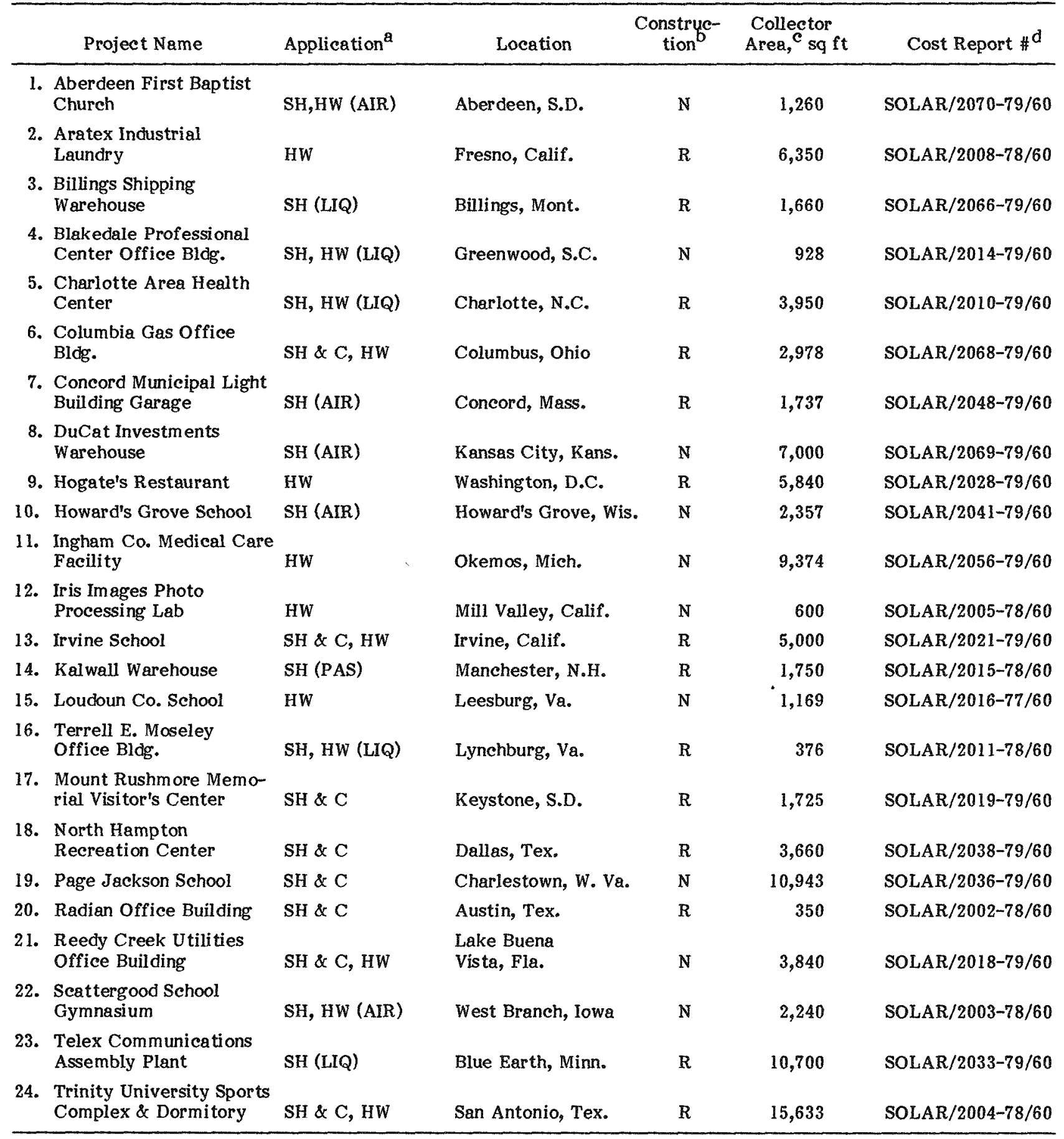

$a_{\mathrm{SH}}=$ Space Heating, HW $=$ Hot Water, $\mathrm{SH} \& \mathrm{C}=$ Space Heating and Cooling, (AIR) = Air Systems, (LIQ) $=$ Liquid Systems, $($ PAS $)=$ Passive System .

$\mathrm{b}_{\mathrm{N}}=$ New construction, $\mathrm{R}=$ Retrofit construction.

$\mathbf{C}_{\mathrm{Net}}$ aperture area.

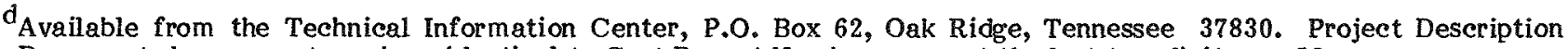
Documents have report numbers identical to Cost Report Numbers, except the last two digits are 50. 
Table 17-6. SUMMARY OF SYSTEM COSTS

\begin{tabular}{|c|c|c|c|c|c|c|c|c|c|c|c|c|c|c|c|c|c|}
\hline \multirow[b]{2}{*}{ Application } & \multirow[b]{2}{*}{ Project } & \multirow{2}{*}{$\begin{array}{l}\text { Total }^{a} \\
\text { System } \\
\text { Cost, } \$\end{array}$} & \multirow{2}{*}{$\begin{array}{l}\text { Total } \\
\text { System } \\
\$ / \text { sq ft }\end{array}$} & \multicolumn{2}{|c|}{ Collector } & \multicolumn{2}{|c|}{$\begin{array}{l}\text { Support } \\
\text { Structure }\end{array}$} & \multicolumn{2}{|c|}{$\begin{array}{c}\text { Piping, } \\
\text { Ductwork, } \\
\text { \& Insulation }\end{array}$} & \multicolumn{2}{|c|}{$\begin{array}{l}\text { Heating } \\
\text { Cooling/ } \\
\text { Equipment }\end{array}$} & \multicolumn{2}{|c|}{ Storage } & \multicolumn{2}{|c|}{$\begin{array}{l}\text { Electrical } \\
\& \text { Controls }\end{array}$} & \multicolumn{2}{|c|}{$\begin{array}{c}\text { General } \\
\text { Construction }\end{array}$} \\
\hline & & & & $\$ / \mathrm{sq} f \mathrm{t}$ & $\%^{\mathrm{c}}$ & $\$ / \mathrm{sq} \mathrm{ft}^{\mathrm{d}}$ & $\%$ & $\$ / \mathrm{sg} \mathrm{ft}$ & $\%$ & $\$ / \mathrm{sq} \mathrm{ft}$ & $\%$ & $\$ / \mathrm{sq} \mathrm{ft}$ & $\%$ & $\$ / s q f t$ & $\%$ & $\$ / s q f t$ & $\%$ \\
\hline $\begin{array}{l}\text { Passive } \\
\text { Heating }\end{array}$ & Kalwall & 13,530 & 7.7 & 6.1 & 79 & - & - & - & - & 0.6 & 8 & 0.8 & 10 & 0.3 & 3 & - & - \\
\hline $\begin{array}{l}\text { Process } \\
\text { Hot } \\
\text { Water }\end{array}$ & $\begin{array}{l}\text { Aratex } \\
\text { Iris Images } \\
\text { Ingham Co. } \\
\text { Hogate's } \\
\text { Loudoun Co. }\end{array}$ & $\begin{array}{r}18,240 \\
18,115 \\
337,260 \\
283,955 \\
70,940\end{array}$ & $\begin{array}{l}29.0 \\
30.2 \\
36.0 \\
48.6 \\
60.7\end{array}$ & $\begin{array}{l}11.7 \\
10.5 \\
10.3 \\
18.2 \\
21.8\end{array}$ & $\begin{array}{l}40 \\
35 \\
29 \\
37 \\
36\end{array}$ & $\begin{array}{r}2.8 \\
7.2 \\
11.2 \\
8.7 \\
17.2\end{array}$ & $\begin{array}{l}10 \\
24 \\
31 \\
18 \\
28\end{array}$ & $\begin{array}{r}10.4 \\
4.0 \\
11.2 \\
13.1 \\
12.2\end{array}$ & $\begin{array}{l}36 \\
13 \\
31 \\
27 \\
20\end{array}$ & $\begin{array}{l}- \\
\overline{-} \\
-\end{array}$ & $\begin{array}{l}- \\
- \\
-\end{array}$ & $\begin{array}{l}2.4 \\
2.1 \\
1.2 \\
4.1 \\
5.4\end{array}$ & $\begin{array}{l}8 \\
7 \\
3 \\
8 \\
9\end{array}$ & $\begin{array}{l}1.3 \\
1.8 \\
1.7 \\
1.1 \\
3.3\end{array}$ & $\begin{array}{l}4 \\
6 \\
5 \\
2 \\
5\end{array}$ & $\begin{array}{l}1.0 \\
4.4 \\
0.8 \\
3.4 \\
0.8\end{array}$ & $\begin{array}{r}3 \\
15 \\
2 \\
7 \\
1\end{array}$ \\
\hline & Average & - & 40.9 & 14.5 & 35 & 9.4 & 23 & 10.2 & 25 & - & - & 3.0 & 7 & 1.8 & 4 & 2.1 & 5 \\
\hline $\begin{array}{l}\text { Liquid } \\
\text { Space } \\
\text { Heating }\end{array}$ & $\begin{array}{l}\text { Moseley } \\
\text { Telex } \\
\text { Billings } \\
\text { Charlotte } \\
\text { Blakedale }\end{array}$ & $\begin{array}{r}14,295 \\
462,305 \\
77,430 \\
249,195 \\
60,510\end{array}$ & $\begin{array}{l}38.0 \\
43.2 \\
46.6 \\
60.8 \\
65.2\end{array}$ & $\begin{array}{l}13.8 \\
17.3 \\
20.4 \\
18.0 \\
12.0\end{array}$ & $\begin{array}{l}36 \\
40 \\
44 \\
30 \\
18\end{array}$ & $\begin{array}{r}3.3 \\
6.6 \\
7.8 \\
5.9 \\
15.4\end{array}$ & $\begin{array}{r}9 \\
15 \\
17 \\
10 \\
24\end{array}$ & $\begin{array}{r}6.3 \\
13.9 \\
13.3 \\
24.8 \\
21.0\end{array}$ & $\begin{array}{l}17 \\
32 \\
29 \\
41 \\
32\end{array}$ & $\begin{array}{l}5.2 \\
1.0 \\
0.9 \\
0.2 \\
-\end{array}$ & $\begin{array}{r}14 \\
2 \\
2 \\
<1 \\
-\end{array}$ & $\begin{array}{l}4.1 \\
1.5 \\
1.8 \\
3.3 \\
8.2\end{array}$ & $\begin{array}{r}11 \\
3 \\
4 \\
5 \\
13\end{array}$ & $\begin{array}{l}4.6 \\
2.0 \\
2.5 \\
3.3 \\
8.5\end{array}$ & $\begin{array}{r}12 \\
5 \\
5 \\
5 \\
13\end{array}$ & $\begin{array}{l}0.8 \\
0.9 \\
5.1 \\
0.1\end{array}$ & $\begin{array}{r}2 \\
2 \\
8 \\
<1\end{array}$ \\
\hline & Average & -- & 50.8 & 16.3 & 32 & 7.8 & 15 & 15.9 & 31 & 1.5 & 3 & 3.8 & 7 & 4.2 & 8 & 1.4 & 3 \\
\hline $\begin{array}{l}\text { Air } \\
\text { Space } \\
\text { Heating }\end{array}$ & $\begin{array}{l}\text { Howard's Grove } \\
\text { DuCat } \\
\text { Aberdeen } \\
\text { Scattergood } \\
\text { Concord }\end{array}$ & $\begin{array}{r}53,300 \\
252,435 \\
62,595 \\
113,825 \\
118,740\end{array}$ & $\begin{array}{l}22.6 \\
36.1 \\
49.7 \\
50.8 \\
68.4\end{array}$ & $\begin{array}{l}13.4 \\
21.9 \\
24.8 \\
24.5 \\
18.6\end{array}$ & $\begin{array}{l}59 \\
61 \\
50 \\
48 \\
27\end{array}$ & $\begin{array}{r}2.4 \\
9.3 \\
1.3 \\
11.5 \\
25.7\end{array}$ & $\begin{array}{r}11 \\
26 \\
3 \\
23 \\
38\end{array}$ & $\begin{array}{r}3.2 \\
3.5 \\
13.1 \\
6.0 \\
12.3\end{array}$ & $\begin{array}{l}14 \\
10 \\
26 \\
12 \\
18\end{array}$ & $\begin{array}{l}\bar{z} \\
\overline{2} \\
-1\end{array}$ & $\frac{-}{4}$ & $\begin{array}{l}2.7 \\
-5.6 \\
3.8 \\
5.2\end{array}$ & $\begin{array}{r}\frac{12}{11} \\
7 \\
8\end{array}$ & $\begin{array}{l}0.9 \\
1.4 \\
3.3 \\
2.7 \\
6.2\end{array}$ & $\begin{array}{l}4 \\
4 \\
7 \\
5 \\
9\end{array}$ & $\begin{array}{l}- \\
\overline{0} \\
0.9 \\
0.2\end{array}$ & $\begin{array}{r}- \\
2 \\
<1 \\
1\end{array}$ \\
\hline & Average & - & 45.5 & 20.6 & 45 & 10.0 & 22 & 7.6 & 17 & 0.4 & 1 & 3.5 & 8 & 2.9 & 6 & 0.3 & 1 \\
\hline $\begin{array}{l}\text { Space } \\
\text { Heating } \\
\& \\
\text { Cooling }\end{array}$ & $\begin{array}{l}\text { Page Jackson } \\
\text { Irvine } \\
\text { Trinity } \\
\text { Mt. Rushmore } \\
\text { North Hampton } \\
\text { Columbia Gas } \\
\text { Radian } \\
\text { Reedy Creek }\end{array}$ & $\begin{array}{r}526,845 \\
285,190 \\
958,210 \\
130,705 \\
384,680 \\
352,260 \\
42,150 \\
625,985\end{array}$ & $\begin{array}{r}48.1 \\
57.0 \\
61.3 \\
75.8 \\
105.1 \\
118.3 \\
120.4 \\
163.0\end{array}$ & $\begin{array}{r}15.9 \\
28.3 \\
29.1 \\
21.2 \\
21.4 \\
53.0 \\
37.4 \\
108.4\end{array}$ & $\begin{array}{l}33 \\
50 \\
47 \\
28 \\
20 \\
45 \\
31 \\
67\end{array}$ & $\begin{array}{r}15.8 \\
7.7 \\
5.5 \\
13.9 \\
6.3 \\
10.2 \\
15.7 \\
4.7\end{array}$ & $\begin{array}{r}33 \\
14 \\
9 \\
18 \\
6 \\
9 \\
13 \\
3\end{array}$ & $\begin{array}{r}8.4 \\
15.0 \\
13.2 \\
16.9 \\
31.5 \\
17.1 \\
30.9 \\
18.9\end{array}$ & $\begin{array}{l}17 \\
26 \\
22 \\
22 \\
30 \\
14 \\
26 \\
12\end{array}$ & $\begin{array}{r}3.3 \\
\overline{2.9} \\
8.6 \\
7.4 \\
\overline{14.4} \\
4.7\end{array}$ & $\begin{array}{r}7 \\
5 \\
11 \\
7 \\
-12 \\
3\end{array}$ & $\begin{array}{c}1.5 \\
4.2 \\
3.6 \\
8.9 \\
4.5 \\
7.7 \\
10.9\end{array}$ & $\begin{array}{l}3 \\
7 \\
5 \\
8 \\
4 \\
6 \\
7\end{array}$ & $\begin{array}{r}0.3 \\
4.8 \\
2.9 \\
6.6 \\
16.2 \\
14.6 \\
9.8 \\
5.6\end{array}$ & $\begin{array}{r}1 \\
8 \\
5 \\
9 \\
15 \\
12 \\
8 \\
3\end{array}$ & $\begin{array}{r}3.0 \\
1.3 \\
3.6 \\
5.0 \\
13.4 \\
18.9 \\
4.8 \\
10.4\end{array}$ & $\begin{array}{r}6 \\
2 \\
6 \\
7 \\
13 \\
16 \\
4 \\
6\end{array}$ \\
\hline & Average & - & 93.6 & 39.3 & 42 & 10.0 & 11 & 19.0 & 20 & 5.2 & 6 & 5.2 & 6 & 7.6 & 8 & 7.6 & 8 \\
\hline
\end{tabular}




\section{Total System Cost Analysis}

Table 17-6 summarizes the category cost breakdowns for the 24 sites grouped according to type of application, with cost presented as dollars per unit collector area and percentage of the total system cost. More detailed cost data are presented in the individual cost reports. In Table 17-6 it can be seen that the unit cost for the total system for each application type varies considerably. Thus, one should beware of gross summarizations such as "space heating systems in commercial buildings cost $\mathrm{X}$ $\$ /$ sq ft of collector area."

Also, for most of the subcategories, very large variations are evident in unit costs. For example, collector category costs vary between $\$ 10 / \mathrm{sq} \mathrm{ft}(\$ 108 / \mathrm{sq} \mathrm{m})$ and $\$ 163 / \mathrm{sq} \mathrm{ft}(\$ 1,760 / \mathrm{sq} \mathrm{m})$; support structure costs vary between $\$ 2.40 / \mathrm{sq} \mathrm{ft}(\$ 26 / \mathrm{sq} \mathrm{m})$ and $\$ 26 / \mathrm{sq} \mathrm{ft}(\$ 281 / \mathrm{sq} \mathrm{m})$; and piping, ductwork, and insulation costs vary between $\$ 3.20 / \mathrm{sq}$ ft $(\$ 34.50 / \mathrm{sq} \mathrm{m})$ and $\$ 32 / \mathrm{sq} \mathrm{ft}(\$ 346 / \mathrm{sq} \mathrm{m})$. Each system has unique characteristics that affect these category costs. The system characteristics are described more fully in the Project Deseriptions.

Though most costs vary, some consistency in the figures in Table $17-6$ is also evident. The percentage of total system cost values are relatively uniform within most of the cost categories. Storage costs are also fairly consistent, with only a few systems varying significantly from the average $\$ 3.90 / \mathrm{sq} \mathrm{ft}(\$ 42 / \mathrm{sq} \mathrm{m})$.

Fig. 17-7 illustrates the relationship between the total system unit costs for the 24 sites and for the five different system types: passive heating, process hot water, space heating (air type collectors), space heating (liquid type collectors), and space heating and cooling.

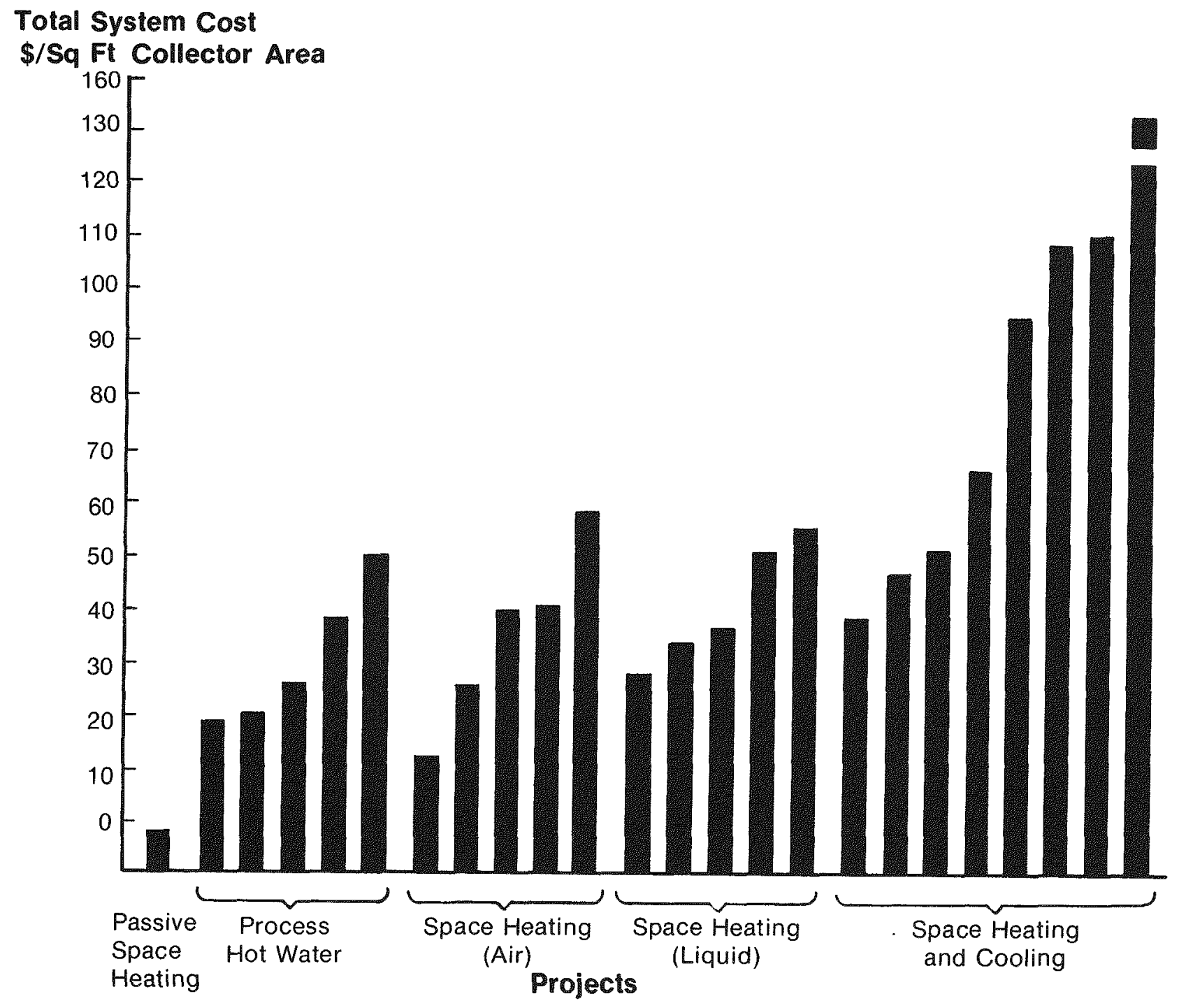

Fig. 17-7. Total system costs grouped by system type 
Only one passive system, Kalwall, is listed; and its total cost of less than $\$ 8 / \mathrm{sq} \mathrm{ft}(\$ 86 / \mathrm{sq} \mathrm{m})$ is much lower than all the other types. The five process hot water systems range from $\$ 29$ to $\$ 61 / \mathrm{sq} \mathrm{ft}(\$ 313-\$ 659 / \mathrm{sq} \mathrm{m})$ with an average of $\$ 41 / \mathrm{sq} \mathrm{ft}(\$ 443 / \mathrm{sq} \mathrm{m})$. The five space heating systems employing air type collectors range between $\$ 23$ and $\$ 68 / \mathrm{sq} \mathrm{ft}(\$ 248-\$ 734 / \mathrm{sq} \mathrm{m})$ with an average of about $\$ 46 / \mathrm{sq} \mathrm{ft}(\$ 497 / \mathrm{sq} \mathrm{m})$. The five space heating systems employing liquid type collectors range between $\$ 38$ and $\$ 65 / \mathrm{sq} \mathrm{ft}(\$ 410-\$ 702 / \mathrm{sq} \mathrm{m})$ and average about $\$ 5 \mathrm{l} / \mathrm{sq} \mathrm{ft}$ $(\$ 551 / \mathrm{sq} \mathrm{m})$. The space heating systems combined average $\$ 48 / \mathrm{sq} \mathrm{ft}(\$ 517 / \mathrm{sg} \mathrm{m})$. The eight space heating and cooling projects range between about $\$ 48$ and $\$ 163 / \mathrm{sq} \mathrm{ft}(\$ 518-\$ 1,760 / \mathrm{sq} \mathrm{m})$ with an average of $\$ 94 / \mathrm{sq}$ ft $(\$ 1,015 / \mathrm{sq} \mathrm{m})$. If the Reedy Creek system costs [the highest by more than $\$ 40 / \mathrm{sq} \mathrm{ft}(\$ 432 / \mathrm{sq} \mathrm{m})$ ] are not included, the average cost for the space heating and cooling projects is $\$ 84 / \mathrm{sq} \mathrm{ft}(\$ 907 / \mathrm{sq} \mathrm{m})$.
The data collected to date and as illustrated in Fig. 17-7 agree with previous conclusions that process water systems are the least expensive active solar application on a per square foot basis, followed closely by space heating applications. Space heating and cooling applications are much more expensive, on the average, than the other system types. However, there are exceptions to these general rules, as can be seen in Fig. 17-7. Some cooling applications have been installed at lower relative cost than some process water systems. Also, there is a very large range of costs for every application type.

Total system costs are presented again in Fig. 17-8, this time divided into two main groups, new and retrofit applications. As shown, new systems have an average cost of about $\$ 44 / \mathrm{sq} \mathrm{ft}(\$ 475 / \mathrm{sq} \mathrm{m})$, and retrofits have an average of $\$ 67 / \mathrm{sq} \mathrm{ft}(\$ 724 / \mathrm{sq} \mathrm{m})$. However, two factors

Total System Cost \$/Sq Ft

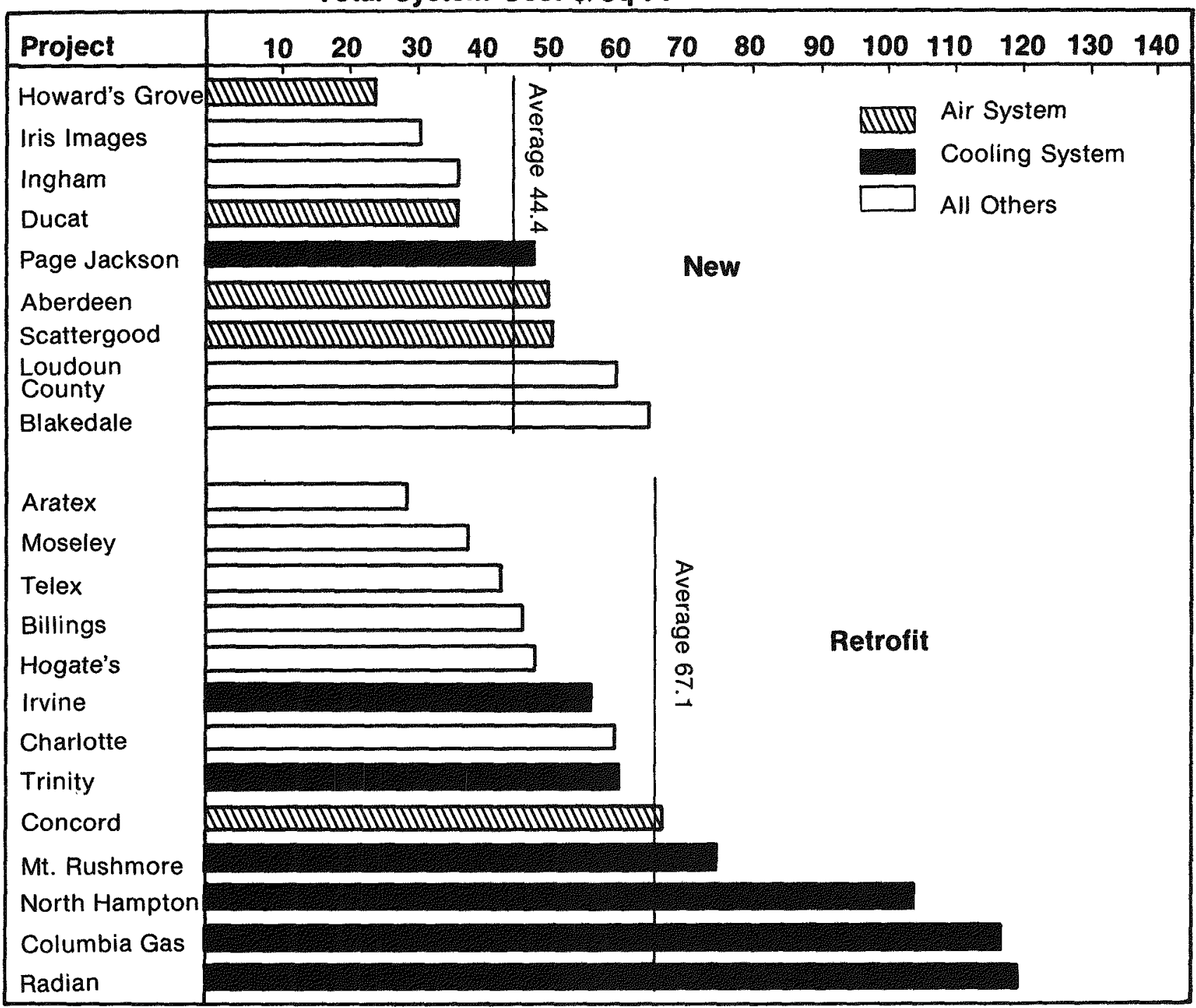

Fig. 17-8. Total system cost for new and retrofit systems 
should be recognized. First, all but one of the cooling projects were retrofit. (This fact may account for some of the higher average costs of the cooling projects in this sample.) Note that Reedy Creek has not been considered in this analysis. If no cooling projects are considered, the average is $\$ 44 / \mathrm{sq} \mathrm{ft}(\$ 475 / \mathrm{sq} \mathrm{m})$ for new and $\$ 48 / \mathrm{sq} \mathrm{ft}$ $(\$ 528 / \mathrm{sq} \mathrm{m})$ for retrofit systems.

The second interesting factor in Fig. 17-8 is that all but one of the five air type space heating systems are new systems. This probably reflects the greater difficulty perceived for retrofitting air systems. Three of the four new air systems have total costs significantly below the average for new systems. Given all of the factors, the conclusion of this analysis is that retrofit systems are only slightly more costly than systems in new construction. This difference may even decrease as a larger sample of projects is obtained.

\section{Economies of Scale}

The cost data were analyzed statistically to investigate possible economies of scale effects for total system costs. "Economies of scale" is the term used when the unit cost of "large" systems is less than the unit cost of "small" systems. The economies of scale analysis consists of plotting total system cost versus collector area on a $\log -\log$ graph. Regression analysis is used to find the best fit line through the points. Fig. 17-9 illustrates the relationship between the slope of lines on a $\log -\log$ plot and the corresponding curves plotted on a linear graph. Note that curve $C$ is the type that would be expected if an economies of scale effect were at work. Curve $B$ indicates no economies of scale, and curve A indicates a reverse economy of scale wherein unit costs increase as system size increases.

The plot of total system costs versus collector area is shown in Fig. 17-10. The solid line is the best fit line determined by regression analysis. The slope of this line is 0.95 . The broken line indicates the result of assuming that no economies of scale are involved (slope $=1.00$ ) and that the costs can be represented by the average cost per unit collector area. Note that while some economies of scale effect is indicated, the broken line (no economy of scale) is nearly as good as a fit through the points. Thus, within the range of systems studied, economies of scale are a relatively unimportant cost factor.

Looking further at Fig. 17-10, it can be seen that all cooling projects are very near or above the best fit line. No other project types are above the line.

\section{Regional Cost Variation}

Another application of regression analysis for identifying cost factors is based on the computation of a correlation coefficient for the best fit line through log costs plotted against log collector areas. The correlation coefficient is a measure of how well the line fits the points. Assume a correlation coefficient is obtained for a sample of cost points. Then, if the cost figures are multiplied by some factor to normalize data and eliminate the effect of some parameter and plotted again, an increase in the correlation coefficient would result. The impact of a cost factor on system cost could be measured by the increase in the correlation coefficient when that normalization factor is applied.

For example, as shown in Fig. 17-10, the log of the system cost was plotted against the $\log$ of the collector area for the 24 systems; and regression analysis yielded a correlation coefficient of 0.90 . The costs were then divided by the mechancial system city cost indexes in Means Mechanical and Electrical Cost Data 1978. These city cost indexes are an indication of the geographic

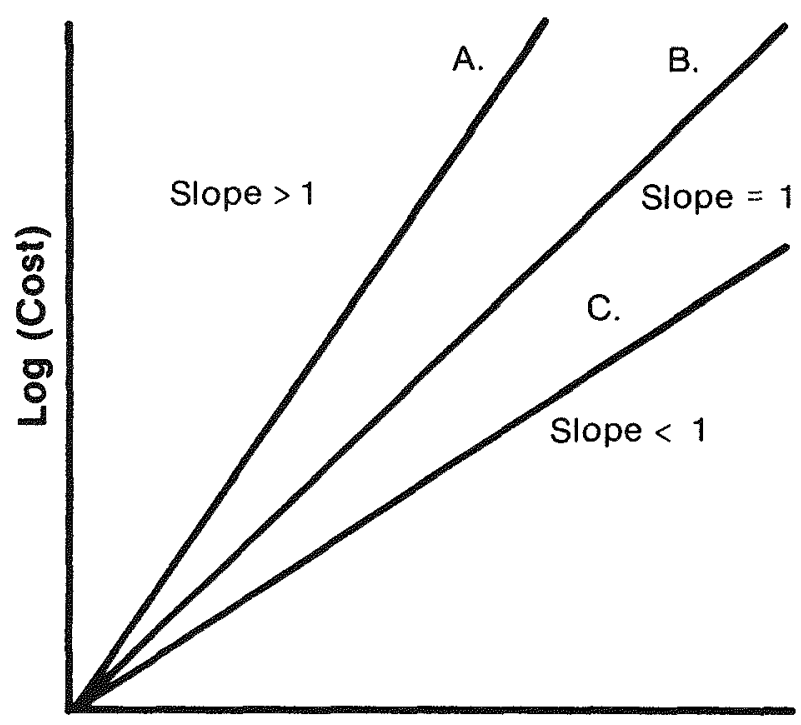

Log (Collector Area)

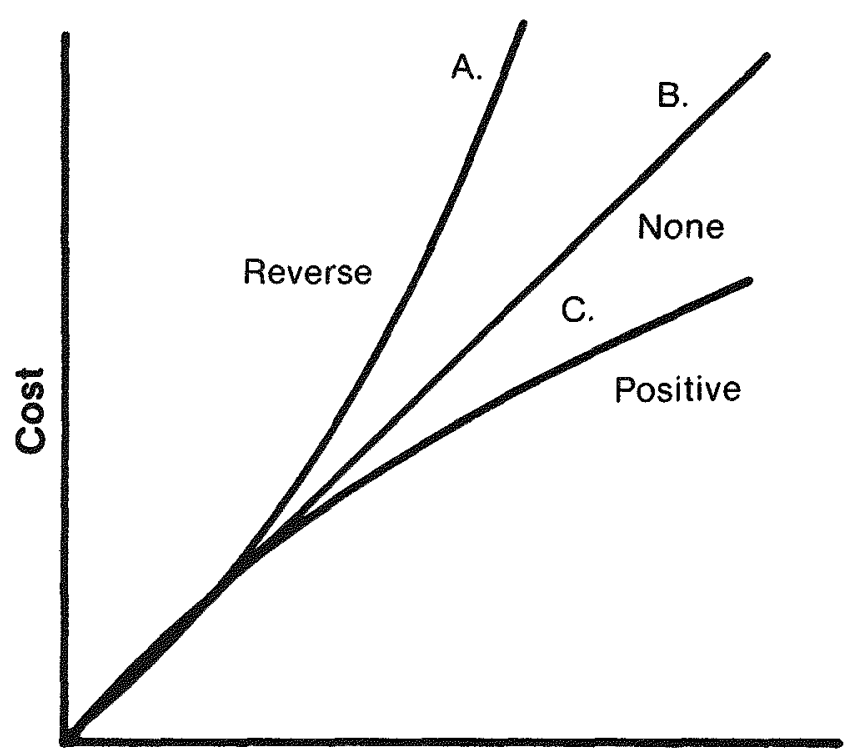

Collector Area

Fig. 17-9. Lines on log-log scale and corresponding curves on linear scale 


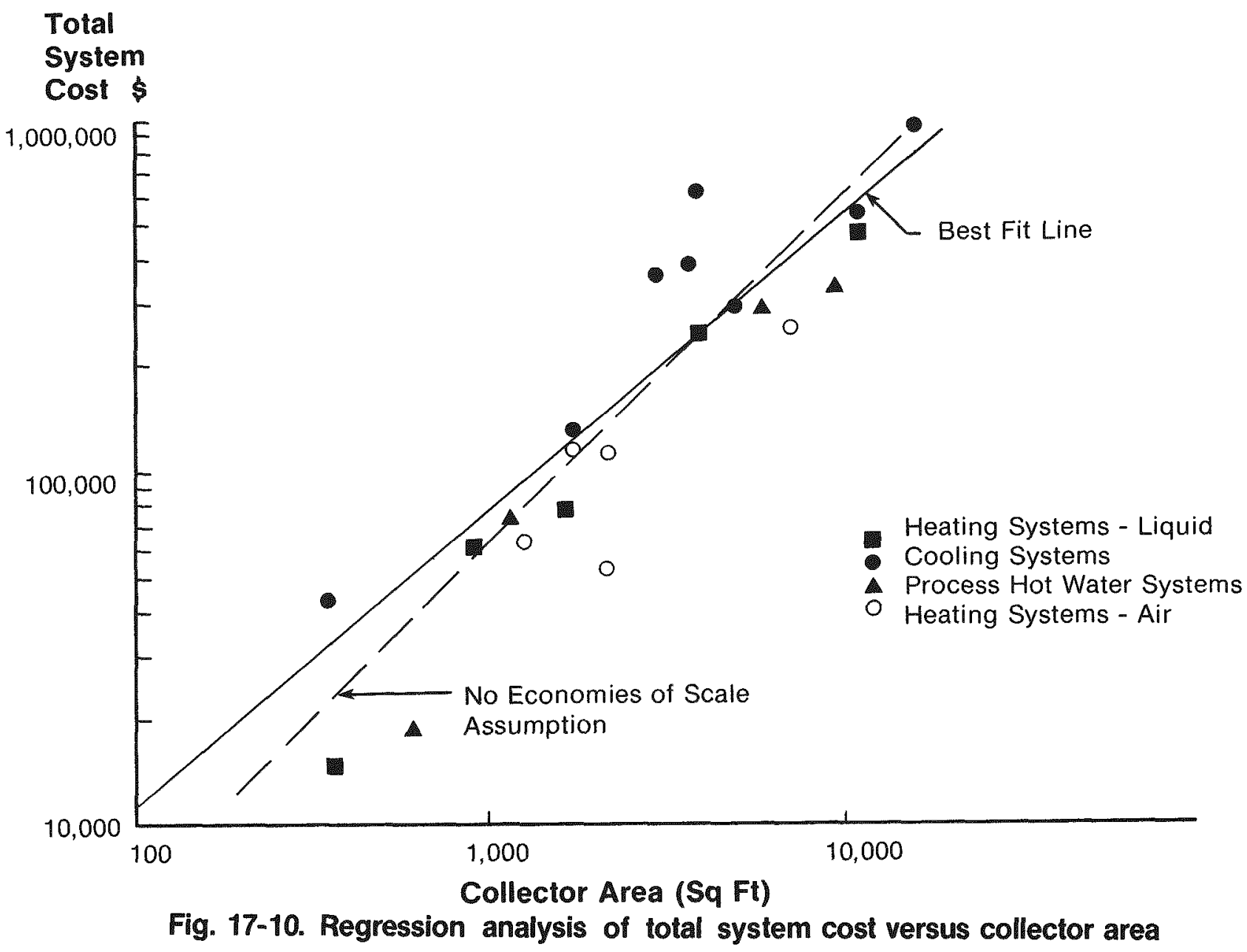

Table 17-7. REGIONAL COST INDEXES FROM 1978 MEANS MECHANICAL AND RLECTRICAL COST DATA

\begin{tabular}{llr}
\hline \multicolumn{1}{c}{ System } & \multicolumn{1}{c}{$\begin{array}{c}\text { Nearest } \\
\text { Means City }\end{array}$} & $\begin{array}{r}\text { City } \\
\text { Cost } \\
\text { Index }\end{array}$ \\
\hline Aberdeen & Sioux Falls, S.D. & 90.6 \\
Aratex & Fresno, Calif. & 107.0 \\
Billings & Billings, Mont. & 96.5 \\
Blakedale & Columbia, S.C. & 82.7 \\
Charlotte & Charlotte, N.C. & 82.4 \\
Columbia Gas & Columbus, Ohio & 98.2 \\
Concord & Lowell, Mass. & 99.3 \\
DuCat & Topeka, Kans. & 93.5 \\
Hogate's & Washington, D.C. & 98.5 \\
Howard's Grove & Madison, Wis. & 96.6 \\
Ingham & Lansing, Mich. & 99.4 \\
Iris Images & San Francisco, Calif. & 119.0 \\
Irvine & Los Angeles, Calif. & 108.7 \\
Loudoun County & Richmond, Va. & 90.9 \\
Moseley & Roanoke, Va. & 88.1 \\
Mt. Rushmore & Sioux Falls, S.D. & 90.6 \\
North Hampton & Dallas, Tex. & 91.2 \\
Page Jackson & Huntington, W. Va. & 99.0 \\
Radian & Austin, Tex. & 90.7 \\
Reedy Creek & Orlando, Fla. & 90.5 \\
Scattergood & Davenport, Iowa & 94.5 \\
Telex & Minneapolis, Minn. & 94.8 \\
Trinity & San Antonio, Tex. & 91.9 \\
\hline
\end{tabular}

variation in mechanical system materials and installation costs. Table 17-7 lists the 24 projects, the closest cities for which cost index information was available, and the total mechanical system cost indexes used.

After the system costs were divided by the city cost index, which normalized the costs against regional variations in materials and labor costs, a regression analysis was performed again. The resulting correlation coefficient was 0.89 . The fact that the correlation coefficient actually decreased by $1 \%$ indicates that regional influences have not been significant in the systems cost studied to date. The slope of the line resulting from this analysis was 0.94 , indicating that even after normalizing the data to account for regional variations, there are no appreciable economies of scale.

\section{SUBSYSTEM COST ANALYSIS}

\section{Collectors}

Much attention has been focused on solar collectors as an area for cost reduction because collectors represent a significant portion of total system cost. Fig. 17-11 presents the cost data for the solar collectors for the 24 sites grouped according to collector type. These costs do not agree with the costs listed in Table 17-6 under "Collector Array" because the array costs include installation labor; Fig. 17-11 includes only material costs. 


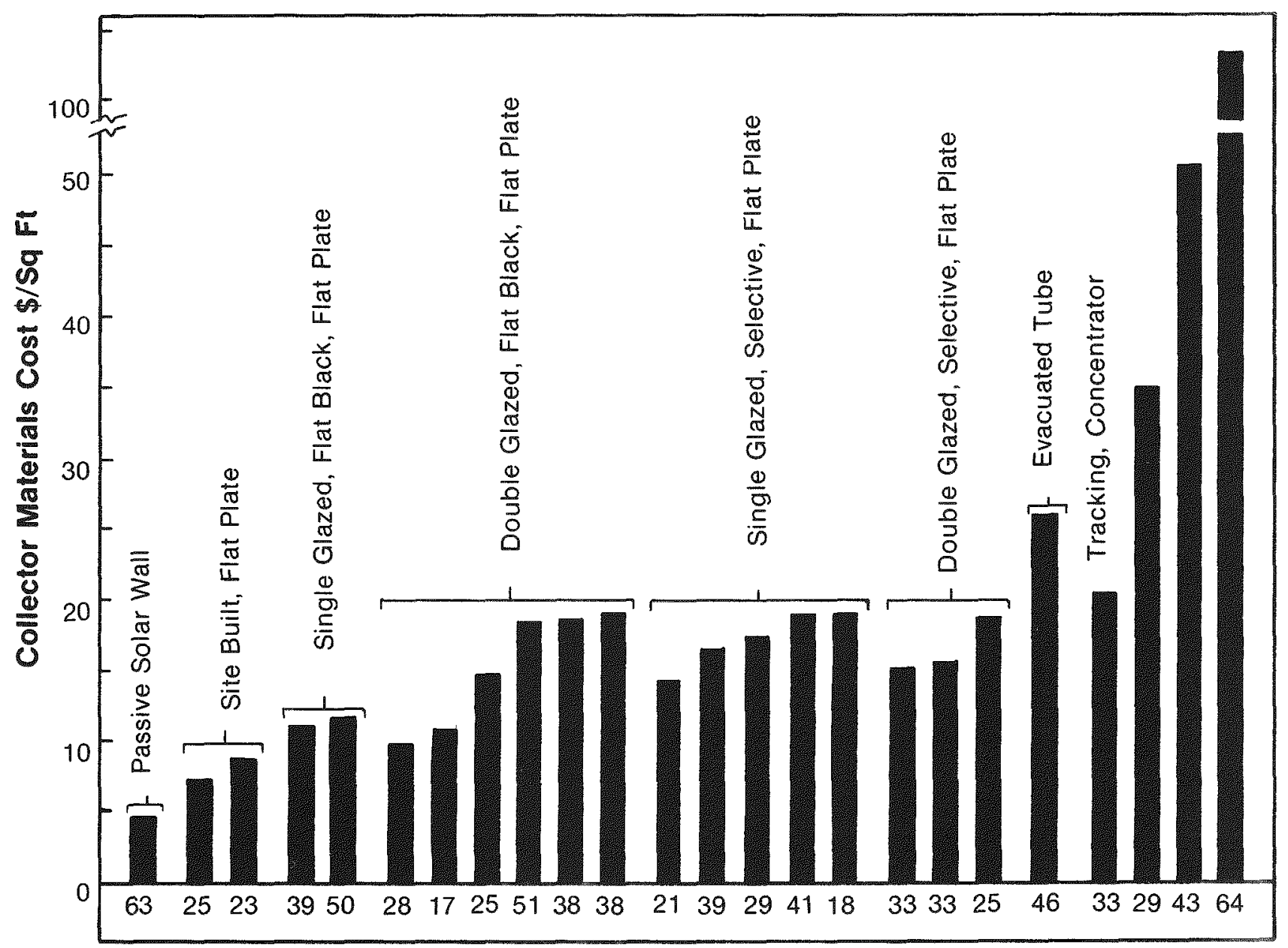

Percent of Total System Cost
Fig. 17-11. Collector materials cost in dollars per square foot and percent of total
system cost

In Fig. 17-11, it can be seen that the two site-built flat plate collectors were less expensive than the other flat plate collectors. There appears to be little cost variation between double glazed, flat black surface collectors; single glazed, selective surface collectors; and double glazed, selective surface collectors. The average cost for these three types is $\$ 16 / \mathrm{sq} \mathrm{ft}(\$ 173 / \mathrm{sq} \mathrm{m})$, which includes overhead and profit. (These costs are in 1977 dollars.) In all cases, the concentrating, tracking collectors and the single evacuated tube collector were more expensive per square foot than the flat plate collectors. Only one evacuated tube collector was employed in the systems studied. The prototype collector at Reedy Creek which integrated the roof and the collector reflector troughs was more than twice as expensive as the next highest cost collector.

Also shown in Fig. 17-11 is the percentage of the total system cost represented by the collector materials. Of the active systems studied the collector materials varied from 17 to $64 \%$ of the total system cost with an average of $34 \%$.

\section{Support Strueture}

Significant variation in system collector support structure costs has been observed. Support structure costs vary from $\$ 2.40 / \mathrm{sq} \mathrm{ft}(\$ 26 / \mathrm{sq} \mathrm{m}$ ) at Howard's Grove to $\$ 25.70 / \mathrm{sq} \mathrm{ft}(\$ 277.50 / \mathrm{sq} \mathrm{m})$ at Concord. The factor that seems to affect cost most is whether the support structure is used for functions in addition to collector support. These additional functions include the following:

- House equipment

- Improve system appearance

- Provide reflectors

- Form building roof structure

- Form building waterproof membrane.

Fig. 17-12 compares the costs of the support structures that serve multiple functions with those that merely support the collectors. There is a $\$ 5.50 / \mathrm{sq} \mathrm{ft}$ 


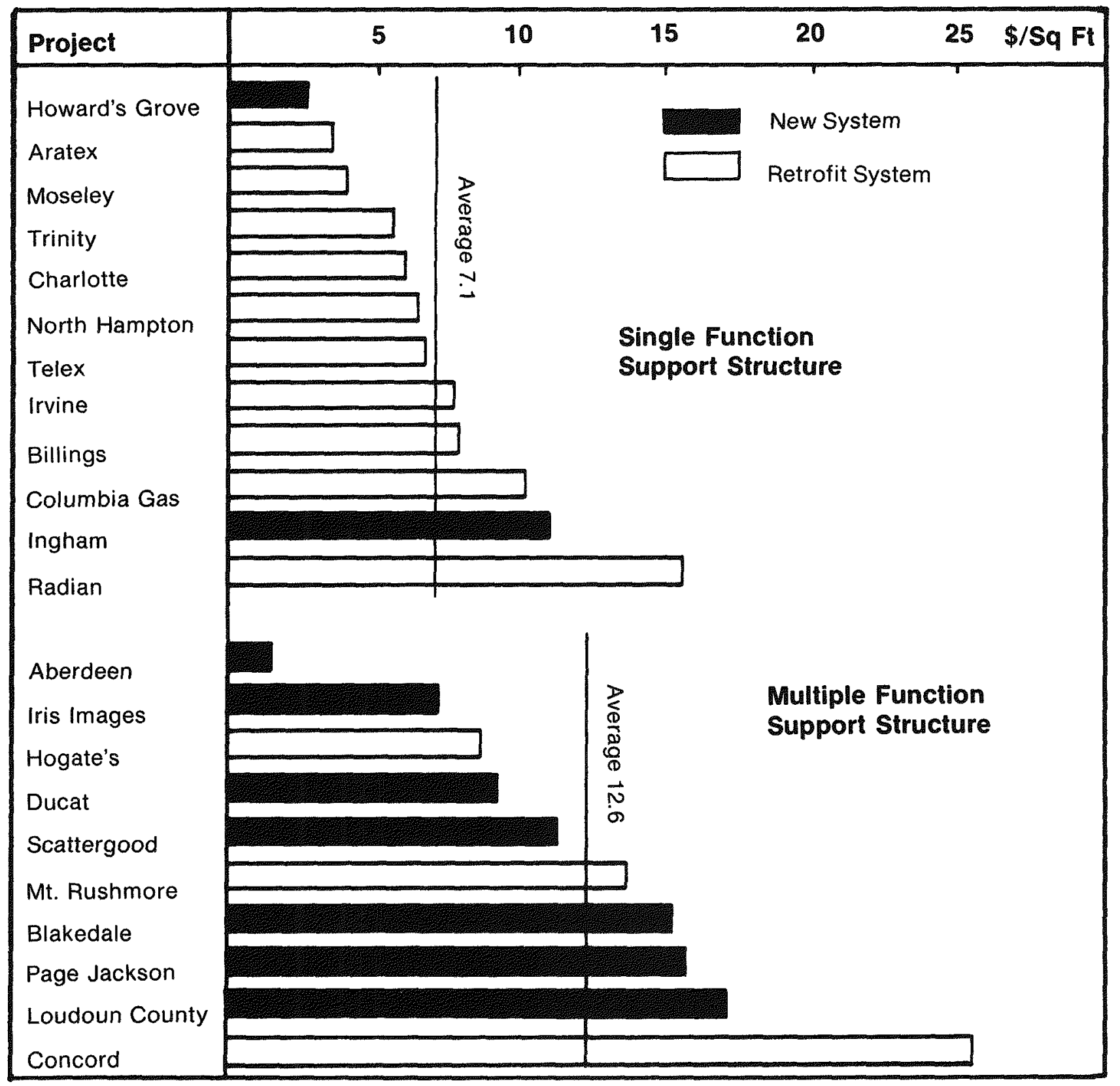

Fig. 17-12 Support structure costs grouped by single and multiple function

$(\$ 59.40 / \mathrm{sq} \mathrm{m})$ difference in average costs between those two groups. Another interesting fact is that all but two of the 12 single function support structures are for retrofit systems. Conversely, only three of the 10 multiple function support structures are for retrofit systems. Apparently, the constraints of retrofit systems lead designers to use simpler support structures. The flexibility that new systems provide the designer apparently encourages multiple uses for the support structure. The lesson of Fig. 17-12 is that these extra functions will increase the support structure cost. In some cases, the extra functions that the support structure performs result in reduced cost in other areas, and credit would have to be provided. If the support structure provides reflectors, the reflectors will improve system performance. A tradeoff will be required to determine the cost benefit of the reflectors. In most cases, however, the support structure does not contribute to performance, so that least cost to perform the support function should be sought. Thus, for the support structure, except when reflectors are used, dollars per square foot is a better evaluation factor than dollars per million Btu. From Table 17-6, the support structure on the average represents $15 \%$ of the total system cost, more than twice as much as the storage subsystem. 


\section{Piping, Ductwork, and Insulation}

If retrofit systems are more expensive than solar systems on new buildings, one would expect added costs to occur in the energy transport system. Fig. 17-13 illustrates the piping, ductwork, and insulation category cost totals. The systems are divided into new and retrofit construction. Approximately an $\$ 8 / \mathrm{sq} \mathrm{ft}(\$ 86 / \mathrm{sq} \mathrm{m})$ difference exists between the averages for the two groups with retrofit applications higher, as expected. However, most of the cooling projects are again retrofit; and their costs in this category are higher. Also, three of the four lowest costs for piping, ductwork, and insulation are for air systems. Referring to Table 17-6, this category average cost is $\$ 7.60 / \mathrm{sq} \mathrm{ft}(\$ 82 / \mathrm{sq} \mathrm{m})$ for air systems, $\$ 15.90 / \mathrm{sq} \mathrm{ft}(\$ 172 / \mathrm{sq} \mathrm{m})$ for liquid type heating systems, and $\$ 19 / \mathrm{sq} \mathrm{ft}(\$ 205 / \mathrm{sq})$ for heating and cooling systems.

In Table 17-6, piping, ductwork, and insulation are seen to represent $22 \%$ of the total system cost on the average for all system types. For space heating systems using liquid type collectors, this portion is $31 \%$ and for air type collector systems, $17 \%$.

\section{Storage}

Storage subsystems are generally easy to define within solar energy systems, and their costs have been found to be easily separable from total system costs. On the average, storage subsystems represent $6 \%$ of the total system cost. This is a very small percentage considering the importance of this subsystem to overall system performance. A number of systems have been monitored in which from 20 to $50 \%$ of the energy placed in storage is lost from storage. However, it should be noted that other systems indicate "storage efficiencies" greater than $90 \%$.

Analysis shows that storage costs are strongly dependent on the type of storage vessel used. Fig. 17-14 indicates the storage cost per unit storage capacity $(\$ /$ million Btu/F). The order of increasing cost for storage types is

- Nonpressurized steel tanks,

- Fiberglass tanks,

- Pressurized steel tanks,

- Rock beds, and

- Residential water heater type tank.

Referring to Table 17-6, note that for unpressurized systems, the storage costs are lower but represent a higher percentage of total system cost. This implies perhaps that pressurization impacts other costs as well as storage system costs.

The effect of storage tank location was also investigated although not illustrated here. On the average, buried tanks were found to be least expensive, but only slightly less expensive than exterior tanks. Tanks placed in buildings were, on the average, significantly more expensive than the others. The added cost of piping to and from exterior or buried storage is not reflected here and should be taken into consideration. Also, the analysis does not charge the cost of building space to the costs for interior storage. This finding regarding the effect of storage location is surprising since one would think that interior tanks, without need for waterproofing or protection, would be less expensive.

\section{Controls}

Controls costs were analyzed separately from the electrical costs. The range of costs was large regardless of the methods used to normalize the costs. Fig. 17-15 illustrates the controls costs for the 16 projects for which the controls costs were separable. The vertical scale is dollars per actuator controlled. Pumps, blowers, automatic valves, and motorized dampers are all considered actuators. The number of actuators for each system is provided on top of the respective cost bar. The cost per actuator controlled can be seen to vary from about $\$ 325$ to $\$ 1,800$. The highest four costs appear to be exceptionally high. If these four are not considered, the top end of the range is lowered to about $\$ 925$.

Controls costs, when normalized by the number of actuators controlled, reflect less variation than when normalized to other parameters such as collector area. Thus the number of actuators is a better gauge of controls costs.

Controls and electrical costs combined represented between 1 and $13 \%$ of the total system cost with an average of $7 \%$ as shown in Table 17-6. Controls and electrical costs averaged $\$ 4.40 / \mathrm{sq} \mathrm{ft}(\$ 47.50 / \mathrm{sq} \mathrm{m})$ of collector area for the systems studied.

\section{COST EFPECTIVENESS ANALYSIS}

\section{General}

As has been stated previously, "cost per unit collector area" has definite shortcomings when used to compare solar energy system costs because it does not account for system performance. A relatively low-cost system may actually provide more energy than another, more expensive system. A more complete evaluation of solar energy systems then must take into account the thermal performance.

All systems discussed here are instrumented for performance monitoring by the NSDN. Adequate data to determine annual thermal performance have been obtained for nine commercial systems that do not have major instrumentation or operational difficulties. Table 17-8 indicates that seven of these systems have 12 complete months of data available. For two other systems, Hogate's and Concord, data for 4 and 3 months, respectively, were extrapolated from available data through system simulation and engineering judgment to provide total annual performance values.

Within this section, several economic analytic techniques are used to investigate the cost effectiveness of nine solar energy systems. The simplest index of the cost/performance relationship is the ratio of total installed cost to the annual (first year's) solar energy system output. This ratio is useful only as an indicator for comparing systems. It has no counterpart in 
Piping, Ductwork, and Insulation Costs, $\$ / \mathrm{Sq}$ ft

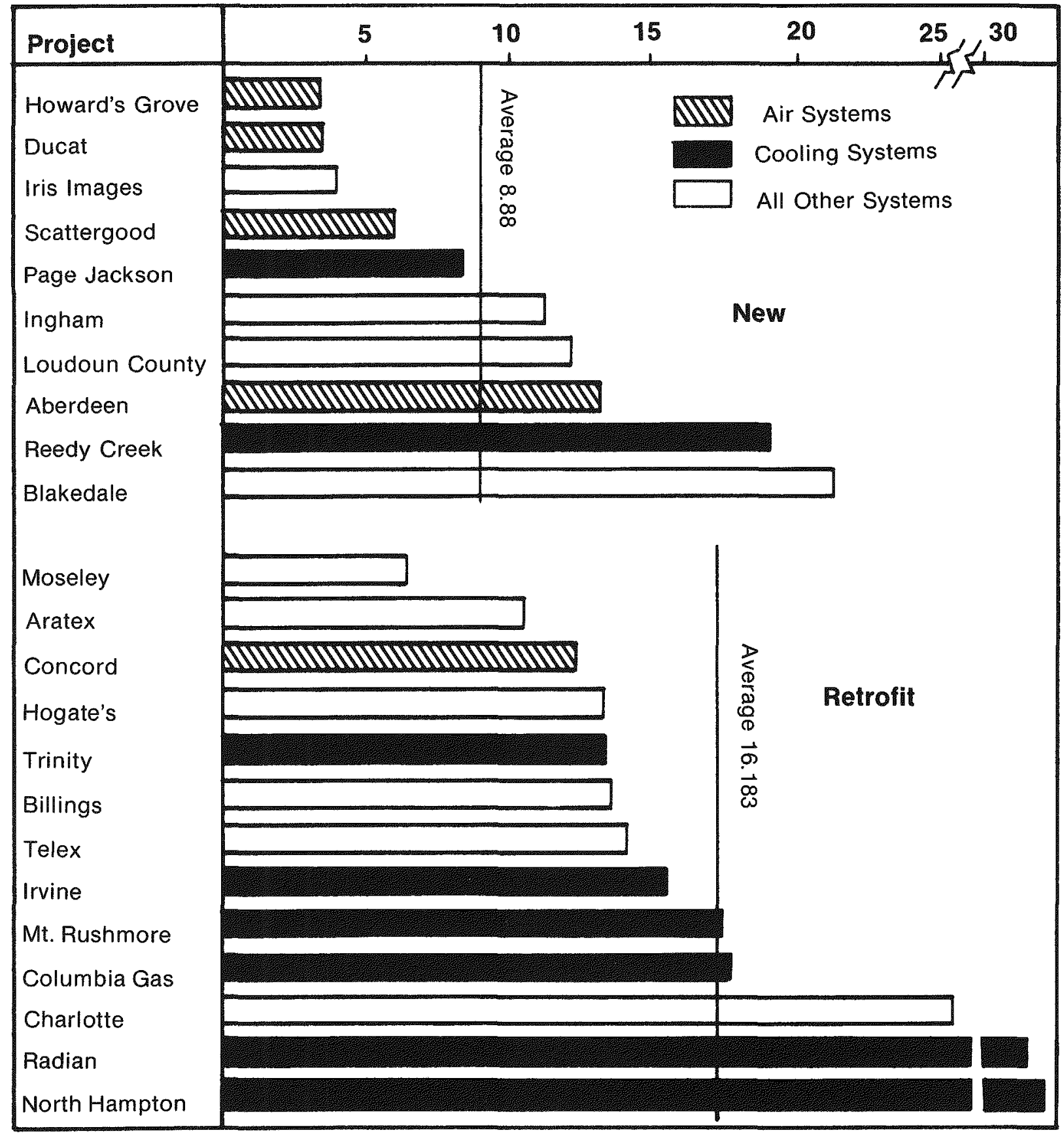

Fig. 17-13. Piping, ductwork, and insulation costs for new and retrofit projects. 


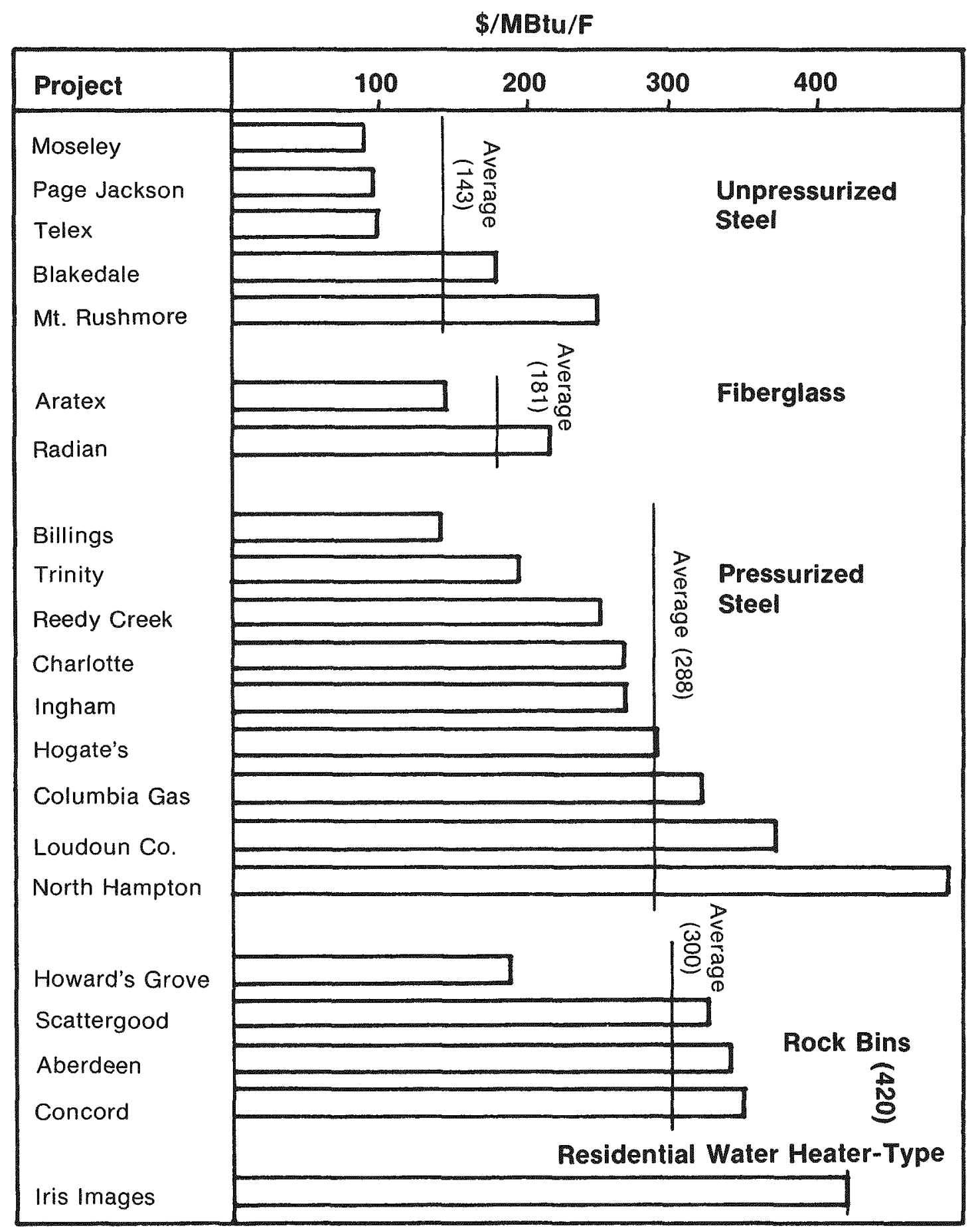

Fig. 17-14. Storage costs by type of storage container 


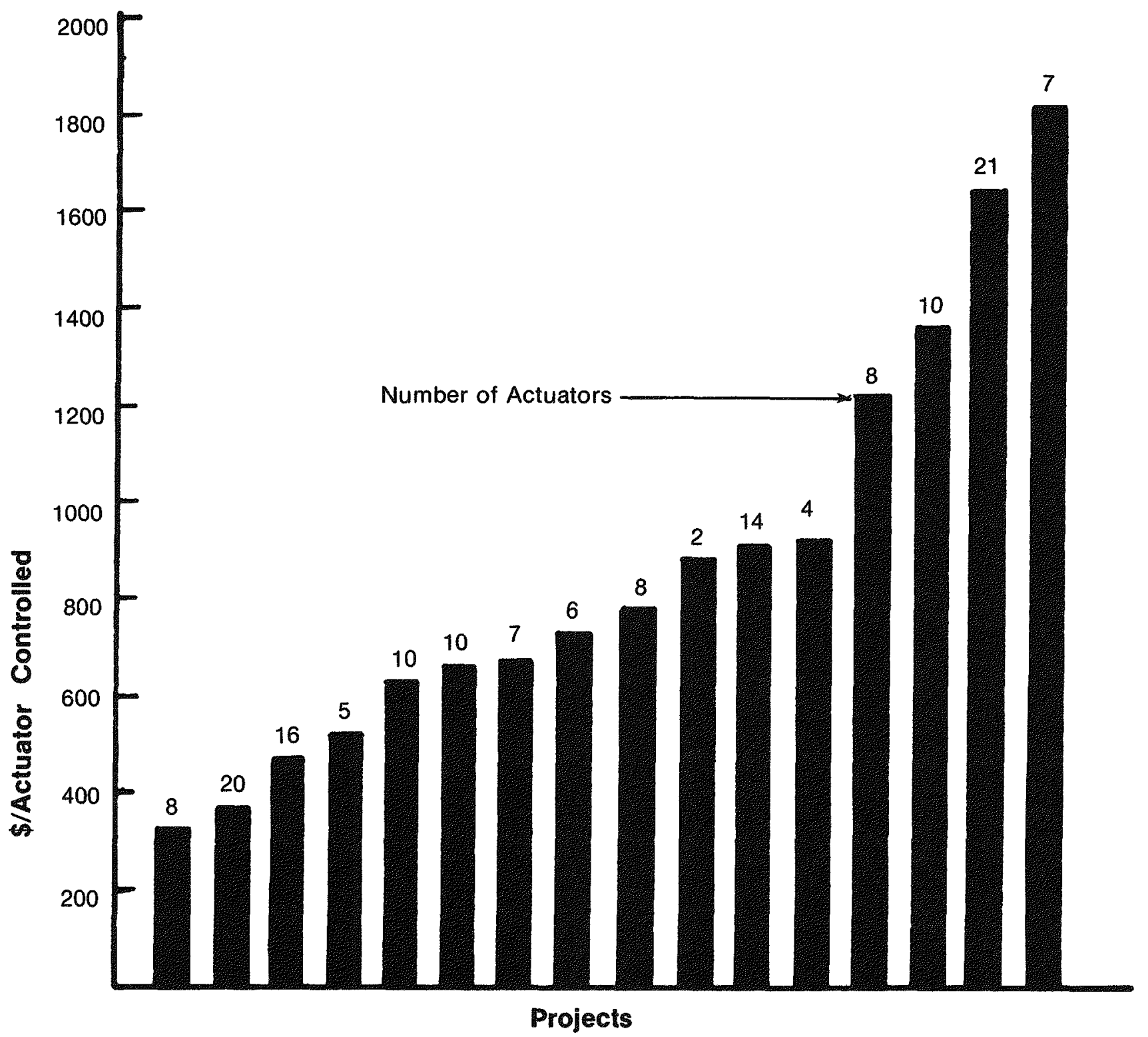

Fig. 17-15. Control costs per actuator controlled

Table 17-8. PERFORMANCE DATA USED IN ECONOMIC ASSESSMENT

\begin{tabular}{llcc}
\hline \multicolumn{1}{c}{ Project } & System Type & $\begin{array}{c}\text { NSDN Monthly Performance } \\
\text { Reports Utilized }\end{array}$ & Extrapolated Data \\
\hline Kalwall & $\begin{array}{l}\text { Passive Space } \\
\text { Heating }\end{array}$ & $9 / 78-4 / 79$ \\
Aratex & Process Hot & $10 / 78-9 / 79$ & $11 / 78-2 / 79$ \\
Hogate's & Water & $3 / 79-10 / 79$ & \\
Moseley & & $3 / 78-2 / 79$ & $9 / 78 ; 11 / 78 ; 5 / 79$ \\
Concord & Space Heating & $10 / 78 ; 12 / 78-4 / 79$ & $9 / 78-8 / 79$ \\
Scattergood & & $11 / 78-10 / 79$ & $11 / 78-10 / 79$ \\
Irvine & & $4 / 78-3 / 79$ \\
Page Jackson & Space Heating & & \\
Reedy Creek & and Cooling & & \\
\hline
\end{tabular}




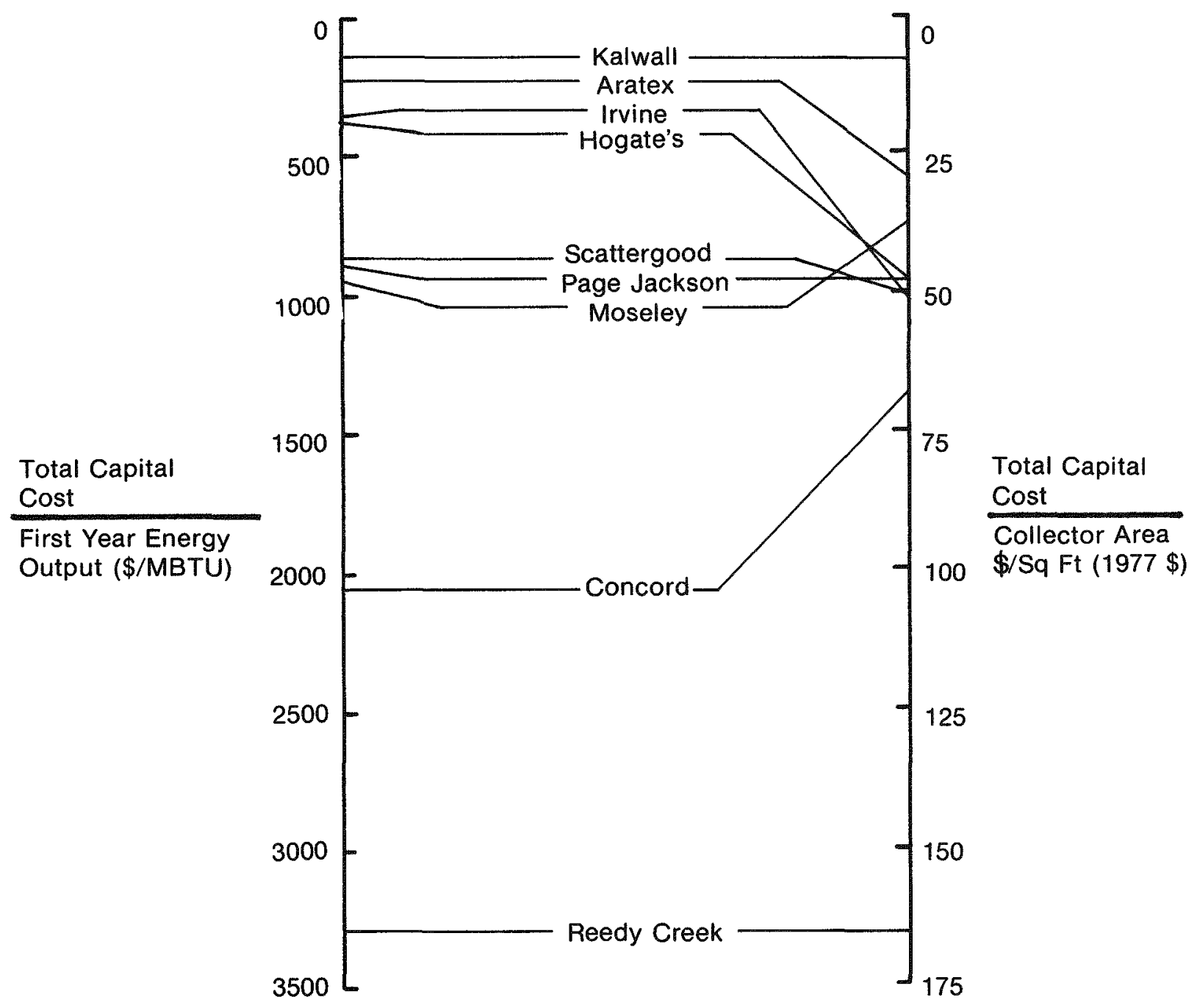

Fig. 17-16. Comparison of cost/collector area to cost/first year energy output

traditional economic analysis. However, the attractiveness of this approach is that direct outputs of the data program are used, and no other assumptions are required. Other methods must assume inflation or interest rates or tax structures. One disadvantage is that the ratio does not take into account the effect of operating energy. Fig. 17-16 compares the system ranking under two ratios-total installed cost/collector area and total installed cost/first year energy output. It can be seen that the ranking of the systems changes significantly when energy output is considered. As a first order comparison of cost effectiveness, this simple index is very valuable.

Concord and Reedy Creek will not be analyzed further here because of their low comparative standing in Fig. 17-16.
Two more sophisticated, commonly used indexes for presenting the cost effectiveness of solar energy systems are payback period and rate of return. The payback period, as defined for use in this analysis, is the length of time required for the accrued net benefits from the solar energy system to equal the net capital investment. The rate of return is the interest (or discount) rate at which the life-cycle costs are equal to the life- cycle benefits. The calculation of both quantities is highly dependent on a variety of economic assumptions chosen for the analysis.

The key variables used in the payback and rate of return analyses and also in the first year cost analysis discussed later are listed in Table 17-9. The nominal values were used in each analysis except where otherwise noted. A $0 \%$ property tax rate was used because most states have passed property tax exemptions for solar equipment. The 
investment tax credit rate used was 20\% (10\% normal investment tax credit and an additional 10\% now allowed for solar investments).

Table 17-10 lists the values used in the analyses for capital investment, solar energy used, cost of operating energy, and auxiliary fuel type for the seven systems.

\section{PAYBACK PERIOD}

The payback period analyses are based on the equation:

$\sum_{n=1}^{k}\left\{Q(F p)(1-\tau)(1+e)^{n}+\tau(r f r+d)(C I)-\right.$

$\left.(1-\tau)\left[\beta_{1}+\beta_{2}+m(1+g)^{n}\right](C I)-(1-\tau)(O)(1+e)^{n}\right\} /$

$(1+1)^{n}=C I-\alpha(C I)$.

Briefly, the term in brackets represents the net annual benefit contributed by the solar energy system; and the right hand side of the equation represents the capital investment for the solar energy system less the investment tax credit.

Using the nominal values listed in Tables 17-9 and 17-10, the only solar energy system that achieved payback within the system lifetime was the Kalwall system, which achieved payback in 13 years. (For the Kalwall ease, an investment tax credit rate of $10 \%$ was used, since this passive site does not qualify for a solar tax eredit under
Table 17-9. ECONOMIC ANALYSIS PARAMETERS

\begin{tabular}{lcc}
\hline \multicolumn{1}{c}{ Parameter } & Symbol & Nominal Value \\
\hline System and Mortgage Life & $\mathrm{N}$ & 20 years \\
Interest Rate & $\mathrm{i}, \mathrm{r}$ & $10 \%$ \\
Income Tax Rate & $\tau$ & $50 \%$ \\
Property Tax Rate & $\beta_{1}$ & 0 \\
Insurance Rate & $\beta_{2}$ & $0.0025 \times \mathrm{CI}$ \\
Investment Tax Credit & $\alpha$ & $20 \%$ \\
Percent Mortgaged & $\mathrm{fr}$ & $40 \%$ \\
General Annual Inflation Rate & $\mathrm{g}$ & $8 \%$ \\
Annual Maintenance Costs & $\mathrm{m}$ & $0.01 \times \mathrm{CI}$ \\
Efficiency Adjusted Fuel Costs & $\mathrm{Fp}$ & See below \\
Capital Recovery Factor & $\mathrm{CRF}$ & 0.1175 \\
Annual Depreciation & $\mathrm{d}$ & $*$ \\
First Year Fuel Cost** & & $\$ 14.65 / \mathrm{MBtu}$ \\
Electricity & & $\$ 10.42 / \mathrm{MBtu} * *$ \\
Oil & & $\$ 10.02 / \mathrm{MBtu} * *$ \\
Propane & & $\$ 5.00 / \mathrm{MBtu} * *$ \\
Natural Gas & & \\
Annual Fuel Escalation Rate & $\mathrm{e}$ & $15 \%$ \\
(includes g) & & $16 \%$ \\
Electricity & & $15 \%$ \\
Oil & & $15 \%$ \\
Propane & & \\
Natural Gas & & \\
\hline
\end{tabular}

$\mathrm{CI}=$ Capital Investment

$\mathrm{MBtu}=$ million $\mathrm{Btu}$

*For the payback and first year energy cost analysis, a sum-of-the-years-digits depreciation was assumed where $d$ for year $n$ is $2(N-n+1) / N(N+1)$. A straight line depreciation was used in the rate of return analysis.

**B Based on $60 \%$ fuel efficiency.

Note: The nominal values listed were meant to be reasonable estimates, and no discussion is provided here regarding their appropriateness. The sensitivity of the resul ts to many factors is discussed, however.

Table 17-10. COST/PERFORMANCE VALUES USED IN THE ANALYSIS

\begin{tabular}{lcccr}
\hline \multicolumn{1}{c}{ Site } & $\begin{array}{c}\text { Capital } \\
\text { Investment } \\
\text { CI }(1979 \$)\end{array}$ & $\begin{array}{c}\text { Annual Solar } \\
\text { Energy Used, Q } \\
\text { (million Btu) }\end{array}$ & $\begin{array}{c}\text { Auxiliary } \\
\text { Fuel }\end{array}$ & $\begin{array}{c}\text { Annual Operating } \\
\text { Energy Cost, } \\
\text { O* (1979 \$) }\end{array}$ \\
\hline Scattergood & $\$ 135,452$ & 154 & Propane & Gas \\
Irvine & 339,393 & 976 & Oil & 1,978 \\
Kalwall & 16,101 & 111 & Gas & 117 \\
Moseley & 17,011 & 18 & Gas & 44 \\
Hogate's & 337,906 & 915 & Oil & 440 \\
Page Jackson & 626,945 & 703 & Steam** & 396 \\
Aratex & 219,246 & 949 & Electricity & 293 \\
Concord & 141,297 & 69 & Steam & 132 \\
Reedy Creek & 744,922 & 227 & 513 \\
\hline
\end{tabular}

* Cost is based on $\$ 14.65 /$ million $B$ tu for electricity.

**Analysis for Aratex used variously electricity, gas, and oil as the auxiliary fuel type. 


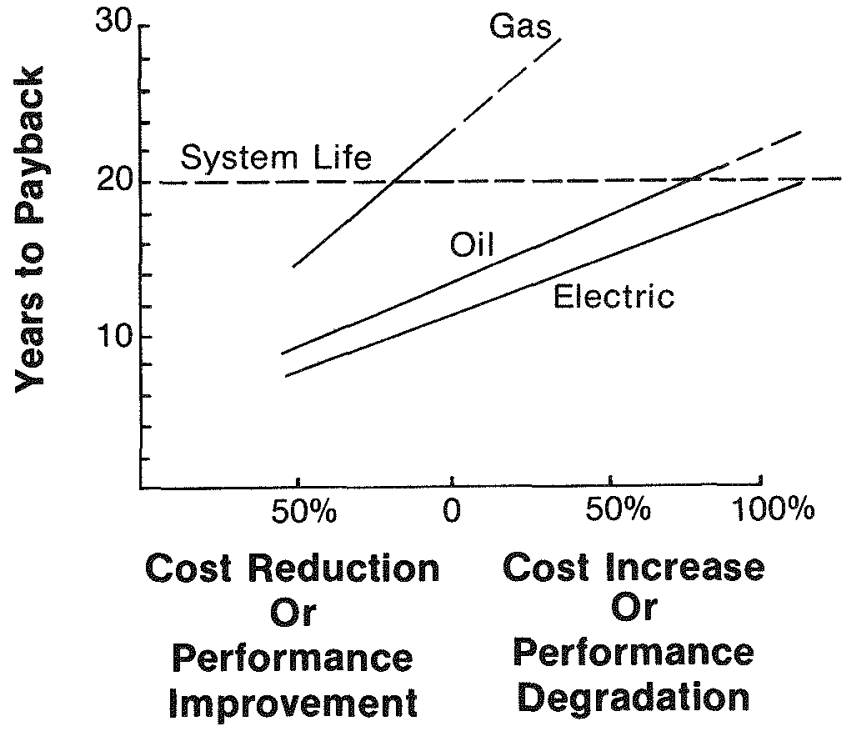

Fig. 17-17. Sensitivity of payback period to changes in initial cost and performance for three fuel types for Aratex

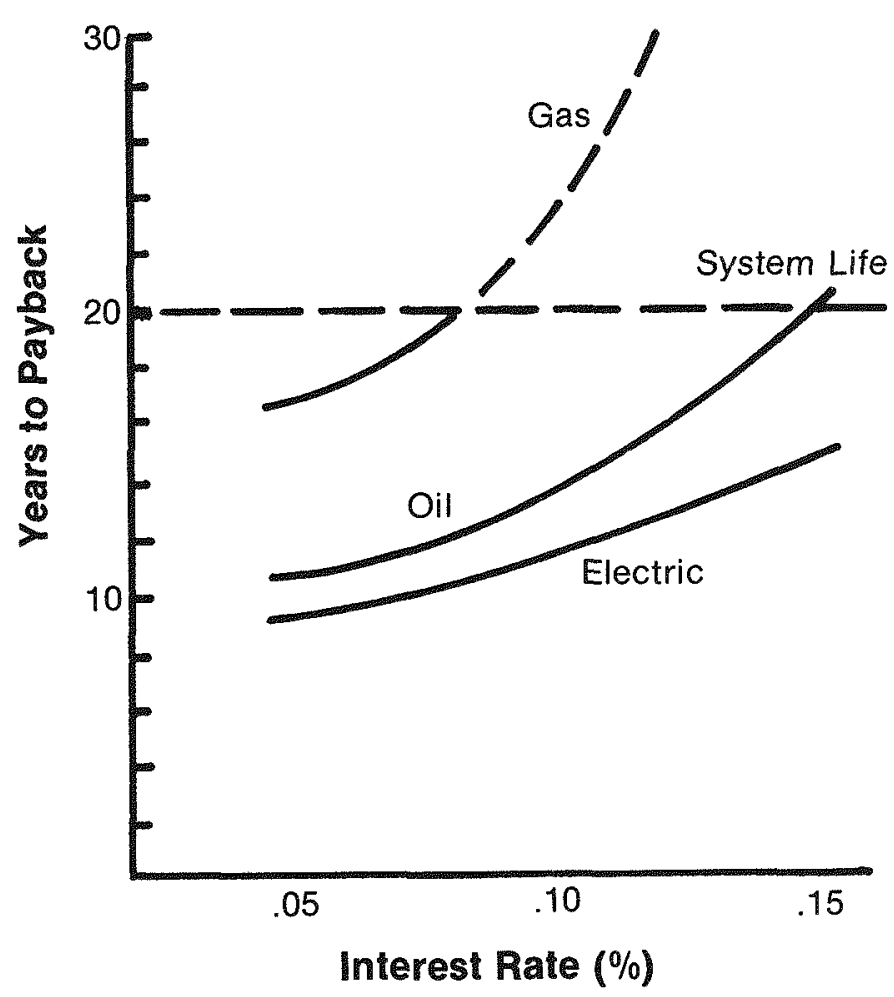

Fig. 17-18. Sensitivity of payback period to interest rate for three fuel types for Aratex

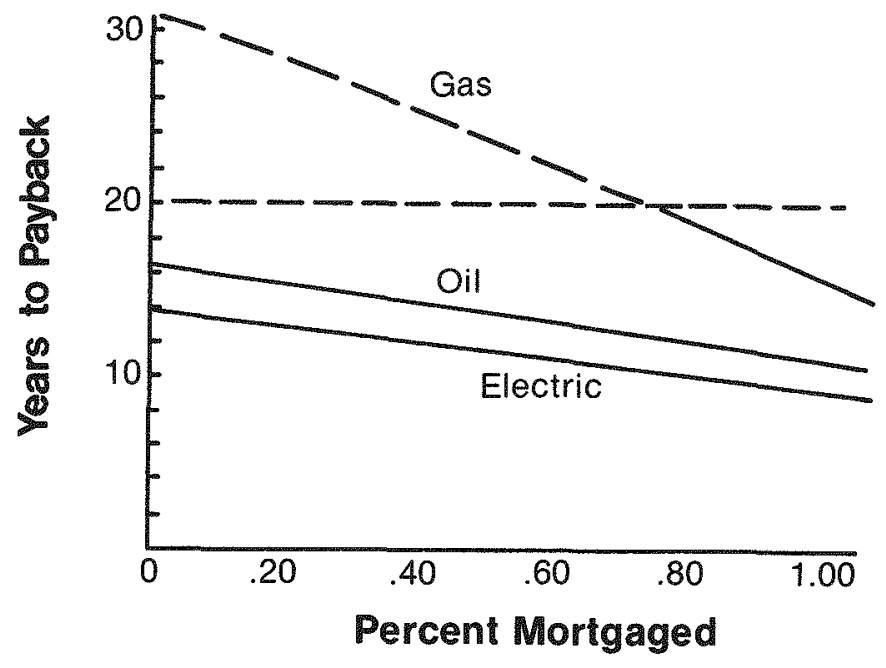

Fig. 17-19. Sensitivity of payback period to percent mortgaged for three fuel types for Aratex

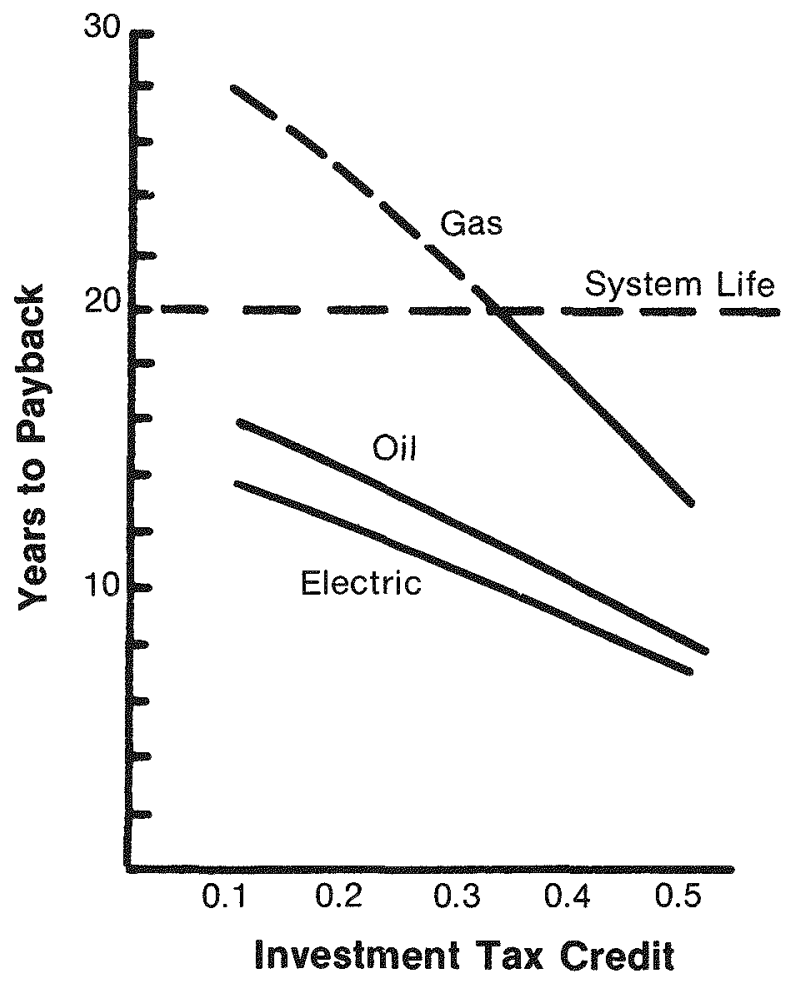

Fig. 17-20. Sensitivity of payback period to investment tax credit for three fuel types for Aratex 
existing law.) If electricity and oil were used as the auxiliary fuel for Aratex, the solar system would pay for itself in 12 and 14 years, respectively.

The payback period calculation is sensitive to the assumed values of the economic parameters in Table 17-9. Some parameters, such as the fuel escalation and general inflation rates, cannot be predicted with any accuracy for more than a few years. Other parameters, such as "percent mortgaged" and maintenance costs, will vary from site to site. Still others, such as the investment tax credit, are subject to change through legislation. Thus, the accuracy of any economic analysis based on these parameters is subject to the accuracy of the parameters themselves.

A series of graphs is presented showing the sensitivity of the calculated payback period for the Aratex system to the system cost, the investment tax credit, the interest rate, the fuel escalation rate, and the percent mortgaged. These graphs were developed by holding all parameters at the nominal values and varying one parameter over a range of values. Three curves are shown in each graph: one with electricity as the auxiliary fuel source, another with oil, and the third with natural gas.

The graphs are presented as Figs. 17-17 through 17-21. Note that in each figure, the sensitivity of payback period to the varied parameter is most pronounced in the case where gas is the auxiliary fuel type. The effect of varying each parameter becomes greater the further in the future that payback is achieved.

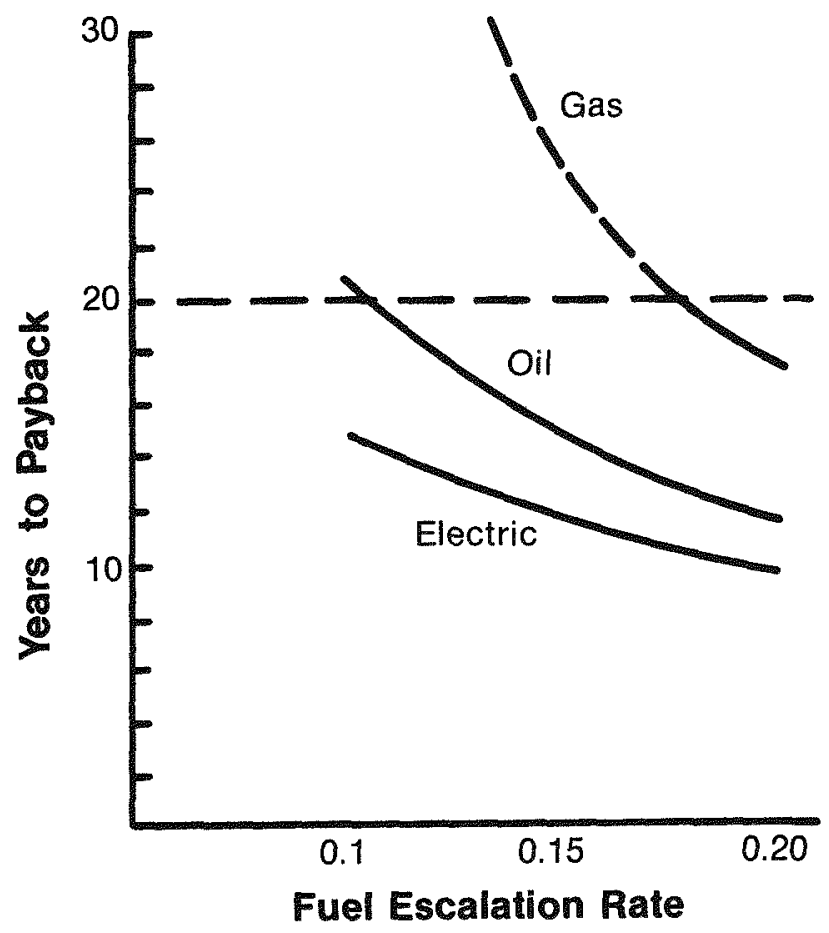

Fig. 17-21. Sensitivity of payback period to fuel escalation rate (includes general inflation) for three fuel types for Aratex
Rate of Return

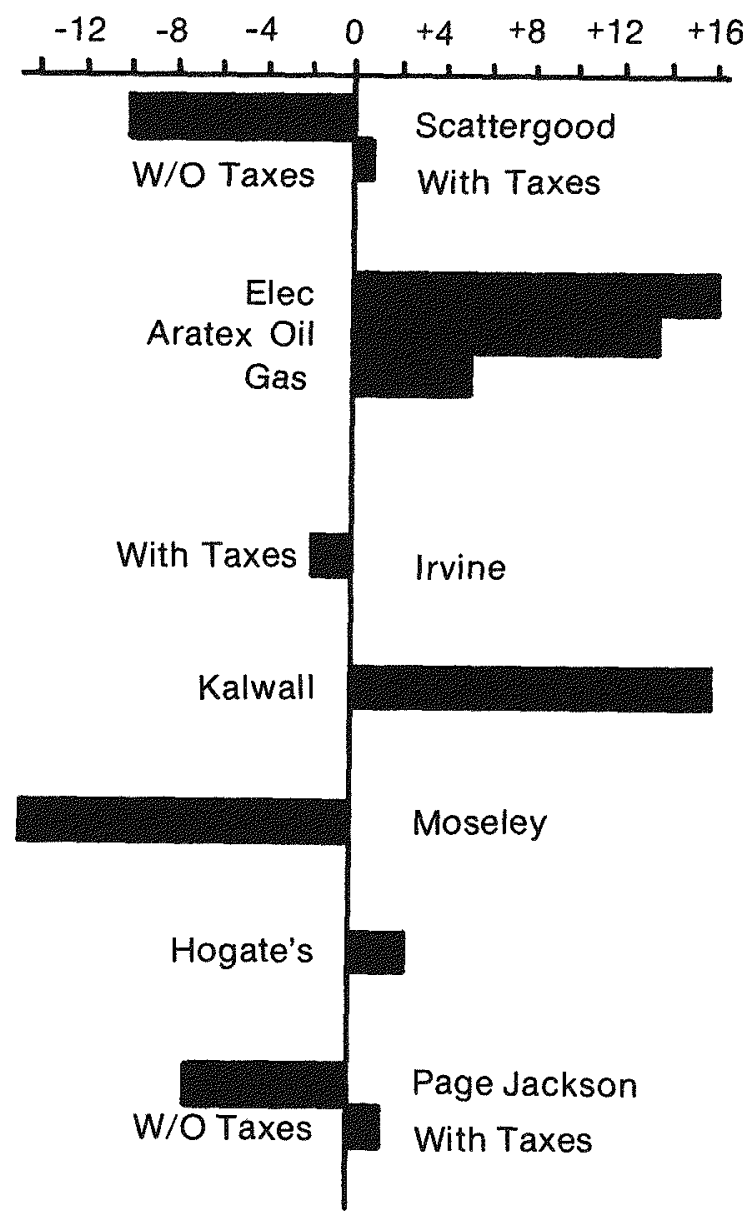
Fig. 17-22. Rates of return for each system
with nominal values

\section{RATE OF RETURN ANALYSIS}

Rate of return analysis is a method appropriate for evaluating and presenting life-cycle costs of solar energy systems. The rate of return (ROR) can be defined as the interest or discount rate at which the solar system lifecycle costs are just equal to the life-cycle revenues. The life-cycle costs include the down payment, mortgage payments, maintenance and operating expenses adjusted for appropriate tax credits, interest and business expense deductions, and fuel escalation and inflation rates. The life-cycle revenues are the yearly energy savings provided by the system and adjusted annually by the fuel escalation rate. This method recognizes the significant effect of the timing of cash flows and the time value of money on the cost effectiveness of an investment. It has been used extensively by the business community to evaluate investment alternatives and has great potential as an indicator of cost effectiveness of solar energy systems. 
ROR expresses the cost effectiveness of a solar energy system in terms that the business community understands; and after all, a solar system represents a true long-term "investment."

The disadvantages of this method are that it is very sensitive to the fuel escalation rate and inflation rate chosen and it does not indicate the actual ROR for intermediate years within the investment analysis period.

A computer program developed by Mueller Associates was used to calculate the rate of return for each of the sites with performance data. The nominal values presented in Table 17-9 were used for each analysis. The appropriate fuel types were specified for each system except for Aratex where cases were run for oil, gas, and electric auxiliary energy. The ROR was determined for the school systems both with and without taxes. These results are presented in Fig. 17-22.
It can be seen that the fuel type and the availability of tax credits can have an effect on the calculated ROR. By assuming that Page Jackson and Scattergood had both investment tax credits and interest deductions, their RORs improved to positive values. Even with tax credits, Irvine did not have a positive ROR. Solar is competing against gas in this case, and the Irvine base costs were high compared with its first year energy output.

To compare all the system outputs and costs in relation to one another, the ROR of each system was calculated assuming the nominal values described in Table 17-9 and that tax credits were available to each system and that the auxiliary energy was electricity. Fig. 17-23 presents the resulting system RORs as a function of the total capital cost/first year energy output.

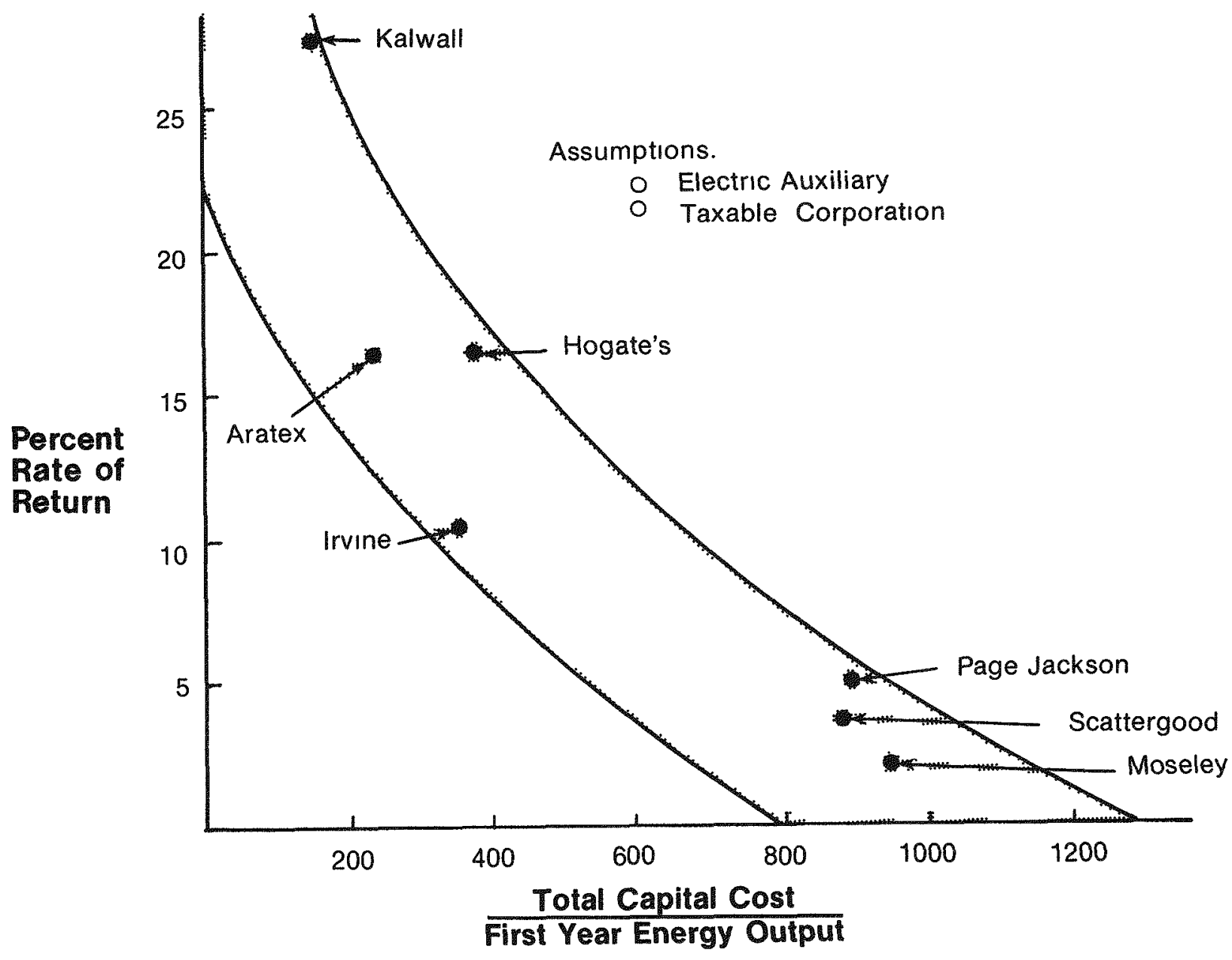

Fig. 17-23. Rate of return for seven systems 
It is apparent that each system studied has a positive ROR when competing against electricity. It is also shown that the amount of operating energy used by a system has a significant impact on its ROR. As an example, consider the Hogate's and Irvine systems. Both systems have basically the same capital cost. However, Hogate's used 30 million Btu operating energy, and Irvine used 135 million Btu operating energy to produce the same amount of energy. Consequently, Irvine's ROR is 5.8 percentage points lower than Hogate's ROR. The band on Fig. 17-23 describes an estimate of the ROR of other systems not analyzed here based on their ratio of total capital cost to first year energy output and ratio of operating energy to first year energy output.

\section{FIRST YEAR SOLAR ENERGY COSTS}

Another method for determining the cost effectiveness of solar energy systems is the comparison of first year energy costs. These costs $\left(\mathrm{P}_{\mathrm{s}}\right)$ for the nine systems are presented in this section and are derived from the following equation:

$$
\begin{aligned}
\mathrm{P}_{\mathrm{s} 1}= & {\left[\overline{\mathrm{CRF}}+\beta_{1}+\beta_{2}+\mathrm{m}_{1}-\tau\left(\beta_{1}+\beta_{2}+\mathrm{m}_{1}\right.\right.} \\
& \left.\left.+\mathrm{rfr}+\mathrm{d}_{1}\right)\right] \frac{\mathrm{CI}}{\mathrm{Q}_{1}}+(1-\tau) \frac{\mathrm{O}}{\mathrm{Q}_{1}} \\
& -\frac{\alpha \mathrm{Cl}}{\mathrm{Q}(1+\mathrm{i})}\left[\overline{\mathrm{CRF}}-\tau \mathrm{rf}_{\mathbf{r}}\right]
\end{aligned}
$$

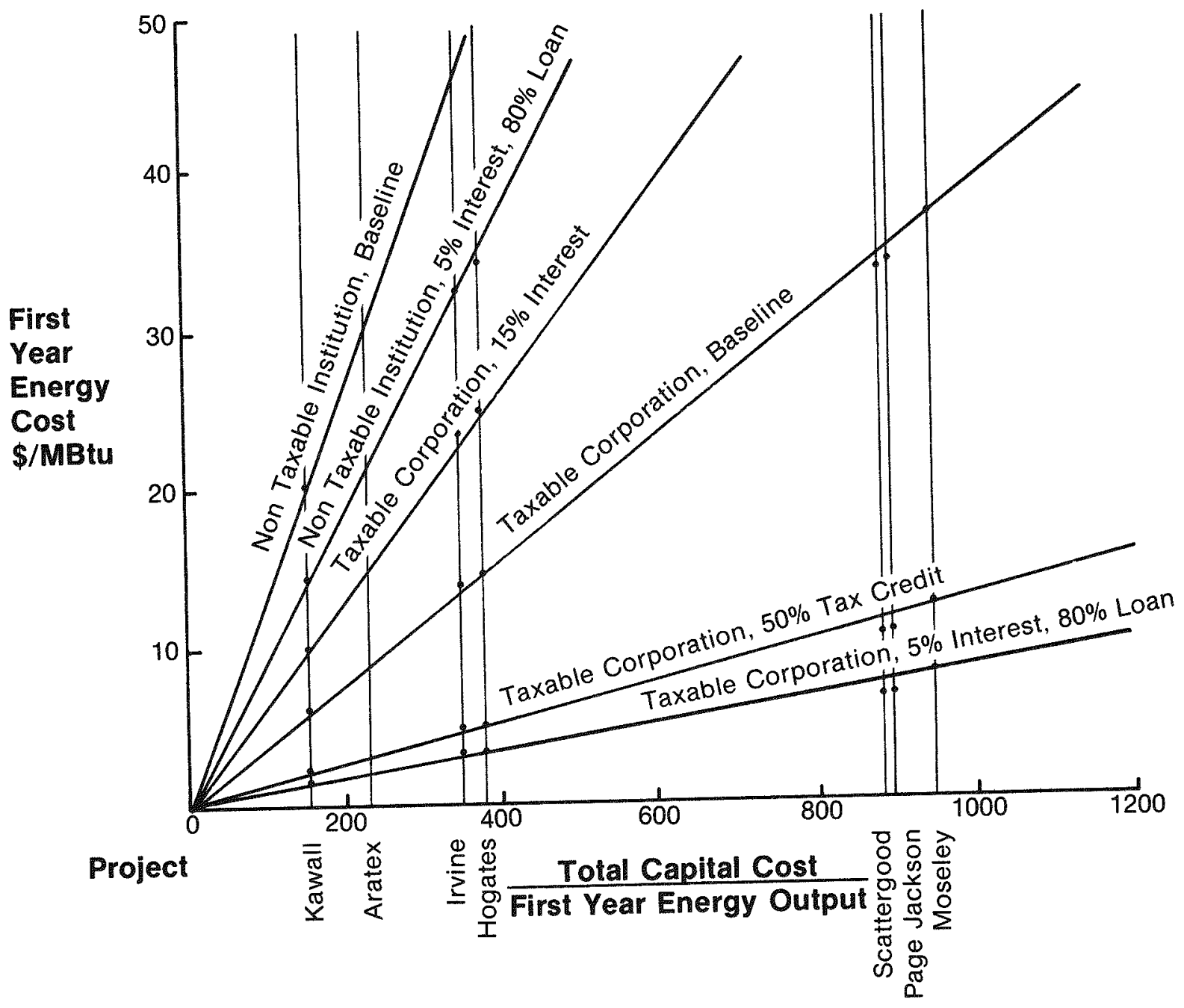

Fig. 17-24. First year cost of energy for different economic conditions 
A description of these parameters and their nominal values are presented in Tables $17-9$ and $17-10$, where the values for $\beta_{1}, \beta_{2}, \mathrm{~m}_{1}, \mathrm{r}, \mathrm{fr}, \mathrm{d}_{1}$, and $\alpha$ are expressed as a fraction of the initial capital investment. The first year energy cost method has a distinet advantage over other economic comparisons in that it does not depend on assumed fuel escalation rates or a general inflation rate over the life of the solar system. Since it does not include these highly speculative rates, this analysis can be based entirely on current data, prices, and rates. Although payback and rate of return methods may provide other comparisons, the first year cost is a valuable indicator of cost effectiveness. For further discussion of the first year energy cost method, see the papers by Sedmak and Ormasa listed in the Bibliography.

The first year cost of energy was calculated for each solar system for a number of different conditions, shown graphically in Fig. 17-24. The parameters varied were $i$ (discount rate), $\tau$ (corporate income tax rate), and $\alpha$ (investment tax credit). For one case, costs were calculated with $\tau$ and $\alpha$ set equal to zero and all other parameters equal to their nominal values in order to simulate the financial situation of a public school. Three of the sites (Scattergood, Irvine, and Page Jackson) are schools. As can be seen from Fig. 17-24, the loss of all tax deductions and credits has a large impact on the first year cost of a solar system. This cost is on the order of $240 \%$ greater than the first year cost for the nominal case.

In the second case, $\tau$ and $\alpha$ were held equal to zero, but $i$ was lowered to $\mathbf{0 . 0 5}$. This simulates the case of a school receiving a low-interest loan $(5 \%)$ to finance its solar system. The effect of these values on first year energy costs can be seen in Figure 17-24. This low-interest loan reduces the cost considerably, but it is still approximately $140 \%$ greater than for the nominal ease.

For the case of corporate ownership $(\tau=0.5)$, the loan interest rate (i) and the investment tax credit $(\alpha)$ were varied while all other parameters were fixed at their nominal values. As shown by Fig. 17-24, an interest rate of $15 \%$ produces a first year cost that is approximately $70 \%$ higher than for the nominal case. When either a low-interest loan $(i=0.05, f r=0.8)$ or a high investment tax credit rate $(\alpha=0.5)$ is applied to the corporate case, dramatic cost reductions are obtained. A loan interest rate of $5 \%$ with $80 \%$ debt financing results in a first year cost that is approximately $21 \%$ as great as for the nominal case. When the interest rate is held at $10 \%$ but the investment tax credit rate is increased to $50 \%$, a first year cost is obtained that is approximately $33 \%$ as great as for the nominal case. These reductions underline the tremendous impact that low-interest loans or high investment tax credits could have upon the solar industry.

In using Fig. 17-24, find the cost of the competing fuel on the vertical axis. Note that for taxable corporations the cost of fuel is effectively halved because of tax deductions for operating expenses. Nontaxable institutions must compare their solar costs to the full competing fuel costs.

For the low interest case $(i=0.05, f r=0.8)$, it can be seen that Kalwall, Aratex, Irvine, Hogate's, Scattergood, and Page Jackson would be cost competitive with electricity. Kalwall, Aratex, Irvine, and Hogate's would be cost competitive with electricity and fuel oil. Only Kalwall and Aratex would be competitive with electricity, fuel oil, and natural gas.

For the high investment tax credit case $(i=0.10, \alpha=0.5)$, Kalwall, Aratex, Irvine, and Hogate's would be cost competitive with electricity and fuel oil. Only Kalwall would be competitive with electricity, fuel oil, and natural gas. By comparison, for the nominal case $(i=0.10$, $\alpha=0.2$ ), the only cost competitive system would be Kalwall against electricity. This points out the great influence that loan interest, investment tax credit, and the tax situation can exert on the economic viability of solar energy systems.

The impact of improvements in system performance or reductions in system cost can be assessed by moving to the left as appropriate. For instance, if the Hogate's system could be installed for $37 \%$ less than it actually cost, its cost effectiveness would be equivalent to the Aratex system.

There has been some question regarding the relationship of federally funded projects to nonfederally funded projects. Although little data are available to determine the relationship, the authors feel that except for cooling projects, the projects discussed here represent the same technology and state of the art found in nonfederally funded projects. Most projects studied were designed in 1975 and 1976. It may be that lessons learned from these early projects have already assisted in the development of the state of the art

\section{SUMMARY AND CONCLUSIONS}

System and subsystem costs are presented and analyzed for 24 commercial National Solar Demonstration projects. The cost data have been obtained through onsite investigations and review of construction contractor records. The distinction between this study and others is utilization of real cost data obtained after the fact for real systems.

Cost data have been combined with actual performance measurements for nine of the systems to obtain various measures of system cost effectiveness. The following are brief summarizations and conclusions from the findings of the study.

\section{Costs}

- System type has a major impact on system cost as summarized below:

\begin{tabular}{lcc}
\hline \multicolumn{1}{c}{ System Type } & No. of Systems & $\begin{array}{c}\text { Average Cost } \\
(\$ / \mathrm{sq} \mathrm{ft})\end{array}$ \\
\hline Passive Heating & 1 & $\$ 7.70$ \\
Process Hot water & 5 & $\$ 41$ \\
Space Heating & 10 & $\$ 48$ \\
Space Cooling & 8 & $\$ 94$ \\
\hline
\end{tabular}

Large variations in total system cost were observed in all types. The reader is advised to be aware of the limited sample size and its implications regarding the validity of the averages presented. 
- Retrofit systems were found to be more expensive than systems installed in new construction. The actual impact on system cost is difficult to determine because of the characteristics of the sample. Almost all of the cooling projects were retrofit. However, even when the cooling projects were not included, new systems were still approximately $\$ 4 / \mathrm{sq} \mathrm{ft} \quad(\$ 43 / \mathrm{sq} \mathrm{m})$ less expensive than retrofit systems.

- Much of the added cost of retrofit construction has been identified with piping, ductwork, and insulation categories.

- The support structure category was found to have the opposite relationship; that is, support structures on new buildings were more expensive than for retrofit installation. This is due to the added functions that the support structures are designed to perform on new buildings. These added functions include improving system appearance, housing equipment, and providing reflectors. Approximately $\$ 5 / \mathrm{sq} \mathrm{ft}(\$ 54 / \mathrm{sq} \mathrm{m})$ average cost difference was found between single function and multiple function support structures. The support structure is $15 \%$ of the total system cost on the average.

- Economies of scale, within the range of systems studied, are a relatively unimportant cost factor.

- Regional cost variations, typical for mechanical systems, have not been found in the solar energy systems studied.

- The collectors represented on the average $34 \%$ of the total system cost, although the range was great. The average factory-built flat plate collector cost $\$ 16 / \mathrm{sq} \mathrm{ft}$ $(\$ 173 / \mathrm{sg} \mathrm{m})$.

- The storage subsystem represented $7 \%$ of the total system cost on the average for the active systems that utilized storage. The type of storage vessel was found to be the major cost factor. Unpressurized steel tanks were least expensive, and residential water heater type tanks were found to be most expensive per unit storage capacity.

- The controls cost for most of the systems varied between about $\$ 325$ and $\$ 925$ per actuator controlled.

\section{Cost Effeetiveness}

- Nine systems were subjected to economic analyses to determine cost effectiveness.

- The relative ranking of the systems was found to change when systems were ranked in order of increasing cost per square foot of collector area and then total cost per first year energy output.

- Only the passive Kalwall system was found to pay back within the assumed system lifetime under expected conditions. The Aratex process water system would pay back if oil or electricity were the auxiliary fuel.

- The sensitivity of pay back to a large number of parameters is illustrated.

- In all economic analyses, nontaxable institutions are at a distinct disadvantage in the attempt to make solar energy cost competitive. This is due to the lack of tax deductions and tax credits in their economic analysis.
- Seven of nine systems studied had a positive rate of return when competing against electricity. Four systems had a positive rate of return against their existing competing fuel.

- Only Kalwall had a first year cost of energy competitive with its existing auxiliary fuel. However, if low-interest loans were used or if $50 \%$ investment tax credits were given, four systems would be first year cost competitive. In addition to the passive Kalwall system, one of those four systems is a cooling project, and two are process hot water systems.

\section{ACKNOWLEDGMENT}

This section and the collection and reporting of construction cost data were performed as part of the National Solar Data Program. Mr. H. Jackson Hale is the DOE Program Manager. Special thanks to Olen Britnell and Bill McCumber of IBM Federal Systems Division for help in obtaining performance information and Michael Sedmak of Booz-Allen \& Hamilton for suggestions for economic analysis and presentation of results.

\section{SELECTED BIBLOGRAPHY}

Rita E. Ormasa, "An Economic Assessment of Solar Energy Systems in the Commercial Demonstration Program," Presented at DOE Regional Solar Update Conferences, July 1979.

Mueller Associates, Inc., "Summary and Analysis of Construction Costs of Ten Solar Energy Systems on Commercial Buildings," DOE-TIC \#SOLAR/082 1-79/60.

Jet Propulsion Laboratory, California Institute of Technology, The Cost of Energy From Utility-Owned Solar Electric Systems, Report Number JPL 5040-29, June 1976.

Perino, Audry M., A Methodology for Determining the Economic Feasibility of Residential or Commercial Solar Energy Systems, January 1979.

Sedmak, Michael R., "An Analysis of the Actual Cost of Energy Generated by Solar Systems," Conference Proceedings-Solar Heating and Cooling Systems Operational Results, Washington, D.C.: U.S. Government Printing Office, 1979 , pp. 353-360.

Sedmak, Michael R. and Zampelli, Ernest M., The Determination of the Optimal Solar Investment Decision Criteria, Report No. PRC/E702.02.00. PRC Energy Analysis Company, January 1979.

U.S. Department of Commerce, National Bureau of Standards, Life-Cycle Costing: A Guide for Selecting Energy Conservation Projects for Public Buildings, National Bureau of Standards Building Science Series 113, September 1978.

U.S. Department of Commerce, National Bureau of Standards, Solar Heating and Cooling in Buildings, Methods of Economic Evaluation by Rosalie Ruegg. NBSIR 75-712, July 1975 . 


\section{APRENDIX}

\section{SUPPORTING DOCUMENTATON}

Many reports are published annually for the Commercial Demonstration Program. Three of the most helpful reports for those desiring to find an overview of the Program, a list of funded sites, or a list of site contacts are described below.

\section{General Reports}

- Solar Heating and Cooling Project Summaries (DOE/CS-0038-2) presents brief descriptive overviews of the design and operating characteristics of all commercial demonstration projects. Also included are available pictures of the buildings, simplified solar system diagrams, and a bibliography of published reports.

- National Solar Heating and Cooling Commercial Demonstration Program Key Personnel Directory (DOE/CS-0057) identifies those firms and individuals who are principal participants in the DOE solar demonstration projects. This document is published annually to facilitate communication with and among participants.

- Instrumented Solar Demonstration System-Project Deseription Summaries (Solar/0017-79/34) presents brief descriptive overviews of all commercial and residential demonstration projects which are instrumented to provide performance data to the National Solar Data Network. Included are pictures and simplified solar system diagrams.

\section{Conference Reports}

Periodic national conferences and contractors' reviews are held to exchange information on solar systems currently in operation, under construction, or still in the design phase. Benefits from early experience are exchanged, and the progress of the Commercial Demonstration Program as a whole can be assessed. Proceedings of these conferences are made available through the National Technical Information Service, 5285 Port Royal Road, Springfield, VA 22161.

- Proceedings of the Solar Heating and Cooling Demonstration Program Contractors ${ }^{\dagger}$ Review, New Orleans, Louisiana, December 5-7, 1977 (CONF771229-P2);

The Pre-Printed Papers of the Second Solar Heating and Cooling Commercial Demonstration Program Contractors' Review, San Diego, California December 13-15, 1978 (HCP/M-4131-01);

- Conference Proceedings-Solar Heating and Cooling Systems Operational Results, Colorado Springs, Colorado, November 28 - December 1, 1978 (Solar/0500-79-00). 